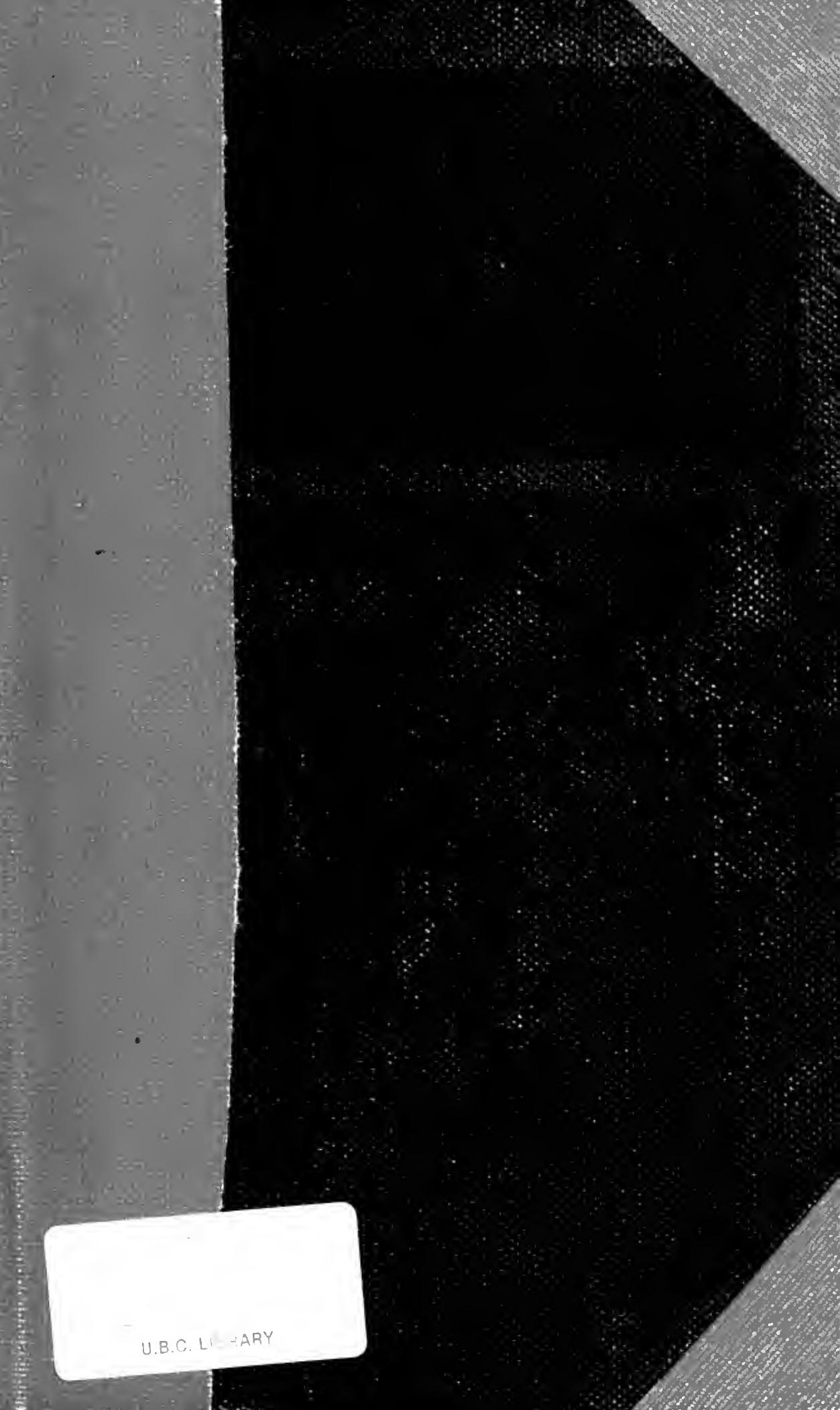




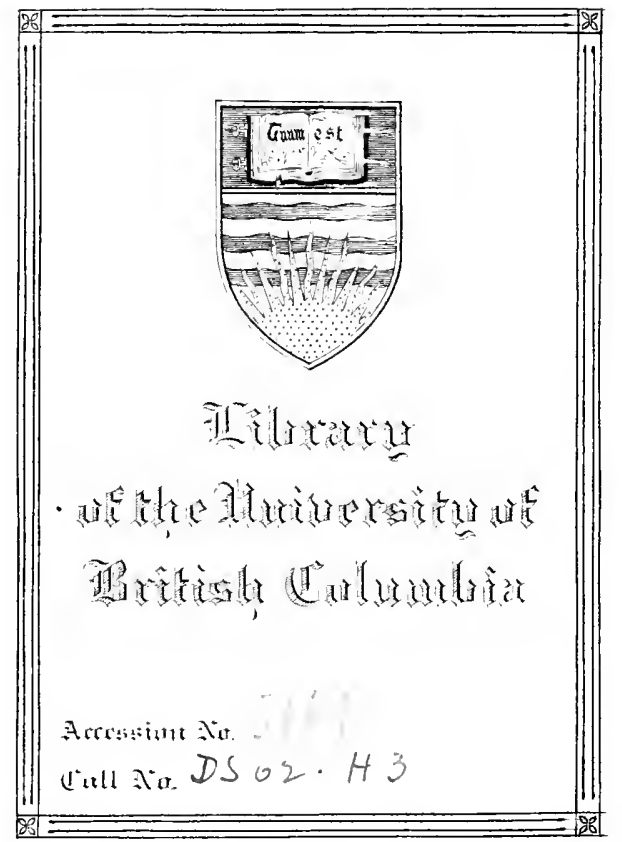


Digitized by the Internet Archive in 2010 with funding from University of British Columbia Library 
THE ANCIENT HISTORY OF THE NEAR EAST 




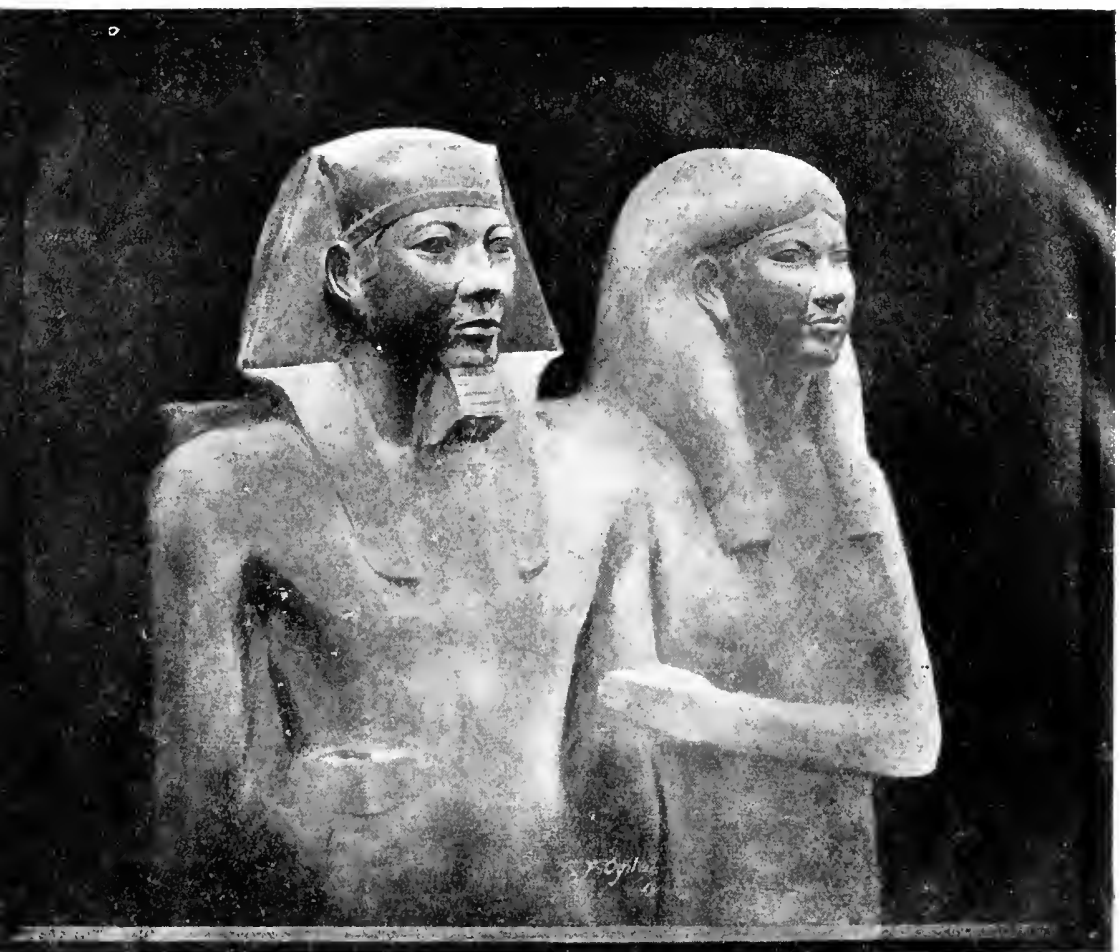

KINI MENKATKA ANH HIS GUEH

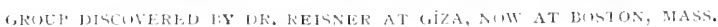

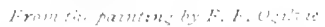




\section{THE}

DS62. $43-C$

\section{ANCIENT HISTORY OF THE NEAR EAST}

FROM THE EARLIEST TIMES TO THE BATTLE OF SALAMIS

BY

H. R. HALL, M.A., F.S.A.

DEPARTMENT OF EGYPTIAN AND ASSYRIAN ANTIQUITIES, BRITISH MUSEUM AUTHOR OF "THE OLDEST CIVILIZATION OF GREECE"

WITH THIRTY-THREE PLATES AND FOURTEEN MAPS

METHUEN \& CO. LTD. 36 ESSEX STREET W.C. LONDON 
First Publisked in 1913 
TO

THE MEMORY

OF

W. G. POGSON-SMITH 



\section{PREFA CE}

$\mathrm{N}$ this book I have endeavoured to tell the story of the ancient history of the Near East within the limits of a 1 single volume. Those who know the great works of Maspero and of Meyer will realize that in order to effect this great compression has been necessary, and will guess that many matters of great interest have had to be treated more cursorily than I would have wished. But, while writing as succinctly as possible, I have of set purpose refused to sacrifice too much on the altar of brevity, and have aspired to make the book readable as well as moderate in size.

Of all regions of the earth probably the Near East has had and will have the greatest interest for us Europeans, for from it sprang our civilization and our religion.

There took place the mingling of the Indo-European from the North with the Mediterranean of the South, which produced the culture, art, and law of the Greeks and Romans; and there, on the Semitic verge of Asia, the home of religious enthusiasms from the beginning, arose the Christian Faith. And if the Near East has from the first seen the mingling of the ideas of the East and West, it has also seen their secular struggle for mastery, the first phase of which ended at Salamis, when the Aryan invader made good his footing in the Mediterranean world, and threw back the Asiatics from Greece, now become the most eastern of western lands instead of the most westerly of the eastern. The second phase ended with Arbela and the complete triumph of the West. At the end of the third, Kossovopolje and Constantinople registered the return of the pendulum, which swung its weight from east to west as far as Vienna. Then it swung back, and the end of the fourth phase seems 
to be approaching as I write, when Bulgars and Greeks are hammering at the gates of Constantinople.

It is with the history of the first phase of the great drama that this book deals, from the beginning of things to the grand climacteric of Salamis. The story begins with prehistoric Greece. Of the Bronze Age civilization of Greece which has been revealed to us by the discoveries of Schliemann, Halbherr, and Evans we cannot yet write the history: we can only guess at the probable course of events from the relics of antiquity which archaeology has revealed to us. It is otherwise with Egypt, with Babylonia, and Assyria. Of them we have intelligible records upon which we can base history. Therefore it seems best to treat the "pre-history" of Greece separately, and before we pass to real history with Egypt and Babylonia. We pass then from Greece to the Nilotic and Mesopotamian communities, treating them separately till in the second millennium B.C. they came into connexion with each other and with the Anatolian culture of Asia Minor. It then becomes impossible to treat them separately any longer. At different periods one or the other more or less dominated the rest and took the most prominent part in the history of the time. I have therefore told the story of each period more or less from the standpoint of the chief actor in it. During the First Egyptian Empire, from about I 550 to I350 B.C., one regards the world from the standpoint of imperial Thebes; during the ensuing period, till about I IOO, one looks down upon it from the bleak heights of Asia Minor; till about 850 the rise of the Israelitish kingdom centres our attention upon Palestine; from 850 to 650 we watch from Nineveh the marching forth of the hosts of Ashur and the smoke of their holocausts spreading over all the lands. Then, with dramatic swiftness of overthrow, comes the Destruction of Nineveh. The destroyers, the Scyths of the Northern Steppes and the Medes and Persians of Iran, found their kingdoms on the ruins of the Semitic empires, while Egypt and even Babylonia spring once more into life. And the great event was contemporaneous with the expansion of the young Greece of the Iron Age, young with the new Indo-European blood from 
the north which had begun to invade the Aegean lands towards the end of the Egyptian imperial period. Persia took the place of Assyria in the world, and all the lands of the Near East but Greece coalesced in her Empire. Greece alone, possessed of a stronger $\tilde{y} \theta 0 s$ and with a brain many times more intelligent than those of the Easterns, resisted successfully. The barbarian recoiled: Greece had saved the West, and with it the future civilization of the world.

I have intended the book mainly for the use of students in the school of Litterae Humaniores at Oxford, whose work necessitates a competent general knowledge of the early history of the west-oriental world, without which the history of Greece cannot be understood fully. Greece was never, as the older historians seemed to think, a land by itself, fully Western in spirit, supremely civilized in a world of foolish Scythians and gibbering black men. Originally she seems to have been as much or as little oriental as originally was Egypt, with whose culture hers may have had, at the beginning, direct affinity. Later she was westernized, but in the fifth century she was not more distinct from the more oriental nations of the Near East than she is now. She called them "barbarian": that only meant that they did not talk Greek. Greece respected Persia while she fought her, Aeschylos knew better than to make Darius a savage. In fact, the Greeks hardly realized as yet how much more intelligent they were than the other nations. Herodotus has no feeling of great superiority to his Median and Egyptian friends. And when he set himself to write the history of the great struggle which the preceding generation had seen, it was in no spirit of contempt and aloofness that he gathered his information as to the early history of the peoples of the Near East who had marched against Greece under the Persian banner. He did not separate Greece absolutely from the rest of mankind, though no doubt he felt that she was better than the rest.

I hope, therefore, that this book may serve as a very general "companion" to Herodotus for university students. But at the same time I have endeavoured to make it no less useful to the general reader whose interest is keen on the history of these 
ancient civilizations, the relics of which have been and are being discovered day by day by the archaeologists. In the case of Egypt and prehistoric Greece, new material of the utmost importance may turn up at any moment. I have tried to make the book as up-to-date as possible, and in order to do so, during the work of writing it, which has occupied several years, several chapters have been re-cast, even wholly re-written, as the work of discovery necessitated. Owing to the indulgence of the publishers I have had unlimited time in which to complete the work, and I hope that the present moment, when there seems to be a lull in the work of discovery, may be a favourable one for its publication, and that I shall not have to wish that I had delayed a little longer in order to register this or that new fact of importance. I have recounted the facts of the history so far as they are known without, I hope, undue generalization or theorizing, except, of course, in the case of prehistoric Greece, where the whole is theory, based however upon the evidence of material things. For an acute generalization of the history of the early peoples of the world I may refer the reader to Prof. J. L. Myres's little book, The Dawn of History, published last year, and for a suggestive study on certain natural causes which have influenced the history of the East to Mr. ELLSwORTH Huntington's most interesting Pulse of Asia.

In dealing with the early history of "classical" Greece I have simply endeavoured to present an impression or sketch of the development of Greek culture and its relations with the Eastern nations. I have not considered it necessary or desirable to treat the history in any detail. So much more is known of it than of the early history of the other lands concerned that to do so would be to make the latter part of the book (and the Greek section especially) totally disproportionate in size. This part too is written rather from the PersianEgyptian than from the Greek standpoint. And Greece when she became Hellenic ceased to belong wholly to the Near East. It is only her "foreign relations," her connexions with the East, that interest us now. Her internal affairs we leave to the historians of Greece. They call for our attention only in so 
far as they bear directly upon the general progress of Hellenic culture, especially towards the east and south, or affect directly the approach of the conflict with Persia.

I have myself specially translated for this book all the Egyptian inscriptions from which I quote at length, with the exception of that containing the hymn of King Akhenaten to the sun-disk (p. 306), which is quoted, with his very kind permission, from Prof. Breasted's translation in his History of Egypt.

I have tried not to weary the reader by too rigid an insistence on the use of diacritical marks on my transliterations of Egyptian and Semitic names, giving the fully-marked forms usually only on the first appearance of a name in the book, and dispensing with them afterwards unless it would seem better to retain them in order to mark the pronunciation.

I have to thank various friends who have assisted me in the reading of portions of my proofs. To them I owe many corrections and suggestions. Chapters I., V., IX. and X., in which Babylonian and Assyrian matters are chiefly dealt with, have been read by my colleague Mr. L. IV. KING, author of The History of Sumer and Akkad. Chapters IX. and X. have also been read by the Rev. C. F. BuRveY, D.D., of St. John's College, Oxford, to whom I am specially indebted for my preservation from the many pitfalls that beset the path of a general historian in dealing with early Jewish history. My friend Prof. M. A. CANNEY, of Manchester University, has also read Chapter IX., and has made several very useful suggestions. Chapter II. has been read by Mr. E. J. FoRSDYKE, of the Greek and Roman Department of the British Museum; and Mr. G. F. Hill, the Keeper of Coins and Medals, and Mr. F. J. MARshall, of Emmanuel College, Cambridge, have most kindly read Chapters XI. and XII., with results valuable both to myself and to the reader. Only in those chapters of the book which are written more or less from the Egyptian point of view, namely, Chapters III., IV., VI., VII. and VIII., have I not submitted my work to the judgment and criticism of another. But in those chapters which any friends have read I alone am responsible for the 
opinions ultimately expressed. Dr. BURNEY, for instance, must not be taken to agree with everything I have said in Chapter IX.; as, for example, with my revival, for which I only am responsible, of Josephus's idea that the Biblical account of the Exodus is possibly a reminiscence of the Expulsion of the Hyksos. I have recorded divergences of view when necessary; and have also, when I am indebted to one of my friends for a new view, indicated the fact in a footnote.

I mustexpress my thanks to the Deutsche ORIENT GesellSCHAft of Berlin, to Messrs. Dietrich Reimer, also of Berlin, and also Mr. EDWARD STANFORD, of London, for permission to base plans on other maps and plans published by them, of which details are given in the List of Maps. For the sketch-map of Knossos and its surroundings I wish to acknowledge my obligation to the plans published in the Anmual of the British School at Athens, on which the small inset-plan of the palace is based. Finally, as regards photographs, I must thank Prof. Garstang for permission to publish the first picture of his Minoan discovery at Abydos (Plate III. I); Mr. A. H. Smith, the Keeper of Greek and Roman Antiquities in the British Museum, for permission to reproduce the photograph, Plate XXX. 2; and Dr. SchäFER and the Administration of the Royal Museums of Berlin for their gift of the photograph, Plate XIX. I. I have also, thanks to the kindness of Dr. REISNER, been able to use as frontispiece a painting, by $\mathrm{Mr}$. F. F. OGILviE, of one of the splendid sculpture groups of the Fourth Dynasty recently found by the Harvard expedition at the Pyramids of Gizeh. The photographs of Plates XXVI. and XXII. were taken respectively by Mr. L. W. KING and by Mr. R. C. Thompson, who have kindly lent me their negatives. Those of six of the plates are of my own taking; most of the rest have either been taken for me by $\mathrm{Mr}$. Donald Macbeth or have been selected by me from the stock of Messrs. Mansell \& Co.

H. R. HALL

November I912 


\section{GONTENTS}

CHAP.

1. PROLEGOMENA

11. THE OLDER CIVILIZATION OF GREECF • • • $\quad 3$ -

III. ARCHAIC EGYPT . $\quad$ - . 80

IV. EGYPT UNDER THE OLD AND MIDDLE KINGDONS • • I2I

I V. THE EARLY HISTORY OF BABYLONIA * * * $\quad$ I7I

VI. THE HYKSOS CONQUEST AND THE FIRST EGYPTIAN EMPIRE 212 VII. EGYPT UNDER THE EMPIRE $\quad$ • $\quad . \quad$ * $\quad$ • $\quad 276$

VIII. THE HITTITE KINGDOM AND THE SECOND EGIPTIAN EMPIRE. 326

IX. THE KINGDOMS OF SYRIA AND PALESTINE $\quad \cdot \quad$ • 398

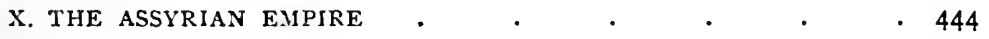

XI. THE RENOVATION OF EGYPT AND RENASCENCE OF GREECE • 518

XII. BABYLON AND THE MEDES AND PERSIANS * * 543

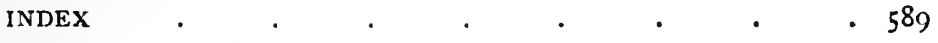





\section{LIST OF ILLUSTRATIONS}

PLATE

I. King Menkaura and his Queen : Group discoverei) BY Dr. G. A. Reisner at Gîza, now at Boston, MASS. . Frontispiece

From the Painting by F, F. Ogrlvie, by permission of Dr. REISNER

II. I. Phaistos and Mount Ida . . . . . 44

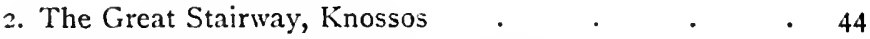

3. Interior of the Treasury of Atreus, Mycenae • . 44

Photos, H. R. HALL

III. Prehistoric Greek Pottery • • • • 46

I. The Abydos Find (Ashmolean) . . . . 46

2. "Schnabelkannen" and "Bügelkanne" . . . . 46

3 L. M. I-III . • . . . . . . 46

4. The "Marseilles Vase"(L.M.I.) • . . . 46

5. Melian Ware $\quad . \quad$. $\quad . \quad$. $\quad . \quad . \quad 46$

IV. Minoan ARt, Knossos and Agia Triada • . 48

I. Fresco of a King . $\quad . \quad$. $\quad$. $\quad$. $\quad$. 48

2. Fresco of Bull-leaping . $\quad$. $\quad$. $\quad$. 48

3. Snake-Goddesses . . . . . . . 48

4. The Chieftain Vase . $\quad$. $\quad$. $\quad . \quad 48$

From a Cast made at the Candia Museum

5. The Boxer Vase . $\quad . \quad$. $\quad$. $\quad . \quad 48$

From a Cast made at the Candia Museum

V. The Cup-bearer, Knossos . . . . . . 50

From Monthly Review, March rgor; by permission of Messrs. Murray 
VI. I. Egyptian Predynastic Pottery . . . $\quad 82$

2. Ceremonial Palette (end of Predynastic period) . $\quad 82$

3. Ceremonial Palette of Narmer (beginning of the Ist Dynasty). . . . . $\quad$. 82

VIl. 1. Ivory figure of a King, Ist Dynasty: From Abydos (British Museum) . . . . . II8

2. Stone figure of Khasekhemui, IIIrd Dynasty: From Hierakonpolis (Ashmolean) . . . . . 118

3. Eannatum and his Soldiers, on the Stele of the Vultures (Louvre) . . . . . . . . II8

By permission of MM. LEROUX

VIII. EARLY ROYAL TOMBS - 122

I. Mastaba of Tjeser, Bêt Khallâf . 122

2. Pyramid of Tjeser, Sakkara - 122

3. Mastabat al-Faraûn, Sakkara - 122

t. Haram al-Kaddâb, Dahshur

Photos, H. R, HALL

IX. Egyptian Portrait-Statues of the Old Kingdom . 124

I. The Scribe Accroupi (Louvre) - 124

2. Nenkheftka (British Museum) . 124 3. A Nobleman and his Wife (Berlin) - 124

Photos, W. A. Mansell \& Co.

X. Temples and Tomes of the Middle Kingdom • 146 I. Mentuhetep-Temple, from above . . . . 146

2. The Mentuhetep-Temple . . . . . 146

3 Tomb No. 15. Beni Hasan . . . . 146 Photos, H. R. Hall,

X1. King Senusert il, Dêr El-Bahri (British Museum) i6? Photo, W. A, Mansell \& Co, 
XII. I. An early Sumerian Portrait, period of Ur-Nina (British

Museum) . $\quad$. $\quad$. $\quad$. . . 174

2. King Gudea (Louvre) . . . . . 174

Photos, W. A. Mansell \& Co.

Xili. The Stele of Narân-Sin (Louvre) . . . I 88

Photo, W. A. Mansel.L \& Co.

XIV. I. The Stele of the Laws of Khanmurabi (Louvre) . . 204

2. Sumerian Deities (Berlin) . . . . . 204

Photos, Graphische Geseillschaft

XV. Wall-Paintings of the XVIIIth Dynasty (BRitish

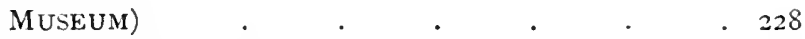

I. Semites bringing Tribute . $\quad$. $\quad$. . 228

2. Egyptian Chariots and Horses . . . . 228

Photos, W. A. Mansell \& Co.

XVI. King Thothmes ill as a young MaN; Karnak (Cairo) 250

Photo, Neue Photographische Gesellschaft

XViI. King Anenhetep ill (British Museum) • . 256

Photo, W. A. Mansell \& Co.

XVIII. I. The two Temples of Dêr el-Bahri . . . . 290

2. The Keftiu in the Tomb of Senmut . . . 290

Photos, H. R. Hall and E. R. Ayrton

XIX I. Akhenaten and Nefertiti (Berlin) . . . 304

2. Akhenaten (British Museum) . . . . 304

XX. I. Thebes from above Dêr el-Balụri . • . . 3 $3^{\mathrm{I} 6}$

2. The Ramesseum . . . . . . . . 316

3. Medinet Habu . . . . . . . 316

Photos, H. R. HALL 
xviii THE ANCIENT HISTORY OF THE NEAR EAST

PLATE

FACING PAGE

XXI, King Rameses il as a young MaN (TuRin)

- 320

Photo, R. ANDERSON

XXil. Hittite Art of the dest Period

- 330

1. Öyïk.

- 330

2. Warriors: Yasili Kayá

- 330

3. King: Bogház Kyöi

- 330

4. Priest : Yasili Kayá.

- 330

Photos, R. C. Thompson

XXIII. HitTite SCUlPTURE.

I. Warrior : Sindjirli (Berlin).

. 340

Photo, Graphische Gesellschaft

2. King or Deity : Carchemish (British Museum)

- 340

Photo, W. A. Maxsell \& Co.

XXIV. r. A Philistine, Medinet $\mathrm{Habu}$

- 360

2. Shardina Warriors, Abydos

- 360

3. Hittite Warriors, Abydos .

- 360

Photos, H. R. HALL

XXV. Assyrian Reliefs of the Ninth Century (British

Museum). .

I. Ashur-nașir-pal Hunting Lions • • . . 454

2. Assyrian Siege-warfare . . . . . . . 454

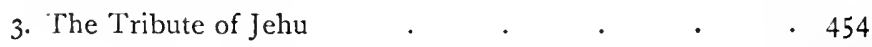

Photos, W. A. Mansell \& Co.

XXVI. I. Carchemish .

2. Kala 'at Sherḳat (Assur)

. 478

3. Birs Nimrûd (Borsippa)

. 478

- 478

Photos, L. W. KING

XXVII. 1. A Phoenician Warship (British Museum).

Photo, W. A. Mansell \& Co.

2. An Assyrian Camp (Berlin) 
XXVIII. I. Lion of Ashur-nașir-pal (British Museum, .

2. The Dying Lioness: Palace of Ashurbanipal (British Museum).

Photos, W. A. Mansell \& Co.

XXIX. I. Psammetichos I (British Museum) - 528

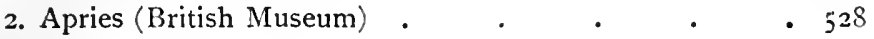

XXX. I. Typhoeus: From the older Parthenon (Athens) .

Photo, English Photographic Co.

2. Ionian Art of the Sixth Century : Frieze on a Clazomenian Sarcophagus (British Museum).

XXXi. Greek Architecture of the Sixth Century - 536 I. The Temple of Aphaia : Aigina . . . . 536

2. The Treasury of Knidos: Delphi . . . . 536

Photos, English Photographic Co.

XXXil. Greek Types of the Sixth Century • • • 574

I. Male figure: Ephesus (British Museum) . . . 574

2. Female figure (Athens) • . . . . 574

Photo, English Photographic Co.

Greek Male Types of the early Fifth Century • 574

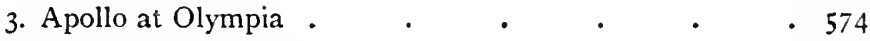

4. Bronze Head (Athens) . $\quad$. $\quad . \quad$. 574

Photos, English Photographic Co.

XXXIII. The Frieze of the ARchers, From the Palace of Darius at Susa (Louvre) . . . . 578 Photo, A. Giraudon 



\section{LIST OF MAPS}

FACING PAGE

The Aegean Basin. To illustrate the Prehistoric (Bronze Age)

Period.

KNossos and its Neighbourhood, with INSET-Plan of the

PaLACE. After plans published by the British School at Athens . 42

EgYPT AND NEIGHBOURING LANDS . . . . . I 20

Ninever. After Commander Felix Jones, "Ichnographic Sketch of

the remains of ancient Nineveh," Vestiges of Assyria, $1855 \quad$ I 82

BABYLONIA AND THE SURROUNDING LANDS . • • . I72

The BatTlefield of Megiddo . . . . . . 236

The Near East in the Fifteenth Century B.C. . . 254

Topography OF Thebes. Based on Murray's Egypt, Plan of

Thebes (Irth edition, p. 379) . . . . . . $\quad 278$

By permission of EDWARD STANFord, London

Bogház Kyör. After Humann and Puchstein, Reisen in Kleinasien,

Tafel XIV. . $\quad . \quad$. $\quad . \quad . \quad . \quad 338$

By permission of DIETRICH REIMER, Berlin

The Near East in the Raniesside Period . . . 368

Palestine. To illustrate the period of the Judges $\quad . \quad \cdot \quad+422$

The Assyrian EMPIRE. $\quad . \quad$. $\quad . \quad$. $\quad . \quad 504$

Babylon. After Koldewey, Die Tempel von Babylon und Borsippa,

Plates I., II., and IV. $\quad . \quad$. $\quad . \quad$. $\quad .550$

By permission of the Deutsche Orient-Gesellschaft

The Persian Empire in the Time of Darius and Xerxes • 580 


\section{LIST OF ABBREVIATIONS}

Abh.k.p. Akad.; Abhandlungen der königlich preussischen Akademie der

iVissenschaften, Berlin.

$\ddot{A} . Z$. ; Zeitschrift für Fgyptische Sprache u. Altertumskunde, Berlin.

A.J.A. ; American Journal of Archæology ; Norwood, Mass.

A.J.S.L. ; American Journal of Semitic Languages, Chicago.

Anc. Rec.; Breasted, Ancient Records of Egypt ; Chicago, Igo6.

Annals; Annals of the Kings of Assyria, British Museum ; 1902.

Annales (Ann. du Service); Annales du Service des Antiquités, Egypt.

Ath. Mitt. (Mitth. Ath. Inst.); Mittheilungen des kaiserlich deutschen Instituts in Athen.

B.S.A. Ann.; Annual of the British School at Athens.

Brit. Mus. Cat.; British Museum Catalogue.

C.I.G. ; Corpus Inscriptionum Graecarum.

C.I.S. ; Corpus Inscriptionum Semiticarum.

Guneiform Texts; L. W. KING, R. C. ThOMPSON, and others; Cuneiform

Texts from Tablets, etc., in the British Museum.

Denkmaeler; LePsius, Denkmaeler aus Ægypten und Ethiopien.

Dict. Bibl. ; Smith's Bible Dictionary.

E.E.F.; Egypt Exploration Fund.

Ency'cl. Bibl.; Encyclopredia Biblica; London, 1899-1903.

Encycl. Britt.; Encyclopædia Britannica, xIth edition.

'E $\phi$. 'А $\rho \chi$. ; 'E $\phi \eta \mu \epsilon \rho$ is 'A $\rho \chi \alpha \iota \lambda о \gamma \iota \kappa \dot{\eta}$, Athens.

Geol. Mag. ; Geological Magazine.

Gesch. Israels; WINCKLER, Geschichte Israels.

Gesch. der M.u. P.; PRÁŠEK, Geschichte der Meder und Peser; Gotha, I9ro. H.S.A. ; KING, History of Sumer and Akkad ; London, r9ro.

J.H.S.; Journal of Hellenic Studies.

Jahrb. Arch. Inst.; Jahrbuch des Archäologischen Instituts in Athen.

Journ. R. Anthrop. Inst.; Journal of the Royal Anthropological Institute.

Keilinschr. Bibl.; SCHRADER, Keilinschriftliche Bibliotek ; Berlin, I889.

Liverp. Ann.; Liverpool University Annals of Art and Archaeology.

Mém. Inst. Fr. Gaire; Mémoires de l'Institut Français au Caire.

Mém.Soc. Ant. Franç.; Mémoires de la Société des Antiquaires Français.

M.D.O.G. ; Mitteilungen der deutschen Orient-Gesellschaft, Berlin.

M.V.G. ; Mitteilungen der Vorderasiatischen Gesellschaft, Berlin. 


\section{LIST OF ABBREVIATIONS}

Xxiii

Mon. Ant.; Monumenti antichi, Rome.

O.G.G. ; HALI., Oldest Civilization of Gieece ; London, I90I.

O.L.Z. ; Orientalistische Litteratur-Zeitung, Berlin.

P.E.F.Q.S. ; Palestine Exploration Fund Quarterly Statement.

P.S.B.A.; Proceedings of the Society of Biblical Archæology.

Proc. Brit. Acad.; Proceedings of the British Academy.

Proc. Soc. Ant.; Proceedings of the Society of Antiquaries.

Rawlinson, Inscriptions; Sir H. Rawlinson, Cuneiform Inscriptions of Western Asia.

R.P.; Records of the Past.

Rec. Trav.; Recueil de Travaux rélatifs a l'archéologie et la philologie égyptiennes et assyriennes, Paris.

Rev. Eg. ; Révue Egyptologique, Paris.

Rév. Hist. Rélig.; Révue de l'Histoire des Réligions, Paris.

Sitzber. k.p. Akad.; Sitzungsberichten der königlich preussischen Akademie der Wissenschaften, Berlin.

Verhandl. Berlin Anthrop. Ges.; Verhandlungen der Berliner Anthropologischen Gesellschaft.

Z. Assyr. ; Zeitschrift für Assyriologie, Strassburg.

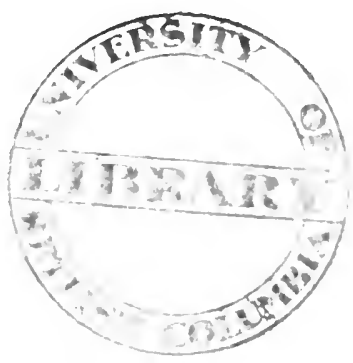





\title{
THE ANCIENT HISTORY OF THE NEAR EAST
}

\section{CHAPTER I}

\author{
PROLEGOMENA
}

\section{Herodotus and Modern Knozuledge}

OME thirty years after the defeat of Xerxes, Herodotus S of Halicarnassus, who had travelled much in the lands of the barbarians as well as in Greece, set himself to write down for the men of his own time and for posterity the events of the great struggle and also to describe, as completely as he could, the long series of events, cause upon cause, effect after effect, which had led up to the final catastrophe. ${ }^{1}$ And he began from the beginning of ancient story, from the Trojan War and before that from the rape of Io. For he rightly saw that the Great Event had indeed had its ultimate origin in the furthest recesses of time, when the ancient civilizations of the Eastern Mediterranean first evolved themselves out of chaos, and the peoples of the Nile-land, of Western Asia, and of the Aegean first came into contact with each other. So he told first all he knew of the peoples of Egypt, Babylonia, Persia, and also Scythia, and of their history, and intended, we know, to tell the story of Assyria also. Everywhere he tried to trace back the first contact of his own people with these barbarians, and to identify this or that element of culture which his Greeks, whom he knew to be far younger as a nation than the Oricntals, owed

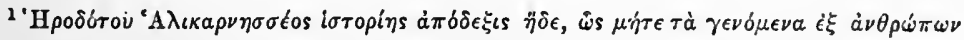

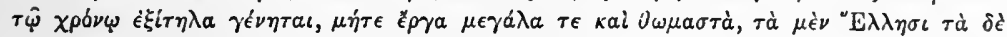

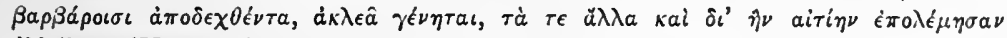
$\dot{\alpha} \lambda \lambda \dot{\eta} \lambda$ oı $\sigma \iota$ (HDT. I. i.). 
to the East which they had defeated. And then he gathered all the threads of his various tales together, as Xerxes gathered the peoples themselves together, for the final story of the collision of East and IVest, and his history marches straight without digression now, to Salamis, Plataeae, and Mykale.

In dealing with the early history of Greece he groped darkly, because, though he had all the varied store of Hellenic legend to his hand, he had no knowledge of what we know now in some degree, the real story of the first development of Greek civilization. We know that Egyptian priests could tell him the history of Cheops and of Rhampsinitos, but that no Greek could tell him that of the strong men who lived before Agamemnon. Nor do we know the true facts of their history as we do that of Cheops or Rhampsinitos, but we may do so one day, when we read the Minoan writing as we can that of ancient Egypt. Till then, we also must grope, but not so darkly as Herodotus, for modern archaeological discovery has told us the development of the heroic culture of Greece, which we can now trace back to its origins, contemporary with those of Egypt itself. So much further beyond the Trojan War and the Phoenician rape of Io

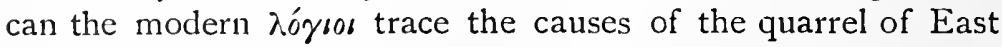
and West. ${ }^{1}$ But until eighty years ago we were as ignorant as Herodotus, and he, with the Biblical history of the Jews beside him, was our sole good authority for the ancient history of the Near East: the Sacred Record and the "profane" irropins тpuraves told us all that mattered of what we knew.

\section{The Increased Modern Knowledge of Ancient History}

But now our knowledge of the early history of mankind is increasing apace. Nowhere is this vast accession of knowledge more noticeable than in the domain of the historian of the ancient peoples of the Nearer East, the portion of the world of which Greece marks the western and Persia the eastern boundary, of which the southern border marches with the lands of the Blacks and the northern is formed by the steppes and deserts of the Scythians and Cimmerians. Now, within the short space of eighty years, the whole history, as distinct from untrustworthy legends of Greek or Jewish origin, of the mighty monarchies of Egypt and of Mesopotamia, of Media and of

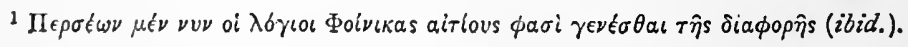


Persia, has been recovered from oblivion for us, and, what is still more interesting, we are now just beginning to realize that Greece itself was, long before the classical culture of the Hellenes was ever heard or thought of, the seat of a civilization at least the equal of that of Egypt or Chaldaca and possibly as ancient. Nor is it in Mesopotamia, in the Nile Vallcy, and in Greece alone that man's knowledge of the earliest history of his race has been so vastly increased during the last eighty years: yet another system of culture, exhibiting in different points resemblances to the three foregoing, while in others perfectly distinct from them, has been shown to have existed at least as early as 1500 B.C. in Central Asia Minor; this extended its sway on the west to Sipylus, on the east to the borders of the Canaanites and to Carchemish on the Euphrates.

Furthermore, on the northern and eastern confines of the Babylonian culture-system, new nations pass within our ken; Vannic men of Armenia, ruled by powerful kings; Kassites of the Zagros, whose language seems to contain clements which if really Aryan are probably the oldest-known monuments of Indo-European speech (c. I600 B.C.); strange-tongued Elamites, also, akin neither to Iranian nor Semite. Nor does it seem to us remarkable that we should read the trilingual proclamations of Darius Hystaspis to his peoples in their original tongues, although an eighteenth-century philosopher would have regarded the prospect of our ever being able to do so as the wildest of chimeras!

And when we read the story of Egypt, of Babylon, and Persia as it really happened, and not through the mouths of Greek or Jewish interpreters, we wonder not so much at the misinterpretations and mistakes of our former guides, but at the fact that they were able to get so close to the truth as they actually did.

In the cases of Egypt and Greece the new knowledge has taken us back to the beginning of things, to the days before history, but this is not the case with Babylonia. Even as far back as we can go, to about the middle of the fourth millennium B.C., we are still within the age of knowable history, and the inscriptions still contain the names of kings and temples which we can decipher. So far are we from reaching any "prehistoric" period that instead of attaining the beginning of Chaldaean civilization we have apparently dug only as far as the latter 


\section{THE ANCIEN' HISTORY OF 'THE NEAR EAST}

end of its early period; we have reached and passed the beginnings of Semitic rule in Mesopotamia only to find ourselves witnessing in this, the most ancient stratum of the known history of the world, the latter end of the pre-Semitic culture to which the civilization of Babylonia owed its inspiration. These evidences of human barbarism which elsewhere in the world precede the traces of civilization are in Babylonia absent; hardly a single weapon of flint or chert testifies to the existence there of a Stone Age; when we first meet with them the Babylonians were already metal-users and already wrote inscriptions which we can read.

In dealing with Mesopotamia, therefore, we never get beyond the domain of true history; we are from the beginning arranging and sifting written contemporary records in order to collect from them the history of the country. In the case of Egypt, however, we go right back to the period before writing began, and have to reconstitute the story of the earliest ages from the evidence which archaeological discovery has recovered as to the earliest development of civilization. And in Greece and Anatolia we depend largely upon the evidence of archaeology alone, for there, though we possess the inscriptions of Greeks and Anatolians who lived in a high state of civilization contemporaneously with Egyptians and Babylonians whose records we read almost as well as our own, they remain a sealed book to us. We cannot yet read a word of them, and so have to guess at the probable course of the history of their authors, with the help of archaeological discovery and the few hints which the Egyptian and Mesopotamian records afford us.

Yet archaeological discovery alone suffices to give us the main outlines of the history of early Greek civilization, though we know nothing of the actual events which moulded its development, and have never heard the names of the authors of these events. Archaeology alone has revealed to us in Greece the monuments of a civilization, "prehistoric" because we cannot yet read its history, which was as highly developed and as important in the annals of the world as those of Egypt and Mesopotamia. And from the study of these monuments and remains we have been enabled to arrive at a knowledge of the cultural relations of early Greece which are nothing less than revolutionary. We see that, instead of belonging originally to the central and North-European "Aryan" race, the group 
of peoples speaking Indo-European languages to which we ourselves belong, and being in its origins radically distinct from the civilization of Egypt and of Asia, the oldest culture of Greece really belongs to the Mediterranean basin, where it originated, and so is from the beginning part of the culture of the other Mediterranean peoples, to which the civilization of Egypt also attaches itself to some extent. We know now that the Mediterranean peoples have always been and are to this day more or less allied to each other racially. ${ }^{1}$ In reality the brunet Italian and Greek of to-day are racially far more closely related to the Palestinian and the Egyptian than to the Celt, the Slav, or the Teuton, although now they speak, and for three thousand years past they have spoken, languages akin to those of their northern neighbours. These languages were imposed upon them by Aryan conquerors, and the period at which this conquest took place is approximately fixed, in Greece at least, by the dark age which intervened between the "prehistoric" and the classical civilizations of Hellas. The Greek civilization which we have always known is the product of the mingling of the invading northern culture of the Aryanspeakers, with the remains of the ancient "Mediterranean" civilization not distantly related to that of Egypt, which had grown up from its earliest beginnings in the Aegean basin, as that of Egypt had grown up in the Nile Valley. That the Aegean "Mediterraneans" were from the first Aryan-speakers is not in the slightest degree probable. ${ }^{2}$ We can trace their

1 The conception of a "Mediterrancan" race to which the typical brunct peoples of the Mediterranean basin (and outside it as far as Britain) belonged and belong, was first crystallized in logical form by an Italian, Sergi (La Stirpe Mediterranea, I895; Englished as The Nediterranean Kace, London, I901). To his views, based on the study of craniology, and (if one may use the phrase) "ethnic chromatology," the philological work of KRETSCHnLR (see below) forms a complement.

${ }^{2}$ It has been argued from the purely philological standpoint by KRETSCHMER in his brilliant Einteitung in die Geschichte der griechischen Spracke (Göttingen, I896) that a non-Aryan language or group of languages, akin to the non-Aryan Lycian of Asia Minor, was spoken in Greece before Aryan Grcek. And presumably this language was spoken by the civilized predecessors of the Aryan-speaking Greeks, whom we call "Aege:uns," "Mfycenaeans," or "Minoans." And since the culture of these pre-Greeks is directly descended from that of the Neolithic Aegeans (see p. 31, below), their language was presumably descended from that of the Neolithic Aegeans. This is not certain, of course, but the presumption is justified. And it is at any rale not probable that, if the Neolithic Aegeans did speak a language radically distinct from that of their culture descendants, this language was Aryan! No one could claim that the Neolithic peoples of the Western Mediterranean probably spoke Aryan 
culture from its Neolithic beginnings, and can even discern a possibility that these beginnings may have been derived from Neolithic Egypt: nobody has yet supposed that the Mediterranean, far less the Nile Valley, was the original home of the Aryans. Yet that seems the necessary corollary of a supposition that the prehistoric Greeks were Indo-Europeans. And we know that almost to the last there survived on the north Mediterranean shores isolated patches of non-Aryan speech (the Basque still survives) which are naturally to be regarded as the survivors of a general pre-Aryan language-stratum.

Archaeology alone has thus assigned the early culture of Greece rather to the Near East, or at any rate to the Mediterranean, than to Europe, to the non-Aryan races than to the Aryan.

The entry of Greece into the ranks of the ancient civilizations of the Near East as the fellow of Egypt and Babylon is one of the most striking results of modern archaeological discovery.

It cannot be denied that the increase of knowledge thus roughly sketched is very considerable, nor can it be doubted that the names of the first discoverers of the New World of ancient history, Champollion and his peers, are full worthy to rank with those of Columbus, of Galileo, of Newton, or of any other discoverer of new worlds of human science.

\section{Archacology and History}

There is no need now to recapitulate the steps by which these discoverers arrived at their knowledge, which is now accepted science. ${ }^{1}$ The languages of ancient Egypt, of

tongues: why then should those of the East have done so? The thesis that the Bronze Age people of Crete and the islands and probably of the Peloponnese also were non-Aryan-speakers, and that "Greek" first came with the northern invaders at the end of the Bronze Age into Greece, is now generally accepted in England and Italy, but elsewhere many writers still cling, in defiance of the philological and ethnological evidence, to the old-fashioned view that the Greeks were all and from the beginning "Aryans." But one is glad to see that one of the latest Slav historians of Greece, M. PERouTKA, fully accepts the new view (Dejiny reckes [History of Greece], i., doba predhistoricka; Prague, I908).

'For an account of the beginnings of Egyptology, see Budge, The Mummy', pp. $108 \mathrm{ff}$; for the beginnings of cuneiform study, sce KING, The Assyrian Language (London, 1901), and Boorh, The Trilingual Cuneiform Inscriptions (London, 1902), passim. 
Assyria, of Elam, even of pre-Semitic Babylonia, are now sufficiently known to enable us to translate their ancient inscriptions with an accuracy sufficient for all practical purposes, and from these, the ancient records, combined with the critical analysis of such traditions as have been handed down to us by classical authors, we derive our knowledge of the actual events of the ancient history of Egypt, Mesopotamia, and Persia. Although the hieroglyphic inscriptions of Anatolia are not yet translated with certainty, the use by the ancient Anatolians of the cuneiform (Babylonian) script side by side with their own hieroglyphs has enabled us lately to obtain glimpses of their history. Only in the case of prehistoric Greece are we denied first-hand knowledge of events, and are forced to content ourselves with a knowledge of the development of culture, derived solely from archaeological discoveries and comparisons. Greek legends no doubt would tell us much, had we any firm standpoint of known history from which to criticize them. As it is, they can but give us doubtful and uncertain hints of the events which they shadow forth. ${ }^{1}$ In the case of Egypt, Mesopotamia, and Persia, more especially in the case of Egypt, the archaeologist is the chief auxiliary of the historian, for he makes it possible, by means of his excavation of the actual remains of ancient civilization, to supplement the record of events with the story of the development of culture. In the case of early Greece we have this story, though it is as yet far from complete, without any framework, any skeleton of known events which it would clothe; with the exception of a few facts supplied us by the Egyptian records. In Greece and in Anatolia the archaeologists go on discovering, besides the actual remains of the culture and art of the "Minoans" and "Hittites," tablet after tablet, inscription after inscription, which we cannot read. But in Egypt and in Mesopotamia they are every day bringing to light new documents which we can read, and from which we are every day learning new facts of history. If most of the larger monuments of Egypt have always been above ground, and needed but the skill of the copyist and the knowledge of the decipherer to make them yield up their secrets, this was by no means the case with Assyria, where the famous excava-

1 On the value of tradition to the historian, see a note by the late Prof. FREDK. YoRk POWrLl in Mr. Oliver Elton's life of him, vol. ii. pp. $242 \mathrm{ff}$. 
tions of Layard resulted in the discovery of Assyrian history. ${ }^{1}$ And during the last thirty years excavation throughout the Nearer East has resulted in the discovery not only of new inscriptions to be read, but also (and this more especially in Egypt and Greece) of the actual remains of ancient art and civilized life which enable the archaeologist, properly so-called, to reconstruct the story of the development of human culture without the aid either from classical historian or ancient inscription. The work of the Egypt Exploration Fund, with which the names of Naville and Petrie will always be associated, ${ }^{2}$ and that of Maciver, ${ }^{3}$ Reisner, ${ }^{4}$ Garstang, ${ }^{5}$ and Legrain ${ }^{6}$ in Egypt, that of the French expeditions of M. de Sarzec at Telloh in Babylonia, ${ }^{7}$ and of M. de Morgan in Persia, ${ }^{8}$ of the Palestine Exploration Fund, ${ }^{9}$ of the Austrian Dr. Sellin ${ }^{10}$ and the German Dr. Schumacher, ${ }^{11}$ and now of the American Reisner in Palestine, ${ }^{12}$ that of Dr. Winckler at Boghaz Kyöi in Anatolia, ${ }^{13}$ and, last but not least, that of Schliemann in Greece, ${ }^{14}$ and of the Italians Halbherr and Pernier, ${ }^{15}$ and the Britons Evans and Mackenzie ${ }^{16}$ (besides others, Italian, British, and American) in Crete,-all this work of actual excavation during the last three decades has resulted in the production of historical material of the first importance. And the historians await each new season's work of the excavators with impatience, knowing that something new is sure to be found which will add to their knowledge and modify their previous ideas.

\footnotetext{
' Published in Monuments of Nineveh and Babylon (London, 1851). The plates of the somewhat earlier work of Botta (Paris, I 849), describing the French discoveries at Khorsabad, are better than Layard's.

2 Publications of the Egypt Exploration Fund, 1883-1912.

${ }^{3}$ El Amrah and Abydos (Egypt Exploration Fund, 1902).

${ }^{4}$ Early Dy'nastic Cometcries of Naga ed.Dir (Leipzig, 1908).

${ }^{5} \mathrm{El}$ Arábah (London, Igor) and later books.

${ }^{6}$ Results of the excavation of Karnak, published chiefly in the Recueil de Travaux (Paris) and the Annales du Service des Antiquités (Cairo).

7 Dirouzvertes en Chaldée (Paris, 1887 et seq.).

${ }^{8}$ Mémoires de la Délisgation en Perse (Paris, igoo et seq.).

${ }^{9}$ Quarterly Statemeints (P.E.F.Q.S.): Macalister and Mackenzle, passim.

10 Tell Táannek (see p. 440, n. 4).

11 Tell el-Mulescllim (see p. 440, n. 4).

12. Dr. Reisner is now excavating at Samaria. His results are not yet published.

${ }^{13}$ Mitteilungen der Deutschen Orient-Gesellschaft (M.D.O.G.), Dec. 1907.

14 Summarized by Schuchhardr (Schliemann's Discoveries, London, 1891).

${ }^{15}$ Published in the Rendiconti della R. Accademia dei Lincci (Rome); and elsewhere.

${ }^{16}$ Annual of the British School at Athens (B.S.A. Ann.), $1904 \mathrm{ff}$.
} 
Our knowledge of the early history of the Near East is still in the making, and the progress cffected after the lapse of some years may well be noted by a comparison of the original and the modern editions of the two great rival histories of Professors Maspero ${ }^{1}$ and Eduard Meyer, ${ }^{2}$ besides the successive landmarks provided by the Egyptian histories of Brugsch (I 879), ${ }^{3}$ Wiedemann (I 884), Pctrie (I 894-1905), ${ }^{4}$ Budge (I90I), and Breasted (1906), ${ }^{6}$ and the histories of Assyria and Babylonia by Rogers (I9OI), ${ }^{7}$ Goodspeed (I903), ${ }^{8}$ and King (I9IO). ${ }^{9}$

\section{Classical Sortrces}

The work of the modern historians is based almost entirely upon our modern knowledge of the ancient records. The accounts of the Greek writers, while of the highest interest as giving the impressions of men in whose time the ancient civilizations still survived, are of little value to the historian. Though they lived when Egyptian was still spoken and the Egyptian culture and religion were still vigorous, they could neither read nor understand Egyptian, while we can. The monuments were a sealed book to them and, indeed, to most of their Egyptian informants. Their material was chiefly folk-tradition, which, in Egypt at lcast passed current for history. With our full knowledge we can see how sometimes they are giving us a very fair version of the truth, while at other times they are wandering in realms of fable. Herodotus, while his story of Egypt is curiously jumbled and unequal in value, has in the case of Media provided us with material of first-rate importance which must have been communicated to him by an unusually accurate authority. ${ }^{10}$ The work of

1 Hisloire Ancienne de POrient Classique (Paris, I895-9), and the successive volumes of the English translation (S.P.C.K.), The Dawn of Cizilization (I $\delta_{94)}$, The Struggle of the Nations (1896), and The Passing of the Empires (1900).

2 Geschichte des Altertums, and ed., I909.

'Egyt usuder the Pharaolis (London, Murray); an improvement on the German edition of 1877 .

+ History of Egypt (London, Methuen), 3 vols.

${ }^{5}$ History of Egypt (London, Kegan Paul), 8 vols.

${ }^{6}$ History of $E_{\delta y}{ }^{\prime} p t$ (London, Hodder \& Stoughton); abridged, Smith Elder, 1908.

' History of Babylonia and Assyria (London, Luzac).

${ }^{8}$ Hislory of the Babylonians and Assyrians (London, Smith Elder).

${ }^{9}$ History of Sumer and Akkad (London, Chatto \& Windus).

${ }^{10}$ Probably family tradition derived from the Median Harpagide fanily of satraps who ruled Caria for the Persians. Ilalikarnassos lay on the Carian coast. 
Ktesias the Knidian, the physician of Artaxerxes Mnêmôn, is, on the contrary, though he had first-hand knowledge of Persia absolutely valueless for history, and appears to be little more than a mere tissue of fables, at least as far as the pre-Persian period is concerned. Diodorus' sketch of Assyrian history is of little value, and seems to be chiefly based upon Ktesias. His history of Egypt, however, is of much greater value; it is not so accurate on the whole as that of Herodotus, and there is much of the purely legendary and even of the fantastic interwoven with his narrative, but it is interesting as giving us an account written by a visitor to Egypt, independent of either Herodotus or Manetho. That this account is partly derived from Ephoros seems extremely probable. In one matter Herodotus seems to be followed: the mis-dating of the kings who built the Pyramids of Giva. Herodotus placed them entirely wrongly, and Diodorus repeats his mistake. But the latter makes some estimates as to the length of the Pharaonic period which, we now know, may have been curiously near the truth. ${ }^{1}$ Herodotus gives, on the whole, a very good account for his time of the different salient periods and characteristic kings, but he has got them in a curiously mixed-up order; he puts the great Pyramid-builders of the IVth Dynasty (c. 3500 B.C.) after Rhampsinitos (Rameses III) of the XXth (c. I 200 B.C.), ${ }^{2}$ and is followed in this mistake by Diodorus. ${ }^{3}$ An explanation may be given of this curious blunder. It may be of Egyptian origin, and we may be blaming the Father of History unjustly for what is not his fault at all. When we come to deal with the Saite period of Egyptian history, the period of the Psammetichi and Amasis, shortly after the close of which Herodotus visited Egypt, we shall see that one of the most curious and characteristic phenomena of the time is the curious archaism which had set in, and not only in the domain of art. The period selected for imitation was that of the Pyramid-builders, whose gigantic monuments, surrounded by the necropoles of their faithful subjects, still towered above Memphis, and insistently compelled the regard and curiosity of all men, as they do to this day. Not only did the artists and architects of the Saite

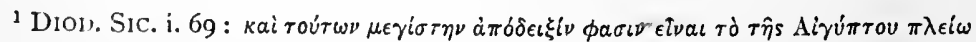

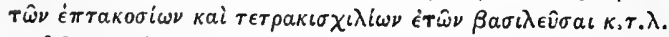

${ }^{2}$ IIDT, ii. $124 \mathrm{ff}$.

${ }^{3}$ i. 63 ff. 
renascence turn away from the caricatures of the work of the XVIIIth and XIXth Dynasties which had been the pride of their immediate predecessors, and seek new models in the ancient triumphs which were constantly before their eyes: the officialdom of Egypt also reverted to ancient and forgotten titles and dignities, with the result that the Saite period was a kind of parody of the IVth and Vth Dynasties, which had flourished three thousand years before. ${ }^{1}$ The idea might then well have grown up among the people generally that the period of the Pyramid-builders was not so very many years before their own time, in any case much nearer to them than the age of Rhampsinitos, the period of the great Theban kings. Herodotus's blunder may then be based upon some such popular mistake as this. ${ }^{2}$

\section{Native Sources}

It remains to speak of the work of ancient Egyptian and Babylonian historians. Besides the contemporary monuments of various periods, we have at our disposal ancient annals, often fragmentary, and usually telling us nothing more than the succession of the kings and sometimes the length of the dynasties. The most ancient official archive that we possess is Egyptian: part of a stelé which when complete contained a regular history of the events of the reigns of the early Egyptian kings up to the time of the Vth Dynasty, when it was compiled. Only a fragment of it is now preserved (in the Museum of Palermo ${ }^{3}$ ): so far as it goes it is the most complete ancient "history" known, and is probably very accurate; its fragmentary condition is the more tantalizing on this account. The later official lists of kings which we find inscribed on the walls of temples and tombs of the XVIIIth and XIXth Dynasties are complete enough, but give us nothing but a bare string of names. Nevertheless, these have been of the greatest use to us, and in

1 A parallel may be found in the modern Greek revival of ancient names and titles for official use.

2 This seems a more probable explanation than another, which would make Herodotus edit his own notes carelessly, and place the kings in the order in which he came to their monuments in going up the Nile.

"Hence it is known as the "Palermo Stele." The latest publication of it is by Schn̈fer, Ein Bruchstïck altaegyptischer Annalen (Abhandl. der $K$. Preuss. Akademic der Wissenschaften, 1902). $\Lambda$ new fragment, as yet unpublished, is reported to be at Cairo. 
conjunction with the work of the priest Manetho, of which we shall shortly spcak, have formed the framework upon which our knowledge of the history of the reigns from the contemporary monuments has been built up. At the same time we have been able to see that one of these lists, that of Karnak, compiled in the reign of Thothmes III, is very inaccurate and of little use; while those of Abydos and Sakkara, ${ }^{1}$ of the reigns of Seti I and Rameses II, are of remarkable accuracy, and have rarely been contradicted by the monuments. The compiler of the Karnak list had included simply prominent traditional names in a guessed order. But Seti's historian, and the priest Tunrei who made the list at Sakkara, were accurate annalists. It seems probable that shortly before the time of Seti the monuments of the most ancient kings at Abydos had been identified, and this may have caused some careful study of the antique archives. ${ }^{2}$ We have a written list of kings on papyrus, now preserved at Turin, which is of the same date as the king-lists of Abydos and Sakliara, and, were it in better condition, would be almost as valuable. It should have been more valuable, since it adds the regnal years of each king, and gives the sum-totals of the years of the several dynasties; but, unluckily, these statements of years do not always agree with the evidence of the monuments. Its mutilated fragments have been studied with care, notably of recent years by Professor Eduard Meyer, 3 and though opinions may differ as to its general value, there is no doubt that it may be used with discretion to supplement the other lists. With these our native sources for Egyptian history before the Greek period close. No real historian is known to us in Pharaonic Egypt, nor is it likely that one will ever be discovered. The Egyptian had very little historical sense, and to him, as to his modern descendant, a popular legend was as worthy of credence as the most veracious chronicle.

The Babylonian scribe was, however, of a more critical and careful turn of mind, and collected what he could of genuine history with great industry. To him we owe several fragmentary chronicies, and a list of kings compiled in the time of the second Babylonian kingdom (sixth century B.C.); and to the official scribes of King Ashurbanipal of Assyria (seventh

\footnotetext{
'Illustrations of the three lists are given by BUDGE, Hist. Es. i. pp. I2 Iff., with
references to publications.

${ }^{2}$ See p. 103.

${ }^{3}$ Aegryptische Chronologie (Abhandl. der K. P. Akad. 1904).
} 
century) we owe an interesting document, a diplomatic memorandum on the ancient relations between Babylon and Assyria, which is known as "The Synchronous History." These Mesopotamian sources are far more historical in character than anything Egyptian save the "Palermo Stone": when they gave more than the bare names of lings they give obvious facts, not mere old wives' tales, like the Egyptians. ${ }^{1}$

IVe now turn to native historiographers who wrote in Greek and under Greek influence. When Greek kings sat on the throne of the Pharaohs and it became fashionable to inquire into the past history of the extraordinary country which had been brought willy-nilly within the pale of Hellenism, a learned priest named Manetho, "The Gift of Thoth" (Manethoth), or possibly "The Gift of Buto" (Manutjo), of Sebennytos in the Delta, was commissioned by Ptolemy Philadelphos to collect all that was known of the Egyptian annals and translate them into Greek as Aigurrouxci. This was done, and until the discoveries of Champollion Manetho's work, half destroyed as it now is, imitated and garbled by generations of ignorant copyists, was, with the exception of the sketches by Herodotus and Diodorus, the sole Egyptian authority on the history of Egypt. A similar rôle with regard to the history of Mesopotamia was played by the work of a Babylonian priest named Bērössos, who is said to have been a contemporary of Antiochus II (250 B.C.). ${ }^{2}$ Like that of Manetho, his work is only known to us through the labours of copyists and compilers. The value of Manetho's work has been differently estimated by different writers. It is quite true that the mistakes of his copyists have caused considerable divergences in many cases as to length of individual reigns and sum-totals of dynasties, but in general it must be said that his work has proved remarkably useful. His arrangement in dynasties, which has been preserved in almost identical form by Julius Africanus, Eusebius, and George the Synkellos, formed the basis of the arrangement by Champollion

I These Babylonian sources are collected in SCHRADER, Keilinschriftliche Bibliothek, and criticized by L. W. KING, Chronicles concerning Early Babylonian Kings (London, 1907).

2 The most accessible edition of Manetho and Berossos is in CoRy's Ancient Fragments (London, I832). See also Müller, Fragm. Hist. Gr. ii. 5II-6I6. A probable reference to Manetho himself has been found in a contemporary papyrus (Grenfell. and Huxt, El Hibeh Papyri, i. 223). On Berossos, see King, Chronicles concerning Early Babylonian Kïgss, i. pp. goff. 


\section{I4 'THE ANCIEN' 1 HISTORY OF THE NEAR EAST}

and Lepsius of the names of the actual kings which had been recovered by the new science of Egyptology from the monuments, and it is worthy of note that these names have fitted on the whole extremely well into the Manethonian dynasties. The number of the kings in each dynasty is usually correct, even if the years of their reigns vary in the different versions, and even if the sum-totals are often added up wrong; and the number of dynasties has been found to be practically correct also, the only apparent mistake being in the intermediate period between the XIIIth and XVIIIth Dynasties; here we seem to have too long a period assigned to the intervening four dynasties. This jumble is, no doubt, primarily due to confusion in the native records from which Manetho drew his materials; the period was one of foreign invasion and conquest. Further, the more important the period is, the more flourishing the dynasty, the more accurately it is given by Manetho; his lists of the XIIth, XVIIIth, and XIXth Dynasties, for instance, the most flourishing periods of Egyptian history, are by no means very widely removed from the truth. In fact, Manetho did what he could: where the native annals were good and complete, his abstract is good; where they were broken and incomplete, his record is incomplete also and confused; and when we take the mistakes of copyists and annal-mongers into account, it will be seen that, as is also the case with Herodotus, so far from stigmatizing Manetho's work as absolutely useless, we may well be surprised at its accuracy, and be grateful for the fact that it agrees with the testimony of the monuments so much as it does! The work of Berossos as it has come down to us is of a slighter character than that of Manetho, and contains much that we should be inclined to assign to the realm of mythology rather than history, but what there is that is historical agrees very well with what has since been discovered. It could never, however, have served as a skeleton whereon to build up the flesh and blood of Mesopotamian history, whereas the scheme of Manetho, fragmentary and disjointed as it is, has actually formed the skeleton which modern discovery has clothed with tangible flesh. The dynasties of Manetho are the dynasties of history.

Other chronographers there were who dealt with Egypt and Assyria, such as Eratosthenes with the one and Abydenus with the other, but their work has not proved very important. With them our survey of the ancient authorities closes. 


\section{Chronology}

Neither the Egyptians nor the Babylonians ever devised a continuous chronological scheme based upon a fixed era. The Sothic cycle of 146I years, though it was used to regulate the calendar, was never used by the Egyptians as an era. The early Egyptians and the Babylonians spote of individual years as "the year in which (such-and-such an event) took place"; later on the Egyptians reckoned by the regnal years of each individual king. Such a reckoning is singularly useless for the purposes of continuous history, when we have no certain information as to how long a king reigned. In Egypt the only list of regnal years we possess, the fragmentary "Turin Papyrus," often disagrees with the evidence of contemporary monuments, while the Ptolemaic chronicler Manetho's figures have, as we shall see, been so garbled by later copyists that they are of little value. In Assyria it is otherwise. There, the years of the king's reign were currently noted by the yearly appointment of an official, a sort of $\alpha \rho^{\prime} \chi \omega \nu \varepsilon^{\prime} \pi \dot{\omega} v \nu \mu \rho s$, who gave his name to the year. The office of this official was called limmu. Of these officials of the limm we have long lists, dating from the reign of Adad-nirari II (9I I-890 B.C.) to that of Ashurbanipal (669-625 B.C.), some of which give an account of events which happened during their years of office. At the same time, on the cylinders and other clay records of Assyrian history, after the account of the events of a particular year, the name of the limmu-official is usually given. It is then evident that, with the lists of the limmi in our hands, if one of these eponymies can be fixed, we can accurately date the events dated by their means in the records. Now we are told that in the eponymy of Pur-shagali (?), in the month Sivan (May-June), there was an eclipse of the moon. This eclipse has been astronomically reckoned to have taken place in 763 B.C. The correctness of the identification is confirmed by the fact that the "Canon of Ptolemy" (a list used by the geographer Ptolemy, giving the names and regnal years of the kings of Babylon from Nabonassar to Alexander the Great, with the eclipses observed during their reigns) assigns to the thirtieth year of the era of Nabonassar (=709 B.C.) the accession of "Arlieanos." Now Sargon of Assyria, who must be "Arkeanos," ascended the Babylonian throne about this time, and the year of his 
accession is that of the thirteenth of his rule in Assyria, and of the eponymy of Mannu-ki-Ashur-li. Therefore this eponymy must fall in 709 B.C. And if we trace back the lists of eponymies from Mannu-ki-Ashur-li to Pur-shagali, we find that the year of the latter falls in 763 . The dates of the limmu are then absolutely certain.

Therefore, as far back as the tenth century B.C., Assyrian dates are certain, and the value of this certainty when we are dealing with the confused chronologies of the Biblical writers may easily be understood. Thus, when we find that Ahab was one of the allies defeated by Shalmaneser II at Karkar in 854 B.C. (an event not mentioned in the Old Testament record) we know that Ahab was reigning over Israel in 854 B.C., and any chronological theorizing as to Old Testament dates which takes no account of this fact is utterly worthless. Then when we find that the same King Shalmaneser received in 842 tribute from Jehu (an event recorded on the famous "Black Obelisk," now in the British Museum), we know that Jehu was reigning in $842 .{ }^{1}$ So that the current Biblical chronology which makes Ahab reign from 899 to 877 and Jehu from 863 to 835 is obviously confused. But with the help of the infallible Assyrian eponym-list we can restore the real dates with some success, with the result that Ahaziah seems to have in reality succeeded Ahab in $85 \mathrm{I}$, and was succeeded by Jehoram about 844 , while Jehu attained the throne in $843-2$, the year of his embassy to Shalmaneser. Reckoning back, we find that the division of the Hebrew kingdom after the death of Solomon must be assigned to somewhere between 950 and 930 B.C. And this fact gives us a very important Egyptian date, that of the beginning of the XXIInd Dynasty, when Sheshenk I invaded Southern Palestine.

1 Mr. Cecil Tork says (Memphis and Nycenae, p. 20): "Ahab of Samaria can hardly be identified with an Ahab of Sirhala in Shalmaneser's inscriptions; or Jehu of Samaria, who was a son of Jehosaphat, with a Jehu, son of Omri, whose country is not named." Mr. Torr's scepticism is unnecessary. Sirhala is simply Israel, and the Ahab king of Sir'ala (Israel) who was defeated by Shalmaneser II can only be the only Ahab of Israel known to us. Mr. Torr might just as well argue that M. de Bismark was not the same person as Fürst von Bismarck! It is true that the Jehu of the "Dlack Obelisk" is called "son of "Omri," while the Jehu of the Bible was the "son of Jehoshaphat, the son of Nimshi," but in another place he is called "son of Nimshi," and anybody who is familiar with Oriental modes of expression knows that "son of" constantly means "descendant of" or merely "of the house of." Jehu was the son of Jehoshaphat, who was either the son or a descendant of Nimshi, of the house of 'Omri. 
That this prince is the Shishak of the Biblical record there is no doubt. If Shishak's date is nearer 930 than 950 B.C., we have approximately settled an important landmark in Egyptian chronology; and know that the last Theban dynasty, that of the "Priest-Kings," came to an end \pm 940 B.C."

The regnal years assigned to Solomon, David, and Saul are too obviously traditional for us to place much reliance upon them, but their reigns were evidently long, so that we can reasonably assign to them the duration of a century: we thus find that the earliest possible date for the election of Saul the son of Kish is 1050 B.C., about the time of the division of Egypt between the dynasties of the priest-kings at Thebes and their lay rivals at Tanis. Palestine, as we know, had always been Egyptian territory since the conquests of Thothmes I, and it was not until the Pharaonic kingdom had fallen into utter weakness under the rois faincants of the XXth Dynasty, and their kingdom had been divided between their ecclesiastical Mayors of the Palace at Thebes and the practically independent viceroy of the Delta, that the last remnant of Egyptian empire in Asia fell away, and the Hebrews were enabled, in default of a legitimate overlord in Egypt, to elect a king of their own. The date of 1050 B.C. is then indicated by both Egyptian and Jewish records for the end of the XXth Dynasty, the decease of the last legitimate Ramesside, and the constitution of an independent kingdom in Palestine.

Egyptian sources do not give us much information which will carry us farther back with much certainty: we must again have recourse to Assyrian help to enable us to reconstitute the chronology not only of Assyrian but of Egyptian history also. As has been said, the Egyptians possessed no continuous era of any kind. They did not even proceed as far as the Babylonians and Assyrians in this direction. It is true that on a stele from Tanis ${ }^{2}$ mention is made of the year 400 of King Nubti, which corresponded to an undetermined year of

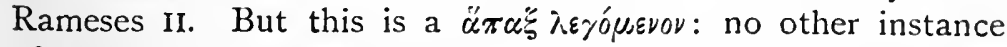
of an era is known in Egypt, and this era, which is dated from the reign of an almost unknown Hyksos king, Set-aa-pehti Nubti, whose only contemporary monument is a scarab in the

1 The best study of the Biblical clironology is that of Professor Karl Marti, Encyclopadia Biblica, s.v. "Chronology."

${ }^{2}$ Illustrated by BuDGE, Hist. Eg. iii. 157. 
British Museum, ${ }^{1}$ is never found repeated. The only date ordinarily used is that of the year of the king, and when, as was often the case, the heir-apparent was associated with the reigning monarch on the throne, complications ensue: the year 5 of one king may be the same as the year 25 of another, and so on. All we can do is simply to reckon back the known number of years of each king, taking into account known co-regencies and collateral reigns as we come to them, and checking the result by the years of kings and dynasties as given by Manetho, and by the known synchronisms with the more definitely fixed dates of Babylonian and Assyrian history. Attempts have been made to find a heroic remedy for these difficulties with the help of astronomical data. Unluckily the Egyptians seem to have attached no particular importance to eclipses, and never chronicled them. Another, and regular, astronomical event was, however, often recorded. This was the heliacal rising of the star Sothis or Sirius. Properly speaking the heliacal rising of a star means its rising contemporaneously with the sun, but it is obvious that such a rising could not be seen or observed: in practice the "heliacal rising" means the latest visible rising of the star before the sunrise, about an hour before sunrise. Sirius rises heliacally about the time of the beginning of the inundation, which was from the earliest times regarded as a convenient time from which to date the beginning of the year. The Egyptian year, which had originally consisted, like the Babylonian year, of lunar months, had, at a very early period, beet re-arranged in an artificial scheme of three seasons, each of four months of thirty days each, with five epagomenal days to make up 365 days. A leap year, to make up the loss of a day in four years, owing to the real length of the year being 3654 days, was never introduced. The first season was that of the Inundation, the second that of the Sowing, the third that of the Harvest. The first month of the first season, originally the month of Mesore, was in later times the month Thoth, and the Ist Thoth was, after the time of the XIIth Dynasty, nominally the beginning of the year. ${ }^{2}$ But the actual feast of

\footnotetext{
${ }^{1}$ Certain doubts as to the historical character of King Nubti have been resolved by this scarab. See p. 219 , post.

2 On Mr. Alan GaRdiner's discovery of the original place of Mesore as the first month of the Egyptian year, and the conclusions which may or may not be drawn from the fact, see below, p. 25 .
} 
the New Year was always celebrated on the day of the heliacal rising of Sirius at the beginning of the inundation. When the calendar was introduced this day must have been the Ist day of the ist month. But eight years later it was the 29th of the preceding month (the $4^{\text {th }}$ of the Harvest Season), because in eight years the calendar, being unprovided with an extra day every fourth year, had lost two days. And so on; and it was not till 1461 years had passed that the heliacal rising of Sirius and the real opening of the year once more fell upon the Ist day of the Ist month, a whole year having been lost out of the 146I. In the meantime the official names of the seasons had of course gradually come to bear no relation to the real periods of Inundation, and Sowing, and Harvest, and then had gradually come into line again.

We are informed by a Latin writer of the third century A.D. named Censorinus ${ }^{1}$ that the rising of Sirius coincided with the Ist Thoth in the year I39 A.D., so that a new Sothic cycle of 1461 years began in that year. We have also an Alexandrian coin of 143 A.D. which commemorates an epoch with the word $A I \Omega N .{ }^{2}$ In the Decree of Canopus (238 B.C.) the rising of Sirius appears as occurring on the Ist of Epiphi, the tenth month: if this were so, the rising would happen on the Ist Thoth in I 43 A.D. ${ }^{3}$ Thus 143 A.D. seems a more probable date for the beginning of a new cycle than I39; but in any case we see that this event must have taken place about I4O A.D.

The fact that the months came round full circle again after a period of I46I years had no doubt been noted by the Egyptians, as we find that Theon of Alexandria, who evidently computes from the date I 39 A.D., makes the preceding cycle begin in 1322 B.C., and calls it the "Era of Menophres." And the name Menophres is extremely like the "throne-name" of Rameses I, Men-peh-ra, whom on other grounds we should be inclined to place very near this date.

But this does not mean that the Egyptians ever used the Sothic cycle as an era: they never computed by its years. This, however, in no way affects the fact that the cycle of the

${ }^{1}$ On Censorinus and his statements, see Burrows, Discoveries in Crete, p. 69, n.

${ }^{2}$ Brit. Mus. Cat. Coins of Alexandria, No. roo,.

3 TORR, Memphis and Mycenae, p. 54. This little book, by the way, should be used with great caution, since while keenly logical in its reasoning it takes no account of probabilities, and ignores the controlling evidence of the Mesopotamian monuments. 
risings of Sirius may be of considerable use to us in reconstructing Egyptian chronology. Thus, were it unknown that the Decree of Canopus was inscribed in 238 B.C., we should have been able, taking Censorinus' date for the end of the cycle, to have arrived very near the correct date by calculating when the star rose heliacally on the last day of Epiphi.

Now, leaving out of account the date of Menophres (since, though he is probably Men-peh-ra, we do not certainly know this), we find that in a certain year of the reign of Thothmes III the New-Year feast fell upon the 28th day of the eleventh month (Epiphi). This can only have been between the years I 474 and I 470, which must therefore have fallen in his reign.

Going farther back, we find that in the ninth year of Amenhetep I, the feast fell upon the 9th Epiphi, which means that his ninth year falls between 1550 and I 546 B.C. Now this period of eighty years between Amenhetep I and Thothmes III is very much what we should have expected from our knowledge of the history of the time.

The date for Thothmes III is confirmed by the identification of two New-Moon festivals in his twenty-third and twentyfourth years (on the 2Ist Pachon and 3oth Mekheir) with those of May I 5, I 479, and Feb. 23, 1477, according to Meyer.

These two very important dates for Thothmes III and Amenhetep I are amply confirmed by evidence from the Babylonian side, which makes it impossible for us to place Thothmes later than the earlier half of the fifteenth century. We know from the great collection of cuneiform tablets containing the official correspondence of the Egyptian kings Amenhetep III and Akhenaten, of the XVIIIth Dynasty, with the kings and governors of Western Asia, which was discovered at Tell el-Amarna in Egypt in I888, that King Ashur-uballit of Assyria communicated with Akhenaten. Assyrian chronological evidence assigns to Ashur-uballit the date of circa I 400 I.C.

Ashur-uballit was the great-great-great-grandfather of the Assyrian king Tukulti-Ninib. Now, Sennacherib made a copy upon clay of an inscription of Tukulti-Ninib which had been cut upon a lapis-lazuli seal; this seal had been carried off to Babylon by some successful conqueror of Assyria, and Sennacherib found it there after he had vanquished the Babylonians and had captured their city. We know that Sennacherib 
reigned from about 705 to 68 I B.C., and he tells us in a few lines added to his copy of the writing on Tukulti-Ninib's seal that the lapis-lazuli seal was carried off to Babylon 600 years before his own time. This "60o years" is obviously a round number, but it shews that Tukulti-Ninib must have reigned about the middle of the thirteenth century B.C. Further, in an inscription recently found at Kala Sherkat, the ancient Ashur, Esarhaddon says that King Shalmaneser I renewed the temple of the god Ashur 580 years before his time, i.e. about I 260 B.C. And Tuliti-Ninib was the successor of Shalmaneser, which gives the same date, about I250 B.C., for him as Sennacherib's statement. ${ }^{1}$

Ashur-uballit can hardly have lived less than Ioo years before Tukulti-Ninib; thus it is clear that the date which we must assign to the reign of Ashur-uballit, and therefore to that of Amenhetep III, cannot be much later than I 400 B.C. ${ }^{2}$ And between Thothmes III and Amenhetep III about half a century had elapsed. Incidentally, Esarhaddon's date for Shalmaneser (confirmed by Sennacherib's for Ashur-uballit) gives us the correct date of the Egyptian king Rameses II. For we know that Shalmaneser was a contemporary of Kadashman-turgu and Kadashman-buriash of Babylonia, and that these were contemporaries of the Hittite king Khattusil, a well-known contemporary of Rameses $\mathrm{II}^{3}$, who therefore was reigning in 1260 B.C.

Before these synchronisms and astronomical dates were known, Heinrich Brugsch, the greatest master of Egyptological science of his time, had devised for his epoch-making book, Egypt under the Pharaohs, a chronological system which, starting from the synchronism of Sheshenk with Rehoboam (which he placed too early, at 975 B.C.), proceeded by simple computation of the known generations of the kings, and with the allowance of probable generations to those whose exact position was unknown, to the round date of I 460 B.C. for Amenhetep III and I 400 for Horemheb, who restored the orthodox religion after the heresy of Akhenaten. This was

${ }^{1}$ M.D.O.G. 36, p. 29.

- This argument from Babylonian sources for the date of Ashur-uballit and Amenhetep III is summed up in Budge, Hist. Eg. i. pp. $153 \mathrm{ft}$. Closer examinalion shews us that Ashur-uballit reigned about 1370-1340 B.c. (see p. 262).

3 The equation of Klattusil with Kadashman-turga and Kadashman-buriash we know from the Boghaz Kyöi Tablets (see p. 369). 
a remarkable approximation to the true date, which is evidently to be placed only half a century later.

These astronomically ascertained dates therefore agree both with each other and with the other evidence, a fact which makes it difficult to discredit them upon grounds of possible mistakes of observation or calculation on the part of the ancients or of possible deliberate alterations in the calendar. We are therefore justified in accepting them as a sound foundation for the chronology of Egypt as far back as the beginning of the XVIIIth Dynasty, which will thus be placed about 15SO B.C. The end of the dynasty, and reign of Menpehra Rameses I, will then coincide with the "Era of Menophres" (I 322 or I 3 IS B.C.). To this time is to be assigned the apogee of the Hittite kingdom, whose great princes, Shubbibiliuma, Mursil, and the rest were contemporaries of Rameses I and his successors. ${ }^{1}$

The settlement of the date of the XVIIIth Dynasty means the fixing of the age of the prehistoric antiquities of Greece. The apogee of the prehistoric culture of Crete, the Second Late Minoan period, when the great palace of Knossos was built as we now see it, was contemporary with the XVIIIth Dynasty, and the Third Late Minoan period, the age of decline, began before the end of that dynasty. This we know from archaeological evidence which admits of one interpretation only, and from contemporary representations of Cretan envoys, bearing vases of Late Minoan form as gifts, to the courts of Hatshepsut and Thothmes III. We can pretty accurately date the destruction and abandonment of Knossos, which ended the Second Late Minoan period and marked the beginning of the Third, to about 1400 B.C. ${ }^{2}$

With the beginning of the XVIIIth Dynasty we have reached the limits of comparative certainty in Egyptian chronology. We may place the Hyksos king Set-aa-pehti about I650 B.C., on the authority of the "Stele of Four Hundred Years," which puts him four centuries before Rameses II, and this date agrees entirely with the evidence sketched above, which puts the end of the Hyksos period about I 580, and with that of his sole contemporary monument, a scarab (already referred to ${ }^{3}$ which from its style cannot be much older than the time of Aahmes, the expeller of Hyksos. This date of

i See later, Ch. VIII.

2 See later, p. 64.

${ }^{3}$ Above, p. IS. 
I650 seems to be the most ancient Egyptian date of which we can be sure with a small possible margin of error.

But the astronomical calculation, based upon a mention of a rising of Sothis, appears to come to our aid again and to provide us with a certain date of 1876 or 1872 B.C. for the seventh year of Senusert III, of the XIIth Dynasty, and therefore, since the length of the reigns of that dynasty are certainly known, with the very definite date of 2000-178S B.C. for the XIIth Dynasty. ${ }^{1}$ Could it be accepted entirely without cavil, this date would be of enormous importance to our knowledge of Egyptian history. There are facts that speak in its favour. There is no doubt that the art of the early XVIIIth Dynasty differs very little from that of the XIIIth: the fact is very well shewn on a small scale in the evolution of the scarab-seal. And the evidence from Crete shews that no very long period of time elapsed between the "Second Middle Ninoan" period of the Aegean culture, which was contemporary with the XlIth Dynasty, and the "First Late Minoan" period, which was contemporary with the beginning of the XVIIIth. On the other hand, as will be seen when we come to discuss the history of the "Intermediate" period (Ch. VI.), there are also facts that speak against it. It seems almost impossible to force all the kings of the XIIIth-XVIIth Dynasties into so small a space as 250 years, cut down their reigns as we may. The XIIIth Dynasty gives us the impression of having reigned for a considerable period; and the new kings, probably to be placed at the beginning of the XVIIth Dynasty, whose statues have lately been found at Karnak, cannot have been purely ephemeral monarchs if they reigned long enough for their colossi to be erected at Thebes. The difficulties in the way of the acceptance of this Sothic date are therefore great. Prof. Petrie cuts the knot by boldly assuming that the calculation is right, but that the date must be pushed back a whole Sothic period of I46I years earlier, so that Senusert III reigned about 3300 B.C. $!^{2}$ It is curious that the distinguished professor should have committed himself so definitely to so difficult a proposition. We cannot make the period between the XIIth and the XVIIIth Dynasties last sixteen hundred years. One must pause to think that sixtecn hundred years is an immense period

1 Borchard?, A.Z. xxxvii. pp. $92 \mathrm{ff}$; Mever, Aegyptische Chronologie, pp. $52 \mathrm{ff}$.

2 Researches in Sinai (1906), ch. xii. ; Historical Studies, pp. Ioff. 


\section{THE ANCIEN'T HISTORY OF THE NEAR EAST}

of time, reckoned by human standards. Sixteen hundred years separated Julius Cæesar from Queen Elizabeth, Diocletian from Queen Victoria. What changes of civilization and language, what abolitions and creations of peoples, has the world not seen in sixteen hundred years? And the civilization and art of the beginning of the XVIIIth Dynasty hardly differs from that of the end of the XIIth: is in no way so different from it as is that of the $\left[V\right.$ th. $^{1}$ Also the compilers of the king-lists made the XVIIIth Dynasty follow immediately the XIIth, jgnoring the intermediate period as that of the rule of pretenders, usurpers, and foreigners.

We cannot suppose that any very long period really elapsed,

${ }^{1}$ Here I am aware that I am directly challenging Prof. Petrie's arguments in Historical Studies, p. I5. The differences between the civilization of the XIIth Dynasty and that of the middle of the XVIIIth are enormous; but we are speaking of the beginning of the XVIIIth Dynasty, which is a very different thing. Between the reign of Amenhetep I and that of Thothmes II the externals of Egyptian culture underwent a sudden and great change, but the near relationship of the art of the early part of the dynasty and that of the XIIth is evident. The decoration of the XVIIIth-Dynasty tombs at El Kab is but a development of that of the XIIIthDynasty tombs there; the early XVIIIth-Dynasty votive tablets from Deir el-Bahri closely resemble typical work of the XIIIth; the scarabs of the early XVIIIth Dynasty are, though they have a characteristic style of their own, to my eyes a direct development, and a near development in time, from those of the XIIth and XIIIth Dynasties, while the spiral and rosette designs of the Middle Kingdon were not only continued far on into the XVIIIth Dynasty, but, with the typical "Hyksos" designs, survived in the Delta till the Ramesside age; and it is more probable that 800 years separated these from their XIIth-Dynasty ancestors than 2200! The gap between the few ushabti-figures of the XIIth Dynasty and the many of the XVIIIth can well be bridged now. At Abydos two years ago was discovered an zushabti of the XIIIth Dynasty, determined as such by the circumstances of the find as well as by the name of the ushabti's owner, Rensenb. On this ushabti (Brit. Mus. No. 49349) the animal hieroglyphs have their legs cut off, to prevent their running away; a quaint idea characteristic of the XIIth and XIIIth Dynasties. Otherwise one would say that the ushabti was of the early XVIIIth Dynasty. There is also the zshabti of Apushere in the British Museum, of the XVIIth Dynasty. One cannot suppose that Rensenb's ushabti is five or six hundred years older than the XVIIIth Dynasty. The one and only great difference between the culture of the XIIth Dynasty and that of the early XVIIIth seems to me to be the abandonment of the practice of burying models of boats and boatmen, granaries, labourers at work, etc., with the dead, which is so characteristic of the earlier period. Had we untouched burials of the later Intermediate Period, we should probably be able to trace the abandonment of this practice. But I do not see why it should not have been a sudden abandonment, comparable to the sudden alteration in sculpture and scarab-making which is characteristic of the time of Hatshepsut and Thothmes III. The last trace of the custom is a big boat in the tomb of Amenhetep II (p. 294), which was stolen. It seems to me that Prof. PITrie exaggerates the differences between the early XVIIIth Dynasty and the XIItl - XIIIt $1_{1}$, 
yet the narrow two centuries and a half which are demanded by the usual interpretation of the new Sothic date seem an impossibly short period. Another century only, and our allesriance to it might have been conceded willingly. Our knowledge of the facts of the history of the time seems to forbid our acceptance of a much less or a much greater period of time than three and a half centuries between the end of the XIIth Dynasty and the beginning of the XVIIth. It does not seem impossible that our interpretation of the date given by the Kahun temple-book has been in some way faulty. Another calculator ${ }^{1}$ has computed the year as I945 B.C., which is seventy years earlier than the date given by Drs. Borchardt and Meyer. Or some deliberate alteration of the calendar may have taken place in ancient times before the time of the XVIIIth Dynasty: such an alteration, which is not impossible, as we see by $\mathrm{Mr}$. Gardiner's discovery that Mesore, later the twelfth, was till the time of the XVIIIth Dynasty the first month of the year, might throw all our calculations into confusion. ${ }^{2}$ It would therefore scem wise to refrain from a complete acceptance of the new Sothic date till further information confirms it. We may rest content for the time with the round date of circa 2000 B.C. for the mid-point of the XIIth Dynasty. This gives us a vaguely approximate date for the Cretan "Middle Minoan" period, when the palace of Phaistos was built. $^{3}$ 'The interesting piece of evidence quoted by Prof. Meyer, ${ }^{4}$ the fact that under the XIIth Dynasty an officer sent to Sinai to seek for turquoise notes in his inscription that in the months of Phamenoth-Pachon, when he was there, it was high summer, and the heat "like fire," would suit Prof. Meyer's date or one a century or two earlier equally well, while it would not suit so well the earlier dates adopted years ago by Brugsch.

Brugsch's dates for the Middle Kingdom are too high, as they are based upon an exaggerated estimate of the length of

${ }^{1}$ Nicklin, in Class. Rev. xiv. (1900), p. 148.

2A.Z. xliii. (1907), pp. $136 \mathrm{ff}$. Whether this discovery really necessitates a revision of our calculations as for the XIIth Dynasty and before is doubtful. Prof. MEYer considers that it does not (Nachträge zur ägyptischen Chronologie, p. 18) ; the alteration being a mere change of name, the first month remaining the first month, whether called in popular parlance Mesore or Thoth : if we were to suppose a real shifting by a month, this would mean the shifting back of the dates of the kings of the XVIIIth and XIXth Dynasties I 20 years, which is impossible.

${ }^{3}$ See later, p. 42.

${ }^{4}$ Chronologie, p. 180. 
the period between the XIIth and the XVIIIth Dynasty, due to a too conservative treatment of the statements of Manetho's copyists, who attribute to the Hyksos 5 Io years and to the XIIIth Dynasty 453, making an absolutely impossibly long period of 963 years between the two dynasties. Brugsch did not go to this length, but archaeology as well as historical probability shew us that he overestimated the length of the second Intermediate period.

The Manethonian year-numbers for the first Intermediate period, between the VIth and the XIth Dynasties, are again exaggerated. But Brugsch accepted them, with the result that his date for Mena goes back to the figure of 4400 B.C., only four centuries later than that to which Prof. Petrie pins his faith.

Babylonian history gives us no help now. We have reached the time when the two kingdoms had little or no connexion with one another, so that synchronisms of kings no longer present themselves, nor are likely to do so. For the dates of the old Egyptian kingdom we must simply employ a dead reckoning, supplementing our knowledge derived from the monuments by the lists of Manetho and the Turin papyrus, back from the beginning of the XIIth Dynasty. The XIth Dynasty lasted less than I 50 years; the period of civil war that preceded it can hardly have endured more than a similar period, as the style of tomb-construction and tomb-furniture in vogue under the XIth Dynasty is little different from that usual under the VIth. So that we can hardly seek earlier than 2500 B.C. for the end of the VIth Dynasty. And this date agrees very well with that indicated for the beginning of the IVth by the dates scribbled in red paint on the casing-blocks of the pyramids of the kings Sneferu and Khufu at Meidum and Gizah: the months given must have fallen at that time in the summer, as it was only in the summer, when the peasantry were not engaged in agricultural work and the Nile was high for transport across the plain, that quarrying could be carried on and great stones transported by river to the desert-marge. The date thus indicated is about 3200-3000 B.C. ${ }^{1}$ And a dead

${ }^{1}$ Prof. Petrie (Exhibition Catalogue, Memphis and Meyaum, 1910, p. 6) gives the date as 4650 B.C. This is because he places all dates before the XVIIIth Dynasty deduced from evidence of this kind a whole Sothic period of 146 I years earlier than do Prof, MEYER and other Egyptologists. 
reckoning would attribute about 500 years to the IVth-VIth Dynasties.

The first three dynasties seem, by dead reckoning, to have lasted over 400 years. We therefore reach circa 3600-3500 B.C. for the beginning of the Ist Dynasty and the foundation of the lingdom. This is of course somewhat of a guess; but it is unlikely that the Ist Dynasty is to be put very much earlier. Prof. Meyer's date, based upon the Sothic date of the reign of Senusert III, is 33 I 5 B.C., which, if one doubts the validity of this date as computed by him, seems too low and also too definite. $\mathrm{He}$ is a bold man who would reckon the date of Menes in anything more closely defined than round centuries.

But it must be remembered that, if we do not accept the placing of the Sothic date of the Kahun book so late as 1945 or 1876-72 B.C., we have no really firm ground for any Egyptian chronology at all before the beginning of the XVIIIth Dynasty. We can only guess, and it is guesswork founded upon what we know of the history of art and civilization as well as of the history of kings' reigns, that brings us to a date for the Ist Dynasty not so very much earlier than that adopted by Prof. Meyer. And it claims to be nothing more than a guess. This being so, those who consider they have no right to reject Manetho's statements as to the length of the two intermediate periods on the strength of purely archaeological evidence, may continue, if they prefer so to do, to use the chronological system of Brugsch. But it must be remembered that this system is a very arbitrary one, that the thirty-year generations on which it is computed are too long, and that its results for the period before the XVIIIth Dynasty are only in the widest sense approximate. It can only be used as a sort of chronologimeter, giving a general idea of time: its clates were never intended by its author to be accepted too strictly. This being so, we can also resort to guesswork, based when possible upon historical and archaeological evidence, otherwise upon probability.

We guess then that the two primitive kingdoms of Northern and Southern Egypt, which preceded the foundation of the monarchy, are to be dated before 3600 B.C., and, seeing that the development of culture was swift in those early days, we may suppose that in 4000 B.C. the inhabitants of Upper Egypt were Neolithic barbarians, and those of Lower Egypt and the Delta little better. Prof. Meyer thinks that in the year 424I B.C., 
when a Sothic period began, the calendar was first established by the New-Year feast being fixed on the occasion of the heliacal rising of Sothis, that the day was called "the Ist Thoth," and the very arbitrary system of the Egyptian months and seasons was then instituted. ${ }^{1}$ Such an arrangement need not have been beyond the mental powers of people in the Neolithic stage of culture, but it would seem more probable that the calendar was really put into its regular shape on the occasion of the Sothic "ron" of 278 I B.C., about the time of the Vth Dynasty.

To guess the age of the Cretan civilization before the time of the Middle Minoan period and the XIIth Dynasty is impossible. We can only vaguely place the "Early Minoan" period and the beginnings of Cretan culture in the fourth millennium B.C.

We have to guess the age of Babylonian history in much the same way. Since the reign of Khammurabi the great lawgiver has been fixed by Mr. L. W. King to somewhere between I950 and I 900 B.C. ${ }^{2}$ (to the confusion of Nabonidus' Babylonian scribe, who said that Khammurabi lived 700 years before Burraburiash, whereas in reality he lived but 500 years before him), 2050 B.C., for the beginning of the Ist Dynasty of Babylon, Khammurabi's dynasty, is the earliest Mesopotamian date of which we have any real certainty. ${ }^{3}$ The well-known date of Nabonidus for Sargon of Agade and Narâm-Sin, which is 3750 B.C., has no authority whatever to support it. All the other known evidence on the subject goes against it, and indubitably it is grossly exaggerated. ${ }^{4}$ We cannot extend the known history of Babylonia before 2050 B.C. by means of a probable dead reckoning further than about 3000 . The patesis of Lagash who played the leading rôle in Babylonia in the period which immediately followed the epoch of Sargon and Narâm-Sin cannot on the basis of our present knowledge be placed earlier than 2500; Gudea, the best known of them, must be dated about 2450. How can we, on the authority of Nabonidus' simple statement, admit a gaping void, a hiatus without content of any kind, of thirteen hundred years between Gudea and Narâm-Sin? An important testimony against this supposition

${ }^{1}$ Chronologie, p. 4I. But cf. ReISNer, Naga-ed-Der, i. p. I26, n. 3 .

2 Chronicles, i. p. 136 .

${ }^{4}$ KING, History of Simer and Akkad (1910), p. 6r. 
(which in itself is so improbable) is the fact that the clay tablets of the two epochs hardly differ in shape, and that the forms of the characters with which they are inscribed are almost identical in both periods. Palæographic evidence makes it impossible to accept any gap between the first Sargonids and the patesis of Lagash, much less a gap of 1300 years! ${ }^{1}$ The thing is as unlikely as Prof. Petrie's 1600 years' interval between the XIlth and XVIIIth Egyptian dynasties. Nabonidus must be wrong, nor is it unlikely that he was wrong. The sixth century was far remote from the time of Sargon and Narâm-Sin, and in the late Assyro-Babylonian period mistakes were made as to early dates. Thus we find that an inscription of Esarhaddon (seventh century), describing the rebuilding of the temple of Ashur by Shalmaneser I (fourteenth century), states that 560 years had elapsed since its first rebuilding by a chief named Irishum. But a contemporary inscription of Shalmaneser's states that 739 years had elapsed since the same event. We cannot doubt that Shalmaneser is more likely to be right than Esarhaddon, since he lived seven centuries nearer to the time of Irishum. But when we are confronted with such discrepancies we may well wonder whether the statements of lings of the later period as to early dates are of much value, and may decide to accept them only when they agree with the archaeological evidence. We reject, then, Nabonidus' date of 3800-3750 B.C. for Sargon and Narâm-Sin on archaeological grounds, and place them, following Mr. L. W. King, about 2600 B.C., ${ }^{2}$ or, emending Nabonidus' figures by altering his " 3200 years before my time" to " 2200 years," as Prof. Lehmann-Haupt ${ }^{3}$ proposed to do, make him reign about 2750 B.C. We are dealing with a piece of false and exaggerated history, which was no doubt quite to the taste of the late Babylonian literati, chief of whom was the king, Nabonidus. ${ }^{4}$ The earlier kings of Sumer, from Ur-Ninat to Urukagina of Lagash, and his contemporary the conqueror Lugal-zaggisi of Erech, will then be placed between 3000 and 2800 B.C., and the oidest Babylonian rulers of whom we have any knowledge will fall not long before 3000 B.C. at the earliest.

Apparently, Babylonian history is not so ancient as that

${ }^{1} \mathrm{King}$, Ifistory of Sumcr and Akkad, l.c.

Ibid. p. 65 .

3 Zwei Hauptprobleme der Babylonischen Geschichte, pp. I $72 \mathrm{ff}$.

4 See later, p. 560. 


\section{THE ANCIEN'T HISTORY OF THE NEAR EAST}

of Egypt by some five hundred years. This is, however, an uncertain point, as we do not know how long before 3000 B.C. the ancient Babylonian Sumerian culture first began to develop. We have no traces of a Neolithic age in Babylonia, while the Egyptians of 3500 B.C. had not long emerged from the neolithic stage. The Egyptian writing of 3500 B.C. is still an extremely primitive pictorial script; the Babylonian writing of 3000 B.C. had already developed into a conventionalized and formal system which bore little resemblance to the original pictures from which it was derived. The Babylonians may well have passed into the age of metal at an earlier period than did the Egyptians, and have evolved their "cuneiform" writing before the Egyptians, at the beginning of the Ist Dynasty, began to codify and stereotype their script.

We might therefore begin our survey with Babylonia but that a more convenient arrangement is afforded by the reverse order, in which prehistoric Greece first claims attention. The whole of the "history" of the Greek Bronze Age being "prehistory," without records, we take it first from its beginning to its end, returning to the known history of Egypt and Babylonia in the order named. 


\section{THE OLDER CIVILIZATION OF GREECE}

\section{Aegean Civilization}

Continuous development of prehistoric Greek civilization in Greece-Presumed absence of ethnic change-Presumed Southern (African) origin of the AegeansSecond ethnic element in Northern Greece-Neolithic Greece-Cyprus and copperworking-Introduction of metal : resulting development of civilization

$7 \mathrm{HE}$ great Aegean civilization of the Bronze Age in no way owed its origin to the West, and cannot have been, L till near its end, more than but slightly influenced by any possible independent Indo-European culture in the North. Civilization must have come to the Northern land of barren steppes and impenetrable forests by way of the Vardar and Danube-valleys from the Aegean, not in the reverse direction. That the seeds of the Minoan culture of Crete could have been brought from the North would be of itself inconceivable, and as a matter of fact we know that the Minoan culture developed out of its Neolithic origins in the Aegean itself. That the older civilization of Greece was a single culture, which developed out of Neolithic beginnings into the full civilization of the Bronze Age without a break in the same place, is now certain. No cataclysm marks the passage from the Age of Stone to that of Metal. The Bronze Age culture develops directly from the Neolithic, and the Bronze Age people of Greece may naturally be presumed to be the same as the Neolithic people. The later transition from the Age of Bronze to that of Iron was certainly accompanied by and due to the invasion of the Indo-Europeans from the North. But we have no reason to suppose that there. was any racial difference between the Neolithic and the Bronze Age Greeks.

The Neolithic Aegeans were then the ancestors of the 
Minoans and Mycenaeans, whose dress of a simple waistcloth (sometimes with additions, and developed strangely in the case of the women) is very good evidence that they were Southerners from Africa rather than Northerners from Europe. ${ }^{1}$ This simple waistcloth, the natural dress of men in a hotter country than Greece, can be traced as far back in time as we can go, and there is no doubt that it was worn by the Neolithic Greeks, and came from Northern Africa with them. The earlier Greeks came then from Africa while they were still stone-users.

There is, however, as we shall see later, a possibility that there existed from the beginning in Northern Greece a second ethnic element, a people which still used stone when the Aegeans had long passed into the Bronze Age. This element, if it is of Northern origin, we can hardly refuse to recognize as of IndoEuropean stock, and to call, if we wish to coin a word, protoAchaian. ${ }^{2}$

The Neolithic stage of the southern Greeks is known to us chiefly from Crete, where, at Knossos, the low hill which was afterwards crowned by the palace of Minos was inhabited for many centuries by a Neolithic population before the knowledge of metal came to Greece. In Asia Minor pottery which must be Neolithic has been found, and on the Asiatic shore of the Aegean, at Troy, evidences of Neolithic culture are visible ${ }^{3}$ in the lowest strata of human habitation. In Euboea and in the Peloponnese stone weapons have been found. But in the Cyclades no trace of Neolithic inhabitants has come to light, and in Cyprus only one or two isolated stone weapons have been noted.

This last fact may possibly be due to the easy accessibility

${ }^{1}$ The first adumbration of a connexion between Crete and Africa was advanced by Evans, "Cretan Pictography" (J.H.S. xvii.). See also Hall, in King and Hall, Egypt and Western Asia (American ed., 1905), pp. 128, 129; and Mackenzie, B.S.A. Annual, xii. (1906), pp. 233 ff., whose argument is largely based upon the African character of the Aegean waistcloth costume.

${ }^{2}$ See p.64. But in view of the fact that the Southern waistcloth is found on Neolithic figurines as far north as Servia, we can hardly assume definitely that this element was not also of southern-Nilotic-origin. But there is always the possibility that while the Southern race may at a very early period have penetrated by way of the Vardar to the Danube, a Northern race may at a later time have come down into the Thessalian and Boeotian plains, bringing with it its primitive Neolithic culture, which still persisted, owing to difference of race, when Southern Greece had developed its metalusing civilization (cf. MACKENZIE, loc. cit.).

${ }^{2}$ Dörpfeld-Götze, Troja und Ilion, i. p. $32 \mathrm{r}$. 


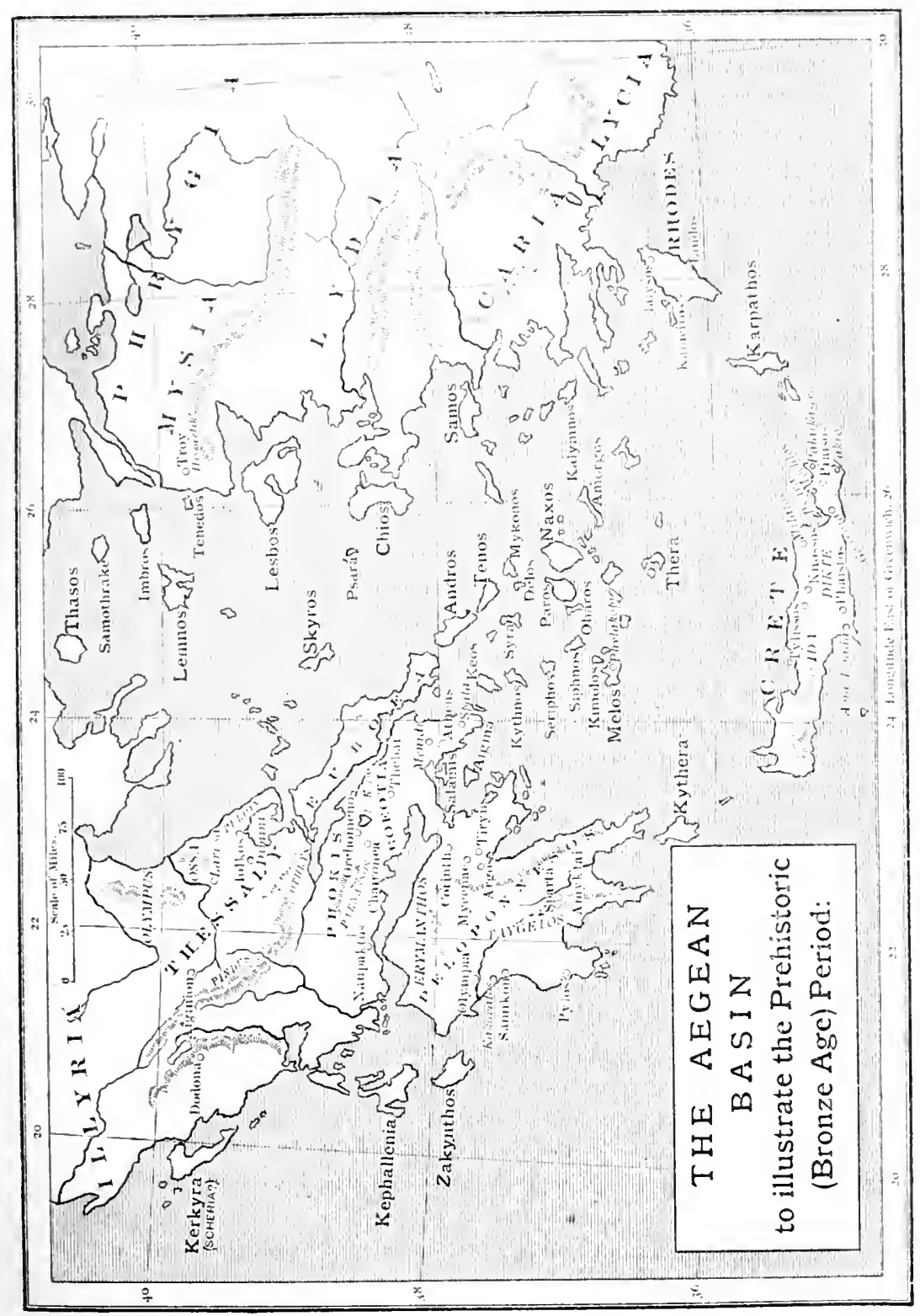



of copper in the castern island. It may well be that Cyprus was the original home of copper-working in the Eastern Mediterranean, ${ }^{1}$ and that the knowledge of metal came thence both to the predynastic Northern Egyptians and to the Aegeans. But there is a difference between the cases of Egypt and Greece, in that while the Egyptians used copper alone, and did not become acquainted with bronze till the time of the Middle Kingdom, the Aegeans from the first seem to have been acquainted with bronze as well as copper, ${ }^{2}$ and among them the use of the alloy soon superseded that of the pure metal. Probably the knowledge of the art of alloying copper with tin or antimony came from the Middle East, where tin is found, to Greece as well as to Babylonia and, eventually, Egypt.

To the introduction of metal the whole development of the prehistoric Greek culture was due. Its appearance is marked by the stirring of an artistic impulse which, swiftly changing and improving, carried the southern Aegeans in a few centuries from the rude hand-made pottery of the Neolithic period to artistic triumphs which have hardly been equalled since. Similarly, in the first few centuries after the introduction of metal, the Egyptians, whose art had early been fixed by religious convention, had progressed in the science of engineering and architecture, where their energies were untrammelled, from the absolute ignorance of the savage to the knowledge of the Pyramid-builders.

\section{Minoan Chronology}

History of prehistoric culture-The " Minoan" periods of Evans-The "Cycladic" and "Trojan" corresponding periods of culture-Chronological base of these schemes depend on synchronisms with Egyptian history-Early connexion with Egypt-Early Minoan period: Aegean relations with Egypt under the Old Kingdom-Middle Minoan period : close relations under the Middle Kingdom: synchronisms with the XIIth Dynasty and the Hyksos - Late Minoan period: synchronisms with the XVIIIth Dynasty and the XXth Dynasty-Ceramic development the mainstay of our reconstruction of prehistoric Greek history

In the absence of intelligible records, the history of this artistic development is practically the only history of early

1 Myres, in Science Progress, 1896, p. 347 ; Cyprus Museum Catalogue, p. I7 ; see also p. 90 , below.

2 At Troy copper is unknown, and bronze immediately succeeds stone (Dör PFELD. Schmid, Troja und Ilion, i. p. 367). But in Crete primitive copper weapons have been found (Mosso, Dazen of Mediterrancan Cizilization, pp. 136 ff.). It is 
Greek civilization that we possess, and we are now able to follow its course with some accuracy, thanks to the acumen of Sir Arthur Evans, who has constructed a chronological scheme of three successive periods of development, each of which again is divided into three sub-periods. ${ }^{1}$. To these periods he gives the name of "Minoan," after the great Cretan lawgiver and thalassocrat. The name may be fanciful, but the scheme itself is by no means so ; it rests upon careful observation and tabulation of ascertained archaeological facts, upon the results of the excavations at Knossos and elsewhere in Crete, and has for the first time given us a solidly based framework upon which we can arrange our facts. The whole of our knowledge of the prehistoric civilization not only of Crete but of Greece generally can with its aid be classified and arranged in chronological sequence. A corresponding scheme of the successive periods of the development of art in the Cyclades, contemporaneously with that of Crete, has been devised; even in the earliest period of the Bronze Age we can bring the culture of Troy into chronological relation with that of the South, while in the latest the Cretan culture has conquered the Greek mainland, and the "Late Minoan" age is as well represented at Mycenae as at Knossos. The scheme agrees very well with the evidence.

The chronological bases of the scheme are given by the various synchronisms with Egyptian history that are known, and have already briefly been mentioned. It is possible that intermittent connexion was maintained by sea between the primitive Northern Egyptians and the primitive Aegeans even in Neolithic times; although the curious resemblances which have been traced between certain religious cults peculiar to the Delta and those of Crete, and the similarities of the funeral rites in both countries, may perhaps be referred rather to an original connexion than to commercial relations. ${ }^{2}$ We cannot

probable that copper was mined to some extent in Crete, as it is found in the island of Gaudos. The supposed mine at Pacheia Ammos, in the isthmus of Hierapetra (Mosso, ib. p. 290) is impossible. The copper was probably brought there to be smelted. Crete probably derived most of her copper from Cyprus, as well as, no doubt, Italy. 1906.

1 Evans, Essai de Classification des Epoques de la civilisation Minoenne, London,

I It seems as yet uncertain whether the striking resemblances between the primitive Cretan figurines of the Second Minoan period (Bronze Age) found at Koumasa and Agia Triada (for the latter see Halbherr, Mem. R. Ist. Lomb. xxi.), and those of the Neolithic period found at Nagada in.Egypt (PETRie, 
find a proof of these relations in the supposed vessels which are depicted on the vases of the predynastic Southern Egyptians," as these (if they are boats at all) are obviously mere Nile boats, and the people who depicted them were Nilotes of the south, not seagoing inhabitants of the Delta and the coast. It was not these African ancestors of the dynastic Southern Egyptians that can have been connected with the Aegeans, but a "Mediterranean" folk in the Delta who perhaps lived there side by side with the Semito-Libyan population which we shall see reason to believe existed in Northern Egypt. Whatever communication there may have been in Neolithic times is not likely to have been increased after the conquest of Northern Egypt by the Southerners, and the foundation of the Egyptian kingdom. The coast population of the Delta, the Haau or swamp-men, as the Egyptians called them, ${ }^{3}$ probably maintained a fitful communication with the Aegeans, and to them as intermediaries we may ascribe the presence in Crete of fragments of Egyptian diorite bowls of the period of the Third Dynasty (if we set on one side temporarily the counter-instance of supposed Cretan vases in the royal tombs of the First Dynasty at Abydos as still doubtful). Direct communication with the true

Nagada and Ballas, Pl. lix.), and the equally striking similarities between the early Cretan stone vases and those of the early period in Egypt, may be ascribed to a primeval connexion of the two civilizations or to later relations between them. Since the Egyptian figures and stone vases belong to the invading Southern Egyptians, not to the Northerners who, ex hypothesi, were the kinsmen of the Aegeans, and the Cretan figures are later in date than the Egyptian (contemporary with the IVth-VIth Dynasties?), the resemblances may be due rather to later connexion than to primitive identity. Religious observances seem to belong to another category. The resemblances between the cults of the Delta and those of Crete were nirst pointed out by Newberry, P.S.B.A. xxviii. p. 73. Cf. Liverpool Annals, i. pp. 24 ff. Another comparison between Minoan and Egyptian religion was made by me in P.S.B.A. xxxi. pp. $144 \mathrm{ff}$. See also p. 53, n. 7, post, on the resemblance of the Cretan funeral rites shewn on the Sarcophagus of Agia Triada to those of Egypt.

1 As is done by I'rof. Petrie (Trans. R. Soc, Lit. xix. I).

${ }^{2}$ KING and Hall, Egypt and Western Asia, p. I29. But the view expressed by TORR in $l$ Anthropologie, ix. 32 , that these pictures do not represent boats at all is by no means to be rejected definitely. They are very unlike an undoubted boat pictured on a vase of the same date in the British Museum (No. 35.324), illustrated by BuDGE, Hist. Eg. i. p. 8o, and cf. post, Plate VI. 2 ; and no river-objects, such as fish or hippopotami, are shewn with them. Mr. Tork's explanation of them may yet prove to be the correct one. M. NAviLLE has recently returned to Mr. ToRR's view (Rec. Trav., iIgII).

"On the Haau and the development of their name into "Yaunebu," by which the Aegeans were meant, and in late times the Greeks were designated, see IIALL, Oldest Civilization of Greece, pp. I5S, I59; B.S.A. Annual, viii. I59, I60. 
Egyptian nation which had now developed there was probably none. That nation had been unified under the hegemony of the kings and people of Upper Egypt, who had conquered the North by force, and had given a Southern complexion to the new state. The Southerners knew nothing of the sea, and the "Fenmen," who still preserved, on account of their proximity to the sea and occasional communication with the Northerners, many peculiarities differing from the orthodox Southern traits of official Egypt, were abhorrent to them. They were foreigners, and the Egypt of the Old Kingdom would have nothing to do with foreigners: she was a world in herself, governed by the gods in human form.

Towards the end of the Old Kingdom, however, this attitude of exclusiveness towards the Northerners began to break down: ${ }^{1}$ Egyptian stone vases were copied by the Cretans of the Early Minoan period, ${ }^{2}$ whose nascent art began in return to attract the attention of the Egyptians, and the spiral design, already characteristic of Aegean art, was adopted from the "seal-stones" of the Northerners to decorate the Egyptian sealscarab. During the Middle Kingdom the beautiful Cretan polychrome pottery of the Middle Minoan period was exported to Egypt, and from its occurrence with objects of the Twelfth Dynasty in Egypt (P1. III. I) we see that the Second Middle Minoan period was contemporary with that dynasty. ${ }^{4}$ The succeeding Third Middle Minoan period must have been contemporary with the end of the Middle Kingdom, as the First and Second Late Minoan periods were certainly contemporary with the Eighteenth Dynasty. To the Third Middle. Minoan period must be assigned the statuette of the Egyptian Abnub, son of Minuser (a name eminently characteristic of the Thirteenth Dynasty), and the alabaster-lid of King Khian, found at Knossos. The evidence of the contemporaneity of the first two. "Late Minoan" periods with the Eighteenth Dynasty is very definite. A possible late "First Late Minoan" vase was found in

1 Probably at first in consequence of attacks on the Delta by the $\Lambda$ egean seafarers. In the reign of Sankhkara, of the XIth Dynasty, the "military mandarin" Henu, who led an expedition to Punt (see p. 147), defeated an attack of the Haau or I Iaunebu (Breasted, Anc. Kec. i. p. 208).

2 As we see from the excavations at Mochlos (Seager, MTochlos, p. IO4). One vase published by Mr. Seager (ih. p. 8o, Pl. ii. M 3 ) is Egyptian of the Sixth Dynasty and was evidently imported at that date.
${ }^{3}$ See p. 4I.
4 See p. I 59. 
a burial of the time of Thothmes III by Petrie at Gurob, ${ }^{1}$ and the vases carried by Keftian ambassadors to the courts of Hatshepsut and Thothmes III are of First Late Minoan style. The Third Late Minoan period certainly began before the end of the Eighteenth Dynasty, as the Aegean sherds found in the ruins of Akhenaten's palace at Tell el-Amarna are exclusively of this style. Therefore the Second Late Minoan period must be placed, so far as Knossos is concerned, ${ }^{2}$ in the short space between the reigns of Thothmes III and Akhenaten. The Third Late Minoan period, the age which we formerly regarded as the "Mycenaean" age par excellence, the period when, as it would seem, the hegemony of Aegean civilization passed from $\mathrm{Knossos}$ and Crete to Mycenae and the mainland, was much longer. It lasted in Greece certainly till the time of the Twenticth Dynasty, in Cyprus probably longer. In a tomb at Enkomi in Cyprus has been found a scarab of Rameses III (c.I200 B.C.), and Mycenaean vases are depicted on the walls of that monarch's tomb. Later traces are doubtful.

Thus Sir Arthur Evans's scheme of the historical development of Aegean culture possesses a solid chronological basis. Using it as our guide, we can now essay to trace the course of Greek "pre-history" in some detail. The story is, as has been said, that of the development of culture as shewn in the evolution of art, and this evolution is traced mainly by means of the careful observation of the development of the ceramic art. The age of metal objects can be told by the style of pottery with which they are found or, in the case of metal vases, with which they can be compared. Similarly the date of a building can be shewn to be not later than the kind of ware which is found in it, and the character of the pottery can sometimes give us clues as to the ethnic character of the people who made it. Invasions and occupations can tentatively be traced, and the indications thus provided by archaeological science can be combined with the information derived from Egyptian and other

1 This vase is considered to be of the Mycenaean (continental L.MI. III) period by Mr. E. J. ForSDYke (J.H.S. xxxi. p. II5). We are fast realizing that the First and Third Late Minoan periods run into one another, the second being a purely local Knossian development, so that a late L.M. I design might quite conceivably be also early L.M. III. Fimmen (Zeit u. Dauer der kretisch-mykenischen Kultur, p. 5I) calls the vase "Mittelmylienisch," and makes it contemporary with L.M. II. It is possibly not Cretan (see Plate III. $2 b$ ).

2 See p. 65 , n. 2. 
Oriental records and the vague hints supplied by the Greek legends to form a probable theory of the course of events.

\section{The Early and Middle Minoan Periods}

Beginnings of culture in Cyprus and the Aegean-Development of metal objectsEarly Minoan period: painted pottery in Crete-Synchronism with primitive Troy: the treasure of Mochlos-Early Cycladic pottery--The cist-graves-The Cycladic images-Stone vases--Spiral decoration-Invention of the furnace and pottery whecl, probably in Egypt-Pottery of the Middle Minoan period--The seal-stones and pictographic script--Great development of architecture-Palace of Phaistos

The most ancient remains of the Bronze Age yet discovered in Greece are perhaps those of the First Cycladic period in the smaller islands of the Aegean, but it is obvicus that the knowledge of bronze must have reached the island of Crete before it was passed on to the Cyclades. From the Cycladic cistgraves and the "Copper Age" necropolis in Cyprus we see how the metal celt was soon supplemented by the short copper or bronze dagger, which was eventually to become a long sword. The spearhead soon followed, and the primitive Aegean was as well armed as the Babylonian, and better than the Egyptian, of his time. The vases of earthenware were now supplemented by vases of the new material and of other and more precious mctals, silver, electrum, and gold. Eventually the characteristic forms of the metal vases wcre imitated in pottery, so that the style of the metal-worker exercised great influence over that of the potter. The development of ceramic art was remarkable. The first Aegean painted ware arose in Crete: in Cyprus an incised red and a similar black ware still carried on during the early Bronze Age the tradition of a Neolithic pottery, akin to that of Crete, of which we have no actual relics. Painted ware came to Cyprus from the Aegean: it was a Cretan invention. The inventors first painted a black ware with dull white pigment in imitation of the incised designs, filled in with white, of the later Neolithic period. ${ }^{1}$ The black ground was now produced artificially by means of a "slip " of black glaze-colour, imitating the hand-burnished black surface of the Neolithic ware. This was a notable invention. The converse use of a white "slip" with black decoration was not long in coming. A wide field of artistic possibilities was now thrown open to the Cretan

${ }^{1}$ An admirable summary of the development of Aegean ceramic styles is given by Miss E. Hall., The Decorative Art of Crele in the Bronze Age (Philadelphia, 1907). 
potter, and he was not slow to enter it. The vases of the next period, the Second "Early Minoan" age of Evans, shew great developments of the potter's art. Strange new forms of vases, such as the "Schnabelkannen" or beaked jugs, appear (Pl. III. 2), and curved lines, soon to develop into regular spirals, are seen in their simple decoration. In the Third Early Minoan period, which succeeds, the spiral decoration has been evolved, and the foundation of all the wonderful designs of the later Minoan pottery has been laid.

In this period we are able to establish a synchronism between the culture of Crete and that of Troy. There is no doubt that "Early Minoan III" is roughly contemporaneous with the Second "City" of Troy: they mark the same stage of culture. The discoveries of Mr. R. B. Seager in the tombs of the little island of Mochlos, ${ }^{1}$ off the north coast of Crete, have shewn that the superfluity of the precious metals which is so characteristic of "Troy II" is equally characteristic of "Early Minoan III." The riches of "Priam's Treasure" with its golden pins and chains and its gold and silver vases ${ }^{2}$ is paralleled by the golden bands, flowers, and pins found in the chieftains' graves at Mochlos. In the Second City of Troy we see the sudden development of civilization under the influence of the "Early Minoan" culture of Crete. But the Trojans retained their own style of black pottery, with its peculiar "owl-headed" vases and incised decoration.

Between Troy and Crete lay the Cyclades, where Cretan influence had developed a culture and an art closely akin to that of Crete, especially in respect of ceramic development. But the painted ware of the Cyclades from the first evolved local styles of its own, and, while the processes are the same as the Cretan, the vase-forms and decoration are by no means the same. We know the Cycladic pottery best from the finds in the tombs of Amorgos, Paros, and Syra (Chalandriane), which are of the type known as "cist-graves," being composed of flat slabs of stone in the form of a long box. ${ }^{3}$ The same type of grave is found in Early Minoan Crete, as, for instance, at

1 SEAGER, Explorations on the Island of Mochlos, Boston, I912.

2 SchuchinRdT, Schliemann's Excavations, pp. $55 \mathrm{ff}$.

3 Dümler, Ath. Mitth. xi. (1886); Bent, J.H.S. v. 47 ; and on their antiquities, BlinkenberG, Aarbgrer af det $\mathrm{kgl}$. Nord. Oldskrift Selsk., i896. On Cycladic pottery, EDGar, in Phylakopi, pp. So ff. 
Mochlos. In Crete another type of tomb is found, in the Second Early Minoan age, the circular grave or "tholos," which later on developed into the "beelive" tomb, which we know in the "Treasuries" of Mycenae and Orchomenos. ${ }^{1}$ In the cist-graves of the Cyclades the dead were buried in the cramped form equally characteristic of the predynastic Egyptians or Babylonians, and the primitive Mediterraneans generally.

We have already mentioned the small idols in human form which were found in these Cretan tholoi as resembling those found in the predynastic Egyptian graves. Similar idols, but of more developed form, are characteristic of the Cycladic cistgraves. In Amorgos and Paros they are sometimes of large size, and are usually made of the local marble.

Characteristic again of the last Early Minoan and Cycladic periods is the development of stone-working. Fine stone vases are now made, of simple yet often beautiful forms, sometimes, in Crete, imitating a flower, sometimes, in the Cyclades, the shape of the sea-urchin. Most of these vases are made of the easily worked steatite found in Crete, but many of those from the Cyclades are of white marble. ${ }^{2}$ On some of them a fully developed system of connected spiral decoration appears. ${ }^{3}$ The system of spiral decoration now makes its appearance in Greece, and is seen in the goldwork of Troy and the stonework of the Cyclades perhaps before it appear's as a decorative motive on pottery. The origin of the Aegean spiral patterns is probably to be sought in metal-working. The "Early Minoan" goldsmith invented it, and we see the first-fruits of his invention in the spiral coils of the gold wire pins of the "Treasure of Priam." From metal the new pattern passed to stonework in relief and then to pottery, painted on the flat. The Egyptians

${ }^{1}$ At Agia Triada, in the plain of the Messará, the Italian excavators discovered a tholos which seems to have been a tribal burial-place, as remains of countless skeletons were found in it. Similar tholoi were found by the Cretan archroologist Dr. Xanthoudides at Koumása, not very far off. The remains found in them date them to the Second and Third Early Minoan periods (see BuRrows, Discovcries in Crete, p. 66).

2 The well-known pyxides (Tsountas-Manat,, Mycenaean Age, Figs. 133, 134) from Melos and Amorgos, which have been considered, perhaps erroneously, to be designed in the shape of wattle-and-daub huts, are fine examples of the Cycladic stone-carving of this period.

${ }^{3}$ It is probable that the art of making stune vases reached Crete from Egypt. Many of the simpler Cretan forms resemble Egyptian originals of the age of the "Old Kingdom" (see p. 35 n.). 
adopted it and incised it on their seals, ${ }^{1}$ an example afterwards followed by the makers of the Cretan "seal-stones." From the Aegean the beautiful pattern spread northwards to Central Europe, to Scandinavia, and eventually to Celtic Britain.

On Cretan pottery the spiral design does not properly appear till the beginning of the next period of artistic devclopment, the "Middle Minoan." At the same time that a pattern derived from the coils of metal wire was used to ornament pottery, the forms of earthenware vases became for the first time directly modelled upon those of vases of metal. The pottery of the Middle Minoan period is constantly made in forms which are obviously imitated from those of metal originals. The potter had now obtained such mastery of his material that he could mould his clay in any form he chose. This mastery had been obtained as the result of two inventions of first-rate importance in the history of art: the baking-furnace and the potter's wheel. It is probable that both were originally invented in Egypt somewhere between the time of the First and the Fourth Dynasties. In the age of the Pyramid-builders we find well-baked wheel-made pottery universal, whereas the predynastic ware had all been built up by hand and baked in an open fire, like the Neolithic and First "Early" Minoan or Cycladic pottery of Greece. Both inventions must have reached Greece during the Third Early Minoan (Cycladic) period (=Troy II). During the Second period pottery made in the old manner was still used in Greece, as we see from the black and red ware of Vasiliki, ${ }^{2}$ and from the primitive pottery of the Cyclades. But in the Third period the new inventions have definitely established themselves, and the result is the remarkable ceramic development of the Middle Minoan age in Crete.

Not only were metal shapes imitated by the Middle Minoan potter, armed with his new mastery of furnace and wheel. For the first time pottery was made of thin and delicate, often of "egg-shell," warc, and plant forms appear in relief, clustering on the sides and over the lips of his vases. And, above all, the painter aided him to beautify the vases he made by introducing polychrome decoration. The pottery of the Middle Minoan period is characterized by a profuse use of colour-red, blue, and white, usually on a black ground. Spiral coils of red and white

${ }^{1}$ IIALr, P.S.B.A. xxxi. (1909), p. 221.

-Seager, Trans. Dept. Arch. Univ. Pennsylvania, i. Pt. 3, pp. 213-221. 
combine with the black ground to produce a hitherto unknown richness of decoration. Combined with the metallic forms of the vases the result is often extraordinarily striking (Pl. III. I). ${ }^{1}$

Characteristic also of this period are the "seal-stones" on which are cut the remarkable signs which Sir Arthur Evans has shown to belong to a hieroglyphic system, which was now giving rise to the regular system of writing which we find, impressed on clay tablets by means of a stilus (much in the Babylonian manner), in the remains of the next age. ${ }^{2}$ Of the origin of this system of writing we know nothing, but it is significant that some of the signs on the seal-stones are closely paralleled by, a few even identical with, certain Egyptian hieroglyphics. $^{3}$ We can at least assume a considerable Egyptian influence on the development of the script.

The Middle Minoan period saw a great advance not only in the arts of the potter, metal-worker, and seal-cutter, but also in that of the architect. The roughly built stone houses of the earlier age had now developed into splendid buildings of hewn and squared stone. The earlier palaces at Knossos and Phaistos were now built. Of the former we can only identify fragments here and there in the great palace of the Late Minoan age, but at Phaistos much of the earlier building still remains. ${ }^{4}$

\section{The Kingdom of Knossos and Phaistos}

The kingdom of Minos-Knossos-General contemporary date of the palacesAgia Triada-First Late Minoan period (c. I700-I 500 B.c.)-Naturalistic ceramic designs-Marine motives in decoration-The palace of Knossos-The king and his court-Prominence of women-Frescoes representing both sexes-Dress of womenMen's costume and armour-The Cupbearer fresco-Wall paintings-Mural inscriptions not used-The writing : clay tablets-Religious ideas-The supreme goddess and her male companion: Anatolian parallel-Funerary customs : Etruscan parallelsMinoan art: its triumphs and limitations-Second Late Minoan period: rococo ceramic designs-Third Late Minoan period : decadence begins

We know nothing of the political constitution of prehistoric Crete, and cannot tell whether in the days when Knossos and

"This Middle Minoan polychrome pottery is often known as "Kamáraes" ware, from the fact that it was first discovered in a cave on the slopes of Mount Ida, above the village of Kamáracs, by Prof. Myres (Proc. Soc. Ant. xv. pp. 351-36; Pll. i.-iv.).

2 "Cretan Pictographs, etc." (J.H.S. xvii.); Scripta Minoa (Oxford, I910). It is by no means improbable that the method of writing in this way came to Crete from Mesopotamia ; though the script itself has no connexion with the cuneiform.

3 IIALL, Oldest Civilization of Greece, p. 255.

${ }^{4}$ See p. 44, n. 3. The excavations of Phaistos have been published by IIALBHerR, Perner, and others in Monumenti Antichi, xii. (I9O2) et seqq. 


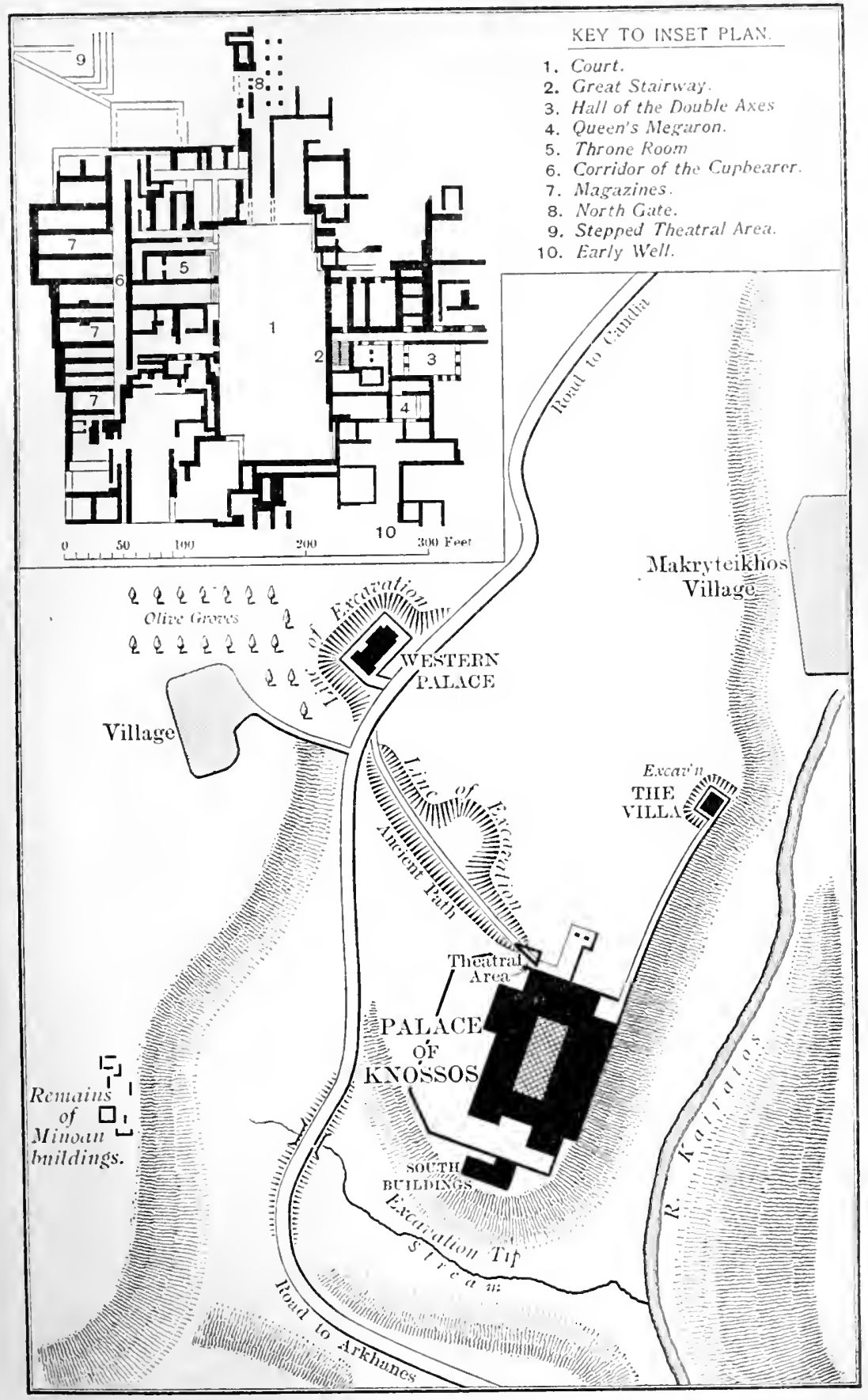

KNOSSOS AND ITS NEI(HHOLRHOOD

WITI INSET-PLAN OF THE PALACF. 

Phaistos were first built the whole island was under one dominance or was divided into several independent kingdoms. Later on, in the heyday of Minoan civilization, we feel that political unity is probable, and that Knossos was the metropolis of a Cretan state. The legend of the thalassocracy of Minos also indicates that Crete was a state united under the rule of the kings of Knossos, and possessed of wide-reaching power over the neighbouring seas and islands. It may be that at least the central portion of Crete, between Ida and Dikte, was already unified from sea to sea under the rule of Knossos as early as the Middle Minoan period, and that Phaistos and the neighbouring palace of Agia Triada were originally built by a Knossian king. Legend makes Phaistos a colony of Knossos.

With the building of the first palace of Knossos above the heaped-up strata of the Neolithic age the kingdom of Minos first takes form and substance. The Neolithic settlement occupieci the sides of a hill that slopes down to the valley of a little river, the Kairatos, which enters the sea four miles away, a short distance to the east of the modern city of Candia, on the north coast of the island. Candia owes its modern importance to its central position. Politically, Canea, at the western extremity of the island, is now the capital, orving partly to its greater proximity to Europe, and partly to its possession of some sort of a harbour, while Candia has, for modern purposes, none. But the central portion of the island, of which Candia is the capital, is the richest and most important part of Crete, and must always have been so. In Roman days the capital was Gortyna, in the Messari, a city which evidently succeeded to the inheritance of the neighbouring Phaistos. In Early Minoan days the central portion of the land must always have been in advance of the mountainous eastern and western portions in civilization, and it is here that the first unified political power must have been formed. All tradition points to Knossos as the original seat of this power, and we cannot doubt that the traditions are correct, and that Knossos owed its pre-eminence to its central position. And its situation on the northern coast contributed largely to make it the centre of an over-sea dominion. So the Neolithic settlement at Knossos developed into the seat of a powerful dynasty and the centre of the culture which has been revealed to us by the excavations of Sir Arthur Evans and 
Dr. Mackenzie. ${ }^{1}$ These excavations are gradually exposing to view the extensive remains of the palace of the kings, built above the Neolithic settlement. The remains of the town which surround it have hitherto not been investigated to any great extent, though some houses have been excavated by $\mathrm{Mr}$. Hogarth. ${ }^{2}$ The cemetery, on a neighbouring hillside called Zafer Papoura, has been explored by Dr. Evans; but all the tombs found contained objects which are much later in date than the time of the first founding of the palace. ${ }^{3}$ A great tomb has, however, been found on the hill of Isopata, a mile or so nearer the sea, which was probably originally constructed at the close of the Middle Minoan age. ${ }^{4}$

Like the potters, the architects of the Middle Minoan age had new and great ideas. The sudden development of civilization which differentiates this age from that which preceded it procluced men with splendid conceptions, just as the similar but earlicr development in Egypt had produced the designs of the Pyramids. The Minoan architects did not design mighty masses like these, but in the grand western entrance and "Stepped Theatral Area" of Phaistos ${ }^{5}$ they translated into stone a fine

'Published in the B.S.A. Annual, vols. vi. sqq.

${ }^{3}$ Evans, Prehistoric Tombs of Knossos, pp. $21 \mathrm{ff}$.

Ibid. vi. $70 \mathrm{ff}$.

4 Ibid. pp. $136 \mathrm{ff}$.

${ }^{5}$ In the Late Minoan period this truly regal entrance to the palace was partly covered up by newer buildings, a fact which certainly shows a fault of taste on the part of the later builders, though we may be grateful to them for committing it. At Phaistos the later palace was built as a whole on the top of and at a higher level than the earlier one, whereas at Knossos the older building was gradually rebuilt and remodelled, so that there the later palace stands more or less on the same level as the older one, and includes in its construction old walls and portions of chambers which it was never thought necessary to remove. The rcsult is that at Knossos it is most difficult to distinguish what is left of the original construction from the later addi. tions. But at Phaistos the covering up of the older palace preserved for us at least partially its west façade, from which we derive an idea of the capacity of the earlier builders which at Knossos is not casily obtainable. Only since the fact of the early date of the west façade of Phaistos has been established has it been possible to suppose that the wcstern entrance of Knossos, with its great open court and fine limestone wall, which in conception closely approach the splendour of Phaistos, were, though actually built during the First Late Minoan period (this is shown by the occurrence of Middle Minoan II potiery in house-ruins below the level of the pavement of the west court and of Middle Minoan II. sherds in the west hall itself; Evans, Ann. B.S.A. x. p. I4; xi. p. $2 \mathrm{I}$ ), probably the realization of a Middle Minoan plan. Probably the wall was a very slightly altered reproduction of the original Middle Minoan western wall. The floor of the court was evidently raised, and the line of the wall altered. The smaller "theatral area" at Knossos may, be either an imitation, cramped probably by exigencies of space, of the Phaestian " area," or may be really its meaner prototype, and so of Middle Minoan date. 


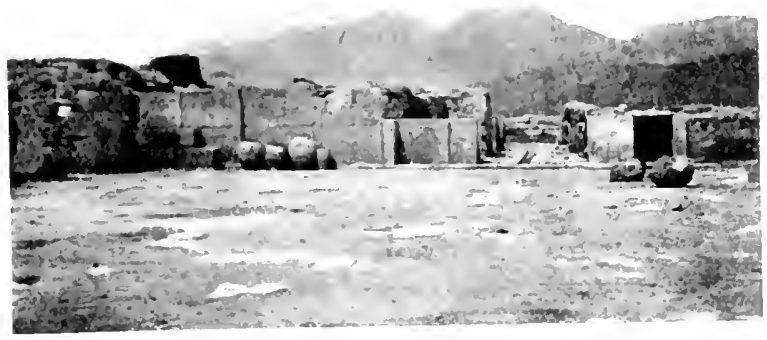

1. PHAIDIOA ANH

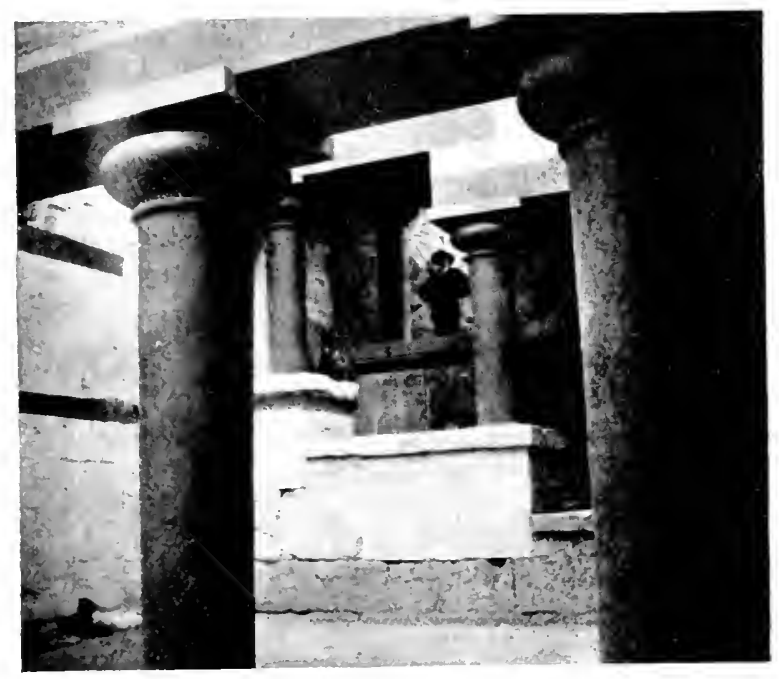

ב. THE RIREAT STAIRHAY, RNOASO

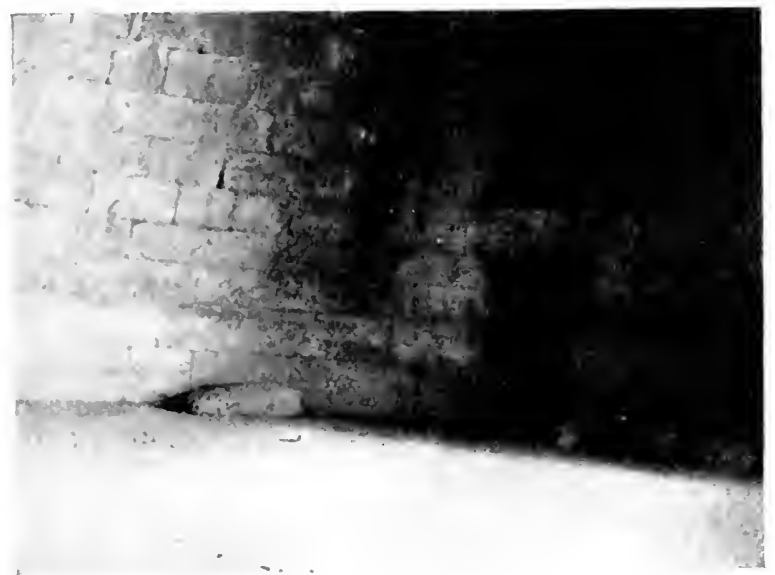

3. INTERIOR OF THE TREASURY OF ATREL 

and spacious architectural conception such as.hitherto only Egypt could have produced.

In both cases when the palaces were designed, a flat platform was prepared for them by the levelling of a portion of the hill on which each stands. ${ }^{1}$ This shews that the architects worked at the bidding of powerful rulers with large ideas, as the levelling must have involved the destruction of a large portion of the old town of the Early Minoan period in which the original king's house stood. ${ }^{2}$ To this designed destruction we owe the fact that our knowledge of the Early Minoan age is derived in small measure from Knossos and Phaistos, but rather from other excavations.

The similarity of the process in both cases points to a practical contemporaneity of execution. At the same time that the king of Knossos built his new palace in his capital, or not long after, he also built himself a southern palace in the Messarà. There was probably an earlier town here also. As at Knossos, a low hill, such as was the usual position of a primitive town, was utilized. As from the near neighbourhood of Knossos a fine view of the sea, the haven, and the ships of the thalassocrats could be obtained, with Dia beyond and perhaps Melos far away on the horizon, so from Phaistos itself an equally fine, but different, prospect greeted the royal eyes ; from this hilltop he could contemplate on one side the snowy tops of Ida (Pl. II. I) and on the other the rich lands of the Messarà; the southern mountain-range shut out the Libyan sea from his view. Later, some king desired to see the southern sea, and built himself a palace, but little inferior to Phaistos in splendour, and not far off, from which the bay of the Messarà, with the island now known as Paximadhi ("Cake"), and the splendid mountaingroup of Kentros and Ida together, were visible. This newer palace is now known as Agia Triada, from a little church of the Holy Trinity that stands upon it. Like Phaistos, it has been excavated by the Italian archaeologists, Halbherr, Pemier, and their colleagues. ${ }^{3}$

1 Mackenzie, B.S.A. xi. p. i $\delta_{3}$.

2An early Minoan "basement-building" has been discovered beneath the palace, which may be an actual dwelling-place of the Early period, covered and used as a basement by the royal architects. And a huge well (at first taken to be a tholos. tomb) has been found, partially cut down in later levelling, which probably dates to the Early Minoan period.

${ }^{3}$ Mem. R. Ist. Lombardo. xxi ; Rendiconti d.R. Acc. Lincei, xiv. ff. 
Here again the site of an older settlement was utilized and levelled for the new royal house: Agia Triada was inhabited in very early days, as we know from the tribal tholos-burial of the Early Minoan period, already mentioned, ${ }^{1}$ which has been discovered there.

Agia Triada is wholly a work of the Late Minoan period, to which we now come. Still tracing the development of Cretan civilization by means of the evolution of its pottery, we find that in the Third Middle Minoan period much of the inspiration of the "Kamàraes" potters was evaporating, and the polychrome decoration was becoming poor in execution and weak in effect. The first stage of the Late Minoan period, which followed, was ushered in by a new course in ceramic decoration. The polychrome principle was abandoned, and a system of plain darls colour upon a light ground was introduced, or rather revived. Contemporaneously with the polychrome ware, the older style of vase-painting had continued to exist, and now came to the front in a perfected form. The Cretan invention of lustrous glaze-paint now finally ousted the older style of matt colour, and with the use of brown colour on the buff-slip of the vase the principle of dark-upon-light decoration finally defeated that of light-upon-dark which had been inherited from Neolithic days. The designs of the vases of the First and Second Late Minoan periods (the "Great Palace style" of Knossos), whether the motives are developments of the spiral, or are derived from plants (P1. III. 3), and from the rocks and seaweed and marine creatures, cuttle-fish, nautili, and the rest, which were so well known to a seafaring people (Pl. III. 4), or from the wall-paintings of the palace itself, are always good, and fully worthy of the civilization that could produce the architecture of Knossos and Phaistos and the splendid metal-work which the Keftiu bore as "tribute" to Egypt.

The Knossian palace was wholly remodelled at the end of the Middle Minoan period, and apparently largely altered and enlarged in the Late Minoan period. As it stands to-day, with its extraordinary complex of halls, staircases, and chambers descending the slope towards the Kairatos, and its outlying buildings such as the "Royal Villa" below it to the north and the "Western House" higher up the hill to the west, it is a monument of the phenomenal growth of Cretan civilization

$$
{ }^{2} \text { See p. 40, n. I. }
$$

${ }^{2}$ Sec pp. 292, 2.93 . 

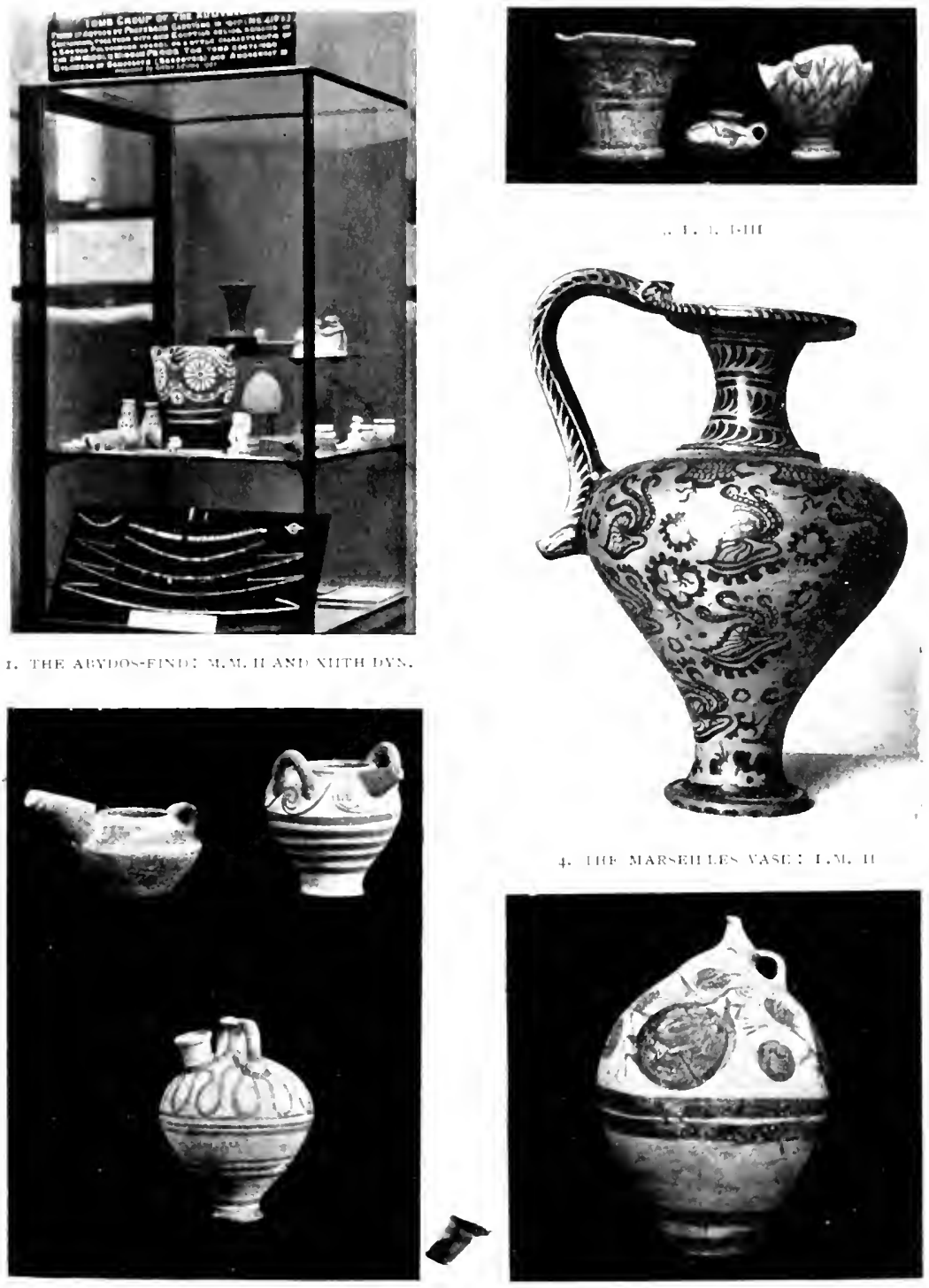

2. "SCHNALELKANNEN" AND " RU GELKA INE.

5. MHAax Ware F.M, $111,1 . .1,1$, AN11 L.M. $11 t$

PREHISURIC ARJEK POIRKR 

during the few centuries that had elapsed since the beginning of the Middle Minoan period, when the Cretans first emerged from barbarism. This palace is, one would say. a modern building. It is far more "modern" than any Greek building of the Classical period, or than anything in Italy before the Augustan age. One of its most modern features is the elaborate system of sanitary drainage with which it is provided, a thing unparalleled till Roman day's, and since then till the nineteenth century. In comparison with this wonderful building (P1. II. 2) the palaces of Egyptian Pharaohs were but elaborate hovels of painted mud. Only the sculptured corridors of Ashurbanipal's Nineveh probably surpassed it in splendour; but Assyrian splendour was after all as old, cold, and lifeless as that of Egyptian temples, while Knossos seems to be eloquent of the teeming life and energy of a young and beauty-loving people for the first time feeling its creative power and exulting with the pure joie de vivre.

No Byzantine emperor and his consort dwelt here alone within the royal palace fenced off even from the nobles by armed guards. No Assyrian monarch paced, followed by eunuchs, solitary here those corridors ornamented with bas-reliefs depicting nothing but his own triumphs in war and the chase and the meaningless, staring visages of his gods. No inhuman Egyptian Pharaoh or Japanese Mikado received here the worship due to a god from prostrate ministers and retainers. The halls of Knossos were inhabited by a crowd of courtiers and retainers, men and women both, who surrounded the king, and lived with him to enjoy the beauties and good things of life. The Minoan Court must have resembled the joyous surroundings of an European prince of the thirteenth and fourteenth centuries, with a touch here and there of the Tuileries under the Second Empire. From the fragments of the paintings, often bizarre and crude in execution, often weirdly powerful in design and framed in decorative borders of every conceivable form and colour, which covered the walls of the palace-corridors, ${ }^{2}$ we see what these people looked like. We see the women depicted as often as, if not more often than, the men, whereas in Assyria they never appear at all. ${ }^{3}$

${ }^{1}$ Cf. Burrows, Discozeries in Crete, chs. i., ii. = Cf. J.H.S. xxi. Pl. v.

${ }^{3}$ Or hardly ever. The queen of Ashurbanipal appears with her lord at Kuyunjik. See p. 506. 
Probably in Minoan Crete women played a greater part than they did even in Egypt, and it may eventually appear that religious matters, perhaps even the government of the State itself as well, were largely controlled by women. It is certain that they must have lived on a footing of greater equality with the men than in any other ancient civilization, and we see in the frescoes of Knossos conclusive indications of an open and easy association of men and women, corresponding to our idea of "Society," at the Minoan Court unparalleled till our own day.

The Minoan artists represented the women as white, the men as red in colour, thus following the same convention as the Egyptians. True to their bizarre summary ways, a crowd of men and women is sometimes shewn by the crude method of outlining merely the heads of a number of men on a red background, and those of a number of women on a white one. But for this distinction in the background it would be impossible to say whether the heads are those of men or women, since the Minoan courtiers were clean-shaved and wore their hair as long and as elaborately dressed as did the women. In the scenes of bull-fighting which often occur, and in which women are represented as taking part, one can only distinguish the girls from the boys by their colour: the same flying hair, of the same length, is common to both sexes (Plate IV. 2).

In some frescoes we see the ladies of Minos' Court depicted sitting at the windows of the palace, openly and unveiled. ${ }^{1}$ Their dress is extraordinarily modern in appearance: it is décolleté, with bare necks and arms, the breasts covered apparently with gold or silver guards reproducing their outline, their waists pinched in, and, below, ample skirts with parallel rows of flounces, resembling nothing so much as the crinolines of the mid-nineteenth century. Anything more unlike our usual conception of "Greek dress" it is impossible to conceive. At an earlier period (Middle Minoan I) we find the women in similar skirts, but with high ruff-like collars and horned headdresses which may or may not be their hair. ${ }^{2}$ The coiffure of the Late Minoan ladies of Knossos, with its knots and sidecurls, closely resembles that of the ladies of the Court of Charles II. On their heads they wear tiaras or head-bands:

${ }^{1}$ B.S.A. Ann. vi. p. 47 ; J.HI.S. xxi. Pl. v.

2 IVe see this fashion in some small figurines found by Prof. J. L. Myres at Petsofá, near I'alaikastro in Eastern Crete (B.S.A. Annual, ix. Pl. viii.). 


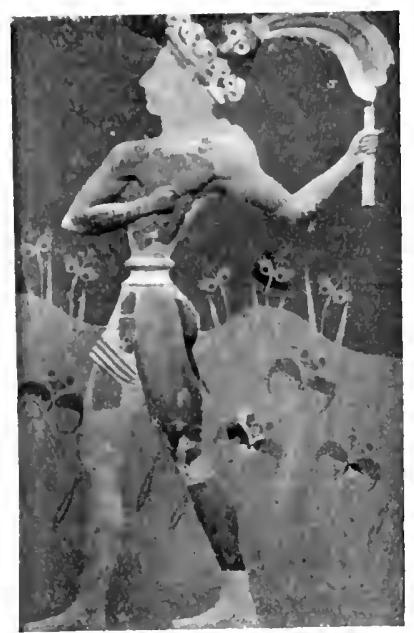

r. FREsco 13 A kisg
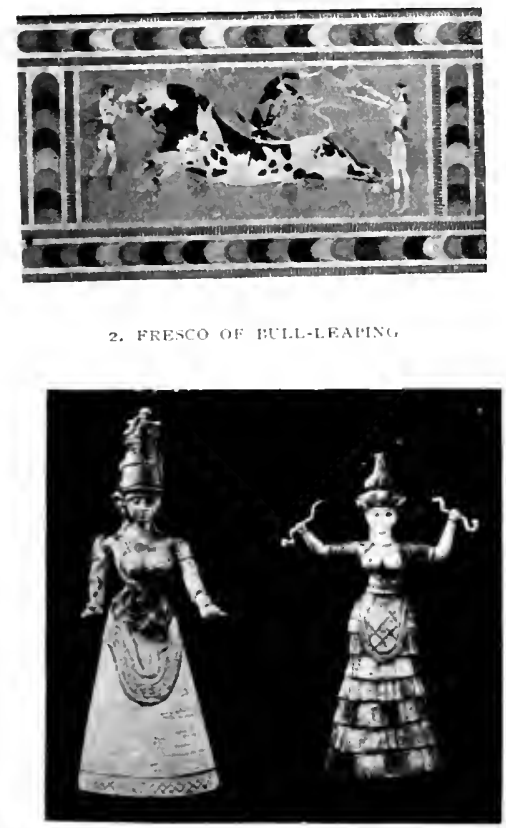

3. SIAKE G(D)HESSE

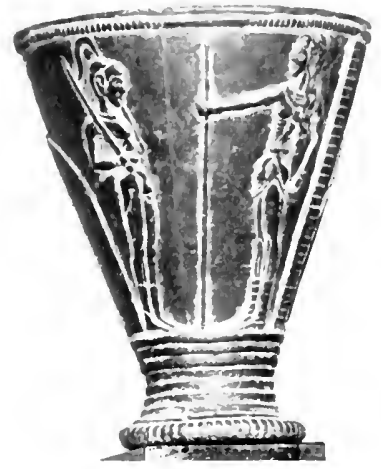

4. THE CIIEFTIIN-IASE

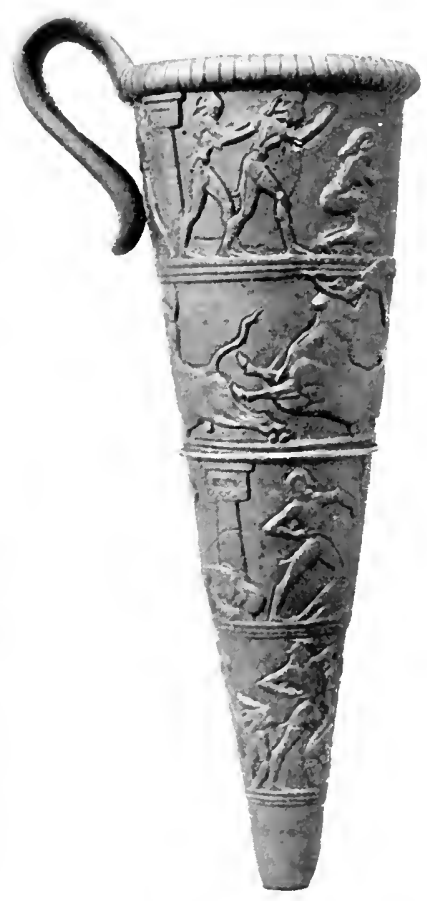

5. THE 1?GYER.YASE

MNOAN IRT: hNOOSOS AND MII TRIAU 

a goddess is represented with an extraordinary high hat (Plate IV. 3). ${ }^{1}$

The dress of the men was simple, consisting merely of a waist-cloth over] which was worn a short kilt, often arranged so as to give the appearance of a pair of bathing-drawers or boating "shorts." 2 This simple costume was ornamented in the usual way with spiral and other designs in bright colour, thus differing from the related Egyptian waist-cloth, which was always pure white: bright colours in costume were regarded by the Egyptians as barbaric. The significance of this costume as indicating the Southern and specifically African origin of the Minoans has already been pointed out: even the women's dress is nothing but a developed kilt. ${ }^{3}$ As in Egypt, the upper part of the men's bodies was nude but for a necklace, except when, on occasions of ceremony, and doubtless often by older men, a gala-robe was donned. ${ }^{4}$

Even in war, no body-panoply was put on. This was an invention of the Northerners, in all probability. For the Minoan, his great 8 -shaped shield ${ }^{5}$ was sufficient protection for his body. A helmet, probably of leather, was, however, often worn in gladiatorial combats as well as in war. This helmet has cheekpieces and is very Roman in appearance. ${ }^{6}$ Sometimes it had a crest, and one appears in a scene of combat on a gold ring found at Mycenae. ${ }^{7}$ The most usual weapon was a straight thin sword meant for thrusting: often ornamented with designs in inlaid metals. ${ }^{8}$

1 B.S.A. Annual, p. 75.

2 Ibicl. Pl. ix. p. 363 ; and cf. the Kampos statuette (Tsountas-ManatT, Afycenacan Age, Pl. xvii.; HAll, Oldest Civilization of Greece, Fig. 65, from PER ROTChiplez, Hist. de lArt, vi. Fig. 355). Sometimes (as on a seal from Zakro, published by Hogarth, J.H.S. xxii. Pl. vi. 6 ; Fig. 5, p. 78 ) this loin-cloth seems to have developed into a pair of baggy breeches not unlike the baggy trousers worn by the Cretans to this day : it is not impossible that this garment is really the modern descendant of the Aegean waist-cloth.

${ }^{3}$ Mackenzie, B.S.A. Annual, xii. p. 246.

${ }^{4} E$.g. on the Agia Triada sarcophagus (see p. 53, n. 7), and on a Late Mfycenaean vase from Cyprus (PERRot-Chipiez, iii. Fig. 526; Hall, Oldest Civilization, p. 278). At Phaistos was also found a fresco with part of a picture of a man in a most extraordinary slashed and tattered robe of many colours.

${ }^{5}$ E.g. B.S.A. Annual, viii. Fig. 41.

"See the "Boxer-Vase," found at Agia Triada (Rendiconti d. R. Acc. Lincei, xiv. Fig. I ; Burrows, Discoveries in Crete, Pl. i., Plate IV. 5, above).

7 SchuchнardT, Schliemann, Fig. 221.

${ }^{8}$ The best-known are those found in the shaft-graves of Mycenae. 
Ordinarily, no headgear was worn by the men, but a conical cap is sometimes represented, ${ }^{1}$ and a prince or god at Knossos wears a mighty head-dress of feathers (Plate IV. r). ${ }^{2}$

The characteristic long hair of the men, which has already been mentioned, was apparently sometimes coiled up on the top of the head, ${ }^{3}$ but, even when the wearer was engaged or about to engage in active work, ${ }^{4}$ it was ordinarily worn hanging down the back to the waist or below it, usually loose, sometimes in plaits or curls. ${ }^{5}$ On the head fantastic knots or curls, like those of the women, were often worn-the "horns" of which Paris was so

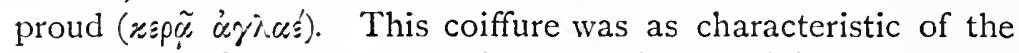
Bronze Age Cretans as was the waist-cloth, and is represented accurately even to the small detail of the curls on the top of the head by the Egyptian artists of the tomb of Rekhmara.

Characteristic also of the Minoan men's dress were the high boots which were worn in Crete then as now, and were also faithfully represented by the Egyptian as well as by the Minoan artists. ${ }^{6}$ Practically the same boot was worn by the Hittites.

Such was the remarkable outward appearance of the men and women of Knossos, which in the case of the men was accurately reproduced by the Egyptian painters of the Keftiu of the reign of Thothmes III; an appearance as distinctive and as characteristic of racial custom as the shaven heads, wigs, and

${ }^{1}$ B.S.A. Annual, ix. Figs. 37, $3^{8}$. With a tassel, viii. Fig. $4 \mathrm{I}$.

? On a fresco, restored, in the Candia Museum.

${ }^{3}$ This is evident from the head of the warrior on the "Chieftain-Yase" (PARIBENI, Rendiconti, xii. p. 324 ; Mosso, Dawn of Mediterranean Civilization, p. 54 ; see Plate IV. 4). (Prof. Burrows is, I think, in error in describing (Discoveries in $C_{r e t e^{2}}$, p. $3^{8)}$ this warrior as wearing a plumed helmet: what looks like a plume is the blade of a great falx-like weapon, probably a ceremonial halberd, which he carries in his left hand. A similar weapon, from Lentini in Sicily, is in the Syracuse Museum.) For another fashion, the hair being rolled up in a sort of turban round the head, perhaps in a kerchief, see Seager, Mlochlos, Fig. 21 : this fashion is usually feminine, however. What seems like short hair on the Petsofá figurines, the "Harvester-Vase," and the Agia Triada sarcophagus is improbably this: probably we are to understand the hair as coiled on or round the head.

"One gathers this from the representations on the "Boxer-Vase." The hair of the boxers falls over their shoulders from beneath their helmets. Cf. also the Vaphio cups.

${ }^{5}$ Loose in the case of the boxer sand of the king on the "Chieftain-Vase" ; tied at the neck on the Vaphio cups; in three curls or plaits on a figure from Gournià (Boyd-Hawes, Goumià, Pl. xi.); in a single plait (B.S.A. Ann. ix. p. 129); and so on.

${ }^{6}$ B.S.A. Amumal, ix. Pl. ix. 


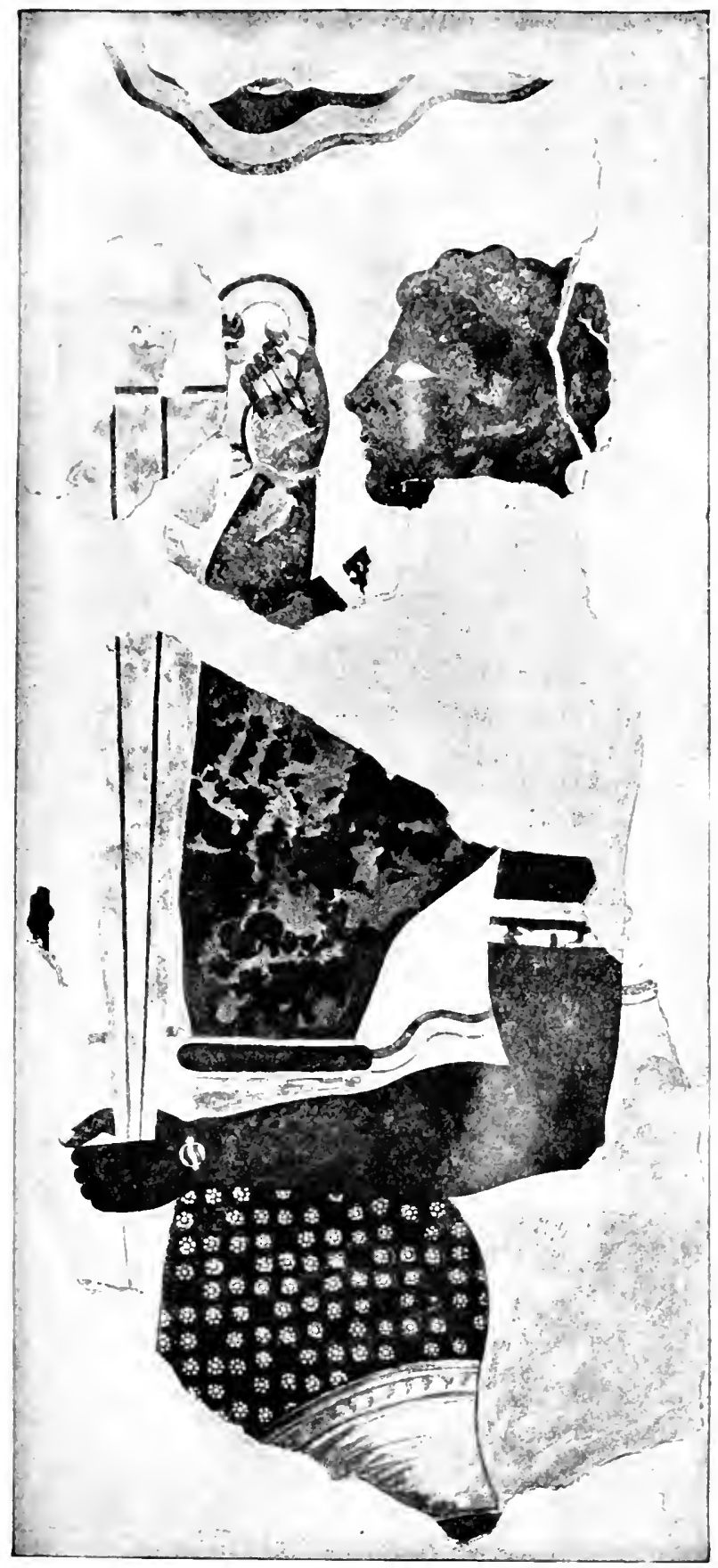

THE CLPIFAKER, kNosidos 

White garments of the Egyptians, or the oiled locks, beards, and parti-coloured robes of the Semites, their contemporaries. ${ }^{1}$

From the pictures we see that the Minoans were a brunet race resembling the modern Italians more than any other people, with ruddy skins, dark brown to black hair, and "Caucasian" features. One of the first representations of them that we have is the famous wall-painting of the "Cupbearer" (Plate V.), ${ }^{2}$ one of the first Knossian discoveries of Mr. Evans, and one which did more than aught else to direct general attention to the new finds in Crete.

Frescoes of this kind were the regular decoration of the Cretan palace-walls. Relief sculpture in stone, like sculpture of the round, on a large scale was rarely used by the Cretan decorators, though its place was taken to some extent by coloured reliefs in hard stucco.

Inscriptions were not used to decorate the walls in the Egyptian and Assyrian manner. No signs appear by the side of the pictures, and this gives us the idea that the Minoans dissociated their script from their art as the Egyptians never did. It is sometimes difficult in Egypt to know where inscription ends and pure picture begins: the inscriptions are themselves pictures, the pictures have meanings. But by the Cretans of the Late Minoan period the cursive writing that had developed out of the older signary of the seal-stones was confined to the clay tablets, of which great stores have been found at Knossos, and some at Phaistos and elsewhere. ${ }^{3}$ These were,

I I have given thesc details of the costume of the prehistoric Greeks since the history of costume is as important as any other branch of the history of human culture and art, though it is often despised by the learned. The prehistoric Greek dress is specially interesting on account of its difference from the Hellenic costume of classical times, though in the elaborately dressed long hair of the Greek man (especially in Ionia) till the beginning of the fifth century we may see a survival of prchistoric custom. I have not thought it necessary to give more than a passing reference here to Egyptian and Asiatic costumes, as their general characteristics are probably known to all. The Egyptian was spotlessly clean in his white robes, and even shaved his skull, wearing a wig (probably the most characteristic point of his costume). Even the women wore wigs. Only the children, boys and girls, wore a single plaited lock, the sign of youth, at the side of the head. The Asiatic inclined then, as he does still, to gaudiness and greasiness : the marvellous robes of the Assyrians, and their elaborately curled hair and beards, shew their beau. idéal.

2 Monthly Review, March 1901, Fig. 6, p. 124.

${ }^{3}$ Evans, Scripta Minoa, passim. 
apparently, but lists and accounts of objects preserved in the palace-magazines, with perhaps a letter or two among them: but we cannot read them. Their picture-signs and those on the seals have, however, told us much concerning the culture of the Minoans that we might not otherwise have known. Thus we know that they possessed chariots at this time (the sixteenth and fifteenth centuries B.C.) and also horses : on a seal-impression ${ }^{1}$ we have a picture of a great war-horse, with proudly arched neck, being carried in a ship (which is, by the way, much smaller, proportionally, than the horse). This may represent a scene of actual importation of a horse, probably from Egypt. The shapes of weapons and vases sketched on the tablets, though rough, are useful as an aid to archaeology.

In material civilization the Minoan Cretans were at least as highly developed as the Egyptians or Mesopotamians, in some ways more highly developed, at any rate as regards the amenities of life. Their sense of beauty and mental freedom seem to have been untrammelled by Semitic asceticism or Egyptian religious conventionality. They lived, cruelly perhaps, and possibly (according to our ideas) wickedly, ${ }^{2}$ but certainly beautifully.

Of their religious ideas we know but little. In later Greek religion there seems to be a stratum, underlying the IndoEuropean mythology which the Aryan Greeks brought with them, and more especially represented in Crete, which probably is the remnant of the old Aegean religion: a stratum of minor deities of woods and streams and stones and of the ocean, of huntress-goddesses and sun-warriors, Dryads, Satyrs, and Fauns, Naiads and Nereids and Old Men of the Sea, ${ }^{3}$ whom we find on many a Minoan seal-intaglio. The water-demon

${ }^{1}$ B.S.A. Annual, xi. p. 13 .

${ }^{2}$ The story of the Minotaur preserves a tradition of a bull-religion at Knossos, which demanded human sacrifices. The sport of the bull-leaping by girls as well as boys is cruel and gives an impression, as does also the "Boxer-Vase," of brutality. The absence of any asceticism or restraint is evident in the art and costume of the people. And the artist who produced the sometimes beautiful, sometimes evil, designs of the seals, impressions of which were found at Zakro (J.H.S. xxii.), had an evil mind. While admiring and enjoying the sight of the remains of this splendid civilization, we cannot shake off the impression that it had a by no means admirable background. It is aesthetic uncontrolled.

${ }^{3}$ The $a \lambda \iota_{o s} \gamma^{t} \rho \omega \nu$, or Nereus. That Poseidon himself was a Greek inheritance from the Minoans is not improbable. He was the chief deity of the Ionians, who more than the other Greeks preserved the old blood (see p. 67). 
with the head of an animal is a familiar appearance there, and

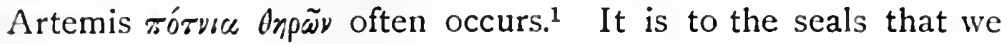
must look for representations of the deities, as the Minoans seem to have made no large figures of them. In official religion a pillar with a horned altar before it represented the devotion of the State: ${ }^{2}$ individuals pictured the gods on their seals or venerated small and rude household images of them. ${ }^{3}$ From the seals we gather a universal worship of a supreme female goddess, the Rhea of later religion, who is accompanied sometimes by a youthful male deity. ${ }^{4}$ The parallel with the Anatolian religion of Kybele and Attis is obvious, and argues a not distant ethnic connexion with Asia Minor and the "Hittites." The goddess appears in many forms; in one of the most peculiar she brandishes serpents. ${ }^{5}$ The god was no doubt in later days identified with Zeus; his symbol was the Double Axe which is so constantly found as a votive object. ${ }^{6}$

Of their funerary religion we know least, but have evidence that the ceremonies at the grave were, if not connected in their origin with certain Nilotic beliefs, certainly influenced by Egyptian rites. ${ }^{7}$ In the internal arrangements of the tombs we

${ }^{1}$ Hall, Oldest Civilization of Greece, pp. 295, 296. With the animal-headed demon may be compared the horse-headed Deneter of Phigaleia. The Minoan representation is certainly influenced by that of the Egyptian hippopotamus-goddess Taueret.

2 Evans, Mycenacan Tree and Pillar Worship, J.H.S. xxi.; confirmed by the fresco B.S.A. Anmual, x. Fig. 14. The Philistines set up pillars as the symbol of their worship at various places ( I Sam. x., xiii. ; see p. 423).

${ }^{3}$ As at Gournià (Boyd-Hawes, Gournià, Pl. xi.) and Knossos in the period of partial reoccupation (Late Minoan III ; B.S.A. Annual, viii. p. 99). Cf. the "owlheaded" figures from Mycenae.

J.H.S. xxi. Figs. 4\$, $5 \mathrm{I}$.

${ }^{5}$ B.S.A. Ann. ix. p. 79 (see Plate IV. 3).

${ }^{6}$ The double axe, $\lambda \alpha \dot{\beta} \rho y^{\prime}$, was the emblem of the Carian god of Labraunda, who was identified with Zets. That the name of the Cretan Labyrinth must be the same as that of Labraunda, and means "place of the double axe," was first pointed out by Mayer, in the Jahrb. Arch. Inst. vii. p. I91. There can be little doubt that Sir Arthur Evaxs' identification of the Labyrinth with the Palace of Knossos is correct (see Hall, "The Two Labyrinths,"J.H.S. xxv.). The bull, who certainly takes an important part at Knossos in fact and, as the Minotaur, in legend, was probably connected with the worship of the god of the Double Axe.

7 This we see from the representations on the painted sarcophagus (Late Minoan III) from Agia Triada (PARIBeni, Rendiconti, xii. pp. 343-4S.). The figure of the dead man before the tomb is directly influenced, one would say, by Egyptian representations of the mummy placed upright before the tomb while the relatives take leave of it (see BUDGE, The Mummy', p. 169). The rest of the ceremony is not very Egyptian, but the two birds on pillars are reminiscent of Egyptian representations (HALL, P.S.B.A. xxxi. Pl. xvii.). 
find, on the other hand, remarkable resemblance to Etruscan funerary customs, ${ }^{1}$ a fact that is of great interest in view of a possible racial connexion between the Aegeans and the Etruscans. ${ }^{2}$ Various forms of tomb were used ${ }^{3}$ in the Late Minoan Age, and the dead were usually placed in pottery coffins or larnakes, sometimes in baths. ${ }^{4}$ The tombs are without mural decoration of any kind.

Of the frescoes with which, on the contrary, the houses of the living were adorned, and of the art of the seal-engravers, we have already spoken. The magazines and chambers of the palaces and towns at Knossos, Phaistos, Agia Triada, Gournià, ${ }^{5}$ Pseira, ${ }^{6}$ Palaikastro, ${ }^{7}$ and Zakro, ${ }^{8}$ have yielded to us the vases and other objects of metal, stone, and pottery which are to be seen in the Museum of Candia, and give us our knowledge of the art of this age. The "small art" is often much finer than the "great art" of the frescoes and stucco-reliefs : stone sculpture in relief or in the round we can hardly mention, as it was never developed to any extent. This draws our attention to the limitations of Minoan art. Probably among the finest pieces of small sculpture in the world are the two steatite vases (of the First Late Minoan period) from Agia Triada, on one of which we see a procession of drunken roistering peasants with agricultural implements, ${ }^{9}$ and on the other the reception or dismissal of a warrior with his followers by a king or prince. ${ }^{10}$ The first is a masterpiece of relief, resembling nothing so much as the best Egyptian reliefs of the reigns of Amenhetep III and Akhenaten, while the second is full of Greek reticence and sense of proportion. But the figures of gladiators on the larger "Boxer" vase of the same period, also from Agia Triada, ${ }^{11}$ are clumsy, as also, in comparison, are the famous reliefs on the gold cups of Vaphio,

1 This is shewn by the excavations of I9Io at Isopata.

2 For arguments drawn from comparisons between Minoan and early Italian art in this connexion, see Burrows, Discoveries in Crete, pp. 35, 125 .

$\because$ Burrows, l.c. p. I6S.

${ }^{4}$ Large numbers of these lamakes were found at Palaikastro (B.S.A. Annual, viii. 297).

"Excavated by Miss Boyd (Mrs. HAwEs): see her work Gournia.

- Excavated by Mr. Seager (Excazations on the Island of Pseira, Philadelphia University, 1910).

'Bosanquet and others, B.S.A. Annual, viii. sqq.

${ }^{8}$ Excavated by Mr. Hogarth (B.S.A. Arnual, vii. ; J.H.S. xxii.).

${ }^{y}$ Mon. Ant. xiii. Pls. i.-iii. ; Burrows, Discozeries, Pl. i.

${ }^{10}$ The "Chieftain-Vase." See Plate IV. 4.

11 Plate IV. 5 . 
also of the same date. ${ }^{1}$ The steatite cups are imitations of gold repousse' work, and herein we see why the Cretan sculptors never became sculptors on the great scale. They were the disciples and imitators of the toreutic artists, and never became independent of them. The example of Egypt never moved them to great sculpture, and it is probable that they would have seen no beauty in the cold lifelessness of Egyptian colossi, magnificent though they might have deemed them. To them the little ivory leapers from Knossos ${ }^{2}$ were the highest expression of the art of sculpture in the round; size had no charm for them. The love of life and beauty dominated the Cretan artists ; they were bound by no trammels of convention, and to this was due the inequality of their work. Side by side, more especially in the domain of wall and vase painting, we see the most childish and the most perfect art. Such inconsistency would have been impossible in rigidly formal Egypt; and even when Akhenaten allowed his artists to break the chain of convention and imitate the freedom of their Cretan brethren, he would never have allowed them to produce such crude works as the Cretan princes often accepted without demur from their subjects. And, indeed, the highly trained hands of the Egyptian craftsman, an artist rather from education than in spirit, would have been incapable of such unequal work. The Cretan, however: a true artist, did what pleased him.

The wall-paintings exercised considerable influence on the decoration of pottery in the Second Minoan period, the "Great Palace" period, to which we have now come. Architectonic motives, copied from the representations of buildings in frescoes, are characteristic of the ceramic art of this time. This fact betrays a certain degeneration in the ideas of the vase-painter, and in other ways we see that the art of the "Great Palace" period was somewhat vulgarized, and even rococo. And indeed degeneracy was fast coming. The rococo period, which seems to have been a local peculiarity of Knossos, ${ }^{3}$ lasted but a century, the period which in Egypt elapsed between the reigns of Thothmes III and Amenhetep III (about I 500-I 400 B.C.). In

1 Perrot-Chipiez, Hist. de lArt, vi. Pl. xv. ; Figs. 369, 370. They are included here, though found in Greece, since they are obviously Cretan importations.

2 B.S.A. Annual, viii. Pls. ii., iii.

3 This is evident from the discoveries at Gournia and Pseira (SEager, Pseira, p. II). 
the reign of Akhenaten (about I380) the Aegean vase-fragments found at Tell el-Amarna are already exclusively of the Third Late Minoan style, which in Crete, elsewhere than at Knossos, and on the mainland, had developed out of the First. The long age of decadence now begins, in which the great art and culture of Crete slowly declined to their fall.

\section{Crete and Greece}

Probable expansion of Cretan culture to Greece-The thalassocracy of MinosNeolithic ceramic art of the East Danubian region, probably of Aegean originNative ceramic of Asia Minor: independent culture-Cretan art spreads to the Peloponnese-“Mycenaean" antiquities of Greece proper-Mycenae-Vaphio-Kakóvatos-Tiryns-Middle Minoan traces and probable first settlement of Aegeans in Greece proper-Boeotia: Treasury of Minyas, probably Late Minoan I-Voice of legend-The heroic princely houses of Cretan origin-The Minyae in BoeotiaThessaly and the Peloponnese-The non-Aegean races of Northern Greece-Neo. lithic culture of Thessaly and Boeotia contemporary with earlier Aegean Bronze Age -Possible origin of Iron Age "Geometric" art-The Northern House-Northern Greeks the ancestors of the Hellenes, ruled by princes of Aegean origin-The destruction of Knossos: c. I 400 B.C. - The Third Late Minoan period-Probable conquest of Crete by the "Mycenaeans"-The death of Minos-Minoans in Cyprus -Discoveries at Enkomi-A fugitive colony from Crete?-Political beginning of Mycenae-Pelops of Anatolian origin?-The Achaeans?-The Ionians

The reason for this decline is probably to be found in the results of the northward expansion of the Cretan culture which, at first slow, had, during the great age of Minoan power, developed greatly, and was probably accompanied by an assertion of temporal as well as spiritual control, which in the end brought about its own inevitable defeat and the wreck of Cretan civilization. Similar results are not always due to similar causes, but there is enough similarity between the contemporary decadence of both Egypt and Crete for us to predicate much the same cause in Crete as in Egypt, the empire-making spirit, which, in its inception and triumph a sign of national energy, brings with it inevitable national exhaustion. That in the end Egypt survived when Crete died is due to the fact that Egypt, though she was temporarily conquered by the Assyrians, was never overrun in her exhaustion by the virile tribes of the North, who in Greece could settle and survive, while in Egypt, had they ever reached her (as the Cimmerians and Scythians nearly did), they would soon have died out and left even a less lasting mark than did the Hyksos.

Contemporary written evidence of the existence of a Cretan 
empire in Greece we have none, of course; but the tradition of the thalassocracy of Minos is well borne out by archacological results.

We have seen that in its earliest days the Aegean culture (reckoning the Cycladic and Cretan civilizations as one) reached the northern ends of the Aegean, and may have penetrated to the Danube valley. ${ }^{1}$ By way, too, of the Black Sea its influence may have reached Bessarabia and Southern Russia, and here, in the North, arose a beautiful ceramic art, owing its inspiration to early Aegean models, belonging to a people which never reached the age of metal at all, but seems to have perished out of the land while still stone-using, leaving no heirs. ${ }^{2}$ These Mediterraneans, as we believe them to be, had spread too far from their base. They perished of pure inappropriateness to their environment, assisted, perhaps, by the more virile IndoEuropean tribes, who by this time must have made their way into Europe from Siberia.

In Asia Minor Aegean culture could not make much headway. The coast-land had its own primitive civilization, akin, no doubt, to that of the Aegean, but distinct from it, with a very different idea of ceramic art, and one which remained uninfluenced by Aegean ideas till near the end of the Bronze Age. ${ }^{3}$ The Peloponnese, however, lay open to Aegean influence, and it was here and in Northern Greece that this influence first translated itself, probably, into actual Aegean domination, through the energy of the Cretan thalassocrats. In the Middle Minoan period, the first great age of Knossos and Phaistos, the art of the Cyclades, at first ahead of that of Crete, gradually approximates more and more to Cretan styles, and actual Cretan works of art begin to be imported. ${ }^{4}$ There is no difference, also, between the script of Crete and that of Melos. ${ }^{5}$ Cretan

I. 31 .

2 A convenient summary, with references, of our knowledge of this Neolithic art is given by Burrows, l.c. ch. xi.

3 The first "Mycenaean" city at Troy is the sixth, and this was but a poor example of Mycenaean culture. It possessed no frescoes on its walls, for instance, so far as we know. On the Neolithic pottery of Asia Minor see Ormerod, B.S.A. Annual, xvi. Mr. Hogarth points out (Ionia and the East, pp. $47 \mathrm{ff}$.) that the Hittite power was no doubt a bar to the extension of Aegean influences.

C. Smith and others, Phylakopi, Pls. xxiii.-xxxii. The fresco of the Flying Fish (Pl. iii.) is evidently the work of a Cretan painter. p. 187.

Evans, in Phylakopi, p. 184; Hall, Class. Rev. xix. p. So; Evans, ibid. 
domination at this period of the obsidian and marble-yielding islands is probable enough. And thence it spread to the mainland, probably in the Middle Minoan period, when the Cretan civilization suddenly expanded to its full efflorescence.

The antiquities found on the mainland of Greece which, before the Cretan discoveries, we called "Mycenaean," are the products of the same culture as the "Minoan" antiquities of Crete. Many of them are evidently actual importations from Crete or the Cyclades; most, if they were made in Greece, were made in the Cretan style, while some perhaps shew evidence of Cycladic rather than Cretan influence. The most ancient of these objects of Aegean art found in Greece itself are no older than the Third Middle Minoan period. These are sherds found in considerable quantity at Tiryns during the recent German excavations. To "Late Minoan I" belong the contents of the shaft-graves on the Acropolis of Mycenae ${ }^{1}$ and of the tholoi or "beehive-tombs" at Kakóvatos (Old Pylos) in Messenia; the famous cups of Vaphio also evidently belong to this period. The objects from Kakóvatos ${ }^{2}$ are of the later period of the First Late Minoan period, when the peculiarly Knossian style which we call the "Second Late Minoan" was just beginning to appear. The newly discovered frescoes of a boar-hunt, from Tiryns, ${ }^{3}$ are, again, of the First Late period. It is evident that the foundations of the "Mycenaean" culture which we find in the Peloponnese in the First Late Minoan period must have been laid during the preceding age, and it is to that time, the later Middle Minoan period, that we must ascribe the first Cretan colonies in Greece. ${ }^{4}$

It is probable that at that time the Aegeans had not confined their colonies to the Peloponnese, but had also

${ }^{1}$ Schuchuardt, Schliemann's Excavations, pp. 152 ff. The M.M. III sherds in Furtwängler-Löscheke, Myken Vasen, mentioned by Fimmen (Zeit $u$. Daner der mykenischen Kultur, p. 2S), were, apparently, found outside the graves, though, of course, at Mycenae. They are therefore as important as those from Tiryns.

2 Ath. Mitt. xxxiv. pp. 269 ff. ; Pll. xil.-xxiv.

${ }^{3}$ Discovered in I9lo (Rodenwaldt, Ath. Mitt. xxxvi. pp. IgS ff.; Pl. viii.). I regard the charioteers in this fresco as young men, not as women, in spite of their being painted white: in Egypt young princes, who led the "sheltered life," were often so represented instead of red, the usual colour of men. The hair-dressing of the Tiryns figures seems to me to be masculine, not feminine, and long robes were in early classical days worn by charioteers (cf. the Delphi statue and a relief from the Mausoleum of Halikarnassos, in the British Museum), and may have been worn in Minoan times also.

${ }^{4}$ Hall, P.S.B.A. xxxi. p. 140. 
advanced from the Saronic Gulf and the Euripus into Boeotia, since we find at Orchomenos the famous and splendid "beehivetomb" called the "Treasury of Minyas," which is of the same type as the "Treasuries of Atreus (PI. II. 3) and Klytaimnestra" at Mycenae, and the tholoi of Kakóvatos. The last are of the First Late Minoan period, ${ }^{1}$ and it is to the same age that the Orchomenos tholos may also be assigned, and perhaps those of Mycenae as well. As one goes backwards in the study of Cretan civilization and its beginnings, one finds that architecture, decadent in the "Second Late Minoan" period, improves fast till it reaches its apogee in the Second Middle Minoan period: the better the style of architecture of a building the more it may be held to be older than the Second Late Minoan period, much more may it be held to be older than the Third, the decadent period of Aegean art. So this criterion, as well as the definite antiquities found at Kakóvatos, dates the great beehivetombs to the First Late Minoan period. And this brings Cretans to Boeotia, as well as to the Peloponnese, in the preceding age; for such a tomb as the "Treasury of Minyas" would not have been built for a prince whose family had not been firmly established in its possession of the land for a considerable period. So splendid a building implies secure possession. Further, ordinary tombs of the I-II Later Minoan period have lately been discovered at Boeotian Thebes.'

It may be asked: why should these Cretan monuments and relics not argue, not Cretan invaders and colonizers at all, but merely the peaceful adoption of the creations of the more civilized Cretans by the native Greek princes? Here legend speaks, and tells us with no uncertain voice that the bringers of civilization to Greece came from across the sea. It must be remembered that we know little of any civilization in the Peloponnese before the Aegean culture appeared there in its "First Late Minoan" stage, while in the North, though a native culture existed, it was of low type, and had hardly emerged from the Stone Age. The coming of the Aegeans was in truth the first bringing of civilization to Greece.

${ }^{1}$ I regard the great painted vases of Kakóvatos as belonging to the later phase of the First Late Minoan period, rather than to the Second Late period, which was purely Knossian (see p. 65, n. 2). And they seem to me to be more probably imported from Crete than of local make.

2 Keramopoullos, 'E $\phi$. 'A $\rho \chi$., I9IO, pp. $177 \mathrm{ff}$. The vases are imitated from Cretan types. 
Now the chief centres in which the oldest Cretan or Aegean antiquities in Greece have been discovered-Mycenae, Orchomenos, Lakonia, and Pylos-are all connected in legend with the heroic houses who ruled Greece in the days before the Trojan War. And these houses are either descended from foreign immigrants, or owe much of their power to the help of foreigners. These foreigners in one case reach Greece by the Gulf of Nauplia, the most obvious haven for Aegean ships and most obvious place for the earliest landing of Cretan conquerors coming from the Cyclades. Tiryns, the fortress at the head of the Gulf, was built for Proitos by the Kyklôpes from Lycia; in them we see the doubles of the wondrous artificers, the Daedalids and Telchines of Crete. ${ }^{1}$ To the valley of the Inachos came Io and Epaphos, in whose story we should perhaps, for Egypt, read Crete. On the Saronic Gulf we have a definite tradition of Cretan overlordship, which demanded a yearly tribute of youths and maidens for the bull-demon of Knossos, an overlordship overthrown by the great folk-hero of Athens, Theseus. And when we come to Boeotia, is it not probable that the builders of the great tomb at Orchomenos were the legendary Minyae, who brought civilization to Boeotia, and were the first to drain Lake Kopais by means of the tunnels through the northern hill-wall to the Euripus? The similarity of the name of Minyas, "son of Chryses" the Golden, to the Cretan royal name Minos may, in spite of the difference in quantity, mean a real connexion. Athamas, Phlegyas, and Minyas, the first kings of Orchomenos, may represent the first Cretan princes who settled among the Neolithic Boeotians, and brought Minoan culture into the land. And then the "Phoenician" Cadmeans of Thebes, whose Phoenician origin seems so inexplicable and improbable, may, in spite of the fact that in legend they are often the foes of the Minyae, be in reality Cretans. ${ }^{2}$

1 They came from Lycia, which is very near Crete, and was connected with it in legend (Sarpedon). Also, the Lycians were probably closely connected in race with the Minoan Cretans and Aegeans generally.

2 Some of the stories of "Phoenician" colonization in Greece may also really point to Minoan Crete rather than Phoenicia. This was probably the case with Boeotian Thebes. Both "Egypt" and "Phoenicia," as well as Karia, may well have been substituted in legend for the civilized people of Crete, who were not of Hellenic race, but seemed in many respects Orientals to the later Greeks, as did the Lycians and Carians. Prof. Myres remarks (in The Year's Work in Classical Studies, I91 I, p.27) à profos of the discovery of Minoan tombs at Boeotian Thebes: "As Keramopoullos points out (p. 244), this date ["Late Minoan II": 
In Thessaly we find Minyae at Iolkos, at the head of the Gulf of Volo, another gulf that points southwards towards the Cyclades, and is a probable point for a Minoan landing. The Nelidac of Pylos (Kakovatos) in the Peloponnese, which, as we have seen, was an early centre of Minoan colonization, were said to be Minyae from Iolkos, though they may just as well have come direct from Crete. For in Thessaly the extant Minoan remains are later than at Thebes or Orchomenos. The tholo $i$ of Volo and Dimini seem to be of the Third Late Minoan period, and we have no proof of Minoan connexion before then. ${ }^{1}$

In the Peloponnese, besides Pylos, we fincl traces of the Minoans in the Eurotas valley in the splendid golden cups from the tomb at Vaphio, which are probably of the First Late Minoan period, judging from their style. And here Leleges (Carians) were said to have lived in early times. ${ }^{2}$ The shore of the Gulf of Lakonia is again a probable place for Cretan occupation.

In the Peloponnese the Minoans must have established themselves during the Middle Minoan age; possibly they reached Boeotia a little later, but as to this we have no evidence. But while in the Peloponnese they probably found an Aegean population akin to themselves, this was by no means the case in Northern Greece. There we have to explain a phenomenon, recently discovered, which to a great extent bears out the view, lately published by Prof. Dörpfeld, that there were from the first two races in Greece, a Southern (the Aegeans or "Karians," as he calls them), and a Northern, who were the Aryan Achaians of history. ${ }^{3}$ Excavations recently carried on in Boeotia and in Thessaly have shewn us that there existed there a race of

I should prefer to say "I-II"] throws these vases into very elose chronological relation with the traditional date of the coming of Cadmus into Bocotia : for the generation of Cadmus stands between I 400 and I350 B.C." With the rest of Prof. Myres' remarks I should hardly agree, for he regards the Cadmeans from Crete (as he says, "Europa in Homer is no Phoenician, but the daughter of a king of Crete") as coming to Boeotia after the fall of Knossos, I as having come long before (and having brought about the fall of Knossos).

${ }^{2}$ The question of the Minyae is complicated by the assignation to them, under the name of "Minyan" ware, of a peculiar style of grey pottery found at Orchomenos and in Thessaly. But there is no proof that this ware has anything to do with the Minyae.

'HALL, Oldest Civilization, p. 98. At Sparta, as was perhaps to be expected, the recent excavations of the British Sehool at Athens have revealed traces of the Mycenaean (Third Late Minoan) period only (B.S.A. Annual, xv. pp. I1 3 ff.).

3 Ath. Hitt. $\mathrm{xxx}$. 
primitive Neolithic culture, which remained stone-using down to the Third Late Minoan period. ${ }^{1}$ Their pottery was peculiar, and in its scheme of ornament quite different from that of the Aegeans. The characteristic curved lines, spirals, and natural forms of the Aegean ceramic decoration are replaced by purely geometric designs unknown at any period to the Aegeans. But at the same time some evidence of Aegean influence is to be seen in them in the shape of clumsy attempts to reproduce spirals, ${ }^{2}$ which appear quite out of place and exotic amid their geometric surroundings; and the polychromy which characterises them may be due to imitation of the Cretan polychromy of the Middle Minoan period. In Boeotia there is evidence in a single Cycladic vase, found in a Neolithic grave at Chaironeia, ${ }^{3}$ of trade with the Acgeans at the end of the preceding age.

That the Boeotians continued stone-users down to the Third Late Minoan period, as the Thessalians certainly did, seems improbable, in view of the fact that among them the Cretan art and architecture of the grand period had been established during the First Late Minoan age. In this fact we see evidence of Cretan princes (Minyae and Cadmeans?), or at least native chiefs, employing Cretan architects and artists, ruling for a space over more barbarous subjects of a different race. And we see the same thing in Thessaly later on. It was only when in the period of its decadence Cretan art had become generally diffused over the Aegean area, and even at Troy temporarily dispossessed the native Trojan art, that Thessaly became Aegeanized. And this was probably also only for a time. For it seems by no means impossible that the Northern geometric art of the "Dipylon" period, which is usually associated with the invading Achaians or Dorians (more generally with the latter), is the descendant of the earlier geometric art of the Neolithic Thessalians, Phocians, and Boeotians. ${ }^{4}$ There is no doubt that the "Geometric" art of Greece is the art of the oldest Aryan Greeks,

${ }^{1}$ WACE and THompson, Prehistoric Thessaly (1912). Cf. with Tsounras (n. 2).

2 Tsountas, II

* I know very well how very different in point of ware and painting the Neolithic geometric pottery of Northern Greece is from the "Dipylon" pottery. It is of the peculiar style of ornament that I am speaking, of the geometric decoration which was national to the Northern potter in both ages and totally different in spirit to the whole system of Aegean, Cycladic, or Cretan vase-decoration. And I claim that it is not extravagant to suppose that the Dipylon potter inherited this tradition from his Neolithic predecessor. 
from the tenth to the eighth centuries, or at any rate as late as the middle of the eighth century. And it seems reasonable to suppose that it was a renascence of the older native art of Northern Greece in the midst of which Cretan art made but a temporary stay, leaving as its chief bequest the technical methods of the Minoan ceramic artists, which were taken on by the "Gcometric" potters, while they kept to their own non-Aegean style of ornament.

This view is confirmed by a further discovery in Thessaly. Characteristic of the later period of the Third Late Minoan age, when the degenerate Cretan ceramic had become a sort of wosvin throughout Greece, is the building of palaces in a style quite different from that which had been in vogue during the great Minoan age in Crete. We find them at Mycenae, at Tiryns, and perhaps in Crete, at Agia Triada. These buildings were much simpler in plan than the older Cretan palaces, and in their main arrangements are identical with the typical Achaian chief's house as described in the Homeric poems. They mark a set of ideas in architecture as distinct from those of the Minoan Cretans as do the earlier and later Geometric ceramics of Northern Greece. They are obviously an introduction from the North, to whose colder climate they are suited, while the Cretan palaces are more appropriate to the South. ${ }^{1}$ Now, in Thessaly have been found in the chiefs' houses of the Neolithic people the prototypes of these "Achaian" palaces. The arrangements of these Neolithic Northern houses are the same, on a smaller scale, as those of the "Achaian" palaces of Mycenae, Tiryns, and Crete. In these last the architectural skill handed down from the Minoan culture has been used with effect; that is the sole difference.

We see, then, that in later times, first the North-Greek type of house found among the Neolithic Thessalians, then later the North-Greek style of pottery found among the Neolithic people of the North, was adopted in the South. And this change was contemporary with the partial substitution of burning for inhumation in the disposal of the dead, with the first adoption

${ }^{1}$ On this whole subject the articles of Dr. D. Mackenzie, "Cretan Palaces," in B.S.A. Amuzal, xi.-xiv,, should be read. His criticism of DörlFeld's theory in Ath. Mitt. xxx. pp. $257 \mathrm{ff}$, is, as regards the building of Phaistos and Knossos, victorious; and hiș examination of NoACK, Homerische Paläste, most useful. One may not agree with all his conclusions, but his articles have greatly illuminated this, the darkest and most uncertain period of all that this history has to describe. 
of iron to replace bronze for weapons and tools, and finally with the coming of the Aryan Greeks into the Aegean and the Peloponnese.

To the introduction of iron (from the Danube-valley) and of cremation we shall return later. At present, we are only concerned to shew that the Aryan Greeks who introduced them, and the "geometric" pottery into the South, were probably the descendants of the Neolithic Northern tribes among whom the Minoan culture had been introduced during the Late Minoan age. And this conclusion seems not impossible from the facts adduced above.

The Neolithic Northerners may then have been the ancestors of some of the Hellenes, whom all tradition brings from Thessaly. They were probably Indo-Europeans, with their own undeveloped culture, which the non-Aryan culture of Crete and the Aegean was only able to displace temporarily after many centuries of contact, when it was itself decadent.

The Cretan domination was unable to affect the native culture, at any rate in Thessaly, more than temporarily. It brought the Northerners the knowledge of bronze, and taught them how to build, but the peculiar artistic ideas of the conquered held true, and when the civilization of their conquerors declined, and the conquered in their turn became the conquerors, the Hellenic (Achaian) house came South with the Hellenes or Achaians even to Crete itself, and later on, the Northern Geometric pottery followed.

The end of the Second Late Minoan period is marked by a catastrophe, the destruction of Knossos. The royal palace-city had been destroyed before, and we see from the small provincial towns of Gournià and Pseira, excavated by American explorers, ${ }^{1}$ that fire and sword were not uncommonly the fate of Aegean settlements in the Minoan age. But the destruction of Knossos was complete, its site was deserted, and its great art disappeared, to be succeeded by the far inferior productions of the Third Late Minoan age, which were not specifically Cretan, but rather the common property of Greece. This marks the difference between the ceramic styles of the First and Second and the Third Late Minoan periods. That of the earlier period is Cretan, that of the later may be only indirectly of Cretan origin. It appears suddenly when the "Great Palace" ceramic style as suddenly

$$
{ }^{1} \text { See p. } 54, \text { nn. } 5,6 .
$$


disappears, about I400 B.C. Its motives of decoration are derived from those of the Cretan potters, but its direct continuity with the Cretan wares is not obvious. There is a gap, though not one of time, between them, and this may be accounted for by supposing that the Third Late Minoan style of pottery is in reality "Mycenaean," as it used to be called, that it is, in fact, a style that arose in the Peloponnese and the islands, developed on Cretan models by the Minoan conquerors of Continental Greece and the Aegean. ${ }^{2}$

And the coming of this pottery to Crete may tell us who the conquerors were who destroyed Knossos and brought the Ninoan empire to an end. They were, it may be, the descendants of those Cretans who had gone forth to colonize Pylos, Mycenae, and Orchomenos, and had sent the yearly tribute of Athenian youth to be sacrificed to the deity of Knossos. And with them marched their subjects, the Achaeans or Danaoi of the Nortl.

Did the Minoans simply submit to their conquerors, or did they seek refuge in another land? The coming of the Cadmeans to Boeotia ought, we think, to be assigned to an earlier period, and the descendants of the Cadmeans probably took part in the destruction of Knossos. The legends of the expedition of Minos to Sicily against Kokalos, King of Kamikos, and his death, of the second expedition to avenge his death, and of the Cretan colonization of Hyria in Italy, may have arisen from a confusion of an actual attempt of the Knossian thalassocrats to wage war in Sicily, and an actual colonization in Italy of dispossessed Minoans after the fall of Knossos. A more definite answer to our question may perhaps be found in the history of the civilization of Cyprus. The Bronze Age culture of Cyprus pursued a path of its own, producing a peculiar style of art, as exemplified in its pottery, related rather to that of Asia Minor than that of the Aegean, till, suddenly, the Cretan culture appears in its midst. And the

${ }^{1}$ Its first and most sudden appearance is at Tell el-Amarna, in the palace of Akhcnaten. At Ialysos it is of much the same date.

2 The "I ate Minoan II" slyle, the specifically "Palace" style of Knossos, will then be a peculiarly Knossian development (at Gournia and Pseira the "Late Minoan I" goes on to the end, and it is impossible to draw a hard and fast line between it and "Late Minoan II," which hardly appears). "Late Minoan III" was developed in continental Greece and the islands from "Late Minoan I." On this see FORSDYKE, J.H.S. xxxi. pp. I Ioff. 
earliest Cretan art found in Cyprus, as we see it in certain of the remains discovered at Enkomi, Curium, and Hala Sultan Tekke, ${ }^{1}$ are of the Second and Third Late Minoan periods, or at any rate of the beginning of the Third. Of the First style (only a century older) but a few examples have been found; of the Middle Minoan a single sherd. ${ }^{2}$ With these remains were found Egyptian objects which are of one period only, the end of the XVIIIth Dynasty, that is to say the very time of the destruction of Knossos. Is it too rash to suppose that the Cretan colony in Cyprus, which appears so suddenly at this time, with no previous history behind it, was a colony of fugitives from Crete, who, by virtue of their superior culture, easily and soon won for themselves a dominant position amid the lethargic eastern islanders? These seem to have submitted at once to the conquerors, as we find their pottery placed side by side with that of the new-comers in the same sepulchres.

Henceforward a peculiar form of decadent Minoan culture, a Cyprian version of "Late Minoan III," lived on in Cyprus, and of it we have splendid relics in the later remains from Enkomi, now, with those of the period of the conquest, in the British Museum. The later vases shew an important modification of Minoan traditions in that the human form is constantly depicted on them (in Crete it had never occurred), and their forms shew the strong Northern influence of the later "Third Late Minoan" style in Greece. ${ }^{3}$

The "Third Late Minoan" period must be the period of the

${ }^{1}$ A. S. Murrax, A. H. Smith, and H. B. Walters, Excavations in Cyprus, London, 1900.

${ }^{2}$ Forsdyke, J.H.S. loc. cit.

${ }^{3}$ There is little doubt that the antiquities discovered by the British Museum expedition at Enkomi date roughly to two main periods, the first contemporary with the end of the XVIIIth Dynasty in Egypt, the second to a much later time, perhaps three centuries later. On the dates of the jewellery found see Marshall, Brit. Mius. Catalogue of Jewellery (I9II), pp. xvii ff.; and on the general question Poulsen, Jahrb. Inst. Arch. xxvi. (I9I I), pp. 215 ff. The objects of the earlier period comprise some of the finest known specimens of Minoan art, especially notable being a bronze ewer, some goldwork and ivories, and the horse-head and other rhytons of faience. Of the later objects the pottery and the ivory draught-box with an Assyrian scene of hunting from chariots are the most remarkable (see Excavations in Cyprus, passim). All the chief objects are in the British Museum, making its "Mycenaean" collection the next in importance, so far as "capital" objects are concerned, in the world after Candia and Athens. Oxford is a good fourth : other collections are comparatively unimportant. 
political hegemony of the kings of Mycenae and the Argolid in Greece, to which the Homeric poets ascribed the ancient glories of the heroic civilization of Greece. It was they who destroyed Knossos and to whom the sceptre of Minos passed. Whether the poets were right in calling them "Achaians" and "Danaoi" we do not know. Legend brought Pelops, the founder of the house of Agamemnon, from Asia Minor, and it is by no means impossible that some Anatolian invasion may not have established rulers of Anatolian (Hittite) origin in Greece. ${ }^{1}$ There is nothing Achaian about the Pelopids. The Homeric poets were themselves Achaians, and may well have made their heroes Achaians. And, as we shall see, it is by no means impossible that the whole poetical description of the Peloponnesian princes as Achaians was a mistake, due to a confusion of the Thessalian Argos, where Achaians certainly lived, with the Peloponnesian Argos. There may never have been any Achaians in the Peloponnese till, much later, the great invasion of the Thesprotian tribes from beyond Pindus, of which Herodotus speaks, drove the Achaians and the later Boeotians and Dorians out of Thessaly, and resulted in the expulsion of the Minyae from Boeotia and the settlement of the Pelasgi in Attica. It was only then that the Achaians possessed themselves of the Peloponnese, and succeeded to the heritage of the older Mycenaean chiefs, to lose it after a short time to the Dorians. The use of the word "Achaians" to describe the Mycenaeans of the Pelopid dynasty is therefore to be deprecated; they may more probably have been Ionians, for the Achaians took the north coast of the Peloponnese from its inhabitants, who were Ionians. And the Ionians were certainly less purely Hellenic in race than the other Greeks, and were probably just such a mixture of Indo-European (Greek) and Aegean elements as the "Mycenaeans" of the Third Late Minoan period probably were, a mixture of Achaians (if one likes) with Aegeans, but not pure Achaians. ${ }^{2}$

1 Hall, Mursil and Myrtilos (J.H.S. xxix. (1909), pp. 19 ff.).

2 I am quite unable to follow Mr. T. IV. Allen (Class. Ker., Dec. I9I1) in equating Achaians with Minoans and bringing the former from the South. The IIomeric Achaians were fair-haired Greek-speaking people. 


\section{The Period of the Invasions}

The Thesprotian invasion-The emigrations to Cyprus and Pamphylia-Wandering of the Philistines and Trojan War-Egyptian evidence : the Peoples of the SeaThe Shardina and Danuna-The Tjakaray of Dor-The Luka-The Akaiuasha and Tuirsha-The great movement in the time of Rameses III-Uashasha-The Philistines in Palestine-Later history of the Philistines-Aegean pottery in Philistia

The great Thessalian or Thesprotian invasion, which probably took place in the thirteenth century B.C., and followed that of the Boeotians, had far-reaching effects. By it an overwhelming Aryan and iron-using population was first brought into Greece. The earlier Achaian (?) tribes of Aryans in Thessaly, who had perhaps lived there from time immemorial, and had probably already infiltrated southwards to form the mixed Ionian population about the Isthmus, were scattered, only a small portion of the nation remaining in its original home, while of the rest part conquered the South and another part emigrated across the sea to the Phrygian coast. Of this emigration to Asia the first event must have been the war of Troy, originally, as we shall see, perhaps an expedition of Thessalian Achaians and Thessalian Argives, not of Peloponnesians at all. The Boeotian and Achaian invasion of the South scattered the Minyae, Pelasgians, and Ionians. The remnant of the Minyae emigrated to Lemnos, the Pelasgi and Ionians were concentrated in Attica and another body of Ionians in the later Achaia, while the Southern Achaeans pressed forward into the Peloponnese. A mixed body of Peloponnesians, Ionians, Kythnians, Arcadians, Ionians, and Laconians took ship across the sea and appeared in the midst of the probably non-Greek Minoan colonists of Cyprus, who had established themselves there some two centuries before. These second colonists from Greece brought with them a Peloponnesian dialect of Greek, which henceforth became the language of the island. ${ }^{1}$ With the same movement must be associated the immigration into Pisidia of the Pamphylians, a similar

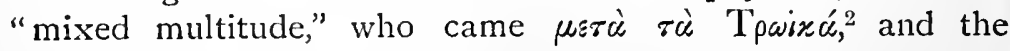
colonization of the Aleian plain in Cilicia by Mopsos and his men, who occupied the cities of Mallos and Tarsus. ${ }^{3}$

${ }^{1}$ References in J. L. Myres, s.v. "Cyprus," Encycl. Britt. I th ed. (I910), p. 698, n. 8 .

2 HDT. vii. 91 .

${ }^{2}$ On the legends of Tarsus, see Ramsay, Cities of St. Paul, pp. I $6 \mathrm{ff}$. 
Further, with the same migration must be associated the great wandering of the Philistines and their allies from Crete, ${ }^{1}$ driven out probably by Achaians, who overran Palestine and were finally brought to a stop by Rameses III on the borders of Egypt. The traditional date of the Trojan War, as given by the Parian Chronicle, I I94-II 84 B.C., accords remarkably with the known date of the war of Rameses III with the Philistines, about I 190 B.C. ${ }^{2}$

The indications of archeology and of legend agree marvellously well with those of the Egyptian records in making the Third Late Minoan period one of incessant disturbance, very different from the comparative peace of the great Minoan days. The whole basin of the Eastern Mediterrancan seems to have been a seething turmoil of migrations, expulsions, wars, and piracies, started first by the Mycenaean (Achaian) conquest of Crete, and then intensified by the constant impulse of the Northern iron-users into Greece. "The Isles were restless: disturbed among themselves," say the Egyptian chroniclers, who, as we shall see, record at least two distinct attacks upon Egypt by the "Peoples of the Sea" in the thirteenth and twelfth centuries. $^{3}$ Some of these tribes, Lukki or Luka (Lycians), the Danuna, who were Greeks ( $\Delta$ avcoob), while others, the Shardina and Shakalsha, may have been Italians or from Asia Minor, are already found hovering on the Asiatic coasts and taking service in the wars of Palestine as early as the time of the Tell el-Amarna letters (c. I370 B.C.), ${ }^{4}$ very shortly after the destruction of Knossos and the Keftian power.

Already the first wave of disturbance had reached the coast of Asia, and the sea-tribes were endeavouring to possess themselves of strongholds on the Palestinian coast from which to carry on their piracies. The Danuna had apparently already succeeded in doing this, ${ }^{5}$ and others soon followed. For three centuries these outposts of Greek pirates maintained themselves, and at the end of the XXth Dynasty we find the town of

1 We might associale with the expulsion of the Philistines from Crete the dim legends of early (pre-Ionian) colonization of Ionia from Crete, as that of Rhakios at Klaros and Kolophon (PAus. vii. 3). The eponymous hero of Miletos is called a Cretan, and the name certainly has a Cretan sound : the Cretan Milatos on the north coast is a Minoan site.

${ }^{2}$ Generally speaking, I am very chary of using the legendary Greek dates for the Heroic period for purposes of history ; but this particular date is curiously apposite.
${ }^{3}$ See pp. $377,3^{\text {Si. }}$
See pp. 343, 349.
s. 377, n. I. 
Dor still occupied by the Aegean Tjakarai, whom we shall soon mention. ${ }^{1}$

None of the tribes who made war on Rameses II (c. I 295 B.C.) as subject-allies of the Hittites were Aegeans, all being natives of Asia Minor. The westernmost of them, the Dardenui or Dardanians and the Masa or Mysians, were (if correctly so identified), though dwellers by the Aegean, probably not included within the circle of Aegean civilization, as, owing to the domination of the Hittites as far as the Aegean, the Minoan culture had never been able to effect any foothold on the coast of Asia Minor.2 The Luka or Lycians, who had already appeared a century before as sea-rovers, and had then attacked Alashiya and the coast of the Egyptian Delta, ${ }^{3}$ were the only seafaring tribe among them, and the only one which was probably affected at all by Aegean influence. But the Akaiwasha who directly attacked Egypt from the sea, in company with Shardina and Shakalsha and another tribe, the Tursha, together with a horde of the restless Libyans, in the reign of Meneptah, ${ }^{4}$ were probably Greeks. If we regard the termination of their name as a "Mediterranean" ethnic suffix akin to the Lycian $-a z i$ or $-a z \alpha,{ }^{5}$ we can fairly regard these Aliaiwasha as the first representatives in history of the Achaians. The date of their expedition is about I230 B.C. This date agrees very well with the probable time of their wanderings after the conquest of Thessaly by the Thesprotians, and we can regard the Akaiwasha ravagers of the Egyptians as a body of Achaian warriors of the same kind as those who laid siege to Troy and founded the colonies of Aeolis at this same period. The Tursha may very well be Tyrsenians, Turs(c)i, whose sea-migration from Asia Minor to I taly is probably to be placed about this time (see p. 336).

The main body of the horde which passed through Asia Minor and Palestine to the borders of Egypt in the reign of Rameses III (c. I I96 B.C.) seems to have come from Greece. "Their main strength," says the inscription recording this great

1 In the Report of the Egyptian envoy Unamon (II 7 B.C.): see p. 393.

2 Hogartir, Ionia and the East, pp. $47 \mathrm{ff}$.

3 See p. 270.

${ }^{4}$ See p. 377.

${ }^{5}$ This possibility was first pointed out by me in $0 . C . G$., p. 178. The name would come to the Egyptians in a Cretan-Lycian or at least "Mediterranean" form. The Lycians in historic times called the Athenians Atenäzi and the Spartans Spfartäzi (KRETSCHMER, Einleitung, pp. 3 II ff, , 329). 
event, "was Pulesatha (Pulesti), Tjakarai, Danauna, and Uashasha." All these tribes were probably Aegeans, and one was certainly, two were probably, of Cretan origin. For the Pulesti were the Philistines, whom both Hebrew and Greek traditions bring from Caphtor (Keftiu) or Crete to Palestine, and, this being certain, the identity of the Uashasha with the Cretan Axians ${ }^{1}$ is rendered highly probable, while the possibility that the Tjakarai came from the eastern end of Crete, where the place-name Zakro still exists, ${ }^{2}$ is by no means to be dismissed lightly. There are evidently dispossessed Cretans, who migrated both by land and sea from Lycia, probably in alliance with a horde of western Anatolians, perhaps displaced by the Phrygian invasion, which must have taken place about this time, ${ }^{3}$ along the Asiatic coast, "no land standing before them, beginning from Kheta and Alashiya." The western dominion of the Hittites of $\mathrm{Khatti}^{4}$ bowed before this irresistible storm, while Alashiya, the coast-land of Cilicia (and N. Phoenicia ?), ${ }^{5}$ fell an easy prey. The aim of the Pulesti and their allies was no doubt to reach the rich land of Palestine, with the coast of which they had been familiar for centuries; and they passed on thither. Rameses III prevented them from going farther, and raiding the Egyptian Delta, which they no doubt also intended to do, though they could never have hoped to settle there permanently. A permanent occupation of Palestine was, however, evidently intended, as they came with women, children, and all their belongings. And they succeeded in effecting their aim: the Egyptians, though they defeated them, could do no more than bring the great migratory mass to a standstill, and left them in occupation of the Shephelah, exacting, perhaps, some sort of recognition of Egyptian overlordship, to which it is not probable that the Philistines paid very much attention. The transplanted Aegeans imposed a powerful yoke on Canaan, which lasted till, nearly two centuries later, they had become weakened by all

1 HaLl, O.C.G., p. 177.

2 Petrie, Hist. Eg. iii. p. I 51.

3 Owing to the large extent of country overrun by the migrating horde in Syria, and to the fact that so large a part of the wandering was conducted by land, it would scem not improbable that western Anatolians formed the best part of the land force the Cretans and Lycians (?) forming, as is probable enough, the naval force. For the Phrygian invasion of North-western Asia Minor from Thrace, see pp. $475 \mathrm{ff}$. The repercussion of the tribes displaced by the Phrygians may well have caused the immediate overthrow of the Hittite kingdom (see p. $3^{8} 3$ ).

${ }^{4}$ See p. ${ }_{3} \mathrm{~S}$.

${ }^{5}$ See p. $243, n$. 
the unfavourable conditions of their existence as a foreign garrison in a strange land, and had begun to be absorbed by the conquered Semites. Then the Israelitish tribes, whom at first they had driven into the hills, and whose budding civilization they had destroyed, gathered themselves together into a national kingdom, which forced the foreigners back towards the sea-coast and finally destroyed their separate existence. Three centuries after their first coming the separate nationality of the Philistines had entirely disappeared, and of their language nothing but a few personal names survived in use in Philistia. ${ }^{1}$ The parallel to the extinction of the Danish language and nationality of the Northmen in Normandy two hundred years after Rollo's conquest is curiously exact. So history always repeats itself when conditions are similar.

Of their presence many traces have been found in the shape of Aegean pottery of debased "Late Minoan III" style, such as we should expect to find Cretans using in the twelfth century, chiefly at Tell es-Safi, the ancient Gath, the town of Goliath; and in buildings at Gath and at Gezer. ${ }^{2}$ This fact is a conclusive confirmation of the truth of the legend that brings the Philistines from Crete. ${ }^{3}$ And with them they brought iron.

${ }^{1}$ Yet it is curious that in later days the Philistine cities were specially receptive of Hellenic culture and eager to claim relationship with the Greeks and dissociate themselves from the Semites. Their coin-types shew this, see p. 399, n.

"The greater part of the "pre-Israelite" pottery found at Tell es-Sâfi, described as "Palestinian" in the publication of the Palestine Exploration Fund (see p. 4I7), is Palestinian only in the sense of "Philistine": it is Aegean "Minoan" pottery of the latest style, exactly such as we should expect would have been used by a population of Aegean origin in the twelfth century B.C. The only distinctions that can be made between it and the latest Minoan (or "sub-Minoan") ware in Crete are evidently due to the fact that some of the Philistine pottery was made, not in Greece, but in Palestine. The buildings are more doubtful cvidence. At Tell es-Sâfi (Gath) is a hall with two square pillars and, apparently, "light-wells" for illumination, as at Knossos (BLISs, Excavations in Palestine, Fig. 9). At Gezer are vaulted brick tombs with objects of silver, alabaster, and iron, which point to occupation by a foreign race of CarianLycian affinities (MaCAlister, Gezer, i. pp. 289 ff.); and the Philistines were just such a race. We shall see that though they came from Crete, they are not necessarily identical with the old Minoan Cretans, and the feather head-dress so characteristic of them points decisively to Lycia as their original home (HALL, J.H.S. xxxi. pp. $119 \mathrm{ff}$ ).

3 As to the Greek (Cretan) origin of the Philistines there is no longer any doubt : the evidence of archreology combined with that of tradition is definite on the point. See Moore, in Encycl. Bibl., art. "Philistines"; Hall, P.S.B.A. xxxi. (1909), passim. Mr. S. A. Cook's article in the eleventh edition of the Encyclopadia Britannica is admirable, but perbaps suffers from an insufficient appreciation of the evidence for Cretan origin. There is no doubt that the Biblical "Caphtor," from 


\section{The Iron Age}

Int roduction of iron and cremation-Decline of culture : piracy-Cyprian cultureThe Ilomeric Age : the Iliad-The wrath of Achillcus-Original form of the poem -The Homeric culture-Polity-The Dorian invasion-Sparta-Ionian migration-Dorian migration-Rebirth of Greek civilization in Ionia, where the Mycenaean tradition had been preserved

\section{It is to the Thesprotian invasion, which displaced the} Achaians, that, in all probability, the general introduction of iron

which the Philistines came, is the "Keftiu" of the Egyptians, whether we explain the final $r$ with SPIEGELliERG (O.L.Z. xi. 426 f.) as existing in the original name but dropped by the Egyptians, who often elided a final $-r$ into $-y$, or see in it the Egyptian expression Keft-hor ("Upper Kefii," analogous to K'etenu-hor, "Upper Retenu," i.e. Syria, as opposed to "Lower Retenu," Palestine; Wiedemann, O.L.Z. xiii. (1910) 52). And that Keft, Kefti, or Keftiu is Crete there is no doubt (Hall, B.S.A. Ann. viii. pp. I62 ff.). For "Casluhim," which accompanies "Caphtor" in the Biblical passage referred to (Gen. x. I4), no original has yet been found (HALl, "Caphtor and Casluhim," in Man, 1903, 92). NoordTziJ, De Filistijnen (Kampen, 1905), is generally good, but fails in an uncritical attempt to treat the pre-Mosaic references to Philistines (the story of Abimelech in Gen. xx., xxvi.) as historical (see HaLl, P.S.B.A. xxxi. p. 233 n.). Noordtzij also talks of the Philistines as "Indo-Germans." It is highly improbable that the Greek islanders of the twelfth century B.c. yet spoke Aryan Greek. It is in the non-Aryan Lycians and Carians that we must seek their ethnic and probably their linguistic relatives (see p. 5), if we regard them as descendants of the ancient Minoans, driven out by the invading Northemers. This is, however, by no means certain. Though they came from Caphtor, they are as represented on the monuments of Rameses III by no means like the Keftians and Minoans in personal appearance. Their peculiar feather head-dress is, it is true, represented as worn by a warrior on a fragnent of pottery from Mycenae and by the warriors on a fragment of a silver bowl, also found at Mycenae, and of old Minoan date; but it is probable that these feathered bowmen are not Cretans, but foreigners represented defending a town against a Cretan at lack (HALl, J.H.S. xxxi. p. 120). And a similar hcad-dress appears on the men's heads which are impressed with other non-Cretan hieroglyphs on a curious clay disk, found at Phaistos, which may well be taken to be a foreign letter of some kind, probably from Lycia (Evans, Scripta Mlinoa, p. 287). It is, so far as we know, a non-Cretan head-dress, and the Philistines are also never represented with the great 8-shaped Minoan shield, but with a round shield like those of the nonAegean Shardina and the Homeric Greeks. And also they wear a brazen corslet like the later Greeks, whereas the Minoans had worn no body-armour. It is possible that they were descendants, not of the old Minoans (most of whom had perhaps gone to Cyprus two centuries before the Philistine migration), but of some Lycian or Carian tribe who had migrated to Crete. (The Lycians in Ferxes' army wore a feathered head-dress ( $\mathrm{HDT}$. vii. 92), and Ionians or Carians are represented oll Assyrian monuments as wearing such.) But, on the other hand, in the two centuries and more that had elapsed since the fall of Kinossos those of the Cretans who remained in the island may have abandoned their characteristic armature and have adopted the round shield and brazen armour which was probably in use among the Northern Greeks. If so, they may be of Minoan race. The survival of the Minoan name of Keftiz in the tradition that brings then from Caphtor points in this direction. 


\section{THE ANCIENT HISTORY OF 'THE NEAR EAST}

into Greece is to be assigned. The invaders came ultimately from the Danube region, where iron was probably first used in Europe, ${ }^{1}$ whereas their kindred, the Achaians, had possibly already lived in Thessaly in the Stone Age, and derived the knowledge of metal from the Aegeans. The speedy victory of the new-comers over the older Aryan inhabitants of Northern Greece may be ascribed to their possession of iron weapons. But the defeated must soon have acquired the knowledge of the new metal from the conquerors, and it is to the dispersion of the defeated Achaians throughout the Greek world that we must assign the spreading of the use of iron. Even to Crete Northerners, probably Achaians, brought their iron weapons, with the practice of cremation and the "Geometrical" pottery of the North, which we find in Crete (at Moulianà) in graves side by side with bodies buried in pottery coffins (larnakes) and Mycenaean ware of the latest and most debased type. Whether the Achaeans had always burnt their dead we do not know, but whereas they had probably learnt the use of iron from the Illyrian invaders, the "Geometrical" pottery must, if it is the descendant of the older geometric styles of North Greece developed under Late Mycenaean influence, be Achaian, and have, originally, nothing to do with the Illyrian iron-bringers. However this may be, we know that now the Aryan practice of cremation first appears in Southern Greece, with geometric pottery and iron weapons. And that these new features of national civilization are to be associated with the final conquest of Greece by the Aryan Greeks there is no doubt. And that this conquest was largely effected by the southern and eastern movement of the Achaians, driven out of Thessaly by the Illyrian invaders, seems very probable.

The Cretan discovery at Moulianà ${ }^{2}$ shews us how for a time bronze and iron were used side by side, while the old Aegean

If they were Minoans, they cannot, $e x$ hypolhesi, be regarded as "an advanced post of the Indo-Europeans" (NOORDTZIJ). Only if they were of Northern origin can the possible presence of Indo-European blood in them be admitted. The peculiar name of the screns, as the five great Philistine chiefs were called, is doubtless the same word as the Greek ripavpos, but this need not mean that they spoke Aryan Greek: Túpavpos is just one of these Greek words which has a non-Aryan, preHellenic, aspect.

1 Ridgeway, Early Age of Greece (London, igor).

2 Xanthoudides, 'E $\phi$. 'A $p \chi$., 1904, pp. 22 ff. See Burrows, Discoveries, p. 101. On the Cretan development of the Geometric pottery, see Droop, B.S.A. Ann. xii. 
culture was dying. Other explorations in Crete shew us that the terrible wars and confusion of this period had almost destroyed the ancient culture of the island. The old Minoan cities, unfenced from the attacks of the destroyers, were abandoned, and the population, terribly reduced by strife and emigration, fled to fortresses in the hills. ${ }^{1}$ The shore was abandoned to the pirates, Achaians, Italians, and probably Carians and Lycians (Philistines), who infested the seas, while the Phoenician traders, who now for the first time entered the Greek seas, trafficked, as we know from the Homeric poems, with the barbarized Aegeans and stole them to be sold as slaves in the markets of Sidon and Tyre.

So the Iron Age began, amid the ruins of the old Aegean civilization. Only in Cyprus did the bronze-using Minoan culture still persist a little while longer ${ }^{2}$ the copper of that island would favour the continuance of the Bronze Age there, as in Egypt.

We know something of this time, when iron had not yet displaced the use of bronze, but both were used together, from the older lays of the Iliad. A Chian poet, who bore the name Homeros, seems in the ninth century B.C. (this is the traditional date for him) to have welded into a magnificent whole poems which had themselves been put together by earlier poets from lays which described a great event in the story of the Achaian colonization of Aeolis, namely the siege of the Phrygian city of Troy or Ilios, by Agamemnon, King of Argos, and the great quarrel between him and his ally Achilleus, King of the Thessalian Myrmidones. We all know the form which the poem took in the hands of the Chian, but it is improbable that the conception that a huge host, drawn from all parts of Hellas, under the leadership of the king of Peloponnesian Argos and Mycenae, marched against Priam, in any way corresponds to the facts or to

${ }^{1}$ Good examples are the Iron Age settlements in Crete, which are always more or less inaccessible. Such are "Thunder Hill" and the Kastro of Kavousi, excavated by Miss Boyd, the settlement recently found by Mr. Seager in the Monasteraki gorge, near by, and that at Vrokastro, now being excavated by Miss Hall.

2 There is little doubt of this. The Late-Mycenaean vases from Cyprus are of a kind later than any yet found in Crete or Greece, and the pictographic script con. tinued to be used there after the rest of Greece had adopted the alphabet. The civilization of Cyprus in the early historic period was rigidly conservative, preserving old-fashioned names for persons, old-fashioned usages in war such as the use of the chariot, etc. The old Bronze Age culture lasted there later than in the rest of Greece, and its traditions were still retained in the historic period. 
the statements of the oldest lays. In them the war was doubtless waged only by the Thessalian Achaians against the Phrygians, who lived on the coast of the Aegean over against them. We have a hint of this in the fact that Argos is called "horse-feeding." This epithet can only refer to the Thessalian Argos. It was this Argos which Agamemnon really ruled, but in the later days when the poems were put together, the chief centre of Achaian power was, or had but latelybeen, Peloponnesian Argos, ${ }^{1}$ which they had taken from the Ionian (?) Mycenaeans when, driven from Thessaly by the Thesprotians, they entered the Peloponnese. To Asiatic Achaian poets of the ninth century Argos could only mean the great neo-Achaian Argos in the plain of the Inachos, and so the Thessalian Achaian chiefs who warred against Troy in the twelfth century were identified with the neo-Achaian lords who ruled the Peloponnesian Argos and Mycenae from the twelfth to the eleventh, and then the whole traditional dominion of the ancient CretanIonian princes of Mycenae in the fourteenth and thirteenth centuries, with their allies from Lakonia, Pylos, and Crete, was brought up in warlike array against Troy beside her original and probably historical enemies, the Thessalian Argeioi. So the ancient glories of Mycenae were appropriated by the Achaians, and the Achaian poets of Asia made the ancient Thessalian heroes of their race lords and kings of all Greece. ${ }^{2}$

The poems probably give us a general idea of Greece as it was from the thirteenth to the tenth centuries: here we see a trait that must belong to the earlier rather than the later time, here is something that bears the impress of later date. In many things the latest poet of all no doubt introduces ideas which belonged to his own time, as in the appearance of Thersites, the first Greek demagogue, meet to be held up to the derision of an aristocratic audience of Achaian chiefs. But in the main the poem which

\footnotetext{
${ }^{1}$ Even when the poens were finally redacted the last scene of the long wars which had been inaugurated by the siege of Troy was probably not entirely played out to its end. It is doubtful whether even in the ninth century the Dorians had finally completed their conquest of the Peloponnese, and certainly in the apparently later portions of the lliad, in which the transmutation of Argos has been effected, and the whole Peloponnese marches under Mycenaean-Achaian banners against Troy, we have no hint of any but Achaian lords in Southern Greece. In the time of the last Homer, or at any rate till shortly before it, Achaians still ruled in the Peloponnese.

2 For the "transmutation of Argos" (as Prof. Bury calls it, Hist. Gr. p. 67), see Busolt, Griech. Gesch. i. ${ }^{2} 223$ n. ${ }^{1}$; Weloch, Griech. Gesch. i. I57; Cauer, Grundfragen der Homerkritik, pp. $153 \mathrm{ff}$.
} 
he welded together describes a society older than that which must have existed in the ninth century. Perhaps we cannot say that he consciously archaïzed : the older songs which he used and put together, and had been put together by his predecessors, described the manners and customs of the old days when they were first sung, the oldest of them probably not very long after the migration. ${ }^{1}$ Homer did not translate them into the manners and customs of his own day, though he allows traces of the later idcas of his own time here and there to appear.

We can then say that the Homeric culture is rather that of the Achaians of the twelfth or eleventh than of the ninth century. Bronze is still the usual metal for weapons, but iron is known, and occasionally appears. It is the period when both metals were in use, but bronze was still commoner than iron, and less valuable. The dead are usually burnt in the new fashion, but are also buried (and indeed the older custom always persisted in Greece alongside the newer). The polity of the tribes is entirely of the new age, but is still of the simple Aryan type which has so often been described. Only a few traits, like that of Thersites, shew the influence of the period of final redaction, when the political problems of the new Greece were beginning to make themselves felt. The island of Lesbos is described as still in the possession of a Phrygian population : ${ }^{2}$ by the ninth century it must long have been hellenized. Thrace is the land of a rich and civilized prince; we may doubt if this was still the case in the ninth century. The Phoenician traders were no doubt still in evidence then; but it is noticeable that they are called Sidonians, not Tyrians: by the ninth century Tyre had long supplanted Sidon as the chief city of Phoenicia.

The Iliad, and those older parts of the Odyssey that are directly influenced by the more ancient poem, shew us then a Greece that is not yet the Greece of classical days, though this later Greece was already beginning its history when the last Homer sang. A final event had then happened which was to bring about the birth of the new Greece, but of it we find no trace in the poems, the stuff of which belonged to the older day. This was the Dorian invasion, the Return of the Heraklids.

1 Miletus, for instance, is not inhabited by Greeks, but by barbarian Karians. The Phrygians, too, are in full possession, not only of the coast, but even of the islands. This points to a contemporaneity of some of the lays with the actual migration.

2ll. ix. 29, xxiv. 544 . 
That the later legends give the main story of this event more or less correctly we need not doubt. Its result was the bringing into Southern Greece of a population that was the most Aryan of all the Greek tribes, the most free from Aegean admixture. The Dorians, like the Boeotians, were a tribe that had originally lived in Illyria, and had advanced into the Achaian land before the pressure of the Thesprotians behind them. We can hardly doubt that the impulse to their final southward movement was given by the Thesprotians who had taken Thessaly from the Achaians, and that under the name of Dorians were included many tribes of the vigorous Illyrian new-comers. The Dorians properly speaking can only have been a small clan, and were possibly but the leaders of a host of the new inhabitants of the North. That their kings were of Achaian blood is probable enough. That they were at first defeated, in trying to pass the Isthmus, by the Achaian princes of Argolis, and that eventually they gained their purpose by crossing the Gulf of Corinth at Naupaktos ("the place where they made ships"), is no doubt a historical fact. The result we know. The Peloponnese was dorized. Messenia and Argolis exchanged Achaian for Dorian princes, the dispossessed Achaians were driven into the Ionian territory which became the historical Achaia, while in Laconia was established the most definitely Dorian state of all, which enslaved the older population, Achaian as well as Aegean (as the Thessalians had reduced their predecessors to the status of Penestae), and ruled with a rod of iron from the village which they built by the older Achaian capital, Lacedaemon. The peculiar Spartan institution of the double kingship may conceivably represent the dual character of the new nation, Illyrian as well as Dorian-Achaian.

In Northern Greece Boeotia was also dorized, and the Megarid was torn from Attica, from which land the great Ionian migration now carried a crowd of the dispossessed, Achaians no doubt as well as Ionians, to the shores of Asia, where Achaians from Thessaly and Cretans from Crete ${ }^{1}$ had already gone a century or more before. The Dorian invasion and Ionian migration may safely be placed in the eleventh century, though it may be doubted whether the conquest of the Peloponnese and establishment of the new Spartan and Argive kingdoms was finally effected till the tenth, and the occupation

I See p. 69, n. I. 
of Aigina may have taken place still later. The Dorian seamigration, which took Dorians to Crete $_{1}{ }^{1}$ and the Southern Cyclades, and eventually to the new Doris in Asia, can hardly have begun till the ninth century, only a hundred years or less before the beginning of the great colonizing movement from Ionia that proclaimed the dawn of the Greek renascence.

With the Dorian migration the prehistoric and legendary period of Greek history ends. The dawn of the historic period, though not yet the dawn of history, may be seen in the time of the Homeric poets of Asia, who lived at the courts of Aeolis and Ionia, where the remnants of the old Aegean culture which had been brought by the Aeolian and Ionian emigrants were now working with the ruder elements of Aryan Greek culture to form the second civilization of Greece. It was in Aegean Ionia that the torch of Greek civilization was kept alight while the home-land was in a mediaeval condition of comparative barbarism: ${ }^{2}$ Cyprus too, helped, though she was too far off for her purer Minoan culture to affect the Aegean peoples very greatly. It was in Ionia that the new Greek civilization arose : Ionia, in whom the old Aegean blood and spirit most survived, taught the new Greece, gave her coined money and letters, art and poesy, and her shipmen, forcing the Phoenicians from before them, carried her new culture to what were then deemed the ends of the earth. ${ }^{3}$

1 The island was only partly Dorian in the days of the Odyssey, but eventually became wholly dorized, and a seat of the strictest Dorian $\dot{a} \gamma \omega \gamma \dot{\eta}$, with the institution of common meals (syssitia), etc. Throughout the classical period the Cretan Dorians kept up close relations with Argos, rather than with Sparta, which points perhaps to a coming of the Dorian colonists from Argos, the expedition of Althaimenes.

2 Of comparative barbarism only, for even the Dorians brought with them a North. ern (Danubian) Iron Age culture of their own. And the recent finds in Laconia (see p. 522) shew that the Spartan was not quite so uncivilized in earlier days as he later became. The old pre-Dorian culture of Laconia which we find in the Homeric poems must have had considerable influence on the new-comers.

${ }^{3}$ This view, that the tradition of the Bronze Age culture of Greece was preserved in Ionia to become the origin of the Hellenic civilization, has been held by several writers. I mentioned it ten years ago in my Oldest Civilization of Greece, and Mr. HogarTu has lately reaffirmed it with cmphasis in his series of lectures on Ionia and the East (Oxford, 1909). 


\section{CHAPTER III}

\section{ARCHAIC EGYPT}

\section{The Stone Age}

Palaeolithic remains-Primitive conditions-Reclamation of the river valley-Beginnings of art-Necropoles of the Neolithic period-Neolithic implements, pottery, etc. - Neolithic method of burial-The survival into historic times-The change to mummification and full-length burial-Continuity of archaic with predynastic culture

7 HAT Upper Egypt was already inhabited during the earlier Stone Age we know from various discoveries of implements of palaeolithic type which have been discovered upon the crests of the limestone and sandstone walls which bound the Nile valley on either side. ${ }^{1}$ The valley must at that time, before fertilizing mud left by the yearly inundation had been turned to account for the production of cereals, and a system of irrigation introduced for the purpose of conveying water to the boundaries of the cultivated land when the flood had subsided, have been mere jungle and swamp, the home of great herds of hippopotami and of innumerable crocodiles. Man was confined to the arid waste on either hand, and there, even if the oryx and the gazelle afforded him occasional food, he was still in the midst of deadly enemies: the desert is the abiding-place of scorpion and deadly snake, the horned cerastes and the death-dealing cobra. Nevertheless, mankind continued to increase and multiply, and slowlyand painfully Man raised himself from the position of a mere beast among other beasts to that of lord of the other animals: the Man that stood erect sharpened flints, made fire, and cooked. Slowly his flint-

${ }^{1}$ Schweinfurtir, Terhandl. Berlin Anthrop. Ges., 1902, p. 293 ; PitT-Rivers, Anthrop. Journ. xi. (1SS2), p. 3S2 ; BlanCKenHORN, Zeits. Ges. Erdkunde, 1902, pp. $694 \mathrm{ff}$.; HALl, "Palæolithic Implements from the Thebaid," Man, 1905, 19; Beadnel. , Geol. Mag., I903, pp. 53 ff. 
knapping improved, he descended into the side wadys, he ventured into the swamp which the waters left when each year they retired from off the face of the earth, he began to plant and to irrigate. Villages of mud and reeds arose upon the small palm-crowned mounds which stood up here and there above the plain, and were never overflowed even by the highest inundation; reed canoes carried men from one to the other in flood-time and across the swift main stream itself; eventually artificial dykes began to be made to connect village with village in flood-time; these are still there as one of the most characteristic features of Egypt, the gisrs or causeways, and will always be necessary. So the Egyptian gradually learnt the arts of ditch-digging and embanking, and came to understand the amount of work that can be done by gangs of men acting together. It was by means of the inclined plane of earth and the hauling power of gangs of men that in later days he erected his mightiest temples and even raised the Pyramids themselves.

Then the first beginnings of art and handicraft arose: reed mats were plaited and cloth was woven; pottery, made of the Nile mud without the aid of the wheel, but often of the most beautiful form, was rudely decorated in colour; the flint implements reached a pitch of accuracy in their chipping that was never attained elsewhere in the world $:^{1}$ the Neolithic Egyptian was already passing out of barbarism into civilization. ${ }^{2}$

All this we know from the necropoles of the primitive inhabitants of Upper Egypt which have been of late years discovered in many places. These primitive Egyptians belonged to the Late Neolithic period; in a few of the later cemeteries copper already appears; towards the end of the prehistoric age, therefore, the Egyptians had already passed into the "Chalcolithic" stage of development, in which, to all intents and purposes, they remained till the end of the "Old Kingdom." Their implements of chert and flint are often of types unknown to Europe, and are always beautifully chipped and finished.

Towards the end of the prehistoric period the art of making stone vases arose. These were often made of the hardest

1 These Neolithic implements must be distinguished from the palaeolithic fints mentioned above.

s That the Neolithic Egyptian was at least partly descended from the desertdweller of palaeolithic days seems probable enough ; but, as we shall see, many considerations go to prove that the main stock of the predynastic Upper Egyptians came from North Central Africa. 
stones, and the art of making them continued under the earliest dynasties. $^{\text {I }}$ Some of the latest prehistoric pottery is evidently imitated from these stone vases. But a much earlier type of the same ware, buff in colour with decoration in red, is more characteristic of the prehistoric pottery (Plate VI. I-3). Its decorations represent men, women, antelopes, ostriches, palm trees, boats, etc. The same style of decoration is found on the walls of a tomb near Hierakonpolis, which are the earliest known Egyptian paintings. ${ }^{2}$ An earlier type, ${ }^{3}$ also well known to us now, is a plain polished ware, usually without decoration, of polished red with black tops; another and later type is of white or pale buff ware, and for its shapes greatly affects the simple cylinder, thus producing a sort of tall jam-pot, usually decorated merely with a wavy lug or bracket-handle just below the lip. This type continued in use into the historical period: the black and red style belongs mainly to the Neolithic age, though it may have survived in the hands of more backward sections of the population even as late as the VIth Dynasty, and in Nubia continued to be made always. ${ }^{4}$ Queer ivory and bone figures of men and women, the men often represented as fully bearded, a fashion unknown in later days, are also characteristic of this period, and peculiar flat objects of slate, usually rudely fashioned to represent an antelope, or a tortoise, or a bat, were used as palettes ${ }^{5}$ upon which to grind the green malachite which the prehistoric Egyptians used to paint their faces. ${ }^{6}$

1 They often bear a remarkable resemblance to the stone vases which are characteristic of the early Minoan age in Crete. The early Cretan had the same taste in this regard as the carly Egyptian (see p. 34, n. 2).

2 Quibell and Green, Hierakonpolis, ii. pp. 20 ff. ; Pll. lxxv.-lxxviii.

3 Petrie, Diospolis Parva, p. 13.

4 See p. 95.

5 The use of these objects as palettes has finally been decided by M. Naville's excavations at Abydos, 1909-10, in the course of which they were found with the antimony used for making the paint and with pebbles for grinding it.

${ }^{6}$ Under the Ist Dynasty these curious palettes developed very strangely into great shield-like objects upon which were sculptured in relief commemorations of victories over his enemies gained by the king (Plate VI. 5); they were apparently preserved in the temples with great ceremonial mace-heads decorated in much the same fashion. Upon some, which apparently date to the very beginning of the Ist Dynasty, if not to the period of the Shemsu-Hor (see p. 100, n. I), circular spaces are left which represent the place where the antimony-paint was ground. We may perhaps assume that the painting with this $k o l h l$, as the Arabs call it, was, at any rate as far as the king or the image of the god was concerned, a ceremonial act of mystic signifi. cance, and that the palette on which the paint was ground for the earthly monarch or for the image of the deity was a very sacred object, on which the royal or divine 


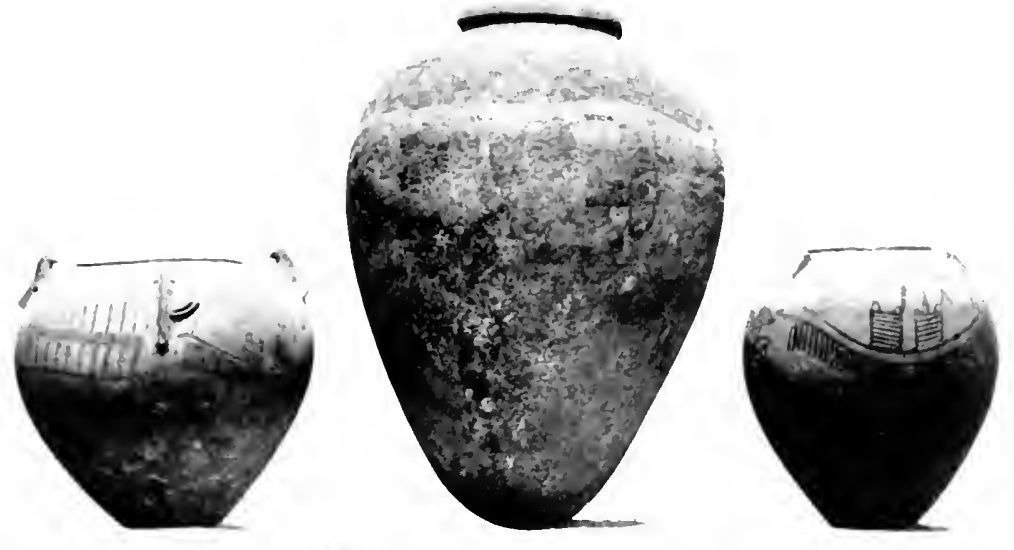

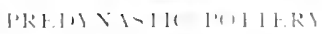

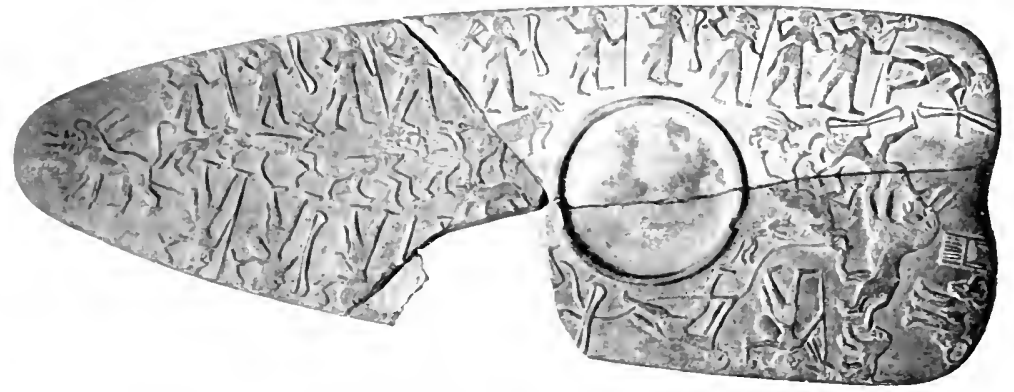

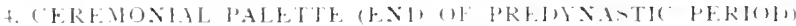

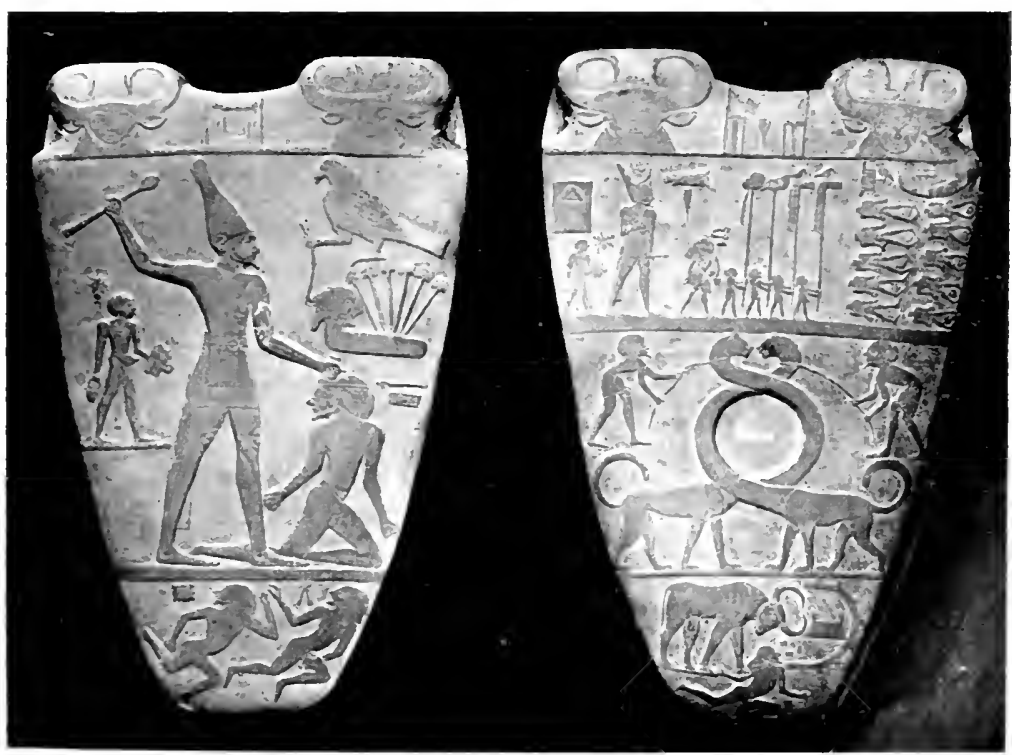

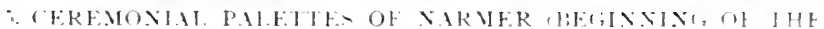
$1 \mathrm{H}-\mathrm{T} \| \mathrm{N}, \mathrm{l}-\mathrm{l})$ 

The Ncolithic Egyptian was buried, usually in a curled-up position with his head resting upon his knees, lying upon his left side, in a very shallow grave, usually oval in shape. With him were buried his pots, his flint knives, his kolnl palette, and his reed mat, so that he might pass fully equipped into the next world. These graves are not found isolated, but are always grouped together in necropoles, often consisting of many hundred graves. Between one grave and its neighbour sometimes not more than a few inches of desert sand intervenes. ${ }^{1}$ This close packing often led to disturbance in Neolithic times, and it is possible that the many cases of dismemberment of the bodies, usually considered to indicate a regular practice of piecemeal burial, ${ }^{2}$ is really to a great extent due to ancient disturbance. ${ }^{3}$ Until further evidence is available on this point, it would be as well to hold in abeyance the conclusion that the Neolithic Egyptian constantly separated the limbs of the deceased before burial. ${ }^{4}$

The contracted method of burial survived in Egypt among the poorer classes of the settled population as late as the time of the VIth Dynasty, when even the primitive and half-named tribes of the desert-fringe, corresponding to the Beduins and 'Ababdeh of to-day, though still, perhaps, making pottery of the Neolithic fashion, had already adopted the new fashion of burying at length, ${ }^{5}$ which after the VIth Dynasty became universal. This custom is first seen at the end of the IIIrd Dynasty in the case of the higher classes only; and with it had come into fashion the practice of mummification: the Neolithic bodies had merely been

deeds might fitly be sculptured, to be preserved in the temple for ever. The macehead, as a symbol of authority, would also recommend itself as a significant medium of such commemoration. These post-Neolithic objects of both kinds have been found among the most ancient temple-treasures at IIierakonpolis and elsewhere, and are preserved in the Museuns of Cairo, London, and Oxford. See further p. I00; cf. Capart, Dibuts de l'Art en Esypte, ch. v.

${ }^{1}$ On the prehistoric method of burial, see DE MORGaN, Recherches sur les Origines de TEgypte; Petrie and Quiber., Naqada and Ballas; Maciver, El Amrah; Reisner, MACe, and Lytrigoe, Early Dynastic Cemeteries of Naga ed-Dêr, passim.

2 Wiedenann, in De Morgan, loc. cit. Ethnographie prethistorique, pp. $203 \mathrm{ff}$. ; Petrie agrees with Wiedemann more or less.

${ }^{3}$ Elliot Smith, The Ancient Esyptians, p. 48 ; following ReIsNer's opinion.

4 The religious evidence is in favour of piecemeal burial on occasion : in the prayers of the Book of the Dead the deceased prays that his limbs may be reunited, and so forth. Such evidence cannot be ignored.

5 This conclusion appears deducible from the excavations of M. Naville in the VIth-Dynasty necropolis of Abydos (1910). 
dried or smoked. The contracted bodies of the VIth Dynasty were to some extent mummified. ${ }^{1}$-Here we have an interesting alteration of primitive custom, almost corresponding to the substitution of cremation for inhumation in prehistoric Europe. That we are to assign it to a change of race is more than doubtful. We have, as we shall see, evidence that an ethnic element, distinct from that of Upper Egypt, existed in Lower Egypt before the beginning of the Ist Dynasty. But there is no doubt that while this foreign element in Northern Egypt contributed not a little to the common culture of dynastic times, the main fabric of archaic Egyptian civilization was developed straight out of the Upper Egyptian culture of the Neolithic period. This fact has been proved beyond dispute by the work of Maciver at Al-Amrah, ${ }^{2}$ followed by that of Reisner and Mace at $\mathrm{Nag}^{\mathrm{e}}$ ed-Dêr, ${ }^{3}$ and in nothing is the continuity of the archaic culture with the neolithic of Upper Egypt shewn more clearly than in the development of the graves, which progress uniformly from the oldest shallow oval pit to the characteristic chambers of the Ist Dynasty, and through the staircased graves of the IIIrd to the Vth, ${ }^{4}$ to the deep pits with chambers of the VIth and the XIth. ${ }^{5}$ The gradual change in the form of the tomb was evidently merely a change in fashion, a natural development, and thus also we must regard the gradual change in the mode of treating and laying out the body. Ideas were altering at the time; civilization was advancing, and religious views were by no means yet fixed.

All that is most characteristically Egyptian, especially in the religion and in the writing, is to be found in germ in the Upper Egyptian predynastic period. The gods and their emblems were known to the Neolithic Egyptian, and he used their sacred animals as the symbols of his village and name. The standards of the gods already appear, and in these primitive

1 The developed practice of mummification did not become universal till the time of the XVIIIth Dynasty. Under the Middle Kingdom (XIth-XIIIth Dynasties) the dead were usually not mummified in the proper sense of the term, and their remains are generally found skeletonized.

2 El Amrah (E.E.F., 1902).

${ }^{3}$ Reisner and MACE, Early Dynastic Cemeteries at Naga-ed-Dîr, i., ii. (Univ. California, 1908-9).

${ }^{4}$ Garstanc, Tombs of the Third Egyptian Dynasty (1904). Some of these tombs are really of the Vth Dynasty.

5 There are typical VIth-Dynasty graves at Abydos: for XIth-Dynasty graves, see IIAll and Ayrton, in Deir el-Bahari, XIth Dynasty, i. (E.E.F., 1907), pp. $43 \mathrm{ff}$. 
representations of the divine emblems we see the beginnings of writing. They are the first Egyptian hicroglyphs. Under the Ist Dynasty the writing developed swiftly; answering to the needs of a swiftly developing civilization. But in the hieroglyphs of the Ist Dynasty we cannot see any exotic clement that we recognize: the signs are all Egyptian and represent Egyptian objects, and their descent from the simple predynastic ideographs is evident.2

\section{The Races of Egypt and the Introduction of Mctal}

Semitic element in religion and language-Craniological evidence-The Mediterranean element-African character of the Southern Egyptians-Evidence of he legends-Traditional connexion with Somaliland-Funt-Legends of Horus of Edfu - The invaders from the South who founded the kingdom of Hierakonpolis, the first Egyptian kingdom-Early Egyptians in Nubia

Yet in the religion there was a foreign element, though it does not assert itself vigorously till the time of the IVth and Vth Dynasties. This was the worship of the Sun, and his sacred stones, the forerunners of the obelisks; a cult that is apparently of Semitic, and at any rate of Palestinian, origin. As we find it under the IVth and Vth Dynasties, this worship centred in the important town of Annu, On, or Heliopolis, on the eastern edge of the Delta, next to the lands of the Semites. We can find no trace of Sun-worship in what we can see of the religious beliefs of the Neolithic Egyptians. It is the old veneration of the sacred animals and the weird visions of the Lower IVorld that are so characteristically Egyptian, and undoubtedly go back to the beginning of things in the Nile valley: the Sun-god was an invader from the East. He bore, too, a Semitic name. ${ }^{3}$ Further, another god of the North, Ptah, the "opener," bears from the first a purely Semitic name. ${ }^{4}$

And with this possible Semitic invasion must be connected a most important fact. The language which was written with these characteristically native and Egyptian hieroglyphs was, even as we know it as early as the time of the IVth Dynasty or earlier, strongly affected by Semitic influence. That it is

${ }^{1}$ Cf. De Morgan, Recherches: Elhnostaphie frihistorigue, p. 93.

2 See further, p. I 6 .

"The word li'a, "Sun," is probably connected with the Semitic "or, "light."

"The Hebrew pathach. 
entirely "proto-Semitic" in character may be doubted, but that it contained Semitic elements is certain. The personal pronouns are Semitic in character, and it has been supposed by philologists, though the supposition is not yet universally accepted, that the verbs follow Semitic rules of conjugation. This original Semitic element in the language must be dissociated from later Semitic "contaminations" due to later connexion with the Semites.

We thus see that while archaeology knows of no definite foreign invasion of the Nile valley, and can with justification regard the whole of Egyptian culture as of indigenous growth, a study of Egyptian religion does seem to shew a very early Semitic element, and the philologists claim Ancient Egyptian as a more or less Semitic language. Craniological study contributes the important fact that during the early dynastic period the physical type of the Egyptians altered from that of predynastic days, and it seems most natural to suppose that this alteration was due to infiltration of a different population from the North, which would naturally ensue when the two parts of the country were united under one crown. This postulates a separate population in the North. ${ }^{1}$

Now the early representations of Northern Egyptians on the monuments of the Southern king Narmer at Hierakonpolis shew them as decidedly Semitic or Semito-Libyan in type. ${ }^{2}$ And we find this Semitic type in a Ist-Dynasty representation of a Beduin from the First Cataract. This type is not the same as that of the predynastic Egyptian of the South, who, as we know from skulls and from contemporary representations, was smallerheaded and smaller-featured than the Beduin and the North Egyptian "Semite," though racially he may have been distantly connected with him. ${ }^{3}$ We have then in the South the delicate, small-bearded Upper Egyptian prehistoric race, the makers of the pots and flints we have described, who greatly resembled the Gallas and Somali of farther South, and probably belonged to that "Hamitic" race, which may be akin to the Southern Arabians. Evidently they came from the South. Then we have in Northern Egypt the Semito-Libyans, bridging the

${ }^{1}$ Elliot Smith, "The People of Egypt" (Cairo Scientific Joumal 30, vol. iii., March 1909).

2 See pp. 95, 06.

${ }^{3}$ Ellolot Sintri, The Ancicut Esyptians (London, 1911), p. 52. 
gap between the Berbers of North Africa, whose languages are akin both to Semitic and to Ancient Egyptian, and the true Semites. Evidently they came from the East. They brought Sun-worship and the more definitely Semitic elements in the Egyptian language. ${ }^{1}$

Finally, craniological research has shewn that there was a third racial element in early Egypt, large-skulled, round-faced, and short-nosed. This element is not apparent, however, in prehistoric times in Upper Egypt: it only gradually spread southwards under the early dynasties. ${ }^{2}$ And we have interesting confirmation of the Northern origin of this type in the portraitstatues of the Pharaohs and great men of Memphis from the IVth to the VIth Dynasties, which shew the type of the ruling classes in the North as that of the large-skulled people. Now these people were almost European in features (Plate IX.), and not in the slightest degree "Semitic," whether of the strongnosed Syrian or slight-nosed Arab type. They were not Semites, nor again were they Anatolians, as their noses were not of the Armenian or "Hittite" style or their skulls of the strongly brachycephalic type of Asia Minor. ${ }^{3}$ I regard them as Mediterraneans, akin to the early Cretans, who had been settled in Northern Egypt from time immemorial, and belonged to the North African stock from which perhaps the early Aegeans sprang. This stock will have been at an early period overrun by the Semite-Libyans, but when the Southern or true Nilotic Egyptians conquered the latter and founded the kingdom, the Mediterraneans, naturally more gifted and more civilized than the Semite-Libyans, reasserted themselves in the North, and gradually, owing to their superior intelligence, became more and more dominant in the nation, and their blood naturally diffused

1 The Semitic element in Ancient Egyptian might be duc simply 10 an original relationship of the Hamitic tongues to the Semitic, but for the fact that the "Semitism" of Egyptian seems so much stronger than that of the other Hamitic languages. So that when we find evidence of a properly Semitic population in Lower Egypt, we cannot but think it more probable that the Semitic element in Egyptian comes from these Semites.

2 Elliot Smith, op. cit. pp. I roff.

${ }^{3}$ Here 'I differ from Dr. Elliot Smith, who, making these Egyptians members of the "Armenoid" race of v. Luschan, would bring them from Syria and Anatolia. But I see no resemblance whatever between the facial traits of the Memphite grandees of the Old Kingdom and those of Hittites, Syrians, or modern Anatolians, Armenians, or Kurds. They were much more like South Europeans, like modern Italians or Cretans. 
itself southward as they amalgamated with the Southern race. If this was so, there can be little doubt that many of the resemblances both in religious cults and in art between early Egyptians and Cretans are due to this North Egyptian race.

The above is a theory which may or may not be correct, but at least endeavours to give some explanation of the facts. IVe see at any rate that we have to deal with a second element in Northern Egypt by the side of the Semite-Libyans, and that it is this element, and not the Semite-Libyan, that modified the Egyptian race so materially under the early dynasties. ${ }^{1}$

We have still to reconcile the archaeological with the philological and other facts mentioned. It might be urged that archaeology does not altogether reject the possibility of an early Semitic element even in Upper Egypt, so long as the similarities between certain early objects of Egyptian and Babylonian culture remain otherwise unexplained. These objects are the seal-cylinder, the mace-head, and the method of building crenellated brick walls, which were alike in both countries. ${ }^{2}$ It has been supposed that the invention of brick itself came to Egypt from Babylonia.

In the first place, these resemblances might be considered to prove, properly speaking, not a Semitic invasion or even connexion at all, but an invasion by or connexion with the Sumerian Babylonians, who were not Semites. Nevertheless, as there were probably Semites in Babylonia before the invasion of the Sumerians, this objection may be waived. The similarity of the crenellated walls of Egypt and Babylonia might be dismissed at once as proving, if anything, Babylonian indebtedness to Egypt rather than the reverse, as the crenellated walls of Telloh, which are compared with Egyptian fortress and mastabawalls of the first three dynasties, are perhaps a thousand years later in date than these. But it is probable that this custom was in Babylonia as old as in Egypt, where we find crenellated

${ }^{1}$ Confirmation of the idea of a non-Semitic (indigenous) and a Semitic race in Egypt has been sought in the alteration of burial customs already mentioned. The practice of mummification and of burial at length has been supposed to have been introduced by the "Semites," and analogies for both practices have been sought in Babylonia, These analogies are, however, weak, and the recent excavations at Fârah in Babylonia, the first modern and scientific explorations of an early Babylonian necropolis, have revealed the fact that the primitive Babylonians buried in a contracted position, just as the primitive Egyptians did.

2 KING and HaLl, Egypt and Western Asia, p. 35. 
walls represented as characteristic of the cities of the Northerners or Anu, who were probably of proto-Semitic blood. ${ }^{2}$ The cylinder cannot be dismissed at all. The fact that from the beginning both Egyptians and Babylonians used the same peculiar method of impressing seals on clay by means of a rolling cylinder, instead of, like other nations, stamping directly upon the clay, was a powerful argument in favour of early conuexion. ${ }^{2}$ The conclusion that Egypt owed the cylinder to Babylonia derived support from the fact that in Egypt, after about a thousand years of use, the cylinder was practically given up in favour of the direct-stamping scarab or signet-ring, while in Babylonia it remained always in general use: this looked as if the cylinder-seal were in Egypt a foreign importation, an exotic which did not survive on a strange soil. But we have in Egypt more primitive cylinders than those of Babylonia: wooden seal-cylinders of the late predynastic period which are not far removed from the original notched piece of reed, which, according to a most plausible theory, was the original cylinderseal. The cylinder-seal and the mace-head are the most difficult objects which the antagonists of an early connexion with Babylonia have to deal with. It is difficult to explain their absolute identity in form in both countries by anything but a cultural connexion of some kind. And it is significant that from the first the Egyptians called the seal by the Semitic name of khetm. The invention of brick was probably made independently in Babylonia and in Egypt, as the oldest Babylonian bricks are of a completely different form (plano-convex) from the Egyptian, which are rectangular.

It has been supposed that the knowledge of corn came to Egypt from Babylonia, because wheat grows wild in the province of Irak. But wild wheat has also been found in Palestine, ${ }^{3}$ and it seems more probable that it was from Palestine that the knowledge of corn passed on the one side to Babylonia, on the other to Egypt. The knowledge of the grape and of wine-making very probably came in the same way to both countries from Palestine, which may well be the Nysa whence, according to Diodorus (i. I4 ff.), Osiris brought the knowledge of corn and wine to Egypt.

See p. 95, post.

2 BuDge, Hist. Es. i. p. 4 I.

${ }^{3}$ Sec Schweinfurth, Entdeckuns des wilden Urwcizens in Palästina: Ann. du Service, vii. pp. $193 \mathrm{ff}$. It is notalle that Dr. Schweinfurth scems, however, 
The resemblances of the mace-head, the cylinder-seal, and possibly the crenellated walls may point to some connexion between early Egypt and Babylonia through the medium of the Northern Semito-Libyans, but no more. To these Semites the nation that was to arise after the union of North and South owed elements in its language and its religion, and possibly the introduction of corn, as well as the knowledge of agriculture and viticulture, ${ }^{1}$ and probably that of metal, if, as seems likely, Sinai, Syria, and Cyprus were the original focus of the distribution of copper over Europe and the Near East. Copper came gradually into use among the prehistoric Southern Egyptians towards the end of the predynastic age. And they must have obtained their knowledge of it from the Northerners. ${ }^{2}$

We now turn to the question of the origin of the Southern Egyptian race, the predynastic Nilotes whose remains we have described. They can only have come from the South, if they were not absolutely indigenous. Egypt is a tube, which can only be entered at top and bottom. ${ }^{3}$ If the "Semitic" Northerners entered at the top, as they obviously did, the nonSemitic Southerners must have entered at the bottom, from Africa. And it must be admitted that their primitive culture has a decidedly African appearance. Yet they were not negroes or even negroid: their skull-form shews this conclusively. We can only call them Hamites, and class them under this head with the Gallas and other related races of the North-Eastern "Horn" of Africa and Southern Arabia, to whom they undoubtedly bore a considerable resemblance. If they were not indigenous Nilotes, it is from this quarter that they must have

to be still under the impression that the Egyptians must have learnt to cultivate wheat from the Babylonians-a conclusion for which one can see no reason.

'If corn was first cultivated in Palestine, as scems probable (see preceding note), its introduction into Egypt must be ascribed to the primitive proto-Semitic people of the Delta, and viticulture certainly, agriculture probably, were introduced by them from the "land of milk and honey." It is certain that the Hamitic Upper Egyptians, whose Neolithic remains we have described, did not bring the knowledge of the vine, and probable that they did not bring that of corn, from East Africa.

${ }^{2}$ On Cyprus as the original home of copper-working, see Myres in Science Progress, I896. Dr. Reisner is of opinion (Naga-ed-Dîr, i. p. 134) that the predynastic Egyptians invented the use of copper, and is followed in this view by Elliot SMith, The Ancient Egyptians, p. 3, but I hardly think the point is proved. Dr. REISNER considers the Egyptian evidence alone, and not in connexion with that from the rest of the Levant.

${ }^{3}$ I owe this very apposile simile to Dr. Ellior Sinth, The People of Egypt, p. I5. 
come. And the evidence of their legends indicates that they actually did migrate thence to the Nile valley.

When, a few years ago, it still seemed probable that the impulse of the great development of civilization that produced the Pharaonic kingdom was due to an invasion of Semites from Arabia who were influenced by Babylonian culture, these legends were used to prove that the predynastic people of Upper Egypt were conquered by a Semitic or proto-Semitic people which came from Somaliland and Southern Arabia by way of the Red Sea coast and the Wadi Hammamat, a great depression in the Eastern Desert which leads directly from Kuscêr on the Red Sea to Koptos on the Nile. ${ }^{1}$ Now, however, that it seems more probable that the (undoubted) proto-Semitic element in early Egypt belongs to the conquered North, rather than to the conquering South, and must have entered the Nile valley by way of the isthmus of Suez, and that the early Pharaonic culture was directly descended from that of the predynastic people of the South, who were not conquered by any Semites, either from South or North, but conquered them, these legends may be explained in a different way.

Tradition brings Hathor and the great gods 2 from the "Holy Land," Ta-neter, which lay south of Egypt. This land appears to be in the neighbourhood of, if not identical with, the country which the Egyptians called Punt (Puene-t), the modern coast of Eritrea and Somaliland, with which the Egyptians of historical times had relations of a somewhat peculiar nature. The Punites are represented on the monuments as almost identical with the Egyptians in features and dress, with a significant exception: they wear the curious plaited beard, turned up at the ends, which is characteristic of the Egyptian representations of their gods, and is never depicted as worn by mortal men, even by kings. But this beard had been worn by the Egyptians at one time; as we see from the archaic monuments, it was worn by

1 This view will be found in King and HALL, Eypt and Western Asia, pp. $40 \mathrm{ff}$. Prof. Petrie (Hist. Eg. i. [1903], p. 4) held that the "dynastic race . . . entered the country from the Red Sea across the desert at Koptos." Dr. BudGe (Hist. Eg. i. pp. $43 \mathrm{ff}$. [I9OI]) gave the arguments pro and con this view and that which brought the supposed "Semitic conquerors" or "dynastic Egyptians" through the isthmus of Suez; inclining to the Hammamat theory-rightly enough, in the light of our knowledge ten years ago.

2 On these traditions see Setne, Zur altägyptischen Sage zon Sonncnause, dus in der Fremade war (Untersachangen, v. 3), Lcipzig, 1912. 
them in the period immediately preceding and following the beginning of the Ist Dynasty. Only when dead and become a god could the later Egyptian, whether prince or peasant, be represented as wearing his beard in the peculiar fashion characteristic of his gods, his remote ancestors of the time of the followers of Horus, and his contemporaries in the land of Punt. Now this is a very curious piece of evidence directly connecting the Punites with the invaders of Egypt, and confirming the testimony of the tradition which brought some of the Egyptian gods from this part of the world. It is evident from several facts, notably the circumstance that the name of the land of Punt was usually written without the sign "determinative" of a foreign people, ${ }^{1}$ that the Egyptians regarded themselves as racially connected with the Punites. M. Naville, the distinguished excavator of the great temple of Queen Hatshepsut at Dêr el-Bahri which contains the representations of her great expedition to Punt, and at the same time the editor of the legends of Horus of Edfu and his followers,- the chief authority, therefore, on this particular subject, which he has made peculiarly his own,-thinks that there was among the Egyptians a "vague and ancient tradition that they originally came from the land of Punt, and that it had been their home before they invaded and conquered the lower valley of the Nile." ${ }^{2}$

It is then very probable that an invading race originally came from Somaliland to the Nile valley. Ordinarily, one would suppose that they came by way of Abyssinia and the Upper Nile, and another legend points to the same route. This is the story of the followers of the Sky-god Horus, the Mcsniu or "Smiths." According to this legend, as we have it in a Ptolemaic version, ${ }^{3}$ at the beginning of history the god Horus of the Two Horizons (Harmachis or Horakhti) was ruling in Nubia, and in the 363 rd year of his reign his son Horus of Edfu (Hor-Behudet, the winged sun) led a conquering expedition into Egypt against the aboriginal inhabitants or $A m u$, who were adherents of his enemy and rival the god Set. The

${ }^{1}$ This has recently been denied by W. M. MülLER (O.L.Z. xi. (Ig08), p. 508, n. 2), but the facts are against him; he is wrong.

2 Naville, Deir el-Bahari, Pt. iii. p. II.

${ }^{3}$ See Naville, Mythe d"Horts, and Maspero, "Les Forgerons d'Horus," in Études de Mythologie, ii. $312 \mathrm{ff}$.

${ }^{4}$ See p. 95, n. 2. 
"followers of Horus" (Shemsu-Hor) who formed the army of the Southern Sun-god, were also called Mesnin ("Smiths" or "Metal-workers"), and their spears were tipped with metal. The conquest of Egypt was completed after a terrible struggle. We may doubt the accuracy with which battles are chronicled as having taken place at Tjedmet near Thebes, at Khadeneter near Dendera, at the modern Minieh, Behnesa, and Ahnas in Middle Egypt, and finally on the Asiatic borders of the Delta. The influence of the later sagas of the Expulsion of the Hyksos is evidently at work here, especially in the case of the last item; but the fight at Khade-neter may be held to be genuine enough, on account of the ancient name, which means "The God's Slaughter," i.c. the place where Horus slaughtered the Anu. And the general direction of the conquest, from south to north, is a detail which is sure to be original and correct. Further, it agrees with the legend which brings the company of the Great Gods, led by Hathor, from the south-east into Egypt.

Now the leader of the invaders was the Elder Horus, the Sky-god, whose emblem and sacred animal was the hawk. He was the prototype of all Egyptian Pharaohs: kings did not exist before his time in Egypt: i.e. the supreme kingly dignity was an introduction of the invaders. So he was the especial patron and protector of the King of Egypt, one of whose titles was the "Golden Horus," and above whose $k a$-name ${ }^{1}$ the hawk, crowned with the kingly crown of Upper and Lower Egypt, is always represented. The haw $k$ then is the emblem of the king as heir and representative of the deity who was fabled to have led the conquerors who founded the kingdom into the land. The head-centre of the worship of this god was Behdet, in Upper Egypt, the modern Edfu, where the magnificent pylons of his temple, as restored in Ptolemaic days, still stand up in the midst of the town on the western bank of the Nile, a landmark for miles around. Here it was that the worship of the Sky-god, which the invaders brought with them, was first established. Now recent discoveries shew us that at El-Kab and Kom al-Ahmar, which face each other across the Nile somewhat north of $\mathrm{Edfu}$, the ancient cities of Nekheb and Nekhen formed the most ancient political centre of Upper Egypt, where the capital of the oldest kingdom

'The divine name of the king, as identified with Horus. See p. 106, n. 3. 
of Upper Egypt was first fixed, ${ }^{1}$ and this kingdom was, historically, the nucleus of the later Pharaonic realm.

The Horus-legend as we have it is very late in date. The question is, leaving out of account the possible contamination by legends of the expulsion of the Hyksos, how far the older stuff of the story relates to the original immigration of the Southern Egyptians from the South, and how far to the historical conquest of the North and the Semites by the early kings of Hierakonpolis, who founded the united kingdom of Egypt. I think that we can see in the story as we have it a mingled reminiscence of both events, the first invasion from the South and the far later conquest of the North by "Mena" and his predecessors and successors. The predynastic Egyptians came from the South by way of the Upper Nile and Nubia, where, according to the legend, Horus originally reigned. This is at least more probable than that they came by way of the Red Sea coast at the Wadi Hammamat. ${ }^{2}$ The easy way from Punt through Ethiopia and Nubia, which legend assigns to them, was open. This, and not the Hammamat route, was the way by which Egyptian caravans and am-

I Horus was again worshipped at Nekhen, in company, at Nekheb, with Nekhebet, the tutelary goddess of Upper Egypt, whose emblem and sacred animal was the great vulture, which is characteristic of the country to-day. But the Horus of Nekhen is a dead, not, as at Edfu, a living, Horus ; his sceptre has passed to his descendants. Edfu he founded as a living and active conqueror; at Nekhen he is a mummified ancestor.

${ }^{2}$ An argument in favour of the latter view was found in the curious archaic statues of Min, discovered by Prof. Petrie at Koptos, the town where the Wadi Hammamat reaches the Nile (Petrie, Koptos, pp. 7-9). These figures, two of which are in the Ashmolean Museum, are of most primitive style, and bear rudely incised upon them rough designs of an elephant walking on mountains, and pteroceras shells, which certainly belong to the Red Sea. It was natural enough to suppose that these figures were monuments of the earliest arrival of the Egyptians in Egypr, after their migration from the Red Sea coast through the Wadi Iammamat. And this was supposed to have been the route of Horus and his Mesniu.

But further consideration has rendered this view less probable than it was ten years ago. It now seems more likely that the pteroceras shells (which must refer to or symbolize the sea) were cut on these figures of Min simply because Koptos, of which Min was the tutelary deity, was the town at the Nile end of the caravan route through the Wadi Hammamat to the Red Sea; and, as a matter of fact, on a clay seal of the Ist Dynasty (Petrie, Royal Tombs, ii. Pl. xvii. I35) we have the god actually mentioned as the lord of the pteroceras shell, which indeed, with a feather placed above it, seems to have been the original of the peculiar emblem of the god and ideograph of his name. At Koptos, his main seat, he was the protector of the Red Sea caravans, which no doubt already used this route from the Red Sea coast at a very early period. 
bassadors passed in the reverse direction to Punt throughout the period of the Old Kingdom, until negro enmity seems to have closed it; when the Hammamat route and a sea-voyage along the coast necessarily replaced it. Finally, in favour of this vicw is the new discovery that certain Nubian tribes remained in a state of culture closely resembling that of the Neolithic men of Upper Egypt, and clearly of the same origin, cven as late as the time of the XVIIIth Dynasty; nay, even to this day pottery of the Neolithic Egyptian type is made in Nubia. The conclusion is that the Nubians were the descendants (in later times much mixed with negroes) of these Southern tribes which remained in Nubia after the greater part of the race had passed into Egypt, where, by contact with the proto-Semitic Northerners, they developed Egyptian civilization, leaving Nubia as a backwater of barbarism. ${ }^{1}$

The later element in the story is, I think, that which describes the campaign of Horus against the "Anu" with the aid of his Mesniu or "Smiths." Horus Set-worshipping here represents the King of Hierakonpolis, the living "Horus," as Pharaoh was always called, the king being identified with his protecting deity. The Mesniu are his Shemsu or "followers," his soldiers and retainers, now armed with the metal weapons, the use of which was only learnt by the predynastic Egyptians, presumably from the Northerners, shortly before the time of the Hierakonpolite kings and the conquest of the North: their ancestors of the original immigration from the South were stone-users. The "Anu" are the Semite-Libyans or "protoSemites" of the North, ${ }^{2}$ whom we sce on the Hierakonpolite

1 This has been shewn by the recent researches of Dr. Reisner and Mr. Firth for the Egyptian Government (Survey Department) in Lower Nubia. See Ellior Surth, The Ancient Egyptians, pp. $67 \mathrm{ff}$.

2 I ain, personally, strongly inclined to regard the Anu or Antiu as the Semitic Northern ethnic element, whereas M. NAvilite (Rec. Trav., I9Io, p. 52 ff.) identifies them with the predynastic people of Upper Egypt. But in view of the direct descent of the dynastic Egyptian culture from that of the predynastic people, which seems very evident, this view seems to me difficult to adopt. It seems to me more likely that it was the predynastic Upper Egyptians who were the folk of Horus, and the predynastic Northerners (whose existence, as yet unproved, is necessitated by various considerations which we have stated above) who were the Anu, the folk of Set. The name of the Anu or Antiu seems significant in this connexion. It means "the Pillar-folk": the explanation "cave-men" (Trogodytes or Troglodytes) is due to a confusion of the word an, "pillar" (with whose ideograph the name of the Anu, is spelt) and the word $a n-t$, often translated " cave," but more properly meaning simply "valley" or "wadi." Now one knows how eminently characteristic of the Semites 
king Narmer striking down on his monuments. A festival of "Striking down the Anu" was regularly celebrated by the Egyptian kings in memory of the conquest. ${ }^{1}$

We thus see that legend agrees with archaeological discovery in bringing the Southern Egyptians from Nubia. ${ }^{2}$ In the Nile valley as far north probably as the apex of the Delta, they lived for many centuries till the adoption of metal from their neighbours the Semite-Libyans and Mediterraneans of the Delta gave them, as it did to other peoples, an impulse to culture development which resulted in the formation of a strong civilized central government in the district of Edfu and Hierakonpolis, the "home" territory of the national sky-

of Palestine and of the Mediterraneans of Crete and the islands was the veneration of the sacred pillars of the gods, the Massseboth of the Hebrews. It may well be that the Egyptian name of the Amu refers to this Semitic, or at any rate Northern, characteristic. Again, the name $A n u$ in later times was given specially to the inhabitants of the peninsula of Sinai, who can hardly be supposed to have been anything else but Semites or nearly related to Semites. It was also given to the un-Egyptian population of the Eastern Desert, from Sinai to Nubia. These people may well have been more or less related to the Semites, and a Ist-Dynasty representation of a man of the desert of the First Cataract, Satet (PETRIE, Royal Tombs, i. Pl. xvii. 30) shews him as an undoubted Semite. That the modern "Beja" inhabitants of this Eastern Descrt are related to the Semites (and also to the predynastic Egyptians) seems probable. The Anu-Satet therefore, Anu of the Cataract region, cannot be called "Nubians." Again, the same name Anu is undoubtedly given to the Libyans, as Anu-Tehennu. The ethnic relationship of the Libyans to the Semites is also probable. Philologically the modern languages of the Berbers and Tuareg (Imoshagh) are the nearest relatives of the Semitic tongues. Thus there seem to be good grounds for regarding the $A m u$ as the original population of North-Fast Africa, from Libya to the Red Sea Desert (as far south as the First Cataract) and Sinai ; the race which occupied the Nile valley before the coming of the Iamitic Egyptians from the South. This is the contrary of M. NAville's view, which would make the Anz, the predynastic Egyptians, and their conquerors the dynastic Egyptians, Horus and his followers, the founders of the Kingdom, who came from Punt. Certainly the Horus-Egyptians came from Punt and defeated the $A n u$, but for me it is the Horus-Egyptians, not the $A m u$, who were the prehistoric folk of Upper Egypt, whose antiquities we have described.

${ }^{1}$ See Capart, La Fête de frapper les Anou (Rív. IIist. Rélig. xliii., 1901). It may be that the legendary placing of some of the battles in the Thebaid may refer to the original invasion and preserve a rcminiscence of fights between the Southerners and "Anu" who possibly then occupied the whole valley. The name of An or On, the "Pillar-city," occurs in the Thebaid at Tentyra and Hermonthis, spelt with the same ideograph as the city of On in the Delta and the name of the Anu, the "Pillar-folk," themselves. This may commemorate an original southward extension of the Anu.

"In Nubia the ancestors of the Egyptians must long have been in contact with the Negroes to the south of them, and this may explain the many resemblances to Negro beliefs and customs which may be found in Egyptian religion (see BuDGE, Osiris (London, I9II), passim). 
god Horus, whose symbol was the hawk, and of the king, the living "hawk" and representative of Horus. Under the leadership of the Hierakonpolite kings, the Southerners now attacked and conquered the Semite-Libyans of the Delta, whose national gods were the Sun, Ra, and the Memphite Ptal, and possibly the Osiris of Dedu, ${ }^{1}$ and whose political centre was probably the city of Buto. The conquest was probably effected by the lings Narmer and Aha, the historical originals of the legendary "Mena," to whom later legend ascribed the union of the two lands and the founding of the Ist Egyptian Dynasty. ${ }^{2}$

\section{The Kingdoms of the South and North}

The kingdom of Buto-The "Two Lands"-Early kings of Lower Egypt on the "Palermo Stone"-The Hierakonpolite kings

It is noticeable that in later official and priestly legend the Northern kingdom of Buto seems a mere reduplication of that of the South. Buto, its centre, appears as another twin-city, Pe-Dep, analogous to the southern Nekheb-Nekhen; and as Nekheb was ruled by the southern goddess Nekhebet, so Buto was ruled by the northern snake-goddess ${ }^{3}$ Utjoit (Uto). But we may well surmise that all this is a fiction devised out of love of symmetry, and that the original Buto-kingdom was different enough from that of Hierakonpolis, as we see its Semite-Libyan inhabitants were different from the other Egyptians. The Delta king was not the $f_{\text {mmn }}^{0}$, nsuit, the word that always meant "king" in Egyptian, but bore a title meaningless in Egyptian, bit, the ideograph of which

1 The Southern elements in the Osiris-legend may be due to a later confusion of the Delta Osiris with a Southern deity of similar attributes.

${ }^{2}$ See p. Io6.

${ }^{3}$ Boutô is really a name for the combined cities; Pi-Uijoil(l), "the City of Utjôit," pronounced *Uijo or *Uto.

"Prof. Sethe has recently shewn ( $\ddot{A} . Z$. xlix. (I9II) p. I5ff.) that this word hitherto read "sulen," is really to be read nesut or n(e)suit, vocalized at any rate in later times *ins or *insi (the feminine termination $t$ being dropped in pronunciation). That this is correct is shewn by the Babylonian transliteration of the Egyptian double royal title

This also gives us the pronunciation of the title of the king of Lower Egypt, $S$, $b i t$, as "bịa $(t)$. 
was the $b e$, bit. Prof. Petrie has surmised that this royal name was in reality not Egyptian, but was a native word of the presumably half-Libyan half-Semitic original inhabitants of the Delta, taken over by the conquerors, and that it is in reality nothing more or less than the Battos of the Cyrenaeans. ${ }^{\circledR}$

The typical Egyptian nome-system did not exist in the Delta before the conquest. This system of hisaput or nomes (vopoi) was indigenous to the south. The ideographic symbols of the nomes, their crests or cognizances, in fact, are always represented, from the beginning to the end of Egyptian history, as erected upon standards, just as the sacred animals are also represented acting in their case as the totem-symbols of the gods. These totem-standards of gods, tribes, and probably (at that day) of individuals also, already existed, as we have seen, in the prehistoric period in Upper Egypt (see p. 84), so that the nome-system no doubt was southern. The Delta nome-names all have an artificial character, which stamps them as introductions from the south: they are the sort of names that immigrants would give in a conquered land. Here we have another indication of the foreign character of the Deltakingdom.

The fact that the Northern kingdom never entirely lost its separate identity points in the same direction. Though conquered, the North was never absorbed by the South. It was gradually Egyptianized: the ideographic system of the South became its official script, and in this script the names of its gods were written; the gods themselves were absorbed into a common official pantheon with the deities of the South. But still the Northerners preserved their individuality, and this separate individuality was recognized officially from the first. From the beginning the king of South and North (Insibya) ${ }^{2}$

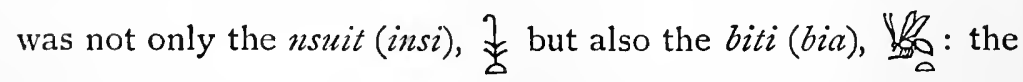

${ }^{1}$ Whether the Lower Egyptian title really means the "Bee-man," or is a mere punning name, we do not know. But nesuit can only mean the "Owner of the Reed" or "the-who-belongs-to-the-Reed," the "Reed-man," whatever the original signification of this may have been. The word bịt for "bee" was vocalized *bīot or ebiōt.

See p. 97 , n. 4 . 
Southern title, as the conqueror, taking precedence of the conquered. The king was, the "Snake-Lord" of Buto, as well as the "Hawk-Lord of Hierakonpolis."

Another archaic title of the same import is "Two Hawks." And the conservatism which retained this memory of the two ancient kingdoms was justified by facts: the Delta has always been distinct from the Upper Country. We are told in a papyrus of the XIXth Dynasty that it was very difficult for a man of the Delta to understand the dialect of a man from Upper Egypt, and at this day the man of Bohera is a very different being from a man of the Sa'îd. After the loss of the Asiatic Empire at the end of the rule of the Ramessides of the XXth Dynasty, Egypt returned for a time to the days of the Followers of Horus, for a king ruled in Tanis and a king ruled at Thebes, each independent of the other. A stray centrifugal and particularist force always balanced the centripetal in Egypt, and was sure to triumph in time of weakness and discord. But in days of prosperity and union no prouder title was borne by the Pharaoh than that of "Lord of the Two Lands."

Of the actual monarchs of the two kingdoms we know little. The Palermo stele, already mentioned, ${ }^{2}$ gives us a list of predynastic kings of Lower Egypt, of which seven are legible: Tiu, Thesh, Nehab, Uatjnar, Ska, Hsekiu, and MEKhat. These are names of a curiously primitive cast, which would have seemed as odd to a XIXth Dynasty Egyptian as our Hengest and Horsa, Cissa and Ælla, clo to us. Of the contemporary kings of Upper Egypt we have no knowledge, since the supposed royal names Tjeser, De(?), Ro, and $\mathrm{Ka}$, discovered at Abydos, ${ }^{3}$ and assigned to the time of the Followers of Horus, are probably not royal names at all. The first Southern monuments which are certainly to be assigned

${ }^{1}$ Later on, when, perhaps, Nekhebet was imagined as a snake-like Utjôit (from love of symmetry), this title becomes $C_{2} C_{i}$, the snake Nekhebet wearing the crown of Upper Egypt, that of Utjôit the peculiar head-dress of the Delta king, which became united as the "Double Crown,"

2 See p. II.

${ }^{3}$ Petrie, lioyal Tombs, i. and ii.; Abyilos, i. The supposed royal name K'a (Abydos, i. Pls. ii. iii.) seems to me to be an inscription ne-ka, the whole reading ne-ka-Hor, "belonging to the ka of the Horus (the king)," probably Aha. 
to historical kings, belong to the beginning of the First Dynasty. ${ }^{1}$ There are the remarkable monuments, found at Hierakonpolis (Nekhen), of the earliest known king of both South and North, NARMER, also called "the Scorpion." They are ceremonial palettes of slate, probably used for the priest to adorn images of the gods at high festivals. On them we see carved in relief representations of the king's triumph over his enemies of the North, who are represented lying headless in rows before him, while, accompanied by a page bearing his sandals and a vase of drink, he inspects them at his leisure (Plate VI. 5). Other representations on this and other similar "palettes" of the time shew highly symbolical representations of the animals typifying the Upper Egyptian nomes making captive the towns and tribes of Lower Egypt.

Of Aha ("the Fighter"), we have an important monument in the shape of his tomb at Nakîda in the Thebaïd; and farther north again, near the holy city of Abydos, a smaller second tomb, or rather funerary chapel, was built for him as a monument on the sacred soil of Abydos. Narmer also perhaps had a similar "tomb" here, and all the succeeding kings of his dynasty were either actually buried close by, or, as seems more probable, had great cenotaphs erected for them on the holy ground. It is the discovery of these tombs or cenotaphs by M. Amélineau, followed by the work upon them carried out by Messrs. Petrie and Mace, that has given us of late years our

1 We have, however, perhaps earlier monuments in the slate palettes of the British Museum and the Louvre (see p. I 6, n. 2, fost), which shew hunting-scenes and the exposure of prisoners in the desert to lions and vultures. On the huntingpalette (Plate VI. 4) we see great chiefs carrying their totem-sticks, and armed with bows and arrows tipped with the spade-like flint arrows of which many original examples are preserved in our museums, and also with twhat are apparently stone celts fixed in recurved wooden hafts, going out to hunt in the desert; and we see also lions, of very archaic type, with gazelle, hares, etc., the destined quarry of the hunters. On the same object are two primitive pictographs, the meaning of which is extremely obscure ; they seem to mean "sunset" and "burial," and it is possible that the idea intended to be conveyed is simply that the action is taking place in the Western Desert, where the Egyptians usually buried their dead; or possibly the object is merely marked as intended for a "burial in the west"; it came, of course, from a tomb, probably royal. The "hunting-palette" is probably the earlier of the two, and obviously dates to the time of the Shemsu-Hor; that of the "prisoners" is probably later, and very little before the time of Narmer. Another slate object of the same class, shewing monstrous animal forms, lions with serpent-necks, etc., is of the time of Narmer, and was found at Hierakonpolis. For a complete publication of these slate objects, see Legge, P.S.B.A., I909; and cf. Capart, Débuts de l'Art en Egypte, pp. 221 ff. 
remarkable accession of knowledge of the carliest history of Egypt.

\section{The Tombs of Abydos}

Thinis and Abydos-The necropoles of Nag' ed-Deir and Abydos-Osiris at Alydos-The royal cenotaphs-The Tablet of Abydos and the "Tomb of Osiris"-The later lists of the early kings

According to the legend preserved by Manetho, the kings of the first three dynasties were Thinites: the centre of their power was the town of Thinis, in the vallcy not far from Abydos. From this it would seem that the capital had been moved northward by the earliest kings from Hierakonpolis to Thinis, although, as we have seen, Nekhen (Hierakonpolis) continued under them to be a centre of religious devotion, as the centre of the Horus-cult. The God of Thinis was Anhur or Onouris, a warrior-deity who is depicted as a king armed with a lance like that of the Mesniul. He was evidently a patron of the ceaseless war against the $A n u$. On the eastern bank of the Nile, at Nag' edDêr, opposite the modern Gîrga, was a great necropolis containing tombs dating from the predynastic period to the IVth Dynasty, which shews us what an important centre of population the Thinite nome was in the earliest period of Egyptian history: it was the metropolitan nome of Upper Egypt, and no doubt, as Manetho implies, the seat of the earliest dynasties. This necropolis has been excavated by Messrs. Reisner, Mace, and Lythgoe for the University of California, and their discoveries, now being published, have shed a flood of light on the development of early Egyptian civilization. ${ }^{1}$ At the place called Abdu, not far from Thinis, on the edge of the western desert, was another necropolis of the new capital, guarded by the jackal or dog-deity Anubis, called Khent-amentiu, "the Head of the Westerners," the chief, that is to say, of the dead who were buried on the western desert. ${ }^{2}$

\section{${ }^{1}$ Reisser and MACE, Early Dynastic Cemeteries of Naga-ed-dèr- (1908-9).}

${ }^{2} \mathrm{He}$ was also originally the patron-deity of the people of the Oasis of El-Khargah, in the desert west of Abydos, and in this capacity bore the title of $A m-U^{\circ} t$, "Ie who is in the Oasis," a title which, when his original connection with the Oasis had been forgotten, was entirely misunderstood. It was understood as meaning "he who is within the bandage" (the word $u^{\circ} \ell$ meaning "bandage"), i.e. the mummy-bandages, and the title was then corrupted to am-u ${ }^{\circ} \cdot f$, "within his bandages." The confusion was natural, since he was a god of the dead, though not represented in mummy form. It would seem by no means improbable that the Libyan inhabitants of the distant oasis were, when they first came within the ken of the primitive Egyptians of the 
The necropolis of the capital naturally became a great centre of the cult of the dead, and the earliest kings, though some of them may, like Aha, have been actually buried elsewhere, naturally erected here what may be the cenotaphy of some of them, the actual tombs of others: Their tombs were placed upon an eminence in the great bay of the desert cliffs west of Abydos, and here they were discovered fifteen years ago.

The chief historical results of the discovery were the recovery of the actual names of the oldest Egyptian kings, which had been forgotten by the later Egyptians themselves. When, under the IIIrd Dynasty, the royal court was moved to Memphis in the far north, Thinis and Abydos were forgotten,'and veneration was no longer paid at the tomb-shrines of the kings of the Ist Dynasty. The later kings were buried in the Memphite necropolis at Sakkâra, the domain of Sokari, the Memphite god of the dead, who now claimed the allegiance of court and capital. It was not till the time of the Middle Kingdom, and the supersession of a Memphite by a Theban dynasty, that Abydos came once more into prominence. And now the (perhaps originally un-Egyptian) dead-god of Busiris in the Delta, Osiris, became identified with Khentamentiu of Abydos, now dissociated from Anubis, who became in the popular theogony the son and minister of Osiris-Khentamentiu. During the time of the Hyksos domination in lower Egypt, Abydos, as the chief necropolis of the national kingdom in the upper country, and Osiris as its god, began to take upon themselves a peculiar atmosphere of holiness, and by the time of the XVIIIth Dynasty the form of Khentamentiu took its final position as the Egyptian metropolis of the dead. Even if an Egyptian could not be himself interred here, he might at least have some memorial of himself set up upon the holy soil. Kings who by patriotic custom and loyalty to Amen, the great god of Thebes, were buried near the capital, could erect cenotaphs for themselves in the "holy land." So Senusert III had a cenotaph and temple here; Aahmes followed his example, and the Queen Tetashera. Then Seti I, of the XIXth Dynasty, erected his great funerary temple here, which still stands, one

Rîf, or river-valley, regarded as uon-human beings, and indeed neither more nor less than the spirits of the ancestors of the Egyptians who from time immemorial had been buried all along the western desert margin in this part of the country. So Anubis was regarded as the deity of these supernatural Westerners. 
of the most interesting remains of Ancient Egypt. His son Rameses II followed his example, and had already been associated with his father on the walls of the latter's temple in a relief shewing the king and prince offering incense to the names of their predecessors upon the throne. This is the famous "Tablet of Abydos." We may well surmise that, not long before, the ancient tombs of the Ist Dynasty kings had been discovered, ${ }^{1}$ and that the cult of the early monarchs had recommenced, in association with that of Osiris. For it is evident that the tomb of one of these kings was now regarded as the sepulchre of Osiris himself. The explanation of this is that the name of this early monarch was read as it appeared upon the stelae marking his grave, as "Khent," and so was identified with that of Khentamentiu-Osiris. This belief was fixed, the mound of Umm el-Ga'ab became covered with the myriad votive pots left by pious pilgrims in honour of Osiris, from which it takes its name ("The Mother of Pots"); and, later on, a figure of Osiris laid out upon a granite lion-headed bier, with protecting hawks at head and feet, was solemnly placed in the tomb of the ancient king, where it was discovered by M. Amélineau.

This misunderstanding, with its interesting sequel, is characteristic of the incapacity of the Egyptians of the XIXth Dynasty fully to understand the ancient relics which they had brought to light. The archaic writing of the Ist Dynasty could no longer be read properly, and so is to be explained the divergence of the royal names in the Tablet of Abydos from the actual archaic forms of the personal names from which those of the list were derived.' Also, no doubt,

1 The excavations of I909-IO at Umm el-Ga'ab, directed by myself until the arrival of M. NAville, have shewn that the Ist Dynasty tombs were venerated up till the time of the IVth and Vth Dynasties; votive pottery of that date has been found. Nothing of the Middle Fingdon was, however, found at all; the strata above that of the Old Kingdom contain only the votive pottery of the XIXth-XXIInd Dynasties. From this it seems to me that the tombs were forgotten from about the time of the VIth Dynasty till they were re-discovered in the time of Seti. Dr. ScuÄfER's objections to the idea of such a re-discovery do not appeal to me, as I do not consider it proved that the mystic place Pekr. "the Gap," is necessarily Unm el.Ga'ab (see SchäFER, Die Mysterien des Osiris in Abydos, Leipzig, 1904).

2 The later lists used only the personal names, not the Horus-names, which are easily identifiable on the early monuments, while the personal names are not, and still remain doubtful for the kings before Den, whose personal name Semti is the first which can be identified without doubt. 
the existence of popular traditions (which the Egyptians, like modern Orientals, accepted uncritically as true history), giving legendary forms of names, served to mislead Seti's historiography.

\section{Menes and the Ist Dynasty}

Mena-Menes and his successors in later legend and on their contemporary monuments-The identification of "Mena," who is a composite figure of legend-His originals of Aba at Nagada and Abydos, of Khent and Tja, and of Semti at AbydosThe Sed-festival-Monuments of Merpeba the founder of Memphis (?), of Semerkha at Abydos and Sinai, and of Ka-The IInd Dynasty

Both they and the writers of the almost contemporary official list on a papyrus, now preserved on fragment at Turin, began their line of kings with Mena, the traditional founder of the kingdom, whom we find in Herodotus, in Manetho, and in Diodorus. This is a legendary name. We have not found it at Hierakonpolis, and not certainly at Nakâda, where it has been supposed to occur on a tablet as the personal name of Aha. On a newly discovered fragment of the "Palermo Stone" 1 Ateti seems to be given as the personal name of Aha. On account of its nearness in time to the reigns of these kings, the authority of the Palermo Stone is great; but if it disagrees with contemporary monuments it must of course yield place as evidence to the latter, as even so early as the time of the Vth Dynasty the events of the beginning of the Ist may have become legendary, and the names of its kings have been confused. It is therefore uncertain whether the personal name of Aha was Men or Ateti. The name Ateti occurs third on the lists of Abydos and Turin, second in Manetho, as Athothis. The second and fourth names in the Abydos list, Teta and Ata (the Turin list is in these cases illegible), very probably correspond to the kings Khent or Shesti (read Zer by Prof. Petrie), and Tja (Petrie's "Zet"), whose personal names may have been $\mathrm{Ta}$ and Ati. But if so, the Abydos list is wrong in placing "Teta" after Mena, and before Ateti, since, whether Aha be Ateti or Mena, there is no doubt that he preceded Khent. The style of his monuments shews this conclusively. Manetho, then, is right in making Athothis the immediate successor of "Menes," and the predecessor of his "Kenkenes" and "Ouenephes." If

1 The "Palermo Stone" is the stele already mentioned, now preserved at Palermo, on which was inscribed in the time of the Vth Dynasty a summary chronicle of the early kings. 
Ati or Tja is "Ata," he follows in the correct order. But here Manetho has got wrong. This "Oucnephes" must be Khent (the "Teta" of the Abydos list); for "Ouenephes" is simply a Greek form of Unnefer ("Good Being"), a common appellation of the god Osiris, and we have seen that the antiquarians of the XIXth Dynasty had identified the tomb of Khent as that of the god Osiris. "Kenkenes" must then be Tja Ati or "Ata" (we cannot trace the origin of the peculiar Manethonian equivalent of his name), placed erroneously before Ouenephes (Khent) For that Tja succeeded Khent is again deduced from the obvious steady development of the art of the period, which from a more primitive stage under Narmer and Aha suddenly developed under Khent and Tja, till we reach the line of the kings Den Semti ${ }^{1}$ and 'Antjab Merpeba, whose works are obviously of far more developed style and therefore of later date than those of Aha and Narmer. With Semti the list (and Manetho, who more or less follows it) first agrees entirely, both in names and order, with the facts. Still, the name of Semti was not properly understood: it was misread as "Hesepti," the original of Manetho's "Ousaphaïs." That of Merpeba was, however, quite well given as "Merbap" or "Merbapen," and with this king the list of Tunrei at Sakkara begins : he does not mention "Mena." The following names of Semerkhat and Ka Sen have been also misunderstood both by the lists and by Manetho, but the identity of "Shemsu" and "Kebhu" with these two kings is certain, and their order is correct.

Narmer is left unidentified. And who was the original of the legendary Mena? It would seem that "Mena" in reality represents the early conquering monarchs of this dynasty: he is

1 The proposition of M. Weil. (Rec. Trav. xxix. (1907), p. 26 ; Annales du Muske Guimet, I90\$) to regard "Semti" not as a king's name, but as a mere title, so that nsuit biti semti would mean "King of the Two Deserts," or "King of Upper and Lower Egypt and the Two Deserts" or "Lands" (on the analogy of the later title, "Lord of the Two Lands"), is sufficiently negatived by the fact that the word "Merpeba" is generally admitted to be the name of Den's successor, and it follows the title nsuit biti ("King of Upper and Lower Egypt") exactly, as does the word "Semti" in the titulary of Den. If the one is a name, so is the other, and the fact that both occur on a single vase-fragment merely shews that the two kings were very near in time to one another. The lists and Manetho are probably right in making Merpeba succeed Semti, and they may conceivably have been associated on the throne for a time, or, more probably, the vase was re-used. Mr. F. LEGGE's support of M. Weill's view (P.S.B.A., I910, p. 233) has been criticized by the present writer (ibid., I9I I, pp. I 5 ff.), to whom Mr. LEGGE replied (ibid. pp. 68 ff.) ; rejoinder from myself (ibid. p. 127). 
a complete personage of tradition, a sort of Egyptian King Arthur who represents the deeds of the Southern kings who conquered Buto and founded the dual kingdom. Perhaps he represents more especially Narmer, who was the first, as far as we know, to wear the Crown of Lower as well as that of Upper Egypt, and shows us on his monuments at Hierakonpolis how he overthrew the Northerners. Aha, if his personal name was really Men, and not Ateti, may have given his name to the traditional Mena, and contributed to his glory, since he ruled over North and South and called himself the "Fighter" (Aha); but he was not the actual conqueror of the North. And unknown kings of the South who preceded Narmer and warred against the North before him, also have been included in the composite personage who for the Egyptians of later days was the founder of their kingdom. It is a tempting theory to suppose that a king existed named Sma ("Uniter"), who came between Narmer and Aha, and was the actual uniter of both kingdoms: but it is by no means certain that this supposed royal name, discovered by Prof. Petrie at Abydos, ${ }^{2}$ is (any more than these of "De," "Ro," "Ka," and "Tjeser," also found there) a name at all.

With Narmer we reach the beginnings of Egyptian history. Since he conquered the North, and therefore more or less corresponds to Menes, we must assign him to the Ist Dynasty, and not to the "Followers of Horus," the Hierakonpolite kings, who appear in the Turin Papyrus and Manetho as midway between the rule of the gods on earth and that of Menes, and are called by Manetho "the semi-divine ghosts" (v'sxuss of inuitsos). ${ }^{3} \quad$ They were indeed ghosts of faraway tradition, while

1 For this view of "Menes" I am alone responsible. It seems to me to explain the facts better than any other, and to be in accordance with historical probability.

2 Petrie, Royal Tombs, ii. p. 4.

${ }^{3}$ The names of these kings, as found at Abydos, are given in two forms; first the Horus-, Hawk-name, or $k a$-name, which, properly speaking, is not the name of the king himself, but that of his $k a$ or spiritual double; secondly, the name of the king him. self, either without a title, or with that of "King of Upper and Lower Egypt" or "Lord of the Hawk and Snake." Of Aha we have both names, of Narmer or Betjumer only the $k a$-name, of $\mathrm{Tja}$ and Khent both the $k a$-names and the personal names (doubtful); thenceforward both names with the full title as King of Upper and Lower Egypt. The names used above are the $k a$-names only; Semti Den and his successors will be spoken of usually under both names, the second being the personal name as king. It is probable that before the unification of the kingdom the $k a$ or hawk-11ame, which was contained in a special standard, called the srekh or "pro- 
Narmer was a very real man, as we see from his monuments. At Hierakonpolis were also found relics of an uncertain king, who is supposed to have borne the appellation of "the Scorpion," but there is no proof that this was his name at all, and in view of the identity of style between his work and that of Narmer, we may assume that he is the same as the latter, ${ }^{1}$ and that "Scorpion" was considered an appropriate epithet of royalty.

AHA, the successor of Narmer, while also a "fighter," a conquerer of the Nubians (probably north of the First Cataract), and an upholder of Southern rule in the North, seems to have been a more peaceful ruler than Narmer, and the tablets of his reign seem to chronicle the erection of temples, notably one of the northern goddess Neith, ${ }^{2}$ whose name is also borne by women of the royal house at this period. This seems to indicate some attempt at conciliating the Northerners. ${ }^{3}$

Of the reigns of KHENT and TJA we have interesting artistic remains, ${ }^{4}$ which shew, as has been said, that in their time art progressed with a sudden bound; a fact which makes it possible for us to assign with certainty the works of Aha and Narmer to the period preceding.

Den Semt (called Udimu Khaskheti by Prof. Sethe) seems to have been an energetic and long-lived monarch. He was the first to call himself by the title of nsuit biti (insiby'a) "king of Upper and Lower Egypt," and built himself a large tomb at Abydos, with the novel addition of two staircases descending into it, and a floor of granite blocks which must have been brought from Aswân; a result probably of the southern victories of Aha. Besides jar-sealings, many of which

claimer," and was always the most sacred appellation of the monarch, was the only written form. This would explain Manetho's curious designation of the kings before "Menes" as $\nu \epsilon \kappa v \in \epsilon$ or ghosts. The ka-name is properly the name of the royal ka or ghost, and it is probable that Nanetho, not quite under same papyrus of the XIXth Dynasty or later which gave the names of the pre-Menic kings in the ka-form only, described them as "ghosts," personal name only, misunderstood though it often was, herein following the XIXth Dynasty lists, which gave only the personal names in, as we have seen, often a misunderstood form. The third name of the king, as "Son of the Sun," did not come into use till the time of the IVth and Vth Dynasties (see p. I29).

1 Budge, Hist. Egr. i. p. 184 , n. 1 .

2 Petrie, Rojal Tombs, ii. I'l. x. 2.

${ }^{3}$ NewberRy and Garstang (Short History of Egypt, p. 20) make the Queen Neit-hetep, of this period, a princess of Saïs, and suggest that her marriage to Aha "united the royal families of the rival countries," North and South.

- See especially, Petrie, Rojal Tombs, ii. Pl. vi. 
commemorate a great official named Hemaka or Hekama, a large number of annalistic tablets, chiefly recording religious acts, were found in his tomb; $;^{1}$ and in later tradition he was celebrated as a pious and learned king, chapters of the Book of the Dead as well as medical treatises being said to have been "found" (i.e. written) in his time, ${ }^{2}$ a statement not unlikely in itself. We see him on one tablet performing a solemn religious dance before the god Osiris. ${ }^{3}$ And in his reign we see the earliest known mention of a celebration of the Festival of Sed, or "the End" (lit. "Tail"). It would appear that, like many other primitive peoples, the early Egyptians put a period to the reigns of their kings. When they had reigned for thirty years they either were killed or were deposed, amid solemn festival, in which the king, at least officially dead, was carried in procession in the death-robes and with the crook and flail of Osiris, the Busirite god of the dead. In historical times the king had refused any longer to be either immolated or deposed, and merely celebrated the festival pro form $\hat{x}$. It became later a jubilee, the distinction of a long reign; while, in the end, any or every king liked to celebrate it, whether he had reigned thirty years or not, sometimes several times in his reign. ${ }^{4}$ We do not know whether the ancient custom still so far survived in Den's time that he had to vacate his throne at the end of his thirty years' reign.

The contemporary monuments of his successor, ANTJAB MERPEBA, are comparatively insignificant; but he is noteworthy from the fact that in all probability he was the founder of the city of Memphis. Later tradition, as Herodotus tells us, assigned this great work to "Menes." But it is significant that the royal list of Tunrei at Sakkara, the necropolis of Memphis, places Merpeba at the head of the kings, and knows nothing of "Mena" or of any king before Merpeba. The conclusion that Memphite tradition in the time of the XIXth Dynasty knew of no king before Merpeba, and that he was the "Menes" who founded

1 Petrie, Royal Tombs, i. Pll. xiv.-xvi. $\quad{ }^{2}$ See Budge, Hist. Eg. i. I98, I99.

${ }^{3}$ This dancing or leaping of the king was a rite connected with the foundation of temples.

${ }^{4}$ This is the view of Prof. Petrie (Researches in Sinai, pp. ISI ff.). It seems to be a satisfactory explanation. The killing of the king is of course a well-known rite among primitive peoples: see Frazer, Golden Bough, i. pp. 22I-23x. The Sed-festival was also that of the jackal-god of the dead, Anubis, who was called Sedi, "the tailed one" : see Miss Murray, The Osireion, p. 34. 
Memphis, seems a very probable one. ${ }^{1}$ Merpeba was sufficiently near in time to the original conquerors of the North, Narmer and Aha, to be easily confounded with "Mena" by the Egyptians of Herodotus' day.

Probably Merpeba merely re-founded Memphis as the official capital of the North in place of Saïs or Buto. The god of Memphis, Ptah, bears a Semitic name, "The Opener"; and, as we have seen, he may well, like the sun god $\mathrm{R}$ 'a ( ${ }^{\prime}$ 'Or, "light") of Heliopolis, have been a pre-Egyptian deity of the proto-Semitic Northerners ${ }^{2}$ (or Anu?) who was worshipped in a town called "The White Wall," which was afterwards re-founded by Merpeba and in the time of the VIth Dynasty took the name of Men-nefor, the "Memphis" of the Greels. The building of the great dike of Koshêish, south of Memphis, also ascribed by Herodotus to Menes, may also have been the work of Merpeba. Memphis speedily increased in importance, and under the IIIrd Dynasty, if not already under the IInd, the king's seat and capital of the whole country was transferred thither from Thinis.

The chief monument of Senerkia Hui (or NekHT?), the next king (who was also buried at Abydos), is also the most ancient monument of Egyptian activity outside the Nile-valley. It is a stele of this king, sculptured on the rocks of the Wadi Maghârah, in the Sinaitic peninsula, and shows two figures of the ling wearing the crowns of Upper and Lower Egypt respectively, followed by a scene of him striking down with a mace a Semitic inhabitant of the peninsula, whom he seizes by the hair: in front of the royal figures comes his "chief and commander of the soldiers," carrying a bow and arrows. ${ }^{3}$ It is thus evident that even so early as the time of the Ist Dynasty the Egyptian kings sent expeditions to Sinai to procure the turquoise or mafkat which was always prized so highly.

Semerkha Nekht is Manetho's Semempses, a name which probably gives the pronunciation which in his time was attributed to the peculiar ideograph of a man with a stick

${ }^{1}$ For this conclusion the present writer is responsible (Kisc and IIALL, Egyth and Westem Asia, pp. 9 I ff.).

${ }^{2}$ See pp. $\$_{5} \mathrm{fr}$.

${ }^{3}$ This stela was discovered by I'rof. Petrie in 1906 (Researcies in Sinai, pp. 37, 41 ; Figs. 45,46$)$. 
with which the king's name is written, probably an early form of the sign usually read "Nekht."

His successor, KA SEN, has been supposed to be Manetho's Bieneches or Ubienthis, but it is more probable that the Manethonian name really belongs to the prince who succeeded $\mathrm{Ka}$ according to the Tablet of Sakkara, Biuneter. Ka, however, is undoubtedly the Kebhu who on that tablet comes between Nekht and Biuneter, and appears as the successor of Nekht, also that of Abydos. The alteration of his name from its true form Sen to "Kebh" has been well explained by Prof. Petrie." We possess fine relics from Ka's tomb at Abydos in the diorite stelae which were set up above it, and an ivory object with a representation of a prisoner from the Cataract-country (Satet), which shows the Semitic type of the eastern desert tribes clearly.2 ${ }^{2}$

With Biuneter or Bieneches, who is a mere name, Manetho brings the Ist Dynasty to an end, and we have no reason to reject his arrangement. Our knowledge of the IInd Dynasty is fragmentary and confused. The outstanding fact of the period is the assertion of the equality of the North and its god Set with the hitherto dominant South.

\section{The IInd and IIIrd Dynasties}

The first kings-Perabsen and Send

The re-founding of Memphis by Merpeba marked the beginning of the shifting of the royal power northwards HeteP-Seknemui, RAneb, and Neneter ${ }^{3}$ (who are probably the Betju, Kakau, and Baneneter of the lists; the Boethos, Kaiechos, and Binothris of Manetho) probably reigned at Memphis, and Kaiechos is said by Manetho to have instituted the worship of the Apis-bull there. ${ }^{4}$ SEKHEMAb, probably the next king (he cannot be identified in the lists), emphasized his connexion with the North by adopting, in addition to his Horus-name, a Set-name, PEREnmaAt preceded by a figure of the sacred animal of Set, the god of the North and enemy

1 Royal Tombs, i. p. 23.

2 Royal Tombs, i. Pl. xvii. 30.

3 The succession of these kings is known from the archaic statuette No. I. of the Cairo Museum (Petrie, Hist. E Es. i." p. 24*). The form "Hetep-ahaui" used by Prof. Petrie is improbable, as it has no meaning (Budge, Hist. Eg. i. p. 211 ). The name is doubtless Hetep-sekhemui.

4 See p. 119. 
of Horus. ${ }^{1}$ Perabsen, who probably succeeded him, bore the Set-name only, but was buried (or more probably, had a cenotaph made for him) at Abydos. ${ }^{2}$ Later on he was venerated at Sakkara in conjuction with another king of the dynasty, SEND or Senedi ${ }^{3}$ ("Terror"), who was sufficiently important for his name to be preserved accurately in the later lists and even by Manetho (as "Sethenes"). He, however, is unknown in the South, and it is probable that he ruled at Memphis. We know nothing of him except that he was venerated there. Several long reigns followed, according to Manetho: then came the founding of a new dynasty by the great Southern conqueror KHASEKHEM or KHASEKIIEMUI, whose known relationship to Tjeser, the great king of the IIIrd Dynasty, makes certain his position at the head of that Dynasty, and probable his identification with the "Tjatjai" or "Bebi" of the lists. ${ }^{5}$

His is an important historical figure. He was a Southerner, and held his court in a great fortress-palace of royal burgh on the edge of the desert at Abydos, now known as the Shunet-ez$Z e b i b{ }^{6}$ There also, near the sepulchres or cenotaphs of the Ist Dynasty, he built his tomb, which has yielded antiquities much resembling those of the older kings. ${ }^{7}$ Like Narmer, whose career he emulated, he regarded Nekhebet, the vulturegoddess of Hierakonpolis, as his special protectress, and in every way revived the traditions of the Southern kingdom, which had become dimmed under the long Northern rule of

${ }^{1}$ Sckhemab and Perabsen were originally considered to be the same person, but this has been shewn to be an error by Mr. E. R. AYrToN's discovery at Abydos of the names of Sekhemab and Perenmaat together (Abydos, iii. Pl. ix. 3).

2 Amélineau, Le Tombeau d" Osiris, p. 125.

3 This vocalization of the consonantal skeleton "Send" is of course hypothetical. Evidently "Sethenes" was originally "Senethes."

4 The tomb of Shere, a priest of Send under the IVth Dynasty, has by chance been divided between different museums at very different periods. One slab, now in the Ashmolean Museum at Oxford, was part of the original collection of the merchant Tradescant in the seventeenth century. Another was acquired by the British Museum not many years ago.

5 This king has been identified with the Betju or Bocthos of the lists, and so has been placed at the head of the IInd Dynasty, and the ground of his personal name having been Besh, which resembles "Betju." But there is no doubt that Tjeser was his son (Meyer, Gesch. All. ${ }^{2}$ (1907), i. p. 135). The forms Tjatjai, Bebi of his name in the lists are due to the usual misunderstanding by the later Egyptians of the signs of his name.

${ }^{6}$ Ayrton, Abydos, iii. pp. I ff.

${ }^{7}$ Petrie, Royal Tombs, ii. pp. $12 \mathrm{ff}$. 


\section{II2 'THE ANCIEN'T HISTORY OF 'IHE NEAR EAST}

the IInd Dynasty. He was not, strictly speaking, an usurper, but ostensibly inherited the throne in right of his wife, who bore the name Ne-maat-Hap, "Possessing the Right of Apis," the tutelary deity of Sakliara." Evidently Ne-maatHap was the last of the long line of the IInd Dynasty, and married the energetic Southern chief, whose personal name was Besh, ${ }^{2}$ though he ascended the throne as Kha-sekhem "Appearance of the Power."

We may doubt, however, that his wooing of Ne-maat-Hap was peaceful. Probably he took her and her right by conquest. On his monuments he tells us of his victories: he claims on a votive statue dedicated at Hierakonpolis (Plate VII. 2) to have slain 47,209 of them. ${ }^{3}$ This massacre secured his power over the North as well as South; and on a vase also dedicated at Hierakonpolis, ${ }^{4}$ in imitation of Narmer, he claims to be a second unifier of the kingdoms, a second Menes. On it we see the vulture of Nekebet offering with her left claw the symbol of the Union of the Two Lands to the king's Horus-name Kha-sekhem, while in her right she holds the royal signet with his personal name Besh: above and behind is inscribed: "In the temple of Nekheb (Hierakonpolis): year of fighting the Northern Enemy." The victory gained, the savage warrior shewed political talent of a high order. Apparently he altered his Horus-name to Kha-sekhemui ("Appearance of the Two Powers"), ${ }^{5}$ added to his titulary the significant phrase, "He hath opened peace to Horus and Set," thus typifying the renewed union and peace between South and North, and legitimized his position by marrying the Memphite princess, Ne-maat-Hap.

There is no doubt that Khasekhemui was a man of great

1 Petrie, Royal Tombs, p. 32.

2 This is controverted by M. NAville (Rec. Traz. xxiv. p. IIS), who has it that the signs read "Besh," and taken to be the king's name, are really 'Bi-to,' "Land of $\mathrm{Bi}-\mathrm{t}$ "(Battos), the North, and refer to his conquest.

${ }^{3}$ Quibell, Hierakonpolis, ii. p. 44.

${ }^{4}$ Ibid.

${ }^{5}$ This view seems to me more probable than that which holds that Khasekhem and Khasekhemui are two separate persons. The names Khasekhem or Khasekhemui may well have been imitated from that of the Hetep-sekhemui, who was probably the first king of the preceding dynasty. If so, this is the earliest evidence of a custom which afterwards was not unusual, of the founder of a new dynasty modelling his official throne-name on that of the founder of the dynasty preceding. An instance is Rameses I of the XIXth Dynasty, who imitated the style of Aahmes, the founder of the XVIIIth. 
energy and power. His tomb at Abydos is enormous, and is remarkable as containing the oldest known complete chamber of hewn granite. That he was a clever ruler is shewn by his reconciliation of the two lands, although this had the perhaps unexpected effect of transferring the royal power finally from the victorious South to the conquered North. His fierce and politic reign is a contrast to those of the preceding kings of the dynasty, who seem to have been peaceful monarchs wholly given over to good works. Of the sixteen yearly entries of events preserved to us on the Palermo Stone out of the long reign (at least 35 years) of Neneter, not one refers to war, and only one to a civil act, and this of little importance, the founding of two palaces; the rest record nothing but the institution and celebration of religious festivals. ${ }^{1}$ Yet by an irony of fate the name of the undistinguished Neneter was preserved in the official lists till the time of Manetho, while that of Khasekhemui, although his birth-year was solemniy commemorated under the Vth Dynasty, ${ }^{2}$ was afterwards wholly forgotten. It is not impossible that his deeds were confused with those of Narmer and "Mena." Certainly none of the five names that follow that of Send or Sethenes in the lists and in Manetho can be identified with his. On the other hand, the name of his son Tjeser survived and was recognized as important till the last. It was correctly preserved in the later lists, and is the Tosorthros of Manetho.

TJESER, who bore the Horus-name Khetneter, was, like his father, a powerful king. He cut a stele on the rocks of Sinai, ${ }^{3}$ and from a late inscription we 'snow that he presented the Nubian territory known in later times as the "Dodekaschoinos," between Aswân and Maharraka, which he had probably conquered, to the gods of the Cataracts. ${ }^{4}$ In the necropolis of Memphis he signalized his power, and shews us the speed at which civilization was developing in his day by the erection of, as his tomb, the first pyramid of stone (Plate VIII. 2). This is the StepPyramid of Sakkâra. ${ }^{5}$ He also built himself a brick mastaba-

${ }^{1} \mathrm{ScHĀFER,} \mathrm{Ein} \mathrm{Bruchstück} \mathrm{altägy'plischer} \mathrm{Annalen,} \mathrm{pp.} 23 \mathrm{ff}$.

2 Naville, Pierre de Palerme, Rec. Traz. xxi.; Schäfer, loc. cit. p. 27. The event took place about the I 4 th (?) year of an unknown successor of Neneter.

${ }^{3}$ Petrie, Sinai, pp. 37-8, 44.

"Sethe, Dodekaschoinos (Untersuchungen zur Gesch. Ag. ii.).

"Manetho says that "Tosorthros (Tjeser) built a house of hewn stone," which is evidently this pyramid, which bears his name, Khetneter. 
tomb in the old style, but of unprecedented size, in the desert at Bêt-Khallâf, north of Abydos (Plate VIII. I). ${ }^{1}$ One of these tombs must have been built as a concession to the local sentiment of either Lower or Upper Egypt, for we do not know in which he was buried. SA-NEKHT, his brother, who probably succeeded him, also built a similar brick tomb at Bêt-Khallâf, in which he seems to have been buried. ${ }^{2}$ Sa-nekht set up stelae in the Wadi Magharah, but we know no more of him. Manetho follows him with four kings of whom neither the monuments nor the XIXth Dynasty lists know anything: one of them, "Soÿphis," is certainly a double of Khufu (Souphis) misplaced. Then comes Manetho's Kerpheres, the historical NEFERKA or NEFERKARA, who has got misplaced before Sephouris (Snefru), who, as we see from the lists, followed him. Of this king we have a mighty unachieved monument: the huge rock-cut excavation at Zawiyet el-Aryân, south of Gîzah, which has been excavated lately by the Service des Antiquités. ${ }^{3}$ It is probably, as M. Maspero thinks, the foundation of a pyramid, which, had it been built, would have marked the transition between the "stone house" of Tjeser and the great pyramids of Snefru and Khufu. On the walls of this excavation occurs besides the name of Neferka, that of Ra-neb-[ka], who is perhaps identical with Sa-nekht. ${ }^{4}$ The redundant names of the lists and Manetho we may dismiss with probability as either mythical or due to some confusion: we have only five historical kings of the dynasty, which was probably short, ${ }^{5}$ concluding with SNEFRU

${ }^{2}$ Garstang, Mahasna and Bêt Khallâf, pp. $8 \mathrm{ff}$.

2 It may seem most probable that Tjeser and Sa-nekht were both buried at Bêt Khallâf, as Khasekhemui probably was at Abydos. They were originally Upper Egyptians.

${ }^{3}$ Under the direction of M. Barsanti (Annales du Service, vii.).

${ }^{4}$ On account of this occurrence of the name Nebka, M. Maspero (l.c.) is inclined to date this monument to the IInd Dynasty, in which a king Neferkara occurs as well as a "Ra-neb." But it seems to me impossible that this vast work can belong to the IInd Dynasty. It takes its place naturally with the great pyramids in its neighbourhood, and it seems to me obvious that it belongs to the IIIrd Dynasty king Neferkara, the predecessor of Sneferu, and that the name Ra-neb is that of the Nebka or Nebkara of the lists, who may be identical with Sa-nekht, who may have been the historical predecessor of Neferkara.

${ }^{5}$ If Sa-nekht (=Nebka) was the predecessor of Neferkara, and there were only five kings in all, the dynasty will have been short, thus agreeing with the evidence of the Turin Papyrus, as given by MEyer, Chronologie, p. 177. (It should be noted that the name "Huni," which has been supposed to precede that of Sneferu in a papyrus, has been shewn by BorchardT $(\ddot{A} . Z$., 1909, p. 12) to be an ancient 
(Sephouris), with whom the age of the great Pyramidbuilders begins, and the archaic period of Egyptian civilization ends.

The period of time covered by the first three dynasties probably did not much exceed four hundred years. There were several long reigns in the first two dynasties, notably those of Den and Neneter: the latter is said to have died at the age of ninety-five, while others of these primitive rulers were very long-lived. But on the other hand the IIIrd Dynasty probably lasted less than a century, of which Tjeser reigned thirteen years, according to the Turin Papyrus.

\section{The Development of Archaic Esyptian Civilization}

Swift course of development-The writing-Second period of development under the IIIrd Dynasty-Architecture-Small art : metal work-Pottery-Religion

These four centuries witnessed the development of Egyptian civilization out of comparative barbarism. Under the Pyramidbuilders of the IVth and Vth Dynasties we find that the free and unrestrained development of art, culture, and religion comes to a stop, when further progress might have anticipated the triumphs of Greek civilization.

But there had been no halt and no falling back under the early dynasties. Development was steady, sometimes quicker, sometimes slower. We can easily see two periods of greatly accelerated progress, periods in which new ideas appear at every turn, and energetic brains were evidently working freely. The first of these periods may be placed between the reigns of Narmer and Den, and the second in those of Khasekhemui and Tjeser. Probably the first period of acceleration might be extended farther back into the age of the Shemsu-Hor. In the representation of men and animals the art of the first period marks a great advance upon the crude Bushman-like productions of the prehistoric period. This advance we see vigorously pressed during the reigns of the kings of the dynasty. During the reigns of Aha and Narmer the hawk above the "Proclaimer" containing the name of the king's ghost is very oddly fashioned $;^{1}$ but in Tja's time an artist arose who could draw a

error for the name of Aha. I think there is a possibility that it may also te confused with that of Nekht or Shemsu).

'Petrie, R'oyal Tombs, i. Pl. iv. I, 2 ; ii. Pl. iii. 


\section{II6 THE ANCIENT HISTORY OF 'THE NEAR EAST}

hawk correctly, ${ }^{1}$ and the hierogiyph as fixed by him remained the standard throughout Egyptian history. So also it is with the reign of Semerkhat that we first find animals in general well drawn in the regular Egyptian fashion; in the time of Khent, a century before, lions, for instance, were represented in the round in a way which strikes us as strangely un-Egyptian. ${ }^{2}$

It is to this period of transition between Neolithic barbarism and the later culture of the Ist Dynasty that the first great progress of the art of writing must also be assigned. The Egyptians never made any strict distinction between painting or drawing and writing, and the development of their script must be regarded as part of the development of their art.

The isolated pictographic signs by which the primitive Nilote had learnt to denote the names of his tribe or his god, perhaps of himself and of the animals he kept and hunted, had developed by the time of the kingdoms of Hierakonpolis and Buto into an ideographic system of writing, in which it was not possible to express the sound of the word, only the idea. This purely ideographic system is, as we see in the case of the monuments of Narmer, very difficult for us to interpret. To the reign of Den belongs the first inscription which is sufficiently like those of later days for us to be able to translate it in the proper sense of the word. It reads literally: "Big Heads Come Tomb : He Give Reward." Neither article nor prepositions are yet expressed: the ideographic writing is not developed much further than the paintings of a Red Indian wigwam. But already the syllabic system had been invented during the early reigns of the Ist Dynasty; when we find it used to express proper names, for which purpose indeed it was probably devised.

\footnotetext{
${ }^{1}$ Petrie, Royal Tombs, i. Pl. iv. 3. (Prof. Petrie reads the name of Tja as "Zet.")
}

2 Ibid. ii. Pl. vi. 3, 4 : the latter is in the British Museum (No. 35529). A small ivory lion in the possession of Mr. J. H. Rea, of Eskdale, Cumberland, is a fine specimen of the art of the times of Khent and Tja. Still earlier, probably rather before the time of Narmer, we have the two large lions discovered by Prof. Petrie in the foundations of the temple of the god Min at Koptos. There were found in company with those other monuments of an extremely archaic character on which are represented elephants crossing mountains, etc., which have been mentioned. The same kind of lion is also represented on a slate "palette" in the British Museum, on which we see a curious scene, apparently depicting the thrusting forth of prisoners of war into the desert to be devoured by lions and.vultures. We also see lions of the same kind on another slate "palette" of even earlier date (of which two-thirds are in the British Museum, and one-third in the Louvre) on which is carved a huntingscene (see p. 100, n.). 
In the reign of Den the progress of the writing is marked, and under the later kings of the dynasty we find its character fixed as a partly ideographic, partly alphabcto-syllabic script. Of course it is still archaic in character, many signs being used which soon afterwards were abandoned, and so is difficult to read.

The second period of swift development began at the end of the IInd Dynasty and came to a stop only when under the Vth Egyptian art reached its first apogec, and the first decline set in. It is chiefly marked by the devclopment of architecture and of sculpture, in relief and in the round. Already at the end of the Ist Dynasty a "king's carpenter" had so far progressed beyond the carving of ivory memorial tablets and slate reliefs as to be able to execute in the round the wonderful little ivory figure of a ling found by Petrie at Abydos, which is one of the greatest treasures of the British Museum (Plate VII. I). ${ }^{1}$ His head is bent forward (which has caused him to be taken for an old man), and he clasps his variegated robe about him; on his face there is a curious smile, almost a sneer. This was indeed an extraordinary result of the first development: perhaps no Egyptian figure so good of its kind was ever made in later days. But the maker of this could not yet create good larger figures in stone; he was still a carver, not yet a sculptor. This he became in the time of Khasekhemui, when such clumsy figures as the Statue No. I at Cairo (probably made under Neneter), ${ }^{2}$ developed into such extremely good representations of the human figure as the sitting statuettes of the conqueror which he dedicated at Hierakonpolis, ${ }^{3}$ and are now at Cairo and Oxford (Plate VII.2). Now the conventional representation of a king is already fixed; he no longer wears such an extraordinary robe as that of the ivory figure of the Ist Dynasty, but might be any later Pharaoh, did we not know who he was. But, as we have said, upon the pedestals of these statuettes we find the bodies of his slain enemies sculptured in a remarkable attempt to represent every conceivable attitude of the dead upon a battlefield, which, though crude and often ill-drawn, is nevertheless

1 Petrie, Aby'dos, i. Pl. xiii. The photographs give a really unflattering likeness of the statuette, which is most deiicate in feeling. I am inclined, for several reasons, to assign this wonderful figure to about the time of Den Semti. If so, it probably represents that king himself.

${ }^{2}$ See p. 110.

${ }^{3}$ Sec p. 112. 
extremely realistic, and would undoubtedly have horrified an Egyptian sculptor of a few hundred years later, when the conventions of art had become sternly fixed. No doubt the picturesque attitudes of the slain had been greatly admired by the king or his artists, and so they were sketched and afterwards transferred to the immortal stone. It was an age of cheerful savage energy, like all ages when peoples and kingdoms are in the making.

The sister art of Architecture naturally found little scope in the early days; we can only chronicle the fact that Den was the first to use hewn stone at all, and that only for a floor. The architectural development also, like that of sculpture, began in the age of Khasekhemui and Tjeser, who, as we have seen, built the first pyramid.

The "small art" of the beginnirig of Egyptian craftsmanship is often wonderfully fine. Gold, perhaps the oldest of metals to be known to man, was commonly employed, and was first used by the Egyptians to ornament necklaces, as its ideograph, a necklace or collar, shews. We possess the ivory lid of a box, inscribed "Golden Seal of Judgment of King Den " ${ }^{1}$ this must have been a cylinder of gold. Silver was unknown. Copper was used ordinarily for tools and weapons, though the Egyptians were still in the "chalcolithic" stage of culture, and used stone side by side with copper. But the stone weapons of the early dynastic period shew a notable falling off from the exquisite workmanship of the purely Neolithic period. Nor is the reason far to seek. The adoption of metal turned all the best skill in the new direction of metal-working. The same phenomenon is noticeable in the case of pottery, which suddenly becomes poor and weak. This was because metal tools had given a new power over hard stones, which were now used for the manufacture of splendid vessels, often of gigantic size, which are among the finest relics of the early dynastic age. Stone vessels of small size now largely took the place of pottery, until the invention of the potter's wheel, somewhere about the time of the IIIrd Dynasty, restored to the potter his rightful place in the hierarchy of artists. But the ceramic artists had already discovered the art of glazing pottery, which, though rarely applied to vases as yet, resulted in the production of beautiful small figures and embleins of

'Petrie, Royal Tombs, ii. Pl. vii. 12. 


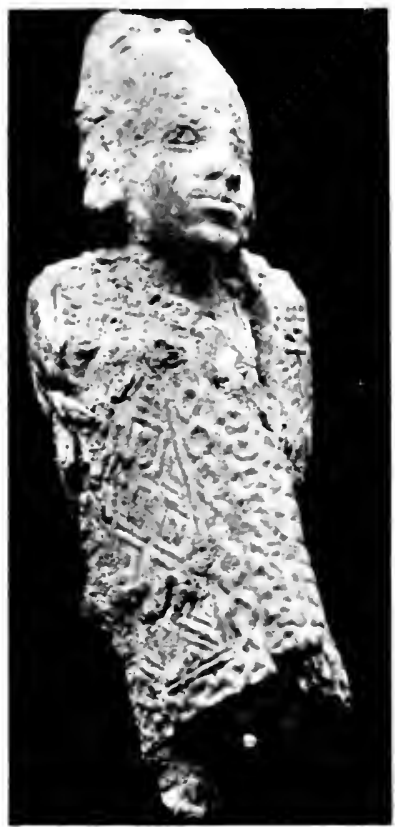

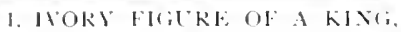

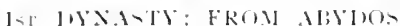
firis , Un

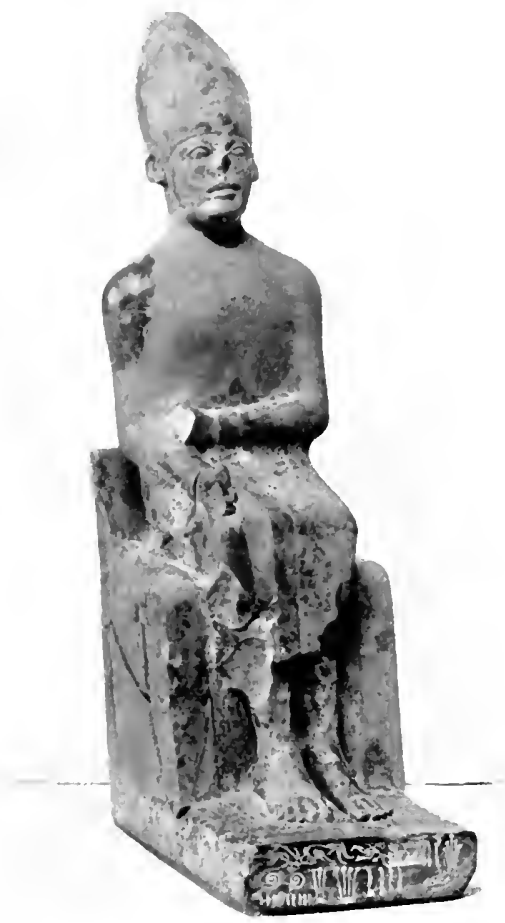

2. STONE FICERE OF hHASEKHEMLI:

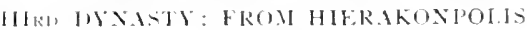

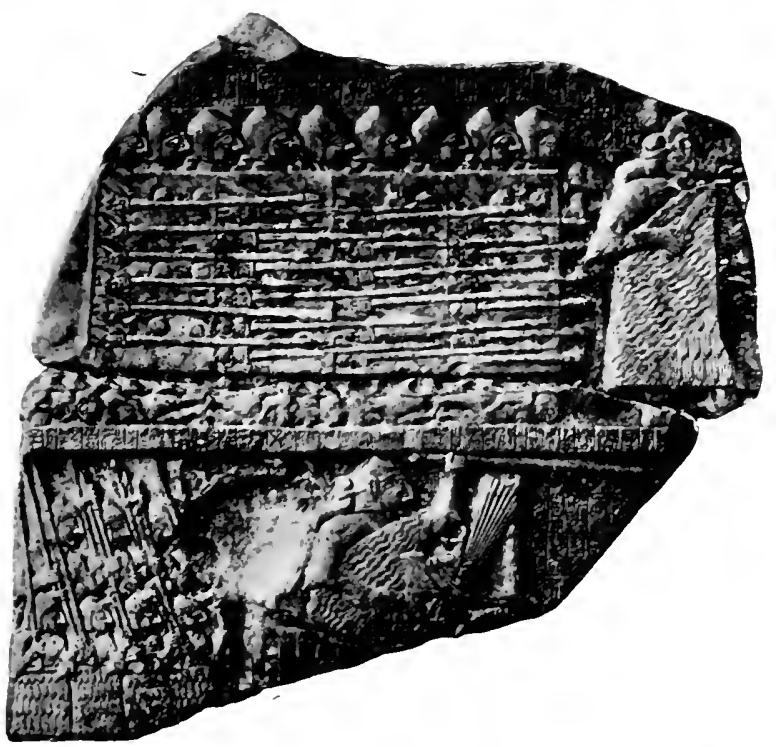

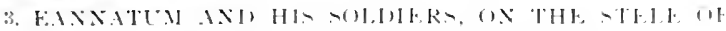

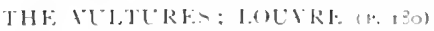

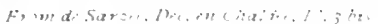



glazed clay. The colour was a light bluc. True glass was to remain unknown for many centuries yet, but the glazed faience of the Ist Dynasty is equal to any of later times. We find it already well developed in the reign of Aha. Ivory and wood were, as we have seen, well known to the craftsman of this early period; great balks of timber were used for the flooring and roofing of the tombs at Abydos which can hardly have come from anywhere else than Palestinc. So that commerce, probably overland across the desert of Suez, with the Semitic world was by no means unknown. By this route was lapislazuli imported from the East; turquoise, as we have seen, was already mined in Sinai.

The early Egyptian artists made figures of their gods which hardly differ from those of the time of the Vth Dynasty, when the conventions of religious art were fixed for all time. We have seen the holy animals of Horus, Set, Anubis, Upuaut, and Sebek represented; and the figures and signs of Osiris, Taueret, Hathor, and Neith show that these deities were all worshipped from the beginning. The more human gods of the Libyan and Semitic Northerners had amalgamated with the theriomorphic deities of the Nubian Southerners; perhaps the "appointment" of the sacred animals of Memphis, Heliopolis, and Mendes "to be gods" in the reign of Kaiechos, ${ }^{2}$ refers to a formal amalgamation of this kind.

${ }^{1}$ Petrie, Abydos, ii. Pl. iv. Brit. Mus. Nos, 3 Solo-3So 42.

a See p. 1 Io. 


\section{LIST OF THE HISTORICAL AND LEGENDARY KINGS OF THE FIRST TIREE DYNASTIES OF MANETHO}

\section{Ist DYNASTY}

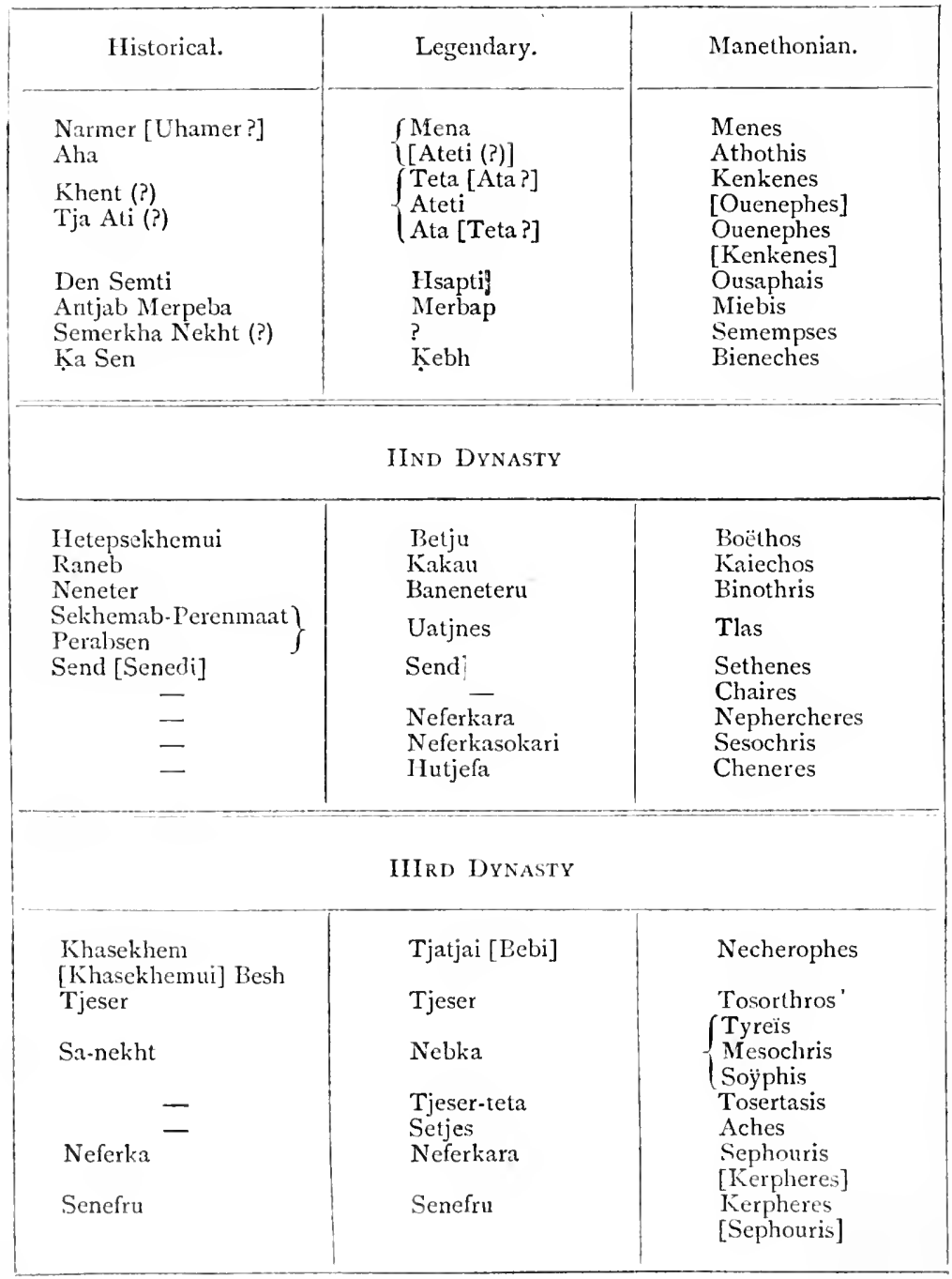




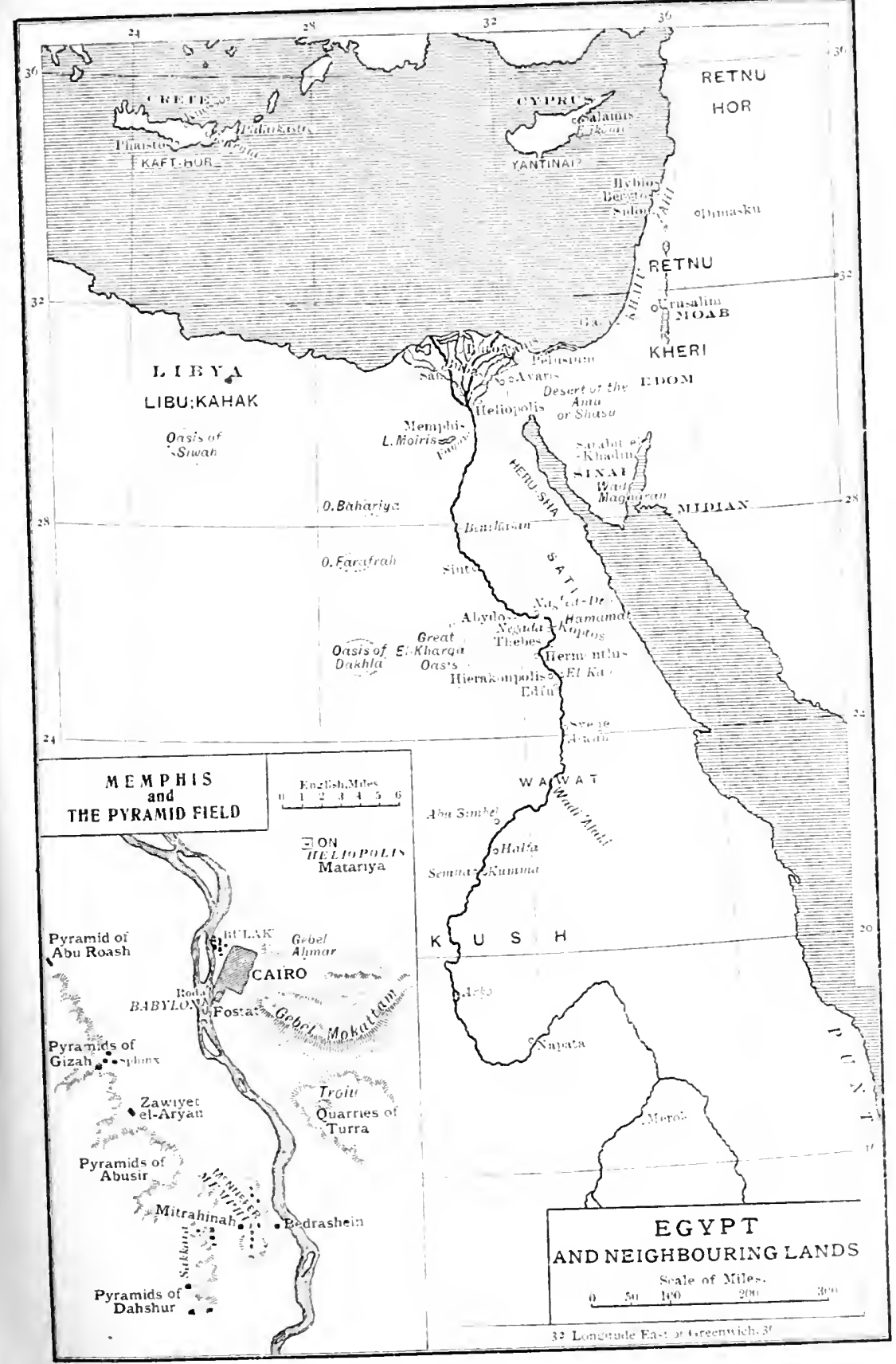



CHAPTER IV

\section{EGYPT UNDER THE OLD AND MIDDLE KINGDOMS-c. 3200-I 800 B.C. (?)}

\section{The IVth Dynasty}

Senefru and Sharu-The Pyramids and funerary temples-The mastabas-Architecture and engineering knowledge-Art-Sculpture in the round-Great men of the kingdom-Relationships of the kings-Khufu-Khafra-Menkaura-Shepseskaf

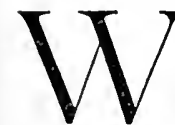

ITH Senefru we begin the second era of Egyptian history: the Age of the Pyramid-builders. This king has sometimes been assigned to the beginning of the IVth Dynasty, but if he is Sephouris, not Soris, and Sharu is Soris as seems most probable, he must be regarded as the last king of the IIIrd Dynasy, Sharu as the first of the IVth. Nevertheless Senefru must be grouped with the kings of the IVth Dynasty rather than with those of the IIIrd. The great kings of the first part of this period are, then, Senefru, and Khufu, Kilafra, and Menkaura, the Cheops, Chephren, and Mykerinos of Herodotus, the Chemmis, KephrenChabryes, and Mencheres of Diodorus, the Souphis I, Souphis II, and Mencheres of Manetho.

The age of these earliest kings, who with the legendary founder of the kingdom were always remembered in Egypt, has been called the Age of the Pyramid-builders. And the great Pyramids of Gîza will remain as their monuments till the end. They are the mark which the kings Khufu, Khafra, and Menkaura have for ever placed upon the land which they ruled nearly six thousand years ago. They are, as is universally known, the tombs of these kings, placed among the necropoles of their subjects on the low ridge of the desert which juts up at the edge of the cultivated land north-west of ancient Memphis and south-west of modern Cairo. Already in their 
time the desert-border in the immediate neighbourhood of the centre of Memphis was too crowded with the sepulchres of kings and commoners to allow of the great structures planned being erected any nearer the city. Tjeser had built the Step Pyramid (Plate VIII. 2), the most ancient in the necropolis, some two or three centuries before in the part nearest the city. Senefru had gone farther south, to Dahshur and Mêdûm, to build his two pyramids. ${ }^{1}$ Khufu went farther north; his successor Radadf, the Ratoises of Manetho, farther north still, to Abu Roash, northwest of Cairo; Khafra and Menkaura came back to the spot chosen by Khufu. The pyramid of Sharu is as yet unidentified. Of his reign, as of that of Radadf, we know nothing, and both were kings too ephemeral to build much. ${ }^{2}$

In front of the royal tombs stood their funerary temples, already important buildings of hewn stone, with pillared courts forming an outer or public temple and an inner fane, and with numerous magazines for the storing of the goods of the king's temple and the offerings made to his spirit. The temples of Khafra and Menkaura have both been excavated recently. The latter has yielded remarkable treasures of art, for the halls of a royal temple were filled with figures of the king whose memory was venerated in it. ${ }^{3}$

As the retainers of the Thinite monarchs were buried in, or at any rate in annexes of, the tombs of their masters, so the courtiers of the Memphite kings were interred in the neighbour-

1 There is little doubt that the northernmost outer pyramid at Dahshur belongs to Seneferu, as well as that at Mêidîm. Like Tjeser before him, he built himself two tombs, but why they were so near one another is not apparent, and we do not know in which he was buried.

${ }^{2}$ For Sharu see SAyce, P.S.B.A. xxi. p. IoS. Green, P.S.B.A. xxv. p. 215 , thinks the name reads "Shufu" (Khufu). But Sayce's reading seems more probable. As these two were unimportant monarchs who probably reigned but a short time, we do not wonder that Ilerodotus does not mention them; but his omission of Seneferu, who certainly rivals in importance his Cheops, Chephren, and Mykerinos, is curious. Perhaps his known connection with the previous dynasty caused him to be omitted in the popular legends of the IVth Dynasty. But when his pyramid at Mêidûm was excavated and identified by Prof. Petrie, hieratic graffiti were found in the small temple which stood before its entrance which shew that it was visited and admired as the "beautiful pyramid of King Senefru" by travelled scribes of the XVIIIth Dynasty (PeTrIe, Medum, p. 40).

${ }^{3}$ The famous statues of Khafra at Cairo were found on the side of that king's funerary temple, which has now been excavated by the German Sieglin expedition. The temple of Menkaura has been excavated for Harvard University by Reisner (see BORCHARDT, in Klio, ix. (I909), pp. 478 ff.; xi. I24 ff.). 

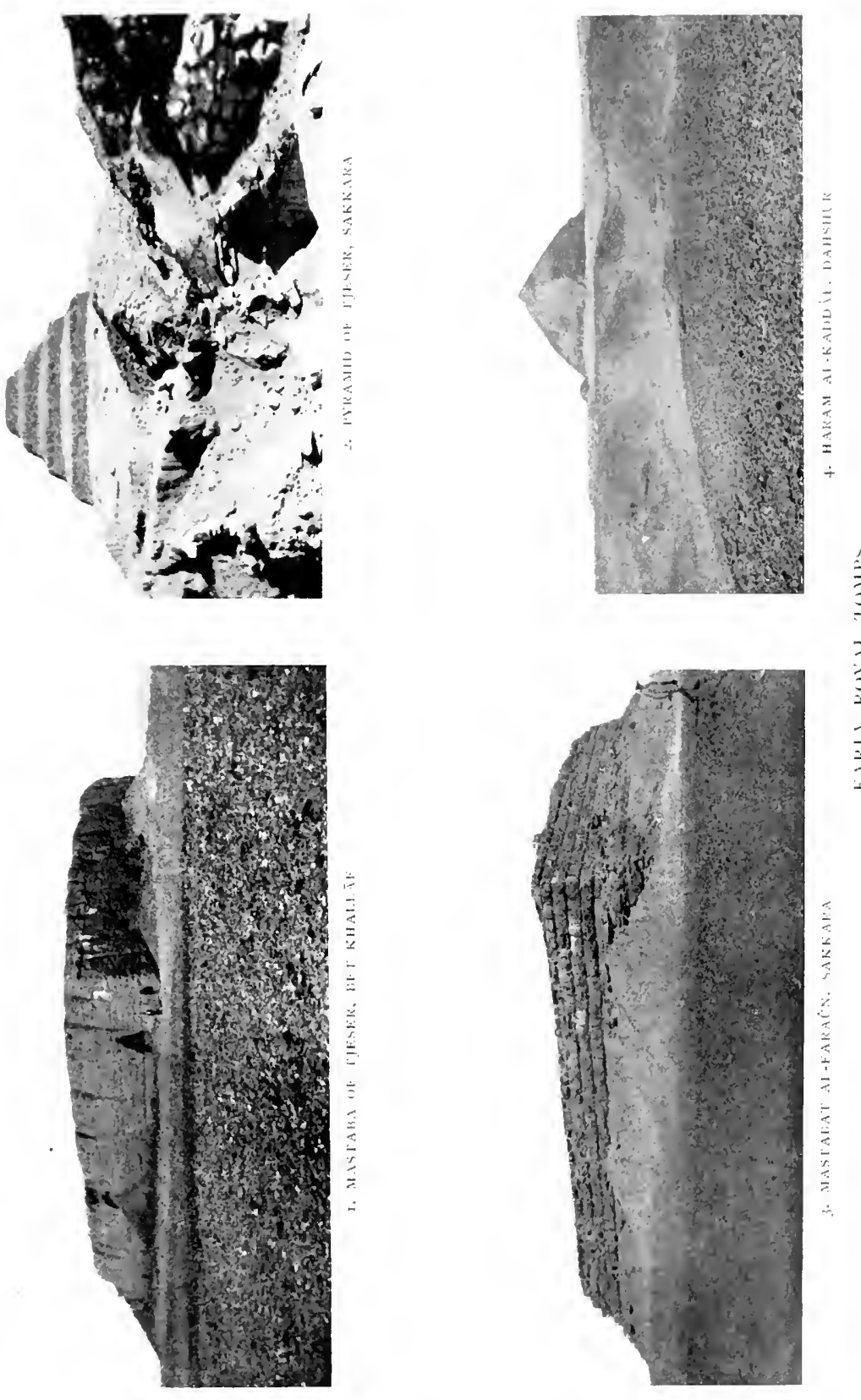

hood of the pyramids of their lords; but the milder manners of a more civilized age probably no longer demanded their enforced departure to the next world in the company of their deccased patrons; when death came to them they were buried as befitted their position in tombs surrounding the tombs of those whom they had faithfully served in life. But while the tombs of the kings were lofty pyramids, those of their nobles were humbler structures, now called, on account of their resemblance to a low bench or seat, mastabas, from the Arabic word mastâba, "bench." These mastabas are on the model of the brick tombs of the earlier period in Upper Egypt, but are built of stone, like the pyramids. Each royal pyramid is surrounded by regular streets of these mastabas, reproducing in death the dwellings of the courtiers round the palace of the king in life.

The pyramids of Seneferu mark a considerable advance in structure on that of Tjeser, but that of Khufu, the "Great Pyramid" of Gîza, marks a greater advance still; in size and mass it is the culminating point of the series. That of Radadf is tiny in comparison; Khafra's rivals Khufu's; Menkaura's is far smaller again. But in art of construction and carefulness of work, Khafra's is superior to Khufu's, and Menkaura's would probably have been the most beautiful of all, only it was never quite completed.

Our wonder at the absolute command of men and material to which the building of the pyramids bears witness, is as nothing to that which is inspired by a contemplation of the grandeur of their design, and, still more, the mathematical accuracy with which not only the design generally, but its details, down to the almost imperceptible junction of the stones in the inner passages and chambers, could be carried out in the fourth millennium B.C. The brain-power which is evinced by the building of the pyramids is in no way inferior to that of the great engineers of the present day. The Egyptians had attained all the essentials of a civilization as fully developed as our own as early as 3000 B.C. ${ }^{1}$

1 The stories told by Herodotus and Diodorus of the building of the Great Pyramid are interesting. The idea of the tunnel from the Nile (HDT. ii. 12) is of course impossible, but the story of the small wooden cranes which lifted the stones from step to step is possible enough, and the Egyptians actually used a prinitive machine of wood for this purpose (CHorsy, L'Art de Batir chez les anciens Egyplicns, pp. Soff.). Diodorus, however, undoubtedly tclls us more correctly the means by which the pyramid was erected, by the use of great inclined 
In art, while relief sculpture had not yet attained the excellence of the next dynasty, and we see crude experiments like the coloured inlay of the tombs of Nefermaat and Atet at Mêdûm, ${ }^{1}$ yet the sculptors of the IVth Dynasty had attained the mastery of sculpture in the round, a mastery which was not reached by the Greeks until after the re-birth of their civilization and the sixth century B.C. ${ }^{2}$ It was to be a limited mastery, and we shall see that the limits that were soon to be set to it were destined never to be passed. ${ }^{3}$ But it was the first great art of the world. ${ }^{4}$ The enthroned diorite statues of Khafra from Gîza, the small standing groups of Menkaura and his queen (Frontispiece), and of Menkaura with the goddesses of the nomes, discovered by Reisner in the king's tomb-temple, and now at Boston and Cairo, the Rahetep and Nefert at Cairo, the "Scribe Accroupi" of the Louvre, the Nenkheftka of the

ramps of earth, $\chi \dot{\omega} \mu a \tau \alpha$ (DIOD. i. 63). The inclined ramp was used by the Egyptians to construct all their large stone buildings; the rest was done by men and ropes, nothing mole, unless we except the Herodotean machines. Herodotus was of course in error in stating that the exteriors of the pyramids were inscribed. The extraordinary story of the completion of Menkaura's pyramid by the courtesan Rhodopis or Doriche, the former slave of Sappho's brother, which Herodotus, followed by Pliny (xxxvi. 3), believed, is considered, by Prof. Piehl (Trans. Soc. Bibl. Arch. xi. pp. 221223) to be due to the red face of the Sphinx, about which the Greeks, according to his theory, assuming as they would that its face was that of a woman, invented a tale that it was a protrait of "Rhodopis." The tale survived for many centuries. Manetho tried to square it with historical facts by supposing that a woman was originally connected with the Third Pyramid, namely, Herodotus's queen Nitokris, because he discovered in the official royal lists two monarchs (at the end of his VIth Dynasty) named Neterkara and Menkara, whom he assumed to be the same person, Ierodotus's Nitokris and the Menkara who built the pyramid. But we know that the real builder of the pyramid was the first Menkara or Menkaura of the IVth Dynasty, and Neterkara and Menkara II were certainly separate persons, and were no donbt kings. The Arab writer Al-Murtadi mentions a story current in his own day to the effect that the pyramids were haunted, and that the spirit of the Third Pyramid was a beautiful naked woman, who appeared to men with a wonderiul smile upon her face, which so infatuated all who saw her, that they immediately followed her and wandered in the desert bereft of their reason. The sphinx (abu'l-hôl, "Father Terror," as the Arabs call it) is of much later date than the pyramids, and is probably to be assigned to the time of Amenembat III (XIIth Dynasty).

1 See Villiers Stuart, Nile Gleanings, pp. 32 ff., and Petrie, Medum (Pl. xvi. ff.), and Meyaum and Memphis (v.). Cf. Brit. Mus. No. 1510, a fragment from the tomb of $\Lambda$ tet.

${ }^{2}$ See pp. $51,5.36$.

${ }^{3} \mathrm{P} . \mathbf{I} 3 \mathrm{I}$.

4 The Babylonian diorite figures of Gudea (Plate XII. 2) are considerably later in date, and were probably inspired by Egyptian influence. The Stele of the Vultures, which more approximates to the date of the Pyramid-builders, is of naive, crude work in comparison with the contemporary masterpieces of sculpture in Egypt (see p. 180). 

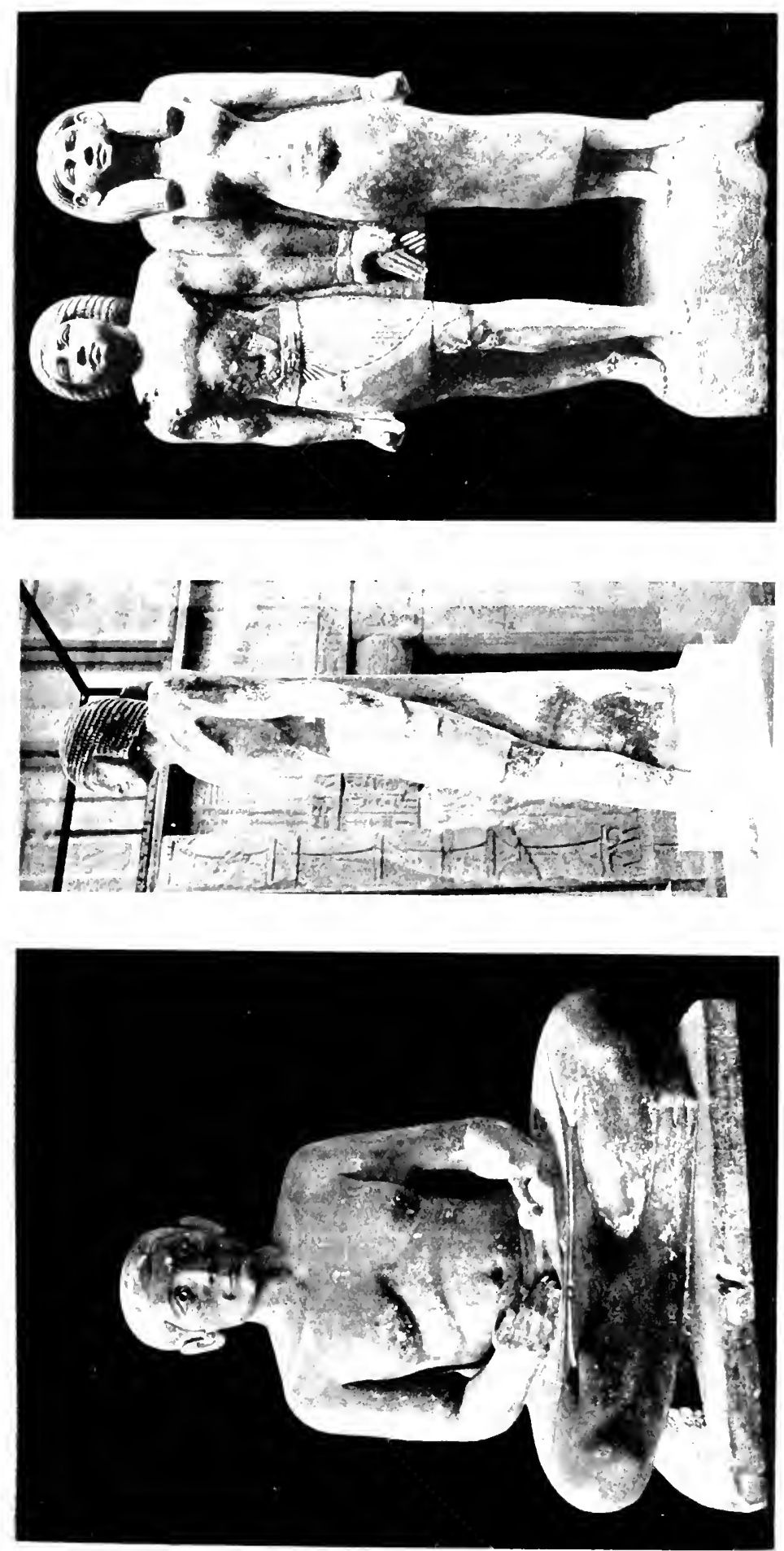

British Museum (Plate IX. I, 2), to name only the works of the very first rank, are (with the exception of that little ivory king of the Ist Dynasty that we have already mentioned), the most ancient masterpieces of all art. ${ }^{1}$ We do not notice coarsely carved legs or wooden arms, when we see those wonderful faces which are the men themselves. The rest of the body is, whether avowedly so or not, a sketch, an impression: it was perhaps not intended to be a faithful transcript as the face was intended to be, and evidently was. Under the next dynasty we find splendid work, and the art of relief-sculpture has now been much developed; but the figures of this time somehow do not please us so well as the freely natural kings and princes of the IVth Dynasty. Statues of this kind were found in most of the chief mastabas of the IVth and VIth Dynasties: they were sealed up in a recess of the tomb, known by the Arabic term serdâb, and were apparently intended as secondary residences for the $k a$ or "double," in case the actual body was destroyed.

The tombs of the members of their courts at Medum and Gîza give us a great deal of information as to the names of the great nobles of the days of the pyramid-builders, and with regard to the various civil offices and priesthoods which they held. ${ }^{2}$ The perusal of a list of these various civil and religious offices shews how far formalism had advanced in Egypt even as early as the days of the IVth Dynasty.

From the inscriptions of these courtiers we gain some hints as to the succession of the kings and their relationship to each other. These hints entirely confirm the testimony of the king-lists ; Manetho's names are correct, but his order and dates seem wrong. Mertitfes, the chief wife of Seneferu, survived him and married his successor, Khufu, who was therefore not nearly related to his predecessor. In fact, he does not seem to have been a native of Memphis, and was probably a prince of Middle Egypt, since an important town near the modern Benihasan, the capital of the nome of the Oryx, was named under the Middle Empire Menat-Khufu, "Nurse of King Khufu": it is probable that he came thence. Queen Mertitfes survived Khufu also, and was "honoured in the presence of King Khafra,"

\footnotetext{
1 Leaving out of account, of course, the art of palaeolithic times (Dordogne and Altanira).

${ }^{2}$ Many of these tombs have been published by LePsi us in the Denkmaeter: others will be found in MARIFTTE's Mastabas. For general references see PETrie, Hist. Es. i., and for translations of certain inscriptions BREASTED'S Ancient Reconls, i.
} 
as she says in her tomb-inscription. She passes over Sharu and Radadf, whose reigns seem to have been very short. Her life was evidently prolonged, but it is quite evident from the fact that she was chief wife of both Seneferu and Khufu, and was an honoured figure at the court of Khafra, that the reigns of these kings can hardly have been as long as the historians pretend. ${ }^{1}$ Diodorus, following Herodotus, makes Khufu reign fifty years and Khafra fifty-six; Manetho assigns them sixtythree and sixty-six years respectively. To Sharu and Radadf can hardly be assigned less than about ten years, so that if we assume that she was far younger than Seneferu, and was perhaps only twenty-five at his death, she must, if Manetho's

1 The chronological list of the kings of the IVth Dynasty, which included the great Pyramid builders, is as follows :-

\begin{tabular}{|c|c|c|c|c|c|c|}
\hline \multirow{2}{*}{$\begin{array}{l}\text { Contemporary } \\
\text { Monuments. }\end{array}$} & \multirow{2}{*}{$\begin{array}{c}\text { XVIIIth- } \\
\text { XIXth } \\
\text { Dynasty } \\
\text { Lists. }\end{array}$} & \multirow{2}{*}{$\begin{array}{l}\text { Manetho. } \\
\text { (order } \\
\text { emended) }\end{array}$} & \multicolumn{4}{|c|}{ Years: Table Total I 57 (?). } \\
\hline & & & Manetho. & Herodotus. & $\begin{array}{c}\text { Turin } \\
\text { Papyrus. }\end{array}$ & Real (?) \\
\hline SHARU & - & $\Sigma \omega \rho t s$ & 29 & 一 & - & $2(?)$ \\
\hline KHUFu . & Khufu & Soupis & 63 & 50 & 23 & 23 (?) \\
\hline RADEDF . & Radedf & 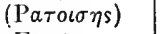 & 25 & 一 & 8 & 8 (?) \\
\hline KHAFRA . & Khafra & Soupis & 66 & $5^{6}$ & (?) & $56(?)$ \\
\hline Menkaura. & Menkaura & $M \epsilon \nu \chi \epsilon \rho \eta s$ & 63 & 6 & (?) & $26(?)$ \\
\hline SHEPSESKAF . & Shepseskaf & $\begin{array}{l}(\Sigma \epsilon \beta \epsilon \rho \chi \epsilon \rho \eta s) \\
(\mathrm{B} \imath \chi \epsilon \rho \iota s)\end{array}$ & $\begin{array}{r}7 \\
22\end{array}$ & - & (?) & $\begin{array}{r}7(?) \\
22(?)\end{array}$ \\
\hline - & - & $\theta \alpha \mu \phi \theta \iota s$ & 9 & - & $\left\{\begin{array}{l}4 \\
2\end{array}\right\}$ & $6(?)$ \\
\hline
\end{tabular}

Manetho's order, as it stands in our authorities, is :-

$$
\begin{aligned}
& \Sigma \omega \rho \text { is } \\
& \text { soupis }
\end{aligned}
$$

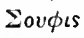

$$
\begin{aligned}
& \text { NI } \epsilon \nu \chi \epsilon \rho \eta s
\end{aligned}
$$

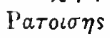

$$
\begin{aligned}
& \mathrm{B} \iota \chi \in \rho \iota s \\
& \Sigma_{\epsilon \beta \epsilon \rho \chi \epsilon \rho \eta \mathrm{s}}
\end{aligned}
$$

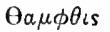

It is evident that his second Souphis is Khafra (Herodotus's Khephren), the builder of the second Pyramid at Gîza, that his Ratoises is Radadf, and that his Seberkheres is Shepseskaf. [I have not inserted the supposed king Khnum-Khufu in the above list, as it has hitherto seemed most probable that he is identical with Khufu. Prof. PETRIE has, however, found evidence (Meydum and Memphis (iii.), p. 43) that he was a separate person. It may be that he is identical with Sharu. The name may mean "the Joined-to Khufu" (i.e. his associate). But cf. BorchandT, Klio, ix. p. 488.] 
figures are correct, have been nearly ninety at Khafra's accession, which is a great age for Egypt, and she lived on after that. Khufu's reign need not have been longer than the twentythree years of the Turin papyrus, and Herodotus' fifty years for Khufu is probably "contaminated" by the (very probable) fifty-six of Khafra.

Khafra is said by Herodotus to have been Khufu's brother, which is manifestly impossible; Diodorus is in doubt between the authority of the great $\pi 0 \lambda v \pi \rho u ́ g \mu w \nu$, which he is afraid to reject, and that of tradition, which told him that Khufu was succeeded by his son Chabryes. Accordingly he doubles Khafra, and speaks of both "Kephren," the brother, and "Chabryes," the son, of Khufu. Chabryes is evidently another Greek form of the name Khafra, and the fact that Khafra was Khufu's son is confirmed by a papyrus. The succession of Menkaura to Khafia is confirmed by the contemporary monument; Diodorus makes him his brother, but this is improbable, if Khafra's reign was as long as the annalists make it. His pyramid was never finished, so that we may credit Diodorus' information that he died before its completion, and Herodotus' implication that his reign was no long one Manetho's sixtythree years for him is, then, evidently a mere copyist's repetition of the same number of years assigned to Khufu. ${ }^{2}$

Menkaura was succeeded by Shepseskaf, "Noble is his Double," the Sebercheres (i.e. Shepseskara, "Noble is the Double (Ghost) of Ra,") of Manetho, the Sasychis of Diodorus, and Asychis of Herodotus. We know nothing of any king corresponding to Bicheris or Thamphthis, who in Manetho's list respectively precede and succeed him. His immediate succession

1 We possess portrait figures of both Khufu and Khafra, which bring the actual personalities of these princes before us. The little ivory figure of Khufu which was discovered by Petrie at Abydos (Abydos, ii. Pll. xiii., xiv.), though worn, shews a strong-jawed face; while the magnificent diorite statues of Khafra, found many years ago at Gîzah by MARIETTE, and so well-known since, shew a more refined and thinking type, though not less energetic, and every inch the king.

2 Interesting portrait statues of Menkaura have recently been discovered in the remains of the gateway of his funerary temple at Gîzah, which has been located and excavated for Harvard University by Dr. Reisner (see Borchardt, in Klio, ix. $48_{3} \mathrm{ff}$. ; xi. $124 \mathrm{ff}$.). The portrait of the king is evidently faithful, representing him with a round visage, somewhat resembling that of the well-known "Sheikh elBeled." Plate I. (Frontispiece) shows a group of the king with his queen, now at Boston, which is one of those found by Reisner. (The type is also shewn in the Brit. Mus. statue of Nenkheftka, from Deshasheh, of the Vth Dynasty (Plate IX.).) 
to Menkaura is made certain by the testimony of his contemporary Shepsesptah, who was admitted among the royal children by Menkaura, married Shepseskaf's daughter Khamaat ("the Goddess of Law appears"), and was raised to fill every office he possibly could fill. It is evident that no man could possibly do all the work which these colossal pluralists were officially credited with doing: the work of most of their offices must have been done by subordinates, but we may be sure that their emoluments went to the noble office-holder.

It is quite evident that the king was, even more than under the Ist Dynasty, the fountain of honour: a despotic monarch surrounded by a servile court to whom he dispensed dignities at his will: the government of the country could be carried out well enough by the stewards and factors of the absentee governors and princes, who were retained in the king's presencechamber in life and were buried at his feet when they died. The common people could be used to build pyramids with. Yet there is a little doubt that the popular stories of the cruelty and impiety of the Pyramid-builders which are related by Herodotus and Diodorus are grossly exaggerated, if not wholly baseless. They seem to have been pious monarchs enough: Khufu and Khafra both contributed to the building of the Temple of Bubastis, and Hordedef, son of Khufu, was, according to old legends, a most pious person, and "discovered" chapters of the Ritual, like King Semti of old.

Khufu, Khafra, and Menkaura must have left a tremendous impression on the minds of the Egyptians, which was always kept alive by the everlasting presence of the three great pyramids on the Libyan hills: when even the meanest Egyptian looked at the mighty Khuit, the lofty Ueret, and the beautiful Hra, ${ }^{1}$ he thought of the three great kings of old whose names his father had told him and which he would repeat to his son, and his son to his son, throughout the generations. The pyramids kept their names fresh in the minds of the people, and folk tales innumerable would naturally gather round them. ${ }^{2}$ The archaistic revival of the XXVIth

1 "The Glorious," "The Great," "The Countenance" ; the Egyptian names of the Great, the Second, and Third Pyramids.

2 We have ancient specimens of these tales in papyri of the New Kingdom, such as the stories of the magician in the Westcar Papyrus, who was brought to Khufu by his son Hordedef (see Petrie, Egyptian Tales, i. Pp. 22 ff.). 
Dynasty, which looked for its inspiration to the models which the tombs of the courtiers of the Pyramid-builders provided, and resuscitated the cults of the kings themselves, must have given a considerable impulse to these popular tales, which Herodotus and Diodorus after him found current in the land in their day, and utilized for their histories.

\section{The Vth Dynasty}

Userkaf-Legend of origin of the Vth Dynasty-The Sun-temple at AbusîApogee of early art and architecture-The Pyramids and temples of Abusîr-Historical reliefs of Sahura-Religious representation-Religious art now stereotypedPyramid of Unas at Sakkarah: the I'yramid texts-The precepts of Ptahhetep and Kagemni-Religion-The VIth Dynasty: Teta

Though we pass out of the presence of the great Pyramidbuilders, we are still in the age of pyramid-building. The civilization of the Vth Dynasty is practically the same as that of the IVth: the face of things is the same. But there is one difference noticeable. Whereas under the older kings Horus had been the supreme deity of Egypt, if supreme deity there was, with the accession of USERKAF, the first king of the Vth Dynasty, the Sun-god $\mathrm{Ra}$ of Annu or Heliopolis, the Biblical On, advances to the first place, which, in conjunction later with the Theban deity Amen, he held ever afterwards, Horus becoming in some aspects identified with him. IVe find the beginnings of this special devotion to Ra already under the IVth Dynasty, when the names of Khafra, Menkaura, and Shepseskaf are compounded with that of Ra, "Shepses-ka-f" meaning "Noble is his (the Sun's) Ghost," as "User-ka-f" means "strong is his Ghost." Names confounded in this way now become common. And in Userkaf's time the royal title "Son of the Sun," which has already appeared under the IVth Dynasty, becomes a regular addition to the royal style. A curious legend current under the Empire relates that a magician named Dedi prophesied to King Khufu that three children should be born to Rud-dedet, the wife of Rauser, a priest of $\mathrm{Ra}$, by $\mathrm{Ra}$, and that the eldest of these, who was to be highpriest of $\mathrm{Ra}$, would succeed to the throne after the reign of Khufu's son. And when the three divinely-begotten children were born, Ra sent the goddesses Isis, Nephthys, Meskhenit who presided over births, and Heket the goddess of sorcery (the original of the Greek Heliate), with the god Khnum who 
forms the bodies and the kas of kings, to Rud-dedet, and they named the children Useref, Sahra, and Kakau. Now the first three kings of the Vth Dynasty, which, as we have seen, was especially devoted to the cult of Ra of Heliopolis, were Userkaf, Sahura, and Kakaa. We can hardly doubt that this legend points to the fact that the kings of the Vth Dynasty belonged to a new family, descended from a priest of the Sun-god: and in all probability Userkaf himself was, as the legend says, originally high-priest of $\mathrm{Ra}$ under the last king of the IVth Dynasty, and succeeded him as king. ${ }^{1}$ Each king of the dynasty built for himself a special sanctuary of the sun-god, the central feature of which was a great single obelisk rising out of a mastaba-like erection, and the priesthoods of these Sun-temples were given to specially honoured nobles. The best preserved of these Sun-temples is that at Abu Gurâb, between Giza and Abusîr, which was built by Ne-user-Ra. On a great mound was erected the truncated obelisk, the stone emblem of the Sun-god. Before it was a great court in which still stands a huge circular altar of alabaster, several feet across, on which slain oxen were offered to the Sun, and behind this are six great basins, also of alabaster, over which the beasts were slain ; drains run out of them to carry away the blood. ${ }^{2}$

${ }^{1}$ Manetho says this dynasty came from Elephantine, a curious statement, which can, however, be explained. The priest Rauser, no doubt the father of Userkaf, is said in the legend to have been priest of $\mathrm{Ra}$ in the town of Sakhebu, probably in the neigh. bourhood of Heliopolis ; Prof. Petrie (Hist. Eg. i. p. 70) has pointed out that this name was probably corrupted in later times to the better known, Abu (Elephantine), and so Manetho's mistake arose. MEYER (Chronologie, p. 148) regards all three as usurpers, of whom only the third, Kakaa, was the founder of a regular royal line. H. BAUER (in Klio, viii. pp. $69 \mathrm{ff}$.) finds that the records of Sahura and Kakaa have been erased on the "Palermo Stone," which was probably erected about the time of Ne-user-Ra (see p. 11). But if Sahura or Kakaa had been objectionable to Ne-user-Ra or his successors, it is hardly likely that their fine pyramid-temples would have been allowed to stand. As a matter of fact the dynasty gives the impression of hanging well together. Its style of building is characteristic, as also is its religion, with its peculiar Sun-temples. We find no break in culture which would be caused by war between usurpers, and the series of royal seals found in the temple of Neferarikara shews that the kings succeeded in as orderly a manner as did those of the XIIth or the XVIIIth Dynasty. I see no reason to doubt the historical character of the main theme of the legend, that Userkaf, Sahura, and Kakaa were brothers who succeeded one another. Kakaa founded the royal line. They were usurpers in the sense that a new dynasty which displaces an old one usurps its place, but we have no proof that they usurped the throne from each other, or succeeded in anything but regular fashion. It is possible that BAUER is mistaken in his conclusion as to a damatio memoriae on the Palermo Stone.

2 Borchardt, Ré-Heiliołum des k. Ne-zoser-Re. 
The great development of art and architecture under the IVth Dynasty was carried to its apogee under the kings of the Vth, who were also Pyramid-builders. Their tombs at Abusir, south of Giza, are neither so large nor so well-built as those of Khufu and Khafra, but the architecture and decoration of the great temples which were attached to them shews a more highly developed art than that of the earlier funerary temples. The Abusîr pyramids are also arranged in a great group of three, the graves of the kings SAHURA, NEFERARIKARA, and NE-USER-RA. The three funerary temples, which have been excavated by German archaeologists, ${ }^{1}$ have provided us with new material which may be said to have in some sort revolutionized our conceptions of the development of art under the Old Kingdom. The sculptures on their walls are the earliest temple-reliefs known, ${ }^{2}$ and it is probable that the custom of decorating the walls of temples, like those of tombs, with sculptured representations of gods and kings and their doings now first began. Important events in the lifetime of the king are now represented on the stone walls of his funerary temple: thus in that of Sahura we have reliefs picturing a naval expedition on the Red Sea, probably sent by him to fetch turquoise from Sinai, where he erected a monumental tablet in the IVadi Magharah. Allegorical representations shew the king, as a hawk-headed sphinx, trampling on his enemies. And as we see them on these ancient monuments the gods appear in their regular hieratic forms and attitudes, and wearing the same costume as in the days of the Ptolemies. This costume of the short waistcloth was that usually worn by the kings and great men of the Old Kingdom. The Vth Dynasty artists depicted the gods dressed like their own contemporary rulers. The proper attire of the gods and of the king when depicted performing religious rites was thus fixed at the time of the Vth Dynasty, and never varied henceforth, though on secular monuments of later times we see the king shewn wearing the actual costume of his period.

In the Abusîr pyramids we as yet find no inscription, but in the pyramid of UNAS, the last king of the dynasty, which was

${ }^{1}$ Borchardt, Grabulenkmal des Königs Ne-user-re'; Klio, viii. I25 ff. (on the temple of Neferarikara); ix. I $24 \mathrm{ff}$. (on the temple of Sahura).

2 The typical Egyptian granite column made in imitation of plant forms, also now first occurs. 


\section{I32 THE ANCIENT HISTORY OF THE NEAR EAST}

built at Sakkara, south of Abusîr, the new custom of inscribing the interior chambers of the tomb itself first appears. These inscriptions, which were copied in the pyramids of the succeeding kings of the VIth Dynasty, consist of a series of invocations and incantations intended to ensure the safety and happiness of the king's spirit in the next world, and, though often savage and absurd enough, are of the highest possible interest to the student of anthropology. ${ }^{1}$

We are yet far from the time when higher minds could supplement the barbarous gibberish of the "Pyramid Texts" by splendid hymns to the gods; the probability is that the primitive beliefs still held unmodified sway. Philosophers had not yet progressed beyond the consideration of the vicissitudes of the daily life around them, and the elaboration of wise saws thereon, they had not yet begun to think about the gods: these were still left without question to the stupid interpretation of the priestly sorcerers. The schools of On had not yet arisen, though it was at this time and under this particular dynasty that the foundations were probably laid at On of that specially Heliopolitan tradition of religious interpretation which was later to develop that "wisdom of the Egyptians" which Moses learnt, and the culminating, the beautiful monotheism of Akhenaten the heretic. ${ }^{2}$

${ }^{1}$ They are the foundation on which the later recensions of the Book of the Dead and the cognate books of funerary spells were based. From them we gain a good idea of the lower and more barbarous side of the Egyptian intelligence, as contrasted with the higher side which produced the Great Pyramids. The spells of the pyramid of Unas, which are typical of the series, are framed so as to enable the dead king, by power of great magic, to compel all beings in the next world to submit to him; even the gods themselves are to bow to his sceptre. This is a most interesting phenomenon, and one very typical of a savage religious belief. The impression of savagery is increased when we find that the dead king is to kill the gods and to fatten upon them; "the old gods shall be thy food in the evering, the young gods shall be thy food in the morning," and we have the weird picture of the dead king boiling the bones of the gods in a cauldron to make his bread. The arrival of the dead ruler is to be the signal for general commotion and fear on the part of the denizens of the other world: " heaven opens and the stars tremble when this Unas cometh forth as a god." The wish was father to the thought; this is the primitive savage simplicity of the pre-dynastic Egyptians surviving in official religion into the time of the Pyramid-builders.

' Such as the precepts of Ptahhetep, who lived in the time of Asesa, the penultimate king of the dynasty. They are preserved in one or two papyri of later date, and a translation of much of Ptahhetep's homely wisdom may be read in BuDGE, Hist. $E_{g}$. ii. pp. $148 \mathrm{ff}$. We may quote the following: (2) "Be not puffed up because of the knowledge that thou hast acquired, and hold converse with the unlettered man as 
From this temple-reliefs at Abusir, and other monuments of this period, as well as from the Pyramid Texts, we see that all the gods of the later pantheon were already worshipped, with the exception of the foreign importations of later days, such as Bes, and of course the Theban Triad, Amen, Mut, and Khensu. The last-named is once mentioned as some sort of inferior djinn in the Pyramid Texts, but Amen is unknown. No doubt he was already worshipped at Thebes, a local form of Min, the presiding deity of the Thebaid, and not to be distinguished from him by the Memphite and Heliopolitan priests. Yet after a few centuries he was to be identified with the great $\mathrm{Ra}$ of Heliopolis himself, and later still to be elevated to the position of "King of the Gods."

According to Manetho, Unas (Onnos) was the last king of the Vth Dynasty, and his successor TETA founded a new dynasty, the VIth, of Memphite origin. ${ }^{1}$ Perhaps by his time the

with the learned, for there is no obstacle to knowledge, and no handicraftsman hath attained to this limit of the knowledge of his art. (5) If thou art in command of a company of men, deal with them after the best manner and in such wise that thou thyself mayest not be reprehended. Law (or justice or right) is great, fixed and unchanging, and it hath not been moved since the time of Osiris. (6) Terrify not men, or God will terrify thee. (7) If thou art among a company of men and women in the abode of a man who is greater than thyself, take whatsoever he giveth thee, making obeisance gratefully. Speak not oftener than he requireth, for one knoweth not what may displease him; speak when he speaketh to thee, and thy words shall be pleasing unto him." This naive aphorismatic literature is characteristic of an intelligent but still simple civilization. We are strongly reminded of the wise sayings of the Havamal, the High Song of "Odin the Old" in the Elder Edda of Sxmund Sigfussen :

\author{
"Do not too frequently \\ Unto the same place \\ Go as a guest; \\ Swect becomes sour \\ When a man often sits \\ At other men's tables. \\ "Never found I so generous, \\ So hospitable a man \\ As to be above taking gifts, \\ Nor one of his money \\ So little regardful \\ But that it vexed him to lend," etc.
}

(LONGrellow's TrANSL.)

1 The chronological list of the Vth and VIth Dynasties is as follows. For the Vth we rely entirely upon Manetho, whose names for the dynasty agree entirely with those given by the Monuments and Lists; for the VIth, Manethu's names and 
Heliopolitan origin of the existing Pharaonic family had become obscured after a long series of reigns in the royal city. From the monuments no change of dynasty can be perceived. Teta's tomb at Sakkara was decorated in the same style as that of Unas with magical texts for the comfort and protection of his soul, and the pyramid itself bears the same style of name as that of his predecessor. The pyramids of his successors are also decorated in the same way.

\section{The VIth Dynasty}

Pepi I-Relations with Nubian tribes-The kinguom of the VIth Dynasty : rise of feudal lords-VIIth and VIIIth Dynasties-IXth Dynasty

The central figure of the VIth Dynasty is the great King Merira PEPI I, the Phiops of Manetho, who left an impression

figures are in general correct, but need some modification. The Turin Papyrus, which is available for these dynasties, seems correct except as regards the reign of Pepi I.

VTH DYNASTY

\begin{tabular}{|c|c|c|c|c|c|}
\hline \multirow{2}{*}{$\begin{array}{l}\text { Contemporary } \\
\text { Monuments. }\end{array}$} & \multirow{2}{*}{$\begin{array}{l}\text { XVIIIth-XIXth } \\
\text { Dynasty Lists. }\end{array}$} & \multirow{2}{*}{ Manetho. } & \multicolumn{3}{|c|}{ Years. } \\
\hline & & & Manetho. & Turin. & Real (?) \\
\hline USERKAF . & Userkaf & 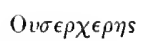 & 28 & 7 & 7 (?) \\
\hline SAHUURA & Sahura & $\Sigma_{\epsilon \phi \rho \eta \bar{s}}$ & I3 & 12 & I 2 (?) \\
\hline $\begin{array}{c}\text { NEFER-ARI-KA-RA } \\
\text { KAKAA }\end{array}$ & $\begin{array}{l}\text { Neferitrikara } \\
\text { Kakaa }\end{array}$ & $\mathrm{N} \epsilon \phi \epsilon \rho \chi \epsilon \rho \eta s$ & 20 & $?$ & IO (?) \\
\hline $\begin{array}{l}\text { NEFER-F-RA } \\
\text { SHEPSESKARA }\end{array}$ & Shepseskara & $\Sigma \iota \sigma \iota \rho \eta s$ & 7 & 7 & 7 (?) \\
\hline . $\quad$. & $\left\{\begin{array}{l}\text { Nefer-f-ra } \\
\text { Kha-nefer-ra }\end{array}\right\}$ & $X \epsilon \rho \eta s$ & 20 & ? & $4(?)$ \\
\hline NE-USER-RA AN. & Ne-user-Ra & 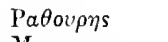 & 44 & $30+$ & $34(?)$ \\
\hline $\begin{array}{l}\text { MENKAUHOR } \\
\text { DAD-KA-RA ASSA. }\end{array}$ & $\begin{array}{l}\text { Menkaubor } \\
\text { Dadkara }\end{array}$ & 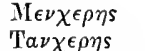 & $\begin{array}{r}9 \\
44\end{array}$ & $\begin{array}{r}S \\
2 S\end{array}$ & $\begin{array}{r}S(?) \\
2 S(?)\end{array}$ \\
\hline UNAS . & Unas & Ovvos (Ouvos) & 33 & 30 & $30(?)$ \\
\hline
\end{tabular}

It is certain that the first five reigns were all short, since, as MFyer (Agyptische Chronologie, p. 150) points out, the priest of Ne-user-Ra's Sun temple at Abusîr was born in the reign of Menkaura, while another dignitary named Sekhemkara was born in the reign of Khafra, and still living in that of Sahura. Therefore we must reject the Manethonian year-numbers for Userkaf and Neferarikara, and accept that of the Turin Papyrus for Userkaf, assigning to Neferarikara ten years at most. Kha-nefer-Ra probably reigned for a much shorter period, as le las left no monuments, so that the whole dynasty probably endured no more than $c$. 140 years, instead of the Mamethonian 2IS. Yet in spite of the inaccuracy of the Manethonian dates, the remarkable agreement of the P'tolemaic anualist with the results of modern research 


\section{on Egypt that was never forgotten. ${ }^{1}$ His younger son, Neferkara PEPI II, born to him late in life, was notable for}

in the case of the names of this dynasty is worthy of special note, and is in itself an answer to those who would regard Manetho as useless. In the names Ouserkheres (Userkan) and Menkheres (Menkauhor) the name of $\mathrm{Ra}$ has been substituted for the termination "his" (as in the case of Sebcrkheres-Shepseskaf of the preceding dynasty), and for the name of the god Horus, who was entirely confounded with

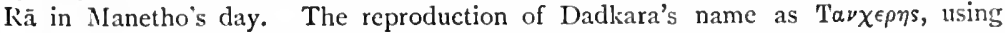
$\nu \chi$ for the consonantal combination $d k$, which would be cacophonous to Greek cars, and impossible for Greek tongues to pronounce, is noticeable.

VITII DyNASTY

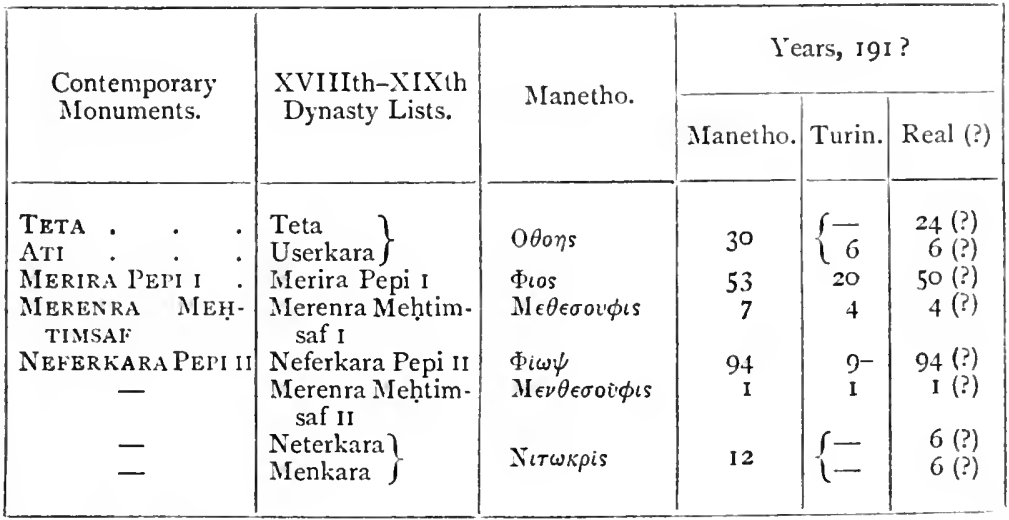

Here Manetho's Othoes is evidently a combination of the names Teta and Ati.

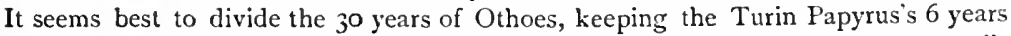
for the less important Ati. The name Userkara of the Lists is evidently Ati's throne-name. Nitokris is a combination of Neterkara and Menkara, apparently, so that her 12 years have been divided between them.

1 As we have monumental evidence of his 49-5oth regnal year (I see no reason, in face of Manetho's 53 years, to suppose that this evidence is as conclusive as does Meyer, Chronologie, p. I7o n. I), assuming that Pepi I was about twenty years of age when he ascended the throne, he probably died at about seventy. He left two sons, one of whom died after a short reign at the age of at most fourteen (as we see from his mummy, now at Cairo, which has the side-lock of boyhood), and was succeeded by his younger brother, aged six. Manetho gives the elder brother a reign of seven years; the Turin Papyrus gives him only four. As Prof. Petrie has pointed out, if Neferkara ascended the throne at the age of six, Merenra cannot have reigned seven years, so that we may accept the four years of the Turin Papyrus as correct. At this rate, Neferkara will have been two years old at the time of his father's death; and his elder brother about ten. So that thesc two sons cannot have been born to him until between the age of forty and fifty at least, probably by a young wife born during his reign. And the name Merira-ankh-nes or Pepiankh-nes, "Merira (resp. Pepi) is her life," which was borne by the two sisters who were the mothers of Merenra and Neferkara respectively, is compounded with his own, and it was a common practice to give children names compounded with that of the monarch reigning at the time of their birth. 
what is probably the longest reign in history, as he ascended the throne at the age of six and died a centenarian.

Traces of the energy of the elder Pepi are seen all over Egypt, from the Delta and Sinai to Elephantine and Sahal. The builder of the great stone temples, forerunners of the triumphs of a later age, which had been begun by the Pyramidbuilders at Tanis and Bubastis, the first monumental evidences of Egyptian activity farther north than the Memphite territory, was pushed on with vigour by Pepi, who also devoted considerable attention to the ancient religious centres of Dendera, Koptos, and Hierakonpolis. At the latter place a magnificent copper group of the king and a small son, perhaps Mehtimsaf, was found by Mr. Quibell in the course of the excavations carried on in 1896 ; the two statues, that of the king being over life-size, that of his son a little more than two feet high, are built up of plates of copper, fastened together with copper nails. The faces are marvellously well modelled, and the inlaid eyes give the two figures an almost uncanny appearance of life. ${ }^{1}$

In the far south the district of the First Cataract, which had apparently been conquered by the kings of the First Dynasty, seems also to have occupied much of Pepi's attention. In his time it had become purely Egyptian, and was administered by Egyptian chiefs who lived and were buried at Aswân. Though related ethnically to the Southern Egyptians, the population south of Elephantine was regarded as barbarian, and the relations between the Egyptians and the Nubians were much the same as those between Europeans and nonEuropeans at the present day. We possess records of the travels of great officials of this period, Uná, ${ }^{2}$ Herkhuf, ${ }^{3}$

'Quibell, Hierakonpolis, ii. Pl. $l$.

${ }^{2}$ Una was a very distinguished official, who not only commanded expeditions in Nubia (and in the north-eastern frontiers as well), but was further entrusted with a inscription is translated in BrEASTED, Anc. Rec. i.

3 Herkhuf was a prince of Aswân, who commanded $34 \mathrm{ff}$.

from one of which he reture of Aswân, who commanded many expeditions to Nubia, appreciated by the boy-kinged with a dwarf, or "deneg," a gift which was so highly traveller enjoining him to keep that he sent a special royal rescript to the returning does not fall into he to keep careful ward over the precious dwarf, and see that he see this Deneg more than anything down the river, "for His Majesty desires to the court, Herkhuf than anything else"; and if he is brought safe and sound to brought back a similar dwe far more honoured than ever was Ba-ur-dad, who recipient of this gracious communication that he caused it to so proud of being the the walls of his tomb in the hill opposite Aswân, where it remains inscribed in full on 
Pepinekht, ${ }^{1}$ and Sabni, ${ }^{2}$ in the southern countries, from which we learn the names of the various Nubian tribes of the day; we see that their territories were regarded as being in some sort included in the Egyptian "sphere of influence," the leaclers of the Egyptian expeditions, sent to bring back products of the southern countries to Egypt, and probably with the ultimate idea of penetrating overland to the "holy land" on the Somali coast (Punt), ${ }^{3}$ were called in to settle tribal disputes as representatives of the higher intelligence of the great civilized empire in the north, much as English travellers of distinction might be called in to advise by an Indian chief to-day. There is even some sort of half-recognition of Egyptian overlordship; but no actual sovereignty is acknowledged.

In the North Egyptian expeditions, which had reached Sinai as early as the time of the Ist Dynasty, are found in Palestine by the time of the Vth, with warlike intent, as in a tomb of that date at Deshasheh we see a picture of an attack upon a Semitic town, ${ }^{4}$ which can only have been situated in Southern Palestine. Under the VIth Dynasty we find the much-travelled Una leading primitive expeditions against the Heriu-Sha, "the Sand-Dwellers" of the Isthmus of Suez and the Gulf coast.

It was a magnificent kingdom which was bequeathed by the first Pepi to his two sons. But, imposing as it was in appearance, it had within it a serious defect which after the reign of the second Pepi brought about swift decay, and eventual disintegration. The great kings of the IVth Dynasty marked the apogee of the original patriarchal kingdom founded by "Mena" and his successors. This kingdom was centralized round the king, whose nobles were courtiers who lived and were buried around him. The local government of the country was carried on by deputies of the ling or of favoured nobles

${ }^{1}$ Pepinekht was a prince of Aswân, who was governor of the Nubian frontier (" Keeper of the Door of the South") under Merenra.

2 Sabni, son of Mekhu, another prince of Aswân, went to Nubia to recover the body of his father, who had been killed there, and brought it back safely. For this deed he was summoned to Memphis, and received great gifts and commendation from the king (Breasted, Anc. Rec. i. pp. $16_{4} \mathrm{ff}$.).

${ }^{3}$ The Hammamat-Red Sea route was also user, and in the reign of Pepi II. an emissary named Enenkhet was murdered on the coast (near lịuṣ̂r) by the desert tribes while he was building ships for the Punt voyage (inscription of Pepinekht: Breasten, Anc. Kec. p. 163).

"Petrie, Deshasheh, Pl. iv. 


\section{8 'THE ANCIENT HISTORY OF 'THE NEAR EAS'I}

who held their lands at the king's pleasure. These deputies were probably not hereditary. From the very beginning Egypt had been divided into hsaput, called by the Greeks "nomes"; we find these nomes already under the Ist Dynasty, and in the South they were probably older. In such a country as Egypt, where the yearly inundation obliterates all landmarks every year, fixed boundaries were very early established. The nomes were ruled by the overseers of absentee courtiers. But the accession of the new' line of the Vth Dynasty seems to have weakened the royal hold over the court. Up to the end of the reign of $\mathrm{Ne}$-user-Ra, who, judging from the magnificence of his works, was a powerful monarch, the centralizing tradition was no doubt more or less kept going, but during the reigns of his weaker successors it must have been given up. We now find a new development. The great nobles, instead of being buried as a dead court around a dead king, are interred in their country estates, which they now rule directly and locally. They are primarily the "Great Men of the Nomes," and their court functions and titles diminish. Under the VIth Dynasty this becomes the settled constitution of the state, which is now a feudal monarchy, resting on the loyalty of the local princes. Under a strong prince like Pepi I, who would make himself obeyed, this condition of affairs was not detrimental to the state, but under weak kings it meant its destruction. This happened : the successors of Pepi II, whose reign was probably a long and a weak one, were nonentities; ${ }^{1}$ the chiefs, having no king whom they could respect, fell to fighting among themselves, and Egypt became a chaos. ${ }^{2}$ Art and civilization degenerated woefully, and the Theban kings of the XIth Dynasty, who, after perhaps two centuries of confusion, eventually restored order, had to re-create both.

A series of shadowy kings, the VIIth and VIIIth Dynasties of Manetho, reigned but did not rule at Memphis.

${ }^{1}$ For Neterkara $($ Nutekri $)$ and Menkara, whose names are responsible for the confusion of Herodotus' Nitokris with the "Woman of the Pyramid" of Menkaura, see p. I 24, n.

2 The recent discoveries of Ad. Reinach and Weill at Koptos have shewn that already in the reign of Pepi II royal grants of immunities to temples in Upper Egypt contained clauses denouncing possible (and evidently expected) attempts on the part of the magnates to override the royal wishes: the princes are spoken of as if it were usual for them to be hostile to the will of the hing (Weill, Dicrets Royaux de l'Ancien Empire (Paris, 1912), p. 57). 
Two of them, Neferkauhor and Neferarikara II, more energetic than the rest, made their authority recognized at Abydos and even as far south as Koptos, ${ }^{1}$ but only for a moment. The princes levied war upon one another without check; nome fought against nome, until at length some chief more energetic and unscrupulous than the rest should find himself able to impose his yoke upon his neighbours and so give peace, perhaps only an ephemeral peace, to at least a portion of the distracted land.

Some such powerful chief fixed the seat of his power, about two centuries and more after the time of the Pepis, in the city of Henen-nsuit or Henen-su, Herakleopolis Magna in Middle Egypt, ${ }^{2}$ and either he or one of his descendants found himself powerful enough to usurp the dignity of the legitimate sovereign at Memphis, and to proclaim himself Pharaoh. It is probable that after this impotent kings of the rightful line still reigned at Memphis, but the centre of real power was Herakleopolis.

\section{The Herakleopolites (IXth Dynasty)}

\section{Akhthoës-Rise of Thebes-Inscriptions of Siût}

Only one of the Herakleopolite kings ${ }^{3}$ has left any very tangible evidence of his presence, and he was possibly the most active of them; perhaps the very man who first supplanted the Memphites and assumed the royal dignity. This was Khati or Ekhati, who bore the throne name MERIABra, "Beloved of the Heart of the Sun." The name of the king occurs as far south as the First Cataract, so that it is evident that he securely controlled the whole Upper Country, as well as upon smaller objects. There is little doubt that this king or a second Khati with the throne name UAHKARA ${ }^{4}$ is identical with the Akhthoes ${ }^{5}$ of Manetho, who places him at the be-

1 We know this from the excavations of Petrie in I902 and of Ad. Reinach and Weill in $\mathbf{1 9 1 0 .}$

2 The Assyrians in later days knew this city as Khininsu; the Copts corrupted the name to Hnes, which is the origin of the modern name Ahnas or Henassia. The Greeks called it Herakleopolis the Great, to distinguish it from another town of the same name.

3 They called themselves by the unusual title "Servant of Hershef," the local god of Herakleopolis (DAREssy, Annales, 1911, p. 47). A title of this form, though usual in Babylonia, was unknown in Egypt, where the king was the "son," not the "servant" of a deity.

+ Lacau, Rec. Traź. xxiv. p. 90.

${ }^{5}$ Vocalizing Khati or Ekhati as * Ekhioi. 
ginning of the IXth Dynasty, and says that he became more terrible than all those who had gone before him, that he did evil unto the people in all Egypt, and that he finally went mad and was devoured by a crocodile. This story has the same ring as others about other kings who left a powerful impression, whether of good or evil, behind them; Menes was devoured by a crocodile, Cheops and Chephren were impious oppressors. ${ }^{1}$

The Herakleopolite rule was at first peacefully acquiesced in by the more southerly nomes, ${ }^{2}$ but later on it was opposed, especially by the princes of the Thebaid, whose original seat seems to have been Erment (Hermonthis), but whose power was early transferred to the more northerly Apet (Thebes). Here was laid the foundation of the future Theban hegemony in Egypt, which was to last undisputed for over fifteen hundred years. Gradually the chiefs of Apet increased in power, the boundary of their territory was gradually pushed northwards beyond Koptos, until it marched with the southern frontier of the land which owed more direct allegiance to Herakleopolis. Then the Herakleopolite allegiance was thrown off, and a series of bloody wars seems to have begun, in the course of which the Theban princes did as the Herakleopolites had done before them, and themselves assumed the Pharaonic dignity. Finally, the Herakleopolite power was overthrown. Memphis had long been a nome, and her kings, the rightful seed of $\mathrm{Ra}$, had disappeared. Egypt, weary of war, accepted the Theban sceptre, and a new period of Egyptian history began, which we know as the "Middle Kingdom," to distinguish it from the "Old Kingdom" of Thinis and Memphis, and from the "New Empire" which commenced after the expulsion of the Hyksos invaders.

We know of the civil war between Herakleopolis and

I Prof. Petrie's identification of him with "Khouthēr Taurus the Tyrant," of whom Eratosthenes speaks, is very probably correct. It is also quite possible that Eratosthenes' Mevrēs $\rightarrow$ whom Prof. Petrie would identify with a king Maa-ab-Ra, who, however, in all probability does not belong to this period at all, -is in reality a double of the same king; the throne-name Meriabra (pronounced in Ptolemaic days Meivrî ?) having been erroneously taken to be the name of another monarch.

2 From a decree found at Koptos (Weill, loc. cit. pp. 59 ff.), we see that a king named UATJKARA, who was probably (judging by the form of his names) a Herakleopolite, peacefully ruled the south and issued a decree regulating the religious affairs of Alydos like his preclecessors of the VIth Dynasty. 
Thebes chiefly from the inscriptions in the tombs of the princes of the important city of Siut, in Middle Egypt, who were adherents of Herakleopolis, and formed the frontier defence of the Herakleopolite kings against the Thebans. They bore the names of Khati and Tefaba alternately from father to son. The first Khati prided himself on not being a rebel: "I," he says, "am one void of rebellion against his lord: Siût is content under my rule, Herakleopolis praiseth God for me, the Nomes of the South and the Lands of the North say, 'Lo! whatsoever the prince commandeth, that is the command of Horus (the king)." It would seem that in his time the South was submissive, but Tefaba his son was compelled to reconquer the South. ${ }^{1}$

In the time of Khati II, son of Tefaba, the Herakleopolite king Merikara was driven from his capital by a Northern attack from Memphis, and took refuge at Siût with his feudatory, who also fought with the South. The later chiefs of Siut were unable to maintain their resistance to Thebes: the princes of the hated "Town of the South," which is angrily mentioned in one of these inscriptions, eventually broke through the barrier which had so long stopped their way northwards, and it is probable that after the fall of Siut the fate of the Herakleopolite dynasty was not long delayed. We do not know the name of the prince of Thebes who took Siut and finally destroyed the Herakleopolite power. The most ancient Theban chief of whom we have any knowledge is a certain Meri, who apparently lived not long after the time of the Pepis: two statues of him, in different costumes, from his tomb at Dra' Abu'l-Nelika, are preserved in the British Museum. In his day Thebes was no doubt under the rule of the Mentu-

1 "The first time," he says, "that the soldiers fought with the Nomes of the South, who had come together, on the south as far as Elephantine, on the north as far as Gau; [I beat these nomes, I ravaged them] to the frontier of the South. I surrounded the West: when I came to a city, I overthrew [its walls, I seized its chief, I sent him] immediately to the prison of the Fort of the South; he gave me territory, but I did not give (him) his town. [I conquered the West Bank; I did not leave] one whose heart was still in him. I attained the East Bank, ascending the stream to another (chief) like a hound who ranges afar; [and when I had separated one chief] from another, one soldier from his company, I advanced against him instantly: he did not defend himself [against me, he did not] rush to battle like the chosen troops of the nome of Siût. I went up-stream (?) like a bull going forth [to combat, and the men of the South fell before] my bow." (From the Egyptian text in GriffirH, Sint and Dír Kifch, Pl. xi. 1l. 16-22.) 
worshipping princes of Erment, who later on transferred their residence to the more northern city. An hereditary nomarch of Thebes, belonging apparently to the line of Erment, is known to us, named Antefi. He seems to have been regarded as the founder of the Theban race of kings, for Senusert I dedicated a statue of him at Karnak, and it is very probable that he was either the first Theban chief of his line or the first to establish a southern principality independent of Herakleopolis. One of his descendants, possibly his immediate successor, assumed the Pharaonic dignity and became the first king of the XIth Dynasty, but whether this was before or after the capture of Siût and destruction of the Herakleopolite dynasty, it is difficult to say.

\section{The XIth Dynasty}

Antefi I and the Mentuheteps-Hor Uahankh-Reign of Neb-hapet-Ra-The temple at Dêr el-Bahri-Art of the XIth Dynasty: Mertisen-Wars of Neb-hapet-Ra -Sankhkara-Expedition to Punt

After Antefi I the only kings of the XIth Dynasty who were remembered in later days were the powerful monarch Nebhapet-Ra Mentuhetep and his successor Sankhkara Mentuhetep, who immediately preceded Amenemhat I, the founder of the XIIth Dynasty. An earlier king, Neb-taui-Ra Mentuhetep, also appears in the lists; he must have preceded Neb-hapet-Ra. From contemporary monuments, however, we know of the existence of a group of three still earlier kings, an Antef " the great" who bore the Horus-name of Uah-ankh, another Antef with the Horus-name Nekhtnebtepnefer, and a Mentuhetep with the Horus-name Sankhabtaui, who succeeded in this order. It is probable that the "Horus Ancestor" (tep- $a$ ) Mentuhetep, and another Antef, mentioned in the inaccurate Karnak list, are to be identified with two of these kings. We know nothing of them, or of one or two kings who ruled in Nubia at this time, and may or may not have been members of the Theban dynasty. Nor is Neb-taui-Ra much more than a shadowy figure. Like the later Egyptians, we know more than a little only of the reigns of Neb-hapet-Ra and Sankhkara. ${ }^{1}$ Nebhepet-Ra was in later times regarded as one of the great

${ }^{1}$ The exact order of success: on of the kings of the XIth Dynasty is still a matter of

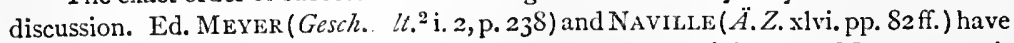
lately proposed schemes, neither of which seem to me very satisfactory. My own contri- 
pharaols, and he appears almost as the progenitor of the royal line of Thebes. Like Uall-ankh, the real founder of the dynasty, he reigned long, and it is probable that the two kings were confused in later tradition. It is by no means improbable that Neb-hapet-Ra was the first Theban who really ruled over the whole country. It is significant that Uah-ankh and his two successors bore no throne-name, as rightful pharaohs would

bution to the matter is simply the suggestion, which I nake here, that the Neb-hapet-Ra whose name was formerly read "Neb-kher-Ra," and the new Neb-hapet-Ra of the Dêr el-Bahri temple, are really one and the same person (see next page). BREASTED's arrangement in MEyer, Chronologie, pp. $156 \mathrm{ff}$., must be modified owing to the discovery of the stele of Teti and Ka-ur-Antef, both now in the British Museum, which give the succession of Uah-ankh, Nekhtnebtepnefer, and Sankbhabtaui : the last king was first known from the stela of Ka-ur-Antef (published by BuDGe, Guide to the Egyptian Collections (Brit. Mus.), Pl. xxii.; SCOTT-MONCRIEFF, Hieroglyphic Texts from Stele, etc., in the British Mutseum, Pl. 53; see also Naville, XIth Dynasty Temple at Deir el-Bahari, i. pp. 3, 7. The stela of Teti was published by Breasted and Pier, Am. Joum. Sem. Lang. xxi. p. 159, and Scott-Moncrieff, loc. cit. Pll. 49, 50: translations in BREASTED, Ancient Records, i. pp. 201 ff.). Prof. Breasted's second arrangement (Anc. Rec. i. p. 197) suffered from his retention of the king "Neb-hetep" Mentuhetep, who is now known never to have existed : his name is a mis-reading of that of the new Neb-hapet-Ra from Dêr el-Bahri (Naville, loc. cit. pp. 3, 7). On my view the monuments of "Neb-hetep" at Gebelên mentioned by Breasted really belong to the monarch whom he calls "Nibkhruri," the Neb-kher-Ra of our knowledge before the discovery of the Dêr el-Bahri temple, which has shown us that the name $\odot$ is to be read Neb-hapet-Ra, like that of $\odot$. The kings Ka-ka-Ra Sa-Ra An [tef], and Hor Gereg-tauicf . . khent-

$\mathrm{Ra}$, whose names have been discovered in Nubia (BREASTED, Temples of Lower Nubia, p. 57 ; Weigall, Report on the Monuments of Lower Nubia, Pll. xlix., l., lxiv., lxv.) are assigned by Prof. Meyer to this dynasty ( $A . Z$. xliv. p. I I5); but it seems to me more probable that they were simply local Nubian chiefs, contemporary with this dynasty, who adopted Egyptian royal names and titles. We cannot admit many kings in the XIth dynasty, which lasted in all not more then 160 years : the grandfather of an Egyptian official who lived in the reign of Senusert I., the second king of the XIIth Dynasty, was born in that of Uah-ankh, the first of the XIth (BREASTED, in MEYER, Chronologie, p. 160). The reigns both of Uah-ankh and Neb-hapet-Ra were long, and we have hardly room for more than six kings in all. This is precisely the number given for the dynasty by the Turin Papyrus, with the sum of I $60 \mathrm{xx}$ years. Manetho, as we have him, has " 16 kings in 43 years," obviously in the original " 6 kings in 143 years." Wve may then assume 6 kings in about 150 years to be a fair account of the dynasty. The six kings will be (omitting the nomarch Antefi, who was never king) : 1. Hor Uah-ankh Antef-aa; 2. Hor Nekhtnebtepnefer Antef; 3. Hor Sankhabtaui Mentuhetep; 4. Neb-taui-Ra Mentuhetep; 5. Neb-hapet-Ra Mentuhetep; 6. Sankhkara Mentuhetep. There is a possibility that Sankhabtaui and Neb-taui-Ra may be the same person, the former being the Horus-name, the latter the throne-name, of the same king Mentuhetep. This would reduce the number of known kings to five. 
but seem to have laid stress upon their Horus-names, which were the appropriate designations of kings who ruled the patrimony of Horus of Edfu, Upper Egypt alone, since originally, as we have seen, the Horus-name was the sacred designation of the Upper Egyptian Kings who founded the Ist Dynasty. Neb-taui-Ra was the first to adopt a thronename, and he included it in his cartouche with his personal name, thus having only one cartouche. Neb-hapet-Ra was the first to bear two cartouches as undisputed king of all Egypt. He may have deposed the last Memphite, as it is probable that the Memphite kings had continued to reign in the North after the end of the Herakleopolite dynasty. He seems to have altered the official spelling of his throne-name and have changed his Horus-name during his reign; appearing first as the Horus "Neter-hetjet" ("Divine White Crown," the crown of Upper Egypt), later as the Horus "Sam-taui" ("Uniting the Two Lands"). ${ }^{1}$ It may well be that this change of name is significant, and that the later Horus-name was adopted to mark the re-union of the two lands, just as, in far earlier days, Khasekhem seems to have changed his name to Khasekhemui ("Appearance of the Two Powers") after he had conquered the North.

Of the details of Neb-hapet-Ra's re-organization we know nothing, but it is probable that even towards the end of his reign a subordinate king, who bore the title of "Son of the Sun," was allowed to exist in Upper Egypt above Thebes. His name was Antef, and it is probable that he is one of the kings whose names are found in Nubia.

Of this important reign an important monument has come down to us, the funerary temple of the king at Dêr el-Bahri, in the western necropolis opposite Thebes (Plate X. I, 2). ${ }^{2}$ Here, in a circus of huge cliffs of extraordinarily impressive

${ }^{1}$ For this view, which does away with the necessity of supposing the existence of two kings named Neb-hapet-Ra, I am alone responsible: my view is not shared by M. Naville. The kings $\odot 5$ and $\odot$ will then be identical : Neb-hapet-Ra changed the spelling of his name and took a new Horus-name. Such changes had occurred before (MöLlek, $\ddot{A} . Z$. xliv. p. I29).

2 Discovered in December 1903, and excavated for the Egypt Exploration Fund. The publication (Naville, Hali, and Ayrton, The XIth Dynasty Temple at Deir el-Bahari) is still in progress: vol. i. 1907 ; vol. ii. 1910; vol. iii. 1912. See also IALL, P.S.B.A., June 1905; Journal of the Society of Arts, iii. pp. 79I ff.; and Man, 1904, 43; 1905, 66; Navilie and Mali., Man, 1906, 64; NAtitle, Man, 1907, 102. 
form and splendid desert colour, Neb-hapet-Ra excavated what is either his tomb or his cenotaph, a long gallery extending far beneath the mountain, and ending in a chamber faced with gigantic blocks of granite and containing a naos or shrine of alabaster and granite, which held either his coffin or the statue of his $k a$. Above the tomb was cut a great trench in which was a temple with its sanctuary, and on a half-artificial platform jutting out towards the cultivated land was, later in his reign, erected a memorial pyramid of brick cased with thin marble slabs, surrounded by a colonnade and approached by a sloping ramp, on either side of which at the lower level was a colonnade marking the face of the platform, which was faced on the other two sides with splendid walls of fine limestone. Everywhere the walls were sculptured with scenes of the king's wars and hunting-expeditions, which, since they are now in a fragmentary condition, have told us less concerning the events of his reign than the development of art in his time: on this they have shed new and valuable light. Between the pyramid and the tomb were erected six small funerary shrines above the tombs of certain priestesses of Hathor, the goddess of the place, who were also concubines of the king, and that of the queen, Aasheit. It seems very probable that these priestesses were all slain at the death of the king, and accompanied him to the tomb to be with him in the next world. In the time of the Ist Dynasty, courtiers and slaves seem to have been killed, as we have seen, and buried with the kings: and the custom was at least occasionally carried out as late as the time of Amenhetep II.

The development of art under the XIth Dynasty, on which the sculptures of this temple have shed considerable light, is perhaps the most interesting characteristic of the dynasty. The fine Memphite art of the Vth and VIth Dynasties had bcen not unsuccessfully imitated in Upper Egypt, but civil war had caused a woeful degeneration in the arts, and the Theban sculptors' work of the beginning of the XIth Dynasty is extraordinarily crude and barbarous: ${ }^{1}$ modelled relief has been forgotten, and both figures and hieroglyphs are badly sized, spaced, and drawn. But an enormous improvement is seen at the beginning of the reign of Neb-hapet-Ra, to which the shrines of the priestesses, which were completed before the temple as a whole, belong. A remarkably high relief, adorned with brilliant

${ }^{1} \mathrm{Cf}$. the stela of Ka.ur-Antef in the British Museum (No. 1203). 
colour, is characteristic of these shrines. ${ }^{1}$ The figures have still an awkward, archaic appearance, however, and this hardly vanishes in the later style of the reign, seen in the decoration of the temple-corridors, which otherwise again approaches the standard of the Vth Dynasty. The portraits of the king and his queen are splendidly executed, and bear the same impress of truth as do those of the IVth and XIIth Dynasties. ${ }^{2}$

These sculptures have a personal interest usually lacking in the worlss of Egyptian art, since we probably know the name of the great artist who carried them out. This was very probably a certain Mertisen, who lived in the reign of Neb-hapet-Ra. $\mathrm{He}$ tells us on his funerary stela, now in the Louvre, "I was an artist skilled in my art. I knew my art, how to represent the forms of going forth and returning, so that each limb may be in its proper place. I knew how the figure of a man should walk and the carriage of a woman; the poising of the arm to bring the hippopotamus low, the going of the runner." $\mathrm{He}$ also tells us that no man shared this knowledge with him but his eldest son. Now since Mertisen and his son were the chief artists of their day, it is more than probable that they were employed to decorate their king's funerary temple.

When, therefore, the kings of the XIth Dynasty reunited the whole land under one sceptre, and the long reign of Nebhapet-Ra Mentuhetep enabled the reconsolidation of the realm to be carried out by one hand, art began to revive; and just as to Neb-hapet-Ra must be attributed the renascence of the Egyptian state under the hegemony of Thebes, so must the revival of art under the XIth Dynasty be attributed to the Theban artists of his time, perhaps to Mertisen and his son. They carried out in the realm of art what their king had carried out in the political realm. ${ }^{3}$

Neb-hapet-Ra was a warrior and warred against Libyans, Nubian, and Semites, the latter being called "Aamu" and (possibly) "Rutenreru," 4 later on to become familiar to the Egyptians as the people of Ruten, or Syria. So that he may have invaded Southern Palestine.

${ }^{1}$ Navilie, Deir el-Bahari, XIth Dyn. ii. Pll. xi. ff.

2 Ibid. i. Pl. xii.

${ }^{3}$ Hall, Deir el-Bahari, XIth Dyn. i. pp. 39-42.

"Sic and not "Rutenu," in the inscription (Deir el-Bahari, XIth Dyn. i. Pl. xv. F.), the meaning of which is, however, doubtful. 

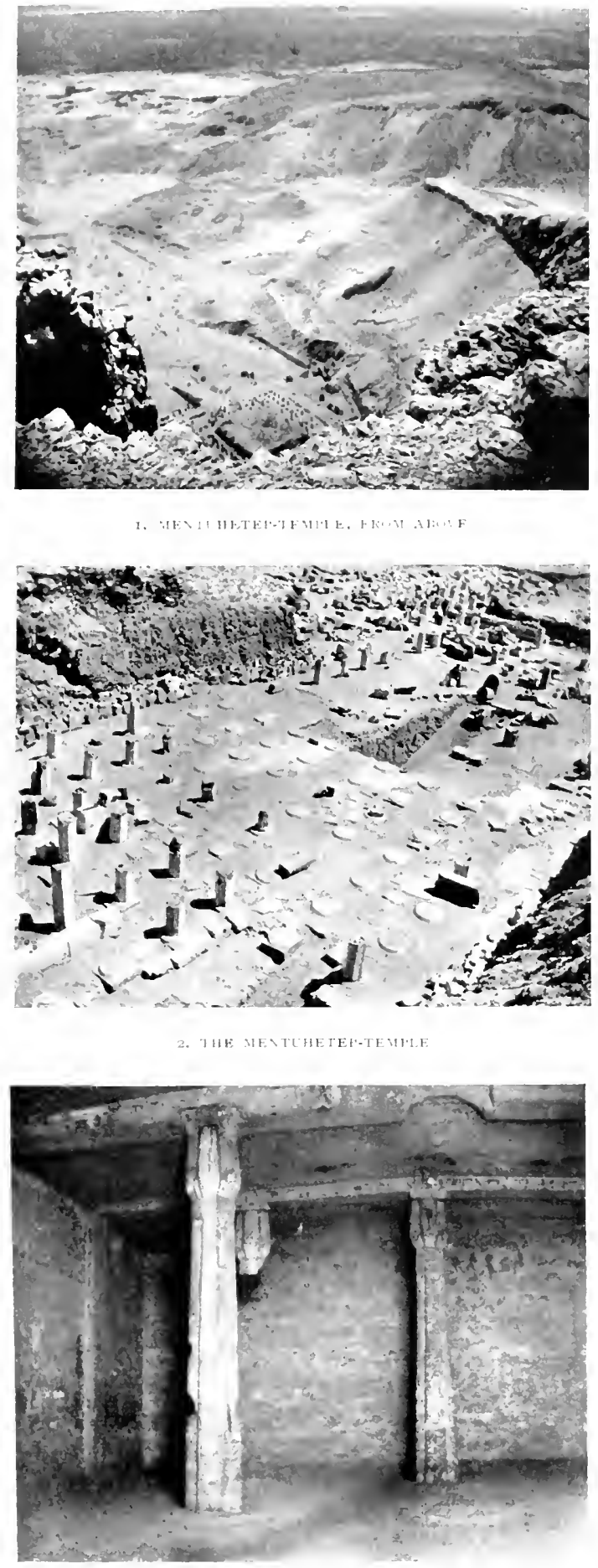

Sankhkara Mentuhetep was no such yraat ligure as his predecessor. His reign was solely distinguished by a great expedition to the Land of Punt, conducted by a military mandarin of the name of Henu. ${ }^{1}$ Henu proceeded by the Hammamat road to the Red Sea coast at Kuṣer, and then, after great sacrifices had been held, proceeded on shipboard and sailed down the coast to Somaliland, returning eventually in safety to Koptos, whence he had set out, laden with the incense, gum, and myrrh which he had been sent to obtain, and with stone which had been quarried for the king in the Hammamat valley. The tradition of connection with Punt is kept up, and we seem to be reading an account of an expedition of the Vth or VIth Dynasty once more: indeed it is improbable that much more than two or three hundred years had elapsed since Baurdad went to Punt, and Una and Herkhuf explored the regions of the Upper Nile. ${ }^{2}$ But there is one point which differentiates Henu's expedition from these of the earlier time. The older explorers often seem to have travelled overland from the Nubian Nile valley by way of Abyssinia to Punt; Henu, like Enenkhet before him, ${ }^{3}$ went to Kuṣer, and thence by sea. It looks as if the overland route was no longer safe for Egyptian caravans ; and the southern military expedition of Mentuhetep II indicates that the peaceful relations of Egypt with her southern neighbours in the days of Asesa had given way to a state of war and unrest, which compelled the Egyptian messengers to Punt to voyage thither by sea. Henceforward, even when Nubia was absolutely subject to Egypt, the sea-route remained the regular way to Punt, and Hatshepsut's great expeditions followed in the steps of that of Sankhkara.

\section{The XIIt/ Dynasty}

"The kings of the court of Itht-taui "-Amenemhat I: his "Instructions"Energy of the kings and renewed prosperity of the land-The local princes-Their power curtailed by the later kings of the dynasty

The XIIth Dynasty, "the Kings of the Court of Itht-taui," as the Turin Papyrus calls them, succeeded the XIth without a break. It is very probable that Amenemliat I, the first ling of the new dynasty, was the vizier of Sankhkara, and from

\footnotetext{
${ }^{1}$ For the inscription of Henu see Breasten, Anc. Rec. i. pp. $208 \mathrm{ff}$.

2 See p. 136.

${ }^{3}$ See p. 137, n. 3 .
} 


\section{THE ANCIENT HISTORY OF THE NEAR EAST}

his name ("Amen at the head") we may suppose that he was a Theban. His descendants, however, specially favoured the district between Memphis and the modem Fayyûm, and there they established their court, in the fortress-palace of Itht-taui, the "Controller of the Two Lands." They were, however, nominally Thebans, and they venerated Amen as well as Sebek, the crocodile-god of the Fayyûm.

We are thoroughly well-informed as to the course of Egyptian history under the XIIth Dynasty. The names of the kings, as given by Manetho and by the older Egyptians themselves, with their regnal years, as far as they have been ascertained, are given below. The names on the XIth Dynasty lists agree perfectly with those recorded on the contemporary monuments of the dynasty.

\begin{tabular}{|c|c|c|c|}
\hline \multirow{2}{*}{ Manetho, etc. } & \multicolumn{2}{|c|}{ Lists and Monuments. } & \multirow{2}{*}{$\begin{array}{l}\text { Yeais of Reigns } \\
\text { approximately. }\end{array}$} \\
\hline & Personal Name. & Throne Name. & \\
\hline Ammenemēs & Amenemhat I & Sehetep-ab-Ra & $\begin{array}{l}30 \text { (Io years co-regency } \\
\text { with Semusert 1). }\end{array}$ \\
\hline $\begin{array}{l}\text { Sesonkhōsis (sic; read } \\
\text { Sesōstris) }\end{array}$ & & Kheper-ka-Ra & $\begin{array}{l}35 \text { (3 years co-regency } \\
\text { with Amenemhat II). }\end{array}$ \\
\hline Ammanemés . & Amenembat il & Nub-kau-Ra & $\begin{array}{l}35 \text { ( } 5 \text { years co-regency } \\
\text { with Senusert II). }\end{array}$ \\
\hline Sesōstris . & Senusert in & Kha-kheper-Ra & $\begin{array}{l}2 S \text { (?) (8 (?) years co- } \\
\text { regency with Senu- } \\
\text { sert III). }\end{array}$ \\
\hline $\begin{array}{c}\text { Lakharēs (sic: read } \\
\text { Khakharés) }\end{array}$ & Senusert III & Kha-kau-Ra & 30 \\
\hline Ammerès (Lamaris) . & Amenemhat III & Ne-maat-Ra & 45 \\
\hline Ammenemēs . & Amenemhat IV & Maa-kheru-Ra & 9 \\
\hline Skemiophris . . & - & Sebek-neferu-Ra & 4 \\
\hline
\end{tabular}

The total number of years thus indicated for the XIth Dynasty is 216 , which is in practical agreement with the 213 of the Turin Papyrus. It must be remembered that the years of the kings as given above are approximate; but they are certainly correct within five years either way. ${ }^{1}$

I In every case the years of co-regency with a predecessor are subtracted from the total number of years in order to obtain the correct chronology; but the Egyptians themselves reckoned the years of a king from the beginning of his co-regency to his death, although the reigns of his father and son, if associated with him in the kingdon, may have overlapped his very consilerably. Nanetho forgot the necessity of this process of subtraction, and added up the official years of the reign of each king in order to make up his sum total for the dynasty, with the result that his figure is in 
Amenemhat's accession was not accepted without a struggle. We know from a very curious papyrus book, regarded as a classic under the XVIIlth and XIXth Dynasties, which was apparently written by King Amenemhat I, the Sbaynt or "Instructions" of the king to his son Senusert, that upon one occasion at least his life was attempted by conspirators within the palace, probably at the beginning of his reign. ${ }^{1}$

The reigns of the kings of the dynasty were hailed by their contemporaries as marking a veritable renascence of the kingdom. The inscriptions of the time are full of references to the time of disunion which preceded them, compared with the present age of plenty and peace within the frontiers of Egypt of restored sanctuaries and widened borders. "Twice joyful are the gods," says a hymn of praise addressed to the third Senusert, "for thou hast established their offerings. Twice excess of the reality by nearly thirty years, giving 245 instead of the 216 which is approximately the true number. The compiler of the Turin Papyrus evidently did not make the same mistake as Manetho. The Manethonian forms of the royal names are quite good reproductions to the Greek ear. Amenemhat could hardly be transcribed otherwise than as $A \mu \mu \epsilon \nu \epsilon \mu \gamma s$ or $A \mu \mu \alpha \nu \epsilon \mu \eta$ s. The aberrant form for Amenemhat III, A $\mu \mu \epsilon \rho \eta s$, is clearly due merely to a confusion, probably due to Manetho himself, of the personal name Amenemhat with the throne-name Ne-maat-Ra, misread as Maat-n-Ra, which to a Greek in Ptolemaic days would have seemed to be pronounced something like $\lambda[\epsilon \rho \eta /(s)$ or $\lambda I \epsilon \rho \rho \eta(s)$; the final $t$ of a feminine word like Maat being always dropped in the later pronunciation of Egyptian. And it is evident, as we shall see, that Amenemhat III is the "Moiris" of Herodotus and Diodorns. Manetho's name for this king, Lamaris, is an exact reproduction of the proper pronunciation of the throne-name Ne-maat-Ra, as Nemarie; the Egyptian $n$ is constantly in later times turned into $l$; thus the word nas, tongue, becomes in Coptic las. " $\Sigma_{\kappa} \epsilon \mu \omega \phi \rho t s "$ is probably garbled by a copyist; but we can see that its original form was probably by no means a bad representation of Sebek-nefert $k$ ha, which a Ptolemaic Egyptian would probably pronounce something like "Soknofric: perhaps Manetho originally

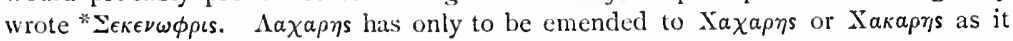
obviously must, and we have the only possible Greek reproduction of Khakaura at once. The replacing of the initial $\mathrm{X}$ by $\Lambda$ was evidently made by a late copyist to whom euphonious Greek names were more familiar than the harsh consonantal comlinations of the ancient Egyptians, so that Xaxapys seemed to him an impossibility;

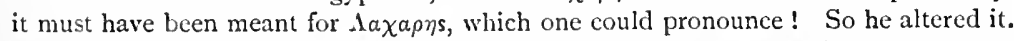
$\Sigma_{\epsilon \sigma \omega \sigma \tau \rho \iota s}$ is, as Prof. Sethe has lately pointed out (Untersuchungen, ii.), an attempt, much older than Manetho, to reproduce the sound of the original Sen-usert (Senzwosiet according to the system of vocalization favoured by German Egyptologists), as the name commonly read Usert-sen was probally really pronounced. Manetho may not liave considered that this was the nost correct form possible, but as it was that consecrated by the authority of Herodotus, he retained it. $\Sigma \epsilon \sigma o \gamma \chi \omega \sigma$ is (Senusert I) is evidently a

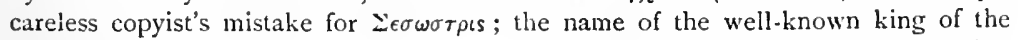
XXIInd Dynasty (Sheshonk) was in error sulstituted for the similar-looking $\Sigma \epsilon \sigma \omega \sigma \tau \rho l s$.

${ }^{1}$ Griffith, $A . Z$. xxxiv. pp. 35 fif. 
joyful are thy princes; thou hast formed their boundaries. . . . Twice joyful is Egypt at thy strong arm; thou hast guarded the ancient order." If the kings of the XIth Dynasty, after reuniting the two lands, "made them to live," and "increased their life," those of the XIIth also marked the renascence of the kingdom out of the slough of despair into which it had fallen during centuries of civil war in their nomes; Amenemhat I is the "Horus who renews the births" of the people (Uhemmesut), Senusert I is the "life of the births" (Ankh-mesut), Senusert II is the "helmsman of the two lands" (Semu-taui). And from the evidence other than that of official titles we can see the living interest which these energetic monarchs took in their law and people. Amenemhat III added a whole province to Egypt by his reclamations in the Fayyûm, and it has been supposed that he regulated the flow of water in and out of Lake Moiris, which served to hold back part of the surplus of the high Nile and to allow it to flow out when the river was low. The regulation of the Nile-flood, the life of Egypt, was their constant care; as their frontiers advanced southwards into Nubia, Nilometers were established at which the height of the water was year by year carefully measured, and whence the important intelligence was transmitted to Egypt. The conquest and annexation of Northern Nubia, if it did not add a fertile province to Egypt, at least enabled the kings to carry out this great object, which seems to have been ever present in their minds, the careful watching and regulation of the Nile. Everywhere throughout the land the boundaries which had been thrown down during the period of confusion were renewed, and it is probable that some sort of cadastral survey was at least partially carried out for this end. The frontiers of the Nomes were finally delimited, and the powers and status of the Nomarch princes carefully defined in relation to each other and to the royal authority. While retaining many tokens of the independence which they had gained during the decline of the central power at Memphis, they were now again brought into due subjection to the royal authority.

We gain a sufficient idea of the wealth and state of the local princes from the splendid tombs of the chiefs who are buried at Beni Hasan and el-Bersheh in Middle Egypt. ${ }^{1}$ The

${ }^{1}$ Newrersv, Beni Hasan (Egypt Exploration Fund Archreological Survey, IS92-3), el-Bersheh (1894). I'rof. MEYer points out (Gesch. Alt.2 i. 2, p. 250) that 
princes were laid to rest in chambers at the bottom of pits which were sunk in the floors of the splendid halls of offering, the walls of which were covered with paintings depicting the life of their owners on earth, executed in the hope of securing for the dead similar well-being in the underworld. Of the art with which these paintings are executed we shall have occasion to speak later. Below them on the slopes of the tomb-hill were buried the officials and functionaries of their little courts, their stewards, physicians, and retainers of various ranks, each like his lord, with his own funerary state of great rectangular wooden coffins and the models of fellah servants and boatmen which were supposed to turn into ghostly ministrants in the underworld, and are so characteristic a feature of the burial customs of this period. ${ }^{1}$

But this wealth and state was not destined to last. It has been supposed, though the fact is not certain, that the powerful monarchs Senusert III and Amenemhat III still further modified the position of the local princes, and laid the foundations of the bureaucratic local government which we find in the time of the Empire. It is certain that splendid nobles of the type of the Khnumheteps of Beni Hasan and the Thutiheteps of el-Bersheh are no longer met with during the second half of the XIIth Dynasty, and that then we find purely royal officials much more prominent than before. Gradually the royal power had increased, largely by means of the king's control of the local levies in war. The continuous wars of Senusert III in Nubia served to establish the control of the king over the bodies of his subjects, to the exclusion of that of their local chiefs. And we cannot imagine that so tremendous a despot as Amenemhat III seems to have been would have allowed local despots like the Khnumheteps and Amenis of Beni Hasan to exist.

\section{The Works of the XIIth Dynasty}

Temples-The Fayyum and Lake Moiris-The labyrinth at Hawara

The power and wealth of the kings of the XIIth Dynasty is well exhibited in the magnificent buildings which they set up.

this wealth and state does not indicate independence ; it really testifies to the strength of the central royal power, which forbade private war, and enabled the monarchs to accumulate wealth instead of wasting their revenues in internecine conflict.

${ }^{2}$ Garsta.ig, Burial Customs (Peni Hasan), London, 1907. 
To them the temples of Amen at Karnak, of $\mathrm{Ra}$ at Heliopolis, of Ubastet at Bubastis, of Min at Koptos, of Hershef at Herakleopolis, not to speak of many others, owe the beginnings of the splendour which we know under the later Empire. Senusert I was a splendid temple-builder; by him were erected the first great obelisks in Egypt, in front of the temple of Heliopolis, and we possess the account of the ceremonies which marked his founding of the temple of Karnak. Colossal statues of the kings adorned the newly erected fanes, and a large number of the colossi which now bear only the names of later monarchs were really erected by the kings of the XIIth Dynasty.

The huge reclamation works carried out by Amenemhat III in the "Lake-Province" of the Fayyûm are a testimony to the energy of this dynasty. The interest of the kings was probably first drawn to this oasis-district by its proximity to their royal burgh or fortress-palace of Itht-taui. Possibly with the view of conciliating Herakleopolitan sentiment, or possibly on account of some family alliance with the descendants of the royal house of Herakleopolis, the earlier kings of the XIIth Dynasty not only devoted special attention to the temples of the erstwhile royal city, but actually transferred their residence from Thebes, where the headquarters of the XII Dynasty had been fixed, to a position midway between Memphis and Herakleopolis, and in close proximity to the Fayyûm. Thebes and Upper Egypt being thoroughly loyal to the royal house which was of Theban origin, and was doing so much for the Nubian frontier-territory, this position, which, as has been said, was admirably adapted to secure a general oversight of the whole country, could be safely adopted as the royal headquarters. The old Memphite tradition of burying the kings in pyramids in the neighbourhood of the necropolis of Memphis was also revived. ${ }^{1}$

The interest of the kings of the XIIth Dynasty in the neighbouring lake-province began with its founder, Amenemhat I, who seems to have erected a temple at Shedit (Crocodilopolis). Senusert $I$ is commemorated there by his tall

${ }^{1}$ Two of the pyramids of Lisht, that of Illahun and one at Dahshur, are the burialplaces of Amenemhat I, Senusert I, Senusert II, and Senusert III, respectively. Amenemhat III was appropriately buried in the Fayyûm itself at Hawara. Illahun is situated at the Nile entrance to the valley which leads to the Fayyûm; Hawara at its farther end. 
boundary-stone or "obelisk" at Begig or Ebgig, not far off. Amenemhat III's great work was, besides the construction of a dyke at Illahun regulating the outflow from the lake, the reclamation by means of a great curved embankment of, according to Prof. Petrie's estimate, about forty square miles of fertile territory to the north and east of Shedit. On the dam, at a point directly north of Shedit, the king placed as a memorial of the work, two colossal statutes of himself, each thirty-nine feet high, and each cut from a single block of white quartzite. These were mounted on a platform, and must have been seen far and wide across the lake; the effect of the sun's rays reflected from the glittering quartzite must have been remarliable. ${ }^{1}$

The famous Labyrinth at Hawara which amazed Herodotus so much, and is described by Diodorus, Strabo, and Pliny, was a great funerary temple erected by Amenemhat III (Lamaris) in front of his pyramid at Hawara. Shining white stone, probably quartzite and alabaster, was largely used in its construction, probably for facing blocks, ${ }^{2}$ and this caused Pliny to describe its walls as of Parian marble. This fact, and the great number of its halls and corridors, caused the Greeks to compare it with the famous labyrinth of Minos at Knossos in Crete, and also, led no doubt by the king's name "Lamaris," to transfer to it the Cretan appellation of "labyrinth." ${ }^{3}$ Its halls were

1 These colossi were seen by Herodotus, who describes them (ii. 149). He speaks of them inaccurately (probably from lapse of memory), as standing in the middle of the lake. When they were destroyed is unknown; the fragments are now in the Ashmolean Museum. In Herodotus' day the lake, which he correctly calls "Moiris" (Mei-uere, "great lakc," or Mu-ucr, "great water"), was still $\theta \hat{\omega} u \mu a$ $\mu \epsilon \gamma a$, for the further Ptolemaic reclamations for the benefit of the Macedonian veterans at Arsinoe, which reduced the lake to nearly the present dimensions of the Birket Karun, had not yet been nade. He is, however, in error in assuming that it was $\chi \epsilon \iota \rho \pi$ oin nemhat's dike. Diodorus (i. 51, 52) transferred the name of the lake to the ling, influenced no doubt by the fact that the prenomen of Amenembat III, Ne-mat-lia (correctly given by Manetho as "Lamaris"), had been misread as "Maa(t)-n-Ra," and hellenized as "Merres" by Manetho, and "Marros" by Diodorus. Diodorus makes the mistake of supposing that "Moiris" (Amenemhat III) dug the lake, and copies Herodotus in saying that the $\pi v p a \mu i \delta \epsilon s$ (platforms) with the statues were erected in the middle of it ; but his general account of the lake is better, and he emphasizes, which Herodotus does not, the connection of MIoiris with the lake as well as with the labyrinth. Strabo's short account (xvii. 37) is good.

${ }^{2}$ Fine stone work is characteristic of the XIth and XIItl Dynasties, and smaller work in white quartzite equally so.

"I have suggested (Joumal of Hellenic Studies, xxv.; "The Two Labyrintlus") 
decorated with representations of the various nomes of Egypt, a fact which has caused the attribution to the building of the character of a sort of state office or clearing-house for the affairs of the nomes, but there is no probability that this view is in any way correct; the nomes were merely represented as ministering to the glory of King Lamaris or Moiris, and his gods.

\section{Foreign Relations}

The Red Sea and Punt-" Tale of the Shipwrecked Sailor "-Sinai-PalestineThe Aamu at Beni Hasan-Story of Sanehat-Phoenicia-Greece-The Libyans

For the building of these mighty works and for their decoration and furniture an extensive provision of fine stone, metal, and wood was necessary. Royal expeditions constantly visited the quarries of Syene and the Western Desert for granite, diorite, and amazon-stone, the mines of Sinai for malachite and turquoise, and the forests of Syria for wood; while the unhappy Nubians were compelled by force to furnish the necessary gold. At the same time commercial relations with the surrounding nations were much developed; in exhange for the products of Egypt, Punt, Syria, and Greece sent to the Nile-land their most valuable commodities.

The Hammamat road led still, as of old, to the port of Sauu (Kuṣer) and the "Holy Land" which was on the way to Punt; under Senusert II we hear that stelae on the figures of the king were set up in $T a-n e t e r,{ }^{1}$ and in the preceding reign an officer named Khentekhtai-uer returned in peace from Punt, his soldiers with him; his ships voyaged prosperously, anchoring at Sauu. Egyptian settlements existed along the coast south of Sauu: at Nehesit, "the Negro-town," Ptolemy's Nechesia ; Tep-Nekhebet, "the head" of the tutelary goddess of Southern Egypt, which is Berenike, and elsewhere. The voyage along this coast to Punt was the theme of many wonder-tales of adventure, one of which, the "Story of the Shipwrecked Sailor," which dates to this period, reminds us of the tale of Sindbad. The hero of this romance set forth

that the name "labyrinth" may have originated in some confusion with the name of its founder, Lamaris or Labaris (Ne-maat-Ra; see note I, above. Prof. J. L. MYRES has lately made some interesting suggestions as to the plan of this building (Lizerp. Ann., 1910, p. 134).

1 In the Wady Gasûs near Ḳuṣêr. 
in a ship 150 cubits long and 40 wide, with a hundred and fifty of the best sailors in the land of Egypt, who had seen heaven and earth and whose hearts were braver than those of lions. But the great ship was wrecked and only the teller of the tale was wafted safely to the shores of a mysterious isle, a sort of Aeaea or Hy-Brasail, whereon dwelt a gigantic serpent, who was 30 cubits long and whose beard exceeded 2 cubits; his body was encrusted with gold and his colour appeared like that of real lapis. "He uprose before me and opened his mouth; and while I prostrated myself before him, he said to me "What hath brought thee, little one, what hath brought thee?" " Then he carried the sailor in his mouth to his dwelling without hurting him, and commanded him to tell his tale, which he did, and to which the serpent, commiserating him, replied that he need fear nothing, for after four months he would return safely to Egypt, while after his departure the island would be changed into waves. ${ }^{1}$

So the frankincense and myrrh of Punt, as well as the fine granites and beautiful green felspar (amazon-stone) of the Eastern Desert, were brought through half-mythical dangers by the king's officers to the royal court. The turquoise and the copper of Sinai also needed capable caravan-leaders and bold soldiers who would bear great hardships to bear them back to their master.

A new mining-centre was established at the Sarâbit-alKhadim, and the works in the Wadi Maghâra were prosecuted with success. An inscription of an official named Hem-uer gives some idea of the trials and disappointments of the mining captains among the arid rocks and deserts of Sinai. Hem-uer was unsuccessful in his search for the turquoise and copper which he was sent to obtain, and his men threatened to desert. In despair he invoked the aid of the goddess of the mines, Hathor-Mafek, and she aided him. "The desert burned like summer," he says, "the mountain seemed on fire, and the vein exhausted; the overseer questioned the miners, and the skilled workers who knew the mine replied: 'There is turquoise to all

1 Probably this tale of the hospitable and kindly dragon, a more amiable Egyptian Calypso, is one of the most naive and delightful of all the Egyptian stories which have come down to us, and will serve to show the reader that ancient Fgyptian literature is no myth. (The tale will be found in Weigald, The Treasury of Ancient Egypt: London, I9⿺ I cf. Maspero, Contes Populaires, pp. I3 1 fi.) 
eternity in the mountain.' And at that moment the vein appeared." 1 Amenemhat III sent many expeditions to Sinai.

The "land flowing with milk and honey" which lay beyond the desert of Suez as yet tempted no Egyptian king to permanent conquest. Already in the time of the Vth and VIth Dynasties warlike expeditions had reached Southern Palestine, sent in reprisal for marauding attacks on the Delta. But they were never followed up: the climatic conditions of Palestine were strange, and the land itself probably seemed uncanny to the Egyptians, nor were its products sufficiently valuable to attract the cupidity of the Egyptian kings. Also, the Rutenu, the settled and civilized Semites who lived north of the Aamu, the pastoral nomads of the Negeb and Southern Judrea, were formidable in war; occasionally their attacks had to be guarded against. In the reign of Senusert III we find that a place named Sekmekem, or Sekmem, ${ }^{2}$ probably some South Palestinian land, had allied itself with the "Vile Rutenu," with the result that an expedition was sent against it, in which an officer named Khusebek took part. He tells us of the war and destruction of the treacherous Sekmelem on his tombstone, which was found at Abydos. No further advance is chronicled, nor any more war with the Rutenu, who continued to live their own civilized life in their "fenced" towns, deriving their civilization chiefly from distant Babylon, and owing but little to the neighbouring Egypt, in spite of a regular commercial connexion with her, which is proved by the fairly common discoveries of Egyptian weapons and scarab-seals of the XIIth Dynasty in Palestine. ${ }^{3}$ A peaceful commerce was carried on by caravans of nomad or half-nomad Beduins, who found it

1 " The desert burned like summer, and the mountain seemed on fire." Even to an Egyptian, used year by year to the heat of an Egyptian summer, Sinai seemed to burn like fire. The fact that the month Phamenoth, in which this inscription is dated, fell in the summer, points to about 2000 B.c. as the date of the expedition. This is, as has already been mentioned (p. 25), an important indication of the date of the XIYth Dynasty.

2 Prof. E. Meyer's identification of Sekmekem or Seknem with the Biblical Shechem $[\mathrm{im}]$ seems very hazardous, though we may allow that the word is a Semitic plural form.

${ }^{3}$ Recent excavations (e.g. at Lachish, Gezer, and Bethshemesh) have revealed traces of the early culture of Palestine, but there is not yet enough material to give us any good idea of Canaan at the time of the XIIth Dynasty or precise information as to its relations with Egypt. All we know is that the Canaanites had long been civilized, and harl long passed the primitive troglodytic state of culture which is revealed by the oldest strata (see p. 183 ). 
prontable to bring their products and those or the Rutenu into Egypt and to sell them at the courts of the nome princes; the nomarch Khnumhetep in the reign of Senusert II records in his tomb at Beni Hasan the arrival in his nome of thirty-seven men and women of the "Aamu," under a lik-khaskliut or "desert-chief" named Abesha (Abishu'a), who brought him the green-eye paint of antimony (mestjamut, Ar. kolul) which the Egyptians so much loved, and other products of their land. We have here a picture on a small scale of the way in which the forefathers of the Israelites journeyed into the land of Goshen. ${ }^{1}$

A remarkable picture of the life of the Beduin tribes of Southern Palestine is given in the autobiography of Sanehat or Sinuhe," a scion of the Egyptian royal house, in fact probably a younger son of Amenemlyat I, who fled alone from Egypt on the announcement of the death of that king, possibly from fear lest he should be maltreated by the new monarch, Senusert I. He fled by sea to Byblos (already an important city), and thence to the land of Kedme in Syria. Here he was well received by a chief named Ammuanshi (the name is characteristic of the time; $c f$. the probably nearly contemporary Babylonian king Ammizaduga ${ }^{3}$ ), and, after a victorious single combat, after the manner of David and Goliath, with a hostile champion, he married the chief's daughter, and eventually succeeded to his possessions. But in his old age he desired to end his days in Egypt, and besought permission to return. King Senusert answered with a gracious rescript, promising him his favour in life and a splendid burial: "then," he writes, "they shall give thee bandages from the hand of Tait ${ }^{4}$ on the night of anointing with the oil of embalming. They shall follow thy funeral, and go to the tomb on the day of burial, which shall be in a gilded coffin, the head painted with blue. Thou shalt be placed upon the bier, and oxen shall draw thee along, the singers shall go before thee, and they shall dance thy funeral dance. The women crouching at the false-door of thy stele shall chant loudly the

${ }^{3}$ Newberry, Beni Hasan, i. Pl. xxviii.

2 Maspero, Contes, pp. $\delta_{7} \mathrm{ff}$; ; the latest critical work on the subject of this papyrus is that of Mr. Alan Gardiner (in Kec. Trav., I9Ioff.).

${ }^{3}$ P. 19 .

- Tait was the goddess of embalming. It should be noted that at this time the Egyptians did not embalm so elaborately as in later days: the body seems often to have been little more than dried, and is usualiy found skeletonized. 
prayers for funeral-offerings; they shall slay victims for thee at the door of thy pit; and thy stela of white limestone shall be set up among those of the royal children. Thou shalt not die in a strange land, nor be buried by the Aamu: thou shalt not be laid in a sheepskin: all people shall smite the earth and lament over thy body as thou goest to the tomb."

On his return the king received him with open arms, and the princesses, placing collars of state about their necks, and each taking a wand of ceremony in one hand and a sistrum in the other, danced the solemn Hathor dance before the king, praising him for his loving-kindness to Sanehat. Then the returned wanderer passed out of the palace hand in hand with the royal children to the house which had been prepared for him. His foreign clothes were taken away from him, and his head was shaved as an Egyptian's should be; he dressed in fine linen, was anointed with the finest oil, and once more slept on a bedstead like a civilized being, instead of on the sand like a barbarian. The king had a magnificent tomb made for him, and he ends his story with the hope that he may ever continue in the royal favour.

Highly interesting in this story is the contrast between the civilization of the Egyptians and the comparative barbarism of the Beduins, which is well brought out in the matter of funeral rites. As a matter of fact, the elaboration and complexity of the Egyptian funeral customs was one of the great points of difference between the culture of Egypt and that of the Semites, and no doubt to the Egyptian seemed conclusive proof of his higher civilization and a mark of his distinction from the surrounding barbarians.

There is little doubt that relations were also already maintained by sea with the Phoenician cities. We do not know when the Semitic migration took place that brought the Phoenicians to the Mediterranean coast, but it is very probable that it is to be placed much farther back in time than it usually has been; and we need not doubt that the chief Phoenician city-states were already in existence at the time of the Egyptian XIIth Dynasty. ${ }^{1}$ Byblos was connected in a very

I The tradition, preserved by IIerodotus (i. I, and vii. 89), that the Phoenicians were emigrants from the Persian gulf is not impossible, and may be connected with the Hebrew tradition of their own Babylonian origin. The Phoenicians may originally have come from the coast of el-Hasa, but probably very many centuries 
curious way with the myths of the Egyptian Delta; part of the dismembered body of Osiris after his murder by Set was said to have been washed up there in a great chest, and Isis journeyed thither to reclaim it. This points to a connection by sea between the Delta and Phoenicia in the very earliest period. ${ }^{1}$ Under the VIth Dynasty the city was well known to the Egyptians by the name of Kabun or Kapun, an evidently very ancient modification of its Semitic name Gebal. It is probable that the ships, called Kabuniut or "Byblos-farers," which sailed from the Nile thither, were Phoenician rather than Egyptian. ${ }^{2}$

Of the relations that existed between Egypt and Greece at this time we have already spoken. ${ }^{3}$

The inhabitants of the coast of Libya, then in all probability less arid than now and more able to sustain a large population, were certainly connected somewhat closely with the Aegeans, and such Greek legends as that of Athene Tritogeneia may point to very ancient relations with Libya. To the Egyptians the Libyans had much the same unsavoury reputation as their friends the Hanebu. ${ }^{4}$ They were always, throughout history, trying to set their feet within the charmed circle of the Delta, and share in its wealth. We hear of wars with them as early as the days of the IIIrd Dynasty, and the Egyptians seem to have been no more tolerant of these pushing poor relations of theirs in the time of the XIIth Dynasty than they had been then. Senusert I was engaged

before the time of the XIIth Dynasty. The tradition given by Ilerodotus (ii. 44) that Tyre and its temple of Melkarth had been founded 2300 years before his time (i.e. about 2730 B.C.), may have some truth in it, but it is impossible to accept it as it stands.

1 See pp. 89, 90.

${ }^{2}$ S.THE, $\ddot{A} . Z$.xlv. (IgOS), pp. 7 ff. Prof. Sethe has recently revived the idea that the name Fenkhu, used for Asiatics by the Egyptians from rery early times (it occurs under the Vth Dynasty at Abusir), was an Egyptian transcript of the original of the Greek ooiv $\xi$, and that therefore the Fenkhu were the Phoenicians ( $\ddot{A} . Z$. xlv. pp. 84 , 140). But, as I have pointed out in Rec. Traz'. xxxiv. (1912), p. 35, this is impossible, because the Greek $\phi$ was originally $p-h$, not $f$, so that $\phi$ oiv $\xi$, if not a Greek word (as seems most probable, = "red"), must have been derived from an original beginning $p-h$, which could not be transcribed in Egyptian as $f$. Therefore Fenkhu cannot $=\phi o i v \xi_{\text {. }}$. If the Egyptian word were "Pehenekhu" it would be quite a different matter. Besides, we have no proof that the Phoenicians called themselves anything but "Canaanites".

${ }^{3}$ See p. 36. An important discovery of Kamárais ware in a XIIth Dynasty tomb at Abydos was made by Prof. Garstang in 1907 (Plate III. 1).

4. 35, above. 
upon a Libyan expedition at the very time of the death of his father.

\section{The Nubian IVars}

Conquest of Nubia-Senusert III : frontier fixed above Wadi Halfa-Semmeh inscription

The warlike energy of the kings of the XIIth Dynasty was chiefly directed towards the prosecution of the feud with the Nubians, which had began under the preceding dynasty. ${ }^{1}$ The chief motive which inspired them to this war of conquest seems to have been a higher one than mere desire of revenge or domination, namely, the wish to control the Nile more effectually, and to be able to foresee more accurately the probable height of the yearly inundation on which the prosperity of Egypt depends. The kings of this dynasty seem to have regarded the regulation of the great river as the highest duty of a ruler of Egypt, as in truth it is. Bound up with this, however, there was also a lower motive; the desire to acquire instant prosperity and wealth by the acquisition of the gold with which the Wadi "Alaki and other Nubian desert valleys were full.

Amenemhat I tells us in his "Instructions" to his son, already referred to, that he overthrew the Wiavat and Matjaiu. The Wawat were the most important tribe of Northern Nubia. And on a rock near Korosko we read the laconic record: "In the 29th year of Sehetepabra, living for ever, they came to overthrow WVawat." Senusert I invaded Nubia in the eighteenth and forty-third years of his reign. He was probably the first Egyptian monarch to march south of Wadi Halfa, as in his second expedition (the first he did not accompany in person) he reached the land of Kush (Ethiopia), now first mentioned in history.

Under his two successors we hear only of gold-seeking expeditions. But Senusert III was a fighter. His eighth, sixteenth, and nineteenth years were marked by military expeditions which finally riveted the Egyptian yoke on the necks of the Nubians. The king prepared his way before him by renewing the canal, originally dating from the time of the VIth Dynasty, ${ }^{2}$ by which the First Cataract was avoided. ${ }^{3}$

${ }^{1}$ P. 146 , above.

2 Budge, Hist. Eg. iii. 35 .

3 This canal, "the excellent way of Khakaura," was renewed under the XVIIIth Dynasty, and Thothmes $11 \mathrm{I}$ issued the standing order that it was to be maintained 
The king finally established the conquest by building, on the hills on each side of the river about thirty miles above the Second Cataract, the two fortresses of Semneh (Eg. Samnin, Gr. Sammina) and Kummeh (Eg. Kummu), which remained important throughout Egyptian history, and the ruins of which are still remarkable. At Semneh was set up a boundary-stone with the following inscription: "This is the Southern Frontier, fixed in the eighth year of His Majesty King Khakaura, living for ever. No negro is permitted to pass this boundary northward, either on foot or by boat, nor any cattle, oxen, goats, or sheep belonging to negroes, except when a negro comes to trade in the land of Akin, or on any business whatsoever; then let him be well treated. But no boat of the negroes is to be allowed to pass Heh northward for ever." The bencvolent feelings of the king seem to have evaporated eight years later, after his second expedition, for a great stela set up then at Semneh contains the following inscription: "Year 16 , third month of Peret, His Majesty fixed the frontier of the South at Heh. I made my boundary, for I advanced upstream beyond my forefathers; I added much thereto, (namely) what was ordained by me. For I am king, and I say it and I do it. What lay in my heart was brought to pass by my hand. I am vigorous in seizing, powerful in succeeding, never resting; one in whose heart there is a word which is unknown to the weak, one who arises against mercy; never showing mercy to the enemy who attacks him, but attacking him who attacks him; silent to the silent, but answering a word according to the circumstances. For to take no notice of a violent attack is to strengthen the heart of the enemy. Vigour is valiant, but cowardice is vile. $\mathrm{He}$ is a coward who is vanquished on his own frontier, since the negro will fall prostrate at a word: answer him, and he retreats; if one is vigorous with him, he turns his back, retiring even when on the way to attack. Behold! these people have nothing terrible about them; they are feeble and insignificant; they have buttocks for hearts! I have seen it, even I, the Majesty; it is no lie! I have seized their women; I have carried off their folk. I marched to their wells, I took their cattle, I destroyed their seed-corn, I set fire to it. By my life and my father's, I speak truth! There is no possibility of henceforth by the Cataract boatmen; but it afterwards fell into desuetude, and has now disappeared. 
gainsaying what cometh forth from my mouth! And, moreover, every son of mine who shall have preserved this frontier which my Majesty hath made is indeed my son and born of my Majesty, verily a son who avengeth his father and preserveth the boundary of him who begat him. But he who shall have abandoned it, he who shall not have fought for it, behold! he is no son of mine, he is none born of me. Behold me! Behold, moreover, my Majesty hath set up an image of my Majesty upon this frontier which my Majesty makes, not from a desire that ye should worship it, but from a desire that ye should fight for it!". 1

This really extraordinary inscription is one of the most remarkable monuments of Egyptian literature that have survived. It gives us a good idea of the vigour of the king. In some ways it conveys the impression of being a manifesto directed against the peaceful and probably somewhat weak methods of the two preceding reigns in dealing with the Nubians; and the half-sarcastic manner in which the king exhorts his subjects not to be afraid of barbarians, and to fight for his image, not merely to worship it, is highly curious. And when we remember that it was to this dynasty that the legendary Sesostris was assigned by Manetho, we also remember the stelae which the great conqueror was said to have set up in various parts of the world, the inscriptions of which, as described by Herodotus and Diodorus, remind us oddly of the phraseology of this stele of Senusert III. ${ }^{2}$

Nubian expeditions were not necessary in the reign of Amenemhat III. His predecessor had done his work well. The great king spent his reign in the prosecution of his vast works of public utility and royal splendour.

\section{IO. Amenemliat III and the Art of the XIIth Dynasty}

Naturalism in art-Tomb of Ameni-Small art: jewellery of Dahshur-Great art: portrait statues-The statues of Amenemhat III

Amenemluat III was a monarch of whom we would fain know more than we do. His building was magnificent, and

1 Text in Lepsius, Denkmaeler, ii. 136, i.

${ }^{2}$ It is in fact by no means improbable that Manetho, knowing the name Khakhares to be certainly that of Senusert III, was induced to confine to Senusert I and II the name and renown of Sesostris which by right belonged to Khakaura as well. 


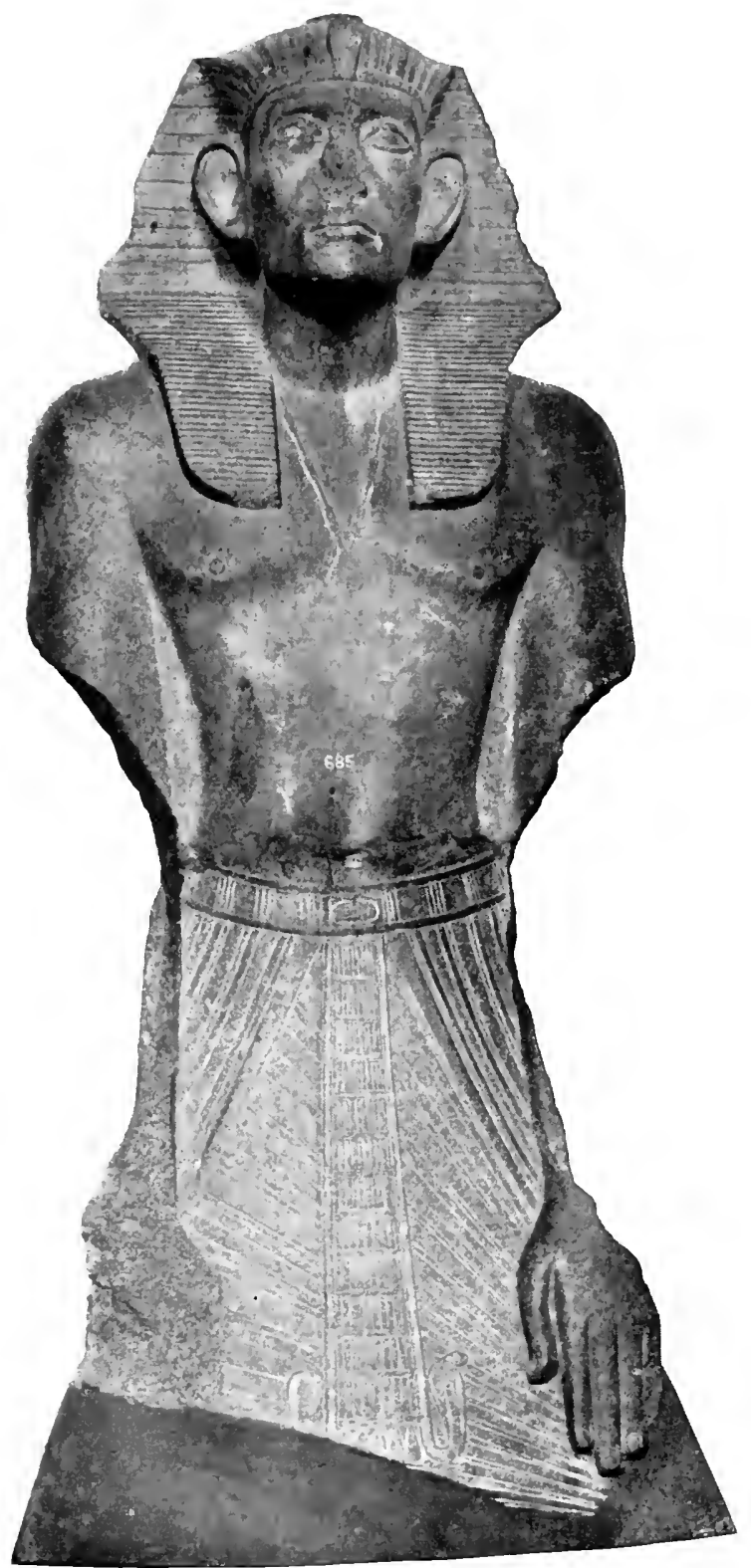

fire. 11ws

KINI: MEUSERI II.

1) ER EI.PAHRI 

in his time Egyptian art reached for a brief space a degrce of naturalism which it was not to know again till the time of the heretic Akhenaten, and of power which it never again attained. The artistic development begun by the sculptors of Neb-hapet-Ra Mentuhetep continued under the kings of the XIIth Dynasty, in whose days Egyptian art may be said to have in most respects reached its apogee. The taste of the artists of the XIIth Dynasty was admirable. They were Japanese in their sense of fitness and their delicacy; Greek in their feeling for balance and proportion. The best work of the XVIIIth Dynasty is vulgar by the side of that of the XIIth. The tomb of Ameni at Beni Hasan is a revelation to those whose knowledge of Egyptian art is derived chiefly from the gigantic abominations of Karnak or Abu Simbel. Nothing so fine as the perfectly-proportioned tombhall of Ameni, with its beautiful pillars, was ever excavated in an Egyptian cliff in later days. And the naturalism of the multitudinous groups of wrestling men which are painted on the walls around the entrance to the inner chamber ${ }^{1}$ is paralleled only by that of the Greek vase-paintings of the best period: the decoration of this wall, with its contending figures painted, where in later days only stiff and formal rows of hieroglyphics would have been permitted, and with its stately geometric frame-design, reminds us of nothing so much as of the decoration of a Clazomenian sarcophagus. Nor are other tombs of this period far behind it in beauty. The smaller art of the time shews the same unparelleled excellence. The ivories, the scarabs, and the goldsmith's work are unrivalled. Nothing like the gold pectorals, and other objects, inlaid with fine stones, of the time of Senusert III which were found at Dashur, ${ }^{2}$ was ever made in later times in Egypt. And the great reliefs and statues of the kings, though their bodies are formal and represented in accordance with the convention fixed under the Pyramid-builders, shew us portraits of a power which the artists of the IVth Dynasty cannot rival. The fidelity of these portraits we cannot question. The sculptor who depicted King Mentuhetep at Dêr el-Bahri set the example, and his successors who shew us the faces of Senusert I at Koptos, ${ }^{3}$ and of Senusert III

1 Newberry, Beni Hasan, i. Pll. xiv.-xvi. I illustrate (Plate X. 3) tomb I5.

2De Morgan, Legrain, and Jênuler, Fouilles de Dahchour, i. Pli. xv. ff.

3 Petrie, hóplos, Pl. ix. 
in the series of statues from Dêr el-Bahri, ${ }^{1}$ followed and surpassed him. At Dêr el-Bahri the great Sesostris is shewn in different figures representing him at different periods of his life, from a young to an old man, and two red granite heads from Abydos ${ }^{2}$ and $\mathrm{Karnak}^{3}$ confirm their portraits of the monarch in old age. It is a remarkable face, but not so remarkable as that of Amenemhat III, whose physiognomy was peculiar. ${ }^{4}$ We have an extraordinary portrait of this king's time apparently, in a weird figure, hung with extraordinary magical ornaments, which shews a king's head crowned with a massive wig of unique fashion. This was found at Tanis. ${ }^{5}$ The strange group of Nile-gods, heavy-haired and bearing offerings of fish, which comes from the same place, also owes its origin to the same school of sculpture. ${ }^{6}$ So apparently do the remarkable sphinxes of Tanis, which for long were regarded, from their remarkable faces, as works of the Hyksos. In them the leonine characteristics of the sphinx are emphasized in a very novel way. ${ }^{7}$

Why the king bade himself and his gods to be represented thus strangely we do not know. It was an aberration from the conventional canons only once paralleled in later days, and that by a king who was half mad and wholly a heretic, in religion as well as art, Akhenaten. We cannot assume any religious heresy in Lamaris, but that he was a monarch of original and powerful mind is obvious. ${ }^{8}$

${ }^{1}$ Plate XI. ; Naville and Hall, Deir el-Bahari: XIth Dyn. i. Pl. xix. ; iii. ch. iii.

a Petrie, Aby'dos, i. Pl. lv. 6, 7.

${ }^{3}$ Discovered by M. Legrain recently.

${ }^{4}$ The best portrait of him is the small statue in the Golénischeff Collection, of which there is a cast in the British Museum (No. 688).

${ }^{5}$ Cairo Museum.

${ }^{6}$ Ibid.

7 The portrait on these sphinxes is a strongly marked face, which is, judging from the Golénischeff statue, perhaps that of Amenemhat III. (GolénischefF, Rec. Trav'. xv. pp. 13 Iff.). The two great heads found by Naville at Bubastis (Bubastis, Pll. x. xi.), which are now in the Museums of London and Cairo, were also formerly thought to be Hyksos, and were ascribed to Khian. It is not impossible that they also may really represent Amenemhat III.

${ }^{8}$ To him we probably owe the Great Sphinx of Gîza, and the simple, uninscribed and undecorated "Temple of the Sphinx" at its foot. The equally inscriptionless Temple of Dîmeh in the Fayyûm may also with probability be assigned to him. These two remarkable alterations from the usual Egyptian style of temple are, if they are his, further testimony to the original character of his mind (see HaLL, J.H.S. xxv. p. 336). 


\section{I. The XIIIth Dynasty and the Hyksos Invasion}

The XIIIth Dynasty: the Sebek-worshippers and the Thehans-The Antefs of Thebes-Nelsesi and the Hyksos-Egypt and the East-Culture of the Middle kingdom

His reign marks the apogee of the Middle Kingdom. His successors, ${ }^{1}$ Amenemhat IV and the queen Sebekneferura (Skemiophris), were of no account, and their successors of the XIIth Dynasty are little more than a series of names marking a swiftly accelerating path of degeneration. All were devoted worshippers of the crocodile-god Sebel, whose name they bore, usually in the compound Sebekhetep. It would seem that from the first there was a division in the kingdom, Thebes being held by a dynasty of Thebans, of whom some bore the name Mentuhetep, and one that of Senusert (IV); while in the north, no doubt at Itht-taui, ruled the descendants of the XIlth Dynasty, Khu-taui-Ra Ugafa, Sekhem-ka-Ra Amenemhatsenbef, Sankhabra Ameni-Antef-A menemhat, and twelve others. We only know of the Thebans from recent discoveries by M. Legrain of their statues at Karnak, and evidently they were not recognized as legitimate, since they are not mentioned in the Turin Papyrus, which only gives Khu-taui-Ra and his fourteen ephemeral successors, ${ }^{2}$ till we come to Sekhem-khutaui-Ra Sebekhetep (I), who certainly ruled over the whole country from Bubastis to Semneh in Nubia. Then we meet with two Thebans named Sebekemsaf, also not mentioned in the Turin Papyrus, but important monarchs in their time.

1 The ephemeral King Auabra Hor, who was buried at Dashur, next to the second pyramid of Amenemhät III, was probably a co-regent who died young, with either Senusert 111 or Amenemhat 111. This beautiful naked statue of wood, found in his tomb, is in the Cairo Museum (DE MORGax and Legraix, Fouilles de Dahchour, Pll. xxxiii.-xxxv.).

2 To the Thebans, contemporary with them, we may perhaps assign the kings Senbmaiu, Dedneferra Dedumes, Sekhaura Mentuhetep, Sekhem-uah-ka-Ka Rahetep, Sekhem-nefer-khan-Ra Upuatemsaf, Sekhem-khu-taui-Ra Pentien, and Sekhemnckht-em-Tj'emel, whose scanty monuments have been found in Upper Egypt, those of the first three only at Gebelein and Deir el-Bahari, while the others are $a ̈ \pi a \xi \lambda \epsilon \gamma \delta \mu \epsilon v a$. Their prenomens are distinctly Upper Egyptian and Theban in character, that of Sekhem-nekht-cm-Tj'emet ("Power-strong-in-the-Thebaid") especially so, while Upuatemsaf is a mame that belongs to Siut. None of them are mentioned in the Turin l'apyrus. I think that this theory, which I put forward with diffidence, of a division of the kingdom at the beginning of the NIIIth Dynasty and during the greater part of its duration, best explains the facts. 
They ruled and were buried at Thebes, ${ }^{1}$ and probably did not control the north, as contemporory with them must be two or three names in the Turin Papyrus, notably that of Ra-smenkh-ka Mermeshau, who set up statues of himself at Tanis. $^{2}$ Then came a group of legitimate monarchs, mentioned in the Turin Papyrus, who ruled the whole land: Sekhem-suatjtaui-Ra Sebekhetep II, and the two brothers Neferhetep and Khaneferra Sebekhetep III. The monuments of the latter are found from Tanis in the north to the island of Arlo in Nubia, ${ }^{3}$ so he probably advanced the southern boundary beyond the limit fixed by Senusert III. The succession of these princes passed in the female line; the father of Neferhetep and Sebekhetep III was a simple priest named Haankhef, but his mother Kcmi was no doubt a daughter of Sebekhetep II; his mother Auhetabu, however, as well as, apparently, his father Mentuhetep, were of non-royal birth, ${ }^{4}$ so that he probably owed his throne to adoption.

Sebekhetep III was the last powerful monarch of the Middle Kingdom. His successors were ephemeral kings, only known to us from scarabs and the Turin Papyrus; Thebes was apparently independent again under princes who bore the name of Antef, ${ }^{5}$ and the Delta was ruled by chiefs who bore allegiance

${ }^{1}$ The tomb of Sebekemsaf II and that of his queen Nubkhas were visited by the royal inspectors of the Theban necropolis under the XXth Dynasty (sce p. 392), and found violated. The chronological position of the Sebekemsafs seems to be settled by inscriptions at El Kab (PIEPER, Die Könige zwischen dem Mittleren und Neuen Reich, pp. 2 ff.). I cannot agree with Prof. MEYER (Nachträge zur äsypt. Chronologie, p. 32) that Pieper is altogether wrong in associating the Sebekemsafs with the Antefs of the XVIIth Dynasty (see p. 220), following NEwBERry (P.S.R.A. xxiv. 385 ff.), since Prof. Newberry is no doubt right in placing the Antefs very near the Sebekemsafs in time, though the princess Sebekemsaf whom Nub-kheperRa Antef married (p. 222) can hardly have been a daughter of Sebekemsaf II : here no doubt Meyer is right. Sebekemsaf I has left several monuments, notably a statue in the British Museum (No. 87I).

${ }^{2}$ Photograph in Petrie, Hist. Eg. i. p. 2Io (Fig. II9). His name need not mean that he was actually a general of soldiers (mermeshau): the name may have been given to him at birth.

${ }^{3}$ I see no reason to suppose that the statue of Sebekhetep III was transported to Arko in later times, perhaps by the Ethiopians, as has been suggested.

4 We know the genealogy of Auhetabu and her family from a stele discovered by Prof. Petrie at Abydos (Abydos, iii. p. 48, Pl. xiii.).

${ }^{5}$ These kings, of whom there are four, were formerly assigned to the XIth Dynasty, but STEINDORFF has shewn that they belong to the period of the XIIIthXVIIth Dynasty (see p. 220, n. I). For various archaeological reasons we must place then not very long after the Sebekemsals, and not very long before the Sekenenras (p. 222). One of them, Nub-kheper-Ra Antef, was certainly an adversary of the 
to foreign conquerors from Palestine, the famous Hyksos, who now first appear in our history. The Antefs are, as usual, not mentioned in the Turin Papyrus, but the Delta chiefs are, and one of them, Nehesi ("the Negro") is also known from a monument on which he worships the god Set or Sutekh, the tutelary deity of the Hyksos, so that he was, apparently, their vassal. ${ }^{1}$ These subjects of the Hyksos are apparently the XIVth (Xoite) dynasty of Manetho.

So the kingdom of the Amenemlats and Senuserts came to its end, in degeneration, ${ }^{2}$ division, and barbarian conquest. The Asiatic conquest is the central climacteric of Egyptian history. With it direct relations were for the first time established between Egypt and the Asiatic world. Hitherto the civilizations of Babylonia and Egypt had pursued their own ways independently, having hardly ever come into any contact with each other, so far as we know, since history first began in the Nile-valley. It is therefore possible to treat the story of Babylonian culture up to the end of Khammurabi's dynasty and Egyptian history up to the Hyksos conquest entirely independently of each other. But with the beginning of the second millennium B.C. this is no longer possible. Egypt has been brought into forcible contact with the civilized Asiatics, and henceforward she remains in close contact with them, for her weal or her woe, throughout her history.

But, while Egyptian civilization after the expulsion of the Hyksos and the conquest of IVestern Asia was in many ways very different from that of the preceding age of isolation, the culture of the Middle Empire differed very little from that of the Old Kingdom, as established at the close of the Archaic Period, the end of the IIIrd Dynasty; the mere transference of the centre of gravity from Memphis to Thebes altered Egyptian civilization very little. The modifications which differentiate the Egypt of the XIIth Dynasty from that of the IVth are merely the effects of time, and in the culture of the VIth Dynasty

Hyksos (p. 220). They ruled and werc buried at Thebes, and the coffins of three of them have been found: one is in the British Museum (No. 6652), which also possesses a "pyramidion" with the name of this king, Seshes-up-maat-Ra Antef-o (No. 578).

${ }^{1}$ Meyer, Nachträge, p. 34.

${ }^{2}$ This degeneration is well seen in the art of the XIIIth Dynasty, which lost all the vigour and spontaneity of the XIIth. The royal statues, for instance, became poor, hard, and dry in the treatment, and characteristically elongated in form. 
we see the transition in progress; here we find something which we have met with under the IVth Dynasty, but do not find under the XIIth, there something which we have not met with before, but which we shall find usual under the XIIth.

\section{I2. The Civilization of the Old and Middle Kingdoms}

Art-Religion: rise of Amen of Thebes-Osiris and Khontamentiu-Funerary customs-Political development

It is therefore difficult to compare the civilization of the Middle Kingdom as a whole with that of the Old Kingdom. We might compare the art of the two periods, for art always followed royal fortunes. Under powerful kings it grew and flourished, under weak kings and amid the internecine conflict of warring nobles it languished and withered. So the fine art of the Pyramid-builders degenerated at the end of the VIth Dynasty into the grotesque caricatures of the beginning of the XIth, out of which, however, from the time of the great Neb-hapet-Ra Mentuhetep, developed again the splendid artistic triumphs of the XIIth Dynasty.

Religion, like art, followed the fortunes of the monarchy, for the religion of the Middle Kingdom presents us with a new phenomenon which differentiates it from that of the Old Kingdom, and was directly due to the political events of the beginning of the XIth Dynasty. This was the appearance of a new deity, previously hardly known, who, as the patron of the Prince of Thebes, soon aspires to rank as king of the gods, as his servant had become ling of men. This was Amen, already identified at the beginning of the XIIth Dynasty with Ra, the ancient patron of the Memphite kings. ${ }^{1}$ The Theban monarchs had to be "Sons of the Sun": the phrase had become fixed in the royal titulary, and carried with it the claim to the loyalty of all Egyptians. But they were also sons of Amen, and therefore the two gods were combined, probably by Senusert I, who built great temples for Ra of Heliopolis and Amen of Thebes, thus shewing his derotion to his double protector. The special

] The earliest mention of Amen-Ra is on a stele of the reign of Senusert I (Brit. Mus. No. 586), and one of the earliest appearances of him in his fully developed form is on a monument of Senusert III found at Dêr el-Bahri (Naville, Deir cl-Bahari: XIth Dynasty, i. Pl. xxiv.); he also occurs on the private stela of a person named Rensenb, found at Abydos in 19 Io by Prof. Naville and Mr. Peet. 
worship of Sebek, the crocodile-god of the Fayyum, in deference to royal predilections, again distinguishes the religion of the Middle Kingdom from that of the Old. And at this time Osiris, the dead-god of Busiris in the Delta, who had under the Old Kingdom already been identified with Sokari, "the Coffined One," who presided over the Memphite necropolis, gradually advanced to the position of "Universal Lord" (Neb$r$-tjer) of the world of the dead by attracting to himself the name and attributes of Khentamentiu, the ancient dead-god of Abydos in the South. " "Osiris-Khentamentiu, Lord of Busiris, Great God, Lord of Abydos," is henceforth always invoked in the funerary inscriptions, and Anubis, though he is " $\mathrm{He}$ who is on the Serpent-Mountain and in the Oasis, Lord of the Holy Land (the Necropolis), Lord of Sepa," is but his inferior rival, and gradually becomes his son and servitor. Funerary customs under the XIIth Dynasty differed, however, but little from those in vogue under the VIth; the only noticeable development being an increase in the number and variety of those characteristic wooden models of servants that accompanied the dead to the tomb, and the first appearance of those little figures, the Ushabtiu, or "Answerers," which later became so typical a feature of Egyptian burials. The function of the usluabti was to arise and "answer" when the dead man was called upon to do work in the Underworld: "Here am I, whensoever thou callest me!" There can be little doubt that these figures of stone or wood (later also of pottery) represented slaves who at a much earlier period were immolated at the grave and buried with their master, to accompany him to the next world.

The actual condition of the living underwent alterations, owing to changes in the actual method of administering the country, which did not coincide with the division into an Old and a Middle Kingdom according to the fortune of the kings. We have a Feudal Period which bridged the gap between the two, lasting from the Vth to the XIIth Dynasty. During this period the royal officials, headed by the Vizier or Tjate ("The Man," as opposed to "the God," i.e. the King), an official who appears already in the time of Narmer, and the Mer-shema or Mertoris, the "Overseer of the South" (for Upper Egypt), had very little authority. $U_{p}$ till the middle of the Vth Dynasty the land and people were, so far as we can sce,

$$
{ }^{1} \text { See p. } 101 .
$$




\section{I70 'THE ANCIEN'T HISTORY OF 'THE NEAR EAST}

exclusively the property of the king, who granted to his courtnobles estates which were administered for them in their absence by his officials. Then the nobles began to reside on their estates. Taxes, at first raised every second year for the royal benefit alone, probably became local imposts, as the court grew poor. And so the great local aristocracy of feudal barons grew up, which administered the land from the end of the Vth till the middle of the XIIth Dynasty. Weak kings allowed this aristocracy to grow up, powerless kings saw it plunge the whole land into war. Then powerful kings again first curbed and then strangled it. There is then but little difference between the local magnates of the XIIth Dynasty and their predecessors of the VIth: here we see no difference between the Old and Middle Kingdoms. But the bureaucracy of townmayors which succeeded the landed aristocracy at the end of the XIIth Dynasty is quite different from anything that had gone before; here the later Middle Kingdom is entirely different from the earlier Middle Kingdom and the Old Kingdom. 


\section{CHAP'TER V}

\section{THE EARLY HISTORY OF BABYLONIA 3000-1500 B.C.}

\section{The Sumerians}

The Sumerian founders of Babylonian culturc-Possible pre-Sumerian (? Semitic) element in Babylonia-The Semitic (?) gods of the Sumerians--Sudden appearance of Sumerian culture-Its early stages not passed in Babylonia but most probably in India, i.e. they were Dravidians who passed through southern Persia to BabyloniaProbably they brought the higher civilization to the Euphrates valley-The first irrigation of the valley: legends of Marduk and Tiâmat-Excavations at Fârah-The beginnings of history, late in the story of Sumerian culture-Berossos' account of the early history of Babylon-Oannes the civilizer-The Deluge-The legend of Kutha -Gilgamesh and Eabâni-The city-states and patesis-Utug, the first known rulerUr-ninâ of Lagash-Sumerian art in his time-Eannatum and the "Stele of the Vultures"-The wars of Lagash and Umma-Sumerian military array-War against Elam-Entemena and the relics from Telloh-Urukagina the reformerLugalzaggisi of Umma conquers Lagash-The empire of Lugalzaggisi reaches the Mediterranean-Early Syria and Palestine

. HE later culture of Semitic Babylonia and Assyria is based almost entirely upon foundations laid by a non-Semitic people, the Sumerians, as we call them, from the fact that the chief seat of their power was the land of Southern Babylonia, which they called "Sumer." To them was due the invention of the cuneiform script, the outward mark and inward bond of Mesopotamian (and so of all early Semitic) culture; and our knowledge of this has shewn us that the language which it was originally devised to express was not Semitic, but an agglutinative tongue.

There are, however, certain indications visible in the remains and representations of Sumerian culture that point to a preSumerian and specifically Semitic element in it. Thus the Sumerian gods are always represented as Semites, with very full and long hair and beard, while the Stimerians werc always 


\section{clean-shaven, as to the face, and usually (though not always)} also as to the head. ${ }^{1}$ The garment worn by the gods is also that assigned in later representation, to Semites, namely, a sort of woollen cloth plaid, while the Sumerians wore cloaks which look as if made of either rough wool or possibly skins, or even palm-leaves. There were probably inhabitants in Mesopotamia before the Sumerians arrived, and it is hardly probable that they can have been of other than Semitic race, so that this curious fact as regards the representation of their gods may be thus explained. On conquering the country the Sumerians adopted the Semitic deities of the soil, a proceeding not improbable of itself and entirely consonant with ancient religious ideas. $^{2}$ Their own gods were at the same time altered in their appearance in order to agree with their new and predominant colleagues.

The Sumerian culture springs into our vicw ready-made, as it were, which is what we should expect if it was, as seems on other grounds probable, brought into Mesopotamia from abroad. We have no knowledge of the time when the Sumerians were savages: when we first meet with them in the fourth millennium B.C., they are already a civilized, metal-using people living in great and populous cities, possessing a complicated system of writing, and living under the government of firmly established civil and religious dynasties and hierarchies. They had imposed their higher culture on the more primitive inhabitants of the river-valley in which they had settled, and had assimilated the civilization of the conquered, whatever it may have been, to their own. The earliest scenes of their own culture-development had perhaps not been played upon the

${ }^{3}$ Long hair is worn by Eannatum and his soldiers on the Stele of the Vultures (Plate VII. 3). We have no warrant whatever to suppose that they wore wigs like the Egyptians; so peculiar a custom is not likely to have been known to more than one nation. Also we have Babylonian laws, which prescribe that as a punishment a man's hair is to be cut off (SAYcE, Babylonians and Assyrians, p. 196). This looks as if it were prized and worn very long, as it is by Eannatum. On the other hand, the representations of Sumerians usually shew then with shaven heads. Are the shaven-polls really all priests? The great men were often priests, and so would be represented with shaven heads. The priests represented performing religious rites (stark-naked, according to Sumerian custom, which the Semites did not follow) are all shaven.

2 This view was first adumbrated by Prof. E. Meyer (Semiten and Sumeritr; Abhandl. k. p. Akad., 1906), and has been adopted in a modified form by the present writer. Mr. KING criticised it (History of Sumer and Akkad, pp. $48 \mathrm{ff}$.), but is inclined to adopt it, also in a modified form. 

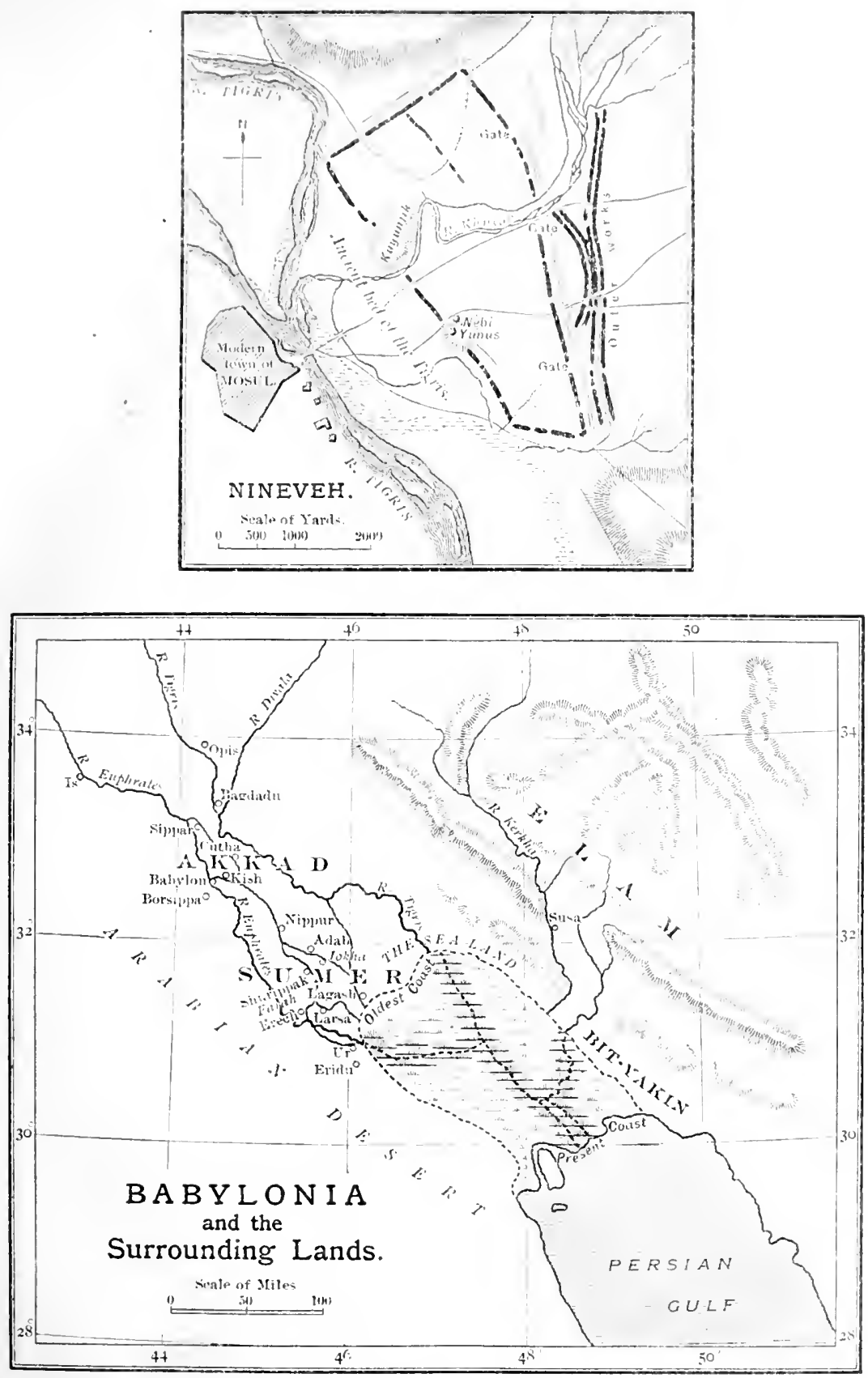

Babylonian stage at all, but in a different country, away across the Persian mountains to the eastward. The land of Elam, the later Susiana, where till the end a non-Semitic nationality of Sumerian culture maintained itself in usual independence of the dominant Mesopotamian power, was no doubt a stage in their progress. There they left the abiding impress of their civilization, although the Elamites developed their art on a distinct line of their own. ${ }^{1}$ Whether the Elamites, whom they probably civilized, were racially related to them we do not know; the languages of both Elamite and Sumerian were agglutinative, but otherwise are not alike. The Elamite tongue may very well have been allied to the modern Georgian, and we may regard it as the southernmost member of a group of nonAryan and non-Semitic tongues, to which has been given the name "Alarodian," which in ancient times stretched from the Caucasus to the Persian Gulf along the line of the Zagros, but now is confined to the Caucasian region. Sumerian may also belong to this group, or may (and this seems more probable) have come from much farther afield. The ethnic type of the Sumerians, so strongly marked in their statues and reliefs, was as different from those of the races which surrounded them as was their language from those of the Semites, Aryans, or others; they were decidedly Indian in type. The face-type of the average Indian of to-day is no doubt much the same as that of his Dravidian race-ancestors thousands of years ago. Among the modern Indians, as amongst the modern Greeks or Italians, the ancient pre-Aryan type of the land has (as the primitive type of the land always does) survived, while that of the Aryan conqueror died out long ago. And it is to this Dravidian ethnic type of India that the ancient Sumerian bears most resemblance, so far as we can judge from his monuments. He was very like a Southern Hindu of the Dekkan (who still speaks Dravidian languages). And it is by no means improbable that the Sumerians were an Indian race which passed,

1 The recent discoveries of the French expedition under M. de Morgan at Susa have brought to light previously undreamt of evidence of early civilization in Elam. The artistic spirit of the Elamites seems to have developed early and has left remarkable proofs of its originality and power (see DE MoRgav, Deligation en Perse, vol. vii. (1905) ff.). Later on, Babylonian influence found on the Sumerian origin of the Elamite culture a fruitful ground for its propagation, and eventually Elamite art, like the rest of Elamite culture, became entirely babylonized (see p. 195). 
certainly by land, ${ }^{1}$ perhaps also by sea, ${ }^{2}$ through Persia to the valley of the Two Rivers. It was in the Indian home (perhaps the Indus valley) that we suppose for them that their culture developed. There their writing may have been invented, and progressed from a purely pictorial to a simplified and abbreviated form, which afterwards in Babylonia took on its peculiar "cuneiform " appearance owing to its being written with a squareended stilus on soft clay. On the way they left the "seeds of their culture in Elam. This seems a plausible theory of Sumerian origins, and it must be clearly understood that it is offered by the present writer merely as a theory, which has little direct evidence to back it, but seems most in accordance with the probabilities of the case. There is little doubt that India must have been one of the earliest centres of human civilization, ${ }^{3}$ and it seems natural to suppose that the strange un-Semitic, un-Aryan people who came from the East to civilize the West were of Indian origin, especially when we see with our eyes how very Indian the Sumerians were in type. ${ }^{4}$

We do not know whether the first foundation of the cities of Babylonia was due to the Sumerians or to their predecessors. At the beginning of history we find the cities of Southern Babylonia (Sumer) exclusively inhabited by them, while

1 We have at the present day a Dravidian population in Baluchistan, the Brahuis ; the Dravidian type has been noted in Southern Persia; and there can be little doubt that the non-Aryan peoples of ancient Persia (the "Anariakoi" of the Greeks) are of the same race, forming a connecting link between Babylonia and India.

2 The legend of Oannes, the "Man-Fish," quoted by Berossus, argues an early marine connection with a civilized land over sea. Oannes swam up the Pcrsian Gulf to the earliest Sumerian cities (Eridu and the rest), bringing with him the arts of civilization.

${ }^{3}$ But this civilization was not Aryan. The culture of India is pre-Aryan in origin; as in Greece, the conquered civilized the conquerors. The Aryan Indian owed his civilization and his degeneration to the Dravidians, as the Aryan Greek did to the Mycenaeans.

${ }^{4}$ Prof. G. Elliot Smith is too positive in rejecting the view that the Sumerians were immigrants from elsewhere into Babylonia (The Ancient Egyptians, pp. I39, 140), and in making them "the eastern wing" of the Mediterranean brunet race (ib. p. I44). If so, they must have been akin to the prehistoric Egyptians, who on his own showing were a people of oval facial type with delicately-modelled aquiline noses (ib. p. 52), whereas the Sumerians were of quite different type, with the strongly developed nose which he regards as characteristic of the "Armenoid" peoples farther north who amalgamated with the Semites. I do not see how the Sumerians can be connected with the Mediterraneans, if the "Hamitic" Galla race to which the proto-Egyptians presumably belonged was "Mediterranean" (which I do not think it was). 

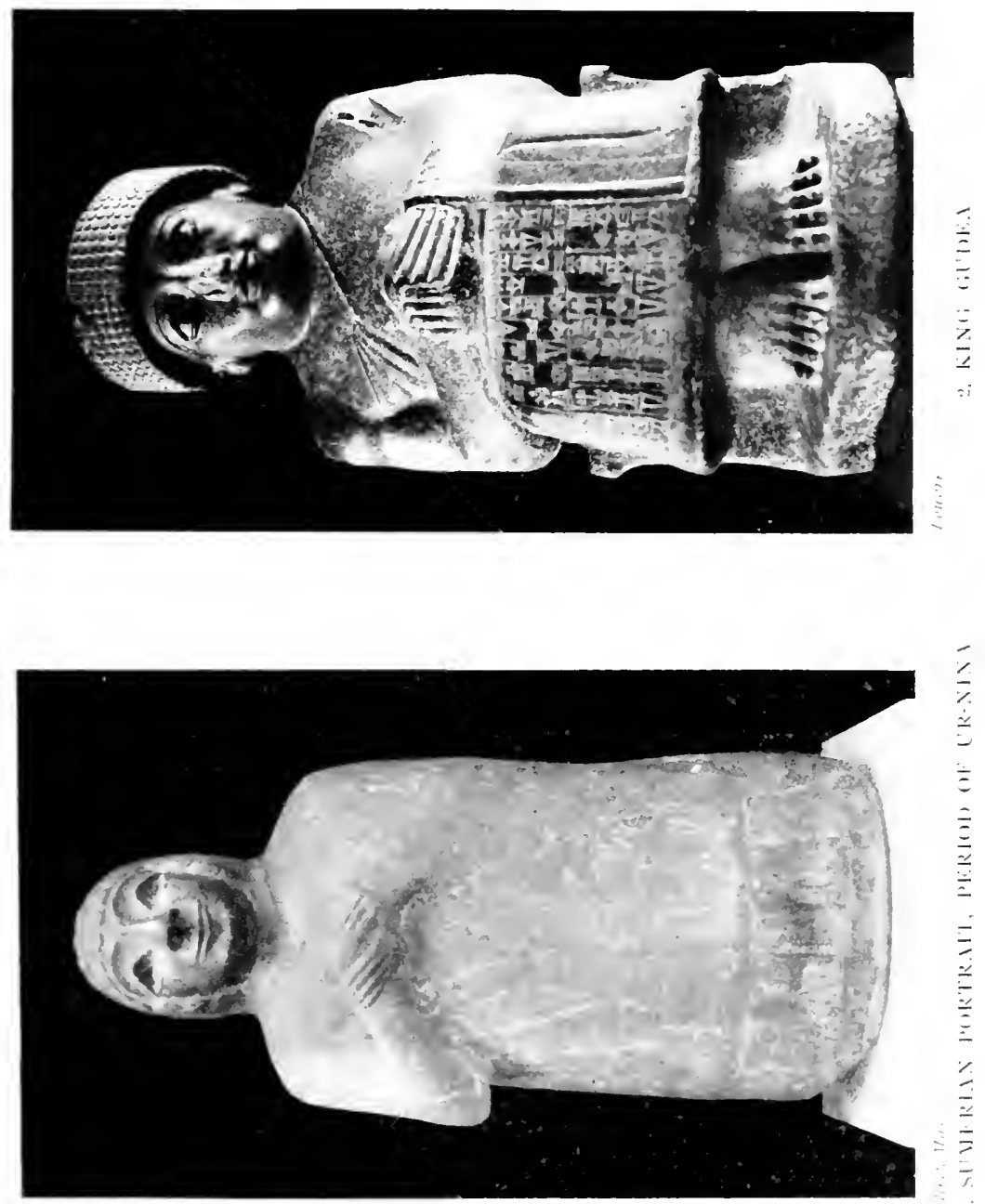

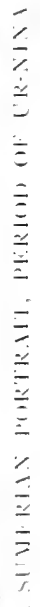



Northern Babylonia (Akkad) has also civilized Semitic inhabitants dwellers in cities, like the Sumerians. A common SemitoSumerian civilization has already been evolved, chiefly, no doubt, on purely Sumerian bases. The Sumerian system of writing is already used to write Semitic. It seems probable that the art of city-building and the practice of town-divelling was brought in by the more highly cultured Sumerians. The primitive Semite of the valley was probably half-nomadic.

Whether it is to the Sumerians that the first drainage and irrigation of the river-swamps is to be assigned is uncertain. Legends, which were put into the shape in which we have them after the unification of Sumer and Akkad under the headship of Babylon, assign to the Babylonian god Marduk the work of reducing the primeval chaos to order by the separation of land from water, and the first founding of the homes of men on the reclaimed earth. Marduk, having, according to another version, vanquished the demon of the primeval watery chaos, Tiâmat, laid a reed upon the face of the waters and poured dust upon it, so that the first land was formed: then he made a dyke by the side of the sea to reclaim the land from it, and manufactured bricks; houses and cities followed, "then was Eridu made, and E-Sagil (the temple of Bel Marduk in Babylon) was built. . . . Nippur he made, E-kur he built ; Erech he made, E-ana he built." ${ }^{1}$ We evidently have here a very vivid recollection of the time when the whole of Southern Babylonia was a swamp : the primitive inhabitants were scattered about on various islands which emerged out of the fens, and on these islands towns arose, just as Ely and Peterborough arose in England under similar circumstances: dykes were heaped up and the shallows were gradually reclaimed, till the demon of the watery chaos, Tiâmat, finally vanquished, retreated from the land; Marduk had created the earth and the two great rivers, and, in the words of the legend, "declared their names to be good." 2

In this legend Marduk no doubt replaces an earlier local god, probably Enki or Ea of Eridu, which appears as the most ancient foundation of all. Ea, the Sumerian Enki, was primarily

${ }^{1}$ KING, Seven Tablets of Creation, i. pp. 133, 137.

2 We may compare with this legend the Hebrew story of the Creation. The Babylonian legend is a reminiscence of the actual way in which Babylonia was reclaimed from the watery tohu-wa.bohu, "when there was neither land nor water, but a mingling of the two"; this was how Babylonia was created, and to the primitive Babylonian Babylonia was the whole world. 
the God of the Waters. Whether Ea was originally a Sumerian or a Semitic god is uncertain; his Semitic name Ea seems primitive in form. It is not impossible that the first reclamation and settlements in the marshes were those of the pre-Sumerian Semites, who presumably inhabited Sumer as well as Akkad, and that the first foundation of the city settlements was due to the predecessors of the Sumerians. But we can well imagine that the Sumerian conquest brought about a great advance in civilized development, and that the characteristic importance of the cities in Babylonia was due to the apparent Sumerian instinct for concentration and organization. The Sumerians were the real conquerors of Tiâmat, although they may not have begun Ea's work.

The most ancient remains that we find in the city-mounds are Sumerian. The site of the ancient Shurippak, at Fârah in Southern Babylonia, has lately been excavated. ${ }^{1}$ The culture revealed by this excavation is Sumerian, and metal-using, even at the lowest levels. ${ }^{2}$ The Sumerians apparently knew the use of copper at the beginning of their occupation of Babylonia, and no doubt brought this knowledge with them.

The most ancient names of Babylonian kings and chiefs known to us are Sumerian in form, and their inscriptions are written in Sumerian, though there is reason to suppose that the early kings of the city of Kish, in Akkad, were Semites. A Semitic revival, so to speak, was beginning; the Sumerized Semites of Northern Babylonia were preparing to gain the upper hand and to absorb their conquerors and civilizers. For we know only the latter end of the story of Sumerian rule in Babylonia. At the beginning of history the Sumerian power is already declining amid a chaos of civil war and Semitic revolt. We do not know whether the warring cities which we see at the dawn of history had ever been urited in one compact Sumerian kingdom under a Sumerian dynasty, with its centre either at ancient Eridu or at Nippur, the primate city of primitive Babylonia and seat of Enlil, the chief god of the country. But it is not impossible that they had been so united.

Legend, at any rate, speaks of a very ancient kingdom of "Babylon," with a long line of semi-divine rulers over the whole

${ }^{1}$ See M.D.O.G. Nos. $15,17$.

${ }^{2}$ For a summary description of the discoveries at Fârah, see KInG, Sumer and Akkad, pp. $24 \mathrm{ff}$. 
land, each of whom reigned for an enormous period of time, thus resembling the Egyptian "Ghosts" and "Followers of Horus." 1 Some of their names have been preserved for us in the extant fragments of the history of Berossos. ${ }^{2}$ He tells us of the first of the kings, who reigned for even longer periods, Alôros, who reigned 36,000 years, and his successors down to Xisuthros, in whose time the Deluge took place. Alôros came after the first civilizer of Babylonia, Oannês, a monster halfman and half-fish, who issued out of the Persian Gulf, and taught the use of writing and other arts to savage mankind. We possess no Babylonian text referring to Oannês, but there is no doubt that he was in some way connected, if not identical, with Ea, the god of the primeval waters, who was worshipped in the most ancient city of Babylonia, Eridu, which ages ago stood on a lake near the Persian Gulf, now over a hundred miles away. Neither have we as yet met with any legends of Alôros and his successors in the cuneiform texts, but there is no doubt that Berosus is entirely to be trusted in his compilation of the legends of his people. Xisuthros is evidently the same as Khasisadra or Atralshasis, in whose time Sît-napishtim went into the Ark, to save himself from the Deluge. Berossos' mention of the Deluge is not derived from Hebrew sources, as used, naturally, to be thought, but is a faithful record of the ancient tradition of his own people, on which the Hebrew legend was founded. After the Deluge, according to the traditions preserved by Berossos, eighty-six kings reigned during 34,080 years, two of them for 2400 and 2700 years respectively, but those at the end of the list for the ordinary span of human life only. It is no wonder that Cicero smiles at the vast antiquity that the Babylonians claimed for themselves. ${ }^{3}$

Other legends, which we hear directly from cuneiform sources, know nothing of a primitive united kingdom. They refer, no doubt, to historical events in a distorted form. Thus there is a legend of an early king of the whole land who reigned in Kutha, which has come down to us in an autobiographical

1 See p. 106.

2 See p. 13.

${ }^{3}$ De Divinatione, xlvi. 97. There is no doubt that this legend of a very ancient kingdom was current in later times in Babylonia, but there is a doubt whether it is really ancient and preserves a tradition of a great Sumerian kingdom, or whether it is not rather an invention of the Babylonians (in the narrower sense), designed by the priests of Bel-Marduk to shew that Babylon and its kings had ruled over the whole land from the beginning; a falsification of history. 


\section{I7 8 THE ANCIENT HISTORY OF THE NEAR EAST}

shape. ${ }^{1}$ The unknown king is made to say that in his days the land was attacked and overrun by a strange people who had the bodies of birds and the faces of ravens, who lived in the mountains to the north of Mesopotamia. Three long years the king contended with the invaders, and finally in the fourth year he routed them. Then we have the voluminous legends concerning a very early king who reigned in Erech, Gilgamesh, who was regarded as a semi-mythical hero, a sort of Herakles, by the Babylonians, and may very well be the original of the Biblical Nimrod. In his days Erech was besieged for three years and was brought to the uttermost straits:-

\footnotetext{
"Men cry aloud like beasts,

And maidens mourn like doves;

The gods of strong-walled Erech

Are changed to flies, and buzz about the streets;

The spirits of strong-walled Erech

Are changed to mice, and glide into holes.

For three years the enemy besieged Erech,

And the doors were barred and the bolts were shot,

And Ishtar did not raise her head against the foe."
}

It is not certain whether Gilgamesh was the besieger or the saviour of Erech : at any rate, he is said to have afterwards ruled the town in a tyrannical fashion, so that the gods made a creature, half-animal, half-beast, named Ea-bâni, who was intended to destroy him. Ea-bâni was however captured by the wiles of a singing-woman of the temple of Ishtar at Erech, and was brought to Gilgamesh, whose devoted friend and ally he soon became. The two then performed many feats of valour in company, the most notable being an expedition against an Elamite ogre named Khumbaba, whose castle they took, and killed its owner.

It is probable that in the expedition against Khumbaba and the defence of Erech we have echoes of far-away historical events. In the stories both of Gilgamesh and of the king of Kutha the cities are independent of one another. And so we find them at the beginning of history.

Each was ruled by a hereditary governor, who was also highpriest of the local god and bore the title of patesi, which signified that its possessor was the earthly vicegerent of the gods. The Sumerian language possessed a word denoting the ruler of a higher political organization: this was lugal, "king" (literally "great man"). This word had no theocratic connotation,

\footnotetext{
${ }^{1}$ King, Seren Tatlets, i. pp. I4I ff.
} 
and whether it was a survival of a time when a stable and unified Sumerian kingdom had existed or not, in the period of confusion which is the earliest as yet known to us, it seems to have been assumed by any patesi who succeeded by force or fraud in uniting several cities under his government: in this case the patesis of the subdued cities, even if one or more of them had themselves previously aspired to be called lugal, reverted to the position of patesis, and the conqueror took the title of lugal, only in all probability to himself lose it in a few years to some patesi stronger than he.

One of the earliest rulers of whom we have any knowledge ${ }^{1}$ seems to be a certain UTUG, of Kish, who dedicated in the great temple of the god Enlil at Nippur, the central navel of Sumer and Akkad, a vase which he had taken as spoil from "the land of Khamazi." Thus we find the internecine war at the beginning of things, and also the position of Nippur as chief city of all Babylonia, which we may, if we please: trace back to an ancient unified Sumerian kingdom with its capital at Nippur.

Utug was probably a Sumerian, but later kings of Kish were Semites. ${ }^{2}$ Later on, the hegemony of Kish disappeared for a time, and Lagash appears as the chief city of Babylonia under the king UR-NINA, the founder of a dynasty, and a most pious servant of the gods, who dedicated countless vases, tablets, and statues in the temples of Ningirsu, Bau his wife, Dunshagga his son, and the goddesses Ninâ, Ninmakh, and Gatumdug, which were already the glory of Lagash. Urninâ was also a great digger of canals, and a builder of granaries and storehouses for the grain-tribute paid to himself and to the gods.

Some of the most ancient relics of Sumerian art date from the time of Urninâ. They are relief-plaques, on which we see the king represented in somewhat primitive wise, seated in a chair and holding a cup, and standing with a basket on his

${ }^{1}$ In the arrangement of these earlier kings I follow generally that of Mr. L. W. Kivg (History of Sumer and Alikad, I910).

2 A new list of early kings published by Schent (Comptes-Rendus de [Acad., I9I I), tells us of kings of Kish who succeeded a dynasty of Opis. But though the Opis list may be historical, that of Kish, headed by a queen named Azag-Bau, originally " a female drink-seller," who reigned one hundred years, seems to belong largely to the realm of legend. This legendary dynasty of Kisb was followed by that of Lugalzaggisi (p. 183), at Erech. 
head, in the guise of a labourer on his own buildingoperations, while around him stand in respectful attitutes his children, headed by his daughter Lidda, and his eldest son Akurgal, who succeeded him on the throne. Behind him is his cupbearer. The intention of the relief is the same as that of the early Egyptian relief palettes of Narmer from Hierakonpolis, but its execution is much inferior, and reminds us very much of the crude work of the early XIth Dynasty in Egypt. Another relief shews a meeting of chieftains and their followers. ${ }^{1}$

The reign of AKURGAL, Urninâ's successor, was undistinguished, but that of EANNATUM, his son, was marked by a great war between Lagash and Umma. We know of this war from the inscriptions and reliefs of the famous "Stele of the Vultures," the most splendid result of M. de Sarzec's excavations at Telloh, and one of the chief glories of the Museum of the Louvre. On this monument ${ }^{2}$ we see Eannatum setting forth to war both on foot and in his assdrawn chariot, at the head of his troops. The soldiers, who march in serried ranks behind, trampling on the bodies of the slain, wear waistcloths of skins round their loins and metal helmets of exactly the same shape as the mediaeval bassinet upon their heads; their hair, which was not shaven, appears from beneath the helmets behind. Eannatum wears the same helmet, behind which his long hair is bound up in a club. Both he and his men are clean-shaven as to the face. Farther on, we see the burial of the slain warriors of Lagash, but the fallen of Umma are represented as lying a prey to the vultures, which are seen carrying off the heads of the slain in their beaks. On another part of the stela we see the god Ningirsu, heavily bearded in Semitic fashion, holding in his hand the strange heraldic emblem of his city of Lagash, and clubbing

${ }^{1}$ DE SARzec, Dicouvertes en Chaldic, Pl. 2 (bis). Contemporary with these relics from Telloh are a statue of a king of Adab, named EsAR, found at Bismaya by the American excavators, and a remarkable figure, found at Telloh, which represents Lupad, a chief of Umma (both illustrated by KiNG, l.c., p. 96). The text upon this figure records a purchase of land, and we possess numerous inscribed clay tablets of this period from Fârah as well as from Telloh, which mostly relate to transactions in land. Matters of this lind had been organized for centuries, it is evident; a regular system of land tenure had grown up, with complicated legal arrangements (see p. 204).

2 See Plate VII. 3. 
with his mace the men of Umma who he has caught in a great net.

The style of this monument is remarkable. It is conspicuous for great vigour of composition and of execution, which accurately reflect the temper of the ruler who caused it to be sculptured. Eannatum was a most vigorous ruler, as we see from the inscriptions of the Vulture-stele, in which he tells us of the genesis of the quarrel between his city and the neighbouring Umma, and of the way in which he brought the enemy to his knees, and finally secured the disputed territory Gu-edin to Lagash.

The loss of life on both sides seems to have been great, and we can well imagine that two armies battling in the formidable array of the Sumerian soldiery would inflict considerable damage upon one another. No shooting with the bow was used, the fighting being based on shock-tactics only, and the victory inclining to the heavier and more thrusting force. The soldiers, protected by efficient body-armour, fought in solid phalanges, six men in a row. The men of the front rank who were armed with battle-axes, carried huge rectangular bucklers which reached their feet, and formed an impenetrable board-wall behind which the men in rear, who carried no shields, could use their long spears with effect. So phalanx moved slowly against phalanx, the shock and thrusting came, and the better men won. Then the bucklerbearers of the victorious side threw away their cumbrous protection, and joined the pursuit with their axes. ${ }^{1}$ This was a highly developed military machine, which had clearly been evolved by long years of constant civil war. The loose order, comparatively feeble armour, and bow-and-arrow and hatchet fighting of the contemporary Egyptians ${ }^{2}$ was by no means so efficient. We do not know whether the chariots in which the Sumerian kings drove to war were ever actually used for charging and fighting in battle: most probably they were not, serving merely as conveyances to the field. They were drawn by asses, the horse being still unknown. ${ }^{3}$

Elam also experienced the weight of Eannatum's arm. "By

${ }^{1} \mathrm{~K} i \mathrm{Ng}$, l.c., p. I 36.

${ }^{2}$ Cf. the ancient models of Egyptian soldiers found at Meir (Maspero, Struggles of the Nations, p. 223).

See pp. 203, 213. 
Eannatum," says the king of Lagash himself, "was Elam broken in the head: Elam was driven back to his own land." Then, as ever afterwards, the hardy mountain-tribes of Elam were always ready for a descent upon the fruitful and wealthy Babylonian plain. In this case also, as after the defeat of Umma, Eannatum says that he "heaped up burial mounds," thus indicating the slaughter he had made.

Whereas Eannatum had been primarily a soldier, and had devoted little time to the service of the gods, ENTEMENA, his second successor, was not only a warrior but also a patron of religion and the arts. One of the finest relics of his reign is a magnificent votive vase of silver, found, mounted on its original copper stand, to which it has become united by oxydization, in the ruins of Telloh. ${ }^{1}$ On this beautiful object we see a row of representations of Imgig, the lion-headed eagle of Ningirsu, grasping either lions or antelopes by their tails, a representation which served as the heraldic cognizance of Lagash. We have already seen this remarkable emblem accompanying Ningirsu on the Stele of the Vultures.

Entemena was succeeded by four short-lived and undistinguished patesis, to whom succeeded the remarkable usurper and reformer URUKAGINA, the last king of Lagash. The prosperity of Lagash, due to the huge amount of taxes and tribute in corn, wood, and other things which she had exacted for years from the whole of Sumer and the greater part of Akkad, had demoralized the ruling officials and priests of Ningirsu's state. They had divided the plunder of the other cities among themselves, and had combined to rob and oppress the common people.

The usurper Urukagina stood forth as a champion of reform, in the interests of the ordinary taxpayer. He cut down the perquisites of the priests and restrained the exactions of the lay officials of the palace, abolishing various extortionate fees and dues to which not only the vizier, but even the patesi or king himself had a right. He enacted new laws respecting divorce, and in his reign he says: "To the widow and the orphan the strong man did no harm." He stands out as the anticipator and predecessor of the lawgiver Khammurabi, who obviously modelled himself upon his Sumerian predecessor. ${ }^{2}$

But his reforms endeared him to none but the poor and De Sarzec, l.c., Pl. 43 (bis). 
the powerless. And the enemy at the gate, Umma, was again independent and strong. LUGALZAGGISI, son of Ukush, patesi of Umma, determined to take advantage of the weakness of the old foe of his city, and attacked her suddenly, with complete success, ending the reign of Urukagina and the dominion of Lagash at one blow. We know of this event only from a remarkable historical composition written by a priest in Lagash shortly afterwards, and discovered at Telloh: in it the writer recounts the sacrilege of the invaders and heaps curses on the name of Lugalzaggisi, the conqueror. ${ }^{1}$

After overthrowing Lagash Lugalzaggisi became naturally the chief power in Babylonia. Leaving Umma, he established his capital at Erech, and took the title of king of that city, and of the land of Sumer. Then he carried his arms beyond Babylonia into Syria or Amurru, the Land of the IVest, which he subdued, reaching the Mediterranean at the end of his march. "When the god Enlil, ling of the lands," says the conqueror, "had bestowed upon Lugalzaggisi the kingdom of the land, and had granted him success in the eyes of the land, and when his might had cast the lands down, and he had conquered them from the rising of the sun unto the setting of the same, at that time he made straight his path from the Lower Sea, from Euphrates and Tigris, unto the Upper Sea. From the rising of the sun unto the setting of the same has Enlil granted him dominion." 2

By this march to the Mediterranean the foundations were laid of the actual dominion over Syria exercised by the Semitic kings of Akkad some two centuries later. ${ }^{3}$

We have very little knowledge of the state of Syria and Palestine at this period, when they first appear in history. It is possible that the influence of Sumerian civilization had been perceptible in the West at an even earlier period, but we have no direct proof of this. The recent excavations of the Palestine Exploration Fund at Gezer and of the Germans at Megiddo 4 have shewn that Palestine was originally inhabited by a neolithic population that lived in caves, and was probably related to the troglodytic people of the desert between the Nile

\footnotetext{
${ }^{1}$ King, l.c., p. I89.

2 Thureau-Dangin, Königsinschriften, pp. 152 ff.

${ }^{3}$ See p. I 86.

4 For references see p. 440 , n. 4.
} 
and the Red Sea, who are mentioned by Strabo. ${ }^{1}$ We may identify them with the pre-Canaanite Horites or Avvim of Biblical tradition. They developed into or were succeeded by the Anakim or Rephaim, the "Giants" of tradition, who built the megalithic monuments, the dolmens and menhirs, of Moab and eastern Palestine. To them may be due the earliest stone walls of the Canaanite cities. Whether they were Semites or not we do not know. It is probable that in Palestine a pre-Semitic "Mediterranean" population existed," which mingled with the Semitic-speakers who came from Arabia (?). By Lugalzaggisi's time the Palestinians had long been semitized, and the Rephaim and the sons of Anak had already given place to the civilized Canaanites, who were perhaps already adopting the script of Sumer for their writing and incorporating the deities of Babylon into their religion. ${ }^{3}$

\section{Sumerians and Semites}

The Semitic kings of Kish-Sharru-gi-Manishtusu—"Sargon of Agadé" and the Semitic hegemony-Empire of Sargon and Narâm-Sin-Mâgan and MelukhkhaThe "omen-tablets"-The stela of Narâm-Sin-The later patesis of Lagash-Gudea -Dungi-Elamite conquest-The dynasty of Isin

The inscriptions of Lugalzaggisi have been discovered at Nippur, in the shrine of Enlil, the chief god of the Babylonian pantheon, to whom the King of Erech ascribed his success. He was succeeded in his dominion by three kings of whom we know simply the names. War broke out with Kish, of old the ally of Umma, but now her enemy. Semitic kings now ruled Kish.

1 xvii. 786.

2 The curious resemblances of the tree and pillar worship of the early Cretans, for instance, to the Palestinian veneration of Asherah and Massebah, point to a racial connexion between the Mediterraneans and the Palestinians which must antedate the coming of the Semites. The tree and pillar worship of Palestine will have been retained by the Semitized Canaanites from their older beliefs.

${ }^{3}$ We find the Babylonian language, writing and culture so absolutely dominant in Palestine in the fourteenth century B.c., that we can scarcely doubt that it had long been fully at home in the West. In the twentieth century the kings of Khammurabi's dynasty, who were Westerners, do not come before us in the guise of foreigners. They were of the West, but their culture was Babylonian. In the time of Sargon of Akkad we find the West politically dependent on Babylonia; before him, Lugaizaggisi made it tributary. The dependence of the whole "West" on Babylonia seems to have been absolute; Egypt never exercised any authority there, nor wished to, apparently (except possibly on the Phoenician coast, see p. 158), so that Egyptian culture never competed with the Babylonian for the allegiance of the Palestinians. 
To Semitic rulers in Akkad the hegemony of Babylonia now passed, and they, like their predecessors, dedicated their gifts in the central shrine of Enlil at Nippur. SHarRu-Gr (or SHarKUKiN), the first Semitic king who has left monuments of any importance, was in later days confused with Shargani-sharri, King of Akkad, whom we shall presently discuss, and the two together formed a kind of "conflate" personage, the hero "Sargon," who inaugurated Semitic rule in Babylonia." Sharru-gi is known to us directly from a monolithic stone, sculptured in relief with battlescenes, which was found by the French excavators at Susa, whither it had been carried by the Elamites; and indirectly from other monuments. MANisitusu, who came after him, was a powerful monarch. Of him again we possess an important monument which was found at Susa, having been removed thither by the Elamites: this is a great obelisk inscribed in Semitic Babylonian with a list of his lands, in which the patesi of Lagash (Urukagina II, son of Engilsa) and men from Umma appear as his humble vassals. Part of an alabaster portraitstatuette of Manishtusu was also found at Susa, which shews him fully-bearded in the Semitic style. The art is not so good as that of the work of Sharru-gi, but the face is unmistakably a portrait.

Whether Mesalim, son of Manishtusu, succeeded him or not, we do not know. ${ }^{2}$ RIMUSH, or URUMUSH, who followed Manishtusu at no long interval, and preceded Shargani-sharri of Akkad, conquered Elam and evidently greatly increased the Babylonian power. He was said in a later tradition to have lost his life in a palace-revolution. At any rate, his successor is unknown, and it is highly probable that the helm of Babylonia was now taken by two other Semitic chicfs, SHARGANI-SIIARRI and NARÂM-SIN of Akkad. ${ }^{3}$

Few monarchs of the ancient world are so well known to us moderns as "Sargon of Agadé," and we may say that to

${ }^{1}$ See L. W. King, P.S.B.A. xxx. (1908), pp. $239 \mathrm{ff}$.

${ }^{2} \mathrm{He}$ is not to be confused with Mesilim, a much earlier king of Kish.

' UNGNAD (O.L.Z., 19II, pp. 225, 226) makes Shargâni-sharri identical with Sharriken (Sharru-gi), who, on this theory, changed his name to Shargâni-sharri when he (on the hypothesis) changed his capital from Kish to Akkad. Then Rimush and Manishtusu will have followed Narâm-Sin, instead of preceding him and Shargâni-sharri. I have, however, preferred to follow Mr. King's view and regard Sharru-gi and Shargâni-sharri as two distinct persons confused in later legend, owing to the similarity of their names. 
the Babylonians he was their hero of heroes, their Menes, Charlemagne, or Alfred the Great. A foundling brought up by a water-carrier, according to tradition, he ended as ruler of all Western Asia. His doings were taken as an ensample of life for later kings, and if the omens had been such-and-such when Sargon went forth to battle, under similar omens the later King of Babylonia or Assyria would also march to victory. He, confused naturally enough with the earlier Sharru-gi, typified the first triumphant establishment of the Semites as the dominant race in Babylonia.

Historically, Shargani-sharri was the son of a certain DatiEnlil, probably the ruler of the town of Agade under the ling of Kish. He lived, according to the evidence which has already been discussed, probably about 2750-2700 B.C. ${ }^{1}$ That Shargâni extended his rule over the whole of Babylonia is clear. Lugal-ushumgal, patesi of Lagash, owed him allegiance; at Nippur he built the great temple of Enlil, E-kur ; at Babylon he erected a palace; and he founded a new city, Dur-Shargâni, "Shargâniburgh," with inhabitants drawn from Kish and Babylon. In Agade itself he built the temple E-ulbar in honour of Anunitum, the Semitic goddess of the morning-star. As a conqueror beyond the bounds of Babylonia we know from his own contemporary record that he extended his dominions northward and eastward over the land of Guti, in the Zagros mountains, on the modern frontier of Persia and Turkey. Here, and in the neighbouring district of Lulubu, Semitic chiefs ruled, of whom Anu-banini of Guti and Lasirab of Lulubu are known to us in the age before Shargani-sharri, who reduced the Guti king of his day, Sharlak, to obedience.

NARÂM-SIN, whose position with regard to Shargani-sharri is uncertain, conquered Satuni of Lulubu, and commemorated the exploit on a magnificent monument which will shortly be described. He also carried his arms to the far north of Mesopotamia, where a relief-stele of himself, set up in an ancient town ${ }^{2}$ near the modern Diarbekr, commemorates his deeds.

1 The date for Narâm-Sin and Shargâni-sharri given us by Nabonidus has already been discussed (pp. 28, 29), and reasons given for its necessary rejection. We can only reckon back from the comparatively certain later dates, and if Gudea is, with Mr. L. W. KiNG, to be placed about 2450 B.C., we can hardly go farther back than about 2700 B.c. for Narâm-Sin.

2 The tell of the ancient city is close to the modern village of Pir Hussein. The determination of the place of origin of this stele was made by Mr. L. W. King 
He brought stone from Mâgan (Eastern Arabia ${ }^{1}$ ), a stone vase inscribed by him with the words "Vase from the booty of Mâgan" has been discovered, and at Susa has been found a statue with an inscription directly recording the conquest and submission of Mannudannu, King of Mâgan. ${ }^{2}$ He calls himself "King of the Four Quarters of the World"; he erected a temple at Sippar, where Nabonidus discovered his inscription, and ruled as king in Nippur: a cylinder of Nabonidus describes him also as "King of Babylon," but this is probably an error of that blundering royal antiquarian.

Thus far we have derived our information as to these two great kings from their own contemporary monuments and from the archaeological researches of Nabonidus: we have now to turn to a further source of information regarding them, Babylonian legend.

On one of the omen-tablets (of the seventh century B.C.) discovered at Kuyunjik (Nineveh) ${ }^{3}$ we read respecting Sargon that "he traversed the Sea of the IVest, and for three years his hand prevailed in the West. He established his undisputed rule, and in the West his statues [he set up]: he caused the booty of the Sea-lands to be brought." Another version substitutes "Sea of the East" (i.e. the Persian Gulf) for "Sea of the West," and we also read that under certain omens the great king had carried his arms to the Persian Gulf, where the island of Dilmun came under his sway: he also is said, no doubt with truth, to have invaded Elam. An unsuccessful rebellion, in the course of which he was besieged in Agade, is also said to have taken

(H.S.A., pp. 42, 244 f.). It seems more probable that it was set up at Pir Hussein by Narâm-Sin than that it was originally erected at Babylon and carried off to Pir Hussein by some Hittite or Mitannian raider (as at the end of Samsuditana's reign, nearly a thousand years later; see p. 199); whose capital might well be in the neighbourhood of Diarbekr. But this possibility is not wholly to be excluded.

1 That the name Mágan was never at any time used to designate the Sinaitic Peninsula, with which it used to be identified, now seems certain. It can only have been the Arabian coast of the Persian Gulf (see Kisg, l.c., p. 242). And Melukhkha, which is so often mentioned with Mâgan, can at this early time have meant Western Arabia, with its Red Sea littoral. Later on, the name was easily extended to include the African littoral of the Red Sea, and so came in the Assyrian period to mean Nubia.

2 Scheil, in De Morgan, Diligation en Perse, vi. pp. $2 \mathrm{ff}$.

${ }^{3}$ For a full discussion of these omen-tablets and the conclusions which have been drawn from them as regards "Sargon of Agade," see HALL, Oldest Civilization of Greece, pp. 314, 317. 
place during his reign. With respect to Narâm-Sin, the astrological tablets say that he attacked the city of Apirak, on the borders of Elam, killed its king, Rishrammân, and led its people away into slavery. We are led to repose some confidence in the historical accuracy of these traditional accounts because they also mention Narâm-Sin's expedition against Mâgan, which, as we know from his own inscription, did actually take place. If Narâm-Sin could go to Mâgan, so could his father, and the legends of the expedition to Dilmun and the "Sea of the East" state nothing incredible. The variant version which implies an expedition to the Mediterranean may also state a fact, since, if Lugalzaggisi speaks of his own dominion as reaching to the Upper Sea, it is in no way impossible that Sargon also actually waged war and ruled in Syria and Palestine for the space of three years, and set up his statues on the shores of the Mediterranean. ${ }^{1}$

The greatness of these two reigns is worthily commemorated in the splendid stela (Plate XIII.), found by M. de Morgan at Susa (whither it had been carried off, probably by the Elamite king, Shutruk-Nakhkhunte), which records the subjection of Satuni, King of Lulubu, in his mountain-fastness. This is one of the triumphs of ancient art : in it ancient Babylonian art reached its apogee. King Narâm-Sin is shewn in high relief, ascending the slopes of a great mountain, bow and arrow in hand. Before him falls Satuni, stricken by an arrow which he strives to pull out of his neck; behind, a retreating figure turns to beg for mercy. Be-

${ }^{1} \mathrm{KING}$, Chronicles concerning Early Babylonian Kings, i. pp. 27 ff. A further conclusion from this legend has, however, been drawn that is inadmissible (see HALL, O.C.G., p. 113). We have no proof in the statement that Shargani "traversed" the Sea of the West of anything more than a voyage along the Phoenician coast, and have no right to assume a voyage across the sea to Cyprus and a conquest of that island, far less to assume any warlike expeditions farther afield, to the isles of the Aegean (no less!), as is rather absurdly supposed by Winckier (Die Euphratländer und das Nittelmeer, in the "Alter Orient" Series). I have criticized this extreme view in P.S.B.A., Dec. 1909, p. 316. My criticism of the original theory in O.C.G., l.c., has been fully confirmed by Mr. L. W. KING (Sumer and Akkad, pp. 234-243ff.). The supposed proof of this expedition to Cyprus which has been found in a cylinder-seal of Narâm-Sin found at Curium is valueless, since the seal is of much later date than Narâm-Sin, and merely mentions him as deified: it is merely a later importation. Needless to say, no statue of Sargon has been found in Cyprus, which indeed, though Babylonian seals were imported to the island, was never directly influenced by Babylonian or Semitic culture in general till the time of the first Phoenician colonies in the ninth century B.c. 


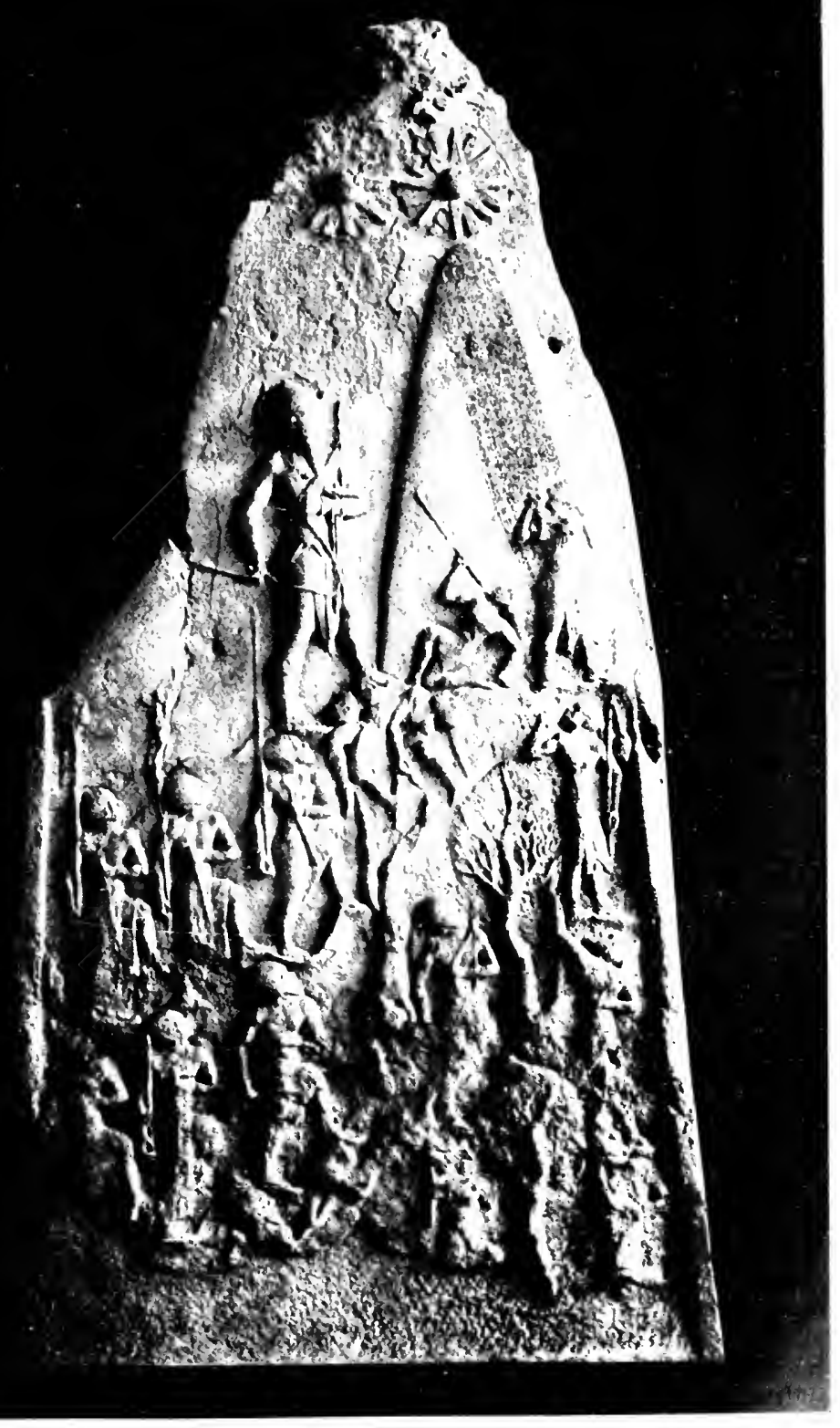

$1 H 1-11.1+11 \times 12111-1 \%$ 

hind and below, on the lower tree-clad slopes of the mountain, climb the king's officers, bearing bows, spears, and standards with heraldic emblems; all in the same attitude of resolute advance, step by step, into the heart of the mountains. Above, shine the sun and stars. The king is bearded, and wears no body-armour, but has a conical horned helmet. His officers are shaven, but wear the helmet without horns. Satuni and his follower have beards and either long hair or hoods with long liripipes like those worn by the Scythians in later times. The use of archery by Narâm-Sin and his men is significant: the bow, which was unknown to the Sumerians, had been introduced by the Semites, and was now acclimatized in Babylonia.

Narâm-Sin evidently extended the empire bequeathed to lim by his father, and assumed the resounding title of " $\mathrm{King}$ of the Four Quarters of the World," which henceforth became a regular appellation of the Babylonian kings, often with little reason.

Of the immediate successors of Shargâni and Narâm-Sin we know little. ${ }^{1}$ A period of some two hundred years now elapses, during which an as yet unpenetrated veil of obscurity lies over Babylonia, and when it is lifted we find that the sceptre has departed from Agade and has passed again to Lagash, where about 2500 B.C. a line of princes reigned who called themselves simply patesis, after the old custom of Lagash. Like their ancestors, they were Sumerians, not Semites. ${ }^{2}$

The greatest of these later patesis of Lagash was GudEA (c. 2450 B.C.), statues of whom ${ }^{3}$ are now in the Museum of the Louvre. This king conquered the district of Anshan in Elam, and, being commanded to do so in a clream, erected a great temple in honour of the goddess Ninâ, stone for which was brought from Syria, gold and precious stones from Arabia (?), great beams of cedar-wood from the forests of Mount Amanus and Lebanon, and asphalt from the Dead Sea region. With

1 The new lists of Scueil (see p. 179, n. 2) give us a dynasty of Erech, following that of Agade. The Erech dynasty is said to have consisted only of five kings in twenty-six years, so that in any case it was of no importance. After its fall, the country seems to have fallen for a time into the possession of the people of Guti, the mountaineers of the Zagros.

2 I'robably they were descended from Lugal-ushumgal, patesi of Lagash in the time of Shargani-sharri. 6 I 3 .

${ }^{3}$ Illustrated in Plate XII. 2, and hy Maspero, Dazen of Civilization, pp. 6i1, 
him $^{1}$ the glory of his dynasty ended, however: his son, UR-NINGIRSU, was compelled to submit to the power of a new dynasty, also Sumerian, which had arisen at Ur. DUNGI, the second king of this dynasty, who reigned for fifty-eight years (c. 2386-2328 B.C.), adopted a new and unprecedented style in order to signify his donsinion over the whole of Babylonia: besides "King of Ur" and "King of the Four Quarters," he called himself "King of Sumer and Akkad," which no king before him had done, and arrogated to himself the divine title. $^{2} \mathrm{He}$ also erected or restored temples,-at Ur, Erech, Lagash, and Kutha,-and even at Susa, the capital of Elam, which seems to have been completely subdued by his arms. Throughout his long reign he was constantly campaigning in Elam and along the Zagros, and it seems to have been his endeavour to outdo the Semite Narâm-Sin.

The dynasty of Ur represents a very definite Sumerian reaction against the Semites. Dungi specially favours the ancient Sumerian city of Eridu, and reduces Babylon, ${ }^{3}$ sacking E-sagila, the holy shrine of Marduk, and carrying off the temple-treasures. So strong was the force of reaction against the empire of Sargon. Orthodox Babylonian scribes in later times could not forgive him for the insult offered to the shrine of Bel-Marduk, even though it were offered in the name of Enlil of Nippur, most revered deity of Babylonia. So the annalist who tells us of these events says: "Dungi, the son of Ur-Engur, cared greatly for the city of Eridu, which was on the shore of the sea. But he sought after evil, and the treasure of E-sagila and of Babylon he brought out as spoil. And Bêl was [wroth?] and [smote?] his body and so made an end of him." Certainly his dynasty did not last. As it had from Lagash, so after three more reigns, lasting forty-three years, the sceptre departed from Ur. The cause of the collapse was a disaster: IBI-Sin, the third successor of Dungi, was carried off a captive to Elam. The Elamite conqueror who took Ur and carried away the High-King of Babylonia captive was probably Kudur-nankhundi, ${ }^{4}$ who, we are told in an inscrip-

${ }^{1}$ For a translation of his rery interesting inscription by Mr. King, see King and HAll, Egypt and Western Asia, pp. $195 \mathrm{ff}$.

2 A practice known hitherto only arnong the Semites (and in Egypt).

${ }^{3}$ Now first mentioned as important.

- This is the view of Mr. KINC (H.S.A., p. 304), and it seems very probable. 
tion of Ashurbanipal of Assyria, had sacked Erech and taken away its goddess Nanâ to Susa, 1635 years before 650 B.C., when Ashurbanipal took Susa and brought back the image of the goddess in triumph. This would place the end of the dynasty of $U r$ in 2285 B.C., or thereabouts, as the Assyrian date is probably not literally correct.

The collapse of Dungi's dynasty was followed by the accession to power of an undistinguished series of kings who form the dynasty of Isin, that city being the town of its founder, ISHBI-URA. We know from a later chronicle the years of the reigns of these kings. With the fifth king, LIBIT-ISHTAR, the family of Ishbi-Ura ended (about 2ISO B.C.), probably amid civil war and foreign invasion. ${ }^{1}$ At this time, or a little later, the family of Syrian conquerors which founded the dynasty of Khammurabi first established their authority at Babylon, and at the same time comparatively ephemeral dynasties were also set up at Erech and Larsam. The dynasty of Larsam later became Elamite. An Elamite lord named KUDUR-MABUG ${ }^{2}$ established himself as King of $\operatorname{Ur}(c .1950$ B.C.), and was succeeded by his sons, Arad-Sin and Rim-Sin, who made themselves kings of Larsam as well. Rim-Sin was a notable figure in the history of Babylonia, as the contemporary and rival of the great Khammurabi. He ended his days in the reign of the successor of Khammurabi, when the final unification of Sumer and Akkad under the leadership of Babylon was accomplished.

\section{The First Dynasty of Babylon}

A dynasty of Semites from the West-Sumu-abu-Sin-muballit extends the dominion of Babylon-The reign of Khammurabi-War with Larsam-Conquest of Asshur-Early Assyria-Empire of Khammurabi-His relations with Chedorla'omer the Elamite-The four kings in Palestine-History preserved in the legend of

1 Of the successors of Libit-Ishtar the most notable was a certain Ura-imitti, who was notorious in later legend as having bequeathed his throne to his gardener, with a resultant civil war, in which the gardener ultimately got the upper hand, and reigned for twenty-four years as King Enlil-bani. Enlil-bani is a historical personage, and reigned about 2116-2092 B.C. The story has nothing impossible or even improbable in it, in an Oriental country. Mr. KING (Chronicles, i. pp. 62 ff.) pointed out that this tradition is preserved by Agathias, who makes Ura-imitti and Enlil-bani "Beleous and Beletaras, kings of Assyria." In his History of Sumer and Akkad, p. 312, Mr. King has further shown that they were kings, not of Assyria, but of Babylonia.

'Kudur-mabug, son of Simti-shilkhak, was, as the names shew, an Elamite. He is called in an inscription of Arad-Sin (published by Thureau-Dangin, kec. Trav. xxxii. (1910), p. 44) "adda of Martu," a title which may point to some real or pretended authority in the West. 
Abraham-Relations with Elam-The war of Emutbalim-Letters and despatches of Khammurabi-Khammurabi as lawgiver-Samsu-iluna-Iluma-ilu and the "Dynasty of the Sea-Land"--The Kassites, the first Indo-European people in the Near East -Overthrow of Babylon by the Hittites-The Kassite conquest

The princes who accomplished this work were foreign Semites, South-Syrian Arabs or Palestinians from Amurru, "the West," which had now for a thousand years been influenced by Babylonian civilization. These "Amorites" were then no strangers to the culture of the land which they were invading. ${ }^{1}$ Whether their first appearance in Babylonia is to be dated to the end of Libit-Ishtar's reign (about 2200 B.C.) or not is, as we have seen, uncertain, but we can be sure that the troubles of a century later were caused by their irruption with their tribesmen in force. The city of Babylon lay much exposed to attack from the Western Desert, and offered, probably, an easy prey. Hitherto, Babylon had been an insignificant factor in the history of Akkad, and its god, Marduk, had little renown or wealth. The energy of its new conquerors made it the chief city of Babylonia, and transfigured the humble Marduk into a king of gods, identifying him with Enlil or Bel of Nippur, the old chief deity of the land, much as in contemporary Egypt the new-fangled Amen of Thebes was identified with the ancient Ra. $^{2}$

Whether Sumu-Alu (c. 2050 B.C. ${ }^{3}$ ), the first king of the new Babylonian dynasty, was the actual conqueror or his son we do not know.

His successors in order until Khammurabi ascended the throne were Sumula-ILU, ZABUm, Immerum (a short-lived usurper), APIL-Sin, and Sin-MUBallit, the latter being the father of Khammurabi. None of these kings seem ever to have acknowledged the overlordship of the kings of Isin or Larsam, and they seem to have themselves gradually increased their authority in an ever widening circle around Babylon. Sippar, Kutha, and Nippur were added to the dominion of Babylon by these kings, and also after the death of its last king, DAMIएILISHU, Isin, taken by Sin-muballit in his seventeenth year (c. 1947 B.C.) from the King of Larsam, who had occupied it. When Khammurabi came to the throne, he found himself ruling over a prosperous state extending from Sippar in the north to

${ }^{1}$ See p. I 84 .

${ }^{2}$ See p. 168.

${ }^{3}$ I adopt the date of Mr. L. W. King (Chronitles, i. p. I Io). 
Nippur in the south, i.e. the whole extent of the ancient Akkad. Southwards, Sumer was still in the state of confusion caused by the devastating inroads of the Elamite conquerors, Erech and Ur had both been destroyed, and the rightful king of Larsam, Siniddinam, was still contending for his throne with the Elamite usurper Rim-Sin. It seems that Khammurabi soon after his accession attacked Rim-Sin; in his fourth year (about 1940 B.C.) he seems to have carried his arms to the border of Elam, and in his seventh he took Erech and Isin from Rim-Sin. But after this year his annals are silent as to any successes against the Elamites, until his thirtieth year is reached. During this period he extended his rule over the greater part of Mesopotamia, and the ex-king of Larsam, Siniddinam, became not only his feudatory, but also took command of the Babylonian troops in the war against Rim-Sin. Further, he reduced to a state of willing obedience the country of Shitullum, to the north of Akkad, and also the still more northerly district of Ashur, ${ }^{1}$ on the Tigris, whose capital Ashur (Assur; the modern Kala'at Sherliat, more than two hundred miles north-west of Babylon), became in later times the seat of the monarchs who succeeded to the inheritance of Khammurabi and created the empire of Assyria. Ilu-shuma of Ashir (as the later Ashur or Assyria was then called) attacked Sumu-abu, the founder of the new Babylonian dynasty, and in Khammurabi's time the King of Ashir or Ashur (Shamsi-Adad I, the sixth successor of Ilu-shuma) was tributary to the great King of Babylon. We cannot go much farther back than Ilu-shuma in the history of Assyria. ${ }^{2}$ Before him we hear (in an inscription of Esarhaddon's) of an early king, Bel-ibni, son of Adasi, "the founder of the kingdom of Assyria," and before him there are two dim figures of tradition, Ushpia and Kikia, of whom the former was a priest, and the founder of E-kharsag-kurkurra, the temple of

1A despatch from Khammurabi himself to the ex-King of Larsam, now preserved in the British Museum (No. 12863), orders his distinguished general to take command of some Assyrian troops, no doubt intended for the war against Elam. It reads as follows: "Unto Siniddinam say: Thus saith Khammurabi. Two hundred and forty men of the King's Battalion, under the command of Nannar-iddinam, who form part of the troops under thy command and who have left Ashur and Shitullum, and . . . let them march, in order that their force may be completed by the addition of Ibni-Martu's troops. Let not these troops delay. Despatch them in all haste that they may march" (KING, Letters of Hammurabi, iii. 4 ff.)

${ }^{2}$ See King, Chronicles, i. p. I26. 
Ashur in the city of Ashur, and so the holiest and most ancient sanctuary of Assyria. Ushpia is mentioned in an inscription of Shalmaneser I. His name is of the Northern and probably nonSemitic type which is associated with the mountain-tribes of Armenia, and it is not impossible that the inhabitants of Assyria were of this race, semitized.

Shamshi-Adad supported Khammurabi loyally in his wars against his great enemies, the Elamites of Larsam. While Khammurabi controlled an empire reaching to Armenia and Palestine, his capital was within easy attack from the forces of Arad-Sin and Rim-Sin, who ruled Southern Babylonia and the coast-lands north of the Persian Gulf. Rim-Sin was never able to jeopardize his enemy's position seriously, and eventually he was worn down to extinction by Khammurabi's successor. For a time it would seem, judging from a most interesting Hebrew tradition, that the kings of Babylon and Larsam were subjected to the power of a great Elamite conqueror named Chedorla'omer, a name which is good Elamite, and would be, properly written, Kudur-Lagamar. The Hebrews' account of the origin of their nation brings, in one legend, the ancestral hero Abraham into warlike contact with "Amraphel king of Shinar, Arioch king of Ellasar, Chedorla'omer, king of Elam, and Tid'al king of the Goyyim," who in alliance were engaged in subduing the revolted Arab tribes of Moab and the Hauran. ${ }^{1}$ The conjunction of these names makes it probable that Amraphel is Khammurabi, that Arioch of Ellasar represents the dynasty of Kudur-mabug at Larsam, and that Chedorla'omer represents the power of Elam, Tid'al that of the Khatti or Hittites of Anatolia. The "Goyyim" of the Hebrews were the non-Semitic "Gentile" tribes, the "nations" which lived in the North, and Tid'al is a Hittite name; a Hittite king five centuries later was called Dûdhalia. ${ }^{2}$ The names are altered: Arioch cannot be identified, as it stands, with either Arad-Sin or Rim-Sin ${ }^{3}$ and Tid'al may owe its existence to a scribe of Dûdhalia's time who wrote down the best-known royal

${ }^{1}$ GEN. xiv. This chapter is one of the oldest parts of the Book of Genessis. Cf. Driver, Genesis, pp. I 55 ff.

2 See p. 374, and cf. SAYce in Garstang, The Hittites, p. 324, n. 4.

${ }^{3}$ The supposed forms Rim-aku or Eri-aku are not probable. Aku was a Sumerian value for the moon-ideograph of $\mathrm{Sin}$, but there is no conceivable reason why the name of Arad-Sin or Rim-Sin should have been known to the Jewish scribe in a very unusual and wrongly written Sumerian form. 
Hittite name of his day. ${ }^{1}$ But our modern knowledge shews that the tradition is based upon historical fact: Amraphel was a historical king of Shinar (Babylonia), in whose days a powerful king of Ellasar (Larsam) existed side by side with him, and in whose time Elamite conquerors with names of the type of Kudur-lagamar existed (such as Kudur-mabug and the earlier Kudur-nakhkhunte), ${ }^{2}$ who from time to time imposed their will on Babylonia, while at this time also the Hittite "Goyyim" of Anatolia were beginning to bestir themselves, and were shortly to overrun Babylonia." The collocation of names is impossible at a later period, and we must regard the tradition as, originally, a piece of contemporary history, adapted later to the Abrahamic legend, and possibly first written down by a Hebrew scribe some five or six centuries after the time of Khammurabi. ${ }^{4}$ In the account we see the Elamite Chedorlacomer taking the leading position among the kings: and it may be that a conqueror named Kudur-lagamar did at this time issue from Elam, impose his will upon the rival kings of Babylonia, and so enter into short-lived relations with even the outlying tribes of Hittites.

The tables were turned since the days of Dungi, or even Narâm-Sin. In those days the native patesis of Susa, the first Elamite rulers of whom we have any knowledge, Bashashushinak, Khutrun-tepti, Kal-Rukhurașir, and others, were the obedient vassals of the King of Sumer and Akkad, who even replaced them at will by Babylonian officials. ${ }^{5}$ Thus in Dungi's reign the patesis and local governors are all either Babylonians or had adopted Babylonian names, both Semitic

"As the Jewish scribes of the eighth and seventh centuries adopted the contemporary Egyptian names "Zaphnath-paaneakh," "Potipherah," and "Asenath" for the characters of the Joseph story, a legend of the Hyksos period, when no such names were in vogue (see p. 405).

'See p. 190.

3 See p. I99.

${ }^{4}$ On the evidence of the name Tideal. But since the other names are all contem. porary with Khammurabi, it is perfectly possible that an early Hittite king named Dûdhalia may have existed in his time, of whom we know no more from contemporary documents than we do of Chedorla'omer. The name Tid'al is associated with that of Rim-Sin in a tradition prescrved on a tablet of the Pcrsian period; it appears in the form "Tudkhula," a nearer approach to the original. This was no doubt derived from the same original Babylonian tradition as the Biblical account.

${ }^{5}$ At this time, as was natural, the Elamite culture and art (originally very different from that of Babylonia) became strongly babylonized, and the Semitic Babylonian language was used as much as Elaunite for business and other purposes (KING, H.S.A., pp. 336 ff.). 


\section{Ig6 THE ANCIENT HISTORY OF THE NEAR EAST}

and Sumerian. Later on, we find native Elamite names again. These chiefs called themselves usually "patesi of Susa and shakkanakku (governor) of Elam." Their inscriptions have been found by the French excavators of Susa, where Dungi built a temple of Shushinak, the chief Elamite deity. The lands of Anshan, Kimash, Umliash, and other Elamite districts seem to have been administered by them. Kudur-nankhundi, the conqueror of Ur, came from Anshan; Kudur-mabug from Emutbalim, a district nearer the sea. From the time of Kudurnankhundi to the latter part of Khammurabi's reign the Elamites were independent, and for a time even dominated Babylonia. As we have seen, Khammurabi warred with Larsam at the beginning of his reign; then there is a cessation of war and a silence which may mean a pax slamitica imposed upon both by Chedorla'omer; then comes war again. In his thirty-first year (about I9I3 B.C.) the armies of Khammurabi, directed by the king from Babylon, and under the command of the veteran Siniddinam, who must by this time have been an old man, and a general named Inukhsamar, took $U r$ and Larsam, and invaded Emutbalim, the hereditary kingdom of Kudur-mabug and Rim-Sin. For two years the war was waged, and we have an interesting glimpse of the religious ideas of the time in connexion with it. Siniddinam had captured the chief city of Emutbalim and with them the images of the goddesses of the country: these he proposed to send as trophies to Babylon. In answer to his report, Khammurabi writes, ${ }^{1}$ ordering him to bring them in state. It seems, however, that some time after this the royal troops experienced some severe check at the hands of the Elamites, and it was thought that this was due to the anger of the goddesses at being taken to Babylon, so, in a second letter, Khammurabi writes to Siniddinam to take them back to their own dwellings

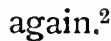

${ }^{1}$ B.M. No. $23 \mathrm{I} 31$; KiNG, Letters of Hammurabi, p. 7 .

2 This procedure is quite in accordance with the ideas of the time: so "the Philistines sent back the ark of the covenant, which they had captured at Aphek, in order to save their own god Dagon from destruction, and their land from plague" (I Sam. v., vi.; KING, op. cit. i. xlii). The image of a god was regarded as more or less the same thing as the god's own personality : if it was taken into a foreign land, the god himself was regarded as journeying thither, and was considered able to benefit or injure the foreign people among whom he sojourned, according to whether he was stronger than the native gods and approved of his transfer and of the character of his hosts or not. So in the reign of Amenhetep III of Egypt, the 
Khammurabi did not penetrate farther into Elam itself, and was unable to effect the recapture of the goddesses of Erech who had been carried off to Susa by Kudur-nankhundi three centuries before: this restitution was not effected until I635 years after their removal, by Ashurbanipal. As a more lasting trophy of his victories than the idols of Emutbalim, he retained Larsam, Ur, and Southern Surner, the borderland of Ashnunak, and the adjoining district of Umliash. In peace he was even more conspicuous as an organizer of victory than in war. The testimony of those actual letters, rescripts, and despatches of his which can be seen any day in the galleries of the British Museum, shew us that the later kings of Babylonia were by no means in error when they looked back to him as their exemplar of what a patriarchal ruler should be. In them, "we see the facts of history in the making." 1

Of his laws, the discovery of which on a stele found at Susa has made the name of Khammurabi so familiar in these modern days, ${ }^{2}$ something will be said later. ${ }^{3}$ But it must be remembered that though no doubt there is in them an original element due to the king himself, yet in the main his code was but a reissue of ancient Sumerian laws, and he has little claim to be regarded as himself a great lawgiver. ${ }^{4}$ His own actual

goddess Ishtar of Nineveh expressed a wish to be taken to Egypt, and went there and back twice. In a letter to the Pharaoh, King Dushratta of Mitanni, who then ruled Assyria, with respect to the second journey, writes: "Verily now have I sent her and she is gone. Indeed, in the time of my father, the lady Ishtar went into that land (Egypt); and, just as she dwelt there formerly and they honoured her, so now may my brother (Amenhetep) honour her ten times more than before. May my brother honour her, may he allow her to return with joy." Similarly, at a later date, the Egyptian god Khonsu of Thebes was sent with a suitable escort to the far-away land of Kheta (see p. 372, below), in order that he might cure the daughter of the king of that country, who was possessed of a devil : he abode in Kheta several years.

${ }^{1}$ The titles under which these letters are catalogued are sufficient to reveal to us the many-sided character of this great king : typical are such entries as "Order for the Insertion of an Intercalary Month in the Calendar," "Orders to finish clearing out a canal in the city of Erech," "Order for the Investigation of a charge of bribery," "Order for the restoration of property illegally claimed by a Money-lender," "Enquiry concerning the Misappropriation of Temple Revenues," "Order for Ship. captains to proceed to Babylon with their Ships," "Order for the despatch of a ship with troops from the city of Ur," "Order for the Appointment of Additional Sheep-shearers," and so forth.

${ }^{2}$ For references to the literature of Khammurabi's laws, see p. 205, n. I.

${ }^{3}$ See p. 205.

${ }^{4}$ It is necessary to insist on this point, as the concentration of attention on Khammurabi's edition of the Sumerian code seems likely to give the great king a largely fictitious importance as a lawgiver. 
letters which we possess, are far more interesting evidence of the man's personality. So far as we know, he was the first great organizer in history, and the kingdom of Babylonia, with its capital at Babylon, was the lasting result of his work. Babylon remained the capital of the Mesopotamian world henceforth throughout ancient history.

But he could not secure an undisputed empire to his successors. The Elamite danger had no sooner been removed than others even more formidable appeared. Babylonia was too rich and too vulnerable to go free from attack for long.

Khammurabi was succeeded, after a long reign of fortythree years (about B.C. 1944-I901) by his son, SAMSU-ILUNA, at the beginning of whose reign (second year) the indefatigable Rim-Sin again gave trouble. He had apparently taken Isin, which was recaptured by Samsu-iluna, who also subdued Kish, which had revolted. In Samsu-iluna's tenth year Rim-Sin still lived (having reigned by that time certainly not less than fifty-seven years), ${ }^{1}$ but shortly afterwards he was finally defeated and slain. Samsu-iluna was then confronted with a new enemy. ILUMA-ILU, a chief of the South, made himself master of the coast of the Persian Gulf, the "Land of the Sea," and founded there (about 1875 B.C.) an independent dynasty which neither Samsu-iluna nor his successors were able to destroy. ${ }^{2}$ The "Dynasty of the Sea-Land" continued to rule on the sea-coast well on into the Kassite period. Elam, however, was recovered, and in the reign of AMMI-ZADUGA, the fourth successor of Khammurabi (c. B.C. 1798-1777), we find it once again tributary. Possibly Babylonia and Elam were drawn together by the necessity of common defence against the inroads of the Kashshu or Kassites, an Indo-European nation of the northeast, whose tribes were now pressing from Media through the 'Zagros towards the fertility and wealth of Babylonia. We hear of their attacks already in the reign of Samsu-iluna. They were, however, not strong enough to attack Babylon. Their work was done for them by another power, whose strokes were sudden, unexpected, and irresistible, the terrible "Goyyim" of Asia Minor. The reign of Samsu-Ditana, the eleventh and last monarch of the Ist Dynasty of Babylon (c. B.C. I777-1746),

1 On Rim-Sin see Ungnad, Zeits. Assyr. xxiii. pp. 73 ff.; Thureau-Dangin, Rev. Asiat., 1909, pp. $335 \mathrm{ff}$.

" KIng, Chronicles, i. pp. $96 \mathrm{ff}$. 
seems to have been brought to a bloody end by a conquering raid of the King of Khatti (his name is not preserved), in which Babylon was stormed and sacked by the fierce Anatolians (c. B.C. 1746). ${ }^{1}$ They retreated, probably, as soon as they came, leaving death and ruin behind them; and the Kassites seized their opportunity. Their leader, GANDASH, appropriated the city and vacant throne of Babylon (or Kar-Duniyash, as it was now called in the tongue of the conquerors), and founded the Kassite dynasty, which endured for six hundred years.

\section{The Kassites}

The South independent under the last Sumerian dynasty, till the time of Eagamil, who is deposed by the Kassites-The Kassite kings-A Dark Age, and probable retrogression in culture, due to the rule of alien kings-Aryan gods of the Kassites-The Indo-European invasion: the kingdom of Mitanni and its Aryan gods--Relations with the Hittites and Assyrians-Mesopotamian civilization unaffected

The new lords of Babylonia did not for a long time interfere with the southern kingdom of the Sea-Land, which pursued its independent existence for nearly three centuries (c. $1875-1600$ B.C.) under kings whose names are mostly Sumerian, a fact which seems to shew that the Sumerian nationality, finally deposed from its position of equality with the Semites after the fall of the dynasty of $U r$, was eking out the last remnants of its separate existence in the southernmost portions of the country. The kingdom of the Sea-Land was the last expression of the national consciousness of the ancient Sumerian race. When it fell, the Sumerians disappear, and their language becomes a dead speech, known only to priests and scribes, the Latin of Mesopotamia. ${ }^{2}$

The end of the Sumerians came in the reign of EA-GAMIL, the tenth successor of Iluma-ilu, probably about I5So B.C. Ea-camil attempted to invade Elam, but was defeated and clriven back. A Kassite leader named Ulam-buriash, "son of Burnaburariash, the king," ${ }^{3}$ then attacked him and overthrew

${ }^{1}$ King, Chronicles, i. p. I4S. Mr. KING deduces this from the mention of a Hittite invasion in the reign of Samsu-ditana and the fact that the Kassite king Agum n brought back from Khani, the Hittite country on the Syrian side of Taurus, statues of Marduk and Șarpanitum, which must have been taken from Babylon (see p. 200).

${ }^{2} \mathrm{~K} I \mathrm{NG}$, Chronicles, i. pp. ${ }^{2} 2 \mathrm{ff}$.

${ }^{3}$ RADAu (Letters to Cassite Kings, p. IO, n. 3) makes this " Burnaburariash" the same as the Burraburiash who was contemporary with Amenhetep ill, and so puts 
his kingdom, reigning in the Sea-Land in his stead as a vassal of his father the King of Babylon. The final scene was reached a few years later, when the Kassite king of Babylon, Agum III (a nephew of Ulam-buriash), finally took Dûr-Ea (Ea's Burgh), the last fortified place of the Sea-Landers.

Of the Kassite kings we know very little. Gandash was succeeded by AGUM I, who was followed by KASHTILIASH I, Ushshi, Adumetash, Urshigurmash, and Agum II; the last waged war with the Hittite land of Khani, and triumphantly brought back to Babylon statues of the city-gods Marduk and Șarpanitum, which had no doubt been carried off by the Hittites in their great raid. Then there is a gap, followed by BURNABURARIASH, KASHTILIASH II, and AGUM III. ${ }^{1}$ Then comes a darkness of a century and a half till the veil is again lifted, after the Egyptian conquest of Syria, in the reign of KARA-INDASH, ${ }^{2}$ the contemporary of Thothmes IV. The continuous history of Babylonia begins again with him. The Kassite period thus appears as a very uneventful one. The kings, of whom our list is very imperfect, are mere names, and nothing in particular seems to have happened during their reigns. This impression may be due simply to our unusual lack of information with regard to this period. But it may well be that this lack of information reflects a real lack of incident. The conquest, too, by the Kassite barbarians may very well have caused a temporary retrogression in culture, when the arts of the scribe and historiographer were not so much in demand, in royal circles at any rate, as before. And it is the fact that we find very few records of temple-building or restoration at this period. The Kassite kings worshipped their own deities, and probably did not hasten to put themselves under the protection of the gods of Babylon. Obviously they cared very little for the religion and probably less for the literature and arts of their highly civilized subjects.

Ulam-buriash's conquest of the Sea-Land in the fifteenth century B.c., whereas from the statements of the chronicle published by KING (l.c.) it must have taken place at latest more than a century before, and probably earlier, since the reigns assigned to the kings of the Sea-Land in this document seem impossibly long. Eagamil can hardly have reigned much later than I600 B.C., so that "Burnaburariash" must have lived nearly two centuries before the Burraburiash of the el-Amarna tablets!

1 I assume, what seems probable, that "Kashtiliash the Kassite" was king, and Agum his son also. Burnaburariash, father of Kashtiliash and Ulam-buriash, was certainly King of Babylon.

${ }^{2}$ About B.C. I420. P. 262, post. 
The racial difference between the new conquerors and their subjects was great. There is little doubt that the Kassites were Indo-Europeans, and spoke an Aryan tongue. Their chief god was Suryash, the sun, the Indian Surya and Greek "Hخ.bos; their word for "god" was bugash, the Slav bogü and Phrygian Bagaios." The termination -ash which regularly appears at the end of their names is a nominative, corresponding to the Greek -o5. Such a name as Indabugash ${ }^{2}$ is clearly Aryan. They were evidently the advance-guard of the IndoEuropean southern movement which colonized Iran and pushed westward to the borders of Asia Minor. In the north the kingdom of Mitanni ${ }^{3}$ was about this time established between the Euphrates and Tigris by Aryans who must have been of the same stock as the Kassites who conquered Babylonia. The names of the kings of Mitanni which are known to us in later times are Aryan, ${ }^{4}$ and among the gods of Mitanni we find the Indian Varuna, Indra, and the Nāsātya-twins (Açvins). ${ }^{5}$ It is possible that the mass of the population in Mitanni was of partly Semitic, partly Hittite blood, and that the Aryans there were merely a ruling caste: the language of Mitanni was of the Caucasic or Alarodian type. ${ }^{6}$ Their further westward progress was barred by the Hittites, who were firmly entrenched in the land of Khani (Coele-Syria) and had already swarmed across the Taurus into Northern Syria, founding outpost principalities on the Euphrates, of which Carchemish may already have existed as the most important. At first the Mitannians must have been checked at the Euphrates, but later on they seem to have crossed the river and have made themselves masters of both Semites and Hittites in Northern Syria, which

1 I would also suggest that the Kassite god Maruttash may be the Sanskrit Marut, a deity of wind and storm. We know nothing of how the Kassites represented these deities (with Kharbe, Dunyash, Shakhe, Shipak, Shugamuna, and others, whose names only we know): probably no Kassite art of any kind existed. RADAU, in Letters to Cassite Kings (Phila., I908), p. 9, n. 1, notes the equivalent of bugash to the Babylonian AN (god), but does not draw the evident conclusion.

${ }^{2}$ Cf. the Persian Inta-phernes.

${ }^{3}$ See pp. 257 ff. ; 34 I ff.

4 Saushshatar (.... khshatra), Artatama, Shutarna, Dushratta. See Meyre, Sitzber. kgl. preuss. Akad., r9o7.

${ }^{5}$ WiNckler, M.D.O.G., Dec. 1907, p. 5 I ; Meyer, loc. cit.; Hall, J.H.S. xxix., and p. 33r, post.

${ }^{6}$ BORK, Die Mitanni-Sprache (M.V.G., 1909), shews that it was like the modern Abkhasian of the Caucasus and the ancient Elamite. But that the ruling house was Aryan is certain, and no doubt the aristocracy were too: they were "barons" of the usual Iranian types and called themselves "Aryans" (Kharrî). 
probably remained tributary to them till the Egyptian conquest in the sixteenth century. The young state of Assyria, of which we know nothing at this period, is found tributary to Mitanni later on, and we cannot doubt that its allegiance was very soon forcibly transferred from the Kassite kings of Babylonia to the rulers of Mitanni.

Mesopotamian civilization was unaffected by the Mitannians and Kassites, who seem to have been entirely uncultured. They learnt civilization from the conquered. The process seems to have taken about two centuries: by the time of Kurigalzu and Burnaburiash the Kassite kings have adopted the Babylonian religion, at any rate for official purposes, and differ from their subjects only in the retention of their Kassite names, which they affected to the last, six hundred years after the time of Gandash. It would seem that the racial distinction between the Kassite settlers and the Babylonians was long preserved, in much the same way as in China the Manchu noble families who came with the late Manchu dynasty still keep separate from the Chinese. The tenacity of power by one dynasty for so many centuries points to a health and vigour in the ruling family and race which was unwonted in highly civilized Babylonia.

\section{Babylonian Civilization}

The unification under Khammurabi-Agriculture-Irrigation-Taxes-Land and labourers-Judiciary-Sumerian laws codified by Urukagina and KhammurabiDivorce-Women-Legal instruments: seals-Religion-Sumerian and Semitic deities-Ishtar-Myths: Etana and Adapa-Babylonian and Hebrew religionComparisons with Greek mythology

With the Kassite conquest we have then reached a pause in the current of Babylonian history which well marks the end of its first period. Looking back, the history of the period which has been sketched above is practically the history of the gradual semitizing of Babylonia, which was finally completed when Khammurabi unified the whole of the country into oneSemitic state, which remained one and remained Semitic even when ruled by a foreign dynasty.

The Babylonian culture of Khammurabi's day was not very different from that of old-Sumerian times. Only the writing had developed, the bow had been introduced by the Semites ${ }^{1}$

\footnotetext{
${ }^{1}$ See p. I8g. Kivg, Hist. Sumer and Akiad, pp. $247 \mathrm{ff}$.
} 
and the horse from Media: ${ }^{1}$ and a unified state with its centre at Babylon had been created. We cannot suppose that the methods of irrigation in use under the first king of united Babylonia were more highly developed or more time- and labour-saving than those in vogue under the earlier patesis of Lagash. The usual conception of the Babylonian is an energetic tradesman, a $x u ́ \pi \eta \lambda .0 s$ and a money-lender, with a turn for astronomy: this is, however, the man of a later age. ${ }^{2}$ The Babylonian of the earlier time was a merchant also, and a keen litigant as well, as hundreds of early tablets testify, and the astronomical tendencies of his later descendant were founded on the observations of remote forefathers, but first and foremost he was an agriculturist. ${ }^{3}$ We know how the cornbearing capacity of Babylonia astounded Herodotus, ${ }^{4}$ and we can well imagine that his statements as to the phenomenal yield of the land, the breadth to which the blades of wheat and barley would grow, and the height of the millet and sesamum there would dispose many of his hearers to unbelief. Yet there is nothing improbable in what he says. Important as was Babylonian agriculture in his day, in the earlier period it was far more important, and in the letters and inscriptions of that the care of the land appears as even more important than the maintenance of the temples of the gods. Marduk himself was said to have inaugurated the irrigation-system of Babylonia, and from the earliest period every king of whom we possess more than fragmentary mention prides himself upon having either constructed or renewed canals to bring water from the two rivers to the broad lands lying between them. ${ }^{5}$

${ }^{1}$ Probably through the medium of the Kassites, but while the Ist Dynasty was still ruling, before Khammurabi's time (UNGNAD, O.L.Z., 1907, pp. 638f.). The Babylonians wrote its name sîsu with the ideographs "mountain-ass," as it came to them from the mountain-tribes. For the further introduction of the horse into Egypt and the West see p. 2 r 3 .

2 Of, indeed, the post-Herodotean age. Herodotus does not yet give us this impression, which is derived from the Babylonian of the Seleucid period. The astronomical knowledge of the Babylonians was probably nothing remarkable before that time: we know that at any rate it was not systematized till then, as the earlier Babylonian accounts of the stars are extremely confused and contradictory.

${ }^{3}$ The huckster-quality of the Babylonians began to become prominent under the later Kassites, probably, and is in full vigour in the Assyrian period (see p. 455, post).

- HDT. i. r93.

S Irrigation in Egypt was of course a very different matter from irrigation in Babylonia, and the difference is carefully noted by Herodotus; in Babylonia, he 


\section{THE ANCIENT HISTORY OF THE NEAR EAST}

A very good reason for a watchful eye being kept by the Government upon the proper repair of the canals was the fact that upon properly regulated irrigation depended a good harvest, and upon a good harvest depended a good inflow of taxes into the treasuries of the king and the gods. Taxes were generally paid in kind, and chiefly in corn, though dates, oil, and wine, etc., also contributed to swell the total. Prices also might be reckoned in grain, dates, or oil, and though metal weights, the talent, the maneh, and the shekel, were all in use, no idea of a true currency had as yet arisen in Babylonia any more than in Egypt : in a purchase of land, for example, the purchase price was first settled in shekel-weights of silver, and the various items exchanged against the land (corn, slaves, weapons, or what not), were often separately valued on the same basis till the purchase price was made up. This was the transition stage between pure barter and a regular currency. ${ }^{1}$ Much of the land was owned by the great temples, and the royal domains were no doubt much mixed up with those of the gods: in some places, as in Egypt, the two would be identical, since the king, in his capacity of patesi, would often be a high-priest; but there was apparently, also, besides the class of free labourers, a large number of freeholding farmers. The free labourers were in all probability in some ways the worst off of the population, for their pay rarely amounted to more than their daily food, and they were not entitled to the protection which the slave received from his master. Even the slave was protected from his master by the law. The Babylonians had a most modern idea of "law and order," and to this was no doubt due their commercial stability, which survived all wars and conquests unimpaired. The judges were named by the king, and were his deputies, and they seem to have gone on circuit: their decisions were irrevocable.

The laws which they administered were of Sumerian origin.

observes, "the crop is ripened by being watered from the river, and thus the grain comes to maturity; not, as in Egypt, by the river itself overflowing the fields, but by irrigation by means of the hand and shadifs ( $\kappa \eta \lambda \omega \nu \eta i a)$. For the whole land of Babylonia is, like Egypt, cut up by canals, and the largest of the canals is navigable, stretching towards the south-east ( $\pi \rho \delta s \quad \eta \lambda \iota \nu \nu \tau \delta \nu \chi \epsilon \iota \mu \epsilon \rho \iota \nu \delta)$, from the Euphrates to another river, the Tigris." The canal to which he refers is probably the Nahr Malik, or "King's River," in the neighbourhood of the ancient Agadé.

${ }^{1}$ For this information I am indebted to Mr. L. W. KING. 


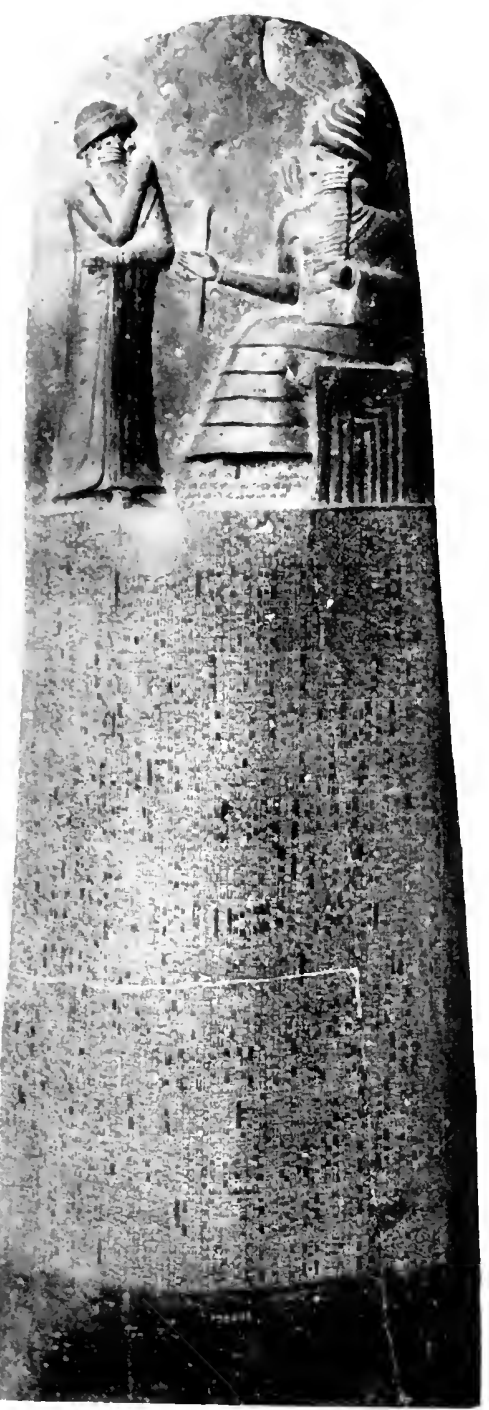

Lore're

1. THE NTHLF OF THF I.IW KH.IMMLRAl:I
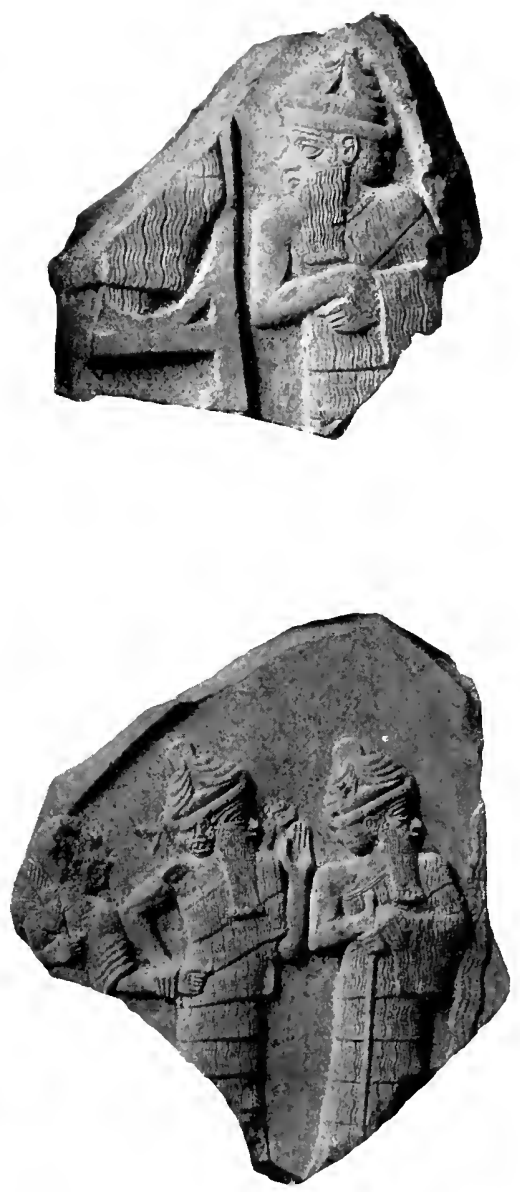

Nerlin

$\because$ SUMHKLAN DITIF 

Under Khammurabi the laws of his day, no doubt with improvements initiated in the highest quarter, were specially codified, as they doubtless had been under previous kings of reforming ideas, like Urukagina. They were inscribed upon a magnificent stela of diorite, found by the French at Susa, whither it had been carried off like the stela of Narâm-Sin, and now in the Louvre. ${ }^{1}$ Above the writing we see Khammurabi, in relief, receiving the code from the sun-god Shamash (Plate XIV. I).

From this monument we have gained a complete knowledge of ancient Babylonian law, and have seen how very equitable most of its enactments were. Those relating to agriculture, to the recovery of debt, and to the conditions of divorce are especially interesting. ${ }^{2}$ In the latter improvement had been made since old-Sumerian times, when the wife had no rights of divorce whatever, these being reserved only to the man. In Khammurabi's time, however, the law had been modified in favour of the woman, for if she was divorced her husband had to make proper provision for her maintenance and that of her children, of whom she had the custody, besides returning the marriage-portion. He could only evade these provisions by proving that his wife had been unfaithful or a careless householder; in the latter case he might enslave her. In the ancient Sumerian laws quoted above it will be noticed that the man is more important than the woman, the father than the mother, the husband than the wife. This is in striking contrast to Egypt, where the "Lady of the House" was usually a more important personage than the mere "Male," as the husband was called, and where men often preferably traced their descent in the female line. In Egypt ${ }^{3}$ there were always strong traces of Mutterrecht, but none in Babylonia. Still, women were, generally speaking, quite as independent in Babylonia as in Egypt: they could own property, whether in houses or slaves, and could personally plead in the courts. Also, we find there a remarkable class of honoured women, votaresses who in some ways resembled the Roman Vestals, and possessed unusual rights and

1 A large literature has grown tp with regard to the laws of Khammurabi. For references see Johns, Encycl. Britt. (xith edl.), s.v. "Babylonian Law."

${ }^{2} \mathrm{KING}$ and HaLl, Egypt and Western Asia, pp. $267 \mathrm{ff}$.

${ }^{3}$ And in Anatolia; p. 374 . In Minoan Crete, too, the women evidently played a very prominent rôle (see p. 48 ). 
privileges. These are not to be confused with the religious prostitutes, mentioned by Herodotus, ${ }^{1}$ who were certainly a prominent feature of Babylonian religion. They were women who took vows of celibacy, though usually dwelling together in special convents, could nevertheless live in the world, and were often nominally married. If married (and to possess a votaresswife was probably regarded as a distinction), a concubine was provided to bear children to the husband, but had no legal wifely rights, which belonged to the votaress. ${ }^{2}$

The accessibility of the law made lawsuits easy, and the Babylonians were highly litigious in consequence ; most of these lawsuits were in connexion with the sale or lease of land, houses, etc. Such sales and leases, as well as wills, had always to be drawn up in legal form to be valid, as was also the case in Egypt. For a document to be valid, it had to be attested by witnesses, and was usually impressed with the seals of the parties to it: when one of the parties had no seal he might impress the mark of his nail upon the soft clay of the tablet on which the deed was written. The absolute necessity of the seal as part of the array of a Babylonian is duly noted by Herodotus, ${ }^{3}$ whose description of the Babylonian dress of his day is entirely applicable to the early period also, for, though fashions in tiaras altered from time to time, the long robes never changed. Many of the cylinder-seals, used to roll over the clay tablets as a blotting-roller is used nowadays, may be seen in our museums. They are made of black hamatite or deep red jasper or white chalcedony, sometimes of translucent crystal: on them was sometimes the name of the owner, always some mythological scene, such as Shamash the sun-god rising above the mountain of the world, Eabani and Gilgamesh contending with the bull of Ishtar, etc., and they are usually triumphs of the glyptic art, far superior to any work of the kind from Egypt.

Attempts have been made to distinguish between the religion of the Sumerians and that of the Semitic Babylonians, but without very great success. It is as difficult to say with certainty that this element in Babylonian religion is of Sumerian origin and that of Semitic as to say that this element in Hellenic religion is preAryan or Pelasgic and that Aryan: one cannot disentangle the

${ }^{1}$ Hot. i. 199.
${ }^{3}$ HDT. i. 193.

${ }^{2} \mathrm{KING}$, Egypt and Western Asia, pp. $272 \mathrm{ff}$. 
Sumerian strands from the rest. Not even can it be said with certainty that a particular deity is non-Semitic, because purely Semitic deities seem very often for the sake of uniformity to have been given Sumerian names by the Babylonian archaeologists. ${ }^{1}$

We do not know whether the oldest deities of Shumer, such as Ea (Sum. En-lii), Sin or Nannar (Sum. En-zu; the Moon), Ningirsu of Lagash and others, were really pre-Sumerian or not. En-lil ("Great Spirit") of Nippur, who is probably purely Sumerian, was translated into Semitic as Bel (Ba'al, "Lord"); Utu the Sumerian sun-god was identified with a Semitic sun-god, Shamash. Marduk, the god of Babylon, was no doubt originally Sumerian: his name sounds like a Semitic garbling of a Sumerian name. Rammân or Adad, the thunder-god, seems Semitic; he has a purely Semitic name. When we find by the side of a god a goddess as his consort who is but a shadowy female edition of himself and often bears a feminine form of his name, as Belit by the side of Bel, we know that the goddess is of Semitic origin, and very often the god also, but not necessarily, for in later days the goddess Damkina was invented to stand by the side of the Sumerian Ea, who like others of the Sumerian gods, had no consort. So also Șarpanitum was invented for Marduk, Laz for Nergal, and so on. The deities, male or female, who stand alone, appear to be Sumerian, but here again we find that the independent goddess Ishtar, who on this theory should be of Sumerian origin, bears an apparently Semitic name. It is by no means certain that she is originally the same as the Sumerian goddess Ninâ, whom she nearly resembles, and a form of her, Anunitum, the goddess of the morning-star, is purely Semitic, though derived from the Sumerian male deity Ana (Sem. Anu), the sky-god. Ishtar seems of Syrian or Canaanite origin, and there is a possibility, if not a probability, that she, like the Syrian war-goddess whom she so closely resembles, was at an early period modified by a confusion with the Anatolian mother-goddess: like her, she was served by eunuch-priests. Tammuz, her favourite (who does not bear the same relation to her as a Semitic doublegod would), would then be, in spite of his occurrence in Sumerian religious texts, the Anatolian Attis, and came to Mesopotamia from beyond the Taurus. In Babylonia Ishtar-Ninâ was a stargoddess, in Syria Ashtoreth-Tanit was a moon-goddess also, and in Anatolia the Great Mother and Attis, in Syria Astarte

${ }^{1}$ On the Sumerian deities see KING, H.S.A., pp. 47 ff. 
and Tammuz, seem to be the female Moon attended by the less important male Sun. ${ }^{1}$ The Semitic name of the Sun, Shamash, seems to mean the "servant" or "follower" 2 of Mistress Moon, whom the sun was regarded as attending in her wanderings. No doubt the human face of the moon, its changes, and the obvious means of counting time which could be derived from these changes, ${ }^{3}$ marked it out from the beginning as the superior of the brighter, but less changing, sun.

Our knowledge of Babylonian mythical and legendary literature is extensive: the stories of Gilgamesh and of the Deluge have already been mentioned: of other such tales one of the most remarkable is the legend of Etana and the Eagle. On one occasion Etana's friend the Eagle carried him up to heaven mounted on his back, and he saw the thrones of the gods, but when they flew still higher to explore the dwelling of Ishtar, some accident happened, and they fell headlong to earth and were dashed to pieces. The parallel with the Greek story of Ikaros is obvious. Another hero, Adapa, son of Ea, was fishing from a boat in the Persian Gulf, when the South Wind suddenly blew and upset his boat. Adapa, furious at this attack, caught the South Wind by her wings, and broke them. Other legends refer to the great "Tablets of Destiny," upon which the fate of gods and men were inscribed, and which constituted the title-deeds of the gods to rule the earth. These had originally been in the possession of the demon of chaos, Tiâmat, but in the great conflict with her and her giant brood, Enlil or Marduk had won them from Kingu, the leader of her hosts. Afterwards they were stolen from Marduk by a demon named $\mathrm{Zu}$, who aspired to rule the universe. The confusion

1 See p. 330, on the Anatolian deities.

2 If this etymology be correct, the word may be compared with the Egyptian shems, "follower": the Shemsu-Hor (p. 93) are the "followers" or servants of the sky-god.

${ }^{3}$ The cuneiform sign for the moon is not derived from a picture of it, but is simply the numeral " 30 ": the Babylonian year was also exclusively lunar, with the result that its constantly recurring discrepancies with the actual year had constantly to be corrected. A letter of Khammurabi's refers to a correction of this kind: " Unto Siniddinam say: thus saith Khammurabi :-Since the year hath a deficiency, let the month now beginning be registered as a sceond Elul. And instead of the tribute arriving in Babylon on the twenty-fifth day of the month Tisri, let it arrive in Babylon on the twenty-fifth day of the second Elul." The months Nisan and Adar were often duplicated also. The king was warned by the astronomers when such a duplication was necessary, and he gives directions to the viceroys to see it carried out in the provinces under their charge. 
caused among the gods by this audacious theft was great, a council was held, and Adad and two other gods were asked to rescue them, but they refused. Eventually, however, they were recovered by Shamash, the sun-god, who caught $\mathrm{Zu}$ in his net.

There is undoubtedly much in Babylonian religion and myth that can be paralleled in the religious literature of the Hebrews, though whether this resemblance is due to the ancient spread of Babylonian culture into Canaan and its continuous influence from the earliest days, to an actual migration of an Abrahamic clan into Canaan from Ur of the Chaldees by way of Harran, or simply to the influence of the Babylonian environment during the Captivity, cannot yet be determined with certainty. Perhaps all three causes combined to bring about the resemblance. But there are other features of Babylonian legend which can only be paralleled in the mythology of the Greeks, ${ }^{1}$ and so close are these parallels sometimes that we can hardly doubt that many Greek myths, especially those of a cosmogonic character, came originally to Greece from Babylonia, probably through the medium of Asia Minor.

${ }^{1}$ Gilgamesh for instance is extraordinarily like Herakles. We have already com. pared Etana with Ikaros. The whole question of the possible connexions between Hellenic, Anatolian, and Babylonian religion has recently been well treated by Dr. Lewis FarNelL in his Greece and Babylon (Edinburgh, I9II). He finds that there was but little real connexion between Hellenic and Semitic religion, and on the main point is undoubtedly right : there is no resemblance whatever either in cult and ritual or in spirit of worship. But that Babylonian religious myths may have reached Greece through the Ilittites and Phrygians is very possible, and this is allowed by Dr.

FARNeLL. 


\section{IO THE ANCIENT HISTORY OF THE NEAR EAST}

\section{CHRONOLOGICAL LIST OF THE EARLY PATESIS AND KINGS OF BABYLONIA}

(Based on L. W. King, History of Sumer and Akkad, pp. $360 \mathrm{ff}$., and Chronicles Concerning Early Babylonian Kings, i. pp. 136,137 .)

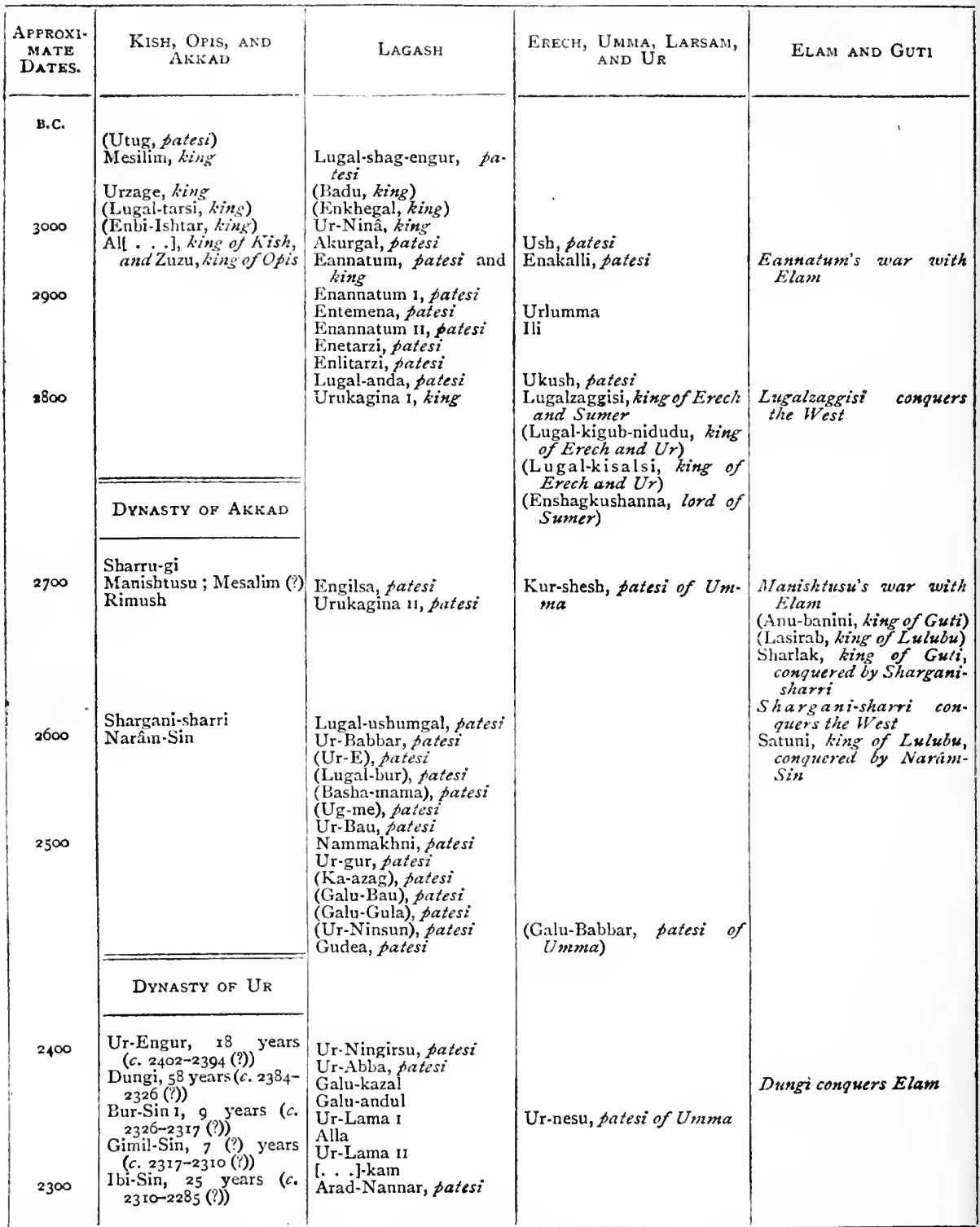

Note:-The new lists of kings of Opis, Kish, and Erech, published by ScheIL, C.R. de l'Acad., I9I I, has not been incorporated above as it is not yet evident how, exactly, we are to combine the information they give us with that already known which will be found above, and because the historical value of the information given by the new lists is in some respects rather doubtful; much of it seems purely legendary (see pp. 179, 189). 


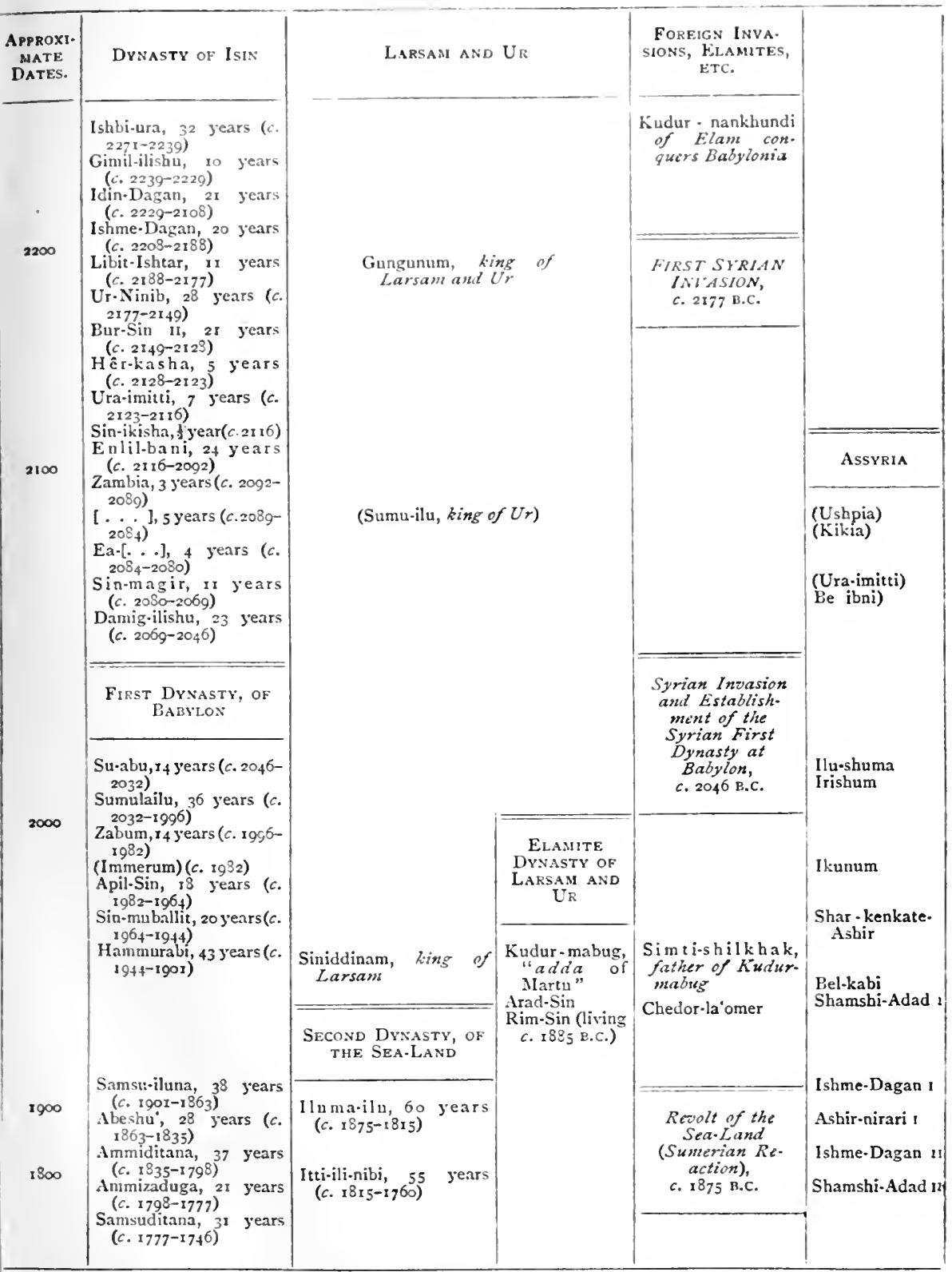

Note :-The precise chronological position of names in brackets is uncertain. 


\section{THE HYKSOS CONQUEST AND THE FIRST EGYPTIAN EMPIRE}

\section{(Circt 1800?-I 350 B.C.)}

\section{The Asiatic Invasion}

The chariot and horses-The Manethonian account

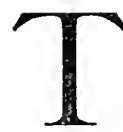

$\mathrm{HE}$ almost contemporary incursion of the Aryans from Irân and of the Anatolians from Asia Minor into at first a considerable displacement of the Semitic population, which was pressed south-westwards into Southern Syria and Palestine. The result was that the Semites burst the ancient barrier of Egypt, which had weakened in strength under the kings of the XIIIth Dynasty, and the Nile-land was overrun and conquered by the hated Retenu and the despised Aamu. The later Egyptians spoke of their conquerors slightingly as mere "Shepherds," Beduins of the desert," but there is little doubt that they were mainly civilized Syrians and Canaanites, and they may have brought with them Anatolian and even Indo-European warriors. They found a ready welcome from their kin already settled in the land of Goshen, and Manetho tells us that the conquest was consummated with little trouble and that the conquerors were savage and cruel.

Very possibly the swiftness and completeness of the conquest was due not only to the weakness and disunion of the

${ }^{1} \mathrm{Hyksos},{ }^{\top} \Upsilon \kappa-\sigma \hat{\omega} s$, correctly explained in Manetho as "Prince of the Shepherds." His authorities evidently called the invaders hiku-Shasu, "princes of the Beduin." The appellation is analogous to that of hik-khaskhut, "prince of the deserts," which is given to the Semitic chief Abishai who visited the court of the nomarch Khnumhetp at Beni Hasan in the reign of Senusert II. And the Hyksos king Khian called himself by this very title hik-khaskhut. 
Egyptians, but to the possession by the invaders of a new engine of war, previously unknown to the Egyptian military system, the war-chariot and its horses. The chariot, drawn by asses, had been used by the Babylonians in war from time immemorial, and must have been known, at least by hearsay, to the Egyptians for centuries, but they never adopted it for use with their asses. When the horse was introduced, probably not much before 2000 B.C., into Western Asia from Irân, where it was first domesticated, it replaced the ass in the chariot, ${ }^{1}$ which now, with fiery steeds yoked to it, became a terrible instrument of war. But the Egyptians still knew nothing of it; neither horse nor chariot are represented on any Egyptian monument or mentioned in any document before the Hyksos invasion. After it, however, they appear in common use, and one of the words for "chariot" is that used by the Semites, markabata, Assyrian narkabat. The conclusion is obvious: disaster taught the Egyptians once and for all not to despise their eastern neighbours; they adopted the weapon of their adversaries, and to such purpose that they themselves used it to conquer Palestine, and henceforth the strength of Egypt lay not only in her bowmen but in the multitudes of her horses and chariots also.

Manetho's account of the conquest is worth quoting in full. ${ }^{2}$ He says : "We had once a king whose name was Timaios. In his time it came to pass, I know not how, that God

${ }^{1}$ See p. $18 \mathrm{r}$.

'Manetho's account happens to be very full just at this point, because here we are not, as usual, forced to rely upon a mere bald summary of his names and dates, but have an actual verbatim quotation from his text, made by Josephus. The great Jewish writer believed (and he may not have been far wrong) that the episode of the Hyksos conquest of Egypt and expulsion therefrom was the real basis of his national legend of the dwelling of the Israelites in Egypt and their exodus, and in order to confute Apion, who had cast doubts upon the antiquity and renown of the Jewish people, he called in Manetho to shew that they had once conquered and ruled Egypt.

Manetho's story, as quoted and paraphrased by Josephus, is probably a fairly accurate account of what we know to be historical fact. We have a notable reference to the dominion of the Hyksos on an Egyptian monument in the inscription of Queen Hatshepsut over the entrance to the rock-cut temple now called the "Stabl Antar," or "Speos Artemidos," near Beni Hasan. The queen here states that she repaired temples which had been destroyed by the Aamu (Arabs), who had been in the land, knowing nothing of the gods. Manetho's story also agrces in all essentials with the history of the expulsion of the Hyksos as we know it from a historical tale current in later days and also from contemporary monuments (see p. 223). 
was adverse to us, and there came out of the East in an extraordinary manner men of ignoble race, who had the temerity to invade our country, and easily subdued it by force without a battle. And when they had our rulers in their power they burnt our cities, and demolished the temples of the gods, and used the inhabitants after a most barbarous manner, slaying some, and leading the wives and children of others into captivity. At length they made one of themselves king, whose name was Salatis; he lived at Memphis, and made both the Upper and Lower Countries tributary, and stationed garrisons in the places best adapted for them. He chiefly aimed to secure the eastern frontier, for he regarded with misgiving the great power of the Assyrians, who, he foresaw, would one day invade the kingdom. And, finding in the Saite (? Sethroite) nome to the east of the Bubastite channel a city well adapted for his purpose, which was called from some ancient mythological reference Avaris, ${ }^{1}$ he rebuilt it and made it very strong with walls, and garrisoned it with a force of two hundred and forty thousand men completely armed. Thither Salatis repaired in summer, to collect his tribute and pay his troops, and to exercise them so as to strike foreigners with terror. And when this man had reigned nineteen years, after him reigned another, named Bnon, for forty-four years; after him another, called Apakhnas, thirty-six years and seven months; after him Apophis, who reigned sixty-one years, and then Ianias fifty years and one month. After all these reigned Assis forty-nine years and two months. These six were the first rulers among them, and during the whole period of their power they made war upon the Egyptians, being desirous of destroying them utterly." 2

\section{The Hyksos Kings}

Salatis-Apakhnas-Apophis-The scarab-names-Khian-Apepi II-Apcpi III -Nubti-The Hyksos egyptianized-Extent of their rule

Naturally we have no contemporary record of the actual invasion, but the king "Timaios" in whose reign it occurred may be a certain Nefer-Temu who comes in the Turin Papyrus

"Het-uaret, "the House of the Leg." Apparently a supposed leg of Osiris was preserved there as a relic, or was supposcd to have been found therc.

'Ioseph. contra Apionem, i. I4. 
shortly before the Nehesi, who, as we know from his own monuments, was a vassal of the Hyksos and their god Set. ${ }^{I}$ Of Salatis we know nothing from Egyptian sources. ${ }^{2}$ Avaris, the city which he fortified, is certainly Tell el-Yahudiyah, in the Eastern Delta at the mouth of the Wadi Tumilât (the land of Goshen), where Prof. Petrie has found conclusive proofs of special Hyksos occupation. ${ }^{3}$

The original forms of the names Beon or Bnon and Apakhnas or Pakhnas have not yet been certainly identified. Prof. Erman compared Apakhnas with the name Aapehti, which is certainly that of a king of this dynasty, though the only Aapehti known to us was one of the last of the Hyksos kings, and only preceded their expulsion by a few years. If he is Apakhnas, Manetho has misplaced him.

For Manetho's Apophis we have several candidates, for there were at least four Hyksos kings known from the monuments named Pepi or Apepi :-(I) Maa-ab-Ra Pepi, (2) Neb-khepesh-Ra Apepi, (3) Aa-user-Ra ( ${ }^{\circ} \mathrm{O}$-user-R'a) Apepi, and (4) Aa-kenen-Ra ('O-kenen-R'a) Apepi. Of these kings Aa-kenen-Ra is evidently, from the form of his name, a contemporary of the later Theban kings of the XVIIth Dynasty who bore the style of Sekenenra Taa: he is therefore Apepi III. Aa-user-Ra is probably for the same reason the predecessor or successor of the king who, as we shall see, was probably the greatest of the Hyksos, Seuserenra

1 See p. I67.

${ }^{2} \mathrm{~A}$ king of this period with a very peculiar name is Ne-maat-n-kha-Ra Khenzer, who held Abydos, but has been taken to be a Hyksos (PIEPER, Könige zwischen dem mittleren und neuen Reich, p. 32); his name has even been identified by PIEPER with that of the conqueror Salatis. It is possible that in Ptolemaic times the name which we conventionally write "Khenzer" may have been pronounced something like "Shalti(r)." It is remarkable, too, that there is a Babylonian name Ukinzir, which is not unlike "Khenzer." But it is unsafe to suppose that it is not Egyptian. MEYer does not regard him as a Hyksos (Nachträge, p. 37).

3 Petrie, Hyksos and Israelite Cities, p. 9. Like other places (e.g. Tanis) associated with the Hyksos, Tell el-Yahudiyah became prominent again under the kings of the XIXth Dynasty, who to some cxtent revived Hyksos traditions in the Delta ; and Rameses III, of the XXth Dynasty, built a great palace there (see p. 320 , post). The statement that Salatis fortified Avaris on account of his fear of the Assyrians contains no anachronism, for all the Mesopotamians, Babylonians as well as Assyrians proper, were called 'A $\sigma \sigma u p l o r$ by the Greeks; Herodotus calls the Babylonians "Assyrians." And, as we have seen, the great Babylonian dynasty of Khammurabi was the dominant power of Western Asia at the time of or not long before the Hyksos invasion, and Salatis might well fear an attack from them, or from the Elamites, who might just as well be called 'A $\sigma \sigma u p i o$. We find the

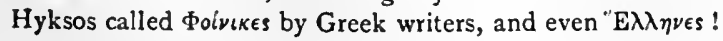


Khian. He too ruled the whole of Egypt, for his name is found at Gebelên, south of Thebes, and it was, as we can judge from what we know of the activity of the contemporary Theban kings of the XVIIth Dynasty, not for very long that the Hyksos actually possessed the whole of Egypt. We may with great probability place the apogee of the Hyksos power at about the middle point of their rule, so that this Apepi will be Apepi II. Neb-khepesh-ra is then APEPI I, and either he or Maa-ab-Ra Pepi may well be Manetho's Apophis, the fourth Hyksos king. His name, Neb-khepesh, "Lord of the Sword," would be very appropriate to one of the kings who, as Manetho tells us, occupied themselves with ceaseless war in the first century of their rule. Only two relics of this king are known : a dagger with embossed gold handle on which is represented a warrior stabbing a lion which is pursuing an antelope (now at Cairo), ${ }^{1}$ and part of a vase of siliceous stone with the king's cartouche, in the British Museum. ${ }^{2}$ Maa-ab-Ra PEPI is known only from scarabs. ${ }^{3}$ Stä̈n or Iannas is no doubt the great king KHIAN, and Assis or Aseth ${ }^{4}$ is evidently UATJED or UAZED, a king whose scarabs are of the same type as those of Khian.

Besides the few names given by Manetho, who has evidently preserved only those of the most notorious of the foreign invaders, we know many other names of Hyksos kings or chiefs from scarabs, ${ }^{5}$ which can be fixed to this period by

${ }^{1}$ Published by Daressy, Annales du Service, vii. p. II5. The name of the Hyksos owner, Nhiman, is below the hunting-scene. The name of the king upon the handle was misread "Neb-nem-Ra," but the true reading is Neb-khepesh-Ra, as was tentatively pointed out by SAYCE, P.S.B.A., 1902, p. 86 . The style of the warrior-relief is remarkable, and resembles that of the scarabs associated with the Hyksos.

2 No. 32069. The inscription is cut in a style closely resembling that of the royal seal-cylinders of the XIIth Dynasty. It reads: "The Horus . . Good God, Lord of the Two lands, RA-NEB-KHEPESH .... Son [of the Sun], whom he loveth, APEP........ as a monument. ..." This interesting and important object of the Hyksos period was found at Tell el-Yahudiyah.

${ }^{3}$ I have no doubt that the name is Pepi or Apepi, not Shesha, Sheshi, as it has been read.

"In Syncellus' version of Manetho. I believe that I am the first to make this very probable identification. $\Sigma_{\tau \alpha \alpha \nu}\left(\Sigma_{i \alpha a \nu}\right)=$ Khian was shewn by v. BISSING.

${ }^{5}$ These scarab-names are collected by PETRIE, Hyksos and Israelite Cities, pp. $67 \mathrm{ff}$. His argument (Historicai Studies, p. 14) that they argue a long period of Hyksos rule seems at first sight justified, and Prof. Mever is certainly not justified in dismissing them as he does in Nachträge, p. 38, n. 2. Many of these may not have been kings who succecded one another in regular form, but simply 
their style. Of much the same style as the scarabs of Uazed are those of a king named IEPEK-HUR, or IEKEB-HUR. The element Iepce is also found in the name of a "king's son Apek," which occurs on scarabs of the same period. It has been proposed to identify this name with the Semitic Yakîb, Jacob, who is supposed by some to have been a Syrian god. Whether this be so or not, the identification with the name Jacob is probably correct. ${ }^{1}$

The throne-name of this king was Mer-user-Ra. Other royal names, certainly of Hyksos, and probably successors or contemporaries of Iekeb-hur, are SEMKEN and ANT-HAR. The initial element of the second name is no doubt the name of the Syrian goddess Anta or Anait. The prenomens of these kings may no doubt be found in several prenomens of this period found, like the names we have mentioned, on scarabs: Sekhanra, Aa-hetep-Ra, Uatjkara II, and Nekara II. Judging from the style of his scarabs, Nekara II was probably the immediate predecessor of the great Khian. ${ }^{2}$

With this king we reach the first of the later Hyksos, who are known to us from monuments of size and importance, and seem to have been pharaohs of the first rank. Khian dedicated statues of himself in the temple of Bubastis; one of these was discovered by Prof. Naville, and is now in the Museum of Cairo. ${ }^{3}$ Great attention has been directed to this king because relics bearing his name have been found at places so far distant from Egypt and so far apart as Bagdad in Mesopotamia and Knossos in Crete. The small lion from Bagdad which bears his thronename Seuserenra is in the British Museum (No. 987); the alabastron-lid with his personal name Khian, which was dis-

autonomous chiefs who adopted each the style of a pharaoh contemporaneously with one another; still the list of Hyksos kings can hardly be brought within the compass of the bare century which is exigk for the Hyksos by the chronology adopted by Prof. Meyer. In fact, the thing is almost impossible; and only if we suppose that the "Mesore-year" used by the Egyptians at this time allows us to add I 20 years to the period between the XIIth and XVIIIth Dynasties shewn by the Kahun Sothic date for Senusert III (see Chapter I. pp. 23 ff, antea) can we find barely sufficient time for the Hyksos. Vet even this licence is denied us by Prof. Meyer. The question remains insoluble, as Prof. Petrie's long dates seem equally impossible (see p. 24).

${ }^{2}$ It has been suggested that we may identify the element -hur with the word $2 l$, god, that this king's name was "Jacob-el." But whether this is justifiable or not is uncertain. On Joseph-el and Jacob-el tribes in Palestine see pp. 405, 409.

2 Cf. his scarab, Brit. Mus., No. 32305.

3 Naville, Bubustis, Pl. xii. 
covered in I90I by Mr. Arthur Evans in the course of his excavations in the Minoan palace at Knossos, is now in the Museum of Candia. ${ }^{1}$ Now it is remarkable that Khian assumed an unusual title, that of "Embracer of Territories" ( $\dot{a} n k \dot{a} d e b u)$; is it possible that his rule actually extended further than that of any Egyptian king before him or after him, and that these objects are actual relics of his dominion over Southern Mesopotamia and the Isles of the Great Sea? It is hardly possible, and we need not jump to so far-reaching a conclusion. The lion of Bagdad may merely be an Assyrian trophy brought back by Esarhaddon; the alabastron-lid of Knossos is evidently a mere (contemporary) importation. So we have no reason to suppose that Khian really owned a rood of land beyond the frontiers of Egypt, though, as a Hyksôs, he may well have exercised greater authority than any former Egyptian king over the Southern Palestinians and Bedawîn. As a Bedawî, and lord of the Bedu'w, he also bore the title of hik khaskhut, "Prince of the Deserts," which has already been mentioned.

In all probability, judging again from the style of scarabs, the successor of Khian was AA-USER-RA APEPI II, who, as a mutilated inscription in the British Museum tells us, set up "great pillars, and gates of copper," in the temple of Bubastis," and left his name at Gebelên in token of his rule over South as well as North. An important date in his reign is given in the famous Rhind Mathematical Papyrus; in it the scribe Aahmes states that he wrote it in the 33rd year of the King of the South and North, Aa-user-Ra, from an ancient copy made in the reign of Ne-maa-Ra (Amenemhat III). Our present copy, the Rhind Papyrus, was written at a later period, and its scribe copied the autograph and date of the scribe Aahmes with the rest. The high date agrees with the long reigns ascribed to the former Hyksos kings by Manetho. ${ }^{3}$

AA-SEH-RA, whose name is only known to us from a fragment of an obelisk at Tanis, possibly comes between Apepi II and Aa-kenen-Ra Apepi III, who added an inscription to a statue of Mermeshau at Tanis and dedicated an altar of

1 Annual of the British School at Athens, vii. p. 64 ; Fig. 20.

${ }^{2}$ Brit. Mus., No. IIOI ; Naville, Bubastis, Pl. xxxv. c.

${ }^{3}$ These long reigns are hard to square with a short chronology of the Hyksos period (see pp. $23 \mathrm{ff}$.). 
black granite, now in the Cairo Museum, in honour of the god Set of Avaris. In his reign the final revolt of the South seems to have begun, which hardly ceased until the Hyksos were expelled. In the Papyrus Sallier is given an account of the genesis of the quarrel between him and his vassal Sekenenra Tau-aa-ken of the Theban XVIIth Dynasty. Apepi seems to have been victorious at first, and the Theban was killed. ${ }^{1}$ The name of the last Hyksos king is unknown to us, but it is probable that between Apepi III and him comes the king SET (or RA)-AAPEHTI NUBTI, who is mentioned as living 400 years before Rameses II on the "Stele of Four Hundred Years," and is also known to us from a scarab in the British Museum, ${ }^{2}$ the style of which is identical with that of those of the early XVIIIth Dynasty and differs from those of the other Hyksos. This would place him about I650 B.C. ${ }^{3}$

The later Hyksos seem to have become entirely egyptianized. They adopted the full pharaonic dignity, and, as good Egyptian kings, built Egyptian temples and venerated Egyptian gods. The god of the deserts, Sutekh or Set, was naturally adopted by them as their especial patron, and identified with their own Baal or "lord." Since their rule was undisputed from first to last in the Delta, Set became specially identified in the minds of the Egyptians with the Delta, and in later times it was only at Tanis, the capital of the Delta, that he could be worshipped openly and the rule of the Hyksos be referred to with anything but obloquy. At the same time new religious ideas were imported into Egypt by the Hyksos; the naked goddess Ishtar or Anait is now (and never afterwards) seen represented on scarabs, and the Syrian winged sphinx makes its first appearance in Egyptian iconography.

Manetho implies that the first Hyksos conquered the whole country, and it is possible that they did overrun it; but it seems that their successors could not maintain their hold over it in face of the fanatical opposition of the population of Upper

${ }^{1}$ See pp. 2 I 9 ff.

2 No. 32368 .

3 This scarab alone is a sufficient argument against Prof. Meyer's placing of Nubti at the beginning of the Hyksos period (Gesch. Alt. $\mathrm{i}^{2}$. 2. p. 294). It is impossible that the scarabs of Khian, Nekara, and Apepi II and those of the typically "Middle Kingdom "style of Maa-ab-Ra and Sekhanra can come between that of Nubti and those of Aahmes 1, which that of Nubti exactly resembles. If Nubti reigned about I650 B.C., these others must have reigned some time before him. This is, it must be confessed, another argument against the short chronology. 
Egypt. Later on, however, they succeeded in imposing their rule over the South, and continued to hold it till the war of liberation began in the reign of Apepi III.

\section{The Egyptian Kings of the South}

The Antefs of Thebes-Nub-kheper-ra Antef-The Sekenenras-XVIIth Dynasty

In all probability the South had already become independent in the time of the later kings of the XIIIth Dynasty, under princes of Theban origin, several of whom bore the characteristic Middle Empire Theban name of Antef. ${ }^{1}$

Of these kings, Nub-kheper-Ra is the best known. His most important monument is an inscription upon a gateway of Senusert I in the temple of Min at Koptos, which is a decree of excommunication and degradation, and solemn curse directed against the person, descendants, and heirs of a certain Teta, who had apparently received the king's enemies in the temple. The decree, which is a historical document of importance, reads as follows :-

"Year 3, third month of Peret, 25th day: under the Majesty of the King of Upper and Lower Egypt Nubu-kheper-Ra Son of the Sun Antef, giving life like the Sun for ever! Decree of the King to the Chancellor, the prince of Koptos Minemhat, the King's Son and Governor of Koptos Kanen, to the Chancellor Menkhmin, the Scribe of the Temple Neferhetep the elder, all the soldiers of Koptos, and all the officials of the temple. Now ye, behold! this decree is brought to you to inform you that My Majesty (life, health, and strength!) hath caused to come the God's Scribe and Chancellor of Amen, Siamen, and the Chief Inspector User-'a-Amen to make inquisition in the temple of Min. Now seeing that an official of the temple of my father Min approached My Majesty (life, health, and strength!), and said: 'An evil thing has come to pass in the temple, for Teta

${ }^{3}$ On account of their name, these Antefs used to be assigned to the XIth Dynasty, till SteIndorfF proved their true position to be in the XIIIth (XVIIth) Dynasty (Ä.Z., I895, pp. $77 \mathrm{ff}$.). They are not mentioned in the Turin Papyrus, which consistently ignores the Theban monarchs at this time, since they were probably regarded as anti-kings opposed to the legitimate monarchs of the North, whose succession of names, of puppet-kings who reigned but for a few months or days, are carefully chronicled till the papyrus breaks off. All, after Nefer-Temu and Nehesi, must have been slaves of the Hyksos. 
(blasted be his name!) son of Minhetep hath received the Enemy there'; behold! let him be cast out upon the ground from the temple of my father Min; behold! let him be expelled from his dignity in the temple; even unto his son's son and the heir of his heir cast forth upon the ground! Take his loaves and sacred food, let not his name be remembered in this temple, as it is done to one who like him hath transgressed with regard to the Enemy of his God. Let his writings in the temple of Min be destroyed and in the treasury on every roll likewise. And any king and any powerful ruler who shall give him peace, may he not receive the White Crown, may he not support the Red Crown, may he not sit upon the Horus' throne of the living gods, ${ }^{2}$ may Nekhebet and Uatjit not give him peace as one who loves them! And any official and any prince who shall approach the Master (life, strength, and health!) to give him peace, let his people and his possessions and his lands be given as a god's offering to my father Min of Koptos, also let not any man of his kinsfolk or of the relations of his father or his mother be raised to this office! Also let this office be given to the Chancellor and Controller in the Palace Minemhat; give to him its loaves and sacred food, established unto him in writing in the temple of my father Min of Koptos unto his son's son and the heir of his heir!" 3

This is one of the most important Egyptian inscriptions that has come down to us: from it we not only learn the way in which was exercised the royal prerogative of summarily and utterly degrading and excommunicating a high official, but obtain a priceless reference to the relations of Nub-kheper-Ra with the Hyksos. We can have little doubt as to the nature of Teta's offence: "the Enemy of the God" can hardly be other than the abhorred Hyksos. From the mention of a garrison at Koptos we may conclude that this town, the modern Kuft, which even now is the most important strategical point of Upper Egypt, was the northern bulwark of Nub-kheper-Ra's kingdom, and that the traitorous temple-official Teta had either received a Hyksos emissary in its temple or had even

1 The crowns of Upper and Lower Egypt.

2 The phrase eset Hor nt anbu does not mean "the throne of Horus the living" (Petrie, Koptos, p. Io; Hist. Eg. i. 137), but "the Horus' throne of the living [gods]," i.e. the kings, who inherited the throne of Horus.

${ }^{3}$ Text in PeTrie, Koptos, P1. viii. 
treacherously surrendered it to the Hyksos in a siege, and that it was recovered by Minemhat and Kanen. There was evidently no truce with the "Enemy." Of all the Southern kings Nubkheper-Ra was probably their most energetic and successful antagonist, but it is evident that even he was unable to conquer the North, or even to advance his power much beyond Koptos. But he, like the other kings of his dynasty, never thought for a moment of abandoning his legitimate claims to the rule of the whole of Egypt, and even carried the war into the enemy's camp by assuming the title of "Sopd, lord of the Deserts." Sopd, a form of Horus, was the god of the eastern frontier of the Delta and of the "Red Land," the deserts between the Nile and the Red Sea north of the Wadi Hammamat, and by assuming his appellation as a title Nub-kheper-Ra emphasized his right to rule the very deserts from which the Hyksos came. $\mathrm{He}$ was buried at Thebes, his capital, like the other Antefs, and his tomb was examined by the royal commission in the reign of Rameses IX. ${ }^{1}$ His portrait at Koptos is that of a keen and energetic man of early middle age. ${ }^{2}$

The connexion of the Sebekemsafs and Antefs with the Sekenenra Taas of the latter part of the XVIIth Dynasty is not clear, but it is probable that the Sekenenras were descended from them, for Aahhetep, the queen of Sekenenra III, repaired the tomb of a queen Sebekemsas (the wife of one of the Antefs) at Edfu, and evinced an interest in her which argues relationship. ${ }^{3}$ Probably the throne passed by marriage again. It seems very probable that the reigns of Nubkheperra and his immediate predecessors and successors were contemporary with a period of Hyksos weakness, to which the reigns of Maa-äb$\mathrm{Ra}$, Sekha-n-Ra, and the others enumerated on pp. $216 \mathrm{f}$, are to be assigned. With them the first Hyksos dynasty (the XVth) no doubt came to an end, and a new and more energetic dynasty (the XVIth) followed, the first kings of which were Nekara, Khian, and Apepi II, who attacked the successors of Nub-kheper-ra and overthrew them, ${ }^{4}$ reducing the South to a position of vassalage in which it continued for two or three reigns, until the revolt of Sekenenra Taa-ken and the War of Liberation.

1 See p. 322.

2 Petrie, Hist. Eg. ii. p. 135.

3 Newberry, P.S.B.A. xxiv. p. 286.

- Probably after the reign of Seshes-her-her-maat-Ra Antef. 
The period of the Sekenenras shews no great alteration from that of the Antefs: the royal tombs were in the same cemetery at Dra' $\mathrm{Abu}$ 'l-Nekka and the style of the coffin of Sekenenra Taa-aa-ken is much the same as that of those of the Antefs. ${ }^{1}$ It is improbable that a period of even as much as a century of Hyksos rule intervened between the two families. During this period, however, the subjection of the South was complete, and Apepi II controlled the whole country as far as Elephantine, as is shewn by his use of the red granite of Aswân in his works in the Delta. ${ }^{2}$

\section{The War of Liberation (c. 1620-1573 B.C.)}

Beginning of the war-The Sallier Papyrus-Sekenenra I and II (c. I630?-1605) -Sekenenra III (c. I605-I59I B.C.)-Kames (c. I59I-I58I)-Capture of Memphis (c. 1582)-Aahmes (c. 1580-1559)-Siege of Avaris : inscription of Aabmes, son of Abana-Siege of Sherohan (c. 1578-1573)-Nubian war (c. 1572)-Attack of Aata (c. 1572 ?)-Rebellion of Teta- an (c. 157 I ?)

The rule of the Sekenenras was marked by the final revolt of the Southerners against the Hyksos. A fragment of a historical composition, the "Sallier Papyrus," written under the XIXth Dynasty, gives us the legend of the final cause of quarrel, the beginning of the end, which was current three centuries later.

The Ra-Apepi of the story is doubtless Apepi III, Aakenen-ra, whose name shews him to have been a contemporary of the Sekenenras. The ruler of the South Sekenenra has usually been supposed to be Sekenenra III, Taa-aa-ken, but this is not absolutely certain. Manetho says that the kings of the Thebaid and of the rest of Egypt revolted against the Shepherds, and a long and mighty war was carried on until Misphragmouthosis (Aahmes) finally expelled them. But if the war began under Sekenenra III it would not be very long, for this Selenenra was comparatively young when he was killed in battle, as we can see from his mummy, ${ }^{3}$ and the reigns of Kames and Senekhtenra, who intervened between him and Aahmes, were both very short, that of the latter being apparently quite ephemeral. Probably not more than ten or twelve years elapsed between the death of Sekenenra and the accession of Aahmes, and this does not give enough time for a

$$
{ }^{1} \text { See p. } 167, n . \quad{ }^{2} \text { See p. } 218 . \quad{ }^{3} \text { Now at Cairo. }
$$


long war according to ancient ideas. Further, the queen of Sekenenra bore the name of Aahhetep, "Offered to the Moongod," Kames calls himself "begotten of Aah and born of Thoth," and his brother Aahmase or Aahmes was "born of the Moon"; the name Thutmase or Thothmes ("born of Thoth") became common under the XVIIIth Dynasty. The lunar Thoth was the tutelary deity of the city of Khmenu, Hermopolis, the modern Eshmûnên. The choice of these Moon-names argues a special connexion of the later XVIlth and the XVIIIth Dynasties with Hermopolis, and the chronicle of Castor says that the XVIIIth Dynasty was of Hermopolite origin, obviously on account of the names of its founder Aahmes and his descendants the Thothmes. But Hermopolis lay far to the north of the northern frontier of the southern kingdom under the Antefs and within easy striking-distance of the Delta. It cannot have belonged to the Sekenenra of the Sallier Papyrus, and can hardly have been taken from the Hyksos by the Southerners until the War of Liberation had already continued for some time. Therefore the war must have begun before the birth of the wife of Sekenenra III, in the reign of one or the other of the earlier Sekenenras.

We have several relics of Sekenenra I, Tau-aa, and his tomb, as well as that of his successor Sekenenra II, Tau-aa-aa ("Tau the Twice-Great," who was a short-lived monarch in spite of his name), was examined and found intact by the inspectors under the XXth Dynasty. All three Sekenenras bore the full titles of a king of Egypt. It would seem hardly likely that the Apepi of the Sallier Papyrus would have permitted his southern vassal to bear the title of king, and so it seems probable the Sekenenra of the story is really Sekenenra I, who assumed the full royal style as a gage of defiance to the Hyksos after the rupture with his suzerain had taken place. $\mathrm{He}$ and his successors thenceforth pursued the long war as the rightful kings of Egypt fighting to expel a dynasty of usurpers. Hermopolis may well have been wrested by him from the Northerners, and in commemoration of this victory, which would call forth a great outburst of royal and national devotion to the liberated Moon-god, the Aah- and Thoth-names were probably adopted by the royal family, and the future queen of Sekenenra III, probably a daughter of Selcenenra I, received the name Aaḥhetep. These Hermopolite names were after- 
wards retained in the royal family in memory of the War of Liberation. $^{1}$

Sekenenra III was killed in battle, as we know from the appearance of his mummy, found with the other royal bodies at Thebes in ISSI, and now in the Cairo Museum.

From the arrangement of the reigns of this dynasty which will be given later, it would seem probable that he had reigned about fourteen years, and was succeeded by his son KAMES, a boy of twelve. Since the capture of Memphis is not mentioned in the inscriptions of the reign of Aahmes, the son of Kames, that city was probably recovered by his father. But before this event took place the Egyptian cause had received a serious set-back, for in a newly discovered hieratic inscription (a literary composition on a writing-board) we see that in the seventh year of Kames the territory in his possession only extended as far north as Cusae in Middle Egypt. ${ }^{2}$ Probably after the death of Selenenra III and defeat of his troops the Hyksos pushed the Egyptians back from Hermopolis to Cusae. During the first seven years of the boy-king's reign some sort of truce probably existed, but then in the twentieth year of his age Kames took up the family struggle, and probably marched victoriously to Memphis. He then died or was killed after a reign of not more than ten years, and was succeeded by his younger brother SENEKHTNRA, whose position is only known from a later inscription in which his name has been garbled as "Sekhentnebra." He either died or was killed very shortly afterwards, and was succeeded by the third brother, AAHuES NeBPEHTIRA, the liberator of Egypt and founder of the XVIIIth Dynasty, who was then, if we consider him to have been about forty-five at the time of his death (which from the appearance of his mummy at Cairo seems very probable), a young man of nineteen or twenty.

The capture of Memphis had sounded the death-knell of the foreign power. The Hyksos king, whoever he was, Set'aapeliti Nubti or an ephemeral successor, was driven north and east to Tanis and the great entrenched camp at Avaris in the Wadi

I I put forward this explanation of the occurrence of Hermopolite names in the royal family of the XVIIth and XVIIIth Dynasties with diffidence, but it seems to me to give the probable reason for them.

"The "Carnarron Tablet I." verso (GRIFFITH, in LORD CARNARvon and II. Carter, Five Years' Explorations at Thebes, p. 36 ; P1. xxviii.). 
Tumilat, whither the young king followed him in hot pursuit. We possess in an inscription ${ }^{1}$ an actual account of the final scene of the long war by one who in his youth was one of the actors in it, the admiral Aahmes, son of Baba and Abana. "He says: I speak unto you, all men, in order that I may inform you of the honours which have fallen to my lot." After describing the taking of the fortress of Avaris, he proceeds: "We sat down before Sherohan for three years," and His Majesty took it. I carried off thence two women and one hand, and the gold for valour was given me. The captives were given to me as slaves.

"And when His Majesty had made an end of slaughtering the Asiatics, he went south to Khent-hen-nefer (Nubia), to destroy the Nubians, and His Majesty made a great slaughter of them. I carried into captivity two live men and three hands ; I was presented once more with the gold, and behold the two slaves were given to me. Then came His Majesty down the river, his heart swelled with valour and victory, for he had conquered the people of the South as well as of the North. ${ }^{3}$

"Then came Aata southwards, bringing on his fate, namely, his destruction, for the Gods of the South seized upon him. His Majesty found him at Thent-ta-a, and took him prisoner alive, and all his men, with swiftness of capture. ${ }^{4}$ And I brought away two slaves whom I had taken on Aata's ship, and there were given to me five heads as my booty and five sta of land at my own city. All the sailors were treated in like manner.

"Then came that enemy Teta-'an, who had raised rebellion. But His Majesty slaughtered him and his retainers even to extinction. ${ }^{5}$ And there were given to me three heads and five sta of land at my own city."

1 At El-Kab. Lepsius, Denkmaeler, iii. 12a, d.

2 Breasted's reading (Anc. Rec. ii. 8), "six years," is incorrect (Sethe, Urkunden der I8. Dynastie, i. p. 4).

${ }^{3}$ No doubt the Nubians had revolted during the long war, and Aahmes took the first opportunity after the expulsion of the Hyksos to chastise them (see p. 270).

4 Aata was probably a Hyksos, perhaps the last Hyksos king, who took advantage of the absence of Aaḅmes in Nubia to invade Egypt and make a fierce dash southwards by river into Upper Egypt, where he was annihilated by the Egyptians returning from the South.

${ }_{5}^{5}$ Teta-'an must have been an Egyptian, some noble discontented with the new order of things, which promised to restore the powerful monarchy of the XIIth Dynasty. 
Thus the long War of Liberation ended, having lasted about forty-five years, ${ }^{1}$ off and on.

\section{The Restoration and the Empire}

With the liberation and reunification of the kingdom by Aahmes closes one of the most interesting episodes of the ancient history of the Near East. But if the period of the Hyksos conquest of Egypt is interesting on account of its very

1 This estimate of about forty-five y'ears (probably forty-seven) from the beginning of the war under Selenenra I rests upon the data given by the recorded events of the life of the queen Aaḥhetep, claughter of Sekenenra I (?), wife of Selienenra II (?) and Sekenenra III, and mother of Kames, Sekhentnra, and Aahmes. Prof. Petrie uses these data to construct a probable scheme of the events of this period, but as he apparently thinks that the war began under Sekenenra III, he allows more time for Aaḥhetep's life than seems probable if it really began under Sekenenra I, as I think most likely. If we compress the events of Aahhetep's life somewhat, and assumc that Aahmes was about forty-five, instead of fifty-five (as Prof. Petrie assumes) years old at the time of his death, we obtain the following approximate scheme of events, as far as the duration of the war is concerned :-

$$
\text { Year of the War B.c. }
$$

Hermopolis taken(?); Aaḥhetep born in

Sekenenra II succeeded in

Selenenra III succeeded in

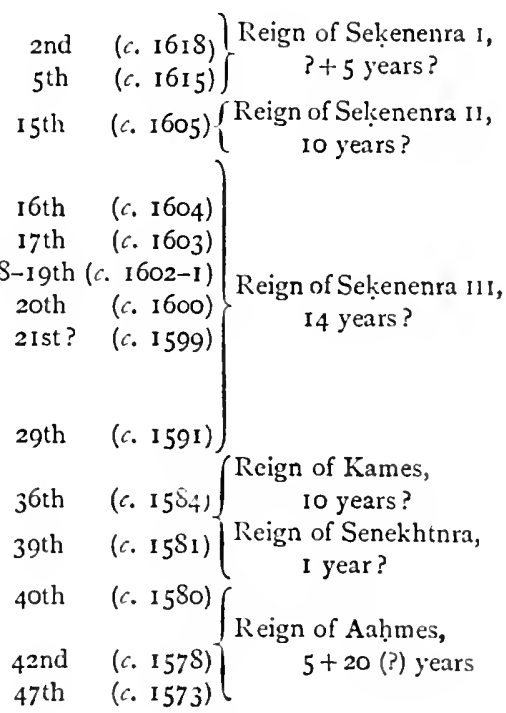

Aahhetep married Selsenenra III in

Kames born in $\quad \cdot \quad \cdot$

Senekhtnra born in . . I S-19th (c. 1602-1) Reign of Sekenenra I11,

Defeat and death of Sekenen.

ra III: Kames succeeded: truce (?) in . War resumed: Memphis taken in

Senekhtnra succeeded in

Aahmes succeeded in

Avaris taken : Hyksos expelled in

Sherohan taken in. $\quad . \quad$. $47^{\text {th }}$ (c. 1573$)$

My arrangement seems to me nore probable than Prof. Petrie's, and does not make Aabhetep too old in the reign of Thothmes I, when she was still living. Instead of being, as on Prof. Petrie's theory, from ninety-six to a hundred years old then, she would according to this scheme then have been an octogenarian, which is far more probable. 
obscurity and difficulty, that of the new epoch of energy and prosperity which now dawned upon the Nile-land is also of surpassing interest for the opposite reason; for no period of Egyptian history are the contemporary public and private records so full, of none have we so many actual remains, as of that of the XVIIIth Dynasty, which Aahmes founded; at no period of the early history of Western Asia have we such detailed information of events as in the fifteenth century B.C., when the famous cuneiform letters and despatches found at Tell el-Amarna were written. Egypt now enters upon her epoch of imperial greatness, the period of the "First Empire" begins. $^{1}$ Having rendered their military power equal to that of the Semites by the acquisition of the charict, schooled to war by the long struggle against the Hyksos, and inspired to enthusiasm by the restoration of their ancient monarchy to the full extent of its ancestral dominion, the Egyptians were eager to wreak vengeance upon the Semites for the oppression which they and their gods had suffered at foreign hands. Half a century of quiet watching after the expulsion of the Hyksos showed the kings of the XVIIIth Dynasty that the Semites, though formidable to those weaker than themselves, had no real cohesion, and

${ }^{1}$ Appended is a list of the kings of the XVIIIth Dynasty :--

\begin{tabular}{|c|c|c|c|}
\hline & $\begin{array}{l}\text { Manethonian } \\
\text { Equivalents. }\end{array}$ & $\begin{array}{l}\text { Order in } \\
\text { Manetho. }\end{array}$ & $\begin{array}{l}\text { Approximate } \\
\text { Date B.c. }\end{array}$ \\
\hline I. Nebpehtira Aahmes I . & Amosis & I & I $580-1559$ \\
\hline 2. Tjeserkara Amenhetep I & Amenōphis & 3 & I $559-1539$ \\
\hline 3. Aakheperkara Thothmes I & Tethmōsis & (I) & I $539-1514$ \\
\hline 4. Aakhepernera Thothmes II & Khebron & 2 & I $514-1501$ \\
\hline 5. Maatkara Hatshepsut . & Amensis & 4 & $1501-1479$ \\
\hline $\begin{array}{l}\text { 6. Menkheperra Thothmes III . } \\
\text { [Manakhpirriya] }\end{array}$ & $\left\{\begin{array}{l}\text { Mephres } \\
\quad \text { (Misaphris) } \\
\text { Misphragmouthosis }\end{array}\right.$ & $6\}$ & I $501-1447$ \\
\hline 7. Aakheperura Amenhetep II . & Amenōphis & s & I $447-1421$ \\
\hline S. Menkheperura Thothmes IV . & Touthmōsis & 7 & $1421-1412$ \\
\hline $\begin{array}{l}\text { 9. Nebmaatra Amenhetep III } \\
\text { [Nimmuriya] }\end{array}$ & Horos & 9 & $1412-1376$ \\
\hline $\begin{array}{l}\text { Io. Neferkheperura Amenhetep IV } \\
\text { Akhenaten [Napkhururiya] }\end{array}$ & \multirow{5}{*}{\multicolumn{2}{|c|}{ 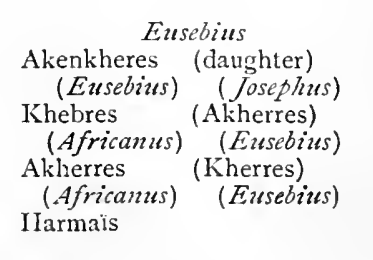 }} & $1380-13^{62}$ \\
\hline II. Smenkhkara. & & & $1362-1360$ \\
\hline I2. Nebkheperura Tutankhamen. & & & $1360-1350$ \\
\hline 13. Kheperkhepruarimaatra $\mathrm{Ai}$ & & & I350-1345 \\
\hline $\begin{array}{l}\text { I4. Tjeserkheprura Harmahabi } \\
\text { [Horen'neb] }\end{array}$ & & & $1345-1321$ \\
\hline
\end{tabular}



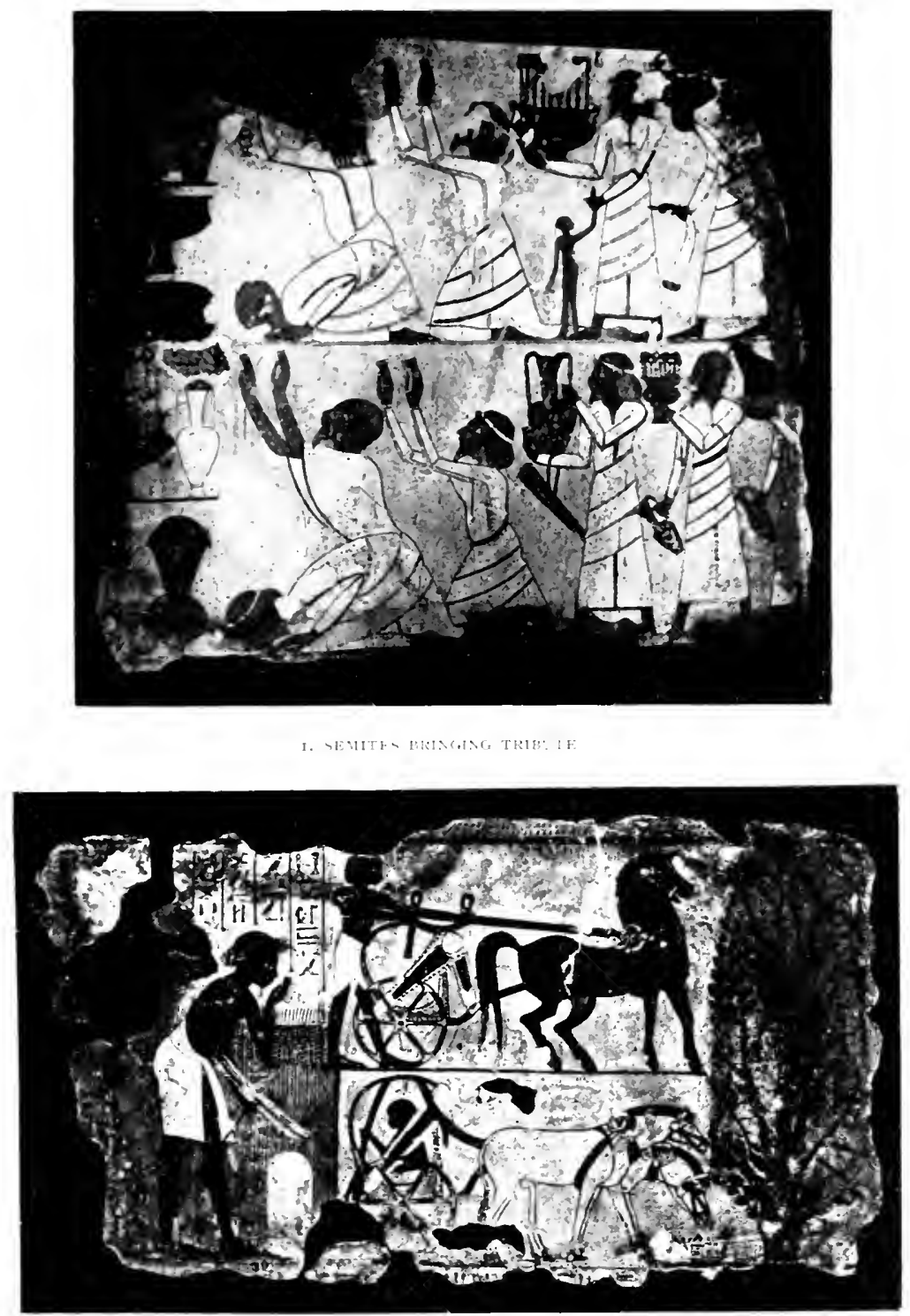

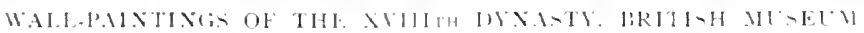


$\therefore-4 j \operatorname{con}$. 
were only dangerous when united from time to time in shortlived confederacies under the military leadership of some momentarily powerful king or dynasty, such as a KudurNankhundi, a Khammurabi, or a Salatis. No such military hegemony existed now; the Babylonians were weakened under the foreign rule of the Kassites; the Hittites had not yet penetrated far to the south, except in an occasional raid; the Hyksos were broken and flying, bringing war and confusion into Palestine in their train; Western Asia lay opcn to an Egyptian attack. The opportunity was seized, and Thothmes I, the second successor of Aahmes, invaded and overran Palestine and Syria.

Egyptian kings had raided Palestine before, and in the time of the XIIth Dynasty, or even in that of the VIth, may have reached the slopes of Hermon. But the land north of Lebanon and east of the Hauran was now traversed by Egyptian warriors for the first time. From Galilee and the territory of Damascus (already a city of note), the descent of the Orontes valley led into a wide, wealthy, and well-inhabited land, studded with cities, stretching away to the great river Euphrates and the mountainwall of Amanus. This land the Egyptians called Naharin, "Two River-Land" (using a Semitic appellation derived from the two limiting features of the region, the Orontes and the Euphrates). The native Syrians called their land Nukhashshi. Across the Euphrates lay the more barren North Mesopotamia, the modern districts of Urfa, Diarbekr, and Mardin, then dominated by the Aryan aristocracy of Mitanni: ${ }^{1}$ between it and Amanus the way lay into a land more fertile yet than Syria, the Cilicia of the two rivers, Sihon and Gihon, between Amanus and Taurus. Here the great northern wall of mountain scemed to bar all further progress from the south, and bcyond it lay the Anatolian uplands and the strange European world of the north, which i.ier Babylonian nor Egyptian desired to enter. The cis-Taurus land was, however, well worth raiding, and the successors of Thothmes I rightly deemed it well worth holding and keeping. The whole country between Taurus and Euphrates and farther south is covered with the tells, the mounds which mark the sites of the ancient cities. Northern Syria was from early days a great focus of human life and activity, and did we know more of its history we should see, probably, that 
this land played from early days ${ }^{1}$ a great part in the development of Mediterranean civilization. Its inhabitants were primarily Semites, no doubt. of the same Canaanite stock as those of Palestine. But in Cilicia there must from the beginning have been a considerable Anatolian admixture, and, as we have seen, a large part of Northern Syria had been overrun and conquered by the Hittites of Anatolia. As the Hittite population never crossed to the left bank of the Euphrates, and Mitanni appears later as in political control of Nukhashshi, the probabilities are that the Mitannians established a political ascendancy over both the Anatolian invaders and the Syrians. ${ }^{2}$

Aryan chiefs from Mitanni now migrated into Syria, ${ }^{3}$ and later on we find Aryan names even in Palestine. Mitannian overlordship probably stopped at the Lebanon, and the Phoenician cities preserved each its own independence, owning no overlord, but in constant relations with Egypt on the one side and with Cilicia and the lands farther west on the other. Palestine and no doubt Damascus owned Babylonian hegemony, but the Kassite king of Karduniyash was too far away to give any protection to the Canaanites against an attack from Egypt.

\section{The Conquest of Thothmes I and the Truce under Hatshepsut}

Previous attack on Asia by Amenhetep I improbable-The attack of Thothmes IPeaceful policy of Hatshepsut

From the fact that Thothmes I claims the Euphrates as his northern boundary at his succession, and certainly seems to have met with but little resistance in his Asiatic campaign, which carried him to the Euphrates, it has been concluded that the way was perhaps paved for him by some unrecorded conquests of the preceding king Amenhetep I, son of Aahmes. Still, the captains Aahmes son of Abana and Aahmes-Penneliheb, who accompanied Amenhetep in his Nubian and Libyan expedi-

1 Neolithic remains probably exist at the base of every tell.

2 This is easily conceivable, since the Mitannian barons ruled their subjects absulutely while the Syrian Hittites seem to have expelled some of the natives, but mixed themselves with the rest, occupying one town but not another; so that the Syrian princes and population were partly Anatolian, partly Semitic, neither controlling the other absolutely, though probably the Anatolians had the upper hand.

3 These Aryan barons bore the name of mary'a or maryannu, which appears in Egyptian inscriptions in the time of Thothmes IJ (Winckler, O.L.Z., I9Io, pp. 290 ff.). 
tions, ${ }^{1}$ and his son in his Asiatic campaign, can hardly have been left behind if Amenhetep invaded Asia, and would certainly, if they had accompanied him, not omitted to chronicle the fact in their inscriptions. The coronation inscription of Thothmes ${ }^{2}$ may well have been emended afterwards to include an assertion of his Syrian sovereignty, and the ease with which he reached the Euphrates may have been due simply to the suddenness and unexpectedness of his attack. Unluckily we have nothing but the accounts of the two gencrals to tell us of the events of this, the first Egyptian conquest. Conquest indeed it hardly was: it was little more than a razzia like those which every king conducted in Nubia. In the land of Naharin the more organized and formidable tribes of the North collected themselves together to oppose the Egyptian advance, but were overthrown, chariots and horses falling to the booty of the two Aahmes, who were decorated as usual for their valour. Then the ling set up a stone tablet by the side of Euphrates to mark the farthest limit of his advance and of his dominion, and returned to Thebes to boast to the priests that he had "made the boundary of Egypt as far as the circuit of the sun," 3 to "that inverted Nile which runs downstream in going upstream," the Euphrates. ${ }^{4}$

For centuries before him Egyptian kings had set up similar tablets in Nubia, and there, among barbarians, the monuments of raids might well be also the monuments of consecutive dominion. In Asia, however, it was otherwise. The Asiatics were not savages like the Nubians, though it is probable that the Egyptians had not quite realized the fact yet, and there is little doubt that the mere setting up of an Egyptian tablet in their midst by no means immediately disposed them to consider themselves the vassals of Egypt. We can be sure that the tablet of Thothmes was thrown down by the Syrians as soon as he had departed, and that tribute to Egypt was only paid so long as there were Egyptian soldiers near to enforce it.

${ }^{1}$ For the inscription of Aahmcs.Pennekheb at El-Kab, see BrE.ssted, ii. pp. $9 \mathrm{ff}$.

2 Transl., Breasted, Anc. R'ec. ii. p. 31 .

${ }^{3}$ Stela of Abydos: Mariette, Abydos, ii. 31.

4 Tombos-stela; Breasted, l.c. The Egyptians on this, their first acquaintance with the Euphrates, were eridently puzzled by the fact that this new "Nile" ran south instead of north, and that therefore one sailed on it downstream when according to Nilutic analogy one ought to be sailing upstream. 
If Syria was to be an Egyptian possession some sort of permanent organization binding the various tribes to the Egyptian state was necessary, and this could not be enforced without complete conquest and permanent occupation. This lesson was learnt by Thothmes III during the course of his long wars, and the result was the organized Asiatic empire of Egypt under his successors.

The sudden attack of the Egyptians must have driven the Asiatic princes into some sort of alliance, so far as their mutual jealousies made this possible, in preparation for its renewal. Mitanni dominated North Syria, and the Southern Syrian and Palestinian chiefs seem to have acknowledged some sort of primate in the Prince of Kadesh on the Orontes, probably an immigrant Hittite from Anatolia. It is under this prince that we find the Canaanites arrayed at Megiddo against Thothmes III. During the reign of Hatshepsut the Asiatics gained a breathingspace in which to organize their forces. While the peaceful queen controlled affairs no campaigns were waged either in Nubia or in Asia. The personal presence of a warrior-king, able to march at the head of his troops, was lacking. The young king Thothmes III, her half-brother or nephew, ${ }^{1}$ who was associated with her on the throne after the death of her husband, was evidently not permitted by the peaceful queen to follow the example of his male predecessors and satisfy his love of fighting on the vile bodies of Kush and Rutenu. The queen thought more of sending peaceful expeditions to Somaliland to bring back "marvels of Punt" 2 for the embellishment of her temple at Dêr el-Bahri than of warlike razzias and pyramids of hands : and certainly she would never have allowed her male colleague to obtain ar opportunity to reap warlike prestige which might enable him to throw off her yoke and depose her. And she herself, man-like though she was, arrogating to herself the dignities of a king and causing herself to be depicted on the walls of the temples in male attire, never went so far as to imitate the gooldess of her Syrian tributaries, and take the field herself, armed with battleaxe and shield. So the young Thothmes was compelled to fret in silence while the Syrians, gradually losing their fear of an armed raid from Egypt, dared again to raise their heads in independence. Though the queen speaks of herself grandiloquently as ruling such 
of the Asiatics as remained after the conquests of her father, and though the lands of Roshau and Iu, which may be supposed to represent Asia, may poetically be said to be subject to her, it is probable that she exercised very little control over Palestine. Cedar for her temples she could obtain from the Lebanon by sea, but we know from the opening words of the annals of her succcssor's campaigns in Syria that at the time of his accession all Palestine had fallen away. Even Sherohan, the old conquest of Aahmes, and Yeraza, not far north of it, had revolted, when the peaceful queen at last died, and Thothmes, freed at last from her control, immediately took the field to restore his father's dominion to Egypt.

\section{The "Annals" of Thothmes III}

Thothmes III invades Palestine (1479 b.c.)-The Asiatic alliance under the Prince of Kadesh-The allies tike position at Megiddo-Thothmes holds a council of war and decides to advance by the Wadi Arah-Fighting in the wadi-The Egyptian army debouches into the plain-The battle of Megiddo (2Ist Pakhon, 1478 B.c.)-Rout of the allies-The town of Megiddo not taken-Surrender of Megiddo: the booty-Thothmes advances to Phoenicia and the Lebanon-Assyrian embassy received-Rebellion in Northern Syria subdued (1475 ?)-Capture of ArvadThothmes attacks Kadesh from Simyra, making Phoenicia his base ( 1471 ?)--Influence of sea-power-Capture of Kadesh-Phoenician campaign of 1470-Conquest of Northern Syria (Naharin): taking of Aleppo and advance to the Euphrates (1468?)-Tribute of Alashiya (1467?)-Fighting in Naharin ( 466 ?)-Beduin revolt in Southern Palestine (I462 ?)-Last campaign (1459)-Embassy from Cyprus-The Asiatic empire of Egypt

Of his campaigns, which lasted for the greater part of his reign, we have a full description in the annals set up on the walls of the corridor enclosing the sanctuary of the great temple of Amen in Karnak. ${ }^{1}$ This is the largest and most important historical inscription in Egypt, and it is at the same time one of the most graphic, often rising to the highest level of descriptive writing, and shewing considerable literary power, especially when dealing with the events of the first campaign. This, the oldest official record of a war that we possess, was probably prepared by Thununi (who was charged with the oversight of the tribute and booty collected during the various campaigns) no doubt under the supervision of the king himself, whose energetic personality seems to live in every line of it.

1 Transl, Breasted, Anc. Rec. ii. pp. $163 \mathrm{ff}$. 


\section{THE ANCIEN'T HISTORY OF' THE NEAR EAST}

It was on the twenty-fifth day of the month Pharmuthi in the twenty-second year of his reign (counted from the date of his association with Hatshepsut) that King Thothmes broke up from the frontier town of Tjaru and crossed the desert to Gaza, where he arrived on the anniversary of his coronationfeast, ten days later. One night only did he halt: the next day saw the army march out with all pomp and circumstance, and a few days later, on the sixteenth Pakhon, in his twentythird year, the town of Yehem was reached, and with it the vicinity of the enemy. Here a council of war was held, and the king explained the actual situation to the captains of his host. "That wretched enemy," said he, "the chief of Kadesh, has come and has entered Megiddo: he is there at this moment. He has gathered to himself the chiefs of all the lands which are linked with Egypt, even as far as Naharin, and including both Kharu and Kedu, with their horses and their soldiers. Says he: I have arisen to fight against the king in Megiddo. Now tell ye me [your plans]." From this it is evident that the revolt of the Southern Palestinians "from Yeraza to the marshes of Egypt" 1 was but the last phase of a general revolt which had spread from the north southwards under the leadership of the King of Kadesh on the Orontes, a city which, not yet a frontier fortress of the Hittites, was in Thothmes' day the focus of all the Syrian national spirit that might be said to have existed. It was not till Kadesh was finally taken that the Egyptian king could regard his conquests as secure. But at present, when the council of war was held at Yehem, there was no possibility of any direct advance on the stronghold of the ringleader of the rebellion. Kadesh lay far away beyond the Lebanon in the direction of Hamath. All Palestine between was in active revolt.

No inconsiderable knowledge of the art of war was shewn by the Prince of Kadesh and his allies when in order to stop the Egyptian advance they took up their position along the ridge, called the "Ruhah," which connects Carmel with the hillmass of Samaria and Judaea, and separates the Plain of Sharon from that of Esdraelon. An army with chariots and horsemen would naturally cross this comparatively low ridge in order to

1 "The marshes of the land": this does not mean the country "from Northwestern Judaea to beyond the Euphrates," as Breasted thinks (Anc. Rec. ii. p. I79, note), but to the Serbonian bog and Lake Menzâla. 
reach Northern Syria, and it offered the greatest possibility of a successful defence. When, therefore, Thothmes reached Yehem (probably in the present Wadi Yahmur), at the foot of the southern slope of the ridge, he found that the Syrians were preparing to bar his further northward way here, with their headquarters in the town of Megiddo, and their left wing at Taanach, between four and five English miles away to the southeast. Both Megiddo and Taanach were ancient and important towns, the seats of local chicfs, and were fortified. The name of Taanach still survives in the modern Tell Ta'annek, where an Austrian expedition under Prof. Sellin has been engaged on successful excavations. Megiddo is Tell el-Mutesellim, where the German expedition of Schumacher has also excavated. ${ }^{1}$ Both towns stand back behind the ridge half-way down to the plain. They were the natural bases for an army defending the ridge, across which three main roads passed then, as now, from the Plain of Sharon to that of Esdraelon. The southernmost was the easiest for the passage of armies, as it passed over the lowest portion of the ridge through the broad "plain" of Dothan: here had always passed the main road from Egypt and the Shephelah to Damascus, and through it the armies of the first Thothmes had doubtless marched. Just where the Dothan pass spreads out into the Plain of Esdraelon lay to the north-west, but four miles distant, Taanach, where the Prince of Kadesh had posted his left wing. This was in order that he might be able to defend easily either the Dothan road or another, which passed directly between the fronts of the opposing armies, from Yehem to Megiddo, by way of Aruna, the modern Wadi Arah, a long and winding, narrow and stony, glen which reaches the watershed at the spring of ${ }^{\circ} \mathrm{Ain}-\mathrm{Ibrahim}$, from which the path descends swiftly along the sides of the Ruhah to the site of Megiddo. It is not probable that the Syrians expected Thothmes to use this difficult mountain-way, but their position at Megiddo enabled them to be ready for a possible advance by the third road, that by which the modern telegraph-wire now passes across the moor of the Ruhah at the foot of Carmel to Haifa: this road lay some seven miles north of Megiddo. Thus the Syrians were ready to move either to the south or to the north according as they heard that the Egyptians were advancing by the regular road of Dothan or were intending first

${ }^{1}$ For references see p. 440 , n. 4. 
of all to reach Phoenicia by the "Zefti road," as the Egyptians called it.

The Egyptian king determined to do neither, but to strike direct at the enemy's central position at Megiddo through the narrow Wadi Arah, and thus surprise him. At the council of war he communicated his decision to his captains, who were much troubled at the rashness of the royal plan of battle. "They spoke in the presence of His Majesty," says the official account, "saying, How are we to advance on this narrow path? The enemy will await us there and (a small force) can hold the way against a multitude. Will not horse come behind horse and man behind man likewise? Shall our van be fighting while our rear is still standing there in Aruna, unable to fight? There are yet two other roads: there is that one which is [best] for us, for it comes out at Taanach, and the other, behold! it will bring us upon the way north of Zefti, so that we shall come out to the north of Megiddo. Let our victorious lord proceed upon the road he desires: but cause us not to go by this difficult path!" But the king would not be turned from his purpose in spite of the very excellent arguments advanced by his captains against the engagement of a large army of chariots and horses in a narrow ravine: he vowed that he himself would lead the van so that if the head of the advancing host were successfully cut off by the defenders of the pass, he himself would fall. Doubtless he saw the clanger of his plan, but sought to neutralize it by concentrating all the loyalty and valour of his warriors to fight with him in the van, so that they could carry all before them. "I swear," said he at the council, "that as $\mathrm{Ra}$ loveth me and Amen favoureth me, my Majesty will proceed upon this path by Aruna. Let him who will among you go upon those roads ye have mentioned, and let him who will among you come in the following of my Majesty." This, of course, was impossible: submissively replied the captains, "May thy father Amen grant thee life! Behold, we follow thy Majesty everywhere thy Majesty proceedeth; as the servant is behind his master." "Then," says Thununi's account, "His Majesty ordered the whole army to march upon the narrow road. His Majesty swore: 'None shall go forth in the way before my Majesty.' He went forth at the head of his army himself, shewing the way by his own footsteps; horse behind horse, His Majesty being at the head of the army." 


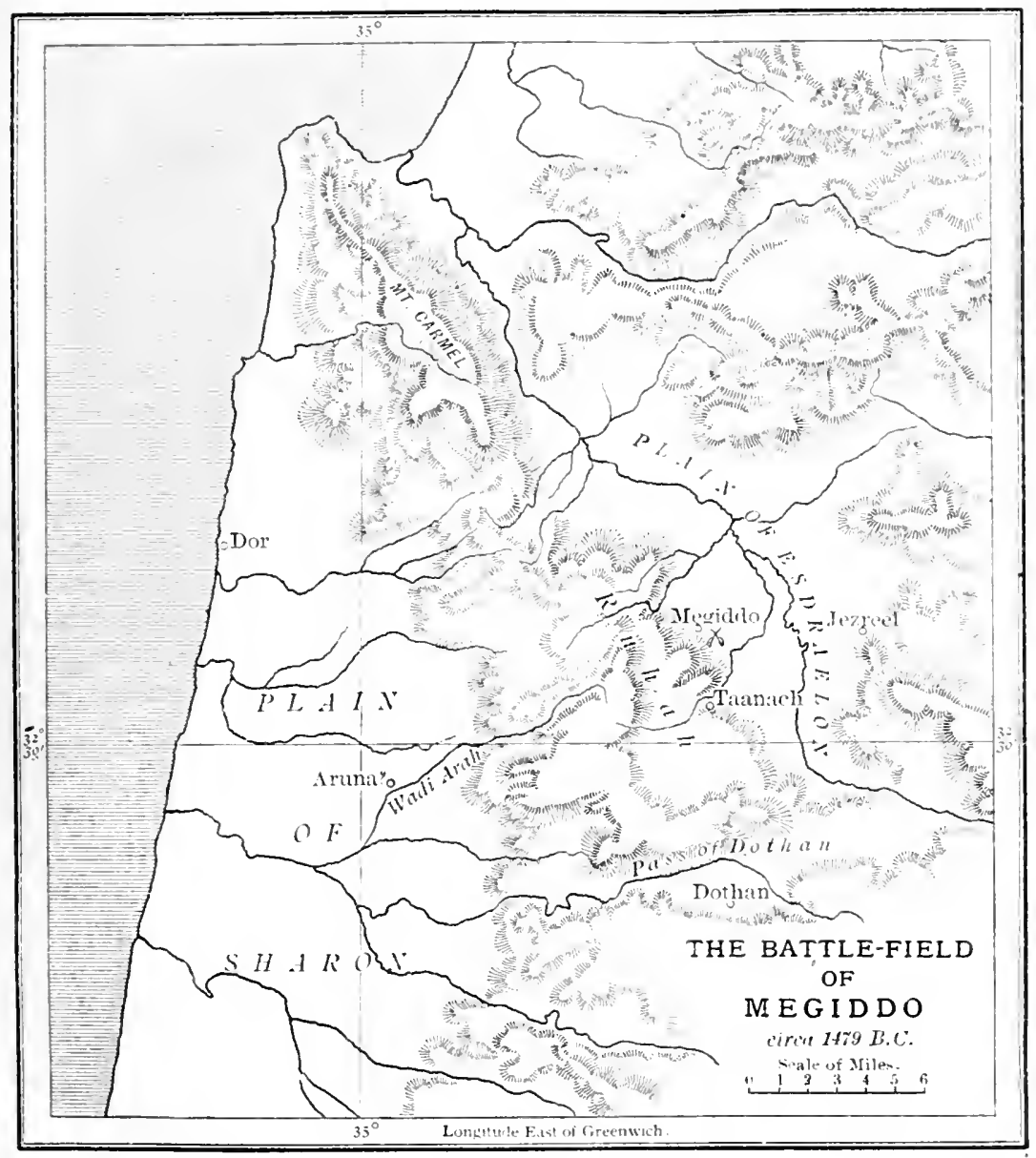



So the host threaded the glen of Arah, in Indian file ("horse behind horse"), the king leading, perhaps himself on foot. The passage was not made without opposition. The people of the village of Aruna, where on the night of the I th Pakhon the rcyal headquarters had been placed, attacked the troops on the next day, and caused considerable annoyance to the rearguard, which was fighting near Aruna while the king with the van had crossed the head of the pass without resistance and was descending the slope of the Ruhah towards Megiddo. As, however, the main body of the army issued from the hills, it became possible to bring up the rearguard more quickly, so that the whole army debouched into the plain on a broad front under the eye of the king himself, who waited at the mouth of the pass till the rear had come up from Aruna. The official account attributes to the advance of the captains this mancuvre, which would correspond in the phraseology of a modern drill-book to a change from column of route perhaps merely two deep to a general advance in line of battle.

By the time the whole army had carried out this manœuvre the day was far spent, "and when His Majesty arrived at the south of Megiddo on the bank of the brook Kina, the seventh hour was turning, measured by the sun." If by the seventh hour is to be understood one or two o'clock p.m., the army had successfully traversed the dreaded ravine in a single morning; and if Aruna itself is the modern Ararah, the rate of advance had been swift, as Ararah is at least eight miles from the brook Kina, and six of the miles are uphill. No modern army could march so fast, and though it is evident that the Egyptian force consisted largely of chariotry, therc were, we know, foot soldiers as well. ${ }^{1}$

Evidently the afternoon was considered to provide insufficient time for a regular battle, so the army bivouacked where it stood on the slope reaching down to the southern bank of the brook Kina, opposite Megiddo. The orders for the morrow's fight were given out and all weapons and equipment were overhauled and got ready for the fray. The adjutants or chiefs-of-staff then presented their reports: "All is well." The king rested in his tent, and during the night the guards and

${ }^{1}$ As we see them depicted on the walls of Dêr el-Bahri the Egyptian infantry seem actually to have moved with a swift springing pas, resembling that of the Italian bersaglieri, and no doubt they could cover the ground at a considerable speed. 
sentries went their rounds crying the watchwords: "Firmheart! firm-heart! be vigilant! be vigilant! watch for life at the royal tent!"

On the morning of the 2Ist Pakhon the host was arrayed against the Syrians, who though no doubt surprised by the swift advance of the Egyptians, do not seem to have wished to decline the battle. Whether they had been able to bring up their left wing from Taanach during the preceding afternoon and night is not evident; but if they did they were not helped thereby. The result of the fight was a complete victory for the Egyptians, who advanced in line, pivoting on their right wing, which remained upon the spur of hill above el-Lejjâ and south of the brook Kina, until the left wing had swung round to the north-west of Megiddo (Tell el-Mutesellim) itself. The Egyptian line must have been fully a mile long. In the centre, which must have advanced north of the brook Kina, fought the king himself, "in a chariot of electron, arrayed with his weapons of war, like Horus, the Smiter, lord of power; like Ment of Thebes, while his father Amen strengthened his arms. ... Then His Majesty prevailed against them at the head of his army, and when they saw His Majesty prevailing against them, they fled headlong to Megiddo in fear, abandoning their horses and their chariots of gold and silver."

The routed army of the Syrians seems to have attempted to take refuge within the walled town of Megiddo, and most picturesque details are given of how the fugitives were hauled up the walls by ropes made of robes knotted together, since the gates had been closed to prevent the entrance of the Egyptians pell-mell with the defeated.

This might have occurred, or at any rate Megiddo might have been taken by storm in the moment of defeat and confusion, so the official chronicler relates: "had not His Majesty's soldiers given their hearts to plundering the enemy's possessions," says he regretfully, "they would have taken Megiddo at this moment, when the wretched foe of Kadesh and the wretched foe of this town were being hauled up in haste in order to bring them into this city." This is a curiously outspoken piece of military criticism on the part of the official historian of the war.

The ling was heavily displeased at the failure to take Megiddo, in spite of the rejoicings of the army itself at its 
victory: "it is as the capture of a thousand cities, this capture of Megiddo, for every chief of every country that has revolted is within it." However, all that could be done now was to invest the town, and a palisade was constructed round it under the inspection of the king, to which the name Menkheperrais-the-Surrounder-of-the-Asiatics" was given. Eventually the place surrenclered, and a rich booty was captured in it and sent to Egypt, the inventory being recorded on a leather roll in the temple of Amen in Thebes. The list gives a good idea of the civilization of the Canaanites, which was evidently as luxurious as that of Egypt or Mesopotamia. ${ }^{1}$ It included so many as 924 chariots, some of which were wrought with gold, 200 suits of armour, and a large number of flocks and herds. The tent and family of the King of Kadesh had been captured and most of the allied chiefs surrendered in the city. The harvests of the people of Megiddo were reaped by the army. It is evident that the prisoners and the people of the city were treated with clemency, as usual with the Egyptians, who never put whole populations to the sword in the barbarous manner of the Semites.

From Megiddo Thothmes seems to have marched northwards into Phoenicia, and probably took Tyre. Eastwards, in the Lebanon, the towns of Yenoam, Anaugasa, and Hurenkaru, which formed a kind of Tripolis under the dominion of the King of Kadesh, were taken, with a rich booty of slaves and of gold and silver vases of Phoenician workmanship and work in ebony and ivory.

Farther into the mountains the king did not penetrate: he returned to Egypt, but the next year saw him again in the field. No resistance was offered to his triumphal march either in this or in the succeeding campaigns. The chiefs vied with each other in heaping up tribute at the feet of the conqueror, and so far had the impression of the victory of Megiddo penetrated that for the first time we read of ambassadors from Assyria coming to greet the King of Egypt with presents from their master, probably Ashir-rabi or Ashir-nirari. ${ }^{2}$

1 As will be seen in Chapter IX, the recent excavations in Palestine have yielded but few fine relics of this culture, which was probably largely destroyed in the centuries of war between Egypt and the Asiatics. After the Israelite invasion Palestinian civilization probably degenerated.

2 See p. 260, n. 2. 
The "tribute," as it is called, of the Assyrian king, is thus specified: "genuine lapis-lazuli, a large block, weighing 20 deben 9 kedet; genuine lapis-lazuli, two blocks (total three), weighing 30 deben: total 50 deben 8 kedet; fine lapis-lazuli from Babylon; vessels of Assur of variegated kherti-stone, . . . very many." Later on, further presents of rare woods and a leopard-skin for the sides of a chariot wcre dispatched by the propitiatory Assyrian. ${ }^{1}$

The lists of the booty of the third campaign are remarkable for a catalogue of the rare plants and trees which Thothmes caused to be collected in Palestine and removed to Thebes, where he decorated a chamber of his new buildings at Karnak with sculptured representations of them in relief "as a memorial before my father Amen for ever."

Of the fourth campaign we have no record. It was perhaps marked by temporary ill-success; apparently a revolt was brought about by the Prince of Kadesh in Phoenicia, for the fifth campaign was waged there. In this, his twenty-ninth ycar, we find the king "in Phoenicia (Tjahi), subduing the countries revolting against him." The rebellion seems to have been largely instigated by the Prince of Tunip (a town lying northward of Aleppo), whose army was defeated at a place the name of which is destroyed, but which was on the sea, as many ships were captured in its harbour. The far northern maritime city of Arvad was now taken for the first time, with so much booty that regrettable results followed: "Behold!" says the official account naïvely, "His Majesty's army was drunk and anointed with oil every day as at a feast in Egypt." Prof. Breasted ${ }^{2}$ supposes that after this the king returned to Egypt by sea in the captured ships, but no absolute indication of this can be found in the inscriptions, though it is possible enough, since next year we find him striking out a new line of his own in strategical combinations by sailing with his army to Phoenicia and marching to an attack upon Kadesh from a maritime base, Simyra, at the mouth of the Nahr elKebîr, the seaport nearest to the threatened city. The successful

1 This is not actually the earliest mention of the names of Assyria (Assur) and Babylon (Babel) by the Egyptians, as in the excavations of 1903 at Deir el-Bahri an ostrakon inscribed in hieratic of the time of Hatshepsut was found, on which an Assyrian (pa-Asszer) is mentioned.

Anc. Rec. ii. p. 196. 
voyage from Arvad to Egypt may well have given him the idea of this new move, the importance of which in the history of the development of the art of war is very great. We may indeed see in it the first instance of the importance of seapower to an invading army.

The campaign was entirely successful. So surprised was the enemy at the new move that he seems to have allowed the Egyptians to cross the mountains unscathed, and Kadesh was taken. In this campaign fought a distinguished captain named Amenemheb, whom wc shall meet again in later wars.

The king then returned to his base at Simyra, and after again chastising Arvad, sailed back to Egypt, taking with him "the children of the chiefs and their brothers," who were to be kept as hostages, and sent to Syria to take the place of any reigning chief who died. Meanwhile they were educated "in all the wisdom of the Egyptians," impressed with the power of their suzerain, and as far as possible egyptianized. This new act of policy, devised in order to bind the families of the Syrian chiefs to Egypt as much as possible, is a strong testimony to the statesmanship of Thothmes. ${ }^{1}$

During the next year Phoenicia still needed vigorous punishment to bring the cities entirely to their knees, as the Prince of Tunip was still inciting them to resistance. Ullaza was taken, and in it the son of Tunip, with chariots and horses. The king coasted in his ships from harbour to harbour, where the tribute of the mountain-chiefs and their supplies of food were collected to await him. By the end of the campaign the whole of Phoenicia was sufficiently pacified and organized for him to carry out systematically the real conquest of Northern Syria and the Euphrates-land, which his predecessors had merely raided. Phoenicia was his base. Landing again at Simyra, he advanced rapidly across the mountains and down the valley of the Orontes, probably taking Tunip on the way, past Senzar (Kala'at Seidjâr?), where a victorious battle was fought, Hamath, and Homs to Aleppo, in the neighbourhood of which he gained the victory of "the Heights of Wan" (Gebel Simeân?), in which Amenemheb distinguished himself. His opponents were now the tribes of the land of Naharin, the "Two Rivers," probably under the leadership of the king of Mitanni, as well as the chief of Tunip, whose city was now 
in imminent danger. Pursuing them to the north-eastward, the Egyptians took Tunip and soon reached the Euphrates at Carchemish, where a decisive victory was gained, the enemy being driven into the river, followed by the victors, who crossed hot-foot in pursuit, led by the valiant Amenemheb.

And now the king was enabled to set up a tablet on the eastern bank of the Euphrates, "beside the tablet of his father, King Aakheperkara" (Thothmes.I). He made no attempt to extend his dominion into Mesopotamia, but was satisfied with the frontier of the Euphrates, that "inverted Nile" which seemed to be placed athwart the path of the Egyptian kings as their natural boundary. Mitanni no doubt sent tribute, and Ashur also, while the Lord of the mountains of Sinjar (Sengara), ${ }^{1}$ sent large quantities of both real and artificial lapis-lazuli of Babylon. And now for the first time the chiefs of the Great Kheta, the Hittites of Cappadocia, thought it advisable to send presents, consisting of eight silver rings, weighing $40 \mathrm{I}$ deben, a great block of crystal(?), and much tigu-wood. This is the first recorded political meeting of the Egyptians with the Hittites.

On the return to Egypt the king took part in a great elephant-hunt on the plain of $\mathrm{Nii}$ (Kefr-Naya), west of Aleppo, and Amenemheb distinguished himself by cutting off the trunk of the largest "which fought against his Majesty; I cut off his hand (i.e. trunk) while he was alive in his Majesty's presence, while I stood in the water between two rocks." The elephant evidently having pursued him into a rocky streambed, he had taken refuge between two rocks, where the great beast could not well reach him except with his trunk, which the hunter cut off with his small war-axe. ${ }^{2}$

It seems to me more probable that Scngara is the modern Gebel Sinjar than "Shin'ar" or Babylonia, as the Biblical name Shin'ar is not corroborated in any way loy the Babylonian monuments.

2 This picture of the king hunting the Indian (?) clephant in Northern Syria is an intcresting one. The great animal was probably exterminated in these parts, owing to the continual hunts of the kings and chiefs, by about 1000 B.C., as we hear nothing of him in the full descriptions of the Assyrian hunts in the seventh century. The lion, however, ranged over the whole of the Near East, including Palestine, Anatolia, and Continental Greece to a much later period. No doubt the elephant never existed (in historical times) west of the Taurus, but the lion was found in the whole of south-eastern Europe as far west as the Alps (with the possible exception of the Italian peninsula) until a comparatively late period. It needed two thousand years of constant hunting by the lings and chiefs before this ferocions beast, one of 
Of the ninth compaign few warlike operations are recorded. Tribute was received by the king in Phoenicia from the more northerly coast-land, here mentioned for the first time under the name of A'seya, a mistake for its real name of Alashiya, which was shortly to become very familiar in Egypt. The Alashiyan king sent IoS blocks of pure copper, weighing 2040 deben; together with blocks and pegs of lead, lapis-lazuli, and a single tusk of ivory, which must have come from inner Syria. ${ }^{1}$

But though they abode still for a year, the chiefs of Naharin were not yet disposed to accept the Egyptian yoke. In spite of the lesson of the complete subjugation of first Canaan and then Phoenicia, they once more tried conclusions with Thothmes, under the headship of a prince called "that foe of Naharin," probably the chief of Tunip or his son. At Arayna, an unidentified place, probably in the neighbourhood of Aleppo, the confederates werc defeated, and the usual booty taken.

\section{Of the eleventh and twelfth campaigns no records are pre-}

the most terrible enemies that primitive man ever had to encounter, was finally driven into Central Africa and the Middle East.

1 Of late years it has been usual to identify this land of Asi (A'seya) or Alashiya with Cyprus, because in the Ptolemaic inscriptions Cyprus is called by this name in the form Asi or Asebi, as well as "Kufrus" (Müller, Asien u. Europa, p. 336). I have myself hitherto doubtfully held this view (Oldest Civilization of Grece, p. 163 ; B.S.A. Ann. viii. p. I70. But it now seems to me difficult to reconcile the identification of Alashiya with Cyprus with the way in which the country is mentioned in one of the Tell el-Amarna letters. Ribadda, king of Gebal, writes (letter KNUDTZON I I4) to Akhenaten requesting him to ask Amanmasha (an Egyptian official) if he, Ribadda, has not sent him from Alashija. This is the country in which Ribadda is striving to uphold the royal authority : it is not the far-away island of Cyprus, in which we have no reason to suppose the King of Gebal had any authority, and to which he certainly had no time to go while the revolt was in progress. Previously also the King of Alashiya had warned either Akhenaten or his father to be wary in his dealings with the kings of the Kheta and of Babylon, of whom the Alashiyan evidently stood in some fear. A King of Cyprus would have little to fear from either. And the tribute from ivory from Alashiya has always been a difficulty, if that country is Cyprus ; whereas, if it is Northern Phoenicia, it is natural enough. It seenis therefore most probable that, as in the case of their identification of Keftiu with Phocnicia (B.S.A. Ann., l.c. p. 163) the Ptolemaic archacologists were wrong also in their identification of Asi with Cyprus. Asi or Alashiya may have been the coast-land immediately north of Phoenicia. Cyprus is, however, mentioned in the time of Thothmes III. In the tribute of the 42 nd year is mentioned tribute of the land of . . . tanai, which, as I have shown (O.C.G., l.c., B.S.A.Ann., l.c.), is certainly Cyprus, and is the same name as Yatnan, by which the Assyrians knew the island. In the Ptolemaic inscriptions this name was also used for Cyprus in the corrupt form "Nebinaiti." 
served: the thirteenth was occupied with a chastisement of Anaugasa in the southern Lebanon. Alashiya sent tribute of copper in this year for the second time and the chief of distant Arrapachitis ${ }^{1}$ (Ararpakh) on the Upper Zab, north-east of Nineveh, for the first time.

The fourteenth yearly campaign was not conducted from Phoenicia. The king was compelled by a revolt of the Beduins of Southern Palestine to advance by land, and defeated the rebels in the Negeb of Judaea. The records of the fifteenth and sixteenth years of war chronicle the reception of tribute only, notably that of the Hittites, who sent gold.

In the forty-second year of his reign, however, after sixteen campaigns, the old king was compelled to take the field in force by a general revolt of Naharin in combination with the original and irreconcilable rebel at Kadesh on the Orontes. Landing at Simyra, Thothmes marched northwards to the towns of Irkata and Kana, and thence struck inland to Tunip, which was taken by storm. Then he turned south and marched up the Orontesvalley to Kadesh, which was stormed also, the valiant Amenemheb being the first to enter the breach in the enemy's wall of defence. Before the battle, so Amenemheb tells us, the prince of Kadesh tried a curious stratagem. He sent forth a mare among the Egyptian stallions, in order to confuse their array, but Amenemheb pursued her on foot, caught her, killed her, and presented her tail as a trophy to the king. $^{2}$

In this year a very interesting event is recorded, the reception of tribute from the prince of Yantinai (Yatnan) or Cyprus, ${ }^{3}$ which included a "shuibti-vase of the work of Keftiu," together with other vessels of metal. This vase, "the work of Keftiu," may have come from Minoan Crete, whose ambassadors, as we shall see later, had already appeared at Thebes itself in the reign of Hatshepsut.

Here the record ends. For the remaining twelve years of his life, so far as we know, the veteran warrior was never again called upon to take the field. The fear of his name had sunk

'PTolemy, vi. 1, 2.

2 We must remember that the horse of that day was probably a much more fiery and untamed animal than his modern descendant, who has become civilized by centuries of domestication.

${ }^{3}$ See p. 243 , n. I. 
into the souls of the Asiatics, and none dared to rebel while he lived. Still less were the foreign powers of the Hittites, Mitanni, Ashur, and Babel inclined to challenge his lordship of the lands west of the Euphrates. Babylon under the Kassite kings was eminently peaceful, and at the same time not inclined to open up relations with Egypt which might eventually prove but a prelude to war. No presents from Babel are recorded in the tribute-lists, though objects of Babylonian origin were presented by the princes of Ashur, Arrapachitis, and the Sinjar, who were too near the Euphrates to ignore the Egyptian king's existence. Mitanni was defeated and sulky, and so sent nothing: the king might come and take it if he willed, but he had no intention of venturing beyond the Euphrates. The Kheta sent presents, as the Cretans did, as a polite recognition of the existence of a great Power which had done them no harm. Cyprus was too near Phoenicia to avoid actual tribute: the king's ships could reach her too easily.

The Asiatic empire of Egypt had in fact been extended to its natural frontiers, the Amanus range and the Euphrates. All within this boundary was Egyptian territory, bound by rightful allegiance to the Egyptian king. Kode, "the land Kuê" of the Assyrians, the Cilician coast-region between Amanus and Taurus, was no doubt also subject to Egypt as a frontierterritory. Alashiya was a subject ally. More than this Egypt could not hold. The organization of the vast territory thus annexed-vast in comparison with the actual area of Egypt itself-demanded all the resources of the Nile-land. In the superintendence of this work of organization the king no doubt spent most of the rest of his reign, and in it he shewed the same power that he had displayed upon the field of battle.

\section{The Organization of the Empire}

Native princes educated in Egypt-Egyptian commissioners and garrisonsIshtar-washur, the prince of Taanach

When, in the days of the idealist Akhenaten, the King of Egypt thought more of religious theories and artistic whims than of defending his empire, the people of the far northern dependency of Tunip, harassed by the Hittites, looked back regretfully to the days of their great conqueror and defender, Thothmes III. " Who," they cried, " could have plundered Tunip 
in the old days without being plundered by Manakhbirìa?"1 Even to the Euphrates the organization was complete. We gain an insight into the method of this organization by the passage in the Annals, already quoted, which tells us how the king removed the sons and brethren of the different chiefs to Egypt and there brought them up as Egyptians, sending them back more or less devoted to Egypt to take up their posts as chiefs when their reigning relatives died. We do almost the same thing now in India, though the existence of such seminaries of native princes as the college at Aligarh does not necessitate the deportation of young Indian chiefs to far England. The Romans did the same thing also with Germans and Thracians. And side by side with the Egyptianized chiefs ${ }^{2}$ stood Egyptian officials, not so much residents as travelling inspectors, with regular circuits, who collected the tribute, advised, and controlled, with the power of falling back upon the help of Egyptian garrisons when necessary. These garrisons were established in the chief cities and in fortresses specially constructed to overawe specially recalcitrant regions, such as the Lebanon, where, for instance, Fort "Thothmes-Binder-of-the-Barbarians" controlled the upper valleys of the Orontes and Leontes. From the "Tell el-Amarna Letters" we see this organization at work under the most unfavourable auspices: Egyptianized princes at Bèrût or Jerusalem strive to keep the dominions of the king in spite of the idiocy of the ruler himself, which paralysed the movements of his Egyptian inspectors and commanders, who were utterly unable to obtain proper support even when they were capable of dealing with a threatening situation at all, which does not seem to have been by any means the case with most of them. Far otherwise had it been in the glorious days of Manakhbirîa. Then even if the princes were recalcitrant and sullen instead of, as they were in Akhenaten's day, almost

1 The Semitic pronunciation of the prenomen of Thothmes II, Menkheperra, which in his time was probably pronounced by the Egyptians "Man-akhpi(r)-r'a." Manetho's form of the name, Misaphris, is evidently an attempt to reproduce the Egyptian pronunciation of Ptolemaic days, probably "Men-shap(e)-rî." To use the late form "Misaphris" for the ling's prenomen is therefore misleading.

2 The local princes were anointed and installed by the Pharaoh, as was Adadnirari, Fing of Nukhashshi, in Northern Syria, by Thothmes II, as we hear in the Tell elAmarna letters (IVincki.er, Tell el-Amarna Letters, No. $37 ;=$ Knudtzun, AmarnaTafeln, No. 51). So in later days Aziru the Amorite was anointed by Akhenaten (p. 350, post), and Put-akhi by Rameses II (p. 362). 
pathetically loyal, there had becn no possibility of an incapable being appointed to civil or military command, and the pa.r aegyptiaca was sternly kept. We have a momentary peep into the working of the governmental machine in the cuneiform letters discovered not long ago in the Canaanite citadel of Taanach by Dr. Sellin. ${ }^{1}$ Herc, at some time between the epoch-making victory gained by Thothmes in its vicinity and the degenerate days of Akhenaten, lived a chief named Ishtarwashur, who left behind him in his castle-keep a box full of clay tablets inscribed in cuneiform, some of which are despatches from the Egyptian travelling inspector Amânkhashir, whose headquarters were at Gaza. From these we see what kind of orders were issued by the Egyptian officials to the subject chiefs, and how they were expected to obey. "To Ishtar-washur, Amânkhashir: may Adad protect thy life! Send thy brothers with their chariots, and send a horse, thy tribute, and presents and all captives that thou hast: send them to-morrow to Megiddo!" 2 Another interesting point in this correspondence to be noted is the fact that the daughters of the chiefs were sent to Egypt to be added to the royal harim: one of Ishtar-washur's daughters was destined to be given to "the lord." And the Egyptian god Amen is mentioned: no doubt the Theban priests took their tribute, even from the Canaanite baron of Taanach. ${ }^{3}$

\section{Thothmes and his Companions}

Thutii-Amenemheb-Sennefer-Antef the herald-Thothmes himself

Of the great king's offices we know the names of the highest only. Chief among them was Tahutia or Thutii, the "Administrator of the Lands of the Northermers," who must have governed Naharin and Phoenicia. He probably looked after Cyprus as well, in the important matter of the tribute which the island paid, and doubtless carried on diplomatic relations with the peoples of Southern Asia and Crete, since he is

1 "Eine Nachlese auf dem Tell Ta'annek," in the Denkschriften der Kais, Akad. I'iss., Vienna, I906, III.

2 Translated by Hrozisy, l.c. p. 36. But Ishtar-washur does not seem to have been always very obedient, as we have another letter from Amânkhashir, from Gaza this time instead of Megiddo, complaining that his orders have not been carried out. Amânkhashir may not have been a full-blooded Egyptian, as the second element of his name is probably Semitic.

"Sellix, Tell Ta'anilek, l.e., I904, IV., trans. by Hrö̈s', pp. II4, IIg. 
called "the prince and priest who satisfies the king in every country and in the Isles in the midst of the Sea, filling the treasury with lapis-lazuli, silver, and gold, the governor of foreign countries, general of the army, favourite of the king, the royal scribe, Thutii." 1 The term "Isles" no doubt included the southern coast of Asia Minor, which to the Egyptians appeared to consist of a series of islands, much as the Antarctic continent has until lately appeared to us. "Keftiu" was, as its name implies, the "Back-land" the "Back-of-Beyond" to the Egyptians. So that we need not insist on a personal visit of Thutii to Crete : ${ }^{2}$ no doubt in his capacity of "Governor of the North-lands" and expeditor of the tribute and gifts of Asia Minor and Cyprus, he acted as "Introducer of Ambassadors" from the Isles to the Court of Thebes. ${ }^{3}$

As organizer of the tribute of the North his office was important. The flow of valuables into Egypt as a result of the conquest of Western Asia was enormous, and we see its speedy effect in the greatly increased wealth and luxury characteristic of Egypt in the reigns of Thothmes' successors.

Of the other "companions" of the king the warrior Amenemheb, whose deeds we have already mentioned, is one of the most interesting. As a paladin he succeeded to the place of the two Aahmes, the younger of whom, Aahmes-Pennekhebet, had died in the preceding reign. Like them he tells us of his deeds on the walls of his tomb, ${ }^{4}$ which was at Thebes, for he was a man of the capital, like all the new leaders of the empire, not provincials as the antagonists of the Hyksos had been.

From the sixth campaign to the seventeenth Amenemheb fought with his lord, and when, in the fullness of time, "the

1 Text in Birch, Mimoire surune Pat'résgyptienne (Mim. Soc. Ant. Fr.xxiv., I858).

2 He may, however, have visited Crete (perhaps on a return mission after the embassy from Keftiu and the "Princes of the Isles" which is recorded on the walls of the tomb of Rekhmara, Thothmes' Theban vizier: see p. 292), as he was an adventurous person, and is the hero of a romance of later days, which described how he took the town of Joppa by means of a stratagem which is precisely that of Ali Baba and the Forty Thieves. He introduced his soldiers into the town in loads borne upon the backs of a train of asses (Maspero, Contes Populaires, pp. $149 \mathrm{ff}$.). No doubt the tale is founded on fact, since its hero is a historical person.

3 The gifts of the Isles and of Kheta were of course called "tribute," as much as if they had come from Naharin or Phoenicia. Egyptian vanity chose to ignore the distinction, as Chinese vanity did, not long before our own day, when Lord Macartney's embassy to Peking was preceded on its way from the coast by men bearing banners inscribed "Tribute from the Country of England."

${ }^{4}$ Breasted, Anc. Rec. ii. pp. 227 ff. 
king completed his lifetime of many years, splendid in valour, in might, and in triumph, from year I to year $54, \ldots$ he mounted to heaven, he joined the sun, the divine limbs mingling with him who begat him," the veteran captain was addressed with courteous words by the new ling: "I know thy worth: lo, while I was in the nest, thou wert in the following of my father: I commission thee to be commander of the army as I have said; inspect thou the chosen troops of the king!" And when the aged marshal laid down his staff and followed his master to the tomb, we cannot doubt that it was Amenhetep II who provided for him his sumptuous burial in Vestern Thebes, where the young king 'stands in veneration before the figure of Thothmes, enthroned as Osiris, on the walls of the tomb of Amenemheb.

Another important personage connected with the king's expeditions to Asia was a certain Sennefer, who was sent to get cedar from Lebanon, and in his inscription he tells us that he pitched his tents on the mountains "above the clouds," an experience which no Egyptian could obtain in his own country. ${ }^{1}$

Nearer to the person of the conqueror than Amenemheb or Thutii stood Antef, the herald, court-marshal, and grand chamberlain, who also acted as chief-of-staff. We do not doubt that he was a doughty warrior like the others: Thothmes left his civilian ministers, such as Rekhmara the vizier, ${ }^{2}$ at home. Antef, whose hereditary position in the nobility was that of Count of Thinis and of the Oases (of el- Kharga and Dakhla), tells us on a stela, now in the Louvre, ${ }^{3}$ how he acted as intermediary between the king and his army and ministers; how he superintended the movements of the royal headquarters, preparing the king's tents each day and making them "better than the palaces of Egypt"; how he numbered the personal body-guard of the king, and so forth.

Of the conqueror himself we know, after all, but little, though we can gaze upon his face, as it was when he died, while he lies in the Cairo Museum. The face is very much that of an old soldier. To call it brutal is merely to shew the prejudice of the man of books against the man of war. So intelligent a man as

${ }^{1}$ Sethe, Sitzber. K'. preuss. Akad. 1907, 27 März.

2 See p. 2 So.

${ }^{3}$ C. 26 . Transl. Breasted, Ani. Rec. ii. pp. $295 \mathrm{ff}$. 
Thothmes was not brutal. The mouth is large and, if we can discount the deformity caused by the embalming, not illhumoured: the chin is vast and strong, as becomes the man. The nose is of course erased by the bandages, but we know that it was prominent, with a pronounced bridge; a "Roman nose," in fact, such as is uncommon among Egyptians, but certainly befits a conqueror. This we know from the beautiful portrait statue of him as a very young man discovered by $M$. Legrain lately at Karnak, probably one of the fincst Egyptian portraits extant (Plate XVI.). His face here is intelligent and handsome. That he was of short stature, like many other great soldiers, we know from his mummy. ${ }^{1}$

\section{The Renown of Thothmes the Great}

\section{Hymn of Victory}

We can well understand how his name became one to conjure with even to the end of Egyptian history, and how at all periods scarabs bearing his name were regarded as the most potent of talismans to protect their wearers against the attacks of men or devils. To the later Egyptian he was what Alexander the Great, Iskender of the two Horns, is to the modern Oriental, a name of reverence and fear. And in his own day we can well understand how the patriotic pride of an unknown poet among the confraternity of Amen could compose the splendid Hymn of Victory, inscribed on a stela discovered in the temple of Karnak, ${ }^{2}$ in which Amen is represented as addressing his glorious son in strophes which are in some ways the finest example of Egyptian poetry, and form the most fitting epodos to our account of the deeds of the great king :-

"Saith Amen-Ra, lord of Karnak :

Thou comest to me, thou rejoicest, seeing my beauty,

My son, my avenger, Menkheperra, living for ever.

I shine because of thy love;

My heart expandeth at thy beautiful comings to my temple;

My two hands make thy limbs to have protection and life.

Doubly sweet is thy might to my bodily form.

I have established thee in my dwelling-place

I have done wondrous things for thee;

${ }^{1}$ His ancestor Aahmes, the conqueror of the Hyksos, was also a very short man for an Egyptian, as the race is, as a rule, tall.

- Mariette, Album Photographique, Pl. 32. Budge, Hist. Eg. iv. p. 49. 


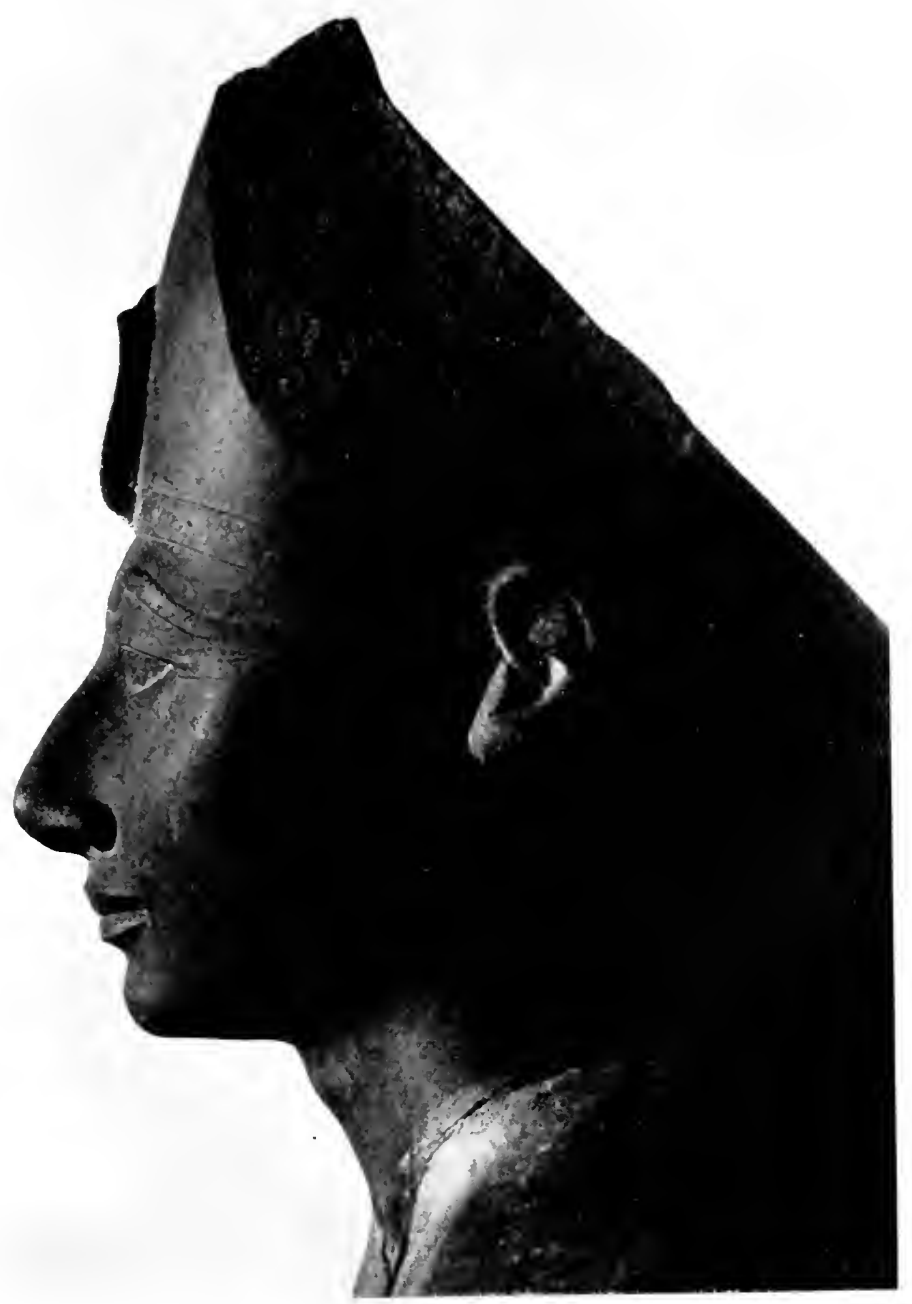

Carro

KING; THOTHMES II AS I YOUNG MAN ;

K.।RN.\K 

I have given to thee might and victory over all lands;

I have set thy will and the fear of thee in all countries,

Thy terror ats far as the four pillars of heaven.

I have magnified the dread of thee in all creatures,

I have caused the roaring of thy Majesty to go among the Nine Bows.

The chiefs of all lands are gathered in thy grasp;

I myself have stretched forth my two hands and bound them for thee.

I have bound together the Anu of Satet by myriads,

And the Northerners by hundreds of thousands as captives;

I have struck down thine enemies beneath thy sandals,

Thou hast smitten the hosts of rebels according to ny command.

The Earth in its length and breadth, Westerners and Eastemers are subject to thee.

Thou treadest down all lands, thy heart is glad . . . .

Thou hast crossed the Stream of the Great Circle of Naharin ${ }^{1}$ with victory and with might.

I have come: I have caused thee to smite the princes of Tjahi,"

I have hurled them beneath thy fect among their mountains.

I have caused them to see thy Majesty as a lord of radiance;

Thou hast shone in their faces like my image.

I have come: I have caused thee to smite the Imilt-setit, ${ }^{3}$

Thou hast made captive the chiefs of the Aamm of Retnu,

I have caused them to see thy Majesty equipped in thy panoply,

When thou takest weapons and fightest in the chariot.

I have come: I have caused thee to smite the land of the East, 5

Thou hast trodden down those who are in the regions of God's Land : ${ }^{5}$

I have caused them to see thy Majesty like a circling star,

When it scattereth its flame and shooteth forth its fire.

I have come: I have caused thee to smite the lands of the West, ${ }^{7}$

Keftiu ${ }^{8}$ and $\mathrm{Asi}^{y}$ are in fear.

I have caused them to see thy Majesty as a young bull,

Firm of heart, sharp-horned, unapproachable.

I have come, I have caused thee to smite those who are in their fens,

The lands of Mitan ${ }^{10}$ tremble from fear of thee:

I have caused them to see thy Majesty as a crocodile,

Lord of terror in the water, unassailable.

1 The Euphrates. The "Great Circle" is formed by the convergence of Euphrates and Orontes.

2 Phoenicia and the Lebanon.

${ }^{3}$ Arabs.

${ }^{4}$ Syrians generally.

5 To our ideas, south. To the Egyptian, since Syria was in the north and Nubia in the south, the Red Sea seemed to be in the east and the Mediterranean lands in the west. There was, so to speak, a kink in the Egyptian conception of the cardinal points.

${ }^{6}$ Punt : Abyssinia.

i To our ideas, north-west.

srete.

${ }^{9}$ The North Syrian coast (see p. 243, n. I.)

10 Mitanni. 


\section{THE ANCIENT HISTORY OF THE NEAR EAST}

I have come: I have caused thee to smite the Dwellers in the Isles: ${ }^{1}$ They who are in the midst of the Sea cower beneath thy roarings: I have caused them to see thy Majesty as the Slayer, Who riseth above the back of his victim.

I have come: I have caused thee to smite the Tehenu ${ }^{2}$ :

The isles of the Utentiu ${ }^{3}$ are subject to thy will.

I have caused them to see thy Majesty as a lion,

As thou makest them corpses in their wadis.

I have come: I have caused thee to smite the Ilinder-lands: ${ }^{4}$

That which the Great Ring ${ }^{5}$ encircleth is enclosed in thy grasp.

I have caused them to see thy Najesty as a soaring hawk, ${ }^{6}$

Who seizeth upon that which he spieth, whatever he may desire.

I have come: I have caused thee to smite the people of the Fore-lands : ${ }^{7}$

Thou hast smitten the Sand-dwellers as living captives.

I have caused them to see thy Majesty as a jackal of the south, Master of running, stealthy-going, roving the two lands."

\section{I. The Empire under Amenhetep II, Thothmes IV, and Amenhetep III}

Amenhetep II (c. I447-I42I B.C.)-Few monuments of this reign-Campaign of I 445 B.C.--Invasion of Mitanni-Fate of the chiefs of Takhisa-Thothmes IV (c. 142I-I412 B.c.)-Mitannian marriage?-Amenhetep III (c. 1412-I376 B.c.)-Queen Tii and her parents-Marriage with Gilukhipa

As was fitting, the son of Thothmes was a soldier also, but one of a different and more ordinary type. Personally, as we can see from his mummy, which still lies in state in its original resting-place, the royal tomb at Thebes, Aakheperura (Okhprur'a) AMENHETEP II was a tall man, of imposing presence, and with an intelligent, stern face. He was proud of his physical strength: one of his inscriptions says: " $\mathrm{He}$ is a king weighty of arm: neither among his soldiers, nor among the Canaanite chiefs, nor among the princes of Syria is there one who can draw his bow." ${ }^{8}$ The identical weapon was found in his tomb, and is

${ }^{1}$ The coasts of Asia Minor and the Aegean Islands.

2 Libyans. $\quad{ }^{3}$ Probably the North African coast.

"Tau kefatiu: "The uttermost parts of the earth."

"The great ring of land encircling the eastern Mediterranean basin : corresponding mulatis mulandis to the Greek idea of Okeanos. The northern "backlands," Asia Minor and the isles, are meant.

${ }^{6}$ Literally, "lord of the wing."

7 The peoples close to Egypt, in antithesis to those of the "Hinder-lands."

${ }^{8}$ We have no authority for saying, as Breasted does (Anc. Kec. ii. p. 3Io n. d), 
now in the Cairo Muscum. That he was intelligent is shewn by the fact that after a revolt at the beginning of his reign had been quelled, he made no wars unnecessarily, and never harried the Asiatics with merely cruel raids. That he could be stern enough is shewn by his treatment of the captive princes of Takhisa, which was almost Assyrian in its ferocity. Though the reign of Amenhetep II was long, having lasted twenty-six years, ${ }^{1}$ we possess but few monuments of it. Though he was evidently a keen soldier, we hear nothing of further war after his first campaign. ${ }^{2}$

The immediate cause of Amenhetep's campaign, which took place, then, in the second year after the death of Thothmes III, scems to have been a revolt of the ever-intransigeant tribes of the Lebanon. At Shamshu-etume (=Shemesh-edom) in Northern Palestine, the new king met the enemy and overthrew them, capturing eighteen prisoners and sixteen chariot-horses with his own hand. He then entered the Orontes-valley, and took Kadesh and Senzar: then, crossing the river at a ford, he defeated a small force of desert horsemen in a skirmish, again distinguishing himself personally, spearing one of the leaders, who drove a chariot, and capturing his two horses, his chariot, and his armour, in Homeric style. Aleppo was then taken, with the territory of Keden and the town of Takhisa, which seems to have been the centre of the revolt in Naharin. Then "turning southward towards Egypt," he drove his chariot to Nii, which surrendered without resistance. A plot to expel his garrison from the town of Ikathi recalled him to that place, where he succeeded in stamping out the revolt. Then a further northward advances seem to have been made into the land of

that "this is the basis for the well-known legend of Herodotus (iii. 21), which represents Cambyses as unable to draw the bow of the king of Ethiopia." Why should it be the basis of this story, which is common enough? In the case of Amenhetep it is probably true.

${ }^{1}$ Griffith, P.S.B.A. xxxi. p. 42 , held that the reign was short. I have criticized this view in P.S.B.A. xxxiv. (1912), p. 143.

2 On this account it has lately been supposed (by Prof. Toftees, Ancicut Chronolosy, i. p. I96) that Amenhetep did not succeed to the throne after the death of his father, but had been associated with him in the thirty-second year, had reigned jointly with him ever since, and died after but three years of sole reign in 1447 B.C., the date of the death of Thothmes III having been 1450. Amenhetep's Asiatic campaign being identical with that of the thirty-third year of Thothmes II, when that king took Nii. The impossibility of this theory has been shewn by me, P.S.B.A. xxxiv. p. 107 . 
Khatithana, which was defeated, and its people enslaved. ${ }^{1}$ Either now or after the taking of Takhisa the king crossed the Euphrates and advanced some distance into the territory of Mitanni, which immediately purchased peace by submissions which it had never done to his father, whose farthest marches he had thus surpassed north and east. "A great event," says an inscription at Karnak, "was this, and unheard of since the times of the gods, when this country (Mitanni), which knew not Egypt, besought the good god (Amenhetep)." A result of this submission seems to have been the establishment in Mitanni of a new royal family, devoted to Egyptian interests, and shortly to be allied with the pharaonic household by marriage. The king Saushshatar, the father of Artatama, who may have been the father-in-law of Amenhetep's successor, Thothmes IV, and ancestor of Dushratta, the friend and correspondent of Amenhetep III, Tii, and Akhenaten, was the first of his line. It is reasonable to suppose that he owed his throne to Egypt at the time of Amenhetep's conquest. Henceforth Mitanni was a subject-ally of Egypt.2

A memorial inscription was later on set up by Minhetep the quarry-master of Turra, near Memphis, in Naharina, no doubt by the side of those of his father and grandfather of the conqueror. They had doubtless used convenient rocks for their stelae, but Amenhetep had a tablet of Egyptian limestone cut at Turra, and transported by the quarry-master to the banks of the Euphrates. A similar tablet was set up at the far southern border of the empire, on the Nubian land of Karei, south of Gebel Barkal. ${ }^{3}$

The young king returned to Egypt in triumph, bringing with him seven chiefs captured at Takhisa, and sailed up the river with them hanging head downwards from the prow of his boat. And when they finally reached Thebes, more dead than alive, the wretched victims were personally sacrificed by the

1 Khatithana may or may not be identical with Katawadana (Kataonia?), which is mentioned as a Hittite sub.kingdom in somewhat later days (see p. 374, n. I). But evidently it was a Hittite land, and probably lay well in the Taurus region, so that by its conquest Amenhetep carried the Egyptian arms farther north than his father or than any Pharaoh before or after.

2 Assyria, now ruled by Ashur-uballit $I$, must have followed Mitanni in acknowledgment of Egyptian supremacy. The Kassite overlords of Assyria were powerless and supine.

${ }^{3}$ VySE, Pyramids, iii. 95. 


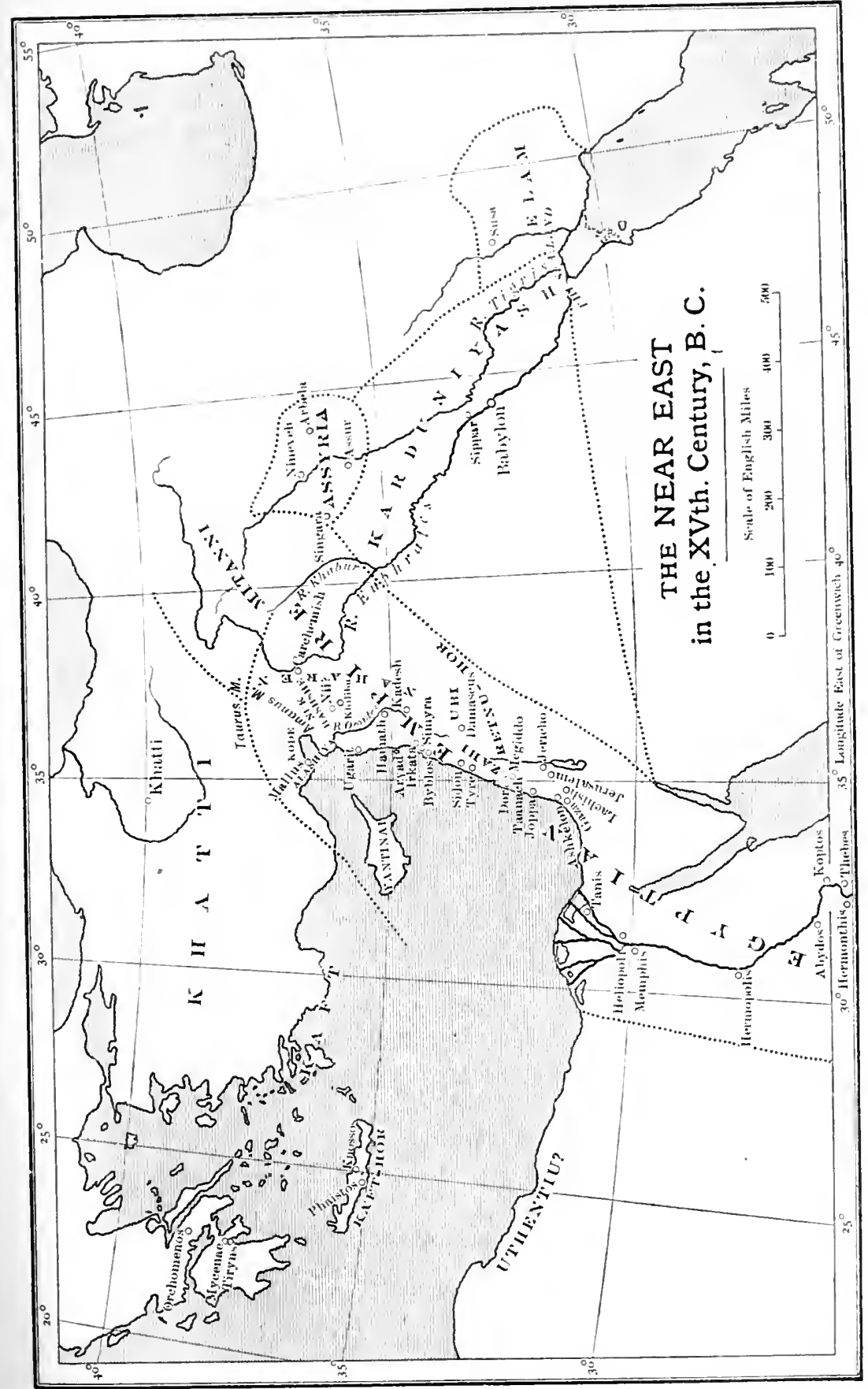



ling before Amen at Karnak. Six of the bodies were then hung up on the walls of Thebes, with their hands likewise, while the seventh "was taken up the river to Nubia and hung up on the wall of Napata (at Gebel Barkal), in order to make manifest the victories of his majesty for ever in the lands of the Blacks." It was a gruesome object-lesson in the imperial idea. ${ }^{1}$

Thothues IV went on a campaign in Naharin soon after the beginning of his reign, but we may well doubt whether it was a serious one. So far as we know, since his father had crossed the Euphrates, no serious challenge to the Egyptian dominion had been given by any Asiatic prince. His master of the horse, Amenhetep, says he went "from Naharin to Karei (upper Nubia) behind His Majesty, while he was upon the battlefield," but it is most probable that these expeditions were but military parades, designed to impress the foreigners with the fact that though a new king reigned, no alteration would be made in the statu quo. And we see how in the course of time matters had altered when Thothmes IV (as has been supposed ${ }^{2}$ ) marries the daughter of Artatama, King of Mitanni, the first Pharaoh, if this supposition is correct, to marry the daughter of a foreign ruling house. Apparently the daughter of Mitanni took the Egyptian name of Mutemua, "Mother-inthe-Boat" (sc. of the sun) on her marriage. Foreign names were not yet possible for the "king's chief wife." She was the mother of the third Amenhetep, whose reign marked the culminating point of the First Empire.

When his father died at the early age of thirty, an united empire was left to his son Neb-maat-Ra (Nimmurîa) AMENHETEP III, extending from the Euphrates to the Third Cataract of the Nile. Tii, his queen, was indeed, as the inscriptions on the great memorial scarabs commemorating their marriage ${ }^{3}$ say, "the wife of a mighty king, whose northern boundary is set in Naharin, and his southern extendeth to Karei (upper Nubia)." In marrying Tii, the new Amenhetep had not followed the example of his father. She was not a foreigner, though not, strictly speaking, an Egyptian of pure blood. Her mother,

S Stela of Amada : I.epsius, Denkmaler, iii. 65 a.

2 BREASTED, Hist. Eg. p. 328.

3 Newberry, Scarabs, p. I72. These great scarabs closely resemble in intention our medals, as several kinds were made to commemorate important events in this king's reign. 
Tuiu, a lady of the court of Queen Mutemua, was probably an Egyptian, but her father, Iuaa, may have belonged to the Abadeh or Beja race of desert-dwellers, which, then as now, inhabited the Eastern Desert, but was more probably a Semite. So much we can tell from the appearance of the mummies of Iuaa and Tuiu as they lie in their glass cases in the Cairo Museum, surrounded by the gorgeous funeral state in which they were found when their tomb was discovered by $\mathrm{Mr}$. Theodore Davis and Mr. Quibell in 1904. ${ }^{1}$ Judging, too, from the portraits of Queen Tii herself which have been found in her tomb, discovered by Mr. Davis and Mr. Ayrton in 1907,2 at Sarabit el-Khadim, ${ }^{3}$ and in the Fayyûm, ${ }^{4}$ of late years, she nerself was facially of pronounced or foreign type. ${ }^{5}$

But though Amenlietep did not imitate his father in taking to wife an entirely foreign princess, yet he admitted a daughter of Mitanni to his harem as an inferior wife. This was Gilukhipa, daughter of the king, Shutarna, who was probably Amenhetep's maternal uncle. Later on another princess from Mitanni, Tadukhipa, daughter of Dushratta, succeeded her aunt Gilukhipa. Amenhetep signalized his marriage with Gilukhipa to the people by an issue of gigantic scarabs, just as he had previously commemorated his marriage with $\mathrm{Tii}$; but there was no possibility of the Mitannian obtaining any real power at the Egyptian court. Tii ruled not only the court but the king also, and we do not wonder at it, when we see the energy of her face as shown in her portraits.

We may, if we please, see in the union of Amenhetep III with Tii, evidence of a romantic element in the king's character

${ }^{1}$ See Davis, The Tomb of Ioniya and Toniyou (London, I907).

2 Davis, Tomb of Tîyi (London, 1910).

"Petrie, Researches in Sinai, Fig. 133 ; Davis, op. cit. PI. xxxiv.

${ }^{4}$ Davis, op. cit. PI. xxxv. This, however, may be a portrait of Nefertiti, the queen of Akhenaten. It is uncertain whether the heads of the Canopic jars found in the tomb of Tii (DAvis, op. cit. Pls. vii. ff.) represent her or her son Akhenaten.

5 The idea that she was of Mitannian origin is now known to be erroneous. Only one of the titles of Iuaa gives a hint of his foreign origin. On a small bowl, belonging to Mr. Towry White, he is called "Prince of Tjahi" (the Lebanon-district). He became attached to the court as the king's Master of the Horse and Captain of the Chariotry. Now, no doubt, he married the court lady Tuiu, and their daughter Tii attracted the attention of the young king, who married her. The father then was raised to the rank of first among the most trusted counsellors of the king. The fact of his having been also a priest at Akhmim has been taken to shew that he was of Abadeh origin, and that he sprang from a family of desert-dwellers which had settled in that town. 


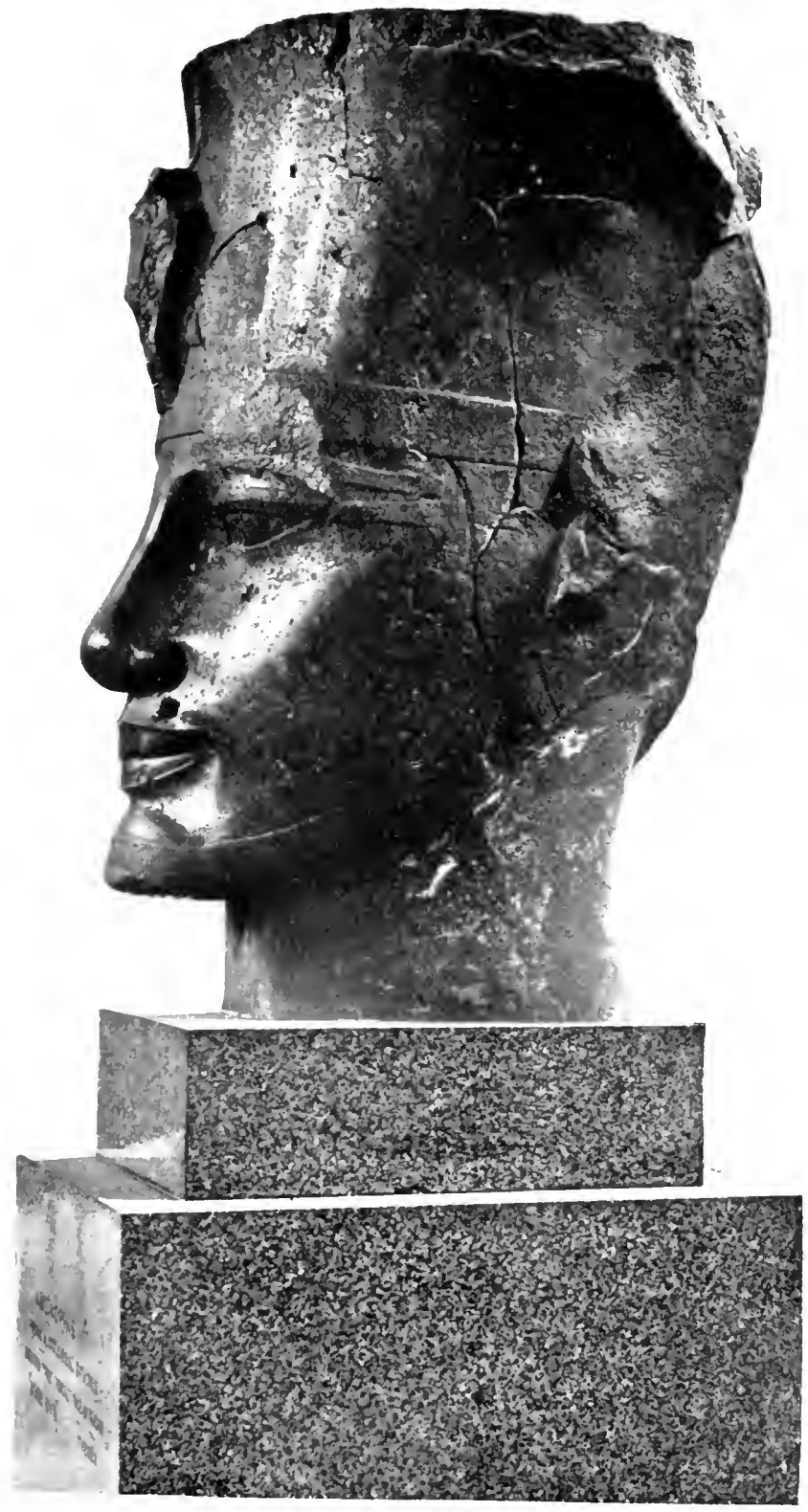

Brit. 1/us

KING .MENHFTEP III 

which would not be unlikely in the father of the artist-philosopher, Akhenaten. But the marriage had a political effect also. It enabled Amenhetep to keep the foreign princes at a more respectful distance than if he had taken the Mitannian princess Gilukhipa as his chief wife.

\section{The Empire of Amenhetep 111. Forcign Relations: with Mitanni and Assyria}

The tablets of Tell el-Amarna and Bogház Kyöi-Letters of Dushratta, king of Mitanni-Assyria controlled by Dushratta-Letters from Ashur-uballit of AssyriaRelations of Assyria and Babylonia-Assyrian independence of Mitanni effected by Ashur-uballit

We now know much of the relations of Amenhetep III and IV with these outer kingdoms, as well as much of the story of the loss of the Asiatic dominion of Egypt under the latter king, from the huge store of letters and despatches, written in cuneiform on clay tablets in the Babylonian manner, which were found in 1887 in the ruins of the city of Amenhetep IV (Akhenaten) at Tell el-Amarna in Middle Egypt. These priceless documents are now divided, chiefly between the museums of London, Berlin, and Cairo. They have been fully published and annotated. ${ }^{1}$ In all, no less than 173 despatches and letters from Tell el-Amarna have been published. Quite lately the great find of tablets at Bogház Kyöi in Asia Minor, the site of Pterion, the ancient capital of the Khatti, has given us still further information as to international relations at this period. ${ }^{2}$ It is with the most profound interest that we read these, the actual letters of the kings and princes of the fifteenth century before Christ; the dry bones of history derived from their monuments are indeed vivified by such documents as these. Those of the Tell el-Amarna letters that refer to Mitanni were all sent to Egypt by the king Dushratta to his brother-in-law Amenhetep III (Nimmuria = Neb-maat-Ra), to Tii, and to Amenhetep IV (Napkhururîa= Nefer-kheperu-Ra). To them, as his relatives, Dushratta writes in a confidential, almost affectionate, tone. His first letter is to Amenhetep III after his own acces-

${ }^{1}$ The latest and fullest publication is that of KNuDTzon, in the Altorientalischer Bibliotek, Leipzig, I907. Older publications are those of WINCKLER (1S96) and Bezold-Budge (of the British Museum Tablets). Knudtzos's publication will hereinafter be distinguised as $\mathrm{K}$, WINCKLER's as $\mathrm{W}$.

M.D.O.G., Dec. I907. 
sion, when, as he says, he had to wage war against a certain Pirkhi, who had murdered Artashumara, his brother. When he had slain Pirkhi and his accomplices, he had to face an invasion of the Hittites, whose army he surrounded and exterminated. Then he wrote to the king of Egypt, greeting him and Gilukhipa, and announcing the despatch of a chariot and horses of the booty of the Hittites as a present to the king, with a pair of breast ornaments for his sister, the king's wife. In later letters Tadukhipa is greeted. When Amenhetep III died, Dushratta writes profuse condolences both to his successor, with greetings to the queen-mother Tii, and also to Tadukhipa, whom he mentions as Amenhetep IV's wife. It is evident that Amenhetep had succeeded to his father's young Mitannian wife, nominally at present, for he was but a boy of eight or nine at his accession. ${ }^{2}$

From an interesting letter to Amenhetep III, sent shortly before the latter's death, we gather that the neighbouring kingdom of Assyria was then in some respects under the control of Dushratta. He says that he is sending to Egypt the holy goddess Ishtar of Nineveh, ${ }^{3}$ since she has expressed a wish to visit Egypt, "the land which she loves"; just as many years before she had paid a previous visit to Egypt, had been greatly honoured there, and had returned. If he could send the image of the Ninevite goddess from Nineveh to Egypt, Dushratta must have exercised political control over Assyria. This may account for some expressions in a letter sent to Amenhetep IV somewhat later, by the king of Assyria, Ashur-uballit, son of Erba-Adad. ${ }^{4}$ This king writes to Akhen-

1 Such a succession of a son to one of his father's inferior wives, if she were young, would be natural enough in Egypt. The son took over his father's harim.

2 The Mitannian princess, however, never became queen of Egypt, for there is no doubt that Tadukhipa is not the same person as Nefertiti, the queen of Akhenaten, as Prof. Petrie (Hist. ii. p. 207) supposed. This is proved by an inscription mentioned by LEgraIn, Thébes et le Schisme de Khouniatonou (Bessarione, 1906, serie 3, vol. i. 91, 92), which speaks of Nefertiti as the daughter of Tii. This explains the great facial resemblance between Akhenaten and Nefertiti on the monuments. Nefertiti must have been full sister of Akhenaten, daughter of Amenhetep III and Tii, for her titles assert her hereditary right to the throne like that of Aahmes or Hatshepsut : she was married to her brother in accordance with old Egyptian court custom, as Isis, was to Osiris.

${ }^{3}$ This curious religious episode has already been mentioned (p. 196, n. 2).

"It is now known that Ashur-uballit was the son of Erba-Adad, and that his reference to Ashur-nadin-akhi as his "father" in the letter $\mathrm{K} I 6$ is to be taken as meaning "forefather." 
aten in a friendly, perhaps rather impertinent, tone, evidently in some surprise at having received a communication from Egypt at all, and expressing considerable pleasure at the unwonted event. In his letter ${ }^{1}$ he says that if the king of Khanigalbat (Mitanni) has received twenty talents of gold from Egypt, so ought he. Evidently Ashur-uballit wished to be regarded as the equal of Dushratta, although the latter had not so very long before dominated his country. At the same time Babylonia also laid claim to the allegiance of Ashur. Writing to Akhenaten, Burraburiash of Babylonia says: "Now the Assyrians, my subjects, have I not written to thee concerning them? Why, then, have they come to thy land? If thou lovest me, they shall have no success: let them accomplish nothing at all. As a present for thee, 3 minas of lapis, and 5 span of horses for 5 chariots, have I sent thee." 2 Here we find the Babylonian king laying claim to the overlordship of Ashur, jealous of the direct relations which had been established between Akhenaten and Ashur-uballit, and cndeavouring to upset them. As far as we know, the Kassite kings of Babylonia had never succeeded in imposing any real control on Assyria: in this respect they had not retained the heritage of Khammurabi's dynasty. No doubt the union of Elam with Babylonia under their rule had tended to throw the weight of the Babylonian kingdom more over to the south-east and away from the north. Treaties had been concluded by Kara-indash I of Babylonia with Ashur-bêl-nishêshu of Assyria ${ }^{3}$ and by Burraburiash with PuzurAshur II, who must have been the immediate predecessor of

1 Amarna Letter W I 5.

2 Letter W 7 .

3 The chronological position of these two kings is uncertain, but it seems most probable that they are to be placed before Kurigalzu $n$ and Erba-Adad. Ashur-belnishêshu is said, from inscriptions found by the German excavators at Kala' Sherḳat (Ashur), to have been the son of Ashir-nirari, the son of Ashir-rabi (I see no reason to duplicate Ashur-bel-nishêshu, making two kings of that name, as SCHNABEL does, M. V.G., Igo\$).

4 There must have been two kings of this name, as the contemporary of Eurraburiash must be a different person from the Puzur-Ashir (here the name is spelt in a different and older form) who, as we see from a liala Sherkat inscription, built a great wall at Ashur, which was repaired by Ashur-bel-nishếshu, who must have preceded Erba-Adad, who must have preceled Puzur-Ashur, the contemporary of Burraburiash. And the first Puzur-Ashur must be placed before Ashir-rabi, the grandfather of Ashur-bel-nishêshu, if, as I think most probable, there was only one king of that name: there is no reason to suppose that Puzur-Ashur immediately preceded the Ashur-bel-nisheshu who repaired his wall, as Schnabel, (loc. cit.) thinks. 


\section{Ashur-uballit. ${ }^{1}$ The treaties referred to the settlement of the} boundaries of the two kingdoms. In reality they implied the independence of Assyria, but evidently it was a point of pride with a Babylonian king to recognize the fact as little as possible, and to prevent others from doing so. During the reigns of Puzur-Ashur and of Ashur-nadin-akhi (the probable predecessor of Erba-Adad, the father of Ashur-uballit), possibly even before, Ashur had evidently been really controlled by Mitanni. In all probability it was Ashur-uballit who threw off the Mitannian yoke.

The Egyptians evidently considered it politic to recognize this independence and enter into communication with the new power, a step which was resented by the Babylonians, who protested, ${ }^{2}$ while we do not know that Dushratta made any objection to this first symptom of Egypt's desertion of him.

I Though Erba-Adad was the father of Ashur-uballit, he need not have preceded him on the throne immediately. And since Kurigalzu I was a contemporary of Akhenaten as well as of Amenhetep iII, Burraburiash must have come to the throne of Babylonia some few years after the accession of Akhenaten, so that as Puzur-Ashur was his contemporary and must have preceded Ashur-uballit, also his contemporary, Puzur-Ashur must have occupied the throne between Erba-Adad and Ashur-uballit, so that he was probably a son of Erba-Adad and was succeeded after a short reign by his brother Ashur-uballit. This arrangement seems to me preferable to that of UNGNad (O.L.Z., 1908, p. 13), who makes the order: Puzur-Ashur, Ashur-nadinakhi, Erba-Adad.

2 Schnabel (M.V.G., I908) places Ashur-nadin-alhi farther back than the generation preceding Erba-Adad's, and makes him the contemporary of Thothmes III who sent tribute to Egypt (p. 239), on the strength of a letter (K 16) in which Ashur-uballit speaks of Ashur-nadin-akhi having sent presents thither. But this seems a mere presumption, which may or may not be correct. ScHNABEL makes a gap in the Assyrian royal line between Ashur-nadin-akhi and Erba-Adad corresponding to the Mitannian rule, which he supposes to have begun when Saushshatar (the contemporary of Thothmes III : see p. 254) took Nineveh and carried off one of its gates to his capital, Waraganni (M.D.O.G., Dec. 1907). But there is no proof that the Mitannian control had not begun long before Saushshatar's time, and there must have been kings in Assyria under Mitannian control between Saushshatar's contem. porary and Erba-Adad. For instance, if, as we assume, Ashur-bel-nishêshu and Kara-indash of Babylonia reigned not long before Erba-Adad and Kurigalzu II (the predecessors of Puzur-Ashur II, Burraburiash, and Ashur-uballit), then Ashur-belnishêshu and his forebears must have been subject to Mitanni. And Ashur-bel. nishêshu's father, Ashir-nirari, will have been the contemporary of Thothmes III rather than Ashur-nadin-akhi, whom we must place after Ashur-bel-nishêshu, not before Ashir-rabi, on the score of the spelling of the divine element in his name as "Ashur" rather than the old "Ashir," which seems to have gone out of fashion in the fifteenth century. We must then put Ashur-nadin-akhi between Ashur-belnishêshu and Erba-Adad. 


\section{HYKSOS CONQUEST AND FIRS'T EG YP'TIAN EMI'IRE $26 \mathrm{r}$}

\section{Relations with Babylonia}

Babylon and Egypt : marriagc-alliance-Kadashman-Enlil (c. 1410-1390 B.C.)Kurigalzu I (c. I 390-1375 B.c.)-Burraburiash (c. 1 375-1365 i.c.)

The kings of Karduniyash ${ }^{1}$ no doubt laid claim to a dignity more imperial than that of the young rulers of Ashur, and certainly deemed themselves the full equals of the king of Egypt. Hence, perhaps, a certain asperity which is noticeable in the official communications of the Babylonian king Kadashman-Enlil with Amenhetep III. The Habsburg and the Bourbon met, and neither would cede the pas to the other. It was a new experience for a king of Babylon to meet with a monarch who considered it beneath his dignity to give him his daughter to wife, and for a king of Egypt to meet with one who considered himself worthy of so unprecedented an honour. "From of old," wrote Amenhetep to Kadashman-Enlil, "a daughter of the King of Egypt has not been given to anybody": to which the Kassite retorted: "Why? Thou art a king, and canst do according to thy heart's wish: if thou givest her, who shall say anything? . . . if however thou sendest nobody, then hast thou no regard whatever for brotherhood and friendship. ... Why has not my brother sent me a wife? If thou sendest none, then I, like thee, will withhold from thee a wife." ${ }^{2}$ The course of this correspondence is often distinctly amusing to the modern reader.

Kadashman-Enlil ${ }^{3}$ (whose name was formerly read in error

I After Tashzigurmash and Agum II (p. 200), our knowledge of the Kassite kings of Babylonia is very fragmentary. All that can be said is that between them (about 1600 B.c.) and Kara-indash, whom we have supposed to precede KadashmanEnlil and Kurigalzu 1I, is a group of kings (Kadashman-kharbe I, Kurigalzu I, and Melishipak I) whose date is uncertain. For the first two the authority is the inscription published by KING, Inscriptions of Kudurrus or Boundary-stones in the British Museum, p. 3, which finally distinguishes the name "Kadashmankharbe" from "Kadashman-Enlil," and shews that the king referred to is not the Kadashman-Enlil of the Amarna letters, predecessor of Kurigalzu 11, the father of Burraburiash (King, l.c., n. I). For the second see Scinabel, l.c., p. 94.

${ }^{2}$ Letter $\mathrm{K}_{4}$.

${ }^{3}$ Ka-lim-ma-EN-ZU for Ka-dash-man-Ex-LIL, "Enlil is my helper," which is the correct reading. Prof. Breasted in his History (1905) still speaks of "KalimmaSin," but this form of the name is certainly erroneous. Mr. King prefers to read the name as Kadashman-Enlil, not Kadashman-kharbe, the reading of KNUDTZON (Die el-Amarna Tafeln, pp. 6r ff.). Dr. Knudtzon wishes to see in this king the original of a Kadashman-kharbe mentioned in the Babylonian annals and usually supposed to belong to the next generation (sce p. 267, n. 1). He therefore supposes that $\mathrm{Ex}_{\mathrm{L}} \mathrm{IL}=\mathrm{a}$ Kassite god Kliarbe. If, however, the Kadashman-kharbe 
"Kalimma-Sin) is a king who is not mentioned in the Babylonian lists, though it is not probable that he was a usurper. He mentions his father, probably Kara-indash, as also contemporary with Amenhetep III. His successor ${ }^{1}$ seems to have been Kurigalzu II, ${ }^{2}$ who, like Dushratta of Mitanni, was contemporary with both Amenhetep III and IV, and friendly with both. From the letters of Burraburiash, son of Kurigalzu, to Amenhetep IV, ${ }^{3}$ we learn that in Kurigalzu's time the

of the annals belongs to the next generation, as seems most probable, and there is no need to accept Knudtzon's theory, we may retain the name Kadashman-Enlil for the contemporary of Amenhetep III. And Mr. KING has now shewn that the names and persons were quite distinct (see note ${ }^{1}$, above).

1 Of the end of Kadashman-Enlil we know no more than we do of his relation to his predecessor Kara-indash I and his successor Kurigalzu III. He may have been an elder brother of the latter, hardly his father, as the reigns seem too short for this relation. Kara-indash I was probably the father of both Kadashman-Enlil and Kurigalzu III, if he immediately preceded the former and his contemporary Ashurbel-nishêshu of Assyria immediately preceded Ashur-nadin-akhi.

2 The second Kurigalzu, successor and probably brother of Kadashman-Enlil, is to be distinguished from the first, son of the first Kadashman-kharbe. With Kurigalzu II we reach a greater degree of certainty in the relationships and succession of the Babylonian kings.

3 The contemporary relations and lengths of reigns of all these monarchs will best be understood from the accompanying list, which embodies the latest investi-

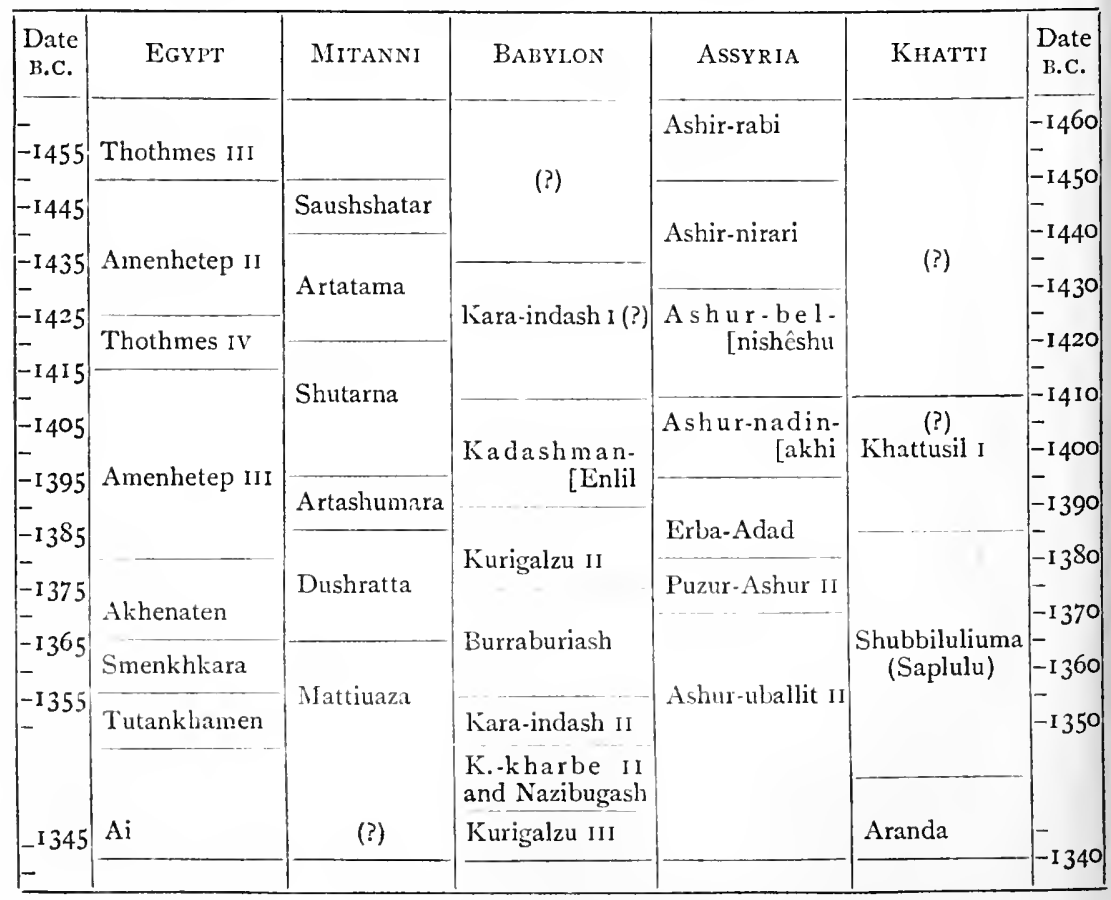




\section{HYKSOS CONQUES'T AND FIRS'I EG Y'P'TAN EMPIRE 263}

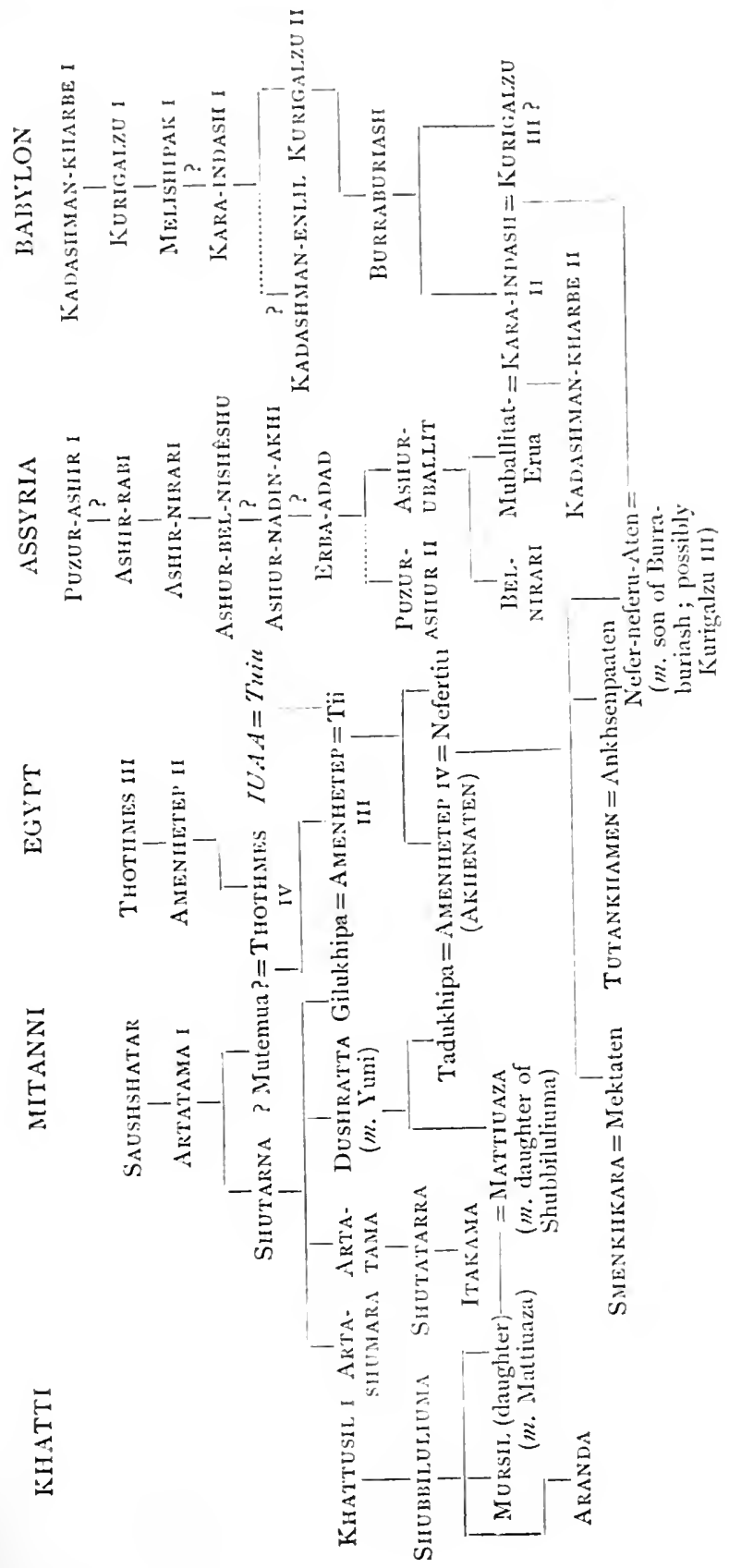


Canaanites plotted revolt against Amenhetep III, and attempted to enlist the Babylonian king on their side. $\mathrm{He}$, however, not only refused, but, as an ally of Amenhetep, threatened them with reprisals from his side should they go up against Egypt. ${ }^{1}$ Burraburiash contrasts his father's action in this case with the conduct of Amenhetep IV in receiving the envoys of Ashur-uballit of Assyria. We also learn from this correspondence that Kurigalzu was on friendly terms with Amenhetep IV, and to this amity Burraburiash succeeded on the death of Kurigalzu. ${ }^{2}$ His letters to "Napkhurarî" (Amenhetep IV: Akhenaten) ${ }^{3}$ are very friendly, and in

gatory work on the subject, which in the case of the kings of Babylonia and Assyria is very confused. I have formed my own opinion as to the succession of these kings, which has been partly expressed in the notes on pp. $259 \mathrm{ff}$, and which I here give. It will not be found to agree absolutely with what has been said by other authorities, but, since our information is always increasing and ehanging, and what may seem good evidence for a statement to one investigator does not seem so to another; so that the historian has to deal with his authorities on his own judgment of what seems best and most probable. Of all the arrangements proposed I prefer that of UNGNAD (O.L.Z., 1908, pp. I $1 \mathrm{ff}$.), necessarily modified to some extent by later work. SchNabeL's ( $I . V . G .$, I 908, pp. $3 \mathrm{ff}$.) seems to me, in spite of important contributions to knowledge, far too complicated and duplicatory. Triureau-Dangin's (O.L.Z., 1908, pp. 275, $445 \mathrm{ff.}$ ) seems least probable. Peiser (O.L.Z., I90S, pp. $7 \mathrm{ff.}$ ) is good as regards the genealogy (see p. 263), but invents an unnecessary Kurigalzu ("III") after Kadashman-kharbe II and Kurigalzu III, sikhru. The subjoined list shews ten-year intervals from about I460 to I340 B.C., and the approximate regnal years of the various kings contemporary with Amenhetep III and for forty years before and forty years after his reign. The probable years of the two known kings of Khat ti at this period are also given. Shubbiluliuma, the Saplulu of the Egyptians, was contemporary with the later years of Amenhetep In and dethroned Dushratta: as his son Mursil was a contemporary of Seti 1 , he must have reigned fully forty years, if not more. The list covers the whole known history of the kingdom of Mitanni, from Saushshatar, the maternal great-grandfather of Amenhetep III, to Mattiuaza, the son of Dushratta, who reigned as the vassal of Shubbiluliuma.

The seeond table shews the actual relationships by marriage of these kings during this most interesting century. Such relationships rarely were contracted in later days, and never on so extended a scale: when they do occur, also, our information is so slight that in no case can we draw up a similar seheme. Conjectural relationships are indicated by dotted lines. In this diagram all the daughters of Akhenaten are not given. The others were married to Egyptians. Nefer-neferu-aten was probably the daughter married to a son of Burraburiash, whose name we do not know. She may: of course, have been another wife of Kara-indash II, or his chief wife, if Muballitat-Erua was really married not to him but to his father, which seems improbable, as we shall see (note to p. 267).

${ }^{1}$ Letter W 7.

${ }^{2} \mathrm{~W} 6$.

${ }^{3}$ An attempt to write in cuneiform the pronunciation of Akhenaten's thronename Nefer-kheperu-Ra, which must have sounded something like "Nafe(r)ekhpru-R'a," "Nafkliprur a." 
reference to the episode of the dealings of Egypt with Ashuruballit, which certainly savoured of treachery both to Mitanni and to Babylon, he writes more in sorrow than in anger. ${ }^{1}$ Later on his son was nominally betrothed to one of Akhenaten's daughters. ${ }^{2}$

One piece of politic wisdom communicated to Akhenaten by Burraburiash is amusing enough : "If gold is given to kings, then brotherhood, goodness, and peace rule, and there are friendly relations." 3 So the Egyptian king was to keep the dependent princes quiet by bribing them-for that was, in fact, what under his rule the Egyptian control had come down to. And even when the king dispensed his gifts with imperial lavishness," it was not always that even the half of what he had intended to give ever reached the recipients. All through these letters we read complaints of the dishonesty of the Egyptian officials, who send plated statues for golden to Mitanni, and muchdiminished minas to Babylon. And, lastly, we find Burraburiash sharply calling the attention of the Egyptian king to his international obligations. The second revolt of Canaan had spread to the south, and the Babylonian caravans had been plundered. "Since," writes the Babylonian king, "they have plundered him (Salmu, a messenger) in thy land, which is a land of vassalage, let therefore my brother adjust this strife. When my messenger comes into my brother's presence, let Salmu also come before my brother, that they may refund him his ransom. and make good his loss." 5 The Egyptian king is thus expected to compensate the Babylonians for their losses at the hands of his Canaanite subjects. Again, Burraburiash writes more sharply, giving details of the murder of Babylonian merchants in the city of Khinatuni (Khut-aten, "Glory of the Disk"), which Akhenaten had founded in Canaan. "Now," he says, "Canaan is thy land, and thou art the king. I have been violently dealt with in thy land: subdue these people. Malie good the money they have stolen, and as for the people who killed my servants, kill them, and avenge their blood. If thou dost not kill these people, they will come again, and they will kill my caravans, or even thy messengers, and the trade between us will be destroyed, and the people (of Canaan) will became alienated from thee." 6 This counsel, in which we read the irritation and
1 See above, p. 259.
$2 \mathrm{~W} 7$.
- See the list of giits to Burraburiash, $\mathrm{K}$ 14.
${ }^{5} \mathrm{~K} 7$.
3 KII.
${ }^{6} \mathrm{~K} S$. 
contempt which Akhenaten's inactivity was already beginning to arouse, was not followed, as we shall see in the sequel. As Burraburiash had prophesied, the revolt cut off communication between Babylon and Egypt: this letter is the last of the series. We have an interesting document of the time in a passport issued probably by the Babylonian king: ${ }^{1}$ "To the Kings of Canaan, Vassals of my brother, the Great King. Verily, Akîa, my messenger, to the King of Egypt, my brother, in order to condole with him, have I sent. Let none detain him. In safety to Egypt bring him, and as far as the city of Zukhli in Egypt you shall bring him in haste. And let no violence be done him." This was at the time of the death of Amenhetep III.

\section{The Assyrian and Babylonian Succession}

Kara-indash I and Assyria (c. I365-I360) - Nazibugash (c. I360-1355 B.c.) Kurigalzu II (c. I355-I3I 5 B.C.)

Burraburiash lived to see the power of his rival Ashuruballit gradually increase, and either he or his son Kara-indash II, more probably the latter, consented to wed Muballitat-Erua, the daughter of Ashur-uballit. The question as to the succession of the kings following the Burraburiash who was conternporary with Akhenaten is not yet settled, but from the evidence of the Tell el-Amarna letters it would seem most probable that there was only a single king named Burraburiash (instead of two, as has often been supposed), and that he was the son and the father of a Kurigalzu. The first fact he states himself in a letter already mentioned; the second rests upon the statement of a later chronicler that the king Kurigalzu "Sikhru" (the Little), who was raised to the throne by Ashur-uballit after the defeat of the usurper Nazibugash or Shuzigash, was the son of Burraburiash and, presumably, Muballitat-Erua. It is perhaps more probable that he was a grandson of Burraburiash, who was the contemporary or possibly the senior of Ashur-uballit, and that he was really the son of Kara-indash II, who was probably the immediate successor of Burraburiash and the real husband of Muballitat-Erua. The reign of Kara-indash II was short, and his son Kadashman-kharbe, who must have been a mere boy, was murdered by Nazibugash, who is called "a son of nobody" and seems to have been the leader of a popular revolt 
against the Assyrian control which Ashur-uballit had brought about by the marriage of his daughter to the Babylonian king. It was not long, however, before Ashur-uballit appeared in Babylonia to avenge his murdered grandson. Nazibugash was slain, and the young Kurigalzu III, who was a younger son of Burraburiash, possibly by Muballitat-Erua, was placed upon the throne. He was the founder of a stable race of Kassite sovereigns who by no means unsuccessfully maintained their independence of Assyrian tutelage.

This seems to be the most probable explanation of a confused set of events of which uncertain and often mutually contradictory accounts are preserved in the later chronicles: we have to square these accounts as best we can with the contemporary information given us by the Tell el-Amarna tablets. ${ }^{1}$

${ }^{1}$ Few events in ancient history have been discussed more volubly and with less result than this question of the succession of the Kassite kings. The Assyrian "Synchronous History" and the Babylonian chronicle " $\mathrm{P}$ " agree neither with each other nor with the facts ascertained from contemporary documents or the necessary chronological limits. In the above account we have endeavoured to obtain an approximation to the facts underlying the traditions given in the two chronicles. "P" is probably correct in apparently making Muballitat-Erua the wife of Kara-indash II, son of Burraburiash, and not of Burraburiash himself. (But as Tadukhipa was married first to Amenhetep III and afterwards to his son, so Muballitat-Erua may have been given to Burraburiash first and then to his son.) " $\mathrm{P}$ " again is certainly correct in saying that it was not Kara-indash himself, but his son, who was murdered, and is no doubt correct in giving the son's name as Kadash. man-kharbe. But there can be little doubt that "P's" assignation of a powerful and energetic reign to Kadashman-kharbe is erroneous. If Kadashman-kharbe was the grandson of Ashur-uballit II, as " $\mathrm{P}$ " states, and as is probable, he cannot have been more than a mere child when he was put on one side, as Ashur-uballit must, since his predecessor Puzur-Ashur was contemporary with Burraburiash, have been a junior contemporary of the latter (they were more or less aequales) and Ashuruballit's son Bel-nirari was a senior contemporary of the younger Kurigalzu, who will then be very probably, as the Synchronous History states, a son of Burraburiash and so a younger brother of Kara-indash II and uncle of Kadashman-kharbe. The omission of Kadashman-kharbe from the list of the Synchronous History is probably due simply to the ephemeral character of his reign. From this omission it naturally followed that the manner of his death was transferred to his father, Kara-indash. Again, "P" cannot possibly be correct in stating that Kadashman-kharbe was the father of Kurigalzu "șikhru." He was much more probably his nephew. If " $\mathrm{P}$ " were right, Ashur-uballit must have marched into Babylonia to set on the throne his great-grandson (or even, if Kara-indash II was the son of Muballitat-Erua, his great-great-grandson) after the murder of his grandson or great-grandson, who had enjoyed a long and prospcrous reign! " $\mathrm{P}$ " is here inconsistent. It is obvious that Ashur-uballit cannot have been the great-grandfather, much less the great-greatgrandfather, of a man who was the contemporary of his son Bel-nirari. Probably Kurigalzu was merely mechanically written down as the son of Kadashman-kharbe because he was the successor of the latler. The statement of the Synchronous 


\section{5. Khatti and Alashiya}

Shubbiluliuma of Khatti (c. 13\$5-1345 B.C.)-Tarkhundaraush of ArzawaAlashiya

No direct connexion between the royal houses of Egypt and Khatti existed as yet. Possibly the Hittites were too barbaric and probably too hostile for marriage-relations with them. The few letters from Shubbiluliuma to Akhenaten (which

History that he was the son of Burraburiash is borne out by the known contemporary inscriptions of a king Kurigalzu, son of Lurraburiash, who must be Kurigalzu "șikhru." Some writers regard this king Kurigalzı as the father of the Burraburiash of the Tell el-Amarna letters, so that we seem to have another Burraburiash between Kara-indash I and Kadashman-Enlil. These suppositions are only rendered necessary by an entire acceptance of the statements of " $\mathrm{I}$," which, as we have seen, were inconsistent and impossible. If, however, there was, as we have assumed, only one Burraburiash, son of Kurigalzu II and father of Kurigalzu "sikhru," much of this complication disappears, and we kecp within possible chronological limits. The assignation by "P" of an impossible energetic reign to Kadashman-kharbe may lee due to a confusion of him with his father Kara-indash II, who in the course of a short reign may well have acted with energy, or, as is more likely, to confusion with the earlier king of similar name. Thic, however, need not disposc us to accept the theory of KNUDTzON, mentioned above, which makes Nazibugash and Shuzigash two distinct persons, the latter (who is given as the murderer of the energetic Kadashman-kharbe in " $\mathrm{P}$ ") being in reality the nurderer of Kadashman-Bel, the contemporary of Amenhetep III, and the former the murderer of the son of Muballitat-Erua, whom KNuDrzon calls Karakhardash (since the name of the king who was murdered is at first so spelt in the Synchronous History, which calls him the son of Muballitat-Erua). We have seen how much the Synchronous History is here at fault, and it is quite evident that "Karakhardash" is a mere erroneous writing of Kara-indash : the name is spelt correctly two or three lines farther on. Kadashman-kharbe must be the real name of the son of Kara-indash, and it seems most probable that both chronicles are referring to the same events, but that " $\mathrm{P}$," while right about the names, assigns the deeds of Kadashman-Bel to the Kadashman-kharbe murdered by Nazibugash or Shuzigash (the exact form of the name was evidently uncertain). There is too much likeness between the two stories for them to be distinct, and Ashur-uballit is mentioned in both. The elaborate rearrangement of these kings proposed by KNUITZON thus seems to be unnecessary, as that of ScHNabel (l.c.) also seems to be. The simpler the arrangement can be made, the more likely it is to be correct. And that given here is the simplest that takes account of all the names mentioned and of chronological possibilities. The genealogy here adopted agrees with that of PEISER (O.L.Z., I908, p. 9) except that this Kurigalzu ("III"), son of Kadashman-kharbe [1I], is not included: Mr. KinG's boundary-stone inscription (see p. 26I, n. I) shews that "Kurigalzu, son of Kadashman-kharbe," belongs to a generation earlier than Kadashman-Enlil, and is to be regarded as Kurigalzu I, son of Kadashman-kharbe I. Kurigalzu Sikhru is Kurigalzu III, and we know nothing of any son of Kadashman-kharbe II. UNGNAD's arrangement of the Babylonians (O.L.Z., 1908, 13), admitting only one Burraburiash, seems unquestionably the right one, though he, like most of the writers on the subject, has erroneously identified Kadashman-kharbe with Kadashman-Enlil. 
mention previous relations with Amenhetep III) found at Tell el-Amarna ${ }^{1}$ are less courtly than are those of the other kings, and in fact, though professedly friendly, are rough in tone. Probably Egypt's friendship for his enemy Dushratta did not dispose Shubbiluliuma to be over polite. And as a matter of fact it was difficult for him to be so. Already at the end of Amenhetep III's reign he had invaded Naharin, which he regarded as belonging to Dushratta, and had taken the city of Katna, whose king, Akizzi, sent fruitless appeals for help to Egypt. ${ }^{2}$ The Hittite king's letters to Akhenaten were a mere blind, intended to deceive the Egyptian Court into a belief in his friendliness.

A subsidiary Hittite kingdom, however, that of Arzawa, in Cilicia, whose southern march probably ran with that of Alashiya, a subject-ally of Egypt, had considerable dealings with Egypt, and Amenhetep III sent one of his daughters (no doubt borne to him by a subordinate wife) to Tarlshundaraush or Tarkhundaraba, ${ }^{3}$ its king.

From Alashiya, which, as we have seen, is more probably Northern Phoenicia than Cyprus, several letters are preserved, which evidently date from the time of Amenhetep III. The subjects of the letters, with the exception of an enigmatical request that an "Eagle-Conjurer" or "Eagle-Charmer" (possibly merely a falconer) may be sent, ${ }^{4}$ are usually commercial relations and tribute, the sending of wood and copper to Egypt in exchange for gold and oil, and so forth. Alashiyan ships and merchants are often mentioned, and there is an interesting request for the return to Alashiya of the goods of a merchant who had died in Egypt. ${ }^{5}$ Such references as this give a good idea of the high organization of international relations at this period. So far as Egypt was concerned, this organization had grown up since the expulsion of the Hyksos, when Egypt first entered the world as one nation among others. The organization of political matters is also exemplified in the case of Alashiya by a letter from the prime minister, the rabîsu, of that state to his brother-official in Egypt, whom he addresses as "the rabissu of Egypt, my brother," and to whom

$1 \mathrm{~K} 4 \mathrm{I}, 42$.

${ }^{2} \mathrm{~K} 52 \mathrm{ff}$.

3 Tarklundaraush, WINCKLER; Tarkhundaraba, Knurtzon. A later king of Arzawa, Alakshandu, is mentioned in the lime of Rameses 1 (M.D.O.G., Dec. I907).

${ }^{4} \mathrm{~K} 35$.

$5 \mathrm{~K} 35$. 
he sends a present for himself of eight talents of copper and a tusk of ivory from Mesopotamia, as well as wood, which was always and is now valuable in Egypt. ${ }^{1}$ There is a reference to Lycian pirates in another letter.'

Such were the relations of Egypt with the states of Western Asia from the time of the epoch-making marriage of Thothmes IV with Mutemua to the immediate imminence of the Hittite invasion of Northern Syria, and the consequent revolt of Canaan, which, unrepressed by the religious reformer Akhenaten, caused the temporary loss of the whole, and the permanent loss of the greater part, of the empire of the Thothmosids. ${ }^{3}$

We now turn from the Asiatic to the African empire, from the boundary in Naharin to that in Karei.

\section{The Nubian Empire}

Thothmes III in Nubia (c. I499 B.c.)-Honours Senusret III at Semneh-Southern advance of Thothmes III (c. I45 I B.c.) - Napata and Gebel Barkal-The EthiopiansSouthern campaign of Amenhetep III (c. I407-6 B.c.) - Temple of Soleb-SedeiyaAten-temple at Sedeiya

No doubt the long final struggle with the Hyksos had caused a weakening of the Theban power, not merely in Kush, ${ }^{4}$ but also in the long subdued lands of Amam and Wawat, the "Lower Nubia" of the present day. Here Egyptian authority was soon restored by the earlier kings of the XVIIIth Dynasty, Turi, the viceroy ${ }^{5}$ under Amenhetep $I^{6}$ and Thothmes I, being specially active in this regard. In the time of Amenhetep I Egyptian authority had already been extended to the land of Karei, the region of the Third Cataract. ${ }^{7}$ Hitherto the island

${ }^{1} \mathrm{~K} 40$.

${ }^{2} \mathrm{~K} 38$. See p. 377.

${ }^{3}$ P. $34 \mathrm{Iff}$.

4 This we know from the Carnarvon Tablet (see p. 225).

${ }^{5}$ We have little knowledge of the precise form of the administration of Nubia before the time of the XVIIIth Dynasty. Apparently on account of its distance from Thebes, the country had become regarded as a viceroyalty, and the noble placed in charge of it bore the honorary title of "King's son" as well as "Governor of the Lands of the South." His viceroyalty extended from El Kab in the north to the southem limit of Egyptian dominion. The title "King's son of Kush" has an old-fashioned ring about it, and is not likely to have been invented under the XVIIIth Dynasty. We may compare it with many instances of "king's sons" at an earlier period (notably under the Hyksos and the XVIIth Dynasty), who were not all royal princes. So that Turi probably was not (as WEIGaLl, Report on the Monuments of Lower Nubia, p. 14, seems to think) the first viceroy of Nubia.

${ }^{6}$ Inscription at Gezlret el-Melek (Ouronarti), south of Wadi Halfa.

Sethe, Urkunden der XVIII. Dynastie, i. p. 50. 
of Arko, in the Dongola province, had been one of the southernmost outposts of Egyptian rule, ${ }^{1}$ but Amenhetep I or his Viceroy Turi passed round the bend of the Nile where it turns northeastward towards Abu Hâmed, and reached the "Pure Mountain," the isolated Gebel Barkal in whose shadow lay the Nubian town of Napata.

It is by no means impossible that the people whose centre was at Napata were not pure negroes, but belonged to the Abyssinian or Punite race, and had entered the Nile valley not long before to occupy the valley depopulated of its original negro inhabitants by the constant razzias of the XIIth Dynasty kings. But of this we cannot be certain. All we know is that the Kushites of the XIIth Dynasty were negroes but that the "blameless Ethiopians" of later days were not, although they had a large admixture of both negro and Egyptian blood. ${ }^{2}$ They must therefore have reached the Nile somewhere between the time of the XIIth and that of the XVIIIth Dynasty, as from the latter period Kush was in the full and peaceful occupation of the Egyptians, whose culture gradually made great progress among the Ethiopians. There is no period for the irruption of the Ethiopians into the Nile valley more probable than that when the contest with the Hyksos left the Theban kings too weak to hold any of their ancient possessions south of Wadi Halfa. Napata, too, the Ethiopian chief town, seems to have been before the conquest more important a place than a mere negro chief's kraal. Its Nubian name was retained by the Egyptians, whereas a negro kraal would have had none. So that it must have been the centre of a culture and of a race more highly developed than the negro's.

The capture of Napata therefore marked a new epoch in the development of the southern empire of Egypt. Napata was a town, a more or less civilized centre, to which Egyptian civilization could be transplanted and find a home, and whence it could exercise an influence more appreciated than it had been by the harried and raided barbarians of Wawat, who were incapable of receiving it. It was not long before a flourishing Egyptian colony grew up beneath Mount Barkal, which, as we

${ }^{1}$ Under Sebekhetep III : see p. I66.

2 Like the modern Abyssinians, they were probably partly of Galla, partly of South Arabian origin. 
shall see, exercised in the fullness of time a most important influence on the history of the mother-land. It is probable that the organization of the new territory was the work of Thothmes III, who seems to have done much for the civilization and organization of Lower Nubia, which lay at Egypt's doors, and may be supposed to have extended his work to Upper Nubia also. Then, as now, the land of Lower Nubia was a mere nothing, a strip of palm-land with a village here and there along the inhospitable desert banks of the Nile. It was then capable of no greater development than it is now. All that Thothmes could do was to extend Egyptian civilization among its inhabitants. He built and endowed temples, where the Nubians could worship Egyptian gods and their own in Egyptian fashion and with Egyptian ceremonies, while the Egyptians shared their worship with them. This was a great step towards the incorporation of the Nubians with Egypt, which no previous king had thought of taking: in former days the wretched Wawat and Kush had been regarded merely as outcasts.

Already in his second year, before, apparently, his masterful co-regent Hatshepsut had succeeded in relegating him entirely to the background, he carried out on his own account a renovation of the temple which Senusert III had erected in the fortress of Semneh, ${ }^{1}$ rededicating it not only to Khnum the god of the cataracts and to the local Ethiopian god Didun (the Tithonos of the Greeks), but also to the deified Senusert, who thus became tutelary deity of the reconquered land. Here the young hero-worshipper already shewed by his veneration for the great conqueror of the XIIth Dynasty in what direction his ideals tended. He venerated Senusert as the genius of the empire, as he himself was afterwards venerated throughout the centuries, being indeed in popular story more or less identified with the great "Sesostris," and adding to the Nubian renown of his predecessor his own Asiatic glory. Then, after offering to Didun "The water of Wawat," the Nile-water of the Second Cataract, and enjoining the due care of the shrine on the local chiefs and governors of the fortresses of the new "Southern Elephantine," as he not inaptly called the shores and isles of the Second Cataract, he returned to his slavery in the court of the peaceful queen at Thebes. ${ }^{2}$

The peace was unbroken in Nubia till near the end of his

'See p. I61.

${ }^{2}$ Breasted, Anc. Rec. ii. pp. 69 ff. 
long reign, and his viceroy Nehi, the successor of Turi, seems, so far as we can tell, to have ruled peaceably and benignly over the Nubians. But nearly fifty years after he had endowed the temple of Semneh, the king gave the word for the advance of his armies to the south, probably in consequence of some rebellion. Whether the king accompanied the army or not we do not know, nor do we know many details of the war.

Amenhetep II succeeded to the possession of an organized Nubia, whose southern border reached to Karei, where Minhetep the quarrier set up frontier-tablets as he had beyond Euphrates. Napata was a town with a wall, on which rebel chiefs from Naharin could be hung as a warning against similar behaviour among the newly conquered Ethiopians. In the next reign (of Thothmes IV), however, a revolt occurred "above Wawat," which was suppressed without much difficulty, and a colony of Kushite prisoners was established on the domain of the royal mortuary chapel at Thebes.

Amenhetep III, who warred on Nubia at the beginning of his reign, penetrated farther south than any previous Egyptian king." "He made his boundary as far as he desired, as far as the four pillars which bear the heaven." He set up a tablet of victory as far as the "Springs of Horus" (the Sixth Cataract?); no king of Egypt had done the like. The farthest point reached seems to have been a month's sailing from Napata, "until the mountain of Hua (Jebel Rawiyan or Tyem?) came in sight": south of this a camp was made in the land of Wenshek. The mountain of Hua is described as "behind western Kheskhet," another unknown land. ${ }^{1}$

Later on the viceroy Merimes had to quell a revolt in the land of Abhet (the Dongola province ?), but the peace was not again disturbed during the long reign of Amenhetep III, who extended on a large scale to Upper Nubia the civilizing work: that had been begun by Thothmes III. Following the example of the latter, Amenhetep II and Thothmes IV had built and endowed temples in Lower Nubia: Amenhetep III now erected south of the Second Cataract sanctuaries on a scale of imperial magnificence which was worthy of him. At Sulb or Soleb, 163 miles south of Buhen or WVadi Ilalfa, he raised a splendir temple, much resembling in style the Colonnades which he

${ }^{1}$ For his inscriptions see Breasten, Anc. Rec. ii. pp. 334 ff. I follow Prof. Breasted in his interpretation of the geographical details. 
added to the Temple of Luxor at Thebes. The traveller Hoskins describes it ${ }^{1}$ as being "very imposing, standing proudly at the extremity of the desert, the only beacon of civilisation in this sea of barrenness." And it was as a beacon of civilization that Amenhetep intended it. The god to be worshipped within it by the Nubians was none other than himself, the tutelary genius of the. Empire. As, long after, the Roman provincial was expected to worship the Emperor and Roma, so the conquered Nubian was to be bound to the Egyptian Empire by a worship of his Emperor. Thothmes III had, more modestly, enjoined him to venerate the spirit of his ancient conqueror, Senusert III : Thothmes himself after his death was associated in this worship. But Amenhetep developed this idea into a contemporary worship of himself as the impersonification of the Empire, and called his temple after himself, Kha-m-maat, "He who appears as Maat (the goddess of Right and Law)." This sanctuary was built in the most magnificent style of the most magnificent reign in Egyptian history, and was embellished with works of art which were never afterwards rivalled. The famous "Prudhoe Lions," now in the British Museum, which Ruskin declared to be the finest works of sculpture of their kind existing, were dedicated in Kha-m-maat, though afterwards removed to Napata; ${ }^{2}$ and so were the great rams, one of which is now at Berlin.

At Sedeinga, a few miles to the north, Amenhetep also built a fine temple in honour of his consort, Queen Tii. In that of his successor the neighbourhood of Soleb was considered one of the chief places of the empire, and worthy to receive the honour of a temple of the Sun-Disk, a "Gem-Aten," or "place where the Aten is found," like Thebes, Memphis, Tell el-Amarna, and probably Napata. ${ }^{3}$ This was at Sesebi, a little south of Soleb.

Thus the Nubian province of Egypt was gradually

1 Travels in Nubia, p. 245.

2 The inscriptions of Amenhetep were erased by Akhenaten, and restored by Tutankhamen. Prof. Breasted does not appear to be correct in ascribing their removal to Napata to the late Ethiopian king Amenasru (Anc. Rec. ii. p. 363, n. ${ }^{\mathrm{d}}$ ). The inscription of the king who removed them, "Good god, Lion of Rulers, . . . who brought it," is not cut in the same style as that of Amenasru's, but is of far finer workmanship, indistinguishable from that of the XVIIIth Dynasty. But the titles of this king have a barbaric ring, and so he may have been an earlier Ethiopian, probably Taharka, as Lepsius thought, possibly Piankhi. Amenasru only inscribed them after they had been for some lime at Napala.

${ }^{3}$ See p. 300 . 


\section{HYKSOS CONQUES'T AND FIRS'I EGYP'TIAN EMPIRE 275}

recovered by the earlier kings of the XVIIIth Dynasty, enlarged and reorganized by the genius of Thothmes III, and magnified into a truly imperial dominion by the splendid Amenhetep III.

Probably the religious revolution of Akhenaten was not sufficiently prolonged to bring this to ruin, as the northern empire had been. The viceroys were, apparently, strong, and there was no rebellion. In Ai's reign, Paser the viceroy set up inscriptions at Gebel Adda, north of Wadi Halfa. He or his predecessor had no doubt already abolished the Aten-temples at Sesebi and Napata; but, oddly enough, the name of that at Napata persisted, and is found still existing in the days of the Nubian king Nastasenen, a thousand years later. ${ }^{1}$

We now turn to the internal history of Egypt under the First Empire.

1 Breasted, Ä.Z. xl. p. 106.

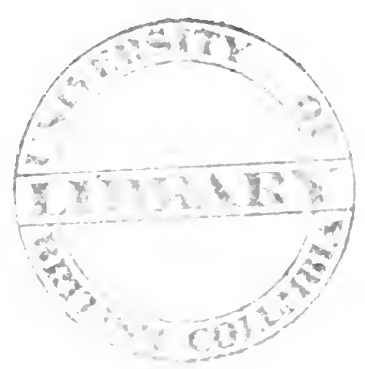


CHAPTER VII

\section{EGYPT UNDER THE EMPIRE}

\section{(I600-I IOO B.C.)}

\section{The Reorganization}

Restoration of temples-Reign of Amenhetep I-Thebes, tije city of Amen, and capital of the Empire-Alteration in position of the king

F the general reorganization of the whole kingdom which was carried out during the two first reigns of the XVIIIth Dynasty we have an example in the restoration of temples which had fallen into ruin during the Hyksos domination in Lower and Middle Egypt, as we know from Hatshepsut's inscription, already mentioned, at Beni Hasan. ${ }^{1}$ The great temples were no doubt restored as soon as possible after their liberation. Memphis, which had probably been retaken shortly before the beginning of his reign, was the especial care of Aahmes; to later monarchs like Hatshepsut were left the smaller and less important fanes, such as that of Hermopolis and this of Cusae. For the necessary works in the temple of Ptah at Memphis, Aahmes reopened the quarries of Turra, and employed Hyksos captives, described as Fonkhu, ${ }^{2}$ to cut the stone. Amenhetep I also restored temples on the extreme south, which had possibly been damaged by Nubian raids. But of all the sanctuaries of Egypt that of the god of Thebes, the especial patron of the royal house which had led the Egyptians to victory and restored to Egypt the full extent of her patrimony, was most honoured. Aahmes seems to have restored the sanctuary of the XIIth Dynasty in "the Seats of Apet" (Apet-esut; Karnak), and Annenhetep I continued his

${ }^{1}$ See p. 213 , n. 2.
2 See p. 159, n. 2. 
work on a magnificent scalc. ${ }^{1}$ Amenhetep seems also to have thoroughly reorganized the whole confraternity of the priests of Amen, and probably added greatly to their possessions: on the coffins of the priests of a later period he is constantly depicted as receiving the offerings of a deceased as a god in company with Osiris Unmefer, Ptah-Tanen, and Anubis, and it would seem that he was the greatest of the benefactors for whom the priests of Thebes were more especially bound to pray. ${ }^{2}$

With this pious monarch and his mother the old Egypt came to an end. His successor, the first Thothmes, inaugurated the new imperial era. ${ }^{3}$

Thebes now finally became the undisputed capital of Egypt and residence of the kings. For we can now speak of a common centre of royal and national strength in Egypt. The kings no longer lived apart and divinely aloof in a royal burgh like Itht-taui, from which they "controlled the two lands," inhabited merely by their ministers, their feudatories, and their people, who were all more or less their slaves. A god no longer ruled the heaven of Egypt, beyond which was nothing in the world but an indefinite hell of foreign "ghosts," who could not penetrate into the heaven unless its god-ruler so willed. Overthrow of their heaven by the forces of devildom had brought king and people together, and henceforth they lived and fought together as far as was compatible with the ideas of the time: a combined royal and national warlike spirit had come into being. And the king lived with his people in

${ }^{1}$ It is possible that he was the original founder of the great temple in Southern Apet (Luxor), which was the especial favourite of the later kings of his dynasty, and in two centuries became so magnificent as to rival the original foundation at Karnak.

2 So highly were he and his mother, Aahmes-Nefertari, apotheosized that they seem to have been more or less identified with Osiris, and wcre depicted with their skins of the blue-black colour which is characteristic of the god of the dead. This connection with Osiris may have been originally due to some special new work carried out by Amenhetep and his mother in the great Theban necropolis on the west bank of the Nile. Ife was certainly the first of the Theban kings to excavate for himself a great tunnel-like tomb like those in the long desert valley which runs parallel with the Nile behind the cliffs of Dêr el-Bahri, and is known as the Biban al-Mulukk, the "Gates (i.e. Tombs) of the Kings," where so many of his greatest successors excavated similar tombs for themselves after him.

${ }^{3}$ The exact relationship of Thothmes I to Amenhetep I is not absolutely certain. His mother, Sensenb, was not certainly a wife of Amenhelep I. On the disputed relationships of Thothmes I, Hatshepsut, Thothmes II, and Thothmes III, see pp. $2 \& 6 \mathrm{ff}$. I have here regarded it as most probable that Thothmes III was a son of Thothmes II. The following is a genealogy of the royal family of the XVIIIth 


\section{THE ANCIEN'T HISTORY OF THE NEAR EAST}

his faithful City of Thebes. ${ }^{1}$ This alteration in the position of the monarch is one of the most striking characteristics of the imperial period. He was still nominally as divine as before, but one sees the difference between an Amenhetep and a Khufu, or even a Senusert. He was only called a god by his own people. There were other peoples in the world now, and they did not regard the Egyptian King as a god any more than the Egyptians looked upon the King of Babylon or of the Hittites

Dynasty from Kames to Horemheb. Females are denoted by an asterisk, queens by italics, kings by capitals :-

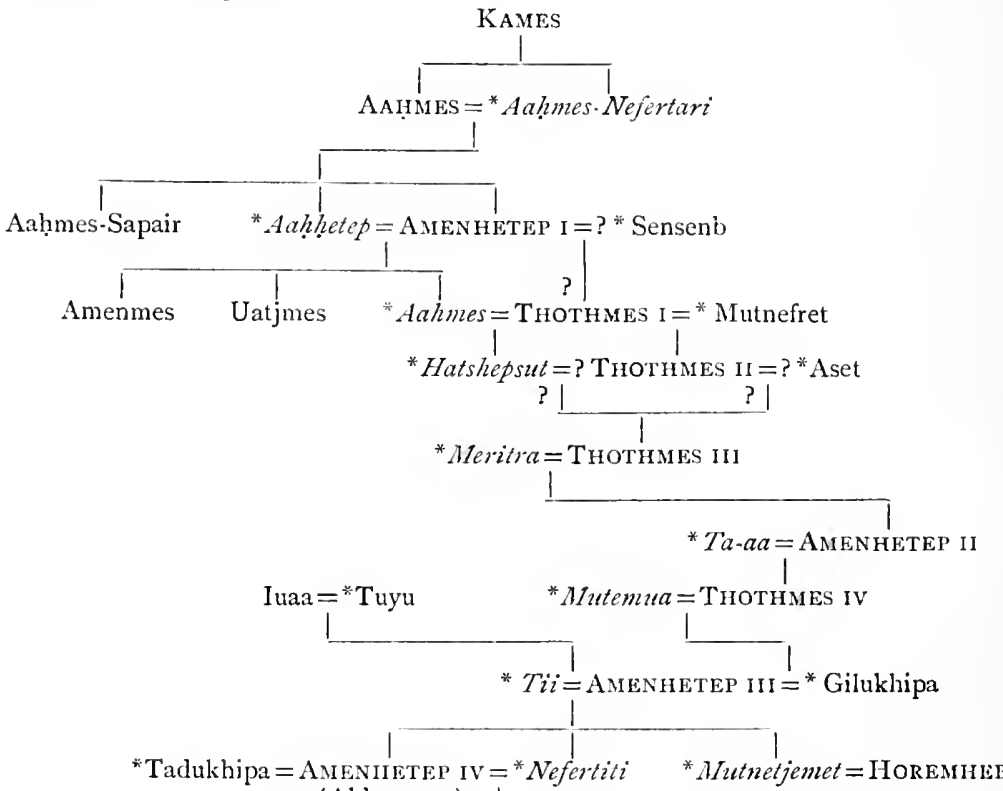

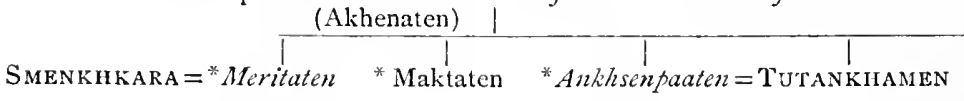

Three other daughters

${ }^{1}$ The city consisted of two towns, Apet proper, or Apet-esut, "The Seats of Apet," the modern Karnak, and Apet-resit, "Southern Apet," the modern AlUkșur, "the Castles" (plural of kasşr, "castle"; so-called from the towering colonnades and pylons of the great temple), which has been Europeanized into "Luxor." These two towns, with their surrounding and connecting subsidiary towns, villages, and private domains, and with the scattered villages, palaces, temples, and necropoles on the west bank, formed No-Amon, "the city of Amon," or simply $N o$, "The city," as the capital seems usually to have been called. The Thebaic nome bore the ancient name of Ueset or $\mathrm{Tj}^{\prime}$ 'emet. 


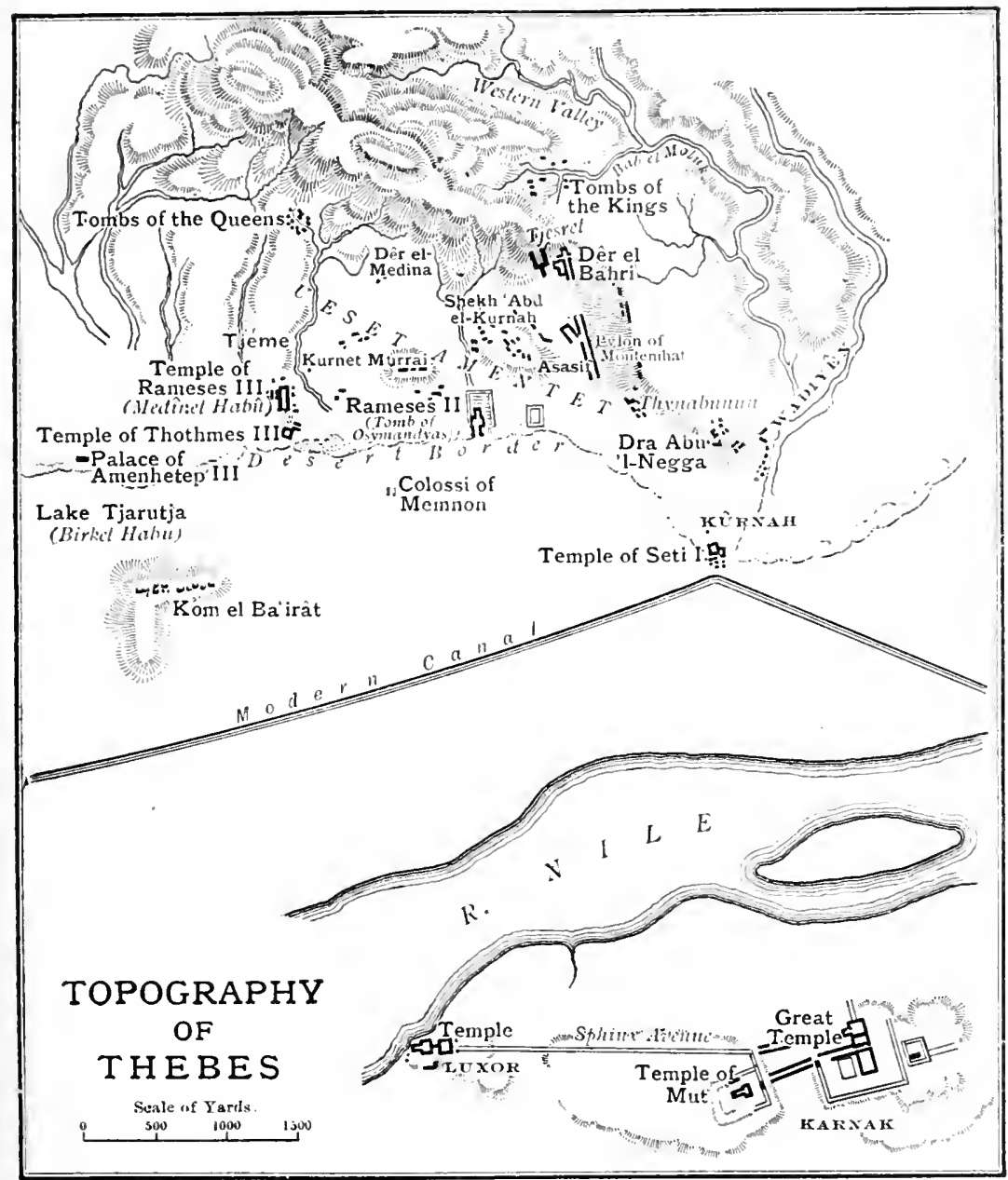



as divine. Babylon or Mitanni wrote to Egypt as his brother, as "Monsieur mon frère," just as a modern monarch might, and Egypt returned the same compliment. And the growing intercommunication between their peoples naturally tended to lower the ancient divine prestige of Pharaoh even in his own land. But instead of the old theocratic relation, a new one grew up now between Pharaoh and his people. They obeyed him now as the leader, their prince and war-lord, the imperator of their armies, who had led them to victory in war and would lead them on to victory still. And in peace-time the king dwelt in his capital like a modern king, and was little more removed from the ken of his subjects than is the latter.

\section{The Imperial Administration in Esypt}

The royal bureaucracy-The viziers-Rekhmara; southern vizier under Thothmes III-Premier position of the southern vizier-His duties-The Treasurer-Local government-Taxes-Royal and ecclesiastical dues-Justice-"The Vizier's Hall" and its development, the "Great Tribunal"-Legal proceedings-The king and the government-His offices-The ecclesiastical state: priests of Amen controlled by a strong king

It is, then, natural that in civil administration, no less than in military and religious matters, we find under the Empire the new phenomenon of centralization in the one capital city. The civil wars and the struggle against the foreigner during the Hyksos period had much the same effect in Egypt as the Wars of the Roses had in England. We have seen that the local authority of the ancient feudal nobility of the land, which was so powerful at the beginning of the XIIth Dynasty, had been curtailed by the later kings of that dynasty, ${ }^{1}$ and the foundations laid of a bureaucratic system of local government. When peace was restored the few great families that remained ${ }^{2}$ found all their influence and power gone. The definite leadership of the king in the war of liberation, with no committee of nobles around him, but merely captains trained to war and the faithful officials and priests of Thebes, resulted in the establish-

${ }^{1}$ See pp. I5I, 170.

${ }^{2}$ Nekheb, the modern El-Kab, alone shows us a survival of local princely power in the family of Paheri, to which the captain Aahmes, son of Abana (p. 226), belonged. The tombs of this family are very fine, and are important as exemplifying the "Middle Kingdom" style of art which still prevailed at the beginning of the XVIIIth Dynasty (TYIOR and Griffith, Tomb of Paheri; E.E.F., IS94). This fanily was strongly devoted to the royal interests, and so retained its local power. 
ment of a strongly centralized royal power, which governed the whole country by means of an official bureaucracy. ${ }^{1}$

At the beginning of the XVIIIth Dynasty the details of government were left by the kings to the city-governer of Thebes, who united with his police-control the ancient dignity of the Tjate, or "Man" par excellcnce, as the vizier was called, as opposed to the Neter, the "God," i.e. the king. ${ }^{2}$ This arrangement worked well as long as the king was usually himself at Thebes, or at any rate in Egypt. But when Thothmes III for a long series of years came to spend half the year in Asia, the burden of the home government became too much for one man, and the functions of the Theban governor were restricted to the south, a "Vizier of the North" being created with his seat at Memphis. The first holder of this office seems to have been himself a Mernphite, named Ptahmes. The boundary between the provinces of the two viziers was fixed north of Siut. ${ }^{3}$ In the south the authority of the Southern Vizier was extended over the valley south of El-Kab, which had hitherto been, and was afterwards, considered to belong to the domain of the viceroy of Nubia, "the king's son of Kush." Here the boundary was fixed south of the Island of Senemet, the modern Bigeh, close to Philae.

We know much of the office of the Southern Vizier from an inscription in the tomb of Rekhmara, who held the post from the thirty-second year of Thothmes III till after the accession of Amenhetep II, at latest about 1450 B.C. Rekhmara was a Theban, and was buried in the tomb-hill of Shêkh 'Abd elKûna at Thebes. It is in his tomb that one of the most important paintings of the reception of the Keftians of Crete and other foreign tribute-bearers, already mentioned, is to be seen. As was often the case with the viziers, his great office had been hereditary in his family for many years, and his greatgrandfather Aahmes had held it, probably under Amenhetep I and Thothmes I. Under Thothmes II and Hatshepsut a certain Hapuseneb, who was a partisan of the queen, occupied the vizier's chair for a short time, but he was probably dispossessed by

1 The best general account of the imperial administration in the time of the XVIIIth Dynasty is that of I'REASTED, Hist. Eg, ch. xiii., to which I am much indebted.

2 See p. 169.

${ }^{3}$ In this reform we see another example of the political capacity of Thothmes IIr. An ordinary Egyptian ruler would have allowed matters to drag on as they had always been, with inevitable governmental chaos as the result. 
Thothmes III, and the dignity restored to the family of Aahmes. After the death of Rekhmara, who succeeded his father User, Amenhetep III gave it to Amenemapet, a scion of another family. Similarly, ltahmes in the north was succeeded by his son Thothmes. The dignity of vizier, then, though by royal favour it could be continued from father to son, was never so continued indefinitely. No doubt this was politic: the kings had no desire to concentrate too much power in the hands of a single family. As it was, the Southern Tjate was very near the throne. We cannot doubt that his office, combined as it was with that of governor of the capital, was far more important than that of the Northern Vizier, and that when the king was absent in Asia or Kush he became automatically Regent of the whole land. In this case his power could only be checked by a masterful queen, like Tii. He is no doubt the first minister, or rabisu, of Egypt mentioned in the Tell el-Amarna letters. ${ }^{1}$

In his tomb-inscription Rekhmara tells us much of his duties and powers. ${ }^{2}$ He was formally installed by the king, and lectured on the duties of his office: charged to hold the scales of justice evenly between rich and poor, and to do unright to no man. The whole business of the administration was handed over to him, with the significant exception of the power of the purse. The king's treasurer was responsible only to the king, and to him the vizier had to go for gold. This was a politic check on his power. He, however, superintended the collection and incoming of the taxes, which were received by him from the local authorities, in whom the powers of police, magistrates, and tax-gatherers were concentrated. Relihmara gives us much information as to this organization in his time, including the statistics of the different provinces of his government from Siût to Bigeh. We see from this list that the local authorities differed in name and powers in different places. In some towns of strategic importance, such as Bigeh on the Nubian border, or Koptos at the mouth of the great Wadi Hamamat, the government seems to have been military in character: in others we find the descendants of the local princes still nominally ruling, but really controlled by a sheriff or royal

I See p. 269.

2 Neweerry, Rekhmara, pp. 22 ff. ; Garninfr, Rec. Tiav. xxvi. pp. I ff.; Sethre, Die Einsetzung des Veziers; Untersuchungen, v. 2 (1909). On the succession of the viziers, see Wert, Die Veziere des Pharaonenreiches, Strassburg, Igo8. 
officer, called the uhem ("herald"). $\mathrm{He}$ had his reeve and subordinate officials. At Thebes the king was the chief, and the vizier was his assessor. A Theban herald probably existed, but was attached to the king personally, as comptroller of the household of his chief. We have seen that a certain Antef performed this function for Thothmes InI. ${ }^{1}$

The amount of taxes received from the local officials is stated by Rekhmara. It always consisted primarily of so many deben weight of gold, with oxen, pigeons, honey, grain, cloth, beads, and other tribute in kind according to the local circumstances in each case.

These were the king's dues, which Rekhmara collected as vizier: as he held also the office of Steward of the Estates of Amen, he also received the local Theban dues of the god and the proportion of foreign tribute assigned to him.

Of old the office of $T a$, or "Chief Justice," had been inseparable from that of the Tjate. So that Rekhmara was Chief Justice as well as Minister of the Interior, as well as, incidentally, Chancellor and Steward of Amen. As Ta, the vizier controlled the higher judges, who were attached to the royal court, and so had their seat in the capital.

Of the "Great Tribunal" (Kenbet aat) which assisted the vizier under the Ramessides, we hear nothing from Rekhmara's inscription. This formal assembly of councillors was probably developed from the Vizier's Hall, as Rekhmara describes it, at the time of the legal reforms of Horemheb, who put things straight after the confusion of Akhenaten's mad reign. ${ }^{2}$ We learn from the inscription of a certain Mose or Mes, who lived under Rameses II, and was buried at Sakkara, much of the legal arrangements of his time, and can draw a good idea of how a lawsuit was conducted in the vizier's court. The procedure must have been much the same in Rekhmara's time, but for the fact that the "Great Council" did not then exist. The usual petitions are made, the plaintiff and defendant plead their causes in person (the recorded speeches of Mes and his opponent Khai in this case are the oldest specimens of forensic oratory known), the Vizier sends his apparitor to take the cause back to the local Kenbet of Memphis (the Kenbet aat of the North sat at Heliopolis) that the circumstances might be 
examined more fully, and so forth: finally, the Vizier himself pronounces judgment. ${ }^{1}$

To the state-organization the Pharaoh bore much the same relation as a Russian Tsar, or other modern autocratic monarch, bears to his state to-day. The army and foreign relations were his real sphere of action. With them the viziers had nothing to do. He was at once the War-Lord, Foreign Minister, and Colonial Administrator of the nation. He represented it in dealings with the gods as well as with other earthly sovereigns. For his people he offered sacrifices and presided over festivals. Thothmes III was for many years absent during the hot Egyptian spring and summer on campaign; the winter he spent in Egypt, returning every year punctually in order to be present at the great metropolitan festival of the goddess Apet.

The king's immediate officers, the chamberlains and comptrollers, accompanied him to Asia and attended him in Egypt, with the exception of the stewards of his estates, who were probably subordinate, not to the viziers, but to their colleague, the Chief Treasurer. Another officer who probably also remained behind was probably responsible to the king only, and watched both the viziers and the treasurer. This was "The two Eyes of the King in the North, the two Ears of the King in the South," as his significant title runs, with variations.

Such was the Egyptian civil state under the Empire. The ecclesiastical state, previously unknown as such, had not yet so far differentiated itself from the civil state as it did a few centuries later. The power of the king was too great. In his ecclesiastical capacity (he was himself always a priest of Amen, though necessarily of subordinate rank), he formed a link between priests and laymen, and so long as he continued to be, while devout enough, in his soul a warrior and a ruler, he was a link that controlled both. Subordinate links which checked priestly ambitions were created by the appointment of the lay vizier to the stewardship of the domains of Amen, and of other lay officials and royal princes to the chief priesthoods. The priests had already begun to be a caste apart, as they never had been before, when the noble was also naturally the priest; but the time had not yet come when priests were to usurp the natural functions of laymen. This only came about when the

\footnotetext{
'For the actual text see A. H. Gardiner, The Inscription of Mes (in Sethe's Untersuchungen, iv., I905), pp. $7 \mathrm{ff}$.
} 
strength of the strongest controlling link, the king, was weakened by religious heresy and loss of foreign dominion, and its resultant poverty and loss of royal prestige.

\section{Rise of the Priests of Amen}

Royal gifts to Amen-Tutelary deity of the empire-The other gods

Yet already under the XVIIIth Dynasty the foundations were laid of the future priestly domination by the enormous benefactions which the kings, in gratitude, laid upon the altars of Amen. Thothmes III, undisputed ruler though he was, before whom no priest would have dared to raise his head, did more than all. His gratitude to the god who had guided him to victory was great. To his metropolitan temple in "the Seats of Apet" (Karnak) he added the colonnades and halls at its eastern end, among which is the chamber decorated with representations of the rare plants and animals which he had brought back from his campaigns. The architect Menkheperrasenb here essayed a new variation in architecture: he reversed the papyrus-capitals on the columns, with a peculiar effect which was not imitated in later days. But the king shewed his gratitude to Amen in a more tangible fashion. Amenhetep I had been the first to heap favours upon the priests of Amen: his descendant gave them riches. The larger proportion of the slaves and tribute of Asia was given to them: the three towns of Anaugasa, Yenoam, and Hurenkaru in the Lebanon, were bestowed upon them as domains of the god, besides countless lands and serfs in Egypt itself: and so the dominant position of the priesthood of Amen, "King of the Gods," was assured, and with it their favour and support to the kings. Amen became the tutelary deity of the empire abroad, as he was of the metropolis. His name and fame in Asia bid fair to rival that of the native deities, and he was venerated by the Canaanites as the equal of Baal and Ashtoreth. His temples arose in the towns of Canaan and in the sea-cities of Phoenicia. Semitic chiefs and officials, like Amankhashir, ${ }^{1}$ bore his name like any Egyptian Amenheteps or Amenemhebs. ${ }^{2}$

${ }^{1}$ See p. 247.

IIow powerful the name of the Egyptian god lecame in Syria is shewn by the story of the envoy Unamon, four hundred years later, when even in the hour 
In the empire of the South also, so far as it was newly conquered by the kings of the XVIIIth Dynasty, Amen was tutelary deity. His subsidiary shrine at Napata, a sort of filiale of Thebes, became a centre of his worship and focus of anti-Assyrian patriotism under the Ethiopians, ${ }^{1}$ much as the temples at Thebes had been the focus of resistance against the Hyksos. The other Egyptian gods do not appear outside Egypt. He was the imperial deity, they remained in their own land: with the new domains of Amen they had nothing to do. The kings naturally conferred favours upon the older local gods also; there was no possibility of Amen-Ra overshadowing the other gods so far as to create even a semblance of monotheism. But Amen-Ra was their king.

Naturally this predominance soon caused the jealousy of the older and rival deities to spring into life. Of all, the priests of $\mathrm{Ra}$ at Heliopolis must have been most outraged by the annexation of their god, the most ancient of all, to the comparatively new-fangled Amen. And we can with great' probability trace to their influence, as well as to the growing royal displeasure at the power of Amen's priests, the religious revolution of Akhenaten, which amid the collapse of the First Empire momentarily dethroned Amen, and made a transformed idea of $\mathrm{Ra}$ the One God of Egypt." This revolution failed, as, being an artificial creation of the ling and a few heretical priests, it was bound to clo: and the only result of the failure was to rivet the yoke of the priests of Amen on the necks of the kings in a fashion previously undreamt of.

\section{The Reign of Hatshepsut}

Internal peace-The royal house and the "Thronwirren"-Professor Sethe's theory-Possible explanation-Hatshepsut as "king "-Her pacific policy-Building of Deir el-Bahri-The expedition to Punt (c. I 492 I3.C.)-Death of Hatshepsut (c. I479)

The history of Egypt at this time is the history of her external empire. At home the fellah tilled his lands and worshipped his gods ${ }^{3}$ in peace. Nothing happened to disturb of the decline of the Empire and of Thebes, he, the envoy of the priest-king Herhor, was evilly entreated by a I'hoenician princeling: he asseverates his dignity as an ambassador of Amen, and goes free (see p. 394).

${ }^{1}$ See p. 467 .

2See p. 299.

${ }^{3}$ Interesting light upon the popular worship of the gods at this time has been shed by the vast number of small votive offerings discovered at lèr el-Baḩri by 
the internal tranquillity of the country. There is one mention of some abortive rebellion against Hatshepsut, which seems to have been quelled by Neb-uaui, the High Priest of Abydos, who was high in favour with Thothmes III at the beginning of his reign. ${ }^{1}$ We have no other evidence of internal disorder from the repression of the rebellions against Aahmes to the religious revolution of Akhenaten, a period of nearly two centuries. Disorder in the royal house there certainly was at the beginning of this period, if we are to credit Prof. Sethe's theory of the "Thronwirren," or confused succession of Thothmes I and II, Hatshepsut, and Thothmes III. This theory ${ }^{2}$ has been not only accepted, but stated to be historical fact, by Prof. Breasted, ${ }^{3}$ but has been rejected in toto by Prof. Naville. ${ }^{4}$

The precise relationship of Thothmes I to Amenhetep I is uncertain, and it is supposed by Prof. Sethe that he was not his son, but only ascended the throne in right of his wife, Queen Aahmes. Prof. Sethe is then of opinion that on the death of Aahmes, his wife, Thothmes I was compelled to resign the throne, and Thothmes III, his elder son, ascended it by right of his half-sister and wife, Hatshepsut, who was the eldest surviving descendant of Thothmes I. He himself, being the son of a subsidiary wife, Aset, had no immediate right to it.

NAvILLE and the present writer during the excavation of the XIh Dynasty temple (see p. 145) for the Egypt Exploration Fund (1903-7). These votive offerings of the people were nearly all of the time of IIatshepsut and Thothomes III, and were dedicated chiefly to Hathor, the tutelary goddess of the place, and one of the most popular of Egyptian deities. They consist of all kinds of objects, mostly the veriest trumpery, but of great archaeological and anthropological interest. It would seem that the older temple was at this time used as a depository for the offerings of the people to the shrine of the Hathor-cow, discovered by NAville in 1906 (Deir el-Bahari: XIth Dyn. i. p. 63). The whole place seems to have been filled up with them, much as the shrine of a popular Virgin or saint is filled with the offerings of the faithful in a Roman Catholic country to-day. Probably most of these offerings were manufactured close to the temple, and we can imagine it as surrounded by a sort of permanent fair of booths for the sale of them, and so much resembling such shrines as Lourdes, Loreto, or Mariazell to-day (sce Hall, Deir el-Bahari, Ylth Dyn. iii. ch. iv.). Nothing can be less true than the statement, sometimes met with (e.g. Sourdille, Voyage d'Hérodote, p. 184), that the Egyptian religion was an affair of priests and kings only. Cf. Herodotus' description of the Festival at Bubastis, ii. 60.

${ }^{1}$ Spiegelberg, Rec. Trav. xix. 99. Stela in Brit. Mus. No. 1199.

${ }^{2}$ Sethe, Untersuchungen, i. (1896) pp. I-58; $A . Z$. xxxvi. pp. 24 ff.

${ }^{3} A$ New Chapter in the Life of Thutmose III, in SeTHe, Untersuchungen, ii. (I900); and Hisi. Eg. p. 268.

4 A.Z. xxxv. pp. 30 ff. ; xxхvii. pp. 48 ff. 
Thothmes III then ruled for a time alone, Hatshepsut being merely his "Great Wife," as Aahmes had been merely the "Great Wife" of Thothmes I. About the fifth year of his reign, the "legitimists" compelled him to accept his wife as his co-regent and fellow-king. Thothmes aftci some years got rid of her for a short time, and erased her name on the monuments. Then came a new revolution. Thothmes II took the sceptre from the hands of Thothmes III, and by his side reappeared the ex-king Thothmes I, as co-regent. Thothmes II obliterated the name of Hatshepsut, like Thothmes III. Thothmes I died at last, and Thothmes II ruled alone for a short time after his death, probably from the seventh to the ninth year of Thothmes III. Then Thothmes II also died, and Thothmes III and Hatshepsut returned to power together, having apparently made peace after their quarrel. Hatshepsut finally died, and Thothmes III reigned in peace for the rest of his life.

This (it would really seem improbably) complicated hypothesis is chiefly based on the facts of obliteration and restoration of royal names in Hatshepsut's temple at Dêr elBahri, and other arguments which seem somewhat weak, ${ }^{1}$ though

' Prof. von Bissing has shown ( $A . Z$. xli. pp. I26ff.) that a king did not invariably replace an excised or usurped name by his own, as Prof. Sethe believed, but constantly restored the original name, or replaced it by some other which he considered appropriate. This discovery invalidates many of Prof. Sethe's conclusions. Indeed, by it one of the three "basic facts" on which, according to Prof. Breasted (in the Preface to $A$ New Chapter in the Life of Thut mose $11 I$ ), these conclusions entirely rest, is shewn to have no existence. Also, there can be absolutely no doubt, as we have said already, that Thothmes III was the son, and not the brother, of Thothmes II. The statue-inscription of Anebni in the British Museum (No. 113I), calls Thothmes II the "brother" of Hatshepsut, but only in the sense of "husband," in which sense the word is used by Queen Tii in speaking of her husband Amenhetep III, who was the son of Thothmes IV and Mutemua, while she was the daughter of Iuaa and Tuiu. Also, though it may be doubtful whether Thothmes I derived his right to the throne exclusively through his wife Aahmes or not, we have no reason to suppose, as Prof. Sethe does, that at her death his right automatically ceased, and that he was compelled to resign his throne to Thothmes III, who ruled by right of his wife IIatshepsut, who as the daughter of Aahmes had a better right to it than he. To Prof. Breasted's further discovery in an inscription of Thothmes III of a hitherto "unknown chapter" in the life of that king, according to which the young prince was standing as a simple priest in the hall of the temple of Karnak when the procession of Amen passed, and the god halted in front of him, and (through the mouth of his ministers) recognized him as king, when Thothmes I was compelled to resign his crown to him there and then, it can only be said that, even were it necessary to see all this in the words of the inscription, such an official tale would be no 
we are hardly justified in rejecting them absolutely, as Prof. Naville has done. Until decisive confirmation of Prof. Sethe's theory is discovered, it would seem best to hold (with Prof. Naville to a great extent) that Thothmes I, after having associated his son Thothmes II in the normal way before his death, was succeeded by the latter. Whether Thothmes II married Hatshepsut or not is doubtful: Prof. Naville believes that he did, while Prof. Sethe denies it. In this matter perhaps Prof. Sethe is right. Thothmes II died after a very short reign, at about the age of thirty, leaving behind him a young son Thothmes, by a lady named Aset. ${ }^{k}$ It is evident from his mummy (now at Cairo) that Thothmes II was a man of feeble physique, and was probably diseased: his wife Aset was a person of no account. During his reign it is probable that his half-sister Hatshepsut exercised great influence over the government. If with Prof. Sethe we hold that Thothmes I was not the son of Amenhetep I, she was the eldest, perhaps now the only, member of the royal house directly descended from Aahmes the Liberator, whereas the king Thothmes II was not descended from him at all. Further, she was a woman endowed with no small amount of the energetic spirit of her father, as well as her mother's pride of race; and no doubt, as she says in an inscription at Dêr el-Bahri, and in this we need not disbelieve her, she was the favourite child of Thothmes I, and intended by him to share the throne of the ruler who should succeed him. If she had been a weak woman, the loyalty of the people to her as the true representative of the descendants of $\mathrm{Ra}$ would have amounted to nothing more than mere affection: as it was, it was she,

more worthy of credit than Hatshepsut's very similar tale of her presentation to the nation by her father as his successor and the future king, which is quite rightly rejected as of no historical value by Prof. Sethe (in opposition to Naville, who accepts it as true). Both stories bear the obvious stamp of official inventions by Hatshepsut and by Thothmes at the periods of their respective apogees of power. Hatshepsut wished it to be believed that her father had desired her to rule alone as king, not as the queen of her nephew; and when the nephew succeeded to her power, he wished it to be believed that Amen in his temple had indicated him, Thothmes, to Thothmes I as his proper successor, Thothmes II and Hatshepsut being ignored.

${ }^{1}$ Prof. SETHE regards Aset as a wife of Thothmes I, but it seems to me that the dedication of a statue by Thothmes III to "his father" Thothmes II (MARIETTE, Karnak, $38 \mathrm{~b}, \mathrm{z})$ is more definite than the reference on the statue of Anebni in the British Museum to Thothmes III as the "brother" of Hatshepsut. The expressions "brother" and "sister" scem often to have indicated marital relations (see preceding note). 
rather than Thothmes II, who was regarded as the real rulcr. She may have married him. Whether she did so or not, and it is possible that she refused to do so on account of his sickness, at his death it was natural that she should at least act as regent for his young son. But her blood and her natural energy could not brook this subordinate position perhaps without the title even of queen. Assisted by a great body of influential partisans, whose names we know, and acclaimed by the loyalty of the people, she took the first step by marrying her child-nephew. Then, justifying the act by her pure descent and appealing to the wishes of her father, she took the final step, and, a woman, assumed the king's crown herself, relegating her husband and nephew to the position of associate kings. Thothmes II soon died, but Thothmes III continued to reign as a shadow-king: he was "His Majesty," Menkheper-Ra, always; but of real power he had none till her death. This we see from the fact that his natural inclination towards militarism and conquest had to be suppressed while she lived. That he hated her profoundly, that afterwards he should strive to obliterate her memory from the monuments of their joint rule, was natural. But it may well be that the long years of necessary self-repression in reality exercised a good effect upon his character, and that when he came to his full power he was the better and the wiser king for the discipline and schooling which he had received from Hatshepsut. Few other kings of Egypt had had so severe a training; few other kings of Egypt shewed the same real power of governing and organization as Thothmes the Great.

The result of the extraordinary appearance of a woman as king we see upon her monuments, the peculiarities of which are well known. That she actually wore the male royal costume, as she is represented on them as doing, cannot be doubted. But she did not go forth to war, nor would she allow her young consort to obtain prestige by doing so. The great acts of her reign were the enlargement of Karnak, ${ }^{1}$ her great expedition to Punt (which took place in the ninth year of Thothmes III), ${ }^{2}$ and the building of Dèr el-Bahri, the

${ }^{1}$ Here she, or rather her great minister Senmut, set up two of the finest obelisks in Egypt.

2 The inscription at Dêr el-Bahri describing the expedition is dated in this year, when Thothmes was still a boy. 
magnificent temple which she erected by the side of the ancient funerary fane of Mentuhetep, in the necropolis of Western Thebes. This building, by which her name is best known to us, was dedicated to Amen, and, as we should say, "to the memory" of her father Thothmes I; Hathor also, as the tutelary deity of the place, was honoured within it, and Anubis as protector of the western necropoles. It also served to commemorate the glory of her own reign, and more especially the expedition to Punt. In its design it was remarkable and unprecedented, except in so far as its architect had borrowed some ideas from the neighbouring temple of Mentuhetep. Like this, it had to be reared up against the face of a great cliff, and Mentuhetep's plan of a terrace, approached by a ramp between two colonnades, was followed; but instead of one, two terraces were built, one behind the other, to lead up to the rock-cut sanctuary. The boldness of the conception, the splendour of the architecture, and the beauty of its sculptured and painted decoration, were the worthy firstfruits of the new imperial grandeur of Egypt, and mark the first progress beyond the ideas of the XIIth Dynasty. Magnificent conceptions were in the air. The great queen, glorying in her "years of peace," 1 sends an expedition of great ships to Punt, which brings back to her treasures of gold, ivory, precious woods, myrrh-trees in pots for transplantation to Egypt, sacks of myrrh and frankincense, apes and all rare denizens of the earth, the air, and the waters, "the like of which was not brought for other kings, being marvels of Punt, because of the greatness of the fame of this revered god, Amen-Ra, lord of Thebes." These the queen presented in solemn state to Amen, and on the walls of Dêr el-Bahri she employed her artists to represent the events and fruits of her great expedition. The triumph of both artists and architects in the new temple, in which they engrafted the new spirit on to the old, is now evident to our eyes since its complete excavation and publication by Prof. Edouard Naville at the expense of the Egypt Exploration Fund (Plate XVIII. r). ${ }^{2}$

Hatshepsut was buried in a rather extraordinary rock-tomb, with a gallery of immense length, but of unfinished appearance, ${ }^{3}$

I Inscr. at Dêr el-Bahri.

2 Naville, Deir el-Bahari, i-vi. (E.E.F., IS95-I908).

- Very probably Thothmes 111 refused to decorate it in any way. It was dis- 


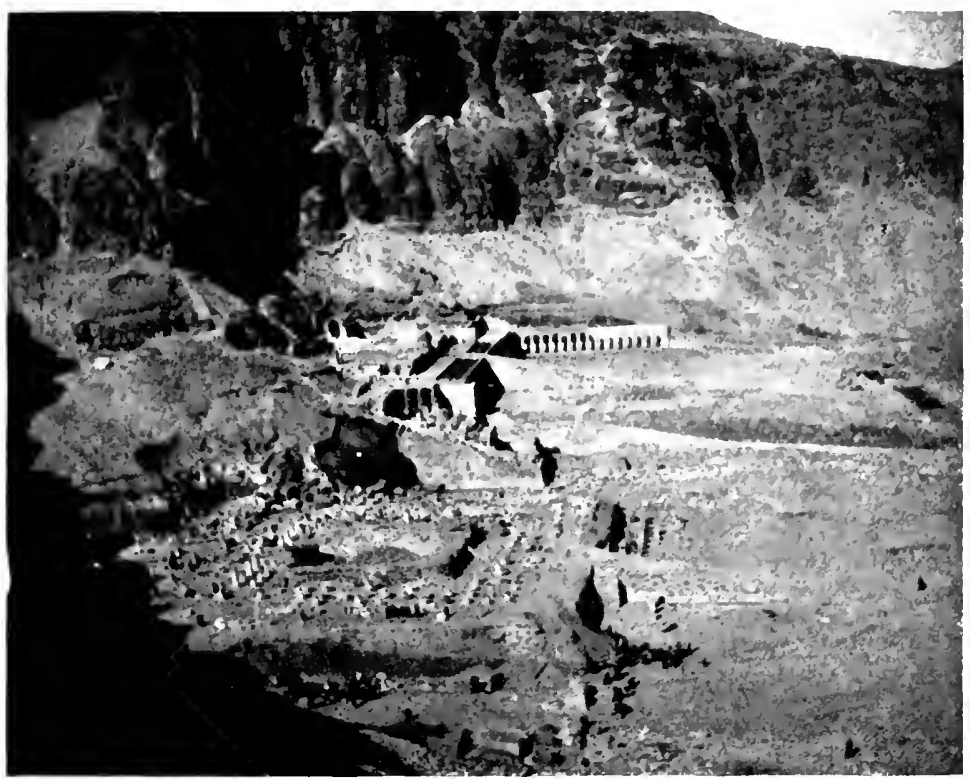

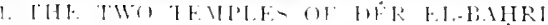

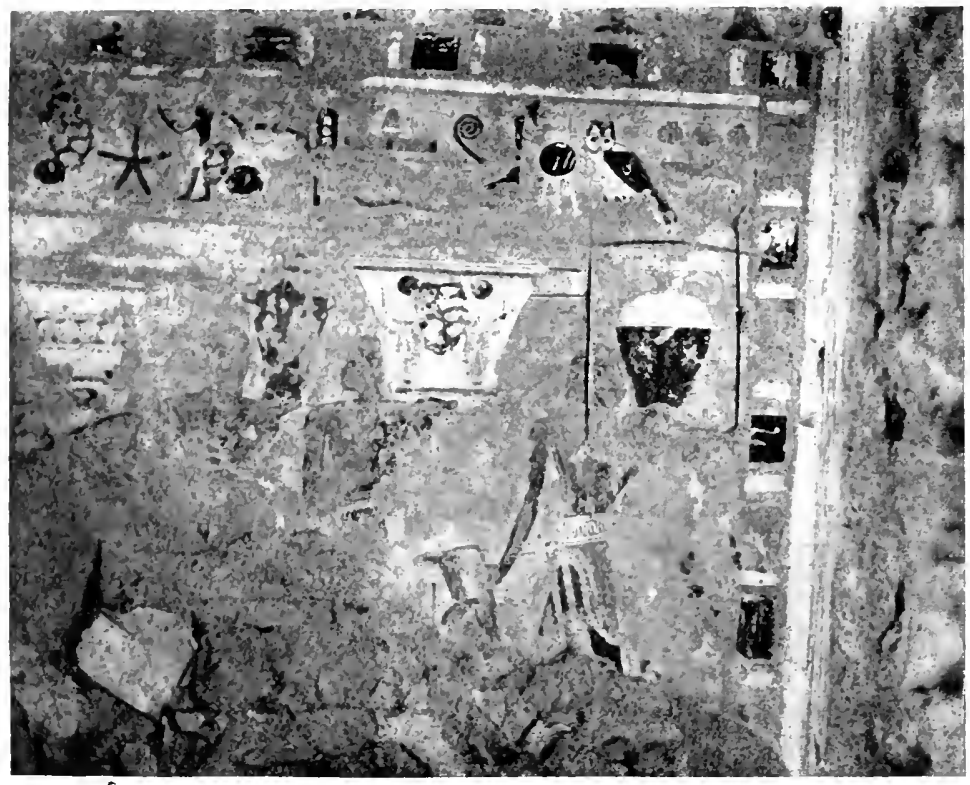

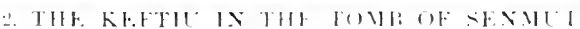



in the Valley of the Tombs of the Kings, the winding wadi at the back of the hill of Dra' Abu 'l-Negga. In this valley her father had been buried, and here all the great pharaohs of the empire were laid to rest after her in the splendid subterranean sepulchres which from Greek times till now have been reckoned among the wonders of the world. The latest date of her reign known is apparently that of her 22nd year, and as it was in his 22nd year that Thothmes III set forth to war, we cannot cloubt that their reigns began together, and that she died in the 22nd year of their joint reign. On the lowest chronological scheme both then ascended the throne about I 5 OI B.C.

Thothmes III's persecution of her name after her death extended also to the names of her chief supporters, and no doubt to the persons of those of them who survived her. Chief among these was the architect Senmut, ${ }^{1}$ the designer of the temple of Dêr el-Bahri, and the vizier Hapuseneb.

\section{Thothmes III to Amenhetep III}

The apogee of Egypt-Culture and art : relations with Crete and the AegeanThe chiefs of Kefti come to the Egyptian court-Phoenician merchants at Thebes -Royal tombs

Rid of Hatshepsut and her supporters, the thirty-two years' sole reign of Thothmes III passed in Egypt quietly enough. The family of Rekhmara governed well in his absence from the kingdom, the booty of Asia conciliated the priests of Amen, who, under Hapuseneb, had previously been the foremost supporters of Hatshepsut, the land grew rich by leaps and bounds, and all went well. Nothing happened but the building of temples till the reign of Amenhetep III. Under Thothmes III the imperial destiny of Egypt was consummated, and she became for two centuries the most powerful, the wealthiest, and, all things considered, the most civilized, country in the world. The connexion with the "Minoan" civilization in the Aegean which had already existed under the Hyksos, was

covered by Lepsius, and excavated by Mr. Theodore M. Davis in 1902 : it had been violated, but in it were found not only her own sarcophagus, but also those of Thothmes I and Thothmes II (DAvis, Tomb of Hatshopsitta, London, I906).

1 The inscriptions of Senmut and the other ministers mentioned will be found translated by BREASTED, Anc. Rec. ii. pp. $144 \mathrm{ff}$. 
greatly developed by the approach of the Egyptian arms to Asia Minor and the submission of Cyprus. Cretan embassies brought the triumphs of the Minoan metal-worker and embosser to Thebes, and specimens of the beautiful faience of Egypt were prized at Mycenae and in Cyprus. We have already spoken ${ }^{1}$ of the influence of Egyptian and Aegean art upon each other. It is chiefly in the domain of metal-work that we see the clearest trace of the Minoan influence in Egypt, where magnificent embossed bowls of silver and bronze with scenes of lions hunting deer amid trees, fish amid lilies, and processions of gods, first came into vogue in the reign of Thothmes III. One of the finest known of these was significantly presented by the king to his officer Thutii, the Governor of the Northern Lands and representative of the king among the islanders of the great Green Sea. The designs on these bowls are Egyptian, but the spirit of their execution and their workmanship must be inspired by Minoan originals. ${ }^{2}$ In return the Cretan artists borrowed the Egyptian designs of lions and cats hunting deer and wild-fowl for the adornment of their own swords, daggers, and other metal-work. For importation to their own islands they seem to have prized above all the ceramic products of Egypt, which they had themselves imitated with success since the time of the XIIth Dynasty, when; probably, they first became acquainted with the Egyptian art of glazing earthenware. In return, again, the Egyptians strove to imitate in faience, as well as in metal, the bronze one-handled vase-fillers and other vessels, later on the remarkable stirrup-vases, or "Bügelkannen," which were characteristic of the metal-work and pottery of Later Minoan Greece. This welcoming of a foreign influence is characteristic of a period of foreign empire and contact with strange races.

The pride as well as the curiosity of the Egyptians was greatly stirred by the coming and going of the ambassadors and tribute-bearers of the foreigners, who brought these beautiful things to Thebes, and few of the great nobles of the time failed to record upon the walls of their tombs the faces and appearance of the ambassadors of Crete or the tribute-bearers of Syria and the black Sudan who had come in their time. Senmut, the architect of Hatshepsut, and Rekhmara, the chancellor of Thothmes III, thus record the procession of the chiefs of Keftiu ${ }^{1} \mathrm{P} .3^{6}$.

${ }^{2}$ v. BIssing, Jahrb. Arch. Inst. xiii. 
(Crete) and the Isles in the midst of the Sea. ${ }^{1}$ Confidently the ruddy Minoans or Mycenaeans march along the walls, wearing their high Cretan boots, their typically "Mycenaean" waistcloths, and with their long black hair hanging to their waists, or knotted on their heads, just as we see them on the walls of their own home, Knossos, where the famous fresco of the Cupbearer, discovered by Dr. Arthur Evans, ${ }^{2}$ might be a replica of one of these contemporary Egyptian figures. Hc bears a great vase, just as do the ambassadors to Egypt, who bring their gifts to the court of Hatshepsut or Thothmes III. Confidently they advance to the foot of the throne, in the picture in the tomb of Rekhmara, led by their "Great Chief," a young man with fair face and small European mouth,markedly small it appeared to the large-mouthed Egyptian who sketched him for the picture,- - and followed by a darker and older man whose Roman nose and heavy jowl remind us strongly of an Italian type. Another, a young man, follows, who bears a sword in his hand as well as a great vase on his shoulder; and as he walks he looks back with open mouth to make some loud remark to the next man, much as a young Gothic ambassador might have guffawed in the presence of a Roman Cresar. All is represented to the life. These Minoans were no servile Semites or cowed negroes.

In another tomb we see depicted the arrival of a Phoenician merchant-ship at the Theban quay. ${ }^{3}$ She had sailed from Byblos or Tyre along the coast and then up the Nile to the capital, laden with such things as the Sidonian craftsmen could make then as well as in later days, and among them we see Mycenaean vases. Cretan ambassadors might bring treasures

${ }^{1}$ Senmut's fresco (Plate XVIII. 2) is published by myself (Hall, B.S.A., Am . viii. pp. $172 \mathrm{ff}$; x.pp. 154 ff.) ; and Prof. W. M. MÜlLLer, Esyptological Kesearches, i. Pls. 5-7. My last publication included a photograph of a fine drawing made by Robert Hay in 1837 , not previously noticed, which shews the fresco as it was in his time, including figures now destroyed. Prof. Müller's photograph of a part of the representations is more satisfactory than are his coloured plates, which give a poor idea of the original. A scene from the pictures in the tomb of Rekhmara was published by S'TEIN DORFF (in the Archöologische Anzeiger of the Jahrb. Arch. Inst., 1892), and poor drawings by VIREY (Tombean de Rekhmara; Mim. Inst. Fr. Caire, 1889); Lichtenberg (M.V.G., I9I I ; Figs. 2, 3) is better. It is to be hoped that Prof. Newberry will publish coloured tracings of the whole in the long awaited second volume of his work on Rekhmara.

${ }^{2}$ See p. 51 ; Plate V.

${ }^{3}$ Daressy, Reo. Arch. xxvii.; Hall, Oldest Civilization of Grece, Pp. I68, 160. 
to give: Phoenician middlemen brought their commoner goods to sell.

The sepulchre of Thothmes III in the Valley of the Tombs of the Kings is not remarkable, but that of his son Amenhetep II is interesting in many ways. It is the first royal tomb in which the occupant was found lying in his funeral state as he was buried. ${ }^{1}$ And some bodies found lying in the tomb-chamber may be those of servants killed at the funeral in order that they might accompany the king to the next world.

The tomb of Thothmes IV was discovered by Mr. Theodore Davis in 1904: in it was found an embossed leather chariot-body, besides beautiful faience vases. This tomb was violated as early as the confusion of Akhenaten's reign, and restored by Horemheb, as we learn from a hieratic inscription on one of its walls. ${ }^{2}$

Amenhetep III chose a different position for his tomb. $\mathrm{He}$ was buried not with the other princes of his house, but in the remoter "Western Valley," beneath a magnificent hill which rises as a natural pyramid above it: a fitting resting-place for the most imperial monarch of Egypt. Tii his wife may originally have been buried by Akhenaten at Tell el-Amarna, from which her body was removed to Thebes by Tutankhamen, who wished to place it with Akhenaten's in a small tomb in the Valley of the Tombs of the Kings, which had probably been made for a prince. The operation of removal was, however, effected in such haste and confusion that though Tii's catafalque, dedicated for her by Akhenaten, and her golden diadem were placed in the tomb, her body was either left behind at Tell el-Amarna or buried elsewhere at Thebes: the "canopic jars" and the coffin found with Tii's funeral furniture are apparently that of Akhenaten, and the human remains found are those of a man, apparently Akhenaten himself. ${ }^{3}$ The tomb resembles that of Tii's parents Iuaa and Tuiu, also discovered close by a few years ago by Mr. Theodore Davis and Mr. J. E. Quibell. Both are of the simpler type intended for

'From the others the royal mummies had all been removed in the time of the priest-kings either to the pit near Dêr el-Bahri in which the mummies of Seti I, Rameses II, and others were found by M. Maspero in IS8I, or to this tomb of Amenhetep II, in which, besides the original owner, the mummies of Meneptah and other kings were found when it was discovered in IS9S. Amenhetep II still quite rightly remains in his tomb: the others have been removed to Cairo (see p. 392).

2 Newberry, Tomb of Thouthmosis $I V$, p. xxxiii.

${ }^{3}$ Davis, Tomb of Quecn Tíyi, London, I9I0; cf. IVeigall, Akhnaion, p. 280. 
princely personages. But very different in Iuaa and 'Tuiu's tomb was the scene that greeted the eyes of the discoverers from that which met them in that of Tii. Instead of utter confusion everything was found as it had been left by the undertakers. The father and mother of Tii lay in their gilded coffins surrounded by the state in which they had lived: splendidly upholstered chairs, gilt and silvered ushabti-figures, clothes- and wig-boxes of reeds, even a perfectly preserved chariot, were placed with them for their use in the next world. ${ }^{1}$ We obtain from this funerary furniture a very complete idca of the magnificence and luxury of the court of Egypt in the time of Amenhetep III. Well might the Mitannian Dushratta say, "Gold is as the dust in thy land, my brother!" 2

\section{The Reign of Amcnhetep the Magnificent}

The palace of Amenhetep III-The pleasure-lake of Tjar-ukha-The Colossi of Memnon-The court of Amenhetep III-Amenhetep, son of Hapu

It is true, however, that we do not obtain any idea of very great magnificence from the ruins of the Theban palace of Amenhetep III, which were excavated by Messrs. Newberry and Tytus some years ago, and have recently been re-examined by Messrs. Winlock and Evelyn White for the Metropolitan Museum of New York. All we see are the remains of mudbrick walls like those of any fellah's hovel, with a few white limestone column-bases here and there. These walls are however stuccoed, with the peeling remains of fine wallpaintings, including one of a bull galloping among flowers which reminds us of a Mycenaean fresco: and from the floor of one of the rooms a very beautiful painting of ducks and waterfowl has been happily removed to the Cairo Museum. This was a palace of mud, it is true, but it was beautifully decorated, and we must imagine it as a painted summer-house of cool passages and loggias, with light roofs upheld by carved wooden pillars on stone bases, and tent-like awnings of brightly coloured stuffs to keep off the sun, placed by the side of the great artificial lake of Tjarukha, ${ }^{3}$ on which Amenhetep and

${ }^{1}$ Davis, Tomb of Toutya and Touiyou, London, 1907.

2 Tell-el-Amarna letter KNUDTZON 19.

3 The dyke-walls of the lake are now represented by the rectangle of mounds on part of which is placed the modern village of El-Bâ'îrâi. 
Tii were wont to sail with their court in the golden barge Teken-Aten, "The Sun-Disk gleams."

But if Amenhetep had a more permanent palace in the city of Thebes itself, on the eastern bank of the river, it was probably hardly more substantial, and also built of mud-brick, like all the houses of ancient and modern Egypt. Stone was used for the temples of the gods alone. ${ }^{1}$ And for them Amenhetep erected houses the like of which Egypt had hardly seen before and was never to see again till the days of the Ptolemies. The great court of Luxor and the temple of Soleb shew how magnificent were the conceptions of Egyptian architects at this period, the apogee of Egyptian civilization and art; and did Amenhetep's funerary temple on the western bank at Thebes survive, we should probably deem it the most splendid temple in Egypt. But the stupid vandal Rameses II destroyed it to build his own "Ramesseum" with its stones, and nothing of it remains but the two huge Colossi which still sit in solitary state amid the waters of the inundation and the waving fields of millet, unchanging throughout the changing years, unchanging as Egypt, and still bearing mute witness to the imperial greatness of the third Amenhetep, "called by the Greeks Memnon."

An imperial magnificence it was, perhaps, rather than true greatness. Thothmes III had been really great: Amenhetep deserves rather the title of "The Magnificent," and he owed his magnificence to the greatness of his ancestor, who had made his empire for him. For, after his first campaign in the Sudan, ${ }^{2}$ we hear nothing of any warlike undertakings by the third Amenhetep, who spent his days in peace and in a luxury which, however, was an intelligent and art-loving luxury, in no way symptomatic of decadence in itself. Yet in the golden days of Amenhetep the Magnificent Egypt was beginning to decay. Unchallenged power, unexampled wealth and unbridled luxury worked for decay in an Eastern state whose great men heard no insistent summons to go forth to war. The courtiers of Amenhetep III were lovers of art and of beauty, probably they were men of intelligence and taste in matters literary as well as artistic, but they were not warriors. And an ancient state lacked that activity in scientific discovery and in

${ }^{1}$ At this time stone mastaba-tombs (see p. 123, ante) were no longer built: the tombs were excavated in the rock-cliffs, with brick chapels before them.

${ }^{2}$ See p. 273, antc. 
mechanical invention which in modern states compensates largely for the comparative absence of the mental stimulus of war. The men who surrounded Hatshepsut, Thothmes III, and Amenhetep II had experienced this stimulus; their fathers and grandfathers had fought with Aahmes in the life-and-death struggle against the Hyksos: they themselves or their fathers had marched with Thothmes $I$ in the enthusiasm of the first revenge upon Asia: they themselves were actors in the epopie of Thothmes the Great. We know them all, the aged Aahmes Pen-Nekhebet, Senmut and Hapuseneb the faithful to Hatshepsut, Thutii the taker of Joppa, Amenemheb the elephantslayer, Rekhmara the great vizier, and Menkheperrasenb his son; and they were men of sterner stuff than their artistic and peaceful descendants who ministered to the luxury of Amenhetep III or obsequiously acclaimed the mad genius of his son Akhenaten. Of them all only one stands out beyond the others, and he was an old man; the wise minister Amenhetep son of Hapu, who was venerated in later ages as a godlike sage, and whose venerable face still steadfastly regards us in its sculptured presentment, now in the Museum of Cairo. We may hope that the son of Hapu, who was probably born in the reign of Thothmes III, did not live to see the wreck of the empire which his father had perhaps helped to build. When he died, the last of the great men of the XVIIIth Dynasty passed away.

\section{The Domination of Quecn Tii and the Heresy of Akhenatcn}

Queen Tii-Amenhetep iv-His abnormal character-The doctrine of the AtenProclamation of the doctrine (c. I 374 B.c.) - Tenets of the Atenist monotheism-Higher character of the creed-Imperial temples erected to the Aten-The king retires from Thebes to Akhetaten (Tell el-Amarna)-Proscription of Amen and confiscation of his goods-Erasure of the name of Amen-Probable revolt of Thebes-The North is quiet-The court at Akhetaten-The tomb-reliefs-Bizarre character of art-Sculpture under Amenhetep III-Naturalism-The relief at Berlin-The hymns to the Aten

His place was taken by the masterful Queen Tii, and an era of feminine influence ensued, directed from behind the curtains of the harem ; a "regiment of women" very different from and far more harmful than the man-like rule of Hatshepsut from Pharaoh's own throne, "monstrous" though that inay have been. 
The son of Amenhetep III and Tii was no Egyptian warrior like his ancestors. Of mixed race, with, probably, the alien blood of Aryan Mitanni inherited from his father and of the wild desert tribes of the Beja or Ababdeh derived from his mother running in his veins as well as the ichor of the descendants of $\mathrm{Ra}$, the son of a luxurious and art-loving father and of a clever and energetic mother, he was brought up under strong feminine influence. All the requisites for the creation of a striking and abnormal character were present. Amenhetep IV was a man of entirely original brain, untrammelled on account of his position by those salutary checks which the necessity of mixing with and agreeing with other men of lesser mental calibre imposes on those not born in the purple. His genius had full play. And the result was disaster. So insensate, so disastrous, was his obliviousness to everything else but his own "fads" in religion and art that we can well wonder if Amenhetep IV was not really half insane. Certainly his genius was closely akin to madness. Dithyrambs have been penned, especially of late years, ${ }^{1}$ in praise of this philosophic and artistic reformer, "the first individual in ancient history." We might point out that others have an equal right to this characterization, for instance Khammurabi, Hatshepsut, or Thothmes III, or even the shadowy Urukagina. Certainly Akhenaten was the first doctrinaire in history, and, what is much the same thing, the first prig.

His religious heresy, the central fact of his reign, was not altogether his own idea. The veneration of the Aten, the disk of the sun, had been growing in court favour during his father's last years. ${ }^{2}$ Both Amenhetep III and Tii venerated the Aten as well as Amen-Ra and the other gods. Amenhetep III, as the son probably of a Mitannian mother, was half an Iranian, and may well have felt drawn towards a cult which resembled not remotely Iranian religion. But at the same time he gives us (also an Iranian trait) the impression of a tolerant and easygoing prince, and even if he believed privately that the Aten was the one real god, he would be the last to make enemies of the priests and plunge his country into civil war by publicly announcing his belief. His son was of a different spirit. The feminine cast of his character shewed itself at once in a reckless

\footnotetext{
${ }^{1}$ Cf. Breasten, Hist. Eg. pp. 367 ff. ; and Weigall, Aklmaton, Pharaoh of Esypt (London, I9I0).

2 See Legrain, in Bessarione, 1906, 3, vol. i. 91, 92.
} 
doctrinaire proclamation of a belief which could only be anathema to his less clever subjects, of an adhesion to a "principle" which admitted of no compromise even if it brought his kingdom about his ears and plunged the world in war, which it did. His reign lasted in all not more than eighteen years. ${ }^{1}$ If the body found in the "tomb of Tii" at Thebes be really his, he was not more than twenty-six or twenty-seven years old at the time of his death. So that he was a boy of eight or nine at his accession, four years before his father's death. Much of the extravagance that followed would probably have been avoided had his father lived longer, and been able to keep him in check. The influence of Tii, which must have been paramount during the first years of his reign, when she apparently acted as regent, ${ }^{2}$ can hardly have been wisely exercised.

At first the young Amenhetep IV was represented on the monuments in the conventional style of his forefathers. His real peculiarities of body (which was as strangely constituted as his brain) were ignored. Amen and the other gods are still officially worshipped by him five years after his father's death and his accession. In the thirteenth year of his age, probably, he was married to his sister Nefretiti, who evidently sympathized entirely with his ideas. Then came emancipation. In the sixth year of his reign, when he was presumably fifteen years old, and therefore fully a man in Egypt, he openly proclaimed his heresy, and the religious revolution was begun. ${ }^{3}$

The young reformer proclaimed that the whole pantheon of Egypt, including even the mighty "King of the Gods" at Thebes, was a fiction, and that only one deity in reality existed, an unknown heavenly force which manifested itself to men through the medium of the visible disk of the sun, the Aten of Ra. This heretical doctrine (we do not know how far

1 The highest known year is the seventeenth.

a Judging from the way in which Dushratta, the King of Mitanni, writes to her (see pp. 258, 345).

${ }^{3}$ It is difficult for a Northemer, accustomed to regard a boy of fifteen as little more than a child, to believe that this revolution can have been effected by a boy. But at fifteen an Egyptian has often reached the highest point of his mental vigour. Then comes the revenge of Nature for this premature precocity. The necessary lack of experience and knowledge makes it of no practical value, and when, as in the case of Akhenaten, it is excessive and has unbounded opportunity of action, being unrestrained by the compulsion of the stupider elders, dire confusion must follow. 
the king had improved upon the form in which it had been held previously by his father and his teachers) was a monotheism of a very high order. Amenhetep IV (or, as he now preferred to call himself, Akhenaten, "Pleasing to the Sun-Disk" ${ }^{1}$ ) did not, as has usually been supposed, worship merely the sun-disk itself as the giver of life. He venerated the glowing disk merely as the visible emanation of the Deity behind it, who dispersed heat and life to all living things through its medium. The disk was, so to speak, the window in heaven through which the unknown God, the "Lord of the Disk," shed a portion of his radiance upon the world. Given an ignorance of the true astronomical nature of the sun, this was an absolutely rational religion, differing toto mundo from the irrational congeries of irreconcilable superstitions which composed the national faith of Egypt. In effect, the sun is the source of all life upon this earth, and so Akhenaten caused its rays to be depicted each with a hand holding out the sign of life to the earth. But Akhenaten or his teachers went farther than a monotheistic worship of the sun itself. He saw behind the sun a Deity unnamed and unnameable, "the Lord of the Disk." We see in his heresy, therefore, the highest development of religious ideas before the days of the Hebrew prophets.

This, by decree of her ruler, was now to be the official religion of Egypt. Temples were erected to the Aten, to exemplify his character as the new supreme and only deity of the empire, not only in the capital, but also at Sesebi (and possibly Napata) in $\mathrm{Nubia}^{2}$ and at a place, possibly Jerusalem or Bethshemesh, in Palestine. These buildings bore the name of Gem-Aten, "Found-is-the-Disk " ; ${ }^{3}$ the Palestinian town was shortly afterwards known as "Khinatuni," ${ }^{4}$ the same name as that of Akhenaten's later capital at Tell el-Amarna.

It may well be that the Heliopolitan heresy ${ }^{5}$ had been encouraged by Amenletep III as a protest against the growing

'SeTrie, $\ddot{A} . Z$. xliv. p. I 6 .

2 See p. 274 .

3 Breasted, Ä.Z. xl. pp. $106 \mathrm{ff}$.

+ Khinatuni is mentioned in the Tell el-Amarna letters (WInCkler I96). The name seems to shew that this letter is of the reign of Akhenaten.

${ }^{5}$ We may imagine the Aten-heresy originating among some group of the priests of Heliopolis resembling a modern tekiya of Bektashite dervishes, which bears the same relation to orthodox Islam as such a heretical Egyptian college would to the urthodux polytheism. 
imperiousness and domination of the priests of Amen, who, enormously enriched by the donations of the earlier kings of the dynasty, and gorged with the lands, cattle, gold, and precious stones of Egypt, Asia, and Nubia, now bade fair to control the whole state. Akhenaten had the courage of his opinions, and by the founding of the Theban Gem-Aten declared open war upon Amen and his priests in their own city.

The result was curious. The difficulty of governing Thebes must have been enormous, and it may well be that the king was not safe from assassination there. He therefore combined discretion with valour by ostentatiously shaking the dust of Thebes from off his shoes, and proceeding to a new capital which should be free of Amen and his devotees. He would worship his god in his own way, and his court, as was fitting, should worship him too, in his way, in a spot uncontaminated by the previous presence of the absurd superstitions of his unenlightened ancestors. In a desert place, where the unregenerate did not exist, he would found a city called "Akhetaten," "Glory of the Disk," where he could teach his "doctrine" to willing hearers only; and hence the light of the Aten could be dispersed to those without who would listen. The city was founded in a spot north of Siût, where no town had previously been: the spot is the modern Tell el-Amarna. Here, where the desert-cliffs opened out on both sides of the river, the king made his Utopia, or rather Laputa, where he could philosophize, teach, and dally with the arts surrounded by his philosophers and artists, while the rest of his kingdom was left to itself, as far as he personally was concerned. For he marked its boundaries by great stelae carved on the rocks, on which he solemnly recorded his vow never to stir beyond the limits of his Laputa.

We can imagine the effect of these proceedings upon his people: the fury of the priests of Amen; the bitterness of the soldiers and statesmen who saw the work of a dynasty abandoned and thrown aside at the caprice of a boy; the amazement of the Asiatics at the news that the young Napkhurria had gone suddenly mad and had vowed never to stir out of his city for the defence of his empire; the resentment of the mass of the Egyptians, soon to crystallize into active hatred of the "criminal of Akhetaten." Yet no overt resistance was possible. The whole machinery of the state was in the king's hands, and 
his behests were obeyed by the royal officers, probably many of them convinced adherents of the "doctrine." The king's religion was for the moment the religion of the empire, and Amen was deposed from his imperial throne to make way for the Aten. The whole of the property of Amen was simply transferred to the new god, and the Theban priests were driven out or proscribed. The name of the king of the gods, whom Akhenaten abominated more than all the rest, since he was the arch-enemy of Aten, was ordered to be erased from all the monuments throughout the kingdom. This was done, not even the name of his own father, which contained that of the hated deity, being spared. The names of the other gods soon followed, and even the word "gods" was proscribed as denying the monotheism of the imperial faith.

Yet a king cannot abolish a national religion by decree, although he may obliterate the names of its gods from their temples, and this fact must soon have been learnt by Akhenaten. We do not know the details of the story, but for the last few years of his reign Thebes must have been in more or less open revolt, no doubt under the leadership of Amen's high-priest, whom the king did not recognize as existing. Administrative anarchy must have resulted throughout the South. It was perhaps this revolt of Thebes that in the twelfth year of the reign drove the queen-mother Tii to take up her residence in her son's city, where, probably not long afterwards, she died. In the North, however, less purely Egyptian in feeling, and in no way really bound to the worship of the Theban god, hardly seeing in the Aten-worship much more than a peculiar form of the worship of the Heliopolitan $\mathrm{Ra}$, no revolt probably took place at all. Although the king would not go forth to save Syria for Egypt, his communications with the Asiatic provinces were never severed, as we see from the unbroken series of letters from the Canaanite chiefs and governors preserved in the archives of Tell el-Amarna. The preservation of the royal authority in the North was also in all probability largely due to the energy of its military governor, Horemheb, whom we shall meet with later as king. He was not a monotheistic Atenworshipper, but served the king well nevertheless.

Foiled by the dispossessed priests of Amen in his attempt to abolish them and their god utterly, the king finally abandoned his empire to go its own way, while he lived his 
own life with his family and court in the city which he had created. Many of his courtiers no doubt really believed in the new religion, but others, as we see from the readiness with which they abandoned it after his death, never really believed in it, but only conformed to it because it was the king's religion. They were required to worship the Aten with the king, and to accept from him tombs in the cliffs behind Tell elAmarna, where they, like their king, should be buried when they died. We know the names of many of these courtiers from the inscriptions on their tombs. Chief among them were Rames, the vizier; Merira, the high-priest of the new god, the most favoured of all; Hui, the chief of the harem; Mahu, the chief of police; Tutu, who is mentioned in the Tell el-Amarna letters; and $\mathrm{Ai}$, who eventually for a short time occupied the throne of Egypt. The king's architect and chief sculptor, Bek, "whom the king himself taught," is also mentioned in the tombs. To him was entrusted the execution of the beautiful reliefs which are the chief feature of these tombs, ${ }^{1}$ and he carried them out in accordance with the new ideas of freedom and naturalism in art which accompanied the new religion.

It will be noticed that Akhenaten's religion did not demand that the Egyptians should give up their ancient burial-customs. It is somewhat uncertain whether the name of Osiris was or was not actually proscribed as were those of the other gods. ${ }^{2}$ Probably the belief in Osiris was restrained to the simple idea that every dead man became an Osiris, while the Aten received the funerary prayer. If it had been deemed necessary to give up the old ideas as to the constitution of the soul, mummification would no longer have been considered necessary. Possibly Akhenaten never clearly formulated his ideas on this subject. As of old, the life of the dead man on earth was represented on the walls of the Tell el-Amarna tombs, and as the life of a

1 The complete publication of these tombs has been carried out by the Egypt Exploration Fund (Archæological Survey) by Mr. N. de G. Davies (El Amarna, vols. i.-vi.).

2 On a single funerary stela, found at Memphis, the funerary prayer is directed not to Osiris or Amen, but to the Aten. It must be remembered that at this period the god Osiris had at any rate at Thebes become largely overshadowed by Amen, who had begun to usurp his functions in virtue of his position as king of the gods. On Theban funerary stelae of this time the funerary prayer is usually addressed to Amen-Ra in the first place, so that the Aten would naturally occupy his position when he was deposed. 
courtier at Akhetaten centred in the king and his consort, we find them the central figures of these pictures, represented as they really appeared, with their children, driving in public, or (a favourite scene) appearing on the balcony of the palace, from which they lean to throw necklaces of honour over the heads of favoured officers, while the court bows down before them. The bizarre naturalism of these representations, grafted on to the traditional methods of Egyptian art, reminds us strongly of the same trait in the contemporary Mycenaean art of Greece, by which Bek and his fellow-craftsmen may have been influenced to a considerable extent. ${ }^{1}$

During the reign of Amenhetep III the art of sculpture in relief had developed considerably. In tombs, when the rock was suitable, the place of wall-paintings was taken by reliefs. The outline of many of these was executed en creux in a new and characteristic style, very different from the delicate low relief of Dêr el-Bahri or the work of Thothmes III at Karnak. Under Amenhetep III we find the delicate low relief used for tombs, as in the sepulchre of Khaemhat at Thebes. At Memphis we find a fine example of the new style of cavo rilievo, in the tomb of a high-priest of Ptah, in which we see the funeral procession admirably represented: the abandon of the two weeping sons who immediately follow the bier contrasts well with the sympathetic dignity and solemnity of the great officials representing the king, who come next. ${ }^{2}$ In this relief we have the first sign of the naturalism and fidelity to truth that is characteristic of the work of Akhenaten's sculptors, as we see it in the tombs of Tell el-Amarna. The king always speaks in his inscriptions of his adherence to "truth" with an emphasis worthy of Darius the Persian." He wished everything and everybody, including himself, to be represented as they really were. And Bek and Tuti, the sculptors whom he taught, took him at his word. In the relief of Tell el-Amarna, executed in the new style en creux, we see the king represented in what must be almost a caricature of his facial and bodily peculiarities. Probably he liked these peculiarities to be so

'Mycenaean influence may also be seen in the spiral decorations on the pillars of the palace at Tell el-Amarna, now in the Ashmolean Museum. The spiral was never used in Egyptian architecture till Akhenaten's time.

2 Illustrated by Breasted, Hist. Eg. p. $35^{8}$.

${ }^{3}$ Is this an Iranian trait, inherited from his father? He calls himself slnkh $m$ Mat, "living in Truth," in his titulary. 

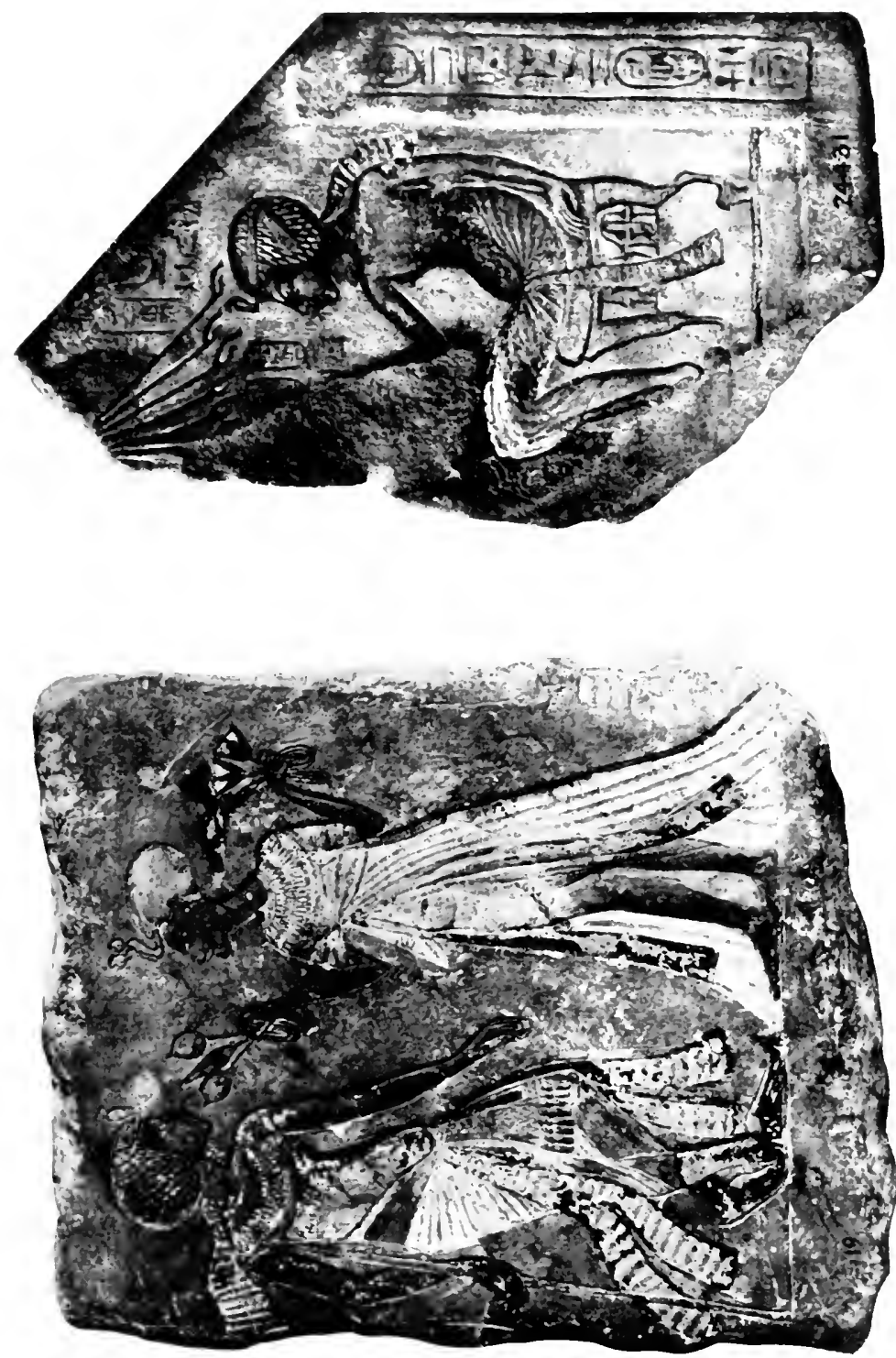

exaggerated; his already long nose and chin to be made longer, his belly to be represented as pendulous, his legs as bowed. The contrast to the ancient idealized representations of the kings would thus be accentuated. On Plate XIX. we illustrate a small relief in the British Museum, shewing the usual representation of him. That in reality he was not (at any rate at first) so ugly as he is represented to have been by Bek seems to be shewn by another representation of him, a remarkable little relief picture in the Berlin Museum, which is the finest known specimen of the art of Tell el-Amarna; we illustrate it side by side with the British Museum relief. Here we see the king, represented as a by no means ungracefully shaped young man, with a not unpleasing face, which is evidently a faithful portrait, ${ }^{1}$ standing with his legs crossed and leaning negligently upon a staff, while Nefertiti his wife, with her garments blown about by the wind, offers her lord a bunch of flowers to smell. The streamers of the king's wig and of his dress, like the queen's robe, fly in the wind. From the mere description it will be seen how very different is this sculptured picture from the ordinarily accepted ideas of Egyptian conventions in art. In it we see what the Egyptian artist shewed promise of doing, once these conventions were abandoned. There is some crudity in the figure of the queen, and the whole picture is bizarre: but the king's figure could hardly have been bettered by a Greek : the pose, and especially the treatment of the legs and sandalled feet, is quite Greek, and reminds one of a Hermes. Bek dealt as faithfully with the queen as with her spouse. Both seem to have resembled their mother Tii, who was of much the same Bishari or Abâdeh type.

The six daughters with whom they were blessed (for Akhenaten had no son to carry on his doctrine) are all represented with the same type of countenance, which is natural, but it is by no means natural that many of the courtiers should, as they do, shew in the reliefs a decided approximation to

1 The realism of this representation forbids us to suppose that the portrait is flattered. We can only suppose that in Bek's reliefs his peculiarities are intentionally exaggerated, though, of course, he may have degenerated in body rapidly aftcr this picture was made. Lunatics do degenerate rapidly in this way, and it is by no means improbable that Akhenaten died mad. The body found in the tomb of "Tii" undoubtedly shews signs of cretinism, and it may quite possibly be his. The rachitism with which he is credited by some, to account for his extraorainary figure in Bek's reliefs, may have gone with this, and have developed rapidly. 


\section{THE ANCIENT HISTORY OF THE NEAR EAST}

the same degenerate type. Probably fashion decreed that convinced adherents of the doctrine should be made to ape the countenance and figure, as well as the religion, of their royal teachers, whom the true courtier would vow to be the mirrors of all beauty as well as truth. ${ }^{1}$

It is on the walls of these tombs, too (for they were spared as inviolable houses of the dead when the temples of the Aten were destroyed), that we read the beautiful hymns to the sundisk that were composed by the poet-king himself. Their phraseology is strangely reminiscent of that of Psalm civ." "When thou," he sings in honour of the Aten, "settest in the horizon of heaven, the world is in darkness like the dead. . . . Every lion cometh forth from his den; all serpents, they sting; Darkness reigns, the world is in silence. He that made them has gone to rest in his horizon.

"Bright is the Earth when thou risest in the horizon.

When thou shinest as Aten by day, the darkness is banished.

When thou sendest forth thy rays, the Two Lands rejoice daily,

Awake and standing upon their feet, for thou hast raised them up.

Their limbs bathed, they take their clothing;

Their arms uplifted in adoration to thy dawning;

Then in all the world, they do their work.

The ships sail upstream and downstream,

Every road is open because thou hast dawned.

The fish in the river leap up before thee,

And thy rays are in the midst of the great sea.

Thou art he who createst the man-child in woman,

Who makest seed in man,

Who giveth life to the son in the body of his mother,

Who soothest him that he may not weep,

A nurse even in the womb,

Who giveth breath to animate every one that he maketh.

When he cometh forth from the body,

On the day of his birth,

Thou openest his mouth in speech,

Thou suppliest his needs.

When the fledgeling crieth in the egg,

Thou givest him breath therein, to preserve him alive.

${ }^{1}$ Quite possibly the king developed an insane admiration for his own degenerating body, and Bek and the courtiers had to pander to this perverted idea of beauty. This perversion contrasts strangely with the lofty character of the king's religious and philosophical ideas, and still more with the beauty of his poetry. Yet such contrasts are by no means unfamiliar to alienists.

${ }^{2}$ This resemblance was first pointed out by Prof. Breasted (Hist. ES., p. 371 ). 
Whe'n thou hast perfected him

That he may pierce the egg-shell,

He cometh forth from the egs,

To chirp with all his might;

He runneth about upon his two feet,

When he hath come forth therefrom.

How manifold are all thy works !

They are hidden from us.

O thou only god, whose powers no other possesseth;

Thou didst create the earth according to thy desire.

Thou art in my heart: there is none other that knoweth thee

Save thy son Akhenaten.

Thou hast made him wise in thy designs and in thy might.

The king, living in Iruth, the lord of the Two Lands Neferkheperura Uanra, The son of $\mathrm{Ra}$, living in truth, the crowned lord,

Akhenaten, living for ever;

And for the Great King's Wife whom he loveth, the mistress of the Two Lands, Neferneferuaten Nefretiti, who liveth for ever."1

Alas for the poet-king! His kingdom had already fallen into anarchy, and the foreign empire which his predecessors had built up had been thrown to the winds in his pursuit of his beautiful ideal. How, we shall see later. ${ }^{2}$ The whole story is an example of the confusion and disorganization which, pace Plato, always ensue when a philosopher rules. Not long after the heretic's early death the old religion was fully restored, the cult of the disk was blotted out, and the Egyptians returned joyfully to the worship of their myriad deities. ${ }^{3}$ Akhenaten's ideals were too high for them. The debris of the foreign empire was, as usual in such cases, put together again, and customary, conventional law and order restored by the stupid, conservative reactionaries who succeeded him. Henceforward Egyptian civilization ran an uninspired and undeveloping course till the days of the Saïtes and the l'tolemies.

1 The above translation is that of Prof. BREASTED in his History of Egypt, pp. $37 \mathrm{If}$., slightly modified here and there in phraseology.

2 See Chap. VIII.

${ }^{3}$ The poet of the Aten was thus answered by a poet of Amen in the time of Horemheb: "Woe to him who attacks thee, $\mathrm{O}$ Amen! Thy city (Thebes) endures, but he who assails thee is overthrown. . . The sun of him who knew thee not has set, but he who knows thee shines. The sanctuary of him who assailed thee is overwhelmed in darkness, but the whole earth is light!" (ERMan, A.Z. xlii. p. 106). And the king was known to later generations as "the Great Criminal of Akhet-aten." 


\section{The Successors of Akhenaten (c. 1 362-1 321 B.C.)}

Smenkhkara (c. 1362-1360)-Tutankhamen (c. 1360-1350 B.c.)-Ai (c. 1350I345 B.c.)-Horemheb or Harmahabi (Harmais) (c. I 345-I32 I B.c.)-Horemheb's vice-royalty of the North-Regent under Tutankhamen and $\mathrm{Ai}$ : restoration of orthodoxy-Made king by the priests of Amen: legitimized by marriage to Mutnetjemet, daughter of Amenhetep III-Conservative restoration and reorganization-Code of laws

Akhenaten died young, and probably insane, after a reign of some eighteen years ( $\operatorname{circa}$ I380-I 362 B.C.). His body was buried in a tomb at Tell el-Amarna, whence, as we have seen, it was by some confusion substituted for that of his mother Tii, also buried at Tell el-Amarna, when Tutankhamen wished to transfer her mummy to Thebes. The confusion was probably due to hasty transport, hurried for fear of some fanatical attack upon the bodies of the heretical rulers.

His successor, Smenkhkara, was an ephemeral appearance. In all probability he did not reign more than two or three years, as the highest date we possess of him is year 2. The twelve years assigned to him by Prof. Petrie on the supposed authority of Manetho can hardly be accepted without further confirmation. He ascended the throne as the son-in-law and creature of Akhenaten : he had married the princess Meritaten, and was evidently a convinced adherent of the doctrine. On the faience finger-rings of his time, bearing the names of the monarchs, he is often called "the beloved of Akhenaten," who had associated him in the kingship not long before his death. Smenkhkara was succeeded by a monarch of whom we have greater knowledge, Nebkheperura Tutankhamen. As this king's name shews, it was in his reign that the episode of the Aten-heresy finally died out, and the monarch and court returned to their allegiance to the great god of Thebes. The new king ascended the throne as an Atenite: he called himself Tutankhaten, "the living image of Aten." His wife was Ankhsenpaaten, "Her life belongeth to the Aten," and she was the third daughter of Akhenaten and Nefretiti. Tutankhaten himself was probably a son of Amenhetep III by an inferior wife: when he restored the lions of Soleb ${ }^{1}$ (now in the British Museum) he called Amenhetep his father. So that he had a claim to the throne resembling that of Thothmes III. Not long after his accession it became evident that the Aten-heresy 
was dead, and so both the king and queen formally returned to the national religion, changing their names to Tutankhamen and Ankhsenamen. A proof of the reality of their conversion was an attempt to complete the magnificent colonnade leading out of the halls of Amenhetep III in the temple of Amen at Luxor. The Theban temple of Aten was now demolished, and its materials were used to build walls to enclose the colonnade, which, originally intended by Amenhetep III to be the nave of a great hypostyle hall, had remained unfinished since the death of its founder. Horemheb completed the enclosure of Tutankhamen, and hence the whole building has usually been known as the "Colonnade of Horemheb."

The poverty-stricken nature of the work undertaken, the abandonment of the grandiose plan of Amenhetep III, shews what Akhenaten's revolution had done for the wealth of Egypt. Alihenaten's abandonment of the Asiatic Empire ${ }^{1}$ had proved a severe blow to the Amen-priesthood and to Thebes. He could have aimed no more effective blow at Amen than this; and we may indeed see some explanation of his otherwise incredible policy in the fact that the priesthood of Amen was identified with the policy of expansion and conquest on which its wealth largely depended.

However this may be, no sooner had Tutankhamen given his submission to Amen than an attempt was made to reconquer some part of Southern Palestine, with what success we do not know. ${ }^{2}$

The reign of Tutankhamen can hardly have lasted a decade; that of $\mathrm{Ai}$, his successor, probably not more than five years. This Ai had been a priestly official, an iot-neter or "god's father," at Akhet-aten, and had married the lady Ti, who was "the great royal nurse, pleasing the good god" Akhenaten. At Tell el-Amarna $\mathrm{Ai}$ and $\mathrm{Ti}$ were given a splendid tomb, in which they naturally were never buried. $\mathrm{Ai}$ was placed upon the throne after the death of Tutankhamen (although he was of no kin to the royal house), and so, when he died, was buried in a royal tomb in the Western Theban valley. ${ }^{3}$

In all probability $\mathrm{Ai}$ owed his position to the powerful

1 See Chap. VIII.

2 See p. 353.

3 The Turbet el-Kurnd, or "Tomb of the Apes," so called from the pictures of the apes of Thoth on its walls. The tomb of Tutankhamen, which is probably in the same valley, bas not yet been found. 
"mayor of the palace," Horemheb, who succeeded him as king. It has been supposed that $\mathrm{Ai}$ made a futile attempt to restore the religion of the Aten; if so, his short reign may have ended in his deposition by Horemheb, who was a fanatical devotee of Amen.

With HoremheB the XVIIIth Dynasty comes to an inglorious end. Prof. Breasted ${ }^{1}$ reckons him rather as the first king of the XIXth Dynasty than the last of the XVIIIth, on the ground that he was in no way really related to the kings of the latter dynasty. But we have no right to depart from the tradition of Manetho, who makes him, as Harmais, ${ }^{2}$ the last monarch of the XVIIIth Dynasty. We have no knowledge that he was related to Rameses I, who is usually consiciered as the first king of the XIXth Dynasty, and there is an absolute break in type of name as well as in many other things between him, and his son Seti, and Horemheb. Also Rameses I definitely marks himself as the founder of a new dynasty by imitating in his throne-name or prenomen, Men-pehti-Ra, the form adopted by Aahmes, the founder of the preceding dynasty, $N e b-p e h t i-R a .^{3}$ So that Manetho's statement is clearly confirmed. Further, Horemheb did ally himself with the preceding dynasty by marrying the princess Mutnetjemet, a sister of Akhenaten and Nefretiti. ${ }^{4}$ If we are to begin the XIXth Dynasty with the first king who was in no way connected with the old royal family, we should begin it with Ai.

Horemheb is a dull and uninteresting figure in Egyptian history. He was a soldier, with some organizing ability, but dévote and rigidly conservative. He was not a Theban, but a native of the town of Alabastronpolis in Middle Egypt. He rose to high office in Northern Egypt, not at Thebes, and seems to have carried on a military administration of the North under Akhenaten, in succession to the viceroy Yankhamu

1 Hist. Eg., p. 395.

2 This form points to some such Ptolemaic vocalization as "Harmahib," but "Haremehbe" is quite as probable in Ptolemaic times. Strictly, and without regard to probable pronunciation, the name should be spelt "Heru-em-heb" or "Hur-em-heb." Prof. Breasted calls him "Harmhab." I have preferred to use the usual form Horemheb, as in the case of "Thothmes." For the contemporary XVIIIth-Dynasty pronunciation we may prefer "Harmahabi."

${ }^{3}$ Cf. p. 225, ante.

${ }^{4}$ Prof. Sethe denies the identity of Queen Mutnetjemet with the sister of Nefretiti, whom he calls Mutbenret $\left(\ddot{A} . Z\right.$. xlii. p. $\left.{ }^{1} 34\right)$. His arguments are, however, not convincing. 
who is mentioned in the Tell el-Amarna letters. ${ }^{1}$ In the necropolis of Sakkara he built a tomb for himself while still simply Commander-in-Chief, in which, while loyally giving thanks to the king for his favours, he resolutely ignores the royal heresy. Probably he was so powerful that it was impossible to interfere with him in religious matters. Under Tutankhamen he seems to have become the real ruler of the country, a sort of Mayor of the Palace, and, as has been said, to him Ai probably owed his elevation to the throne. In the inscription which he afterwards set up at Thebes to commemorate his coronation he states that he was appointed (probably by Tutankhamen) as "Regent of the Land, to administer the laws of the Two Lands as hereditary prince of all this land: he was alone, without a peer. . . . When he was summoned before the king, the court began to fear." This is a somewhat significant statement as to his relations with the court, which was no doubt the sole refuge of Atenism. He represented orthodoxy, and his work was to restore it, with the active aid of the priests of Amen. ${ }^{2}$ So that when the reign of $\mathrm{Ai}$ had come to an end, and, in the words of his inscription, he had "administered the Two Lands during a period of many years," and had earned (in literal phrase) the title of "Father of his Country," the priests of Amen summoned him to the vacant throne: Horus, his god, lord of Alabastronpolis, led him to Thebes into the presence of Amen, "who assigned to him his office of king, therein to pass his life." The legitimizing marriage with Mutnetjemet followed, and the counter-revolution was consummated.

The new king's mandate from Amen and from the whole people was peaceful regeneration. We have proof of his reconstructive work in the code of revised laws which he promulgated on a stele in the temple of Karnak. These laws arc mostly petty regulations of police, shewing that during the carnival of political degeneration under Akhenaten law and order had almost disappeared: the anarchy of Palestine had spread in minor matters to Egypt. ${ }^{3}$ Only in the North,

1 See pp. 316, n. 2 ; $346 \mathrm{ff}$., post.

2 At this period of his regency the royal ureus, symbol of the power of death, was inserted on his head in the reliefs of the Sakkara tomb. As king he was finally buried at Thebes, where his tomb was found by DAvIS and AYRTON in I9OS.

${ }^{3}$ We have seen that the tomb of Thothmes IV had been violated at this time, and was restored by IIoremheb (p. 294). 
where the soldier Horemheb had ruled, probably with extraordinary and, as we should say, "unconstitutional" powers, which he had assumed himself, was there a proper government at all. Then, when, after the death of the "Criminal," the ruler of the North had assumed a virtual regency, and more definitely when he had ascended the throne, was the civil organization of the kingdom restored by "the Father of his Country." The provisions of the new regulations are phrased prosaically enough, as we should expect from their author, and the punishment of evil-doers is for most offences the same simple but no doubt efficacious one of cutting off their noses and exiling them to Tjaru, on the desert-border of Asia. ${ }^{1}$

Horemheb's reign was wholly taken up by this uneventful reorganization. Judging from the date of the 59th year recorded in the Papyrus of Mes, already mentioned, ${ }^{2}$ it would seem to have been of extraordinary length. But it is obviously quite impossible that a man who was commander-in-chief under Akhenaten can have reigned for sixty years after the death of $\mathrm{Ai}$. Therefore it is evident that, at any rate in the later years of his life, Horemheb's hatred of the Disk-worshippers, even when they had recanted their heresy, was so great that he ignored their reigns, and counted his own from the death of Amenhetep III. This is confirmed by the fact that Akhenaten and his three successors are ignored in the official lists of Seti I at Abydos, set up little more than half a century after their reigns, and by the reference in the Papyrus of Mes to Akhenaten as no king, but as "that Wicked One of Akhetaten." At the beginning of his reign Horemheb did not yet ignore his predecessors, but certainly up to his seventh year, and perhaps longer, counted his years as beginning with his real accession. Later on, the complete victory of orthodoxy resulted in the heretical period being considered officially as never having existed. If we count the reigns of Akhenaten's three successors as having amounted to twenty years in all, we see that Horemheb's real reign was one of considerable length, having lasted about twenty-two years. $\mathrm{He}$ is not likely to have reigned beyond his sixtieth nominal year, when, about

1 This is a curious confirmation of Strabo's statement that convicts were sent to Rhinokolura (the modern el-Arish), which was so called because their noses were cut off (Strabo, xvi. ii. \$3i. Cf. IIDT. ii. I37; Dion. i. 60, 65).

${ }^{2}$ P. $2 S 2$. 
I 32 I B.C., he died, a very old man, and was succeeded by the founder of the XIXth Dynasty, Men-pehti-Ra Rameses I.

\section{The XIXth Dynasty}

Rameses I (c. I32I B.c.)-Seti I (c. I320-I300 B.c.)-Temple of AbydosKarnak-Royal worship of Ptah and Set-Set-worship in the Delta, a relic of the Hyksos-Northern sympathies of the new dynasty-Military convenience of royal headquarters in the Delta-Rameses "the Great"-The Ramesseum : "Tomb of Osymandyas"-The Hittite War

Rameses I was, as Manetho says, the founder of an entirely new dynasty, which had no connexion of any kind with the kings who had gone before. The name of Rameses's son Seti, the devotion of many of his descendants to the worship of Ptah, and the predilection of Rameses II for the Delta, where he preferred to reside, point to a Lower Egyptian origin for the family. Thebes continued to be the national capital on account of the predominance of the priests of Amen and the associations of the city with the imperial idea, revived by Seti I and Rameses II. Therefore Manetho calls the new dynasty Theban, though in all probability it was really of Memphite origin. This being so, it is highly probable that Rameses I was not a relation of Horemheb, who came from Alabastronpolis, but one of his old assistants or companionsin-arms, whom he had met while military governor-general of the North at Memphis under Akhenaten. Such a man would naturally have the reversion of the supreme power after the death without issue of his old chief, by whose side he had doubtless served all his life. This probability would make Rameses an elderly, if not an old, man at his accession, and his very short reign of not more than two years confirms this idea. ${ }^{1}$ His successor was his son Seti, who was a middle-aged man when his father died. By his time the tangle left by Akhenaten at home had finally been straightened out, and the new king, a man of vigour and military talent, was ready to essay the task of restoring the foreign empire which the philosopher had lost. To do this, Egypt had resolutely to attack and if possible defeat the formidable kingdom of the Hittites, which had engineered the Canaanite revolt against her, and was now exercising dominion over the greater part

${ }^{1}$ If, as is very probable, he (as Men-peh-Ra) is the Menophres after whom the era which began in $132 \mathrm{I}$ B.C. was named, he may have reigned about I322-I 320 . 
of the territories that had once been hers. With the march of Seti the First into Palestine to do battle with Mursil the Hittite, the history of the Second Egyptian Empire begins.

The story of the long and exhausting campaigns of Seti's son, Rameses II, with the Hittites will be read in the next chapter. Having achieved the defeat of Mursil, and recovered Palestine for Egypt, Seti desisted from war, and found a worthy expression for his energies in furthering and directing the restoration of the prosperity of his kingdom, now slowly recovering from the effects of the Atenist inferno. Templebuilding occupied much of his time and fitly marked the loyalty of the new dynasty to the gods. A new departure was inaugurated in building a great royal funerary temple at Abydos, where the earliest kings had either been buried or had erected cenotaphs. ${ }^{1}$ To express veneration for the most ancient kings, and to proclaim the solidarity of the new dynasty with those that had preceded it, the temple was built, and on its walls we see Seti and his son Rameses offering to the name-cartouches of the imperial ancestors back to the legendary Mena, the supposed founder of the monarchy. This is the "List of Abydos," which is so important a document for the historian of Egypt. The temple itself is of very unusual plan, and from the architectural point of view is not of great beauty. In contrast, however, to the architecture, the sculptured reliefs with which the walls are decorated are of the greatest beauty and delicacy, and mark the zenith of Egyptian art in this type of work. It was, so to speak, the swan-song of the splendid art of the XVIIIth Dynasty that was sung by the artists of Abydos. We know their names, Hui and Amenuahsu. The other work of the reign was not good. The funerary temple begun by Seti in memory of his father at Thebes is poor. At Karnak the world-famous Hypostyle Hall, begun by Rameses I, mainly carried out by Seti, and completed by Rameses II, is heavy, majestic, magnificent, but it is not beautiful.

The Theban buildings emphasize the continued devotion of the new rulers to Amen, but since they were of Northern (and probably specifically of Memphite) origin, the worship of Ptah, the ancient god of Memphis, came under them once more into fashion. At the same time Set, the desert-god, who had been associated with Lower Egypt since the time of the Hyksos, 
who had made him their chicf deity, shared with Ptah the devotion of the royal family, at any rate in the Delta. During the XVIIIth Dynasty his worship was unpopular, and except at Ombos, where he had always received special veneration, he seems in Upper Egypt to have been proscribed henceforth for all time. In the Delta, however, this was not the case. There is good reason to suppose that the expulsion of the Hyksos was not as complete as the official accounts of the Thebans would have had us believe. Many of the foreigners doubtless remained behind in the land of Goshen, where the ancient fortress capital of Salatis ${ }^{1}$ still stood, and we cannot doubt that in the course of the four centuries which had elapsed since their invasion they had considerably modified the religion as well as the blood of the Delta Egyptians. So we find Set in his Asiatic Sutekh-like aspect, akin on the one side to Resheph of the Canaanites and on the other to Teshub of the Hittites (with whom he was directly identified), as the chief god of the Northern Egyptians ${ }^{2}$ and giving his name to the first king of the new Northern dynasty. ${ }^{3}$ The Set-ivorship was abandoned by the kings of the next dynasty, who were Theban in sentiment, which Seti I and Rameses II certainly were not. ${ }^{*}$

The new Northern kings made their chief home in the

\section{${ }^{1}$ See p. 215, ante.}

2 It is not impossible that the Set-cult of the Northerners was more or less tolerated, as it would be regarded as a sort of protest against the cult of the Aten, who in the North would certainly be identified to a great extent with Ra-Harmachis of Heliopolis, a figure compounded of $\mathrm{Ra}$ and Horus. Horus having become at least tainted with heresy, Set-worship would naturally come into some vogue, probably at Memphis, the old rival of Heliopolis, side by side with the worship of I'tah.

${ }^{3}$ The names of the royal family shew that Set and Ptaln were its tutelary deities, besides Ra. An explanation of Seti's devotion to Osiris may be found in a politic desire to cover this Set-worship from too much criticism by ostentatious veneration for Set's great rival, the father of llorus. For the same reason, on many temples his name appears as "Osirei," not as Seti, the symbol of Osiris being substituted for that of Set.

${ }^{4}$ Whether their Set-worship points to actual descent from Hyksos forefathers or not is uncertain. Both Seti and Rameses repaired the Iyksos fortress of Avaris, and there is no doubt that at Tanis, in the midst of a population partly descended from the conquerors, Rameses II directly honoured the memory of the Hyksos. On the famous "Tablet of Four Hundred Ycars," dated according to the era of the Iyksos ling Nubti (see p. 219, ante), he places a ligure of Set in Sutekh-form and gives the name of a Hyksos monarch in a royal cartouche as rightful pharaoh, which no king of the XVIIIth Dynasty can possibly be conceived as doing. Here we have at least an official alteration of view with regard to the Hyksos, no doubt due to the Northern origin of the new dynasty. 
North-Seti at Memphis, Rameses at Tanis. Thebes was probably in a dismantled condition after the ravages of Akhenaten's reign, and did not fully recover its old prosperity for some time. Both Seti and Rameses built largely at Thebes, it is true, and were buried there like their predecessors, ${ }^{1}$ but for most of the time they ruled they never went there except to dedicate spoil to Amen, the official head of the imperial pantheon, in his own city.

For military reasons, also, royal residence in the Delta was preferable. If the Asiatic empire was to be retained even in its diminished extent, and the threatening power of the Hittites warded off from Egypt, it was best that the king should reside near the frontier. ${ }^{2}$ From this time dates a new dualism in the Egyptian state, in which Tanite (Bubastite) and Theban elements are to struggle for the mastery just as in the old days Memphis had struggled with Thebes.

The reign of Seti I probably lasted about twenty years (circa 1320-1300 B.C.). This date is rendered necessary if the astronomical date for the birth of Rameses II given by his horoscope (13I\& B.C.) ${ }^{3}$ is correctly calculated, as Rameses can hardly have been more than eighteen years old when he ascended the throne. And it agrees with that of $1321-1318$ for Rameses II (Menophres). ${ }^{4}$

RAMESES II, who ascended the throne under the title of User-ma-Ra Setep-n-Ra Rameses Meri-Amen, ${ }^{5}$ was neither the eldest son nor, probably, the destined successor of Seti. The name of the original crown-prince we do not know, as it

1 Seti's tomb was designed to be more magnificent than any sepulchre of his predecessors, and the design was well carried out. It remains the most splendid of the Tombs of the Kings, and the alabaster sarcophagus (now in Sir John Soane's Museum) which held his body was and is one of the finest achievements of Egyptian funerary art.

2 Under the XVIIIth Dynasty we see the difficulty of watching Asiatic affairs from Thebes growing till the viceroy of the Delta, the "Yankhamu of Yarimuta" of the Tell el-Amarna tablets, is charged with their supervision, and, subject to the control of the king, governs the Asiatic dominion. Horemheb and Rameses succeeded to the power of Yankhamu in the Delta, and Rameses naturally succeeds Horemheb upon the throne, thus transferring the centre of royal power from Thebes to the Delta.

${ }^{3}$ Petrie, Hist. Eg. iii. p. $4 \mathrm{I}$.

See p. I9.

"Probably vocalized "Wasi(r)-ma-Rîe Satep-ni-Rie Rîamases Ma(r)i-Amana," to judge from the cuneiform version "Uashmuariya Satepuariya Riyamasesa maiAmana" of the Boghaz Kyöi tablets (see p. 338 , post). The medial $r$ was silent. 


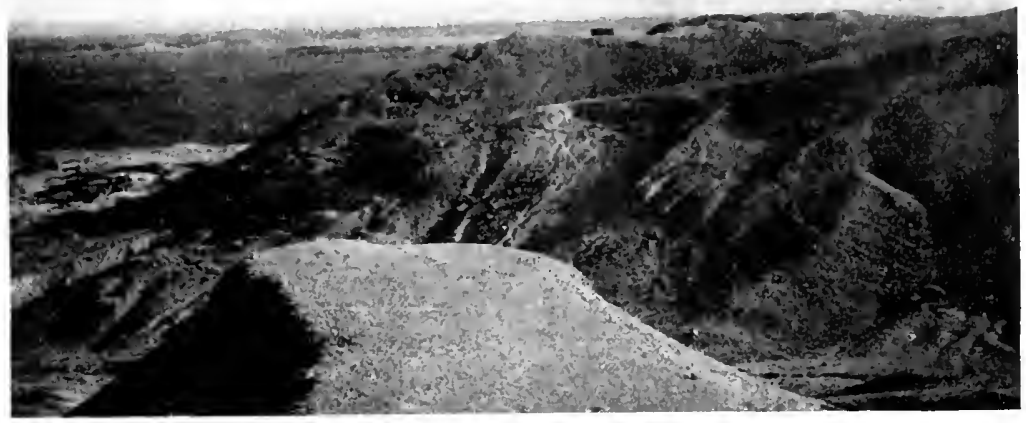

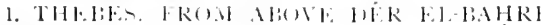

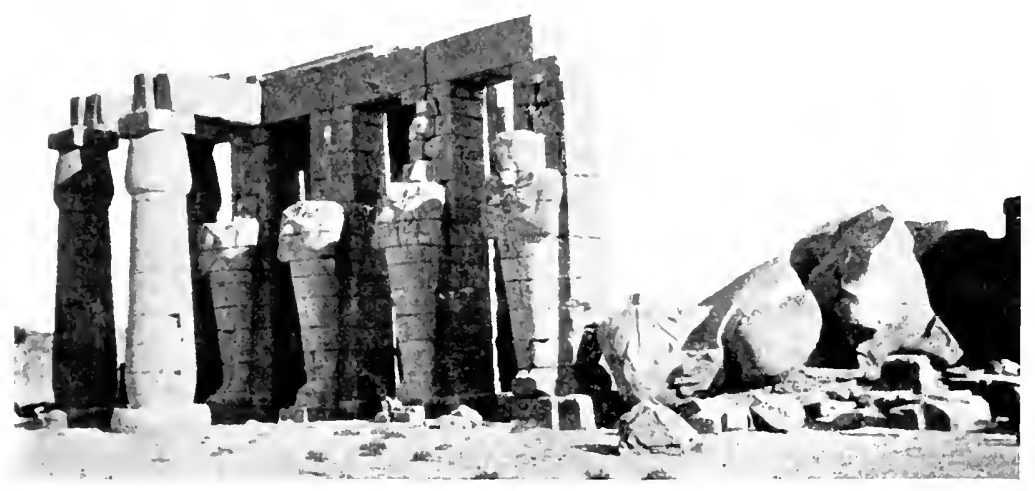

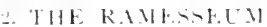

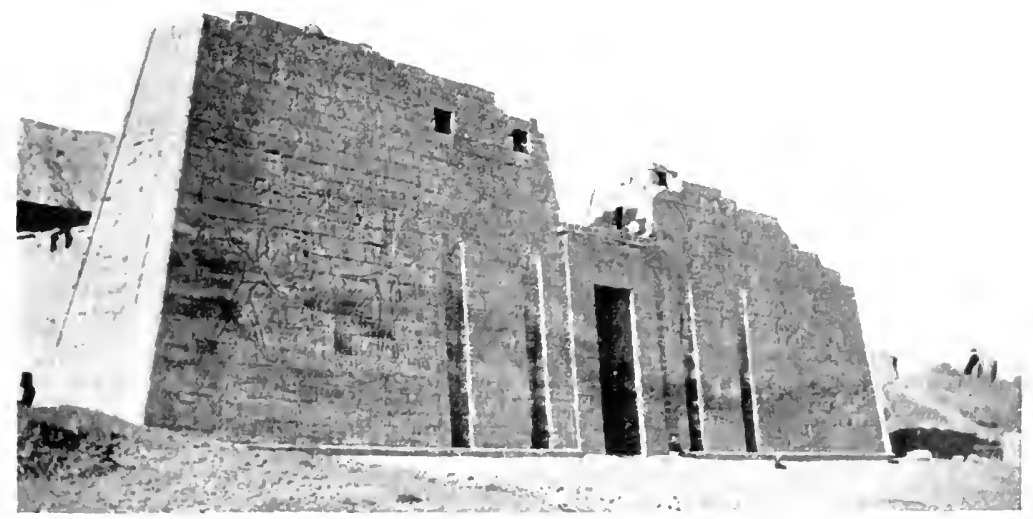



and his figure seem to have been destroyed carefully or replaced by the jealous Rameses whenever they occurred on the monuments. ${ }^{1}$ The actual successor, who thus supplanted his elder brother or half-brother, was destined to enjoy one of the longest reigns in Egyptian history, and partly on that account to hand down to posterity so exaggerated an idea of the importance of that reign that he has until lately been commonly dubbed by the moderns "Rameses the Great," thus usurping an honorific which may fitly be conceded to Thothmes III, but is in no way deserved by Rameses II.

The name of Rameses II bulks largely in Egypt. It is impossible to get away from it for long. Hardly a temple but has been "restored" or otherwise spoilt by him, hardly a statue of a preceding king that has not been partially or wholly usurped by him. Whenever an opportunity offered itself the name of Usermara Setepenra was set up. His most important building was a gigantic usurpation, being erected, apparently, with the stones of the splendid funerary temple of Amenhetep III. This was his own funerary temple, the Ramesseum, which still in Roman days was described by Diodorus Siculus ${ }^{2}$ as "the Tomb of Osymandyas" (User-ma-Ra, or "Uashmuariya," as the Semites called him). Strabo ${ }^{3}$ named it the "Memnonium," on account of its nearness to the great statues of Amenhetep III, who had long been identified with the Homeric Memnon, owing to a fancied resemblance between his name Men-ma-Ra and that of the Ethiopian hero. Diodorus specially mentions the Osiride figures of one of the courts $^{4}$ (though he errs in stating that they were monolithic), the black granite statues, and one, which can hardly be other than the huge red granite colossus which now lies broken upon the ground, "the greatest of all in Egypt," though we know it never bore the inscription which he assigns to it: "Osymandyas the king of kings am I: if any one wisheth to know what kind of man I am and where I lie, let him beat one of my works!" 5 Such an inscription, typical of those put into the mouths of Egyptian kings by the informants of the Greek writers, is

${ }^{1}$ BREASTED, Hist. Eg., pp. $418 \mathrm{ff}$.

2 i. 47.

3 xvii. $1,46$.

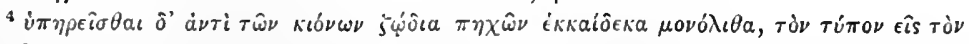

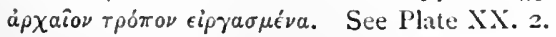

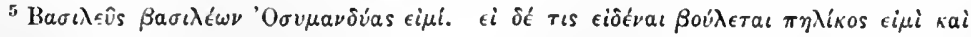

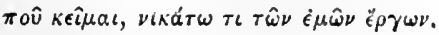


perhaps possible under Senusert III, but never appcared on any Egyptian monument of the Ramesside period.

The pylon-walls of the Ramesseum served as a canvas on which the king's artists could depict, on a scale and with a detail never previously attempted, the heroic events of his war with the Hittites, the battle of Kadesh, and the siege of Dapur. A little rock-temple at Beit el-Wali is adorned with reliefs depicting a Nubian war, which seems to have taken place in the second year of the king's reign. In his first year he seems to have conducted a similar razzia against the Libyans of the Oases. The great war with the Hittites began in the fifth year (about I 295 B.C.), and lasted, on and off, till the conclusion of peace, more than fifteen years later (about I 279 B.C.).

This struggle, which left both combatants terribly weakened, was the turning-point of Egyptian history, which henceforth is a story of decline, which energetic monarchs like Rameses III and Shishak could do nothing to arrest. Rameses "the Great" had drained the strength of Egypt, and we see in the decadence of art and of general morale during the last century of the imperial period which followed his reign how exhausted the nation was, only three hundred years after the time of the heroes who expelled the Hyksos and founded the empire.

With the events of this period after his death (about I 234 B.C.) and the accession of his son Meneptah, the first of the weak and incapable monarchs of the decadence, we shall deal in the next chapter. But the main characteristics of the time may fitly be dealt with here.

\section{IO. Egypt under the Second Empire}

Comparison with XVIIIth-Dynasty Egypt-Modernization of official languageArt after Akhenaten-The Turin statue of Rameses II-Decline in taste and workmanship-Poverty-Increase of foreign influence and immigration-Foreign quarters in the cities-Mercenaries-Foreign elements in language and religionThe police of Thebes-Priests sit in the tribunal-Dominance of the priests of Amen -The priest-kings-The Bubastites: Amen loses prestige, and finally loses his predominant position in the pantlieon-Power of the scribe, contempt for the soldier -Ramesside literature-The Book of the Dead-Letters, etc,-The Fellahin

Ramesside Egypt presents characteristic contrasts to the Egypt of the First Empire. The Atenist convulsion had torn the national nind to fragments, and when the fragments reunited they did not join precisely as they had been before. 
Egypt was as a man whose brain has temporarily given way: he regains his right mind, but he is not his old self. So Egypt was never again her old self. Externally XIXth-Dynasty Egypt may seem to resemble XVIIIth Dynasty Egypt closely enough, but if wc look beneath the surface we see that in many respects the Egypt of Hatshepsut or Thothmes III was more like that of the Senuserts and Amenemhats than like that of the Ramessides. The XIIth Dynasty would have understood the XVIIIth: the XIXth, still more the XXth, would have seemed strange to it and, pre-eminently, foreign. The XVIIthXVIIIth Dynasty was directly continuous with the XIIIth and preserved many of the traditions of the Middle Kingdom: to the people of Upper Egypt the Hyksos invasion had not been so catastrophic as the Atenist revolution proved to be. Although the language was changing with the lapse of time, the chancerics of the XVIIIth Dynasty retained the official phraseology of the XIIth. The cult of reality which was introduced by Akhenaten had one permanent result in the modernization of the written language. Official inscriptions now contained colloquial, almost slangy, expressions, which would have horrified the purists of the preceding dynasty. The ordinary colloquial mode of speech was reproduced in the monumental inscriptions. Laxity in phraseology was accompanied by laxity in inscription: under the XIXth Dynasty the sign-cutters first began to do poor and careless work on a large scale. The hieroglyphs, too, alter in appearance, becoming jejune and elongated: there is little possibility of mistaking an inscription of the XIXth Dynasty for one of the XVIIIth. In art, the naturalism of Akhenaten's time had its effect, and produced, among other results, the extraordinary battle-scenes with which the Rameses loved to cover whole temple-pylons, as at the Ramesseum. Rameses III's picture-record of the Defeat of the Northerners on the outer walls of Medinet Habu is in no way inferior in this regard to the Kadesh-reliefs of Rameses II. In these reliefs is well seen the style of sculpture in sunk relief (cavo rilievo) which now first makes its appearance on the grand scale, and is characteristic of the art of the Later Empire. A magnificent piece of naturalism in portraiture is the famous Turin statue of Rameses II, in which the monarch, then young, is represented in a loose dress of semi-state, such as no king had ever been depicted wearing since the archaic period. This, 
however, and the reliefs at Abydos, are too good to be regarded as typical Ramesside works of art. The degenerate results of the Atenist naturalism were usually allied to carelessness and bad work, which became usual in the lethargic later years of Rameses II, and may be considered characteristically Ramesside.

In other arts besides architecture and sculpture this long reign marked a decline. One sees a progressive degeneration of taste in the decoration of the tombs and in the workmanship of the small objects of art, the scarabs and jewellery. The reign of Rameses IIr scems to shew a momentary revival of art in the fine polychrome reliefs of faience which decorated the royal palace at Tell el-Yahudiya, and the design of the entrance-gate of Medinet Habu is certainly remarkable. But the inner courts of that temple shew heavy work, sausage-like columns and enormous hieroglyphs, deeply cut and hideous, which exhibit a terrible lack of taste. All the old style and cignity have gone. ${ }^{1}$

Medinet Habu (Plate XX. 3) is by far the best work of the XXth Dynasty. Of the later kings we have practically no monuments of art but their tombs and those of their courtiers, and these are often decorated with a meretricious and vulgar taste that offends the eye. Growing poverty of idea accompanying poverty of purse is the chief characteristic of the later Ramesside period, after the collapse which followed the death of Rameses IIr.

The reinforcement of foreign blood and foreign ideas that empire had brought into Egypt did nothing to retard the decline of the nation: in fact, it hastened this process by introducing a confused hotchpotch of exotic ideas, as well as exotic blood, which, far from improving the national spirit, vitiated it and weakened it. The Delta was naturally far more overrun by foreign immigrants than the Upper country, and since Tanis, the de facto capital, was in the Delta, it was in the chief city of the kingdom and the residence of king and court that the foreign influences were most evident and did most harm. Semites and Iranians from the East and from Asia Minor, Mediterranean Greeks of Cyprus and the Aegean, Italians even,

\footnotetext{
${ }^{1}$ Wealth there was in plenty in the Egypt of Rameses 111 wherewith to build monster temples and heap them with golden offerings (see later, p. 379). The collapse and the swift oncoming of poverty began after his death. A century later the priest-kings were not rich enough even to make themselves tombs, and were buried in the graves of their great predecessors or huddled away with the ancient mummies in secret pits to avoid desecration and robbery (see p. 392).
} 


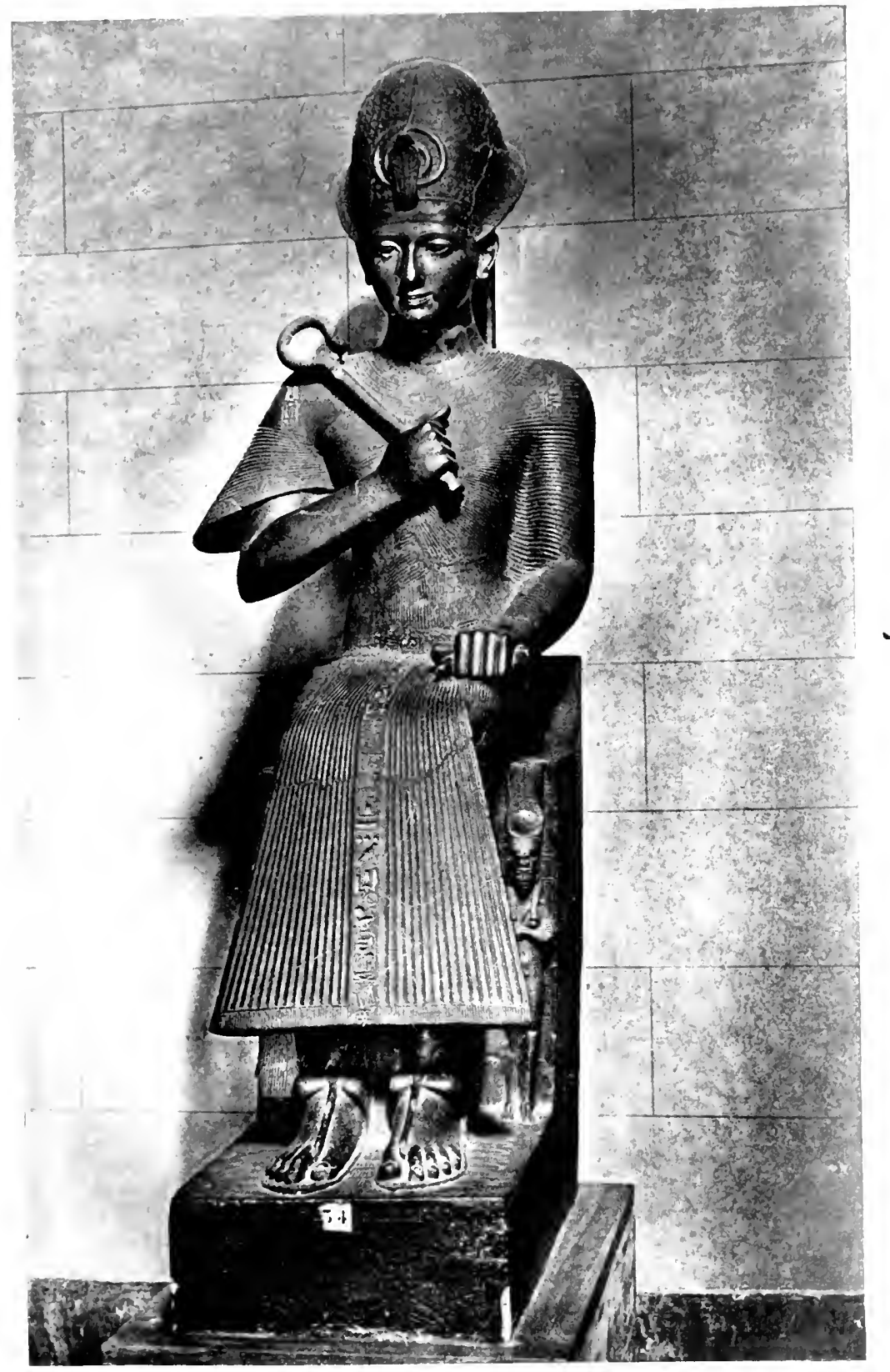

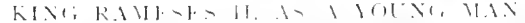



besides the half-barbarous Libyans from the West, crowded Tanis, Memphis, and the other cities of the Delta, and even Thebes had its foreign population. Some were slaves attached to the court of the king or the households of the great, some were warriors, others were merchants. ${ }^{1}$ In the reign of Rameses III we find many of the king's personal attendants foreigners: in the report of the trial of persons accused of conspiracy in the royal harem, ${ }^{2}$ among the judges are mentioned the cupbearers: Kedendenna, probably a Libyan or Northerner; Pirsun, also a foreigner; and Maharbaal, an obvious Phoenician; while among the accused was a Libyan named Inini. ${ }^{3}$ The warriors were mercenaries, chiefly Shardina, who were taken into the Egyptian service at the time of the Palestinian revolt, and since then had lived in the country, probably in camps in the Delta. Already in Meneptah's reign we find victory over the Libyans hailed partly because it allowed the mercenaries to lie down in the shade and do nothing, and in the Harris Papyrus ${ }^{4}$ Rameses III says proudly, detailing his good works: "I made the foot-soldiers and the chariotry to dwell (in their homes) in my time; the Shardina and the Kahak (Libyan mercenaries) stayed in their villages, lying full length on their backs; they feared nothing, for there was no enemy from Kush or from Syria. Their bows and their weapons reposed in their magazines, while they were satisfied and drunk with joy. Their wives were with them, their children at their side."

Despite this idyllic picture, the evils that would result from this mingling of unemployed and degenerating mercenaries with the people can be imagined. ${ }^{5}$

1 The idea that all foreign merchants were excluded from Egypt till the founding of Naukratis under the XXVIth Dynasty is erroneous. That prohibition referred only to the Greek trader-pirates of that time, and never to Phoenicians then or at any other period. At the time of the XXth Dynasty the merchants were nearly all Phoenicians. In the Report of Unamon (p. 393) we hear of a great merchantprince at Tanis named Barakāt-el, who owned "ten thousand" ships trading between Egypt and Sidon. And we can well suppose that there were many like him, and with them crowds of their fellow-countrymen, playing the same part of general merchant, from petty huckster to millionaire, that the Greeks do in Egypt now.

2 Judicial Papyrus of Turin; transl. Breasted, Anc. Rec. iv, pp. $208 \mathrm{f}$.

3 We shall see that a descendant of a Masha chief named Buiuwawa placed himself upon the throne of Egypt little more than two centuries after the wars of Rameses III.

${ }^{4}$ See p. 389 .

5Many of the mercenaries were Syrians, so that Nhal-shere, "young Syrian,"

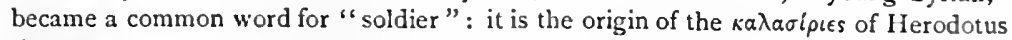
(ii. I6.4). 
With all these foreigners came their languages and their gods. New locutions, chiefly of Semitic origin, therefore be. came common in Egyptian mouths, and new gods, also mostly Semitic or at any rate Canaanitish, demanded worship from the votaries of Amen and of Ra. The Egyptian kings might erect temples to Amen or to the Aten in Canaan (Rameses III was the last to do so, as he was the last who had the power), to which the Syrians were bound to bow down, but the Syrian gods-Resheph, Baal, Kedeshet, Anaïtis, and the rest-revenged themselves by filching from Amen and his peers much of their worship in Egypt. ${ }^{1}$

The growing weakness and decadence shewed itself in the increasing insecurity of the country. A vizier revolted in the reign of Rameses III. ${ }^{2}$ The viziers had little but police duties to perform, and very badly they seem to have performed them, to judge from the tale of the tomb-robberies in the time of Rameses Ix. ${ }^{3}$ The actual policing of Thebes was performed under their supervision by negroes of the tribe of the Matjoi, which seems to have been transplanted to Thebes and provided a sort of hereditary professional slave-police for the capital, rather like the Scythians at Athens. ${ }^{4}$ We know from the proces-verbaux of the trials of the tomb-robbers that in the judge's seat by the side of the vizier sat the High-Priest of Amen with another priest, besides two of the king's courtiers or cup-bearers, one of whom was his herald or sheriff, one military officer, one civil officer, and the mayor of the city. This was a sufficiently representative court; but

${ }^{2}$ Under the XVIIIth Dynasty this invasion of Syrian religious ideas had already begun in the Delta, which had never been thoroughly purged of the Hyksos invaders, and was severely neglected by the Theban kings. But when a dynasty of North Egyptians ascended the throne, probably with foreign blood in its veins, and certainly under the direct patronage of the foreign god Sutekh, of old worshipped by the Hyksos and now identified with the Hittite ' $\mathrm{T}$ eshub, this invasion and naturalization of Syrian deities was suddenly accentuated, and Egyptian religion seems under the XIXth Dynasty half semitized, not only in the Delta, but at Thebes as well. Here, however, Amen well held his own against the exotic godlings of popular superstition; and when, under the XXth Dynasty, the court returned from Tanis to Thebes, the Syrian religious element began to weaken as suddenly as it had spread, and in a century or two had entirely disappeared. And under the Saites no man felt any desire to worship the gods of the Semites, who had brought fire and sword into the most holy sanctuaries of Memphis and Thebes.
2 Pap. Harris, Pl. 59.
${ }^{3}$ Pap. Abbott.

"Their name eventually became a synonym for "armed man," and is the only Coptic word for "soldier." 
though the vizier presides over the court, it is evident that the days of his absolute power and pre-eminence as the king's representative are gone. No priests had sat by his side in the time of the XVIIIth Dynasty, but now we may be sure that both he and the king's herald deferred in everything to the priests who had usurped seats on the bench, and that no decision would have been given, or if given would have been carried out, with which the High-Priest of Amen did not concur.

Of the growth of the priestly power, which under the XXth Dynasty reached its apogee, and of its decline, we shall speak later. Under the priest-kings of the XXIst the powerlessness of Amen and of his ministers to rule the country was evident to all, and no doubt the deposition of the last priest-king and the reunion of the kingdom under the descendant of a Libyan mercenary of the Tanites was welcomed even at Thebes, especially since the Bubastites were politic enough to keep the worship of the "king of the gods" always in the forefront of the official religion. But he was no longer a real king of the gods of a whole kingdom, much less of an empire that had ceased to exist, and no longer commanded any special devotion except in his own city. Gradually in the popular religion of the rest of the country he became identified with Osiris, the god of the dead, whom he had eclipsed, and so the ancient deities came back to their own.

The dominance of the priest was accompanied by that of the scribe, and by the subservience of the soldier. Reverence for letters went hand in hand, as usual and ever unjustly, with contempt for the military profession. In this regard Ramesside Egypt reminds us not distantly of China. Priestly scribes, writing for the instruction of their pupils, deride the misery of the soldier who has always to be on guard on the desert frontier, or the wretched life of the mohar or royal messenger who is always restlessly wandering amid the clangers of foreign parts. ${ }^{1}$ This is often the tone of the pundit in an unmilitary nation, as the Egyptians really were and are, in spite of the deeds which they had once performed under the overmastery of the idea of revenge upon Asia. That impulse exhausted, the reaction was intense, and the scribes were now well in train to reduce the Egyptians to the condition of a

\footnotetext{
${ }^{1}$ Pap. Anastasi I. See p. 324, n. 3.
} 
nation guarded and ruled by foreigners, which they finally entered under the XXIInd Dynasty, and in which they have remained ever since.

In itself, however, the literary activity of the Ramesside period is very interesting. It was perhaps an activity of copyists rather than of authors, but to this copying we owe most of the monuments of ancient Egyptian literature that we possess. And it is a literature, for we have Egyptian lovepoetry ${ }^{1}$ and novels ${ }^{2}$ as well as didactic ${ }^{3}$ and religious papyri. The love-songs are often very beautiful, and their imagery is strongly reminiscent of that of the "Song of Solomon," the Egyptian character of which is very striking. The novels and wonder-tales are equally Oriental, and the obvious parallel to them of the "Thousand Nights and a Night" is by no means far-fetched. The religious papyri are chiefly the work of the confraternity of Amen, and in them we see an organized attempt to exalt Amen at the expense of the other deities of the land. The henotheistic hymns in which the Theban deity is celebrated are often very fine in thought and diction: the example of Akhenaten's hymns to the Aten was by no means lost. And from the inscriptions which cover the walls of the royal tombs of this epoch we learn that the ancient chapters of the "Book of Coming Forth from the Day" into the night of the tomb (the "Book of the Dead," as we call it ${ }^{4}$ ) were largely supplanted as guides to the next world by two compilations of the priests of Amen called "The Book of the Gates" (of the underworld) and "The Book of what is in the Underworld." But, under the Saïtes, when Amen's prestige had gone, the regular scriptures came once more into general vogue.

We possess, too, diaries and letters of officials of this period which are not without interest as throwing light upon the condition of the people, ${ }^{5}$ though their actual contents are usually jejune and dull. The spirit of the nation had become dulled: there was nothing of interest to record, and there were no interesting men to record it. What would we not give for diaries and letters of the reigns of Hatshepsut and Thothmes

1 W. M. MüLlER, Die Liebespoesie der alten Ägyfter (Leipzig, I899).

2 E.g. the famous "Tale of the Two Brothers," Pap. d'Orbiney.

s The story of the "Mohar" is really a didactic geographical treatise in rhetorical form (A. H. Gardiner, Egyptian Hieratic Texts, I. i. (Leipzig, I9I I)).

${ }^{4}$ Fully edited and translated by Dr. Budgr (London, Kegan Paul, I898).

" Paps. Sallier and Anastasi. 
III? We have seen how interesting the letters of foreigners were in the time of Amenhetep III.

And as to the condition of the people on which these scanty letters throw a little light, all that can be said is that in spite of the changes in the persons and spirit of their rulers from age to age, the fellahîn, though weakened and disorganized for a time by foreisn admixture, remained the same in the Ramesside period that they had been under the XIIth and XVIIIth Dynasties, as they were to be under the Romans, and as they are now: working for their masters from year to year and season to season with and like their oxen, unchanging like their unchanging Nile. ${ }^{1}$

${ }^{1}$ Only a bad Nile and resulting famine could stir them: in the reign of Rameses in. we hear of a strike of labourers at Thebes, who refused to work till corn was given to them. 


\title{
THE HITTITE KINGDOM AND THE SECOND EGYPTIAN EMPIRE
}

\author{
(I $400-$ I IOO B.C.)
}

\section{The Folk and Land of Khatti}

The Anatolians and Mesopotamia - Early Hittite invasions-Hittites in Northern Syria-Semitic influence on Hittite art-Hittite hieroglyphs-Anatolian religionThe gods of Yasili Kayà-The priests-Religion non-Aryan-Racial type that of the modern Armenians-Names non-Aryan-Certain resemblances to Aegeans-Legends of Etruscan connexion-Possible relationship with Aegean culture not close-National characteristics of Anatolians-The Hittite lingdom-Khattusil I (c. 1400 B.C.)Shubbiluliuma ( $c$. I385-1345 B.c.)-The capital : Boghaz Köi-Other centres

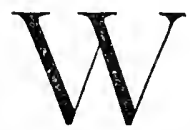

ITH the appearance of the Hittite king Shubbiluliuma as the conqueror and arbiter of Western Asia and successor to the heritage of Egypt we are finally brought into close contact with the world beyond the Taurus, the fourth region of the Nearer East. This world was as foreign to the Semites as was Egypt. Its natural conditions and its inhabitants were as strange to the peoples of Western Asia as were Egypt and the Nilotes, notwithstanding the fact that a certain amount of Mesopotamian culture had penetrated across the Taurus even in the earliest times, and, working gradually, had by the time of Shubbiluliuma given to the peoples of Asia Minor a slight veneer of the Eastern civilization above their own less-developed culture. But the Semite could never cross the Taurus in force, and even his influence soon became attenuated beyond it. The land was too high and rough for him, its air too keen. To the Egyptian the Kheta-land was probably a horror: the snow of Taurus alone would be enough to set a bar to any desire to make its acquaintance on his part. No Egyptian army ever attempted to cross it till Ibrahim Pasha marched to Konia and Kiutahia in I $_{326} 2$. 
But to the hardy Anatolian the Semitic lands lay open as a prey. For the Mesopotamian he was a raider and spoiler who periodically descended upon the northern cities to slay and rob. No tic of common race or religion softened the antagonism between Semites and Anatolians; for the former the Northerners were outer barbarians, Goyyim, "the nations" who swarmed in the mountains which bounded the Semitic world on the north, and ruled the strange lands away to the dim northern sea. Generally they were called Khatti, a name which was used by themselves, the Biblical Hcth, our "Hittites." 1 IFor Asia Minor generally the usual Mesopotamian name was Mushki, and the Khatti were reckoned as Mushkaya. Of the fierce raids of the Khatti we hear early in Mesopotamian history. In later omen sagas the name of Sargon of Agade was associated with that of a king of Khatti. The first historical mention of them is that which records a calamitous invasion by the Khatti which took place at the end of the reign of Samsuditana, king of Babylon, about 1750 B.C. As we have seen," the invaders probably took Babylon, killed the king, and then retired, carrying with them the captured deities of Babylonia, and leaving the country and its capital desolate and open to the Kassites from the Zagros, who now founded the royal house of Karduniyash, which lasted for over four hundred years. This invasion was a mere raid from end to end of the great rivervalley: when it was over the raiders returned at their leisure with their booty to their home beyond Taurus, where no avenger dared follow them before Tiglath-pileser I. Doubtless there had been other Hittite invasions of similar character before that which overthrew the First Dynasty of Babylon, and were to be others later; they served to stamp on the minds of the Asiatics the conception of the Khatti as a fierce and superhumanly energetic enemy.

The whole mountain complex of the Taurus and Anti. Taurus had been inhabited by the Anatolians from the beginning: the Semitic population stopped at the foothills, just as it does now; the boundary between Arabic and Turkish speech to-day is the ancient boundary between Semite and Hittite. But about the beginning of the second nillennium H.C. a Hittite invasion or series of invasions which were not mere raids resulted, as we have seen, in the settlement in Northern

1 The Egyptians knew them by the same name, Kicta.

'2. 199. 
Syria of a Hittite garrison, and many of the chief cities of the land were henceforth ruled by Hittite princes side by side with native dynasts and Aryan barons from Mitanni. ${ }^{1}$ The two foreign elements in Syria naturally soon came under the influence of the native culture, and it is probable that of the two the Anatolian element resisted it the best, since the Aryans probably had very little civilization, while the Anatolians had a very distinctive culture of their own. Carchemish has lately yielded good Hittite sculpture of the earlier period, resembling that of Oyiik. ${ }^{2}$ But eventually the Syrian Hittites succumbed, and though they retained much of their own culture, including their peculiar hieroglyphic system, yet their art became entirely babylonized or assyrized, as we see it in the later sculptures of the palaces of Sindjirli and Saktjegözii. ${ }^{3}$

North of the Taurus, however, the Semitic influence could not pass. Only at Bor and Ivrìz, just north of the passes, do we see a Semitic influence in sculpture; and these particular monuments are evidently of the latest of all Hittite productions. ${ }^{4}$

In Anatolia the strong national consciousness of the Hittites prevented their culture from being deprived of its peculiar character by foreign influence, although it was surrounded on three sides by the more highly developed civilizations of Minoan Greece, Egypt, and Mesopotamia. Though at an early period

I Pp. 20I, 230, ante.

2 On the results of the excavations of Messrs. HogAR'TH, R. C. ThOmpson, and IVoolley for the British Museum at Carchemish, see Hogarth, Hittite Problems and the Excazation of Carchemish (Proc. Brit. Acad., vol. v., Dec. 13, I9I I), and the Times of July 24, I912.

${ }^{3}$ Von Luschan and Koldewey, Ausgrabungen in Sendschirli (Berlin, IS93i9i I) ; Ganstang, Liverpool Annals of Art and Archaology, i. pp. 97 ff.; The Land of the Hittites, pp. $270 \mathrm{ff} ., 298 \mathrm{ff}$.

${ }^{4}$ For references, see Garstang, l.c. pp. I $\delta_{5}$ ff. ; illustrations, ibid. Pls, lvi, lvii. The art of Sindjirli and Saktjegözii was later than that of Carchemish, probably belonging to the eighth century, and was no longer that of Hittites : its makers were no doubt Aramaeans (see p. 400). MEsSerschmidt (an authority whose recent premature death all archæologists deplore) maintained that the art of Sindjirli and Saktjegözü is "Aramaean art" (O.L.Z., I909, pp. 378 ff.). The art of the Aramaean princes of the eighth century was of Hittite origin, derived from that of the Hittites of Carchemish, and still more strongly affected by Assyrian (Babylonian) influence. It often becomes a mere crude copy of the Assyrian art of the time of Ashur-nașir-pal (ninth century: see p. 515, post). So that whether we can speak of "Aramaean art" is doubtful. The art of North Syria seems to have been a Mischkunst, affected strongly by Aegean as well as Hittite and Babylonian influences, and shewing more originality than the purely imitative "art" of Phonicia (see p. 515, n. 3). 
the knowledge of the cuneiform writing on clay tablets had penetrated beyond the Taurus, ${ }^{1}$ and at the period of the empire of Khatti was used in the royal chancery at Boghaz Kyöi ${ }^{2}$ for the writing of letters and despatches and the keeping of archives, ${ }^{3}$ yet the national system of hieroglyphic inscription ${ }^{4}$ was always retained for sculpture on monuments, and even used by the semitized Hittites of Carchemish till a late period. The art which we see on the monuments of Boghaz Kyöi, Öyiik, and Yasili-Kayà, in the heart of Cappadocia, is purely national in feeling, and it is not often that there, in contrast to the Hittite sites south of the Taurus, we can descry traces of Babylonian or Egyptian influence in it. ${ }^{5}$

${ }^{1}$ It was probably by the land route that the knowledge of the elay tablet first came to Crete (see p. 42).

2 This we know from the series of elneiform letters and dispatches discovered at Boghaz Kyöi by Winckler in 1907 (WINCkLER, M.D.O.G., Dec. 1907). It may eventually appear that some of the actual remains at Boghaz Kyöi are of later date than the archives found by Winckler, but it is improbable that they can be much later, since the archives seem to come down to within a century of the destruction of the Hittite kingdom of Tiglath-pileser I ( I 100 B.c. : see p. 388). No tablets later than $\mathbf{1} 200$ B.C. have been found. We are therefore justified in regarding the remains at Boghaz Kyöi, including the fortified citadels and walls, as belonging, with the rock-sculpture of Yasili Kayà and the reliefs of Öyiik, to the period when Boghaz Kyöi was the capital of a great state. To the same time must belong the rock-stelae of the Karabel and Giaour-Kalessi (J.H.S. xxix. p. 21 , n. I2).

${ }^{3}$ As by the Egyptians at Tell el-Amarna for purposes of communication with the Asiatics. But the Egyptians never tried to write Egyptian in cluneiform, whereas the Hittites, apparently, commonly wrote their own language in cuneiform (this, however, is not quite eertain: it is possible that the "Arzawa" languagre they used was not the Hittite language of the hieroglyphic inscriptions).

${ }^{4}$ The Hittite hieroglyphic system, as we know it from the monuments of Carchemish, seems to be constructed much after the Egyptian manner, probably with syllabic signs, determinatives, and simple ideographs. No relation whatever between it and the Egyptian system can be traced, but comparisons with the unread Cretan script might give results. Many attempts have been made, notably by Conder, Sayce, and Jensen, to decipher the Hittite hieroglyphs. That of Conder (Altaï Hieroglyphs, $\mathrm{x} 887$, etc.) cannot be sustained in any way: it is vitiated ab initio by his curious belief that the Hittites were Mongolians, and spoke a Finnish tongue. That of Jenson (Hittiter . Armenier, I 898 ) rests upon an equally doubtful hypothesis, that they were Aryans, and spoke an Indo-European tongue, the ancestor of Armenian. For a criticism of this idea see p. 335, n. 4. The system of SAICE (P.S.B.A., 1903-4) does not yet offer any results which can be utilized in a general history. Mr. R. C. THoxipson has lately proposed a new system.

${ }^{5}$ Egyptian influence is more apparent than Babylonian. At Boghaz Kyöi we find lion-heads of Egyptian style, and at Öyük we have proof of Egyptian influence in the two colossal sphinxes which guard its entrance (Plate XXII. I). These have the heads of the Egyptian Hathor with the peculiar curling locks at the side. In Egypt, sphinxes with the heads of Hathor are never found: the Hitlite sculptor, 
The native art and writing of Asia Minor disappeared in time. But the national religion, which had given birth to both, survived them, and even to the latest days of paganism continued to mark out Asia Minor as a religious province distinct from Greece, from the Semitic world, and from Egypt. Characteristic was the universal worship of the Mother-goddess $\mathrm{Ma}$, known to the Greeks and Romans as Cybele, and generally identified with Rhea or Demeter, at Ephesus with Artemis, elsewhere as the "Mother" simply, the Dindymene Mother or the Zinzimmene Mother, probably the original of the Mesopotamian Ishtar. Closely associated with her was the equivocal Attis or Agdistis, represented as male, but regarded sometimes as a eunuch, sometimes as either male or female. He was the sun, attending the mother-moon. Both were served by the eunuch priests, the Galli, who sometimes wandered throughout the country in troops, sometimes lived as the ministers of the deities on temple-lands of enormous extent, served by multitudes of serfs. The two chief of these temple-domains known to us are those of Komana in the valley of the Sarus amid the mountains of Taurus, and of Pessinus in Phrygia. In Roman times these lands became the property of the emperors.

By the side of Ma and Attis, whose worship was evidently the most ancient cult of Asia Minor, stood in later days Mithras the sun and Mên the moon. These two deities would seem, however, not to be of Anatolian origin. Both are probably Aryan or Proto-Iranian gods introduced from the East. ${ }^{1}$ Mèn is

wishing to imitate Egyptian sphinxes, confused the royal male head with the Hathorhead, and gave his sphinxes the latter. We can hardly doubt that the period when this mistaken attempt at imitation of Egypt was made was that when Egyptian influence was probably greatest in Khatti, after the conclusion of peace with Rameses II and the establishment of marriage-relations between the heads of the two states.

${ }^{1}$ Mên can hardly have been Phrygian, as was Papas, Bagaios, or Osogo (the "Father" and "Thunderer"), with whom we are not now concerned, as the Phrygians had probably not yet entered Asia Minor from Thrace. The Iranian moongod Mâô is represented on the coins of the Graeco-Scythian kings of Bactria, Kanishka and Huvishka (first century B.c.), by the same type as the Anatolian Mên, with the crescent moon behind his shoulders, just as the certainiy Iranian sun-god Mitra has the sun behind his shoulders (Percy Gardner, Coins of the Greek and Sicythian Kings of Bactria and India, Pls. xxvi, 9, xxviii, 5). Sir W. M. Ramsay's idea (Cities of St. Paul, p. 286) that this moon behind the shoulders of the Mên-type was originally not a moon at all, but "probably only wings as represented in archaic art," will hardly hold, in view of the Iranian Mitra-type, with its sun behind the shoulders, parallel with the Mâô type, with its moon just like that of Mên, corre- 


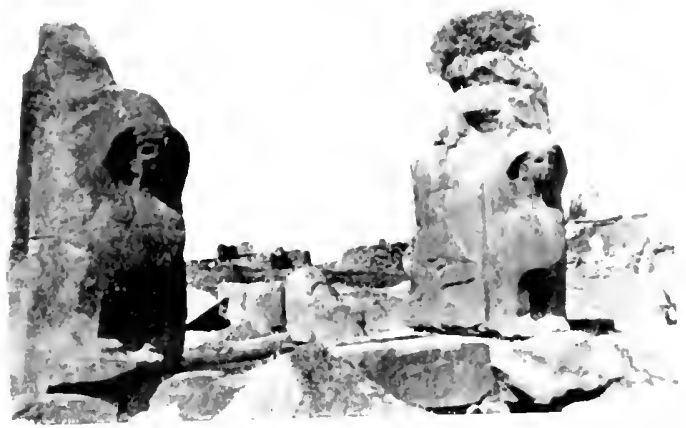

เ.
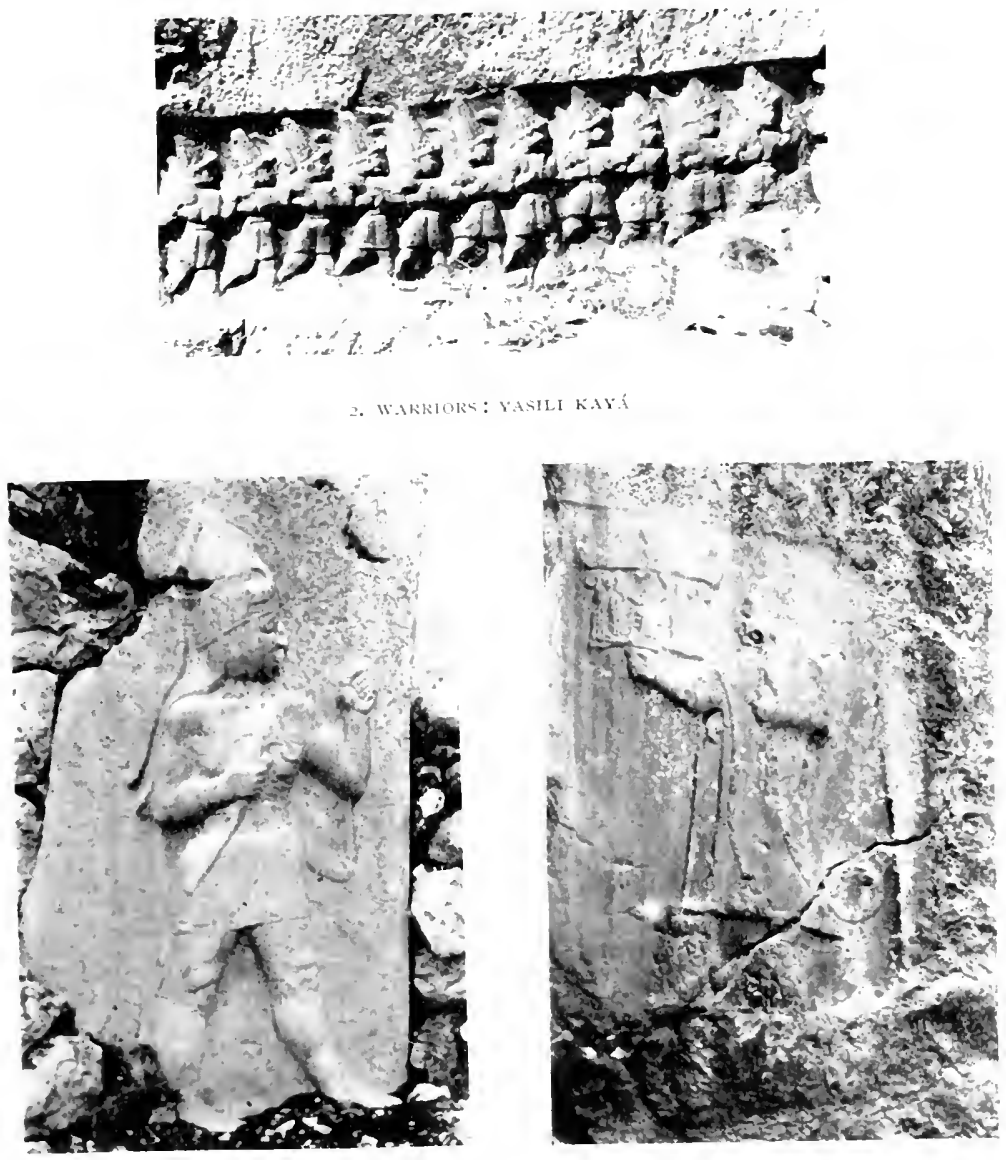

HITITE IRl (IF THE, IESL PERIOI 

identical with the Iranian Mâô, Mithras with the Indian Mitra, and was worshipped, with the Aryan deities Indra and Varuna, by the Iranian royal family and nobles of the land of Mitanni, the nearest eastern neighbour of the Khatti kingdom, in the time of Shubbiluliuma and Dushratta. ${ }^{1}$ Then, or before, the worship of Mitra probably passed into Asia Minor, and with it that of Indra and Varuna may well have come also.

The Iranian deities are not, however, mentioned in the list of Hittite gods in the Treaty of Rameses II with Khattusil, and it seems impossible to identify them among those on the sculptured rocks of the shrine of Yasili Kayà. ${ }^{2}$ Only the native Anatolian gods are seen at Yasili Kayà. ${ }^{3}$ We see a goddess, Cybele or Ma, standing upon a lion as she does on the coins of Greek and Roman times, and wearing upon her head a turreted head-dress almost identical with that which she is represented wearing in later days. Behind her is a youthful war-god armed with an axe and also mounted upon a lion, who accompanies her as the young god does the goddess on Cretan seals. He must be Attis. Behind him are two goddesses, also wearing

sponding to the similar Indian iconographic types of Surya and Candra. Therc seems to be no reason why Mên's moon should not have been a moon, and Mien a moon-god and nothing else.

1 See E. Meyer, Das Erste Auftreten der Arier in die Geschichte (Sitzber. kgl. preuss. Akad., I907).

${ }^{2}$ In later Indian iconography, Indra, the god of Heaven, is represented covered with eyes (the stars), and, usually, riding upon an elephant : he is a warrior, and is accompanied by an army of celestial soldiers. Varuna, the god of the waters, is rarely represented at all now, and Mitra never. These Vedic deities appear more often in priestly prayers than in popular pictures. How the ancient Aryans may have represented them we do not know. There is nothing like the later representations of Indra or Varuna or Mitra at Vasili Kayà, but there and at Malâtiya the IIttite deities are often accompanied by animals in quite Indian fashion, and someIimcs stand upon them. This was a peculiarity characteristic of Anatolian iconography down to the latest times. It may be that it was a featurc borrowed from Aryan religion. Another element that has a strangely Iranian look is a peculiar object, evidently of very sacred import, that is held in onc hand by a eunuch priest at Yasili Kayà, while in the other he holds a long liturts. This sacred object consists of a tiny figure of a male deity in a small shrine with pillars, above which is a solar disk, from which on either side streams out a sheaf of flames, resembling wings. The resemblance of this to the Persian ferwer, or small figure of Ahuramazda with flames (often rendered as wings), which is represented accompanying Darius on the rock of Behistun, and to the very similar Assyrian emblem of Ashur (which may be of Iranian origin), is evident (Plate XXII. 4).

${ }^{3}$ The most handy publications of Yasili Kaya are PErrot and Chipiez, Hist. de l'Art, iv. pp. 623 ff., and Ciakstang, Land of the Hittite', I'ls. Ixiii.-lxxi. See also Plitte X.XII. aliove. 
the turreted head-dress, who stand above that extraordinary symbol, the Double Eagle, which, originating in the brain of some Hittite priest, was fancifully adopted by the Seljuk Turks of Anatolia as their symbol three thousand years later, and by them handed on to Byzantium, to become the cognizance of the modern states of Austria and Russia. Cybele, Attis, and the twin goddesses of the Double Eagle are approaching a venerable and bearded male god, who stands upon the shoulders of two spirits or worshippers of male form, bowing their heads beneath him. In one hand he holds a roundheaded mace, in the other the curious symbol of divinity, which Cybele also holds, and above Attis has the body and legs of a man. Both this great god and Cybele are accompanied by crowned goats. Behind the god is a beardless duplicate of him, standing upon mountain-peaks, and beyond him yet another more remote deity, of more peaceful aspect. All wear the high cap and upturned shoes of the Anatolians, and all are evidently gods of the mountains: they or the animals that carry them are treading the topmost peaks. In another representation we see other gods, especially a male figure with two pointed wings.

Of these deities, it would seem very probable that the last is a form of Teshub, or, as the Egyptians called him, Sutekh, identifying him with the old deity of the Hyksos, whom the recorcled traditions of the Delta and the Northern tendencies of the Ramesside kings had restored to a prominent position in the Egyptian pantheon in common with the old Egyptian god Set, with whom he had always been identified. ${ }^{1}$

But though the winged god at Yasili Kayà is probably the same as this winged Teshub or Sutekh, his place there seems to be among the lesser deities. Judging, however, from the Egyptian evidence and that of the Boghaz Kyöi tablets, Teshub was the paramount deity of the Hittite state. How his worship was combined with that of $\mathrm{Ma}$ and Attis we do not know. He was primarily a god of war, and was perhaps regarded as a wholly masculine form of Attis. Later on, when the Khatti state disappeared, the prestige of the royal war-god

1 Sutekh or Set in his Hittite form appears on Egyptian scarabs (though rarely on the monuments, Set in Egyptian form alone appearing there) winged and wearing a high cap from which depends a long tassel or pigtail : the same head-dress appears in the representations of a war-god at Sindjirli : he is without doubt Teshub, and probably the Sandon of later times. 
would naturally tend to diminish, and he would recede into the background of the national religion. But while warlike monarchs ruled, the worship of the war-god had naturally come to the front, and he had impressed himself on the minds of foreigners as the all-powerful deity of Khatti.

It is possible that the popular war-god was by no means very popular with the priests of $\mathrm{Ma}$ and Attis, and that his comparative insignificance at Yasili Kayà may thus be explained; unless, as is very possible, the winged god identified with Sutekh was but a form of Teshub, who in his highest manifestation is the bearded god standing upon the shoulders of his subjects, who solemnly receives $\mathrm{Ma}$ and $\mathrm{Attis}$ on their lions. This may be Teshub as Zeus, and the other Teshub as Ares. ${ }^{1}$

Besides these chief gods crowds of other deities were worshipped by the Anatolians. They are mentioned in the famous treaty between Rameses II and the Hittite king Khattusil, which we shall discuss later, as the deities of various places, such as "the sun-god of Arnena," 2 "the god of Khilpantiris," "the goddess of Khauka," "the god of Sarp," besides "the deities of the heavens, the earth, the Great Sea, the wind, and the storms." 3 Important was Taskhil, "mistress of the mountains," who also presided over the taking of oaths and punished the oathbreaker. Among the djinns of the Anatolians we may place the two curious horned Cabiric figures that uphold a great crescent moon on the rocks of Yasili Kayà. These seem to be related to the animal-headed figures of the Aegeans. ${ }^{4}$

Together with the gods in the sculptures appear the eunuch priests, bearing the magic lituus and carrying the curious emblem of the divinity that has already been described. On one relief at Yasili Kayà, Teshub himself (for it is, no doubt,

${ }^{1}$ Another male god, perhaps more or less identical with Teshub, seems to have been named Tarku. His name appears in many personal appellations of men of Eastern Asia Minor, both now and in later times, from Tarkhundaraush, king of Cilicia, the correspondent of Amenhetep III (see p. 269), to Tarkondemos and Tarkombigremis, his successors in the days of Augustus. The hieroglyph of this deity, if correctly identified, was the head of a horse or ass, which often takes forms indistinguishable from the ass-head of the Egyptian Set or Sutekh (we know that Set was ass-headed from representations on coffins of the Middle Kingdom).

2 Probably identical with the Ariunna of the Egyptians (see p. 359), possibly the later Oroanda, the town of the Orondeis, in Pisidia. The sun-god was no doubt a form of Attis.

3 The long processions of minor deities at Vasili Kayà well illustrate this passage of the treaty.

4 See p. 52. 
he), wearing a great conical crown that is strongly reminiscent of the high feathers of the Egyptian Amen, places his arm affectionately round the shoulder of his priest, and both advance thus together, naturally giving rise to the mistaken impression which some observers have received that this group represents the king with his queen. But the true nature of the relief is evident enough. No king (unless this is the king in the capacity of priest) is represented at Yasili Kayà. ${ }^{1}$

The native religion of the Anatolians seems non-Aryan. And other characteristics of this people-as, for instance, their matriarchal system - indicate a non-Aryan origin. Their personal appearance on the ancient monuments is neither Semitic nor Aryan. The men seem to have shaved the face regularly. We thus see their facial type plainly. It was peculiar, with high nose and retreating forehead and chin. The type is still common in Eastern Anatolia; it is the type of the modern Armenian, and is unlike any other in the Near East. Prof. v. Luschan calls it the "Armenoid" type. That it is Mongolian is not in the least evident. ${ }^{2}$ Their language also does not seem to have been Aryan, while the names of the kings of Mitanni were all Indo-European-Saushshatar, Shutarna, Artashumara, Artatama, Dushratta, Mattiuaza. In Khatti the kings all have native Anatolian names, which have no Aryan sound-Shubbiluliuma, Aranta, Mursil, Mutallu, Khattusil,

${ }^{1}$ At Boghaz Kyöi the male warrior-figures guarding a gate (p. 338, Plate XXII. 3) may be royal. (I see no reason to suppose that these figures are female, and are Amazons, as has been thought. On the relation of the Amazon-legend to the Hittites see J.H.S. xxix. p. 20, n. 8.)

${ }_{2}$ On this type see v. Luschan, Huxley Lecture, I9II, Journ. R. Anthrop. Inst. It is true that the men wore their hair in a pigtail ; but this fashion is not necessarily Mongolian, as it seenss often and absurdly to be regarded as being, probably because of the Tartar and Chinese fashion. Frederick the Great wore a pigtail, and so did British sailors till about I8I5; and German dandy knights of the thirteenth century often sported two plaited tails à la Marguerite below their waists : " ic truog zwên zoepfe schoen unt lanc, die hîngen ueber den guertel mîn," sings one of them. If we are to seek for ethnic connexions for the Hittites on the score of their pigtails, we can find them in their own time and neighbourhood in the Minoan Greeks, who wore their hair to their waists and evidently often in pigtails (see p. 50). Prof. GARSTANG (Land of the Hittites, p. 318) still speaks of a "Mongolian" type among the Hittites. But neither for his Mongol nor his "proto-Greek" types, which he gives from Egyptian representations of the Hittites (Pl. lxxxiii.), can I find justification. One can see nothing "Greek" in the second type but the straight nose of popular superstition, and the faces in question seem to me to be strongly influenced by the Egyptian sculptor's familiarity with the Egyptian types of his day, which they most resemble. 
Dudhâlia, and Amuanta; and the queens, as Pudukhipa and Muni-Dan, likewise. ${ }^{1}$ Mursil and Mutallu are typical names of Asia Minor: the former is well known in Greek times in the form Myrsilos, and the treacherous charioteer of Oinomaos of Elis, who delivered his master into the hands of Pelops the Anatolian, and was afterwards slain by him, was named Myrtilos. ${ }^{2}$ Motelis (Mutallu) was a Carian name, ${ }^{3}$ and the Carians spoke a non-Aryan tongue, like the Lycians, whose speech was probably akin to that of the prehistoric Greeks. ${ }^{4}$

Probably the race was indigenous to Anatolia. The religion presents some apparent resemblances to that of the Minoan Greeks, who were certainly not Aryan speakers. But their facial type was not in the least like that of the prehistoric Greeks; it was much heavier and less prepossessing, and the modern people of Hittite type (we have no ancient Hittite skulls) are brachycephalic, while the Minoans were usually dolichocephalic like other Mediterraneans. We also see resemblances between the externals of Hittite religion and

1 We can see evidence of intermarriage and interchange of blood between the Hittites and the Aryan Mitannians in the occurrence of Aryan-sounding names among the Hittites; e.g. a queen Tawâshshi .... (WINCKLER, loc. cit., p. 29) and the chief Javajasa mentioned by Rameses 11 (see p. 36I); while in Mitanni the princesses Tadukhipa and Gilukhipa (see p. I32) bore possibly Anatolian names. But probably neither people was much affected by such princely intermarriages, and the Mitannian people were very possibly of Anatolian or Caucasic blood (intruded like the Syrian Hittites), ruled by Aryan princes.

2 PAUS, vi. 20.

${ }^{3}$ On these names see Hall, Mursil and Myrtilos, J.H.S, xxix. p. I9.

4 Kretschmer, Einleitung in die Geschichte der griechischen Sprache, p. 377. The language of Arzawa, and that in which the tablets of Boghaz Kyoi are written, do not seem to be Indo-European. But if they were, this would not prove that the Hittites were Aryans, as we have no proof that the language in which they wrote these cuneiform tablets was their own, the tongue of the Anatolian hieroglyphs written in cuneiform characters. The fact that the Armenians, who, judging by their facial type, are descendants of the ancient Anatolians, speak an Indo-European tongue, is no proof that the Hittites were Aryans. For the Armenian language was said to be closely connected with Phrygian, an Aryan language, connected both with Greek and with Slav, which was first brought into Asia Minor by the Phrygians: or Bebrykes from Thrace about the tenth century 3.c. Herodotus (vii. 73) says that the Armenians were $\Phi \rho v \gamma \hat{\omega} \nu \ddot{a} \pi \circ \kappa \circ$, and with this statement agrees Stephanus of

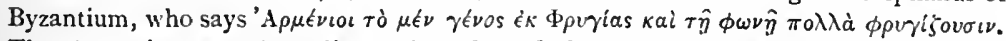
The Armenians are Anatolians who adopted the Aryan language of the Phrygian conquerors. Prof. Jensen's attempt (see p. 329, n. 4) to elucidate the Hittite hieroglyphs by means of Armenian seems hardly likely to succeed. It is uncritically adopted by Práśek, Geschichte der Meder u. Perser. 
culture and those of the Etruscans in Italy. In this connexion the Greek legends of the Lydian origin of the Etruscans almost materalize into history. ${ }^{2}$ It is not impossible that in the course of the Great Migrations of the "Peoples of the Sea" in the fourteenth and fifteenth centuries B.C. ${ }^{3}$ tribes of Anatolians may have settled in Italy, though we can hardly conceive of the Hittites as a seagoing people. Also prehistoric Greek religion (at any rate in Crete) seems at times very Etruscan in character. How far the Anatolian, Aegean, and Etruscan cultures were related is one of the problems that now invite the attention of archaeologists, and it is a very interesting one. But we may doubt whether racially the upland Anatolians were akin, unless remotely, to the Mediterraneans.

The early history of the Western Anatolians, the Lycians, Karians, and Lydians living upon the shores of the Aegean, is unknown to us. Geographically always, and in the times of which we are speaking probably racially and linguistically also, they belonged to Greece. At the present time the Turks occupy the eastern shore of the Aegean in force, but the land they have taken, like the islands (still inhabited exclusively by Greeks), nearest to it, is geographically part of Greece, which, if we desired a new name for her, might well be called "Aegaea." Greece consists of the shores and islands of the Aegean. Her real eastern boundary is the sudden rise of land at the sources of the Aegean rivers of Asia Minor. The Anatolian highlands

${ }^{1}$ Etruscan art shews most curious resemblances to that of Anatolia. In the Museum of Florence (No. $7 S_{714}$ ) is a relief from Volterra of a certian Larthi Atharnies, which is absolutely Hittite in style and feeling, and might have come from Asia Minor. Even the pigtail and the upturned boots are there.

${ }^{2}$ HdT. i. 94 (cf. Thuc. iv. I09: Tyrrhenians in Thrace); TAC. Ann. iv. 55; Strabo, v. 220. There is an interesting legend (HDT. l.c.) that Tyrrhenos was the son of Atys. Tarchon was said to have been the brother of Tyrsenos (TzETz. ad Lyc. 1242, 1249), and the resemblance between the Tarku-, Tarko-names of Anatolia and the Etruscan Tarqu- is striking. There are various other resemblances. On the Tursha of the Egyptians, who may well be $T u(r) s c i$, see p. 70 . I have to retract the scepticism which I expressed in O.C.G., p. I23. There is no doubt that DE CARA drove his hobby to death, and spoilt his work with impossible connexions and derivations. But the credit of first working at this important matter is his (Gli Hetei e gli loro Migrazioni: Civiltà Cattolica, I\$92. The famous inscription of Lemnos is now generally considered to be Etruscan; but it is of course much later in date than the times of which we are speaking.

${ }^{3}$ We have a single and most tantalizing relic of the contemporary culture of the Lycian-Carian coast in the remarkable clay disk, stamped with characters of a nonCretan script, found by the Italians at Phaistos in Crete (see p. $73, \mathrm{n}$. ). 
beyond are a different land, and we should expect to find there a civilization which, if related to that of the Acgean shores, would differ from it much to the same extent as the culture of the Hittites did differ from that of the Minoans. We should expect to find in these upland steppes and arid plains of Eastern Phrygia, Lycaonia, and Cappadocia a ruder and less developed culture, the civilization of a virile race of horse ${ }^{1}$ and sheep breeders, of warrior-farmers like the Anatolian Turks of to-day, and that is what we do seem to find. Such were the people of Khatti.

In later days, after the Indo-European Phrygians had invaded the land, the Halys marked the frontier between the races, between the Phrygians of the West and the "White Syrians" of the East. These "White Syrians" were the descendants of the earlier Khatti. In their day it is not probable that the western boundary of their race and dominion was fixed by the Halys: before the Phrygians came from Thrace it is most probable that the "White Syrians" extended westward to their natural boundary, the western edge of the central plateau, and the Hittite capital at Boghaz Kyöi, instead of being not far from the western frontier of the kingdom, was in reality set towards its north centre.

Of the beginnings of the kingdom of the Hittites we have no knowledge. Of their earliest history we know nothing as yet, but probably excavation, as yet hardly begun in upper Asia Minor, will tell us much. Surface explorations have shewn that neolithic sites occur all over Asia Minor, ${ }^{2}$ as in Armenia ${ }^{3}$ and Northern Syria. ${ }^{4}$ We know nothing of the development of the Bronze Age culture of the Hittites out of these beginnings, and nothing of its political history till the age of Shubbiluliuma. Probably there was no organized kingdom with a definite centre before the time of Shubbiluliuma; the early

${ }^{1}$ It is probable that Anatolia was one of the earliest centres of horse-brecding, though the animal probably came there, as it did to Western Asia generally, from farther East.

2 On Anatolian Neolithic pottery see MYREs, "The Early Pot-Fabrics of Asia Minor," Journ. Anthrop. Inst. xxxiii. (1903), pp. 390 ff. ; in Lycia, Ormerod and Woonward, B.S.A. Ann. xvi. pp. $76 \mathrm{ff}$.

${ }^{3} \mathrm{~L}$. W. KING, "The Prehistoric Cemetery at Shamiram-alti near Van in Armenia," P.S.B.A. xxxiv. (Igr 2), pp. rgs ff.

E.g. at Saktjegözii : Garstanc, Lizerfool Annals, i. p. 112 ; at Carchemish, see The Times, July 24, rgr2. 
invaders of Mesopotamia need not have been the organized armies of an empire, but more probably were merely tribes temporarily confederated under a single head. Eventually, in the person of KHATTUSIL I, king of Kûssar, one of these leaders founded the great dynasty which was to combine the Hittites under one rule for two centuries. SHubBiluliuma, ${ }^{1}$ his son, the great conqueror, is the first whose records, inscribed in cuneiform on tablets, in the Babylonian manner, have been found at Boghaz Kyöi. Here, in an upland valley east of the Halys, are the remains of the capital city of the Hittites, Khatti, which perhaps bears the name of the people rather than the people that of the city, and was probably an artificial creation of Shubbiluliuma himself. This was the inmost lair of the Hittite spider.

The city lay ${ }^{2}$ upon the slope of hill overlooking the valley through which passes the modern route from Angora to Yuzgat. It commanded the pass from which the modern village of Boghaz Kyöi takes its name. The space occupied by it measured 2200 metres by I IOO, and the circuit of the walls was about 5500 metres in length. Towers were placed along the walls at intervals, and a great citadel rose on the rock now known as Biiyuik Kalé. Smaller forts such as the Sary Kalé and Yenidje Kalé were placed on lesser rocky eminences. The walls are solid and formidable, being built of polygonal masonry. Subterranean corridors resembling the casemates of Tiryns occur. But though we have undoubted resemblances to Mycenaean fortification, the two styles are not quite the same. Several small posterns and three larger gates, one with a relief of a guardian-warrior on the doorpost (Plate XXII. 3), gave access and egress. In the acropolis of Büyiik Kalé were found many of the archives discovered and published by Winckler. They had no doubt been stored there for safety.

On a great space in the northern part of the city are the remains of a great rectilineal edifice, with halls and passages and magazines, which perhaps resembles in plan the palaces of Achaian Greece. ${ }^{3} \quad$ The latest explorers, however, consider it to have been a temple. Its walls, like those of other smaller

1 The "Sapalulu" of the Egyptian monuments.

${ }^{2}$ Humann and Puchstein, Reisen in Kleinasien (pp. 73 ff.); and Garstang, Land of the Hittites, pp. $192 \mathrm{ff}$.

${ }^{3}$ See p. 63. 


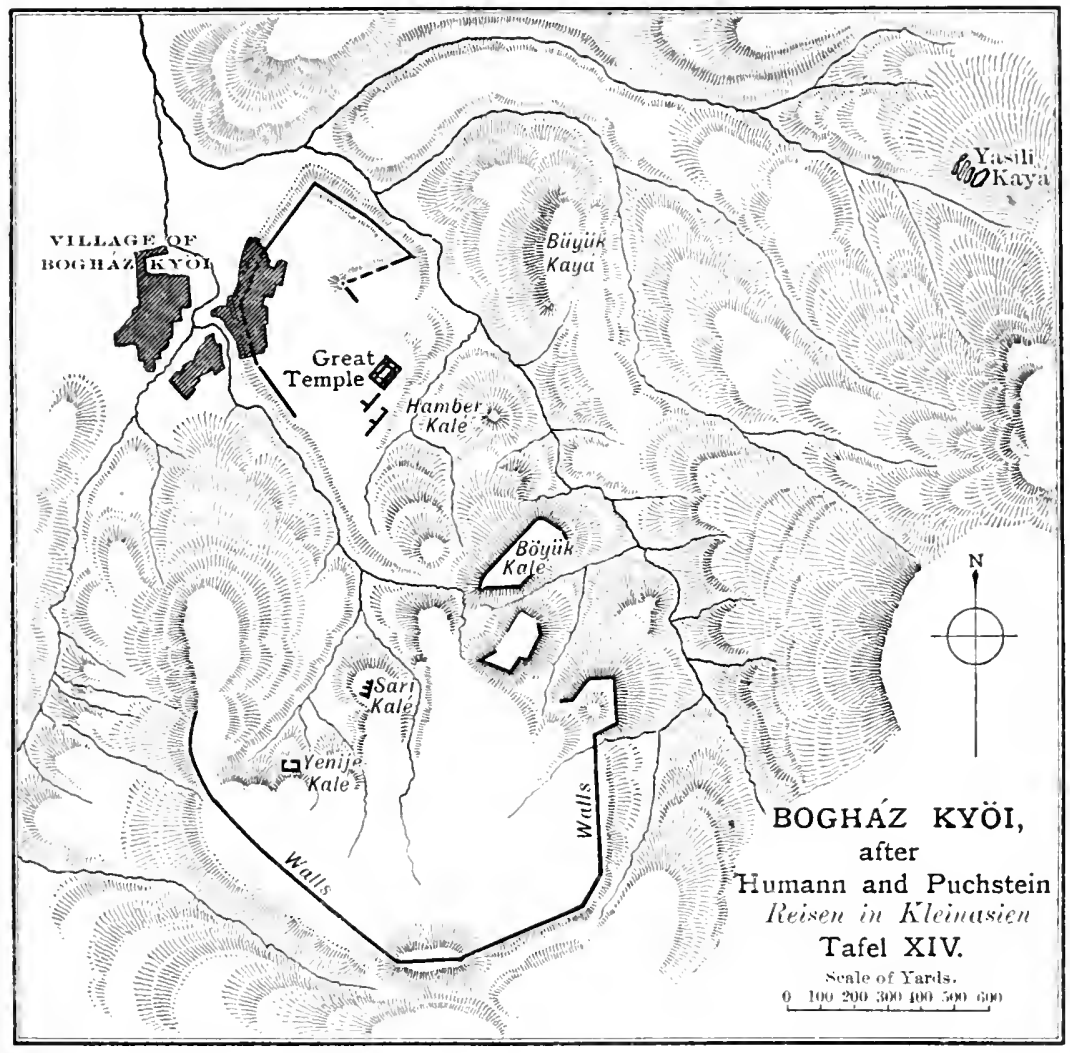



buildings on the site, were built of brick upon a thick and solid foundation of stone. Remains of these other buildings, also of European rather than Oriental character, are clearly visible.

The contrast afforded by this national capital to the chicf cities of Western Asia and of Egypt is great. Instead of a huge riverain metropolis seated in a plain basking in the warmth and light of the East, we have a fortress-city situated 3000 feet above the sea in a rugged land where snow lies throughout the winter, and the summer is as bright and invigorating as that of Europe. Khatti was a city built uncler European, not Asiatic, conditions; and, except in the matter of size, bore much the same relation to Thebes or Babylon that Sofia or Cetinje do to Constantinople or Cairo now. ${ }^{1}$

Besides the palace and (probably) town at Öyiik not far off, ${ }^{2}$ there were other town-centres in the Hittite territory, such as the ancient Iconium (which boasted herself older even than Damascus), the probably equally ancient ancestor of Caesarea Mazaca (the modern Kaisariyah at the foot of Argaeus), Tyana, or the holy places Komana and Pessinus, one at the eastern, the other at the western extremity of the land. ${ }^{3}$ But it is unlikely that, with the exception of Iconium, any of these were ever really great cities of the Mesopotamian or Egyptian type. Great cities are found only in fertile plains and by or near the banks of rivers. The Hittite towns must have been simple centres of the religious and marketing life of the peasant-farmers, and at the same time fortresses of refuge, into which not only men, but vast herds of horses, cattle, and flocks could crowd for safety in time of war. Of these "cities of refuge" Khatti itself was probably the greatest, and the circuit of its walls, as we have seen, is of enormous extent. Long after the fall of

1 The hardy, comparatively uncivilized, and very European folk of the Hittites indeed bear in their relations with Babylon and Egypt no inconsiderable resemblance to the Balkan Slavs in their relations to Byzantium and Stambûl.

${ }^{2}$ For references and illustrations see GarSTANG, l.c., pp. 242 ff.; and Plate XXII. I, above.

${ }^{3}$ This list comprises the chief cities known in Iater times to be very ancient. Of these only Komana is mentioned in contemporary records (Boghaz Kyöi tablets and Assyrian inscriptions of Tiglath-pileser I) as Kumani, and as a land rather than as a city. The Boghaz Kyöi tablets and the Egyptian inscriptions mention various Hittite places, such as Ariunna, Arnena (perhaps identical), Khauka, and of course, Carchemish. This last we know to have been a town, but of the others we are uncertain whether they were lands or towns. 
Shubbiluliuma's empire it remained a place of importance, and as Pteria it was well known to Herodotus ${ }^{1}$ as a city on the line of the "Royal Road" from the coast to Persia, the successor of a very ancient trade-route from west to east.

Outside Anatolia the chief Hittite city was Carchemish, and this, being no doubt of Syrian origin, was of the Asiatic riverain type. Hamath, Kadesh, and Aleppo also were merely Syrian towns conquered by the Hittites. Sindjirli was a small refugefortress, resembling Boghaz Kyöi (but very much smaller), and no doubt originally dating from the same period. ${ }^{2}$ Saktjegözii was a palace of later date, built upon a very ancient site. ${ }^{3}$

Such were the chief centres of the Hittite kingdom, which we can imagine as a confederacy of tribes each with its centre round some shrine served by the strange eunuch priests, and all owing an allegiance to the "Great King" of Khatti, the sun (the incarnate sun-god, like the Incas), who ruled at Boghaz Kyöi with near him the central national shrine of Yasili Kayà, and no doubt the central controlling power of the priesthood, whose relations to the royal house we do not know.

From their own and the Egyptian monuments(Plate XXIV.3) we know something of the personal appearance and costume of the kings, priests, and warriors of the Hittites, and also something of the gods whom they worshipped, and the writing which they used. Archaeological exploration is also beginning to tell us something of other matters, such as their burial customs and their ceramic art. At Carchemish we know that they buried their dead in cists beneath the floors of their houses, and both there and at Egri Kyöi in Asia Minor, we find a custom of partial cremation and burial in jars." Vases were buried with the dead. The earliest pottery at Carchemish is simple in character, and vases of a peculiar "champagne glass" form are found. Later on painted pottery appears, ${ }^{5}$ and painted ware has been found at Boghaz Kyöi and at Kara Öyük in Cappadocia. ${ }^{6}$

1 HDT. i. 76.

2 For the excavations of Sindjirli see references, p. 328, n. 3 .

${ }^{3}$ Saktjegözü, which is not far from Sindjirli, was excavated by Prof. Garstang in 1908 ; see p. 328 n. 3 .

1LOGARTh, Hittite Problems and the Excazation of Carchemish, pp. 6, 10 ; Oumstead, Charles, and Wrench, Travels and Studies in the Nearer East, (Ithaca, N.Y., r9II), p. 23. At Carchemish the urn-isurials seem to belong to the Syrian rather than the IIttite inhabitants, and cremation is of post-Iittite date.

\footnotetext{
"The Times, l.c.
}

${ }^{6}$ Chantre, Mission en Cappadoce (Paris, 1898). 

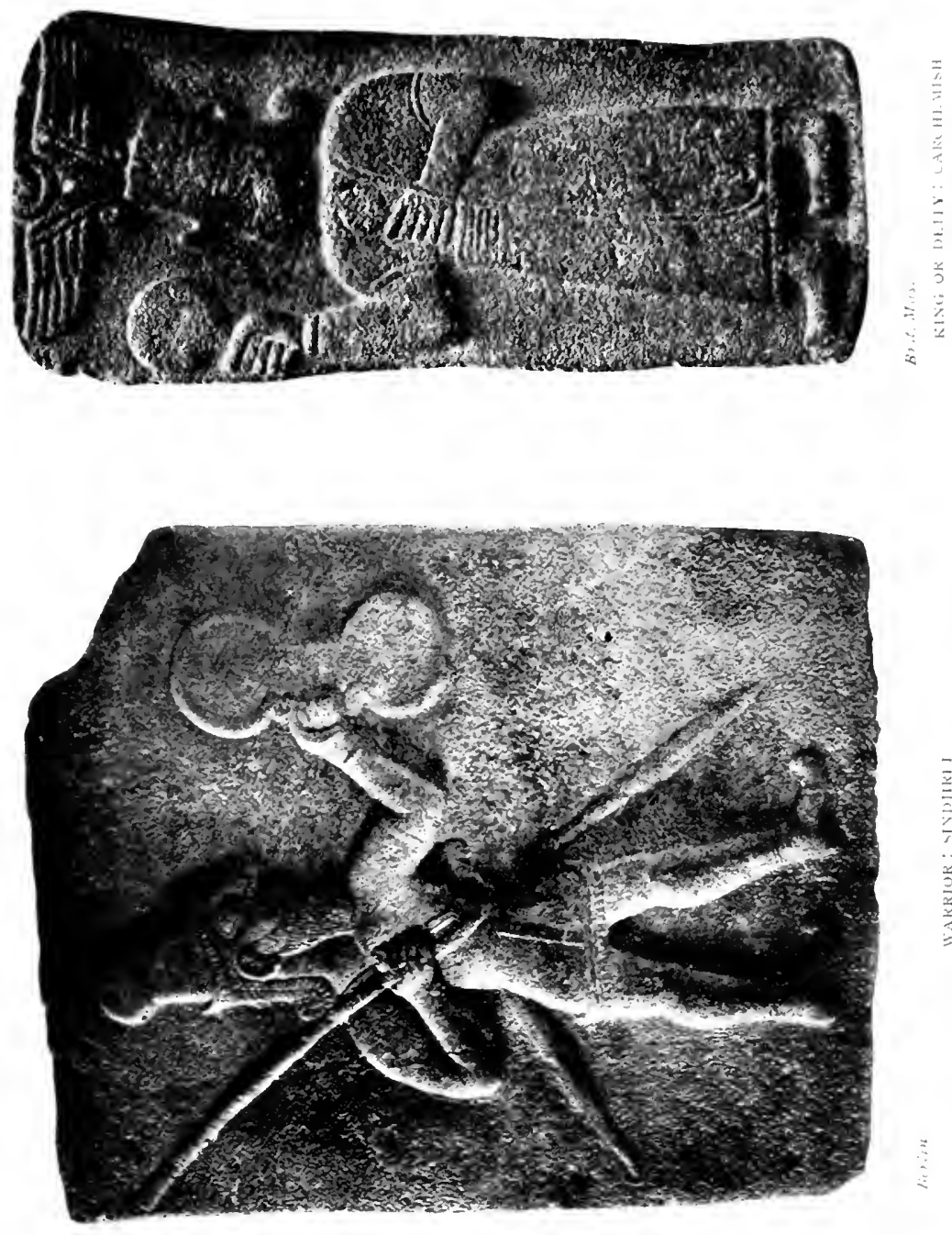



\section{The Revolt of Palestine and Conques/s of Shubbiluliuma}

Weakness of Mitanni under Dushratta-Intrigues of Shubbiluliuma-Veiled revult of the Amorite princes-Abdashirta and Aziru-Loyalty of Phoenicia : RibaddaEysptians advance and soon retire (c. 1378 B.c.)-Naharin, Shubbiluliuma and Dushratta-Iittites conquer Naharin (c. 1377 B.c.)-Death of Amenhetep III (c. 1376 13.c.)-Dushratta marches to Phocnicia and returns (c. I375 B.c.)-Death of Abdashirta-Incompetent Egyptian commissioners- Progress of the revoltIntrigues of Aziru in Egypt against Ribadda-Letters of Ribadda-Fall of Simyra (c. 1372 B.C.) - The revolt in the South-Abdkhiba of Jerusalem-The black troops at Jerusalem-General revolt and war (c. 137 I B.c.)-Fall of Byblos (c. 1370 B.c.)Akhenaten summons Aziru-Aziru goes to court and is confirmed as ruler of Syria (c. 1369 B.c.), but is compelled to submit to Shubbiluliuma (c. I 368 1.c.)-Egyptians abandon Palestine-Death of Dushratta and civil war in Mitanni (c. 1367 B.C.)Intervention of Shubbiluliuma, who makes Mattiuaza king of Mitanni (c. 1367 B.c.) -Later events-Treaty of Shubbiluliuma and Horemheb (c. 1345 B.c.)

In the confusion which marked the end of the reign of Amenhetep III the North Syrian princes seem to have been uncertain whether their allegiance was due to Egypt or to Mitanni. The opportunity was opened to Shubbiluliuma, an energetic prince, to extend for the first time the central power of the "Great King" of Khatti from Cappadocia over the debated territory of Naharin. It might seem a dangerous policy to provoke the allied arms of both Mitanni and Egypt. But the king and his nation were young and vigorous, with an unassailable base and citadel in the highlands of Asia Minor from which to operate and to which retirement in case of check or defeat was easy. Mitanni, on the other hand, was an artificial state, without good natural frontiers, planted in the defenceless plain of Northern Mesopotamia, and surrounded by enemies. One of these, the young state of Assyria, was ready to take advantage of any disaster to Mitanni to push northward again the power of the Semites, which had been displaced southwards by the intruding Iranians who had founded the Mitannian kingdom; in Assyria Shubbiluliuma could expect an ally. Further, Mitanni was weakened by internal dissensions. The reigning king, Dushratta, was one of three brothers, sons of the king Shutarna. One of these brothers, named Artashumara, had succeeded Shutarna, but was apparently murdered. Dushratta, as we have seen from his letter to Amenhetep III, ${ }^{1}$ succeeded Artashumara and punished the murderers. From the Boghaz Kyöi documents we know that a third brother, named Artatama after his grand- 


\section{THE ANCIENT HISTORY OF THE NEAR EAST}

father, the Artatama whose daughter Thothmes IV had possibly married, was throughout the reign of Dushratta the enemy of the latter, and had taken refuge in Naharin, beyond Dushratta's reach. Here he, with his son Shutarna or Shutatarra, and his grandson Itakama or Aitugama, seem to have lived as semi-independent dynasts, Itakama being prince of the town of Kinza; and here they intrigued against Dushratta with the Hittite king. ${ }^{1}$ Shubbiluliuma was not now concerned to attack Mitanni directly: the defeat which he had already suffered at the hands of Dushratta no doubt made him avoid this course, and with Naharin in his hands Mitanni, unsupported by Egypt, would be powerless. He accordingly stirred up a revolt of the Hittite and Amorite princes of the Lebanon, behind which he could occupy Naharin undisturbed.

The princes of the Lebanon had never been really loyal to Egypt, and had given much trouble to Thothmes III and Amenhetep II. Their disposition to disloyalty had always been checked by the loyalty of the settled cities of Naharin and Phoenicia, which had soon learnt to appreciate the benefits of the pax aegyptiaca, which secured them against the raids of both Hittite and Amorite. Now, however, the towns of Naharin were harried by the Hittite invasion of Shubbiluliuma, in alliance with Itakama. But Phoenicia, the base of Egyptian power in the North, was still safe, its egyptianized princes were faithful to Egypt, and had little love for the tribes of the Lebanon.

From them authentic intelligence of the proceedings of the Amorites could speedily be transmitted to Egypt. The Amorite chiefs therefore had at first to temporize. While in reality aiding the Hittites, they pretended to be defending Phoenicia for the king, and with a strange fatuity the Egyptians believed them. Then they threw off the mask as far as Phoenicia itself was concerned and set to work to subdue one city after another. But Egypt could still be deceived,

' It is very probable that Artatama's flight was directly connected with the murder of Artashumara, and that he was an accomplice of the Pirkhi whom, as we know from his letter to Amenhetep III, Dushratta had slain, at the time of his first defeat of Shubbiluliuma, who was no doubt equally the accomplice of Pirkhi. In any case, Shubbiluliuma seems for a time to have set up Artatama as a sort of rival king of Mitanni, though when, later on, Dushratta was murdered, probably by Artatama and Shutatarra, he turned against them, and placed Mattiuaza, son of Dushratla, on his father's throne as a Hittite vassal. 
and with consummate impudence messengers as well as letters were sent to Amenhetep III and to Akhenaten explaining away these inexplicable proceedings, and throwing discredit on the true despatches of the loyal princes, like Ribadda the chief of Byblos, who found themselves actually censured by the king for defending the king's land against his enemies. Abdashirta and his son Aziru, the leaders of the Amorites, conducted this campaign of mingled war and diplomacy with incredible craft and success.

Abdashirta, it is true, was checked at last, owing to the representations of Ribadda and the final conviction of the Egyptians that his protestations of loyalty were deceptive. Abdashirta had occupied the important strategical position of Simyra, which was garrisoned by mercenary warriors of the Shekhlal, who are evidently the Shakalsha of later history and are probably to be identified with Pisidians of Sagalassos. ${ }^{1}$ When charged with this act of war Abdashirta pleaded that he had been asked to deliver Simyra from the Shelshlal, and that the Egyptians in the city were with him in the matter.' Ribadda, however, never ceased to point out his treachery to the king, to Egyptian representatives in Phoenicia, ${ }^{3}$ and to Amanappa (Amenemapet ?), who was apparently a travelling commissioner. ${ }^{4}$ In revenge Abdashirta tried to have him assassinated by a Shardina mercenary, whom he killed but not until after he had received nine wounds. ${ }^{5}$ Insistently he demands troops to restore the king's authority. Finally Amenhetep III seems to have been convinced, and sent an army under Amanappa, which retook Simyra, and apparently marched on into Naharin, where Egyptian authority was for a brief space restored. $^{6}$ Shubbiluliuma, who had no intention of coming into direct conflict with Egypt (so strong still was the renown of the great Thothmes), retreated, abandoning Itakama, who on his next invasion fought against him. The Egyptian force soon retired, from Phoenicia as well as from Naharin, but Shubbiluliuma did not at once advance. The road was again open for an Egyptian army to march against him had he invaded Naharin. An Amorite revolt against Egypt was necessary, and there can be little doubt, after perusal of

${ }^{1}$ Hal.t, P.S.B.A. xxxi. p. 23 I. See pp. 70, $38 \mathrm{r}$.

2 Amarna letter, KNudtzon (K) 62.

473 .

5 K $\mathrm{S}$.

${ }^{3}$ Letter $\mathrm{K} 69$, etc.

' $\mathrm{K}$ I I $7, l .2 \mathrm{Iff}$. 
Ribadda's letters, that the speedy recrudescence of the revolt, under Abdashirta and Aziru, was brought about and supported by him. Meanwhile, till it should have gained head, he turned against Mitanni. In his account of his struggle with Dushratta, discovered at Boghaz Kyöi, he states that Dushratta had "risen against him," thus breaking the treaty which had been concluded between him, probably at his accession, and Artatama, Dushratta's grandfather, no doubt at the end of Artatama's reign. In consequence of this Shubbiluliuma now crossed the Euphrates and plundered the northern border of Mitanni. Dushratta, protesting, threatened that if he plundered the left bank of the Euphrates, which was his territory, he would plunder the right bank, whether it were his or not. ${ }^{1}$

From this it would appear that both kings already laid claim to Naharin, which was rightfully Egyptian territory. Dushratta does not, however, seem to have carried out his threat. They formally defied each other, but never actually came to blows. Shubbiluliuma had been made wary by his first defeat. He replied to a second defiance from Dushratta by an expedition against the land of Isuwa and by another against Alshe, probably the territory immediately north of Mitanni, and presumably then tributary to Dushratta. The latter marched out to attack the Hittites, but Shubbiluliuma avoided battle, and returned to the Euphrates, which he crossed, and marched in force into Naharin, which Aziru's revolt had now again cut off from Egypt. The princes, who preferred Egyptian or Mitannian rule to that of the Hittites, resisted him; but Aleppo, Nii, Arakhti, and Katna were all conquered, and the people of Katna were carried off to Khatti. ${ }^{2}$ Of the capture of Katna we hear from a letter of its loyal prince Akizzi, who seems to have escaped. ${ }^{3}$ The land of Nukhashshi was conquered, and its king Sarrupsi fled, but his family was sent to Khatti. Kinza, the city of Itakama, his former ally, says Shubbiluliuma, he had not intended to attack, but Itakama, who no doubt resented his desertion in the previous Hittite invasion (in the year before?), and had probably made his submission to the Egyptian army of Amanappa, now attacked him with his father Shutatarra. The two were, however, defeated, and carried off to Khatti,

M.D.O.G., l.c. p. 32 .

${ }^{2}$ Ibid. p. 34. This expedition is referred to by Ribadda in letter $\mathrm{K} 75$.

${ }^{3} \mathrm{~K} 55$. 
whither the Hittite now retired with his booty. "On account of the disobedience of the king Dushratta have I plundered all these lands in one year, and brought them to Khatti," he says. "From the mountain Niblani, from the Euphrates have I made them my territory." 1 He thus chooses to regard Naharin and Nukhashshi as Mitannian, not Egyptian, territory."

The death of Amenhetep III now probably occurred. Shubbiluliuma waited to see whether the new king of Egypt would be likely to attempt the recovery of Syria from the rebels, in which case the Hittites would probably have abandoned the latter and left Naharin to Egypt. Accordingly, when messengers from Egypt came to him with news of the accession of Amenhetep IV, Shubbiluliuma sent with an ill grace a somewhat surly letter of congratulation to the new king of Egypt, and refrained from any overt acts of hostility in Naharin. ${ }^{3}$ He awaited events. The Egyptian government took no measures to put down the revolt, in spite of the urgent advice of the King of Babylon. ${ }^{4}$ And though Dushratta badly needed the friendship of Egypt, and wrote to Amenhetep IV and his mother invoking it and reminding them of the political plans (against Shubbiluliuma) which he had concerted with Amenhetep III, Tii seems to have been unfriendly to him, and he complains of her irritation against him. ${ }^{5}$ Possibly in Egypt Dushratta was distrusted almost as much as Shubbiluliuma. Abdashirta was now attacking Byblos, and Ribadda writes to Egypt that he fears he will take it as he did Simyra. ${ }^{6}$ Dushratta now, with the idea of conciliating Egypt and gaining her assistance against his great enemy, marched to Phoenicia, and Ribadda reports that he had occupied Simyra, but was prevented from relieving Byblos from want of water, and so had retired again to his own land. ${ }^{7}$ This movement was really, in view of the threatening attitude of Shubbiluliuma on the flank of his line of march, a great proof of his desire for Egyptian friendship, but it was no doubt misrepresented to Egypt as an attempt at conquest of Egyptian territory. Either now, or shortly afterwards, Abdashirta was captured and killed, whether by one of the robber-bands or by Ribadda's

${ }^{1}$ M.D.O.G., l.c. p. 35 .

${ }^{2}$ So also does Ribadda, even when writing to Egypt ( $K$ 75).

$\begin{array}{lll}{ }^{3} \mathrm{~K} 4 \mathrm{I} . & { }^{4} \mathrm{~K} \mathrm{~S} \text {; see p. } 265 . \\ { }^{6} \mathrm{~K} 9 \mathrm{I} . & { }^{7} \mathrm{~K} \mathrm{~S} \text {. }\end{array}$ 


\section{THE ANCIEN'T HISTORY OF THE NEAR FAST}

men is not clear. ${ }^{1}$ His place was, however, at once taken by his sons, especially by the energetic Aziru, who had distinguished himself by assisting the Hittites to take the town of Katna, and by stirring up the land of Ube (Hobah) and its capital, Damascus, to revolt. ${ }^{2}$ He now attacked Simyra again. In Phoenicia the men of Arvad, the northernmost city, seem to have been the most anti-Egyptian in sentiment, as they had been in the days of Thothmes III. ${ }^{3}$ Probably this was caused by jealousy of the Southern cities, especially Byblos, which had always submitted peacefully to Egyptian supremacy. The Arvadites now appear in full alliance with the sons of Aziru, and Ribadda writes to Egypt to urge that their merchant-ships in the Delta ports should be seized. ${ }^{4}$ He could do little else. The Egyptian troops had been withdrawn, and the Amorites were in no mood to be awed by the appearance and reappearance of Egyptian commissioners such as Turbikha, the lieutenant in the North of the viceroy Yankhamu, or a certain Khai, whose loyalty, as well as energy, was suspected by Ribadda. ${ }^{5}$ Turbikha seems to have been as ill-informed as most of the Egyptian commissioners. The Syrian seaport town of Irkata, south of Arvad, still held out for the king, though pressed by the sons of Aziru. But Turbikha, instead of encouraging the men of Irkata, seems to have rated and abused them, and told them that the king "hated Irkata." The result was a letter of complaint from the town to the king. ${ }^{6}$ When the faithful adherents of Egypt were treated thus, it is no wonder that the revolt grew apace. Ullaza was soon taken by the sons of Aziru, and Simyra was besieged by them in alliance with the Arvadites. Ribadda's communications with Egypt were seriously interfered with by the Phoenician pirate Yapa'addi of Dor, ${ }^{7}$ and the corn from Egypt on which he relied for subsistence for his garrisons was not sent. His letters grew more insistent and finally indignant in tone. Why, he asks, will the king not allow Yankhamu, the viceroy of Yarimuta (the Delta), to come to his assistance? he is a wise man and the king has no better servant than he. ${ }^{8}$ It would seem that jealousy of the powerful viceroy determined

\footnotetext{
${ }^{1} \mathrm{~K}$ 101.

${ }^{2} \mathrm{~K} 107$.

${ }^{3}$ See pp. $240 \mathrm{ff}$.

${ }^{4} \mathrm{~K}$ 105.

${ }^{5} \mathrm{~K}$ ior.

${ }^{6} \mathrm{~K}$ 100. Irkata was on the coast (at Kala'at Arkâ), south of Arvad.

' $\mathrm{K} 105 \mathrm{ff}$; $\mathrm{II} 3 \mathrm{ff}$.

${ }^{8} \mathrm{~K}$ II 8, l. 55.
} 
the king to retain him in Egypt even at the hazard of losing the empire, and Ribadda's praise of him probably did Yankhamu no good at the court, where the impression would be given that the viceroy had prompted Ribadda to ask for him. Also the sinister influence of the sons of Abdashirta at the court, where Aziru had a powerful friend in the Egyptian noble Dudu, ${ }^{1}$ would be actively exerted to prevent a decision so dangerous to their schemes as the dispatch of Yankhamu to l'hoenicia. Constantly Ribadda asks for troops, especially for the redoubtable Sudanese, the men of Melukhkha and of Kush,? whom in all probability the Semites feared far more than they did the Egyptians or the mercenaries from Asia Minor. He is ordered to "defend": how can he do so with no troops? His ancestors had never been abandoned in this way by the king's ancestors. ${ }^{4}$ Of old at the sight of an Egyptian the kings of Canaan fled, but now the sons of Abdashirta mock at the Egyptians! ${ }^{5}$ Finally his rage gets the better of him, and he roundly tells the pharaoh that he has lied in saying that he has sent troops. ${ }^{6}$ He was now hard pressed by Aziru, and all that the king cared about was that the despatch of tribute should go on as usual. The Egyptian commissioners seem to have had no orders but to see that tribute was sent, in spite of the impossibility of getting it. How can he obtain wood from Ugarit and Zalkhi with Aziru and the Arvadites in the way? ${ }^{7}$ All had gone wrong since Khai and Amanappa left Simyra with copper for Egypt.s Finally Simyra fell, surrendered by the Egyptian commander Khaib: Biwari, another Egyptian officer, was killed. ${ }^{9}$

The result was an alarming increase of the revolt. Zimrida, King of Sidon, gave up the Egyptian cause as hopeless, and allied himself with Aziru and the Arvadites against Byblos and the ancient rival of Sidon, Tyre, whose king, Abimilki, imitates Ribadda in writing despairing letters to Egypt. ${ }^{10} \mathrm{He}$ is, however, more courtly in his phraseology than the energetic King of Byblos, and gives the impression of being a weaker man. He was honestly loyal to Egypt: in his fathers' time "the gods of his city had gone over to Egypt," and he obeys

\footnotetext{
${ }^{1} \mathrm{KI} 58,164$.

${ }^{4} \mathrm{~K}$ 109, $l l .6 \mathrm{ff}$.

$7 \mathrm{~K} 126$.

${ }^{10} \mathrm{~K} \mathrm{I46-155.}$
}

${ }^{2} \mathrm{~K} 127, \mathrm{I}_{3} \mathrm{I}, \mathrm{I3} 2,133$.

5 Ibid. ll. 44 ff.

${ }^{8} \mathrm{~K}$ 109, ll. 6r fi.

${ }^{3} \mathrm{~K}$ II 2.

${ }^{6} \mathrm{~K}$ I 39.

${ }^{9} \mathrm{~K} 127, \mathrm{I} 29$. 
their behests. He tries to gain help by means of obsequious reports of his evil case. He is "a servant of tears," and is shut up in his island-city by Zimrida. But neither Ribadda's anger nor Abimilki's tears brought any assistance from Egypt. The time had indeed now gone by when it was possible to do anything to save the North, which was now entirely in the hands of Aziru, who had finally succeeded in taking Irkata as well as Simyra, and had killed the king who had so indignantly protested against the stupidity of Turbikha. Any soldiers that were left to Egypt by the pacifist fanaticism of Akhenaten were now all needed in the South, where the simmering anarchy caused by the wanderings of the Khabiri, $S a-G a z$, and other masterless men (Sutu or Beduins) blazed out into open revolt as a consequence of the Amorite rebellion. ${ }^{1}$ Here also Milkili and Labaya, two Canaanite chiefs, while in reality allied with the Khabiri, at the same time tried to delude the Egyptian court into believing them to be its loyal and energetic supporters. This they did, in spite of the protests of the Iranian princes of Megiddo, Biridiya and Yazdâta, ${ }^{2}$ and of the insistent despatches of Abdkhiba, the native governor of Jerusalem, on one of which is written a note to the royal scribe who should translate it: "To the scribe of my lord the king, Abdkhiba thy servant: Bring these words plainly before my lord the king." And the gist of this letter is in the words: "The whole land of the king is going to ruin." 3 Thus in the South Milkili and Labaya played the same "game of bluff" as Abdashirta and Aziru in the North, and Abdkhiba in the South had the same thankless task of combating the incredible apathy and ignorance of Akhenaten and his court as Ribadda had in the North. Perhaps he had more success in the end, as Jerusalem was nearer to Egypt than Byblos, and Yankhamu the viceroy of the Delta, to whose province Southern Palestine was attached, could hardly be deceived as to the truth of the protestations of Milkili and Labaya, and their allies Zimrida of Lachish (who was soon killed), and the Iranian immigrant, Shuyardâta. ${ }^{4}$ Sudanese troops were sent to Jerusalem, but there they seem to have come into collision with the population, and caused such trouble that Abdkhiba complains bitterly of them. They had nearly killed him in his own house. ${ }^{5}$ Nothing went well for the

${ }^{1}$ See p. 342. $\quad 2$ K 243-248. $\quad{ }^{3} \mathrm{~K} 2 \mathrm{S9} . \quad 4 \mathrm{~K} 270,290$.

${ }^{5} \mathrm{~K} 287,288$; "men of Kashi," not of Kashshi, which was a land of Syria. 
Egyptians, and the whole country was terrorized by the Khabiri and the Sutu, who in the South seem to have attacked both the Egyptians and the Canaanites impartially. And here, too, the king demanded his tribute as if nothing was happening. Widya of Ashkelon has to send the tribute of Aten, as ordered. ${ }^{1}$ We can obtain no clearer idea of the obsession of the king's mind by his religious mania. Abdkhiba tries to arrest his attention by asking him to succour the territory of Jerusalem which bore his name: ${ }^{2}$ probably a temple of the Aten had been set up in Jerusalem, which may be the "Khinatuni" which has already been mentioned. ${ }^{3}$ But we hear nothing of the result of this clever appeal. Matters went from bad to worse. The Egyptian officials on the spot were utterly confused by the contradiction between the facts as they saw them and the foolish orders they received from home, and those specially sent from Egypt, ignorant of the local conditions, and not knowing whom to believe, committed mistake after mistake. Bikhuru, a general sent by Yankhamu to restore order, actually was so ignorant of his friends and foes that he sent a body of Arab auxiliaries against Byblos, who massacred Ribadda's garrison of Mediterranean mercenaries (Shardina) ${ }_{d}^{4}$ in Egyptian pay. The unhappy Ribadda may well have cursed the day when he refused to follow the counsels of his family and throw in his lot with the Amorites.

Finally, returning from some expedition without the walls, he found the gates of Byblos shut against him, and had to flee for refuge to Bêrût, where the king Ammunira received him. ${ }^{5}$

The fall of Simyra and Byblos seems to have caused some commotion in Egypt. The loss of the gateway of Naharin and the expulsion of so prominent an Egyptian sympathizer as Ribadda from his city could hardly be ignored by the philosopher-king or explained away by the (probably well-paid) friends of Aziru at court. A wordy and pompous, weakly threatening, letter was sent by the king's orders ${ }^{6}$ to Aziru, bidding him restore Ribadda to his city, and demanding the reason of his friendship with Itakama, the Prince of Kadesh, who was now again an active ally of the Hittites. A bombastic

\footnotetext{
1 "The tribute of the Sun" (nol "of Amen"): K 325, l. $2 \mathrm{I}$.

$\because \mathrm{K} 287, l .60 \mathrm{ff}$.

4 K 122. For the Shardina, see pp. 70, 38 r.

${ }^{3} \mathrm{~K} \mathrm{I} 38$.

"See p. 300.

${ }^{\circ} \mathrm{K} 162$.
} 
threat that if he is an enemy he and all his house will be sacrificed (before Amen) by the king's own axe is followed by the tearful remonstrance, "Thou knowest that the king doth not wish to carry war through Canaan"; and the letter ends with a significant demand for the surrender of some Egyptian enemies of the king, Sharru, Tuya [Tui], Leia [Rei], Uishiari [Osirei, for Seti?], the son-in-law of Mania [Mena], Daasharti, Pâlûma, and Nimmakhê [Nebemhat?] with their sons and wives. We can hardly doubt that these were prominent Amonists who had taken refuge with Aziru from the king's fanatical wrath. ${ }^{1}$ So here again the religious obsession comes forth, and clouds the king's counsel.

Finally, after Aziru had killed Ribadda and the ruler of Bêrût, Ammunira, he was summoned to Egypt, and eventually he had to go. He went ${ }^{2}$ as a great vassal prince, slayer of the king's enemies, and defender of the empire against the Northern barbarians. The accusing voices of Akizzi of Katna, of Ribadda of Byblos, and of Abimilki of Tyre were now silent, and the Egyptian court was only too glad to compromise and accept the accomplished fact with as little loss of dignity as possible. Aziru probably acknowledged Egyptian suzerainty and returned to Syria as the ruler of a practically independent state of considerable extent. But he did not rule it long undisturbed. Shubbiluliuma's support had enabled Aziru to effect his first conquests after the death of Amenhetep III. Aziru had no doubt kept him quiet hitherto by protestations of friendship, if not by actual admission of supremacy. But his visit to Egypt and return to Syria, blessed by Egyptian recognition and no doubt anointed with the sacred oil as an Egyptian sub-king, must have been enough to provoke Shubbiluliuma to attack him at once. From the letters of the Hittite king lately discovered at Boghaz Kyöi we learn that he had regarded Aziru as his vassal, that he now considered that he had revolted from him, and that he defeated him and compelled him to swear allegiance to him and to obey Hittite orders. ${ }^{3}$ Thus the whole of Syria and Phoenicia was lost to Egypt. Bikhuru the general

${ }^{1}$ I think it far more probable that these names are Egyptian than Mitannian, as. Weber thinks (KNudtzon, Amarna-Tafeln, Anm., p. 1268). While some of them have a non-Egyptian sound, most are distinctly Egyptian in character.

ㅈ 169.

${ }^{3}$ M.D.O.G., l.c. p. 43 . 
fell back on Jerusalem, and it cannot have been long before even that strong city also was abandoned to its Jebusite inhabitants, and all Palestine to the Khabiri, the wandering Hebrew tribes who three centuries afterwards founded, in the lands of which they had thus taken possession, settled and enduring kingdoms of their own. ${ }^{1}$

Dushratta was thus isolated, and shortly afterwards was murdered by one of his sons. "When his son with his servants conspired and slew his father Dushratta and death found Dushratta, Teshub decided the right of Artatama and gave life to his son Artatama," says Shubbiluliuma in the preface to a treaty with Mattiuaza, son of Dushratta, found at Boghaz Kyöi, from which much of our information as to the Hittite wars is derived. $^{2}$ Apparently Dushratta's exiled brother and rival Artatama and his son Shutatarra now seized the throne, driving out the son (Mattiuaza?) who had murdered Dushratta. He fled to Khatti. The result was a period of anarchy. "The land of Mitanni was entirely destroyed," says Shubbiluliuma, "and the Assyrians and the people of Alshe divided it between them." 3 So Ashur-uballit seized the opportunity to occupy the portion of Dushratta's kingdom nearest to him. Saushshatar, the father of Artatama I, and the first Mitannian king of whom we have any knowledge, had carried off from Ashur a door of gold and silver and had set it up in his palace at Waraganni, his capital. Shutatarra gave it back to Ashur-uballit, no doubt under compulsion. ${ }^{4}$

Shubbiluliuma now appeared upon the scene. "Till now had the Sun, Shubbiluliuma, the Great King, the noble King of Khatti, beloved of Teshub, refrained from crossing the Euphrates, and had taken neither taxes nor tribute from the land of Mitanni. But when the Great King saw the desolation of the land of Mitanni, he sent men of the palace, oxen, sheep, and horses, for the men of Khani (the Mitannians) there were in misery. Shutatarra and his nobles endeavoured to slay Mattiuaza, the son of the king; but he fled, and came to the Sun Shubbiluliuma, the Great King. The Great King spake: 'Teshub hath decicled his right for him, since now I take Mattiuaza, the son of King Dushratta, by the hand, and set him upon his throne. In order that the land of Mitanni, the great land, may not disappear, hath the Great King Shubbiluliuma

$$
{ }^{1} \text { See Ch. IX. }
$$$$
2 \text { M.D.O.G., l.c. p. } 36 .
$$

3 Ihid.

4 loid. p. ${ }_{3}^{8 .}$ 
summoned it to life for the sake of his daughter. For Mattiuaza, the son of Dushratta, have I taken by the hand, and have given him my daughter to wife." "1 The fruit was now quite ripe: by waiting Shubbiluliuma had attained all. "That the great land of Mitanni might not be destroyed utterly," and with a fine touch of contempt not for the sake of the rightful king, Dushratta's son, but for that of his daughter, to whom he now married him, the Hittite Bismarck entered Mitanni, drove out the Assyrians and the men of Alshe, ejected Artatama and Shutatarra, whom he had used and abandoned, and placed Mattiuaza on the throne of Dushratta as his son-in-law and vassal. The cautious yet calculating policy of years was finally crowned with the attainment of the position at which he had aimed from the first, and Shubbiluliuma now as an old man reigned undisputed lord over the whole of North-western Asia. Even the energetic Ashur-uballit had to give way before him. Assyria was not yet powerful enough to withstand the king of the Hittites in war, and her king had no desire to see the treasures of Ashur carried off to Asia Minor. By his politic evasion of direct conflict with Shubbiluliuma Ashur-uballit himself gave evidence of political sagacity not inferior to that of the Shubbiluliuma, and it may well be that from watching the career of the older Hittite monarch the Assyrian king learnt lessons which made him in after years, when he was himself an old man, the conqueror of Babylon and the dictator of Mesopotamia. ${ }^{2}$

How long the revolt lasted till the final abandonment of Palestine after the subjection of Aziru by Shubbiluliuma we do not know. Before Aziru's capture of Simyra Ribadda speaks of the war as having lasted already five years, ${ }^{3}$ but we do not know whether he is referring only to the second revolt after the death of Amenhetep III or dates his five years from the beginning of the trouble, when Abdashirta took Simyra, probably a year or two before Amenhetep's death. Perhaps twelve or fifteen years (c. 1378-1 365 B.C.) saw the whole tragedy played out from start to finish. ${ }^{4}$

${ }^{1}$ M.D.O.G., loc. cit. p. 36 .

${ }^{2}$ See pp. $266,368$.

${ }^{3}$ Letter K 106.

${ }^{4}$ We are able to trace the course of these events with tolerable certainty, in spite of the absence of all indications of date or time in the various letters and despatches found at Tell el-Amarna from which the above account is drawn. That Simyra was twice besieged and captured, first in the reign of Amenhetep III by Abdashirta, secondly in that of Amenhetep IV by Aziru, is quite certain. There were two distinct 
Of the Egyptian actors in the revolts we know nothing from Egyptian sources with the exception of Dudu, who is the Tutu buried at Tell el-Amarna. Yankhamu, the powerful viceroy of the Delta (Yarimuta ${ }^{1}$ ) is unknown to the inscriptions. Perhaps Akhenaten or Horemheb destroyed all record of him.

Thus the conquests of Thothmes I and III were lost, by the ignorance and incapacity of the king, the folly and probably the venality of his courtiers, and the stupidity and possible treachery of some of his officers. The soldiers must have been utterly divided in opinion by the religious revolution, and without Amon to help them were, as they would have phrased it, as rudderless ships in the storm. Their world had been turned upside down, and it is little wonder that their brains and hands were paralysed.

Tutankhamen, the second successor of Akhenaten, seems, after the restoration of the ancient religion, to have attempted to recover Southern Palestine. In the tomb of Hui, viceroy of Kush, at Thebes, we have pictures of the bringing of tribute

revolts of the Amorites, separated by the "small expedition" under Amanappa sent by Amenhetep III, which retook Phoenicia " in a few days," as Ribadda says, and, as we know from the letters of Akizzi of Katna, penetrated into Mitanni, but was probably recalled by the news of the old king's death. The end of the first revolt is also marked by the death of Abdashirta.

Then among the mass of letters referring to the second revolt in Akhenaten's reign, we can distinguish the earlier from the later by the test of the recognition of the king's Aten-worship by the writers. In the earlier letters of the second revolt the king's god is referred to as Amen, and Amen (Amana) is invoked to protect him. Then, about the time of Aziru's capture of Simyra, and probably not long after the letter speaking of the war as having already lasted six years was written, Ribadda prays that "the Sun" (Aten) may give the king strength. Abimilki rather later on, after Zimrida of Sidon had revolted, fully recognizes Atenism, and tells the king that he "is the Sun who rises over the lands daily like the Sun his father." The despatches of the Southern revolt refer only to the Aten as the king's god, never to Amen. The King of Ashkelon sends the tribute "of the Sun ": Abdkhiba refers probably to the Aten-name as having been given to Jerusalem; and the letter from Burraburiash to Akhenaten referring to the robbery of his caravan at "Khinatuni" (? Jerusalem or Bethshemesh) evidently is of the same period; the actual robbers he mentions by name are also mentioned in the war despatches from Southern Palestine. With the help of such indications as these and study of the probable interdependences and cross-references in the letters it is possible to evolve some such connected account of the two revolts as that given above.

1 The word "Yarimuta" seems to be Egyptian, and probably refers to the Delta. The element "yari" must be the Egyptian iaro, ioor (spelt in hieroglyphs "itur"), "river," the Nile: "mûta" is unexplained; it cannot be meh, mehet, "north," which would be transcribed as "mêkhi" or "mûkhi" in cuneiform. So the word cannot mean "River of the North." The name Yankhamu seems to be Semitic, not Egyptian. 


\section{THE ANCIENT HISTORY OF THE NEAR EAST}

by the Asiatic chiefs, who say to the ling: "Give us the breath which thou givest, $\mathrm{O}$ lord! Tell us thy victories, and there shall be no revolters in thy time, but the land shall be in peace." This is evidently a reference to the Canaanite revolt. That it was impossible in his reign to reconstitute in any way the old imperial officialdom of the Asiatic subject-lands seems to be shewn by the fact that this tribute of the North is presented by the two viceroys of the South and Kush, Hui and his brother Amenhetep, not by an officer detailed to deal with the affairs of the North. ${ }^{1}$

Before his death Shubbiluliuma saw the coping-stone placed on the edifice he had raised, by the conclusion of a treaty with Egypt," probably under Horemheb, by which he must have been left in undisturbed possession of Naharin and Amurru, while Canaan and Phoenicia were left for Egypt to recover if she could.

\section{Mursil and Seti I}

Mursil (c. I345 B.c.)-Seti I invades Palestine (c. IjIS B.c.)-Conflict with the Hittites, who are defeated-Treaty of peace

At Shubbiluliuma's death his sceptre passed to his son MURSIL, ${ }^{3}$ after the short intervening reign of an elder brother of the latter, named ARANDA. ${ }^{4}$ The empire which Mursil inherited stretched from the Phrygian mountains, probably, and from the Black Sea to Carmel and Galilee in the south, and to the circumscribed northern frontier of Assyria and the mountains of Armenia in the east. We cannot doubt that Shubbiluliuma paid attention to the westward as well as to the southern and eastern expansion of his kingdom, and it may be he who is depicted on the rocks of Tmolos (Karabel) and Sipylos in Lydia, ${ }^{5}$ but from the references to unknown lands in his tablets we can at present learn nothing of possible campaigns as far as

${ }^{1}$ In an inscription, recently discovered at Karnak, which records his restoration of the priesthood of Amen at Karnak, it is sadly confessed, with a candour extraordinary in an ancient record, that "if one sent men to the coast of Phoenicia to enlarge the borders of Egypt, it would be impossible for them to succeed there."

2 This treaty is referred to in the time of Rameses II. (p. 364).

3 The name was spelt by the Egyptians "Maursar," but we know the true pronunciation "Mursil" from the Boghaz Kyöi documents. I use the short form "Mursil," not the longer "Mursilis," because the Egyptian form shews that the final $-i$ s was not pronounced : it is a personal suffix or definite article.

M.D.O.G., loc. cit. p. 18.

${ }^{5}$ See p. 329, n. 2. 
the Aegean: we may well do so later, however, when these tablets found at Boghaz Kyöi have been fully studied and published. Then we may gain important knowledge as to his relations with the now decaying and war-harried "Mycenaean" peoples of the Aegean basin. Over the contending Canaanites, Khabiri, and Beduins of Palestine south of Syria, left to their fate by Egypt for a time, neither he nor Mursil seem to have attempted to extend their rule.

They had no desire to come to close quarters with Egypt. The advent of a new dynasty had infused new energy into the counsels of Egypt, which was fast recovering from the stupor which the boulezersement under Alhenaten had laid upon her. Under Seti I she marched forth once more to reassert her Asiatic dominion. The "neutral territory" of Palestine which the Hittites had not attempted to occupy was retaken almost without a blow, Seti and his army entered Galilec, and for the first time the Egyptians and the Hittites met on the field. Shubbiluliuma had never crossed swords with Egypt.

The details of the campaigns of Seti I and Rameses II ${ }^{1}$ are neither so important nor so interesting as those of the campaigns of Thothmes III. We know much less of what happened, though the complete decipherment of the Boghaz. Kyöi tablets may fill up the gaps in the Egyptian accounts. Seti undoubtedly modelled his action upon that of Thothmes. Like him, he started on his enterprise as soon as he had attained the supreme power, in the first year of his reign. Like him, also, his first campaign was directed towards the securing of Southern Palestine and Phoenicia, from which, as his base, he could attack the Orontes valley. As before, Phoenicia had

'The order and approximate dates of the kings at the XIXth and following dynasties will be found given in the chronological table at the end of this chapter. Manetho is still available to shew us that the Egyptians of his time had an approximately correct idea of the names and succession of the Ramessides, though his list is by no means complete. As arranged by SchNabel, O.L.Z., I9I1, p. 69, the Manethonian list is as follows :-

I. Sethōs [Seti I] .

$$
5 \text { I years. }
$$

2. Ramesses (Rapsakes) [Rameses II] . . . 66 , 2 months.

3. Amenephthes (Amenophath) [Merenptah] . . I9 " 6 ",

4. Sethōs [Seti i1] . • . . . . 5 ,"

5. Thouöris [Queen Tausret] . . . . . 7 ",

The years of Rameses II are given correctly, and those of his successors are probably by no means incorrect. Rameses I, Rameses-Siptah, and Amenmeses are omitted. 
to be subdued from the land side first, in order that her ships might be seized and utilized for the transport of troops directly to Northern Syria. ${ }^{1}$

Advancing from the frontier-city of Tjaru, Seti pushed across the desert into Palestine, and the city of Pe-kanana, "the Canaan," was captured. It is probable that this was the capital city of Canaan, Jerusalem itself. Then the Jordan was crossed, and the king set up his boundary-stela at Tell esh-Shihâb in the Haurân, ${ }^{2}$ marking his border over against the confines of the king of Karduniyash. Turning westward then, and still meeting with little resistance, apparently, he marched through the plain of Jezreel into Phoenicia, where also the princes seem to have made no opposition to the restoration of Egyptian supremacy.

Very possibly they welcomed the restoration. The connexion with highly civilized and luxurious Egypt could not but be more profitable to their commercial interests than subjection to the control of the Hittites. Further, Egyptian overlordship secured to the city-folk the control of the uplands, while Hittite predominance meant domination of the coast cities by the hill-folk of the Lebanon and the Orontes valley.

Probably it was the Phoenician feeling in favour of Egypt that lamed the arm of Mursil. At any rate, he made no attempt to prevent a seizure of Phoenicia. Had it been intended to exclude Egyptian dominion from Asia, Seti ought to have been met in the plain of Jezreel, where a Hittite victory would probably have shattered the projects of the Egyptian king. But apparently the king of Khatti regarded Southern Palestine, and Phoenicia also, as outside his regular dominion, and an Egyptian occupation of those countries as no infraction of Shubbiluliuma's treaty; he trusted also in the mountains of Lebanon and Hermon as his southern frontier, and his generalship was not sufficiently inspired to make him see the strategic importance of Phoenicia. He left considerations of strategy to the Egyptians, being content to let them (if

It is evident that the Egyptians still possessed no navy of their own by whose means a direct occupation of Phoenicia might have been effected. When Phoenicia was lost to them they had no ships. Egyptian vessels do not appear upon the sea till the reign of Rameses III, and then they seem to be but an ephemeral phenomenon.

2Palestine Exploration Fund Quarterly' Statement, I901, pp. 347-48; I904, pp. 78-8o. Tell esh-Shihâb lies $22 \mathrm{~m}$. E. of the Lake of Tiberias. 
they really intended to attack him afterwards) take what advantage they would, sure that in the end the hard bodies and sharp swords of his Anatolian soldiers would prevail against the weaker warriors of the South.

Countless prisoners of the Beduins and Kluabiri were brought back to Egypt, where at the border, on the farther shore of the "Crocodile-river," Seti was met by a stately deputation of white-robed nobles and priests, who acclaimed him as victor over the Semites. Arrived in the Delta, Seti seems to have made his headquarters there for nearly two years without prosecuting his Northern campaign any further. ${ }^{1}$

Probably he had no immediate intention of attacking the Hittites, but it may well be that in the third year Mursil shewed signs of invading Phoenicia, with the result that Seti put into operation the second phase of the Thothmosid strategy. Probably in his fourth year he advanced from Phoenicia (whether he went there by sea or land we do not know) over the mountains into the Orontes valley and attacked Kadesh, whether successfully or not is uncertain. In the field, however, a Hittite army was certainly overthrown, with considerable loss. ${ }^{2}$ It was the first time, as far as we know, that the Egyptians had come into actual conflict with the Hittites, and in the first bout victory declared for the Southerners. Whether the defenders of Kadesh were the redoubtable Anatolians, the real Hittites from beyond the Taurus, or not rather merely the local half-Semitic levies of the Orontes valley captained by Hittite and Mitannian chiefs, is, however, doubtful.

The result of the battle was that Mursil gave up all idea of ousting the Egyptians from Palestine and Phoenicia, while

${ }^{1}$ A series of hicratic bills for the maintenance of his court, which have been lately published, shew that he was either at Memphis or elsewhere in the Eastern Delta throughout his second year, and at any rate for part of his third. It has been supposed by Prof. Breasted (who restricts this period to one year) that it was nuw that Seti carried out the campaign against the Libyans which is mentioned in his inscriptions at Karnak without a precise date being given. This may be, but the evidence of the court-bills shews that the king was in the Eastern, not the Western, Delta most of the time. It seems, on the whole, more probable that the Libyan campaign took place later in the reign, and that the reason of Seti's residence in the Delta is simply to be found in the fact that it was the home of his family (who were certainly Northerners: see p. 3I4), and that he preferred IIemphis to Thebes as a place of residence.

${ }^{2}$ Inscriptions at Karnak; see l'ErRı, Hist. Es. iii. pp. Ii fi. 


\section{THE ANCIEN'T HISTORY OF THE NEAR EAST}

the Egyptian king was not anxious to try conclusions with him further. The prestige of Egypt had been restored and a Hittite army defeated in the open field: rich Phoenicia was once more Egyptian, and by its possession a complete check upon further southward extension of the Hittite power assured. Meanwhile the Hittites retained all the conquests of Shubbiluliuma practically unimpaired. A treaty between the two kings was concluded no doubt on much the same lines as the former one. ${ }^{1}$

\section{Rameses 11 and the Hittites}

Aggression of Rameses II-Opposed by Mursil with the full force of his einpireOrganization of the Egyptian army-The battle of Kadesh (c. 1295 B.C.)-Defeat of the Hittites-Death of Mursil?-Mutallu (c. 1295-1280 B.c.)-Successful operations of the Hittites-Rameses takes Ashkelon and advances into Syria-Battle at TunipPut-akhi the Amorite-Death of Mutallu: Khattusil (c. 1280-1255 B.c.) proposes peace to Rameses, which is accepted as the basis of the status quo ante bellumUselessness and bad results of the struggle-The negotiations and Treaty of Peace and Alliance ( $c .1279$ B.c.)-Contents of the Treaty-Preface and articles of peaceFormer treaties reaffirmed-Status of tributaries-Extradition clauses-EmigrantsAmnesty clause-The witness of the gods-Naptera's letter-Peace ( $c$. 1279-1200)

For the remainder of the reign of Seti, some fifteen ycars, the peace seems to have remained unbroken. But Rameses II deliberately broke it, with results in the long-run disastrous to his country. He was young, impetuous, and proud, and, to judge from his face as we see it in his mummy, not very intelligent. To count the cost of what he was about to do was probably beyond his mental capacity. He was aggressive from the first. Already in his fourth year (c. I $297-6$ B.C.), he visited Phoenicia, which with Canaan had been partly occupied by the Egyptians since Seti's campaigns, without interference from the Hittites. In Phoenicia Rameses set up a boundary stela on the rocks at the entrance of the Nahr el-Kelb, "the Dog River," north of Beirût. Tyre, Sidon, and Beirût had evidently continued faithful to Egypt since their re-occupation by Seti, while Byblos, Simyra, and Arvad had never been recovered. Arvad had been anti-Egyptian in Akhenaten's time, and there is no doubt that the coast farther still to the north, the land of Alashiya ${ }^{2}$ and the town of Ugarit, were more or less part of the Hittite kingdom: Arvad and Ugarit sent contingents to aid Mursil in opposing Rameses.

${ }^{1}$ See p. 354 .

2 P. 243 , n. I. 
The young king now definitely determined, in spite of the two former treaties, to attempt the recovery of the lost conquests of Thothmes III. His intention was obvious and well known, and Mursil summoned the ban and arrière-ban of his loosely confederated empire to oppose him. Besides the host of the Khatti themselves from the highlands of Anatolia and their close allies of Katawadana (Kataonia), he marshalled the Hittites of Carchemish on the Euphrates and of Kadesh on the Orontes, the men of Aleppo (Khilibu), of Nukhashshi and of Naharin, the Phoenicians of Arvad, and the people of Ugarit and Kedi (the Gulf of Iskanderûn), all former tributaries of Egypt, while from the western bounds of his empire came the Pedasa or Pisidians (Pedasians), the Ariunna, the Luka or Lycians, and even the Mysians (Masa) and Dardanians (Dardani) : from Cilicia marched also the Kalakisha and the Mushant. Mursil collected his whole host to bar the only road by which the Egyptians could advance, the valley of the Orontes, with his frontier-fortress of Kadesh at his back. Rameses marched directly to meet him. He had with him the Shardina mercenaries (Plate XXIV. 2) who had been settled in Phoenicia or Egypt since the time of Amenhetep III, and no doubt the negro troops whom the Northerners so much feared; but the main body of his army seems to have been Egyptian, marshalled in a form which we have not previously met with in Egyptian history, as regular legions or divisions, each marching under the banner of a god. There were four of these, the legions of Amen, Ra, Ptah, and Sutekh (Set), the deities who were more especially venerated by the king's house. In all probability the Egyptian army was considerably less in number than that of the Hittites, but more mobile and better organized for battle. We know the events of the war from the relief sculptures of the Ramesseum, ${ }^{1}$ Karnak, and Luxor, as well as from two papyri. ${ }^{2}$

Crossing the mountains from Phoenicia, the Egyptian army debouched into the valley of the Orontes, and marched downstream on Kadesh. The resulting struggle is interesting as the second pitched battle in history (the first was Megiddo ${ }^{3}$ )

'Sallier ii. and iii. The second of these and the inscriptions accompanying the reliefs coniain the "Poem of Pentaur," mentioned below, p. $36 \mathrm{r}$.

2 For the various inscriptions describing the war, see Rev. Eg. iii. 149 to vii. IS2 ; transl. Breasted, Anc. Rec. iii. pp. 123 ff. ; summary in Budge, Hist. Eg. v. pp. 25 ff., who gives illustrations of the temple reliefs accompanying the inscriptions.

${ }^{3}$ See p. 233 . 
of which we have a detailed description, of course only from the Egyptian side, and that from the point of view of the king himself. There is little doubt, even when we make allowances for the royal vanity, that the chief part in the battle was actually borne by Rameses, whose youthful impetuosity and valour undoubtedly saved the Egyptian army from destruction. Mursil must have been an old man, and, though his tactics were well-thought-out and clever, was unable to supplement them by personal dash and vigour at the critical moment. We can restore the actual events of the fight with much accuracy, as Prof. Breasted has pointed out. ${ }^{1}$ It is evident that, misled by the false report of spies specially sent out by Mursil, with orders to let themselves be captured and say that he was still in the vicinity of Aleppo, he pushed on with a small force ahead of his army to Kadesh, and was there cut off by the Hittites, who had been concealed to the north of the fortress, and now extended their left between the two portions of the Egyptian army, cutting the legion of $\mathrm{Ra}$, which was marching up unprepared for battle, in two. ${ }^{2}$ Then Rameses' camp was surprised and taken while the king, unaware of what was happening in his rear, was attacking the right wing of the Hittites north of Kadesh. ${ }^{3}$ Swiftly turning about, Rameses retook the camp, and was compelled to fight his way with his chariots through the masses of opposing chariotry to join the legion of Ptah, which, with the vizier at its head and the survivors of the legion of $\mathrm{Ra}$ with it, was striving to effect his rescue. Of the prodigies of valour which he performed Rameses had much to tell, and no doubt he and his men did fight well. Finally the combined attack from north and south cut through the masses of the Hittite chariotry, which broke for the river, on the farther bank of which Mursil with the rest of his army awaited the decision of fortune, apparently unable to do much to succour his right wing. His good generalship had been brought to nought by the hard fighting and grcater mobility

1 The Battle of Kadesh, Decennial Publication of the University of Chicago, V. 81-127; Anc. Rec. iii. pp. 125 ff. ; History, pp. 427 ff.

2 This is certain from the "Poem of Pentaur," which says: "They came forth from the southern side of Kadesh, and they cut through the division of $\mathrm{Ra}$ in its middle, while they were marching without knowing and without being drawn up for battle. The infantry and chariotry of His Majesty retreated before them."

${ }^{3}$ So Breasted thinks, but this detail is doubtful. 


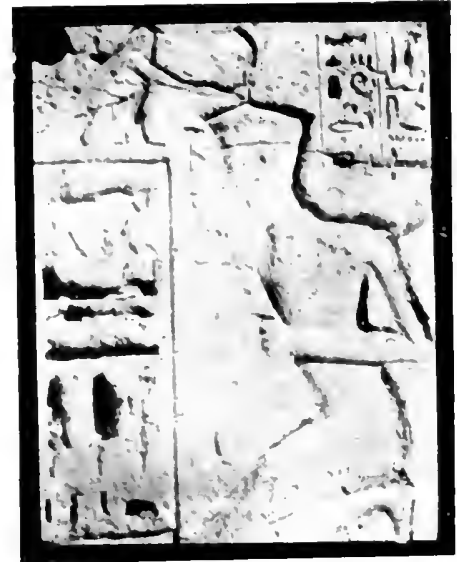

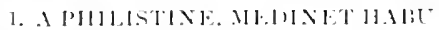

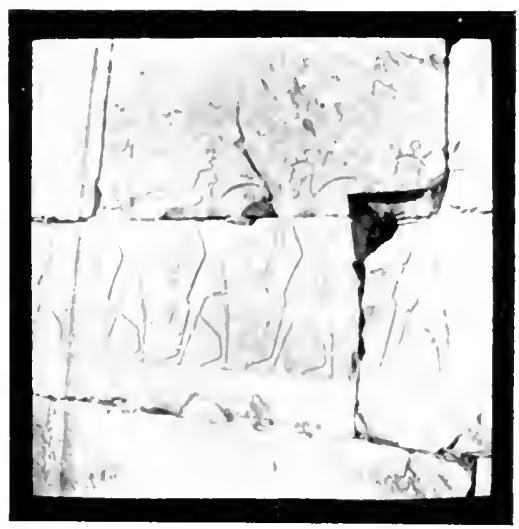

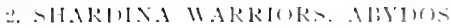

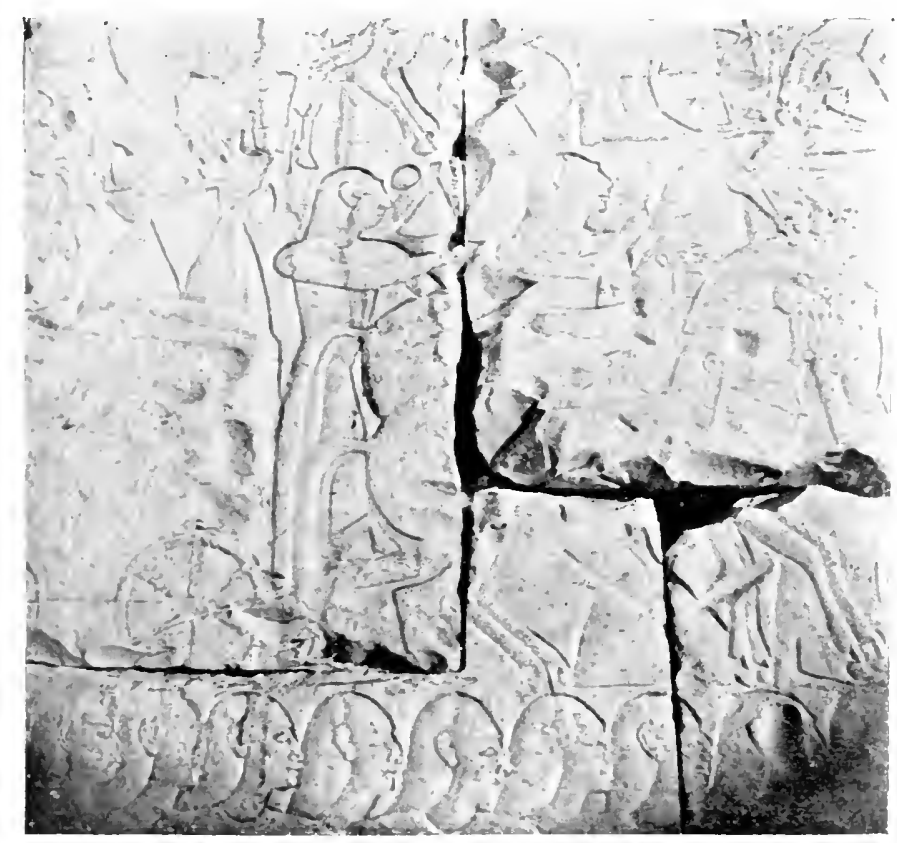

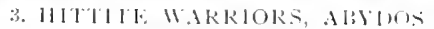



of the Egyytians. In the rout many of the forcmost leaders of the Hittites fell, slain by the sword or drowned in the river, before Mursil's eyes. Among them were Targamenasa and Payasa, his own kajens or charioteers; Kemaija and Tidur, chiefs of the "Tuhiru" or men of valour: Targatijasa and Agma, captains of the bowmen; Khilpsil, his scribe; Irbasunna, chief of the archers of Annasa; Garbatusa, Samartusa, Mejarima, Irbaur, Javajasa, chief of the land of Tanisa; and the Hittitc king's own brother, Shubbijil or Sapajar. ${ }^{1}$ The flower of the Hittite host had perished.

The magnitude of the disaster probably determined Mursil to retreat northwards at once with the rest of his army, while the Egyptians were too exhausted to pursue. They also had suffered too heavily for any further operations to be attempted. We do not know that Rameses even attempted to take Kadesh or whether it surrendered without resistance. The Egyptian army certainly returned at once to Egypt with its prisoners, and we can well believe that Rameses' return was triumphal. The sculptors and scribes were put to work at once to immortalize this mighty battle, and we see the result of their labours in the temple-reliefs already mentioned and in the written poetical accounts which are associated with the name of the scribe Pentaur (Pentaueret) who copied them, though whether he was the original author of the poem (a veritable Ramessiad) that bears his name as copyist is doubtful.

At this juncture the aged Mursil, who, it is probable, was still reigning at the time of Rameses' invasion, and to whom we have ascribed the clever Hittite tactics at the battle of Kadesh, probably died, crushed by the disaster that had befallen his armies, and was succeeded by his son MUTALLU, ${ }^{2}$ to whom fell the task of restoring the prestige of Shubbiluliuma's empirc.

Mutallu was the second son of Mursil. His elder brother, Halpashulubi, ${ }^{3}$ had apparently died before his father.

1 The names of these chiefs are carefully given in the reliefs of Rameses. I have vocalized the consonantal skeletons of the names as seems most probable. The Egyptian forms of cuurse only reproduce the real Hittite names indifferently: thus the Hittite original of "Sapajar" may have been something like "Shubbijil(is)" ; the Egyptian reproduction of "Shubbiluliuma" was "Sapalulu." Khilpsil(is), which is certain, was written in Egyptian "Khirpasar," Mursil(is) "Maursar," Khattusil(is) "Khetasar." (On the termination -is, which, the Egyptian forms shew ss, was often not pronounced, see p. 354, n. 3.)

"The Egyptians reproduced the name as "Mutanro" ("Mautenar").

${ }^{3}$ This nane may be the same as that of the scribe Khirpasar or Khilpsil, who was 
The new king determined on a vigorous offensive against Egypt. While Rameses was still pluming himself on the victory of Kadesh, the Hittite hosts were silently recruited, during a pause of one or two years, and then suddenly launched from the Orontes valley into Galilee. South Palestine was plunged once more into a ferment of war and revolt. The whole country went over to the Hittites, and probably only Phoenicia remained more or less faithful to Egypt. Rameses was compelled to reconquer all Palestine in the campaign of his eighth year (about I292), beginning with Ashkelon, which was taken by storm, and ending with Dapur or Tabor, which was also captured after a siege. Ashkelon was defended by its revolted citizens only, but at Dapur a Hittite contingent fought with the Amorites. These exploits were commemorated at Karnak and the Ramesseum in the same style as the battle of Kadesh.

Mutallu's plan of campaign, momentarily successful, had failed, and he was now to see the war carried into Naharin, where no Egyptian had been seen for nearly a century. He does not seem to have made a very stout resistance against the northward advance which Rameses now undertook, to chastise his foe. Probably he was handicapped by revolt in other portions of his dominions: we hear of a general of the army and of a certain Sin-Teshub, son of Zidâ, who took up arms against him. ${ }^{1}$ The result was that Rameses took Katna and Tunip, and set up his statue in the latter city, while on the coast Arvad submitted, probably about the ninth or tenth year (1290). Egyptian supremacy appeared to be restored as it had been in the days of Amenhetep III, and Bentishina or Put-akhi, the king or paramount chief of the Amorites, the fourth successor of Aziru, was compelled to abandon his allegiance to Khatti, which had been maintained since the time of Aziru, and went over to Egypt. ${ }^{2}$ How long this renewed Egyptian supremacy in Naharin lasted we do not know. Mutallu never made peace, and Rameses had to be constantly fighting to maintain his conquests. Tunip revolted to the Hittites, and was attacked by Rameses, who seems to have been so suddenly surprised outside the city by a Hittite army

killed at Kadesh. Both names may in fact refer to the same person, and Halpashulubi be the "scribe" killed at Kadesh.

${ }^{1}$ M.D.O.G., Dec. I907, p. I9.

2 Ibid. p. 45 . 
that he had to fight without his armour- "his coat of mail was not upon him." This is related as an exploit at the Ramesscum, but that he retook Tunip is not stated, and the fight may in reality have been a severe defeat, glozed over by paeans concerning the ling's personal bravery.

In any case, Mutallu eventually recovered control of both Naharin and Amurru, and removed the faithless Put-akhi from his kingdom, replacing him by a certain Shabili, and taking him as a prisoner to distant Khatti. There, so we are told in the Boghaz Kyöi tablets, ${ }^{1}$ Khattusil, the king's brother, begged his person from Mutallu, and liept him as a noble prisoner in the town or castle of Haggamissa, whence he emerged at the death of Mutallu, and was replaced on his throne by his protector Khattusil, now ling of Khatti.

Mutallu died, after a reign of probably some fifteen years of incessant war, about $12 S O$ B.C., and was succeeded by his younger brother, KHATTUSIL, ${ }^{2}$ the third son of Mursil. Mutallu seems to have had sons, but possibly they were by wives of non-royal rank, so that nonc could succeed: one, named UrkhiTeshub, is mentioned in the Boghaz Kyöi tablets as an emissary of his uncle Khattusil to the king of Egypt.

On his accession Khattusil was probably no longer young, and, weary of war, he seems to have proposed peace to Egypt. Reversing his brother's uncompromising policy, he also, as we have seen, restored the pro-Egyptian Bentishina or Put-akhi to his kingdom of Amurri. This was a stroke of policy likely to placate Rameses, who could at least set off the facts that the Hittites had proposed peace and had restored his man Put-akhi to rule over the Amorites against the unpalatable truth that fifteen years of war had been in vain, and that the territory actually held by the two empires was exactly what it had been in Seti's day, with not one rood, apparently, in favour of the original assailant, Egypt. The Hittites had simply been expelled from Palestine by the Egyptians, and the Egyptians from Northern Syria by the Hittites. No doubt both peoples were exhausted by the war: we can indeed, as we have seen, with some show of truth ascribe much of the decadence of Egypt during the rest of Rameses' reign, and that of the Hittite power under the successors of Khattusil, to the effects of this long and tcrrible struggle. The negotiations resulted in the conclusion 


\section{THE ANCIEN'T HISTORY OF THE NEAR EAST}

of a formal treaty not only of peace but also of alliance between the two Great Powers, the Egyptian text of which has been preserved for us on the walls of Karnak and the Ramesseum, ${ }^{1}$ while parts of the cuneiform original draft seem to be preserved among the clay archives of Boghaz Kyöi. ${ }^{2}$ The actual negotiations seem to have taken place in Syria, and on the 2 Ist day of the first month of the second season, in the 2Ist year of Rameses (I279 B.C. ?), the Egyptian delegates returned to PerRameses, where the king then was, with a Hittite envoy named Tartisibu and his assistant, who brought with them the text of the treaty, probably in Egyptian hieroglyphs and in cuneiform, ${ }^{3}$ engraved upon a silver tablet, which was solemnly presented to the king.

The text of the treaty is one of the most important diplomatic documents of antiquity. It is the cnly one of its kind that has been preserved, though we know that such treaties were common between Asiatic princes, such as the rulers of Babylon and Assyria, and that this was the third treaty that had been made between Khatti and Egypt. As a diplomatic document it is well ordered and logically arranged; and in its phraseology a curiously modern note is sometimes struck, especially in the extradition clauses, which attracted much attention before the discovery of the Tell el-Amarna letters and the correspondence of Khammurabi shewed us how very modern in some respects even these most ancient "ancients" were."

The high contracting parties are on a footing of perfect equality, according to the protocol: both are given the same epithet of $p$-tenil, "the valiant," and the one is styled "the Great Chief of Kheta" ( $p$-sar-o $n$ Khcta), while the other is "the Great Prince of Egypt" ( $p$-l.ik-s 0 Kcmet). The treaty begins with the statement that " at the beginning, for ever, the relations of the Great Prince of Egypt with the Great Chief of Kheta were that the God did not cause hostilities between them, by

\footnotetext{
${ }^{1}$ Best edition of text by W. M. Müller, in Mitth. Vorderasiat. Gcs, vii. 5, Pls. i.-xvi.

2 M.D.O.G., l.c. p. $2 \mathrm{I}$.

${ }^{3}$ It is probable that the Hittite inscription was engraved in cuneiform rather than in the hieroglyphics of Khatti, as the cuneiform script was universally used for all official purposes throughout Western Asia, and was well adapted to be engraved on metal.

"Though in reality it is we who are ancient, not the Egyptians or Hittites "modern."
} 
treaties." Mutallu, however, had fought with Rameses, but now that Mutallu had succumbed to his evil fate, and Khattusil was king, the latter had determined to be friends with Rameses and his sons' sons and with the descendants of Rameses for ever. "There shall be no hostilities between them, for ever. The great chief of Kheta shall not invade the land of Egypt, for ever, to take anything therefrom, and Rameses-Meriamen, the great prince of Egypt, shall not invade the land of Kheta, to take anything therefrom, for cver."

Then both kings declared their adhesion to the former treaties concluded in the times of Shubbiluliuma (Saplulu) and Mursil (called, by mistake, in the text "Mutallu"), but their provisions are not recapitulated. Two clauses then follow which specify the terms of a defensive alliance between Egypt and Khatti, directed against rebellious subjects of the one or the other as well as against foreign enemies. The Hittite king scems to have inserted here a clause to the effect that if on the occasion of a rebellion of one of his tributaries he has notified Egypt of his intention to proceed against him, and the subjects of the offending tributary have acknowlcdged him, the king of Khatti, as their lord, the king of Egypt shall make no claim upon the allegiance of this tributary or his vassals: "Uscrmara Setepenra, the great prince of Egypt, shall be for ever silent."

Follow the very important articles dealing with the extradition of political fugitives and of ordinary emigrants from one country to the other. There is no doubt that during the long war many "traitors" had taken refuge from the vengeance of their own monarch with his enemy, and we have seen that, a ccitury before, Akhenaten had demanded from Aziru the bodies of certain persons, no doubt stubborn Amonists, who had fled from before his face to seek sanctuary in Amurri. ${ }^{1}$ The two kings being now friends, handed over their "rebellious slaves" to one another (but not, as we shall see, to be dealt with at pleasure), and each promised not to reccive any "great men" of the other's land who might seek to take refuge with him. Similarly, if "unknown men" (that is to say, commoners) should come from Egypt to Kheta or from Kheta to Egypt, with the intent to settle and become foreign subjects, it was stipulated that they should be brought back at once to their own country. 
Evidently the legal principle that no man can change his country or his allegiance at his own will was fully recognized. ${ }^{1}$

The next clauses of the treaty seem to be misplaced, no doubt by an oversight of the stone-cutter. The witness of the gods of Kheta and Egypt, which actually comes next, ought to be placed after the two clauses dealing with the amnesty of extradited persons, which should follow the other clauses dealing with extradition. The misplaced clauses provide that if any great men are handed over by one king to the other no punishment whatever shall be inflicted upon them: "let not one cause his wickedness to arise against him, let not his house be injured nor his wives nor his children, let him not be killed, let no injury be done to his ears, to his eyes, to his mouth, to his feet: let not one cause any wickedness to arise against him." These amnesty clauses no doubt refer to persons who had fled from one side to the other during the war, and not to future occurrences.

With these clauses the actual treaty was complete, and now came the witnessing by "the thousand deities, male and female," of Khatti and of Egypt. As the treaty is sent by the king of Khatti to Rameses for his final assent, these deities bear witness only to the words of Khattusil, not to Rameses' acceptance. The Hittite king invokes the whole of his pantheon, as well as "Amen, the Sun-god, Sutekh, the gods and the goddesses of the mountains and the rivers of the land of Egypt, of the heavens, the earth, the Great Sea, the winds, and the storms." Follow the regular curses on the violator and blessings on the observer of the treaty, whose house, land, and servants will be blasted or preserved by the thousand gods of Khatti and Egypt according as he breaks or keeps it.

The final paragraph in the monumental inscription no doubt is not part of the treaty: it is a mere description, for the admiration of posterity, of the Hittite figures and seals on the silver plate: the seals of Sutekh, of the king Khattusil, and

1 One does not ordinarily think of emigration from one country to another as going on to any great extent in these ancient days, but it is very evident that it did, and in Egypt we have abundant proof of the existence of many foreign colonies-of Phoenicians, Syrians, Alashiyans, Cretans, "Tursha," and even Hittites-just at this very time. They were mostly commercial settlements, of merchants and artists (see p. $32 \mathrm{I}$ ). We do not know how many of them would be regarded as Hittite subjects, and so what effect the enforcement of these clauses of the treaty had upon these settlements. 
of his wife the queen I'udukhipa, ${ }^{1}$ and, most important of all, the seal of "the Sun-god of the land of Arnena," ${ }^{2}$ who here seems to take a more important position than Teshub.

The conclusion of the treaty was apparently received with great satisfaction by both sides. Pudukhipa the Hittite queen received a letter from the consort of Rameses, Nefertari (who is called "Naptera"), expressing her delight at the restoration of peace. ${ }^{3}$ Then Rameses was left to the congenial task of blazoning his victories over his new friends on the walls of the temples of Egypt, in order to persuade himself and his subjects into believing that he had been the conqueror, while Khattusil, as a sardonic comment on the vauntings of his "brother," quietly concluded a new treaty with Put-akhi which finally placed the Amorites under the heel of Khatti. ${ }^{4}$

The peace lasted unbroken throughout the reigns of both kings. To the incessant wars of the two centuries since the invasion of Thothmes I succeeded a peace a slumber of exhaustion, over all Syria and Palestine, which lasted till the movement of the Northerners in the reign of Rameses III once more awakened the peoples to the realities of war and conflict.

Meanwhile, Phoenicia south of ever-rebellious Arvad continued to gather in wealth by exchange of commercial products and slaves under the congenial protection of Egypt, while the feuds of Canaanites and Khabiri seem to have been temporarily stilled. Egyptian residents no doubt sate in Gaza, Ashkelon, Jerusalem, or Megiddo, as in Tyre or Sidon, to watch and guide the local princes and chieftains. Peace being resolutely maintained between the two great protagonists, there was no opportunity for intriguc or revolt. To the north, the Amorites bore true allegiance to Khatti, while exporting to Egypt their cedar of Lebanon and the other wood which Egypt had always

1 The importance of the name and seal of Khattusil's wife Pudukhipa is significant (see p. 374, post).

${ }^{2}$ See p. 333, ante. It is noticeable that the Sun-god of Arnena seems to be more especially the patron-deity of the queen, while Teshub is the king's god.

${ }^{3}$ M.D.O.G., Dec. I907, p. 2 I.

${ }^{4}$ Put-akhi of Amurri owed his life and crown to the protection of Khattusil (see above, p. 363), and as by the treaty Egypt made no further claim to his allegiance, he was absolutely bound to Khatti. The connexion was cemented by the marriage of his daughter to Nerigga-Shams, a son of Khattusil, while the princess Gashuliawi (?), daughter of Khattusil, was given to Put-akhi himself as queen of Amurri. Put-akhi no doubt paid, like his forefathers since Aziru, three hundred shekels of gold as yearly tribute (M.D.O.G., l.c. p. 43). 
needed from their land. Egyptian emissaries cut down the valued timber in the territory of Khattusil, and no doubt paid for it much gold into the treasury of his vassal Put-akhi. ${ }^{1}$

\section{Assyria and Babylon in the Thirteenth Century B.C.}

Kurigalzu șikhru (1355-1315) and Adad-nirari of Assyria (c. 1320-1290 B.C.)Shalmaneser I and the Hittites (c. I290-1252 B.C.)-Khattusil and Kadashmanburiash (c. I $2 S 0$ B.C.) -Tukulti-Ninib I conquers Babylon (c. I250 B.C.)

The mixed Iranian and Semitic populations of Naharin and Mitanni, however, apparently formed part of Khattusil's immediate dominions, and were not handed over to a sub-king like Amurri. The important Euphratean city of Carchemish, with a purely Hittite population, was the central fortress of this southern portion of Khattusil's realm, and the watch-tower from which the conquerors could observe the Assyrians and Babylonians. The Hittites did not attempt to conquer Assyria: the, valour of the Assyrian soldiery was already well known, and would have made the enterprise too costly even had the Hittites been in the mood for further wars after their long struggle with Rameses. At the same time, the Assyrians feared the Hittites too much to provoke them to war, and contented themselves with insulting the weaker Babylonians on occasions when it could be done safely. This was not always the case. Kurigalzu "the Younger," who was placed upon the Babylonian throne by his grandfather the Assyrian king Ashuruballit, ${ }^{2}$ had developed into a monarch of firm character and, for a Babylonian, of unusually warlike propensities. He attacked the Elamites, captured their king Khurbatila with his own hands, sacked the capital, Susa, and brought back great spoil to Babylon." All through his long reign he seems to have been quietly disembarrassing himself of the Assyrian tutelage imposed by Ashuruballit, and the two elderly men who succeeded each other on the Assyrian throne, Belnirari and his son Arik-dên-

${ }^{1}$ The king of the Amorites was a powerful vassal of Khatti, for his authority extended over all Southern Syria, including Damascus, and down southwards over the steppe and desert to the northern limits of Arabia. We find the Hittite Great King regarded as responsible for attacks on caravans made by desert Beduins under the authority of the Amorite king even on the borders of Akkad! So that the Hittite empire extended, nominally at any rate, almost from the Aegean to the Persian Gulf.

${ }^{2}$ See p. 266, ante.

${ }^{3}$ Rogers, Hist. Bab. Ass. i. p. 420. 


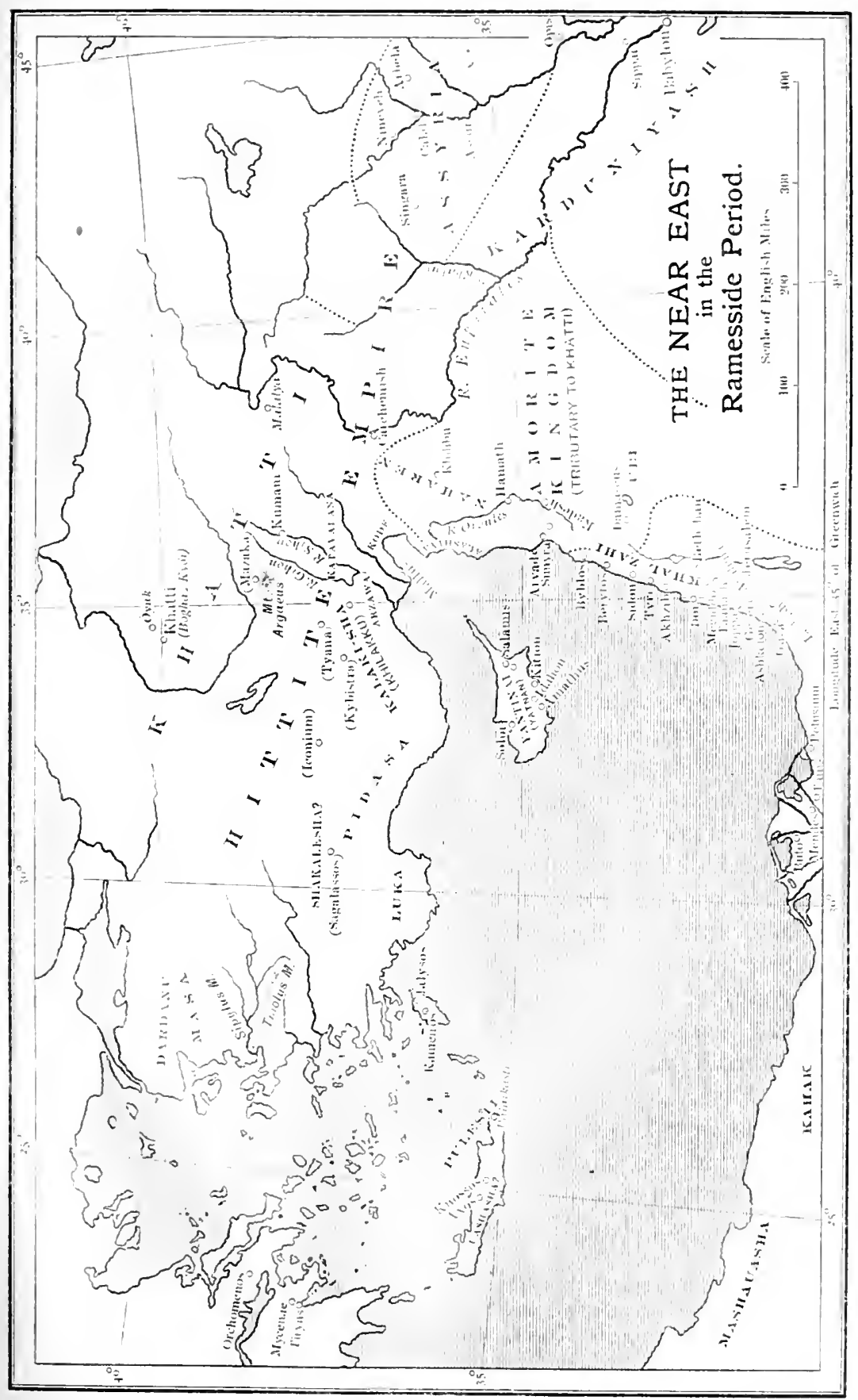



ilu, ${ }^{1}$ were not energetic enough to assert it. Adad-nirari, however, the son of Arik-dên-ilu, was young at his accession, while Kurigalzu was getting old. He accordingly arrogantly attempted to bring the Babylonian to book, with an unfortunate result: the Babylonians were victorious in the open field, and Kurigalzu imposed on the Assyrians his own views of the proper borders and relations between the two nations. Shortly afterwards he died, and Adad-nirari, smarting under defeat, seized the opportunity to attack his son and successor Nazimaruttash, but with what fortune we do not know: the old boundaries seem merely to have been reaffirmed afterwards.

SHALMANESER I, the son of Adad-nirari, was probably encouraged by the long-continued war between Rameses II and the Hittites to endeavour to extend his territory in a northwesterly direction. He appears to have ascended the Tigris to its source and then to have entered the Euphrates valley, which he descended in the direction of the later Samosata, taking tribute from the North Syrian lands of Mușri and Arami. ${ }^{2}$ This expedition could hardly be regarded as otherwise than hostile to Khatti, though no conflict with the Hittites took place, and it may well have been planned in conjunction with Rameses as a diversion in favour of the Egyptians. When peace was concluded with Egypt, the Hittite distrust of Shalmaneser soon shewed itself. Khattusil opened most friendly relations with Kadashman-turgu, the king of Babylon (the successor of Nazimaruttash), and when he died compelled the Babylonian officials to place his son Kadashman-buriash on the throne, by threat of war and conquest, in spite of the irritated protests of the Babylonian minister Itti-Marduk-balațu, who complained that Khatti did not write to the Babylonians in a brotherly manner but ordered them about as if they were vassals. ${ }^{3}$

The death of Kadashman-turgu and accession of Kadashman-buriash must have taken place between the accession of Khattusil and the conclusion of the peace with Egypt, as we find Khattusil, in a letter to Kadashman-buriash to inform him of the treaty with Egypt, ${ }^{4}$ saying that he had formerly notified his father Kadashman-turgu when the king of Egypt had

${ }^{1}$ SchNabel, M.V.G., I908, p. 96, assigns impossibly long reigns, totalling fifty years, to these two ! He is misled by his far too early date for Ashur-uballit.

2 Rogers, l.c. ii. p. 12.

3.D.O.G., Dec. 1907, p. 22.

4 M.D.O.G., l.C. p. 24. 
attacked Khatti (that is to say, on his accession, when he found the war going on). Khattusil cannot have been very long on the throne before the conclusion of peace, so that we can place the end of Kadashman-turgu's reign about I2SO B.C. This gives us the date of the Assyrian Shalmaneser I also.

Kadashman-buriash seems to have reigned but two or three years, and as, at the instigation of Khattusil, he made war upon Shalmaneser, there is every probability that he was defeated and slain by that monarch. ${ }^{1}$ Or perhaps treachery at home may have had something to do with his death. There was no doubt a pro-Assyrian party in Babylonia, which regarded the Northern kinsmen as much the same people as themselves, and desired the union of both countries under the rule of the Assyrian monarchs, who were pure Semitic Mesopotamians, and not foreigners like the Kassites. To this party the apparent dependence of Kadashman-buriash upon the dreaded Great King of Khatti gave a good pretext for action : if Babylonia was not to be absorbed like Mitanni or reduced to the position of a Hittite vassal like Amurri, the friend of Khatti must be deposed and the arms of Shalmaneser must be allowed to prevail. Assyrian domination was preferable to Hittite.

We do not know whether Is-ammi .... (the rest of his name is lost) and Shagarakti-Shuriash, the successors of Kadashmanburiash, were pro-Assyrian or not. Probably the first was, and a nominee of Shalmaneser; and the second not, since his son Kashtiliashu was strongly anti-Assyrian, and was attacked, defeated, and deposed by the energetic son of Shalmaneser, Tukulti-Ninis, I, who assumed the Babylonian crown, and ruled for seven years in Babylon over both kingdoms (c. $1250-1243$ B.C.). ${ }^{2}$

The reign of Tukulti-Ninib marked the first advance of Assyria to a position of equality with Khatti. The inability of the Hittites to prevent the overthrow of their ally and the absorption of his kingdom by Assyria is proof of their decadence during the thirty years of peace that had elapsed since the conclusion of the war with Egypt. Probably Khattusil was now dead, and Dudhâlia his son ${ }^{3}$ reigned in his stead.

${ }^{1}$ In this same letter Khattusil urges Kadashman-buriash to attack an enemy of them both, who can only have been Shalmaneser.

2 See L. W. KING, Records of the Reign of Tukulti-Ninib I (London, I904).

"See p. 374. 


\section{The Decline of Khatti}

Khattusil visits Egypt (c. 1266 r.c.) : Hittite marriage of Rameses II-The god Khonsu of Thebes goes to "Bekhten": "the Tale of the Possessed Princess"Dudhâlia and Amuanta (c. $1255^{-1200 ~ B . c .)-D e a t h ~ o f ~ R a m e s e s ~ I I ~: ~ a c c e s s i o n ~ o f ~}$ Meneptah (c. 1234 B.C.)

During the whole of his reign Khattusil seems to have kept the peace resolutely, never allowing himself to be provoked into war by the restless aggressions of Assyria. Thirteen years after the signing of the Egyptian treaty, in the thirty-fourth year of Rameses II (about I 266 B.C.), the friendship of Egypt and Khatti was reaffirmed by the marriage to Rameses of a Hittite princess, daughter of Khattusil and Pudukhipa, who in Egypt received the name of Ueret-maait-neferu-Ra, "The Princess who seeth the beauties of Ra." Khattusil brought his daughter to Egypt himself in person, thus making a state visit to his brother-monarch, a thing probably unprecedented. Kings were not accustomed to visit one another's territory except with hostile intent. The Hittite emperor was accompanied in his progress to Egypt by a train of sub-kings and chiefs, among whom Put-akhi or his successors no doubt took the foremost place, with his brother-vassal the king of Kedi or Arzawa. They brought with them an immense amount of presents in gold and silver. They came in winter, much to the astonishment of the Egyptians, in spite of snow in the passes of Taurus and rain among the hills of Palestine, as the summer. heat of Egypt would have been felt unbearable by the Anatolians. And no doubt the snow and rain which seemed to the Egyptians to be so terrible an obstacle to marching in the winter-season in Asia were nothing to the Hittites.

The visitors were probably receivcd, and the marriage celebrated, at Tanis (Per-Rameses): it is improbable that they journeyed to Thebes, where, indeed, the Court rarely was. At Abu Simbel we find a stela recording the marriage which ends with the words of Rameses speeding his departing guests and expressing the hope that they will not meet with snow and ice ${ }^{1}$ in the northern passes (Taurus) on the way back to far Anatolia.

1 Selg in Egyptian, the Semitic word telg (our talc). The very interesting identification and correct translation of this word in the inscription of Abu Simbel was made by Breasted, A.J.S.L., Oct. 1906, p. 27. That the Egyptian word for ice should have been discovered on a monument in hot Nubia is curious : 
No doubt the Hittite king remained several months at Tanis, and his stay was probably a veritable prototype of "the Field of the Cloth of Gold."

We do not hear anything of a return-visit paid by Rameses to Khatti. Had he gone there he certainly would have been farther than any other Egyptian king: none before had ever attempted to pass the Taurus, even in war. Had he reached the Halys-land in peace as the guest of Khattusil he certainly would have given some ground for the later legends about Sesostris, who went to Colchis and Bactria. We do not know that he did not go. But if he did not, he did the next best thing, in sending one of his most valuable and venerated deities, Khonsu of Thebes, to the Hittite court just as Dushratta had sent Ishtar of Nineveh to Amenhetep III a century or more before. ${ }^{1}$ For there is little doubt that the famous story of "The Possessed Princess of Bekhten," 2 though known to us only in a late and inaccurate copy made by priestly antiquarians in the time of the Ptolemies, refers to the reign of Rameses II, and that "Bekhten" (often supposed to be Bactria) is really nothing but "Kheta" misread in true Ptolemaic style. It is evident that the main facts of the tale are correct, and that it records a visit paid in the reign of Rameses II by the god Khonsu, son of Amen and Mut, to the court of the King of Khatti in order to cure his daughter Bintresh, ${ }^{3}$ sister of the Queen Ueret-maait-neferu-Ra. Previously Thutiemheb, an Egyptian wise man, had been sent by Rameses to attempt a cure, but had failed, for the Princess Bintresh appeared to be possessed of a devil. Accordingly it was determined to send her the wonder-working image of Khonsu Ari-sekheru, "the Plan-Maker," renowned as an expeller of evil spirits. The tale tells how Rameses asked leave of the great god Khonsu-em-Uaset-Neferhetep, the chief image of Khonsu at Thebes, for permission to send the Plan-Maker to Khatti. "Then said His Majesty before Khonsu-em-Uaset-Neferhetep, ' $O$ good lord, if thou turnest thy face towards Khonsu the Plan-Maker, the great god, driving away evil spirits, he shall go to Bekhten.' The head was inclined deeply, deeply. Then

${ }^{1}$ See pp. 196, 258, ante.

$\approx$ On the inscription containing this story' see BrEaSted, Anc. Rec. iii. pp. $188 \mathrm{ff}$; BuDGE, Legcnds of the Gods, pp. $106 \mathrm{ff}$.

${ }^{3}$ It is noticeable that this Hittite princess bears a Semitic name. 
said His Majesty: 'Send thy protection with him, that I may cause His Majesty to go to Bekhten, to save the daughter of the chief of Bekhten.' Khonsu-em-Uaset-Neferhetep inclined his head decply, deeply." Then the Plan-Maker was taken to Khatti in great state, with ships (no doubt as far as Cilicia), chariots, and horses. Arrived in "Bekhten," he immediately effected the cure of Bintresh, and the tale recounts a marvellous dialogue between him and the expelled devil, who confesses himself his slave, and offers to go away to his own place, if the god will celebrate a feast with him and with the King of Bekhten. "Then this god bent down to his priest, saying, 'Let the King of Bekhten make a great offering before this devil.'” The king, who had been standing by during this remarkable interview, in great fear, did as he was bidden, and the devil finally departed. The king was now so convinced of the prowess of the god that he determined to keep him with him, and did so for three years and nine months, till one night he dreamt that he saw the god fly out of his shrine towards Egypt in the form of a golden hawk. "Then the King of Bekhten caused this god to proceed to Egypt, and gave to him very many gifts of every good thing, very many soldiers and horses. . . Khonsu-the-Plan-Maker-inThebes arrived at his temple in peace in the year 33, the second month, the ninth day, of King Usermara Setepnera."

This date, and that of year 26 given for the departure of the god, should probably be emended to 43 and 36 respectively, as Ueret-maait-neferu- $\mathrm{Ra}$ is mentioned as queen, and the mission to cure her younger sister is very likely to have been sent out a year or two after her marriage, which took place in the year 34 . The journey of Thutiemheb and the retention of the god are paralleled by the mission of a Babylonian physician and an exorciser to Khatti, which is mentioned in a letter from Khattusil to Kadashman-buriash in answer to an inquiry as to what had becume of the two wise men, as they had never come back: the necromancer, Khattusil replied, was dead, but the physician would be returned at once. ${ }^{1}$ Khattusil seems to have been desirous of retaining the science of his wiser neighbours, whether exercised by human, daemonic, or divine agency, at his disposition as long as possible, when it was once in his power. ${ }^{2}$

1 M.D.O.G., Dec. 1907, p. 26.

2The tale of the "Possessed Princess," though worked up to some extent by the Ptolemaic copyists, is still a very faithful transcript of the customs and beliefs of the 
If it was Khattusil who sent back the image of Khonsu in the 43 rd year of Rameses, we must credit him with a reign of at least twenty-two years. As he was the son of Mursil it is not probable that he reigned longer, and he must have been a very old man when he died, like his father and grandfather. We may therefore place the accession of his son DUDHÂlia about 1255 B.C. at latest.

Of Dudhâlia, and his son ARnUANTA, our only information is derived from the Boghaz Kyöi tablets. From them we see that Pudukhipa, the heiress of Katawadana, and powerfu? queen of Khattusil, still held supreme power during the early years of her son's reign : ${ }^{1}$ Rameses addresses a personal letter to her as queen, and when Dudhâlia's name is first mentioned, she appears with him as co-regent. This is testimony to the important part played by the queen in the Hittite state, and no doubt more especially by the queen-mother, on the analogy of the relations between Cybele, the mother-goddess, and her son Atys. Similarly Arnuanta is mentioned in his records with his mother 'Tawâshi. . .., Dudhâlia's wife, and his own wife Muni-Dan, "the Great Queen," who seems to have been at the same time his own sister. It is not impossible that this practice was now begun in imitation of the pharaonic usage, which originated in the desire to keep the royal blood pure, and soon resulted in destroying dynasty after dynasty. ${ }^{2}$

people of the empire with regard to the gods. Whether the images were actually made to nod their heads by the priests, as has been supposed, or not, is uncertain. I'robably the priest merely gave out that the god had nodded in the dark recesses of the sanctuary and amid the obscuring clouds of incense. The respect shewn by Khonsu to the devil and the extraordinary history of the sacrifice and feast made by the King of Bekhten in honour of both are probably priestly embroidery, but the rest of the story is no doubt a but slightly varnished tale of an event that actually took place in the reign of Rameses II (BUDGe, Hist. Eg. v. p. 55 ; BrEasted, Hist. Eg. p. 440).

"In the treaty between Rameses and Khattusil Pudukhipa is spoken of as "the Great Lady of the Land of Kheta, the daughter of the land of Katawadana (Kataonia), the .... of Arnena, the mistress of the land, the votaress of the goddess" (not named, probably Cybele). It may be that her practical equality with her husband was due to her having brought him the kingdom of Katawadana at their marriage, but this is uncertain, and it may well be that a matriarchal system obtained in the royal family of Khatti by which the throne passed in the female line: Pudukhipa may have been married first to Mutallu, and after his death to Khattusil, who became king as much by her right as his own.

2 It is curions that this obvious result did not cause the speedy abandonment of the practice by the Egyptians. Most primitive races are careful to guard against incestuous wedlock, and it is not probable that the practice of brother-and-sister 
The introduction of the practice seems to have synchronized with a decline in the royal house and state of Khatti. Arnuanta was probably the last powerful successor of Shubbiluliuma. After him we hear of no more Great Kings at Boghaz Kyöi.

We have seen that already in Khattusil's reign the central power at Boghaz Kyöi was unable to protect the eastern provinces of the empire from Assyrian attack, and was powerless to resent Shalmaneser's insolent march into Syria, so severely was it weakened by the struggle with Egypt. In Dudhâlia's time these eastern provinces or dependent kingdoms were again ravaged by the Assyrians under Shalmaneser's son, TukultiNinib, without a finger being stirred to help them, although the excuse of the absorbing war with Egypt was no longer available.

It must have been in the reign of Arnuanta that one of the southern Hittite kingdoms, probably that of Kadesh, came into collision once more with Egypt. After a reign of sixty-seven years Rameses II had died (about I234 B.C.) and was succeeded by his eldest surviving son, MENEPTAH (Merenptah). Twelve of his sons had died before him, including his favourite, Kha-em-uaset, the high-priest of Ptah, who seems to have been a man of considerable energy and mental power. ${ }^{1}$ In the latter years of his father's reign he seems to have represented him in various ways, making progresses throughout Egypt to organize the repeated jubilees or Sed-festivals which Rameses celebrated at short intervals after his thirtieth year, and leaving the record of his presence in many temples. Had he lived, he would probably have been a worthy successor to his father. But he died, and the thirteenth brother, Merenptah, succeeded as an elderly man to a throne that was to prove uneasy.

\section{Meneptall and Isracl: the Libyan Invasion of Egypt}

Meneptah's invasion of P'alestine (c. 123 I B.C.) : the Israel-stela-Libyan attacks on Egypt in conjunction with Aegeans

The death of the old monarch of Egypt seems to have been regarded by the Palestinian tribes as a signal for revolt, and in his

marriage was indigenous among the Anatolian highlanders : it was very probably an imitation of Egyptian court customs, the court of Charles I copying that of Louis Xiv.

${ }^{1}$ In later times Kha-em-uaset had a great reputation as a sorcerer. 
third year Meneptah was compelled to subdue afresh the now restricted Asiatic dominion of Egypt. The main movers of the revolt seem to have been the Israelites, now mentioned for the first time in history under their corporate name of Israel (Isirail), and the cities of the Shephelah, specially Ashkelon and Gezer, soon to be occupied by the invading western tribes of the Philistines. Ashkelon and Gezer were taken, the latter after a formidable resistance, apparently, and the Israelites were severely chastised. In a triumphal inscription ${ }^{1}$ which Meneptah set up in his funerary temple in Western Thebes, built with the spoil of Amenhetep III's ruined fane, ${ }^{2}$ we read: "The kings are overthrown, saying 'Salaam!' Not one holds up his head among the Nine Bows. Wasted is Tehenu (Libya), Kheta is pacified, plundered is Canaan with every evil, Ashkelon is carried away, taken is Gezer, Yenoam is made as a thing that is not, Israel is wasted, he hath no seed, Khal (Palestine) has become as a (defenceless) widow before Egypt. All lands are united, and are pacified. Every one that is rebellious is bound by King Merenptah, given life like the Sun every day !" The king was so proud of the taking of Gezer that he added "Binder of Gezer" to his titles. The reference to Kheta, taken with other indications, probably points to a raid upon the Hittites of the Orontes valley, who had presumably afforded assistance to the Canaanites. With the kingdom of "Great Kheta" in Anatolia, however, Meneptah's relations were good, and he had already sent shiploads of corn, no doubt to Arnuanta, to succour "that Kheta-land" when it was devastated by a great famine, a severe blow to the disintegrating empire of Boghaz Kyöi.

The rising of the Canaanites had probably been planned owing to the growing weakness of Egypt in the Delta, which had for some time been threatened by a most formidable invasion of Libyans from the west, in alliance with certain tribes of the Mediterranean, which internal convulsions in Greece, Italy, and the Aegean, caused probably by invasion from Northern Europe, had now driven forth to lead a life of piracy. With these events, and with their probable causes, the second

${ }^{1}$ Discovered by Petrie at Thebes in I8g6 (Six Temples of Thebes, pp. $26 \mathrm{ff}$ ) ; SPIEGELBerg, Ä.Z. xxxiv. I ff.

${ }^{2}$ See pp. 296, 3I7. Meneptah utilized for his inscription the back of a great stela of Amenhetep II1. 
chapter has already dealt. Here it will suffice to say that not long before his death the generals of Rameses II had repulsed a first attack, apparently of Libyans alone, upon the Western Delta, and that two years after his repression of the Palestinian revolt, Meneptah had to face a renewed attack of the Libyans, this time in alliance with a confederation of seafaring tribes from Greece and the coast of Asia Minor, A kaiwasha (possibly Achaians from Greece), Tursha (Tyrsenians from Italy or Asia Minor ?), Luka (Lycians), Shardina (Sardinians or else Sardians from Asia Minor), and Shakalsha (Sagalassians from Asia Minor), "Northerners coming from all lands." The confederated tribes were defeated and more or less annihilated by the Egyptians at Piari in the Western Delta, and Egypt had peace from them, for a time. ${ }^{1}$

\section{The Successors of Meneptah and the Reign of Rameses III}

End of the XIXth Dynasty-The XXth Dynasty: Setnekht and Rameses III (c. 1205 B.C.)-The Great Harris Papyrus- "Rhampsinitos"

The invasion had severely shaken the Egyptian state, already much weakened by the apathy of the last half of the reign of Rameses II. Meneptah died, an old man, after a short reign (about I 225 B.C.), and was buried at Thebes, where his body has recently been found. Then a period of thirty years of confusion in the state began, which had been unexampled for five centuries. Three kings reigned after him whose actual order of succession is by no means yet certainly determined-Amenmeses, RamesesSiptah, and Seti-Meneptah, usually known as Seti II. The most recent view is that they succeeded in the order in which they are here named. ${ }^{2}$ Amenmeses seems to have been certainly a usurper; he reigned for a very short time, his tomb at Thebes was never completed and he was probably never buried in it; also he was never regarded as a legitimate king in later days. Nor was Siptah, who seems, however, to have reigned for some time, and to have been an active monarch.

${ }^{1}$ Inscriptions at Karnak and Kurnah (Breasted, Anc. Rec. iii. pp. $238 \mathrm{ff}$.). On the identifications of these tribes see IIALl, Oldest Civilization of Greece, p. 173; and Keftiu and the Peoples of the Sea (B.S.A. Ann. viii. p. 173). The Luka are already mentioned, as Lukki, in the time of the Amarna letters as raiding Alashiya (see p. 270) ; the Shakalsha, Danuna, and Shardina appear at the same time on the coast of Palestine (pp. 343, 349).

"Maspero, in Davis, Tomb of Siphtah, pp. xiv ff. 
His energy was probably, however, not his own, as by his side stood an energetic man and woman, his chancellor Bai and his queen Tausret, the Thouoris of Manetho. Bai seems to have been the real ruler of the kingdom, in conjunction with the queen, who left a tradition of masterfulness behind her which was still current in Manetho's day.

Seti II was regarded as a legitimate king: possibly he was a cadet of the royal house who was viceroy of Ethiopia under Siptah, and used this prominent position as his stepping-stone to the throne. Since the time of Amenhetep III no serious wars had interfered with the peaceful development of Nubia: the few razzias under Rameses II were mere chastisements of isolated tribes. The gold-mines of the Etbai were steadily worked by the gangs of miserable slaves whom fate had sent there, and he who controlled Nubia now controlled most of the wealth of Egypt. Thus an energetic viceroy could interfere with effect in Egypt if the course of events gave him the opportunity. And the opportunity came to Seti as it had not come to any previous viceroy of Kush, who under the great kings of the last three centuries had had no chance of asserting himself. As king, however, Seti made no mark, and when he died anarchy resulted, the kingdom for a time falling into the power of a Syrian adventurer, whose name is not certainly known. ${ }^{1}$

From this degradation it was, however, soon rescued by a soldier named Setnekht, a Northerner who was probably related to the royal house. He made himself king, expelled the Syrian, but reigned but a year, being succeeded by his son Rameses, who aspired to be a second Rameses the Great. RAMESES III took as his titulary a careful adaptation of the titles of Rameses II, he gave his sons the same names as those of the sons of Rameses II, and his whole reign was a sort of elaborate parody of that of his great predecessor, whom he imitated in every detail. This was a settled policy, designed to inspire the Egyptians anew with the spirit of the first half of the reign of Rameses II, when the young and victorious "Grand Monarque" was dazzling Egypt with the renewed glory of Thothmes IIr, and before the long-drawn-out struggle with the Hittites had exhausted the nation. The policy succeeded

\footnotetext{
${ }^{1}$ It used to be read "Aarsu " or "Arisu," but this word is certainly not a name at all. The passage occurs in the Harris Papyrus,
} 
temporarily: for a short time Egypt was roused from her lethargy of over half a century, and was once more imposing and splendid till the artificial revival of Rameses III collapsed under his successors, and the empire fell into final decay. The fact that this breathing of life into the dying body was essayed and was for a time successful shews that Rameses III was no common man, and that had he chosen to strike out a new line of his own instead of imitating his predecessor, he would have left the mark of a great king of original genius like Thothmes IIr. But he chose his policy and followed it, with the result that his name is overshadowed by that of his probably much less capable but superficially more brilliant model.

In one important respect, however, Rameses III did not follow the example of his prototype; he embarked on no wars of aggression. He had the evils of this policy before his eyes in the exhaustion which he was trying to cure. In Egypt, as in other countries, strong government had too often, indeed usually, meant war and foreign conquests. Rameses III did successfully what Hatshepsut had tried to do in advance of her time; he combined strong government with peace, with the result that, at his death, after a reign of thirty-one years and forty days, he left an Egypt peaceful and wealthy, even wealthier perhaps than in the days of Amenhetep III, but unhappily without the stamina which she had possessed in the days of the magnificent emperor. We know how rich Rameses left Egypt in the record of his benefactions to his people and to the gods, which was copied on papyrus at the time of his death and buried with him as a testimony of his virtue to the gods of the underworld, and is now in the British Museum, where it is known as "the Great Harris Papyrus." 1 The wealth of the country in grain, cattle, silver, and gold was largely shared between the king and the gods, and we can well imagine that so astute and careful a ruler as Rameses III knew well how to turn much of it into his own coffers. So that we can understand how in later days he was regarded as the legendary wealthy king, the Crœsus of ancient Egypt, and is so commemorated by Herodotus in the figure of his "Rhampsinitos." 2 On the walls of the treasure-

1 Transl. by BIrcir in Records of the Past, vi. 21, viii. 5 ; Breasted, Anc. Rec. ii. pp. $87 \mathrm{ft}$.

2HDT, ii. I2I. The name Rhampsinitos is a curious example of later Egyptian confusion: it is "Rameses p-si-Nit: Rameses the son of Neith," the goddess 
chambers of the splendid funerary temple which he built at Medînet Habu, in Western Thebes, we see reliefs representing the magnificent specimens of the goldsmith's art, the heaps of gold rings, the bags of gold-dust and ingots of gold which Rhampsinitos presented to his own shrine. In his day indeed "the heaps of precious ingots gleamed" in hundred-gated Thebes. ${ }^{1}$ But all the gold of Nubia could not serve to arrest the progress of Egyptian decay more than a short time. The spiendour of Rhampsinitos did not mean real strength.

\section{The Great Libyan and Northern Invasions of Egypt}

Libyan attacks defeated-Defeat of the islanders (c. II96 B.c.)-The great sea-fight-Settlement of the Philistines in Palestine--Egyptian invasion of Palestine -Final Libyan attack-The conspiracy trial

However, under this king, the state was still strong enough to defend itself victoriously against external enemies. Rameses III had to defend Egypt against renewed attacks by the Libyans and Mediterranean tribes. Recovered from the blow dealt them by Meneptah thirty years before, and encouraged by the rumours that reached them of the internal dissensions of the Egyptian state, the barbarian tribes again combined to possess themselves of the fat lands of the Egyptian Delta. Twice did they make the attempt, and twice they were driven back into Libya. Between these two attacks from Libya, Rameses was threatened by a danger from the east even more serious than that from the west, and this also was warded off and victory gained for Egypt by the energetic king.

The first Libyan attack was defeated in the fifth year of the reign; the great victory over the European and West-Anatolian tribes who came down through Palestine in a regular Völkerwanderung nearly as far as the borders of Egypt, was gained in the eighth year (about I I96 B.C.). ${ }^{2}$ This war was the greatest national danger that the Egyptians had experienced since the invasion of the Hyksos. The catastrophe is concisely recorded thus in the inscription of Rameses III : "The Isles were restless, of Saïs, who was greatly venerated in the time of the Saïte kings of the XXVIth Dynasty, and in that of Herodotus, shortly after, but not in the time of Rameses III. A religious idea of the Saite period has been tacked on to the name of the XXth-Dynasty king.

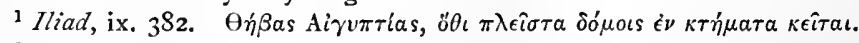

IInscr. Medinet Habu; Breasted, Anc, Rec. iv. pp. 12 ff. See p. 7I, above. 
disturbed among themselves at one and the same time. No land stood before them, beginning from Kheta, Kedi (Cilicia), Carchemish, Arvad, and Alashiya. They destroyed [them, and assembled in their] camp in one place in the midst of Amor (Amurru; Palestine). They desolated its people and its land like that which is not. They came with fire prepared before them, forward towards Egypt. Their main strength was [composed of] Pulesti, Tjakaray, Shakalsha, Daanau, and Uashasha. These lands were united, and they laid their hands upon the land as far as the Circle of the Earth. ${ }^{1}$ Their hearts were confident, full of their plans."

Khatti was already probably weakened by the great famine in Meneptah's reign, and so, at the end of the reign of Armuanta or early in that of an unknown successor, ended Shubbiluliuma's empire, after two centuries of power. But Egypt was not yet to be overrun a second time by a foreign conqueror. Her king saw that a vigorous offensive was the best defence. Advancing by sea and land along the coast towards Palestine, he fell with ships and chariots upon the barbarian host, wearied by long journeying and incessant fighting, and inflicted upon it a complete defeat. The foreign fleet was annihilated, the warriors on land were killed, taken, or put to flight, and no doubt most of the women and children were carried into captivity. As the king says in his inscription, they were trapped like wild-fowl. Taken by surprise in the "harbour-mouths" where their ships had collected, they found their escape seawards barred by an undreamt-of Egyptian fleet which attacked them like "a full flame" as they lay anchored or drawn up upon the shore, while they were taken in rear from the land side, for the arrival of the Egyptian fleet upon the scene had accurately sychronized with the appearance of Rameses with his army. Then, when the seafarers had been disposed of, the army met and defeated the slower moving land horde, which had not yet reached the rendezvous. "Those who reached my frontier, their seed is not; their heart and their soul are perished for ever. As for those who had assembled before them on the sea, the full flame was in their front, before the harbour-mouths, and a wall of metal upon the shore surrounded them. They were dragged, capsized, and laid low upon the beach; slain and made heaps from stem

${ }^{1}$ Probably meaning the northern boundary of Syria, circling round from the Taurus to the upper reaches of the Euphrates and Tigris. 
to bow of their ships. And all their belongings were cast upon the waters."

The outer walls of the temple of Medinet Habu are sculptured with pictures of the great fight. We see the bird-beaked ships of the Aegeans, some capsized, others with their masts falling. From the crow's nest of one tumbles a feathered warrior of the Pulesti (Pl. XXIV. I), transfixed by an Egyptian arrow. Among them drive the lion-headed galleys of Egypt, manned partly by Egyptians, partly by Shardina mercenaries, who fight with other Shardina who are allied with the Pulesti, like Varangians fighting with their Byzantine masters against their Norman brethren. The appearance of an Egyptian fleet must have been entirely unexpected by the would-be invaders. So far as we know, no former Egyptian ruler had attacked the Northern seafarers on their own element, and the fact that he foresaw the probable success of so unprecedented an attack and organized a war-fleet with which to accomplish it, redounds greatly to the credit of Rameses III as an organizer, as the accurate timing of his operations by land and sea does to his credit as a general.

Where the sea-fight actually took place is unknown. Latterly it has been supposed that it was fought far north on the Palestinian coast, even in one of the Phoenician harbours. ${ }^{1}$ It seems more probable, however, that the older view, according to which it took place close to the actual frontier of Egypt, is the correct one. Possibly the "harbour-mouths" referred to are the mouths of the Pelusiac Nile, a very probable rendezvous for the Northern ships, which had long been accustomed to the navigation of the Nile-mouths. The Egyptian galleys, also, do not look as if they were intended for work so far away from the Nile as Phoenicia: they seem river-craft rather than seagoing ships, being frailer and lower in the water than the long-ships of the Northerners.

Nor is it probable that the land battle took place any farther north than the southern Shephelah. The remnant of the Pulesti and the other tribes who escaped the sword of Rameses were not driven very far north, if, as is probable, it was now that they settled in the Shephelah and founded the new nation of the Philistines. ${ }^{2}$ Rameses himself advanced to the confines of the Egyptian dominion to restore his authority

${ }^{1}$ Breasted, Hist. E.g. p. 4 So.

${ }^{2}$ See Ch. IX. 
which the invasion had shaken, and found occasion to enter Amor or Amurri, which had been undisputed territory of Khatti for nearly a century. No doubt the anarchy caused by the Northern invasion or the destruction of the central Hittite power made it necessary for him to take some guarantee for the peaceableness of the Hittite dynasts on his frontier: he seems to have taken Kadesh and other places which were defended by Hittite soldiery. That he actually advanced to the Euphrates is improbable; though he places in his lists of conquered towns names of places in Naharin which are known to us from the time of the XVIIIth Dynasty, this is due probably to a very bad habit which began in his reign, that of copying the names of cities captured in the wars of Thothmes III and placing them to the credit of kings who never came within hundreds of miles of them. ${ }^{1}$

Returned to Egypt, Rameses had a respite of about two years before the last of the three great Libyan attacks on Egypt was met and vanquished in the eleventh year of his reign. This time the $W$ esterners ${ }^{2}$ came alone, without Northern allies. Probably the Tamahu, or Libyans living immediately on the Egyptian border, would not have been desirous of repeating their disastrous experience of six years before, had they not been driven forward by an invasion of the redoubtable Mashauasha or Maxyes from the modern Tunis, who pushed on forward, carrying the Tamahu with them against Egypt. The result was defeat in the Delta, and the enslavement of those who were not killed. According to the inscriptions, 2175 men were slain, while 1494 men and $55 \mathrm{~S}$ women were captured. Kapul, the chief of the Mashauasha, was captured, and Mashashal, his son, was killed.

The remaining twenty years of the reign of Rameses III were entirely peaceful, and were troubled only at the end by the harem conspiracy, which has already been mentioned. ${ }^{3} \mathrm{He}$ was succeeded by several of his sons in succession to one another, who all bore the same name as he.

${ }^{2}$ This absurdity was commonly practised even in the days of the Ptolemies, when most of the places whose capture is ascribed to this or that king had disappeared from the map a thousand years before (see HaLL, in Man, 1903, 92).

2The term "Westerners" is used here for the Libyans, but in the next section must be used, from the Assyrian point of view, for the invading tribes from Asia Minor and the Mediterranean, who to the Egyptians were Northerners.

3 P. 32. 
To the last Ramessides of the XXth Dynasty, the last of the imperial pharaohs, we shall return later: we have now to turn our attention to the apparent effects of the great invasion from the West $^{1}$ upon Assyria and Babylon.

\section{Assyria and Babylonia (1250-1 100 в.C.)}

Babylonian attacks on Assyria-Melishipak II conquers Assyria (c. I210 B.C.)Revolt of Ashur-dan (c. II85 B.c.)-End of the Kassile dynasty (c. 1180 B.c.) -Anatolian invasion of Assyria (c. I Igo в.с.)-Nebuchadrezzar I and Ashur-rish-ishi (c. 1 I 25 B.C.)-Recovery of Assyria : Tiglath-pileser I (c. I I10-1 100)-Assyrian conquests in Anatolia (c. IIO5 B.C.)

Although the Western invasion never actually reached Assyria, its repercussion nevertheless severely affected the young kingdom of Northern Mesopotamia, which at the same time, after a short period of great energy under Tukulti-Ninib, who had taken and ruled Babylon for seven years, was so vigorously attacked by the Babylonians, whose national spirit had been aroused by their subjection, that in its turn the Assyrian power was temporarily overthrown. The struggle against this fierce onslaught of the Babylonians had occupied all the force that Assyria had to dispose of, and she was utterly unable to prevent the western districts of her kingdom, which had been added to it by the warlike kings of fifty years before, from being overrun by hosts of Anatolians who had been forced out of Asia Minor by the Westerners.

The rule of Tukulti-Ninib ${ }^{2}$ was brought to an abrupt end by a revolt of "the nobles of Akkad and Karduniyash," who set Adad-shum-uṣur, son of Kashtiliashu, the king whom TukultiNinib had carried off to Assyria, upon his father's throne; while "against Tukulti-Ninib, who had brought evil upon Babylon, Ashur-nașir-pal, his son, and the nobles of Assyria revolted, and from his throne they cast him, and they besieged him in a house in the city of Kar-Tukultininib, and they slew him with the sword." 3 Thus perished the conqueror miserably at the hands of his own son, and Kashtiliashu was avenged.

In Assyria Ashur-nașir-pal I, the murderer of his father, was

I What to Egypt was an invasion from the North to Assyria was one from the West.

${ }^{2}$ See p. 370, ante. During his rule several pretenders, Belnadinshum, Kadashmankharbe II, and others, appear in one list as recognized sovereigns.

${ }^{3} \mathrm{KING}$, Records of the Reign of Tutkulti-Ninil I, pp. 98, 99. 
probably succeeded after a very brief reign by Tukulti-Ashur, in whose time, six years after it had been carried off, the image of Marduk was restored to Babylon. Probably this was effected by priestly influence rather than war, and we can well imagine that the weakness and troubles of the Assyrian royal house at this time were popularly ascribed to Tukulti-Ninib's sacrilege. For we know nothing more of Tukulti-Ashur, and very soon afterwards we find two kings seated side by side upon the Assyrian throne, Ashurnarara and Nabudani, and we possess a late Assyrian copy of a letter addressed to them by Adadshum-ușur of Babylon. They disappear in their turn, and next we hear from the later chronicles that Bel-kudur-ușur of Assyria and Adad-shum-uṣur fell in battle with one another, after Adad-shum-usurur had reigned thirty years (about I2431213 B.C.). Victory seems to have rested with the Babylonians.

To Bel-kudur-uṣur succeeded Ninib-apal-ekur, and to Adadshum-ușur his son MELISHIPAK II, who was destined to illuminate the close of the long Kassite dynasty with a brief flash of military energy and glory. Following up the victory which his father had gained, though at the price of his life, Melishipak, with his son Marduk-apal-iddina, triumphantly invaded Assyria, and it is not at all certain that he did not so completely reverse the result of Tukulti-Ninib's time as actually to conquer and hold the whole country, handing it over to his son Mardukapal-iddina to govern as King of Assyria. Our information is most scanty, but from various indications this seems probable. If so, the dominion of Khammurabi was restored, and Assyria was under Babylonian rule for some years, as Melishipak reigned fifteen years, and his son (Merodach-baladan I) thirteen; if they had been expelled from Assyria it is hardly likely that they would have had untroubled reigns at home. Also, we hear noching of any Assyrian king after Ninib-apal-ekur till Ashurdan defeats Zamama-shum-iddina the ephemeral successor of Marduk-apal-iddina (about II85 $\quad$ B.C.), and restores the Assyrian kingdom to its old limits and more, adding to it lands beyond the $Z$ ab which had previously been considered Babylonian. If Ashur-dan was the son of Ninib-apal-ekur, he was probably a little child when, about I2 IO B.C., the Babylonians conquered the country. If his father was killed then, he was probably in hiding or exile till, fifteen years later, as a 
young man, he was able to assert his right to his kingdom. The defeat of Zamama-shum-iddina probably marks the final victory of the young king, who took the trans- $Z$ ab lands as a lesson to Babylonia of the futility of conquest and success.

The failure of Melishipak's revenge sounded the deathknell of the long-enduring Kassite dynasty, which had ruled Babylonia for nearly six hundred years. Bel-nadin-shum, successor of Zamama-shum-iddina, was the last Kassite king, and he died or was murdered after a reign of only three years, about IISO B.C. The new dynasty, "of Pashe," that now took up the reins of power in Babylonia, was probably of native Babylonian origin. Perhaps a really native dynasty was considered to augur a more lasting success of Marduk against his enemy Ashur; but we hear of no collision between the two nations till the time of the sixth king of the new dynasty, Nebuchadrezzar I (about I I 25 B.C.).

Assyria needed time to recover from the disasters that had followed the murder of Tukulti-Ninib. These had not come singly. As has already been mentioned, the Babylonian attack was practically contemporary with the loss of the western conquests of Tukulti-Ninib to a horde of Anatolians from "Mushli" (Meshech), that is to say Asia Minor west of the Taurus. The lands of Alshe and Perikuzzi were lost, and later on Kummukh (Kommagene) was invaded and occupied by the "Mushkaya." Tiglath-pileser I, at the end of the twelfth century, speaks of their invasion as having taken place about fifty years before his time. ${ }^{1}$ This is evidently a very vague number, and we can hardly err in regarding the invasion as a direct result of the great migration of the Westerners which, in the first decade of the twelfth century, "overran all lands, beginning from Kheta," and was only stopped on the borders of Egypt by Rameses III. As the invaders are not called specifically "Khatti," but by the more general term of "Mushkaya," they were probably a horde of Hittites from Cappadocia and other Anatolians, who had been compelled to cross the Taurus in search of new land after their own had been desolated by the passing of the great wandering of Aegeans and Western Anatolians, displaced by the Achaians(?) and Phrygians. $^{2}$ The date of their invasion may with great probability be placed between 190 and IISO B.C., before Assyria 
had yet freed herself from the Babylonian control imposed by Melishipak. As the king and court of Assyria were practically non-existent, the outlying provinces were without any form of control, and no doubt the derelict Alshe and Perikuzzi were an obvious and easy prey to the dispossessed and land-seeking Mushkaya.

Assyria was, however, not dead, though she needed nearly a century to recover from her disasters. Ashur-dan reigned peacefully till he reached a good old age, dying honoured by his descendants as the reconstructor of the state. The short reign of his son and successor, Mutakkil-nusku, was equally peaceful. But in that of his son, Ashur-rish-ishi, the old warlike spirit of Assyria began to reassert itself, expeditions were undertaken against the Northern tribes, and war broke out with Babylon. After several unimportant reigns, the dynasty of Pashe had given to Babylon an energetic king, Nabu-kuduruṣur or Nebuchadrezzar I. He was successful as a warrior against Elam, but against Assyria he failed. The cause of the conflict was not now any attempt on the part of either combatant directly to invade and conquer the other. The fighting took place in North-western Mesopotamia, in the Euphrates valley somewhere about the mouth of the Khabur, where for centuries had run the march between the Hittite empire and that of Babylon. This certainly looks as if the Assyrian had been the aggressor: a Babylonian attack on Assyria would have been directed straight up the Tigris valley. Probably Ashur-rish-ishi, who was a warrior, and had campaigned against the Kuti and other mountain-tribes, had turned his arms eastward and had invaded Babylonian territory in Mesopotamia. Here he was met by a Babylonian army, which was defeated with the loss of forty chariots and its commander-inchief Karastu: Nebuchadrezzar does not seem to have been present in person. The result was that most of the Upper Euphratean territory of Babylon was now transferred to Assyria (I I25 B.C.).

It would seem that Nebuchadrezzar had specially directed his attention towards this outlying region of his empire, and had aspired to succeed to part of the inheritance of the Hittites, which was now being dispersed. Amurri had fallen to him, or to one of his predecessors (perhaps Melishipak), so that at this time Babylon exercised at least a nominal authority in the West 
which had hardly been known since the days of Khammurabi. Egypt, indolent and degenerate under the Ramessides of the XXth Dynasty, had neither wish nor intention to dispute it with her. But Assyria, under Ashur-rish-ishi, was ambitious, and under his successor, TIGLATH-PILESER I (reigning in I IO7 B.C.), ${ }^{1}$ made her first essay as world-conqueror, a sort of rehearsal of the Sargonide conquests of the eighth century. Before Tiglath-pileser Babylon shrank within herself, and not only abandoned all her western possessions, but was twice the prey of the conqueror, who styled himself King of Sumer and Akkad. And in the north Assyria finally triumphed over the relic of Khatti when Tiglath-pileser, having in successive campaigns first expelled from their conquests the Anatolian tribes of Mushki who had been settled in the upper Euphrates valley and Kommagene (Kummukh ${ }^{2}$ ) since the troubles at the beginning of the reign of Ashur-dan, secondly subdued Shubari, and thirdly raided Northern Syria (Naharin) west of the Euphrates, then conquered Musri, a Hittite land, and finally penetrated the Taurus to Kumani, which has been identified with Komana of Kataonia (Katawadana).

The Assyrians then entered Anatolia. The city of Khunusa (possibly Iconium) was taken and burned, its triple wall destroyed, and its site sown with salt. Finally the royal city of Kibshuna (Kybistra?) was besieged and surrounded and its walls destroyed. Then the Assyrian king returned to his own country, having subdued all lands from the Lower Zâb to the "broad land of Kumanî, the land of Khatti and the Upper Sea of the West" (the Black Sea). ${ }^{3}$

Thus were even the remnants of Shubbiluliuma's empire destroyed. The Assyrian had not attempted to penetrate to Boghaz Kyöi: probably the imperial town had lain desolate since the catastrophe of the Western Invasion. The name of Khatti still survived even as late as the eighth century, when

${ }^{1}$ It should be noted that Tiglath-pileser is placed a century later (about 1000 B.c.) by one writer, Prof. LehmanN-Haupt (Zwei Hauptproblemen, p. 99). But this view has not found general acceptance (SchnabeL, M. V.G., 1908, pp. 67 ff.).

2 The people of Kummukh seem to have been wholly in sympathy with the Mushki invaders, and in Tiglath-pileser's inscription the king of their chief town, Urratinash, bears the Hittite name of Shadi-teshub, son of Khattusil. The king of the Kurkhi, a neighbouring tribe, who assisted him, was named Kili-teshub, son of Kaliteshub, "whom men also called Irrupi" (Cyl. Inscr., ii. ; Annals, pp. 40, 42).

3 Ib. vi. ; Annals, pp. 82, 83 . 
Carchemish was still the centre of a Hittite nation, but it was the name merely of a petty people; its glory had long departed.

\section{The Decadence of the Egyptian Empire}

The later Ramessides (c. II 72-I IOO 13,C.)-Growth of power of priests of AmenXXIst Dynasty: Herihor and Ncsubanebded: the dual kingdom-Thebans and Tanites-The royal mummies-The mission of Unamon (c. III7 B.c.)-Tiglathpilescr I in Phoenicia

Meanwhile in Egypt the empire of the Ramessides was tottering to its fall. The symptoms of decay in the body politic were too marked for even the energy of Rameses III to delay the catastrophe for long. And after his death the nation had no capable men left. Rameses IV was a miserable devotee, who spent his days praying to Amen, Osiris, and any god whom he thought would hear him, to grant him length of days like Rameses II, for had he not even in four years of reign given to Amen as much wealth and privileges as Rameses II had in his sixty-seven years of reign? We know from "The Great Harris Papyrus," "the record of the gifts given by or confirmed to the temples by Rameses III at the end of his reign, that the estate of Amen then comprised over ten per cent of the cultivated land of Egypt. We can imagine that during his six years' reign Rameses IV increased this proportion very largely, and that under his successors, who were wax in the hands of the priests, it increased more than ever till (and we are not surprised to see it) in the reign of Rameses $\mathrm{IX}^{2}$ the High-Priest of Amen is in wealth and power on an equality with the king himself, and in that of Rameses XI is regent of the kingdom, the pharaoh being a mere fainéant. ${ }^{3}$

The result was not long delayed. When the life of the eleven and last Rameses came to an end after a reign of nearly

1 See p. 379.

2 This king has hitherto been numbered Rameses $\mathrm{x}$, but from a stela at Abu Simbel published by Maspero (Annales du Service, x. p. 15r) we now know that the king hitherto called Rameses Ix, Siptah, is really the same person as the king Siptah of the xixth Dynasty. Rameses " $\mathrm{x}$, " " $\mathrm{xI}$," and " $\mathrm{xII}$ " are then really" Rameses $\mathrm{Ix}, \mathrm{x}$, and $\mathrm{xI}$.

${ }^{3}$ His predecessors had been little better than this. All bore the Rameses-name. It was an obsession which they could not throw off. All originality had gone out of them : they could not conceive themselves kings and not Rameses. The name was a sort of magic talisman by the use of which they could imagine themselves as great as the great Rameses. 
thirty years (about I IOO B.C.), Herihor the high-priest quietly assumed the crown, inscribing his priestly title before his name within the royal cartouche.

His authority was not recognized in the North. When the kings had abandoned Tanis and removed to Thebes, the city of their god and his priest, their mentor, a governor of the North, was appointed to represent the king at Tanis and was characteristically described by the Thebans as "him to whom Amen (not the king) has committed the charge of his North-land." 1 In the reign of Rameses XII the governor of the North was a certain Nesibanebded," who, from his name ("He who belongs to Mendes"), was a Northerner, but was married to a princess of Thebes, named Tent-Amen. When, in the fifth year of the reign of Rameses XI (c. III 7 B.C.), Herihor sent an official named Unamon ${ }^{3}$ to Byblos to obtain wood for the building of the great festival barges of Amen, he gave him letters to Nesibanebded, the Regent of the North, and his wife Tentamen, in order that he might be given passage on a ship for Byblos, as a messenger of Amen. In Unamon's report Tentamen is always mentioned on an equality with her husband, owing, no doubt, to her royal birth. Unamon gives "them" the letter of Herihor, and they reply: "I will act according to the word of Amen-Ra, king of the gods, our lord." From Unamon's description, it appears that Nesibanebded was in close relations with certain great Phoenician merchants of Tanis, ${ }^{4}$ and himself owned ships, manned by Egyptians, upon the Great Sea. Probably he took a considerable part in the active commerce of the time. The shadowy pharaoh Rameses XI was thus from the beginning of his reign compelled to see the authority that rightfully belonged to him usurped not only in the South by the High-Priest of Amen, but also in the North by a wealthy lay satrap, the associate of the great merchants of Phoenicia.

It was then natural that when he died, Nesibanebded should have proclaimed himself king at Tanis, doubtless in right of his wife, simultaneously with the assumption of royal power in the South by Herihor. No struggle between the two took place. Both were old men, each could be of service to the

\footnotetext{
${ }^{1}$ In the Report of Unamon (p. 393).

"Pronounced *Nsvindid, and græecized by Manetho to "Smendes."

3 See p. 393.

${ }^{4}$ See p. 321 , n. I.
} 
other; the nation, which had not known civil war for centurics, was probably disinclined for it, and since the time of Rameses III the military forces of the crown in South and North had probably fallen into complete disorganization. The situation was accepted during the reign of Herilor, but when he died, after a reign of about seven years, his son, the high-priest l'iankh, was unable to continue the royal dignity, and the whole land acknowledged the authority of the Tanite king Aakheperra Psibkhannu I. Piankh's son, Pinetjem I, married Maatkara Mutemhat, daughter of King Psibkhannu, and at the dcath of the latter (after a long reign of forty-one years according to Manetho) the royal authority over the whole land seems to have devolved upon the Theban, who became ling. Then by a new arrangement, the High-Priesthood of Amen was separated from the kingship, and was held in succession by two of Pinetjem's sons, Masaharta and Menkheperra-Psiblihannu, the last of whom survived him, but did not succeed to the crown, which passed to a Tanite, probably a grandson of Psibkhannu I, named Amenemapet, Menkheperra remaining simply High-Priest. There is little doubt that these curious "rotativist" arrangements were due to a family compact devised at the death of Herihor in order to avoid the anomaly of two pharaohs reigning contemporaneously, a phenomenon to which neither princes nor people were yet used. The compact, if there was one, was, however, not kept by Menkheperra, who soon began to use regnal years, and finally adopted the royal cartouche. He became totally independent of the Tanite king, from whom he evidently feared attack, since he equipped a considcrable fortress at el-Hêbi in Middle Egypt to guard his northern frontier. His second son, Pinetjem II, who succeeded him, reigned contemporaneously with Neter-kheper-Ra Siamon ${ }^{1}$ of Tanis, the successor of Amenemapet. This pair was succeeded by two kings, Ded-khepru-Ra Psibkhannu in the South, and Hetj-hel-Ra Hor-Psiblihannu (Psusennes II) in the North, with whom the XXIst Dynasty caine to an end (c. 945 B.C.), and with it the last trace of the rule of imperial Thebes. The reign of the Bubastite Sheshenk (Shishak) who founded the XXIInd Dynasty belongs to a new age and a later chapter.

Our knowledge of the insignificant kings of the XXIst

IOr Situm: he was probably originally named Situm, the form which appears on his scarabs, "Situm Meritum." 
Dynasty is derived but slightly from monumental records. After Herihor's time the priest-kings had neither the means nor the energy to build much, and had no glorious deeds to chronicle in everlasting stone. A stela at Karnak records how Men-kheper-ra Psibkhannu brought back from the Oasis a body of exiles who had been sent there: we have little else. The Northern kings built at Tanis and at Memphis; Siamon is specially notable as a builder. But their efforts could not effect much, and so little did they do or say that we know hardly anything about them, and can but guess at the length of their reigns with the help of Manetho. ${ }^{1}$ But we have considerable knowledge of the priest-kings through a somewhat peculiar source, the small dockets and inscriptions on the wrappings of the mummies of some of these kings, their relatives, and also of their great predecessors, which were found at Dêr el-Bahri in I88 $\mathbf{I}^{2}$ We have seen ${ }^{3}$ that tomb-robbing was by no means unknown in Egypt; and in the reign of Rameses $\mathrm{x}$ a royal commission was appointed to examine into the reported violation of royal tombs. ${ }^{4}$ Finally, so seriously endangered were the royal mummies (which had been mostly found intact in the time of Rameses $\mathrm{x}$ ), that under the Theban priest-kings the practice began of actually moving them from their tombs and hiding them in deep pits or other places of shelter, such as the tomb of one of them. When things concentrated in one or two places only, better guard could be kept over them. As we know, the device was effectual, and preserved in the pit of Dêr el-Bahri and in the tomb of Amenhetep II the bodies of most of the great Theban kings, and of their successors the family of Herihor, who had themselves buried with them, in order to

${ }^{1}$ Manetho gives us no information about the priest-kings: he ignored them as usurpers, regarding the Tanites only as the legitimate rulers. Of these he gives a very intelligible list, his names being remarkably accurate. "Smendes" is Nesiba-neb-ded, "Psousennes" is Psibkhannu (in Ptolemaic times pronounced evidently *Psushanno), "Amenophthis" is Amenemapet ( ${ }^{*}$ Amenmope(t), *Amenophthe), while "Nephercheres" is probably intended for the Theban Kheperkhara Pinetjem, who reigned over the whole country for a time, and may on account of his marriage have been regarded as legitimate by the historiographer. Of "Osokhor" and "Psinnakhes" no explanation can be given. The total years given for the dynasty by Manetho seem to be very accurate, so that there is every probability that the individual regnal years are more or less accurate also.

${ }^{2}$ Maspero, Mím. Inst. Fr. Caire, i.

${ }^{3}$ See p. 294.

"Its acta are recorded in the Abbott, Amherst, and Mayer Papyri, of which the first-named is preserved in the British Museum, and the last at Liverpool. 
share their safety and at the same time avoid the expense of making elaborate royal tombs for themselves. Many of the ancient royal mummies had been found damaged, and were re-rolled in new bandages. When this was done, the name and year of the priest-king then reigning were inscribed upon the "restored" mummy. The date, too, of the removal from the original tomb was placed upon the corpse, and when, as was sometimes the case, there wcre several different removals from one tomb or pit to another, the date and name of the king under whom it was effected were regularly noted. This custom has told us all that we know as to the lengths of reigns and mutual relationships of the Priest-Kings.

Under the XXIst Dynasty the Egyptian empire no longer existed, except in Nubia. Rameses III had scemed to restore the dominion of Egypt in Asia after the defeat of the Northerners, but as a matter of fact Palestine was abandoned to the Philistines, who settled there, perhaps owning a shadowy Egyptian overlordship for a time. The Sinaitic peninsula was finally abandoned after the reign of Rameses vi. ${ }^{1}$ Then Egypt owned not a rood of land east of the Isthmus.

A curious sidelight on the decline of Egyptian power and prestige in Asia at the end of the XXth Dynasty is given by the Golenischeff Papyrus, ${ }^{2}$ which is a report of the envoy Unamon, who was sent. in the fifth year of Rameses XI by the high-priest Herihor to Phoenicia, which has already been mentioned in connexion with the political arrangements at the beginning of the XXIst Dynasty. Still more interesting is its account of the state of Palestine. The coast-cities are absolutely independent of Egypt. Dor is in the possession of the Cretan (?) Tjakaray, ruled by a prince with the Semitic name Badiel. Zakarbaal, the prince of Byblos, openly contemns Egypt to Amen's ambassador though he came with recommendations from the sovereigns of Tanis and their Phoenician friends. "I am neither thy servant," he says, "nor the servant of him that sent thee." He adds that he had detained ambassadors of Rameses $x$ fifteen years in his land, where they had died, and he will shew Unamon their graves if he likes. One of his retainers tells the envoy that the shadow of Zakarbaal is the

${ }^{1}$ Petrie, Rescarchcs in Sinai, p. 108, notes building by Rameses $v 1$ as the latest in the peninsula.

2 Golenischeff, Rec. Trav. xxi. pp. 74 ff. ; Erman, A.Z. xxxviii. 
shadow of Pharaoh his lord: i.e. that Zakarbaal is Unamon's lord and master. But the name of Amen still commands some veneration in Phoenicia, and Egyptian amour propre is solved by a grudging recognition of spiritual influence, if not precisely authority. The ambassador is saved by the prince of Byblos from the Tjakaray pirates of Dor, who had pursued him to Byblos on a charge of stealing silver from one of their captains, by allowing his ship to start from Byblos ahead of them: they might catch him if they could. This was not very complimentary to Egypt, but Unamon escaped them, only to be wrecked on the coast of Alashiya, where he was well received by Hatiba the queen. The papyrus here breaks off, and we do not know how the envoy of Amen returned to Egypt.

Even were the Report of Unamon a purely literary and imaginary work, a novel of adventure, it would have given us invaluable hints as to the relations between Egypt and her erstwhile subjects at the end of the Empire. But there is no reason to doubt that it is a real report of a real envoy, who went through various surprising adventures, and chronicled them in a picturesque style of writing. It is interesting enough, but it must have been bitter reading at Thebes. ${ }^{1}$

Ten or fifteen years later, in 'the north of Egypt's lost dominion, the coming event of Assyrian empire was to cast its shadow before it when Tiglath-pileser, conqueror of the Hittites, marched to the seacoast at Arvad. Here he embarked upon a ship of the Arvadites to see the wonders of the great deep and assert his sovereignty over it as over the land by the slaughter of one of its mightiest denizens, a great dolphin, as he had slain elephants and wild bulls in Mitanni. The men of Arvad had of old always been opponents of the Egyptian connexion, and since the time of Rameses II they had been independent of and more or less subject to the Hittites. Tiglath-pileser claimed

${ }^{1}$ I have no space here to reproduce the whole of the Report, which shews remarkable descriptive power, especially in the account of the envoy's adventures with the Tjakaray, the theft of the silver, and his casting-away on the shore of Alashiya. A picturesque touch tells us how he found the prince of Byblos "sitting in his upper chamber, leaning his back against a window, while the waves of the great Syrian sea beat against the rocks below." Ilow the prince tried to confort him as he sat bewailing his fate on the seashore by sending him first a sheep and then an Egyptian singing-girl, saying, "Sing to him that he may not grieve," is quaintly told. A convenient translation of the whole will be found in WEIGaLL's Treasury of Ancicnt Egypt, pp. II 2 ff. See also my Oldest Civilization of Greece, pp. $321 \mathrm{ff}$. 
their allegiance as the successor of Khatti in the hegemony of Western Asia. It might well have been expected that he would have extended his dominion southwards over Palestine, now torn by the wars between the Philistines and the Jews, but he did not. His wars with Elam and with Marduk-nadin-akhi of Babylon, second successor of Nebuchadrezzar $\mathrm{I}_{1}{ }^{1}$ occupied him fully for the rest of his short reign, and he never reappeared in Syria, which was left to its own devices. His momentary appearance as a great conqueror in Phoenicia had no doubt caused a certain ccmmotion in Egypt, and we find the king of that country (probably Nesibanebded) sending gifts to please the Assyrian, among them a crocodile and a hippopotamus, which were taken to Nineveh to be shewn to the people as extraordinary trophies. ${ }^{2}$

So the story of the Egyptian Empire ends.

${ }^{1}$ See p. 398.

${ }^{2}$ Annals, p. ${ }^{42 .}$ 


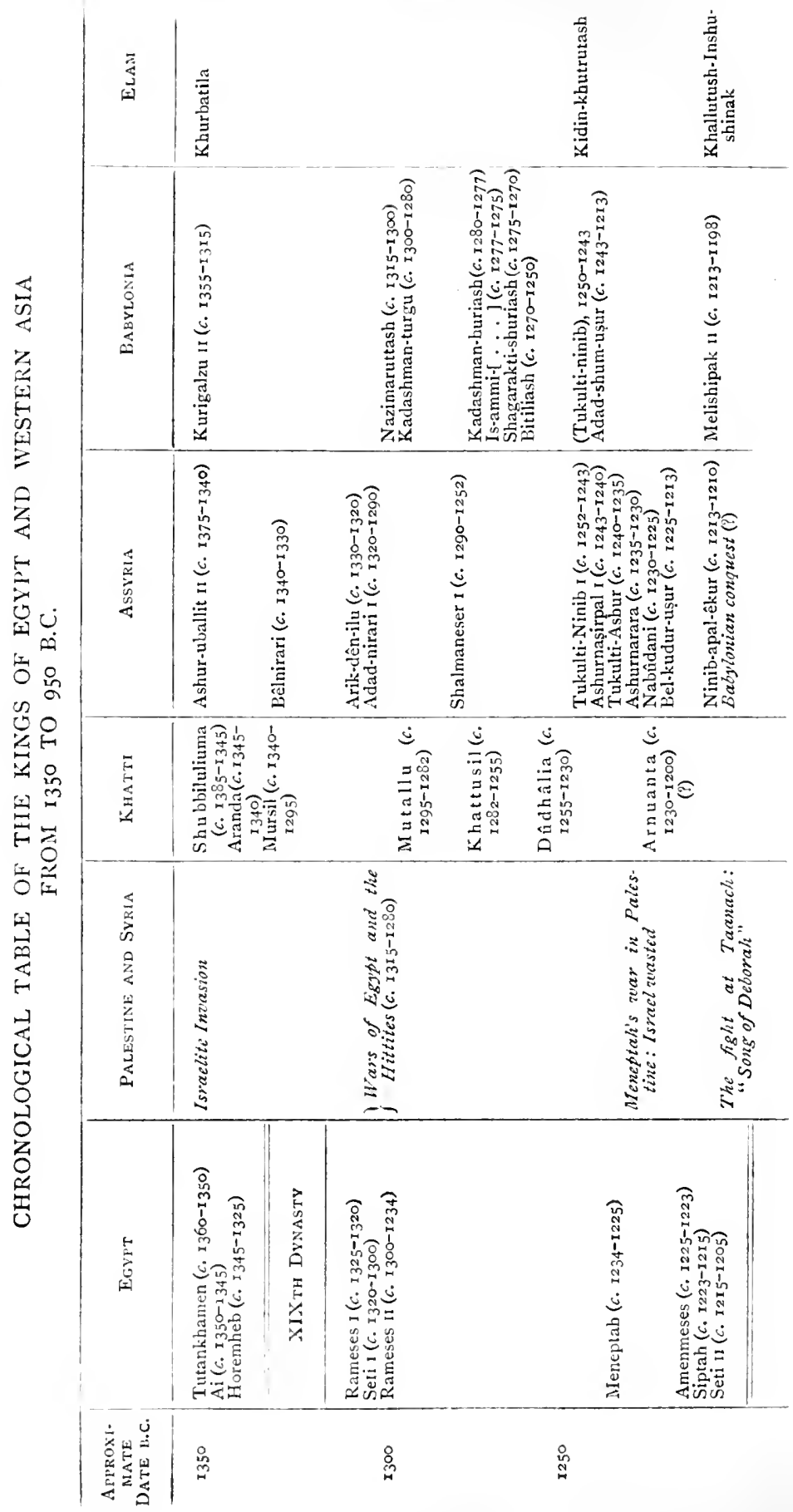




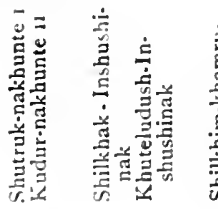

憵

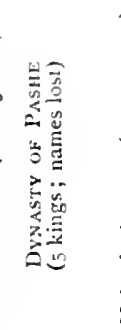

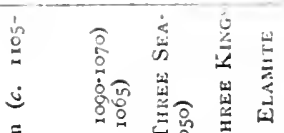

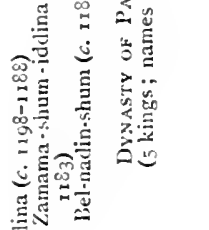

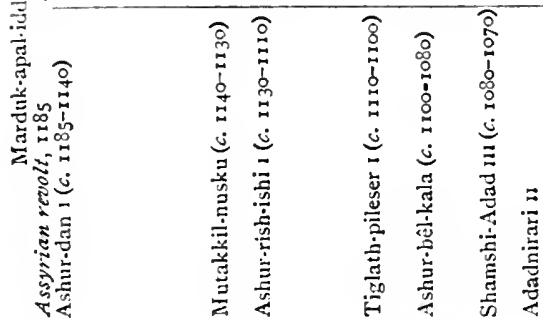

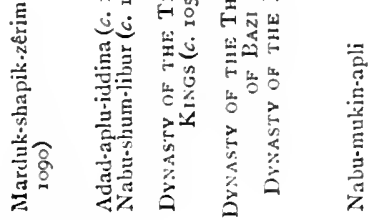

ปับ

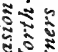

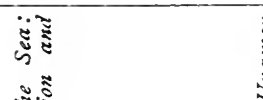

วิำ

ป⿱艹

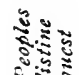

2.

ज्ञां

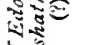

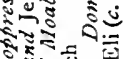

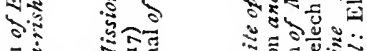

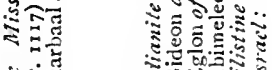

太促

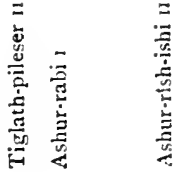

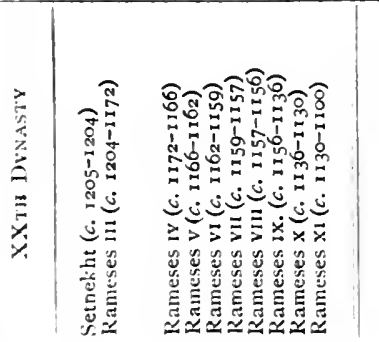

|

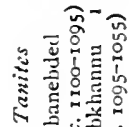

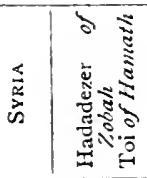

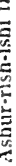




\section{CHAPTER IX}

\section{THE KINGDOMS OF SYRIA AND PALESTINE}

$$
\text { (I 400-854 B.C.) }
$$

\section{Philistines, Hebrezes, and Aramaeans}

Tiglath-pileser I takes Babylon (c. I 105 B.c.)-Weakness of Babylon and Assyria -Palestine-The Aramaeans-Possible Aramaean origin of the stock of AbrahamThe Phoenicians-The colonies: Spain and Carthage

$7 \mathrm{HE}$ advance of Tiglath-pileser I to the shores of the Mediterranean was not followed by any extension

1 of Assyrian power in the West. He was almost immediately recalled to the East by the attack of the Babylonian king Marduk-nadin-akhi, who took the city of Ekallati, and removed to Babylon the statues of Adad and Sala, the gods of the city, which were not recovered till the time of Sennacherib. ${ }^{1}$ Tiglath-pileser took a swift revenge, defeated the Babylonian near the Lower Zab, and overran Babylonia, taking Babylon itself, besides Sippar, Opis, and other cities. This was a deathblow to the Babylonian ideas that had come to the front during the last few reigns: the vain dream of reducing Assyria to obedience to her old mistress was finally given up, and the Babylonians sank back apathetically into an anarchic condition under weak and undistinguished kings whose names are of no interest. The dynasties "of Pashe," "of the Sea-Land" (probably Chaldaeans), and "of Bazi" follow one another, and finally the throne is occupied by "the Elamite," some unnamed usurper

${ }^{1}$ It is uncertain whether the taking of Ekallati occurred before or after Tiglathpileser's capture of Babylon. If before, as we have assumed, it is odd that the looted statues were not restored by Tiglath-pileser. They may, of course, have been hidden, and it seems more probable that the view here takel is the correct one, since the Chronicle speaks of the war in which Babylon was taken as the second one between Tiglath-pileser and Marduk-nadin-akhi. 
from the East. These weak dynasties lasted for over a century : the various kings contended with each other and murdered each other, probably, undisturbed by the advent of a foreign conqueror. For Assyria, too, had fallen into a somewhat similar condition of weakness. The promise of Tiglath-pileser's reign was not fulfilled.

The great king had been a conqueror in peace no less than in war. He changed the capital back from Calah (Nimrûd) to Assur (Kala'at Sherkat), and beautified the royal city in the numcrous new palaces and temples. Foreign trees were planted to give arid Assyria some greenery and shade: herds of oxen and of deer, flocks of sheep and goats and troops of horses, were imported from the West to increase the wealth of the land. But his successors were far less intelligent than he, and his work was abandoned. Ashur-bêl-kala I and Shamshi-Adad, his sons and successors, desired nothing better than to live at peace and in family alliance with Babylonia, and probably hardly stirred from their palaces. Then an eclipse falls over Assyria, and, as in the case of Babylonia, we know nothing of her history for a full century or more.

The moment was auspicious for the rise of a new power in the land of Syria and Palestine. This middle-land had of old been the meeting-place and battlefield of Egypt, of Babylonia, and of the Hittites, and lately Assyria had stretched forth her hand towards it. Now Egypt, Babylon, Khatti, and Assyria seem all at one time to be paralysed. Assyria had done her work in destroying Khatti, only to be herself stricken with a palsy immediately afterwards. Egypt and Babylon were degraded: the kingdoms of drivellers. With Mesopotamia, Anatolia, and Egypt all powerless, the Middle-Land was free. And into this free land fortune had but recently injected three new racial elements, all of which made for freedom and independent development. These were the races of the Philistines and the Israelites in the South, and the Aramaeans in the North. The Israelites and Aramaeans, being Semites, were in time able to absorb the Canaanite and Amorite inhabitants of the land they subdued, but the Philistines were unable to do this. They were not Semites, but Aegean foreigners from Crete, ${ }^{1}$ uncir-

1 On the Cretan origin of the Philistines, which seems well attested, see pp. 7 I ff: anle. The Biblical "Caphtor" is certainly Crete, and that the later inhabitants of Yhilistia in Greek times regarded themselves as of Cretan origin is shewn by the 
cumcised strangers with whom it was impossible for the Semites to amalgamate. The final victory of Israel over the Philistines was as natural a result as the victory of Saladin over the Crusaders: the battle of Baal-perazim was but repeated at the Horns of Hattin. The Philistines were destroyed or absorbed by the Orient, as the Crusaders were later.

The Hebrew and Aramaean invasions preceded that of the Philistines. Probably the Aramaean conquest of Syria was rather a gradual infiltration than a definite conquest achieved at one period of time. The Aramaean tribes, who seem to have developed their nationality on the banks of the middle Euphrates, were originally more or less nomadic "Suti" or Beduin, who were always trying to possess themselves of the outlying lands of their settled neighbours, on the one hand the Babylonians and on the other the Syrians. Their great settlement in the land of Ubi or Hobah, of which the capital was the ancient Damascus (already an important place in the time of Thothmes III), probably took place during or shortly after the confusion caused by the Palestinian rebellion against Akhenaten and the destruction of Mitanni by the Hittites, when, also as we shall see, in all probability the Hebrew invasion of Palestine also took place. Damascus now became the centre of an Aramaean state, and gradually in course of time the Amorites and Hittites of the Orontes valley and Northern Syria were swamped and absorbed or driven out by the steady pressure of the Aramaeans. ${ }^{1}$ On the south the new-comers came into contact with the Hebrews : the boundary between Hebrews and Aramaeans being on the east of the Jordan the Yarmûk, while on the west it ran northwards up the Jordan valley to the mountains where the tribal territory of Asher marched with the seacoast of the Phoenicians.

Between Aramaeans and Hebrews there was probably no very great difference, and it is probable that on the frontiers the two races from the first coalesced, so that the northern tribes, such as Naphtali, could easily change from Israelites into Syrians. And in the heart of the Hebrew nation we might

coin-types and "Minoan" cults of Gaza (G. F. Hill, "Some Palestinian Cults in the Græco-Roman Age"; Proc. Brit. Acad., vol. v. ; March 20, 1912, pp. 13 ff.).

1 The Hittite kings of Boghaz Kyöi and their vassals, the Amorite kings of Palestine (see p. 368 ), seem to have taken no steps forcibly to check the Aramaean flood, which in the north was probably a steady infiltration impossible to stop. 
trace a distinct Aramaean strain in Abraham and his family (who came from Harran in Mesopotamia, which had been Aramaean long before Damascus), if we could assume that the Jahvist writer had misplaced these events in time, and had ascribed to the age of Chedorlaomer and Amraphel an episode which really belongs to the period of Joshua. For in the older period there had been no Aramaeans yet in Harran. But it seems more probable that the Abrahamic legend really relates to the time of the first migration of the ancestors of the Hebrews (the Hyksos?) from Northern Mesopotamia into Canaan, before they entered Egypt, and that his Aramaean connexions were ascribed to him because he came from Harran, where Aramaeans lived in the Jahvist's time. ${ }^{1}$ And it was natural to ascribe Aramaean connexions to the forefather of Israel, since it was easy to see that between Hebrew and Aramaean there was no very great gulf fixed, and it was no doubt traditionally known that both had entered Syria and Palestine from the desert at the same period and more or less in alliance. The genealogy of the children of Nahor (Gen. xxii. 20 ff.) preserves, as Prof. Meyer points out, ${ }^{2}$ an ancient tradition of the lands inhabited by the Aramaeans before they had occupied Southern Syria and Damascus, and, no doubt, before they had crossed the Euphrates valley to Harran. It is noticeable that the full-blooded descendants of Nahor are the true proto-Aramaeans, if we may so call them, of the desert (Uș and Buz, etc.), while his bastards by a concubine are towns of the cultivated land, like Tahash, which is the Takhisa of the Egyptian inscriptions, whose chiefs, a century or more before it became Aramaean, were fastened to the bows of his ship by Amenhetep II and nailed upon the walls of Napata in far Ethiopia. ${ }^{3}$ The inclusion of Tahash, and omission of Damascus and Harran, shew that the list must have been made before I 300 B.C. There is no reason to suppose that in the reign of Amenhetep II (I450 B.C.) Takhisa was Aramaean any more than Damascus was. But in the time of Tiglath-pileser I (I IOo B.C.) there were Aramaeans about Harran, and not very much later we find the kingdoms of Zobah and Damascus at war with David of

${ }^{1}$ This is the reverse of E. MEYER's view (Die Israeliten und ihre Nachbarstämme, p. 248 ) that the Jahvist made him come from Harran because he was an Aramaean.

2 op. cit. p. 239.

${ }^{3}$ See p. 254, antea. 
Israel. These kingdoms must have taken some time to establish and consolidate, so that it is probable that Damascus and Harran both were taken by the Aramaeans in the course of the thirteenth century. Damascus very possibly became Aramaean after the devastating passage of the Northerners from Asia Minor (which shook the Hittite power to its foundations and nearly exterminated the Amorites) had left the ancient city open to occupation by the desert-tribes. ${ }^{1}$

Neither Israelites, Aramaeans, nor Philistines seem to have made much impression on the Phoenicians, who were secure in their island-forts and on the decks of their ships. The Suti and the Khabiri had plagued them in the time of Akhenaten, and that these were the ancestors of the Hebrews seems very probable: but from the Biblical narrative we see that the Hebrews never acquired any Phoenician territory. The tribe of Asher on the Phoenician border became instead almost Phoenician itself, and had little sympathy with the less civilized tribes to the South. Across the Lebanon the Aramaeans could not easily penetrate. In the mountains the remnant of the Amorites and Hittites of the Orontes valley no doubt gathered and formed a protection to the coast-people, who went on with their trafficking undisturbed by the comings and goings of conquerors and conquered at their backs. The terrible progress of the Northerners spared them by land, as the invaders naturally marched by the Syrian Heerstrasse, the historic Orontes valley. But by sea they were vulnerable, and that they learned at the hands of the Philistines and Tjakaray. We see how these pirates plagued them in the eleventh century from Unamon's account of their behaviour at Byblos while he was there, ${ }^{2}$ and the tradition, preserved by Justin, that in I 209 B.C. Tyre was taken by the rex Ascaloniorum, no doubt refers to a Philistine attack not long after the establishment of the foreigners in the Shephelah. But no attack ever really affected the Phoenicians, who preserved their individuality intact from the days of Thothmes III to those of Alexander. Their merchants pursued unhindered and intrepidly their way to the utmost ends of the Mediterranean and beyond, and the trading-factories were now founded that soon developed into

${ }^{1}$ On the early history of the Aramaeans see M. STreck in Klio, vi. (1906), pp. $185 \mathrm{ff}$.

2 See p. 394 . 
the great colonies of Gades, of Tharshish, of Utica and Carthage. This last, the greatest Phoenician colony, was founded not long after the time of Ahab and Ethbaal, towards the end of the ninth century; Utica and Gades were much older; Tharshish was a trading-centre as early as the time of Hiram I and Solomon. ${ }^{1}$

\section{The Hyksos, the Khabiri, and the Hebrows}

The coming of the IIebrews-Date of the Exodus-The Isracl-stele-II cbrews in Palestine before Mencptah-The Khabiri and $S_{A} \cdot G_{A} A Z$ tribes of the Tell el-Amarna tablets-The Khabiri are probably the IIebrews-The Exodus before the Tell el-Amarna period-The Exodus and the Expulsion of the Hyksos

The great racial movements of the Israelites and Aramaeans must have been concluded, and the conquerors settled in their new homes, at latest by the end of the thirteenth century. In the case of the Hebrews this is confirmed by the inscription of the Egyptian king Meneptah," who speaks of the people of "Isirail" in a sense that leaves no doubt that Israel was in his time (not before 1250 B.C.) a settled nation of Palestine, probably in Mount Ephraim. This fact renders it difficult to accept the current view ${ }^{3}$ that places the Exodus (the beginning of the Israelite migration from Egypt, ${ }^{4}$ that was followed by the years of the Wandering) in the reign of Meneptah.

1 I do not doubt the identity of Tharshish with Tartessus in Spain. Tarsus is much too close. Hiram I is said to have reduced Utica to obedience to Tyre, so that its foundation goes back to an early date.

See p. 376 .

${ }^{3}$ This view, which may be said to be the current one, and has been adopted by most recent historians, has been supposed to derive support from Prof. Naville's identification of the route of the Exodus (The Store-City of Pithom, pp. $23 \mathrm{ff}$.). But the traditional route may be that of an exodus at any date, and the name "Rameses" as that of a store-city may have been conferred by a scribe writing long after the Mosaic period (see note, p. 406).

4 It need not be supposed that the ancestors of more than a part of the Hebrew tribes had sojourned in Egypt and had departed from it in the "Exodus." We may well imagine that the tribes who left Egypt were during the period of the Wanderings mixed with and increased by others who had never been there. I am one of those who believe that the Exodus-tradition originally referred to Fgypt, and not to Prof. Winckler's hypothetical North-Arabian "Muṣi" (see p. 466). That the whole story has been so disfigured by later copyists that "in its original form the Mișrim referred to meant not Egypt itself but the North-Arabian land of Muṣ or Mușri," as is held by Cheyne (Encycl. Bibl., s.v.), goes beyond the bounds of all probability, more especially since there never has yet been adduced any convincing proof whatever that this "North-Arabian land of Muṣr or Mussin" ever existed. That the whole of the remarkably correct description of Egypt is to be referred to 
The view that the Exodus took place in Meneptah's reign has always been open to the objection that not enough time was left by it for the period of the Judges. A late Hebrew tradition ${ }^{1}$ ascribed a length of four hundred and eighty years to this period. This tradition had to be ignored, and the period of the Judges reduced by one-half. Yet, in view of the total absence of any information from Egyptian or other contemporary sources concerning the Exodus, it was natural that the reign of Meneptah should have been generally chosen as that of the Pharaoh of the Exodus. Rameses II did very well for the Pharaoh of the Oppression, since he built largely in the Wadi Tûmilât, the Land of Goshen (as, for example, at Pithom), and "Pithom and Raamses" were the store-cities which, according to the Hebrew account, had been built by their ancestors under the pitiless lash of the Egyptian taskmasters. Meneptah, too, was a very weak successor to his masterful father, and after his time Egypt fell into a period of decline. All this was regarded as the result of the blow inflicted upon Egypt by the Exodus.

But the continued study of the Tell el-Amarna tablets and the discovery of the "Israel-stele" 2 have had the result of shaking the confidence even of conservative investigators in the Meneptah theory. The word "Isirail" in the stele cannot be anything else than Israel: it is certainly not Jezreel, as has been suggested, since a Hebrew $z$ could never be reproduced by an Egyptian $s$, and it is not a place-rame but a folk-name, being "determined" by the sign of "people," not that of "town." If we try to combine the fact that there were already Israelites in Palestine who were smitten by Meneptah with the theory that the Exodus took place in his reign, we are driven to suppose, with Prof. Petrie, ${ }^{3}$ that these Israelites of the stela either were a portion of the nation who had been left behind in Canaan or were the result of another Exodus

a later redactor is incredible. The fact of several redactions is clear, if only from a study of the Egyplian names mentioned in the book (see pp. 405, 406). But we cannot suppose that the whole Egyptian part of the Book of Exodus is a pious fraud composed from beginning to end of "faked" "local colour." I nole that S. A. Cook in his article "Exodus" in the Encycl. Britt. (xith ed.) omits all mention of CheYNe's extreme view.

$'$ I Kings vi. I. See Burney, Notes on the Hebreav Text of the Book of Kings, p. $58 \mathrm{ff}$.

2 See p. 376.

${ }^{3}$ Hist. Es. iii. 114. 
previous to the main one, which happened after Meneptah's victory. In the lists of Thothmes III place-names have been noticed which appear to read Yeshap'il and Yakeb'il, and are claimed as indicating settlements of Josephite and Jacobite tribes in Palestine at a time when, according to the current theory, the main body of the "Israelites" was still in Egypt. If these Joseph-el and Jacob-el tribes had come out of Egypt, the earlier Exodus must have taken place before the time of Thothmes III : i.e. the two Exoduses were separated by nearly four hundred years. This seems improbable. So that if we continue to place the Exodus in Meneptah's reign on the authority of the names Pithom and Raamses (of which the latter certainly cannot be earlier than the reign of Rameses II, since it is "Per-Rameses," the royal burgh at Tanis), we must assume that only part of the Hebrew nation had passed into Egypt, the rest having remained in its ancient seats in Palestine, where the Josephites and Jacobites were found by Thothmes III, and we must suppose that it was these stay-athome Israelites that were defeated by Meneptah before the Exodus of their brethren under Moses and Aaron.

Against this view we have the fact that we have from Egyptian annals no trace, other than the doubtful one of these names of Joseph-el and Jacob-el, of the peculiar and independent nationality of the Israelites in Palestine before the defeat of the Isirailu by Meneptah. Till then, the name Israel does not occur. This being so, we should naturally suppose that the Israelite tribes had reached Palestine at a date not so very long before the time of Meneptah, and that at some unknown date (many years) before their arrival, they had come from Egypt, where they had sojourned for a long period of time. On this view it is not necessary to suppose a remnant left behind in Canaan, or an Exodus earlier than the main one, for this will be placed long before Meneptah's days. The only objection to this view, that the names Pithom and Raamses are but little earlier than the time of Meneptah, is easily disposed of. They may perfectly well be the interpretations of a scribe who knew their names as those of Egyptian cities which existed in his time in and near the Land of Goshen. The title Zaphnathpaaneakh, ${ }^{1}$ given to Joseph by "Pharaoh," is known to

1 "Zaphnathpaaneakh" is obviously, as Prof. STEINDORfF pointed out ( $\ddot{A} . Z$. xxvii. pp. $4^{1-42}$ ), the Egyptian name Tjed-pneter-auf-ankh (probably pronounced 
be no older than the tenth century B.C. at the earliest, and may be as late as the seventh, ${ }^{1}$ to which century the names Potiphar, Potipherah (Petephre, "He whom the Sun hath given"), and Asenath, which occur in the Joseph-story, also belong. These names were put into the sacred story by scribes who knew them as typical Egyptian names of their own day. And Pithom and Raamses may well be interpretations of the same character, but of earlier date.

In favour of this view can be adduced another ancient and contemporary authority besides the Israel-stele: the Tell elAmarna letters. It seems very probable that the " $S_{A}-G_{A Z}$ " 2 tribes of Suti and their congeners the Khabiri who devastated Canaan in Akhenaten's time ${ }^{3}$ are no other than the invading Hebrews and other desert-tribes allied with them. It was natural that so far-reaching a conclusion as this should have been treated with the utmost caution at first; but it has now been debated for some years, and many of those who at first

in Upper Egypt "Zepnutefonkh" ; in Northern Egypt, whose pronunciation Hebrew scribes would know best, "Zaphnatafanekh"). KRALL (Abhandl. Wiener Kongress, IS86) was the first to adumbrate this view of the name, but did not succeed in interpreting it completely. I am unable to accept Prof. Naville's explanation of the other names (P.S.B.A. xxxii. $203 \mathrm{ff}$.), which seems to me far-fetched: also, such names as the "P-hetep-Ra" and "P-hetep-Har," which he postulates as the originals of Potipherah and Potiphar, are not known ("Rahetep" and "Harhetep" are another matter). His explanation of "Zaphnathpaaneakh" as Teset-nt-per-ankh, "Master of the House of Life" (or, Sacred College), is certainly ingenious, but I cannot see that it is probable, since how does teset-get altered to $z a p h-$ ? On the other hand, Prof. STeindorff's explanation is both simple and probable. Prof. Naville objects that such a name as Tjed-pneter-auf-ankh has no relevance. That is true, but all the names are characteristic of a certain period in Egypt, and it seems probable enough that all were given by the Mebrew scribe as typical Egyptian names known at the time he wrote. In redacting an account of Hebrew doings in Egypt he called the name of Joseph, when he became an Egyptian, "Zaphnathpaaneakh," much as a French writer might give an English character the names, which he would think current in his time, of "Lord Peambock" or "Sir Smithfield." We find similar procedure in the case of the Hebrew narrator who called the sons of Sennacherib, who slew him in the temple "of Nisroch his god" (2 Kings xix. 37 : sce p. 493), by the names of "Adrammelech" and "Sharezer," which were not their real names, and were probably given to them as sounding sufficiently Assyrian for all practical purposes.

${ }^{1}$ MeYer, Israeliten u. ihre Nachbarstämme, pp. $249 \mathrm{ff}$.

2 We do not know what this tribal name was which is spelt with the two cuneiform deographs which bear the names of $S_{A}$ and $G_{A Z}$. (It is usual in transliterating cuneiform to give such words by means of the names of their component ideographs, spelt in italic capitals, as here.)

${ }^{3}$ See pp. 34I ff. KNUDTZON points out that the Khabiri appear only in South Palestine, the $S_{A} \cdot G A Z$ also in the North. The Hebrews invaded the South. 
doubted now admit the cogency of the identification, which is accepted by competent authorities. ${ }^{1}$ Many writers felt difficulty in accepting the identification of Khabiri with 'Ibrim (Espasss, Hebrew) on account of the difference of the initial guttural, the one being spelt with a $\mathrm{h}(\mathrm{kh}) \mathrm{n}$, and the other with an $x^{2}$. But the difficulty disappears when we realize that in cunciform, the character in which the Tell el-Amarna letters are written, and the name Habiri occurs, it was impossible to represent the guttural $y$, as the sound of $y$ did not exist in Babylonian, and $y$ is often represented by h.. ${ }^{2}$ The only apparently "sound" reason for doubting the identification is thus shewn to be valueless. Any other reasons can only be based on the individual view taken of historical probabilities.

In my own view, the probabilities are all in favour of the identification. We have invading nomad tribes called Khabiri (Habiri), coming out of the south-east, apparently, and overrunning Canaan at a period which can be very definitely dated about I390-I360 B.c. The Tell el-Amarna letters shew us how their raids were feared by the Canaanites, and we see that after Alhenaten's withdrawal of Egyptian authority, they were left at the mercy of the Khabiri, who eventually dominated the whole country. The Biblical narrative tells us of invading nomad tribes called 'Ibrìm, coming out of the south-east, and overrunning Canaan at a period about four hundred years before the time of Solomon. Eventually they settled down under the rule of their own "Judges," and gradually, displacing or absorbing the Canaanites whom he had not destroyed in the first rush of their assault, became the dominant people of Palestine. The parallel is surely very complete when, in the reign of Meneptah, rather more than a century after the invasion of the Khabiri, we find a people called Isirail established in Palestine who are never mentioned before.

If the Hebrews are iclentical with the Khabiri, we must place the Exodus before the reign of Amenhetep III; the question is, how long before? It is at least probable that the ancestors of the Israelites abode very many years in the wilderness before they, taking advantage of the weakness of

1 OrR, Problem of the Old Testament, pp. 422 ff. ; Meyer, Die Israeliten " ihre Nachbarstïmme, p. 225. S. A. COOK (Encycl. Britt., xith ed., s.v. "Exodus" considers that " the equation is philologically sound."

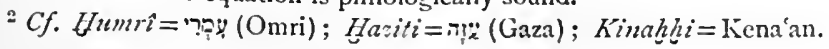


Amenhetep III's later years, crossed the Jordan. "Forty" years means but many, probably very many. The influence of the desert in the moulding of the Israelite character is very evident, and the God of Israel is in his original aspect a god of the desert and the bare mountain, of the gebel rather than of the rîf, the fertile Canaanite plain. Desert Edom was the blood-brother of Israel, though no love was lost between them, and the connexion with purely Arab Midian was close in legend and no doubt also in fact. Whether Sinai was the mount which we call Sinai, or whether the real Sinai is to be found east of the Gulf of Akaba, remains doubtful ; ${ }^{1}$ but, whether the main portion of the Wanderings took place east or west of that gulf, the fact remains that the ancestors of the Hebrews did wander in the desert regions bordering on Canaan and must have so wandered for many years. Two centuries seem hardly too long for this period of nomadism, and thus we are naturally brought back to the moment which seems most appropriate for the departure of a Semitic tribe from Egypt, ${ }^{2}$ pursued by Pharaoh and his host, before the reign of Amenhetep III. This moment is the beginning of the XVIIIth Dynasty, and it surely does not seem so very improbable that Josephus may have been right, and that, as has already been noted above (p. $213, \mathrm{n}$. I), the Biblical account of the Exodus is the Hebrew version of the Expulsion of the Hyksos?" Aahmes was the Pharaoh who "knew not

${ }^{1}$ The view that the real Sinai lay east of the Gulf of Akaba was first propounded by BEkE, Origines Biblicae (I834), and has lately gained favour in connexion with the "Musri" "theory of Winckler. Now, however, that this theory is generally abandoned (p. $466, \mathrm{n} .1$ ), opinion is perhaps turning in the direction of the traditional Sinai. But the view that Sinai was in Edom is in no way bound up with the Mușri theory and has much in its favour. NAviLLE's reconstitution of the Route of the Exodus (on the traditional theory of Sinai) agrees with the Biblical indications, and is not affected by the investigations of PETRIE, who entirely accepts it (Researches in Sinai, pp. 203 ff.).

2 Others have surmised that Josephus may have been right after all, but this view has hardly in modern times received the attention it deserves. We have all been hypnotized by the Meneptah-theory, except LIEBLEIN (Recherches saur l'kistoire et la civilisation de l'ancienne Égypte (Leipzig, 1910), ii. p. 279), who, however, had no grounds whatever for putting the Exodus in the time of Amenhetep III, taking the "forty" years of the Wandering as a serious figure. Torteen's view (The Historic Exodus, Chicago, 1909) that there were two Exoduses, the second after the time of Rameses III, the first at the end of the reign of Thothmes III, seems unnecessarily complicated and improbable.

${ }^{3}$ The purely Egyptian name of the leader of the Exodus and lawgiver of his people, Moses, is interesting. The Hebrew names Levi and Phinehas were also pure Egyptian. It is not impossible that these Egyptian names point to an Egyptian origin for the Hebrew priestly families, and then the legend of the renegade Egyptian pries 
Joseph," who had been raised to favour under the Hyksos kings, whose names were not only Semitic, but in one case, that of Yapekhur or Yakephur (Yekebel?) seem to point to connexion with Jewish tradition. Abraham will on this view be the traditional tribal leader, who in the time of Khammurabi led the Hyksos-Hebrews down from Harran in Northern Mesopotamia, where they originated, through Syria, where he defeated the five kings, to Southern Canaan, where they remained for some generations before they entered Egypt, in the days of Joseph the son of Jacob (Yekeb).

There seems to be no inherent impossibility in this view of the origins of the nation of Israel, though in the present state of our knowledge we cannot regard it as anything more than a theory, which may justifiably be regarded as plausible. ${ }^{1}$ But we may definitely, if we accept the identification of the Khabiri as the Hebrews, say that in the Tell el-Amarna letters we have Joshua's conquest seen from the Egyptian and Canaanite point of view!

\section{The Hebrew Conquest of Palestine}

The IIebrew invasion of Palestine in the Tell el-Amarna period-Jerusalem no taken-The taking of Jericho-The story of Dinah 'and psettlement of Judah and Simeon-Hebrews not mentioned in time of Seti $I$ and Rameses II-War of Meneptah and the Israel-stele - Hebrew wars with the Canaanites: the fight at Taanach and Song of Deborah (c. I 200 B.C.)

The reason for the invasion may well have been the traditional one. These tribes, that had been nomad for generations, cast longing eyes upon the "Promised Land" where their ancestors had lived before they went down into Egypt. The desert-tribes always desire the fat lands of the

Osarsiph (Manetho, apud Joseph. Contra Apionem) recurs to the mind. It is not impossible that this legend is connected with the Exodus.

${ }^{2}$ We need not identify absolutely Hyksos with Hebrews; we may perhaps regard the Hebrews as a small Semitic tribe which entered the land of Goshen during the period of Hyksos domination, and left the country at the time of the expulsion of their patrons, or shortly afterwards. This tribe originally came from Harran and from "Ur of the Chaldees"; i.e. it was of Mesopotamian origin. Whether it is to this Mesopotamian origin of the Hebrews that we are to assign the resemblances of Hebrew and Mesopotamian cosmogonic legends-the story of the Flood, etc.-is uncertain. The possibility that these resemblances may be due to later Babylonian and Assyrian influence at the time of the Israelitish kingdoms, or may even be dated to the period of the Exile "by the waters of Babylon," must not be left out of account. 
settled, and in this case there was an ancient claim of right.

From the Biblical account it would seem that after passing through Moab and sojourning for a time in the neighbourhood of Pisgah, the main body of the invaders crossed the Jordan near its mouth and first entered the territory of the Canaanite city of Jericho, encamping on the way at an ancient stone circle and holy place with the usual name of Gilgal. Jericho was taken "at the edge of the sword," and $\mathrm{Ai}$ followed, after an initial check. The hill-country was then entered, and the ark of the Lord was no doubt now set up at Bethel, ${ }^{1}$ and later at Shiloh, which became the religious centre of the Northern tribes. ${ }^{2}$

The Biblical account goes on to describe a march of Joshua south-west from the hill-country into the Shephelah, in which the kings of Lachish and Gezer were defeated, and Lachish taken; after which Joshua marched to Hebron. ${ }^{3}$ This raid was followed by the war with the confederated kings of the North, under the leadership of Jabin of Hazor. ${ }^{4}$

The whole facies of this account, with its raidings, destroyings, and burnings by the fierce invaders from the desert, reminds us forcibly of the evidence of the Tell el-Amarna tablets as to the doings of the Khabiri and the Suti all over Palestine from North to South. "So Joshua smote all the land, the hill country, and the South, and the lowland, and the slopes, and all their kings." Yet we cannot identify any persons mentioned in the Book of Joshua with any of the men who play a part in the contemporary record of the Tell el-Amarna letters, nor do Biridiya and Shuyardata, Abdkhiba and Labaya, appear in the Biblical narrative. Names, especially foreign names like those of the immigrant Iranian chiefs ("Shuyardata" and similar appellations), ${ }^{5}$ are easily altered and forgotten in traditional accounts.

In one thing the Tell el-Amarna letters and the Book of Joshua agree. The territory of Jerusalem forms a rock against which the waves of Eastern invasion beat in vain: neither Khabiri nor Hebrews can gain a footing therein. Joshua is

\footnotetext{
"Judges ii. I, where, Dr. BuRney informs me, "Bethel" should be read for "Bochim." $C f$. also Judges xx. 18, $26 . \quad{ }^{2}$ Joshua xxiv. $\quad{ }^{3}$ Ibid. x. $\quad{ }^{4}$ Ibid. xi.

"See pp. 230, 348. Shuyardata is "Surya-dâta," ='H xxxi. p. 234). For lazd-data (p. 348) see Weber in Kivudtzon, Amama-Tafeln, p. 1309 .
} 
obliged to avoid it in his march to Lachish and Hebron: and we do not know that Abdkhiba ever lost the city; ${ }^{1}$ Jerusalem, though it might be surprised by a coup-de-main, was not yet to be taken and held by desert-hordes. ${ }^{2}$

Certainly the Biblical account of the invasion by way of Jericho, whether this was really the route of the northern (Israelitish) tribes only ${ }^{3}$ or not, bears all the marks of being a genuine tradition and no doubt states a historical fact. The war with Jabin ${ }^{4}$ may or may not really belong to this period, but that the tradition that Lachish, Ekron, and Gezer were taken at this time is trustworthy seems to be shewn by the nonmention in it of Philistines in the Shephelah. The inhabitants are all Canaanites. ${ }^{5}$

But this flash of light upon the actual invasion, of the Northern tribes at least, is followed by darkness. We have the traditions of the wars against Sihon and $\mathrm{Og}$, which may really belong to the period before the crossing of the Jordan, or may be an echo of later wars transferred to the Mosaic period. We

Sec pp. 349, 351.

- The statement in Judges $\mathrm{i} .8$ that Jerusalem was stormed is doubtful. In Joshua xv. $6_{3}$ its inexpugnability is confessed. To the fact that Jerusalem and the Jebusite territory remained unconquered for so long is due the persistent dualism of the Israelitish state. The Judaeans were separaled from the Northern tribes by a Canaanite enclave for so long that their differences were accentuated to such an extent that the later division into two separate kingdoms was inevitable. How far back inlo time these distinctions really go is doubtful. But we can see that the Southerners, the Judaeans, were always of a rougher and less civilized stock than the Northerners. They were more of the Beduin desert type, and their families were connccted through the shadowy tribe of Simeon with stocks of Edomite or Arab type, such as Jerahmeel and Caleb, in the Negeb or desert region south of Judaea. It may well be that, as is believed by MEYER (Israeliten, pp. $75 \mathrm{ff}$.), the dualism goes back to the beginning of the movement towards Paiestine, and that of the race that had worshipped Yahweh at Kadesh-Barnea, two separate branches had entered the Promised Land-one, Judah, south of the Dead Sea through Edom and the Negeb ; the other, Israel, through Moab, Pisgah, and Jericho. In this case the account of Joshua's march from Mount Ebal round to Hebron may be a confusion of the operations of the two separate bodies of invaders: the Israelite tradition of the entry has prevailed over the Judabite, and the Judaeans are brought round into Judah from Gilgal, where they had sacrificed with the rest of the tribes. So Lachish falls to Joshua coming from the North, and not to Judahites coming from the South, which seems more probable. Nevertheless, the account of Joshua's savage raid right round the unapproachable Jerusalem through the Shephelah into the hill-country of Judaea agrees extremely' well with the account of the ubiquity of the Khabiri and Suti that we derive from the contemporary documents.

${ }^{3}$ On Prof. Meyer's view, see nole above.

See p. 4 I 4 .

${ }^{5}$ The list in Joshua xiv. of unconquered lands, in which the l'hilistines are mentioned, is obviously late. 
have also the remarkable story ${ }^{1}$ of the treaty of the tribes of Simeon and Levi with the Canaanites of Shechem which established an Israelite clan (Dinah) in that city, of the quarrels that ensued, of the massacre of the Shechemites, and of the destruction and expulsion of Levi and Simeon that followed. They were driven southwards, and Judah, if it was originally settled in Mount Ephraim with them, followed to its new seat in the southern land. The first part of the story may well reflect an actual occurrence; the second looks very like another account, from a point of view less favourable to Israel, of the movement of Joshua to Judaea. We seem to be reading in both cases reconciliations of the fact that Judah, Simeon, and Levi lived south of Jerusalem with the view that the whole nation had crossed the Jordan at Gilgal. Yet, just as the story of Joshua's raid is not in the least improbable, neither is it unlikely that these three tribes, defeated by the Canaanites, were cut off from the main body of their people and driven southwards. ${ }^{2}$

Although we know nothing of the details of the war, it is evident that the anarchy depicted in the Tell el-Amarna tablets gradually subsided, leaving the intruding tribes in possession of two enclaves of hill-territory-Mount Ephraim in the north and Judah in the south-with Jerusalem as a Canaanite barrier between them. Although for a time the Judahites occupied the Shephelah, ${ }^{3}$ they were afterwards expelled: in the plains the invaders could do nothing against the Canaanite chariots, ${ }^{4}$ and when, as probably happened, the princes seriously banded themselves together to repel the invaders from the rich lowlands, the immediate issue of the conflict was not doubtful. Also, it is not improbable that Shubbiluliuma intervened in support of the Canaanite chiefs, though he does not seem to have exerted any authority over them.

Of the wars of Seti I and Rameses II with the Hittites we hear nothing from Biblical sources, nor is this to be wondered at if the Hebrews were at this time strictly confined to the hill-country. The Egyptian reoccupation of Palestine was probably no more than a securing of the Heerstrasse from the

${ }^{1}$ Genesis xxxiv. $\quad{ }^{2}$ On the story and its difficulties, see Meyer, l.c. pp. $409 \mathrm{ff}$.

${ }^{3}$ Judges i. 18. Gaza, Ashkelon, and Ekron were taken by the invaders according to a late tradition.

$\checkmark$ Judges i. 19. 
Shephelah to the plain of Jezreel and thence to the valley of the Orontes: the establishment of Egyptian authority over tribes that would be regarded merely as marauding highlanders would hardly have seemed worth the trouble involved. Wholesome fear of the allied Egyptian and Hittite powers no doubt kept the hill-men quiet: it was not till the feeble and apathetic old age of Rameses set in, and his death was followed by the Libyan attacks on Egypt, that the war-flame again blazed up in Palestine. Then it was, no doubt, that the Canaanites combined to throw off the foreign yoke, and the Israclites descended from their hills to help them, with clisastrous results to themselves: "Israel is desolated, his seed is not," says the inscription of Meneptah.

Israel had become a people of sufficient importance to be specially mentioned by a pharaoh. We can imagine that the "men of valour" had been first overthrown in the plain, whither they had sallied forth to help the Canaanites, and that afterwards the Egyptians carried fire and sword through the hill-territory of Mount Ephraim: the whole people, women as well as men, is indicated by the ideographs used in the inscription as "desolated," and their "seed was not."

Recovery from this blow must have taken many years. The darkness remains unbroken till suddenly there is another flash of light which, like that which shews us the crossing of the Jordan, gives us a fleeting glimpse of Israel at a period midway between the war with Meneptah and the Philistine invasion, i.e. about I 200 B.C. This is the account (Judges v.) of the fight at Taanach in the magnificent Song of Deborah-

\footnotetext{
"Awake, awake, Deborah:

Awake, awake, utter a song;

Arise, Barak, and lead thy captivity captive, thou son of Abinoam !

The kings came and fought;

Then fought the kings of Canaan;

In Taanach by the waters of Megiddo:

The stars in their courses fought against Siscra,

The river Kishon swept them away,

That ancient river, the river Kishon.

O my soul, march on with strength!

Then did the horsehooves stanp

By reason of the prancings, the prancings of their strong ones.
} 


\section{THE ANCIENT HISTORY OF THE NEAR EAST}

The Song is undoubtedly contemporary with the event described in it, and records a crushing defeat inflicted upon the Canaanites at Taanach by some of the Israelitish tribes under a leader named Barak, of the tribe of Naphtali. In this fight the formidable chariotry of the Canaanites, against which the Israelites had as yet been able to make but little headway in the plain, was for the first time discomfited, and the Canaanite leader Sisera "lighted down from his chariot, and fled away on his feet." 1 The Song directly mentions Ephraim, Benjamin, Machir (= Manasseh), ${ }^{2}$ Zebulun, Naphtali, and Issachar, as the allied tribes, and the brunt of the fighting fell upon Zebulun and Naphtali. Reuben was undecided how to act, "Gilead abode beyond Jordan," Dan and Asher remained supine in the seacoast territory which they then occupied, south of Phoenicia. $^{3}$ From the fact that Jabin, king of Hazor in the Orontes valley, whose general Sisera is said to be in Judges iv., is not mentioned in the Song, it seems probable that Sisera and he had originally no connexion, and that the mention of him here is due to a confusion of the battle of Taanach with another fight at the period of the first invasion, ${ }^{4}$ in which a king Jabin of Hazor was defeated.

We then find that at the beginning of the twelfth century the Israelites of Mount Ephraim were able to try conclusions with and defeat the most powerful ruler of the Canaanites, and had before this conquered and occupied a seacoast territory, reaching probably from Akko to Dor. The seacoast tribes, Dan and Asher, were already engaged in trading in imitation of the Phoenicians, and were beginning to lose the fierce, warlike energy of the old Khabiri, which was still preserved by the tribes who followed the sword of the son of Abinoam and were inspired by the songs of Deborah.

\section{Israel and the Plitistines}

The invasion of the Philistines-Hebrews abandon the seacoast-Superior military powcr of the Philistines-The Philistine states-The five cities-Aegean culture of the Philistines-They soon become semitized-Wars between Hebrews, Midian, and Moab (c. I 100 r.c.)-The Judges of Israel-The kingdom of Edom-

\footnotetext{
1 Judges iv.

2 Joshua xvii. 1 .

3oshua xix.; Judges v. 17. In the district of Carmel and perhaps as far south as Dor?

4 See p. 410.
} 
Wars with Ammon-Abimelech the would-be king-Ihilistine conquest of Israel (c. IOSo B.c.)-Hebrew revolt: Samuel and Saul-Saul a Gilcadite-Saul's war with Amalek-David becomes a vassal of the Philistines-Ishbaal-War of David and Ishbaal-David takes Jerusalem-David defeats the Philistines at Baal-perazim and founds his kingdom at Jerusalem (c. 995 B.c.)-Taking of Gath : suzcrainty over Philistines

Then must have come the catastrophe, of which we find no contemporary record preserved in the Book of Judges, the invasion of the Northerners, their settlement "in the midst of Amurru," their defeat by Rameses III, and the final occupation by the Philistines of the Canaanite seacoast and the Shephelah. ${ }^{1} \quad$ Israel saved her nationality and name by retreat into the hill-country; the seacoast was given up, and Dan and Asher no longer dwelt by the havens of the sca. A new "oppressor " had entered the land, more formidable by far than the Amorites or Canaanites had ever been, even with all their chariots of iron. Since they had established themselves in the hill-country east of the Jordan, the Israelites had never acknowledged a Canaanite master, but they were compelled to submit to the Philistines, who, used to real mountains and real hill-fighting in their native land of Crete, pursued them to the fastnesses which neither Canaanite nor Egyptian had tried to reach. The superiority of the European armature of the Philistines, with their bronze-plated corselet, large round buckler, great broadsword (possibly of iron), and huge spear "like a weaver's beam," over the feebler weapons of the Semites was so marked that no further reason for their complete subjugation of Palestine need be sought. The legend of Goliath preserves the popular impression among the Israelites of the gigantic stature and impregnable armour of their conquerors. No doubt the possession of iron weapons ${ }^{2}$ contributed materially to bring about the complete victory of the invaders.

The Israelites must have been driven into the hills at the first onset, before Rameses III checked the invasion on the borders of Egypt. The surge-back of the invasion into Palestine, and the following campaign of Rameses, probably began an epoch of sanguinary war which lasted till the invaders had finally established their new state in the cities of the enslaved Canaanites of the plain. Then must have followed perhaps half a century of peace, before, at the beginning of the eleventh century, the conquerors bent themselves to the task of

$$
{ }^{1} \text { See p. } 3 \text { S2, ante. }
$$$$
{ }^{2} \text { See p. } 72 .
$$ 
completing their conquest by the subjugation of the hill-country between the Shephelah and Jordan.

It is possible that the Philistines had already tried to enter the hill-country, and the late remembrance of "Shamgar the son of Anath, who slew of the Philistines six hundred men witl an ox-goad," " probably refers to some repulse of the Philistines by the half-armed Hebrew fellahîn. But no attempt had ever been made to establish Philistine settlements in the highlands. Gath was the farthest settlement inland, on the western slope. This was partly due to the dangerously hostile temper of the driven-in Hebrew population, but also because, as in their native country, the invaders preferred to constitute their cities in places not far from the sea, from which they could at once control the sea-ways and the vine-bearing hills and upland summer pastures of the interior.

Before dealing with the Philistine subjugation of Israel, we must glance at the constitution of the new foreign state in Canaan, which by I I00 B.C. had probably reached its complete development.

With the possible exceptions of Lydda and Ziklag, no new cities were founded: the conquerors lived in the ancient Canaanite settlements of the Shephelah, which had often figured in the Egyptian invasions for centuries back. The chief settlements were established in the five towns of Ashdod, Gaza, Ashkelon, Gath, and Ekron, which apparently retained their Canaanite names under the new rule. Over each of these cities ruled a "tyrant" or seren, assisted by his nobles. The five serens met in council to deliberate on the common affairs of the nation, probably at Ashdod, which seems to have held the hegemony. The tyrant of Ashdod probably commanded in chief when the whole war-force of the confederacy was called out.

The Pentapolis evidently comprised the whole strength of the Philistines, properly so called. The Tjakarai of Dor in the North and the Cherethites of Ziklag, far inland in the Negeb south of Philistia, both tribes of the same Cretan origin as the

${ }^{1}$ Judges iii. 3 I. Dr. Burney points out to me that this is among the latest additions to Judges, so that the author of the addition probably drew the name from Judges v., where Shamgar is mentioned. He probably took the name simply as that of an ancient hero, and ascribed to him the slaying of the Philistines. The Song of Deborah, and Shamgar with it, are pre.Philistine, in all probability (see p. 4I3). 
Philistines and allies in the great invasion, were not formally included in the confederacy, but no doubt their alliance could always be depended upon.

The chief Canaanite cities of the South, which may have been colonized but were not capitals of the serens, such as Rakkon and Joppa on the seacoast, Gezer, Jabneël, Lachish, Sharuhen, and Gerar inland, were probably organized after a time as subject-allies of the confederacy. It is uncertain whether the town of Lod (Lydda), afterwards and now so important, was an ancient Canaanite centre or was not rather a new Philistine foundation, perhaps a colony from one of the chief confederate cities : it is not mentioned in the older Egyptian inscriptions, as the other Canaanite towns are, and its name has a foreign, and even specifically Cretan, appearance: we may compare Lod with the Cretan place-name Lyttos. The Cherethite centre in the south, Ziklag, ${ }^{1}$ oddly drive so far inland into the Negeb, as if in vain search of more fertile territory, has a name which is quite un-Semitic, ${ }^{2}$ and was very probably given it by the Cherethites: the place was probably a new foundation.

As has already been said, of the civilization of the Philistines we have actual remains only in the great quantity of "Late Minoan" pottery found in the excavations of the Palestine Exploration Fund in the mound of Tell es-Safi, the site of Gath, ${ }^{3}$ and at 'A in Shems (Bethshemesh) ${ }^{4}$ and certain peculiar buildings and tombs at Gezer and Tell es-Safi. ${ }^{5}$ Since the Philistines, though they came from Crete, were not originally, it would seem, Cretans (but rather Lycian conquerors who were expelled or had migrated from the island, where they had settled), ${ }^{6}$ and, further, were a people whose civilization had probably been impaired by long migrations and wars, it is probable that any buildings they would erect in Palestine would not shew much trace of the old Minoan architectural genius. Still, admixture with the Canaanites would revive in them something of culture and luxury, and we hear in the Books of Judges and Samuel of temples and palaces in their cities imposing enough to impress the Hebrews, and also of theatres in which crowds of the nobles and their retainers,

${ }^{1}$ See Winckler, Gesch. Israels, ii. 185.

${ }^{2}$ Needless to say, I see no reason to regard it as a textual corruption of some other name (cf. Cheyne, Encycl. Bibl., s.v.).

' Hall, P.S.B.A. xxxi. p. 235.

5 See p. 72, n. 2.

4 Mackenzie, P.E.F.Q.S., I911.

'See p. 73, n. 
besides the common people, could assemble under one roof to watch public spectacles. We are at once reminded of the "Theatral Areas" of the Cretan palaces of Knossos and Phaistos, and of the gladiatorial games that, we know, went on in them, ${ }^{1}$ by the Biblical account of the exhibition of the captured Samson in the theatre of Gaza ${ }^{2}$

"Now the house was full of men and women; and all the lords of the Philistines were there; and there were upon the roof about three thousand men and women, that beheld while Samson made sport."

We seem to see the lords and ladies of Knossos at the palace-sport, as they are depicted on the Knossian frescoes, ${ }^{3}$ with crowds of faces of the men and women of which the halls were full, and the court-ladies looking down from their balconies at the bull-leaping and the boxing! So must many an Israelite captive have been forced to make sport for the Philistines in their theatres, and the indelible memory of many such scenes is preserved for us in the picture of the final victory in death of the Hebrew sun-hero, Samson, ${ }^{4}$ whose oppressors were naturally imagined in the guise of the greatest oppressors the hill-men had ever known. ${ }^{5}$

The Philistine state and culture were but the products of a foreign military garrison, and had only one guarantee of permanence: the continued racial purity and energy of the conquering tribes. When this began to fail, as it did within two centuries of the conquest, the end was at hand. Like the Ionians at Miletus and elsewhere, later on, the Philistines dwelt with the natives in the old native centres, merely adding a veneer of their own culture to that of the Canaanites. They took over the Canaanite gods and worshipped them. The Semitic Dagon at Ashdod was easily identified with some Aegean male deity, and Ashtoreth and Derketo at Ashkelon with

1 See p. 48. 2 Judges xvi.

${ }^{3}$ B.S.A. Annual, vi. pp. 46 ff. ; J.H.S. xxi. Pl. v. See p. 48.

- On Samson see Stahn, Die Simson-Sage (Göttingen, 1908). His name is derived from the Semitic word for the sun, Sms (Shamash).

${ }^{5}$ Hall, P.S.B.A. xxxi. (I909), p. 237. Prof. Canney points out to me that some such fierce sport is referred to in 2 Sam. ii. I4, where the young men "arise and play" before Abner and Joab; "and they caught every one his fellow by the head, and thrust his sword in his fellow's side : so they fell down together." This is a scene remarkably like that on the Cretan Boxer-vase from Agia Triada (Plate IV. 5). The Israelites may well have learnt such "sports" from the Philistines. 
the goddess who, as we see, ruled paramount in Cretan religion. ${ }^{1}$ So the conquerors soon became semitized : probably in a century they were already talking Canaanite. In the time of David we certainly hear nothing which causes us to suppose that Philistines and Israelites, though deadly enemies, did not speak almost the same Semitic tongue. Nothing but a few peculiar names of the Philistine aristocracy, ${ }^{2}$ a few Greek loan-words in Hebrew, ${ }^{3}$ and the "Minoan" traditions of Gaza and Ashkelon" remained in later days to mark a distinction between Philistia and the rest of Palestine.

So the semitized Philistines of David's day were by no means the same men as the warriors of the Migration. They were unable to prevent the founding of the new independent kingdom of Israel, and even lost to David one of the limbs of their confederacy, the city-state of Gath and its dependencies. In the succeeding reign they had become Egyptian tributaries when Sheshank I restored the Egyptian dominion in Palestine. ${ }^{5}$

The confusion into which the Philistine invasion had thrown the whole of Palestine, gave an opportunity to her eastern neighbours to attack her. The Bnê Qedem, the "Sons of the East," gathered like the vultures out of the desert to seize an easy prey. Arab Midian, and Moab and Ammon, always illwishers of their sister Israel since she had conquered her way past them into the rich lands of Canaan, now came up against her to raid and destroy. An interesting legend ${ }^{\theta}$ brings an otherwise unknown king, Kushan "the doubly wicked," 7 from the Euphrates-land to oppress Israel some time in the twelfth century: who he was, we know not. A tribal hero, Othniel, was said to have inflicted a disaster upon him. A more definite "oppression" is that of the Midianites, about I 100 B.C., which must have affected the Phiiistines as well as Israel, for the raids of the Midianites "destroyed the increase of

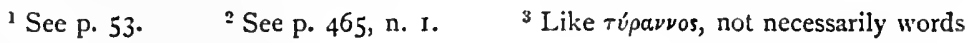
of Indo-European origin.

See p. 399, n. 1 .

5 See p. 437

${ }^{6}$ Judges iii. 8.

7 The "Chushan-Rishathaim" of the A.V. He is a king of Aram-Naharaim (a rare expression in the Hebrew scriptures) or Northern Syria (the "Naharin" of the Egyptians). See MEYer, l.c. p. 374. The Rev. C. J BALL considers that he may have been a Kassite invader, "Kushan"=the element Kash in "Kashtiliash" (p. 200), etc. But he came from Aram-Naharaim, and seems more likely to have been a Syrian. 
the earth, till thou come unto Gaza." 1 The Biblical narrator is very definite as to the loss and disaster inflicted on the Israelites by these raiders; to avoid the Midianites the people fled for refuge to caves in the hills, "and Israel was brought very low because of Midian."

It can hardly be imagined that this would have been the case but for the overwhelming disaster which the whole nation had recently suffered at the hands of the invading Philistines, which in the north had destroyed the budding promise of a civilized Israelitish State with a seaboard, havens, and ships, and in the south had reduced the Hebrews to the position of a mere hill-tribe. Arab razzias, as the Midianite invasions were, could not of themselves alone have brought Israel so low.

We have two legends of successful reprisals against the Midianite raiders, which have been combined into one. ${ }^{2}$ Gideon and Jerubbaal appear to have been two distinct local leaders, one of the Manassites of Ophrah, north of Shechem, the other of the Gadites in Gilead, on the other side of the Jordan. Gideon attacked the Midianite camp beneath Mount Gilboa, and slew the Arab princes Oreb and Zeëb. 3 Jerubbaal led a long chase of a Midianite band, also under two princes, Zebah and Zalmunna, into the eastern desert, where he annihilated them. ${ }^{4}$ The description of the deaths of Zebah and Zalmunna, and of the spoil of golden earrings worn by the Arabs (because they were Ishmaelites), and the necklaces of golden crescents that were about their camels' necks, gives a vivid impression of this victory of the Israelitish frontiersmen over the splendid nomads of the desert.

The Midianite raids were evidently directed roughly by way of the valley of the Jabbok, and thence through the Plain of Jezreel to the Shephelah, so that they may well have raided as far as Gaza in the days before the Philistine power was firmly established. That the northern rather than the southern route was taken shews that the Midianites wished to avoid touching the territories of Edom, Moab, and Ammon. Edom, the country between the Dead Sea and the Gulf of Akaba, was now developing into a strong State under a settled kingly rule, ${ }^{5}$ under a dynasty probably of Aramaean origin; and in the reign
${ }^{1}$ Judges vi. 4 .
${ }^{2}$ Ibid. vi.
3 Ibid. vii. 25.
${ }^{4}$ Ibid. viii.

${ }^{5}$ It is first mentioned by the Egyptians in the reign of Meneptah, and probably its organization as a state dates from the abandonment of Palestine by Egypt in the: 
of the fourth king, Hadad I, had inflicted a severe defeat upon the Midianites in the territory of Moab. ${ }^{1}$ The Moabites may very well at this time have been dominated politically by the Edomite kingdom: Bela', son of Beor, the first, 'alliph or "duke" of Edom, is evidently duplicated in the Balak, "king of Moab," who summoned the prophet Balaam "son of Beor" to curse the Israelites at the time of the invasion." Balak may be the Edomite King Bela' (whose name may also appear in that of Bala'am or Bileam), if it may be supposed that in the list Hadad I is the first really historical king, and that Khusham and Jobab are two traditional names that cover a number of "dukes" between the period of the Hebrew invasion (c. I 370 B.C.) and the time of Hadad (c. II5O B.C.). ${ }^{3}$ Balak and Bala'am are made contemporary with the Hebrew invasion, so that probably the presumed Aramaean conquest which gave Edom a king in Bela' ben-Beor may have taken place about the same time, and was part of the same general unrest of the Suti or desert-tribes, Aramaean as well as Hebrew. ${ }^{4}$

We hear of no direct Edomite attack on Judah at this time, though the eternal fighting between the Judahites and the Amalekite tribes on the borders of Edom and Judah never ceased, and now the border-unrest had without doubt been increased by the incursion of the Cherethites from the coast into the Negeb. The campaign of Saul against Agag $^{5}$ was probably a retaliation for a long series of injuries suffered from Amalek during the period of confusion after the Philistine invasion.

Nor were Moab and Ammon loth to take part in the "oppression" of their weakened Hebrew kinsmen. A king of reign of Akhenaten, when Bela' ben-Beor, the Aramaean (?) founder of the kingdom (Gen. xxxvi. 32), may have lived

${ }^{1}$ Gen. xxxvi. 35 .

2 Num. xxii. 4, 5. Nöldeke, Untersuchungen, p. 87. Addis, Encycl. Bibl., s.v. "Balaam."

${ }^{3}$ Cf. Mryer, Isracliten, p. 3 So. Prof. Meyer does not accept the supposed Aramaean connections of the Edomite royal honse. Nevertheless the names Hadad and Khusham (cf. Kushan "rishathaim" of Aram.Naharain ; p. 419) indicate an Aramaean origin, and the Biblical statement that Balaam came from Pethor on the Euphrates points (since Bala'am, Balak, and Bela' ben-Beor are probably in reality all the same person) the same way, to an Aramaean origin of the Edomite dynasty, which is in no way impossible.

${ }^{4}$ See p. 40I. The theory of an Aramaean conquest of Edom was first suggested by Bp. A. C. Hervey in Smith's Dict. Bibl., s.v. "Bela."

5 See p. 425. 
Moab named Eglon seems, with the help of the Ammonites, and perhaps in conjunction with Amalekite raids from the south, to have possessed himself of territory on the right bank of the Jordan, which he retained till his assassination by a popular hero who is named Ehud. ${ }^{1}$

The Ammonites naturally attacked the territory of Gilead, and the story of Jephthah ${ }^{2}$ is to be referred to a border-war at this period.

So Israel was ringed about with foes, and now the Philistines determined to make their dominance unquestioned as far as the Jordan. ${ }^{3}$ A century had elapsed since the deluge of their advance had swept over Palestine. The anarchy which resulted had died down; the new state which they had founded had become organized as we have seen, and was ready to impose its rule on the recalcitrant hill tribes. An opportunity was probably afforded them by anarchy following the death of the would-be king Abimelech, son of Jerubbaal, the victor against Midian.4 Abimelech seems to have attempted to rule part of Israel definitely as a king, in imitation, no doubt, of Edomite royalty. The result was a fierce civil war centering in Shechem, Abimelech's own town, which had revolted from him. The burning of Shechem and the death of the tyrant Abimelech at Thebez shortly after ${ }^{5}$ seem to have made a very deep impression on men's minds at the time, and the relation of these events is one of the most definitely historical in the Book of Judges. They are probably to be placed not long after I IOO B.C.

The Philistine invasion, which resulted in the speedy subjugation of Israel, is dated at the end of the High-Priesthood of Eli, great-great-grandfather of Abiathar, the companion of David. Eli's grandson, Ichabod, was born immediately after the catastrophe. This would put the event, as Prof. Eduard Meyer has shewn, ${ }^{6}$ about IoSo B.C.

The Philistine victory seems to have been attained at a single blow, in the battle of Eben-ha-ezer, ${ }^{7}$ which resulted in the complete annihilation of the Israelite army and the capture of

${ }^{1}$ Judges iii. I 2 ff.

2 Ibid. xi.

${ }^{3}$ Ibid. ix.

${ }^{4}$ An interesting sidelight on Palestine at this juncture is given by the report of the Egyptian envoy Unamon (see p. 393) to the high priest Herihor (afterwards king) in the reign of Rameses XI about III 7 B.C.

5 Judges ix. 50.

${ }^{6}$ Israeliten, p. $3^{81} \mathrm{I}, \mathrm{n} . \mathrm{I}$.

${ }^{7}$ I Sam. iv. 


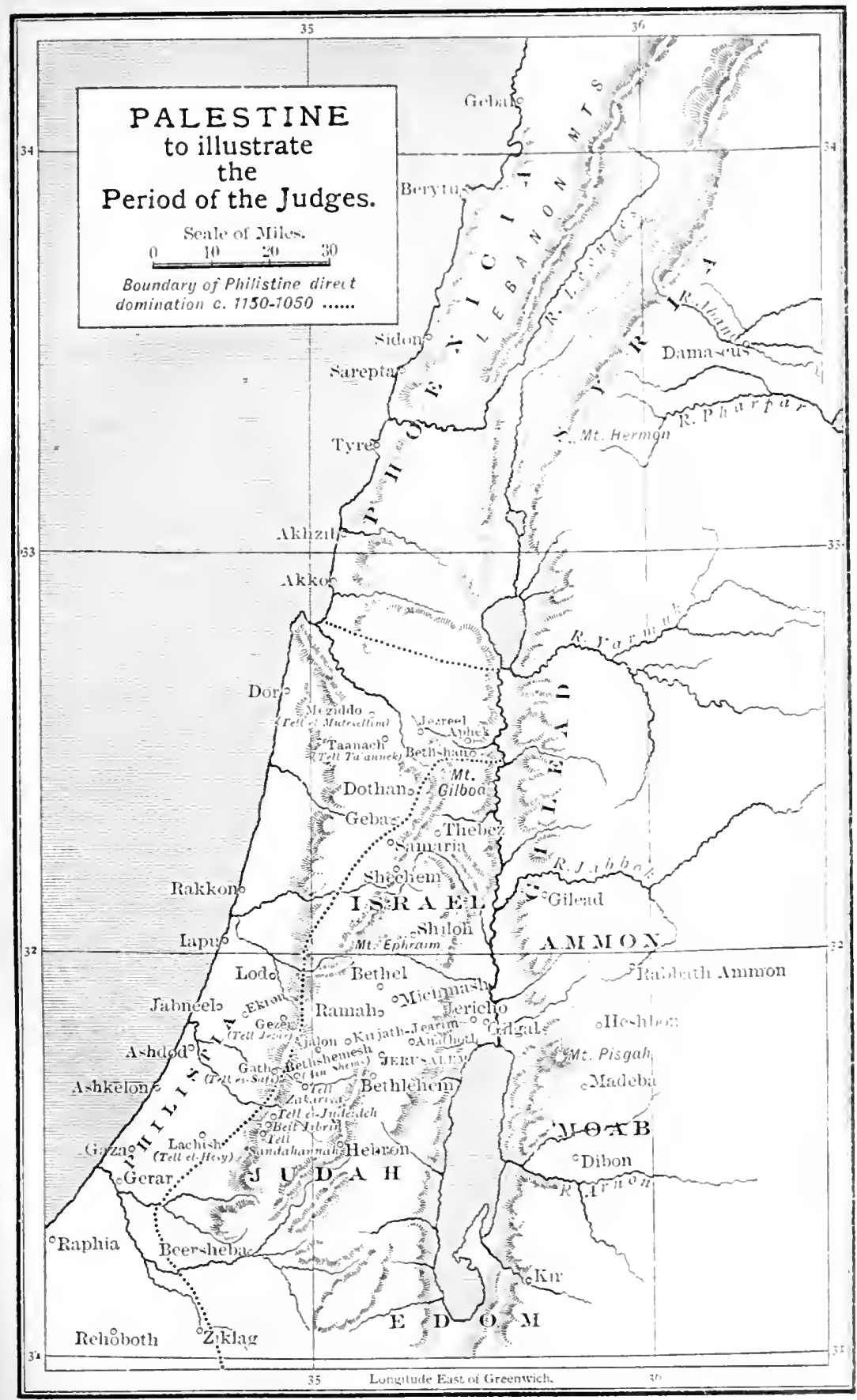



the sacred ark of Yahweh, which had been brought solemnly forth to battle in charge of Hophni and Phinehas, ${ }^{1}$ sons of Eli, its priests. After the capture of the palladium of Israel and the ensuing destruction of the national sanctuary at Shiloh, ${ }^{2}$ probably little resistance was made: the conviction of the divine wrath would be so strong as to paralyse all further action. Yahweh had delivered His people into the hands of the Philistines. And so " the Philistines held rule over Israel." The conquered people was disarmed, and "there was no smith found throughout all the land of Israel: for the Philistines said, Lest the Hebrews make them swords or spears." 3 All metal-working was, apparently, forbidden. Garrisons or posts were established in certain places to hold the land down. The most important seem to have been placed at Beth-shean ${ }^{4}$ in the north (to command the passage from the Jordan to the Vale of Esciraelon), in Mount Ephraim, ${ }^{5}$ and at the pass of Michmash ${ }^{6}$ and Geba ${ }^{7}$ between Mount Ephraim and Jerusalem, and south of Jerusalem at Bethlehem. ${ }^{8}$ Philistine officials (neșibim) were appointed to gather the taxes laid upon the conquered, and kept watch upon them from the fixed posts. $^{9}$

Thus for over half a century, probably, the Philistines controlled all Palestine. The revolt against them, which resulted in the establishment of Saul's kingdom in Israel, was religious in its origin. Though on account of plagues in their cities, which, in accordance with the ideas of the time, they ascribed to the outraged Israelitish god, the Philistines had

\footnotetext{
1 The name Phinehas is interesting, as it is pure Egyptian, meaning "The Negro." It was, however, an ordinary appellation, and was not necessarily borne only by negroes. Unlike "Zaphnath-paaneakh" and "Potiphar," ctc. (see pp. 405, 406), it belongs to the periods in which the various persons called by it are said to have lived, since it was in use from about 1500 to 800 B.C. in Egypt. Hophni is also probably Egyptian, and Levi certainly is (conventionally transcribed "Rui" or "Rei"). On the adoption of these Egyptian names by the Hebrew priestly families, see p. 408, n. 3 .

2 Jer. vii. 12, xxvi. 6: Ps. lxxviii, 60. The fact is not mentioned in the his. torical books.

${ }^{3}$ I Sam. xiii, I9.

4 Ibial. xxxi.

5 Ibid, x. 5 .

"Ibid. xiv. Cf. Encycl. Bibl., s.z'. "Michmash."

${ }^{7}$ Ibid. xiii. 3. $\quad{ }^{8} 2$ Sam. xxiii. I4.

9 Moore, Encycl. Bibl., s.v. "Philistines," \$ 9. This interpretation of = which originally means a "pillar," scems the most probable here: $f f$. the analogous double meaning of the English word "post." But in view of the Cretan origin of the Philistines, the translation "pillar" becomes attractive (see p. 53), since the Cretans venerated pillars. The A.V. translation is "garrisons."
} 
restored the Ark of Yahweh to its sanctuary, ${ }^{1}$ the Hebrew priests had never forgiven the insult which their deity had received at the hands of the "uncircumcised," and Samuel the prophet, a fierce monotheist, and hater of all who worshipped other gods but Yahweh, was the leading spirit of the revolt.

Saul was the creation of Samuel and, possibly, the priests, but seems by no means to have become their slave, as was expected of him. The ecclesiastical control was evidently exercised constantly and irritatingly. Samuel had no intention of setting up a really independent monarch. What he wanted was a leader in war, a man "head and shoulders above the people," who would do the work of getting rid of the Philistines and then obey him, Samuel, for the rest of his life. He thought he had found his man in Saul. The king, however, was a man of character, and was by no means inclined to follow the programme thus marked out for him. Quarrels arose between him and Samuel, who, with the thoroughness of the zealot, wished the enemies of Yahweh to be rooted out with all their possessions, while the king naturally desired the best of the booty and of the slaves captured in war for himself and his followers. The breach widened, and after the death of Samuel culminated in the massacre of the priests at Nob by Saul's retainer, Doeg the Edomite. ${ }^{2}$ The support of the outraged priests was naturally given at once to his young rival, David, who secured the throne with their help, but was able to keep. them subordinate to the royal power, which he firmly established in his stronghold at Jerusalem. ${ }^{3}$

The revolt of Samuel and Saul probably began in the land of the Israelites beyond Jordan, in Gilead, which does not seem to have been subject to the Philistines, who possibly never crossed the Jordan. The current genealogy makes Saul a Benjamite of Gibeah, but Prof. Winckler ${ }^{4}$ has shown reason for the belief that he was really a Gileadite. His first warlike expedition was directed against Nahash, king of the Ammonites. Also it is more probable that the revolt began in the TransJordan lands than in the country dominated by the Philistine garrisons. It is significant that we are told that while in the revolt the Israelites had no weapons owing to the prohibition by the Philistines of metal working in any form, Saul and

1 I Sam. v. 6.

${ }^{3}$ See p. 427.
2 Ibid. xxii.

- Gesch. Israels, ii. I 56. 
Jonathan his son (that is to say, Saul and his men) possessed weapons. ${ }^{l} \quad$ The Gileadites were properly armed.

The defeat of Nahash ${ }^{2}$ secured the allegiance of the people to the new leader, and Saul now crossed the river to attack the Philistines. A sudden attack overwhelmed the garrison at Geba, "and all Israel heard" the sound of Saul's trumpet. The great fight at Michmash ${ }^{4}$ followed, which was decided against the Philistines by the defection of their Hebrew auxiliaries to the insurgent side. The retreating soldiers were followed by the refugees, who had hidden themselves from the conquerors in the hill country of Mount Ephraim, "and they smote the Philistines that day from Michmash to Ajalon."

For a time the Philistines were expelled, and Saul now turned his arms against the Amalekites in the south.

The Hebrew victory was sullied, according to our ideas, by the savage sacrifice of the captured Amalekite king to Yahweh by Samuel with his own hands, ${ }^{5}$ and Saul, as ever, seems to us a more humane man than his fierce mentor. To the men of that day, however, Saul no doubt seemed a leader of somewhat weak character except in actual battle, and it must be remembered that even Egyptian kings were accustomed to sacrifice captured chiefs to Amen with their own hands. ${ }^{6}$ Samuel's action cannot be judged by modern standards of conduct.

The Philistines had been swept out of the hills by the victory at Michmash, but it was not long before they advanced to regain what they had lost. Continuous fighting followed, which lasted during the whole of Saul's (probably short) reign. The king was able to repulse every attack, and among the warriors who distinguished themselves in this fighting was David, son of Jesse of Bethlehem in Judah. "Then the princes of the Philistines went forth, and it came to pass, as often as they went forth, that David behaved himself more wisely than all the servants of Saul: so that his name was much set by." 7 And he married Michal, the king's daughter. ${ }^{8}$

The king's jealousy was eventually roused by the successes of David, whom he at the same time justly suspected of in-

\footnotetext{
1 Sam. xiii. 22.

Ibid. xiv.

Iliil. xi. I1.

${ }^{3}$ Ibid. xiii. 3 .

${ }^{6}$ Even the pacifist Akhenaten threatened to sacrifice the Amorite leader, Aziru

${ }^{7}$ I Sam. xviii. 30.

${ }^{8}$ Ibid. 27 .
} (see p. 350). 
triguing with Samuel, who had already marked him out as the destined successor of the recalcitrant and independent Saul. The royal enmity became so marked that the young warrior was compelled to fly the kingdom. ${ }^{1} \mathrm{He}$ at first pursued the war against the Philistines on his own account, and, after his abandonment of the hill-fort (not "cave" ${ }^{2}$ ) of Adullam, he attacked a Philistine force which. was besieging the town of Keilah, and defeated it, afterwards making the place his headquarters. $^{3}$ Saul's pursuit was, however, so relentless that David was compelled to enter into relations with the Philistines, and became the vassal of Achish, king of Gath (then, apparently, the hêgemôn of Philistia), receiving from him the Cherethite town of Ziklag, far to the south beyond Saul's reach, as a fief. ${ }^{4}$ He and his men were now compelled to march against Saul, as the auxiliaries of Achish, on the great expedition which the Philistines launched against Israel by way of the plain of Jezreel, which had always remained in their hands. In spite, however, of the politic desire of Achish to use David and the prestige of Yahweh's oracle (the presence of which at Ziklag must have considerably weakened the allegiance to Saul of many in Israel) in order to further the designs of the Philistines, the Cretan chiefs refused to admit the Israelite rebel to their councils or to utilize his aid. ${ }^{5}$ They suspected his good faith, and Achish was compelled to send him back to Ziklag (which he found devastated by the Amalekites on his return). David thus took no part in the final struggle on Mount Gilboa, when Saul and Jonathan were both slain. ${ }^{6}$

It is probable that Achish ${ }^{7}$ now re-established the Philistine hegemony over Israel, but in a modified form. Ishbaal (Ishbosheth), son of Saul, was set up as ling of Israel, with his residence at Mahanaim, while the southern part of the country was given to David, 8 who reigned as king at Hebron. The Philistine garrisons were not reinstated, but both kings no doubt remained tributary to the Philistines. David had no intention of remaining in this position for long, however. His submission to Achish had been nothing but a means of escape

1 I Sam. xix. Io.

2 Read meșuduth.

5 Ibid. xxix.

s 1 Sam. xxiii.

4 Ibid. xxvii. 6.

6 Ibid. xxxi.

${ }^{7}$ The name Achish is purely Philistine and Cretan. It occurs in an Egyptian "List of Names of Keftiu" on a tablet (No. 5647), in the British Museum (SPIEGELBERG, Z. für Assyr. viii. 384 ).

82 Sam. ii. 
from Saul. He fully intended to drive out the conquerors, depose Ishbaal, and continue Saul's kingship over the whole land in his own person. The ephod and the priests were with him, ${ }^{1}$ and though Samuel was now dead, his choice of David as Saul's eventual successor held good, and was no doubt accepted by the majority of the people. Ishbaal was only maintained as king in Mahanaim by the sword of his general Abner, against whose skill was soon pitted the fierce military virtue of David's general, Joab, for the king of Hebron lost no time in attacking his northern rival. The Philistines probably saw no reason to support either party against the other, and were well content to let their turbulent vassals destroy one another.

The defeat and defection of Abner and subsequent murder of Ishbaal, ${ }^{2}$ which placed all Israel under the undisputed rule of David, was calculated to disturb their complacency, as putting too much power into the hands of the energetic king of Hebron. And it was followed by an unexpected event which moved them to immediate action against him. The important town of Jerusalem, which three centuries before had been the centre of the Egyptian power in Southern Palestine, had, at the time of the Hebrew invasion, though perhaps carried by a rush, never been retained ${ }^{3}$ by the conquering tribes, and had never been re-taken, probably on account of its strength. It had remained in the power of its Canaanite inhabitants. David now possessed himself of it by a coup-de-main, and transferred himself to it from Hebron.4 At Hebron he had been always under the eye of his overlords, but now he was again the free man, in possession of an impregnable fortress, an inexpugnable focus of renewed rebellion. The distrust of the Philistine lords was amply justified, and Achish, if he still lived, must bitterly have rued his old complaisance towards the clever Hebrew leader. It was at once determined to attack David, and a powerful Philistine army moved up into the hills directly against Jerusalem. The expedition failed disastrously, David won two brilliant victories, at Baal-perazim, where the images of the Philistine gods were captured, and in the valley of Rephaim, where the invaders were so thoroughly routed that David smote them from Geba as far as Gezer, where the broken army regained the plain.

1 I Sam. xxiii. 9.

4 Sam. v. 7 .
22 Sam. ii-iv.

5 Ibid. v. 20.
${ }^{3}$ See pp. 351, 411, n. 2. 
The tables were now turned. David followed up his success by invading Philistia, directing his attack against Gath, the most important Philistine centre at the time, and the nearest to the Israelite hills. Fighting of the fiercest character seems to have taken place round Gath, for the Philistine warrioroligarchy was now at bay, and fighting for life. Gath, however, fell, ${ }^{1}$ and then David seems to have marched directly against the Philistine "mother city," Ashdod, situated about twelve miles to the west, near the coast. Ashdod was taken, ${ }^{2}$ and then the Israelite king returned triumphantly to his capital. Gath and its immediate dependencies, which had originally been Israelite territory, but had been torn from Israel by the Philistines soon after their immigration, were annexed by David, and the new condition of things was significantly shown by the fact that hundreds of Philistine and Cherethite warriors now took service at Jerusalem as the bodyguard of the Israelite conqueror. $^{3}$ Mercenary service was characteristic of the races associated with the Philistines (the Shardina, especially), as of their relatives the Carians in later days; and mercenaries only take service with powerful monarchs who can pay them well and maintain them in plenty; so that his guard of Pelethites and Cherethites is significant evidence of the growing dignity and importance of the king of Israel.

The land was now definitely freed, and the event was marked by the solemn entry of the Ark of Yahweh into the new capital. ${ }^{4}$

\section{The Kingdom of Israel}

David and the priests-The kingdom of David: the king's house-warriorsShavsha the Babylonian scribe-Defeat of Moab and Ammon-Overthrow of Hadadezer and annexation of Damascus-Alliance with Toi of Hamath and Hiram I of Tyre-Destruction of Edom-Philistia not conquered: probably protected by Egypt-Rebellions of Absalom and Adonijah-Death of David : Solomon succeeds (c. 970 B.c.)-Solomon the great and wise-The Temple-Legends of Solomon and the Jann-His kingdom holds the trade-routes from Egypt to the East: wealth and commerce-Marriage alliance with Egypt-Friendship with Hiram of Tyre-The expedition to Ophir-Legend of the Queen of Sheba-Weakness at end of the reign-Successful revolts of Edom and Syria-Death of Solomon (c. 930 B.C.).

${ }^{1}$ I Chron. xviii.

22 Sam. viii. Metheg-ammah is translated "the bridle of the mother-city" in the R.V., and the Philistine " mother-city" was Ashdod.

"Ibid. viii. I8. A Philistine named Ittai, of Gath, was one of David's most trusted officers.

4 Ibial. vi., vii. 
The plans of Samuel had triumphed, but his policy was not destined to be carried out in its entirety. No warrior-king would submit to be the puppet of the prophets and priests. Saul had not, and indirectly owed his death to them in consequence. David, more wily, was devoted to them until the consummation of his kingship, and then had become too great a king to be controlled by such men as Abiathar and Zadok. He then deliberately set to work to bind the priesthood to him in a subordinate position by filling up the priestly offices vacant after the massacre at Nob with his own nominees, chiefly his own sons. ${ }^{1}$ Thus he hoped to prevent the possibility of too much religious interference.

The organization of the kingdom was modelled generally upon those of the neighbouring realms, but was naturally far more military in character than the organizations of either Egypt or Babylonia. Military personages like the sons of Zeruiah, like Benaiah ben-Jehoiada the Hebrew commandant of the Philistine guard and executioner-in-chief, Ittai the Philistine of Gath, one of David's most trusted soldiers, and Uriah the Hittite mercenary from the North, were far more prominent in the actual administration of the kingdom as well as in the royal entourage, than the treasurers and other nonmilitary officials. It would have appeared a very barbarous kingdom, its organization a very rude imitation of those of the great empires, to an Egyptian or a Babylonian. Learning was probably unknown. Scribes existed, but it is uncertain what script they used, as we do not know whether the Phoenician or Aramaic alphabet (which had probably already been devised) ${ }^{2}$ had yet spread to southern Palestine. For foreign correspondence cuneiform may still have been used (though Aramaic is quite possible), and David had a Babylonian scribe, Shavsha (Shamsha) by name, ${ }^{3}$ to conduct the diplomatic correspondence with neighbouring monarchs which followed the rise of himself and his kingdom in the world's estimation.

The soldiers were not content with the defeat of the Philistines and recovery of Gath, and a series of campaigns was soon

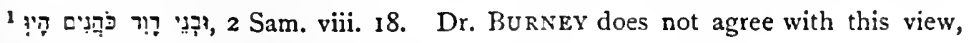
but it seems to me to have much in its favour.

2 The latest theory as to the origin of the alphabet is that it was derived from the Cretan hieroglyphs (Evans, Scrifia Ninoa). Its place of origin was probably North Syria.

${ }^{3}$ I Chron. xviii. I6. 
inaugurated against all the ancient enemies of Israel round about, in turn. Moab, in spite of the hospitality which she had afforded to David's parents when he fled from the anger of Saul, was first attacked, overthrown, and two-thirds of her inhabitants slaughtered. ${ }^{1}$ The remaining third submitted to annexation. Ammon was obviously marked out as the next victim, and so the king Hanun, son of Nahash, formed an alliance with the Aramaean tribes to the north against Israel. Ambassadors sent by David were villainously entreated, and Joab thereupon attacked with his army, completely defeating the allies. ${ }^{2}$ Whether now or somewhat later, the king's town of Rabbath-Ammon was taken, and its people horribly massacred by David. ${ }^{3}$ Ammon then ceased to exist as an independent kingdom.

The defeat of the Aramaean allies of Hanun was news displeasing to Hadadezer, the chief Aramaear: king, who ruled in Zobah (a territory the precise frontier of which is unknown to us, but may be placed south of Damascus), and whose empire extended far to the westward and even included the Aramaean tribes on the other side of the Euphrates. Summoning even these distant subjects, his general Shobach advanced against the presumptuous Israelite king, but was severely defeated at Helam (Aleppo?). The Syrians of Damascus came vainly to his aid, and the end of the war was the annexation of Damascus and its district to the kingdom of David.4

The defeat of the Aramaeans and the conquest of Damascus brought David into immediate contact with the important kings of North-Syria. An old enemy of Hadadezer, Toi, king of Hamath, whose kingdom now probably'marched with that of David, sent him a friendly embassy, ${ }^{5}$ and Hiram of Tyre, the chief Phoenician king, became his friend and ally. ${ }^{6}$

Against the powerful North-Syrian princes David had no mind to carry on war; the forces at his command would not have sufficed in number to effect anything more than a mere raid had he advanced against them victoriously, while success against their vast hosts was improbable. He contented himself with

12 Sam. viii. 2.

2 Ibid. $\mathrm{x}$.

3 Ibid. xii. 29-3I.

${ }^{4} \mathrm{Ibid}$. viii. $3-8, \mathrm{x}$. $16 \mathrm{ff}$. The account in viii. is evidently a less accurate duplicate of that in $x$, , and the Hadadezer of viii. must be the Hadarezer of $x$. The correct form of the name is Hadadezer.

s Ibid. viii. 9-II.

'Ibid. v. II. 
the acquisition of Damascus: no further northward extension of the kingdom is indicated.

The borders of the land being extended thus far northwards, the turn of the south now came. Edom, which, as far as can be learnt from the Biblical narrative, had given Israel no provocation, but had always been disliked by the Israelites, was attacked and overthrown, and a general massacre of the male inhabitants was, as usual, carried out by Joab and Abishai, the savage sons of Zeruiah. ${ }^{1}$ The Edomite king, Hadad II, the eighth of his line, seems to have been killed in battle, and his son Hadad III, whose mother, Mehetabel, was an Egyptian, fled to Egypt, where he married a royal princess, and lived as a pensioner of Pharaoh till the death of David seemed to open for him a prospect of regaining his inheritance. ${ }^{2}$

Edom was annexed as far as the sea at Ezion-geber (Akaba). The Hebrew dominions were not rounded off by a final conquest of the whole of Philistia. Not even tribute seems to have been sent to Jerusalem, and it may well be that the southern Philistine chiefs had voluntarily placed themselves under the protection of the north-Egyptian pharaohs at Tanis, who seem to have been energetic princes (Siamon now reigned), and with whom at any rate the Israelite ling would have no desire to try conclusions. That this is the correct explanation is shown by the fact that when Shishak had invaded Judah after the death of Solomon he recorded the names of all the captured cities, and among them those of the Philistine towns are not mentioned. From this it would seem that they were already re-subjected to Egyptian rule, and in Solomon's time we find that the Pharaoh of Egypt considers Gezer as his, to burn and destroy, without opposition from the Hebrews. ${ }^{3}$

Thus in the course of a few years David had raised Israel to the position of an important kingdom, with considerable territory. For the rest of his life he lived the normal life of an Oriental monarch, troubled by the usual harim-jealousies and hatreds, disobediences, and rebellions of his children. The rebellion of Absalom ${ }^{4}$ was sufficiently serious to necessitate the king's flight from his capital. His last days were troubled by the attempt of Absalom's brother Adonijah to seize the

${ }^{1}$ I Chron. xviii. ; I Kings xi. ; 2 Sam. viii. See Nöldeke, in Encycl. Bibl., s.v. "Edom," § 6.
${ }^{2}$ I Kings xi. I7-22.
${ }^{3}$ See p. 437.
2 Sam. xiii. sqq. 
crown in despite of his half-brother Solomon, the king's son by Bathshe oa, to whom it had been devised by the king under Bathsheba's influence. Solomon was immediately consecrated as king, and associated with his father on the throne, which he occupied without a struggle on the king's death. ${ }^{1}$

Solomon's accession was marked by the proscription of the supporters of Adonijah, chief of whom had been Joab and Abiathar, the ancient friends of David. Despite his services, Joab fell by the hand of the king's executioner, Benaiah, the son of Jehoiada; and Abiathar, saved from death by his holy calling, was banished to his patrimony of Anathoth, the more courtly Zadok succeeding him in his office. ${ }^{2}$ It was said that David, who had no love for his old companion-in-arms, had on his deathbed charged Solomon to put Joab to death.

The new reign marked a new epoch in the history of the Jewish state. Solomon was no "Roi des Gueux" like Saul, no successful condottiere like David; he was a typical Oriental Sultan, magnificent (so far as his means would allow), wise (in the belief of the vulgar), and without doubt tyrannical. He had been born in the purple. The element of simplicity which remained in his father's character till the end was unknown to him and to the men of his generation, who had been born after the close of the old republican days. Israel had now become great, and her king, enriched by the tribute of all the lands from the Euphrates to the River of Egypt, was a monarch by whose side the farmer-leader of the old confederation, Saul, was a mere rustic. Civilization had progressed considerably in Jerusalem during the latter days of David: Solomon was pre-eminently a civilized man, a man of marked aesthetic tastes: he loved the majesty and splendour which his wealth enabled him to show, especially in the building of the great Temple in Jerusalem. This was probably the first building of any architectural pretension erected in Israel, and its wonders, as the Israelites considered them, made an ineffaceable impression on the popular mind. Solomon merely aped the splendours of Egypt and Babylonia, but in Oriental tradition he has become a Sultan more magnificent than Sesostris or Sardanapalus, and the wielder of supernatural power, for he could command the Jann or Jinnis, the Powers of the Air, and they 
did his bidding. He was the wisest as well as the most mighty and magnificent of rulers.

Here we have a true portrait exaggerated. Solomon was no warrior like his father; he had had no experience of war and the camp in his youth, and had no desire to make acquaintance with them. If difficulties arose, he endeavoured to avoid them by diplomatic means, for he had inherited his father's diplomatic talent, and probably his diplomacy was managed with a finesse which, coupled with his patronage of the mysterious arts of civilization and his great ability in the amassing of wealth, gave him his deserved reputation for wisdom.

This "wisdom" was the keynote of his reign. Loving wealth, he bent his whole energies towards its acquisition by the means of peaceful commerce. His kingdom lay athwart the main lines of communication between Egypt and Mesopotamia, Arabia and Asia Minor, and, under wise governance, seemed destined to be wealthy and prosperous. As the heir of the kingdom of Damascus, he ruled up to the Euphrates and held the great trade-crossing at Tiphsah (Thapsacus). ${ }^{1}$ As the heir of Edom, he held Ezion-geber on the Red Sea, ${ }^{2}$ at the head of the Gulf of Akaba. And, though not he, but the Pharaoh of Egypt, was the sovereign of Philistia, yet Gaza is traditionally assigned to his kingdom $;^{3}$ and it is by no means impossible that this important trade-centre was given him by the Egyptian monarch Hor-Psibkhannu, possibly with his daughter, the daughter of Pharaoh, king of Egypt, whom Solomon took to wife. ${ }^{4}$

This marriage-alliance with Egypt secured peace on the south-western frontier, and the alliance with Hiram of Tyre, the most powerful Phoenician prince, at the same time secured Solomon's communications with the Phoenician cities and the Phoenician communications with Arabia. Under the protecting aegis of the king of Palestine the caravans passed continually from Egypt to Mesopotamia, from Phoenicia to Arabia, in peace; the old days of the robberies of the Suti and the " $S A$.

2 I Kings iv. 24.

3 Ibid. iv. 21, 24 (Azzah $=$ Gaza).

2 Ibid. ix, 26.

4 Ibid. iii. I. Gaza would be the royal dowry, while Gezer was given to the daughter of Egypt as a gift by her father after he had destroyed it (I Kings ix. I6), probably some time after the marriage. It is impossible to accept the view of Cheyne (Encycl. Bibl., s.v. "Gezer"), who makes even this "Pharaoh of Egypt" also a "Pir'u king of (an Arabian) Muşri" ; see p. $47 \mathrm{I}$. 


\section{4 'THE ANCIENT HISTORY OF THE NEAR EAST}

$G A Z$ " seemed forgotten. The king himself, we are told, equipped, with the aid of the Phoenician Hiram, a great naval expedition which sailed from Ezion-geber to the land of Ophir, and brought back the famous cargoes of the wealth of Ind which are described with so much detail in the Book of Kings. ${ }^{1}$ The resemblance of this expedition to those of the old Egyptian monarchs, notably Hatshepsut, to Punt has always been remarked, and it has often been assumed that Ophir was Punt, and that it is therefore to be sought on the African Somali coast. Among the products of Ophir, however, there are certain things mentioned, such as the apes and peacocks, for instance, which are certainly Indian; so that it is quite probable that Ophir is really the Konkan or Cochin coast, and that Solomon's Phoenician sailors reached India, unless, as is possible, they went only as far as Southern Arabia, where they received the Indian products brought by the local traders.

Relations with the civilized communities of Southern Arabia are indicated also by the legend of the coming of Balkis, the queen of Sheba, to Jerusalem in order to visit the wise and magnificent king.

A less commendable side to the "wisdom" of Solomon is exhibited in the story of his astute dealing with Hiram in the matter of the Galilaean towns which were handed over to Tyre in payment for cedar and gold. ${ }^{2}$

The reign of Solomon early became the theme of popular romance, and but few really historical events of it are recorded at all. This presents us with a strong contrast to the clear sequence of events, the genuine history, of the reigns of Saul and David. But we can see that towards the end of his reign the power established by David had weakened. "Adversaries were raised up" against him in the shape of Hadad the Edomite and Rezon the Syrian. David's great conquests, Edom and Syria, revolted, and the Jewish power had become so enfeebled by the luxury and pacifist policy of the king that it was unable to retain these conquered lands. Hadad III of Edom, the young son of the second Hadad, who had been killed fighting

1 I Kings ix. 26 ff., x. I I, 22 ; 2 Chron. ix. 21. The ships of "Tharshish" here mentioned must be those that went to Ophir, if they brought back ivory, apes, and peacocks. Tharshish is no doubt Tartessus in Spain, where the Phoenicians had already settlements. Gades was founded about I roo B.C., according to tradition.

${ }^{2}$ I Kings ix. Ir. 
against Joab's cruel invasion, had fled to Egypt, where, as was commonly the case of exiled Asiatic princes, he was maintained at the royal court in a manner befitting his rank, and given Pharaoh's wife's sister as his bride. Their son Genubath, who was born in Egypt, bore, apparently, an Egyptian name. ${ }^{1}$ We do not know the name of the king who patronized Hadad, but it was probably the last Tanite, Hor-Psibkhannu, or Sheshenk I.

The growing weakness of Solomon encouraged Hadad to make his way back from Egypt to his lost kingdom, and he seems to have re-established its independence, ${ }^{2}$ as did Rezon that of Syria,, without much trouble. At the end of Solomon's reign the Israelite kingdom was reduced to its limits in the time of Saul. At his death it split again into its two natural divisions of Judah and Israel, and the kingdoms of David and Ishbaal were restored, with the difference that Jerusalem was now the capital of Juclah, instead of Hebron.

\section{The Kingdoms of Judah and Israel}

Rehoboam-Revolt of Israel under Jeroboam : instigated by the prophetsReligious policy of Jeroboam - Invasion of Shishak (c. 925 B.c.) - Jeroboam's connexion with Egypt

Events had taken their course natural in an Eastern state. To the warrior who had carved out a kingdom for himself succeeded the magnificent son, powerful and wise but feeble in old age, to whom succeeded the prodigal tyrant who brought all things to ruin. David, Solomon, and Rehoboam are paralleled in Egypt by Thothmes III, Amenhetep III, and Akhenaten; in modern history they correspond to Henri IV, Louis XIV, and Louis XV. The folly of Rehoboam was the opportunity of an Israelite David, Jeroboam the son of Nebat, to seize the throne for himself. ${ }^{4}$ Probably he intended to seize the whole inheritance of David, but Judah and Benjamin remained faithful to their worthless sovereign, and Jeroboam

1 I Kings xi. 20. The name "Genubath" may be really a misunderstood Egyptian title. "Speculations based on Egyptian" (see Cheyne, Encycl. Bibl., s.v. "Genubath") are not, in my opinion, "misplaced," for I believe (with MEYER, Israeliten, pp. 360 ff.) that Hadad fled to Egypt, and not to the hypothetical Arabian "Mușri" of Winckler and Cheyne. The Biblical account is quite Egyptian in character.

2 I Kings xi. 2 I.

${ }^{3}$ Ibid. 23 ff.

4 Ibid, xi., xii. 
had to content himself with the northern division of the kingdom. Religious discontent probably gave him a means of exciting disaffection. Solomon, a broad-minded man, interested in all things foreign, had been tolerant in religion, and had even, so men said, been himself prevailed upon by his foreign wives to sacrifice to deities other than his own. ${ }^{1}$ The peculiar temper of the Hebrew prophets, which did not tolerate that any reverence should be paid to other gods but Yahweh, or to Yahweh in iconic form, was excited by this cosmopolitanism, and even before the death of Solomon, a religious fanatic named Ahijah seems to have started in the North the revolt which the ambitious son of Nebat soon used for his own purposes. ${ }^{2}$ Ahijah's purpose was not effected, for no sooner was Jeroboam firmly established in power than he abandoned the aniconic cult of Yahweh and offered public sacrifices to the bull-images at Dan and Bethel. ${ }^{3}$ The Israelitish kingdom was henceforward by no means solely devoted even to the worship of Yahweh, whether aniconic or not, and a constant fight was waged for two centuries by the prophets against the idolatrous tendencies of the royal court and the majority of the population. This struggle produced that splendid prophetic literature of the Old Testament to which we owe so much, not simply as a source of historical information, but as a mighty religious force which has deeply modified the whole national character of the Christian peoples.

Judah and Benjamin remained on the whole more faithful to the God of their forefathers, probably owing to their possession of the national sanctuary that Solomon had built. It must also be remembered that Israel was now and remained far more civilized, as well as more populous and prosperous, than Judah, and so was more open to the corrupting influences of the non-Hebrew peoples with whom she was in constant contact. Judah, isolated in her hills, led a simpler life, in spite of her possession of Solomon's capital.

Jeroboam's easy inclination in religious matters was perhaps natural: both his mother and his wife were Egyptian. And this fact also makes it the more probable that his successful revolt was closely connected with the Egyptian invasion under Shishak (Sheshenk I, first king of the XXIInd Dynasty) in

${ }^{1}$ I Kings xi. I-8, See Burver, Notes on the Heb. Text of Kings, pp. $153 \mathrm{ff}$.

I Ibid. xi. 29 ff.

a Hid. xii. $26 \mathrm{ff}$. 
the fifth year of Rehoboam (about 925 B.C.), which resulted in the capture and sack of Jerusalem. ${ }^{1}$ We can well see that these two events were closely inter-related, ${ }^{2}$ and can assume that the revolt of Israel followed the fall of Jerusalem. ${ }^{3}$ We need not suppose that Jeroboam was merely the tool and nominee of Shishak, but it was natural that, being half-Egyptian himself, he should lean greatly upon Egyptian support, and, as a mark of his alliance, take, like Hadad of Edom and Solomon himself, an Egyptian princess as his wife.

\section{Egypt and Palestine (1000-854 B.C.)}

Egyptian suzerainty in Philistia restored by Siamon?-Psusennes II gives Gezer to Solomon-Sheshenk I (Shishak) founds the XXIInd (Bubastite) Dynasty (c. 942 B.c.) -Reunion of the Two Lands-Sheshenk's works at Karnak-Egyptian record of Shishak's invasion of Palestine-Death of Sheshenk-Asa defeats Zerah (Osorkon 1) (c. 895 B.c.)-Osorkon II (c. 869-85 I B.c.) builds at Bubastis-Battle of Kartiar ( $\mathrm{S}_{54}$ B.C.)

We have seen that the weakening of the Philistine power during the long war with Saul and David probably induced the Philistines to acknowledge Egyptian supremacy as a means of protection against the Hebrews. This was perhaps in the time of Siamon the Tanite (c. 995-977 B.C.), of the XXIst Dynasty, when Gaza probably became Egyptian once more. The Egyptian supremacy seems to have been real. It was not challenged by either David or Solomon, the latter of whom was friendly with Egypt, and married the daughter of the king, probably Hor-Psibkhannu (Psusennes II), the successor of Siamon. We have seen ${ }^{4}$ that Gaza may have been given by Psusennes to Solomon as the dowry of his daughter. $\mathrm{He}$ certainly gave Gezer to his daughter and her husband, after be had chastised it with fire and sword. Solomon re-fortified

1 I Kings xiv. ; 2 Chron. xii.

${ }^{2}$ No connexion between the two events is actually indicated in the Biblical narrative, but no admission that the kingdom of Israel owed its establishment to Egyptian help would naturally be made by a patriotic writer. The facts of the capture of Jerusalem and the sack of the temple by the Egyptian conqueror could not, however, be passed over, especially since they read as a divine judgment on the obstinacy and wickedness of Rehoboam.

${ }^{3}$ Jeroboam probably revolted first in the reign of Solomon and fled to Egypt (I Kings xi. 40), where he abode till the death of Solomon. Then he returned to Falestine, and the rebellion against Rehoboam followed, in connexion with the Egyptian invasion and the disaster which befell the capital.

${ }^{4}$ See p. 433 . 
the city, ${ }^{1}$ which was one of the most important in Palestine, and had been one of the chief places of the Philistines. For these events we have only the evidence of the Biblical history: the Egyptian records, miserably jejune at this period, tell us nothing.

At the death of Psusennes II the Egyptian kingdom passed to another dynasty. A successful soldier, of Libyan descent, ${ }^{2}$ named Sheshonko or Sheshenk, ${ }^{3}$ succeeded him, and as a mark of the change of dynasty the capital was transferred from Tanis to Bubastis, no doubt Sheshenk's own town. He legitimatized his claim by marrying a Tanite princess, Karamat, daughter of Psusennes.

Sheshenk's first enterprise was the assertion of his authority in Upper Egypt, and the termination of the dual system of government which had obtained for over a century. The rule of the theocracy at Thebes was ended by the appointment of the king's own son Auput as High-Priest. Thebes appears to have submitted without demur, and was henceforward specially favoured by Sheshenk and his successors, who aspired to honour Amen not less than their great predecessors of two or three centuries before, and to revive his ancient glories so far as lay in their power. Sheshenk began to build an enormous hall at Karnak before that of Seti and Rameses, but the architects of his day were not as those of the great period: they had no experience in gigantic works, the columns they put up were too weak to carry any roof, the hall was never completed, and now only a single pillar of this badly planned work remains.

To honour Amen fitly records of successful war were also necessary as decorations of his temple. These were provided by Sheshenk's expedition into Palestine, the triumphal record

1 I Kings ix. I5, I7.

2 I do not share Prof. Petrie's doubts (Hist. Eg. iii. 23I) of the Libyan origin of Sheshenk's family, which is generally credited. The names of the family are not Egyptian, and are more probably Libyan than anything else. The confused collection of Eastern identifications, which Prof. Petrie puts forward, cannot have be. longed to one family, as they belong to several different languages-Turanian Elamite, Aryan Zend, Semitic Assyrian, and Sumero-Babylonian! Such eclecticism did not occur in the ancient world. And it is again necessary to point out that the Assyrian word Tuklat-(Tiglath-) is part of a name, and cannot stand alone: there was no more any Assyrian name "Tuklat" (with which Prof. Petrie, and Brugsch before him (Egypt under the Pharaohs, ii. p. 206) have identified Takeloti than there is an Arabic name "Abdul."

3 With the throne-names Hetjkheperra Setepnera. 
of which was placed upon the walls of Karnak, ${ }^{1}$ and has given us a valuable confirmation of the historical truth of the Jewish chronicler's statement as to the captureof Jerusalem by "Shishak." 2 Here again we see that the Egyptian did not strike till he could be fairly sure of victory. Solomon had been too powerful for any attack to be made upon him: but no sooner was he dead, and the tyranny, weakness, and unpopularity of Rehoboam made manifest, than the plans of the pharaoh who had taken Gaza were resumed by his Bubastite successor. Sheshenk had reigned about twelve years, probably, before the death of Solomon took place, and his Palestinian expedition was carried out five ycars later, when he must have been getting on in years. He died, perhaps, less than five years (c. 920 B.C.) after his triumphant return to Egypt. He had brought with him the golden shields of Solomon's temple and the rest of the treasure of Yahweh's service, which it had been the chief object of the expedition to secure for the enrichment of Amen, who was no longer so wealthy as he had been of old. No attempt was made to hold Palestine : the Jewish kingdom on her immediate border seemed to forbid all prospect of any future restoration of the empire that Egypt had held for six hundred years and more. Yet one more attempt at its restoration seems to have been made, if we are to identify the "Ethiopian" Zerah, who was defeated by Asa of Judah, the second successor of Rehoboam, with Osorkon I, the successor of Shishak. ${ }^{3}$ The defeat was final (c. 895 B.C.).

The remaining kings of the XXIInd Dynasty-Takeloti I, Osorkon II, Sheshenk II, Takeloti II, Sheshenk III (who reigned over fifty years), Pimai, and Sheshenk IV-were of no historical

1 Lepsius, Derkmaeler, iii. 252-53a. There is a good account of the Egyptian evidence in ALT, Israel und Aegypten, pp. $27 \mathrm{ff}$.

${ }^{3}$ It should be noted that the doubts of the identification of Sheshenk with Shishak expressed by Prof. CHeyne in Encycl. Bibl. s.v. are absolutely baseless. Why Prof. Cheyne should go out of his way to challenge an obviously correct identification is only comprehensible on the theory that he is convinced that all supposed references to Egypt in the Biblical record must refer, not to Egypt at all, but to the unknown country of the same name, discovered by Winckler, in Northern Arabia. Cf. Petrie, Hist. Eg. iii. 235 and Alt, l.c. p. 35.

32 Chron. xiv. The identity of "Zerah" with Osorkon I is made probable by the perfect coincidence of date (about 900 B.c.). The name is evidently a corruption of the Egyptian. Osorkon or Oserakon has become (O)zerakh(on). The identification was made by Champollion. The numbers given in the Book of Chronicles are of course enormously exaggerated. 
importance whatever. Osorkon II built a splendid "FestivalHall" at Bubastis to commemorate his Sed-festival; ${ }^{1}$ and the land seems to have had peace. But in the same reign the shadow of the tribulation to come at the hands of the Assyrians first appeared, when the great battle of Karkar was fought (854 B.C.), in which Shalmaneser II contended with the Syrian Benhadad II of Damascus, Irkhuleni the Hittite king of Hamath, and Ahab of Israel. ${ }^{2}$ It has been supposed that Egypt sent a force to aid the allies, but this is improbable, as the "Mușri" from which 1000 men came to help Ahab and his allies is more probably the North-Syrian land of this name than Egypt.

With the battle of Karkar the history of the kingdoms of Syria and Palestine merges into that of Assyria.

\section{Archaeological Results in Palestine}

No distinction between Canaanite and Hebrew culture-Comparative barrenness of archaeological results in Palestine-Want of originality in Canaanite civilizationCulture thrown back by constant wars-Civilization of Israel: Syrian art-Town walls-The poets and prophets of Israel

The archaeological discoveries of the last few years in Palestine ${ }^{4}$ have hardly shed as much light as had been hoped upon the ancient culture of Palestine.

An important result for the historian is the fact that no

1 Excavated for the Egypt Exploration Fund, and published by Naville, Festival-Hall of Osorkon 11 (London, E.E.F., i 892). On the Sed-Festival, see p. 108.

2 See p. 450. Syria.

${ }^{3}$ See Budge, Hist. Esr. vi. 85. There was certainly a land of Mușri in North

${ }^{4}$ A useful summary by Prof. DRIVER, Modern Research as illustrating the Bible (Schweich Lectures, I908). The chief work has been that of Dr. Macalister for the Palestine Exploration Fund, whose fine series of explorations were started by Prof. Petrie and Dr. Bliss at Tell el-Hesy (Lachish). Since then, Tell es-Safi (Gath) and Tell Jezzar (Gezer) have been excavated with most successful results, and now Dr. Duncan Mackenzie is attacking the tell of 'Ain Shems, the ancient Bethshemesh, and has found interesting pottery of the Aegean Philistine kiıd (P.E.F.Q.S., I9II). The other important excavations are those of the Austrian Dr. SElin at Taanach (published as "Tell Ta'annek" in the Denkschriften der kais. Akad. der Wissenschaften, Wien, I904-7); of the Germans under Dr. ScHUMACHER at Tell el-Mutesellim (Megiddo : see Schumacher, Tell el-Mutesellim, Leipzig, 1908); at Jericho by Sellin ; and at Samaria by Reisner. The latter excavation is still proceeding, and none of its results have yet been made public, with the exception of the fact that inscribed ostraka of the reign of Ahab have been found (Driver, P.E.F.Q.S., April I9I I), and an alabaster vase with the name of Osorkon II of Egypt, a contemporary of Ahab. 
difference can be traced in the town-strata between what is Canaanite and what is Hebrew. ${ }^{1}$ Their cultures werc indistinguishable as, probably, in reality the peoples were also. The difference between them was exaggerated by the Judahite monotheists. All the Palestinians, from North Phoenicia to Judah, were Canaanites. We cannot therefore talk of pottery or what not from lalestinian sites as "pre-Israelite" and "Israelite," for we cannot distinguish them.

With the exception of the Philistine pottery at Tell es-Safi, ${ }^{2}$ most of the actual spoils of cxcavation are somewhat dull and uninteresting in comparison with the brilliant results of similar work in Egypt and Greece. But this is the fault of the Canaanites themselves. In comparison with the Cretans or the Egyptians they were a dull and uninteresting people: brilliant conceptions or mighty works in art or architecture were not to be expected from them. Still, one is surprised at the absence from the Palestinian excavations of anything of real importance in the history of man's handiworks. For the period I 200-700 B.C., positively the only outstanding object is the strange altar discovered by Sellin at Taanach. ${ }^{3}$ The Tell es-Safi pottery is not Palestinian but Aegean, and so cannot be credited to the Canaanites. So also with the "most artistic" objects from Gezer. ${ }^{4}$ In this lack of originality we can see a considerable resemblance to their cousins, the Phoenicians. The luxurious civilization of the period before the Egyptian conquest, of which we gain an idea only from Thothmes III's loot at Megiddo, ${ }^{5}$ was probably entirely imitative, though this cannot be said definitely, as the excavations have revealed not a trace of it. War no doubt destroyed it. The ceaseless war of Egyptian and Hittite and the Israelite invasion must have lowered the level of culture in Canaan enormously. The comparative peace after the treaty of Rameses II with the Hittites no doubt allowed civilization to raise its head once more: the Israelites were becoming traders and seafarers. Then the Philistine invasion threw all back again, and it was only by slow and painful degrees that in the time of Solomon art and handiwork (still imitative, however, and of Phoenician inspiration) once more began to take high place. The

${ }^{1}$ Driver, Modern Research as illustrating the Bible, p. 37.

${ }^{2}$ See pp. 72, 417 .

- Macalister, Gezcr, i. p. 29 S.

3 Tell Táannek, Fig. 102, pp. $75 \mathrm{ff}$.

"See p. 239. 
tradition of Solomon maintained itself at Samaria, we cannot doubt. But of this we have nothing, as yet. War, probably, has destroyed or spoiled everything of importance. Unless the Assyrian capture and sack in 722 B.C. destroyed all remains of this age, we may, however, hope that the excavation of Samaria, now in progress, may tell us something of the culture of Israel, which must have been affected strongly by that of Northern Syria. From the last excavations and archaeological discussions we are beginning to see a possibility that the Syrians had an art of their own, owing much to Anatolia and much to Babylonia-Assyria, but still with a certain originality which that of Phoenicia lacked. This Syrian art may towards the end of its day have exercised considerable effect upon the nascent art of Greece, and perhaps formed a bridge between the vase-painters of Ionia and the sculptors of Nineveh. ${ }^{1}$

The actual results of the excavations on southern sites are what might have been expected: high-places, bethels, and innumerable sacrificed children buried in pots beneath buildings. $^{2}$ All small objects are crude and poor. Of great interest are the huge stone walls of the towns, going back to megalithic times, and testifying by their existence to the insecurity of the settled inhabitants from Beduin raids and the attacks of conquerors from Egypt or the North. ${ }^{3}$

If the Palestinians as a whole lacked artistic originality and could build nothing but bare walls, if they lacked imagination as regards the works of their hands, if their sense of the beauty of form and line in material objects was blunt and poor, yet we know to what heights and depths of imagination and imagery the poets and prophets of Israel could attain, dowering the

1 This is the view of Mr. D. G. Hogarth (Ionia and the East, p. 6r), which is attractive and explains much. We may, however, depreciate too much the originality of the Ninevite artists if we regard their art as wholly of Syrian origin (see p. 515, n. 3).

2 The high-place of Gezer, excavated by Mr. MAcalister for the Palestine Exploration Fund, is of great interest with its row of masseboth. The sacrificed children are found at Megiddo and Taanach as well as at Gezer. See Driver, l.c. pp. 68 f. ; Macalister, Gezer, ii. pp. $38 \mathrm{I}$ ff.

${ }^{3}$ The walls of Lachish and Gezer, of Megiddo, Taanach, and of Jericho were of great strength, and were constantly rebuilt on the old foundations after each successive sack. Those of Jericho were especially vast (M.D.O.G., Dec. 1909), and the new excavations of the Palestine Exploration Fund at Bethshemesh are shewing the same system of great walls, going back to the megalithic period almost (P.E.F.Q.S., I911). 


\section{THE KINGDOMS OF SYRIA AND PALESTINE}

world with a poesy, a music and frenzy of words, that is one of the greatest possessions of our civilization for all time. ${ }^{1}$

1 The conbination of sublinse poetical gifts with comparative insensibility to material beauty is perhaps characteristic of the highest "Semitic" type of mind (as opposed to the "Greek" type). The "lust of the cye" is often scorned by the poet; to-day one meets poets who have no ear for music and no eye for beauty or for amenity of life. When the ancient Semite did appreciate beautiful things he became too luxurious and prodigal of them, shewing typical "bad taste" as compared with the reticent and proportioned love of art and bcauty that was characteristic of the Egyptians and Greeks, as now of the Japancse. 


\section{CHAPTER X}

\section{THE ASSYRIAN EMPIRE}

\section{Renewed Rise of Assyria: the Reign of Ashur-nașir-pal}

Adad-nirari II (9I I-890 B.c.)-The limmu-list begins (893 B.c.)-TukultiNinib II (890-884)-Ashur-nașir-pal III (884-860)-A savage conqueror-The Assyrian military system : the infantry, archers, siegecraft, and engineering-Comprehensive strategy of Ashur-nașir-pal : the circular sweep of war-Submission of Syria and Phoenicia (c. 875 B.c.)-Ashur-nașir-pal as a builder-CalahShalmaneser II (860-825 B.C.)

$7 \mathrm{HE}$ division of the Jewish kingdom, and the internecine war in Palestine that resulted therefrom, coincided with a renewed rise of the Assyrian power.

Between Ashur-erbi, in whose reign the Syrian cities of Pethor and Mutkinu, and with them probably the whole transEuphratean dominions of Tiglath-pileser I, were lost to the Aramaean invaders, and Ashur-nasir-pal, who recovered North Syria, nearly two centuries elapsed. For over a century after the reign of Ashur-erbi Assyrian history is a blank, till the name of an Assyrian king is once more mentioned; this is Tiglath-pileser III, a contemporary of Solomon and of Shishak. Of this third Tiglath-pileser we have no contemporary record: we know him only from an inscription ${ }^{1}$ of his grandson, Adad-nirari II.

The reign of Adad-nirari II marks a new era, not only in the history of Assyria, but in that of the world, for another reason. It so happens that from his time the list of the limmi or eponymous magistracies of the years was kept without omission till the close of the Assyrian empire. As has already been

1 Published by Winckler, Zeits. fiir Assyriologie, ii. 3 I I ; translated by him in Keilinschr. Bibl. i. pp. 48, 49; British Museum, Annals of the Kings of Assyria, i. p. 154 . 
said, by means of this list we can fix without the possibility of error the exact dates of most of the chief events in the history of Assyria. With the limmu of $\$ 93$ B.C. (the year in which the continuous record starts) accurately dated history begins. ${ }^{1}$

Adad-nirari died in the year 890 , leaving a kingdom heartened by successful conflict with Babylonia to his son Tukulti-Ninib II, a warrior who might have rivalled the exploits of Tiglath-pileser, had he not been carried off early by death $\left(88_{4}\right)$, after a successful campaign on the northern border.

He was succeeded by his son ASHIU R-NAṢIR-PAL III.(884-860), in whose twenty-four years' reign the renewed military activity of Assyria suddenly burst forth from her borders with irresistible force in the direction of Syria, with the result that in a very short time the dominion of Tiglath-pileser I was restored, and the foundation of the empire of the Sargonides was laid. ${ }^{2}$

The new conqueror was a man not only of military genius but of a ruthless and unsparing nature that beat down all opposition by the method of absolute annihilation. No human pity existed in the breast of Ashur-nașir-pal: the sufferings of defeated men whom he tortured were to him no more than those of crushed ants; nay, less, for he gloried in the tortures which he inflicted on the bodies of those who crossed his will. His usual procedure after the capture of a hostile city was to burn it, and then to mutilate all the grown men prisoners by cutting off their hands and ears and putting out their eyes; after which they were piled up in a great heap to perish in torture from sun, flies, their wounds, and suffocation; the children, both boys and girls, were all burnt alive at the stake; and the chief was carried off to Assyria to be flayed alive for the king's delectation. ${ }^{3}$

1 On the limmi, see p. 15.

"We know much of the reign of Ashur-nașir-pal, chiefly from his "standard" inscription, discovered by Layard at Nineveh, and translated by SAYCE in Records of the Past, New Series, ii. pp. 128-77: his inscriptions are collected in the British Museum, Annals of the Kings of Assyria, pp. $155 \mathrm{ff}$.

3 This inhumanity, which seems to have been quite unknown to Tiglath-pileser I, for instance, unhappily set a sort of standard of conduct in war to the Assyrian army, which was followed by later warrior-monarchs to a more or less extent. But no successor of Ashur-nașir-pal seems to have desired to rival the peculiar glory of this "great" king, and burn children alive. At any rate, not one boasts of it, as did this creature, extraordinarily inhuman even for the inhuman lays in which he lived. Nevertheless, they werc as cruel to adult human beings as he, and as, so far as wc know, few rulers before them had ever been. Certainly the Egyptians had always been humane conquerors, while it is staggering to think of the enormous amount of 
To Ashur-nașir-pal and his son Shalmaneser II was due the military organization of the Assyrian state which soon made it mistress of Western Asia. We know little of the actual organization of the nation for war, except that there was a small standing army of royal troops, which was increased in war-time by the mobilization of all the men, who were all ablebodied warriors of a hardy farmer or yeoman class. It was in these sturdy Assyrian fellal. infantry, who were largely armed with the bow, that the strength of Assyria lay. The power and effect of the infantry-soldier was greatly developed by the Assyrian kings, and it was to their bowmen, who could destroy the chariots and horsemen of an enemy at a distance, that they owed their victories, even as the English kings owed the discomfiture of the chivalry of France to the long-bows of the English yeomen. The power of the chariotry now began to wane, and the chariot became somewhat démodé in war. Further, the Assyrians greatly developed siegecraft, and probably were the inventors of military engineering. To so welldevised a machine of war victory fell, if not always easily, at least surely and inevitably, till it fell to pieces, as will be seen, two centuries later. ${ }^{1}$ The chief commander under the king was called turtan, and under him was the rab-shakeh. ${ }^{2}$

The campaign of Tukulti-Ninib in the North was carried to a successful conclusion : it was necessary first to restore Assyrian prestige among the turbulent mountain tribes and ensure their quiescence before proceeding to conquest in the West.

Ashur-nașir-pal shewed his thorough and comprehensive spirit from the first: beginning with the tribes of the Zagros, east of Assyria, he systematically marched through their valleys and mountains with fire and sword in a circular movement like the sweep of a scythe, round through Southern Armenia to

physical suffering that was inflicted upon other human beings by the kings and warriors of Assyria during the two and a half centuries that followed the reign of Ashur-nașir-pal.

1 A description of what is known of the Assyrian military system will be found in the Alter Orient series, by J. HUNGER (Heerwesen und Kriegfïhrung der Assyrer, Leipzig, 191 I). Dr. Hunger does not note the comparison between the Assyrian infantry archer and the English long-bowman at Creçy and Poitiers, a comparison which naturally suggests itself to an Englishman.

2Rab-SAG; prob. rab-shaké, "chief of the officers." The Rab-saris and Rab$m a g$, both mentioned in the Old Testament, were probably semi-military officials of the court: rab-saris is usually translated "chief eunuch," but for this there is no authority. 
Commagene and Cilicia. Then he was ready to cross the Euphrates. Bit-Khallupi, ${ }^{1}$ an Aramaean state on the riverbank, was conquered. Babylon, however, which had remained passive since her defeat by Adad-nirari II, now took alarm, for she always laid claim to the suzerainty of the lands of the Middle Euphrates, through which ran the caravan-routes of her merchants to Syria, and never willingly admitted Assyrian or other control over them. Nabu-pal-iddina, the king of Babylon, accordingly assisted the king of the land of Sukhi (the "Shuhites") to resist Ashur-nașir-pal, with no result but the ruin of the king of Sukhi. The fall of the Sukhi king was the signal for the collapse of the independent states of Naharin which had grown up since the time of Tiglath-pileser I. The Aramaean state of Bit-Adini on the left bank of the Euphrates was finally overthrown and destroyed. Carchemish, the capital of the southern Hittite kingdom that had come into existence at the break-up of the empire of Shubbiluliuma, and had probably attained to considerable power during the eclipse of Assyria, was taken, and its king, Sangara, submitted to the conqueror ( 876 b.C.). The river was then crossed, and Naharin lay at his feet. Apparently without meeting resistance Ashurnașir-pal marched south through Northern Syria to the Orontes, which he crossed, entered the Lebanon, and descended to the sea, where he received the submission of the Phoenician cities. The chief Syrian king, at Damascus, was too paralysed by the swiftness of his advance to offer to dispute his passage.

Then Ashur-nașir-pal turned slowly back to the Euphrates, and completed his work by a movement the reverse of that with which he had commenced his series of campaigns. Starting from Commagene, his scythe swept round the upper valley of the Tigris into Armenia and so round again to the Zagros.

His military work effectually done, Ashur-nașir-pal turned to the peaceful development of his empire, to which he seems to have devoted the same relentless energy. Many fine temples and palaces were built by him. For the ruthless conqueror and enslaver was (whether from mere superstition or not) so far civilized as to build well and finely, and to employ sculptors to decorate his buildings who were unrivalled in Assyria for two centuries and whose work became the model for the artists

1 Bit-Khallupi is probably the modern Tell Halaf, which has been excavated by Freiherr v. Oprenheim (Tell Halaf u, die verschleierte Göttin, Leipzig, 1908). 


\section{THE ANCIEN'T HISTORY OF 'THE NEAR EAST}

of the neighbouring lands. ${ }^{1} \quad$ The military nature of the empire was emphasized by the removal of the capital from the ancient Ashur, with which were associated traditions and memories not always military, and not always pleasing, perhaps, to Ashurnașir-pal, to Calah, the ancient artificial creation of Shalmaneser I, which had been abandoned for many centuries. Here the headquarters of the "supreme war-lord". were set up, and hence, from a barrack-like town, he ruled.

Ashur-nasir-pal left a renewed empire to his son SHalmanESER II (860-825 B.C.), who maintained the tradition of his father's rule to the day of his death, in a duller and less inspired, but perhaps somewhat more humane, manner. At any rate, we do not hear so much of his holocausts as we do of those of his father.

\section{Reign of Shalmaneser $I I$}

War with Bit-Adini (859-856)-Alliance of Syria and Israel-'Omri of IsraelAhab's war with Benhadad of Syria-Ahab helps Benhadad against Assyria-Battle of Karkar ( 854 B.C.) - Battle of Ramoth-Gilead ( 852 B.c.)-Death of Ahab-Mesha and the "Moabite Stone"-War of Assyria and Damascus-Israel and Judah defeated by Moab-Death of Benhadad II-Elisha sets up Jehu against Jehoram - Murder of Jehoram and Ahaziah and massacre of the house of 'Omri-War of Shalmaneser and Hazael: Jehu pays tribute to Assyria: "the Black Obelisk" ( 842 B.c.) - Assyrian failure in Syria - Israel submits to Hazael-BabyloniaBabylon submits to Shalmaneser ( 85 I B.C.)-Commercial spirit of Babylon-Revolt of Ashurdaninpal (82\%-822)-Death of Shalmaneser II : accession of Shamshi-Adad -Battle of Dur-Papsukal (812 в.с.)

The beginning of his reign had to be signalized, as was his father's, by war. During the peace of the latter years of Ashurnasirir-pal the tributary states on the Euphrates had not dared to raise their heads, and there is nothing to shew that they intended to do so at the death of the old king. But it was evidently considered necessary that they should be terror-struck, lest the idea of rebellion should occur to them. In his first year Shalmaneser marched against Bit-Adini, whose king, Akhuni, called to his aid the neighbouring princes beyond the Euphrates. This temerity was punished, after three years, by the total destruction of the little Aramaean kingdom. ${ }^{2}$ Its weak allies had already fallen away. The destruction of the tributary

1 As in the Aramaean palaces of Sindjirli and Salitjegözui (see p. 328).

${ }^{2}$ In 856 B.c. We derive our chief knowlcdge of this and other campaigns of Shalmaneser from the descriptions on his famous Black Obelisk, now in the British Museum. See Rccords of the Past, New Series, iv. pp. $39 \mathrm{ff}$. 
kingdoms now brought Shalmaneser face to face with the more powerful countries of the South, the two Aramaean states of Hamath and Damascus, and the kingdom of Israel. Hamath had submitted to Ashur-nașir-pal, but Damascus had not, nor had the conqueror made any attempt to subdue the southern Syrian kingdom. Israel had stood as yet without the sphere of Assyrian ambitions.

In the year 854 B.C., however, we find Ahab of Israel allied with Irkhuleni of Hamath and Benhadad II of Damascus against Assyria at the great battle of Karkar. It is improbable that Ahab was a very willing ally. Since the Aramaean rebel Rezon, son of Eliada, had revolted from Solomon, Damascus had been a thorn in the side of Israel. The division of the Israelite kingdom gave the rulers of Damascus an opportunity to make their new power seriously felt in the South. Judah, fearing annihilation at the hands of the more powerful northern kingdom, had sought the alliance of Damascus. Abijah, son of Rehoboam, concluded a treaty of amity with Tab-Rimmon, son of Rezon, and Asa, hard pressed by the Israelite usurper Baasha, appealed to this treaty in order to bring up Benhadad I, son of Tab-Rimmon, against Israel. ${ }^{1}$ Baasha was defeated, and Judah had peace for a time. But the attention of Benhadad was now directed towards the North, and the threatening rise of Assyria. Judah was unable to resist the dominance of Israel, under her energetic king 'Omri; and Jehoshaphat, son of Asa, became the vassal of 'Omri's son Ahab. The energy of 'Omri, his subjection of Moab, ${ }^{2}$ and consequent hold on Judah, by no means pleased the Damascenes, and Benhadad II (Hadadezer) attacked him, taking Ramoth-Gilead from him, and compelling him to grant the Syrian merchants privileges in his capital city of Samaria. ${ }^{3}$

Following Assyrian example, Benhadad attacked Israel again after the accession of Ahab, and besieged Samaria, clearly stating a claim to overlordship, which Ahab evidently

1 I Kings xv.

2 The inscription of Mesha' is definite on this point: 1. 8 .

${ }^{3}$ I Kings xx., xxii. 'Omri was one of the most important of the kings of Israel, and may be regarded as the founder of the power of the kingdom. To the Assyrians he was a sort of eponymous hero of his country, for they called it Bit Humri, "House of "Omri" (on the analogy of the Aramaean states Bit Hallupi, Bit Adini, etc.). Israel is now first mentioned in Assyrian inscriptions.

"See Cheyne, art. "Ahab," Encycl. Bibl. 
admitted. The Syrian king seems, however, to have presumed tyrannically on this admission, and Ahab, who had relations with other northern princes who would naturally be none too friendly to the powerful Benhadad (he had married Baalizebel or Jezebel, daughter of Ethbaal of Tyre), may have been able to summon help from the north, possibly from the North Syrian Hittites. ${ }^{1}$ In any case the Syrians, after a severe defeat at Aphek, were compelled to evacuate Israel. A treaty followed which granted Israel the same commercial rights in Damascus that had been given to the Syrians in Samaria. The overlordship of Benhadad seems to have been still admitted, for now Shalmaneser II was marching south, and we find Israelites as well as Hamathites arrayed against him beneath the banner of Benhadad. Had Ahab dared to refuse assistance, he would surely never have helped Benhadad to resist the greatest danger that the Syrian kingdom had yet faced.

Benhadad II (or Adad-'idri, as they called him) was the most redoubtable foe that the Assyrians themselves had yet faced. It is evident that the battle which took place at Karkar in the Orontes valley was indecisive. The Assyrians of course claimed a victory, and it is possible that they remained in possession of the field. ${ }^{2}$ But they retreated immediately afterwards to the Euphrates, leaving Benhadad in undisturbed possession of his realm. The losses of the Syrians had, however, no doubt been terrible, and Ahab, who regained his kingdom with his contingent, evidently thought the moment opportune for revolt against his exacting suzerain. He summoned his own subject-ally Jehoshaphat of Judah to his aid, and the two kings went up to retake Ramoth-Gilead, which had been Syrian since the time of 'Omri. But Ahab had miscalculated Benhadad's weakness, and in the battle that followed, of which we have so picturesque a description in the Book of Kings, ${ }^{3}$ he was killed, fighting valiantly to the last (852 B.C.). Jehoshaphat retreated safely with the defeated army, as the Syrians were too exhausted to pursue. When he regained his kingdom he took the opportunity

1 There is no direct evidence for this, but the Syrian defeat at Aphek seems im. possible at the hands of the Israelites unaided.

"We hear of the battle of Karkar only from the Assyrian record: it is not mentioned in the Biblical narratives. Among the confederates were a thousand men of Musri, and these Mușrites have erroneously been supposed to have been Egyptians (see p. 440); there is no doubt that they were Hittites of the Syrian Mușri.

${ }^{3}$ I Kings $x$ xii. 
to throw off his allegiance to Israel, refusing to allow Ahab's son Ahaziah to participate in the profits of the commercial route which he now opened to the Red Sea at Ezion-geber through the territory of Edom, which was subject to him. ${ }^{1}$ Moab at the same time revolted successfully from Israel under its King Mesha", who tells us on his stela of victory, the famous "Moabite Stone," which he set up at Dibon, how in the latter years of Ahab he destroyed the Israelite garrisons and freed his land, how he made the slaughtered Israelites a "garing-stock" unto Moab, and how he dragged the sacred vessels of Yahweh before his god Chemosh. This inscription is one of the most important, and one of the very few contemporary, documents of Israelite history. ${ }^{2}$

Benhadad was quite unable to interfere further with the southern kingdoms. He needed all his strength to meet the renewed attack of Assyria, which could not be long in coming. The king of Carchemish, no doubt stirred up by Benhadad, delayed it during the year 850 , but after his defeat Shalmaneser marched to glut his vengeance on Damascus. He was again baulked by the fierce resistance of the Syrian king (849). The attack was continued in the next year without result; and in 846 Shalmaneser, furious at this unexpected resistance, called out the enormous army, for that time, of 120,000 men, for the war. How Benhadad resisted this armament successfully we do not know, but he did, and Shalmaneser now abandoned his direct attack. He waited for a more favourable opportunity, more than ever determined, with a doggedness worthy of his father's son, to make Damascus his tributary. Meanwhile he contented himself with consolidating his power in Northern Syria, and received the complete submission of the Phoenician cities (843).

Ahaziah of Israel had been succeeded after a reign of perhaps only a few months by Jehoram, an energetic monarch, whom Jehoshaphat of Judah saw fit to placate by renewing his subjectalliance to Israel, and affording assistance to Jehoram in the re-subjugation of revolted Moab. Probably an independent

1 I Kings xxii. 47-49. See Cheyne, Encycl. Bibl., art. "Jehoshaphat."

2 The latest and most convenient publication of this monument is that of Prof. Driver in the Encycl. Biöl., s.v. "Moab." The "Aramaic" ostraka of Ahab's reign recently discovered at Samaria by REISNER (see p. 440, n. 4) are the only other contemporary documents of this time. 
Moab under an energetic king like Mesha' seemed a greater danger to Judah than an almost nominal subjection to Israel. The attack of the two kings, aided by the contingent which Edom owed to Judah, against Mesha failed. After initial successes, in which Mesha' was reduced to great straits, and sacrificed his eldest son to Chemosh in order to gain the help of the god, the expedition was compelled to evacuate the Moabite territory, and to return by the way it had come, through the waterless deserts round the southern end of the Dead Sea From the curious phrase in which this retreat is chronicled in the Book of Kings, it is evident that the Israelites ascribed their defeat directly to the intervention of their enemy's god, Chemosh, after the king's devotion of his first-born. ${ }^{1}$

This disaster (about 850 B.C.) was followed by the death of Jehoshaphat and the revolt of Edom from Judah. Jehoram of Judah, the successor of Jeshoshaphat, was defeated in an attempt to subdue it, and narrowly escaped with his life." After a reign of a few years he was succeeded by his son Ahaziah. Now came the murder of Benhadad II by his successor Hazael (843), and Jehoram of Israel, baulked in the direction of Moab, eagerly seized the opportunity to effect the recovery of Ramoth-gilead, summoning to his aid'his kinsman and vassal, Ahaziah of Judah, the great-grandson of Ahab and Jezebel. The attack on Syria seems to have been at first successful, and Ramoth-gilead was taken, though Jehoram was wounded in the fight. In order to heal his wounds, the king returned to Jezreel, leaving at Ramoth-gilead a garrison, among the officers of which was a certain Jehu, son of Nimshi. The steady idolatry of the house of 'Omri had always been a scandal to the monotheistic devotees of Yahweh, and Ahab and Jehoram spent the whole of their reigns in continuous religious conflict with the monotheists, led by the great prophets Elijah and Elisha, whose crusade was chiefly directed against the Baal-worship which Jezebel had introduced from Phoenicia. Now, when Jehoram was incapacitated by his wounds, Elisha planned a bold stroke against him. He had evidently marked out Jehu as a warrior fit to lead Israel, and sent one of his younger followers, whose name is not handed down in the chronicle, to Ramoth-gilead with orders to anoint Jehu king. The wily prophet counted upon the awakened ambition of Jehu to do the rest. Nor was he disappointed. 
The garrison of Ramoth-gilead accepted jehu as king, and the would-be usurper struck swiftly. He set out from Ramothgilead and drove "furiously" to Jezreel, where followed the murders of Jehoram, of Ahaziah, who was with him, and that of the old queen Jezebel, which is so stirringly described in the Book of Kings. By a concession to poetic justice, the chronicler makes the murder of the two kings take place in the vineyard of Naboth, which Ahab had unrighteously taken. ${ }^{1}$

A massacre of all the living members of the house of 'Omri followed, and even relatives of the murdered king of Judah were treacherously slain by the usurper. Then came the expected holocaust of the priests of the Phoenician Baal, which Jehu owed to the prophets of Yahweh who had made him king. Jehu, however, while zealous against Baal and his worshippers, was no orthodox votary of Yahweh: he continued the worship of the national Israelitish bull-idols at Dan and Bethel which Jeroboam had set up.'

Now came the opportunity of Shalmaneser. Syria and Israel were both weakened by renewed war, and their new kings were neither of them yet firmly established on their thrones. Although Jehu had murdered Jehoram, the enemy of Hazael, it was not probable that he would voluntarily return to the position of Ahab twelve years before, and assist the Syrians, after the successful recovery of Ramoth-gilead. The neutrality, if not the active help, of Israel could therefore be counted on. Judah, now in the throes of a furious religious proscription of the royal house, which had been tainted by the blood of Jezebel and Ahab, and their Baal-worship, would naturally sympathize with Jehu's attitude.

Accordingly, in the year 842 Shalmaneser marched south. He met Hazael on the slopes of Hermon, defeated him and drove him back to Damascus. The whole of his territory was mercilessly ravaged even as far as the Hauran, but Damascus itself was too strong to be taken. Jehu more than fulfilled expectations as to his attitude, for he sent an embassy to Shalmaneser with rich gifts, which the Assyrian king construed, rightly or wrongly, as tribute. The tribute of Jehu was commem-

12 Kings ix. $f$.

2 It is evident that Elisha and the prophets of Yahweh felt more hatred for the priests and worship of Baal than for the idolatry of Jeroboam, the abolition of which they probably saw was hopeless. 
orated on an obelisk of black stone, set up in the royal palace at Calah, which is now in the British Museum (Plate XXV. 3).

Shalmaneser sought compensation for the failure of his long war against Syria in further conquests in the direction of the Taurus. In a few years the Assyrian yoke was firmly settled on the necks of all the peoples from the Cilician plain to the Euphrates, while the Phoenician cities, and Hamath also, paid tribute to Nineveh rather than to Damascus. In so far the power of Damascus had been definitely curtailed. She obtained compensation in the subjection of Israel, which was abandoned to her without compunction.

More than by the conquest of Cilicia the failure of the Syrian war was overshadowed by Shalmaneser's great success against Babylonia, which he made tributary. The period of Aramaean migration had been of weakness and turmoil for Babylonia as for Assyria. The Chaldaean tribes from the southern shore of the Persian Gulf had also overrun Babylonia, and had given her a short-lived dynasty. An unnamed Elamite is also chronicled at this time as reigning over Babylonia. About 950 B.C. a native Babylonian dynasty began to reign, which soon found itself at war with Assyria. The kings Shamash-mudammik and Nabu-shum-ishkun were defeated in succession by Adad-nirari II, who, however, shewed no desire to conquer Babylonia, and made peace, which was cemented by a mutual marriage-alliance. Nabu-pal-iddina, the next Babylonian king, aided the people of Sukhi, as we have seen, against Ashur-nașir-pal, but otherwise preserved peaceful relations both with him and with Shalmaneser II. ${ }^{1}$ About 853, however, he was deposed, and his son and successor, Marduk-shum-iddina, being seriously threatened by a revolt under his brother Marduk-bel-ușate, was ill-advised enough to call Shalmaneser to his aid. The Assyrian king, smarting from his first repulse at the hands of Benhadad, was by no means averse to this chance of reaping cheap laurels. He invaded Babylonia, defeated the rebels in two campaigns (852-85 I B.C.), drove out the Chaldaeans, and during the rest of his reign the Babylonian king was his vassal. The easy submission of the Babylonians was due to the fact that their commercial relations with Phoenicia and Anatolia were in no way damaged, but rather fostered, by the Assyrian conquests.

' Synchronous History, col. iii. 

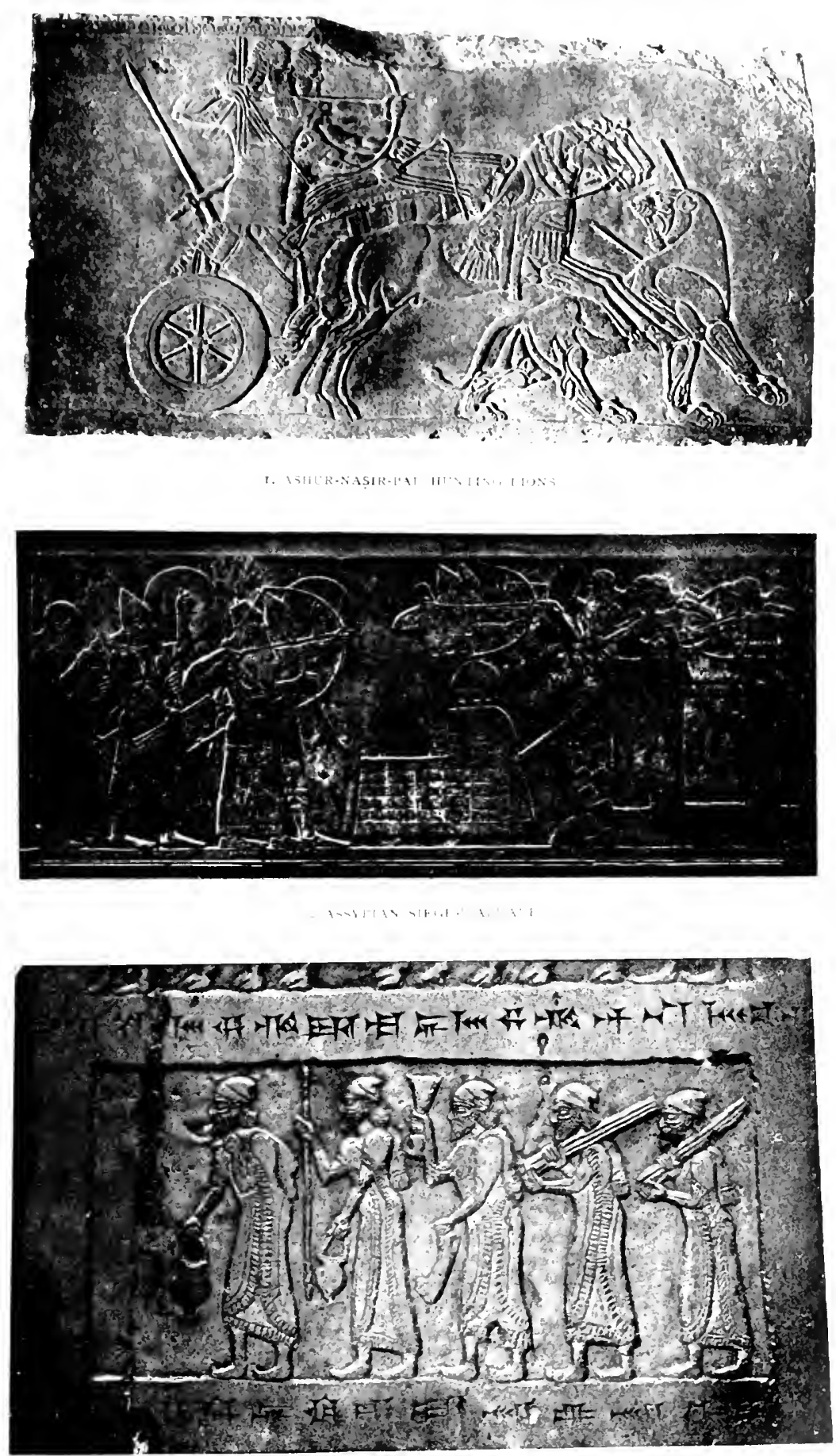

Of old Babylonia had always sought to control the whole course of the Euphrates as far as Northern Syria in the interest of these commercial relations, and Nebuchadrezzar I and Marduk-nadin-akhi had contended for this with some success against Assyria. The Assyrians, however, were not a commercial nation, and had no desire to divert any of the western trade to themselves. They only desired tribute and acknowledgment of their superior prowess, and were quite willing to leave commerce to the Babylonians. When the Babylonian merchants realized this, and saw that under the firm Assyrian rule of Northern Syria their trade was free from possible interference by the petty princes of that region, they naturally became opponents of all war with Assyria, and were perhaps even prepared to welcome Assyrian suzerainty over their own country, as this would guarantee their commerce the full protection of the Assyrian arms. Henceforward opposition to Assyrian control came only from ambitious princes and occasional popular patriotic movements: the merchants, the most important element in the body-politic, formed an unwavering pro-Assyrian party, which was ever ready to barter its self-respect for shekels.

Towards the end of his reign, Shalmaneser II ceased to lead his armies personally, and handed over the supreme command to his turtan or commander-in-chief, Ashur-dayan. At the same time a younger son, Shamshi-Adad, was put forward as the successor to the throne, to the prejudice of an elder brother, Ashurdaninpal. Probably Shamshi-Adad was the candidate of the army and the powerful turtan. At any rate, when Ashurdaninpal revolted and carried with him the greater part of the kingdom, including even Nineveh and Assur, the royal military headquarters of Calah remained faithful to Shalmaneser and Shamshi-Adad, together with probably the whole of the army. So popular was Ashurdaninpal that the whole military strength of the crown was unable to suppress the revolt finally till six years after the death of Shalmaneser and the accession of Shamshi-Adad ( 825 B.C.). It was not till 819 that the civil war ended. In the turmoil both Hamath and Babylonia had revolted. Babylonia was at once attacked (8I8), but it was not till six years later that Shamshi-Adad finally defeated the Babylonian king Marduk-balațsu-ikbi at Dur-Papsukal in northern Babylonia, entirely routing his army, 
which comprised as many Elamite and Chaldaean mercenaries as Babylonians, killing 5000 of them, taking 2000, and capturing a hundred chariots. ${ }^{1}$

\section{Adad-nirari III and his successors}

Adad-nirari III (SI2-7 $S_{3}$ B.c.) - Campaign in Syria: submission of Palestine (8O4) -Amaziah and Jehoash-Jehoash takes Jerusalem-Jeroboam II (c. 782-743 B.c.) defeats the Syrians

Soon after this great fight Shamshi-Adad died (8I I), leaving his kingdom to his son ADAD-NIRARI III, who, now that Babylonia was subdued, was at liberty to turn his attention to the North and West, which Shamshi-Adad had never had time to visit. The first years of Adad-nirari's reign ${ }^{2}$ were occupied in the chastisement of the Kurdish tribes, which had not been carried out since the time of Ashur-nașir-pal. Then he turned to Syria. Hamath submitted, and the Phoenician cities resumed their tribute. Then came the turn of Damascus. Benhadad III or Mari', as the Assyrians called him, the son of Hazael, was besieged in his capital and compelled to pay tribute ( 805 or 804 B.C.). Jehoahaz, the king of Israel, who with his people had had to submit to long years of Syrian tyranny, welcomed the Assyrian as a saviour, and eagerly sent him tribute. Probably Adad-nirari advanced south into Palestine, for he records that not only Bit-Khûmri ("The House of "Omri" or Israel), but also Edom and Palestine (Philistia), "as far as the great sea of the setting sun," submitted and paid tribute. Judah is not mentioned, and was probably regarded as a mere vassal of Israel, Edom had preserved her independence after the defeat of Amaziah, ${ }^{3}$ and so her submission is recorded separately.

In practice this submission meant a restoration of independence to the Palestinian kingdoms, or rather to Israel,

${ }^{1}$ Inscription of Shamshi-Adad: RAwlinson, Inscriptions, i. 29-3I, translated by ABEL in Keilinschr. Bibl. i. p. I74 ff.

${ }^{2}$ His inscriptions are scattered and fragmentary, but the general course of events during his reign can be made out from them. Adad-nirari's queen was named Sammuramat, and this is obviously, as has always been recognized, the original of the name Semiramis given to a legendary Assyrian queen in Herodotus (i. 184 ) and Ktesias. Why special memory of Sammuramat was thus preserved we do not know, but she may have been a queen of special prominence, round whose name legends gathered. As usual, we know nothing more about her from her husband's inscriptions than the fact of her existence.

${ }^{3}$ See below. 
which always treated Judah as a subject-ally. Joash of Judah, who alone survived the massacre of the House of David by Athaliah, and had been made king by the High-priest Jehoiada, ${ }^{1}$ had to submit to Hazael with his suzerain Jehu: an actual Syrian occupation of Jerusalem had only been avoided by heavy bribes. Amaziah, son of Joash, who succeeded after his father's murder, gained a success against Edom, and was so puffed up thereby that he challenged Jehoash of Israel, the son and successor of Jehoahaz, to combat. The contemptuous reply of Jehoash to this challenge, recorded in the Book of Kings, ${ }^{2}$ was justified in the result of the struggle. Amaziah was completely defeated, Jerusalem was taken, its walls broken down, and the golden vessels of the Temple carried off to Samaria (circa 793).

Flushed with this success, Jehoash turned his arms against Syria, and in three campaigns; against Benhadad III, son of Hazael, regained the whole of the original territory of Israel east of the Jordan. His son Jeroboam II (782-743) pursued the war with such vigour that he finally succeeded in taking Damascus and even Hamath. It is not improbable that these successes were gained by him in alliance with the Assyrian kings Shalmaneser III (782-773) and Ashur-dan III (773-764), who warred against Damascus, Arvad, and the Syrian princi. pality of Hatarika or Hadrach, which now appears as a new centre of opposition to Assyria. ${ }^{3}$

Although the resistance of Damascus, exhausted by war, was at last broken, Syria was only held by constantly repeated punitive expeditions. The Assyrians never attempted to organize their conquests in a homogeneous empire as the Egyptians always tried to do. They only raided for tribute, and kept the peace so that the commerce of Babylonia should not suffer so long as Babylonia remained submissive to them.

${ }^{1}$ In 836 в.с. 2 Kings xii., 2 Chron. xxiv.

22 Kings xiv.

${ }^{3}$ I see no reason to doubt the historical character of the northern conquests of Jeroboam II, or to think that Adad-nirari III of Assyria "would never have allowed Jeroboam to conquer Damascus" (CIIIYYNe, Encycl. Bibl., s.v. "Jeroboam"). Adad-nirari was now old, and died in the year of Jeroboam's accession; and his successors were not kings of much account; it seems very probable that they allied themselves with Jeroboam. 


\section{Assyria and Urartu (Van)}

The land of Khaldia - Vannic language-Lutipris and Sarduris I-War of Shalmaneser II and Arame-Sarduris II-Ishpuinis-Menuas-Constant danger to Assyria from Urartu

The task of controlling Syria was rendered the more difficult by the steady growth of a new power in the rear of Assyria, which compelled the kings to keep near home armies which might have been employed in the west. This new power was the Kingdom of Urartu or Ararat, so called by the Assyrians after the central district of the kingdom, in which stood the great mountain which still bears the name of Ararat. The people of Urartu called their kingdom Khaldia, after their chief god Khaldis. They seem to have been a warlike tribe which advanced either westward from the Hellespont, or southward from the Caucasus and by the shores of the Euxine into Armenia, ${ }^{1}$ taking the lands of other tribes or absorbing them, until it came into contact with the outposts of Assyria. The Mesopotamian culture had slowly penetrated up the courses of the two great rivers into the Armenian uplands, and the Khaldian tribes had so far imbibed Babylonian civilization that their kings used the Assyrian script and language for official inscriptions. Later on the cuneiform script was adapted for writing the language of Urartu itself, Vannic as we call it from the fact that its chief monuments, and those first deciphered, were erected on the shores of Lake Van, where was situated Turushpa, the later capital of the kingdom. The decipherment of the Vannic inscriptions has revealed to us the whole history of the state of Khaldia. ${ }^{2}$

The original capital of the land was named Arzashkun, and was situated in the valley of the Araxes. The first kings mentioned in the inscriptions are Lutipris and Sarduris I, who was a contemporary of Ashur-nașir-pal. In the accounts of the

1 The Urartians might be regarded as connected with the Thrako-Phrygian invasion of Asia Minor c. 1000 B.C. : their names, Lutipris, Rusas, Argistis, etc., have a distinctly Phrygiin sound. But "Vannic" was not an Aryan language, so that a Caucasic origin seems more probable.

2 The deciphering of Vannic is due to Prof. Sayce, who published the results of his interpretation in the Journal of the Royal Asiatic Society (New Series), xiv. (ISS2), pp. $378 \mathrm{ff}$. Sayce followed in the footsteps of Hincks, who had already deciphered the names of some of the Vannic kings in I 847 (see Rogers, Hist. Bab. Assyr. i. $215 \mathrm{ff}$.). The succession of the kings has recently been corrected by inscriptions discovered by the German expedition to Armenia (Lemann-Haupt, Armenien einst und jetat, Berlin, 1910). 
sweeping operations from end to end of the northern regions which marked the beginning and end of that great warrior's reign, no mention is made of Sarduris, but it is more than probable that he felt the weight of Ashur-nassir-pal's arm. Shalmaneser II is the first Assyrian king who states that he came into actual hostile contact with Urartu, whose king was then Arame. In 860,857 , and 845 Shalmaneser ravaged Arame's country and finally destroyed Arzashkun. Later, when Sarduris II had succeeded Arame, the Assyrian turtan Ashurdayan attacked (in 833 and 829). Ten years later again the turtan of Shamshi-Adad led an expedition against Ishpuinis, the successor of Sarduris II. These successive attacks seem to have strengthened rather than weakened the hardy mountain-state, while the Assyrians gained no real advantage from them. In alliance, apparently, with Urartu, stood the Mannai, an Iranian folk of Median stock, ${ }^{1}$ and the Protomedes, to whom the name Madai properly belonged (it now first appears in history), in the country east of Lake Urmia. Against them, several expeditions were directed by Adad-nirari III, who is supposed to have reached the Caspian in one of them. Meanwhile Menuas, son of Sarduris II, had extended the dominion of Urartu to the western shores of Lake Urmia. Argistis I, his son, conquered the whole of Kurdistan and Armenia, as far west as Milid or Melitene (Malâtiya). All the conquests of Ashur-nașir-pal were lost, in spite of the feverish efforts of Shalmaneser III to recover them. The proximity of the territory of Urartu to the centre of the Assyrian power now became directly dangerous to the empire. Soon the actual frontier was the mountain-range now known as the Jûdi Dagh, less than a hundred miles from Nineveh itself. But the kings of Urartu did not dare to try conclusions with Assyria in the plain of the Tigris. The humiliation of an actual invasion by the despised peoples of $\mathrm{Na}$ 'iri was spared to the proud Ninevites. Their loss of prestige, however, was enormous, and to this we may ascribe the renewed restlessness of Syria in the reign of Ashur-dan III which the Assyrians, fearful of leaving the mountain-barrier unguarded, were unable to

1 Their chief god was called Bagmasta (i.e. Bag-mazda, "High and Mighty God "), a purely Slavo-Iranian appellation (PRÁs̉ek, Geschichte der Meder u. Perser, i. p. 4I). I do not see that this and the name Mazdaka would prove that they were Zoroastrians (see p. 555), as MEYer thinks (Encycl. Brit. (I Ith ed.), art. "Persia," p. 205): the word niazda presumably existed before Zoroaster. 
pacify. After the unsuccessful expeditions of 772 and 765 B.C. against Hatarika (Hadrach), the centre of the revolt, Ashur-dan and his successor dared not leave Assyria. The west was practically left to itself, and Jeroboam II of Israel seemed likely to be the heir of Assyria in the Aramaean countries.

\section{Assyrian Decline and Revival of Babylonia}

The total solar eclipse of 763 B.c. - Revolt and civil war in Assyria (763-758) Babylon annexed to Assyria-Revolts under Nabu-shum-ishkun-NabonassarDecadence of the Assyrian kings : military revolt at Calah : Pulu (Tiglath-pileser IV) made king (745 B.C.)

The discontent of Ashur-dan's subjects at their loss of territory and prestige was rapidly growing, till in 763 , the year of his death, an event took place which brought matters to a head. The total eclipse of the sun in that year was regarded as a portent, a sign of celestial wrath. Assur, the home of Assyria's most ancient traditions, revolted and was joined by other cities. The king was probably murdered. For six years civil war raged, while pestilence devastated the land. But finally Ashur-dan's successor, Adad-nirari IV, to whom the army continued faithful, prevailed, and in 758 the revolt was quelled by the capture of the city of Gozan.

The civil war had resulted, however, in a further serious loss. During the struggle in Assyria, Babylonia revolted, and re-established its independence under a king named Nabu-shumishkun II. After the suppression of the Assyrian revolt Adadnirari IV made no attempt to regain the authority of Assyria in Babylonia, which had been undisputed almost since the time of the battle of Dur-Papsukal fifty years before. Adad-nirari III had completed the work of Shamshi-Adad by a final expedition, which resulted in the deposition of Bau-akh-iddina, the last Babylonian king of his dynasty, who was carried off to Nineveh with the treasures of his palace. He had no successor, and for nearly fifty years Babylon was without a king, being treated as an integral part of Assyria. This interregnum is marked by the conclusion of the "Synchronous History" 1 of Assyria and Babylon, a chronicle, composed in Assyria probably by order of the third Adad-nirari, of the relations of the two kingdoms down to what no doubt seemed to be the final extinction of Babylonian independence. This event was probably regarded with 
equanimity by the pro-Assyrian party of the merchants. But the sign in the heavens, the eclipse of $7 \sigma_{3}$, and the revolt of Assur, stirred the people to revolt, and Nabu-shum-ishliun restored the ancient kinglom. The Assyrians accepted the accomplished fact, and when Nabu-shum-ishkun died (747), his son Nabunassir (Nabonassar) ascended the throne of an independent kingdom which had before it prospects of regaining the position it had held in the days of Nebuchadrezzar.

For the state of Assyria seemed to be fast going from bad to worse. After the death of Adad-nirari IV in 755, Ashur-nirari III made one fierce attempt to restore the authority of Assyria in the west, and then sank into apathy. For years he did nothing, till at last, in the year following the accession of Nabunâșir in Babylonia, the army, which had hitherto remained faithful, was no longer able to brook the degencracy of the descendants of Ashur-nașirpal. The significant revolt of Calah, the imperial military centre, took place in 746, and in the next year the general Pulu ascended the throne, the way to which had probably been cleared by the assassination of Ashur-nirari.

\section{Tiglath-pileser $I V$ and the Revival of Assyria}

Tiglath-pileser IV (745-727 B.c.)-Defeat of Urartu-Submission of Syria (74I) -Anarchy in Israel-Azariah (Azriyau) of Judah stirs up war against AssyriaHis defeat and death-Assyrian campaigns in Media and Armenia (737-735)General attack on Judah: Jotham succeeded by Ahaz (734)-Tiglath-pileser comes to his aid and marches to Philistia-The Assyrians at Gaza-Hoshea submitsCaptivity of the eastern Israelites and Damascenes-New Assyrian policy of captivity and annexation-Organization and government of conquered lands : frontierwards -Captivities and shifting of subject peoples-Conquest of Babylon (72S)-Death of Tiglath-pileser

The first act of the new king was significant. He named himself Tiglath-pileser, taking the name of Assyria's greatest warrior-king, who had extended the power of Nineveh to regions where it had never been felt before or since, and in whose days Assyria had for a short time attained a greatness which the empire of Ashur-nașir-pal and Shalmaneser II had never reached. The name of TIGLATH-PILESER IV was an earnest to the Assyrians of renewed youth, renewed glory, and renewed empire; a promise of a speedy return to the brave days of old. ${ }^{1}$

${ }^{1}$ For the inscriptions of Tiglath-pileser Iv, see RosT, Die Keilschrifttexte TiglatPilesers III. (Until lately this Tiglath-pileser was supposed to be the third of the name : in reality he is the fourth.) 
Nor was this implied promise belied. With the new blood royal the whole empire seemed suddenly rejuvenated, her military spirit revived as if by magic; while the kings of Urartu checked their advance, the Syrian revolters were cowed, Israel resumed her accustomed position as a suppliant, and the rising hopes of the separatist party in Babylonia were dashed to the ground.

The first concern of the new king was to bring the Babylonians to a sense of their dependence on Assyria. He did not attempt to dethrone Nabunașir or to bring him into subjection, but merely carried out a military promenade into the northern part of the revolted kingdom, at the same time chastising the predatory Aramaean tribes who had occupied the middle course of the Euphrates and were no doubt interfering with the course of commercial traffic. He thus at the same time impressed the Babylonians with a sense of his military power and of the commercial advantages which they would gain by friendship with him.

His first real task lay in the West, in the resuscitation of the Syrian empire of Ashur-nașir-pal. But first a sudden attack delivered across the Jûdi Dagh drove back the tribes who had approached too near the centre of the kingdom from the north-east. All danger of attack in his rear, either from Babylonia or from the direction of Media, being thus removed, in 743 Tiglath-pileser advanced to the Euphrates with the intention of invading Syria. The Syrian chiefs, alarmed at his advance, combined under the headship of Matililu the chief of Arpad, a city north of Aleppo, to resist him, and at the same time summoned to their aid the King of Urartu, Sarduris III, successor of Argistis I, whose dominions included Kummukh (Commagene), and therefore reached the confines of Syria. Sarduris, equally alarmed, determined to strike quickly, and unexpectedly marched down the Euphrates gorges to attack the Assyrian advance in flank. Tiglath-pileser wheeled to meet the danger, and completely defeated Sarduris. Syria was now exposed to the Assyrian attack; about 74I Arpad was taken, and the whole west submitted.

A general alarm now filled all the lands of Syria and Palestine. The independence of the various states was at stake. Jeroboam II of Israel was lately dead (743), and his death was the signal for anarchy in the northern kingdom. His 
son Zachariah was murdered by Shallum, who was in his turn murdered by Menahem. ${ }^{1}$ This anarchy scems to have given an opportunity to the aged Azariah of Judah to create for a moment a Judacan hegemony over the northern state and its northern dependencies, Damascus and Hamath. For some unknown reason we hear little in the Book of $\mathrm{Kings}^{2}$ of Azariah (Uzziah) except that he finally became a leper. But in Chronicles we find legends of his activity as a warrior against the Philistines and the Arabs, ${ }^{3}$ and in this case the usually less trustworthy narrative of the Chronicler is borne out by the Assyrian evidence. For a dispassionate examination of this evidence shows us that it is hardly likely that the "Azriyau of Ya'udi," who now appears as the fomenter of resistance to Assyria in Southern Syria, is any other than the king of Judah." IVe have no warrant for supposing the existence of a Syrian state named "Judah," of which we have no other knowledge whatever, and when the king of this state bears the same name as that of a ling of the historical Judah who actually reigned at this time, we have no option but to conclude that he is this king, and that "Azriyau of Ya'udi" is Azariah of Judah.

Azariah, as the overlord of the Israelitish dependencies conquered by Jeroboam II, would then naturally be regarded by the Assyrians as the instigator of the resistance which they now encountered in southern Syria. In 739 Tiglath-pileser was recalled from a campaign in the Armenian mountains by the threatening aspect of Azariah and his vassals or confederates, of whom Panammu of Samal was the most conspicuous. The Syrian campaigns of 739 and 738 were sufficient to overthrow the confederacy, and with it the dream of a resuscitation of the Solomonic empire. Kullâni (Calno)

$$
22 \text { Kings xv. } \quad 2 \text { Ibid. i. 5. } \quad{ }^{2} 2 \text { Chron. xxvi. }
$$

${ }^{4}$ This conclusion is not generally accepted, and a hypothetical land Ya'udi is sought in Northern Syria for Azriyau (Winckler, $A . F$., i. pp. I 3 ff., followed by Goodspeed, Hist. Bab. Assyr. p. 230). The idea is rejected by Rogers, Hist. Bab. Assyr. ii. II9, I think rightly. The Chronicler's account of the military power and prowess of Uzziah (Azariah), of his soldiers and his engines of war, is remarkable, and we have no reason to doubt its truth. Such a warrior may well have imposed his dominion for a time on the north (Israel was now in the throes of a conflict of usurpers), and appeared as a redoubtable foe of Assyria. That Azariah was by this time an old man is no bar to this conclusion. It is possible that he was not persona grata with the prophets of Yahweh: his deformation in the Book of Kings may be accounted for on this likely supposition. 
fell, Hamath followed, Samal became directly subject to Assyria, and not only Rezin of Damascus, but also Hiram of Tyre and Menahem of Israel, paid tribute to the invader. ${ }^{1}$ Azariah now died, and was succeeded by Jotham (739).

No mention is made of tribute from Judah, probably because Tiglath-pileser was satisfied with the destruction of the confederacy, and was now anxious to return to Assyria to complete the final settlement with Urartu which had been begun in the previous year, but had had to be suspended in order to effect the chastisement of Azariah and his confederates.

Three campaigns carried the Assyrian arms through Media, to the foot of Demavend, and through Urartu to Lake Van, where, on the shore of the lake, lay Turushpa, the capital of Sarduris. Tiglath-pileser was unable to take the city, of which the citadel was an inexpugnable rock (the modern castle of Van), but he broke the power of Urartu for many a year.

During his absence the Palestinian princes raised their heads. They were not yet resigned, as Northern Syria was, to the futility of resistance. Pekahiah, the son of Menahem, had been murdered by Pekah, the son of Remaliah, who now joined with Rezin of Damascus, the Philistine chiefs, and the princes of Edom, to attack Jotham of Judah, the successor of Azariah. The motive of the attack was clearly the desire of revenge for the ephemeral supremacy of Azariah, which all the allies had resented bitterly. It was against the proper order of things that the little kingdom of Judah should control them. as owing to a peculiar combination of circumstances, she had been able for a moment to do. In the midst of the confusion Jotham died, and was succeeded by Ahaz, who sought his only means of immediate salvation in an appeal to Assyria, despite the opposition of the prophet Isaiah, who saw that the result would be the vassalage of Judah. This vassalage, however, Ahaz was ready to accept as the price of safety. ${ }^{2}$

Tiglath-pileser at once answered the appeal, and in 734 he appeared in Syria, immediately after the destruction of Urartu. He did not, however, attack the confederates in the rear. In

12 Kings xv. 20 ; inscr. of Tiglath.pileser.

2 Ibid. xvi. One is unable to account for this general attack on Judah by her neighbours, except as a result of Azariah's domination after the death of Jeroboam II. 
order, probably, to make the Palestinians feel that distance afforded no safety from his arm, he marched down the seacoast to the hitherto unvisited and unconquered land of Philistia, which had even in Solomon's days preserved its independence of Israel, and during the two centuries that had elapsed since, had never acknowledged the suzerainty either of Israel in the warlike days of 'Omri, or of Judah in those of the recently deceased Azariah. So far had the foreign blood of the Cretan immigrants infused a feeling of independence and military capacity into the Canaanites of the coast. ${ }^{1}$

Hanun of Gaza, the paramount chief, was the object of the Assyrian march in 734. Resistance to Assyria was vain; he fled to Egypt. The statue of Tiglath-pileser was set up in his palace, and sacrifice was offered to Ashur in the temples of his gods, who, with the royal treasure, were carried off to Assyria. The enslavement of Israel was postponed for the moment by the murder of Pekah by Hoshea, who immediately made his submission to Tiglath-pileser, and was allowed to remain king with the loss of half his territory: all the land east of the Jordan, Galilee and Naphtali, with the towns of Hazor, Kadesh, Ijon, Yenuam, and others were directly annexed to Assyria, and the tribes of Reuben and Gad and the half-tribe of Manasseh carried away captive. ${ }^{2}$

The turn of Rezin followed. Damascus was taken, its king killed, its territory annexed, and its people carried captive "to Kir" (732).

The Philistines could not reconcile themselves immediately to slavery. Mitinti, king of Ashkelon, tried to revolt when the Assyrians were besieging Damascus, and when the fall of that city, which, apparently, he had not expected, was announced he went mad with fear of the consequences of his rebellion, and his successor Rukipti ${ }^{3}$ hastened to make his submission to the conqueror. Metenna, the king of Tyre, followed suit directly after the death of Rezin, and was mulcted in an enormous

${ }^{1}$ But by this time probably but few traces of the foreign origin of the Philistine aristocracy remained except a few personal names, such as "Rukipti," now (see below, n. 3), and "Mitinti" and "Ikaushu" in the time of Esarhaddon, nearly a century later (see p. $48_{3}$; and $\mathrm{H}_{A L L}, O . C . G .$, p. $134, \mathrm{n} .2$; Ikaushu is the Philistine "Achish" of I Sam. xxvii.). Other names, such as Hanun of Gaza, now are Semitic, and probably the I'hilistines now spoke Semitic.

22 Kings xvii.

${ }^{3}$ On the Philistine names Mitinti and Rukipti, see above and p. 483 . 
tribute, proportionate, no doubt, to the wealth of his city. The neighbouring lands, Ammon, Moab, and Edom, now sent tribute to the all-powerful Assyrian, and even an Arabian queen Shamshi "of Aribi," was forcibly brought under the yoke. At the courts of the subject princes officials called kiphi or "residents" were appointed, and the desert frontier of Egypt was placed under the surveillance of a certain Idibi'ilu, apparently a Beduin chief, who was called the "Kîpu of Mușri" (Egypt). ${ }^{1} \quad$ Over the districts actually annexed to Assyria, which included Philistia and the whole of Palestine and Syria north of Galilee and east of the Jordan, with the exception of Phoenicia, were appointed governors called shuparshaku, (military commandant) or bel pikhâti (district-lord). Nearly half the population in each conquered state was carried into captivity, and their place taken by foreign captives from Armenia and elsewhere, colonists from Eabylonia, and others. Thus the native population in each case was weakened beyond recovery, while the introduced foreigners, being hated by the natives as much as were their Assyrian masters, naturally made common cause with the latter and upheld Assyrian rule. Former kings of Assyria had carried away the conquered captive, but Tiglath-pileser was the first to regulate this practice as a reasoned policy.

The western world being now at his feet, Tiglath-pileser returned to Mesopotamia to put the coping-stone on his edifice of renewed empire by the annexation of Babylonia. The opportunity was favourable. Nabunașir had died in 734, and his son Nabunadinziri had been deposed by a certain Nabushumukin, who in his turn had been swept aside by a Chaldaean chief named Ukinzir, who invaded Babylonia and subjected it to him. We can imagine how the merchant-princes of Babylon cried out to Assyria for deliverance from this disturber of peace and commerce. In 73 I the unwearied Tiglath-pileser entered Babylonia and drove Ukinzir back into his own country

1 This is the natural interpretation of the Assyrian statement. Professor WinckLer, however (in Altorientalische Forschungen, I893, pp. $24 \mathrm{ff}$ ), considered that since Idibi'ilu was an Arab, the Muṣi of which he was kiphu must have been not "Egypt" (i.e. the Egyptian frontier), but a country in Arabia, and on this foundation built up the whole fantastic theory of an Arabian "Mușri," to which most of the Egyptian references in the Old Testament are to be assigned, which unhappily gained general credence till its destruction in the preface to BUDGE, Hist. Eg., vol. vi., followed by E. MEYER, in his Israeliten u. ihre Nachbarstämme, and v. BISSING, in Rec. Trav., I9I 2. 
on the southern shore of the Persian Gulf. In 729 the war ended, and the Chaldaeans of Bit-Amulthâni, Ukinzir's kingdom, and of Bît-Yâkin, the Sea-Land, submitted. And now the crown of Tiglath-pileser's work was attained when in 728 he came to Babylon and "took the hands of Bel" as king of Sumer and Akliad, a title which he had claimed, in the right of his predecessors, on the occasion of his first invasion fifteen years before, but which was only now confirmed by the priests of Bel in Babylon itself. It was fitting that the conqueror should die, as he did, in the course of the next year (727).

\section{Shalmaneser IV: Assyria and Egypt}

End of XXIInd Dynasty-Piankhi the Nubian-Peţubaste-Osorkon 111Activity of Tefnakht-Piankhi's invasion of Middle Egypt (c. 728?)-Fall of Hermopolis (Eshmunein)-Surrender of Herakleopolis (Aḷnas)-Capture of Memphis -Submission of the Delta-Hoshea refuses tribute to Assyria (725) in alliance with Egypt-Siege of Samaria (724-722): death of Shalmaneser 1V-Destruction of Israel

His successor, SHALMANESER IV (727-722), was confronted on his accession by a new situation in Palestine. The advance of Tiglath-pileser to the frontier of Egypt had caused a great stirring of dry bones in the decaying realm of the pharaohs.

The Bubastite dynasty came to an inglorious end about 740 B.C., and the kingdom at once fell apart again into the two distinct regions of North and South, which the first Bubastite, Shishak, had been at such pains to reunite. ${ }^{1}$ The South, true to the cult of the Theban Amen, transferred its allegiance by a natural transition to the descendants of the Priest-Kings of the XXIst Dynasty, who now held sway at Napata in Nubia. Thither, to the southern sanctuary of Amen, established probably under Amenhetep III, the chief priestly families had retired on the accession of Shishak and the deposition of the last high-priest of the line of Herihor in favour of the Bubastite prince Auput. There, in far Nubia, the high-priests of Amen of the old line had continued to reign as kings independent of Egypt, and now the Napatan monarch Piankhi, son of Kashta, naturally resumed sway in the name of Amen over Thebes and Southern Egypt. He claimed, indeed, the sovereignty of the whole land by right of descent, not only distantly, through the blood of the Ramessides which had mingled with that of the high-priests, but also immediately, in right of his mother the 
Egyptian princess Shepenapet, daughter of Osorkon III, the last Bubastite king whose rule was acknowledged at Thebes. Sheshenk IV (c. 777-740 B.C.), the last king of the XXIInd Dynasty, was succeeded by a certain Pețubaste, who is recorded by Manetho as the founder of the XXIIIrd Dynasty. In all probability he had been associated with Sheshenk IV for many years before the death of the latter long-lived king, and in his fifteenth year (c. 740 B.C.) he associated with himself a prince Auput. $^{1}$ He was, however, actually succeeded (c. 735 B.C.), after a reign of twenty-four years, by Osorkon III, whom we cannot suppose to have been associated with him, unless, as is not impossible, he is identical with the prince called Auput in Pețubaste's inscription, and changed his name on his accession. ${ }^{2}$ Osorkon III certainly reigned some twenty years, if not more. With him was associated for a short time a third Takeloti, who probably died before him. He submitted to Piankhi in 728 , and probably went on reigning as sub-king. We do not know whether Kashta, his Ethiopian son-in-law, actually reigned contemporaneously with him for a short space. It is most probable that he had died about 730 B.C., and that Piankhi and Amenirtis his sister-wife, the children of Kashta and Shepenapet, were, as Amen-worshippers and Thebans in origin, welcomed by Thebes as her rightful monarch in despite of their grandfather at Bubastis.

The princes, priests, and people of the North were by no means ready to acknowledge the primacy of Thebes and the supremacy of Amen. The priests of Hershef of Herakleopolis, birthplace of the XXIInd Dynasty, of Bast of Bubastis, and of I'tah of Memphis, would especially be moved by jealousy of Amon to resist the kingship of his worshipper. So the whole of the kingdom north of Siût split up into a dozen or sixteen small principalities, and the rulers of the more important of them who could lay claim to near connexion with royalty assumed the uræus-diadem as kings, just as their forerunners of a thousand years before had done. These kings were Namilt (Nemart) of Ekhmûnû (Hermopolis ; Eshmûnên), Pefnef-didi-

1 The authorities for the names of these kings of the XXIIIrd Dynasty are inscriptions published by LegraIN, $\ddot{A} . Z$. xxxiv. p. 114, and DARESSY, Rec. Trav. xxx. pp. 202 ff.

2 DAREssY, however, regards this Auput as identical with the Auput, prince of Tentrenu, who submitted to Piankhi. This is quite possible. 
Bast (or Pefza-didi-Bast, "Bast-giveth-his-breath ") of Henensu or Hnes (Herakleopolis; Ahnasiya), Auput of Tent-remu, who ruled the Wadi Tumilat from the neighbourhood of Bubastis to the lesert and the Red Sea, and Osorkon III, who maintained a circumscribed state in Bubastis itself. It is evident, from the names they bear or from the cities they ruled, that these princes were all directly connected with the Bubastite family. Of the princes of less royal blood, who did not immediately assume the uræus, the most important were Pabasa of Khriaha (the Egyptian Babylon), Pețisi of Athribis, Pimai of Busiris, Pathenef of Pasopdu, Tjedamenefankh of Mendes, and Alianesha of Sebennytos. Of these the last four were of Libyan descent, and the last of all bears a Libyan name. Eight other less important independent barons are mentioned at the time, of whom one, Tefnakht, chief of a small district on the western border of the desert, near Sais, soon made himself the most important of all. The undisputed rule of Piankhi (established about 730?) only extended as far north as Siut: north of that place Nemart or Namilt ${ }^{1}$ of Herakleopolis merely acknowledged Piankhi's overlordship, retaining his royal position and title. The chiefs farther north owed no allegiance to any suzerain till they were all compelled to submit to Tefnakht, who suddenly came forward as a claimant to general dominion. In a short time he conquered the whole Delta, and established himself at Memphis, where he prepared to invade the Upper Country and extend his authority if possible over the whole land. Namilt, alarmed by his energy, transferred his allegiance from Piankhi to the new power. Purema and Lamersekni, the Ethiopian commanders in Upper Egypt, anticipating an immediate attack, sent an urgent appeal to Piankhi at Napata for aid. An army was despatched, which, after great religious ceremonies at Thebes, advanced north, and defeated the confederates of Tefnakht (who does not seem to have been present himself) in a great battle at Per-pega, near Herakleopolis. The defeated chiefs dispersed, each to his own city, and even Namilt managed to double back southwards to Hermopolis, where he was at once besieged, while the towns of Pemje (Oxyrrhynchus), Tetehne (Tehnah), and Hetbennu were taken by storm. The escape of the chiefs and the prolonged resistance of Hermopolis did not please King Piankhi, who now repaired to the seat of

"Vocalized from the Assyrian form, "Lamintu" (see p." $50 \mathrm{r}, \mathrm{n}$.). 
war to take command in person. The record of his campaign is preserved on a great stela found at Jebel Barkal in I862, and now in the Cairo Museum, which he dedicated on his victorious return to Napata. ${ }^{1}$

The capture of Hermopolis was delayed by the politic generals, probably in collusion with the defenders, till the royal arrival, three days after which Namilt's queen appeared to plead with Piankhi for the safety of her lord and his city, which was granted her. Piankhi received Namilt's submission, and entered the town in state to make offering to the gods. There he found that Namilt's horses were starving, and this seems to have led to an explosion of the royal anger against the unlucky besieged, who was vehemently reproached for treating his horses so. The whole is naîvely chronicled in the inscription, no doubt by express command. Namilt suffered nothing more than the loss of his portable wealth, and retained his royal dignity still.

The fall of Hermopolis determined Pefnefdidibast of Herakleopolis to surrender at once, and Mêdûm, Ithttaui, and the other towns south of Memphis followed the example of Herakleopolis. Memphis, however, resisted.

Apparently the priests of Ptah were devoted to Tefnakht, who was one of their number. To a summons to surrender and promise of lenient treatment from Piankhi defiance was returned. Tefnakht, however, thought it well to abandon the city himself, and rode northwards secretly under the pretext of raising the Delta nomes. Piankhi then attacked, and by a stratagem succeeded in taking the city. The river was high, and the shipping of the town lay high alongside the river-wall. Piankhi embarked his army on his own ships, moored them alongside those of the enemy, boarded them and passed over them on to the wall. "So Memphis was taken as by a flood of water; a multitude of people were slain therein, and brought as living captives to the place where His Majesty was. And afterwards, at dawn of the next day, His Majesty sent men into it, to protect the temples of the god." The king then entered, and was received humbly by the priests. Heliopolis was then visited with great religious ceremony. The submission of all the Delta kings followed, and was solemnly received at a great

\footnotetext{
${ }^{1}$ Most recent translations by Breasted, Anc. Rec., pp. 406 ff.; Budge, Egyptian Literature, ii., Annals of Nubian Kings, pp. I ff.
} 
durbar held at Athribis. Tefnakht, closely pursued into the marshes of the West, finally sent in his submission, and was pardoned after taking an oath of allegiance before the gods in the presence of the chief priest Pediamennesettaui and the general P'urema. Of all the Northern chiefs, only King Namilt was allowed to enter the royal chamber, because he was pure and ate no fish, as the Delta kings did. To the priestly Nubians fish, especially sea-fish, was an abomination. ${ }^{1}$

The whole story is told with a curious naïets and obvious truth which differentiates it very much from other official inscriptions. The Nubian king is much more human than any of his predecessors since Thothmes III. His piety and at the same time his humanity, to beasts as well as men, were evidently characteristic of the man, and throughout there is evident a keen joy in fighting which had been unknown to Egypt for centuries. ${ }^{2}$

His work done, Piankhi returned to Napata, leaving, in all probability, his son Shabaka as his regent and commander-inchief in the North. The great expedition had taken place, probably, in the year 728 or 727 B.C. In the next year Shabaka came into hostile relations with the Assyrians. The energetic young Nubian regent, ignorant of Assyrian power and ferocity, no doubt thought himself and his black soldiers fully a match for all the legions of king or turtan, and was anxious to bid defiance to the new Hyksos. The accession of a new king in Assyria seemed to afford a possibility of successful action. In 726 Hoshea of Israel and the king of Tyre, relying, as we read in the Book of Kings, ${ }^{3}$ on the promised help of "Seve (So), king of Egypt," refused his yearly tribute. Now that the theory of the existence of a hitherto unknown land, bearing the same name as Egypt (Mușri), in North Arabia, to whom this Seve, the Shabi or Sibi of the Assyrians, and the "Pir'u of Mușri" also mentioned in the Assyrian inscriptions, were assigned, is generally discredited, ${ }^{4}$ we have returned to the original and perfectly natural identifications of Seve or Sibi with Shabaka (the

${ }^{1}$ Cf. HDt. ii. 37 .

2 The humanity of the king, who tells the Memphites that in the South no man has been slain but those who actually had fought, and that if they surrender peaceably "not a little child shall weep," was indeed not unknown to Egypt, but it stands out in strange contrast to the brutality of the Assyrian kings, especially to the bestial ferocity of Ashur-nașir-pal, who boasted of having burnt children alive. But then the Nilote was always far more really civilized than his Senitic neighbours.

${ }^{3} 2$ Kings xvii. 4 .

4 See p. 466 , note I. 
Sebichos of the Greeks) and of "Pir'u of Muṣri "with Pharaoh of Egypt. ${ }^{1}$ Unless, therefore, the Biblical mention of Seve in connexion with Hoshea in 725 is not a misplacement from the year of Sargon's victory at Raphia in 720 , when "Sibi, the commanderin-chief (turtan) of Pir'u king of Musri," is mentioned as defeated by the Assyrians (he is not mentioned in 725), we must suppose that Shabaka, who is certainly Sibi the turtan of 720 , was already turtan five years earlier, when Seve, inaccurately described as king, is recorded in the Book of Kings as the fomenter of Hoshea's revolt. He would naturally be left in command in Lower Egypt by his father Piankhi after his return to Napata.

Shalmaneser IV struck quickly at the rebels. Tyre submitted almost immediately, but with Hoshea the duel was to the death. For over two years, from 724 to 722 , Samaria was blockaded and finally closely besieged. The whole land was laid waste. No help came from Egypt. The murder of Shalmaneser and accession of Sargon in 722 happened shortly before the fall of the city. When the end came, Hoshea was blinded and his whole land and people annexed. ${ }^{2}$ The actual captivity of Israel, however, probably did not take place till two years later. ${ }^{3}$

\section{The Reign of Sargon (722-705)}

Elamite-Chaldaean alliance-Defeat of Sargon (721)-Sargon goes to the IVest, and defeats Shabaka at Raphia (720)-Captivity of Israel-The Samaritan colonists -Alliance of Urartu with "Mita of Mushli"

SARGON, the new Assyrian king, ${ }^{4}$ was apparently not present at the fall of Samaria, and threatening events near home prevented him from taking immediate advantage of the great blow which his generals had struck at the rebellious Westerners. The preoccupation of Shalmaneser IV in the West had given an opportunity to the Aramaean and Chaldaean tribes, who were

1 From the late Prof. Goonspeen's reference to this Pir'u of Muṣri in his Hist. Bab. Assyr., p. 249, I am unable to gather certainly whether he regarded him as king of Egypt or an Arab chief : he accepted WinckLER's view of the kipu Idibi'ilu (pp. 234, 248). No proof, of course, has yet been brought forward that such a country as the Arabian Muși ever existed. Prof. Rogers's note on the subject (Hist., ii. 144) is good, but does not go far enough in condemnation of the Muşri-theory. I see no reason, either, to suppose that Sibi is not Shabak himself, who was not yet king.

2 Kings xviii. 9-I I : inscriptions of Sargon.

${ }^{3}$ See p. 474.

4 The inscriptions of Sargon are collected by WinckLer, Die Keilschriftexte Sarsons 11 . 
always persistently pressing into Mesopotamia, to make another bid for the control of the Southern kingdom. The nomad Aramaeans again blocked the Euphratean commercial highway, and Marduk-pal-iddina (Merodach-baladan) of Bit-Yâkin, the Chaldaean chief who had escaped when Ukinzir and his city had been destroyed by Tiglath-pileser IV, again appeared on the scene, this time as a claimant to the kingship of Babylon, presumably in succession to Ukinzir. By himself, Marduk-paliddina would not have been more formidable to Assyria than Ukinzir had been, but he was backed by an unexpected and sinister ally. The kingdom of Elam, which had not meddled with Mesopotamian affairs for centuries, had gradually become alarmed by the growth of the Assyrian power, not only in Babylonia but also in Media, which lay across the Zagros and therefore in rear of Elam. So Khumbanigash, the Elamite king, determined to resist further Assyrian encroachment, in alliance with Marduk-pal-iddina. In $72 \mathrm{I}$ he entered Mesopotamia and laid siege to the fortress of Dur-ilu, on the Lower Tigris. Sargon advanced to its relief, but was defeated by the Elamites before its walls, and compelled to return to Assyria, contenting himself with harrying the Aramaean tribes. Marduk-pal-iddina was acknowledged by the Babylonians as their king.

This defeat had immediate results in the West. The Egyptian intrigues bore fruit in the revolt of Hamath and Damascus under a certain Ya'ubidi, who was joined by the kingless remnant of Israel at Samaria, and by Hanun of Gaza and the Philistines, with Shabaka in Egypt at their back. Sargon, abandoning all plans of recovering Babylonia, marched west in 720, defeated Ya'ubidi at Karkar, and finally met the Philistines and Egyptians, under the leadership of Hanun and Shabaka, at Raphia, on the Egyptian border. It was the first time that the Egyptians had come into hostile contact with the new Assyria, and the result was their complete defeat. The Ethiopians were unable to effect anything against the trained legions of Sargon, and Shabaka fled "like a shepherd whose sheep have been taken," while Hanun was captured. An actual invasion of Egypt was only staved off by the offering of gifts, which the Assyrian king chose to regard as the "tribute" of "Pir'u king of Mușri," 1 and rather insolently chronicled in the same category with the tribute of the Beduin queen Samsi and 
the gifts of the far-away Ithamar, king of Saba, in Southern Arabia, which were brought to him while in Philistia. He then returned to Assyria, completing the punishment of Israel by carrying into captivity twenty-seven thousand two hundred and ninety of the flower of the nation, who, so we are told by the chronicler of the Book of Kings, were settled in the Assyrian territory of Gozan and in distant Media, while their place at Samaria was taken by "men from Babylon, and from Cuthah, and from Ava, and from Hamath, and from Sepharvaim," a mixed horde of Syrian and Babylonian prisoners, from whom, by admixture with the remnant of Israel, the later nation of the Samaritans was formed. ${ }^{3}$

The crushing defeat of Egypt at Raphia and the final destruction of Israel left Sargon free to turn his attention away from the West, not, however, to Babylon but to the wild tribes on the always threatened and disturbed Northern frontier. $\mathrm{He}$ had no desire to renew the contest with Khumbanigash, and Marduk-pal-iddina continued to reign in Babylon under the aegis of the redoubtable Elamite. Campaigns in the Northern mountains promised Sargon cheaper and more certain laurels. An action in that direction was now necessary, since Urartu was once more raising its head, and its king, Rusas I, successor of Sarduris III, was preparing war and trouble for Assyria in alliance with a new power, "Mita king of Mushki" (Anatolia), whose name certainly represents that of the famous Midas-kings of Phrygia.

12 Kings xviii. II. The Jewish writer speaks of the captivity as if it had been carried out by Shalmaneser IV, but we know from the Assyrian record that the siege
was ended after Sargon's accession and that the captivity took place two years later.

22 Kings xvii. 24 .

3 The Hebrew chronicler tells us how (no doubt owing to the utter devastation of the country) the new colonists were plagued by lions, and that they came to the conclusion that this was due to the anger of the god of the country, who did not approve of their presence. They therefore petitioned Nineveh that an Israelite priest might be sent to them, to teach them the worship of the god of the land, in order that they might placate him. This was done, and the returned priest set up an altar at Beth-el as of old, to teach them the way of Yahweh. Howbeit, they continued to worship their own deities at the same time, and it was not till much later that the peculiar heretical Samaritan worship of Yahweh became general among them. The whole story bears every mark of truth, and is fully in accordance with the whole religions spirit of the time. 


\section{Mita of Mushki: the Midas-kings of Phrygia}

The Phrygian invasion of Anatolia-lhrygian settlement at Troy-Phrygian tombs-Phrygian religion-Bucolic nature of Phrygian culture-The Miclas kinglom comes into conflict with Assyria-Mannai-Deroles the Mede-Death of KusasPisiris of Carchemish-Frontier war with Phrygia-Effects of the Raphia battle in Esypt : Ethiopians temporarily abandon Lower Egypt-Tnephachthos and Bocchoris (720-712)-Return of Shabaka (7 I2)-He stirs up revolt in Palestine-Conquest of Babylonia (709) - General peace : organization of Assyrian empire-Religious interests of Sargon: temples built-Death of Sargon (705) : accession of Sennacherib (705-682)

We have heard nothing of Anatolia since the days of the Cappadocian campaign of Tiglath-pileser $I$ and the final break-up of the Hittite power. In these dark centuries must be placed the irruption from Europe of the Indo-European tribes of the Bryges or Phrygians, who were of the same stock as the Thracians, and closely related in race and language to the Hellenic Greeks. These tribes seem to have overrun the peninsula in the tenth and ninth centuries (possibly penetrating as far east as Armenia, where they may have given a European language to the native people whom they ruled ${ }^{1}$ ), and everywhere overlying and mingling with the old native(Hittite)population (except in Lycia and Caria, perhaps in Southern Cappadocia, and certainly in Cilicia). We find a trace of their presence on the historic hill of Troy, in the shape of a post-Mycenaean settlement with bucchero pottery of a barbaric type, and further excavation of the ancient sites of Asia Minor would doubtless reveal many traces of their first semi-barbarous culture overlying the older strata of the Hittite civilization. The black pottery of the seventh settlement at Hissarlik ${ }^{2}$ which is ascribed to them certainly gives the impression of a culture and art semi-barbarous, as was the contemporary culture of the first iron-using inhabitants of Greece, in comparison with that of the Greek islanders of the preceding age. But the description of the armour, chariots, and horses of Rhesos the Thracian in the Iliad ${ }^{3}$ shew that the Aegean culture had reached Thrace by the ninth or eighth

1 The modern Armenian language may, however, rather be of Iranian origin and a relic of the Mitannian-Kassite invasions. The statement of Stephanus (see p. 335,

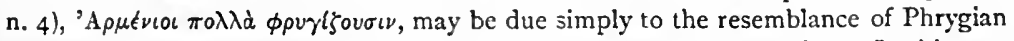
(probably a purer Aryan tongue than Greek) to the Iranian Armenian. In this case there is no necessity to suppose that the Thrako-Phrygian tribes ever reached Armenia or were the founders of the Urartian state (see p. 458 , n. I).

2 Dörpleld-Schmot, Troja ". llion, i. pp. 299 fr.

${ }^{3}$ Pp. 435 ff. 


\section{THE ANCIENT HISTORY OF THE NEAR EAS'T}

century, and that the people from whom the Phrygians sprang were by no means barbarians. Of their later culture and art there remain monuments in the shape of the sculptured façades of tombs in the district of Kiutahia, which though much affected by Hellenic influence, yet retained certain national characteristics, especially in their geometrical ornamentation, an old inheritance from their forefathers; the same ornament which the Aryan Greeks brought with them from the North into Greece. The heraldically opposed figures of lions which appear upon them, and remind us so much of the famous gate at Mycenae, were presumably derived from Minoan art. ${ }^{1}$

The old Anatolian culture must soon have affected that of the invaders, and we see that the Anatolian influence was especially prominent in religion. In Phrygian religion, as we know it later, we can see the two strands of religious ideas side by side, the Indo-European gods with their drunken wine-feasts that came from Thrace, and the adopted deities of the soil with their strange priesthoods and their un-Aryan rites. By the side of their own gods, such as Bagaios (the Persian bhâga, Slav. bogü) or Papas ("Father") or Osogo ("Thunderer"), who is the same as Greek Zeus, as Mên the Moon-god (who keeps his true Aryan sex, while in Greece Selene is feminine from pre-Aryan (?) tradition), and as a young male deity named Sabazios or Atys (who is the Thracian Dionysos), we find the Anatolian Great Mother called by the Phrygian names Mâ or Kybelê, and her sonhusband who was identified with and called by the name of Atys. ${ }^{2}$ The ancient worship of the Mother at Pessinos, with its great priesthood, remained, and secured the veneration of the new-comers.

We may conceive of the Phrygians as a people composed of an Aryan aristocracy ruling over and gradually mixing with the Anatolian peasants, whose language was supplanted by that of their rulers, just as the old idioms of Greece were supplanted by Aryan Greek, and in Ireland Irish was supplanted by English. The Phrygians always appear as a people of peasants, primarily devoted to agriculture, much resembling the modern Anatolian fellahîn. The fostering of agriculture was the main duty of the kings and nobles, and in the mythology of Phrygia the heroes of the tilled field take rank above those of the field

\footnotetext{
'See Perrot-Chipiez, Hist. de l' Art, vol. v., la Phrygie.

2 See p. 330.
} 
of war, and the bucolic pipe of Lityerses is of more account than the trumpet of Ares. For the Phrygian the ark of the covenant was an ancient wain, preserved at Ancyra, in which, it was said, Gordios, the first Phrygian king, had used to bring home his sheaves.

But as the wealth of the state increased, so the kings increased their pride, and finally a Midas (the kings were alternately named Gordios and Midas) went forth to conquer, and established an empire which reached the Halys and beyond, while the state of Lydia was tributary to it. So the poets tell us, and the Assyrian record of Mita of Mushki lends considerable probability to their tale. It may be that he was the wealthy conqueror himself, that very Midas at whose touch all things turned to gold. It may be that the poet's Midas is a compound of several of the kings of the eighth century; but it is more than probable that the historical "Mita of Mushki" is one of those who bore the name of Midas. He, or one of his predecessors, seems certainly to have pushed his dominion as far as the Taurus, where he came into communication with the kingdom of Urartu, and in alliance with it into conflict with Sargon of Assyria about the year 720 .

For ten years Sargon was engaged in the task of combating the ceaseless revolts and attacks of the Northern tribes, urged on by Rusas and Midas in the background. Tiglath-pileser IV had sought to establish in the heart of the borderland between Armenia and Media a dependent state, largely composed of conquered and deported tribes from other parts of Western Asia, which was known by the name of the Mannai, the Median tribe to which, probably, the land really belonged. This tribe perhaps gave its princes to the new state (though imported Semites sometimes appear, as Ashur-li' and Ittî, whose principalities were carved out of Median territory). Iranzu, the prince of Mannai, was loyal to Sargon, and so bore the brunt of the attack organized by Rusas. Year after year the war went on; Ullusunu, the grandson of Iranzu, went over to the enemy, and so did Ashur-li' and Ittî. They were conquered, and the two rebellious Semites were deported to Syria. Ullusunu's submission was the signal for war between him and Rusas, who deposed him, and set up as liing of Mannai the Median prince Daiukku, who was known to history long before the decipherment of the cuneiform inscriptions, for he is the 
"Deiokes" who is stated by Herodotus ${ }^{1}$ to have been the founder of the Median monarchy. There is little doubt that Herodotus' information was correct, but it was not till later that Deïokes established his power, for his first appearance as a ruler was unfortunate: he was deposed by Sargon and deported to Hamath (7 I5). In the next year Sargon was able to crush Rusas himself; the important town of Muṣașir was destroyed; and Rusas in despair killed himself.

Meanwhile, farther west the intrigues of Midas had resulted in a general unrest among the Hittite princes of Melitene and Kommagene, and even Carchemish, undefended though it was by the huge mountains which were the protection of the more northern tribes, was foolish enough to revolt. Pisiris, the last king of Carchemish, paid for his temerity by the loss of his kingdom (7I7). After the destruction of Rusas, Sargon turned to deal with the mountain Hittites. Tarkhunazi of Milid and Mutallu of Gurgum, who had deposed and murdered his own father Tarkhulara, a faithful vassal of Assyria, were both subdued in succession (7 I2-7 I I). Midas himself was too wary to advance into actual contact with Sargon, and was too far off to be attacked by him. He contented himself with carrying on a frontier war in the passes of the Taurus with the Assyrian governor of Kûê (Cilicia), who in 7 I 5 reported successes against him. No attempt was, however, made by Sargon to emulate the victories of Tiglath-pileser I, and invade Cappadocia. Babylon and Egypt both lay in his rear, always ready to cause trouble, and a disaster in the unknown land west of the Taurus would have been the signal for immediate revolt in Palestine and direct attack by Marduk-pal-iddina and his Elamite ally.

In 7 I I a revolt actually did break out in Palestine, which was directly attributable to Egyptian incitement. The disaster at Raphia in 720 had temporarily ruined the power of Shabaka and the prestige of the Ethiopians in Lower Egypt. Shabaka must have abandoned the Delta altogether, and retired to the South for several years, since in 7 I I we again find him in Lower Egypt, now no longer as turtan but as king; and in the intervening period of nine years between his defeat at Raphia and his appearance in $7 \mathrm{I} I$ we must place the independent reigns of Tefnakht and his son Boknrenef, the Tnephachthos and Bocchoris of the Greels (XXIVth Dynasty). It is evident that 


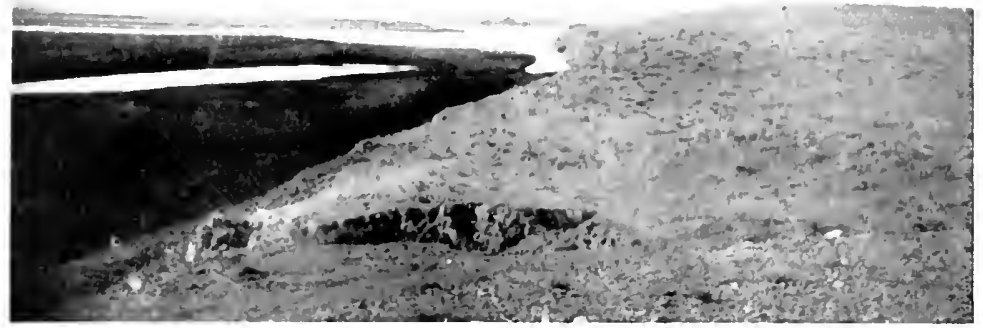

( IRTHEUINH

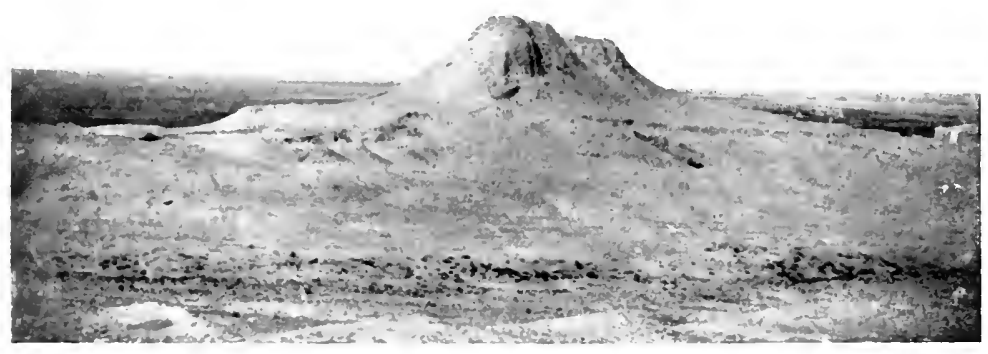

KII I I A HKhII (AMLK)

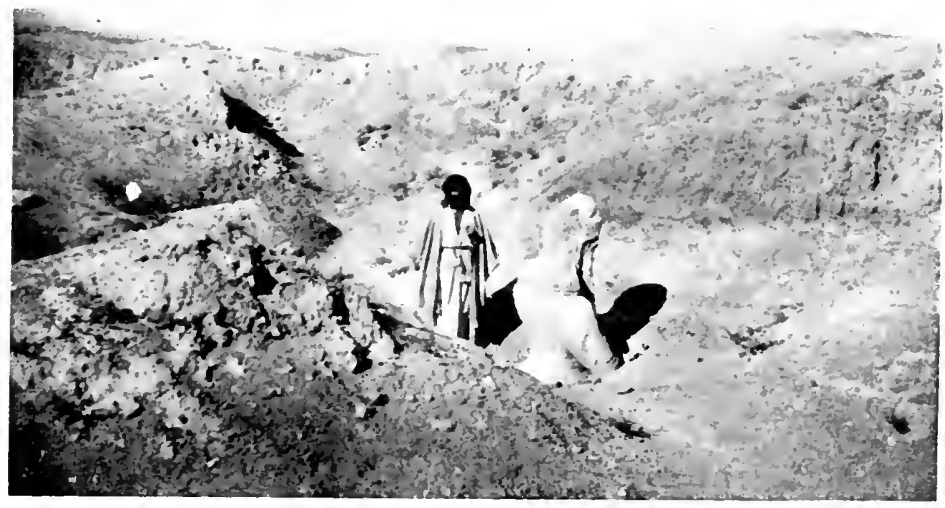

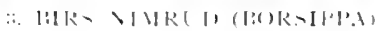



after Raphia Shabaka had fled to Upper Egypt, and that Tefnakht immediately seized the opportunity to revive his old pretensions to the pharaonic dignity. ${ }^{1}$ It is improbable that his reign lasted more than two years, for about $7 \mathrm{I} 8$ he must have been succeeded by Boknrenef, who took the thronc-name of Uahkara ("Vohkere), which was pronounced by the Greeks as "Bokkhoris." This king, who reigned peacefully in Lower Egypt for about six years, was magnified considerably in the stories of Egypt which the Milesian traders who were now beginning to frequent the Nile-mouths brought back with them to Greece. He was reputed to be a prince of very great wisdom, and his father had been a great warrior. ${ }^{2}$ Certainly he shewed his wisdom when in 7 I 5 he pacified any suspicion of his intentions in the mind of Sargon by sending him presents, which were regarded as tribute, and again classed in the same category with the gifts of Samsi and Ithamar. ${ }^{3}$

Some three years later his reign was brought to an end by a second Ethiopian invasion. Shabaka, who had now succeeded Piankhi as king (about 715?), in 712 overwhelmed the Lower Country, and, according to the Greek tradition, which may be perfectly correct, captured Bocchoris and burnt him alive. ${ }^{4}$ This imitation of the customs of the contemporary Assyrian conquerors is significant: the lenity of Piankhi had already begun to go out of fashion, and the iron was soon to bite into the souls of the Egyptians.

Shabaka's renewed rule, now as king, was marked by a renewal of the intrigues of ten years before against the Assyrians in Palestine. He was too energetic to remain passive like Bocchoris, too apprehensive (and probably too insecure in Lower Egypt) to invade Palestine. So, like Rusas and Midas, he sowed revolt. In 715 Ashdod revolted, under the leadership of a Greek adventurer, a "Yavâni," from Cyprus or Ionia, but with little success. ${ }^{5}$ The Yavâni escaped towards Egypt, but was captured by a Sinaitic chief, and sent in chains to Assyria.

I The earlier appearance of Tefnakht at the time of Piankhi's invasion is referred to on p. 469.

2 Diov. i. 79,94 .

${ }^{3}$ Sec p. 47.3 .

4 According to Manetho (af. Syncell. Chronogr. p. 74b).

"It is much more likely that "the Yavâni" was an Ionian than an Arab from Yemen, a "Yamâni." Greece is much nearer than Yemen, and the Ionians were now surging out of the Aegean into the Eastern Mediterranean; the Milesians were at the Nile-mouths. 
Judah seems to have taken part in the rebellion. Hezekiah the king, son of Ahaz, must have submitted promptly, and Sargon called himself "subjugator of the land of Judah, whose situation is far away."

Sargon did not attempt to attack Egypt: he was as unwilling to penetrate into the foreign and unknown Nile-land as into the equally foreign and unknown Asia Minor. And he now intended to subjugate Babylonia finally. Shutruk-nakhunte, the king of Elam, who had succeeded Khumbanigash in 717, made no move to support Marduk-pal-iddina, who was driven into Chaldaea, while Sargon, welcomed as a deliverer from Chaldaean oppression, "took the hands of Bel" as king in Babylon in 709 B.C. The complete defeat of the Chaldaeans in their own country followed, and Bit-Yâkin was annexed and peopled with wretched Hittites from Kommagene, the captured Chaldaeans being probably sent to Samaria or Hamath. And the conqueror celebrated his triumph by a festal reception of gift-bearing ambassadors from Midas, now desirous of peace, and of tribute from seven kings of the island of Cyprus, who had apparently acknowledged Assyrian overlordship in 7 I5 (when Tyre, probably after some unrecorded revolt, had formally submitted). They had set up in their island, probably in the Phoenician city of Kition, a stela with a figure of the Assyrian king as an emblem of their vassalage. ${ }^{1}$

But for two final flares of revolt by Mutallu ${ }^{2}$ of Milid (in alliance with Argistis II of Urartu) and by Median tribes in the next year, all was now peace. Only Judah and the Phoenician cities still preserved a semi-independent position within the empire; elsewhere the local rulers had all been removed and their territories had been directly annexed to Assyria and were administered by Assyrian officials. The boundaries of the empire had been rounded off and fixed from Cilicia to the Persian Gulf. This was the work of Sargon, who had thus brilliantly belied the unfavourable augury of the defeat of Dûr-ilu at the beginning of his reign.

In the midst of his wars Sargon had found time to be one of the greatest builders of temples and palaces that Assyria had known. He seems to have been of a more religious turn

${ }^{1}$ Now at Berlin. Schraner, Die Sargonstele (k. p. Akad., 1882).

2 This Hittite name is noticeable as the same as that of the great king who five hundred years before fought with Rameses II. 
of mind than his immediate predecessors had been, and in his reign the whole pantheon of deities is often mentioned, whereas they seem to have been devoted almost solely to the worship of the soldier's god, Ashur, whose name occurs almost solitary in their inscriptions. Not content with the old royal palace of Calah, and the temples of Nineveh, he erected at a spot a short distance north of Nineveh, now known as Khorsabad, his great royal city of Dûr-Sharrûkin ("Sargonsburgh"), which was excavated by Botta, whose many trophies are now in the Louvre at Paris. The palace of Khorsabad, with its endless sculptured corridors wreathed round a central ziggurat-temple, was of enormous extent, and occupied many years in building. In 707, on his return from Babylon, the king formally took possession of his new abode, and the images of the gods were solemnly inducted into their temples.

He lived at Khorsabad only for two years. In 705 he died, probably by the hand of an assassin, and was succeeded by his son Sin-akhi-irba ("Sin [the moon-god]-has-increased-thebrethren"), known to us as SENNACHERIB, and to the Greeks as Sanacharibos.

\section{The Reign of Sennacherib (705-682)}

Character of the new king-Babylonian revolt and Elamite invasion defeatedLulì of Tyre and Hezekiah of Judah-Hezekiah seizes Philistia, which is reconquered by Sennacherib, who defeats Shabaka at Eltekeh (701)-Siege of Jerusalen-The speech of the Rab-shakeh-Hezekiah surrenders on terms-Monotheistic fervour of Hezekiah-He intrigues with the Chaldaeans-Renewed incursion of Merodachbaladan into Babylonia-Royal campaign in the Jûdi-Dagh (699)-The new cylinderinscription of Sennacherib : campaign in Cilicia (698): Sennacherib not present in person-First collision of Greeks (Ionians) with Assyria-Later traditions of this war -Northern wars-Naval expedition on the Persian Gulf (694)-Elamite invasionBattle of Khaluli (691)-Destruction of Babylon (689)-Events in the West: Shabataka (70I-689)-Taharka (689-663)-Sennacherib's disaster at Pelusium (686?)Arab campaign (c. 683?)-Buildings at Nineveh-Kuyunjik and Nebi Yûnus-The walls of Nineveh-Murder of Sennacherib (68I)-Accession of Esarhaddon

The new king was a man in some ways of lower intellectual calibre than his father, and certainly much less far-seeing and politic. The carefully thought-out schemes by which Sargon had re-established the empire and had sought to organize it in one great whole were unknown to him: he was restless and erratic in his military movements and in his policy. $H$ is campaigns were often planned and his victories achieved in defiance of strategical considerations, and in his policy he allowed 
himself to be carried away by the violence of his character into most impolitic acts. Thus he succeeded in raising for Assyria a furious foe in Elam, and in estranging from the Assyrian connexion the whole population of Babylonia, where priests and merchants now combined with Chaldaeans and Aramaeans against the sacker of Babylon and the desecrator of their holiest shrines. He was a vainer man, too, than his father, and we hear of his deeds not merely as incidents of each year of his reign, but pompously chronicled and arranged in "campaigns," which were inscribed upon clay cylinders, to be kept in the royal library, a custom followed by his successors. ${ }^{1}$

The looseness of the ties that bound the subject-provinces to Assyria, in spite of all that Sargon had achieved, were, as usual, shewn at the beginning of the new reign. The Median conquests of Sargon fell away at once, and no attempt was made to recover them. And in a year's time Marduk-pal-iddina was once more in the field to recover Babylon, this time aided by an Elamite army sent by Ishtar-Khundu, the successor of Shutruk-nakhunte. He was expelled, the Elamites were defeated, and Sennacherib placed a native Babylonian of the old royal house, named Bel-ibni, on the throne of Babylon as a tributary king, thus giving up the claim of Tiglath-pileser IV and Sargon to be kings of Babylon themselves (702). In the next year Sennacherib was called to the West, where a general defiance of Assyrian authority had broken out, no doubt inspired by Egyptian intrigues. Lulî (Elulaios) of Sidon seems to have imposed his authority over all Phoenicia and had tried to subdue Cyprus, while Hezekiah of Judah, with the connivance of Shabaka, had had the temerity to substitute in Philistia his overlordship for that of Sennacherib. ${ }^{2}$ In Ashkelon a revolution had deposed Sharruludari, son of Rukipti, and in Ekron the king Padi was similarly deposed and sent to Jerusalem in chains. Sennacherib struck Lulî first, drove him across the sea

1 The chief records of Sennacherib are the great stele at Bavian, north of Nineveh, an inscription found on the mound of Nebi Yunus (Nineveh), and three great "cylinder" or "prism" inscriptions of baked clay found at Nineveh, of which two were discovered by Layard, and one has only recently come into the market, and has been acquired for the British Museum, where the other two are. The new cylinder has been published by L. W. KING, Cuneiform Texts, xxvi., with translation and commentary. The references to the publications of the other records are given by ROGERS, Hist. ii. 183 .

22 Kings xviii. 8. 
to Cyprus, and put Ethbaal in his place as king of Sidon. Phoenicia submitted, and the kings of Ammon, Moab, and Edom, by no means inclined to view an increase of the power of Jerusalem with pleasure, at once put themselves at the feet of Sennacherib. Mitinti of Ashdod, too, who had reigned there after the expulsion of the "Yavâni" in faithful dependence on Assyria, was eager to assert his loyalty. Leaving Hezekiah on one side for the moment, Sennacherib pushed on to Philistia, where he took Ashkelon, and sent the new king, Sidka, prisoner to Assyria. Beth-dagon and Joppa were then taken, and the Assyrians were nearing the border of Egypt. This time Shabaka was moved to give substantial help to the Palestinians. He assembled an army, composed of the ban of the Delta under the local knights (who still ruled there under the Ethiopian hegemony), stiffened by his own Ethiopian troops, "the army of the kings of Musur, and the soldiers, the archers, the chariots, and horsemen of Melukhkha (Nubia)." Shabaka himself does not seem to have been present. At Eltekeh, near Ekron, the battle was joined, and, as at Raphia, ended in the defeat of the Egyptians. " "The sons of the kings of Muṣur" and some Ethiopian generals were captured, and the beaten army made the best of its way back across the desert to Egypt. Ekron then surrendered, and Padi, who seems to have been handed over by Hezekiah, probably in an attempt to conciliate the anger of Sennacherib, was reinstated as king. Lachish was then formally beseiged, and eventually taken. The siege was specially commemorated in reliefs on the walls of Sennacherib's palace at Nineveh, and seems therefore to have been regarded as a great feat of arms. Hezekiah was now shut up in Jerusalem, "like a caged bird," as Sennacherib says in his account of the compaign. The whole territory of Judaea was ravaged. "200,150 people," probably meaning the whole country's population, were "regarded as spoil," though we are not told that they were carried into captivity, as it is sometimes supposed. ${ }^{2}$ Jerusalem was then besieged, but Sennacherib, probably disinclined to remain any longer in the West, tied to the siege of an almost impregnable fortress, soon returned to Assyria,

1 "Prism" inscription of Sennacherib (Schrader, Keilinschr. Bibl. i. pp. 8r ff.).

2 The transport of so enormous a number of captives, ten times the number of those carried off from Israel by Sargon, would have been well-nigh impossible : also we find no hint of such a wholesale captivity in the Hebrew annals. 
leaving the siege to be conducted by the turtan, the rab-saris, and the rab-shakeh. ${ }^{1}$ In the Book of $\mathrm{Kings}^{2}$ we read a vivid description of Hezekiah's attempts at negotiation with these officers, of their insolent taunts to the Jewish deputies who went to interview them, and especially of the famous speech of the $r a b$-shakeh in Hebrew in order that all the besieged might hear, in spite of the frantic prayers of Hezekiah's deputies that he would speak Aramaic, and not "talk in the Jews' language in the ears of the people that are on the wall." "What confidence is this wherein thou trustest?" shouted the Assyrian. "Thou sayest, but they are but vain words, I have counsel and strength for the war! Now on whom dost thou trust, that thou rebellest against me? Now, behold thou trusteth upon this staff of this bruised reed, even upon Egypt, on which if a man lean it will go into his hand and pierce it: so is Pharaoh, king of Egypt, unto all that trust on him ! . . . . Hath any of the gods of the nations delivered at all his land out of the hand of the king of Assyria? Where are the gods of Hamath and of Arpad? Where are the gods of Samaria, ${ }^{3}$ [Hena, and Ivah]? have they delivered Samaria out of mine hand? Who are they among all the gods of the countries, that have delivered their country out of mine hand, that Yahweh should deliver Jerusalem out of mine hand?" We might be inclined to regard this as a speech of the Thucydidean order and a picturesque concoction of the chronicler, but that it is alive with the spirit of the time, and is exactly what we know the rab-shakeh is likely to have said. Hezekiah's prayer, too, "of a truth, Lord, the kings of Assyria have destroyed the nations and their lands, and have cast their gods into the fire," is no invention of a chronicler living perhaps long after the Assyrian terror had passed away. The whole story of the siege in the Book of Kings is as contemporary with it as is Sennacherib's own account, and we cannot doubt the speech of Rab-shakeh is correctly reported: it must have burnt itself into the brains of all that heard it.

But, cheered by the support of the Prophet Isaiah, Hezekiah held out against capture and storm, until compelled by the defection of the Arab mercenaries who formed part of the defending force, he proffered a modified surrender, which the wearied Assyrians were ready to accept, and sent his tribute

1 On these officers see p. 446, n. 2. 22 Kings xviii. $17 \mathrm{ff}$.

${ }^{3}$ LXX reading. See Burney, Notes on Book of Kings, p. 342. 
back with them to Assyria. The Philistine towns which he had occupied were handed over to Padi of Ekron. Hezekiah, convinced that Yahweh alone had delivered him, signalized the return of peace by an access of monotheistic fervour, and destroyed Nehushtan, the brazen serpent, which, according to legend, Moses had set up in the wilderness, and was, in all probability, actually a very ancient image that had been brought by the ancestors of the Israelites from Egypt. ${ }^{1}$ Hezekiah was sincerely religious, but very little of a politician, and almost immediately after the deliverance of Jerusalem he was foolish enough to receive ambassadors from Merodach-baladan (Mardukpal-iddina) the Chaldean, who was again asserting his claim to the Babylonian throne. For this folly he was deservedly rebuked by Isaiah, ${ }^{2}$ who saw clearly that a friendship with Merodachbaladan would simply result in again bringing Sennacherib down on Jerusalem, which this time would certainly share the fate of Samaria.

Marduk-pal-iddina had taken the opportunity of Sennacherib's absence in the West to invade Babylonia; Sennacherib invaded at once in his turn, after he had come back from Jerusalem, and in 700 expelled the troublesome Chaldaean not only from Babylonia, but also from Bit-Yâkin: he took ship thence, and escaped into the Elamite territory of Nagitu, the neighbourhood of the modern Bushire. Sennacherib now replaced Bel-ibni, the puppet-king of Babylon, by his own son, Ashur-nadin-shum.

The annals of the following years present a curious example of the royal vanity. In 699 Sennacherib deigned to conduct in person a series of raids on the hill-villages of Mount Nipur (the Jûdi Dagh), ${ }^{3}$ north-east of Nineveh. He was carried in his palanquin most of the way, but occasionally was compelled by the roughness of the hill-paths to dismount and go on foot, sometimes even leading the attack himself on foot. This was magnified by the court historians into a marvellous feat, and the whole razzia dignified as the royal "fifth campaign." But a

12 Kings xviii. 4 .

2Ibid. xx. 14. Evidently the Jewish writer does not quite sce the point of Isaiah's objections to I Iezekiah's relations with the Babylonian Merodach-baladan, and turns his words, prophesying an Assyrian captivity as a result, into a prophecy of the Babylonian captivity.

${ }^{3}$ The identification of Mount Nipur with the Judi Dagh was made by L. W. KING. 
very serious campaign in Cilicia, which took place in the next year, was not only not recorded as a royal campaign, since the king himself took no part in it, but was actually omitted from the later records of the king's reign. We know of it only from a recently discovered cylinder, ${ }^{1}$ which was dedicated in the eponymy of Ilu-ittia, 694 B.C., and buried as a foundationdeposit in the wall of one of the new gates of Nineveh which Sennacherib set up in that year. On this cylinder the records of recent important campaigns are given, although they were not conducted by the king in person: but on later cylinders of the reign such campaigns, however important they might be, were omitted and razzias like that of 699 appear in the official records, while the great Cilician campaign of 698 was forgotten. As it is, we are not told the names of the generals who conducted that campaign. Sennacherib merely says that he "sent his army."

The war of 698 is of special interest on account of the fact that certain traditions respecting it have been handed down from Babylonian sources by Greek historians, and the probability that it marked the first open collision between the Greeks of the new Hellenic world and the great Oriental empires. ${ }^{2}$ In 720 a single nameless Greek seems, as we have seen, to have temporarily made himself tyrant of Ashdod till his expulsion by Sargon; and in 709 Cypriote princes, among them no doubt Greeks, had submitted to the same king, who speaks of having drawn the Ionians "like fish from the sea," and given rest to Kûê (Cilicia) and Tyre. This evidently refers to a capture of Greek pirates infesting the coast; no land-warfare between Greeks and Assyrians had taken place, so far as we know, till the year 698 .

Sennacherib tells us that in that year Kirua, governor of Kûê, revolted in alliance with "the people who dwelt in Ingirâ and Tarsus," and seized the great trade-route through the Cilician Gates from Syria to Anatolia, stopping all traffic. After a severe campaign, too dangerous for the ling to accompany it in person, Kirua and his allies were finally defeated by the royal generals. The spoil of Tarsus was carried to Nineveh, and then Sennacherib made a triumphal progress to the scene of the victory and set up a memorial

${ }^{1}$ The third Cylinder of the British Museum, described on p. 482 , n. 1 .

2 See L. W. King, "Sennacherib and the Ionians," J.H.S. xxx. 
of alabaster to commemorate it in Illubru, the conquered city of Kirua.

Now Berossos described a great campaign of Sennacherib in Cilicia against Greeks, and of his description the two versions of Alexander Polyhistor and Abydenus, preserved by Eusebius, differ, the one in making the battle with the "Greeks" a land-fight, the other in making it a naval combat. Polyhistor says that when Sennacherib had received a report that the Greeks had made a hostile descent on Cilicia, he marched against them and defeated them, suffering himself great loss, however. The text of Eusebius goes on to say that to commemorate the victory, Sennacherib erected a statue or likeness of himself at the place where the battle was fought, and commanded that his victory should be described upon it in Chaldaean characters, to hand it down to posterity. Polyhistor adds that Sennacherib built the city of Tarsus in imitation of Babylon. The account of Abydenus makes Sennacherib defeat a fleet of "Greek ships" in a fight off the Cilician coast; he also says that Sennacherib founded an "Athenian" Temple with columns of bronze, on which he engraved his mighty deeds; and explains Polyhistor's remark about the similarity of Tarsus to Babylon, by saying that Sennacherib made the Cydnus traverse the centre of the city as the Euphrates traverses Babylon.

We only know of one expedition to Cilicia in the reign of Sennacherib, that of 698 against Kirua. Before the new cylinder was known, a single reference to war in Cilicia on another document was confused with the "fifth campaign"; Mount Nipur was supposed to be the Taurus, and the raids of 699, which actually took place in the Jûdi Dagh, not fifty miles from Nineveh, were transferred to Cilicia. ${ }^{1}$ We now see how matters really went, and also that the campaign against Kirua and the people of Ingirâ and Tarsus who seized the Cicilian caravan-route can be none other than the campaign against the Greeks in Cilicia described by Berossos. ${ }^{2}$ We can understand how, in spite of Sargon's reprisals, Ionian sea-rovers and would-be colonists had finally effected a landing on the Cilician coast and had probably mixed easily with the population of Tarsus and the Aleian plain, which according to later tradition was of much older Greek origin, and was' descended
${ }^{1}$ E.g. Jonns, Encycl. Bibl., art. "Sennacherib."
${ }^{2}$ King, l.c. 
from those who had followed the hero Mopsos hither after the Trojan war. ${ }^{1}$

When the invaders and the revolted governor had been subdued by his generals, after a hard struggle, the king of Assyria came in state and inaugurated his triumphal stele amid the ruins of Illubru, as both he and Berossos state; and from the Babylonian historian we learn that he re-established the ancient city of Tarsus, after it had been taken from the new-comers, "on the model of Babylon" (Sennacherib would have said Nineveh), ${ }^{2}$ and with a temple, probably of Ashur, the columns of which were bronze, like the bronze columns which he was setting up about the same time at Nineveh. ${ }^{3}$

For several years now the king was busy with the building of his walls and palaces at Nineveh, and led no warlike expeditions personally. In 695 his unnamed generals captured Til-garimmu (the Biblical Togarmah), the capital of the State of Tabal (Tubal), whose people were the Tibareni of the Greeks, in the mountains north of the modern Malatiya and Albistan. Tabal had appeared before in the history of the Assyrian empire; it was probably first subdued by Ashur-nașir-pal, and was chastised by Shalmaneser II (in 838 B.C.); in the time of Tiglath-pileser IV we find it a very submissive vassal; in 7 1 8 it had revolted under the influence of Mita of Mushki; of the cause of the war of 695 we have no knowledge.

In 694 Sennacherib's restless activity moved him to a remarkable adventure, which he calls his sixth campaign. $\mathrm{He}$ resolved to strike at Merodach-baladan in his retreat on the Elamite coast of the Persian Gulf, and in order to do this he had great ships on the Phoenician model built at Til Barsip, ${ }^{4}$ on the upper Euphrates, and manned by Sidonian sailors: the flotilla thus prepared sailed down the river to the gulf with an army on board, which was safely ferried over to the Elamite coast after the favour of Ea, the god of the Ocean, had been propitiated by the offerings of a golden ship, a golden fish, and other objects, which were solemnly cast into the sea.

${ }^{1}$ See above, p. 68.

${ }^{2}$ Nineveh was divided by the Khusur, a river which bore a much greater analogy to the Cydnus than did the Euphrates at Babylon.

3 This note of Abydenus as to the bronze columns is evidently a fragment of a well-founded tradition.

${ }^{4}$ Identified with the modern Tell Ahmar, near Jerabis, by Mr. R. C. THOMPSON in 1911 . 


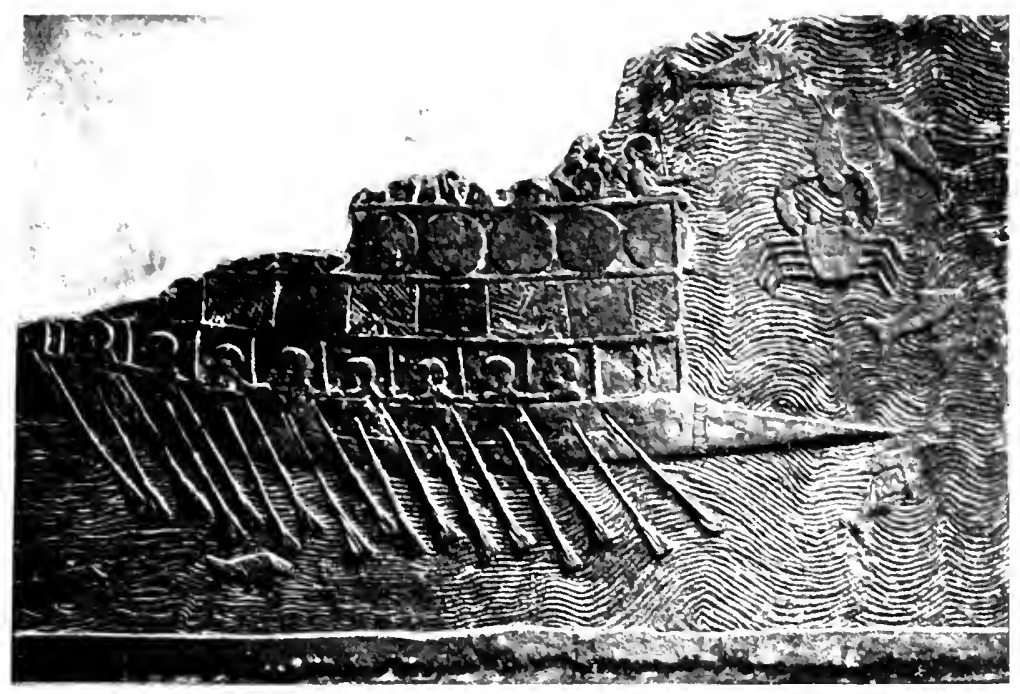

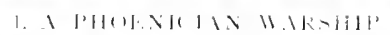

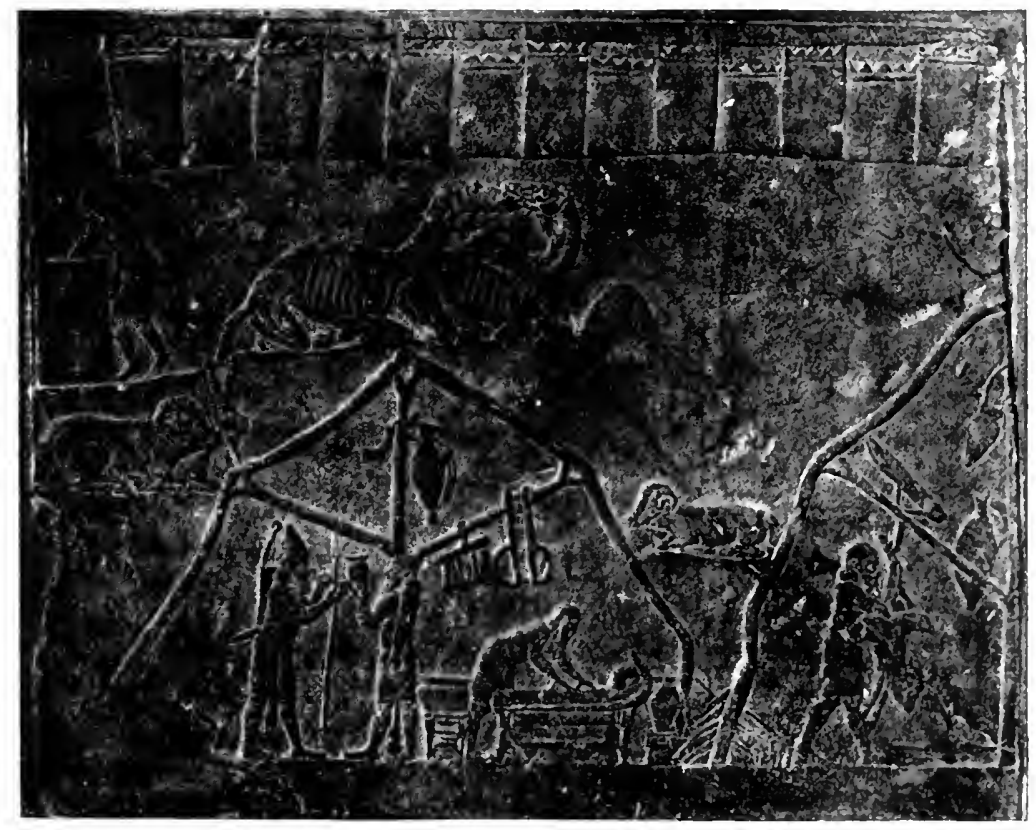



The Elamite coast was ravaged, and hundreds of the fugitive Chaldaeans and their gods, with Elamite prisoners also, were brought back to Babylonia, where Sennacherib, who had not trusted himself to the uncertain favour of the sea-god Ea, awaited them. Whether Merodach-baladan had been killed we do not know; he never reappeared.

This expedition was a declaration of war against Elam, and Khallushu, its king (who had acceded in 699), furious at the ravaging of his coast, delivered an immediate counter-stroke by invading Babylonia and capturing Sippar, with the Assyrian king of Babylon, Ashur-nadin-shum, Sennacherib's son. Khallushu set a certain Nergal-ushezib ${ }^{1}$ on the throne of Babylon, and then returned to Elam, carrying Ashur-nadinshum in his train. Sennacherib was thus cut off from Assyria, but Nergal-ushezib was unable to make headway against his advance from the south, was defeated at Nippur, and carried off to Assyria (693). Sennacherib then attacked Elam, but the king Kudur-nakhkhunte, who had succeeded Khallushu in the meantime, retired before him into the mountains, and the Assyrians effected nothing, finally returning to Nineveh. Directly they left the country, the Babylonians made a certain Mushezibmarduk king (692). In the next year Sennacherib moved south against him, and the terrified Babylonian summoned Kudur-nakhkhunte's successor, Umman-minanu, to his aid, bribing him with the treasures of the temple of Marduk, which he took from their house and sent to Elam. Umman-minanu responded to the bribe, and the Elamite army met Sennacherib at Khaluli on the Tigris. A great battle ensued which is most picturesquely described by Sennacherib's historian. "Like a great swarm of locusts which spreads itself over the land, so marched they in warlike array against me, to bring me to battle. The dust of their feet rose before me like a heavy stormcloud, which covered the copper-coloured face of the wide heaven. By the town Khaluli, on the bank of the Tigris, their forces deployed: they set themselves in order against me, and clashed their weapons together. But I prayed to Ashur, Sin, Shamash, Bel, Nebo, Nergal, Ishtar of Nineveh, and Ishtar of Arbela, the gods in whom I trusted, for the defeat of the

"It is not certain whether the "Shuzub" who is referred to by Sennacherib in his inscriptions is this Nergal-ushezib or the later Mushezib-marduk (see MeIssser, in O.L.Z., I91 I, p. 62). 
mighty foe; and they heard swiftly my prayer and came to my help." The rest of the inscription describes nothing but the personal prowess of the king himself in inflated language, which was no doubt pleasing to the royal ears: how much relation it may have borne to fact we cannot tell. ${ }^{1}$ The description is a paean of victory, but it is not impossible that the battle really resulted in an Assyrian defeat, for Sennacherib certainly had to retreat to Assyria, leaving the Elamites in possession of the field, and Mushezib-marduk in possession of Babylonia. But Khumbanudasha, the Elamite general, was killed, and Nabu-shum-ishkun, son of Merodach-baladan, an exile in Elam, was captured (according to the official account by the king's own hand). This, and the heavy losses of the Elamites, were probably the only Assyrian claims to victory.

For a year Sennacherib remained quiet, till the death of Umman-minanu in 689 gave him the opportunity of carrying out a scheme of revenge on Babylon which should be complete and lasting. Suddenly advancing, he took the city, sent Mushezibmarduk away captive in company with the image of the god Marduk itself, and then deliberately destroyed Babylon. The population was expelled, the city burnt, and the canal of Arakhtu turned over its ruins. The destruction of Babylon effected, Sennacherib returned in triumph to Nineveh.

Of the remaining eight years of his reign we have no information from his own annals, which now cease. This silence probably hides a great disaster in the West of which we gain only fragmentary hints from other sources. The defeat of Eltekeh (7OI) had soon been followed by the death of Shabaka, who was succeeded by his son Shabataka (Shabitoku) an unimportant ruler of whom we know little beyond the fact that he made some sort of treaty with Sennacherib of which the seal has been found in the ruins of Nineveh. ${ }^{2}$ In 689 or 688 he was succeeded by his uncle Taharka (Tirhakah), a younger brother of Shabaka. Probably the new king again endeavoured to stir up rebellion in the West, which had been absolutely quiet for over ten years. But Hezeliah, again wisely counselled by Isaiah, took no part in the rebellion. Sennacherib once more arrived in the West (687 or 686?), and took Libnah, which had

\footnotetext{
${ }^{1}$ As usual under this vain king, the Assyrian generals, who really did the work, are never mentioned.

2 LAYARD, Nineveh and Babylon, p. 156.
} 
revolted. Here he heard that Tirhakah was preparing to advance against him, so, to forestall him, he himself crossed the desert and laid siege to Pelusium. There, however, his army was smitten by pestilence, and he was forced to return with all speed to Assyria. Such is possibly the story of the campaign which is passed over in silence by the Assyrian historian, but is recorded by Herodotus ${ }^{1}$ and by the Jewish chroniclers. ${ }^{2}$ The Jewish account seems, however, to be confused, as it stands, with that of the earlier invasion of $70 \mathrm{I}$. In the story of the Second Book of Kings, Tirhakah is spoken of as king, which he was not till 689 at the earliest. And it is certain that Hezekiah, after the siege of $70 \mathrm{I}$ was raised, sent heavy gifts to Nineveh, which he would hardly have done if in that year Sennacherib's army had been decimated by plague and the king himself forced hurriedly to return to Assyria. The fact of the disaster seems vouched for by the Egyptian testimony quoted by Herodotus not much more than two centuries later, and by that of the Biblical record: it would naturally not be mentioned by the Assyrians. ${ }^{3}$

We have no official Egyptian account of the disaster to Sennacherib. In the popular tradition preserved by Herodotus the name of the Egyptian king is given as "Sethos," but this is no argument against his indentity with Tirhakah; the true appellation of the monarch has disappeared in favour of that of the great Seti, probably on account of the legendary connection of Seti I. and his Palestinian wars with Pelusium, and from a confusion of the name of the Ethiopian king (recorded by Manetho) "Zèt" (who is probably to be identified with Kashta, the grandfather of Taharka), with the better-known "Seti." An Ethiopian had ruled at the time: Zêt (Kashta) was

${ }^{1}$ HDT. ii. 14 I.

22 Kings xix. 35 .

${ }^{3}$ Tirhakah was king after 689 , and it seems reasonable to suppose a second expedition, passed over in silence by the Assyrians, to which the siege of Pelusium and the disaster in the Egyptian tradition, and the mention of Tirhakah, the siege of Libnah, and the disaster in the independent Jewish tradition belong, the rest of the Biblical story belonging to the war of 701 . In a later redaction these two expeditions might easily be confused, the obviously contemporaneous elements of the story of 701 in no way suffering by the confusion; and the confusion may have been assisted by Tirhaliah having possibly acted as Shabaka's turtan in 701 : since we know that he accompanied his brother northward in 713 or 712 and was attached to his court, he may well have commanded at Eltekeh in 70r. His two appearances, the second as king, might well be telescoped into one. 
a well-known Ethiopian: "Zèt" in the popular mouth would easily become confused with "Seti," who was connected in tradition with Pelusium : hence Herodotus' "Sethos." It is impossible to reject the whole story to the actual period of Seti in face of the direct mention of Sennacherib (Sanacharibos), which makes obvious the identity of the disaster to his army in the Egyptian with the disaster to his army in the Jewish legend.

The only campaign recorded of Sennacherib in his later years is one against the Arabs, probably a mere razzia, which is mentioned by his son Esarhaddon. He no doubt busied himself with the rebuilding of Nineveh, which he had transformed during his reign into a mighty capital, worthy of the empire and intended by him to eclipse Babylon. In his inscriptions he tells us how his forefathers had never sought to beautify Nineveh, to straighten its streets, to plant plantations, or even to build a proper wall; and that he was the first to carry out a thorough scheme of reconstruction in the capital: " the people of Chaldaea, the Aramaeans, the Mannai, the men of Kûê and Cilicia, the Phoenicians and Tyrians who had not submitted to my yoke, I carried away, and I set them to forced labour, and they made bricks." The great mound on which the royal palace buildings were set, now known as Kuyunjik, was enlarged by the diversion of the river Khusur, and a new and splendid palace built. The mound of Kuyunjik, and that now known by the name of the prophet Jonah, whose reputed tomb stands upon it (Nebi Yûnus), upon which was situated the imperial armoury, formed two great keeps, joined together by a wall, part of the west wall of the city, facing the Tigris. The huge walls were carried round an irregularly-shaped space enclosing more than double the real area of the city: within this space plantations and parks of great size were included, which were watered by means of elaborate aqueducts constructed from springs in the hills north of Nineveh. The walls were double, and each one bore a sonorous Sumerian name; the inner was Bad-imgalbi-galukurra-shushu (in Assyrian, duru ša namvirusu nakiri sahpu, "The Wall whose splendour overthrows the Enemy"), and the outer was Bad-garnerukhubukhkha, "the Wall that terrifies the Foe." Fifteen gates give access to the city, each bearing an ordinary name, such as the "gate of Ashur" or the "Quay-gate," and an Assyrian honorific title. The ruined walls of Sennacherib still remain 
as a range of high mounds surrounding the site of the ancient city, which was about three miles long and about a mile broad at the northern end, narrowing to little more than a thousand yards at the southern. Such a city, with such walls and palaces, was in truth a worthy rival to Babylon in size, and in splendour there is little doubt that Sennacherib's capital would entirely have eclipsed Babylon had the ancient city still existed. But in 694, when the huge walls of Nineveh were completed, Babylon was a ruin and a waste.

"And it came to pass, as he was worshipping in the house of Nisroch his god, that Adrammelech and Sharezer his sons smote him with the sword: and they escaped into the land of Armenia. And Esarhaddon his son reigned in his stead." So the Biblical tradition ${ }^{1}$ registers the death of Sennacherib, and the Assyrian record agrees indirectly. From a broken cylinder of Esarhaddon we learn that he was suddenly called away from his government to contest the succession to the throne, which had been seized by his enemies, and that he pursued them and defeated them in Khanigalbat (Melitene). Further, he calls himself "the avenger of the father who begat him." Four sons of Sennacherib are mentioned: Ashur-nadin-shum, king of Babylon, who was carried off to Elam; Ardi-Belit, who was certainly regarded as crown-prince as late as 694; Ashurmunik; and Ashur-akh-iddina ("Ashur-hath-given-a-brother"), the Biblical Esarhaddon. We may well identify ArdiBelit and Ashur-munik with Adrammelech and Sharezer, whose names in the Biblical narrative are evidently mere appellations of Assyrian sound, conferred upon them by the chronicler in ignorance of their real names. ${ }^{2}$ Esarhaddon had probably displaced Ardi-Belit in his father's affections towards the end of his reign, as we have a document in which he is given rich gifts and his name is changed to Ashur-etil-ukin-apla ("Ashur-the-hero-hath-established-a-son"): it is probable that Sennacherib now intended him to be his successor. Esarhaddon was certainly away in a provincial government when the two elder sons, seizing the opportunity of his absence, murdered their father in order to secure the inheritance to themselves. It has been suggested, with great probability, that Esarhaddon,

12 Kings xix. 37 .

2 A similar proceeding in the case of Egyptian names may be instanced in the cases of "Zaphnathpaaneakh," "Potiphar," "Potipherah," etc.; see p. 405. 
whose partiality for Babylon was marked during his reign, had been made governor of Babylonia, and was there when the news of his father's murder (at the end of 682) arrived. Six weeks later he had expelled the parricides from Nineveh, and then pursued them into Khanigalbat, whence, after their defeat, they fled into Armenia, no doubt to the court of Rusas II., the King of Urartu.

\section{I. The Reign of Esarhaddon, 68 I-669}

Rebuilding of Babylon-Conciliatory policy of Esarhaddon-The Kimmerian invasion of Asia Minor-The Medes and Scyths-Bartatua (Protothyes)-Submission of Phoenicia-The kings of Cyprus, and Manasseh of Judah-Esarhaddon determines to conquer Egypt-Assyrian invasion of Egypt (670)-Storming of MemphisReturn of Tirhakah-Death of Esarhaddon

The formal assumption of the kingship took place at the beginning of 68I. The first act of the new reign, in contradistinction to all those tilat had gone before, was a peaceful one; an act of conciliation and reparation to the Babylonians for the destruction of their city. Esarhaddon had determined to rebuild Babylon, and in 680, "in the tenth year" after the destruction, the walls, towers, and gates were set up again, the Chaldaeans who had invaded the site were chased away, and the inhabitants were summoned back to their ancient abode. Three years later the rehabilitation of the city was complete. The Babylonians were thus conciliated, and when, about the same time, a son of Merodach-baladan attempted to raise a Chaldaean revolt, he met with no sympathy and was compelled to fly to Elam. The Elamites too, who seized the opportunity of Esarhaddon's absence in the West in 675 to invade Babylonia, and actually captured Sippar, also had to retreat before the general hostility; and soon after the "gods of Agade," which they had taken from Sippar, were peacefully returned by them to Esarhaddon. His abstinence from a campaign of revenge secured their friendship also. Thus we see a notable change from the wild, vain, and unthinking proceedings of Sennacherib. Esarhaddon was a prudent and wise statesman, and he deliberately set out to pursue a peaceful policy in his southern dominions with the object of securing a free hand in the great enterprise on which he had determined, the conquest of Egypt, while at the same time keeping one hand free to strike at the mountain-tribes of the North, who were now threatening to 
burst their barriers under the pressure of the nomad tribes of the Gimirrai. These, the "Gomer" of the Hebrews and "Kimmerians" of the Greeks, had come down from the northern steppes through the passes of the Caucasus, and, contemporaneously with the related tribe of the Trēres, ${ }^{1}$ which had apparently come through Moesia and across the Hellespont, were now in full possession of the northern part of Asia Minor, and meditating a descent upon Mesopotamia. One body actually penetrated the mountains through the gorge of the Euphrates in 678 , and was driven back by the Assyrians into Anatolia. Here for a time the Kimmerians and their allies the Treres ranged unchecked, as great a scourge to the civilized inhabitants as were the Huns to the Romans. The pre-occupation of the Kimmerians in the North-West did not, however, relieve Assyria from the fear of barbarian invasion. Other tribes, set in motion by them, were gathering in the North-East, threatening destruction to the kingdom of Urartu and grave danger to Assyria. A chieftain named Kastarit, lord of Kaskashshi, headed a combination of the Medes under king Mamitiarsu, of the Mannai, and of a horde of Scythians under their king Spâka, which came into collision with Assyria. So redoubtable was this foe considered that the king anxiously consulted the oracles and soothsayers concerning him, and we possess an interesting collection of their answers. ${ }^{2}$ The war lasted for several years, ending in 672 with the reassured inviolability of the northern frontier. Esarhaddon had apparently beaten the barbarians at least partly by fomenting divisions in their ranks. One of the chieftains of the Scythians, ${ }^{3}$ who had entered Mannai in rear of the Kimmerians, was brought by the gift of an Assyrian princess of the blood-royal to aid Assyria against Spâka ${ }^{4}$ and Kastarit. The name of this chieftain was Bartatua, and he appears in the history of Herodotus ${ }^{5}$ as the Scythian prince Protothyes, father of that Madyes who afterwards ravaged Syria to the borders of Egypt. The result of Esarhaddon's war was probably to make Bartatua king of the Scythian horde in Armenia and Mannai in place of

1 Strabo, xiii. 627.

2 Knudtzon, Assyrische Gebete (1893).

${ }^{3}$ The Assyrians called them Ashgûza, a Semitized form of their native name, Skutha; the name was taken over by the Hebrews as Ashkûz, misread in later times as "Ashkenaz."

4 "Ishpâka" in Assyrian.

${ }^{5}$ HDT. i. 103. 
the defeated Spâka, and he was important enough for his name to be faithfully handed down in the chronicles which are the basis of the remarkably accurate Herodotean account of the early history of Media. ${ }^{1}$

After the defeat of this barbarian confederation, the great enterprise of the conquest of Egypt could be entered upon without much danger of an attack from the rear. During the ten years that had elapsed since the beginning of the reign the Palestinians, doubtless stirred up by Egypt, had given trouble. The walls of Sidon were destroyed in 678, and an Assyrian fort called Kar-Esarhaddon was built close by to overawe the town. The king, Abdimilkuti, was beheaded, and the same fate befell a Cilician king, Sanduarri, who had made common cause with the Sidonians. All Phoenicia then submitted under the leadership of Baal, King of Tyre, between whom and Esarhaddon a solemn treaty was signed, which, however, was broken by the faithless Tyrian as soon as he thought he had an opportunity of throwing off the yoke. A few years later (in 673) the kings of Cyprus, nine Greeks and one Phoenician, tendered their homage, ${ }^{2}$ and this was probably a confirmation of a previous submission (not mentioned) after the fall of Sidon. The acknowledgment of Assyrian overlordship made to Sargon in 709 was thus repeated to his grandson. The Cypriotes, Greeks though nost of them were, followed obediently in the wake of the Phoenicians, to preserve their island from the scourge of Assyrian invasion, which would have been quite possible in Phoenician ships. No doubt the tale of Sennacherib's exploit in the Persian Gulf ${ }^{3}$ was well known in Phoenicia, whence he had taken his shipwrights and sailors.

1 See p. 9 , n. 10.

2 On the names of these kings, see HaLl, Oldest Civilization of Greece, p. 262. They were : Aigisthos of Idalion, Pythagoras of Chytroi, Keisos or Kissos of Salamis, Etewandros of Paphos, Heraios of Soloi, Damasos of Kourion, Admetos of Tamassos, Onesagoras of Ledra, Pytheas of Nure (Aphrodision) and Damusi (the only Phoenician) of Kartikhadasti (Kition?). The identifications of the names Heraios and Pytheas, and the equation of Nure (or Upridišsa, as the Assyrians also called it) with

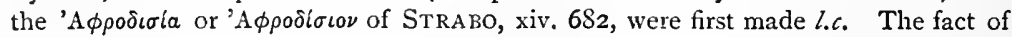
only a single Phoenician ling appearing in Cyprus at this time is significant : the I'hoenicians never had much power in the island, which was always predominantly Greek, as it is to this day (HOGARTH, however, in Ionia and the East, minimizes the Phoenician power too much, and dates the first Phoenician colonies too late; see HaLL, in P.S.B.A. xxxi. p. $2 \mathrm{~S}_{3}$ ).

${ }^{3}$ See p. 488 . 
From Palestine also came assurances of loyalty. King Manasseh of Judah, the son and successor of Hezekiah, whose title is given as "king of the city of Judah" only, thus shewing that his authority extended no farther than the walls of Jerusalem, brought his tribute to Esarhaddon in person, probably at Tyre, in the same season, $677-676$. He was evidently regarded as a personage of quite minor importance, and to the insignificance of himself and his "kingdom" is due the fact of his long and undisturbed reign: Hezekiah must have died about 693, and fifty years later we find Manasseh still king of Judah.

This powerless monarch, content to vegetate interminably within the walls of Zion and feebly persecute the priests and prophets of Yahweh, whose courage and counsel had maintained his father in a position of no little dignity in the terrible days of Sennacherib, could be of no use to Tirhakah as an ally. And the princes of Edom, Moab, and Ammon were as powerless and as fast bound to Esarhaddon's chariot-wheels as was Manasseh. Sidon was destroyed. Tirhakah could do nothing but await the inevitable doom which was fast descending upon Egypt. The intrigues of the past sixty years had done nothing but rouse a determination in the mind of an Assyrian monarch who combined the policy of Sargon with the temerity of Sennacherib to destroy Egypt. We need not blame Esarhaddon for not having realized the impossibility of permanently annexing Egypt. The Assyrians were probably very imperfectly acquainted with the peculiarities of the Nilotes. They did not fully realize the enormous racial difference between the Egyptians and the fellow-Semites over whom they, the Assyrians, had domineered for centuries; they did not understand that they were about to conquer and hold down by the sword a people utterly alien from them, worshipping deities utterly different from theirs, a people, too, whose bitterest memory was that of an enslavement by Semites a thousand years before. Among the Asiatics the Assyrians could everywhere find friends as well as enemies, but every Egyptian was bound to be their fierce enemy, filled through every fibre of his being with loathing of them. Such a country and people could never be held down for long. Dead though Egyptian vigour had seemed to be for centuries, it could not but be roused by the domination of the new Hyksos, as in fact it was: the result of the 
Assyrian domination was the renascence under the Saïtes. Esarhaddon and Ashurbanipal missed, too, the one and only means by which they could have secured Egyptian loyalty: they never mounted the throne of the Pharaohs. Had they done this, had they assumed the insignia of Egyptian royalty, offered their fealty to Amen, entered the sacred Benbenchamber of $\mathrm{Ra}$ at Heliopolis, and come forth Sons of the Sun, it may be that the story of the end of the Assyrian empire might have been different from what it was. But an Assyrian king could no more do this than an ancient Pharaoh could have taken the hands of Bel at Babylon and become king of Sumer and Akkad had he conquered Karduniyash. The gulf fixed between the two races was too great: the mere idea of such a policy would have been rejected by Esarhaddon at once. And so the possibility of making Egypt an Assyrian province was lost. The recless Cambyses had no such scruples, and the wise Persian Darius saw that the policy into which Cambyses had blundered, hardly knowing what he was doing, was the only one by which Egypt could be secured to his empire. And by becoming Pharaoh Darius paved the way for the Macedonian and Roman dynasties. ${ }^{1}$

So Esarhaddon, knowing nothing of these things, and regarding the Egyptians merely as cowardly intriguers and worshippers of cats and dogs who submitted to the rule of black men, prepared for the step which was to go far to weaken his empire and bring about its fall. In 675 he had reconnoitred his desert route to the Egyptian frontier, but the war with Kastarit and Spâka summoned him back, and it was not till $670^{2}$ that at last (after a revolt of Baal of Tyre, instigated by Tirhakah (Taharka), had been subdued) the Assyrians invaded Egypt. The blow which the world had expected for half a century had fallen. Tirhakah could only meet inevitable defeat : but he fought before he fled. During his undisturbed reign of nearly twenty years, secured him probably by the prestige which the retreat of Sennacherib from Pelusium had unjustly given

1 See p. $57 \mathrm{I}$, post.

2 The supposed unsuccessful invasion of 673 , suggested by KNuDTzon, is doubtful. If it took place at all, it was probably not accompanied by the king in person, as he must have been busy with Kastarit. It was possibly an unlucky reconnoitring expedition in the desert. 
him, he had done nothing but build little temples. To organize a defence efficient enough to repel the legions of Assyria was impossible. With careful policy Esarhaddon had been at pains to conciliate the Beduin shêkhs of the desert, who supplied his army with water. So he crossed the wilderness safely, burst through the frontier defences, put Tirhakah and the ban of the Delta to flight, and reached Memphis. The ancient city resisted with fanatical fury, but it was stormed and given to the sword. The queen and the prince Utjanhor were captured, but Tirhakah fled to Thebes, whither Esarhaddon made no attempt to follow him, but received the submission of the princes of the Delta and of the valley immediately south of Memphis: a more extended military occupation was evidently impossible. Twenty kinglets were recognized and Assyrian garrisons placed in their cities to watch them, the henchmen of a "hard lord," the first really foreign conqueror that Egypt had known since the Hyksos. The Assyrian then returned to Assyria, setting up stelae at Samalla and at the mouth of the Nahr el-Kelb in Phoenicia, on which we see him standing in majesty, while Baal of Tyre and Tirhakah of Egypt, whose negroid features are malignantly caricatured, kneel in chains to lick the hem of his robe. With supreme irony, the Assyrian monument is placed immediately by the side of the ancient stele of Rameses II.

But Tirhakah had never been chained and was by no means inclined to lick the hem of Esarhaddon's robe. In the Upper Country he had summoned all to his aid, and no sooner had Esarhaddon left Egypt than he descended suddenly like a storm, took Memphis, and massacred the Assyrian garrisons. Furious, Esarhaddon started to return to Egypt, but was taken ill and died on the way (end of 669). He left a political testament by which he willed that his two sons Ashurbanipal and Shamash-shum-ukin should inherit the empire, the latter as king of Babylon under the general control of his elder brother the king of Assyria. The queen-dowager Nakîa, widow of Sennacherib and mother of Esarhaddon, for whom she had acted as regent during his absences from Assyria, issued a proclamation to the nation enjoining fidelity to the new kings. 


\section{The Reign of Ashurbanipal (669-626)}

Ashurbanipal invades Egypt (668)-Occupation of Thebes-Tirhakah again rcturns and is driven back (667)-Niku made viceroy of Egypt-Invasion of Tanutamon (663)-Submission of the Delta-The Assyrians reconquer Egypt and sack Thebes (66I)-Psamatik viceroy of Egypt-Embassy from Gyges of Lydia (660)Kimmerian raids : end of the Phrygian kingdom-The Elamite war-Battle of Tulliz -Revolt of Shamash-shum-ukin (652-648)-Assyrian invasion of Elam : capture of Susa (647) and destruction of Elam-Arab campaign (646)-Captivity of ManassehDeath of Gyges (650)-War with Tugdammi (Lygdamis) the Kimmerian-Embassy from Ardys (644)-Triumph of Ashurbanipal (642 ?) -Revolt of Egypt tinder Psamatik (c. 651)-He assumes the kingship, and founds the XXVIth Dynasty

ASHURBANIPAL ${ }^{1}$ immediately proceeded with the Egyptian war. In Syria he received the accession of contingents from the subject-states, including a small force sent by Manasseh of Judah. At Karbanit, within the Egyptian frontier, the armies met (668), and Tirhakah was again defeated. Memphis was occupied, apparently without a blow, and a Phoenician flotilla which had been collected for the purpose, and had entered the Nile, sailed up-stream to Thebes. The city was abandoned by Tirhakah, and surrendered by Montemhat the governor. Tirhakah fled to Napata. No harm seems to have been done to Thebes, as Montemhat had surrendered voluntarily. $\mathrm{He}$ was made a petty king of the Thebaid, like the Deltaprinces, whose names are given us in an interesting list of the governors and petty kings confirmed or appointed by Esarhaddon, and reinstated by Ashurbanipal. ${ }^{2}$

1 The ancient authorities for the reign of Ashurbanipal are many and various. Nost of the chief cylinder and other inscriptions are from Nineveh and are in the British Museum. See S. Alden Smith, Keilschrifttexte Asurbanipals (1887-89); George S.IITH, History of Assurbanipal ( $187 \mathrm{I})$. For other references, Rogers, Hist. Bab. Assyr. ii. 246.

2 The list is important also as giving us a very proximate idea of the contemporary pronunciation of Egyptian names. The chief of the princes was Niku (the name usually transcribed from the hieroglyphs as Nekau), prince of Mimpi (Memphis) and Sâi (Saïs). Next to him ranked an Assyrian, Sharruludari, governor of Șinu (Pelusium). Then followed Pishankhuru (Pshenhor), king of Nâtkhî (Natho), Paḳruru of Pishabtu (Pisapd), Bûkkunâni'pi (Baknenefi) of Khâtkhiribi (Athribis), Nâkhki of Khininshi (ITerakleopolis), Putubisti (Pețubast) of Sa'nu (Tanis), Unamunu (Unamon), also of Natho, Kharsiyêshu (I Iarsiese) of Șabnuti (Thebnuter, Sehennytos), Bûaima (Pimai) of Bindidi (Mendes), Shushinḳu (Sheshenḳ) of Bushiru (Busiris), Tabnâkhti (Tefnakhte) of Bunubu (Penub), Bûkkunâni'pi (Baknenefi) of Akhni (Itenit or Ehnet), Iptikhardishu (Ptah-crdi-su, "Ptah-liatligiven-him") of Pikhattikhurunpiki (Pi-Hathor-nebt-tep-ehe, Aphroditopolis), Nâkhtikhuruansini (Nekht-Hor-na.shenu) of Pisabdi'a (Pi-Sapd-'o, Șaft el-Hennah), 
Of these Delta-princes several were important enough to have lived in popular tradition, and in papyri of the Roman period we have the story of the Holy Boat of Amen and the Thirteen Asiatics and that of the Fight for the Armour of King Inarōs, which together form the Petubastis-Saga, the central figure of both stories being the Petubaste of Tanis who is mentioned in Ashurbanipal's list. Palsrur of Pisapd appears prominently in the saga, and the names of Tjeho and Pimai also were preserved. The atmosphere of the time, with its petty warring kinglets, was well preserved in these stories, and the tale of the fights with the Thirteen Asiatics, who with the aid of "the Horus-priest of Buto" seized the holy boat of Amen and desired to possess the revenues of the god, but were finally routed with the aid of Min-neb-mai, "prince of Elephantine,", is obviously reminiscent of the conquest of the country by the Assyrians in alliance with traitorous Egyptians, and the resistance to them of the Thebans and Ethiopians, the latter being personified in Min-neb-mai. The "Asiatics" are called Amu, "Shepherds," just as were the Hylssos: the Assyrians were the Hyksos of this later day. ${ }^{1}$

Bukurninîp (Bakennefi ?) of Pakhnuti, Șikhâ (Tjeho, Tachōs) of Shiyautu (Siût), Lamintu (Namilt) of Khimûni (Khemennu, Hermopolis), Ishpimâtu (Psamut) of Taîni (Thinis), and Mântimekhe (Montemhat) of Ni' (Thebes). The list follows no very careful geographical order; the Southern chiefs, certainly the prince of Thebes, are Ashurbanipal's additions to Esarhaddon's list. A confusion occurs in the case of the name of the third Bakennefi, which is given as an equivalent of the Assyrian Bukur-ninip, though not spelt as that Assyrian name would be. Prof. STEINDORFF points ont ("Die Assyrische Wiedergabe ägyptischer Namen," in the Beiträge zur Assyriologie, i. 384) that the name, formerly read "Mântimeankhe" and equated with a possible "Montemankh," is more probably "Mântimekhe," the inserted sign ax being due to a mistake of the Assyrian scribe (who took the following syllables ki-e to be the name of a god, which would have to have the sign AN, signifying divinity, before it), since there is no doubt that the prince of Thebes here mentioned is the well-known Montemhat. It used to be supposed that the name "Montemankh" was given to the Assyrian scribe in mistake for "Montemhat." But STEINDORFF's explanation is probably the correct one.

1 The Fight for the Armour of Inarōs was first published from a Demotic papyrus by Krall, Demotiscke Studien. New papyri have enabled Prof. SpIEgerberg to revise Krall's work and to give us the story of the Thirteen Asiatics (Der Sagenkreis des Königs Petubastis, Leipzig, I910). A popular translation of the story of the Armour of Inarōs will be found in MASPERo, Contes Populaires (3rd ed.), pp. $204 \mathrm{ff}$. While some of the historical names have survived, and with them much of the spirit of the seventh century has been preserved, in these stories, internal evidence shews that they were completely re-cast in the Ptolemaic period, when, probably, they were first written down, four centuries after the events to which they refer, as priestly editions of popular tales. As they stand they belong therefore to the 
Ashurbanipal's return to Assyria was the signal for Tirhakah's return from Napata. He had opened secret negotiations with the princes Niku of Saïs, Sharruludari of Pelusium, and Pakruru of Pisapd, which, however, were discovered, and Niku and Sharruludari were sent in chains to Nineveh, while Tirhakah, bereft of his allies, was easily driven back to Nubia by the Assyrian generals (667). On the arrival of the two captives at Nineveh we can have little doubt that the traitorous Assyrian Sharruludari was at once flayed alive, but Niku the Egyptian was not only spared but treated in an unprecedented manner, which shewed that Ashurbanipal inherited the diplomacy of Esarhaddon, and knew when to conciliate. Niku was treated as a king, dressed in costly raiment, and a ring was placed on his finger as a token of investiture; then, impressed, as was hoped, by the majesty and clemency of Assyria, he was sent back to Egypt as viceroy, while his son (probably he who was afterwards Psammetichos I) was given the Assyrian name of Nabu-shezibanni and made governor of Athribis.

The new policy worked well for a time, while the Ethiopians remained quiet. But in 663-662, the last year of Tirhakah and first of his successor Tanutamon, who was associated with him in that year, the young Ethiopian king (Tanutamon) invaded Egypt in force. We know the course of events from a triumphal stela set up by him at Napata on his return, in imitation of Piankhi. ${ }^{1}$ He met with no resistance in Upper Egypt, which looks as if Niku's viceroyalty had not extended very far south, certainly not so far as Thebes, which received Tanutamon with open arms. Memphis was taken with great slaughter of the Assyrian garrison, and the ban of the Delta, led by chiefs who could be but half-hearted in the cause of Assyria, was scattered. Niku was killed, and his son Psamatik (Psammetichos) fled to Assyria. Pakrur of Pisapd headed a deputation of the Delta dynasts which, at a durbar summoned by Tanutamon, tendered

literature of the Ptolemaic period, not to that of the seventh century. Our MSS. are of Roman age. The name Inarōs in the tale is probably due to a tradition of the Delta-king Inarōs who fought the Persians in the fourth century being confused with the tales of the princes who fought or were allied with the Assyrians. "Min. neb-mai" is not a historical name.

1 "The Stele of the Dream," from the dream, as recounted on the monument by Tanutamon, which prophesied his conquest of Egypt. A translation of this stela will be found in Records of the Past, iv. 8I (originally published by MARIETTE, Monuments Divers, 7, 8I ; last in BuDGE, Annals of Nubian Kings, pp. 7 I ff. 
to him their submission. Probably Pakrur had taken refuge in Nubia after the failure of the plot of five years before, had accompanied Tanutamon southwards, and was placed by him in authority over the Delta.

Ashurbanipal's punitive expedition was led by the king in person, and was intended to teach the Egyptians a lesson. The Delta was easily recovered, and Tandamane ${ }^{1}$ (as the Assyrians pronounced the name of Tanutamon) was defeated in Middle Egypt, and fled with a swiftness which makes ridiculous the inflated language of his triumphal stela at Napata. Then Thebes, which had been spared seven years before, was given up to sack and destruction. It was utterly plundered, and Ashurbanipal returned to Nineveh laden with loot and prisoners carried away captive: among the trophies are specially mentioned two large pillars or obelisks, "made of shining zakhalu-stone." 2 The city was probably set on fire, and remains of this destruction have recently been uncovered at Karnak, ${ }^{3}$ where the houses burnt probably by the Assyrian soldiery on this occasion can now be seen. A curious relic of the sack has also been discovered in the shape of an Assyrian helmet, found near the Ramesseum. ${ }^{4}$ Montemhat, the prince of Thebes, tells us in his funerary inscription ${ }^{5}$ how the whole city (as well as Upper Egypt generally) was wasted and the temples stripped of all their valuables, and how in the ensuing years he strove to do his best to restore at least the Theban temples to a little of their ancient splendour. But the city never recovered from the blow. Its temples remained the chief sanctuaries of Egypt, but the city itself was destroyed, its inhabitants had been carried off to Assyria and their place taken by unhappy Elamites; henceforward there was no Thebes

1 The reading Tandamane has been doubted, but there is little doubt that it is correct, as the supposed Egyptian form "Ruţ-amen," with which the former reading of the Assyrian signs as "Urdamane" was compared, seems not to be substantiated.

${ }^{2}$ Rassam Cylinder (Schrader, Keilinschr. Bibl. i. p. 169).

${ }^{3}$ By the excavations of M. Legrain. $\quad$ Petrie, Six Temples, Plate xxi.

${ }^{5}$ Latest publication by WREszinski, O.L.Z., I9IO, p. 386 , who, howerer, put the inscription down to $665-664$ B.C., in the reign of Tirhakah. It seems to me that the widespread destruction and desecration revealed by Montemhat can only be ascribed to the invasion of $66 \mathrm{r}$, in Tanutamon's reign, and that the inscription therefore is to be placed after that date, when the growing preoccupation of the Assyrians elsewhere and their increasing military weakness alone made the restoration of temples on so great a scale as Montemhat's an enterprise worth undertaking as likely to be brought to a successful conclusion. 
which could be the civil as well as the religious capital of Egypt. The "Diospolis" of the Graeco-Roman period was but a knot of villages clustering round the ancient and magnificent temples, nothing more.

Psamatik was restored to the position of viceroy, and Egypt, stunned by the destruction of Thebes, lay quiet. Tanutamon made no further attempt to conquer Egypt, and Psamatik secretly prepared for the day when he should be able to cast off the Assyrian yoke and himself ascend the throne of the Pharaohs. The opportunity came some ten years later. For the time, however, Assyria seemed supreme. On his return to Assyria after the defeat of Tanutamon, Ashurbanipal paid Ba'al of Tyre for his treachery by besieging the city, which finally surrendered. The other Phoenician cities, and Sandasharmu of Cilicia, probably the successor of Sanduarri, submitted. The tribute of Mugallu, king of Tabal, now appeared, and was followed by a solemn embassy from Gugu (Gyges), king of Lydia, "a far country across the sea, of which," says Ashurbanipal in his inscription, "the kings my fathers had not heard." I Assyrian prestige had reached its height, and had penetrated through the medium of the Greeks of Cyprus (the way through Anatolia was barred by the Kimmerians) to the shores of the Aegean.

Lydia had now taken the place of Phrygia as the chief Anatolian power. The Phrygian monarchy had broken up under the shock of collision with the Kimmerians, whose hordes, driven westward by Esarhaddon in 678, had carried destruction throughout the peninsula. The last Midas killed himself in despair (by drinking bull's blood, so the story went) at the ruin of his kingdom (about 675), and Gyges of Lydia succeeded to the chief place in Asia Minor and at the same time to the position of protagonist in the war with the Kimmerians, who were still ravaging the land, a horde of half-naked warriors riding wild steeds barebacked and swinging in their hands mighty swords with long and heavy leaf-shaped blades which could shear through many a well-made helm. ${ }^{2}$

The embassy to Ashurbanipal was probably moved by some

${ }^{1}$ Cylinder Inscription E, 11. I-I 2.

${ }^{2}$ As we see on the great Clazomenian sarcophagus in the British Museum, which is decorated with a frieze depicting combats between Ionian warriors and Kimmerians. A scene from this sarcophagus is illustrated Plate XXX. 2. 


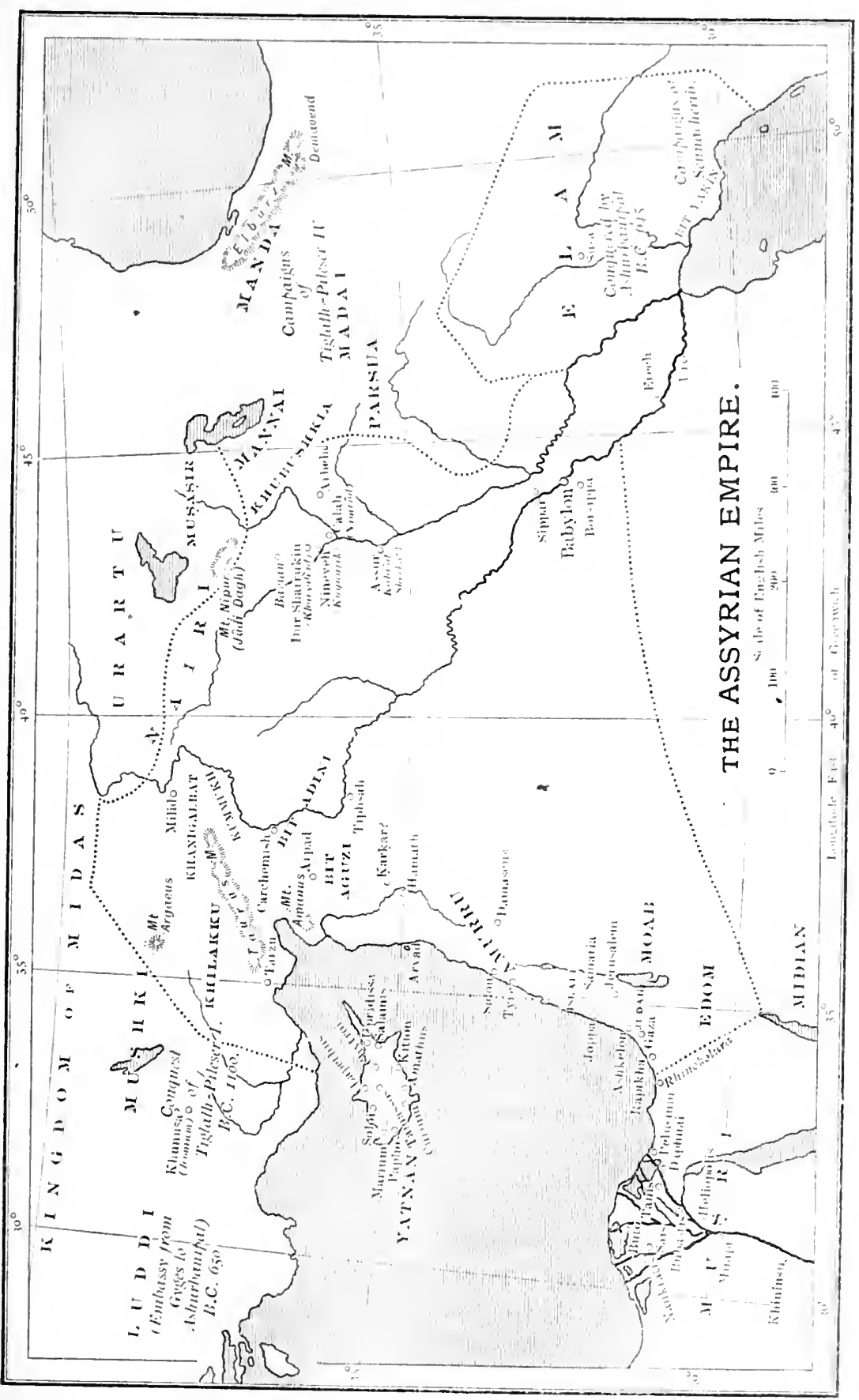



hope of active Assyrian assistance against these Gimirrai. Ashurbanipal gave none at the time, and later on was too busy with the struggle with Elam to be able to give any. Nevertheless Gyges regarded him as an ally against the barbarians, and on one occasion sent him two captive Kimmerian chiefs chained, as an appropriate present. The Lydian king was able to bring the war to a successful conclusion without Assyrian help, and this fact probably decided him later on that he could do without Assyrian friendship; hence his alliance with the revolted Psammetichos of Egypt.

The Elamite war was undoubtedly entered upon by Ashurbanipal with a light heart, after the oracles had assured him of victory. Apparently the war was provoked by an Elamite invasion of Babylonia, and Ashurbanipal seized the opportunity to make an end, as he thought, of Elam for ever, as his father had thought to make an end of Egypt. All seemed favourable for the enterprise: the empire seemed to be at the height of its power and prosperity; Egypt lay prostrate at the feet of Assyria; Lydia courted her friendship; Urartu was powerless; only Elam still defied her. Why, then, should not Elam also be destroyed, and a veritable pax assyriaca be ensured over the greater part of the Near East? The difficulties of the enterprise were underestimated; it was carried through to a successful conclusion in the end, but at terrible expense in men, which contributed even more than the strain of the retention of Egypt to bring about the collapse of the empire. Towards this event Assyria was fast moving; but it would have been a wise prophet who had dared to foretell it in the year 660, when she seemed to dominate the world.

Our information as to the course of events during the last half-century of Assyrian empire is somewhat defective owing to the absence of a list of limmi. ${ }^{1}$ The existing copies of the eponym-lists break off about this time, and no new list giving names after the year 666 has been found. We are therefore reduced to conjecture as to the precise dates of events fully described in the royal annals. The Elamite invasion of Babylonia seems to have taken place while Ashurbanipal was absent in Egypt, probably in 668, after his father's death. Peace was patched up, but Te-umman, the successor of Urtaki, the Elamite invader, was a person of even greater temerity than the latter, and 
again provoked war by making an unjustifiable demand for the surrender of all the male members of the Elamite royal house, who had fled to Assyria at the death of Urtaki. This may have taken place before the Egyptian expedition of 66I. On his return from the West Ashurbanipal found that the bold Te-umman had invaded Assyrian territory in revenge for the rejection of his demand, and was advancing from Dûr-Ilu up the Tigris valley directly upon the capital. Before the counteradvance of Ashurbanipal's army (the king himself did not lead it, though the official account pretends he did) he retired, and was finally manœuvred out of the plain into the mountains, whither the Assyrian army immediately followed him, driving him steadily back to Susa, where, at Tulliz on the river Ula (Eulaeus), a battle was fought in which Te-umman was killed. Ashurbanipal made Khumbanigash, son of Urtaki, king of Elam as a vassal of Assyria, with diminished territory, of which much was given as a fief to Tammaritu, son of Khumbanigash. The Assyrians then evacuated the country (in 658?), and Ashurbanipal commemorated his triumph by representing himself on the walls of his palace-corridor as feasting with his wife with the head of Te-umman suspended from a tree near by. ${ }^{1}$

The spirit of the Elamites was, however, by no means broken, and revived somewhat when an unlooked-for rebellion in Babylonia seemed to give a hope of the recovery of complete independence. In 652 Shamash-shum-ukin, brother of Ashurbanipal, and vassal-king of Babylonia, rebelled, with the object not merely of making himself independent of Assyria, but of conquering Assyria, deposing his brother, and becoming head of both nations himself, but with Babylon, instead of Nineveh, as the centre. Whether other causes beyond mere personal ambition caused Shumash-shum-ukin thus to break the relations which had existed for nineteen years between himself and his brother, it is difficult to say: but it is probable that his revolt was symptomatic of the tendency towards a renascence of Babylonia, now first apparent, which was to find its opportunity in the destruction of Assyria. The Babylonian king's preparations seem to have been of a very far-reaching kind, and he set on foot a general conspiracy among all the chief feudatories of the empire, extending from Elam to Judah and Phoenicia.

\footnotetext{
1 Brit. Mus., Assyrian Basement, No. 12 I.
} 
The conspiracy seems to have been discovered first by the Assyrian officials who actually controlled local government in Babylonia (the king having been a mere figure-head), with the result that Shamash-shum-ukin was forced to shew his hand, probably before he was ready. The rebellion broke out in Southern Babylonia, Ur and Erech were captured, the Chaldaeans appeared under a grandson of Merodach-baladan, and Khumbanigash of Elam also invaded with an army. But the Elamite camp was a mere hotbed of intriguc and murder; Khumbanigash was killed by his son Tammaritu, and he was driven away by Indabigash, ${ }^{1}$ who withdrew his army from Babylonia. The whole revolt was too badly organized to succeed. Ashurbanipal, encouraged by a favourable oracle from the moon-god, marched southward, blockaded Sippar, Kutha, and Babylon, and drove the Chaldaeans into Elam. The three cities were all stormed, and Shamash-shum-ukin set fire to his palace and perished in the flames (648). Ashurbanipal then himself "took the hands of Bcl" and ascended the Babylonian throne under the name of Kandalanu (the "Kineladanos" of Berossos). The Chaldaean army had been driven into Elam, and Ashurbanipal now demanded from Indabigash the surrender of its commander. This being refused, Ashurbanipal's army again entered Elam. Indabigash was murdered by his successor Khumbakhaldash III, who, however, was unable to stem the Assyrian advance. Susa was again captured (647) and this time was utterly destroyed; among its spoil is mentioned the statue of the goddess Nana of Erech, which had been carried away to Elam by Kudur-nankhundi 1635 years before, according to the computation of Ashurbanipal's scribes. ${ }^{2}$ It was now solemnly returned to its shrine. The grandson of Merodachbaladan avoided his inevitable surrender by Khumbakhaldash to Assyria by falling upon the sword of his shield-bearer. Finally Khumbakhaldash himself was captured, and led away captive. IVith his disappearance the kingdom of Elam, utterly destroyed, ceased to exist.

Ashurbanipal now turned to vengeance upon the Western friends of Shamash-shum-ukin. Chief among these had been the Arabs of the Haurân, the "dwellers in the tents of Kedar,"

1 This name is interesting, as it is possibly not Elamite, but Kassite or Persian (see p. 2OI).

2 See p. 190. 
and the Nabataeans. "The king of the land of Aribi," Yailu, who had been appointed by Esarha!ldon, had made common cause with Shamash-shum-ukin, and now an Assyrian army was sent against him. Defeated, and probably killed, he was succeeded by a certain Uaite, who, in no way inclined to submit to Assyria, partly turned the tables by raising war and revolt from Edom to the gates of Damascus. There, however, he was defeated, and fled. Betrayed, probably, to the Assyrians, he was carried off to Nineveh, where Ashurbanipal treated him, and Adiya his wife, and his ally the king of Kedar, literally as dogs; chaining them in kennels like watchdogs before his palace-door. ${ }^{1}$ A body of the Arabs who had actually reached Babylonia in order to aid Shamash-shum-ukin were defeated, and their leader Abiyate made king of "Aribi" instead of Uaite. No sooner was he back on the steppe than he rebelled in his turn, but was eventually subdued; and the Assyrians captured from him so many camels that they were sold in the markets of Nineveh for a mere song-" a half-shekel to a shekel of silver apiece."

It is probable that after the defeat of Uaite, which probably took place about 646 , occurred the captivity of Manasseh, king of Judah, which is recorded in the Book of Chronicles, ${ }^{2}$ though not in that of the Kings. The fact is not in the Assyrian annals either, but there can be little doubt that the account in Chronicles is a piece of genuine history, and that in his old age Manasseh was removed in chains to Babylon, no doubt to answer for a real or suspected participation in the schemes of Shamash-shumukin. $^{3}$ Eventually he returned to Jerusalem, where he died (638).

About the year 645 , also, must have occurred the chastisement of Tyre and Akko, for support which the Phoenicians, always restive under Assyrian rule, had given to the pretensions of Shamash-shum-ukin.

Not long after this the Kimmerians, who under their leader Tugdammi (the Dygdamis or Lygdamis of Strabo) ${ }^{4}$ had defeated

1 So Ashurbanipal tells us himself in one of his cylinder-inscriptions.

22 Chron. xxxiii. II.

${ }^{3}$ There may be some hint of this in the statement of the Chronicler that Manasseh was removed to Babylon instead, as would have been expected, to Nineveh. Perhaps he was taken to Babylon as an object-lesson in what happened to the foes of Assyria.

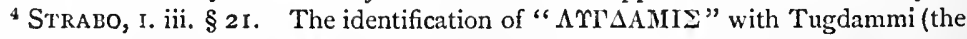
correct form being $\triangle \mathrm{T} \triangle \mathrm{AMI} \Sigma$ ) is due to Prof. SAYce (in the Academy', r893, p. 277). In spite of objections, I have no doubt that is correct. 
and slain Gyges of Lydia (about 650), had in their turn been defeated and driven out of Western Asia Minor by his son Ardys, assisted by the Ionians, whose cities Tugdammi had sacked. They then attempted to break back eastwards over the Taurus by way of the Cilician Gates. Here they were met and defeated (about 645) by the Assyrian army of Syria, returned from the war with Uaite; Tugdammi was killed, and the horde retreated northwards under his son Sandakhshatra. ${ }^{1}$ An embassy from Ardys, probably intended merely to compliment Ashurbanipal on this victory, was of course recorded by the Ninevite courtscribes as a servile offer to come under the Assyrian yoke.

After these victories, and the conclusion of amicable relations with Sarduris IV of Urartu, Ashurbanipal's active work came to an end. There is no doubt that he had not accompanied in person any campaigns since he went to Egypt in 66r, yet about the year 642 (approximately) he celebrated a solemn triumph at Nineveh, to thank the gods for the victories which had marked his twenty years of rule. He rode to the temple of Ishtar in a chariot to the yoke of which were harnessed Khumbakhaldash, the ex-king of Elam; Pa'e, a claimant of the Elamite throne, who had given the Assyrians some trouble after the defeat of Khumbakhaldash; Tammaritu, son of Urtaki, who had once reigned over Elam; and Uaite the Arab.

There was one significant absentee from this company of insulted prisoners. Psamatik of Egypt was not there. The revolt of Shamash-shum-ukin had given him the opportunity of throwing off the weak Assyrian control, and he had taken it (about 65I). ${ }^{2}$ Borrowing Ionian and Karian mercenaries from Gyges of Lydia $^{3}$ (who was by no means inclined to be complaisant to an Assyria weakened by civil war and unable to help him against the Kimmerians), in order to stiffen his native soldiery, Psamatik must easily have mastered any Assyrian garrisons that may still have remained in Egypt. Then, unopposed by the Ethiopians, he assumed the Double Crown, and his rule as pharaoh was soon acknowledged as far south as Syene. Ashurbanipal made no attempt to reduce him.

${ }^{1}$ Kassam Cylinder (see p. 503 n. 2). The name is Iranian, and so was probably adopted. It was probably the horde of Sandakhshatra that was destroyed by Madyes the Scyth (see p. 512).

2 He counted his regnal years as king from the death of Taharka in 663 .

${ }^{3}$ HDT. ii. 152. 
Probably he realized that constantly repeated wars of conquest in the Nile valley would soon use up his already terribly depleted army, and that without such continual conquests de novo it was impossible to keep a hold on the country. Egypt had remained quiet for as long as ten years, it was true, under the viceroyalty of Psamatik, but that was only because the Assyrian suzerainty was nowhere visible, and any Assyrian soldiers stationed there were no doubt regarded by the people as mercenaries in the pay of Psamatik. ${ }^{1} \quad$ We may be sure that the Saite prince in no way flaunted his loyalty to Ashurbanipal before the eyes of his fellow-countrymen.

So Egypt started on a new course of independent development, under a new dynasty, whose founder had shewn abundant signs of political sagacity, and was very different from the tumultuous, ineffective, and unintelligent Ethiopians. The Assyrian decision to abandon the Nile valley was a wise one. But, naturally, the renunciation of the imperial projects of Esarhaddon was not considered a particularly appropriate theme for the court chroniclers: Egypt is simply ignored by them.' If conciliatory ambassadors were expected from Psamatik with presents which might be construed as tribute, and enable the scribes to call him a vassal-king, none came; so Psamatik was not admitted to amity like Sarduris of Urartu. Neither did he figure bound to the imperial chariot-wheels in company with Uaite.

\section{The Destruction of Nineveh}

Death of Ashurbanipal (626)-Assyria at the mercy of the Northern tribes-The Scythian invasion-Revolt of Babylon-Nabopolassar (625?-604)-Necho of Egypt advances to the Euphrates-Nineveh destroyed by the Medes under Kyaxares (606) - Causes of the collapse of Assyria-Military exhaustion causes complete destructionAssyrian art-The Kuyunjik reliefs-The ivories of Nimrûd-Literature: Ashurbanipal as bibliophile: the library of Kuyunjik-Religion and superstition- "Nineveh the great is fallen, is fallen"

The Triumph of Ashurbanipal in 642 closes the history of his reign, so far as his own annals are concerned. All we know (and we do not know this from any contemporary Assyrian

'Much as the modern Egyptian fellahîn regard the British troops in Egypt as servants of "Effendina" (the Khedive).

2 There is only one indirect reference to Psamatik's revolt in a curious passage of Ashurbanipal's annals which ascribes the death of Gyges to imprecations called down upon him by the Assyrian king. The only reason for Ashurbanipal's curses can have been the help given by Gyges to Psamatik. 
source) is that he died in 626, leaving an impoverished and tottering empire to ephemeral successors. The Scythians had probably broken through the Euphrates gorges and overrun Syria ${ }^{1}$ before he died, and the buffer-state of Urartu was no longer able to make any opposition to the attacks of the Medes and Mannai. In his younger days Ashurbanipal had chastised Khshèri (Akhshêri) the king of Mannai, but, so far as we know, he had made no attempt thoroughly to terrorize the Kurdish tribes, as his forefathers would have done. No doubt his military power had become so weak owing to the losses in Elam that he was unable to contemplate a war of conquest in Kurdistan. Elam, which, in spite of its hostility to Assur, had for centuries acted as a buffer between the Mesopotamians and the restless young peoples of Iran, had been removed by Ashurbanipal's own act. Tardy friendship and perhaps alliance with Urartu strove to repair the error by the maintenance of a buffer in the north which should take the place of Mannai, long faithless to Assyria which had created it. But all was in vain, and at the close of Ashurbanipal's life the Medes under their king Uvakhshatra (Kyaxares) and the confederated tribes of the Umman-manda, as the mixed hordes of Scythians, Mannai, and Kimmerians in Armenia were called, were fast gathering behind the Jûdi Dagh, like vultures awaiting the last moments of their victim. That they attacked in 626, and that Ashurbanipal, the Sardanapallos of Greek legend, actually perished in the flames of his palace, is improbable. Ashurbanipal probably died of old age in his bed, like Louis XIV, amid disasters, doubtless, but not yet ruin. ${ }^{2}$ The Greek story of the death of Sardanapallos is probably a mixture of the historical suicide of Shamash-shum. ukin in 648 with the probable similar fate of Sin-shar-ishkun, the last king of Assyria, in 6об. It was natural that Ashurbanipal should represent to the Greek mind both the glory and the tragic end of the Assyrian empire, and that the "sad stories of the deaths of kings" that came to Greece from far Mesopotamia should be told of the great Sardanapallos, for whom

1 See p. 5 I2.

2 The supposed Median invasion under Phraortes about 634 , which was defeated, and that under Kyaxares about 630 , in which Nineveh was besieged but was rescued by the Scythians under Madyes, son of Protothyes, rest solely on the (good) authority of Herodotus (ii. $102 \mathrm{ff}$.). Both events are not impossible, and the Medes and Scyths do not seem to have been always on good terms, as the eventual murder of Madyes by Kyaxares shews. 


\section{THE ANCIENT HIS'TORY OF THE NEAR EAST}

no death could be more fitting than suicide amid the ruins of his glory.

But a blow had been struck between 628 and 626 which brought Assyria to her knees. The barbarian Scyths, led by Madyes, son of that Bartatua or Protothyes, "king of Shkûz," whom Esarhaddon had feared so much, ${ }^{1}$ poured over the empire in resistless swarms, ravaging it even to the borders of Egypt, where King Psamatik was fain to buy them off with rich bribes. ${ }^{2}$ The terror which they inspired in Judah, where the pious Josiah was now reigning, is well reflected in the prophecies of Jeremiah : "they lay hold on bow and spear, they are cruel and have no mercy, their voice roareth like the sea and they ride upon horses." 3 The village of Skythopolis in later times was the sole permanent relic of their invasion. But, as one pest kills another, Madyes in the course of his career of conquest is said to have disposed of the last of the older Kimmerian hordes that were still in the field. ${ }^{4}$ Herodotus relates how he was murdered by Kyaxares the Mede. ${ }^{5}$

The great raid lost the whole west to Assyria. After the waters of the invasion had subsided, Josiah of Judah established an independent dominion. Then Babylon went, at the death of Ashurbanipal. As Kandalânu he reigned as king of Babylon peacefully till his death. And his ephemeral successors were recognized in Babylonia as kings of Babylon. But the national spirit of Babylonia which had been deliberately revived by Esarhaddon and Shamash-shum-ukin, had found a leader in a native Babylonian who, probably not long after the death of Ashurbanipal, established himself in Babylon itself as king, under the name of Nabu-pal-usur (Nabopolassar). The Assyrian monarchs were too weak to eject him: Sin-shum-lishir and Ashur-êtil-ilâni seem to have been miserable successors to the great Sargonide emperors. Assyrian power was soon confined to the home-land and parts of Babylonia. To this shrunken heritage succeeded Sin-shar-

${ }^{1}$ See p. 495. $\quad 2$ HDT. i. 105. $\quad{ }^{3}$ Jer. vi. 23.

${ }^{4}$ Strabo, i. 6I, makes Madyes a Kimmerian, who drove the Trëres out of Asia Minor. He has probably confused the Kimmerians with the Scyths; the origin of this story may be that the Scyths defcated the Kimmerians or Treres.

${ }^{5}$ HDT. i. 106. Like M. MAspero (Passing of the Empires, p. 480, n. 5), I see no reason to doubt this story, which reeks of truth. Such an act on such an occasion would be quite characteristic of Iranians and Scyths. The Herodotean statement in the same chapter that the Scyths "ruled Asia" for twenty-eight years is hardly to be taken literally : but we have no means of checking or correcting it. 
ishkun. He reigned powcrless in Nineveh. The Median king Uvakhshatra (Kyaxares), who had succeeded in wclding his own people and the wild hordes of the Umman-manda into an alliance inspired by a common hatred of the tyrant empire, was awaiting his opportunity to advance. The opportunity came after 608, when the unopposed advance of the Egyptian king Necho to the Euphrates shewed that Assyria had finally become impotent. Nabopolassar took the same event as the sign for the establishment of the complete independence of Babylonia, and concluded an alliance with Kyaxares, with the destruction of Assyria as their common object. Kyaxares then descended to the final scene. In 606 , after a terrible siege, Nineveh was taken by storm, and the last king of Assyria perished in the holocaust of his palace, his courtiers, and his slaves.

The dramatic collapse of Assyria has furnished a theme for many a moralist from the time of Nahum the prophet, in whose lifetime Nineveh fell, to the present day. The tale of the destruction of the mistress of the world was speedily borne to the four quarters of Asia, and the astonishment which it created is evident in all the ancient references to it. We too, at the present day, feel something of this astonishment. Yet this portentous event, as it seemed to be, was the natural and inevitable result of the history of the Assyrian state. The very vigour and energy of the Assyrian kings and their people were the cause of their comparatively speedy downfall. The Assyrians had always been a manly nation: their kings and nobles were devoted to the chase and to war with a keenness which no other people of Near Asia had ever shewed; the people were hardy cultivators and farmers, splendid material for the creation of an incomparable army. This the military capacity of the kings created. So long as their conquests were not too far extended, did not demand too much blood from their subjects, and were not absolutely continuous, their empire was not weakened by the difficulty of controlling distant possessions, and could recuperate itself between its wars of conquest. But the terrible succession of war-lords inaugurated by Tiglath-pileser IV broke the back of the nation. Their insatiable lust of universal dominion pushed them ever forward, till they strained their power to breaking-point by the attempt to rule entirely alien and distant conquests such as Egypt, thus weakening their control over the mountain-regions 


\section{I4 THE ANCIENT HISTORY OF THE NEAR EAST}

immediately north of Assyria itself, that northern frontier which was ever the Achilles' heel of their empire. And the incessant demand for more men and more blood from their own people naturally meant speedy exhaustion even to the hardy Assyrians. The signs of exhaustion are already evident in the time of Sennacherib, who first recruited soldiers from the subject-peoples, to fill up the gaps in the army. This meant the admission of less valiant and less trustworthy elements into the fighting-line. The quality of the troops deteriorated swiftly towards the end, and when, after the slaughter of the Elamite war, Ashurbanipal was left with an army which must have contained but a kernel of genuine Assyrian warriors, he dared not pit them against the Ionian and Karian mercenaries of Psammetichos: so Egypt was abandoned. The confession that the Assyrian troops were no longer even the equals of the western warriors, whom under Sennacherib they had defeated in Cilicia (though even then with great difficulty), meant much. Towards the end of his reign, Ashurbanipal can have had but a shadow of the old Assyrian fighting-force. And in Assyria the degeneracy and disappearance of the army meant the degeneracy and disappearance of the nation. The army was the nation, and when Nineveh was destroyed, literally the Assyrian nation was destroyed also. Babylon and Thebes had been destroyed, but had soon risen again; their peoples continued to exist, and soon revived to resume their national life. But not merely Nineveh, Assyria never rose again, and the final blow killed her. No peace-organization of any proper kind existed to keep the empire together, as the successors of Tiglath-pileser IV were not intelligent enough to develop his system, which in the time of Sennacherib had probably degenerated into military force and nothing else. At home nothing much in the way of organization other than military existed, probably, above the village communities. ${ }^{1}$

The contrast to Egypt and Babylonia, whose age-long civil administrations kept these kingdoms together as indestructible units even when under foreign rule, is great.

${ }^{1}$ In the reign of Ashurbanipal (65I and 648 B.c.) we find cuneiform tablets used in Palestine and discovered at Gezer (P.E.F.Q.S., 1904, $207 \mathrm{ff} ., 229 \mathrm{ff}$; 1905, 185, 206-10, 272), dated in the name of the saknu of Carchemish. The governor-general (saknu) was practically independent as regards the affairs of his government, and here we find him almost independent in form as well as in fact. 


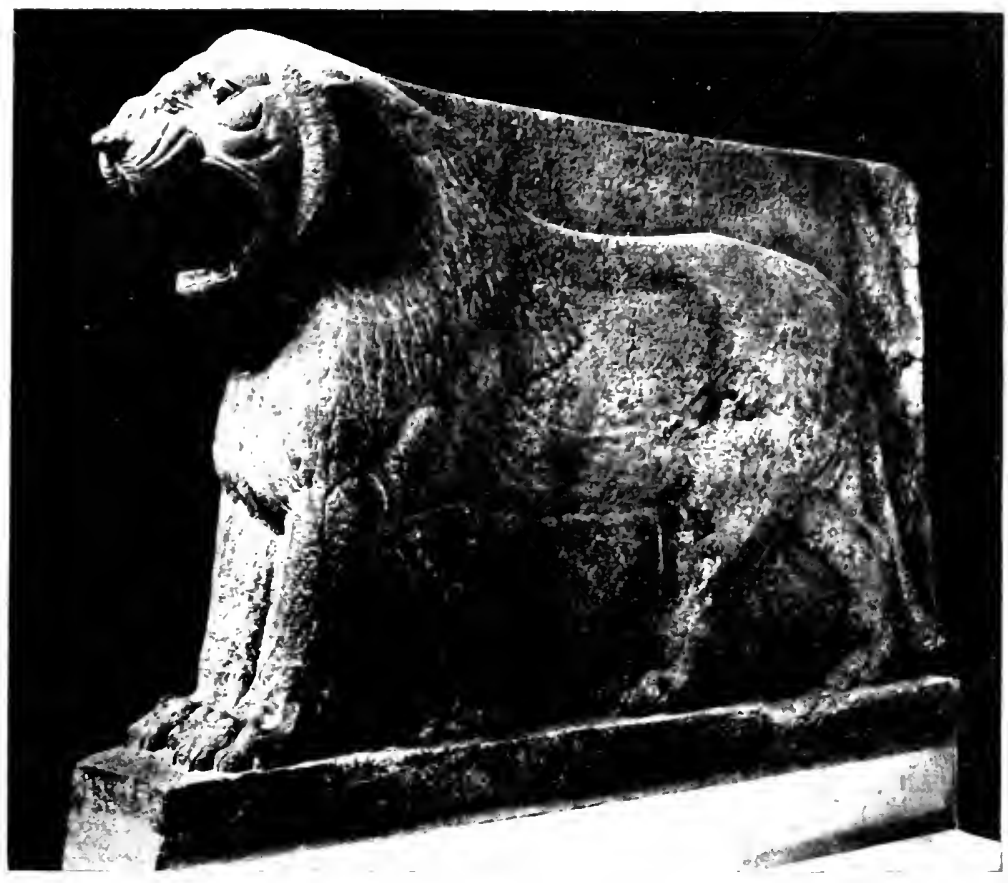

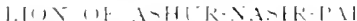

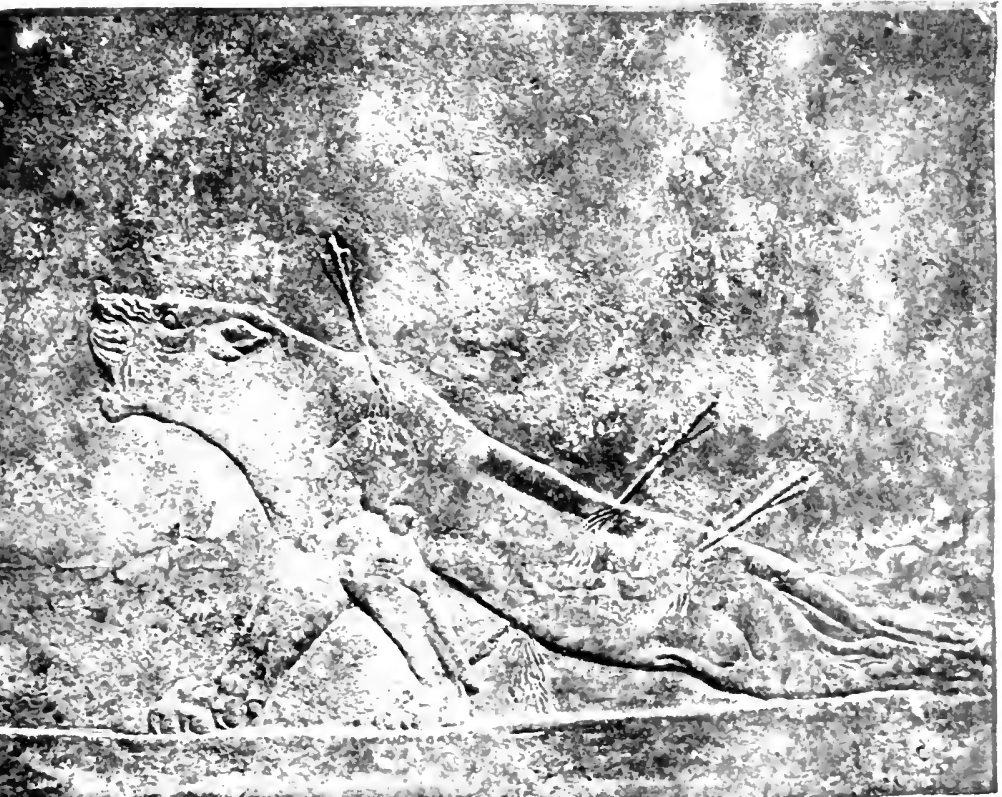



That under more intelligent monarchs Assyria might have becomc a really great nation is evident from the fact that in the last years of her existence, when the army had become weakened and the king no longer went forth to war, her art and general culture took the opportunity to develop in a very. remarkable way. The sculptures of the palace of Ashurbanipal at Nineveh mark great advance on older Assyrian art (as that of Ashurnasirpal's time), and in the representation of animals and the chase the king's sculptors shewed a power of observation, a love of truth, and a skilful hand previously unexampled in ancient art. ${ }^{1}$ The crudenesses of prehistoric Greek art, in spite of its naturalism, the inequalities and deadening conventions of Egyptian art, prevented the Minoan and Nilotic artists from ever producing anything so good as the smitten lioness (Plate XXVIII. 2) or the wild horses of Ashurbanipal's reliefs. The heads of the chariot-horses, the beautiful Nisaean steeds from Media, were designed and carved by the unknown Ninevite sculptor with a mastery that even the horses of the frieze of the Parthenon can hardly excel. There is stiffncss and conventionality in the human figures, there is laboured detail of clothes and accoutrements; but the animals are wonderful. The older carved ivories from Nimrûd shew, too, what the Assyrian craftsman could do; and we need not seek for Phoenician origins or for Ionian inspiration for his work. ${ }^{2}$

Of literature, as we understand it, the Assyrians had little

${ }^{1}$ See the magnificent reliefs in the gallery of the Assyrian Basement of the British Museum. Cf. the lion-hunt of Ashurnasirpal (Pl. XXV. I) with these.

2 The Phoenician has lost his old glamour now, and we know him for but a sorry imitator who could never have made such fine things; the Ionian borrowed oriental ideas to mingle with his Mycenaean art-tradition: he received from Nineveh rather than gave. It has been supposed that it was a Syrian art that produced these works. Granted the existence of a North-Syrian art-centre, this would undoubtedly have largely influenced Assyrian work as well as been influenced by it, and one can see more than possible Syrian influence in the Nimrûd carvings, as we can see it perhaps also in the Cyprian carvings from Enkomi. Some of Ashurnașirpal's ivory carvers may, how. cver, have been native Assyrians, who produced their carvings at Nineveh. Egyptian influence is strongly apparent in their work : this may have been transmitted through l'hoenicia or Syria, but quite as probably reached Assyria through the highly civilized kingdom of Israel, which was always strongly influenced in its culture by Egypt. But in Ashurnașirpal's stone sculpture we see no Egyptian influence, which seems to have been confined to smaller objects of art. And Ashurbanipal's sculpture is the descendant, wonderfully developed, of that of Ashurnașirpal. No foreign influence is to be seen in it : certainly Ashurbanipal's sculptors cannot have owed a whit of their inspiration to any Greek, Ihoenician, or Syrian of the seventh century. Their art was no Mischkunst, but pure Assyrian, descended from the art of Babylonia. 


\section{I6 THE ANCIEN'T HISTORY OF THE NEAR EAST}

notion, whereas the Egyptians had; and the fire of Hebrew poetry was unknown to them. What they possessed in the way of a literature was all taken at second hand from the Babylonians, who themselves possessed little that can be dignified by the name. But they had inherited or acquired something of the cultivated Babylonian antiquarian spirit, and Ashurbanipal, the savage torturer of his prisoners, was a zealous bibliophile, and collected the splendid library of Assyrian and Babylonian clay tablets which is now the greatest archaeological treasure possessed by the British nation.

IVith this artistic development and love of the antique went hand in hand a great increase both of luxury and of superstition. Sennacherib was the first Sargonid who no longer went forth to war himself, but stayed at home in his palace and took all the credit of the victories that his generals won. Esarhaddon was more energetic in the field, but his Babylonian sympathies awoke in him a vein of religiosity that was unknown to Tiglathpileser IV, and both he and his son Ashurbanipal were unusually superstitious for Assyrians, and always invoked the oracle of Ishtar of Arbela before undertaking any war. This religiosity shewed a loss of self-confidence and of the old simple belief in the impossibility of defeat, that was significant of degeneracy.

So Assyria and her kings went down to Sheol amid the curses of the nations. Only half a century after Thebes had been destroyed, "populous No-Amon, situate in the midst of the waters," 1 Nineveh the destroyer had been dealt the same stroke of fate. Can we doubt that the Egyptian saw in this the vengeance of his outraged deities, and derived from it a renewed belief in their power and a renewed self-respect that was to go so far to restore Egypt to her old position of authority among the nations? Less than a century since Rabshakeh had jeered at Hezekiah in the hearing of the people on the wall, his successors had fled away "like the locusts" when the sun arose, "and their place was not known where they were." So the prophet Nahum blazed forth in splendid poetry the good news of the fall of the arch-enemy of Yahweh and of Judah: "Behold upon the mountains the feet of him that bringeth good tidings, that publisheth peace! O Judah, keep thy solemn feasts, perform thy vows, for the wicked shall no

\footnotetext{
i Nahum iii. 8.
} 
(F) IE KIN

[ ILAM, ETS

Khumbanigash 
CHRONOLOGICAL TABLE GF TAL KINGS OF ASSYRIA, BABYLONIA, PERSIA, ETC, AND THEIR CONTEMIORARIES (MEN AND EVEXTS) FROM 950 B.C. TO TIIE REIGN OF DARIUS I

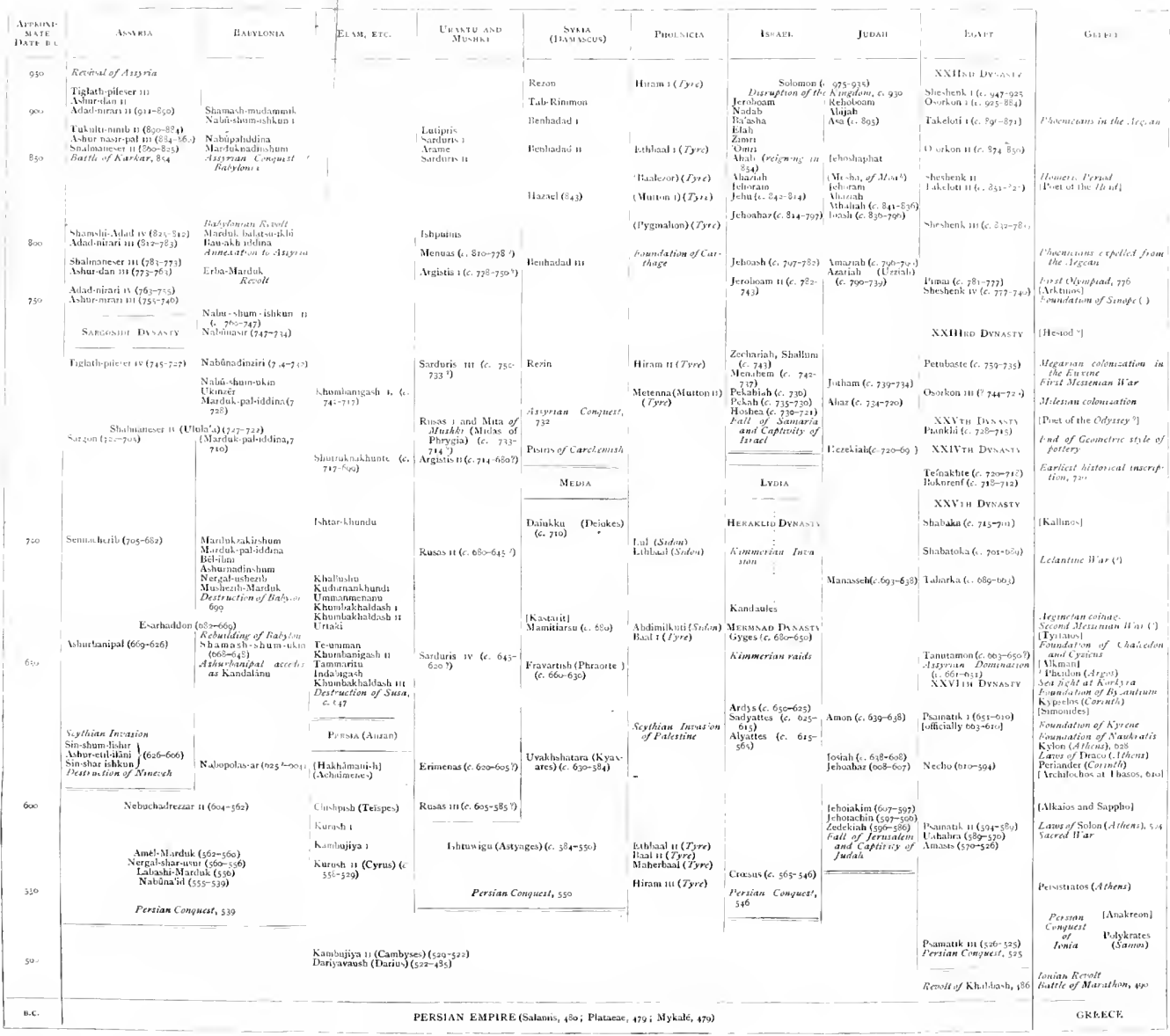


more pass through thee; he is utterly cut off. . . The Lord is good; a stronghold in the day of trouble; and he knoweth them that trust in him.... Woe to the bloody city.... Behold, I am against thee, saith the Lord of Hosts, and I will discover thy skirts upon thy face, and I will shew the nations thy nakedness and the kingdoms thy shame. And I will cast abominable filth upon thee, and make thee vile, and set thee as a gazing-stock. And it shall come to pass, that all they that look upon thee shall flee from thee, and say, Nineveh is laid waste; who will bemoan her?.. Behold, thy people in the midst of thee are women, the gates of thy land shall be set wide open unto thine enemies: the fire shall devour thy walls. . . Thy shepherds slumber, O King of Assyria; thy nobles shall dwell in the dust; thy people is scattered upon the mountains, and no man gathereth them. There is no healing of thy hurt; thy wound is grievous; all that bear the bruit of thee shall clap their hands over thee; for upon whom hath not thy wickedness passed continually?" 


\section{CHAPTER XI}

\section{THE RENOVATION OF EGYPT AND RENASCENCE OF GREECE}

Archaism in Egypt and Babylonia-Youth of Greece and Persia-The sons of Yavan : piracy and trade-The Phoenicians in the Aegean-Corinth-The KabeiroiWithdrawal of the Phoenicians-Ionian sailors in the Euxine : the Odyssey-Tales of Odysseus transferred to the West-The Odyssey and Egypt-Dates of Ionian colonies - Causes of colonization : political changes in the Greek states-Rule of the Aristocrats-Increase of population and necessity for emigration-Magna Graecia and Sicily

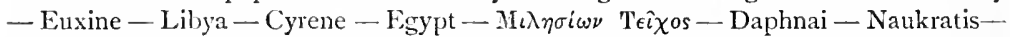
Growth of feeling of Hellenic nationality in the tracling factories-Influence of Delphi - The Sacred War-Trading and religious leagues: Amphiktionies-The Eretrian and Chalkidic alliance-systems-The Lelantine war (c. 700 B.c.)-The TyrantsSpartan and Argive kings: Pheidon-Revival of culture in Ionia-The alphabet and coinage-Proto-Corinthian and later Ceramic styles-The Lakonian style-Metalworking-Egyptian influence in sculpture-Assyrian influences-Architecture-The Egyptian renovation-Political arrangements-Prosperity-Ionia and Lydia-Greek indifference to events in Asia

T might seem that we could use the same term "Renascence" to designate the revivification of the Egyptian state under the rule of the Saites and the awakening to new life of civilization in Greece. But the two phenomena were very different from each other. One was a merely artificial revivification of an old Egypt long passed away, the other was a natural re-florescencc of civilization in a shape very different from the Aegean culture of ancient days. The effect of the Egyptian renovation was but to intensify and emphasize the old age of Egypt, who had but painted her withered cheeks with artificial roses of youth; the Greek renascence was a true re-birth, the new Greece, ignorant of her forebears, was born anew as a young child. The archaistic movement which aimed at reproducing the ancient Egypt of the days before the Empire $^{1}$ had begun in

1 This archaism is strongly marked in the decoration of the tombs of this period, which is imitated from that of the tombs of the Old Kingdom. Often whole scenes $5 \times 8$ 
the time of Ethiopian domination. It set in, apparently, as a fashion of protest against the outworn and vulgarized culture and art of the Empire. The imperial tradition had not in the long run served Egypt, who had lost her empire and seen her own land overrun by conquerors. In the bitterness of subjection the Egyptians turned from the Empire towards the simple old days, as they seemed, of the Pyramid-Builders. Names and titles of that period reappeared, a kind of archaistic crusade sprang up, and eventually, when Psamatik I restored the rule of the Pharaohs over the whole land, the archaistic mode was officially adopted by the state. It was as if a degenerate and worn-out England of the future, tired of the imperial pomp, were to go back for her inspiration to the Anglo-Saxon period, were to imitate that period in every way, in art, in costume, and in manners, to replace the dignitaries of the present day by "ealdormen," "jarls," and "thegns," and substitute for the Imperial Parliament an English comic-opera "Witenagemot." ${ }^{1}$ Such was the artifically rejuvenated state which Psamatik called into being on his attainment of complete independence of Assyria (650 B.C.). Babylonia also was seized at this time with the craze for archaism. The restored kingdom of Nabopolassar, of which we shall follow the fortunes in the next chapter, was marked, like the restored kingdom of Psamatik, by a revival of old days and old ways before the Assyrian imperialism had existed. And Nabonidus, the last king of the last Babylonian dynasty, was, as we shall see, a learned archaeologist, an enthusiastic collector of ancient divine images, and energetic preserver of the most ancient temples.

And in to the midst of this artificial juvenility of Egypt and Babylonia came the real youth of Greece and Persia. The Persian conquest of the Near East, and the final collision

are directly copied from the reliefs of an ancient tomb, as in the case of those of a Saite magnate named $\mathrm{Aba}$ at Thebes, which were so carefully copied from the pictures in the tomb of a vith Dynasty noble of the same name at Deir el-Gebrâwi, that it has bcen possible to reconstitute damaged scenes in one tomb from the evidence of the other ! (Murray's Guide to Egypt, eleventh edition, I907, p. 470). The Theban noble of the Saite period was evidently inspired to this conceit by the identity of his name with that of the ancient, three thousand years before his time, whose tomb was open to Saite sightseers as it is to those of the present day. Such copies are sometimes only distinguishable from real work of the Old Kingdom by a delicacy of execution characteristic of the Saites, and different from the virile touch of the ancient sculptors (see p. 540, n. 2).

1 And this may happen yet. We are hardly yet in our Ramesside period. 
between Greece and Persia, belong to the next and last chapter of this book. With it our story ends. But before the Greeks came into conflict with the Persians they had established their new civilization on the coasts of the Levant and throughout the whole Mediterranean. It is the course of this expansion of renascent Greece that we have to trace as succinctly as possible. The internal affairs of Greece, and especially of the Hellenic mainland, call for our attention only in so far as they bear directly upon the general progress of Hellenic culture, especially towards the east and south, or affect directly the approach of the conflict with Persia. With the history of the Greek colonies of Magna Graecia and Sicily after their foundation we have no concern till Gelon of Syracuse defeats the Carthaginians and aspires to lead Greece against Persia.

The amalgamation of the Indo-European Greek-speakers from the north with the non-Aryan "Minoans" and "Aegeans" of the south had, as we have seen, already combined to form the Greek nation in the Homeric period. The new Aryan deities of the Hellenes either remained unchanged (like Hera, Hestia, Ares, and Apollo), or were identified with the older gods of the land (like Zeus himself), or were taken over unchanged (like Poseidon, Aphrodite, Artemis, Rhea, and Athene). In the Greek religion of the classical period we see a complete combination of the old and the new systems, though naturally those societies, as Athens, Crete, and Arcadia, which were either more strongly tinged with the ancient blood or were more conservative in spirit, clung more to the descendants of the old gods, while the more Aryan-Hellenic a Greek state was the more fervently it worshipped Apollo. ${ }^{1}$ The policy of the new-comers

${ }^{1}$ I can make little apology for thus labelling Greek deities as Hellenic and preHellenic. To those who have an eye for such distinctions of character the Aryan character of Hera, Hestia, Ares and Apollo is evident, while Poseidon, Aphrodite, Artemis, Rhea, and Athene are as evidently pre-Aryan. The Aryan names of Hera "the mistress," of Ares, " the noble " (arya) war-god, of Apollo "the slayer," are plain. Apollo, too, is Aryan by his golden hair; he was no god of the dark Minoans. And I cannot accept WILAMOWITZ-MÖLLENDORFF's well-known theory of his Lycian origin. Though the legend that the worship of Apollo at Delos was brought from Crete may point to some identification with a Minoan male deity of the Attis-type, yet here again he may have been simply brought by Cretan Dorians, who had brought him to Crete. Hestia, the hearth-goddess, is surely Aryan. Zeus has an Aryan name, but he was a compound of the Aryan father-god of the sky (Dyaus, Ju-piter) with the male Attis-like god of Crete, the son and consort of Rhea, who was born and reared on Ida and died on luktas, and in Crete preserved his old name, Velchanos. That Rhea 
conquered entircly. In all probability the older people had had little feeling for civic freedom or desire to take direct part in the government of themselves. Of course, we know nothing directly on this point, but the definitely Aryan character of classical Greek institutions indicates a deficiency of political ideas among the pre-Aryan Greeks analogous to the similar deficiency among the peoples of Egypt and the Orient. When the Aryan Greelss came they were not, of course, savages, and brought some culture of their own. But the civilization of the older race conquered, and its presence brought about the sudden renascence of Greek culture. For a time, however, all was chaos, as we have seen, ${ }^{1}$ and a reflection of this period of confusion may be found in the fact that during several centuries communication between Greece and Egypt, which in the old days had been from the beginning of things so regular, ceased to be so. Though one or two Egyptian scarabs have been found with Geometric (Dipylon) objects in Greece, ${ }^{2}$ not a single pot or sherd of the Geometric style has yet been found in Egypt. ${ }^{3}$ There was but little communication. Phoenician traders and slavers there were who carried on a fitful commerce with the Orient among the warring tribes of Greece, but they only brought goods to barter for slaves; they took away nothing else, seemingly. But amid this confusion the soul of Greece was striving to awaken, and in the Homeric society of Ionia, whither first Cretan colonists, ${ }^{4}$ and then Minoans and minoized "Ionians" from the Peloponnese ${ }^{5}$ and Attica had carried the remains of Minoan culture, the new Greek civilization was arising. The dorized peoples of Greece proper were slow to gain civilization. We must not be too sure that recent discoveries have proved that the Spartans were originally as

of Crete is the oild Mother-goddess of the Minoans, that Aphrodite is another form of her (only connected with the Syrian Ashtoreth, not identical with her), that Artemis is a Cretan huntress, Diktynna or Britomartis, and that Athena is the Minoan war-goddess (opposed to the Aryan war-god Ares), does not require much imagination to see. And that Poseidon is Minoan, in spite of his contest with Athena for the possession of Athens, is more probable than that he was Aryan. I make then no apology for having in my Oldest Civilization of Grecce said: "The iepòs $\gamma$ ámos of Pelasgic Zeus and Achaian IIera at Knossos (DroD. v. 72) may serve for us as an allegory of that mingling of Pelasgian and Aryan which produced the Hellenic race" (p. 205).

${ }^{3} \mathrm{P} .75$.

${ }^{2}$ See 'E $\phi$. 'A $\rho \chi$. ISg8, col. I20 (from Eleusis). Also a XIXth Dynasty scarab from a Geometric tomb at Boeotian Thebes is in the British Museum.
${ }^{3}$ HALL, O.C.G., pp. $297 \mathrm{f}$.
${ }^{4}$ See p. 69, n. I.
${ }^{5}$ See p. 68. 
civilized as the Ionians, and only adopted their historic military semi-barbarism artificially. ${ }^{1}$ For in Crete the Dorians had a similar $\alpha \gamma \omega \gamma \dot{\eta}$, which could hardly be aught but a descendant of the ancient militarism of the most barbarous stream (the Illyrian) of the invading Aryans. ${ }^{2}$ Still it is evident that the Laconians did eventually take part in the renascence of culture, and they received their impetus, apparently, from Ionia. ${ }^{3}$ And from Ionia came the great movement of Greek expansion that altered the history of the world.

The first effects of the Greek renascence and expansion were felt by the Semitic traders who had for so long monopolized the trade of the Mediterranean. By the end of the seventh century the Ionians had not only driven the Phoenicians from Greek seas, but had cut the lines of Phoenician trade in half, dividing Carthage and the colonies of Spain and Sicily from the mothercountry and permanently laming their commerce. For the Greek trader was also commonly a pirate, and probably had as little compunction in warring down Phoenician competitors as ever had Elizabethan adventurers in capturing the galleons of Spain. Hence a Phoenician-Carthaginian hatred for the men of Yavan or Ionia that profoundly influenced the counsels of Persian overlords when the day came for the subjugation of Ionia after the defeat of Croesus.

In the eleventh century, as we have seen, ${ }^{4}$ the Phoenician merchants were supreme in the Delta ports of Egypt, and in the whole Levant. Greek pirates such as the Tjakaray probably did not trade on any great scale: Greece was in confusion and

1 This thesis has recently been maintained by Mr. Guy Dickins, one of the excavators at Sparta, in a paper (J.H.S. xxxii. (I9I2) pp. I ff.) entitled "Chilon and the Growth of Spartan Policy." But I think he exaggerates the extent of the Spartan culture of the early classical period as shewn by the Spartan excavations: the so-called "Laconian" (ex-"Cyrenaic") pottery is certainly inspired by Ionian models. What I think Chilon did was to return to an ancient Spartan virtue which had become somewhat corrupted. The "virtue" was Dorian, as Crete shews.

${ }^{2}$ On the Illyrian stratum of the Dorians, see p. 74. The Albanian type of head is very marked still in Crete (HAwes, B.S.A. Ann. xvi. pp. $258 \mathrm{ff}$.). The dullness of Dorians when unilluminated by Ionian influence is well shewn by the later history of Crete, which took no part in Greek activity (for the Delphic advice to them to abstain from sending help against Xerxes, see IIDT. vii. 169), except to help Ionian Athens against Dorian Sicily for money (THUk. vii. 57), till its end, when they fought the Romans as fiercely as ever Albanians did Turks, to'save their own narrow freedom. Crete was barbarized by the Dorians.
${ }^{3}$ See p. 534.
${ }^{4}$ Sec p. 321, n. I. 
decadence, fast falling into barbarism. The Sidonian traders took their opportunity and, taking the risk of pirates, penetrated into the Aegean and had what trade there was. They established factories here and there, one cannot doubt, and certain Semitic names, as well as the tradition of their presence, bear out the probability. Corinth, for instance, which so far as we know was not a place of importance in the Mycenaean age, and has few heroic traditions, but is definitely associated in legend with a goddess of Semitic appearance (Medeia) and a god with a Phoenician name (Melikertes), was probably a Phoenician foundation. It may well have been the Phoenician traders who first saw the importance of the geographical position of Corinth on the Isthmus and made it an emporium of commerce between the two seas. ${ }^{1}$ Besides the case of Corinth, we have probable Phoenician traces, either in legend or in placenames, at Thera and Kythera, where the purple-fishery had attracted them; at Samos and Adramyttion on the Asiatic coast, whose names are certainly Semitic; in Imbros and Samothrace, seats of the worship of the Kabeiroi, the Kcbirim

2 Many arguments for l'hoenician activity in the Aegean ean now be laken as referring equally well to the Minoan Grecks; in view of what we now are beginning to know of carly Aegean religion, it is unsafe to regard the worship of an Astarte-like soddess, for instance, as indicative of Phoenician infuence. Aphrodite of Paphos may have been a Minoan, not a Phoenician deity at all. Also many tales of the old Alinoans seem, on account of their non-Ilellenic aspect, to have becr transferred by the later Greeks to Phoenician actors: such is without doubt the tale of the Kadmeans at Boeotian Thebes. But we have good reason to suppose that Phoenician traders did actually establish themselves in the Aegean; the fact that they did so is agreed upon by the aneient authorities, and it was natural that to them, whose activity was so much nearer the historical period in time, much of what was really the work of the Minoans should have been referred. It is true that, as MR. IlogarTh says (Ionia and the East, p. 84), no archacological traces of the Phoenicians have yet been found in Grecce (since we know that Kameiros was not a Phoenician but a Graeco-Egyptian (Naukratite) trading station). But what should we find? What traces have the Phoenicians left in their own country, but a few inscriptions and clumsily-imitated sarcophagi and seals? We shonld not cxpect any of these in a mere trading-factory, or anything but the products of other people. The Phoenicians did not leave much trace of themselves anywhere. But while not unduly depreciating the activity of the Phoenicians, one must bewarc of falling into the opposite extreme and of attributing to them a far greater influence and impcrtance in ancient history than they ever possessed. This exaggeration of the lhoenicians is somewhat old-fashioned nowalays, it is true, but among French literary (rather than archacological) writers on ancient history this (to us) out-of-date view is apparently still regarded as holding the field, as we see from reading M. Victor BERARD's extremely interesting but very un-archaeological and unscientific book, Les Phénicicurs et l'Odyssée. 


\section{THE ANCIEN'T HISTORY OF THE NEAR EAST}

or "Great Ones"; and in Thasos and Thrace, where Phoenician miners delved for gold even as late as the seventh century.

By the eighth century, however, their general activity in the Aegean must already have come to an end. In the Iliad they are already in process of withdrawal, though they still retain their commercial monopoly. In the course of the next century, 750-650, they disappeared from Greece, and are described in the Odyssey as trading chiefly outside Greek waters. The founding of Utica and Carthage a century earlier, and the conquest of Phoenicia by the Assyrians just at this period, no cloubt had much to do with this divagation of their maritime activity. And the Ionian traders, freed from Phoenician competition in their own waters, now passed beyond them into seas the monopoly of Tyre and Sidon since the destruction of the ancient Keftian power in Crete. ${ }^{1}$

The stories of the first Ionian shipmen who ventured out of the Aegean are enshrined in the great poem of the Ody'ssey, of which the oldest parts are probably no older than the ninth century. The original poem no doubt described a voyage of an Odysseus in the Black Sea, ${ }^{2}$ like the legend of the Argonauts. And it was probably to the Black Sea that the earliest maritime efforts of the renascent Greeks were directed. Later, as they came more into possession of their own seas, and the western waters attracted their attention, the tales of the sea-wanderer Odysseus were transferred to the West, the traditions of an old heroic Minoan-Achaian kingdom in the western islands of Kephallenia, Ithaka, and Levkas (no doubt quite historical ${ }^{3}$ ) were attached to the story, Odysseus became ling of Ithaka, and his wanderings extended to Italy, Sicily, and the Pillars of Herakles. Generally connected with the story we also find voyages to Egypt and the Libyan coast. The verisimilitude of the Odyssean references to Egypt are remarkable, and we can

"On the traces of the Phoenicians in Greece, see HALL, Oldest Civiliation of Greece, pp. $224 \mathrm{ff}$. The great gift of the Phoenicians to Greece, the knowledge of the alphabet, must have been learnt from them in the ninth and eighth century towards the very end of their activity in the Aegean. Mr. F. H. Marshall points out to me the inscription, C.I.G., xii. (3), 763, from Thera, as a proof of this.

${ }^{2}$ This was first shewn by Prof, r. Wilamowitz-MöllendorfF. The fact is entirely ignored by M. BÉRARD in Les Phénicienset l'Odyssée.

${ }^{3}$ Minoan remains of good period have been found in Kephallenia and Levkas. Whether the Homeric Ithaka was in reality Levkas, as Prof. DöRPFELD maintains, I do not take upon myself, not knowing the ground, to form an opinion. I merely note his view, which has been strongly maintained and opposed. 
almost fix to the eighth century the passage (xiv. $257 \mathrm{ff}$.) in which Odysseus, lying guilefully, invents a tale of how he raided the Delta with his companions and was taken prisoner by the Egyptians. 1 The world of the Ody'ssey is that of the ninth and eighth centuries, when the Ionians had begun their oversea voyages, but before they had actually founded colonies, with the possible cxception of those which are traditionally the oldest, such as those on the Propontis and that at Cumae in Italy.

The traditional dates for the first Ionian colonies in the Propontis and Euxine are perhaps not too early, but those of the Sicilian colonies must be and should be brought down somewhat. Our archaeological information hardly enables us to date the first Greek colonies in Sicily so early as the middle of the eighth century:-2 One may feel grave doubt whether the traditional second founding of Cyzicus on the Propontis in 675 B.C. was not really the first and only one: but we have no grounds to go upon such as those (chiefly connected with the date of the Odyssey, and that of the "proto-Corinthian " pottery) that induce us to take off half a century from the traditional dates of the Western colonies. We have to take off as much or more in the case of other traditional Greek dates, such, for instance, as the Eusebian for the Lydian Ardys, and the Herodotean for Gyges. ${ }^{3}$

By the end of the eighth century, however, the great Greek colonizing movement had begun, which for a time made the whole Mediterranean Greek, until Persian protection enabled the Phoenicians to recover some of their lost ground in the Levant. The changing political conditions of the Greek states, combined with, in Europe, the paucity and poverty of Greek land, and in Asia the obstacle of the foreign power of Lydia, drove thousands of colonists to seek homes in the barbarian lands which their mcrchant adventurers had already reached and reconnoitred. The ancient patriarchal kingship of the Iliad had largely disappeared, and in its place by the beginning of the seventh century aristocratic government had succeeded it in most of the Greek states. This development probably began earlier in rich and prosperous Ionia than on the comparatively poor mainland of Hellas. The wealthy Ionian

${ }^{1}$ Hall, loc. cit. p. 269.

2 Ibid. pp. $254,255$.

3 See p. 50. The date of the poet Archilochos is another case in point. 


\section{THE ANCIENT HISTORY OF THE NEAR EAST}

city-nobles, deriving riches from their new over-sea commerce and their position as middlemen for the Lydians and other inlanders, shared the royal power among themselves, making each city an aristocratic republic. The political discontents and feuds to which this gave rise found its outlet in colonization, by which cadet and frondeur nobles could found with their followers cadet city-states. In most cases the going-forth was entirely friendly and peaceful, and special relations were always kept up between the daughter and the mother-city; and when the colony herself colonized, the oikist of the new foundation came from the original mother-city.

The population of Greece was perhaps, too, increasing beyond the power of Hellas to bear it. In Asia there was no means of pushing farther up the river-valleys into the interior; the compact masses of the native population and their organization under wealthy and powerful kings made this impossible. And Greece proper was no more fitted for a large population then than she is now.

So the Greeks, first the Ionians and then the Continentals, were carried for the first time out of their own lands to make a greater Greece on the shores of the Euxine and the Ionian and Tyrrhenian seas. In Sicily and the Italian Magna Graecia, living side by side with native populations less cultured but willing to learn from, and even to a certain extent to coalesce with, the newcomers, Greek states were able to develop to their full power, and, possessing wider territory and more fertile soil than the parent cities, to attain, in a very short time, wealth and prosperity far surpassing what had been possible in old Greece. The luxury of the Sybarites became a proverb; the power and arrogance of Gelon, the tyrant of Syracuse, led him to claim the leadership of Hellas against the Persian.

The winter cold and the savagery of the Scyths prevented the colonies on the northern shore of the Euxine from developing to the same extent, and the colonies on the southern

'On the archaeological exploration of the North-Euxine colonies of Miletos, see v. STERN, "Die Griechische Kolonisation am Nordgestade des Schwarzen Meeres," in Klio, ix. (I909) pp. $139 \mathrm{ff}$. He describes the results of the excavation of the Ionian settlement at Berezan (in which the name "Borysthenes" is preserved), on

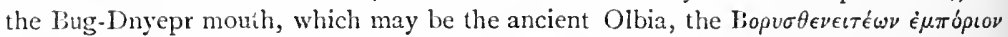
of Herodotus (iv. 18 ). The renains of the actual houses of the settlers were found, and much pottery, from proto-Corinthian to black-figured Attic and later, including Naukratite, Rhodian, and Fikellura (Samian?) sherds, as well as Egyptian faience 
coast were unable to expand for the very reasons that barred the landward progress of the Ionian cities. On the Mediterranean coast of Asia Minor no new colonies had been possible at all; though probably attempts were made, as we see from Assyrian records. ${ }^{1}$ Phocnicia and Assyria were too near. Cyprus already had an ancient Greek population which, however, sent out no new colonies of its own. In Cyprus, largely owing to Oriental influence, the constitutional changes of Greece had awakened no echo: kings still ruled her cities and went forth to war in chariots in the fashion of heroic days till the end. ${ }^{2}$

On the coast of Libya, inhospitable though it was, colonization was possible, and was carried out in spite of great difficultics and only in obedience to the repeated commands of the Delphic oracle, whose priests largely directed the course of many of the colonizing expeditions. The state of Cyrene, ruled by kings who alternately bore the names of Battos and Arkesilas, was prosperous, largely owing to its export of the useful silphionplant, which brought great profit to the royal house. The proximity of Cyrene to Egypt soon brought her under the political infuence of the Nile-kingdom, and from vassalage to Egypt she passed into vassalage to Persia, taking no part in the struggles and glories of true Greece, with which the Cyrenians probably had little sympathy.

The settlements in the Egyptian Delta were of a totally different order. They were not colonies at all, but purely trading-stations, exactly like the "Treaty-Ports" in China. Real Greek colonies on Egyptian territory would have been impossible: only trading establishments were possible, and the Milesian traders had succeeded in founding one, called simply the "Fort of the Milesians," in all probability as early as the beginning of the seventh century. ${ }^{3}$ This foundation, which was

figures from Naukratis, which have been found in great numbers on the Black Sea sites (see p. 529, n. 1). Like the colonies in Egypt (p. 52S), the settlements on the Scythic coast were at first nothing more than trading-factories. But unlike the Egyptian factories, they developed eventually into true colonies and $\pi \dot{\lambda} \lambda \epsilon \iota$. They never, however, rivalled the cities of Magna Graecia or Sicily in prosperity or power.

1 See p. 4 \$6.

2 Hor. v. II3, at the end of the sixth century. In Greece the chariot had been relegated to the games over a century before. For the history of Cyprus at this period, see pp. $486,496,56 \mathrm{r}$.

${ }^{3}$ See Hall, Oldest Civilization of Greece, p. 271 , on the date of the founding of M $\iota \lambda \eta \sigma i \omega \nu$ T $\epsilon \hat{\imath} \chi 0 s$. 
a death-blow to Phoenician trade-dominance in the Levant, was perhaps nearly as old as some of the earliest of the true colonies. At the time of its foundation, Egypt was powerless to resent the intrusion of the Ionian strangers. The Delta was ruled by the local kinglets of Herodotus' dodekarchy; ${ }^{1}$ the Ethiopian Pharaohs had little concern with the extreme north of their kingdom, and the shadow of Assyrian invasion paralysed the whole land. So the Milesians established their fort and mart

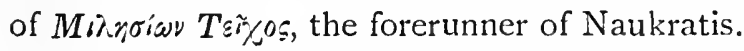

When the Pharaonic kingdom was restored by Psamatik I, the Ionian fort remained untouched by the Egyptians. It was close to Saïs, the new capital, and had, indeed, probably been placed there with the express permission and encouragement of the Saite princely family, who no doubt had found profit in trading the products of their estates to the Milesians. Psamatik as Pharaoh extended his full protection to the Greeks, and, wishing to avail himself of their proved prowess as warriors, as well as merchants, himself established a second trading fort on the opposite eastern edge of the Delta, to which the Greeks gave the name Daphnai: this was intended as a bulwark of defence against possible attack from Syria as well as a tradingplace, ${ }^{2}$ and served as a base for possible warlike expeditions into Palestine. The long siege which Psamatik laid to Ashdod ${ }^{3}$ was no doubt chiefly carried on by Greek soldiers from Daphnai; and its length perhaps testifies to that Greek want of skill in the attack of fortified places which we shall see exemplified in the Persian war. An Assyrian army would hardly have needed so long to reduce Ashdod. Again, it was no doubt not merely Gaza, but also Daphnai, and her formidable armour-clad garrison of Greeks that, as well as the gifts of Psamatil, stayed the flood of Scythian invasion in the early part of the king's reign. ${ }^{4}$

Meanwhile the Fort of the Milesians developed into the unique factory state of Naukratis, autonomous, and governed by its own magistrates chosen by the different states which contributed to the common treasury and participated in the

${ }^{1}$ HDT. ii. I 47.

2 Its name still survives in the modern Tell Dafnah or Défenneh, and its excavation by Prof. Petrie has been most instructive, especially for the dating of the Greek pottery found in it, which must all date within the century 660-560 B.C., as the Greeks were removed from Daphnai by Amasis soon after his accession (PETRIE, Tanis, i.).

${ }^{3}$ HDT. ii. 157.

${ }^{4}$ See p. 512. 


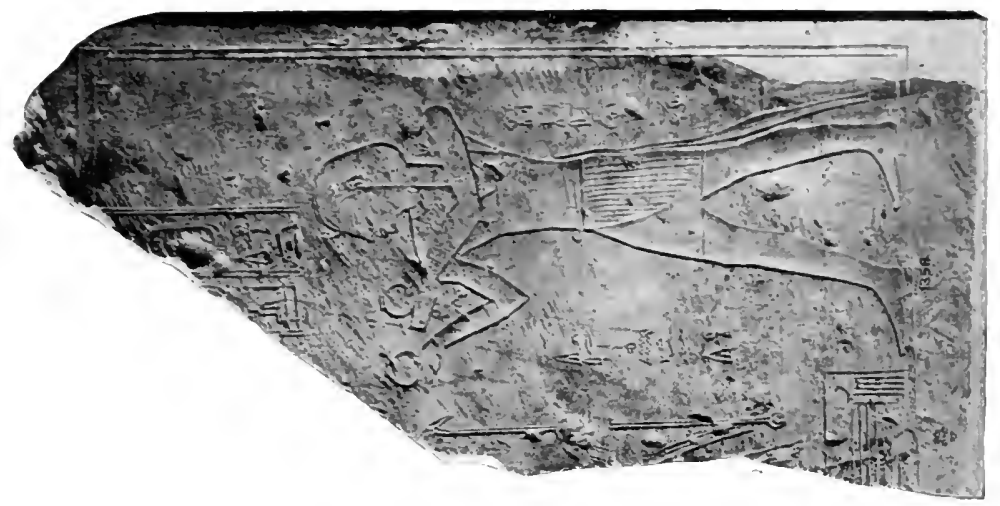

$=$

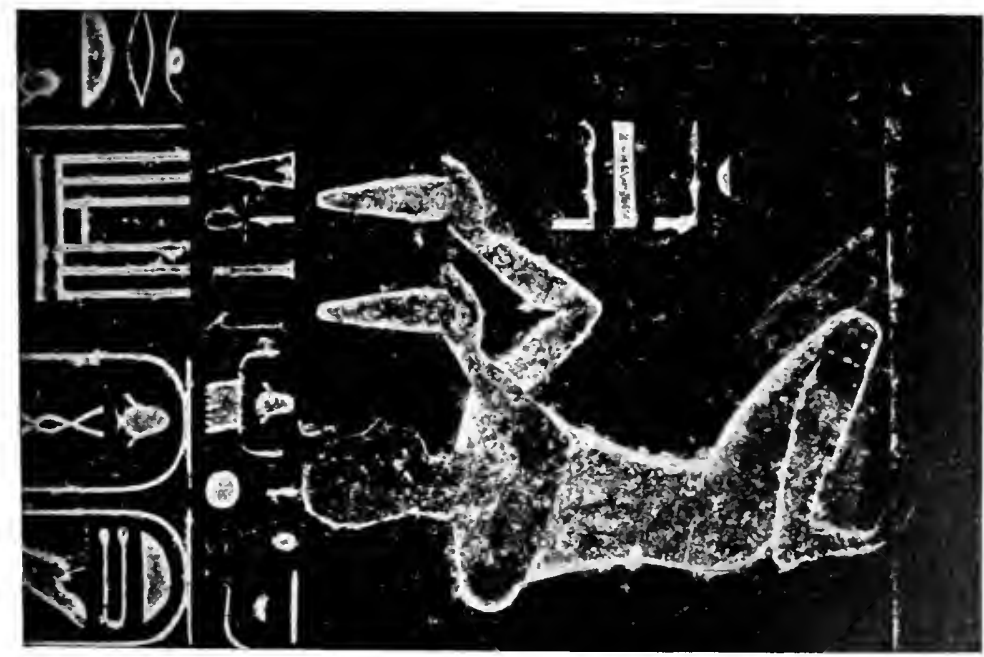

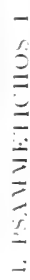



common city-hall, the Helleneion, ${ }^{1}$ just as now at Shanghai the European communities combine in club and municipality.

At Naukratis, indeed, the Greeks must have felt the tie of common Hellenism more strongly than anywhere else in the world. Ringed round by a population of stupid fellalin, fanatically devoted to their gods and to the priests who served them, and hating by immemorial tradition everything foreign and not of their world, the Greeks of Naukratis had nothing but the royal favour and that of some of the great men, beside their own strong right arms, to defend them against a possible catastrophe. And this favour depended on their help in war, and no doubt a goodly share of the trading-profits. Throughout the reigns of Psamatik I and II and Necho this favour continued, but Apries, as we shall see, overdid it, and Egyptian national sentiment compelled Amasis to confine the Greeks to Naukratis, abolishing the settlement at Daphnai.

But meanwhile the Greeks of Naukratis had been made free of Egypt by the kings. They were not confined to the "treaty-ports," but could go where they willed, apparently, and sent home marvellous tales of the strange land in which they and hundreds of other Greeks lived, bound together by the necessity of watchfulness and protection against the weird people that inhabited it. And in the same category with the Greeks came the Carians, Lydians, and other people of Asia Minor, who felt greater kinship with the Greeks than with the Semites or Egyptians. The Semites remained apart from both Greeks and Egyptians. In Egypt at this time the new opposition between young Europe and the old East first became apparent.

The colonial movement, carried on largely under the auspices of the most renowned common oracle of Greece, created Hellenedom. As Prof. Bury has pointed out," by the wide

1 On the synoikismos under Amasis, and the constitution of Naukratis, see post, p. 561. Very interesting relics of the trade of Naukratis are the hundreds of small Egyptian and "egyptizing" objects, chicfly of faience, that have been found not merely at Kameiros in Rhodes, but also in the colonies of Miletos on the far Scythian coast of the Euxine, at Olbia, Pantikapaion, and Tyras (see TurAyev, in K'ez'. Arch. June to August 1911). These all date between the eighth and fifth centuries B.C. At Naukratis were discovered the actual factories where most of these objects were made for export, much as cheap Japanese goods are made now at Kobé or Osaka to be sent to Europe.

2 History of Greece, p. S8. 
diffusion of their race on the fringe of "barbarous" lands, the contrast between Greek and non-Greek was brought home to the Hellenes, and, by consequence, the community of Hellenedom also. The joint-enterprises of different states also made for Greek unity, and nowhere can we find a better example of this than at Naukratis. So the Greeks gradually came to think of themselves as one race opposed to all "barbarians," but more especially to the civilized barbarians of Egypt and the East. The inevitable conflict was approaching. But during the seventh century the opposition of Greek and Oriental had not yet become acute: the Greeks still lived on terms of friendship with the rulers of Egypt, and Greek soldiers of fortune even took service under Nebuchadrezzar in Babylonia. ${ }^{1}$

The schooling of the Greeks towards unity was undertaken to some extent by the Delphic priests, who sought to reinforce by the monitions of the Pythia the unifying tendency that the consciousness of common Hellenism had brought about. ${ }^{2}$ There was, of course, no thought of political unity: that would have been totally opposed to the whole genius of the race, and only possible had it denied its own ideals and adopted the very thing that it abominated as most un-Greek, the imperial despotism of the Easterns. The Sacred War (about 590) shews the reverence in which the Delphic oracle was now regarded by the whole of Greece, and the pan-hellenic vengeance which fell on Krisa testified to the unity that the Greeks could feel when insult was offered to the gods by one of their own numbers. A century later the strength of pan-hellenic feeling was to be tested to the full, not by a single Greek town, but by the whole embattled force of the emperor of Asia, in whose armies conquered Assyria, Babylonia, and Egypt marched but as subject tribes. Hellenic patriotism won through, despite the cowards: but political unity did not come after that tremendous trial, nor was it in the mind of the nation that it should. Athens was punished for her unification of the maritime Greeks: Sparta for her attempt at land-hegemony. The unity of the Greeks was strongest in diversity. And when the Macedonian "unified" them, they died.

I The brother-in-law of Alkaios the poet served under Nebuchadrezzar.

2 The inflnence of the religious games in promoting this national conscionsness was of course very great. 
Leagues, whether temporary or lasting, between the cities meant no subjection to any one of them till the days of Athens and the Confederation of Delos. Such leagues were usually partly religious, partly commercial, and were often very ancicnt. Onc of the oldest religious leagues was the Amphiktiony which was formed (originally at Anthela) to protect Delphi ${ }^{1}$; and of the commercial-religious leagues the oldest known is that of Kalaureia. The states which formed this alliance combined to make common offerings to the sea-god on the island of Kalaureia, off the Argolic coast by Troezen, a very central position for the purpose, and, then as now, an admirable little port. ${ }^{2}$ The original members of the league seem to have been cities of the Argolic and Saronic Gulfs only; Prasiai, Nauplia, Hermione, Troezen, Epidauros, Megara, Aigina, and Athens. As the colonizing movement went on, commerce between the eastern and western Grceks became ever more and more vigorous, and the Kalaureate League developed. The port of Bocotian Orchomenos, Anthedon on the Euripus, was admitted to the league (Orchomenos, as overlord of Anthedon, offering), and now the states of the league combined with Eretria and with Miletos, the ally of Megara, friend of Athens, the pioncer of Ionian oversea commerce and colonization, to control a sea trade-route from east to west, from Miletos to the Cyclades, where Paros was an important member, to the Euripus and the Saronic Gulf, then by way of the Peloponnesian coast round to the Ionian Sea. A land route from Anthedon by Orchomenos to the Corinthian Gulf no doubt supplemented the all-sea route. Eretria became the central point and mainspring of this league.

Commercial jealousies soon resulted in the establishment of a rival commercial route, with its centre in the city of Chalkis, the chief foe of Eretria. Samos, the rival of Miletos, Naxos, the rival of Paros, and Corinth, the rival of Aigina, combined with Chalkis to exploit a route by the Isthmus of Corinth, across which ships could be hauled from the Eastern to the IVestern Sea. The favourable commercial position of Corinth soon assured the predominance of the Chalkidian alliance in the

${ }^{1} \mathrm{Mr}$. Marshall points out to me that this influence of Delphi extended in other directions than the political. The Orestes-legend, for instance, was entirely transformed from its Homeric simplicity under the infuence of Delphi, whose priests wished to exalt Apollo as the avenger of crime (see JEBB, Introd. to Sophocles' Electra).

2 Kalaureia is the modern Poros. 
West; the Eretrian colony of Korkyra was taken, and thereafter only one or two colonies were established in Italy and Sicily by the cities of the rival league. In the East, however, the Eretrian League well maintained its position; Miletos and Megara dominated the Hellespontine region. About the middle of the seventh century, however, broke out a direct conflict between the two Euboean centres of the rival leagues, Eretria and Chalkis. This, the Lelantine War, ended disastrously for Eretria, and her defeat reacted upon her allies. Samos now came more to the front; Corinth increased rapidly in wealth and power, while Aigina and Megara declined, and Athens (since her synoikismos one of the largest states of Greece) sank into temporary obscurity. In Egypt the effect was to throw open the factories of the Milesians to their Samian rivals, and at Naukratis we find the Samians by the side of the Milesians and Aiginetans. Only the eastern members of the Chalkidic League were interested in the Levantine trade: Corinth traded solely with the West. ${ }^{1}$

Meanwhile the class-divisions of the Greek cities, accentuated by the rule of the aristocratic and timocratic oligarchies, were becoming fused to some extent by the common subjection of all, both noble and simple, to the tyrants. ${ }^{2}$ Rulers like Periander, Thrasyboulos, and the Peisistratids formed a necessary transition to the democracy, which was finally established in Athens by Kleisthenes, and to which, well led, Athens owed her greatness and Persia largely her defeat. Sparta underwent none of these radical constitutional changes, but her constitution changed, nevertheless. Her two kings still ruled Lacedaemon, but, unless they were unusually forceful men like the first Kleomenes, they could do little in despite of the checking authority of the Ephors, whose institution was traditionally assigned to Lycurgus in the eighth century, but was probably of later date. Argos was ruled by kings whose power was less trammelled. However, only one of them, Pheidon, was a man of sufficient force to make his state respected for a time in Greece. ${ }^{3}$ But the tyrants who came

${ }^{3}$ On Corinth and her colonies see HALL, O.C.G., pp. 257, 260.

2 On the tyrants see MaHAFFy, Survey of Greek Civilization, pp. 87, $99 \mathrm{ff}$.

${ }^{3}$ The view of Curtius as to the date of Pheidon (668 B.c.) seems more probable than that which places him nearly a century earlier, if he really had money struck for him in Aigina. But see Prof. Percy Gardner's paper, "The Earliest Coins of Greece Proper," Proc. Brit. Acal. vol. v. (I9II). Prof. Gardner denies that Pheidon 
in the sixth century had all to be men of energy and force, or they fell. And while the fact of their rule stirred up democratic feeling, their love of splendour and patronage of the arts of civilization and commercial instinct ${ }^{1}$ greatly forwarded the rise of the new culture of Grecce.

IVe see from the Homeric poems that the old tradition of civilization had never died out in Ionia, whither the expelled Achaians and Ionians had carried it. And it was in Ionia that Greek civilization was reborn, under the influence of the Oriental "mixed culture" that held sway in the inland lingdoms of Asia Minor and had been borne from Syria to the Aegean by the Phoenician traders. ${ }^{2}$ From the Phoenicians the Greeks took over the invention of the alphabet, ${ }^{3}$ and from the Lydians, it was said, that of coined money (though we may well doubt whether this was not really an Ionian invention first devised for the Lydian kings). ${ }^{4}$ In Ionia and the isles the

can have had money struck for him in Aigina, which he did not rule: the Aiginetans struck thcir money on the standard which had been regulated by Pheidon, who lived in the eighth century (Pausanias' date, 74 S B.c.). I owe my knowledge of this paper to Mr. Hill.

1 See URE, J.H.S., I906, pp. 13 I ff.

2 See p. 79 (Ch. II.). Mr. F. H. Marsmall's theories as to Lydian in. fluence on East Greek art as exemplified in jewellery (Brit. . Mus. Cat. of Jewellery', p. xxiv.) have been amply confirmed by the recent American excavations at Sardis (A.J.A., I9I I, p. 457). The best view of the origin of Ionian culture and its relation to that of the Greek Bronze Age is that of HogARTH, Ionia and the East (Oxford, 1909). In this series of six brilliant lectures Mr. Hogarth envisages perfectly the whole of this question as it appears to the archaeologists at the present time. On the influence of Lydia on Ionian culture Mr. Hogarth has said all that is to be said. Only perhaps he has depreciated the Phoenicians unduly (see p. 523, n.). They certainly were at one time in the Aegean, and after they were expelled thence still acted as middlemen between Greece and Syria, and probably shared the Egyptian trade with the Greeks of Naukratis. The Graeco-Egyptian antiquilies from Kameiros in Rhodes are, as Mr. HogarTH says, no doubt largely of Nauliratite origin and have nothing to do with the Phoenicians.

3 The Semitic names and order of the Greel letters prove their Phoenician origin. Is to the origin of the Phoenician alphabet itself see p. 429, n. 2. The Cypriote Greeks preserved their syllabic system, a descendant of the old Minoan pictographic script, till the third century, refusing to adopt the alphabet. This does not say much for the power and prestige of Phoenician influence among them, which, as Hogartu has shewn (Ionia and the East, pp. $86 \mathrm{ff}$.), was in fact very small. The Phoenician settlement at Kition was probably not established till the ninth century (it is mentioned by the Assyrians in the eighth), after the decadence of the Minoan culture. in the island. (Kition is mentioned by the Egyptians in the twelfth century (1 MAL, O.C.G., p. 169, n.2), but probably there were no Phoenicians there then.)

4 If coined money was in reality first used by the Lydians, it is probable enough that it was invented by the Ionians. One can hardly imagine Lydians, a pastoral 


\section{THE ANCIENT HISTORY OF THE NEAR EAST}

debased Late Mycenaean ceramic was transformed into a new style, characterized by a scheme of decoration very Oriental in feeling, which, when art began to raise its head again in Greece proper, was carried thither, and displaced the harsh geometric style of the mainland potters. From Corinth, which seems to have been the main focus of distribution, the new ware was carried to the Corinthian colonies in the West. At Syracuse the earliest Greek vases, which must be almost coeval with the period of colonization, shew an interesting style of transition from the geometric style to this "Proto-Corinthian," as we call it. $^{1}$ 'The further development of this style, and an elimination of its Oriental elements, quickly followed, and the Rhodian style in the islands, the Laconian-Cyrenaic at Cyrene and Sparta, the Daphniote and Naukratite in Egypt and largely under Egyptian influence, carry on the history of Greek pottery to the six th century and the beginnings of the classical style of Greek vase-painting in Attica. The recent excavations at Sparta ${ }^{2}$ have shewn that in ceramic art the Dorian of the seventh and sixth centuries was by no means so inartistic as he has commonly been supposed to have been, and a practical identity of the Early Laconian styles with the Cyrenaic seems well assured, though it is by no means certain yet that the Laconian pottery was not of Cyrenaic origin. In any case the style was ultimately of Ionian origin; the Spartans were indebted for their early ceramic art to the Ionians. ${ }^{3}$

At the same time the arts of metal-working and sculpture were revived, the former with great splendour. Most interesting examples of small metal-work of the eighth and seventh centuries were discovered in the course of the British Museum people ruled by country squires, inventing anything but a new tune on the pipes. But they controlled the gold of their river-beds, and the silver from the mines of the interior, and this gave their kings wealth and the power of employing Ionian intelligences in their service. To the commercial Ionian must be assigned the invention of money, first coined no doubt for his Lydian lords. On the origin of Greek weight standards see Gardner, Earliest Coins of Grecce Proper, pp. Sff. Prof. Gardner doubts their "My"cenaean" origin. But he seems to me to magnify unduly the barbarism of the intermediate period between "Mycenaean" and historic Greece when he doubts whether "so civilised an institution as a weight-standard" would have survived.

${ }^{1}$ Several very interesting early vases in the Syracuse Museum shew this transition well.

${ }^{2}$ Annual of the British School at Athens, vol, xiii. ff. : see especially the articles on the potlery by Mr. J. P. Droop.

${ }^{3}$ Cf. p. 522, n. I. 

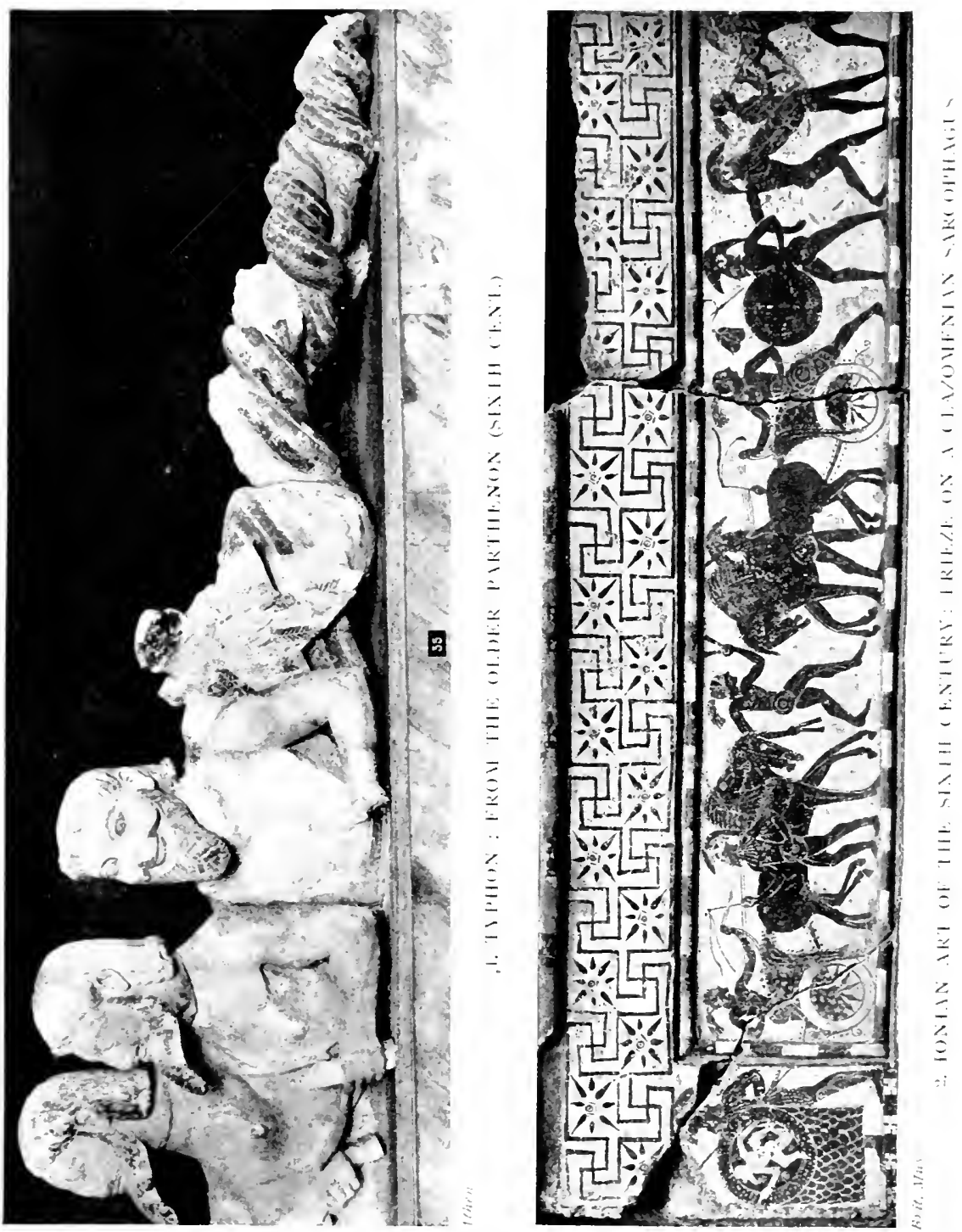

cxcavations at Ephesus in 1904-5. ${ }^{1}$ The relation of some of this gold-work to that of the Mycenacan tombs at Enkomi in Cyprus is of great interest, and is a proof of the permanence of the Myccnaean art-tradition in Ionia. ${ }^{2}$ Some of the finest relics of early metal-work yet discovered, of Ionian origin and shewing the typical Ionian use of Oriental designs, has been found in Crete, in the rotive offerings from the cave of Zeus on Mount Ida, now in the Candia Museum. Crete too has yielded monuments of the most archaic Greek sculpture to Italian excavators at Priniàs, a shrine on the eastern slope of Ida. ${ }^{3}$ They shew work crude and clumsy enough. Sculpture was slow in development at first, and seems to have received its great impetus from the Ionian connexion with Egypt. Ionian sculptors are said, no doubt with truth, to have visited Egypt, and we sec in the works of the earliest sculptors of Greece a strong reflection of the hardness and stiffness of the Egyptian work of the Psammeticid period. Even the curious conventional "archaic smile," which is so characteristic of the carly Greek statues of the renascence, is directly traceable to Egypt, where it was equally characteristic of a certain type of Saïte work. ${ }^{4}$ And everywhere in Greece splendid temples began to rise in honour of the gods, and the architecture of Hellas was born. In Ionia Oriental influences, often specifically Hittite-Assyrian in character, are seen, and the Ionian pillarcapital derived its immediate origin from the Hittites of Boghaz Kyöi. In Greece proper and in the West the sterner Doric column, derived from a simple wooden original, was more popular. In it (except for the fact that the tapering of the shaft is in the rcverse direction) we see a strong reminiscence of the old Minoan column of Knossos, which like it had no base, and was weighted above with a massive swelling capital and abacus. ${ }^{6}$ The Early

1 Hogarth, Ephesus (Brit. Mus., 1908). The ivory carving is also most notable.

IIIogarth, Ionia and the East, p. 54; Marsilall, Brit. Mul. Catalogue of Jezellery, p. xxii.

${ }^{3}$ In tradition the beginnings of classical Greck sculpture are associated specially with Crete and the names of Dipoinos and Skyllis. Minchiöfer (Anfiunge der. Kunst in Griechenlanci, Leipzig, $\mathrm{I}_{3} S_{3}$ ) was the first to note the importance of Crete in the history" of "Archaic" Greek art.

"The same "archaic smile" is seen in Cypriote sculpture of the sixth and fifth centuries, and probably has the same Saite origin.

${ }^{5}$ See Puchsters, Die Ionisihe Sïnle (I907), and King, J.H.S. xxx. p. $33^{2}$.

"The "Caphtor-capital" of Hebrew architecture (Amos ix. I ; Zeph. ii. 14). 


\section{THE ANCIEN'T HISTORY OF THE NEAR EAST}

Doric columns, as at Corinth and Paestum, have enormous capitals of this type, which later on grew more restrained in girth, and shew the new Greek sense of proportion in their relation to the size of the column. The revival of the clumsy, overweighted Minoan capital soon disappears, and finally in the fifth century the grand Doric pillars of the Parthenon mark the apogee of Greek architecture, as its reliefs mark the apogee of Greek sculpture, now entirely freed from archaic clumsiness and Oriental convention.

When the Parthenon was built Greece had defeated the Persian, and had attained full consciousness of her superiority to the barbarian in culture as in arms. But a century earlier her art had seemed to shew no superiority to that of the Orientals. At the end of the seventh century Ashurbanipal's sculptors at Nineveh were representing horses which the frieze of the Parthenon can hardly equal, and lions which no sculptor has ever surpassed in careful observation and truthful delineation. Ages before, Egypt had produced portrait sculpture which no Greek or modern can rival for fidelity and force. But yet already a century or more before Pheidias one can see in Greek art the one thing that was to make it the first true unified art in the world, the sense of proportion. Truth for an Assyrian or Egyptian could be exercised in the case of a horse or a lion, or (in a simple age) a human portrait. But if a god or a king was to be represented proportion was not considered, and even an ordinary human being could not, though his size might be correct, be shewn with fidelity to nature. Similarly in imperial Assyria, as in imperial Egypt (the renascent Egypt of the Saites had better taste), the houses of gods and kings, though their detail might be good, had to be enormous and entirely disproportionate in total size to the scale of its ornamentation. The Greek temple was small, but looked more splendid than any tower of Babel: it was built with a sense of proportion. The Greek sculptor and vase-painter gave to their deities a proportionately more majestic stature than to ordinary mankind: they did not represent them twice the size or in any unnatural guise or in accordance with any barbarous convention that made the semblance of truth impossible. ${ }^{1}$ Kings

'One must except the conventional representation of monsters. But they were monstrous, and were so represented: in them there could be no "truth." 

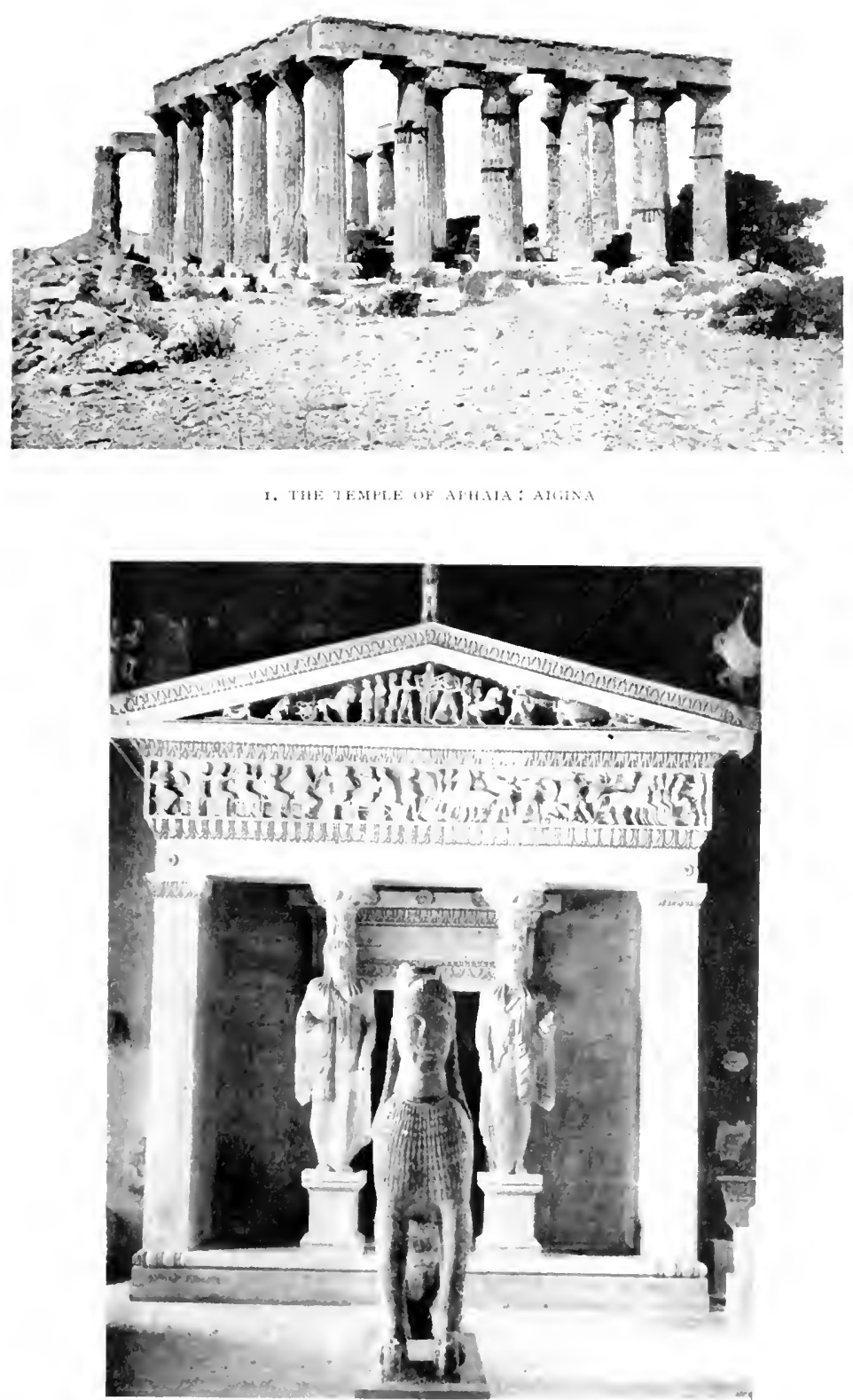

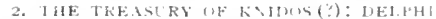

GREFK ARCHITECTURF OF IIIE SISIH CFNTERS 

were ordinary mortals, and were so represented. This was the new spirit in art that the Greeks, already before the Persian wars, had brought into the world. And it was a new spirit not only in art but in civilization generally.

Knowing what we do of the psychological peculiarities of the different races of mankind, it is perhaps not an illegitimate speculation to wonder whence the Greeks inherited this sense of proportion in their whole mental outlook. The feeling of the Hellenes for art in gencral was surely inherited from their forcbears on the Aegean, not the Indo-European, side. ${ }^{1}$ The feeling for naturalistic art, for truth of representation, may have come from the Aegeans, but the equally characteristic Aegean love of the crude and bizarre was not inherited: the sense of proportion inhibited it. In fact, we may ascribe this sense to the Aryan element in the Hellenic brain, to which must also be attributed the Greek political sense, the idea of the rights of the folk and of the individual in it. ${ }^{2}$ The Mediterranean possessed the artistic sense without the sense of proportion: the Aryan had little artistic sense but had the sense of proportion and justice, and with it the political sense. The result of the fusion of the two races we see in the true canon of taste and beauty in all things that had become the ideal of the Greeks, ${ }^{3}$ and was through them to become the ideal of mankind. The sense of clarity and proportion permeated the whole cultured mind of the nation. We see it already in the seventh and sixth centuries in the arts of speech and song which now asserted their power over men, when the great lyric poets,

1 We have only to look round and seek, vainly, for any self-developed artistic feeling among pure Indo-Europeans. The Kassites had none and blighted that of Babylonia for centuries: the Persians had none and merely adopted that of Assyria: the Goths and Vandals had none: the Celts and Teutons have throughout the centuries derived theirs from the Mediterranean region.

2 The predominance of the Aryan element in Greek political ideas is obvious. It is not probable that the old Aegean had any more definite political ideas than had his relative the Egyptian.

${ }^{3}$ In matters of political and ordinary justice between man and man they fell short of their ideal often enough, but they had the reasonable ideal : the "barbarians" had none. The Egyptians were an imaginative race, but their imagination was untrammelled by the sense of proportion: their only thinker with reasonable and logical ideas, Akhenaten (see pp. $29 S \mathrm{ff}$.), soon became as mad a fanatic as any unreasonable Nitrian monk or Arab Mahdi. Ordinarily speaking, Egyptian and Semitic ideals were purely religious, and so, to the Greek mind, beyond the domain of reason. The Babylonians, Assyrians, and Phoenicians cannot be said ever to have possessed any ideals of any kind. 
whose inspiration was first gained in the tense struggle between the aristocrats and the demos, shed lustre on the names of the demos-born princes who fostered and protected them at their courts. ${ }^{1}$ We see it in the work of the Aisymnetai and lawgivers such as Pittakos, Zaleukos, and Charondas, who now heralded the development of reasonable law in the West. ${ }^{2}$ In politics we see it in the Solonian reform of the constitution of Athens in the first decade of the sixth century, a reform which for the first time in the world's history proclaimed justice for the common people, and firmly planted the democratic ideal (with all the defects of its qualities) in the soil of Athens. Finally we see it as clear and logical thought in the realms of abstract speculation, where the Greeks were already conquering their eternal place of priority and pre-eminence. So far as we know, the human intelligence first reached in sixth-century Greece the height which, lost for a thousand years during the Dark Ages, it has now since the Renaissance again attained. The contrast between even the average Greek mind and that of the Oriental or Egyptian of the sixth century B.C. must have been enormous: the gulf between the Greek philosopher or poet and the most learned of Babylon or Egypt, almost impassable. The somnolent priestly antiquarians of the Nile-land could communicate nothing more tangible to the Greek inquirer than the fact of the passing of innumerable generations of "men and the sons of men." Yet this fact of antiquity impressed the Greek because he was intelligent: he realized his youth in the world; but a few generations back his ancestors had been heroes, perhaps demigods, in the mist of the dark age of barbarism

' See Manaffy, Survey of Greek Civilization, pp. $88 \mathrm{ff}$, 10I ff. In Hesiod we get the first inkling of the poetry of the new age, but his form is that of the ancient heroic lays : he lived probably in the eighth century. The inrolved and artificial odes of Pindar $(c \cdot 522-443$ s.c. ) belonged in their form to the aristocratic age, in his time long passed away.

E Elaborate legal codes had been characteristic of Babylonian culture, not from any high-flown ideal of justice, but because the Babylonian was a severely accurate and practical person who had everything regulated and written down. In Egypt the laws, other than certain ancient customs, were probably both made and administered very much at haphazard: the Egyptians had and have naturally careless and inaccurate minds. What the "Laws of Minos" may have been like we do not know. Oriental influence, ultimately traceable to Babylonia, must have had considerable influence in the forming of Greek legal systems, but the muin legal ideas were no doubt of Indo-European origin. That of Gortyn in Crete is the oldest Greek code. 
from which his race had but lately emerged. ${ }^{1}$ So it may be that Thales and I'ythagoras really visited the Nile-land, ${ }^{2}$ as did many others of their countrymen at the time, and tried to gain some wisdom from the Egyptian priests, but they must soon have found Egyptian religious and "philosophical" ideas utterly unreasonable and useless to them: their own thought, cven when it is mystical enough (as in the case of what we know of the Pythagorean teaching), has little in it of the barbarous confusion characteristic of Egyptian religious ideas : it is well-ordered and logical, and in it we see the final triumph of the European soul in the new Greece. The Greek philosopher created the disciplined mind of Europe, which rules the world to-day. From religion too Oriental ideas were kept far apart, and Semitic religious fanaticism was never admitted to it, ${ }^{3}$ though the Greek found hardly repellent, rather amusing in fact, the drunken orgies of the Aryan wine-god from Thrace and his crew. In the fury of the wine-intoxication there was also certainly something divine and mysterious. ${ }^{4}$ Mysteries he did not refuse, but they must be reverently and sanely mystical, as probably were those of Eleusis in comparison with those of Egypt.5

1 HuT. ii. 143 .

2 Burnet, Early Greek Philosophy, pp. 38, 92.

${ }^{3}$ On this Dr. FarNei.l has written admiratly in his Greece and Babylon; but I demur to his siatement (p. 202): "The history of Hellas is not stained by any "war of religion.'" Surely the Sacred War and the destruction of Krisa (p. 530) hardly bear this out. But we may admit that the event in question was exceptional. When the all-holy Apollo was in question Greek sweet-reasonableness in religious matters often disappeared. And he was the most "Aryan" Greek of the Greek gods. So that we cannot say that the Aryan spirit brought an entire absence of religious fanaticism to the Greel mind. It brought a sense of the holiness of a deity. which when irritated could resemble fanaticism, but was not it, in the Semitic sense, since it was combined with perfect toleration of other gods and religions. The Aryan Persian Zoroastrians possessed an exactly similar spirit (see p. 576). Whether the Greeks would not have benefited in character by an infusion of Semitic earnestness is another question.

"There was nothing of religious fanaticism, properly so called, in the Bacchic fury. The attempts which have been made to connect the Dionysiac cull with the Semitic East have been entirely unsuccessful, since it is quite evident that there is nothing Semitic about it. Dionysos was a Thracian god, and owing to his late introduction the most purely and barbarously Indo-European deity in Olympus (cf. Aristophases). There never was a Semitic wine-god of any kind, and the philological arguments connecting Dionysiac names with Semitic roots are absurd. Semele's name, if anything, is Slav ! (HaLL, O.C.G., pp. 239, 240).

${ }^{5}$ How far the Eleusinian nysteries may be connected with the pre-Ilellenic religion of Greece we do not know. The Orphic beliefs seem to be of Oriental (Anatolian or Semitic) origin, and were quite foreign to the true Greek religious spirit. 
So "the early Hellene asserted his spiritual independence of the East." 1

Meanwhile in Egypt the renovation of the kingdom produced no real renascence. The archaism of art and government-titles, which sought to go back to the models of the Old Kingdom, was but a fashion, and meant nothing. The results of the decadent Empire and of the Ethiopian rule remained. Though the kingdom was reunified politically, the old division between North and South which had been revived by the Theban Priest-Kings continued in a peculiar political arrangement which first appeared under the Ethiopians: Thebes was ruled by a princess of the royal house as High-Priestess of Amen, bearing the title "Praiser of the God." The great queen Amenartas bore it under the Ethiopians, and under the Saites the best-known priestess-queen of Thebes is Nitakrit (Nitokris) in the reign of Psamatik $I$; it was her name that was transferred in Greek tales to the courtesan Rhodopis. Archaism had no power to abolish this political inheritance from the Ethiopians. The renovation of the kingdom was real in that it brought to the nation a prosperity that had been unknown since the time of the XXth Dynasty: the evidence of royal and general wealth is undeniable, and is best seen in the works of the Saite kings in the temples, especially those of the Delta, which reach their culmination of splendour under Amasis, just before the catastrophe which finally destroyed Egyptian independence. ${ }^{2}$ And it was this very prosperity, which rested on no real defensive power, but merely on the spears of Greek and Carian mercenaries, that was Egypt's ruin, the bait that drew the conqueror to her.

None in the seventh century, while Assyria still stood, erect though swaying, a corpse in armour, could have foreseen a

${ }^{2}$ FarNel, loc, cit., p. 203.

2 Much of the temple-magnificence that Herodotus saw was the product of the Saite century. At this time the temple-architects seem to have rivalled one another in the production of wonderful shrines carved out of solid blocks of granite (HDT. ii. 155,175$)$. The relief-sculpture of the time is fine, and often shews remarkable taste and a characteristic delicacy of execution. This delicacy is seen in all the artistic products of the period, especially in the ceramic objects, which are usually of a peculiar light-biue colour. This was an instance of the archaistic spirit of the time, for the most ancient products of the Egyptian glaze-potters under the Old Kingdom had been coloured palc-blue. The archaism of the relief-decoration of the tombs is very marked (see p. $5_{1} \&$, n.), but they are distinguisbable from the real productions of the Old Kingdom by their peculiar delicacy. 
conquest of rich and magnificent Egypt by the barbarous mountaineers of Elam and Anshan, still less the eventual struggle between Persia and Greece. Yet Persia came to the conflict merely as the heir of Lydia, whose kings, free from the fear of Assyria though still obsequious to her, had turned their faces to the West and aspired to subdue the Ionian cities to their will. But for the invasion and long-continued raids of the Kimmerians, ${ }^{1}$ which afflicted Phrygians, Lydians, and Ionians alike, they might have succeeded. After the fear of the Kimmerians was removed, Miletus, then the first of all the states of Ionia, had to bear the brunt of long wars with Sadyattes and Alyattes of Lydia, which only came to an end after the great battle on the Halys in 585 B.C., in which Lydia and Media came face to face. ${ }^{2}$ Behind the Mede stood his heir, the Persian, but none saw him. Crcesus of Lydia, proud of his wealth and power, first made war on the Ionians, but soon the overthrow of Astyages by Cyrus brought his schemes of conquest to an end, and hurriedly he sought Greek friendship and alliance. But events, and the Persian, marched too quickly for him. And meanwhile, the continental Greeks continued to the end oblivious to the danger to their budding civilization which might arise from the East. That the Orientals were not all weaklings who required defending by Greek mercenaries they might have learnt from the struggle of Miletus with Lydia ; but they took no thought of their Eastern march which had been so well defended by their Ionian brethren, whom they despised as themselves half-Oriental. Sparta had no thought but to impose her domination on the Peloponnese, Corinth no thought but for her commerce and the preservation of her colonies in dependence upon her, Athens no thought for anything but her local politics and constitution-making. Still, the iron wars of Sparta gave Greece the warriors who defended Thermopylai and nerved the Greeks to resist Persia in the open field, while the revolutions and constitutions of Athens gave her the democratic spirit which stood fast for Hellenic freedom against alien subjection, and the splendid culture of the Peisistratid age, as we know it from the sculptures in the Acropolis Museum (Plate XXXII. 2) and from the tradition of its literary energy, gave her citizens the feeling that their city was indeed no mean one, and fully worthy to be a protagonist for

$$
1 \text { See pp. 495, } 508 .
$$

2 P. 551 . 


\section{2 'THE ANCIENT HISTORY OF THE NEAR EAST}

Hellas. ${ }^{1}$ Corinth, swayed by baser ideals than either of the other two, came worst of the three chief continental states out of the trial. ${ }^{2}$

So the Greeks stood, energetic indeed, and doughty in war, but divided in mind, incapable of unity against a common foe, and, except the Ionians, ignorant of his power, at the moment when Cyrus destroyed the kingdom of Croesus. Egypt, incapable of action, could only watch the death that was coming upon her. Babylon already lay dead, Assyria was dead and forgotten.

We turn now to the events in the East which led up to the final catastrophe of the old order, and the new era of the world's history which began upon the day of Salamis.

${ }^{1}$ I continue to believe that the democracy was the moving spirit of the resistance of Athens to Persia. A curious distortion of history is to be found in Nordin, Aesymnetie und Tyrannis (Klio, v. pp. $392 \mathrm{ff}$. ), where the victory of Greece is ascribed to the Tyrants, especially the Peisistratidae, who so strengthened Athens. Had the Tyrants continued their rule, he says, and formed Greece into "Reiche" (like that of Syracuse), how much more easily would they have withstood Persia! But this is highly questionable; tyrannic empires were possible in Sicily, but not only the history but also the geography of the Greek mainland forbade them there. The fact is that all the Tyrants did was to make Athens splendid : they were ready enough in order to save their skins to submit to Persia, as the Peisistratids did; it was to keep out tyranny and foreign domination that the Athenians helped to burn Sardis. The energy of the Athenian democracy was of course also inspired by desire to save its own skin, as was the energy of the French democracy in 1792. And in both cases the result was the victory of a new principle and the dawn of a new era in the world.

${ }^{2}$ Argos, bludgeoned by Sparta to a condition almost of insensibility, was no longer a state of the first rank, and incapable of ljelping Greece, which to her would only mean helping Sparta. She produced no second Pheidon. 


\section{CHAPTER XII}

\section{BABYLON AND THE MEDES AND PERSIANS: FROM THE FALL OF NINEVEH TO THE DEFEAT OF XERXES}

\section{$(606-479$ B.C.)}

\section{Babylon and Esypt}

Necho seizes Palestine (608)-Battle of Carchemish (604)-Babylonian conquest of Palestine-Nebuchadrezzar takes Jerusalem (596)-Necho's work in Egypt-l'samatik II in Nubia-The inscription of Abu Simbel-The "Asmak"-Uahabra (Apries) interferes in Palestine, occupying Phoenicia (5\$8)-Nebuchadrezzar advances into Syria $(587)$-Fall of Jerusalem and captivity of the Jews (586)-Jeremiah at Tahpanhes (Daphnai)-Siege of Tyre (586-573)-Uahabra defeated by the Cyrenaeans-Amasis (569-526)-Apries revolts (566)-Battle of Momemphis-Death of Apries-Supposed Babylonian invasion of Egypt not proved-Death of Nebuchadrezzar (562)-Nabonidus (556-539)-Nebuchadrezzar's buildings at Babylon-Antiquarian tastes of Nabonidus-Belshazzar

A FTER the fall of Nineveh, the Assyrian claims to empire in Syria and the West naturally fell to Babylon, while the Medes took the Ninevite territory and the lands north and east of Tigris. Southern Assyria and Northern Mesopotamia were occupied by Nabopolassar, who ruled unchallenged to the bend of the Euphrates. Beyond the river, however, Pharaoh Necho, easily destroying Josiah and his army in the historic field of Megiddo, had seized the whole of Syria and Palestine, ${ }^{1}$ and a conflict was inevitable if Babylon intended to make good her claims to the inheritance of Asshur. Two years after the fall of Nineveh the collision between Egypt and Babylon took place, at Carchemish, and the motley host of Necho, composed of all the strange African subjects of Egypt

12 Kings xxiii. 29 ; HDT. ii. 159 . It is significant of the grateful attitude of the Egyptian kings towards the mercenaries who gained them their victories that when Necho took Gaza he dedicated some of its spoil to Apollo at Branchidai. 


\section{THE ANCIENT HISTORY OF 'THE NEAR EAST}

with a (probably untrustworthy) "stiffening" of Greek and Carian mercenaries, went down before the Babylonians, led by Nebuchadrezzar, Nabopolassar's energetic son. ${ }^{1}$ Routed and disorganized, Pharaoh's host hurried back to Egypt, abandoning all the conquests of five years before, 2 pursued by Nebuchadrezzar, who halted only on the borders of Egypt, where the news of his father's death reached him. This decided him to stop his advance, and return to Babylon to secure his succession to the throne, which, however, was undisputed. The whole of Syria as far as the border of Egypt became Babylonian, and the rule of Nebuchadrezzar was accepted everywhere but in Judah, where Jehoiakim, the nominee of Necho, had been left undisturbed as king. He paid tribute at first, but then, carried away by the religious fanaticism which Josiah had called into being, king, priests, and people united in a mad defiance of Babylon, in spite of the vigorous warnings of the prophet Jeremiah. The first capture of Jerusalem by Nebuchadrezzar followed (596), and Jeconiah or Jehoiachin, the young son and successor of Jehoiakim, was carried into captivity, with a portion of the population. ${ }^{3}$

The revolt was probably not inspired in any way by the Egyptians. Necho was busy with great plans of internal development, and especially with the carrying out of his project to unite the Nile with the Red Sea by a canal : he had no desire to interfere further in Asia, and left Jeconiah to his fate.

Nor was Psamatik II (593-589 B.C.), the successor of Necho, desirous of war with Babylon. ${ }^{4}$ He was too much interested in Nubia to think of Asia. During his short reign serious attempts were made to recover part of the old southern dominion from the power of the Napatan kings. The Greek and Carian mercenaries were, as usual, employed to stiffen the native troops, and we have a record of them and their officers engaged on the expedition in a Greek inscription cut on the leg of one of the great colossi of Rameses II at Abu Simbel. ${ }^{5}$ This tells the

${ }^{1}$ Jer. xlvi. 2. Herodotus knew nothing from his Egyptian and Graeco-Egyptian sources of the battle of Carchemish.

22 Kings xxiv. 7 .

3 Ibid. Io ff.

${ }^{4}$ An expedition to Palestine in 590 under Psamatik II is referred to in one of the John Rylands demotic papyri (at Manchester) of the time of Darius; but this may really be a confusion, the expedition referred to being that of Apries in 588 (see p. 545).

${ }^{5}$ Hicks and Hill, Greek Historical Inscriptions, 3. The name 'Potasimto,' 
passer-by that "when King Psamatichos came to Elephantine, those who sailed with Psamatichos, son of Theokles, wrote this. Now they came above Kerkis as far as the river let them go up. And Potasimto led the foreigners, and Amasis the Egyptians. And Archon the son of Amoibichos, and Peleqos the son of nobody, wrote this (lit. us)." Signatures follow: "Elesibios the Teian. Telephos wrote me, the Ialysian. Pabis the Qolophonian..... with Psamatichos.... what time the king sent the army for the first time." It is not impossible that this expedition was that ascribed by Herodotus to Psammetichos I. ${ }^{1}$ The historian says that Psammetichos pursued into Nubia a body of 240,000 native troops (Asmakh) who, tired of their three years' service at Syene, had deserted and were flying to Ethiopia. The inscription is certainly of the time of Psamatik II, ${ }^{2}$ and it seems quite possible that Herodotus ascribed to the great Psamatik's reign an event that really took place in the time of his less-known successor. ${ }^{3}$

HAA-AB-RA UAHABRA (589-565 B.C.), the Hophra of the Hebrews and Apries of the Greeks, is said by Herodotus to have been the son of Psamatik II. He was a warlike prince, but was not gifted with over-much wisdom. Nebuchadrezzar had kept the peace inviolate since the battle of Carchemish, and had employed his energies solely in the erection of his magnificent temples and other works at Babylon. It is possible that Apries took this military inactivity to mean powerlessness; he determined to make another bid for empire in Asia.

The Phoenician cities do not seem formally to have acknowledged the overlordship of Nebuchadrezzar, and, it may be, were more disposed to admit Egyptian than Babylonian dominion, Apries therefore took Phoenicia as his starting-point. Sidon submitted to him without striking a blow; whether Tyre also submitted peacefully or (probably in traditional opposition to Sidon) risked a sea-fight, is uncertain. In any case Tyre

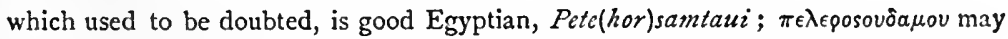
be "Peleqos, son of Oudamos," but to me it seems more probable that " nobody" is meant.

IIDT. ii. 30.

${ }^{2}$ As WIEDEMANN rightly saw.

${ }^{3}$ Also, a similar exodus of discontented soldiers is known to have taken place in the succeeding reign of Apries, and such events are more probable under weak kings than in the time of so strong a ruler as the first Psamatik.

${ }^{4}$ This is, however, difficult to believe, as MASPERo points out (Passing of the Empires, p. 542). He was probably a younger brother or nephew of Psamatik 11. 
joined with Sidon in stirring up the embers of revolt in Judah, and King Zedekiah, relying upon the energy of Apries, gave way to the insensate war party. The gloomy prophecies of Jeremiah, who had no belief in the real power of Egypt, were disregarded, and the tribute due to Babylon was refused. ${ }^{1}$

Nebuchadrezzar at once moved westward and appeared in North Syria (587 B.C.). There he personally remained, with his headquarters at Riblah on the Orontes, while a portion of his army marched south to the final conquest of Judah. He remained at Riblah in order to be able to meet in person any possible Egyptian attack from Phoenicia while his army was engaged in the South. ${ }^{2}$ Apries, however, had no intention of risking an attack on the redoubtable Babylonian king in his own chosen position, and returned by sea to Egypt, whence he advanced through the Negeb to the relief of Jerusalem, now being besieged. ${ }^{\mathbf{3}}$ On his approach the siege was temporarily raised while the Babylonians moved south to meet him. Whether he was actually defeated or simply retired before the threatening Babylonian advance we do not know. He returned to his own country; Jerusalem fell, and Zedekiah the king was taken to Riblah, where, in the presence of the overlord whom he had betrayed, his sons were slain before his eyes, which were then put out. The majority of the Jewish nation was carried into captivity, only a miserable remnant being left behind, which, after the murder of Gedaliah, the governor appointed by Nebuchadrezzar, emigrated, under the leadership of Johanan the captain and Jeremiah the prophet, to Egypt, where Apries established them in the "king's house at Tahpanhes," the fortress which dominated the foreign settlement of Daphnai. ${ }^{4}$

${ }^{1}$ Ezek. xvii.; Jer. xxxvii.

2 Maspero, Passing of the Empires, p. 543, n. ${ }^{1}$.

${ }^{3}$ Joserhus, Ant. x. IO.

${ }^{4} 2$ Kings xxv. There is no doubt that there was a very considerable Jewish immigration into Egypt at this time. Several communities were formed, retaining their national peculiarities and independence of worship intact, each, apparently, possessing its own temple of Yahweh. This unexpected fact we know from the recent discoveries of Aramaic papyri at Elephantiné of the fifth century (published by Sayce and Cowley, Aramaic Pafyri discovered at Assuan, igo6; and Sachau, Drei aramäische Papyrusurkunden aus Elephantine, Abh. k.p. Akad., 1907) which contain the lawsuits of a Jewish family and the petition, written in 408 в.c., of the priests of Yahu (Yahweh) at Elephantiné to Bagohi (Bagoas), the Persian governor of Judah, craving his intervention and help against Waidrang, the Persian general at Syene, who had been bribed by the Egyptian priests of Khnum to destroy the temple 
Tyre was now besieged, and the siege wats prosecuted in a desultory fashion for no less than thirteen years. Finally, in 573 , a treaty was made by which I thobaal the king acknowledged the supremacy of Nebuchadrezzar. Sidon had submitted long before, no doubt. ${ }^{1}$

Apries had afforded no help to the beleaguered Tyrians Probably no troops, either Egyptian or mercenary, could have been got to follow him against the Babylonians. We hear of a military revolt of the mercenary troops at Syene, which was quelled by the governor Nesuhor, ${ }^{2}$ and at the end of his reign he sent an Egyptian army against the Greeks of Cyrene, the disastrous defeat of which brought his absolute power to an end. ${ }^{3}$

A Libyan chief named Adikran had begged Egyptian help against the Cyrenaeans, who were dispossessing his people of their lands. The Egyptian military class, hating and ignorantly despising the Greeks and other foreign soldiers who were so high in favour at court, clamoured to be allowed

of Yahu: they entreat Bagohi and the sons of Sanballat, governor of Samaria, to gain permission for them to rebuild it, saying that it had existed over 120 years, and had been respected by Cambyses when he conquered Egypt. It was a stone building with seven gates, and stone pillars; it was not used for prayer only, but for full sacrificial rites, and therefore was a true temple, not a mere synagogue. We see then that Jews werc settled in the extreme south of Egypt at least as early as $53^{\circ}$ B.C., half a century after the capture of Jerusalem, and that wherever they went they erected temples of Yahweh, not merely synagogues. For questions concerning the origin of the Passover, which have been discussed in regard to these papyri, see DaICHes, in P.S.B.A., Jan. I912, pp. I7 ff. On the whole subject STAERK, Die Anfänge der juidischen Diaspora in Aegypten, O.L.Z., Beiheft, 1908. (It should be noted that certain doubts that have recently been cast upon the genuineness of these papyri do not seem to be based upon any cogent evidence. Therc is no reason what ever to doubt their authenticity.)

${ }^{1}$ I do not see that it is necessary to suppose with Maspero, Passing of the Empires, p. 550 (followed by PeTrie, Hist. Eg. iii. 345) that Apries waged a second war in Phoenicia between 574 (after the capture of Tyre by the Babylonians) and 569,

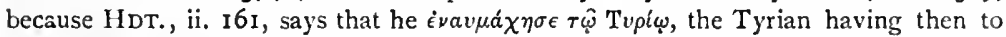
be on the side of the Babylonian, which could only be after the subjection of his city. It seems to me unlikely that Apries attempted to do anything in Phoenicia

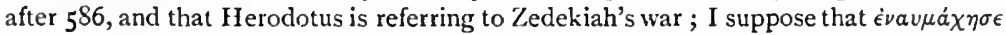
$\tau \hat{\varphi}$ Tupi $\omega$ either refers to an unsuccessful resistancc on the part of Tyre to the arms of Apries in 587 , before she joined his alliance, or is simply a mistake of Herodotus due to defective information.

2 Transl. by Breastis, Anc. Rec. iv. pp. $506 \mathrm{ff}$. (This inscription used to be misunderstood as a reference to an invasion of Egypt by Neluchadrezzar, whom Nesuhor was supposed to have defeated at Syene; see p. 549.)

${ }^{3}$ IIDT. ii. 161 , iv. $150 \mathrm{ff}$. 


\section{THE ANCIENT HISTORY OF THE NEAR EAST}

to help the Libyans. Their annihilation by the Cyrenaeans turned the fury of the anti-foreign party at home against the king, who was no doubt suspected of having sent his warriors to their death by the advice of his foreign friends. A nationalist rebellion broke out, and a capable Egyptian general named Aahmes (Amasis), who had risen from the ranks, was sent by the king against the rebels, probably with the idea that being an Egyptian, they would obey him. They hailed him, however, as king; for Apries had become so hated by the common people on account of his foreign predilections that they were prepared to go the length of dethroning him. This, however, was not to happen. Apries, who had now alienated the nobles by cruelly punishing one of their number who returned unsuccessful from an attempt to treat with Amasis, was deserted by all, and Amasis was made co-regent with him (569 B.C.). The king remained in seclusion at Saïs, while Amasis took over the actual government of the country.

But the fiery Apries could not brook control for long. Three years later he fled suddenly from Saïs, and gathering round him a large force of Greek and Carian mercenary freebooters, prepared to attack Amasis. A battle ensued, of which we have two accounts, one contemporary, given by Amasis in an official inscription, ${ }^{1}$ the other by Herodotus a century later. Both agree that Apries was completely defeated and afterwards slain, but while Amasis states that he was slain by his own followers as he slept in the cabin of the boat in which he had fled, Herodotus tells us that he was handed over by Amasis to "the Egyptians," who strangled him. ${ }^{2}$ Very possibly the Herodotean account is near the truth: it is more probable that Apries was killed at any rate with the connivance of Amasis than that he was murdered by his own men.

It is evident that his conduct in allying himself with the marauding foreigners of the North had put Apries entirely beyond the pale. He was regarded as an utter renegade, and it was only owing to the respect due to one who had been

${ }^{1}$ Published by M. Daressy in Kec. 7 rav. xxii. pp. I ff., with a tentative French translation. English translation, from Daressy's Egyptian text, by Hatl (Oldest Civilization of Greece, p. 323); by BREASTED, from his own copy of the original, Anc. Rec. iv. pp. $509 \mathrm{ff}$.

${ }^{2}$ HDT. ii. 169. 
pharaoh that he was, as Amasis ${ }^{1}$ and Herodotus ${ }^{2}$ both testify, buried in royal state.

It has often been supposed that about the time of the conflict between Amasis and Apries (in 567 B.C.), Egypt was invaded by Nebuchadrezzar, who is even supposed to have marched as far as the First Cataract. This supposition rests on a misunderstanding of an inscription, ${ }^{3}$ and there is no proof of any such invasion. Jeremiah's prophecy ${ }^{4}$ that the Babylonian king would set up his tent on the platform outside the "royal house" at Tahpanhes cannot be taken (on the principle that the prophecies were made after the event) as proof that Nebuchadrezzar ever did anything of the kind. Jeremiah's knowledge of the world and the times had rightly served him in his predictions as to the futility of the Jewish resistance to Babylon; and it was natural that, with the knowledge of the Assyrian conquest of Egypt a century before, he should have prophesied the sequel, a coming subjection of Egypt to Nebuchadrezzar. But in the absence of contemporary proof from Egyptian or Babylonian inscriptions ${ }^{5}$ we cannot assume that the expected invasion ever took place. It is unlikely, for Nebuchadrezzar was growing old, and may have been afflicted with madness before the end. At any rate, in 562 he died. His successors, Amil-Marduk (Evil-merodach), Nergal-shar-ușur (Neriglissar), and Labashi-Marduk(Labassoarchos), were undistinguished and short-lived. With the last, a boy who was allowed to reign only a few months, the Chaldaean dynasty of Nabopolassar came to an end (B.C. 556). The priests of Babylon, to whom the wars of Nebuchadrezzar seem never to have been very palatable, now themselves selected a king after their own hearts, the pious and peaceful archaeologist and amateur of ancient records, Nabuna'id (Nabonidus), son of Nabu-balațsu-iksbi, who was probably a wealthy merchant.

All the kings of Nabopolassar's dynasty had been great builders, of palaces as well as temples, and Nebuchadrezzar

1 " $\mathrm{His}$ Majesty buried him himself, in order to establish him as a king possessing virtue, for His Majesty decreed that the hatred of the gods should be removed from him."

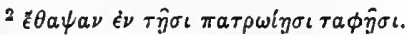

${ }^{3}$ See note 2, p. 547, antea, on the inscription of Nesuhor.

4 Jer. xliii. Io.

5 The inscriptions of Nebuchadrezzar are scanty; for what is known of them see Johns, in Encycl. Bibl., s.v. 
had been the greatest of them. The temples E-sagila at Babylon and E-zida at Borsippa were rebuilt by him, but his greatest work was the building of the walls of Babylon. He was primarily a soldier, and military works appealed to him more than religious. The plan was due to Nabopolassar, who had begun the work. Imgur-Bel, the ancient wall of the inner town, was completed, and the huge outer wall, Nimitti-Bel, was constructed round the whole vast city. Then at one point a great citadel was formed by the construction between the two walls, and connecting them, of a mighty platform of brick, on which rose a seemingly impregnable fortress. In addition to this isolated covering walls and ditches were constructed outside the great outer wall. The king also constructed new streets and secular buildings within the city, which now reached its apogee of splendour, and was the greatest in the world. ${ }^{1}$

Nabonidus carried on the tradition of temple building and repairing. His archaeological instincts led him to conduct researches into the history of the temples which he repaired, and in inscriptions he commemorates the discovery of a foundationstone of Naram-Sin or of Shagarakti-buriash with as much ceremony as an Assyrian king would have commemorated the defeat of an enemy. His knowledge of the period at which the early kings had lived was not always correct, and the guesswork dates which he seems at times to have ascribed to them (the instance of Naram-Sin is certain) have much misled modern historians (see Ch. I.).

The chief temples rebuilt by him were the sun-temple, E-babbar, at Sippar; the temple of Anunitum, E-ulbar, also at Sippar; and E-khulkhul, the far-away shrine of Sin at Harran in Northern Mesopotamia, which had been ruined by the Scyths or Medes half a century before. ${ }^{2}$ The king was entirely

1 The recent German excavations of KoLDEwey have recovered much of ancient Babylon (M.D.O.G., passim). Specially notable is the "Ishtar-Gate," with its relief-decoration in coloured brick, as at Persepolis (Plate XXXIII.).

2 Nabonidus (Abu Habba) Cylinder. I am unable to draw from this inscription the same conclusion as PrÁŠEK (Gesch. M. $u$. P., p. 169), who assumes that Harran was destroyed by the Medes in the first year of Nabonidus. There is nothing in the wording of the inscription to warrant this, which postulates an otherwise unknown invasion of Babylonian territory by Astyages in 555 B.C. That Nabonidus, when in the inscription he is supposed to be urged by Marduk to rebuild E-khulkhul, says to the god that " the Manda surrounds the temple, and widespreading are his armies," is merely speaking in general terms of the proximity of IIarran to the Northern tribes, not referring to an actual possession of the temple 


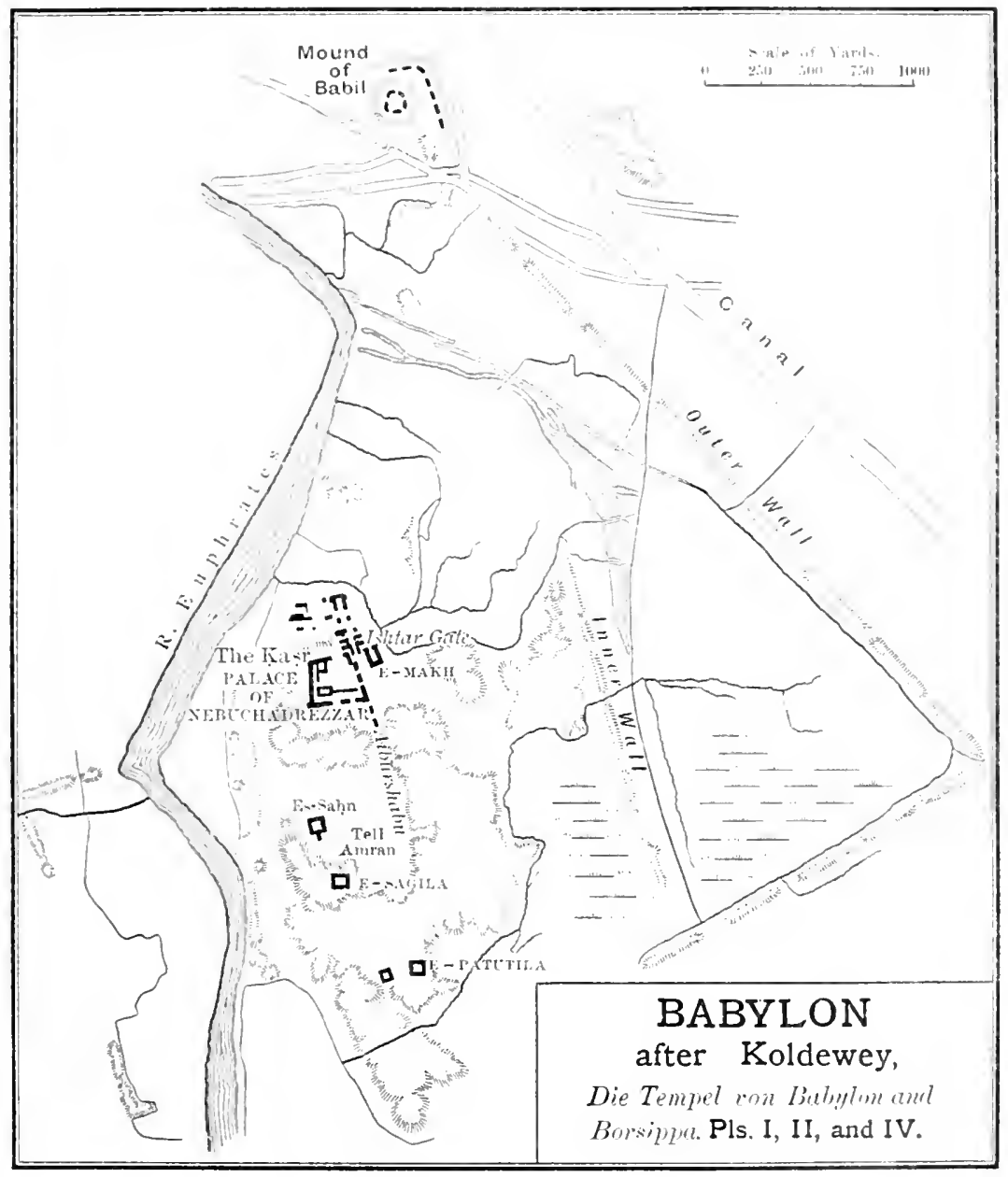



absorbed in architecture and archaeology, and left the civil and military direction of the empire very largely to his son Belsharutsur (Belsharezer or Belshazzar), who in the Hebrew accounts appears as "king" of Babylon.

\section{The Medes and Persians}

The Syennesis of Cilicia-War between Media and Lydia-The great battle of 585 B.c.-Ishtuwigu (Astyages) $\left(5 \delta_{4}-550\right)$-Cyrus the Persian-The Persian nation -The Achaemenian family-Deposition of Astyages-Zoroaster-The Zoroastrian religion

The peace was kept unbroken with the Medes, who do not appear to have attempted to attack their old allies. ${ }^{1}$ North of Babylonia the Tigris formed the boundary between the two empires; north of Assyria the boundary probably ran near the modern Diarbekr to the Euphrates, the right bank of which, perhaps as far north as the district of Malatiya, was now in the possession of the independent king, the Syennesis, who ruled Cilicia. His frontier with the Medes probably ran across the plateau of the Üzün Yaila to the Halys, which from Argaeus to the Black Sea separated the empire of Astyages from that of Alyattes of Lydia, as of old it had separated the "White Syrians" or Hittites from the Phrygians.

This boundary had been won by the Medes after a severe struggle with the Lydians (59I-585 B.C.). The kingdom of Gyges had been severely shaken by the ravages of the Kimmerians, and Ardys and Sadyattes, his successors, had spent their strength in ceaseless attacks on the Greek cities of the Aegean coast. ${ }^{2}$ Accordingly, when Kyaxares attacked him, Alyattes, the successor of Sadyattes, was unable to retain his dominion beyond the Halys. The famous battle of May 28, 585 B.C., which was interrupted by a total eclipse

by the Medes, is shewn by the god's reply, which tells him that Harran was no longer in the power of the "Manda." It is obvious that the devastation referred to took place at the time of the destruction of Assyria; the only question is whether it was effected by the Medes or by the Scyths. Both were called "Manda," a generic term for all the Northern barbarians, by the Babylonian scribes. The point cannot be decided definitely, but if the Scyths of Madyes really invaded Mesopotamia as the allies of Assyria (see p. 5II, n. 2), it may well be that Harran, a town always Babylonian in sentiment, had shewn enmity to Assur, and was destroyed in consequence by Madyes. Harran also seems too far west for a Median attack, while we know that the Scyths ravaged as far as Palestine.

${ }^{1}$ See p. 513 .

See p. $5+1$. 
of the sun, ${ }^{1}$ was followed by a treaty which settled the Halys as the frontier of the two kingdoms, negotiated by the Syennesis of Cilicia and Nebuchadrezzar of Babylon, whose mediation had been sought by the belligerents. ${ }^{2}$ The kingdom of Urartu was finally extinguished, and absorbed into the Median dominions. $^{3}$

Kyaxares now died, an old man, and was succeeded by his son Astyages, the Ishtuwigu of the Babylonian inscriptions, ${ }^{4}$ who reigned till 550, when his kingdom was taken by Cyrus the Persian. How far we may trust the stories of his ferocity it is impossible to say, but at all events the oldest Greek authority, Aeschylos, gives him a good character, ${ }^{5}$ and evidently regarded him as a great and dignified monarch. Under him the rule which the Indo-Europeans of Iran, swarming westwards like their ancestors the Mitannians and Kassites a thousand years before, had imposed on Armenia and Anatolia was consolidated; and when Cyrus deposed him and a Persian ruling house succeeded the Median no disintegration of the new empire took place. The Persians were of the same race as the Iranian Medes, their languages were almost identical; the accession of Cyrus was but a revolution in the ruling dynasty which in no way affected the empire. For this reason it seems unlikely that Cyrus was, as has often been supposed, of non-Persian race, and that Darius Hystaspis was the first genuinely Persian king. Cyrus is called king of Anshan in Elam by the Babylonians, but it does not follow that he was a non-Aryan Elamite in race: probably the Achaemenid house was purely Persian in blood, though ruling over non-Aryan Elamites. Also, it is hardly probable that if Cyrus had not been a Persian, he would have been known, as he was, to the Greeks as specifically "the Persian," and the succession of his house have been regarded, as it was, as a substitution for a Median of a Persian dynasty.

${ }^{1}$ HDT. i. 74. The eclipse had been foretold by Thales the Milesian (see p. 539).

${ }^{2}$ HDT. ibid. He confuses Nebuchadrezzar with Nabonidus, and calls him "Labynêtos." The Cilician "Syennesis" seems to have been a title rather than a name.

${ }^{3}$ According to Lehmann-Haupt, Armenien einst $u$. jetzt, p. 532, Rusas III of Urartu ceased to reign $c .5^{85}$.

- That PrÁšEK, Gesch. M. u. P., p. 167, is right in rejecting Winckler's theory (Untersuchungen, pp. I 24 ff.) that Ishtuwigu was a Scyth, is quite certain.

- Persae, 767. 
The Persians were the southernmost of the Aryan tribes of Iran. How long before the time of Cyrus they had established themselves eastward of Elam we do not know, or whether they were identical with the pcople of "Parsua" who are mentioned at a much earlier period as living in the Zagros region; if they were, they must have moved considerably to the eastward in the intervening period. We have no knowledge of how far eastward the dominion of the old Elamite kingdom extended, or whether Elamite tribes were dispossessed by the Persians from the land in which they founded their national capital Pasargadae, ${ }^{1}$ corresponding to the Agbatana of the Medes. Evidently the exhaustion of Elam in the struggle with Ashurbanipal gave them the opportunity to extend their dominion westward, and so we now find their ancient capital Susa in the possession of the Persian prince Cyrus, who was soon to make it the capital of the Eastern world.

The founder of the Persian kingdom in Anshan seems to have been Chishpish, the Teïspes of the Greeks, son of Hakhâmanish or Achaimenes. Teîspes must have reigned during the last quarter of the seventh century. The Babylonian annals 2 tell us that Cyrus was the son of Kambuzia (Cambyses I), son of Kurush (Cyrus I), son of Shishpish, all of whom are given the title of "great king, king of Anshan." Darius Hystaspis, in the great inscription of Behistun or Bisitûn, ${ }^{3}$ tells us that "My father is Vishtâspa (Hystaspes); the father of Vishtâspa was Arshâma (Arsames); the father of Arshâma was Ariyâramna (Ariaramnes); the father of Ariyarâmna was Chishpish (Teïspes); the father of Chishpish was Hakhâmanish (Achaimenes)." That is to say, both Cyrus and Darius were descended from a common ancestor, Teïspes son of Achaimenes, and since Darius belonged to the same generation as Cambyses (II), son of the great Cyrus, the number of generations agrees in both lines. Then Darius goes on to say: "Eight of my race were kings before; I am the ninth. In two lines (duvitaparnam) have we been kings." Evidently this refers to the two lines of descent, that of Cyrus and that of Darius himself, in the Achaemenid family

${ }^{1}$ On Pasargadae see Herzfeld in Klio, viii. I ff.

2SChRADER, Kéilinschr. Bibliotek, iii. 2, I25. "Shishpish" and "Kambuzia" are so spelt in Babylonian.

${ }^{3}$ KING and Thompson, Sculptures and Inscription of Darius the Great, pp. I, 2. 


\section{THE ANCIENT HISTORY OF THE NEAR EAST}

from Teïspes. We cannot suppose, ${ }^{1}$ on the authority of the genealogical speech put into the mouth of Xerxes by Herodotus, ${ }^{2}$ that an earlier Cyrus, an earlier Cambyses, and an earlier Teisspes reigned between Teispes (the father of Ariaramnes) and Achaimenes, and thus make nine generations of kings before Darius in one line, in face of the direct statement of Darius himself at Bisitûn. The earlier Cyrus, Cambyses, and Teïspes of Herodotus are evidently mere doublets, and we can arrange the genealogy of the Achaimenids as follows :-

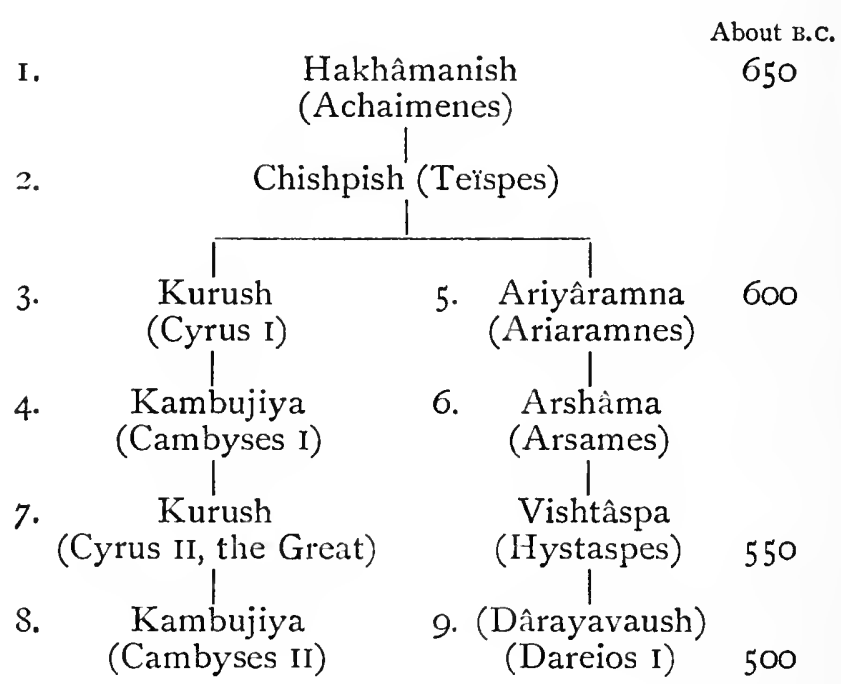

In this list the kings are numbered. ${ }^{3}$ It is evident that Darius counts his father Hystaspes as a king; whether from filial reverence or, as is very probable, because Hystaspes really was to all intents and purposes king of a distant portion of the Persian kingdom, the lands of Parthia and Hyrcania (Parthva and Varkana), the modern Khorassan, which he still governed under the rule of his son. There is no need for us to suppose the existence of two Teispes, three Cyrus, and three Cambyses, any more than that of two Kyaxares.

2 As PrÁšck (Gesch. der Meder u. Perser, pp. I79 ff.) does, quite unnecessarily.

${ }^{2}$ HDT. vii. II.

"According 10 the arrangement of Lehmann-HAUPT, Klio, viii. 495, with which I am fully in agreement. 
The mention of Teispes as the first king of Anshan by the Babylonians shews that he was the first Persian to rule in Elam, and he obviously seized that country at the death of Ashurbanipal, if not before. Achaimenes probably ruled Persia proper only. Whether it was he or a later king who brought Parthia and Hyrcania under Persian dominion we do not know, but it is probable that Cyrus already disposed of the forces of the north-eastern lands as well as of Persia and Elam before he attacked Media.

We need not suppose that Astyages was engaged in any war with Babylonia when Cyrus attacked him. ${ }^{1}$ Of the details of the ensuing war we only know that the Median king defended himself energetically, but was eventually defeated and handed over to the conqueror owing to the treachery of the Median chief Harpagos (550 B.C.).

The deposition of Astyages was evidently received without much opposition by the Medes, and the great Median noble house of Harpagos actively supported the usurper, who made little distinction between Medes and Persians, welding them into a people of which the two component parts were not more distinct than are Scots and English, Bavarians and Prussians, at the present day. The Greeks could speak of a Persian king or say that their traitors "medized," and call their temporary conquerors Medes or Persians indiscriminately.

It has been supposed ${ }^{2}$ that about this time lived in Iran the great religious reformer Zoroaster, and that the impulse which drove the Persians under Cyrus, Cambyses, and Darius to the conquest of the world was in its essence a spiritual enthusiasm inspired by the teaching of Zoroaster. Certainly tradition places the life of Zoroaster in the sixth century B.C. According to one tradition he must have been born about 599 B.C., and commenced his teaching, when forty years old, in Khorassan. There, at Kishmar, in the district of Turshiz, not far south-west

'Prišek's idea (loc. cit. p. 210) that Astyages was besieging Harran when Cyrus attacked him rests solely on his unwarranted conclusion from the cylinder of Abu Habba, which records the restoration of the temple of Sin by Nabonidus, that this destruction was carried out by the Medes under Astyages in the first year of Nabonidus (see p. 550, n. 3).

2 By PrÁsek, l.c. i. pp. 204 ff. This view is not accepted by Prof. E. MeYer (see p. $459, \mathrm{n}$. antea). I do not see that the fact of the occurrence of the word mazda at an earlier period than thi; is a fatal objection to the theory. The word must have existed and been used: Zoroaster gave it a new meaning 
of Mashhad, he planted, to commemorate the conversion of King Vishtâspa (Gushtasp), the famous cypress tree which was said to have lived until $86 \mathrm{I}$ A.D., when the khalif el-Mutawakkil had it felled and taken to Samarra on the Tigris, to be used in the construction of his palace. Now Vishtâspa (Hystaspes), the father of Darius, was historically the ruler of Khorassan (and Darius seems to call him king), so that the tradition may well refer to him, and he may have been converted by Zoroaster, who, if the traditional date be accepted, was not seventy years old at the accession of the son of Hystaspes. The influence of Zoroaster may perhaps be traced in the enthusiasm of Darius for truth and in his hatred of lies; "the lie" which he so constantly denounces in the inscription of Bisitûn may well be the old unreformed Magianism which again and again strove to raise its head against the Zoroastrian reform. In any case he was probably the first strongly Zoroastrian king. It may then be that the doctrine of the prophet of Khorassan did, if he really lived at this time, have something to do with the enthusiasm and energy that gave the Persians in the sixth century the empire of the Eastern world.

At any rate the Zoroastrian reform must be dated before the time of Darius and probably long after the old days when, as we have seen, ${ }^{1}$ the Mitannians venerated the old Aryan deities, Indra, Varuna, and the Nâsatya-twins (Açvins) as their chief gods. Under Darius we find the Zoroastrian Ahura-Mazdâ the chief Iranian deity, and in the Avesta Indra and the Açvins (Naonhaithya) have become daêvas or evil demons. Herodotus's description of the religion of the Persians in his day is a description of Zoroastrianism: he specially notes the peculiar Zoroastrian custom of allowing the bodies of the dead to be torn by birds and dogs. ${ }^{2}$ The Magi whom he describes are Zoroastrian priests, but their peculiarly powerful status in Persia was an inheritance from pre-Zoroastrian days. No Aryan, even before the separation of Indians and Iranians, had been able to sacrifice to the gods without the presence of the magus, the Indian Brahman (Lat. flamen); the magus was the

1 P. 201.

${ }^{3}$ HDT. i. r40. He seems to imply that the body was only first torn by a bird or $\mathrm{dog}$, and then buried. From the Avesta it would seem that the body had always to be seen by a dog before it was sent to the "Tower of Silence" : whether Herodotus is right in implying that the complete surrendering of the body to the vultures had not yet come into rogue we do not know. 
embodiment of all wisdom and the sole interpreter of the gods. It was natural that so powerful a priesthood should come into conflict with the powerful Achaemenian kings, who were little inclined to tolerate opposition to their will, and we shall see that in the reign of Cambyses the royal and priestly authorities did come into collision. It is difficult to see whether Cyrus and Cambyses or the Magi who conspired against Cambyses represent Zoroastrianism: if Cyrus really wished to burn Croesus alive he can have been no Zoroastrian, as such a defilement of the sacred fire of Agni would never have been devised by a Zoroastrian prince. On the other hand, Darius, who was certainly a Zoroastrian, was opposed to the Magi who had conspired against Cambyses, and these therefore appear as anti-Zoroastrians. With Darius, however, the pre-Zoroastrian religion certainly come to an end.

\section{The Conquests of Cyrus}

Croesus attacks Cyrus : battle of Pteria (547)-Croesus summons aid from Greece -Capture of Sardis (546)-The Ionians subdued-The defence of Xanthos-Invasion of Babylonia-Death of Nabonidus (539)-Fall of Babylon (538)-Cyrus conciliates the priesthood-Zerubbabel at Jerusalem-Persian religious tolerance-Amasis takes Cyprus and controls Cyrene : marriage with Ladike-The synoikismos at Naukratis originally an anti-Hellenic measure-Later, Amasis favours the Greeks in order to secure their help against Persia-Friendship with Polykrates-Gifts to Greek shrines -Death of Amasis (526) -Death of Cyrus and accession of Kambyses (529)

The deposition of Astyages seems to have moved Croesus of Lydia to cross the Halys. Before advancing, he consulted the oracles of Greece, and though we may doubt the perspicacity of the Pythia in guessing the boiling of tortoise and lamb together in a brazen vessel, we may accept the final verdict, that if Croesus crossed the Halys he would destroy a great kingdom, as probably the actual historical answer. ${ }^{1}$ So Croesus, interpreting the Delphic saying in the only manner that occurred to him, crossed the river and seized Cappadocia. Cyrus had, however, no intention of accepting a truncated inheritance; he advanced in his turn, in the autumn of 547 B.C., and the

1 1 DDT. i. $46 \mathrm{ff}$. Whether the further oracle, warning Croesus to fly when a mule should become king of the Medes, is historical or not, it is impossible to say. It is by no means impossible that the priests of Delphi may have heard that Cyrus was not a pure Persian, but partly Median in blood, or knew that his subjects were not all Persians, or even Aryans in race. 


\section{THE ANCIENT HISTORY OF THE NEAR EAS'T}

indecisive battle of Pteria took place. Croesus now saw the formidable character of his adversary, and retreated across the Halys to Sardis, proposing to use the winter in summoning aid not only from Sparta, but also from his old ally, Amasis of Egypt, and even from the distant Nabonidus, whom he no doubt wished to stir into an attack on Persia from the rear. ${ }^{1}$ Though Sparta certainly, and Amasis probably, would have sent active succours, it is highly improbable that the timid Nabonidus would have moved in response to the Lydian solicitation. But no time was given even for Sparta to help. Cyrus, knowing the hardihood of his Persians, had no hesitation about marching in winter, and advanced. The Lydian cavalry would not face the Persian camels. Croesus was defeated and shut up in Sardis, which finally fell before the slow-moving Spartans could come to the rescue. That Croesus was removed to Persia as a prisoner, and afterwards lived as a great noble at the royal court, seems highly probable, since Cyrus had not even put his old enemy Astyages to death. ${ }^{2}$

Now followed the subjugation of the Ionian Greeks, which was completed by the cleparture of the Phocaeans to Alalia, ${ }^{3}$ and of the Teians to Abdera. What the Lydians had never been able to do, the energy of the Persians, allied to the knowledge of the art of siege-warfare which they had inherited from the Assyrians, effected in three years. ${ }^{4}$ Against the great mounds heaped up by Cyrus' general, Harpagos, to dominate their walls, against the battering-rams and "tortoises," ${ }^{5}$ the Ionians could effect little. For the first time Greeks were in the inferior military position. In addition to numbers, the Asiatics now brought science into the field. The experience of half-acentury later shewed that in the open field the heavy-armed Greek warriors were more than a match for the Persians; but the first Greek experience of the new rulers of Asia was gained in siege-operations, and the result must have caused a great wave of depression to pass through all Ionia. It is no wonder that Bias of Priene advised a wholesale migration to Sardinia. ${ }^{6}$ The outlook must have seemed hopeless, and the pompous warning which the Spartan envoy Lakrinas had delivered to

\section{${ }^{1} \mathrm{HDT} . \mathrm{i} .75 \mathrm{ff} . \quad 2 \mathrm{Ibid} . \quad{ }^{3} \mathrm{Ibid}$. i. $164 \mathrm{ff} . \quad{ }^{4} \mathrm{Ibill} . \mathrm{i} .14 \mathrm{Iff}$.}

${ }^{5}$ Catapults and movable towers $\left(\epsilon \lambda \epsilon \pi \delta \lambda_{\epsilon \iota s}\right)$ seem as yet to have been unknown. The latter were probably inventions of the Hellenistic siege-engineers.

${ }^{6}$ HDT. i. 170. 
Cyrus at Sardis ${ }^{1}$ must have caused many a wry smile among the Ionians after Phocaea had fallen. The reply of Cyrus, Zoroastrian-sounding enough in its contempt for those who met together in the agora to cheat each other with lies and false oaths, shews the Persian's estimate of his new subjects. But the Persians did not yet know that all Greeks were not tunic-trailing nobles and chaffering hucksters. The Spartans went back as pompously as they had come, and placidly continued to rule the Peloponnese from their unwalled village under the shadow of Taygetus, while the Milesians confirmed the contempt of the Persians by their treacherous submission, in the interests of their trade. This made a united Ionian resistance impossible. Harpagos completed his work by the conquest of Caria and Lycia, after a Lycian resistance which is rendered immortal by the holocaust of Xanthus. ${ }^{2}$

Cyrus, meanwhile, had returned in triumph to Iran, and was now to complete his work by the overthrow of Babylon. This took place speedily. The enemy in the rear was not to be permitted further existence. Already in 546 we find that Southern Babylonia had been invaded from Elam, and a Persian governor installed at Erech. ${ }^{3}$ Then came a pause, due perhaps to complications elsewhere, and it was not till October, 539, that the blow finally fell. Then Gaubaruva (Gobryas), the Persian satrap of Assyria, crossed the Diyâla (Gyndes), and completely defeated the Babylonians at Opis. Belshazzar, who commanded the Babylonians, was probably slain. Nabonidus, who was at Sippar, fled to Borsippa, and Sippar was taken. Two days later Gobryas entered Babylon without fighting. ${ }^{4}$ But the great citadel and royal palace of Nebuchadrezzar may still have held out even after the death of Nabonidus, which now occurred at Borsippa. The siege of the citadel continued throughout the winter. Finally, when its resistance was almost overcome, Cyrus himself appeared upon the scene, and entered Babylon in triumph, amid the jubilation of priests and people. Not long after, the citadel seems to have been stormed (March, 538 ) in the presence of the conqueror. ${ }^{5}$

${ }^{1}$ HDT. i. $15^{2}$.

2 Ibid. i. 176 .

${ }^{3}$ R.P. v. ${ }^{2}$ 161. See Encycl. Bibl., art. "Cyrus."

4 The story of Herodotus (i. 190, 19I), that he obtaincd access to the city by diverting the Tigris and entering by way of its bed, is not borne out by the contemporary annals.

${ }^{5}$ This is uncertain, but seems to be indicated by one or two doubtful passages in 


\section{THE ANCIENT HISTORY OF THE NEAR EAST}

Thus the neo-Babylonian monarchy came to an end. Its miserable collapse was largely due to the rather absurd character of Nabonidus and his foolish quarrel with the priesthood, which had raised him to the throne. In pursuit of his archaeological hobby he had insisted on turning Babylon into a sort of central museum for the ancient images of the gods of all the other cities, collecting them there from all parts of the land. He was simply a collector of old gods, and in his enthusiasm for this occupation he recked nothing of the anger of the local priesthoods and the despair of the people at being deprived of their divine protectors. Also, he was deficient in respect for Marduk, and preferred Sippar to Babylon as his residence. The result was that the whole nation was disaffected, and on the walls of Nebuchadrezzar's palace the writing was clear to all, that his kingdom would be taken by the Medes and Persians.

Cyrus was hailed by the Babylonians as a deliverer. $\mathrm{He}$ posed as the protector of the gods, whose images he sent back to their shrines all over Babylonia. And henceforth, except during the reigns of Darius and Xerxes, the Babylonians were the obedient subjects of the Great King.

The whole Babylonian empire acknowledged Persian rule. Tyre $^{1}$ and Sidon transferred their allegiance without difficulty to the new king of the world, and the Syennesis of Cilicia became his tributary. In Palestine the deported Jews of Babylon were allowed to essay the foundation of a new Jewish subject-community at Jerusalem, under the leadership of Sheshbassar (or Shenazzar) and Zerubbabel (537). ${ }^{2}$ Herein Cyrus again shewed the wise tolerance of the religions of the subject-races that became a characteristic of Persian policy, and contributed very greatly to the stability of the empire.

Amasis made no attempt to dispute the Babylonian inheritance with Cyrus. He was now an old man, and though a soldier in his youth, had never shewn any sign of warlike tendencies, although the weakness of Babylon under Nabonidus

the Nabonidus-annals. It seems more probable that Belshazzar was killed at Opis than than the citadel was defended by him.

${ }^{1}$ Hiram III was now king of Tyre. Under the Persians Sidon became once again more important than Tyre, which was hampered by the small size of her island.

${ }^{2}$ Ezra i.-v. 
would have made it easy for him to have taken Palestine from her, at any rate before the conquest of Lydia made it advisable for him to support Babylon as much as possible against Cyrus. His only act of foreign aggression was the conquest of Cyprus, ${ }^{1}$ which was effected by the arms of his Greek mercenaries. Cyrene voluntarily became his tributary, and he interfered as suzerain in the affairs of the royal house, ${ }^{2}$ besides making a Cyrenaean lady, Ladike, his queen. ${ }^{3}$ This connexion, and the force of circumstances, gradually made him who had been placed upon the throne as a protest against Greck influence in Egypt as great a supporter of the Greeks as Apries himself. At the beginning of his reign he had compelled all the Greek settlements in the Delta to a synoikismos in one place, Naukratis, which was close to the royal capital, Saîs, and so immediately under the royal eye. ${ }^{4}$ Daphnai was abandoned, and all the Greek colonists concentrated at Naukratis, which was a purely Greek city-state, with a constitution partly Dorian, partly Ionian. All the most popular deities of the Greeks had their temples within it, and a great temenos and hall of assembly, the Helleneion, was built by the offerings of the Greek states whose merchants frequented Naukratis. ${ }^{5}$ The city flourished exceedingly, and in it the trade connection between Greece and Egypt developed enormously. Besides traders, Greek artists and thinkers now came to Egypt, and were well received by the king, who had thrown off all restraint in his intercourse with

${ }^{1}$ HDT. ii. I82. The effects of this conquest are soon seen in the suddenly Egyptizing character of Cyprian sculpture at this period. Saite models were largely followed in a more or less modified form.

${ }^{2}$ Maspero, Passing of the Empires, p. 645. In the reign of Arkesilas II, the successor of Battos II, the colony of Barka had been founded, with the result of causing a civil war, in which Arkesilas was defeated and afterwards murdered. The interference of Amasis was now solicited, and Battos III, the Lame, was made king under Egyptian auspices.

${ }^{3}$ HDr. ii. I8r.

${ }^{4}$ Discovered by Petrie in 1884 (PrTrie, Naukratis, i.). His conclusions have been revised by HOGARTH (J.H.S., 1905, p. 105) after further excavations in 1899 and 1903.

${ }^{5}$ On the constitution of Naukratis see Maspero, Passing of the Empires, p. 647. The chief magistrates were called timouchoi, a term of Ionian origin. The temples of the Dioscuri, of the Samian Hera, of Zeus of Aigina, of Athena (then identified with the Egypto-Libyan warrior-goddess of Sais, Neith), and of the Milesian Apollo have either been discovered by the excavations at Naukratis or are mentioned by Herodotus (ii. 178). The states which participated in the Helleneion and appointed the mart-inspectors, were Chios, Teos, Phocæa, Klazomenai, Rhodes, Knidos, Halikarnassos, Phaselis, and Mytilene (HDr. l.c.). 
the foreigners. ${ }^{1}$ The proximity of Naukratis to Saïs enabled him to see the useful side of Greek civilization, and the coming of men of finer brain than the ordinary merchants and mercenaries enabled him to appreciate its higher side, which afforded such a contrast to the dull conservatism and fanaticism of his own people. Also political reasons moved him to court the Greeks in every way. They indeed were his sole hope in case of a Persian attack. Nabonidus was useless. Only from his Greek friends could any effective succour be expected. Polykrates, tyrant of Samos, was now the most powerful ruler in Greece, and with him Amasis concluded a friendship ${ }^{2}$ which only ended when the Samian seemed unable to resist any longer the pressure of Persia. To Hera of Samos he sent divine images, and to the Dorian Athena of Lindos in Rhodes two stone statues and a corslet of linen marvellously woven. ${ }^{3}$ The Greeks of the mainland were also courted, and specially the shrine of Delphi had been honoured by the politic Egyptian king, as by his ally Croesus. When in 548 the temple was burnt to the ground, and the Athenian Alkmaeonidae undertook its restoration, Amasis sent a thousand talents of the then valuable mineral alum to Greece for the work. ${ }^{4}$ But after the overthrow of Croesus the Ionians were too fearful, and the Continental Greeks too careless of the Persian danger, to be likely ever to give direct help to Egypt. Polykrates was a broken reed upon which to rely, and the Spartans, the only Greeks who seemed capable of meeting the Persians on equal terms, were too few and too unused to foreign war to attack Persia in Ionia, still less to bring active aid to Egypt. And as yet their slow minds would have been incapable of so revolutionary a conception, though they could, and did, attack the Ionian allies of Persia when it was too late. ${ }^{5}$ So Amasis fell back into apathy, dying, happily for himself, before the blow fell (526). His son Psamatik III was left to meet it.

But the expected stroke was not delivered by Cyrus. After the conquest of Babylon the great king seems to have waged

${ }^{1}$ HDT, ii. 178.

2 Ibid. iii. 39.

${ }^{3} \mathrm{Ibid}$. ii. I82.

4 Iibd. 180.

5 Their first oversea expedition was directed against Polykrates in 525, and was a failure (HDT. iii. 39, 54). One of its ostensible reasons was the seizure by the Samians of a woven corselet for the goddess Athena of the Brazen House, which had been sent to them by Amasis, a duplicate of that sent to Lindos. It is quite probable that the expedition was really undertaken in some sort of alliance with Amasis, in order to prevent Polykrates from sending the aid which he had proffered to Cambyses. 
war, according to Berossos against the Dahae of Parthia, ${ }^{1}$ according to Herodotus against the Massagetae, a Scythian tribe of the arid region beyond the Jaxartes, to which his dominions certainly now extended. Here he met his death, either in battle or from sickness, ${ }^{2}$ and his crown passed to his son Kambujiya (Cambyses), who had already reigned as subordinate king of Babylon (529 B.C.).

\section{Cambyses in Egypt}

Batlle of Pelusium -Capture of Memphis and deposilion of Psamalik I1-Cambyses becomes pharaoh-Uzahor-resenet-Cambyses' further plans-Expedition to the oasis-Atlack on Nubia-The native kings of Nubia-Nastasenen retires to Meroë-Madness of Cambyses historical-Rebellion of the false Smerdis

Cambyses at once prepared to carry out the next act of the Achaemenid programme, the conquest of Egypt. The successive steps of the Persian progress to the dominion of the world seemed to be the inevitable blows of fate. Like Babylon, Egypt lay inert, as if fascinated, before the Persian approach, and unable to defend herself. The native Egyptians did nothing. The only resistance was offered by the hireling Greek soldiers, themselves disheartened by the conquest of Ionia, and probably largely reduced in numbers since that event. Also, the fleets of their countrymen, both enslaved and free, were arrayed against Egypt in conjunction with those of Phoenicia. For Polykrates, seeing which way the wind was blowing, had placed his ships at the disposition of Persia, ${ }^{3}$ and though the Spartans decided to interfere in order to prevent this, their interference, as we have seen, came too late to help Egypt or hearten the Greeks in Egypt to strike stoutly in her defence. ${ }^{4}$ True, at the battle of Pelusium, when Psamatik III gave battle to the Persian, the mercenaries endeavoured to hearten themselves, it is said, by a bloody sacrifice of the children of Phanes the Halikarnassian, who had deserted from Egypt to Persia; ${ }^{5}$ but the scale was weighted against them, and

As usual, the Spartans tried to lock the door after the horse was stolen. Their ill. success gave them no further appetite for oversea war for many a year.

1 Fragm. Hist. Gr. ii. 505.

${ }^{2}$ Herodotus says in battle (i. 207). He was buried at Pasargadae, in a tomb which still exists.

${ }^{3}$ HDT. iii. 44.

${ }^{4}$ See p. 562, n. 5 .

${ }^{5}$ HDT. iii. 4, II. Phanes, an important commander of mercenaries under Amasis, is also known from a contemporary monument in the shape of a lebes which 
their valour evaporated when battle was joined. The native Egyptians were massacred, and the remnant fled with the king into Memphis, where the strong fortress of the "White Wall" afforded shelter and promised some hope of successful resistance. The prospect of a new Asiatic conquest had driven both king and people mad with rage; a Persian herald, sent on a Mytilenian ship to demand surrender, was torn to pieces, together with his Greek crew. ${ }^{1}$ But mere fury was of little avail against the warriors of Persia, and the few remaining Greeks in the service of Egypt had probably already deserted; Memphis was taken, and, so we are told, vengeance taken by Cambyses for the murder of his herald. As a matter of course, the king of Egypt was deposed, and removed to Asia; ${ }^{2}$ Cambyses ascended the throne of the Pharaohs. ${ }^{3}$

As at Babylon, so in Egypt. The Persian king became an

he dedicated at Naukratis to the Milesian Apollo. It was discovered by Petrie, and is now in the British Museum. The inscription reads: $\Phi a \nu \eta s \mu \epsilon$ a $\nu \epsilon \theta \eta \epsilon \epsilon \tau \pi \sigma \lambda \lambda \omega \nu \iota$

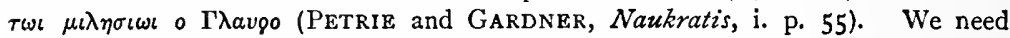
not doubt the Herodotean story of the sacrifice of his children, whom he had left in Egypt. The soldiers slew them over a brazen bowl in sight of both armies; then poured wine and water into the bowl, and drank the horrible mixture. They thus revenged themselves on their leader for his desertion, and offered up a sacrifice of the enemy's men, as the Greeks did before Salamis. The drinking of the blood was an act of mad rage and despair, for the mercenaries could have had little doubt of the issue of the battle.

1 HDT. iii. I3.

2 He was shortly afterwards killed on suspicion of plotting (HDT. iii. I5).

${ }^{3}$ An interesting sidelight upon the Persian conquest of Egypt is probably thrown by a Minaean (South Arabian) inscription of this time (GLASER, II35; Halêvy, 535). This inscription, in the Himyaritic character, records the gratitude of certain Arab merchants who traded between Egypt, Assyr in Arabia, and Mesopotamia ("'bher-hannahar, "the other side of the river" [Euphrates]), to the gods "Athtar, Wadd, and Nekrakh for having protected their camel caravans from attacks by the men of Saba and Khawlan, and having saved them, their goods, and camels in the war between Ma'in and Ragmat, and that between Madai and Mișr, which seems to be otherwise referred to as that between the Lord of the North and the Lord of the South. That "Madai and Mișr" are Persia and Egypt is evident enough, and the only war which is likely to be mentioned thus is that between Cambyses and Psamatik III (Hartmann, Z. Assyr., I895, x. p. 32). Hartmann's view is accepted here without question. The impossibility of the views of GLASER and HOMMEL, which would ascribe a much greater antiquity to these Minaean inscriptions, has been pointed out by HARTMANN, and the use made of their views by Winckier to bolster up his wild "North Arabian Muşri" theory (see p. 466, n. I), has been criticized with just severity in the preface to vol. vi. of BuDGE's Hist. Eg., pp. 16-22. None of the Minaean inscriptions can be shewn to be any older than the sixth century, and this is probably one of the oldest of them. Others are of Ptolemaic date. 
Egyptian pharaoh. The Assyrian kings had taken the $f^{f}$ ands of $\mathrm{Bel}$, and become kings of Babylon, but the gods of Babylon were their gods, and the idea of becoming Egyptian monarchs and bowing down before Amen and Ptah had probably never occurred to them. Such a means of conciliating the conquered would have been beyond their comprehension. To the Persian, however, who himself worshipped Ahuramazdâ, and concerned himself nothing as to the religion of others, Bel was every whit as foreign a deity as Amen; and when a Persian king had naturally become king of Babylon, as the Assyrians had before him, by taking the lands of Bel, there was no reason why his successor should not don the double crown, and make offerings to the deities of Egypt as king. It is to the Gallio-like indifference of the Persians as to the religions of their "slaves," rather than to deep and calculated statecraft, that we may attribute the first adoption of this policy, which was singularly successful in attaching both Babylon and Egypt (the latter for a time at least) to Persia.

The appearance of Cambyses on the throne of Horus "of the living" was stage-managed by a prominent Egyptian functionary named Uzahor-resenet, Admiral of the Fleet, and Lay Warden of the Temple of Neith at Sais, and so one of the most important men in the kingdom, and one most likely to be consulted by the new ruler on all questions relating to the religious side of the Egyptian state. He tells us on his statue (now in the Vatican Museum) ${ }^{1}$ how he was charged to compose the new king's religious or "Horus" name (which, by the way, he did very badly, devising a most uncouth and unusual appellation), ${ }^{2}$ and how he expounded to the ignorant monarch the mysteries of the temple of Neith. He also obtained the royal firman to remove from the precincts of the temple the foreigners who had taken up their abode there, and to restore to the priests

1 References in Petrie, Hist. Eg. iii. 6o, and partial translation. See also BUDGE, Hist. Eg. vii. 44. It is regrettable that Prof. Breasted brings his Ancient Records to an end with the reign of Amasis, and so does not include this important inscription. The form of the name as "Horuzasutennet" given by PRAŚEK, Gesch. $M T$. 2 . P. i. 255, is erroneous; the sign res has been confused by him (or his authorities) with the similar nesut (suten).

2 Ra-mesuti, "She who hath given birth to $\mathrm{Ra}$," in reality a title of the goddess Neith! The Egyptian writing of the name Kambujîya as "Kambeatie(t)," with final $t$ written, but mute, as it was at this period, is interesting. The final $t$ evidently simply expressed the last syllable $y e, y^{\prime} a$, of the Persian name: a vowel was necessary before it, and this alone was pronounced, being inferred from the $t$. 
of Neith the revenues which had been taken from her, as from the other deities, by Amasis for the support of the Greek mercenaries who had proved so useless in the day of trial.

Cambyses was, in his own mind, only on the threshold of his career of conquest. Cyrene submitted hastily to her new overlord in Egypt, ${ }^{1}$ and Cyrene seemed a handy stepping-stone to the conquest of distant Carthage. . On the way thither also was the mysterious oasis of Ammon (the modern Sîwah), where, a few centuries before, emigrants from Thebes had set up an oracular shrine of the Theban god. ${ }^{2}$ Cambyses had occupied Egypt as far as Aswân with his troops, and no doubt abode some time at Thebes. Thence, since the Phoenician sailors definitely refused to sail against their Carthaginian kinsmen, and it was impossible to force them to do so, $^{3}$ he determined to send an army to the Oasis of Ammon. The expedition reached the oases of el-Khargah and ed-Dakhlah safely, but then, striking north-westward towards Sîwah, was lost in the sands of the desert and never heard of again. ${ }^{*}$ The Persians recked little of deserts ; they knew their own hard salt waste of the Kavir and the terrible Dasht-i-Lut, they thought little of the mere steppe between Mesopotamia and Syria; but they did not know the moving sand-dunes of the Sahra, which make it impossible (as Rohlfs found in 1874$)^{5}$ to march north-westward from Dakhlah too far south of the regular route to Farafrah. The Persians must have missed this, the proper way to Sîwah, and so perished miserably.

Meanwhile, Cambyses himself prepared to restore Nubia to Egypt and to overthrow the kingdom of Napata. Since Tanutamon had retired from Egypt, the Napatan realm had

\section{${ }^{1}$ HDT. iii. 13.}

${ }^{2}$ It seems quite possible, if not probable, that the foundation of the temple of Sîwah was directly due to the Theban exiles who were in "the Oasis" in the reign of the Priest-King Menkheperra (see p. 392). This Oasis may just as well have been Sîwah as Khargah. In any case, the founders of the Ammonian temple must have come from Thebes, not from Lower Egypt.

${ }^{3}$ HDT. iii. 19.

4 Ibid. iii. 26. Why this story is rejected as impossible by Petrie, Hist. Eg. iii. 363, and PRÁṠEK, l.c. 257, in face of the experience of the Rohlfs expedition, I do not know. PrAS̉ek is at a loss to know why Cambyses chose to send his army to Sîwah by the roundabout route via Thebes. The reason obviously is that Cambyses was in Upper Egypt at the time, preparing for his Nubian expëdition, and his headquarters were doubtless fixed at Thebes. Thence both expeditions started.

${ }^{5}$ Rohlrs, Drei Monaie in der Libyschen Wiiste, pp. I6I ff. 
been ruled by a succession of princes, whose names are known to us from their inscriptions at Gebel Barkal. Probably in the reign of Aspalut or Aspelta, the successor of Tanutamon, we hear of a heretical sect of "raw-meat-eaters" who took possession of the temples, and were exterminated by the king. ${ }^{1}$ Other kings, Piankh-aluro, Horsiotef, and Nastasenen or Nastesen, followed. Horsiotef seems to have held Syene, and it was in his time that the Asmakh, probably, emigrated to Ethiopia. ${ }^{2}$

Nastasenen was probably the king against whom Cambyses marched. He seems to have been the viceroy of Meroë, the southern centre of the Nubian kingdom at the modern Bagarawiylah near Shendi, which later became the sole capital of the Ethiopian kings. ${ }^{3}$ On his stela at Gebel Barkal, Nastasenen says ${ }^{4}$ that he was called by Amen from Meroë to rule in Napata, and sent messengers north to Dongu-uer (Dongola) to announce his accession to "the royal crown of Horsiotef and the might of Piankh-aluro." The expedition of Cambyses, unsuccessful though it was, seems to have shaken the Nubian kingdom considerably. We need not suppose that Cambyses ever actually reached Napata, but it seems that about this time the Nubian capital was transferred to Meroë. It is probable that Nastasenen took the step of retiring to his own city of Meroë in alarm at the approach of the conqueror, although he says he routed "the man Kambasauden," and took all the flocks and herds which his soldiers had brought with them for their subsistence. It was easy, after the Persian retreat, for him to boast that he had beaten Cambyses, and it is probable that he did no more than capture the Persian convoys; this, however, necessitated the retirement of the invaders, and caused the terrible loss of life from starvation in the retreat through the

${ }^{1}$ Maspero, Rev. Arch. xxi. (I 87 I) p. 329 ; illustrated by Budge, The Egyptian Súdan, p. 71. SCHÄFER (Klio, vi. (1906) pp. $2 \delta 7$ ff.) prefers to take the words Tm. psyu-pr-dl-hayu, which has been translated, "Do not cook that which cometh from the hand of the slaughterers," as Nubian, not Egyptian, and of uncertain meaning ; probably the names of the proscribed families.

${ }^{2}$ HDT. ii. 30. See p. 545. For a sketch of Nubian history at this time, see Hall, in MTurray's Guide to Egypl (1907), p. 552.

${ }^{3}$ The recent excavations of GARSTANG and SAYCE at Meroë have resulted in the discovery of a temple of Amen, the foundation of which probably is to be ascribed to Nastasenen. The remains found are probably of Roman age.

4 This stela is now at Berlin : it was first published by Lepsius, Denkmaeler, Abth. 5, Bl. I6. See Sch ÄFER, Die Aethiopische Königsinschrift des Berliner Museums (IgOI), and Budge, The Esyptian Sidain, ii. pp. $88 \mathrm{ff}$. 
barren region of the Second Cataract, which ruined Cambyses' army. 1

That the two disasters partially unhinged the mind of the Persian conqueror is probable enough. We have no valid reasons to dispute the Herodotean account of his fury, and of the outrages which he offered to the Egyptians and their gods, to doubt that he slew Apis, or even that he violated the mummy of Amasis. ${ }^{2}$ To put these stories down to a supposed "EgyptianGreek" campaign of calumny against the virtuous Persian is, while apparently so critical, in reality quite uncritical procedure. ${ }^{3}$ These wild things are exactly what an infuriated Aryan, maddened by utterly unexpected failure, would do in such a land of "devils" (dcêvas) as "Mudrâya" (Egypt) would now appear to him to be. To the sorceries of Egypt and her demon-gods, creatures of Angromainyus, he would ascribe these catastrophes, and run amok among them. And we have the testimony of Uzahorresenet, writing in the reign of Darius, to the terrible "calamity" which came to pass in Egypt, when the divine offerings were discontinued, the temples desecrated, and the school of sacred scribes (no doubt necromancers in Persian eyes) was ruined. His rage was scarcely glutted, when more news of ill-omen reached Cambyses from Persia. This was the rebellion of the false Smerdis, with regard to which the account of Herodotus ${ }^{4}$ has been completed by the inscription of Darius at Bisitûn. ${ }^{5}$

\section{The False Smerdis and the Reign of Darius}

Death of Cambyses (522)-Death of the false Smerdis-Darius the king (522485 )-Suppresions of revolts-The rock of Bisitûn (Behistun)-Oroites and Aryandes -Darius in Egypt (517)-Temple of el-Khargah-Persian irrigation in the Khargah oasis-Darius at Sardis: the Scythian expedition (515 or 512$)$-The tyrants at the

${ }^{1}$ HDT. iii. 25. I am unable to see any reasons for supposing that Cambyses actually reached Napata, far less Meroë, as Strabo (790) and Diodorus (i. 33)

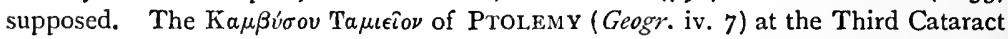
(above Napata!) seems to have been named after it had been supposed that Cambyses got so far. It is evident that Cambyses did not cross the desert from Korosko to Abu Hammad, but went and returned by way of the Nile. His men perished not of thirst in the desert, but of hunger amid the cataracts, where at the present day there is absolutely nothing to eat.

${ }^{2}$ HDT. iii. 16, 27.

3 This is the procedure adopted by PRÁS̆EK (l.c. p. 257), who whitewashes Cambyses, like the rest of his Iranian heroes.

${ }^{4}$ HDT. iii. 6I ff.

${ }^{5}$ See p. 571 . 
Ister bridge-Megabyzos subdues Thrace-Events at Athens: establishment of democracy - The Ionian revolt : burning of Sardis-The hattle of Marathon (490) Effect of the battle in Greece-Themistokles persuades the Athenians to build a fleet -Revolt of Khabbash (486) and death of Darius (485)-High personal character of Cyrus and Darius-The Scythian expedition due to characteristic Aryan recklessness - The organization of the empire-Comparison with Egyptian and Assyrian systems - Persian system developed from the Assyrian-The twenty satrapies-The satrap and his coadjutors-The tribute and the gold "daric"-Travelling commissionersSubject-rulers

Bardiya (Smerdis), the brother of Cambyses, had been privily murdered by the latter before the expedition to Egypt. The long absence of Cambyses, and probably the rumours of his defeat in Nubia that had reached Persia, moved the Patizeithes or chief minister ${ }^{1}$ who had been left in charge at Pasargadae ${ }^{2}$ to bring forward his brother, a magus named Gaumâta, as Bardîya, and to set him up as king. As the murder of the prince was not known, the false Bardîya was generally accepted by the Persians, and even by the Babylonians, as king. Gaumâta was a Magian, and from the terms in which Darius speaks of his rebellion as connected, with "the lie," which, after Cambyses had gone to Egypt, "multiplied in the land," it seems very possible that he was an anti-Zoroastrian, and represented the believers in the older Magian cult. ${ }^{3}$ To put down this revolt Cambyses now left Egypt, placing Aryandes there as satrap, and taking with him the strong Zoroastrian, Darius, son of Hystaspes, ${ }^{4}$ and the other chief leaders of his army. On the way, in Syria, either at Damascus or at Hamath, ${ }^{5}$ the king died suddenly (522 B.C.) It is uncertain whether he killed himself or died from the effects of an accident. ${ }^{6}$ The army, however, did not halt. Taking the body with them, the soldiers pressed

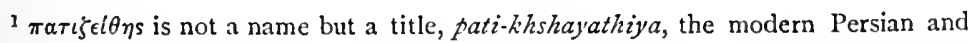
Turkish padishah, which, from meaning "rcgent," has in Turkish become the ordinary appellation of the Sultan.

2 The revolt began at Paishiyauvâda (Pasargadae), according to Darius.

${ }^{3}$ See p. 556.

${ }^{4}$ Dariyavaush, son of Vishtâspa (sce p. 553).

5 The "Agbatana" of HDT. iii. 64, may be a mistake for Akmatha (IIamath); see Nöldeke, in Gurschmid, Neue Beiträge, p. 96. The mention of Damascus rests on the authority of Josephus, Ant. Ind. xi. 2, 2.

${ }^{6}$ It is uncertain whether the Persian noumarsijus amariyat? and the Babylonian mitutu ramani-šu mîti of the Bisitûn Inscription really mean that " he died by his own hand" in the sense of suicide or by accident, as Ilerodotus says (iii. 64). In any case the theory of assassination is impossible in view of the phrase used by Darius. 
on, led by Darius, eager to crush "the lie" and the impudent personator of the dead prince. The Magian retired from Persia into Media, which was probably more inclined towards the old religion, and the Persian nobles who were aware of his fraud prepared on the arrival of Darius and the army from Egypt to act against him. Gaumâta was living in royal state at Sikayauvatish, a castle in the Median district of Nisâya. Thither Darius repaired, accompanied by six other nobles, Viñdafranâ (Intaphernes) son of Vayâspara, Utâna (Otanes) son of Çukhra, Gaubaruva (Gobryas) son of Marduniya, Vidarna (Hydarnes) son of Bagabigna, Bagabukhsha (Megabyzos) son of Dâduhya, and Ardumanish son of Vahauka. ${ }^{1}$ Having forced an entrance into the castle, they fell upon and murdered Gaumâta. Then Darius, in virtue of his royal descent, was made king in succession to the childless Cambyses, his father Vishtâspa (Hystaspes), who was ruling Parthid and Hyrcania as satrap, ${ }^{2}$ being passed over, probably on account of age. $\mathrm{He}$ acknowledged his son as king and served him faithfully.

The new king was not, however, generally acknowledged by his subjects, and the first three years of his reign were taken up by the task of reducing to obedience the various provinces that revolted against him. ${ }^{3}$ The most formidable rebellion was that of Babylonia, under a certain Nadintu-Bel, who made himself king as Nebuchadrezzar III. After two defeats, Nadintu-Bel was shut up in Babylon, which underwent a long and wearisome siege before it was finally taken and the usurper slain. Meanwhile, Elam, Armenia, and Media had revolted, the latter under a certain Fravartish, who "said unto the people, I am Khshathrita, of the family of Kyaxares." This final attempt to restore the old Median kingdom was put down, and the Median cruelly executed. The revolt of Elam, under a Persian who gave himself out to be a native Elamite prince named Ummanish, had been easily overcome, and with it the Elamites disappeared from history. But now even Persia itself revolted under a second pseudo-Smerdis, named Vahyazdâta, who resisted long until the fall of Babylon enabled Darius to

${ }^{1}$ The Herodotean list is Otanes, Gobryas, Aspathines, Intaphernes, Megabyzos, and Hydarnes. The list agrees exactly with that of Darius, as Aspathines must be Ardumanish : only one name has been misunderstood. The list given by Ktesias has the names nearly all wrong.

2 See above, p. 556.

3 The authority for these wars is the inscription of Bisitûn. 
bring his whole power to bear upon him. But then Babylon revolted again under a certain Arakha, and had to be subdued again. A Scythian or Sâka, probably of the Caspian steppes, named Skunka, remained to be vanquished, and with him the last of the enemies of Darius near home disappeared. To commemorate his victories the king caused to be sculptured on a rock-cliff overhanging the main route from Mesopotamia into Persia, through the Zagros, a great tablet on which he represented himself with the conquered rebels bound before him; the accompanying inscription in Persian, Susian, and Babylonian describes his campaigns, and gives the glory to Auramazdâ. This is the tablet of Behistûn or Bisitûn, which was discovered by the late Sir Henry Rawlinson in 1837 and afterwards translated by him. To it we owe not only our firsthand knowledge of the early campaigns of Darius, but also our first real knowledge of the cuneiform inscriptions. ${ }^{1}$

It now remained to Darius to consolidate his power on the confines of his empire. Oroites, the masterful satrap of Sardis, who had decoyed Polykrates from his island and slain him miserably, and had also murdered his fellow-satrap of Daskyleion (the Persian centre of government in Bithynia), was killed by a royal envoy. ${ }^{2}$ Then Aryandes, satrap of Egypt, who had arrogated to himself royal privileges, and seems to have revolted, had to submit on the approach of the king himself, and was executed, in spite of the fact that he had conquered Barka in Cyrene, and had carried the Persian arms as far west as the city of Euesperides (Benghazi). ${ }^{3}$ Darius came to Egypt in 5 I 7 B.C., and at once set himself to conciliate Egyptian sentiment by every means in his power. Uzahorresenet, who had inducted Cambyses into the kingdom, was entrusted by Darius with the task of winning over his countrymen, and seems to have been successful. Darius appears in the list of Egyptian pharaohs as SETETU-RA ("Ra-hath-begotten-him") NTARIUASH. ${ }^{*}$ As king of Egypt his reign was marked by

1 See p. 553. The latest edition of the inscription is that of L. W. King and R. C. THOMPSON, who recopied it in 1904 (The Inscription of Darius the Great at Behistin, 1907).

2 HDT. iii. I $20-27$.

${ }^{3}$ Ibid. iv. 166, 167, 200.

4 The Greek $\delta$ was represented in Egyptian by $n t$-, exactly as the Greeks themselves now represent the Latin $d$-by $\nu \tau-$. A form Tortcsh also occurs in demolic Egyptian documents (BURCHARDT, $\ddot{A} .2$. xlix. p. 70); this must be derived from the Persian through the Greek medium $\Delta a \rho \in$ เos. 
peaceful energy, and the temple of Hibis in the Oasis of elKhargah remains as an important monument of it. ${ }^{1}$ The Oasis seems to have interested the Persian monarch, probably from the resemblance of its natural conditions to those of the eastern parts of his own country, and a Persian method of irrigation by means of underground conduits beneath the beds of the desert-wadis, which collected water from the faults in the sandstone strata, was introduced at el-Khargah, no doubt by Persian engineers. ${ }^{2}$

Darius now turned his attention to the West. In 516 Samos was taken by his generals in the interest of Syloson, brother of Polykrates, who was installed there as a tyrant without subjects, as the resistance of the Samians had provoked the Persians, against the wishes of Darius, to severe measures, and the island was "swept as with a net," and its inhabitants carried away to the mainland. ${ }^{3}$ Darius now himself came to Sardis, and determined to lead a great expedition against the Scythians of Europe, in revenge, so it was said, for the great Scythian invasion of Asia a century before. The whole force of the Ionian cities, under their tyrants, was convoked to the Bosphorus to meet the royal army, and among them were Histiaios of Miletos and Miltiades, the Athenian despot of the Chersonese. The Ionian fleet was sent on to the mouth of the Danube to build the great bridge which carried over the royal army, and guarded it while the king was engaged in his fruitless pursuit of the mocking Scythian, Idanthyrsos. According to Herodotus, the Ionians had the opportunity of breaking up the bridge, and leaving Darius to his fate in the Russian steppes, and Miltiades urged this course upon them. But he (according to the story) was overruled by the counsel of Histiaios, who pointed out to his assembled fellow-rulers that their rule in the cities depended on the Persian power alone, and that, were that destroyed, they would all be driven out, and democracies be installed in their place. This was true enough: the age of the tyrants was fast coming to an end in Greece itself, and only four years later the Peisistratids were

${ }^{1}$ Brugsch, Reise nach der grossen Oase el-Khargeh (Berlin, I878). The temple has recently been excavated and repaired by an American expedition, under Mr. J. Winlock, with the assistance of M. BARAIZE, the engineer of the Service des Antiquités at Thebes. A full account of the excavations, which were carried on for the Metropolitan Museum of New York, will shortly appear.

${ }^{2}$ See Beannell, Air Egyptian Oasis, pp. $170 \mathrm{ff}$.

${ }^{3}$ HUT. iii. I 49. 
to be expelled from Athens for the last time. So, naturally, their own interest prevailed with the Ionian rulers; the great opportunity was lost, and the way left open for a Persian conquest of Greece. ${ }^{1}$

Darius returned in safety to Persia, while his lieutenant Megabazos subdued Thrace, and even received the unwilling allegiance of Amyntas, the king of Macedon.

About the same time (5I4), at the great Panathenaea, the deed of Harmodios and Aristogeiton ${ }^{2}$ proclaimed the fidelity of Athens to the democratic principles of Solon, and her hatred for the tyrant-system which played into the hands of Persia. And three years later Hippias was expelled by Kleomenes and the Spartans, acting in stupid obedience to the Delphic oracle, cleverly manipulated by the exiled Alkmaeonidae. ${ }^{3}$ The constitution of Kleisthenes followed (509), and Athens, despite the temporary episode of the aristocrat Isagoras (507), now became a free and democratic state.

The prestige of her resistance to Persia, which made her for all time the centre of "the glory that was Greece," was soon to follow. Anxious to conciliate Persia, she was first bidden to take back her tyrants and give earth and water to the Great King. She saw that there was no choice for her if she would not be ruled by tyrants again, and when a few years later the failure of the Persian attempt on $\mathrm{Naxos}^{4}$ had for the first time caused the Greeks to doubt the invincibility of the Asiatics, and the intrigue of Histiaios had stirred the Ionians to revolt, ${ }^{5}$ she threw in her

${ }^{1}$ HDT. iv. 137. A proposal may have been made to this effect, and rejected for the reason given, at the instance of Histiaios. But the assigning of the part of patriot to Miltiades is, as was pointed out by ThırLwall (Hist. Gr. ii. App. 2), probably an invention, devised in order to shield Miltiades from the charge of tyranny preferred against him at Athens in 493 (HDT. vi. ro4): he had to be made out to be a Persian-hater. OBst, in Klio, ix. (Igog) p. 4I3, denies that Miltiades took any part in the Scythian expedition at all, but one does not see that this is a necessary supposition, nor is it probable that the tyrant of the Chersonese absented himself when his Persian overlord was on campaign so near him.

2 Hvт. v. 55 ; Thuk. vi. 56-58.

+ In 501 ; HDT. v. $30 \mathrm{ff}$.

${ }^{3}$ HDT. v. 65 ; Thuk. vi. 59.

The connexion of Histiaios with the Ionian revolt has recently been examined by S. HEINLEIN in Klio, ix. (I909) pp. 34I ff. He comes to the conclusion that the tyrant of Miletos was no mere adventurer as he has often been considered, but a ruler of great and constructive ideas, who aspired to unite all the Ionian Greeks into one state-under his own rule-as a Persian dependency, and endeavoured to utilize the revolt for this purpose. There is much to be said for this point of view, 
lot with her brethren, and the burning of Sardis was her gage of battle thrown down to the ancient Eastern world (499). ${ }^{1}$ "Sire, remember the Athenians!" said daily the slave to Darius at Susa, and when first Cyprus and then Ionia were subdued, he ordered his satraps to destroy the insolent little city. The first expedition (in 492) by land and sea under Mardonius, proceeding by way of Thrace, was wrecked by the disaster off Mt. Athos, when the fleet of the Persians was destroyed by a storm. ${ }^{2}$ Then, taking advantage of the factious attack of the Aeginetans upon Athens, the second expedition was launched, this time by way of the islands, under Datis and Artaphernes, and Hippias with them. Eretria was taken, and Athens seemed in instant jeopardy. Madly ran Pheidippides to. Sparta, to invoke the immediate assistance of the titular head of Greece. But before the full moon allowed the pedantic Lacedaemonians to move without breaking their custom, the battle had been fought and won. Led by Miltiades, Kallimachos, and the other strategi, the Athenians and their solitary friends from little Plataeae had drawn up the line of their tribes on the seaplain of Marathon, where Hippias had bidden the Persians land. And when battle was joined, the Persians were met not only with unexpected resistance, but with defeat. For the Athenians indeed "fought in a way worthy to be told. Of all the Greeks whom we know of they were the first to charge the foe at a run; they were the first to endure the sight of the Median dress and the men who wore it; for till then the very name of the Medes had been a terror to the Greeks." Panic took the Persians back to their ships, and the sailors shoved off with those who had got on board ; those left behind were massacred Six thousand of the barbarians perished, and of the Athenians one hundred and ninety-two; and we have no reason to doubt the figures. After a half-hearted reconnoitring of the landingplace at Phaleron the defeated Persians set sail for Asia; and when the Spartans came, they could only inspect the bodies of the slain Medes, commend the Athenians, and march home again, as astonished, probably, as the Persians themselves. ${ }^{3}$

which does not exclude the probability that Histiaios originally fomented the revolt for the purpose of getting himself sent back from Susa to Ionia. And Prof. Percy GARDNER's interesting paper in J.H.S., 19II, pp. I5I ff., in which he makes it probable that the revolting Ionian cities had a common coinage, favours HeINLein's view.
1 HDT. v. $99 \mathrm{ff}$.
2 Ibid. vi. 45 .

${ }^{3}$ Ibid. vi. $97 \mathrm{ff}$. 


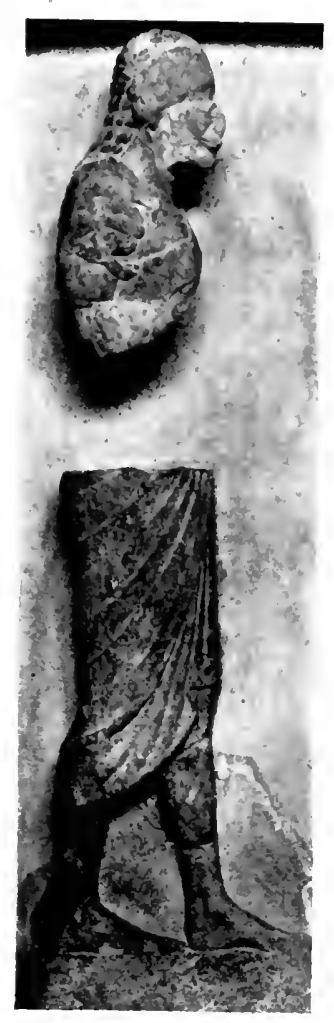

Brip. IIIS.

I. MAIE FIGLRE: FPHESUL

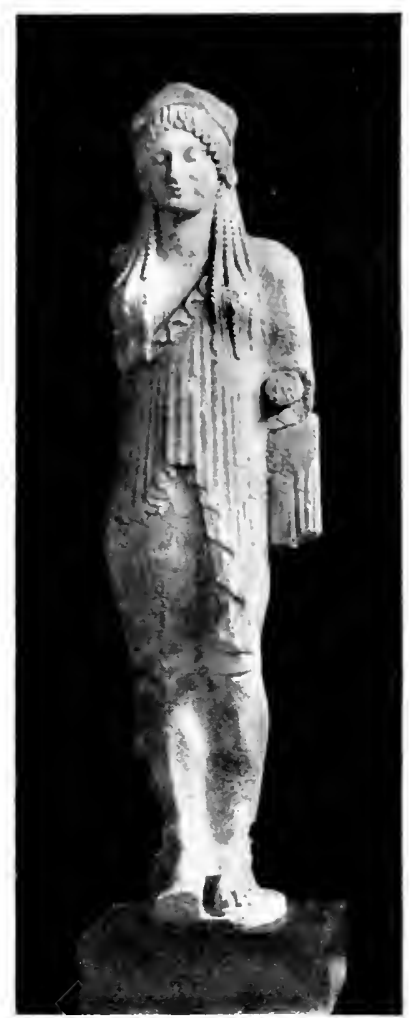

Akropoles Aftsement

2. FEUALE HGLLRE: ATHHXY

GREEK TYPES OF THE SIXTH CENTIRI

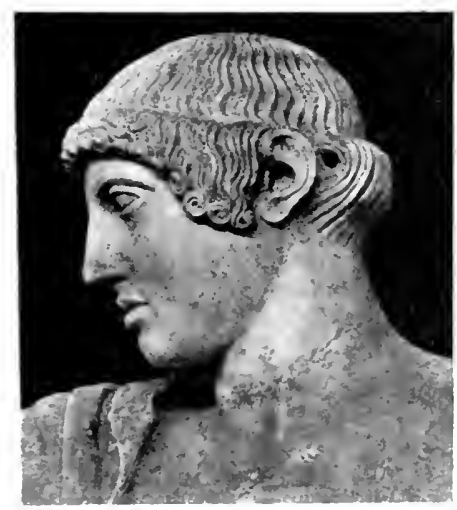

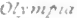

A APrLla A T OLYSIP.

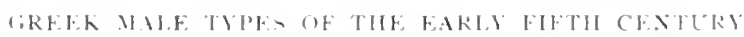

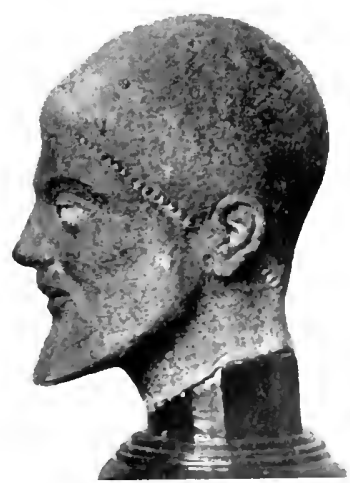

lliens

4. HIRT/E HE.M 

The tremendous importance to the world's history, as we now know it, of the battle of Marathon must not lead us to a disproportionate estimate of its importance as it appeared to men at the timc. To the Persians it was nothing; an "untoward event" of little importance that had happened to a small detached local force owing to the stupidity of its commanders. The failure of Miltiades at Paros shortly afterwards removed any doubts of the Persian power among the islanders who remained subject to the satrap of Sardis. That the news of Marathon in any way contributed to the Egyptian revolt four years later is not in the least likely. In Greece it merely caused the Dorian hatred of Athens to burn anew with the fuel of jealousy, and contributed largely to the "medizing" of Boeotia and Corinth ten years later. ${ }^{1}$ The Spartans, indeed, now began to regard the Athenians with respect, but its most important result was the effect it had on the Athenians themselves, the self-respect it gave them, and the confidence with which, when the grand struggle came, they unhesitatingly declared for resistance, and took the Greeks in spite of themselves to Salamis, Plataeae, and Mykale.

And in Themistokles, who succeeded Miltiades as the leader of Athens, the man appeared who knew how to use the new pride of his fellow-citizens in themselves for the purpose of defending Greece against Persia. He saw that now the Ionian fleets were at the disposition of Persia, the Orientals were masters of the sea, and since Korkyra was far away and her help doubtful, and Aigina was the enemy of Athens, Hellas had no fleet with which to prevent the ferrying of a vast armada across the Aegean. On land, too, the Athenians must always take place very far behind Sparta, the acknowledged military leader of Greece. Had Athens a great fleet, however, she would take on the sea a place equal to that of Sparta on land, and do her part in the defence of Greece as the peer, not the humble follower, of Lacedaemon. And such a place alone was worthy of the city that had defied Darius to the death. So he utilized

1 The Boeotian medizing was probably largely connected also with hatred of Athens for the crushing defeat which the Boeotians and Chalkidians (aristocrats and plutocrats) had suffered at the hands of the new Athenian democracy in 506 (HDT. v. 77). Fragments of the famous inscription in the Athenian akropolis which Herodotus saw,

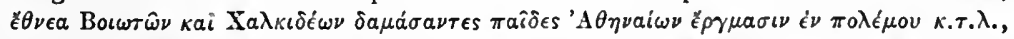
have been discovered, and one at Delphi, mentioned by Pausanias, x. I1. 1. 5, dedicating spoil : Hick.S and Hil.L, Gk. Hist. Inscr. II, 12.) 


\section{THE ANCIENT HISTORY OF THE NEAR EAST}

the necessities of the war with Aigina ${ }^{1}$ to persuade his fellowcitizens to the building of the great fleet that won Salamis for Greece, and thereby raised Athens to the splendid position which she held in the world throughout the next century, and which she will hold in the minds of men to the end of time: Themistokles might not, like Kimon, know how to twang the cithara and shine with the graces of society, but he did know how to turn a little city into a great one.

He was not, however, sufficiently powerful yet in the years that immediately followed Marathon, and had Darius himself led his hosts against Greece then, we may well doubt whether Athens and Themistokles could have saved Greece, and whether the civilization of Rome and Europe would have existed to-day. Furious at the insolent rejection of his demands for earth and water and at the small check, as it appeared to be, which the incapacity of his generals had brought upen the expedition sent to avenge the insult, Darius prepared to crush Greece, or rather Athens, for Sparta was unknown to him and he dreamt only of resistance from the Athenians. All Asia rang with his preparations. But, at the critical moment, Egypt, inspired by the oracle of Buto, revolted under Khabbash (486 B.C.). The rage of the Great King was thus diverted, and then, when preparing to crush ungrateful Egypt in person, he died (485).

Darius, the son of Hystaspes, is one of the greatest figures of antiquity. Like Cyrus, on whom he obviously modelled himself to a great extent, he was a new figure in the East which for a thousand years had groaned under the continual wickedness of the Assyrians. He was an intelligent and reasonable Great King. The like of Cyrus and Darius had hardly been seen ${ }^{2}$ since the days of the great Egyptian pharaohs of the XVIIIth Dynasty, and they, intelligent as they were, and far more humane than the Assyrians, fell far short of the Persians in virtue. The religion of Zoroaster seems to have really given the Persian monarchs high and noble ideas, and in them also we see, as well as his Berserker rage, the fundamental good-nature and "sweet reasonableness" of the Aryan, which was the chief virtue of the culture of the Greeks. This trait is more marked in Cyrus than in Darius, and Darius himself undoubtedly degenerated during his reign.

${ }^{1}$ In 482 : HDT. vii. I 44.

2 Though we may make an exception in the case of Esarhaddon, who is a "sympathique" figure on account of his fine treatment of the Babylonians. 
Under Cambyses the Persian king had taken on many of the vices of the Semitic despots who ruled the world before him, and the generous warrior who so liberally rewarded Syloson, ${ }^{1}$ the great king who conferred benefits on conquered Egypt, was the same man who impaled Fravartish and would have enslaved Greece. Xerxes, his son, was as typical an Oriental despot of the weak kind as any of the weaker Egyptians or Assyrians before him. So the Aryan leader of his people, become an Eastern world-ruler, too soon became a degenerate Oriental. But, unlike his son, Darius had the old Persian virtue in his soul, and, despotic as he became, seems always to have set before himself the ideal of ruling as a beneficent leader of the people whom the grace of Ahuramazdâ had committed to his guidance. His only mistake was the expedition to Scythia, which nearly cost him his life and crown, and this was probably an instance of the characteristic recklessness of the Aryan. His expedition to Greece, had it been accomplished, would probably not have been a mistake. In the incapable hands of Xerxes, it was. The military genius of Darius we have seen in the fierce civil wars at the beginning of his reign; his political genius we see in his treatment of Egypt and in his great work, the organization of the empire in satrapies efficiently controlled by the king. ${ }^{1}$

As an example of imperial organization, combining local autonomy and devolution of authority with an unquestioned central power, that of the Persian empire created by Darius stands unrivalled to this day. ${ }^{2}$ The organization of the Asiatic empire of Egypt by Thothmes III, remarkable as it was for its time, was loose and incohesive; the system of Egyptian residents at the courts of tributary kings and of the travelling commissioners who went round inspecting them was an extraordinary advance in the political development of the world, but it was constantly breaking down, and the regular appearance of the king with his army was necessary to hold the subject pririces to their allegiance. A weak king at Thebes meant the collapse of the system; but a weak king at Susa meant nothing of the kind. The Assyrian system, such as it was, also needed a strong warrior-king to maintain it. For this was simply a crude method of forcible government by major-

1 Hrit. iii. I 39 ti.

2 General account of the system in How and WeLLS, Commentary on Herodolus (Oxford, rg12), i. pp. 399 ff. 
generals, and it was only fear that kept the nations subject; while the instinctive loyalty of the Assyrians to their king and Ashur their "lord" made revolts of distant military governors infrequent. But here also the king and his generals must always go forth to war to make their authority respected. This was not necessary in Persia. The Persian system developed out of the Assyrian; the Assyrian method was taken over by Cyrus, and the first satraps were the successors of the Assyrian military governors. But the greater distance from the centre of some of the governors made revolt more possible than in Assyrian days, and the conduct of Aryandes and Oroites brought about the reorganization of Darius.

The number of the satrapies was now fixed at twenty, including India (the Panjab, which had been subdued by Darius after the Scythian expedition, about 5 IO B.C.), or twenty-one including Thrace, which was lost by Xerxes. Persia itself, as the land of the royal house, was not included, and paid no taxes, but voluntary contributions. Media (Mada), Elam (Uvaja), Babylon (Babirus), and Assyria (Athurâ) formed separate governments. All Syria and Palestine was included in the Arabian satrapy. With Egypt (Mudrâya) were associated the Phoenicians and Cypriotes, as well as the Cyrenaeans, and after the Iorian revolt for a short time Crete (?) and the Cyclades also. Yauna (lonia) comprised the continental Greeks, the Carians, and Lycians, with its capital at Sardis. The northern centre of government in the Aegean region, Daskyleion, was the capital of the satrapy of Sparda, which comprised Phrygia and Mysia. Katpatuka (Cappadocia) and Armenia comprised the rest of Asia Minor to the borders of Athurâ (Assyria) and Media. ${ }^{1}$

In each government by the side of the satrap, now a civil governor only, stood a general and a secretary, each independent of one another, but in direct communication with Susa. Each satrapy was absolutely independent as regards its internal affairs, but had to pay a fixed quotil of tribute, usually in coined money now, to the royal treasury. For the

${ }^{1}$ Lists of the satrapies are given by Darius in the inscriptions of Behistun, Naksh-iRustam, and Persepolis. See SAyCe, Herodotos, i.-iii. pp. 273, 442 ; SPIEgel, Altpers. Keilinschr. pp. 55, I i9. The orderly, organizing mind of Darius is seen in the Behist un inscription itself, in the careful and logical catalogue of the various revolts against his authority. An Egyptian inscription would probably have jumbled them up in confusion. On the Herodotean list, which is remarkably accurate, see WELLS, in How and WeLLS, op. cit. p. 406. 


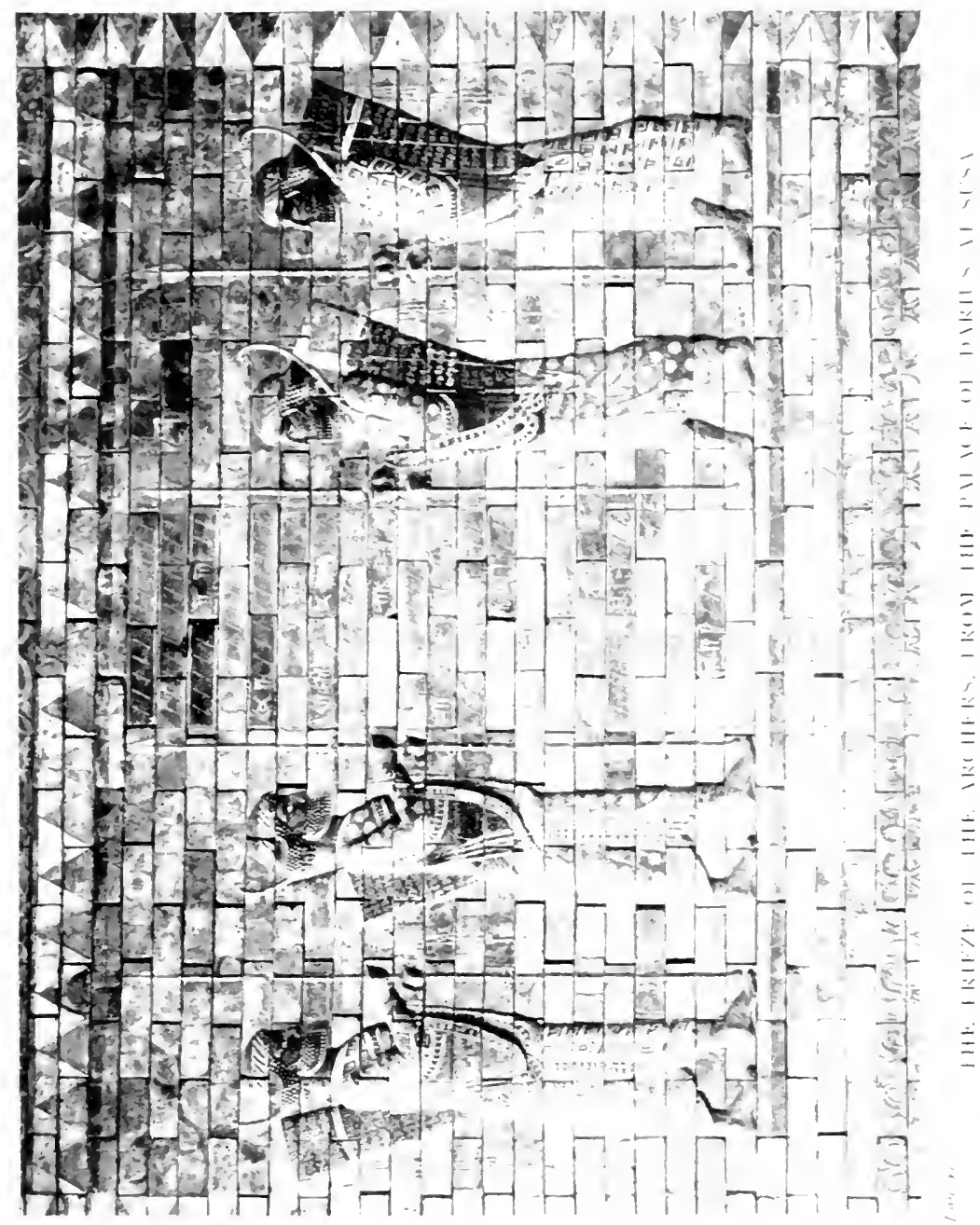



purpose of the payment of this tribute, Darius imitated the Lydians and Greeks in coining money of a fixed standard, the gold "daric" which bore his name, one of the purest gold coins that ever was struck. ${ }^{1}$ This innovation in itself was a strong bond in the empire when all the Eastern world used the same gold coin with its device of the running Persian archer, bow in hand and kidaris on head. The royal authority was further safeguarded by travelling commissioners, the "eyes and ears" of the king; both office and name were probably borrowed by Darius from Egypt. Many of the subject nations still preserved their own native rulers, as Cilicia and the Phoenician and Ionian cities (the Persians naturally took the Ionian tyrants to be kings); Darius, following the policy of Cyrus, allowed the returned Jews at Jerusalem much political liberty under their own leaders, and permitted them to rebuild the Temple. In Egypt the problem was solved by the national acceptance of Darius, like Cambyses, as absolute Pharaoh, by priestly fiction "begotten of Ra." Like his predecessor, he was formally inducted as king, sacrificed to the gods, and especially honoured the Apis who had just died on his arrival in 5 I 7 B.C. But to Babylon he shewed no such grace; though he bore the title "King of Babylon," he never "took the hands of Bel," and "Babirus" was an ordinary province like Media or Parthia. But the Egyptians were too peculiar a people to be thus annihilated politically.

Such was the organization carried out by Darius, and it remained till the overthrow of Asia by Alexander, bringing peace and prosperity to the nations, notwithstanding the revolts of alien Egypt and the attacks of the freed Greeks.

The intention of Darius to enslave Greece must not, then, make us oblivious to his greatness as a king and ruler. Of the Greeks he knew hardly anything but their bad side; of the superiority of their culture to his he could naturally have little idea; he could only regard them as pestilent sea-pirates and incessant troublers of the coasts of Asia and enemies of his Phoenician and Egyptian subjects from time immemorial-a constant source of unrest on the borders of the empire.

${ }^{1}$ It is not certain that the daric was really started by Darius I (HILL, Historical Greck Coins, p. 27). It may have been first coined by Cyrus, though the Greeks ascribed it to Darius. As Mr. Hill says, the derivation of the word sapeckós from the Greek $\Delta a \rho \epsilon$ ios is obvious and certain. 


\section{Greece and Persia}

Babylonian revolt in $48_{3}$-Ostracism of Aristeides (483)-Themistokles archon (482)-Xerxes comes to Sardis (48I)-The Congress at the Isthmus: proposal of Gelon $(48 I)$-Gelon defeats the Carthaginians (48I)-March of Xerxes (480)-The Athos canal-Battles of Artemision and Thermopylai-Delphi saved by an oracleOccupation of Athens-Battle of Salamis-Aeschylean description-Retreat of Xerxes - The battle of Plataeae (479)

The revolt of Khabbash was not subdued by Xerxes till 484 ; then a new Babylonian rising, under a certain Shemserib, ${ }^{1}$ delayed the preparations against Greece for another year, and it was not till 482 that the project could be taken up again at Susa. The delay of four years had stood Greece in good stead, and given Themistokles his chance.

The ostracism of Aristeides, too "just" a man for the stern necessities of the time, too upright to be of practical use when the Mede was knocking at the gate, left the field free to his great rival, the warrior-diplomat who saved Athens, Greece, and with her Rome and ourselves. Though, driven forth in his turn by his ungrateful fellow-citizens, Themistokles died the pensioner of Persia, he died so rather than in any way help to enslave Hellas: and when we praise our famous men, none is more worthy of our honour and praise than Themistokles, son of Neokles, the Athenian. ${ }^{2}$

As archon in 482 he carried his proposals with regard to the navy, and laid the foundations of the maritime power of Athens. He also began the fortifications of the Peiraieus. The struggle was not long to be delayed. Next year Xerxes, full of the vain pomp of an Oriental emperor, came down (as the Greek phrase was) in state from Susa to Sardis, to be ready for the great campaign. In the spring of 480 his march to the Hellespont began. And now events began to move quickly. The imminence of the danger brought together all the Greeks

1 There had also been a rising in the previous year, just before the death of Darius, under a certain Bêl-shı̀manni (UNGNAD, O.L.Z., I907, pp. 464-67).

2 Interesting relics of the Athenian custom of ostracism have been discovered in the shape of actual inscribed ostraka (see J.H.S., 19II, p. 297; ZAH N, Mitth. Ath. Inst., I897, pp. 345 ff.; Hicks and Hill, Gk. Hist. Inscr., p. 16), one bearing the name of Megakles, the uncle of Perikles, who was ostracized in $487-486$; two that of Xanthippos (spelt "Chsanthippos"), son of Arriphron, father of Perikles, ostracized in $485-484$; and one that of Themistokles himself, $\theta \epsilon \mu \tau \sigma \theta \kappa \lambda \eta s s \rho \epsilon a \rho \rho \iota[s]$, which probably is a relic of the actual ostracism of Aristeides in $48_{4-4} 8_{3}$. Themistokles received the lesser number of ostraka, Aristeides the greater, and so went into exile. (See illustration in the British Museum Guide: Greck and Roman Life, p. 7.) 


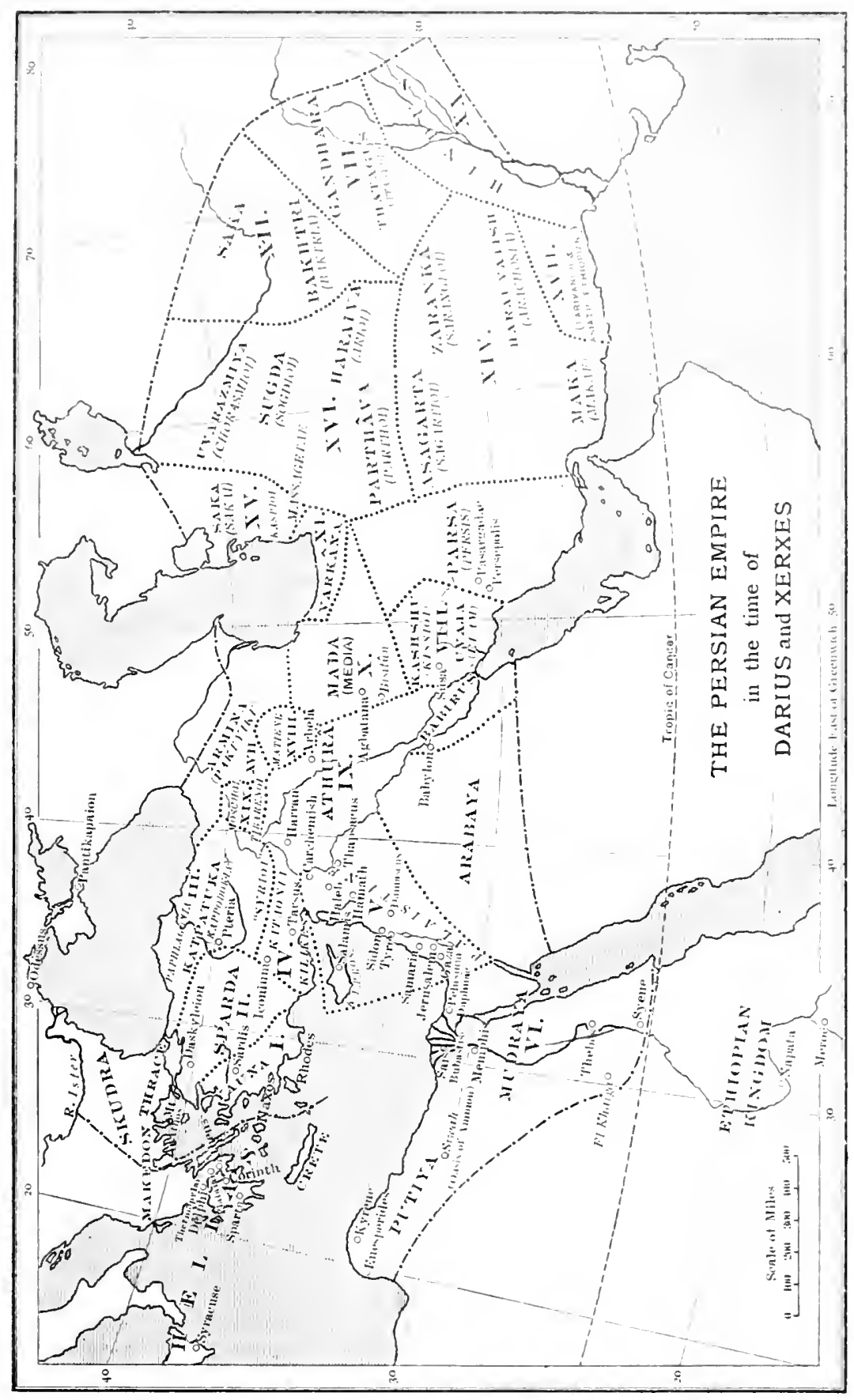



who had not already, like the Thessalians and Boeotians, determined to submit to Persia without fighting. ${ }^{1}$

A congress at the Isthmus put aside all local wars and disputes, and an embassy was sent to the distant colonists of Sicily to seek help from the wealthy and powerful Gelon, tyrant of Syracuse. But the arrogant colonial demanded as the price of his assistance the leadership of Greece either on land or sea. To this neither Sparta nor Athens would consent, and he bade the ambassadors go their ways. ${ }^{2}$ His arrogance was no doubt caused by the great defeat which, probably in the same year (48I), he had inflicted on Hamilkar and his invading host of Carthaginians. ${ }^{3}$ It may well be that this Carthaginian attack on the Western Greeks was arranged in concert with Persia through the medium of the Phoenicians. It was of the highest moment to Persia that the wealthy and powerful Greeks of the West should be prevented from assisting the mother-country, and no means to this end more efficient could have been devised than an attack from Carthage. But the Carthaginian diversion was defeated too soon to enable this aim to be effected, and the powerful Gelon, made confident by his victory, would have proved a formidable ally to the Greeks had not his pride made him overstep the courtesy due to the ancient states of the motherland. Of the Western Hellenes, but a single trireme from Kroton took part in the battle of Salamis.

Meanwhile, Xerxes was pursuing his way to Thessaly. The numbers of his grand army were, of course, enormously exaggerated by the Greeks. So huge a force as they tell of could never have been maintained by any possible commissariat, and

1 The motive of the Aleuadae of Thessaly and of the oligarchic rulers of the Boeotian cities was of course the preservation of their own power, which would be guaranteed by Persia.

2 HDT. vii. $145 \mathrm{ff}$., I 56.

${ }^{3}$ I3id. I66. Hamilkar, son of Hanno, was king of Carthage, nephew, apparently, of Hasdrubal the son of Mago, the successor of Malchos, who (about 575 B.C.) had been executed, according to Justin (vii. I8), adfectati regni accusatus. See BELOCH, Die Konige zon Karthago (in Klio, vii.), who shews that until the middle of the fifth century Carthage was ruled by kings unchecked by the Council of the Hundred and Four Shophetim or Suffetes. Thereafter the power of the kings was greatly curtailed, and eventually they became simple officials like the Roman consuls. Aristotle compares them with the Spartan kings. There were usually two, and the regal dignity was more or less hereditary. We know very little of the early history of Carthage ; and the process of her subjugation of the Numidian tribes is unknown. Her culture was alway's somewhat crude and apparently without either art or literature. 
it is not probable that the whole force ever exceeded two, or at most three, hundred thousand men. Such a force is enormous enough for that time, and even now no modern general, equipped with all modern means of provisionment, would care to take it on one line of march from Asia Minor to Macedonia. A divided line of approach there became necessary, and by two routes the army debouched into 'Thessaly, where it was welcomed by the ruling Aleuadae.

The fleet coasted along the shore. In order to avoid the storms of Athos, which had destroyed the fleet of Mardonius twelve years before, it used the great canal which in the preceding year had been dug through the isthmus of Sanè for this purpose. Finally, at Thermopylae the army, and at Artemision the fleet, came into contact with the Greeks. Thermopylae covered the name of Sparta and of Leonidas with an undying glory, Artemision first showed what the Athenians could do on the sea, though the command of the ships was given to the Spartan Eurybiadas: the Greeks were not used to Athenian command. But it was fated that Xerxes should reach his goal, Athens, and there lose the prize he had come so far to win. The Spartans at Thermopylae died, faithful to the traditions of their race, with a devotion which in modern days no nation but the Japanese can show. This little band could not stay the advancing hordes for more than three days, but that it did that was wonderful, and must severely have shaken the confidence of the Persians in their own prowess and have disquieted the unstable and ignorant king. And Demaratos, the exiled Spartan king who followed in his train, could only tell him that Sparta had eight thousand more warriors, every whit as good as these that had been slain. Xerxes marched on, trusting now only in his numbers. Delphi he left untouched, owing to a clever oracle which the Pythia had put forward to the effect that if Delphi were touched his cause would be lost. Thus indeed the god had defended his shrine. Phokis resisted; Boeotia submitted, as expected. Then Athens fell, and her citizens went on board their ships, to the protection of the wooden walls in which the Pythia had promised them salvation.

The Persian fleet now approached, and in spite of the selfishness of the Corinthian Adeimantos, who thought only of sailing away to defend Peloponnesos, the Greeks, thanks to the adroit stratagem of Themistokles, were compelled to remain 
and fight at Salamis, while Xerxes, from his golden throne on the slopes of Aigaleos, watched the fray in imperial state. ${ }^{1}$ Never had the world seen such a spectacle before, and it was indeed unparalleled, for here now and for the first time the ancient Oriental world met the new European world in deadly conflict, and, before the eyes of its omnipotent ruler, was defeated. All the nations of the Near East were assembled to do battle with their erstwhile sister, who had changed her character and was now no longer the most western nation of the East but the most eastern of the West, and had become the protagonist of the new civilization of Europe against the attack of the ancient civilizations of Asia and Africa. Phoenician, Cypriote, ${ }^{2}$ and Ionian ships formed the main body of the fleet, but Egyptian galleys were there also, manned by "the dwellers in the fens, skilful rowers of galleys." 3 And on board fought not only Persians, Bactrians, and all the dwellers of Asia Minor, but also Egyptians * and, if Aeschylus is not here using a poet's licence, even Babylonians. ${ }^{5}$ The fierce verse of Aeschylus, ${ }^{6}$ who himself fought in the battle, tells us how when day broke the whole of the Greek fleet advanced to the attack, raising the paean, while the trumpets blared defiance to

1 I have not thought it necessary, in a book of such wide scope as this is, to enter into any discussion of the actual tactics of Salamis. It is not absolutely certain how the battle was actually fought, and the identity of the island of Psyttaleia, which played an important part in it, is not definitely settled (see p. $584, n$.). The great fact merely remains that the battle was fought here, in the sound between Salamis and the foot of Aigaleos, where Xerxes sat. I see no reason to doubt the fact of Themistokles' stratagem. See generally on the campaign and battle Macan, Herodotus, ii. App. vi.; How, in How and WeldL, op. cit. ii. pp. $378 \mathrm{ff}$.

${ }^{2}$ Cyprus had passed automatically to Persia with Egypt. The Cypriotes, after an unsuccessful attempt at rebellion in concert with the Ionians (HDT. v. IOS ff.), fell back under the Persian dominion, from which all the efforts of Athens and the patriotism of Evagoras in later years could never rescue them.

${ }^{3}$ Aesch. Persae, 39.

${ }^{4}$ The Egyptian names given by Aeschylus are no doubt fictitious, but they are interesting, as giving the contemporary Greek idea of Egyptian appellations. "Susiskanes" (? Susinkases) is evidently Shushinku, Sheshenk (a name still common at this period) ; Psammis is Psamatik ; "Pegastagon" is not recognizable; Ariomardos, "ruler of ancient Thebes," is Persian, and in another passage he is a Sardian. "Arkteus," in one line an Ethiopian, so that we might compare his name with Tehrak (Etearchos), is also in another a Lydian, as is also Arsames (a purely Persian name), who is elsewhere called "lord of holy Memphis."

5 Persae, 54. It is not improbable that Chaldaean navigators of the Persian Gulf were marched overland to man Phoenician ships as Phoenicians had been taken to man the Assyrian fleet in the time of Sennacherib (see p. 488).

Ibid. $355 \mathrm{ft}$. 
the foe; and how ship met ship with the crash of brazen prows and the rending of timbers as figureheads were torn off and whole banks of oars were overridden and smashed, overturning and killing the rowers as they sat. The barbarian line was at once thrown into confusion; ship collided with ship; while the Greeks, still with order and method, smote remorselessly in all directions, striking and hacking at the wrecked and drowning barbarians as men do at tunnies, with fragments of oars and any weapon that came handy. The arrows of the Persian archers could do but little execution when their ships were foundering beneath them, and the rout became a mere massacre. Troops which had been placed (without any prospect of effecting anything, so far as we can see) on the island of Psyttaleia, ${ }^{1}$ were slain to a man by Greek marines landed there under Aristeides. The Persian allies now sought safety in flight, including Artemisia, the brave Carian queen, who was present in person with her ships. Those who could not escape were slain, "and the sea was filled with shrieks and cries, till with dark night the wailing ceased." Of the Persians a brother of Darius, Ariabignes, was slain, and Aeschylus tells us many another name of note, some genuine no doubt, others fictitious to suit the poet's rime. ${ }^{2}$ Long before the end, Xerxes, who had watched the disaster with growing horror, had risen frantically from his throne, and with a loud cry rent his robes and departed hastily from the scene.

He left Greece at once, pressing furiously homewards towards the Hellespont, lest his bridge should be broken down by the Ionians on hearing of his defeat; and his flight was urged on the faster by the politic ruse of Themistokles, who sent him a message saying that it was proposed to break down the bridge, but that he would hold back the Greeks as long as possible. And this he intended to do, for he wished to facilitate

${ }^{1}$ HDT. viii. 76. BELOCH (Klio, viii. (1908) 477 ff.) has propounded the theory that Psyttaleia is not the modern Lipsokoutali, as it has always been supposed to be, but the island of Agios Georgios in the narrow part of the sound between Salamis and the mainland. He quotes Strabo's description (ix. 395) in support of this. But Strabo speaks of Psyttaleia after Phoron-limen, whereas, if the latter is the bay of Keratsini, Lipsokoutali comes after it, Agios Georgios before it. And Strabo would not have confused Psyttaleia with Aigina in calling it $\lambda \dot{\eta} \mu \eta \nu$ rov $\Pi \epsilon \iota p a \iota t \omega s$ had it lain not, as Lipsokoutali does, right "in the eye" of the Peiraieus but as Agios Giorgios does, far up the sound of Salamis. It would have been just as useless and absurd to put troops on Agios Georgios as on Lipsokoutali.

'See n. 4, p. 583 . 
the departure of the Persians from Europe, and not to retard it. The frantic flight of Xerxes caused great miseries to the troops that accompanied him. Winter set in early, and the Strymon was crossed half-frozen, drowning many when the thin ice broke up as the morning sun grew powerful. He reached the Bosphorus to find the bridge broken down by storms, but crossed safely on shipboard, and returned to Sardis.

Mardonius was left behind in Thessaly with an army which is said to have numbered 300,000 men; a figure which may safely be reduced by one-half or more. He had offered to carry out the conquest with the troops at his disposal. Early in the next year he advanced again to Athens, which was again abandoned. The insistence of Themistokles, and the threat of the Athenians to negotiate with Persia if they were not helped, compelled the Spartans to send out the largest army they had ever equipped, numbering in all about 50,000 men (of whom 5000 were Spartiates), to the Isthmus, although they had not yet finished celebrating the festival of the Hyakinthia. And for the Spartans to move before they had fulfilled their religious duties was unprecedented, and marked their appreciation of the need. The campaign of Plataeae followed, in which the Spartans, owing to the indecision of their leader, Pausanias, did not do very well till the actual shock of battle came. Then they acquitted themselves like Spartans, while the Athenians fought as well on land as they had at sea. The other Greeks did but little. The death of Mardonius and destruction of his army freed Greece; Artabazos with the remnant fled back to Asia, and after the final destruction of his fleet at Mykale, Xerxes, defeated and despondent, went up to Susa, the first king of the Persians who had been decisively worsted in war. Well might the Aeschylean chorus of Persians weep because Darius had not lived to lead the host to victory, "Darius, the master of the bow, beloved sovereign of Susa"! The flower of the Persian chivalry had perished in Greece, but it was perhaps for this very reason that no pretender arose among the nobles to challenge the rule of the defeated king. The disaster, even the defection of Ionia, in no way affected the equilibrium of the empire that Darius had organized so well. ${ }^{1}$ And, encouraged by the dissensions of Greece, Xerxes

1 The Babylonians mistook the signs of the times, and again revolted both in $48 \mathrm{I}$, just before the king went down to Ionia, and in the next year, when he was absent. 
dreamed, thirteen years later, of his revenge. But the battles of the Eurymedon finally shattered this dream, and again it was Athens, now led by Kimon, which was the defender of Greece and of Europe.

On the At-Maidán of Constantinople, the ancient Hippodrome, still stands the stump of the brazen column of twisted serpents which Pausanias dedicated at Delphi in honour of his victory. On it we still read the names of the tribes of Hellenes who together defeated the invader. And among these are the names of the Mycenaeans and Tirynthians: Murnvaíw жxi

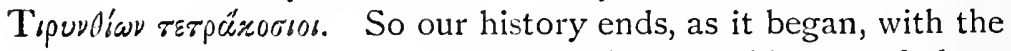
name of Mycenae, and we see the last inhabitants of these ancient towns fighting to preserve intact that European civilization of which in the far-away heroic age their remote predecessors had helped to lay the foundation. ${ }^{1}$

\section{Conclusion}

We have traced the story of the Near East from its beginnings till the climacteric year of Salamis and Plataeae. Greece, whose oldest culture was as old as Babylon and perhaps derived its ultimate origin from Northern Egypt, had gradually in the course of the ages become possessed by the spirit of the Aryan from the North and West. Then, after a terrible internal struggle, won through in a darkness which we cannot penetrate, the Eastern spirit left her, and she stood forth with a Western soul. The songs of Homer proclaimed her new spirit, and the war of Troy was but a rehearsal of the struggle of which Herodotus wrote the story and Aeschylus sang the victory.

The first phase of the conflict between the East and West thus came to an end, the first act of the drama that was to end with the conquest of Persia by Alexander. Then for a time the West imposed its ideals upon the East. But the Hellenistic East was an artificial creation. In its midst Judaism, thanks to the Maccabees, still kept pure the ancient traditions

The result of these revolts was that on his return Babylon was devastated, its walls destroyed, and the temple of Bel sacked, the statue of the god being carried off (HDT. i. I83; cf. ARRIAN, vii. I7). The king also ceased to use the title "king of Babylon." See LehmanN-Haupt in Klio, vii. p. 447.

1 Oldest Civilisation of Greece, p. 29r. This is the last appearance of Mycenae in history. In 468 it was finally destroyed by Argos. 
of the East. And when Jerusalem fell, and all the world seemed Roman, Christianity came, and, an Eastern religion, once more led the East back towards its old ideals. Then, after it had lasted a thousand years, Mohammed destroyed the work of Two-horned Alexander. The Crusades brought again into the Near East another artificial Western dominance, of the most extreme Western type, the incongruous remains of which are among the most interesting relics of past history in the world to-day. And now again, the Western world of railways and of finance is striving to impose its control over the dully resisting Easterns with what eventual result who can say?

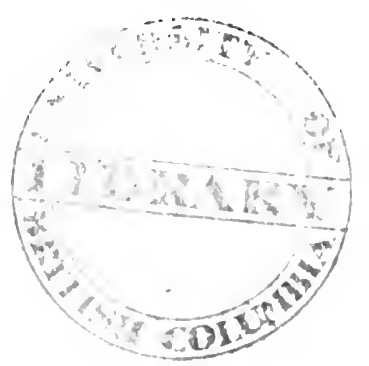




\section{N D E X}

\section{The chief royal names are printed in capitals}

AAinMes I, king of Egypt, 225, 267

Aarmes II. Sie Amasis

Aabmes, son of Abana, 226

Aahmes-Nefertari, queen, 277

Aahimes-Pennekheb, 230

Aamu, I46, 157

AAPE

AA-SEH-RA, Hyksos king, 218

Aasheit, queen, I 45

Abdashirta, 343, 345

Abdkhiba, 348

Abiathar, 429

AвIJAH, 449

Abimelech, 422

Abimilki of Tyre, 347

Abner, 427

Abrahamic legend, 195, 401

Absalom, 432

Abu Simbel, inscription, 544

Abusir pyramids, I3 I

Abydenus, chronicler, 14

Abydos, tombs of, 100, I02; temple of Seti I, 314 ; king-list, 12,103

Achaians, 63, 67, 76, 78, 553

Achish of Gath, 426

Adad, god, 209, 398

ADAD-Nirari I, king of Assyra, 369

ADAD-NIRARI II, 444

ADAD-NIRARI III, 456,460

ADAD-NIRARI IV, 460

ADAD-SHUMi-UȘU R of Babylon, $38 j$

Adapa-legend, 208

Adeimantos, Corinthian admiral, 582

Adikran, 547

Admetos of Tamassos, 496

Administration in Egypt, 279 ff. ; Assyrian, 466

Adonijah, 432

Adullam, 426

Aegean culture, 3 I ff., 57 ; religion, 35

Aeschylos' description of Salamis, 583

Agia Triada, 34, 40, 45; vases, 54 ; sarcophagus, 53

Agriculture, Babylonian, 203

Agun, Kassite king, 200

AHA, king of Egypt, 100, 107

AHAB, king of Israel, 16, $449 \mathrm{ff}$.

AHAZ, 464

AHAZIAH, 16, 452
Ahuramazda, 556

AI, king of Egypt, 303, 309

Ai (town), 410

Aigina, 532, 574 ; coinage of, 532

Aigisthos of Idalion, 496

'Ain Shems (Bethshemesh), $4^{17}$

Aisymnetai, 538

Akaiwasha (Achaians?), 70, 377

AKHENATEN (AMENHETEP IV), king of

Egypt, 20, 298 ff., 306, 349

Akhetaten, 301

Aknthiols (see Kinati), king of Egypt

Akizzi of Katna, 344

Akkad, 176, 185

AKURGal, I 80

Alakshandu of Arzawa, 269, n. 3

Alashiya, 243, 269, 394

Aleppo, 340

Aleuadae, 581,582

Alkmaionidae, 56r, 573

Alôros, 177

Alphabet, origin of the, 429, n. 2, 533

AlYATTES, king of Lydia, 541, 55 I

Amalek, 421, 425

Amanappa, Egyptian general, 343

Amankhâshir, Egyptian official, 247

Amarna, Tell el-, 3OI ; tablets of, 257

AMASIS (AAHMES II), king of Egypt, $548 \mathrm{ff}, 5^{61}$

Amaziah, 457

Amen, god, I33, I52 ; Amen-Ra, I68 ; rise of priests of, $2 \delta_{4} \mathrm{ff}$. ; estates and dues of, $2 \mathrm{~S}_{2}, 2 \mathrm{~S}_{4}$; decay of worship, 323

Amenemapet, Egyptian official, 391

AMENEMHAT I, king of Egypt, I 49

AMENEMHAT III, I62

Amenemheb, Egyptian general, $24 \mathrm{Iff}$.

AMEnheTEP I, king of Egypt, 20, 277

AMENHeteP II, 252

AMENHETEP III, 255, 273, 295; letters of, 261 ; tomb of, 294

Amenthetep iv. See Akilenaten

Amenhetep, son of Hapu, Egyptian minister, 297

Amenirtis, queen, 468

A.menieses, ling of Egypt, 377

Ammi-zadUGa, king of Babylon, 198

Ammonites conquered by David, 430 
Ammunira, Egyptian official, 350

Amorite kingdom, 368

Amphiktionies, 53I

'Amrah, al-, 84

Amraphel, I94

Amurru, 183

AMYNTAS of Makedon, 573

Anakim, I $S_{4}$

Anatolia, 326 ff.

Anshan, 189

Antef-kings of XIth Dynasty, I43

ANTEF Nub-KHEPER-RA, king of Egypt, 220

Antef the herald, 249

Ant-har (Anait-el ?), Hyksos, 217

Anu, 95, n. 2

Anu-banini of Guti, I $\$ 6$

Anubis, god, Io I

APAKHNAS, Hyksos, 215

APEPI I, II, Hyksos kings, 2 I 8

Apries (UAHABra, Hophra), king of Egypt, 545 ff.

ARAD-Sin, I9I

Aramaeans, 400 ; art of, 328 , n. 4 ; writing, 429

Aramaic papyri, 546

ARAME, king of Urartu, 459

ARANDA, ling of Khatti, 354

Ararpakh, 244

Archaeology, 4; relation and history, $6 \mathrm{ff}$.

Archaism in Egypt, IO, 5I9; in Babylonia, 5 I 9

Architecture, Cretan, 42 ; Greek, 535 ; archaic Egyptian, I 8

Archery, I $\$ 9$

ARDYS, king of Lydia, 509

ARgistis I, of Urartu, 459 ; II, 4 So

Argos, 542 ; "transmutation of," 76

ARIK-DEN-ILU, king of Assyria, 368

Arioch of Ellasar, 194

Aristeides, 580

ARkEsilas II, of Cyrene, 56 I

Arko, island, I66

Armenian language, 335 , n. 4

"Armenoid," ethnographic type, 334; race in Egypt?, 87

Arms, Minoan, $38 ;$ Babylonian and Egyptian, I8I

Army, Assyrian, 446, 514

ARNUANTA, king of Khatti, 374

Arpad (Syrian city), 462

Art, Minoan, 46, 54 ; influence of, in Esypt, 292; archaic Egyptian, I 15 ; IVth Dynasty, I24; XIth Dynasty, 145 ; XIIth Dynasty, I63 ; Babylonian, 179; Canaanite, 44I; of Tell el. Amarna, 304; Phoenician, 515, n. 3 ; of Ramesside period, $319 \mathrm{f}$.; Hittite, 329 ; Etruscan and Hittite, 336, n. I ; Syrian, 442, 515, n. 3; Assyrian, 515 ; early Laconian, 534; Greek, propor- tion in, 536; Athenian, under the Peisistratids, 54I : archaic Greek, Egyptian influence in, 535

Artashumara 1 and Il, of Mitanni, 342 Artatama, of Mitanni, 255

ARTEMisia, queen, $5^{84}$

Artemision, battle of, $5^{82}$

Arvad, 240, 346, 362, 394

Aryan. See Indo-European.

Aryandes, satrap of Egypt, 569, 57 I

Arzashkun, $45^{8}$

Arzawa, 269

AsA, king of Judah, 449

Asenath, 406

Aseya $($ Asi $)=$ Alashiya, 243

Ashdod, 416, 528

Asher, tribe of, 414

Asherah, 184, n. 2

AsHiR-Nirari, ) kings of Assyria, 260,

ASHIR-RABI, $\}$ n. 2

Ashkelon, 349, 362, 465, 48 3

Ashtureth, 207, 4I 8

Ashur, god, 331, n. 2

Ashurpanipai, 500, 503, 5II ; art of his time, 5 I 5

ASHUR-BEL-NISHÊSHU, 259

ASHUR-DAN I, $38_{5}$

AsHuR-DAN III, 460

Ashurdaninpal, 455

Ashur-dayan, Assyrian general, 455

ASHUR-NADIN-AKHI, 260

ASHUR-NASIR-PAL 1, $39_{4}$

ASHUR-NASIR-PAL 11I, 445 ; art of, 515

ASHUR-RISH-ISHI, 387

Ashur-Uballit II, 20, 258, 352

Asmakh, 545, 567

ASPELTA, ling of Nubia, 567

Assa, king of Egypt, I32

Assur (city), 399, 460

Assyria, history of, I5 ; early, I93, 260 ; later, $335,445 \mathrm{ff}$. ; relations with Babylon, 259; with Mitanni, 258; with Egypt, 239, 25 I ; military system of, 446 ; decadence, 513

Astronomical dates, 22

Astyages, 552, 555

Aswân (Egypt), chiefs of, 136

Asychis, I27

Aten-worship, 298 f. ; in Nubia, 274; in Palestine, 3.19; abolished, 3 I I

ATETI, king of Egypt, $\mathrm{OO}_{4}$

Athens, synoikismos, 532 ; policy of, 54 I ; under Peisistratids, 54I ; democracy, 542, n. I ; navy, 575; in Persian war, $5^{82}$ Athos-canal, 582

Attis (god), $33^{\circ}$

Auput, 409

Avaris, 21 5, 226

Avvim, I 84

Azariah (UzzIair, Azriya'u of Ya'udi), 463

Aziru, 343, 350 
Baal, king of Tyre, 496

Baal-perazim, battle of, 427

Baal-worship, $45^{2}$

BAASIIA, 449

Babylon, 192 fi. : taken by Hittites, 327 ; taken by Tiglath-pileser $1 \mathrm{~V}, 467$; destroyed by $\mathrm{S}$ nnacherib, 490 ; rebuilt by Esarhaddon, 494; revolt of Shamash-shum-ukin, 506: rebuilt by Nabunasir, 550; buildings of Nebuchadrezzar, 550; taken by Persians, 559; resists Darius, 570; revolts against Persia, 580, 585, n. 1

Babylonia, 4, $203 \mathrm{ff}$; unified by Khammurabi, I9S ; relations with Assyria, 454

Babylonian historians, II ; influence of Bab. culture on the West, $184, n .3$; Bab. and Greek religious myths, 209 ; and Hebrew religion, 209; writing, 175

Bagaios, god, 330, n. I

Bagohi (Bagoas), 546, n. 4

Bai, Egyptian chancellor, 378

Bala'am, 421

BANENETER (Binothris), king of Egypt, I IO

Barak, 414

Barakāt-el (Phoenician merchant), 32I.

Bartatua (Protothyes). 495

BAU-AKH-IDDINA, king of Babylon, 460 .

Beehive-tombs (tholoi), 40, 58

Behistun (Bisitun), inscription, $57 \mathrm{I}$

Bek, Egyptian sculptor, 304

Bekhten (= Kheta), 372

Bel, god (=Enlil), 190

Bela $a^{\circ}$ ben-Beor, $42 \mathrm{l}$

BeLNIRARI, king of Assyria, 368

Belshazzar, 551, 559

Benaiah, son of Jehoiada, 429

BENHADAD II, king of Syria, 449

BENHADAD III (Mari'), 456

Beni Hasan tombs, 151 ; art of, 163

Bentishina (Put-akhi) of Amurri, 362

Berossos, 1 3, 177

Bersheh, el-, tombs, i 50

Besh (Khasekhemul, q.v.), king of Egypt

Bethel, 4 10

BetJu, king of Egypt, I IO

Bêt Khallâf, tombs, I 14

Bias of Priene, $55^{8}$

Bikhuru, Egyptian general, 349

Biridiya, Canaanite prince, 348

Bismaya (Babylonia), discoveries at, 180, n. I

Bit-Adini, 447

Bit-Hallupi, 447

Bit-Humri (Israel), 449

Bit-Yâkin, 467, 480

BiUneter (Ubienthis), king of Egypt, I 10
Black Obelisk, 448, 454

BOCCHORIs, king of Egypt, 479

Bocotia, Neolithic culture of, 62

Boghaz Kyöi, 329, 338 ; tablets, 257

Book of the Dead, 324

Borchardt, Dr., on chronology of XIIth Dynasty, $23 \mathrm{ff}$.

"Boxer Vase," 54

Brabuis, 174, 11. I

Breasted, Prof., history of, 9 ; theory of, on Thothmes 111,287 , n. I ; transl. poem of Alkhenaten, 306

Bronze, origin of, 33 ; at Troy, it.

Brugsch, Heinrich, chronology of, 21, 25,27 ; history, 9

Bubastis, 164, 440

Budge, Dr., history of, 9

Bureaucracy in Egypt, 170, 279

Burials, Egyptian prehistoric, 83 ; Hittite, 340

BurNaburariash, king of Babylon, 200

BURRABURIASH, king of Babylon, 259 ; letters of, 264

Buto, kingdom of, 97

Buyuuk Kalé, $33 \mathrm{~S}$

Byblos, 1 57, 159, 345, 349

Cadmeans, 60

Calah, 448, $46 \mathrm{I}$

Calendar, Babylonian, 208

Calno, 463

Canblses, king of Persia, $565 \mathrm{ff}$.

Canaan, revolt of, under Akhenaten, 265,302 ; culture of, 239,441

Caphtor (Crete), 73

Captivity of Israel, 465, 474; of Judah, 544,546

Carchemish, 340, 447, 451, 478 ; battles of, 242, 543

"Carnarvon Tablet," 225, n. 2

Carthage, 403,581

Censorinus, 19

Ceramics. See Pottery

Chaldaeans, 454,466

Chalkis, 531

Chariots, 181, 213, 446

Charondas, 538

Chedorla'omer, 194

Chemosh, 45I

Cherethites, 416

"Chieftain-vase," 54

Chishpish (Teïspes), 553

Chronology, 15; Minoan, 33 ; Egyptian, $26 \mathrm{ff}$; Babylonian, $28 \mathrm{ff}$.

Cilicia, 229, 486, $55^{1}$

Cist-graves, 38,39

Coinage, Lydian and Ionian, 533; Aeginetan, 532 ; Persian, 579

Colonization, Greek, 526

Colossi of Memnon, 296

Commerce of Egypt, 321 ; Babylon, 20.4; Greek, 53I 
Copper, origin of, $33,38,90$, n. 2

Corinth, $523,530,54 \mathrm{I}$

Costume, Minoan, 48 ff., 58, n. 3

Craniological research in Egypt, 87

Crete, early relations with Egypt, 34, 36 ; expansion of culture, 56 ; legendary connection with Greece, 60; script of, 42,51 ; art, 54

Croesus, king of Lydia, 54I, 557

Cupbearer-Fresco (Knossos), 5 I

Cybele, $33^{\circ}$

Cyclades, $3^{8}, 39$

Cylinder-seals, 89, 206

Cyprus in Neolithic period, 32 ; in Bronze Age, 66, 75, 90, n. 2 ; necropoles, 38 ; Greek colonization, 68 ; tributary to Thothmes I1I, 243 ; submits to Assyria, 480, 496; conquered by Amasis, 56I; revolts against Persia, 583

Cyrene, 527 ; defeats Apries, 547 ; submits to Persia, 566

Cyrus, king of Persia, $552 \mathrm{ff}$; defeats Astyages, 555 ; takes Sardis, $55^{8}$; at Babylon, 560 ; death, 563

Daanua, Danuna, 69, 377, n. I, 381

Datdalids, 60

Dagon, 4 I8

Dahshur pyramids, I 52

Daiukku (Deiokes), 477

Damascus, 346, 400, 43I, 449, 45I, 463

Damasos of Kourion, 496

DAMIKG-ILISHU, I92

Damusi of Kition, 496

Dan, tribe of, 4 I 4

Danube-region, 64

Daplnai (Tahpanhes), 528, 56r

Dapur, siege of, 362

Dardani, 70, 359

Daric, 579

DARIUS, king of Persia, 3 ; genealogy of, 553 ; accession, 570; in Egypt, 571; invades Scythia, 572 ; death of, 576 ; character, 576

Daskyleion, 57 I

DAVID, king of Israel, I 7, 424, $43^{\circ}$

Deborah, Song of, $4 \mathrm{I} 3$

Decadence in ancient states caused by peace, 296 ; in Egypt, 319

Delphi, priests of, 530 ; burning of, $56 \mathrm{I}$; and Persian invasion, 582

Delta, princes of, 500 ; Greek factories in, 527

Deluge-legend, the, 177

Demaratos of Sparta, 582

Democracy at Athens, $532,542, \mathrm{n}$. I

Den SEMTI, king of Egypt, IO7

Dér el-Bahri, XIth Dynasty temple, I44 ; XVIIIth Dynasty temple, 290

Derketo, goddess, 4 is

De Sarzec, discoveries of, I 80
Deshasheh, tombs, I37

Dibon, 45I

Dilmun, I 88

Diodorus Siculus, history of, I0, I26, I 29

Dionysiac cult, 539

"Dipylon" period, 62

Disk, Phaistos, 73 n., 336, n. 3

Disk-worshippers. See Aten-worship

Dodekarchy, 528

Dorians, $522,11.2$; culture of, 522 ; Dorian invasion, 78

Doric column, 535

Dörpfeld, Prof., theories of, $6 \mathrm{I}$

Double Axe, Minoan symbol, 53

Dravidian race, 173

DUlHALIA, king of Khatti, 374

Dudu ('Tutu), Egyptian noble, 347

DUNGI, king of Ur, I9o

Dur-ilu, battle of, 473

Dur-Papsukal, battle of, 455

Dushratta, king of Mitanni, 341, 345 ; letters of, 258 ; death, 35 I

Dynasty, Ist Babylonian, 28, $192 \mathrm{ff}$. ; Ist Egyptian, 27, $106 \mathrm{ff}$. ; IInd, I Io ; IJIrd, III; IVth, IO, I 2 I; Vth, I $29 \mathrm{ff}$; VIth, I34; IXth, I39; XIth, I40, I 42 ; XIIth, 23, I47 ; XIIIth, I65 ff. ; XVIIIth, $228 \mathrm{ff} ., 286 \mathrm{ff}$; XIXth, $313 \mathrm{ff}$, 355, n. I ; XXth, I7, 389 ; XXIst, 390 ; XXIInd, 438 ff. ; XXIIIrd, 468 ; XXIVth, 478; XXVth, 468, 479 ; XXVIth, 5 IS ff. ; Babylonian, of Isin, I9I ; of the Sea-land, I9S; of Pashe, ${ }^{8} 6$

Ea, Babylonian god, 175

EA-GAMIL, I99

EanNatum, i8off.

Eben-ha-ezer, battle of, 422

Edfu, 92

Edom, 420, 43I, 452 ; royal house, $42 \mathrm{I}$

Egri Kyöi, 340

Egypt Exploration Fund, 8

Egyptian prehistoric races, 86 ; early Eg. chronology, 26; Eg. historians, 17 ; language, 86 ; religion, 53,84 , I 19 , I68; art, I I 5, 124, I 45, I63, 304, 319

Ekron, 4II, 483

Elam, I 73, I 82, I 85, I90, I94, 196, 368, 489, 494, 505

Elephantine, discovery of Aramaic papyri at, 546, n. 4

Elephant-hunting, 242

Eli, 422

Elijah, 452

Elisha, 452

El Kab, 93, 279, n. 2

Elliot Smith, Dr., discoveries of, 87 ; theories, 174

Eltekeh, battle of, $48_{3}$

Empire, Egyptian, 230 ff. ; organization 
of, 246 ; Assyrian, 444 ff. ; Persian, $560 \mathrm{ff}$.

Emuthalim, 196

Enkomi tomlss, date of, 37,66, n. 3

Enlil, Babylonian god, 176

ExLIL-13ATI, I0I

ENTEMENA, IS2

Epaphos, legend of, 60

Ephesus, excarations at, 535

Ephraim, Nount, 412

Eponym-canon, Assyrian, I 5

Eratosthenes, If

ERBA-ADAI, kingr of Assyria, 260

Erech, $178,19 \mathrm{tft}$.

Eretria, $53 \mathrm{I}$

'Eridu, I75, 190

EsakHADDON, ling of Assyria, 493, 499

Etana-legend, 208

Ethbaal of Tyre, $45^{\circ}$

Ethiopians, 271; hings, 467

Etruscans, Lydian origin of, 336 : Etruscan and Minoan religion, 54

Euesperides (Benglhazi), taken by Persians, 571

Europa-legend, $6 \mathrm{I} \mathrm{n}$.

Eurybiadas, $5 \mathrm{~S}_{2}$

Eurymedon, battles of the, $5 \$ 6$

Evans, Sir Arthur I., discoveries of, $S$, $34 \mathrm{ff}, 43 \mathrm{ff}$.

EVIL-MERODACH, king of Babylon, 549

Exodus, the, date, $403 \mathrm{ff}$.

Ezion-geber, $43 \mathrm{I}$

Famine in Khatti, 376

Fârah, excavations at, 176

Fayyum, the, 150, 152

Fenkhu, 159, 276

Foreigners in Egypt, 321, 366, n. I

Forsdyke, E. J., views of, $37, n_{1}, 65, n$. 2

Fravartish, revolt of, 570

Frescoes, Minoan, 54

Gades, founding of, 403

GANDASH, Kassite king, 199

Gardiner, A. H., work of, Is

Gardner, Prof. Percy, views of, 534, n.

Garstang, Prof., discoveries of, 8, I 5 I

Gath, 428

Gaumâta (pseudo-Smerdis), 569

Gaza, 433, 465; Minoan cults of, 399, n.

Geba, 423

Gebel Barkal, 27 I

Gelo of Syracuse, $58 \mathrm{I}$

Gem-Aten, temples, 274, 300

Genubath, 435

Geometric pottery of N. Greece(Neolithic), 62; (Iron Age, "Dipylon"), 74, 521 ; origin of, 63

Gezer, 410,417 ; destroyed by Egyptians, 437 ; excavations at, 72,442 , n. 2
Ghost-kings of Egypt (

Giaur-Kalessi, 329, n. 2

Gideon, 420

(iilboa, Mount, battle of, 426

(iilearl, 424

(iilgamesh-legrend, ${ }_{7} \mathrm{~S}$

Gilukhipa, 256

Gobryas (Gaubaruva), I'ersian general, 559 .

Gods, Babylonian, 207 ; Egyptian, 1 19, $16 \mathrm{~S}$; Hittite, 332; Greek, 520

Gold-mines of Nubia, $37 \mathrm{~S}$

Goodspeed, Prof., history of, 9

Gordios, king of l'lorygia, 477

Goshen, land of, 404

Goyyin (Hittites), 194, 327

Greece, prehistoric civilization of, $4 \mathrm{ft}$. ; prehistoric inhabitants not IndoEuropeans, $5 \mathrm{ff}$; relations of mainland with Crete in Bronze Age, $56 \mathrm{ff}$; later culture of, 537

GuDEA, 28, is 9

(iuti, 186

GyGES, king of Lydia, 504, 509

Haau (Haunebu), $35 \mathrm{ff}$.

IlADAD II, III, kings of Edom, 43I, 434

IIADADEZER, king of Syria, $43^{\circ}$

Haggamissa, castle of, $36_{3}$

Hakhâmanish (Achaimenes), 553

Halbherr, Prof., work of, $S$

Halpashulut,j, Hittite prince, 36r

Halys, river, 337

Hamath, 340, 4jo, 449

Hamilkar, $58 \mathrm{~s}$

Hamites in Egypt, $\$ 6$

Ilammamat, Wadi, 9I, I54

Hanun of Gaza, 465,473

Hapuseneb, Egyptian vizier, 280, 29 I

Harem-conspiracy under Rameses III, ${ }_{3} S_{3}$

Harmodios and Aristogeiton, 573

Harpagide tradition of Median history in Helt., 7

Harpagos, $555,55 \mathrm{~S}$

Harran, $55^{\circ}$

"Harrester-vase," 54

Hatarika, 460

Hathor, goddess, 91, 155 : pricstesses of, 145 ; popular worship of, $2 S 6, \mathrm{n}$.

ILatiba, queen of Alashiya, 394

Hatshersut, queen of Egypt, 232, $286 \mathrm{ff}$.

Ilawara pyramids, 152

HAZAEL, king of Syria, $452 \mathrm{ff}$.

Hebrew Kingdom, division of, 16, 435

Ilebrews invade Palestine, 4 IO

Heliopolis, 85 , I 29, I 52

IIellenes, 520

Hellenism, 529

Hemaka, Egyptian official, IoS

Henu, Egyptian official, 36, n. I, 147 


\section{THE ANCIENT HISTORY OF THE NEAR EAST}

Heraios of Soloi, 496

Herakleopolite kings, 139

Heralds, 249, 282

HERIHOR, king of Egypt, 390

Heriu-sha, 137

Ḧerkhuf, chief of Aswân, I36

Hermonthis, chiefs of, I 40

Hermopolis and the XVIIIth Dynasty, 224 ; sicge of, $469 \mathrm{ff}$.

Herodotus, scope of his history, I ; Harpagide tradition used by, 9 ; de. scription of Pyramid-kings, Io, 126, I29; of Babylonia, 203, 206; Median history, 496

"Hesepti," king of Egypt. See Semti Hesiod, 538 , n. I

HetepsekHEMUi, king of Egypt, i 10

HezeKiali, 480 ff.

Hibis, temple of, 572

IIierakonpolite kingdom, 97

Himera, battle of, $58 \mathrm{I}$

Hippias expelled from Athens, 573

Hiram of Tyre, 239, 430, 434, 46.4

Hissarlik (Troy), 39; Buckelkeranik of, 475

Histiaios, 572

Hittites (Khatti, Kheta) raid Babylonia, 199 ; in Syria, 230; inscriptions of, 329; racial affinities of, 334 ; culture, 337 ; names of, 36I ; gifts to Thothmes III, 242, kingdom, 34I ff. ; decline, 37 I ff.

Hogarth, D. G., work of, 44

Homeric question, 75; Homeric age, 76 ; description of Egyptian Thebes, 380

Hophni, 423

Hordedef, I 28

HOREMHEB, king of Egypt, 3 IO

Horites, i 84

Horse unknown to Sumerians, ISI ; introduced into Egypt, 213; on a Minoan tablet, 5 I

HorsioteF, king of Nubia, 567

Horus-legends, 92

HosheA, ling of Israel, 465, 47 I

House, Northern, in Greece, 63

Hui, Egyptian viceroy, 353

Hyksos, 167, 212 ; chronology of, 23, 24 ; and the Exodus, 213 , 40S; survivals of, 3 I 5

Hymns, Egyptian, to the Aten, 306 ;

"Hymn of Victory," 250

Hyria and the Minos-legend, 65

Iconium, 339

Idaean Cave, 535

Idanthyrsos, 572

Idibi'ilu, kiphu of Musri, 466

Illahun, pyramid, 152

Illubru (Lyrbe), 488

ILUMA-ILU, I 9 S
ILU-shuma, king of Assyria, 193

Illyrians, 74

Inarōs, Tale of the Armour of, 501

India and the Sumerians? I 73

Indo-Europeans, 3; Kassites, 20I ; Mitannians, 201 ; in Greece, 32, 64, $68,520,537$

Indra, Aryan god, 201, 33I

Ingirâ, 486

Inukhsamar, Babylonian general, I96

Io, legend of, I, 60

Iolkos, 6I

Ionians, $67,78,79,486$; Cretan colonists in Ionia, 52I ; Ionian expansion, 522 ; rebirth of Greek culture among Ionians, 533; Ionians conquered by Cyrus, $55^{8}$; Ionian revolt, 574

Ionic column, 535

IRISHUM, 29

Irkata, 346,348

Irkhuleni, Syrian prince, 449

Iron, introduction of, into Greece, 64 , 73 ; in Palestine, 4I5

Irrigation in Babylonia, 203; Persian, at el-Khargah, 572

Isaiah, 464,485

ISHBAAL, 426

IsHPUINIs, king of Urartu, 459

Ishtar, goddess, 207, 219, $197 \mathrm{n}, 25 \mathrm{~S}$

Ishtar-Gate, at Babylon, 550, n. I.

Ishtar-washur, Canaanite prince, 247

Isin, dynasty of, 191

Isopata tomb, 44

Israel, $7 \mathrm{I}$; and Meneptah, $4 \mathrm{I} 3$; division of kingdom, 435; civilization of, 442 ; captive, 474

Israel-stele, 403,576

Isthmus, Congress of the, $5 \delta_{\text {I }}$

Isuwa, land of, 344

Itakama, Syrian prince, $342 \mathrm{ff}$.

Ithamar, king of Saba, 474

Ithobaal of Tyre, 347

Itht-taui, $14 \mathrm{~S}$

Ittai, 429

Itti-Marduk-balâțu, Babylonian minister, 369

Iuaa and Tuiu, 256; tomb of, 294

Ivory-carving, archaic Egyptian, II7 ; Syrian (?), 515 ; Ionian, 535

Jacob, 409

Jacob-el, 217

JECONIAH (JEHOIACHIN), 544

JEHOAHAZ, 456

JEHOASH, 457

JEHOIAKIM, 544

JEHORAM, I 6, $451 \mathrm{ff}$.

JEHOSHAPHAT, $45^{\circ}$

JEHU, I 6, 452

Jephthah, 422

Jeremiah, 544

Jericho, 4 IO 
JEROBOAM I, 435

JеRоволм II, 457

Jerubbaal, 420

Jerusalem, $3 \mathrm{I} S, 410,427,4 S_{3}, 544,586,560$

Jezelsel, 450,453

Joab, 427

JOASH, 457

Joppa, 248 , n. 2

Joseph, 409

JosiAH, 5I2, 543

Jotham, 464

Judaeans, 4 II , n. 2

Judah captive, 544

Judges, Babylonian, 204; Egyptian, 282 ; liebrew, period ( $f$ the, $409 \mathrm{ff}$; Carthaginian (Shophetim, Suffetes), 58I, n. 3

Jûdi Dagh, 459,485

KADASHMAN-BURIASH, king of Babylon, 2I, 369

KADASHMAN-ENLIL, 26 I

KADASHMAN-KHARBE I, 26I, n. I ; II, 266

Kadashman-TURGU, 21, 369

Kadesh on the Orontes, 232, 244, 340 ; battle of, 360

KAKAA NEFERARIKARA, king of Egypt, 130

KAKAU, king of Egypt, 1 Io

Kakóvatos, 58

Kalaureia, League of, 531

Kamárais ware, 4I, I 59

Kameiros, 533, n. 2

KAMES, king of Egypt, 225

Kandalânu (ASIIURBanipal, q. $\bar{c}^{\circ}$ )

Karabel, 329, n. 2

KARA-INDASH I, king of Babylon, 200 ; II, 266

Kara Öyük, 340

Karbanit, battle of, 500

Karei, 255, 270

Karkar, battle of, 16, 440, $449 \mathrm{ff}$.

Karnak, 152, 276 ; hings, list of, i2

KA SEN, king of Egypt, I IO

KASITA, 467

KASHTILIASH, king of Babylon, 200

Kashtiliashu, 370

Kassites, 3, 198, 201

Kastarit, 495

Katawadana, land of, 359, 374, n. I

Kaṭna, 344

Ka-ur-Antef, stele of, 143

Keftiu, 244, 248, 293

"Kenkenes," king of Egypt, I05

K'habbash, 576

Khabiri (= Hebrews), 348, 406

Kha-em-uaset, 375

KHAFRA, king of Egypt, 127

Khaluli, battle of, 489

KhamMurabi, king of Babylon, $192 \mathrm{ff}$. ; letters and laws of, 197 ; el-Khargah, IO1, 572
KHASEKHEMUi, king of Egypt, i I ff.

Kinati (AkHthoEs), king of Egypt, I39

Khatithana, land of, 254

Klhatti, city, 339 ; land, 268, 327, 381

KHATtusil I, king of Khatti, $33^{8} ; 11$, $21,363,37$ I

KHENT, king of Egypt, I03, 107

Khentamentiu, Egyptian god, IOI

Khenzer, king of Egypt, 2 I 5, n. 2

KnIAN, Hyksos king of Egypt, 2I

Khilpsil, Hittite scribe, 361

Khinatuni, town of, 349

Khonsu, Egyptian god, 197, 372

Khorsabad, 48 I

KHUFU, king of Egypt, 120, 126

KHUMPANIGASH, ling of Elam, $47 j$

Khusebek, Egyptian commander, 156

Kimmerians, 495, 504

Kimon, $5^{86}$

King, L. WV., history of, 9; on Babylonian chronology, 28

Kings, Egyptian, 99, 106, n. 3, 27 8 , $28_{3}$

Kinza, 342

Kirua, Assyrian governor, 486

Kish, Labylonian city, 176

Kissos of Salamis, 496

Kleisthenes, reforms of, 532, 573

Kleomenes, king of Sparta, expels Hippias, 573

Knossos, Neolithic remains, 32 ; palace, $43 \mathrm{ff}$; destruction of, 22, 64

Kokalos, Sikel king, 65

Komana, 330, 339, n. 3

Kom el-A ḥmar (Hierakonpolis), 93

Koptos, 94, 138 ; stele of, 220

Korkyra, $53^{2}$

Koumasa, 34, n. 2, 40, n. I

Kretschmer, I'rof., philological views of, 5

Kroton, $5^{81}$

Ktesias, Io

KUDUR-MABUG, Elamite, IgI.

KUdUR-NankHund, Elamite king, 190

Kummulh (Commagene), 388

KURIGalzU I, king of Babylon, 26I, n. I ;

II, 262 ; III (sibru), 267,36S

Kush, 27o, n. 4, 28o

Kushan-rishathaim, 419

Kutha, legend of, 178

Kyaxares, king of Nedia, $5 \mathrm{II}, 55 \mathrm{I}$

Kyklôpes, 60

Lachish, $410,4_{3}$

Ladiké, queen, 56 I

Lagash, $179 \mathrm{ff}$.

"Lamaris," king of Egypt (Amenembat III), I 53

"LABASSOARCHOS," king of Babylon, 549

Labâya, Canaanite chief, $34 \mathrm{~S}$

"LABYNÊTOS," king of Babylon, 552, n.2

Labyrinth, Egyptian, I 53 ; Cretan, 53, n. 6

Lamersekni, Ethiopian general, 469 
Language, Egyptian, 86, 322 ; Hittite, 335 ; Armenian, 335

Larsam, I9I ff.

Larthi Atharnies (Etruscan), relief of, 336

Lasirab, king of Lulubu, IS6

Laws, Babylonian, 205; of Urukagina, I82; of Khammurabi, I97; courts of, 204 ; Egyptian, 282, 322; of Horemheb, 312; Greek laws and lawgivers, $53^{8}$

Lebanon, 342.

Legends of Greece, 59 ; of Egypt, 92 ; of Etruscans, 336

Legrain, M., work of, at Karnak, $\$$

Lehmann-Haupt, Prof,, chronology of, $29,388, \mathrm{n}$. I

Lelantine War, 532

Leonidas, 582

Letters, Babylonian; of Khammurabi, 197; Tell el-Amarna, 257; Boghaz Kyöi, $33^{8}$

Levi, 423 , n. I

LIBIT-ISHTAR, I9I

Libyans, 96 n., I 59 ; attacks on Egypt, 377,380

Limma (eponymy), I5, 445

Lisht, pyramids of, 152

Literature, Egyptian, 155, 324; Babylonian and Assyrian, 516; Hebrew, 442 ; Greek, 538

LUGALZAGGISI, 29, $18_{3}$

Luli, king of Sidon, 482

LUTIPRIS, king of Urartu, $45^{8}$

Luxor, temple of, 296

Lycians 60, 69, 270 (Lukki) ; 359, 377 (Luka)

Lydda. 416

Lydia, 54I, $55 \mathrm{I}$.

Lyric poets, Greel; $53^{8}$

Ma, goddess, 330 .

Macalister, Prof., work of, 72, 440, n. 4

Maciver, Randall-, Mr., work of, 8

Mackenzie, Dr. Duncan, work of, 8, $43 \mathrm{ff}$.

Madai, 459

Madyes, 5II, 17. 2, 5 I2

Mâgan, land of, I87.

Magi, 556

Magna Graecia, 526

Mamitiarsu, 495

MANASSEH, king of Judah, 497, 508

Manetho, 26, 213

Manishtusu, I 85

Mannai, 459, 477

Marathon, battle of, 574

Mardonius, $5^{8} 5$

Marduk, Babylonian god, 175

Masaharta, 39 I

Mashauasha, Libyan tribe, $38_{3}$

Maspero, Sir G., history of, 9

Mașsebah (-oth), I84, n. 2

Mastaba-tombs, 123
Matjaiu, Matjoi, I6o, 322

Mattiuaza, 35 I

Media, 496, 5 II

Medinet Habu, 320

Mediterranean race, 5

Mêdım, 124

Megalithic montiments of Palestine, I $S_{4}$

Megiddo, first battle of, $234 \mathrm{ff}$; ; second, 543

Mehetabel, 43I

MELISHIPAK I, king of Babylon, 26r, $\mathrm{n}$. I; 11,385

Melos, prehistoric art of, 57

Meluklikha, land of, $187, \mathrm{n}$. I

Memnon, 296

Memphis, founding of, rog; capture of in War of Liberation, 226; taken by Piankhi, 470; by Esarhaddon, 499; by Cambyses, 564

Mên (moon-god), 330

"MENA" (MENES) legend, $104 \mathrm{ff}$.

Menahem, 464

MENEPTA1I, king of Egypt, 375, 413

Menkaura(Myrerinos), ling of Egypt, I 27

Menophres, Era of, 19, 22

Mentuhetep kings of xith Dynasty, 143 ; NEB-HAPET-RA, $q . v$.

MENUAS, king of Urartu, 459

Mercenaries, Egyptian use of, 321

Merchants, foreign, in Egypt, 321

Merenta (Pepi iI), king of Egypt, I35

Merikara, I 4 I

Merodach-baladan I, $385 ; 11,473,480$, 485.

Meroë, 567

Merpeba, ling of Egypt, 105, 108

Mertisen, Egyptian artist, ${ }_{4} 6$

Mertitfes, queen, 125

Mes, inscription of, $\mathbf{2} 8 \mathbf{2}$

Mesha', 45 I ff.

Mesniu, 92

Mesore, Egyptian month, is

Messerschmidt, Dr., views of, 328, n. 4

Metallurgy, Greek, 534

Metenna of Tyre, 465

Meyer, Prof. E., history of, 9 ; chronology of, $23 \mathrm{ff}$.

Michmash, 423 ; battle of, 425

Midas-kings of Phrygia, 477; Mita of Mushki, 474

Mirlianites, 419

Miletos, 69. 559 ; Milesians in Egypt, 527

Military organization of Egypt, I8I, 359; Sumerian, ISo ; Assyrian, 446

Milkili, Canaanite prince, 348

Miltiades, 572

Min, Egyptian god, 94, n. 2, I 52

Minaean (S. Arabian) inscriptions, 564 , n. 3

Mines, Egyptian, I 54

Minoan art, 55 ; court-life, 47 
Minoan periods of Evans, 34; Early Minoan period, 38,39 ; Niddle Minoan, $36,4 \mathrm{I}, 5^{8}$; Late Minoan I, 46 ; II, 37, 55, 65, n. 2 ; III, 56

Minos-legend, 43,65

Minyac, 60

Mitanni, 20I, 229, 254, 34I

Mithras, 330.

Mitinti of Ashkelon, $46_{5}$; of Ashdod, ${ }_{4} \delta_{3}$

Noab, 430, 45I

Moabite Stone, $45 \mathbf{I}$

Mochlos, discoveries at, 36, n, 2, 39

Moiris, lake, I 53

Momemphis, battle of, 548

Money, lonian invention, 533

Montembat, prince of Thebes, 500, 503

Morgan, de, work of, 8

Muballitat-Erua, queen of Babylon, 266

Muni-Dan, queen of Khatti, 374

MURsIL, king of Khatti, 354

Musașir, 478

Mushiki, 327, 386

Musri-theory, 466, n. I, 47 I

Mutallu, king of Khatti, $36 \mathrm{I}$

Mutallu of Gurgunı, 428

Mutemua, queen of Egy.pt, 255

Mycenae, $5^{8}$; Mycenaean period, $37, \mathrm{n}$. I, 58

Mykale, battle of, 585

Mysians (Masa), 70, 359

Mysteries of Eleusis, 539

Myths, Greek and Babylonian, 209

Nabataeans, 508

Naboxidus, king of Babylon, 519, 549, 559 ; chronology of, 28,29

NABOPOLASSAR, king of Babylon, 512

NABUNÂSir (NABONASSAR), 46I; era of, 15

NABU-PAL-1DDINA, 447

NABU-SHUM-ISHKUN, 46

$\mathrm{Nag}^{e}$ ed-Dêr, $\mathrm{S}_{4}, \mathrm{IOI}$

Naharin, 229, 344

Nahor, genealogy of, 4 oI

Nahr el-Kelb, 358, 499

Naḳâda (Negada), tombs, 100

Namilt, Egyptian prince, 468

Napata, 27 1, 285, 467, 502, 567

Naptera (Nefertari), queen of Egypt, 367

NARÂM-SIN, 28, 29, I 86 ; stele of, I 88

NARMER, king of Egypt, 100, 107

Nāsātya-twins (Açvins), $20 \mathrm{I}$

Nastasen(EN), king of Nubia, 567

Naukratis, 528; trade, 529 ; constitution, $56 \mathrm{I}$

Naville, Professor E., work of, \$, 92, 95 , n. 2 ; and Hall, H. R., discoverie of, at Dêr el-Bahrii, I44

Naxos, 573

Nazibugash (Shuzigash), 266

Nrb-HAPET-RA MENTUHETEP, king of Egypt, I42
Neb-KHetriti-RA Afert, llyksos king, 216

Nen-TAUI-RA MENTUheTEr, 143

Neb-uaui, Egyptian high-priest, 286

NunUCHADREZzar 1, king of labylon, $3^{87} ; 11,544$; rebuilels Babylon, $55^{\circ}$

Necho, king of Egypt, $543 \mathrm{ff}$.

NEFERARIKARA, king of ligypt, I 31

Nilerlieter, i 66

Nefertiti, queen of Ligy pt, 258, n. 2

Nehesi, king, 167

Nehushtan, Jewish idol, 485

Neit-lyetep, yueen of Egypt, 107, n. 3

NEKARA II, Hyksos king, 217

Nekheb-Nekhen, 93

Nekhebet, Egyptian goddess, 93

NekHTNEBTEPNEFER ANTEF, king of Egypt, 143

Nelidac, 6 $\mathbf{I}$

Ne-maat-Hap, queen, II 2

NeMAatka (AMENEMIIAT III, $q . v^{2}$.)

Nenetek, i IO

Neolithic period in Acgean, 32 ; Crete, $3 S$; Cyprus, 32 ; Troy, 32 ; Northern Greece, 62; Asia Minor, 57, n. 3: Russia, 57, n. 2; Egypt, SI ; l'alcstine, 183

Nerigilissar, king of Babylon, 549

Nesibanebded, king of Egypt, 390

Nesuhor, Egyptian general, 547

N L-USER-RA, king of Egypt, I30

Newberr;, Prof., work of, 150

$\mathrm{Nii}, 242,253$

Nineveh, 260, n.2; walls of, 492 ; destruction of, 513

Ningirsu, Babylonian god, I So

Nipur, Mount (Jûdi Dagh, q.v.)

Nippur, 176, 179

Nitokris, queen of Egypt, I 24 11., I 35

Nobles, power of, in Egypt, I38, I69

Nomes, Egyptian, 98, i 38 , 150

Nubia, early, 95: VIth Dynasty, I 36 ; XIIth Dynasty, I50, I60 ff. ; government of, 270 ; under XVIIIth Dynasty, 274 ; later, $37 \mathrm{~S}, 544$

Nu BT1, Hyksos king, era of, 17, 219

Nukhashshi, 229, 334

Oannes-legend, 174, n. 2

Oases, I01, 392, 566

Oligarchies, Greek, 532

Omen-tablets, I 87

'OMIRI, king of Israel, 449

Onesagoras of Ledra, 496

Ophir, 434

Oracles, Egyptian, 372 ; Greek, 53

Orchomenos, 59

Oroites, satrap, $57^{1}$

Orphic cults, 539, n. 5

Osiris, 97 ; Abydos, 102 ; tomb of, 103 ; and Byblos, I59; XIIth Dynasty, I69

Osogo, Phrygian god, $33 \mathrm{o}$, n. I 


\section{THE ANCIENT HISTORY OF THE NEAR EAST}

OSORKON I, king of Egypt, 439; 11, 440; III, $46 \mathrm{~S}$

Ostracism, 5 So

"Osymandyas," tomb of (Ramesseum), 317

Othniel, 4 I9

"OUEnephes," king, 105

"Ousarhaïs," king, I05

Öyük, 328, 329, n. 5, 339

Pakrur, 50I

Palaeolithic period in Egypt, so

Palermo stele, I I, 99, I04

Palestine, early, $137,156,183$; in time of XVIIIth Dynasty, 229; invaded by Hebrews, 410.

Palestine Exploration Fund, 8

Papyri, Aramaean, 546, n. 4 ; Papyrus Abbott, 322; Anastasi, 324; Golénischeff, 393; Harris, 321, 379; Rhind, 2I8; Sallier, 223; Turin, I2

Parsua, 553

Pasargadae, 553

Paser, viceroy of Nubia, 275

Pashe, dynasty of, 386

Patesis, in Babylonia, $178 \mathrm{ff}$.

Patizeithes, the, 569

Pausanias, king of Sparta, $5 \$ 6$

Pefnefdidibast, 469

Peisistratids, 54I

Pekah, Pekahiah, 464

Pelethites and Cherethites, $42 \mathrm{~S}$

Peloponnese, Minoans in, 6I

Pelops-legend, 67

Pelusium, battle of, 563

Penije, 469

Pentaur, poem of, 361

Peoples of the Sea, 69, 377, 380

PePI I, I35; II, I.35, I38

Pepinekht, 137

Perabsen, i i I

Pernier, Signor, work of, $S$

Perpega, battle of, 469

Persians, 552 ff. ; Persian Empire, 577

Pessinus, 330

Petrie, Professor W. M. F., work of, 8 ; chronology, 23

Petsofá figurines, $4 \hat{S}, \mathrm{n} .2$

Peturaste, king of Egypt, $46 \mathrm{~S}$

Petubastis-Saga, 501

Phaistos, 43, 45; disk, 73, n.; 336, n. 3

Phanes, 563

Pheidon, 532

Philistines, Cretan, origin of, 73 ; migration of, 3 So; conquest of Palestine, 415, 422 ; state, 4I6 ; religion, $399 \mathrm{n}$.; remains, 72 ; tributary to Egypt, 43I ; defeated by David, 428

Philosophy, Greek, 539

Phinehas, 423

Phocaea, 559
Phoenicians, 77, 158, 293, 367, 402; conquered by Thothmes III, 239, 24I ; by Shalmaneser, II, 454; in Cyprus, 496, n. 2 ; in Aegean, 523 ; alphabet, 429

Phrygians, 7I, 475; tomb, 476

PIANKH-ALURO, king of Nubia, 567

PiANkHI, king of Egypt, $467 \mathrm{ff}$.

Piari, battle of, 377

Pictographs, Cretan, 42

Pidasa, 359

Pillar-worship, 96

Pindar, 538 , n. I

Pinetjeni I, 39I

Piracy, Greek, 522

"Pir'u, king of Musri," 472

Pisiris of Carchemish, $47 \mathrm{~S}$

Pithom and Raamses, 405

I'ittakos, 538

I'lataeae, battle of, $5^{8} 5$

Poetry, Egyptian, 306, 324 ; Hebrew, 442 ; Greek, $53^{8}$

Polykrates, 56I, 57I

Poseidon, 52, n. 3

"Possessed Princess," story of the, 372

"Potipherah," "Potiphar," 406

Pottery, prehistoric Egyptian, 82 ; archaic Egyptian, IIS ; early Nubian, 95; early Cretan, $38 \mathrm{ff}$; painted, origin of, in Greece, $3 S$; polychrome Cretan, 4I ; naturalistic Cretan (L M I), 46 ; Neolithic polychrome in North Greece, 62 ; Minyan, 6I, n. 2 ; Philistine, 72 ; Canaanite, 44I ; Hittite, 340; geometric in Greece (Dipylon), 521; archaic Greek styles (Proto-Corinthian, Rhodian, Laconian-Cyrenaic, Daphniote, Naukratite), 534

Priesthood, Egyptian, 323; of Amen, $2 \mathrm{~S}_{4} \mathrm{ff}$.

Priest-kings, Egyptian, 17, 390

Priniás, discoveries at, 535

Proitos-legend, 60

Prophetic literature, Hebrew, 436

Protothyes, 495

PSAMATIK (PSAMMETICHOS) I, 502, 509, 5 I2 ; II, 544; III, 56I

Psibkhannu (Psusennes) 1,391 ; 11 , 391

Psyttaleia, 584, n. I

Ptah, Egyptian god, $S_{5}$

Ptahhetep, precepts of, 132

Pteria, 340 ; battle of, $53 \mathrm{~S}$

Pudukhipa, queen of Khatti, 367

Pulesti (Philistines, q.v.)

Pulu (Tiglath-Pileser iv, q.v.)

Punt, I 37, I 47, I 55, 290

Purema, Nubian general, 469

Pur-shagali (?), eponymy of, I5

Put-akhi, 362

PUzUR-ASHI(U)R I, II, kings of Assyria, 259 
Pylos, 6r

Pyramids, I 20 ff. I3I ; pyramid-builders, 10, 12 Iff.; temple at Dêr el-Bahriri, 145 ; texts, 132

Pythagoras, 539

Pythagoras of Chytroi, 496

Pytheas of Nure, 496

Quibell, MIr. J. E., work of, I36

Rab-mag, Rab-saris, k'ab-shakeh, 446, n. $2 ; 484$

RAMESES I, 313 ; RAMESES II, 21, 316 ff.; campaigns of, $358 \mathrm{ff}$.

RAMESES-SIPTAII, 377

RAMESES III (Rhampsinitos), 71, 378, $3^{8 I}$

Ramesseum, the, $3 \mathbf{I 7}$

Ramessides, later (XXth I)ynasty), 389 ; Ramesside Egypt, 3 I $S$ ff.

Ramoth-gilead, battle of, $45^{\circ}$

RANEB, king of Egypt, 110

Raphia, battle of, 473

REHOBOAM, 435

Reisner, Dr., work of, 8

Rekhmara, Egyptian vizier, 280 ff. ; 293

Religion, Cretan, 52, 53; Egyptian and Cretan compared, 35, n. ; prehistoric Egyptian, 84 ; archaic Egyptian, I19; XIIth Dynasty, I68 ; Babylonian, 172, 206; Babylon and Elamite, I96; Phrygian, 476; Assyrian, 576; Ana. tolian (Hittite), 330 ff. ; Greek and barbarian compared, 539

Renascence in Greece, 518

Rephaim, 184; battle of the Valley of, 427

REzIN, king of Syria, 404

REzON, king of Syria, 434

Rhampsinitos-legend, 379

Rhea, goddess, 53

Rhesos, armour of, 475

Ribadda of Byblos, $343 \mathrm{ff}$.

Riblah, 546

Ridgeway, Professor, work of, 74

Rim-Sin, king of Larsam, 19 I ff. 198

Rimush, king of Babylon, i 85

Rogers, Professor, history of, 9

Rukipti, 465

RUSAS I, king of Urartu, 474,478 ; II, 494 ; III, 552, n. 3

Sabni, 137

Sacred War, 530

Sacrifices of children, Canaanitish, 442

SADYATTES, king of Lydia, 54 I

Sa-Gaz, 348, 406

SAHURA, king of Egypt, I3 I

Saïtes, archaïsm of, IO; Egypt under the, 540

Sakkâra, 102 ; list of, 12

Saktjegözii, discoveries at, 328

Saiamis, battle of, 583
Salatis, Ifykos king, 214

Samaria, 442 ; siege of 472 ; excavations at, 440, n. 4

Samos, 531, 572

Samson-legend, 4 I 8

Samsu-ditana, king of Babylon, igs

SAMSU-ILUNA, igS

Samuel, 424

Sandakhshatra, Kimmerian leader, 509

Sanehat (Sinuhe), story of, 157

SA-NEKIT, king of Egypt, 114

Sangara of Carchemish, 447

Sankilabtaui-ra Mentuhetep, 143

SANKHKARA, king of Egypt, 147

Sapalulu. See Silubeiluliuma

Sarâbit al-Khadim, 155

Sardanapallos-legend, 5 II

Sardis (Sardeis), taken by Cyrus, 558 ; burning of, 574 ; Xerxes at, 580 ; excavations, 533, n. 2

SARDURIS I, king of Urartu, $45^{8}$; III, 462 ; IV, 509

Sargon I, 28, 29. See Shargani

SARGON, king of Assyria, $472,4 \mathrm{SO}$

Sarzec M. de., work of, $S$

Satrapies, Persian, 578

Satuni of Lulubu, IS6

SAUL, king of Israel, $17,424 \mathrm{ff}$.

SAUSHSHATAR, king of Mitanni, 260,n. 2

Scarabs of Amenhetep III, 256

Schliemann, work of, 8

Schnabelkannen, 39

Schumacher, I'rofessor, work of, 8

"Scorpion-king," the, Ioo

Scribes, Egyptian, 323 ; Hittite, "361

Script, early Egyptian, 84, I 6 ; Baby. lonian (cuneiform), I71; Hittile, 329 ; Minoan, 5 I

Sculpture, Egyptian, I24, 163, 304 ; Assyrian, 515; Minoan, 51; archaic Greek, 535

Scythians, 495, 51 I, 572

Seager, R. B., work of, 39

Sea-Land, Dynasty of the, 198

Seals, 206; Minoan seal-stones, 42

Sea-power, Egyptian, under Thothmes III, 24I; Assyrian, under!Sennacherib, 488

Sebek, Egyptian god, 165

SEBEKENiSAF-kings, 166

Sebekemsas, queen, 222

SEBEKHETEP-kings, I66

Sedeinga, 274

Sed-festival, 108

SEKGENENRA-kings, 224

Sekhemab Perenmaat, ilo

Sekmern, 156

Sellin, Dr., work of, 8

"Srmempses." See Semerkha

Semerkha Hui (Nekht ?), 109

Semites in Egypt, 86; in Babylonia, 172, I 76, I 55 ; culture of, $443, n$. I 
Semneh and Kummeh, 161, 272

SEMTI (DEN), ling of Egypt, 105

SENn ("SETHENES "), king of Egypt, I I I

SENEFERU, ling of Egypt, $120 \mathrm{ff}$.

Senmut, 291, 293

SENNACHERIb, king of Assyria, 21, 48I, $4 S 8,493$

SeNusert I, king of Egypt, I49; III, $23,161,272$

Sergi, Professor, theories of, 5

Serpent-Columm, the, 586

Sesebi, 274

Sesostris-legend, I 49 n., 162

Set, Egyptian god, IIO, 219, 333, n. I, $3 \mathrm{I} 5$

Sethe, Professor, theories of, 286

SETI I, 3I 4, 355, 357 ; ling-list of, 12

SETI-MENEITAH, 377

SETNEKHT, 378

Seve (So), 47I, See Shabaka

SHABAKA, 47 I, 479, $4 S_{3}$

Shabataka, 490

Shakalsha, 377,38 I

Silalmaneser I, ling of Assyria, 2I, 369 ; III, 16, 44S, 453; Iv, 467

Shamash-shum-ukin, revolt of, 506

Shamgar, $4 \mathrm{I} 6$

Shamshi-Adad i, king of Assyria, 193 ; II, 455

Shardina, 321, 359, 377

SHARGANI-SHARRI, ling of Akkad, 185

Sharlak, king of Guti, I 66

Sharru-gi (Sharrukîn), king of Akkad, I ${ }_{5}$

SHARU (?), king of Egypt, I22, n. 2

Shavsha, 429

Sheba, queen of, 434

Shechem, 412, 422

Shekhlal (Shakalsha), 343

Shemsu-Hor, 93

Shepherd-kings (Hyksos), 212

ShePsESkaf, king of Egypt, I 27

Sherohan, siege of, 226

Sheshbassar, 560

SHESIEENI I (SHISHAK), I6, 438 ; IV , 468

Shiloh, 410, 423

"Shipwrecked Sailor," tale of the, I 54

Shishak. See Sheshenk

Shubbiluliuma (Sapalulu), king of Khatti, 338, 34I ; war with Mitanni, 344 ; takes Mitanni, 35I ; letters of, 268, 345; treaty with Horemheb, 354

Shutarna, king of Mitanni, 256

Shutatarra (Shutarna), 342

Shutruk-Nakhkhunte, king of Elam, 4 So

Shuyardâta, Canaanite chief, 348,410

Siamen (Situm), king of Egypt, 39r

Sicily, 526

Sidon, $347,483,496,560$; Sidonians in Homer, 77

Siegecraft, Assyrian, 446
Simti-ShilkHak, king of Elam, I9I, n. 2

Simyra, 240, 343, 347

Sinai, 109, 155, 40 S

Sindjirli, discoveries at, 328

Siniddinam of Larsam, 193

SiN-MUBallit, king of Babylon, 192

SIN-SHAR-ISHKUN, king of Assyria, 5I 3

Sisera, 4I 4

Sitnapishtim legend, 177

Siut, princes of, I4 I

Skunka, Scythian chief, 57 I

Slaves, Babylonian, 204

SMENKHKARA, king of Egypt, 308

Smerdis, the pseudo-, 569

Soleb, temple of, 273, 296

SOLONION, I6, 432

Sopd, Egyptian god, 222

Sothic cycle, 15, IS ff. ; dates, 23, $2 S$

Spâka, Scythian king, 495

Sparta, early history and art of, 522 ,

534 ; constitution of, 532 ; $\alpha \dot{\gamma} \omega \gamma \eta \dot{\eta}, 522$;

policy, 54I ; embassy to Cyrus, 559 ; at Plataeae, 535

Sphinx, the Great, I64; of Tanis, I64; winged, 219

Spiral-design, origin and history of, 40, 41

Stone-working, vases, 35 n., 40, I I 8

Sudanese troops, 347

Suffetes (Shophetim, of Carthage), $5 \mathrm{~S}$, n. 3

Sumer, I 7 I ; Sumerians, I 7 Iff.; Sumerian soldiery, ISo; Sum. reaction under Dungi, I90: in the Sea-Land, 199

SUMU-ABU, king of Babylon, I92

Sun-god, 208; Sun-worship in Egypt, S5, I29; temple of Abu Gurâb, I3O ; Hittite, 333

Susa, sacked by Kurigalzu III, 368 ; taken by Ashurbanipal, 507; Persian capital, 5 So

Sutekh, god, 2 I 9

Suti, 402

Sword, origin of the, $3^{8}$

Syene under the Persians, 546 , n. 4

Syennesis, the, of Cilicia, $55 \mathrm{I}$

Syloson of Samos, 572

"Synchronous History," the, I3, 460

Synoikismos of Attica, 532 ; of Naukratis, 561

Syracuse, Corinthian pottery at, 534

Syria conquered by Lugalzaggisi, i 83 ; Hittites in, 328 ; conquered by Jeroboam II, 457; culture of North Syria, $229,5 \mathrm{I} 5$

TAA (TAU), kings of Egypt (XVIIth Dynasty), 224

Taanach, 235, 247; battle of, 413; excavations, altar of, 44I

Tabal, 488

TAB-RIMMON, king of Syria, 449 
Tadukhipa, queen, 256

Tahpanhes (Daphnai, q.v.)

Takhisa (Tahash), 254, 401

Tammuz, god, 207

Tanis, 316

Tanite, kings of Egypt (XXIst Dynasty), 39 I

Tanutamon, 502

Tarkhundaraba (Tarkhundaraush), liing of Arzawa, 269

Tarku, Hittite god, 333, n. I

Tarsus, 486

Tartisibu, Hittite envoy, 364

Tausret (Thouōris), Egyptian queen, 378

Taxation, Babylonian, 204 ; Egyptian, 282

Tefaba, prince of Siût, I4 I

TEFNAKHT, king of Egypt, 469, 478

Teïspes (Chishpish, q.v.)

Telchines, 60

Tell el-Amarna, 301 ; tablets, 20

Tell esh-Shihâb, 356

Tell es-Safi, 72, 4 I 7

Tell el-Yahûdiya, 21 5, 315,320

Teshub, Hittite god, 332

TETA I, king of Egypt, IO4; II, 133

Te-umman, king of Elam, 505

Thalassocracy, Minoan, 57

Thales, 539, 552, n. I

Tharshish (Tartessus), 434

Thebes, Boeotian, 57, 60

Thebes, Egyptian, under the empire, 277 ; destroyed by Ashurbanipal, 503 ; under the Saites, 540

Themistokles, $575 \mathrm{ff}$.

Thermopylai, battle of, 582

Thesprotian invasion of Greece, 67,68

Thessaly, Neolithic culture of, 62

Thinis, Thinite kings of Egypt, IOI, 102

Tholoi (Beehive-tombs, y.v.)

Tirothues I, king of Egypt, 230; TH. II, 287; TH. III, 20; campaigns of, 233 ff. ; statesmanship of, $24 \mathrm{I}$; organization of empire, 246 ; portrait of, 250 ; TH. IV, 255, 294

Thrace, 475

Thununi, annalist of Thothmes III, 233

Thutii, general of Thothmes III, 247, 292

Tiâmat, Babylonian myth of, I 75

Tid'al, I94

Tiglath-PILfeser I, king of Assyria, $388,394,398$; IV, 46 I ff.

TrI (Teie), queen of Egypt, $255 \mathrm{ff}$., 294

Til Barsip, 488

"Timaios," king of Egypt, 215

Tiphsah, 433

TIRIIAKAH, king of Egypt, 49I, 497, 500

Tiryns, $5^{8}$

TJA $(Z A, M=Z E T)$, king of Egypt, IO4, 107

Tjakarai (Zakari), Mediterranean tribe, $70,381,394,416$
Tjarukha (Zarukha), lake, 295

Tjedamenefankh, 469

TIESER KHETNETER, hing of Egypt, I 13

Togarmah, 488

ToI, king of Ianath, $43^{\circ}$

Tomb-robbery in Egypt, 322

Tombs, Cretan, 44, 54; ligyptian, 84; Ilittite, 340 ; l'hrygian, 476

Towns, Minoan, 44

Tradition, value of, to historian, 7 ; prehistoric Greek, 60

Treasurers, Egyptian, $2 \$_{3}$

"Treasuries"(beehive-tombs), Minoan, 59

Treaty of kameses If with the llittites, 364

Treres, 495

Tribute of Amen and Aten from Cana:ı, 349

Triumph of Ashurbanipal, 509

Troglodytes, I 83

Trojan War, 69, 75

Troy, Neolithic remains, 32 ; early culture, 39

Tugdammi (Dygdamis), Kimmerian chief, 508

Tuiu, 256

TUKULTI-NiNiE I, 21, 370

Tulliz, battle of, 506

Tunip, 24 I, 244, 362

Tunrei, and list of Șakkâra, I 2

Turbikha, Egyptian general, 346

Turi, viceroy of Nubia, 270

Turin papyrus, I 2

Tursha (Tu(r)sci), Mediterranean tribe $70,336,377$

Turtan (Assyrian generalissimo), 446

Turushpa, 464

TUTANKIIAMEx, king of Egypt, $30 \mathrm{~S}$

Tuti, Egyptian sculptor, 304

Tutu. See Dudu

Tyrants, Greek, 532

Tyre, 347; taken by Philistines, 402 ; submits to Assyria, 472; taken by Ashurbanipal, 504 ; siege by Nebuchadnezzar, $5+7$

Tyrsenians (Etruscans). See Tursha

UAYABRA (APRIES, q.v.)

UAH-ANKH ANTEF-AA, king of Upper Egypt, 143

UAIKARI KHATI, 139

UAHKARA II (Hyksos), 2 I 7

Uaite, Arab chief, 508

Uan, battle of the Heights of, 24I

Uashasha, Cretan tribe, $7 \mathrm{I}, 3 \mathrm{SI}$

UATJED, Hyksos king, 216

UATJKARA, king of Egypt, 140, n. 2

Ubastet (Bast), Egyptian goddess, 152

Ueret-maait-neferu- $\mathrm{Ra}$, queen, $37 \mathrm{I}$

Ugarit, Phoenician town, 347

Ukinzir, Chaldaean prince, 466 


\section{THE ANCIENT HISTORY OF THE NEAR EAST}

Ullaza, Syrian town, 241

Umma, Babylonian town, wars with Lagash, I8o ff.

Unman-manda, 5 II

Una, Egyptian noble, I36

Unamon, Egyptian envoy, 390, $393 \mathrm{f}$.

UNAS, king of Egypt, I $\mathbf{3} \mathbf{I}$

Ur (Babylonia), kings of, I90

Urartu, kingdom of, 3,458 ff., 464,474

Uriah, 429

URNINÂ, king of Lagash, 29, I79

URUKAGINA, I 82

USERKAF, king of Egypt, 129

Utica, founding of, 403

Utjahorresenet, 565, 57 I

UTUG, early Babylonian king, I79

UZZIAH (AZARIAH, q.v.)

Vahyazdâta, 570

Vannic language, $45^{8}$

Vaphio-cups, 54, 6I

Varuna, Aryan god, 20I, 33I

Vishtâspa (Hystaspes), $554 \mathrm{f}$.

Vizier, Egyptian, 169, $280 \mathrm{f}$.

Votaresses, Babylonian, 206

"Vultures, Stele of the," I8o

Wadi Maghâra, I 55

Waidrang, Persian governor, 546, n. 4

Waistcloth, Mediterranean costume, 32

Walls of Canaanite towns, 442

Waraganni, Mitannian town, 260, n. 2, $35 \mathrm{I}$

Wawat, I6o

Wealth of Egypt, 379

Wheat indigenous in Palestine, 89

"White Syrians," 337

Widya, Canaanite prince, 349

Winckler, Professor, work of, 8, 329; theories of, $466, n$. I, $47 \mathrm{I}$

Women, position of, in Crete, 47, 205 ; Egypt and Babylon, 205, 206

Xerxes, king of Persia, 577, $580 \mathrm{ff}$.

Yahweh, worship of, 436 ; temples of, in Egypt, 546, n. 4

Ya'ket'il, 405

Yankhamu, viceroy of the Delta (?), 346, 353

Yantinai (Cyprus?), 243, n. I

Yapa'addi, 346

YAPEKHUR, Hyksos, 2I 7, 409

Yarimûta (Egyptian Delta?), 346

Yasili Kayà, 329, 33 I f.

Ya'ubidi, 473

"Yavâni," the, 479

Yazdâta, Canaanite prince, 348

Yeshep'il, 405

Zadok, 429

Zafer Papousa, 44

Zaphnathpaaneakh (Joseph), 405

Zawîyet el-Aryân, 14

ZEDEKIAH, 546

Zerah, 439

Zerubbabel, 560

Zēt, 49I

Ziklag, 4I6, 426

Zimrida of Sidon, 347

Zoroaster, 555

$\mathrm{Zu}$, legend of, 208

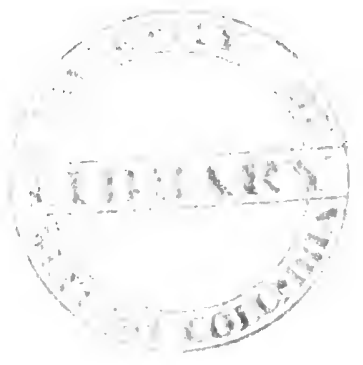



Printed by

Morrison \& Girb Limited

Edinburgh: 


\section{A SELECTION OF BOOKS}

PUBLISHED BY METHUEN

\section{AND CO. LTD., LONDON}

\section{ESSEX STREET}

\section{W.C.}

\section{CONTENTS}

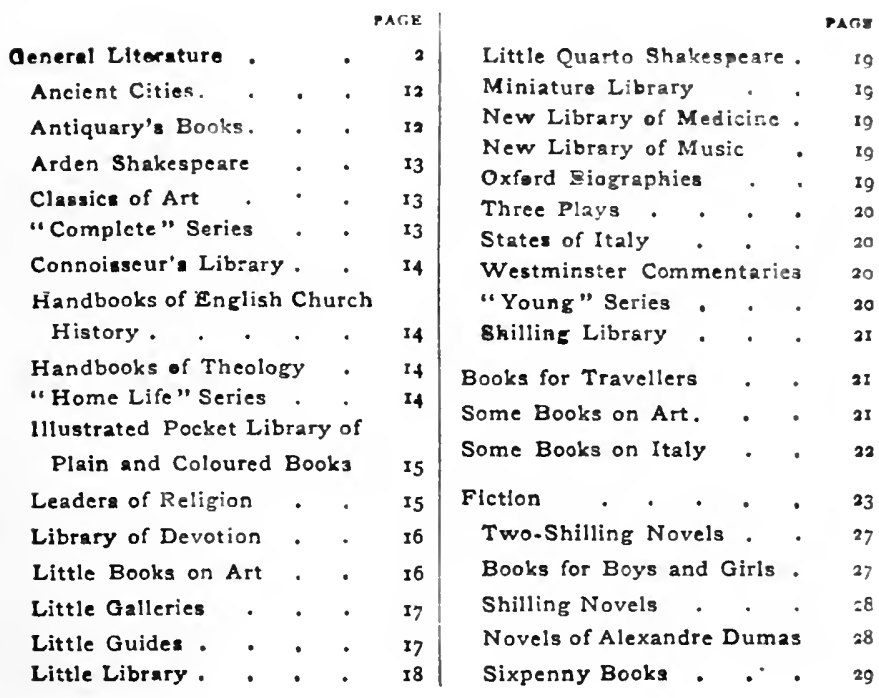




\section{A SELECTION OF}

\section{MESSRS. METHUEN'S}

\section{PUBLICATIONS}

In this Catalogne the order is according to authors. An asterisk denotes that the book is in the press.

Colonial Editions are published of all Messrs. Methuen's Novels issued at a price above $2 s .6 d$., and similar editions are published of some works of General Literature. Colonial editions are only for circulation in the British Colonies and India.

All books marked net are not subject to discount, and cannot be bought at less than the published price. Books not marked net are subject to the discount which the bookseller allows.

Messrs. Methuen's books are kept in stock by all good booksellers. If there is any difficulty in seeing copies, Messrs. Methuen will be very glad to have early information, and specimen copies of any books will be sent on receipt of the published price plus postage for net books, and of tbe published price for ordinary books.

This Catalogue contains only a selection of the more important books published by Messrs. Methuen. A complete and illustrated catalogue of their nul lications may be obtained on application.

Andrewes (Lancelot). PRECES PRIVATAE. Translated and edited, with Notes, by F. E. Brightman. Cr. 8vo. $6 s$.

Aristotle. THE ETHICS. Edited, with an Introduction and Notes, by JoHN BURnet. Demy 8vo. ror. 6d, net.

Atkinson (C. T.). A HISTORY OF GERMANY, 1715-1815. Demy 8vo. r2s. 6d. net.

Atikinson (T. D.). ENGLISH ARCHITECTURE. Illystrated. Fcap. 8vo. 3s.6d. net.

A GLOSSARY OF TERMS USED IN ENGLISH ARCHITECTURE. Illustrated. Second Edition. Fcap. 8vo. 3s.6d. net.

ENGLISH AND WELSH CATHEDRALS. lllustrated. Demy 8vo. xos. $6 d$. net.

Bain (F. W.). A DIGIT OF THE MOON: A HiNdOO LOVE STORY. Ninth Edition. Ficap. 8vo. 3s. 6d. net.

THE DESCENT OH THE SUN : A CrCLE OF BIRTH. Fifth Edition. Ficap. 8vo. 3s. $6 d$. net.

A HEIFER OF THE DAWN. Seventh Edition. Ficap. 8vo. 2s. 6d. net.

IN THE GREAT GOD'S HAIR. Fifth Edition. Ficap, 8\%o. 2s. 6d. net.

A DRAUGHT OF THE BLUE. Fourth Edition. Fcap. 8vo. 2s. 6d. net.
AN ESSENCE OF THE DUSK. Thirt Edition. Fcas. 8vo. 2s, 6d. net.

AN INCARNATION OF THE SNOW. Second Edition. Fcap. \&vo. 3s. 6d. net.

A MINE OF FAULTS. Second Edition. Fcap. 8vo. 3s. 6d. net.

THE ASHES OF A GOD. Fcap. 8vo. 3s. 6d. net.

-BUBBLES OF THE FOAM. Fcap ${ }_{4}$ to. 5s. net. Also Fcap. 8vo. 3s. 6d. net.

Balfour (Graham). THE LIFE OF ROBERT LOUIS STEVENSON. Illistrated. Fifth Edition in one Volume. Cr. 8vo. Buckram, 6s. Also Fcap. 8vo. rs. net.

Baring (Hon. Maurice). A YEAR IN RUSSIA. Second Edition. Denty $8 v o$. ros. $6 a$. net.

LANDMARKS IN RUSSIAN LITERATURE. Second Eation. Crown $8 v 0$. 6s, net.

RUSSIAN ESSAYS AND STORIES. Second Edition. Crown 8vo. 5s. net.

THE RUSSIAN PEOPLE. Demy 8ro. r5s. net.

Baring-Gould (S.). THE LIFE OF NAPOLEON BONAPARTE. Illustrated. Second Edition. Roval 8vo. ros. 6 d. net. 
THE TRAGEDY OF THE CESARS : A STUdY OP THE CIIARACTERS OF THE Casars or the Julian and Cl.audian Housks. Illustrated. Seventh Edition. Royial 8vo. tos. 6it, net.

THF VICAR OF MORIVENSTOW. With a Portrait. Third Edition. Cr. 8vo. 3s. 6it. - Also Fate 8zo is. net.

OLD COUN'RY LIFE. Illustrated. Fifth Edition. Large Cr. 87'o. $6 s$.

A BOOK OF COKNWALL. Illustrated. 1hird Edition. Cr. 8z'0. 6s.

A BOOK OF DARTMOOR. Illustrated. Second Edition. Cr. 8*'o, os.

A BOOK OF DEVON. Illustrated. Third Edition. Cr. 8vo. 6s.

Baring-Gould ( $S_{.}$) and Sheppard ( $H$. Fleetwood) A GARLANU OH COUNTRY SONG. E.uglish Folk Songs with their Traditional Melodies. Demy 4 to. $6 s$.

SONGS OF THE WEST: Folk Songs of Devon and Cornwall. Collected from the Mouths of the People. New and Revised Edition, under the musical editorship of CFClL J. Sharp. Large Imperial 8vo. 5s. net.

Barker (E.). THE POLITICAL IHOUGHT OF PLATO AND ARISTOTLE. Demy 8vo. ros. 6d. net.

Bastable (C. F.). THE COMMERCE OF NATIONS. Fifth Edition. Cr. 8vo. 2s. $6 d$.

Beckford (Peter). THOUGHTS ON HUN'ING. Edited by J. Отно PAGET. Illustrated. Third Edition. Demy 8vo. 6s.

Belloc (H.). PARIS. Illustrated. Second Edition, Revised. Cr. 8vo. 6s.

HILLS AND THE SEA. Fourth Edition. Fcap. 8vo. 55 .

ON NOTHING AND KINDRED SUBJEC'TS. Third Edition. Fcap. 8vo. 5 s. ON EVERYTHING. Third Edition. Fcap. 8 \% 5 .

ON SOMETHING. Second Edition. Fcas.

FIRST ${ }^{85}$ AND LAST. Second Edition. Ficap. 8vo. 55 .

MARIE AN'TOINETTE. Illustrated. Third Edition. Demy 8*o. 15s. net.

THE PYRENEES. Illustrated. Second Edition. Demy 8io. 7s. 6d. net.

Bennett (W. H.). A PRIMER OF THE BIBLE. Fifth Edition. Cr. 8vo. 2s. $6 d$.

Bennett (W.H.) and Adeney (W.F.). A BIBLICAL INTRODUClION. With a concise Bibliography. Sixth Edition. Cr. 810. 75. 6d. Also in Two Volumei, Cr. 8vo. Each 3 s. 6d. net.

Benson (Archblshop). GOD'S ECijid. Communion Addresses. Second Eifition. Fcap. 8v0. 3s. 6d. net.
Bicknell (Ethel E.). PARIS AND HER TRR F.SURE.S. llilustrated. Ficap. 8vo. Round comers. 5s, net.

Blako Willam, ILLUSTRATIONS OF "THE LOOK OF JOJ?. With a General Iniroduction by LAURrice bisvon. lllustrited. Quarto. 21s. net.

Bloemfontein (Blshop of). ARA CCELI: An Essar in Mrstical Theologr. lifth Edition. Cr. 8vo. 3s. 6d. net.

FAIIH ANI) EXPLRIENCE. Second Fidition. C'r. 8ro. 3s. 6d. net.

Eowden (E. M.). IHE IMITATION OF li U DD If A: Quotations from Buddhist Literature for each Day in the Year. Sixth Edition, Cr. 16ino. 2s. 6d.

Brabant (F. G.). RAMBIES IN SUSSEX. Illustrated. Cr. 8zo. 6s.

Bradley (A. G.). ROUND ABOUT IVILTSHIRE. Illustrated. Second Edition. Cr. $87^{\prime}$. $6 s$.

THE ROMANCE OF NORTHUMBER. LAXD. lllustrated. Second Edition. Deny 8vo. 7s. 6al. "ret.

Braid (James). ADVANCED GOLF. lllustrated. Seienth Edition. Demy 8vo. 10s. $6 d$. net.

Brodrick (Mary) and Morton (A. Ander son). A CONCISE DICIIONARY OF EGYPTIAN ARCHAOLOGY. A Handbook for Students and Travellers. Illustrated. Cr. 8vo. $3^{s .6 d}$.

Browning (Robert). PARACELSUS. Edited with an Introduction, Notes, and Bibliography by MARGARET L. LeE and Katharine B. Locuck. Fcap. 8vo. 3s.6d. net.

Buckton (A. M.). EAGER HEART: A Christmas Mystery-Play. Tenth Edition. Cr. 8vo. is. net.

Bull (Paul). GOD AND OUR SOLDIERS. Second Edition. Cr. 8z'o. 6s.

Burns (Robert). THE POEMS AND SONGS. Edited by ANDREW LANG and W. A. Cralgiv. With Portrait. Third Edition. Wide Demy 8vo. 6s.

Calman (W. T.). THE LIFE OF CRUSTACEA. Illustrated. Cr. 8ro. Gr.

Carlyle (Thomas) THE FRENCH REVOLUTION. Edited by C. R. L. FteTCHER. Three Volumes. Cr. 8vo. I8s. THE LETIERS AND SPEECHES OF OLIVER CROMWELL. With an Introduction by C. H. FirTH, and Notes and Appendices by S. C. Lomas. Three Volumes. Demy 8vo. I8s. net. 
Celano (Brother Thomas of). THE LIVES OF S. FRANCIS OF ASSISI. Translated by A. G. Ferrers Howell. With a Frontispiece. Cr. 8vo. 5s. net.

Chambers (Mrs. Lambert). LAWN TENNIS FOR LADIES. Illustrated. Cr. 8vo. 2s. 6 d. net.

*Chesser, (Ellzaboth Sloan). PER. FECT HEALIH FOR WOMEN AND CHILDREN. Cr. 8\%o. 3s. 6d. net.

Chesterfleld (Lord). THE LETTERS OF THE EARL OF CHESTERFIELD TO HIS SON. Edited, with an Introduction by C. Strachey, and Notes by A. Calthrop. Two Volumes. Cr. 8vo. I2s.

Chesterton (G.K.). CHARLFS DICKENS. With two Portraits in Photogravure. Seventh Edition. Cr. 8vo. 6s.

ALI THINGS CONSIDERED. Sixth Edition. Fiap. 8vo. 5 s.

TRUMENDOUS TRIFLES. Fourth Edition. Fcap. 8vo. 5 s.

ALARMS AND DISCURSIONS. Second Edition. Fcap. 8ro. 5 s.

THE BALLAD OF THE WHITE HORSE. Third Edition. Ficap. 8vo. $5^{\text {s. }}$

-TYPES OF MEN. Fcap. 8vo. $5^{s}$.

Clausen (George). SIX LECTURES ON PAINTIN. Illustrated. Tinird Edition. Large Post 8vo. $35.6 d$. net.

AIMS AND IDEALS IN ART. Eight Lectures delivered to the Students of the Royal Acadomy of Arts. 1llustrated. Second Eastion. Large Fost 8vo. 5s. net.

Clutton-Brock (A.) SHELLEY : THE MAN AND THE POET. Illustrated. Demy 8zio. is. 6il. net.

Cobb (W.F.). THE BOOK OF PSALMS. With an Introduction and Notes. Demy 8vo. ros. $6 d$. net.

Conrad (Joseph). THE MIRROR OF THE SEA: Memories and Impressions. Third Edition. Cr. 8vo. 6s.

Coolidge (W. A. B.). THE ALPS : IN NATURE ANU HISTORY. Illustrated. Demy 8vo. 7s. 6d. net.

*Correvon (H.). Alpine flora. Trans. lated and enlarged by E. W. Clayforth. Illustrated. Square Demy 8vo. I6s. net.

Coulton (G. G.). CHAUCER AND HIS ENGLAND. illustrated. Second Edition. Demy 8vo. Ios. 64. net.

Cowper (William). THE POEMS. Edited with all introduction and Notes by J. C. BAIley. Illustrated. Demy 8a'o. ros. $6 d$. ret.
COX (J. C.). RAMBLES IN SURREY. Second Edition. Cr. 8vo. 6s.

Crowley (Ralph H.). THE HYGIENE UF SCHOUL LIFE. Illustrated. $C r$. 8vo. 3s. 6d. net.

Davis (H. W. C.). ENGLAND UNDER THE NORMANS ANU ANGEVINS: 1066-1272. Thind Edition. Deny 8\%o. Ior. $6 d$, net.

Dawbarn (Charles). FRANCE AND TIL FRENCH. Hlustrated. Demy $8 v 0$. ros. $6 d$. net.

Daarmel' (Mabel). A CHILD'S LIFE OF CHRIST. Illustrated. Large $C_{r}$ 8vo. $6 s$.

Deffand (Madame du). LETTRES DE MADAME DU DEFFAND À HORACE WALPOLE. Edited, with Introduction, Notes, and Index, by Mrs. Pagrt Toyn Ber. In Three lolumes. Demy 8vo. $\delta_{3} 3$ s. net.

Dickinson (G. L.). THE GREEK VIEW UF LIFE. Sezenth Edition. Crown 8vo. 2s. 6 d. net.

Ditchfleld (P. H.). THE PARISH CLERK. Illustrated. Third Edition. Demy 8vo. 7s. 6al net.

THE OLD.TIME PARSON. Illustıated. Second fidition. Demy 8zo. 7s. 6d. net.

* THE OLD ENGLISH COUNTRY SQUIRE. Illustrated. Demy 8zo, ror. $6 d$. ntt.

Ditchifold (P. H.) and Roe (Fred). VANISHING ENGLAND. The look by P. H. Ditchfield. lllustrated by FREU RoE. Second Edition. Wide Demy 8vo. iss.net.

Douglas (Hugh A.). VENICE ON FOOT. With the Itinerary of the Grand Canal. Illustrated. Second Edition. Round corners. Fcap. 8zo. 5s. net.

VENICE AND HER TREASURES. lliustrated. Round corners. Fcap. 8vo. 5s. net.

Dowden (J.). FURTHER STUDIES IN THE PRAYER BOOK. Cr. 8vo. $6 s$.

Driver (S. R.). SERMONS ON SUHJECTS CONNECTED WITH THE OLU TESTAMENT. Cr. 8zo. 6s.

Dumas (Alexandre). THE CRIMES OF THE BURGIAS AND OTHERS. With an Introduction by $R$. S. GARnetT. Illustrated. Second Edition. Cr. 8vo. 6s. THE CRIMES OF URBAIN GRAN. DIER AND OTHERS. Illustrated. $C r$. 8vo. 6s.

THE CRIMES OF THE MAROUISE DE BRINVILLIERS AND OTHERS. Illustrated. $C r .8 v o$. $6 s$.

THE CRIMES OF ALI PACHA AND OTHERS. Illustrated. Cr. 8vo. 6 s. 
MY MEMOIRS. Translated by E. M. WALLER. With an Inisoduction by ANDREW I.ANG. With Frontispieces in Photogravure. In six Volumes. Cr. 8vo. 6s. cach z'olume. VOL. I. $3802-1828$. VOL. IV. 1830-183?. VOL. II. 1822-1825. V'OL. V. 183t-1832. Vi).. III. 1526-x830. VUL. VI. 1832-1833

If PETS. Newiy translated by A. R. Altinson. lliustrated. Cr. 8vo. 6s.

Duncan (F. M.). OUR INSECT FRIE.NDS AND FOES. Illustrated. Cr. Yvo. 6o.

Dunn-Pattison (R. P.). NAPOLEON'S MAKSHALS. lifustrated. Demy $8 v 0$. secord Eitition. z2s. 6 d. ret.

$1 \mathrm{IHE}$ IILACK PKINCE. Illustrated. second Edition. Demy 8v0. 75. 6d. net.

Durham (The Earl on. THE REPORT ON CANADA. With an Introductory Note. Demy 8vo. 4s. 6d. net.

Dut:(W. A.). THE NORFOLK BROADS. litultrated. Secord Edition. Cr. 8vo. 6s.

Egerton (H. B.). A SHORT HISTORY OF BRITISH COLONIAL POLICY. Third Edition. Lemy 8vo. 75. 6d. net.

Evans (Herbert A.). CASTLES OF ENGLAND AND WALES. Illustrated. Demy 8vo. 12s. 64. net.

Exeter (Bishep of). REG N U M DEI. (The bamptosi Leclures of zoor.) A Cheaper Fitition. Demy 8vo. 75. 6d. net.

Ewald (Carl). MY LITTLE BOY. Translated by Alexander Teixeira DB Mattos. Illustrated. Fcap. 8vo. 5s.

Fairbrother (W. H.). THE PHILOSOPHY OF T. H. GREEN. Second Edition. Cr. 8vo, 3s. 6d.

-ffoulkes (Charles). THE ARMOURER AND HIS CRAFT. Illustrated. Royal 45o. E2 as. net.

Firth (C. H.). CROMWELL'S ARMY : A History of the English Soldier during the Civit Wars, the Commonwealth, and the Protectorate. Illustrated. Second Edition. Cr. Evo. 6s.

Fisher (H. A. L.). THE REPUBLICAN TRADITION IN EUROPE. Cr. 8vo. 6s. net.

FitzGerald (Edward). THE RUBA'IYAT OF OMAK KHAYYÁM. Printed from the Fifth and last Edition. With a Commentary by H. M. BATSON, and a Biograph. ical Introduction by E. D. Ross. Cr. evo. 6s.

Flux (A. W.). ECONOMIC PRINCIPLES. Demy 8v0. 75. 6d. met.
Fraser (J, F.). ROUND THE WORLD ON A WHEEL. Illustrated. Fi/h Ellition. Cr. 8zo. 6s.

Galton (Sir Francis). MEMORIES OF MY LIFE. Illustrated. Thir ${ }^{2}$ Edition. Demy zvo. ras. 6d. ant.

Gibblns (H. de B.). INDUSTRY IN ENGLAND: HISTORICAL OUTLINES. With Maps and Plans. Seventh Eulition, Revised. Demy 8vo. 10s. 6d.

THE INDUSTRIAL HISTORY OF ENGLAND. With 5 Maps and a Plan. Eighteenth and Revised Edution. Cr. $8 v 0$.

E ${ }^{3 s}$ (ILISH SOCIAL REFORMERS. Second Edition. Cr. 8vo. 2s. 6d.

Gibbon (Edward? THE MEMOIRS OF THE LIFE OF EDWARD GIBBON. Edited by G. BIRKBECK HiLL Cr. 8vo. 6s. THF DECIINE AND FALL OF THE ROMAN EMIPIRE. Edited, with Notes, Appendices, and Maps, by J. B. Burr, Iilustrated. In Seren Volumes. Demy 8vo. Each ros. 61. net. Also in Severn Volumes. Cr. 8zo. Gs. each.

Glover (T. R.). THE CONFLICT OF RELIGIONS IN THE EARLY ROMAN EMPIRE. Fourth Eation. Demy 8vo. 75. 64 . ret.

Godley (A, D.). LYRA FRIVOLA. Fourth Edition. Fcat. 8vo. 2s. 6d.

VERSES TO ORDER. Second Edition. Fcap. 8vo. 25. 64.

SECUND STRINGS. Fcap. 8vo. 2s. $6 d$.

Gostling (Frances M.). THE BRETONS AT HOME. Illustrated. Third Eaition. Cr. 8\%0. 6s.

AUVERGNE AND ITS PEOPLE. Illustrated. Demy 8vo. 10s. 6d. net.

-Gray (Arthur). CAMBRIDGE AND ITS STURY. Illustrated. Dcmy 8vo. 7s. 6d. net.

Grahame (Kenneth). THE WIND IN THE WILLOWS. Illustrated. Sixth Edition. Cr.8vo. 6s.

Granger (Frank). HISTORICAL SOCI. OLOGY : A TEXT-BOOK of POLITICS. Cr. 8v0. 3s. 64. net.

Grew (Edwin Sharpe). THE GROWTH OF A PLANET. Illustrated. Cr. 8vo. $6 s$.

Griffln (W. Hall) and Minchin (H. C.). THE LIFE OF ROBER I" BROWNING. Illustrated. Secont Edition. Demy $8 v 0$. 12s. 6.t. net.

Hale (J. R.). FAMOUS SEA FIGHTS: FROM SALAMIS TO TSU-SHIMA. Illustrated. Cr. Ber. 6s. net. 
-Hall H R. THE ANCIENT HISTORY OF THE NEAR EAST FROM THE EARLIEST PERIOD TO THE PERSIAN INVASION OF GREECE. Illustrated. Demy 8vo. 15s. Het.

Hannay (D.). A SHORT HISTORY OF THE ROYAL NAVY. Vol. I., 1217-1688. Vol. II., 1689-r815. Demy 8vo. Each 7s. 6d. net.

Harper (Charles G.). THE AUTOCAR ROAD-BOOK. With Maps. In Four Volumes. Cr. 8vo. Each 7 s. 6al. net.

Vol. I.-SOUTH OF THE THAMES.

Vol. II.-NOrth aND South Wales AND WEST MIDLANDS.

Vol. III.-East Anglia and East MidLANDS.

- Vol. IV.-The North of ENGland and South op ScotLand.

Harris (Frank). THE WOMEN OF SHAKESPEARE. Demy 8vo. 7s. 6a. net.

Hassall (Arthur). THE LIFE OF NAPOLEON. Illustrated. Demy 8vo. 75. 64 . net.

Headley (F. W.). DARWINISM AND MODERN SOCIALISM. Second Edition. Cr. 8zio. 5s. net.

Henderson (M. Sturge). GEORGE MEREDITH : NOVELIST, POET, REFORMER. With a Portrait. Second Edition. Cr. 8vo. 6s.

Henley (W. E.). ENGLISH LYRICS : CHAUCER TO POE. Second Edition. Cr. 8vo. 2s, 6d. net.

Hill (George Francis). ONE HUNDRED MASTERPIECES GF SCULPTURE. Illustrated. Demy 8vo. ros. 6d. net.

Hind (C. Lewls). DAYS IN CORNWALL. Illustrated. Third Edition. Cr. 8vo. 6s.

Hobhouse (L. T.). THE THEORY OF KNOWLEDGE. Demy 8vo. ros. 6d, net.

Hobson (J. A.). INTERNATIONAL TRADE: AN APplication op ECONOMIC THEORY. Cr. Bvo. 2s. fid. net.

PROBLEMS OF POVERTY: AN INQUIRY INTO THE INDUSTRIAL CONDITION CF THE Poor. Seventh Edition. Cr. 8vo. 25. $6 d$.

THE PROBLEM OF THE UNEMPLOYED : AN ENQUIRY AND AN ECONOMI: Policy. Fifth Edition. Cr. 8vo. 25. $6 d$.

Hodgson (Mrs. W.). HOW TO IDENTIFY OID CHINESE PORCELAIN. Illustrated. Third Edition. Post 8v0. Gs.

Holdich (Slr T. H.). THE INDIAN BORDERLAND, $1880-r 900$. Illustrated. Second Edition. Demy 8vo. ros. 6d. net.
Holdsworth (W. S.). A HISTORY OF ENGLISH LAW. In Four Volumes. Vols. I., II., III. Demy 8vo. Each 1os. $6 d$. net.

Holland (Clive). TYROL AND ITS PEOPLE. Illustrated. Demy 8vo. ros. 6d. net.

THE BELGIANS AT HOME. Illustrated. Demy 8vo. ros. 6d. net.

Horsburgh (E. L. S.). LORENZO THE MAGNIFICENT: AND FLORENCF IN HER Golden AGE. Illustrated. Second Edition. Demv 8vo. 15s. net.

Watérloo: a Narrative and a Crit. ICISa. With Plans, Second Edition. Cr. 8vo. 5 s.

THE LIFE OF SAVONAROLA. Illus. trated. Cr. 8vo. 55. net.

Hosio (Alexander). MANCHURIA. Illustrated. Second Edition. Demy 8vo. 7s. 6d. net.

Hudson (W. H.), A SHEPHERD'S LIFE: IMPRESSIONS OF THE SOUTH WILTSHIRE Downs. illustrated. Third Edi. tion. Demy 8vo. 7s. 6d. wet.

Humphreys (John H.). PROPOK TIONAL REPRESENTATION. Cr. 8vo. ss. net.

Hutehinson (Horace G.). THE NEW FOREST. Illustrated. Fourth Edition. Cr. 8vo. 6s.

Hutton (Edward). THE CITIES OF SPAIN. Illustrated. Fourth Edition. Cr. 8vo. 6s.

THE CITIES OF UMBRIA. Illustrated. Fourth Edition. Cr. 8vo. 6s.

- THE CITIES OF LOMBARDY. IJlustrated. Cr. 8\%0. 6s.

FLORENCE AND NORTHERN TUS. CA N Y W I H GE NOA. Illustrated. Second Edition. Cr. 8vo. 6s.

SIENA AND SOUTHERN TUSCANY. Illustrated. Second Edition. Cr. 8vo. 6s. VENICE AND VENETIA. Illustrated. Cr. 8vo. 6s.

ROME. Illustrated. Third Edition. $C r$. $8 v 0$. $6 \mathrm{~s}$.

COUNTRY WALKS ABOUT FLORENCE. Illustrated. Second Edition. Fcap. 8vo. 5s. net.

IN UNKNOWN TUSCANY. With Notes by Willia. HeYwood. Illustrated. Second Edition. Demy 8vo. 7s. 6d. net.

A BOOK OE THE WYE. Illustrated. Demy 8vo. 7s. 6d. net.

Ibsen (Henrik). BRAND. A Dramatic Poem, Translated by WILliam WILSON. Fourth Edition. Cr. 8vo. 3s. 6d.

Inge (W. R.). CHRISTIAN MYSTICISM. (The Bampton Lectures of 1899 .) Second and Cheaper Edition. Cr. 8vo. 5s. mot. 


\section{General Literature}

Innes (A. D.). A HISTORY OF THE BRITISH iN INDIA. Witb Maps and Plans. Cr. 8ve. 6s.

ENGIAND UNDER THE TUDORS. With Maps. Tritul Edition. Demy 8vo. sos. $6 d$, net.

Innes (Mary) SCHOOLS OF PAINT. ING. Illustrated. Second Edition. Cr. 8ve. ss. net.

Jenks (E.). AN OUTLINE OF ENG. LISH LOCAL GOVERNMENT. Secord Edition. Revised by R, C. K. ENSOR, Cr. 8vo. 2s. 6d. net.

A SHORT IIISTORY OF ENGLISH LAW: FROM THR EAKLIRST TIMES TO THE END of the Year igxi. Demy 8vo. ras. 6il. net.

Jern!ngham (Charles Edward). THE MAXIMS OF MARMADUKE. Second Edition. Cr. 8vo. 55.

Johnston (SIr H. H.). BRITISH CEN. TRAL AFRICA. Illustrated. Third Edition. Cr. 4 to. 18 s. net.

THE NEGRO IN THE NEW WORLD. Illustrated. Demy 8vo. 215. net.

Jullan (Lady) of Norwlch. REVELATIONS OF DIVINE LOVE. Edited by GRACB WaRRACK. Fonth Edition. Cr. 8vo. 3s. 6d.

Keats (John). THE POEMS. Edited with Introduction and Notes by $E$. de SÉlincourt. With a Frontispiece in Photogravure. Third Edition. Demy $8 v 0$. 7s. 6 d. net.

Keble (John). THE CHRISTIAN YEAR. With an Introduction and Notes by W. Lock. Illustrated. Third Edition. Feap. 8vo. 35. $6 d$.

Kempls (Thomas a). THE IMITATION OF CHRIST. From the Latin, with an Introduction by DrAN FARRAR. Illustrated. Third Edition. Fcap. 8vo. 3s. 6 d.

Kingston (Edward) A GUIDE TO THE BRITISH PICTURES IN THE NATIONAL GALLERY. Illustrated. Feap. 8vo. 3s. 6d. net.

Kipling (Rudyard). BARRACK-ROOM BALLADS. 308th Thousard. Thirty-first Edition. Cr. 8vo. 6s. Also Fatp. 8vo, Leather. 5s, net.

THE SEVEN SEAS. 89th Thowand. Niveteenth Edition. Cr. 8vo. 6s. Also Fatp. 8vo, Leather. ss. net.

THE FIVE NATIONS. 72nd Thousand Eighth Edition. Cr. 8vo. 6s. Also Fiat. 8vo, Leather. ss. net.

DEHARTMENTAL DITTIES. Twentieth Edition. Cr. 8vo. Gs. Also Frap. 8vo, Leather. ss. wet.
Lamb (Charles and Mary). THE COMPLETE WORKS. Edited with an Introduction and Notes by E. V. Lucas. A New ard Revised Edition in Six Volumes. With Frontispiece. Fiap Bvo. 5s. each. The volumes are :-

1. Miscellaneous Prose. ti. Elia and tha last Essays of Elia. ilt. Books for Childeren. iv. Plays and Posms. v. and VI. LKTTERS.

Lankester (SIr Ray). SCIENCE FROM AN EASY CHAIR. Illustrated. Fifth Edition. Cr. 8vo. 6s.

Le Braz (Anatole). THE LAND OF PARDONS. Translated by Frances $\mathbf{M}$. Gostling. Illustrated. Thirt Edition. Cr. 8vo. 6s.

Lock (Walter). ST, PAUL, THE MASTER-BUILDER. Third Edition. Cr. 8vo. 3s. 64 .

THE BIBLE AND CHRISTIAN LIFE. Cr. 8vo. 6s.

Lodge (SIr Ollver). THE SUBSTANCE OF FAITH, ALLIED WITH SCIENCE: A Catechism for Parents and Teachers. Eleverth Edition. Cr. 8zo. 2s. net.

MAN AND THE UNIVERSE: A STUDY OP THE INPLUENCE OP THB ADVANCE IN SCIENTIFIC KNOWLEDGE UPON OUR UNDERStandiNG OP Christianitr. Ninth Edition. Demy 8vo. 5s. net. Also Fiap. 8vo. Is. net.

THE SURVIVAL OF MAN. A Study ik UNRECOGNISED HUMaN FaCUlty. Fifth Edition. Wide Crown 8vo. 5s. net.

REASON AND BELIEF. Fifth Edition. Cr. 8vo. 35. 6d. ret.

-MODERN PROBLEMS. Cr. 8vo. ss. net.

Lorimer (George Hurace). LETTERS FROM A SELF-MADE MERCHANT TO HIS SON. Illustrated. Twenty-second Edition. Cr. 8vo. 3s. $6 d$. Also Fcap. 8vo. is. ret.

OLD GORGON GRAHAM. Illustrated. Second Edition. Cr. Bvo. 6s.

Lueas (B. V.). THE LIFE OF CHARLES LAMB. Illustrated. Fifth Edition. Demy 8vo. 7s. 6d. net.

A WANDERER IN HOLLAND. Illustrated. Thirteenth Edition. Cr. 8vo. 6s. A WANDERER IN LONDON. Illustrated. Tzuelfth Edition. Cr. 8z'o. 6s.

A WANDERER IN PARIS. Illustrated. Ninth Edition. Cr. 8vo. 6 s. Also FCap. 8vo. 55 .

- A WaNderer iN florence. Illusstrated. Cr. 8vo. 6s.

THE OPEN ROAD: A Little book for Wayfarers. Eighteenth Edition. Fiap. 8vo. 5s.; India Paper, 7s. 6d.

- Also Iilwstrated in colowr. Cr. 460155. wot. 
THE FRIENDLY TOWN : A Little Book for the Urbane. Sixth Edition. Fcap. 8vo. 5s.: India Paher, 7s. 6d.

FIRESIDE AND SUNSHINE. Sixth Edition. Fcap. 8zo. 5 s.

CHARACTER AND COMEDY. Sixth Edition. Fcap. 8vo. ${ }^{55}$. A Choice of Letters by Entertaining Hands. Seventh Fdition. Fatp 8v\%. 5 s.

THE SECOND POST. Third Edition. Fcap. 8vo. 5 s.

HER INFINITE VARIETY : A FEMININR Portrait Gallery. Sixth Edition. Fcap. Suo. 5 s.

GOOD COMPANY: A Rally of MEN. Second Edition. Fanp. 8wo. 5 s.

ONE DAY AND ANOTHER. Fifth Edition. Fcaf. 8\%o. $5^{5}$.

OLD LAMPS FOR NEW. Fourth Edition. Fcap. 8\%o. 5 s.

LISTENER'S LURE: AN ORlique NARRATION. Ninth Edition. Fcap. 8vo. 5 s.

OVER BEMERTON'S: AN EAST-GOING Chronicle. Winth Edition. Fcap. $8 v 0$. $5 s$.

MR. INGLESIDE. Ninth Edition. Fcap. 820. $5^{5}$. See also Lamb (Charles).

Lydekker (R. and Others). REPTILES, AMPHIBIA, FISHES, AND LOWER CHORDATA. Edited by J. C. CUNNINGham. Illustrated. Demy 8vo. 1or. 6d. net,

Lydekker (h.). THE OX AND ITS KINDRED. Illustrated. Cr. 8vo. 6s.

Macaulay (LOid). CRITICAL AND HISTORICAL ESSAYS. Edited by F. C. Montaguis. Three Volumes. Cr. Bvo. 185.

MeCabe (Joseph). THE DECAY OF THE CHURCH OF ROME. Third Edition. Demy 8vo. 7s. 6d. net.

THE EMPRESSES OF ROME. Illustrated. Demy 8vo. 12s. 6d. net.

MacCarthy (Desmond) and Russell (Agatha). LADY JOHN RUSSELL: A Memor. Illustrated. Fourth Edition. Demy 8vo. ros. 6d. net.

MeCullagh (Franels). THE FALL OF ABD-UL-HAMID. Illustrated. Demy 8vo. 1os. 6d. net.

MeDougall (William). AN INTRODUCTION TO SOCIAL PSYCHOLOGY. Fourth Eution. Cr. 8vo. 5s. net.

BODY AND MIIND: A HISTORY AND A Defence of Animisi. Demiy 8vo. ios. $6 \dot{d}$. net.

- Mdlie. Mori' Author of. ST. CATHER. INE OF SIENA AND HER TIMES. Illustrated. Second Edition. Demy 820. 75. 6d. net.
Maeterlinek (Maurlec). THE BLUE BIRD: A FAIRY Play In Six Acts. Translated by ALEXANDER TeIXeIRA DR Matros. Fcap.8vo. Deckle Edges. 3s. 6d. net. Also Fcap. 8vo. Cloth, is. net. An Edition, illustrated in colour by F. CAYLEY Roginson, is also published. Cr. 4 to. Gilt top. 215. net. Of the above book Twentynine Editions in all have been issued.

MARY MAGDALENE: A Play in ThreE Acts. Translated by AlexandrR TEIXEIRA DE Mattos. Third Edition. Fcap. 8vo. Deckle Ed d'es. 3s. 6d. het. Also Fcap.8vo. Is. nct.

DEATH, Translated by ALExANDER Teixeira de MatTos. Fourth Edition. Fcap. 8vo. 3s. 6a. net.

Mahafiy (J. P.). A HISTORY OF EGYPT UNDER THE P'TOLEMAIC DYNASTY. Illustrated. Cr. 8vo. 6 s.

Maltland (F. W.). ROMAN CANON IAW IN THE CHURCH OF ENG LAND. Royal 8vo. 7s. 6d.

Marett (R. R.). THE THRESHOLD OF RELIGION. Cr. 8vo. $3^{\text {s. } 6 d \text {. net. }}$

Marlott (Charles). A SPANISH HOLI. DAY. Illustrated. Demy 8vo. 7s. 6d. net. THE ROMANCE OF THE RHINE. Illustrated. Demy 8vo, 1or. 6d. net.

Marpiote (J. A. R.). THE LIFE AND IIMLS OF YUCIUS CARY, VISCOUNT FALKLAND. Illustrated. Second Edition. Demy 8vo. 7s. 6d. net.

Masefleld (John). SEA IIFE IN NEL. SON'S IIME. Illustrated. Cr. $8 v 0$. 3s. $6 d$. net.

A SAILOR'S GARIAND. Selected and Edited. Second Edition. Cr. 8vo. 3s.6d. net.

Masterman (C. F. G.). TENNYSON AS A RELIGIOUS TEACHER. Second Edition. Cr.8vo. 6s.

THE CONDITION OF ENGLAND. Fourth Edition. Cr.8vo. 6s. Also Fcap. 8vo. Is. net.

* Mayne (Ethel Colburn). BYRON. Illus. trated. In two volumes. Demy 8vo. 21 s. net.

Medley (D. J.). ORIGINAL ILLUSTRATIONS OF ENGLISH CONSTITUTIONAL HISTORY. Cr. 8vo. 75.6d, net.

Methuen (A.M.S.). ENGLAND'S RUIN : Discussed in FuURTEen LetTERs TO A Protectionist. Ninth Edition. Cr. svo. 3. net.

Miles (Eustace). LIFE AFTER LIFE: o ?, The Theory OF Reincarnation. Cr. 8vo. 2s. 6ul. net.

THE POWER OF CONCENTRATION : How ro ACQUiRe IT. Fowrth Edition. Cr. 8vo. 3s. $6 d$. net. 
Millals (J. G.). THE I.IFE AND I.ET. 'IERS OF" SIR JOIIN EVERIEI'I' MILLAIS. lllustrated. Nerv Édition. Demy 8vo. 7s. 6.6. net.

Milne (J. G.). A HISTORY OF EGYPI UNDER RONAN RULE. lllusirated. Cr. 8vo. 6s.

Mofrat (Mary M.). QUEEN LOUISA OF PRUSSIA. Illustrated. Fourth Edition. Cr. 8vo. os.

MARIA THFRESA. Illustrated. Demy 8z'o. jos. 6ut. net.

Money (L. G. Chlozza). RICHES AND POVERTY, t9so. Tenth and Revised Edition. Demy 8zio. 5s. net.

MONEY'S FISCAL DILTIONARY, IOI. Second Edition. Demy 8z'o. 5s. net.

INSURANCE VERSUS POVER'Y. $8 v 0$. 5s, net.

THINGS THAT MATTER: PATERS ON SUBJECTS WHICH AKE, OR OUGHT TO BE, UNDER Discusiton. Demy 8vo. 5s. net.

Montague (C.E.). DRAMATIC VALUES. Second Edition. Fcat. 8vo. 5s.

Moorhouse (E. Hallam). NELSON'S LADY HANILTUN. Illustrated. 7 hird Edition. Demy 8vo. 7s. 6it. net.

- Morgan (C. Lloyd). INSTINCT AND EXPERIENCE. C'r. 8vo. 5s. net.

- Nevill (Lady Dorothy). MY OWN TIMES. Edited by her son. Demy 8zo. 15s. net.

Norway (A. H.). NAPLES: Past ano PRESENT. lllustrated. fowrth Ldition. Cr. 8vo. 6s.

-O'Donnell (Elliott). WEREWOLVES Cr. 8vo. 5s. met.

Oman (C. W. C.), A HISTORY OF TIIE ART OF WAR IN THE MIDILLE AGES. Illustrated. Demy 8vo. 10s. 6d. net.

ENGLAND BEFORE THE NORMAN CONQUEST. With Maps. Secund Edition. Demy 8vo. ros. 6al. net.

Oxford (M. N.), A HANDDBOK OF NURSING. Sixth Edition, Rerised. Cr. 8vo. 35. 6i. net.

Pakes (W. C. C.). THE SCIENCE OF HYGIENE. Illustrated. Second and Cheaper Edition. Revised by A. 1 . Nankivell. Cr. 8vo. ss. net.

Parker (Eric). THE BOOK OF THE ZOO. Illustrated. Second Editun. Cr. $8 \pi 0.65$.

Pears (Sir EdwIn). TURKEY ANDITS PEOPLE. Second Edition. Demy svo. 12s. 6d. net.
Petrle (W. M. Filnders). ^ HISTORY OF EGYPT. Illustrated. In Six Volumes. Cr. 8vo. 6s. each.

VOL. I. FROM THE IST to тHE XVITH Uvistr. Sezienth Edition.

Vol. II. THн XVIITH ANo XVIIIth Drvastres. Fourth fidition.

Vol. III. XIXth to XXXth Drnasties.

Vol. IV. Ei;ft Uniler thr Ptolmalc UYNASTY. J. P. MAHAFFY.

Vol. V. Egvpt Under Roman Rule. J. G. Mitne.

Vol. Vil. Ecypt in the Midole Agrs. Stanley lane-Poole.

RELIUION AND CONSCIENCE IN ANCIENI FGI'P'. lllustrated. Cr. 8vo. 2s. $6 a$.

SYliIA AND EGYPT, FROM THE TELL EL A.ARNA LETLERS. Cr. 8vo. 25. $6 d$.

EBVITIAN TALES. Translated from the Papyri. First Series, wth to xuth Dynasty. Illustrated. Sccond Eilition. Cr. 8vo. $35.6 d$.

EGYPIIAN TALES. Translated from the Papyri. Second Series, xvinth to xixth Dynasty. lllustrated. Cr. 8vo. 35. $6 d$.

EGYPTIAN DECORATIVE ART. lllustrated. Cr. $8 v n_{*} 3 s .6 d$.

Phelps Ruth S.). SKIES ITALIAN: A LitTle Breviaky for Travellers in lialy. Fcap.8zo. Leather. 5s. net.

Pollard (Alfred W.). SHAKESPEARE FOLIOS ANU QUARTOS. A Study in the Bibliography of Shakespeare's Plays, 1594-r685. lllustrated. Folio. 22s. net.

Porter (G. R.). THE PROGRESS OF IHE NATION. A New Edition. Edited by F. W. Hirst. Demy $8: 0.2$ is. net.

Power (J. O'Connor). THE MAKING OF AN ORATOR. Cr. 8zo. 6s.

Price (Eleanor C.). CARDINAL DE RICHELIEU. lilustrated. Second Eidition. nemy 8vo. ras, 6i, net.

Price (L. L.) A SHORT HISTORY OF POLITLAL, ECONOMY IN ENGLANH FROA ADAM SAITH IO ARNUIL TOYNBEE. Sezenth Edition. Cr. szo. 2s. $t$ id.

Pycraft (W. P.). A HISTORY OF EIRDS. lllustrated. Demy 8\%o. ros. Gd, net.

Rawlings (Gertrude B.). COINS AND HOW IO KNUAV I HEM. Illustrated. Third Edition. Cr. Svo. is.

Regan (C. Tate). THE FRESHWATER HISHES OF THE l3RIIISII ISLES. lllustrated. Cr. Sro. ós.

Reid (Archiall). THE LAIWS OF IIEREDI'T. Second Édition. Demy 8zo. zis. net. 
Robertson (C. Grant). SELECT STATUTES, CASES, AND DOCUMENTS, 1660-1804. Derry 8vo. ros. 6d. net.

ENGLAND UNDER THE HANOVER. IANS. Illustrated. Second Edition. Demy 800. 10s. 6a. net.

Roe (Fred). OLD OAK FURNITURE. Illustrated. Second Edition. Demy $8 v 0$. 10s. 6a. net.

-Ryan (P. F. W.). STUART LIFE AND MANNERS: A Social HistuRv. Illustrated. Deniy 8vo. 10s. 6d. net.

St. Francis of Assisi. THE LITTLE FLOWERS OF THE GLORIOUS MESSER, AND OF HIS FRIARS. Done into English, with Notes by WII.LIAM Hevwood. Illustrated. Denty 8vo. 5 s. net.

'Saki' (H. H. Munro). REGINALD. Third Edition. Fiap. Sz.0. 2s. 6d. net.

REGINALD IN RUSSIA. Fcap. 8vo. 2s. Gd. net.

Sandeman (G. A. C.). METTERNICH. Illuntrated. Demy 8z'o. ros. $6 d$. net.

Schidrowitz (Philip). RUBEER. Illustrated. Demy 8vo. tos. 6d. net.

Sclous (Edmund). TOMMY SMITH'S ANIMALS. Illustrated. Eleventh Edition. Fcap. 8vo. $2 s .6 d$.

TOMMY SMITH'S OTHER ANIMALS. Illustrated. Fifth Edition. Fcap. 8vo. 2s. $6 d$.

JACK'S INSECTS. Illustrated. Cr.8vo. 6s.

Shakespeare (William).

THE FOUR FOLIOS, 1623; 1632; 1664; 1685. Eacb $£_{4} 4^{s}$. net, or a complete set, EI 2 ras. net.

7 HE POEMS OF WILLIAM SHAKESPEARE. With an Introduction and Notes by GeORGe WYNDhaM. Demy $8 v 0$. Buckram. 10 . $6 d$.

- helley (Percy Bysshe). THE POEMS OF PLRCY BYSSHE SHELLEY. With an Introduction by A. CLUTTON-BROCK and notes by C. D. Locock. Tzeo Volumes. Demy 8vo. is. net.

Sladen (Douglas). SICILY: The New Winier Resort. Illustrated. Second Edition. Cr. 8vo. 55, net.

Smith (Adam). THE WEALTH OF NATIONS. Edized by Euwin Cannan. Two Volumes. Demy 8vo. 21s. net.

Smith (G. Herbert). GEM-STONES AND THEIR DISTINCTIVE CHARACTERS. [l]ustrated. Cr. 8vo. 6s. net.

Snell (F. J.). A BOOK OF EXMOOR. Illustrated. Cr. 8vo. 6s. Illustrated. Cr. 8vo. 6.
'Stancliffe.' GOLF DO'S AND DONT'S. Fourth Edition. Fcap. 8\%o. is. net.

Stevenson (R. L.). THE LETTERS OF ROBERT LUUIS STEVENSON. Edited by Sir Sidney Colvin. $A$ New and Enlarged Edition in four volumes. Third Edition. Fcap. 8vo. Each 5s. Leather, each ss. net.

Stevenson (M. I.). FROM SARANAC TO THE MARQUESAS AND BEYOND. Being Letters written by Mrs. M. I. STtveNson during 1887-88. Illustrated. $C r$. 8vo. 6s. net.

LETTERS FROM SAMOA, $1891-95$. Edited and arranged by $M$. C. BALFour. Illustrated. Second Edition. Cr. 8vo. 6s. net.

Storr (Vernon F.). DEVELOPMENT AND DIVINE PURPOSE. Cr. 8vo. 5 s. net.

Strcatfeild (R. A.). MODERN MUSIC AND MUSICIANS. Illustrated. Second Edition. Demy 8vo. 75. 6d. net.

Swanton (E. W.). FUNGI AND HOW TO KNOW THEM. Illustrated. Cr. 8vo. 6s. net.

Symes (J. E.). THE FRENCH REVOLUTION. Second Edition. Cr. 8vo. 2s. $6 d$.

Tabor (Margaret E.). THE SAINTS IN ART. Illustrated. Fcap. 8vo. 3s. 6d. net.

Taylop (A. E.). ELEMENTS OF METAPHYSICS. Second Edition. Demy 8vo. Ios. $6 d$. net.

Taylor (Mrs. Basil) (Harriet Osgood). JAPANESE GARDENS. Illustrated. Cr. Ato. 21 s. net.

Thibaudeau (A. C.). BONAPARTE AND THE CONSULATE. Translated and Edited by G. K. Fortescue. Illustrated. Demy 8vo. ros. 6d. net.

Thomas (Edward). MAURICE MAETERLINCK. Illustrated. Second Edition. Cr. 8vo. 5s. net.

Thompson (Francis). SELE C T E D POEMS OF FRANCIS THIOMPSON. With a Biographical Note by Wilfrid Mevnell. With a Portrait in Photogravure. Seventh Edition. Fcap. 8vo. 5s, net.

Tileston (Mary W.). DAILY STRENGTH FOR DAILY NEEDS. Nineteenth Edition. Medium 16 mo. 2s. 6d. net. Lamb.

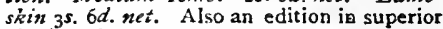
binding, $6 s$.

THE STRONGHOLD OF HOPE. Nedium 16 mo. $2 s .6 d$, net.

Toynbee (Paget). DANTE ALIGHIERI His Life AND WORKs. With I6 Illustrations. Fourth and Enlarged Edition. Cr. 8vo. 5s. net. 
Trevelyan (G. M.). ENGLAND UNDER THE SIUAR'TS. With Maps and Plans. Fijth Edition. Demy 8vo. Ios. 6d. net.

Triggs (H. Inlgo). TOWN PLANNING: PAST, PRESENT, and Possialz. Hllustrated. Second Edition. Wide Royal 8 vo. 35. net.

* Turner (SIr AIfred E.). SIXTY YEARS OF A SOLDIEK'S LIFE. Demy $8 \%$. 12s. 6d. net.

Underhlll (Evelyn). MYSIICISM. A Study in the Nature and Development of Man's Spiritual Consciousness. Fourth Edition. Demy 8vo. Iss. net.

-Underwood (F. M.). UNITED ITALY. Demy 8vo. ros. 6 d. net.

Urwick (E. J.). A PHILOSOPHY OF SOCIAL PROGRESS. Cr. 8vo. $6 s$.

Vaughan (Herbert iI.). THE NAPLES KIVIERA. Illustrated. Second Edition. Cr. 8io. 6s.

FLORENCE AND HER TREASURES. Illustrated. Fcap. 8vo. Round corners. 5. net.

Vernon (Hon. W. Warron). READINGS ON THE INFERNU UF DANTE. With an Introduction by the REv. I'R. Mocke. Two Volumes. Second Edition. Cr. Evo. 35s. net.

READINGS ON THE PURGATORIO OF DANTE. With an In:roduction by the late Deas Church. Two Volumes. Third Edition. Cr. 8vo. I5s. net.

READINGS ON THE PARADISO OF DANTE. With an Introduction by the Lishop or Ripon. Two Volumes. Second Edition. Cr.8vo. I5s. net.

Wade (G. W.), and Wade (J. H.) RAMBLES IN SOMERSET. Illustrated. Cr. 8zo. 6s.

Waddell (L. A.). IHASA AND ITS MYSTEKIES. With a Record of the Expedition of $1903-1904$. Illustrated. I Ihird and Cheaper Edition. Medium 8vo. 7s.6d. net.

Wagner (Richard), RICHARD WAG NLK'S MUSIC DRAMAS: Interpretatiors, embodying Wagner's own explanations. By Alicr Leighton Cleather and Basil Crump. Fcap. 8vo. 2s. 6d. cach. The Risg of the Nibelung. Fifth Edition.

Parsifal, Lohengrin, and the Holy GrAIL.

TRISTAN AND IsOLDE.

Tannhäuser and the Mastersingers OF NUREMBERG.
Waterhouse (Elizabeth), WITH THI SIMPLE-HEAKTED: Litte Homilies to Women in Country Places. TYird Eidition. Small Pot: 8vo. 2.s. net.

THE HOUSE BY THE CHERRY TREE. A Second Series of Little blamilies to Women in Country Places. Small P'olt 8zo. 2s. net.

COMPANIONS OF THE WAY. Being Selections for Morning and Evening kead. ing. Chosen and arranged by ELIZADHTI Waterhouse. Larre Cr. 8zo, 5s, net.

'THOUGHTS OF A TERTLARY. Small Pott 8vo. 2s. net.

Waters (W. G.). ITALIAN SCUI,PTORS AND SMITHS. Illustrated. $C r .8 v 0$. 7s. 6ul. net.

Watt (Francis). EIINBURGII AND THE LOTHIANS. Illustrated. Secont Edition. Cr. 8vo. ros. 6d. net.

-Wedmoro (SIr Frederlck). MEMO. RIES. Demy 8z'o. 7s. 6i. net.

Welgall (Arthur E. P.). A GUIDE TO THE ANTIQUITIES OF UPPEL EGYPT: From Abydos to the Sudar Frontier. Illustrated. Cr. 8vo. 7s. 6d. nci.

Welch (Catharine). THE I I T T L E DAUPHIN. lllustrated. Cr.8vo. 6s.

Wells (J.). OXFORD AND OXFORD LIFE. Third Edition. Cr. 8vo. 35.6\%. A SHORT HISTORY OF ROME. Elez'enth Edition. With 3 Maps. Cr. 8\%o. 3s. 6u.

Wilde (Oscar). THE WORKS OF OSCAR WILDE. In Twelve Volwmes. Fcap. 8vo. 5s. net each zolume.

1. LoRd ARthur Savil.e's Crime and the PORTRait of Mik. W. H. II. THE Duchess of PadUa. III. POEMS. IV. LADV WINDERMERE'S FAN. v. A WOMAN of No Importance. VI. AN IDEal HUSBAND. VII. THE IMPORTANCE OP BEING Earnest. vili. A House of Povegranates. ix. Intentions. $x$. De Pro. FUNdis and Prison LetTers. XI. EsSAys. xir. Salomé, A Florentine Tragedy, and La Sainte Courtisane.

Williams (H. Noel). THE WOM E N BONAPARTES. The Mother and three Sisters of Napoleon. Illustrated. Two Volumes. Demy $8 v 0$. 24s. net.

A ROSE OF SAVOY : MARIE Adet.aloe o? Savoy, Duchisse de Bourgogne, Mother or Lou Is $x v$. Illustrated. Seconit Edition. Demy 8vo. 15 s. net.

THE FASCINATING DUC DE RICHELIEU: LOUIS FRANCOIS ARMAND DV Plessis (1696-1788). Illustrated. Demy 8vo. 25s. net.

A PRINCESS OF ADVENTURE : MARTE Caroline, Duchesse de Br.rry (I7981870). Illustrated. Demy 8vo. 155. net. 
Wood (SIr Evelyn). FROM MIDSHIP. MAN TO FIELD-MARSHAL. Illustrated. Fifth Edition. Demy 8vo. 7s. 6a. net. Also Fcap. 8ro. Is. net.

THE REVOLT IN HINDUSTAN (1857-59). Illustrated. Second Edition. Cr.8vo. 6s.

Wood (W. Birkbeck), and Edmonds (Col. J. E.). A HISTORY OF THK CIVIL WAR IN THE UNITED STATES $(186 t-5)$. With an Introduction by SPRnser Wilkinson. With 24 Maps and Plans. Third Edition. Demy $8 v 0$. 12s. 6d. net.
Wordsworth (W.). THE POEMS. With an Introduction and Notes by Nowal C. Sмith. In Three Volumes. Demy $8 v 0$. 15s. net.

Yeats (W, B.). A BOOK OF IRISH VERSE. Third Edition. Cr. 8vo. 3s. $6 d$.

\section{Part II.-A Selection of Series.}

\section{Ancient Cities.}

General Editor, B. C. A. WINDLE.

Cr. 8vo. 4s. 6d. net each volume.

With Illustrations by E. H. NEw, and other Artists.

Brtstol. Alfred Harvey.

Canterbury. J. C. Cox.

Chrstar. B. C. A. Windle.

Dublis. S. A. O. Fitzpatrick.
EDinburgk. M. G. Williamson.

LinCOLN. E. Mansel Sympson.

ShrRwgBury. T. Auden.

Wells and GLaston BuRY. T. S. Holmes.

\section{The Antiquary's Books.}

\section{. General Editor, J. CHARLES COX \\ Demy 8vo. 7s. 6d. net each volume. \\ With Numerous Illustrations.}

Archelogt aNd False Antiquitirs. R. Munro.

Bells of England, The. Canon J. J. Raven. Second Edition.

Brasses of England, The. Herbert W. Macklin. Second Edition.

Celtic art in Pagan and Christian Timrs. J. Romilly Allen. Second Édition. Castles and Walled Towns of England, Thr. A. Harvey.

DOMESdaY Inqugst, Thr. Adolphus Ballard.

English Church Furnitura. J. C. Cox and A. Harvey. Second Edition.

Exglisn Costume. From Prebistoric Times to the End of the Eighteenth Century. George Clinch.

EnGLish Monastic Life. Abbot Gasquet. Fourth Edition.

Engligh Seals. J. Hatvey Bloom.

FOzK-LORE As aN Historical Scinxcr. Sir G. L. Gomme.

Gilds and Companizs or London, The. Georgo Unwin.
Manor and Manoxial Records, The Nathaniel J. Hone. Second Edition.

Mrdiatal Hospitals of Enoland, The. Rotha Mary Clay.

Oly Enalish INSTRUMENTS or Music. F. W. Galpin. Second Edition.

OLd ENGLisk Lisraries. James Hutt.

OLD SERYice Books of THR ENGLISH CHuRcH. Christophor Wordsworth, and Henry Littlehales. Second Edition.

Parish Lifr in Mrdiaval England. Abbot Gasquet. Third Edition.

Parish Registers or England, The. J. C. Cox.

Rrmains of the Prenistoric Age in England. B. C. A. Windle. Second Edition.

Roman Era in Britain, The. J. Ward. Romano-British BUILDINGS AND EARThWORK5. J. Ward.

Royal Forests of England. Thx. I. C. Cox.

Shrings or British SAints. I. C. Wall. 


\title{
The Arden Shakespeare.
}

Demy 8vo. 2s. 6d. net each volume.

An edition of Shakespeare in single Plays; each edited with a full Introduction, Textual Notes, and a Commentary at the foot of the page.

ALL'S WBLL That ENDS WELL.

ANTONY AND CLEOPATRA.

CVMBELINR.

Comkdy of ERRORS, ThR.

HAMLET. Thind Edition.

julius Carsar.

- King Henry iv. Pr. I.

KING HENRY Y.

King Henry vi. PT. 1 .

KING HENRY VI. PT. It.

King Henry vi. PT. IIr.

King Lear.

- King Richard il.

King Richard III.

LifE AND DEATH OP KING John, ThE.

LOVE'S LABOUR'S LOST.

МАСввтн.

\author{
MEASURE FOR MEASURE. \\ Merchant of Venice, Thr. \\ Merev Wives of Windsor, The. \\ Midsummer Night's Dream, A. \\ ОтнгLL. \\ Praicless. \\ ROMBO AND JULIET. \\ TAMING of Thr ShREW, The. \\ TEMPEST, THE. \\ TIMON OP ATHENS. \\ Titus Andronicus. \\ TroILUS AND CRESSIDA. \\ Two Grentlemen of Verona, The. \\ TWELPTH Night. \\ VRnus and Adonis. \\ -Winter's TALE, The.
}

\section{Classics of Art.}

Edited by DR. J. H. W. LAING.

With numerous Illustrations. Wide Royal 8vo.

The ART of The Gregks. H. B. Walters. 12s. 6 d. net.

THE ART OF THE Romans. H. B. Walters. 15s. net.

Chardin. H. E. A. Furst. 12s. 6d. net.

Domatello. Maud Cruttwell. 15s. net.

FlorkNtiNe SCUlptors op THE RENaisSANCE. Wilhelm Bode. Translated by Jessie Haynes. 12s. 6d. net.

Grorge Romwey. Arthur B. Chamberlain. I25. $6 d$. net.

Ghirlandaio. Gerald S. Davies. Second Edition. 10s. 6d.
Michelangrlo. Gerald S. Davies. r2s. $6 d$. net.

RUBrns. Edward Dillon, 255. net.

RAPHAEL. A. P. Oppś. 12s. 6 d. met.

Rgmarandt's Etchings. A. M. Hind.

- Sir Thomas Lawrence. Sir Walter Armstrong. 21s. net.

Titian. Charles Ricketts. 15s, ret.

Tintoretro. Evelyn March Phillipps. $15 s$. net.

TURner's Sketches and Drawings. A. J FINBERG. 12s. 6d. net. Second Edition.

Velazuugz. A. de Beruete. ras. 6 d. net.

\section{The "Complete" Series.}

\section{Fully Illustrated. Demy 8vo.}

The Complete Billiard Player. Charles Roberts. ros. $6 d$. net.

The Complete CoOk. Lilian Whitling. 75. 6d. net.

The Completr CRicketrer. Albert E. Knight. 7s. 6d. net. Second Edition.

The Compratz Foxhunter. Charles Richardson. 12s. 6d, net. Second Edition.

The Complete Golfer. Harry Vardon. I0s. 6d. net. Twelfth Edition.

THE CoMplete HockeY-Player. Eustace E. While. 5s. met. Second Edition.

The Complete Lawn TenNis Player. A. Wallis Myers. ros. 6d. net. Third Edition, Revised.

The Complete Mотовist. Filson Young. 12s. 6d. net. New Edition (Srventh).
Thr Complete Mountaineer. G. D. Abraham. Iss. net. Second Edition.

Thr Completr Oarsman. R. C. Lehmann. ros. 6 d. net.

Thr Complete Photographer. R. Child Bayley. Ios. 6 d. net. Fourth Edition.

The Conplete Rugby Footballer, on the New Zealdend Systrm. D. Gallaher and W. J. Stead. Ios. $6 d$. net. Second Edition.

Thв Cомpetre Shot. G. T. Teasdale Buckell. I2s. 6 d. net. Third Edition.

Тив Сом PLetв Swimmer. F. Sachs. 75. 6d. net.

- Thr Complete Yachtsman. B. HeckstallSmith and $E$. du Boulay. 15s. not. 


\section{The Connoisseur's Library.}

With numerous Illustrations. Wide Royal 8vo. 25s. net each volume.

ENGlish Furniture. F. S. Robinson.

ENGLish Coloured Books. Martin Hardie.

Erchings. Sir F. Wedmore. Second Edition.

European Enamels. Henry H. Cunyng. hame.

Giass. Edward Dillon.

Goldsmiths' and Silversmiths' Work. Nelson Dawson. Second Editions.

Illuminated Manuscripts. J. A. Herbert. Second Edition.
Ivorias. Alfred Maskell.

Jewrllery. H. Clifiord Smith. Second Edition.

Mezzotints. Cyril Davenport.

Miniatures. Dudley Heath.

Porcelain. Edward Dillon.

- Fine Books. A. W. Pollard.

Seals. Walter de Gray Birch.

Wood Sculrturn. Alfred Maskell. Second Edition.

\section{Handbooks of English Church History.}

Edited by J. H. BURN, Crown 8vo. 2s. 6d. net each volume.

The Foundations of the English Chutch. J. H. Maude.

Thz Saxon Church and the Norman ConQUest. C. T. Cruttwell.

Thi Medifival Church and the Papact. A. C. Jennings.
The Reformation Pariod. Henty Gee. The Struggle with Puritanism. Bruce Blaxland.

The Church of England in the Eightegnth Century. Alfred Plummer.

\section{Handbooks of Theology.} The Doctrine of THE InCarnation. R. L.
Ottley. Fifth Edition, Revised. Demy 8vo. 12s. 6 .

A Historv of Early Christian Doctrine. J. F. Bethune-Baker. Demy 8vo. ros. $6 d$.

AN INTRODUCTION TO THE 'History OP Religion. F. B. Jevons. Fifth Edition. Demiy 8ve. ras. $6 \alpha$
AN INTRODUCTION TO THE HistokT OF THE Creeds. A. E. Burn. Demy 8vo. ros. $6 d$.

The Philosophy of Rhligion in England AND AmERICA. Alfred Caldecott. Demy $8 v 0$. Ios. $6 d$.

The XXXIX ARticles of the Church of England. Edited by E. C. S. Gibson, Severth Edition. Demy 8ve. 12s. 6d.

\section{The "Home Life" Series.}

Illustrated. Demy 8vo. 6s. to I0s. 6d. net.

Home Lifz in America. Katherine G. Home Life in Italy. Lina Duff Gordon: Busbey. Second Edition.

Home Life in France. Miss Betham. Edwards. Fifth Edition.

Home Life in Germany. Mrs. A. Sidgwick. Second Edition.

Home Iitrg in Holland. D. S. Meldram. Secord Edition. Second Edition.

Homr Life in Norway. H. K. Daniels. Home Life in Russia. Dr. A. S. Rappoport. Home Life in Srain. S. L. Bensusan.
Second Edition. 
The Illustrated Pocket Library of Plain and Coloured Books. Fcap. 8vo. 3s. 6\%. net each volume.

\section{WITH COLOURED ILLUSTRATIONS.}

Old Colouren Books. George Paston. 2s. net.

THE Lift and Drath OP JohN MivtTon, EsQ. Nimrod. Fifth Edition.

The Lifz of a Sportsman. Nimrod.

Handlay Cross. R. S. Surtees. Fourth Edition.

Mr. SPonge's Sporting Tour. R. S. Surtees. Second Edition.

JORROCKS'S JAUNTS AND JOLLITIBS. R. S. Surtees. Third Edition.

Ask Mamsa. R. S. Surtees.

Thr Analysis of the Hunting Field. R. S. Surtees.

The Tour of Dr. Syntax in Search op the Picturesqur. William Combe.

The Tour of Dr. Syntax in Search of Consolation. William Combe.

The Third Tour of Dr. Syitax in Search OF A Wifk. William Combe.

Thr History of Johnny Quae Genus. The Author of 'The Three Tours.'

The English Dance of Denth, from the Designs of $T$. Rowlandson, with Metrical Illustrations by the Author of 'Doctor Syatax.' Two Volumes.

\section{WITH PLAIN ILLUSTRATIONS.}

The Grave: A Poem. Robert Blair.

ILLUSTRATIONS OF THE BOOK OF JOB. Invented and engraved by William Eda.e.

Windsor Castle. W. Harrison Ainswortb. The Tower of London. W. Harrison Ainsworth.
The Dance of Life: A Poem. The Autbor of 'Dr. Syntax.'

IAfR in London. Pierce Egan.

Real Lifr in London. An Amateur (Pierce Egan). Two Volumes.

The Life of an Actor. Pierce Egan.

The Vicar of Wakefired. Oliver Goldsmith.

Thr Mulitary Adventures or JohnNy Newcome. An Offeer.

Thr National Sports of Great Britain. With Descriptions and 50 Coloured Plates by Henry Alken.

The Adventures of a Post Captain. A Naval Officer.

GAMONiA. Lawrence Rawstorne.

AN ACAdemy For Grown Horsemen. Geoffrey Gambado.

Real Lifa in Ireland. A Real Paddy.

The Adventures of JohnNy Newcome in THE NAVY. Alfred Burton.

The Old English Squirz. John Careless.

The ENGlish Spy. Bernard Blackmantle. Two Volumes. 7 s, net.

Frank Fairlegk. F. E. Smedley.

The Conpleat ANGler. Izazk Walton and Charles Cotton.

The Pickwick PApers. Charles Dickens.

\section{Leaders of Religion.}

Edited by H. C. BEECHING. With Portraits.

Crown 8vo. 2.r. net each volume.

Cardinal Newman. R. H. Hutton.

John Wesley. J. H. Overton.

Bishop Wilberforce. G. W. Daniell.

Cardinal manning. A. W. Huttod.

Charles Simeon. H. C. G. Moule.

Јонм Knox. F. MacCunn. Second Edition. JонN Howr. R. F. Horton.

Thosias Ken. F. A. Clarke.

Grorge Fox, THE QUaker. T. Hodgkin. Third Edition.

JонN KËLE. Walter Lock.
Thomas Chalmers. Mrs. Oliphant. Secend Edition.

Lancelot Andrewes. R. L. Ottley. Seconit Edition.

Augustine of Canterbury. E. L. Cutts.

William Laud. W. H. Hutton. Third Ed.

Jomn Donne. Augustus Jessop.

Thomas Cranmer. A. J. Mason.

LAtimer. R. M. Carlyle and A. J. Carlyle.

Bishor Butler. W. A. Spooner. 


\section{The Library of Devotion.}

With Introductions and (where necessary) Notes. Small Fott Svo, cloth, 2s. ; leather, 2s. 6d. net each volume.

ThE Conifessions of ST. Augustine.
Seventh Edition.

The Imitation of Christ. Sixth Edition.

The Christian Year. Fifth Edition.

Lyiza Innocentium. Third Edition.

The Temple. Second Edition.

A Book of Devotions. Second Edition.

a Serious Call to a Devout and Holy LiFE. Fourth Edition.

A Guide to Eternity.

The INNBK WAY. Second Edition.

ON THE Love OF GOD.

The Psalms of David.

Lvra Apostolica.

The Song of Songs.

The Thoughts of Pascat. Second Edition.

a Manual of Consolation from the Saints and Fathers.

Devotions from the Apockypha.

The Spiritual Combat.

The Devotions of St. Anselm. bishor Wilson's Sacra Privata.

Grace Abounding to the Chiar or Sin. NERS.

LvRA SACra: A Book of Sacred Verse. Second Edition.

A DAv Book From the SAINTS and FATHERS.

A Littie Book of Heaventy Wisdom. A Selection from the Englisb Mystics.

Light, L1FE, and Love. A Selection from the German Mystics.

AN Introduction to the Devout Life. The Little Flowers of the Glorious Messer St. Francis and of his Friars.

Death and Immortality.

The Spiritual Guide. Second Edition.

Devotions for Every Dav in the Whek aNd THE GReAT Festivals.

Preces Privatae.

Horas Mysticar: A Day Book from the Writings of Mystics of Many Nations.

\section{Little Books on Art.}

\section{With many Illustrations. Demy $16 \mathrm{mo}$. 2s. 6 d. net each volume.}

Each volume consists of about 200 pages, and contains from 30 to 40 Illustrations, including a Frontispiece in Photogravure.

Albrecht Dürer. L. J. Allen. ARTS OF JAPAN, THE. E. Dillon. Third Edition.

Bookplates. E. Almack.

Botticelli. Mary L. Bonnor.

Burne-Jones. F. de Lisle.

Cellini. R. H. H. Cust.

Christian Srmbolism. Mrs. H. Jenner.

Christ in Akt. Mrs. H. Jenper.

Claude. E. Dillon.

Constable. H. W. Tompkins. Second Edition.

Corot. A. Pollard and E. Birnstingl.

ENAMEls. Mrs. N. Dawson. Second Edition.

Frederic Lejghton. A. Corkran.

George Rominey. G. Paston.

Greek Art. H. B. Walters. Fourth Edition.

Greuze and Boucher. E. F. Pollard.
Holbein. Mrs. G. Fortescue.

Illuminated Manuscrifts. J. W. Bradley.

JeWellery. C. Davenport.

John Hoppner. H. P. K. Skipton.

Sir Joshua Reynolds. J. Sime. Second Edition.

Millet. N. Peacock.

Miniatures. C. Davenport.

OUr Lady in ARt. Mrs. H. Jenner.

Raphael. A. R. Dryhurst.

Rembrandt. Mrs. E. A. Sharp.

* Rodin. Muriel Ciolkowska.

TURNer. F. Tyrrell-Gill.

VANDYCK. M. G. Smallwood.

VelazQuez. W. Wilberforce and A. $R$. Gilbert.

WATtS. R. E. D. Sketchley. Second Edition. 


\section{General Literature}

\section{The Little Galleries.}

Demy $16 m o$. 2s. 6d. net each volume.

Each volume contains 20 plates in Photogravure, together with a short outline (ग) the life and work of the master to whom the book is devoted.

A Little Galleky of Reynolds.

A LitTle Galleky of Romney.

A LitTle Galleky OP Hoppner.
A Little Gallery op Mill.ais.

A Little Gallery of English Ports.

\section{The Little Guides.}

With many Illustrations by E. H. NEw and other artists, and from photograpbs.

Small Pott Svo, cloth, 2s. 6d. net; leather, 3s. 6\%. net, each volume.

The main features of these Guides are (I) a handy and charming form ; (2) illustrations from photographs and by well-known artists ; (3) good plans and maps; (4) an adequate but compact presentation of everything that is interesting in the natural features, history, archæology, and architecture of the town or district treated.

Cambridge and its Colleges. A. H. Thompson. Thiru Edition, Revised.

Channrl Islands, The. E. E. Bicknell.

English Lakes, Thr. F. G. Brabant.

Isle of Wight, The. G. Clinch.

London. G. Clinch.

Malvera Country, The. B. C. A. Windle.

North Wales. A. T. Story.

Oxford and its Colleges. J. Wells. Ninth Edition.

Shakespzare's Country. B. C. A. Windle. Fourth Edition.

St. Paul's Cathedraz. G. Clinch.

Westuinster Abbey. G. E. Troutbeck. Second Edition.

Berkshire. F. G. Brabant.

Buckinghamshire. E. S. Roscoe.

Chrshirr. W. M. Gallichan.

Cornwall. A. L. Salmon.

Derbyshirk. J. C. Cox.

Drvon. S. Baring-Gould. Second Edition.

Dorset. F. R. Heath. Second Edition.

Essex. J. C. Cox.

HAMPShiRE. J. C. Cox.

Hertfordshire. H. W. Tompkins.

KENT. G. Clinch.

haxkr. C. P. Crane.
LeicestershiRR AND RUtLand. A. Harvey and V. B. Crowther-Beynon.

Middesex. J. B. Firth.

Monmouthshtre. G. W. Wade and J. $\mathrm{H}$ Wade.

Norfolk. W. A. Dutt. Second Edition, Kevised.

Northamptonshire. W. Dry. Second Ed.

Northumberland. J. E. Mozris.

Notringhamshire. L. Guilford.

OXFordshiRe. F. G. Brabant.

Shropshire. J. E. Aucien.

Somerset. G. W. and J. H. Wade. Second Edition.

Stafpordshire. C. Masefield.

SuFFolk. W. A. Dutt.

SURrey. J. C. Cox.

Sussex. F. G. Brabant. Third Edition.

Wiltshire. F. R. Heach.

YoRKSHIRE, THE EAST RIDING. J. E. Morris.

Yorkshirg, The North Riding. J. E. Morris.

Yorkshire, The West Rining. J. E. Morris. Cloth, 3s. 6d. net; leather, is. 6al. net.

Brittany. S. Baring-Gould.

Normandv, C. Scudamore.

Rоме. C. G. Ellaby.

Sicily, F. H. Jacksun. 


\section{The Little Library.}

With Introductions, Notes, and Photogravure Frontispieces.

Small Pott Svo. Each Volume, cloth, is. 6d. net.

Anon. A LITTLE BOOK OF ENGLISH LYRICS. Second Edition.

Austen (Jane). PRIDE AND PREJUDICE. Two lolumes.

NOR'HANGER ABPEY.

Bacon (Franeis). THE ESSAYS OF LORD BACON.

Barham (R. H.). THE INGOLDSBY LEGENUS. Trwo Volumes.

Barnett (Annie). A LITTLE BOOK OF ENGLISH YROSE.

Beckford (Willam). THE HISTORY OF $1 \mathrm{HE}$ CALIJH VATHEK.

Blake (William). SELECTIONS FROM THE WORKS OF WILLIAM BLAKE.

Borrow (George). LAVENGRO. Two Lolumes.

THE ROMANY RYE.

Browning (Robert). SELECTIONS FRON THE EARLY POEMS OF ROBERT DROWNING.

Canning (George). SFLECTIONS FROM THE ANTI-JACOBIN : with some later Poems by Geugge CANing

Cowley (Abraham). THE ESSAYS OF ABRAHAM COWLEY.

Crabbe (George). SELECTIONS FROM THE YOEMS OF GEORGE CRABBE.

Craik (Mrs.) JOHN H ALIFAX, GENTLEMAN. Two Volumes.

Crashaw (Richard). THE ENGLISH POEMS OF RICHARD CRASHAW.

Dante Allghieri. THE INFERNO OF DAN'E. Translated by H. F. CARY.

THE PURGATORIO OF DANTE. Translated by H. F. CAKY.

THE PARADISO OE DANTE. Translated by $\mathrm{H}$. H. Cary.

Darley (George). SELECTIONS FROM THE IUENS OF GEORGE DARLEY.

Deane (A. C.). A IITTLE BOOK OF J.IGH V VLRSE.

Dickens (Charles). CHRISTMAS BOOKS. Tzo volunes.
Ferrier (Susan). MARRIAGE. Two lolumes. TIE INHERITANCE. Two Volumes.

Gaskell (Mrs.). CRANFORD. SeconiEd.

Hawthorne (Nathanlel). THE SCARLET LE IIEK.

Henderson (T. F.). A LITTLE BOOK OF SCOITISH VERSE.

Kinglake (A. W.). EOTHEN. Second Edition.

Lamb (Charles). ELIA, AND THE LAST ESSAYS OF ELIA.

Locker (F.). LONDON LYRICS.

Marvell (Andrew). THE POEMS OF ANDREW MARVELL.

Ifilton (John). THE MINOR POEMS OF JOHN MIILTON.

Molr (D. M.). MtANSIE WAUCH.

Nichols (Bowyer). A LITTLE BOOK OF ENGLISH SONNETS.

Smith (Horace and James). REJECTED ADDRESSES.

Sterne (Laurence). A SENTIMENTAL JOURNEY.

Tennyson (Alfred, Lord). THE EARLY POEMS OF ALFRED, LORD TENNY. SON.

IN MEMORIAM.

THE PRINCESS.

MAUD.

Thackeray (W. M.). VANITY FAIR. Three Volumes.

PENDENNIS. Three Volumes.

HENRV ESMOND.

CHRISTMAS BGOKS.

Vaughan (Henry). THE POEMS OF HENRY VAUGHAN.

Waterhouse (Elizabeth). A LITTLE BOOK OF I.IFE AND DEATH. Thirteenth Edition.

Wordsworth (W.). SELECTIONS FROM THF PUENIS OF WILLIAM WORDS. WOR'IH.

Wordsworth (W.) and Coleridge (S. T.). LIRICAL BALLADS. Second Edition. 


\section{The Little Quarto Shakespeare.}

Elited by W. J. CRAIG. With Introductions and Notes. rott 16 mo. In 40 Volumes. Leather, price 1 s. net each volume. Mahogany Revolving Book Case. Ios. net.

\section{Miniature Library. \\ Demy j2mo. Leather, 1 s. net each volume.}

Euphranor: A Dialogue on Youth. Edward Polonius: or Wise Saws and Modera in. FitzGerald. stances. Edward FitzGerald.

The Lifw of EDward, Lord Herbekt of Thr RubAtykt of Omar Khayykm. Edward CHEквUкY. Written by bimself.

FitzGerald. Fourth Euition.

\section{The New Jibrary of Medicine.}

Edited by C. W. SALEEBY. Demy 8vo.

CARE of the Eody, The. F. Cavanagh. Second Edition, 7s. 6d. net.

Childeren of the Nation, The. The Right Hon. Sir John Gorst. Second Edition. 7s. 6a. net.

Control of a Scourge: or, How Cancer is Curable, The. Chas. P. Childe. 7s. $6 d$. net.

Diseases of Occupation. Sir Thomas Oliver. ros. 6d. net. Second Edition.

Drink Problem, in its Medico-Sociological Aspects, The. Edited by T. N. Kelynack. 7s. 6ul, net.
Drugs and the Drug Habit. H. Sainsbury.

Functional Nerve Diseases. A. T. Scho field. 7 s. $6 d$. net.

Hygienr of Mind, ThF. T. S. Clouston. Fifth Edition. 7s. 6d. net.

Infant Mortality. Sir George Newman. 7s. $6 d$. net.

Prevention of Turerculosis (Consump. TION), Tне. Arthur Newsholme. ros. $6 d$. net. Second Edition.

Air and Health. Ronald C. Macfie. 7s. $6 d$ net. Second Edition.

\section{The New Library of Music.}

Edited by ERNEST NEWMAN. Illustrated, Demy 8vo. 7s.6d. net.

Brahms. J. A. Fuller-Maitland. Second HANDEL R. A. Streatfeild. Second Edition Edition.

\section{Oxford Biographies.}

Illustrated. Fcap. 8vo. Each volume, cloth, 2s. 6d. net; leather, 3s. 6d. net.

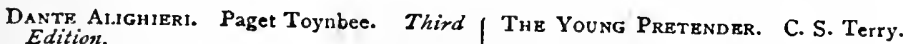

Robert BURNS. T. F. Henderson.

Girolamo Savonaroza. E. L. S. Horsburgh. Fourth Edition.

Chatham. A. S. NicDowall.

JonN Howakd. E. C. S. Gibson.

Alfred Tennyson. A. C. Benson. Second Edition.

Francis of Assisi. Anna M. Stoddart.

Canning. W. Alison Phillips.

Beaconspield. Walter Sichel.

Sir Walter Raleigh. I. A. Taylor,

Erasmus. E. F. H. Capey.

Johann Wolfgang Goethe. H. G. Atkins.

François de Fénelon. Viscount St. Cyres. 


\title{
Three Plays.
}

Fcap. 8vo. 2s. net.

The Honeymoon. A Comedy in Three Acts. Micestones. Arnold Bennett and Edward Arnold Bennett. Second Edition. Kismet. Edward Knoblauch.

\section{The States of Italy.}

Edited by E. ARMSTRONG and R. LANGTON DOUGLAS.

Illustrated. Demy 8vo. A History of MiLAn Under the Sforza.
Cecilia M. Ady. Ios. 6d. net.

A History of Perugia. W. Heywood. 12s. 6d. met.

\section{The Westminster Commentaries.}

\section{General Editor, WALTER LOCK.}

\author{
i Demy 8vo.
}

THE Acts of THE ApostLes. Edited by R. B. Rackham. Sixth Edition. ros. 6 d.

The First Epistle of Paul the Apostle to thr Corinthians. Edited by H. L. Goudge. Third Edition. 6.

THe Book op Exopus Edited by A. H. M'Neile. With a Map and 3 Plans. ros. $6 d$. The Book of EzkKiel. Edited by H. A. Redpath. ros. $6 d$.

Тнв Book of Genesis, Edited with Introduction and Notes by $S$. R. Driver. Eighth Edition. tos. 6 .
The Book of the Prophet Isalak. Edited by G. W. Wade. Ios. $6 d$.

ADditions AND CoRrECTIONS IN THE SEVENTH AND EIGHTh EDITIONS OF ThE BOOK or Grensis. S. R. Driver. Is.

Tив Boок оғ Joв. Edited by E. C. S. Gibson. Second Edition. 6s.

Thr Epistle of St. James. Edited with Introduction and Notes by $R$. J. Knowling. Second Edition. Gs.

\section{The "Young" Series.}

\section{Illustrated. Crown 8vo.}

Thr Young Botanist. W. P. Westell and C. S. Cooper. 3s. 6d. net.

The Young Carpenter. Cyril Hall. $5 s$. The Young Electrician. Hammond Hall. ss.
Thr Young ENGINerR. Hammond Hall. Third Edition. 5 s.

The Young Naturalist. W. P. Westell. Second Edition. 6s.

ThE YOUNG ORNITHOLOGIST. W. P. Westell 5 s. 


\section{Methuen's Shilling Library.}

Fcap. 8vo. Is. net.

Condition of England, Thz G. F. G.
Masterman.

De Profundis. Oscar Wilde.

From Midshipman to Field-Marshal.

Sir Evelyn Wood, F.M., V.C.

- Ideal husband, An. Oscar Wilde.

- Jimmr Glorer, His Book. James M. Glover.

- John Boyes, King of the WA-KikuYu. John Boyes.

LAdY WINDRRMERE's FAN. Oscar Wilde.

Letters frou a Self-Made Merchant TO HIS Son. George Horace Lorimer.

Life of John Ruskis, TrR. W. G. Colling. wood.

Lipz op Robert Louis Struenson, The. Grabam Balfour.
-Litr or Tennyson, Tre. A. C. Benson. - Little of Everything, A. E. V. Lucas. Lord Arthur Savile's Crime. Oscar Wilde. LoRE OP THE HONRY.BeE, The. Tickner Edwardes.

Man and ThI Univrese. Sir Olivet Lodge. Mart Magdalene. Maurice Maeterlinck. Selrctrd Porms. Oscar Wilde.

SEVAstopol, aNd Other Storirs. Leo Tolstoy.

Thr Blue Bird. Maurice Maeterlinck.

UNDER Five Rmigns. Lady Dorothy Nevill. - Vailima letters. Robert Louis Stevenson.

- Vicar of Morwenstow, Thr. S. Baring. Gould.

\section{Books for Travellers.}

\section{Crown 8vo. 6s. each.}

Each volume contains a number of Illustrations in Colour.

- A Wamdrrer in Florence. E. V. Lucas.

A Wanderer in Paris. E. V. Lucas.

a Wanderer in Holland. F. V. Lucas.

A WANDRRER in LoNDON. E. V. Lueas.

Thr Norfolx Bronds. W. A. Dutt.

Trz New Forrst. Hotace G. Hutchinson.

Naples. Arthur H. Norway.

The Citirs of Umbria. Edward Hutton.

The Citizs of Sfain. Edward Hutton.

-Thz Citizs of Lombardy. Edwatd Hutton.

Florence and Northern Tuscany, with Greoa. Edward Hutton.

Siena and Southern Tuscany. Edward Hutton.
Rome. Edward Hutton.

Venicr and Venetia. Edward Huton.

The Bretons at Home. F. M. Gostling.

THR LAND OP PARDoNs (Brittany). Anatole Le Braz.

A BOOK OP the RHINe. S. Baring-Gould. The Nafles Riyjera. H. M. Vaughan.

Dats in Cornwall. C. Lewis Hind.

Throvgh East angla in a Motor Car. J. E. Vincent.

The Skikts of the Great City. Mrs. A. G. Bell.

Round about Wiltshire. A. G. Bradley. SCOTLAND OF TO-DAY. T. F. Henderson and Francis Watt.

Norway aNd its Fjords. M. A. Wyllie.

\section{Some Books on Art.}

ART AND Lifz. T. Sturge Moore. Illustrated. Cr. 8vo. 55, net.

Aims and Idrals in Art. George Clausen. Illustrated. Second Edition. Large Post 8vo. s. met.

Six Lrctures on Painting. George Clausen. Illustrated. Third Edition. Large Post 8vo. 3s. 6d. net.

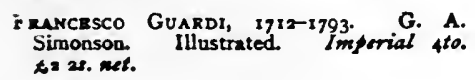

ILLUSTRATIONS OF THE BOOK OF JOB.

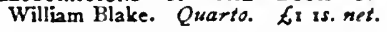

John Lucas, Portrait Painter, I828-1874. Arthur Lucas. Illustrated. Imperial $4 t 0$. $\delta_{3} 3^{\text {* }}$ net.

One Hundred Masterieces of Painting. With an Introduction by R. C. Witt. Jllustrated. Second Edition. Demy 8vo. ros. 6d. net.

A Guide to the British Picturgs in the National Gallery. Edward Kingston. Illustrated. Fcap. 8v0. 35. 6d. net. 
SOME Books on ArT-continued.

One HunDRPd MAsterpieces of SCUt.ptuRE. With an Introduction by G. F. Hill. lllus: trated. Demy 8vo. 10s. 6d. net.

A Rominy Follo. With an Essay by A. B. Chinberlain. Imperial Folio. $\ell_{15} 15 s$. net.

Thil Saints in ARt. Margaret E. Tabor. lilustrated. Foip. 8vo. 3s. 6d. net.

Schools of Painting. Mary Innes. Illustrated. Cr. 8ro. 55. net.
The Post Impressionists. C. Lewis Hind. Illustrated. Royal 8vo. 7s. 6d. net.

Celitic Art in Pagan and Christian Times. J. R. Allen. lllustrated. Second Edition. Demy 8vo. 7s.6d. net.

"Classics of Art." See page 13.

“The Connoisseur's Library." See page 14

"Little Books on Art." See page 16.

"The Little Gallerims." See page 7 7.

\section{Some Books on Italy.}

a History of Milan under the Sporza. Cecilia M. Ady. Illustrated. Demy 8vo. 10s. $6 d$. net.

A History of Virons. A. M. Allen. Illustrated. Demy 8z'o. 12s. 6al. net.

A History of Perugla. William Heywood. lllustrated. Demy 8\%o. 12s. 6d. net.

THE LAKES OF NORThern Italy. Richard Bagot. Illustrated. Fcap. 8vo. 5s. net.

Woman in Italy. W. Boulting. lllustrated. Deiny 8vo. 10s. 6d. net.

Oli Etruria ann Modern Tuscany. Mary L. Cameron. Illustrated. Second Edition. Cr. 8vo. 6s. net.

Florence and the Citigs of Northern Tuscany, with Genoa. Edward Hutton. Illustrated. Second Edition. C'r. 8x'o. 6s.

Signa and Southern Tuscany. Edward Hutton. Illustrated. Second Edition. Cr. 8vo. 6s.

In Unknown Tuscany. Edward Hutton. Illustrated. Second Edition. Demy $8 v 0$. 7s. 6al. net.

Venick AND Venetia. Edward Hutton. Illustrated. Cr. 8vo. 6 s.

Venice on Foot. H. A. Douglas. Illustrated. Fcip. 8vo. 5s. net.

Venick and Her Treasures. "H. A. Douglas. Illustrated. Fcap. 8vo. 5s. net.

- The Doges of Venice. Mrs. Aubrey Richardson. Illustrated. Demy 8v0. 10s. 6d. net.

Florence: Her History and Art to the Fall of the Republic. F. A. Hyett. Demy 8vo. 7s. 6i. net.

Flokenck ann IJer Theasures. H. M. Vaughan. llitustrated. Ficap. 8vo. 5s, net.

Country Walks about Flokence. Edward Hutton. Illustrated. Ficup. 8no. 5s. net.

Naples: Past and Present. A. H. Norway. Illustrated. Third Edition. Cr. 8vo. 6 s.

THE NAples Riviera. H. M. Vaughan. Illustrated. Second Edition. Cr. 8vo. 6s.

Sicily: The New Winter Resort. Douglas Sladen. Illustrated. Second Edition. Cr. 8vo. ss. net.
Sicily. F. H. Jackson. Illustrated. Small Pott 8vo. Cloth, 2s. 6d. net; leather, $3^{s .6 d}$ net.

Rome. Edward Hutton. Illustrated. Second Edition. Cr. 8vo. 6s.

A Roman Pilgrimage. R. E. Roberts. Illustrated. Demy 2vo. 1os. 6d. net.

Rome, C. G. Ellaby. Illustrated. Small Pott 8vo. Cloth, 2s. 6d. net; leather, 3s. 6d. net.

The Cities of Umbria. Edward Hutton. Illustrated. Fourth Edition. Cr. 8vo. 6s.

* The Cities of Lombardy. Edward Hutton. Illustrated. Cr. 8\%o. 6s.

The Lives of S. Francis of Assisi. Brotber Thomas of Celano. Cr. 8vo. $5^{s}$. net.

Lorenzo the Magnificent. E. L. S. Horsburgh. Illustrated. Second Edition. Demy 8vo. 15s. net.

Girolamo Savonarola. E. L. S. Horsburgh. Illustrated. Cr. 8vo. 5s, net.

St. Catherine of Siena and Her Times. By the Author of " Mdlle Mori." Illustrated. Secord Edition. Demy 8vo. 7s. 6d. net.

Dante and his Italy. Lonsdale Ragg. Illustrated. Demy 8vo. 12s. 6d. net.

Dante Alighieri: His Life and Works. Paget Toynbee. Illustrated. Cr. 8vo. $5^{s}$. net.

The Medici Popes. H. M. Vaughan. 1llustrated. Demy 8vo. 15s. net.

Shelley and His Friends in Italy. Helen R. Angeli. Illustrated. Demy $8 v 0$. ror. $6 d$. net.

Home Life in Italy. Lina Duff Gordon. lllustrated. Second Edition. Demy 8ro. 10s. $6 d$. net.

Skies I TALiAn : A Little Breviary for Travellers in Italy. Ruth S. Phelps. Fcap. 8vo. $5^{s .}$ net.

*A Wanderer in Florenct. E. V. Lucas. Illustrated. Cr. 8vo. 6s.

* United Italy. F. M. Underwood. Demy 8vo. 10s. $6 d$. met. 


\section{Part III.-A Selection of Works of Fiction}

Albanesi (E. Maria). SUSANNAH AND ONE OTHER. Fourth Editior. Cr. 8vo. 6s.

LOVE AND LOUISA. Second Edition. Cr. 8zo. 6s.

THE BRGWN EYES OF MARY. Third Edition. Cr. 8vo. 6s.

I KNOW A MAIDEN. Third Edition. Cr. 8vo. 6s.

THE INVINCIBLE AMEIIA: OR, THR Polite Auventukrss. Third Edition. Cr. 8vo. 3s. 6.t.

THE GLAD IEART. Fifth Edition. Cr. 8\%o. 6s.

- Olivia MaRy. Cr. 8zo. 6s.

Bagot (Richard): A ROMAN MYSTERY. Third Edition. Cr. 8vo. 6s.

THE PASSPORT. Fourth Edition. Cr. $8 \% 0$. 6s.

ANTHONY CUTHBERT. Fourth Edition. Cr. 8vo. 6s.

LOVE'S PROXY. Cr. 8vo. 6s.

DONNA DIANA. Second Edition. $C r$. $8 v 0.6 s$.

CASIING OF NETS. Twelfth Edition. Cr. 8vo. 6s.

THE HOUSE OF SERRAVALLE. Third Edition Cr. 8vo. 6 s.

Balley (H.C.). STORM AND TREASURE. Third Edition. Cr. 8vo. 6s.

THE LONELY QUEEN, Third Edition. Cr. 8vo. $6 s$.

Baring-Gould (S.). IN THE ROAR OF THESEA. Eighth Edition. Cr.8vo.

Gs.
MARGERY OF QUETHER.

THE QUEEN OF LOVE. Fifth Edition. Cr. 8vo. 6s.

JACOUETTA. Third Edition. Cr. 8vo. 6s.

KITTY ALONE. Fifth Edition. Cr.8vo. 6s.

NOÉMI. Illustrated. Fourth Edition. Cr. 8थo. $6 s$

THE BROOM - SQUIRE. Illustrated. Fifth Edition. Cr. 8vo. 6s.

DARTMOOR IDYLLS. Cr. 8vo. 6s.

GUAVAS THE TINNER. Illustrated. Second Edition. Cr. 8vo. 6s.

BLADYS OF 'THE STEWPONEX. Illustrated. Second Edition. Cr. 8vo. 6s.

PABO THE PRIEST. Cr. $8 v o$. 6 s.

WINEFRED. Illustrated. Second Edition. Cr. 8vo. 6s.

ROYAL GEORGIE. Illustrated. Cr. 8vo.6s. CHRIS OF ALL SORTS. Cr. 8vo. 6s. IN DEWISLAND. Secord Edition. $C r$. 8vo. 6s.

MRS. CURGENVEN OF CURGENVEN. Fifth Edition. Cr. 8vo. 6s.
Barr (Robert). IN THE MIDST OF ALARMS. Third Edition. Cr. 8vo. 6s. THL COUNTESS TEKLA. Fifth Edition. Cr. 8vo. 6s.

THE MUTABLE MANY. Third Edition. Cr. 8vo. 6s.

Begble (Harold). THE CURIOUS AND DIVERIING ADVENTURES OF SIR JOIN SPARROW, IART.; OR, 'THL Progrkss of aN Oren Mind. Second Edition. Cr. 8vo. 6s.

Belloc (H.). EMMANUEL BURDEN, MERCHANT. Illustrated. Second Edition. Cr. 8vo. 6s.

A CHANGE IN THE CABINET. Third Edition. Cr. 8vo. 6s.

Belloc-Lowndes (Mrs.). THE CHINK IN THE $A$ RMOUR. Fourth Edition. Cr. Evo. 6s.

- MIARY PECHELl. Cr. 8vo. 6s.

Bennett (Arnold). CLAYHANGER. Tenth Edition. Cr. 8vo. 6s.

THE CARD. Sixth Edition. Cr. 8vo. 6s. HILDA LESSWAYS. Seventh Edition. Cr. Evo. 6s.

* BURIED Alive. A New Edition. Cr. 8\%o. 6s.

A MAN FROM THE NORTH. A New Edition. Cr. 8vo. 6s.

THE MATADOR OF THE FIVE TOWNS. Secord Edition. Cr.8vo. 6s.

Benson (E. F.). DODO: A DETall OF THE DAY. Sixteenth Edition. Cr. 8z'o. 6s.

Birmingham (George A.). SPANISII GOLD. Sixth Edition. Cr. 8zo. 6 s. THE SEAKCH PARTY. Fifth Edition. Cr 8vo. 6s.

LALIGE'S LOVERS. Third Edition. $C r$. $8 v o$. $6 s$.

Bowen (Marjorle). I WILL MAIN. TAIN. Srverth Edition. Cr. 8vo. 6s.

DEFENDER OF THE FAITH. Fifth Edition. Cr. 8vo. 6s.

*A KNIGHT OF SPAIN. Cr. 8vo. 6s.

THE QUEST OF GLORY. Third Edition. Cr. 8vo. 6s.

GOD AND THE KING. Fourth Edition. Cr. 8vo. 6s.

Clifford (Mrs. W. K.). THE GETTING WELL OF DOROTII'. Iltustrated Second Edition. Cr. 8vo. 3s. 6d.

Conrad (Joseph). THE SECRET AGENT : A simple Tale. Fourth Edt. Cr. 8vo. 6s. A SEI OF SIX. Fourth Edition. Cr.8vo. 6s. UNDER IVESTERN EYES. Second Ed. Cr. 8vo. Gs. 
- Conyers (Dorothea.). THE LONELY $M A N$. Cr. 8zo. $6 s$.

Corelli (Marle). A ROMANCE OF TWO WORLDS. Thirty-first Ed. Cr. 8vo. 6s. VENDETTA; OR, THE STORY OF ONE FORGoTten. Twenty-ninth Edition. Cr. $8 v 0$. $6 s$.

THELMA : A Norwegian Princrss. Forty-second Edition. Cr.8vo. 6s.

ARDATH : The Story of a Dead Self. Trentieth Edition. Cr. 8vo. 6s.

THE SOUL OF LILITH. Seventeerth Edition. Cr. 8vo. 6s.

WORMWOOD : A DRAMa OF Paris. Eightcenth Edition. Cr. 8vo, 6s.

PARABBAS: A DREAM OF THE WORLD's TRAGEDY. Forty-sixth Edition. Cr. 8vo. $6 s$.

THESORROWV OF SATAN. Fifty-seventh Edition. Cr. 8vo. 6s.

THE MASTER-CHRISTIAN. Thirteenth Edition. 179th Thousand. Cr. 8vo. 6s.

TEMPORAL POWER : A STUDY iN SUPREMACY. Second Edition. r5oth Thousand. Cr. 8vo. 6s.

GOD'S GOOD MAN : A SimpLE LOVE STORY. Fifteenth Edition. 154th Thowsand. Cr. 8vo. 6s.

HOLY ORDERS: THE TRAGEDY OF A QUIET LIFE. Second Edition. 120th Thousand. Cromen 8no. 6s.

THE MIGHTY ATOM. Twenty-rinth Edition. Cr. 8vo. 6s.

BOY: a Sketch. Truelfth Edition. Cr. 8vo. $6 s$.

CAMEOS. Fourteerth Edition. Cr. 8vo. 6s,

THE LIFE EVERLASTING. Fifth Ed. Cr. 8vo. 6s.

Crockett (S. R.). LOCHINVAR. Illustrated. Third Edition. Cr. 8vo. 6s.

THE STANDARD BEARER. Second Edition. Cr. 8vo. 6s.

Croker (B. M.). THE OLD CANTONMENT. Second Edition. Cr. 8vo. 6s.

JOHANNA. Second Edition. Cr. 8vo."6s.

THE HAPPY VALLEY. Fourth Edition. Cr. 8\%o. 6s.

A NINE 'DAYS' WONDER. Fourth Edition. Cr. 8vo. 6s.

PEGGY OF THE BARTONS. Seventh Edition. Cr. 8vo. 6s.

ANGEL. Fifth Edition. Cr. 8vo. 6s.

KATHERINE. THE ARROGANT. Sixth Edition. Cr. 8\%o. 6s.

BABES IN THE WOOD. Fourth Edition. Cr. 8vo. 6s.

Danby (Frank.). JOSEPH IN JEOPARDY. Third Edition. Cr. 8vo. $6 \mathrm{~s}$.

Doyle (Sir A. Conan). ROUND THE RED LAMP. Twelfth Edition. Cr. 8vo. 6s.

Fenn (G. Manville). SYD BELTON: THE BOY WHO WOULD NOT GO TO SEA. Illustrated. Second Ed. Cr. 8ve. 3s. $6 d$.
Findlater (J. H.). THE GREEN GRAVES OF BALGOWRIE. Fifth Edition. Cr. 8vo. 6s.

THE LADDER TO THE STARS. Second Edition. Cr.8vo. 6 s.

Findlater (Mary). A NARROW WAY. Third Edition. Cr. 8vo. 6s.

OVER THE HILLS. Second Edition. Cr. 8vo. $6 s$.

THE ROSE OF JOY. Third Edition. Cr. 8vo. 6s.

A BLIND BIRD'S NEST. Illustrated. Second Edition. Cr. 8vo. 6s.

Fry (B. and C. B.). A MOTHER'S SON Fifth Edition. Cr. 8vo. 6 s.

Harraden (Beatrice). IN VARYING MOODS. Fourtecnth Edition. Cr. 8vo. 6s. HILDA STRAFFORD and THE REMITTANCE MAN. Twelfth Ed. Cr. 8vo. 6s. INTERPLAY. Fifth Edition. Cr. 8vo. 6s.

Hichens (Robert). THE PROPHET OF BERKELEY SQUARE. Second Edition. Cr. 8vo. 6s.

TONGUES OF CONSCIENCE. Third Edition. Cr. 8vo. 6s.

THE WOMAN WITH THE FAN. Eighth Edition. Cr.8vo. 6s.

BYEWAYS. Cr. 8vo. 6s.

THE GARDEN OF ALLAH. Twenty. first Edition. Cr. 8vo. 6s.

THE BLACK SPANIEL. Cr. 8vo. 6s.

THE CALL OF THE BLOOD. Seventh Edition. Cr. 8vo. 6s.

BARBARY SHEEP. Second Edition. Cr. 8vo. 3s. $6 d$.

THE DWELLER ON THE THRESHOLD. Cr. 8vo. 6s.

Hope (Anthony). THE GOD IN THE CAR. Eleventh Edition. Cr. 8vo. 6s.

A CHANGE OF AIR. Sixth Edition. Cr. 8vo. 6s.

A MAN OF MARK. Seventh Ed. Cr. 8vo. 6s. THE CHRONICLES OF COUNT AN. TONIO. Sixth Edition. Cr. 8vo. 6s.

PHROSO. Illustrated. Eighth Edtion. Cr. 8wo. 6s.

SIMON DALE. Illustrated. Eighth Edition. Cr. 8vo. 6s.

THE KING'S MIRROR. Fifth Edition. Cr. 8vo. 6s.

QUISANTE. Fourth Edition. Cr. 8vo. 6s. THE DOLLY DIALOGUES. $C r .8 v 0.6 s$. TALES OF TWO PEOPLE. Third Edi. tion. Cr.8vo. $6 s$.

THE GREAT MISS DRIVER. Fow th Edition. Cr. 8zo. 6s.

MRS. MAXON PROTESTS. Third Edition. Cr. 8vo. 6s.

Hutten (Baroness von). THE HALO. Fifth Edition. Cr. 8ve. 6s. 
-Inner Shrine' (Author of tho). THE WILD UIIVE. Third Edition. Cr. Evo. cs.

Jrcobs (W. W.). MANY CARGOES. Thirty-second Edition. Cr. 8vo. 3s. 6 d. - Also Illustrated in colour. Demy 8vo. 75. 6it. net.

ShA URCHINS, Sixtenth Edition. Cr. 8vo. 3s. 6at.

I MASlKR OF CRAFT. Illustrated. Ninth Edirom. Cr. 8vo. 3s. 6d.

I.IGHT FREIGHTS. Illustrated. Eighth Edition. Cr. 8vo. 3s. 6 d.

THE SKIPPER'S WOOING. Eleventh Edition. Cr. 8vo. 3s. 6ol.

AT SUNWICH PORT. Illustrated. Tenth Eutition. Cr. 8zo. $3^{5.6}$.

DIALSTONE LANE. Illustrated. Eighth Edition. Cr. 8zio. 3s. 6at.

ODI CRAFT. Illustrated. Fifth Edition. Cr. 8vo. 3s. 6\%.

THE LADY OF THE BARGE. Illustrated. Ninth Edition. Cr.8vo. 3s. 6d.

SALTHAVEN, Illustrated. Third Edition. Cr. 8vo. 35. $6 d$

SAILORS' KNOTS. Illustrated. Fifth Edition. Cr. 8i'o. 3s. $6 d$.

SHORT CRUISES. Third Edition. Cr. 8vo. 3s. $6 d$.

James (Henry). THE GOLDEN BOWL. Inird Edition. Cr. 8vo. 6s

Le Queux (William). THE HUNCHBACK OF WESTMINSTER. Third Edition. Cr. 8vo. 6s.

THE CIOSED BOOK. Third Edtion. Cr. 8\%o. 6s.

THE VALLEY OF THE SHADOW. Illustrated Third Edition. C'r. 8vo. 6s. BEHIND THE THRONE. Thard Edition. Cr.8vo. 6s.

London (Jack). WHITE FANG. E E $i_{4}$ hth Edition. Cr. 8vo. 6s.

Lucas (E. V.). LISTENER'S LURE : AN Uiblque Narkation. Eighth Edition. FCaP. 8vo. 55 .

OVLR BEMERTON'S : AN EASY-GOING CHRONICLE. Ninth Eidition. Haip 8vo. $5^{5}$. MR. INGLESIDE. Eishth Edition. Fcap. $8 z^{\circ} 0.5 s$.

LONION LAVENDEK. Cr.6vo. 6s.

Lyall (Edna). DERRICK VAUGHAN, NOVEIIST. 44th Thicusant. Cr. $8 v 0$. $3^{s}, 6 d$.

Macnaughtan (S.). THE FORTUNE OF CHIIITINA N'NAB. Fitth Edition. C. 8vo. 6s.

PE: ER AND JANE. Fourth Edition. C.r. 8vo. 6s.

Malet (Lucas'. A COUNSEL OF PER. sELIION. Second Editun. Cr.8vo. 6s.
THE WAGES OF SIN. Sixteenth Edition. Cr. 8vo. 6s.

THE CARISSIMA. Fifth Ed. Cr. 8vo. 6s THE GATELESS BARRIER. Fifth Edition. Cr. 8vo. 6s.

Maxwell (W. B.). THF RAGGED MES SHNGLR. Third Edition. Cr. 8to. 6s. TIIE GUARDED FLAMIE. Serenth Edition. Cr. 8vo. 6s.

ODD LENGTHS. Secont Ed. Cr. 8vo. 6s.

HilL RISE. Fourth Edition. Cr. 8vo. 6s.

THE COUNTESS OF MAYIUURY: Bв TWEEN You AND 1. Fourth Editior. Cr. \&ขo.6s.

THE REST CURE. Fowrth Edition. Cr. 8v0. 6s.

Milno (A. A.). THE DAY'S PLAY Third Edition. Cr. 8vo. 6s.

*THE HOLIDAY ROUND. Cr. 8vo. 6s.

Montague (C. E.). A HIND LET LOOSE. Third Edition. Cr.8vo. 6s.

Morrison (Arthur). TALES OF MEAY STREETS. Seventh Eation. Cr. 8zo. 6s.

A CHILD OF THE JAGO. Sixth Edition. Cr. 870. 6s.

THE HOLE IN THE WALI. Fowrth Edition. Cr. 8\%o. 6s.

DIVERS VANITIES. Cr. 8vo. 6s.

Ollivant (Alfred). OWD BOB, THE GREY DOG OF KENMUIR. With a Frontispiece. Eleventh Ed. Cr. 8\%o. 6s. THE TAHING OF JOHN BLUNT. Second Edition. Cr. 8vo. 6s.

*THE ROYAL ROAD. Cr. 8vo. 6s.

Onlons (Oliver). GOOD BOY SELDOM : A RoMance of Advertiskment. Second Edition. Cr. 8vo. 6s.

Oppenheim (E. Phlllips). MASTER OF MivN. Fifth Eidition. Cr. 8vo. 6s.

THE MISSING DELORA. Illustrated. Fourth Edition. Cr. 8\%o. 6s.

Orezy (Baroness). FIRE IN STUBBLE. fijth Edition. Cr. 8vo. 6s.

Oxenham (John). A WEAVER OF Whils. Illustrated. Fifth Ed. Cr. 8vo. os. PROFIT AND LOSS. Fourth Edition. Cr. 8vo. 6s.

THE LONG ROAD. Fourth Edition. $C r$. 8 8v. $6 s$.

THE SONG OF HYACINTH, AND Other Storils. Second Edition. Cr. 8vo. 6s.

MY LADY OF SHADOWS. Fourth Edition. Cr. 8vo. 6s.

LAURISTONS. Fourth Edition. Cr. $8 v 0$.

THE COIL OF CARNE. Sixth Edition Cr 8vo. 6s.

- THE QUEST OF THE GOLLEN ROSE. Cr. 8vo. 6s. 
Parker (Gllbert). PIERRE AND IIS PEOPLE. Serenth Edition. Cr. 8vo. 6s. MRS. FALCHION. Fifth Eation. Cr. 8vo. $6 s$.

THE TRANSLATION OF A SAVAGE. Fourth Edition. Cr. 8vo. 6s.

THE TRAIL OF THE SWORD, Illusirated. Tenth Edition. Cr. 8vo. 6s.

WHEN VALMOND CAME TO PONTIAC : The Story of a Lost Napoleon. "Seventh Edition. Cr. 8vo. os.

AN ADVENTURER OF THE NORTH. The Last Adventures of 'Pretty Pierre.' Fifth Edition. Cr. 8vo. 6s.

THE BATTLE OF THE STRONG : a Romance of Two Kingdoms. Illustrated. Severth Edition. Cr.8vo. 6s.

THE POMP OF THE LAVILETTES. Third Edition. Cr. 8vo. 3s. $6 d$.

NORTHERN LIGHTS. Fowrth Edition. Cr. 8vo. 6s.

Pasture (Mrs. Henry de la). THE TYRANT. Fourth Edition. Cr. 8vo. 6s.

Pemberton (Max). THE FOOTSTEPS OF A THRONE. Illustrated. Fourth Edition. Cr. 8vo. 6.s.

I CROWN THEE KING. Illustrated. $C r$. 8vo. $6 s$.

LOVE THE HARVESTER: A STORY or THE SHiRes. Illu-mated. Third Edition. Cr. 8vo. 3s. 6d.

THE MYSTERY "OF THE GREEN HEART. Third Edition. Cr. 8vo. $6 s$.

Perrin (Alice). THE CHARM. Fifth Edition. Cr. 8vo. 6s.

-THE ANGLO-INDIANS. Cr. 8vo. $6 s$.

Philipotts(Eden). LYING PROPHETS. Third Edition. Cr. 8vo. 6s.

CHILDREN OF THE MIST. Sixth Edition. Cr. 8vo. 6s.

THE HUMAN BOY. With a Frontispiece. Seventh Edition. Cr. 8vo. 6s. SONS OF THE MOR
Edition. Cr. 8vo. $6 \mathrm{~s}$.

THE RIVER. Fourth Edition. Cr. 8vo. 6s. THE AMERICAN PRISONER. Fourth Edition. Cr. 8vo. 6s.

KNOCK AT A VENTURE. Third Edition. Cr. 8\%o. 6s.

THE PORTREEVE. Fourth Edition. Cr. 8vo. 6s.

THE POACHER'S WIFE. Second Edition. Cr. 8\%o. 6s.

THE STRIKING HOURS. Second Edition. Cr. 8vo. 6s.

DEMETER'S DAUGHTER.

Third Edition. C Cr. 8:0. 6 s.

Pickthall (Marmaduke). SAID THE FISHERMAN, Eighth Edition. Cr. 8vo. $6 s$.

'Q' (A. T. Quilier Couch). THE WHITE WOLF. Second Edition. Cr. 8vo. 6s.
THE MAYOR OF TROY. Fourth Edition. Cr. 8v. 6s.

MERRY.GARDEN AND OTHER STORIES. Cr. 8vo. 6s

MAJOR VIGOUREUX. Third Edition. Cr.8vo. 6s.

Ridge (W. Pett). ERB. Second Edition. Cr. 8vo. 6s.

A SON OF THE STATE. Third Edition. Cr. 8vo. 3s. 6d.

A BREAKER OF LAWS. Cr. 8vo. 3s. 6d. MRS. GALER'S BUSINESS. Illustrated. Second Edition. Cr. 8vo. 6s.

THE WICKHAMSES. Fourth Edition. Cr. 8vo. 6s.

NAME OF GARLAND. Third Edition. Cr. 8ve. 6s.

SPLENDID BROTHER. Fourth Edition. Cr. 8vo. 6s.

NINE TO SIX-THIRTY. Third Edition. Cr. 8vo. 6s.

THANKS TO SANDERSON. Second Edition. Cr.8vo. Es.

- DEVOTED SPARKES. Cr. 8vo. $6 s$.

Russell (W. Clark). MASTER ROCKAFELLAR'S VOYAGE. Illustrated. Fourth Edition. Cr. 8vo. 3s. 6a.

Sidgwick (Mrs. Alfred). THE KINSMAN. Illustrated. Third Edition. Cr. 8vo. $6 s$.

THE LANTERN-BEARERS. Third Edition. Cr. 8ro. 6s.

ANTHEA'S GUEST. Fifth Edition. $C r$. 8vo. $6 s$.

- LAMORNA. Cr. 8vo. 6s.

Somerville (E. E.) and Ross (Martin). DAN RUSSEL THE FOX. Illustrated. Fourth Edition. Cr.8vo. 6s.

Thurston (E. Temple). MIRAGE. Fourth Editiont. Cr. 8\%o. 6s.

Watson (H. B. Marrlott). THE HIGH TOBY. Third Edition. Cr. 8vo. 6s.

THE PRIVATEERS. Illustrated. Second Edition. Cr. 8vo. 6s.

ALISE OF ASTRA. Third Edition. $c r$. 8vo. $6 s$.

THE BIG FISH. Second Edition. Cr.8vo. 6s.

Webling (Peggy). THE STORY OF VIRGINIA PERFECT. Third Edition. Cr. 8vo. $6 s$.

THE SPIRIT OF MIRTH. Fifth Edition Cr. 8vo. 6s.

FEIIX CHRISTIE. Second Edition. Cr. 8vo. 6s.

Weyman (Stanley). UNDER THE RED RObE. lllustrated. Twenty-third Edition. Cr. 8vo. 6 s.

Whitby (Beatrice). ROSAMUND. Sccond Edition. Cr. 8vo. Gr. 
Williamson (C. N. and A. M.). THE LIGHTNING CONDUCTOR: The Strange Adventures of a Motor Car. Illustrated. Seventeenth Edition. Cr. Bvo. 6s. Also Cr. 8vo. rs. net.

THE PRINCESS PASSES : A Romance of a Notor. Illustrated. Winth Edition. Cr. 8vo. 6s.

I.ADY BETTY ACROSS THE WATER. Eleventh Edition. Cr. 8vo. 6s.

SCARLET RUNNER. Illustrated. Thira Eutition. Cr. 8vo. 6s.

SET IN SILVER. Illustrated. Foxth Edition. Cr. 8vo. 6s.
LOR D I.OVELAND D ISCOVERS AMERICA. Second Edition. Cr. 8to. 6s. THE GOLDEN SILENCE. Sixth Edition. Cr. 8zo. 6s.

THE GUESTS OF HERCULES. Third Edition. Cr. 8ro. 6s.

-THE HEATHER MOON. Cr. 8vo. 6s. Wyllarde (Dolf). THE PATHWAY OF THE PIONEER (Nous Autres). Sixth Edition. Cr. 8vo. 6s.

THE UNOFEICIAL HONEYMOON Seventh Elition. Cr. 8vo. 6s.

THE CAREER OF BEAUTY DARLING. Cr. 8vo. 6s.

\title{
Methuen's Two-Shilling Novels.
}

\author{
Crown 8ze. 2s, net.
}

- Botor Chaperon, The. C. N. and A. M. Williamson.

- Call of the Blood, The. Robert Hichens. Car of DESTINY aNd its ERRAND in SPAIN, THE. C. N. and A. M. Williamson. Clementina. A. E. W. Mason.

Colonel Endhray's Wife. Lucas Malet.

FgLix. Robert Hichens.

Gate of the Desert, The. John Oxenham. My Friend the Chaugheur. C. $N$. and A. M. Williamson.
Princess Virginia, The. C. N. and A. M. Williamson.

Seats of the Mighty, The. Sis Gilberl Parker.

Seryant of the Public, A. Anthony Hope. - Set in Silver. C. N. and A. M. Williamson. Severins, The. Mrs. Alfred Sidgwick. Sir Richard Calmady. Lucas Malet. -Vivign. W. B. Maxwell.

\section{Books for Boys and Girls.}

\section{Illustrated. Crown 8vo. 3s. 6d.}

Cross and Daggre. The Crusade of the Children, r2r2. W. Scott Durrant.

Getring Well of Dorothy, The. Mis. W. K. Clifford.

Girl of the Protle, A. L. T. Meade.

Hepsy Gipsy. L. T. Meade. 2s. $6 d$.

Honouraste Miss, The. L. T. Mezde.

Master Rockarzllar's Voyagz. W. Clark Russell.
OnLY A Guard-Roox Dog. Edith E. Cutbell.

Red Grange, The. Mrs. Molesworth.

Syd Belton: The Boy who would not go to Sea. G. Manville Fenn.

THERE was ONCE a PRJNCE. Mrs. M. K. Mand. 


\section{Methuen's Shilling Novels.}

- Anna of the Five Towns. Arnold Bennett. Barbary Shehf. Robert Hichens.

Charm, The. Alice Perrin.

- Demon, The. C. N. and A. M. Williamson. Guarded Flame, The. IV. B. Maxwell.

Jank. Marie Corelli.

Ladv Betty Across the Water. C. N. \& A. M. Williamsun.

- Long Road, Thr. John Oxenham.

Mighty Atom, The. Marie Corelli.

Mirage. E. Temple Thurston.

Missing Delora, The. E Phillips Oppenbeim.
Round the Red Lamp. Sir A. Conan Doyle. necret Woman, The. Eden Phillpotts. *Severins, The. Mrs. Alfred Sidgwick. Spanish Gold. G. A. Birmingham.

Tales of Mean Streets. Arthur Morrison. ThE Halo. The Baroness von Hutten.

*'Trrant, The. Mrs. Henry de la Pasture.

Under the Red Robr. Stanley J. Wcyman. Virginia Perfect. Peggy Webling.

WOMan with тнв FAN, Thв. Robert Hichens.

\section{The Novels of Alexandre Dumas.}

\section{Medium 8ro. Price 6u. Double Volumes, is.}

ACTE.

Adyentures of Captain Pamfhile, The.

Amaury.

BIRD OF FATE, The.

Black Tulip, The.

BLACK : the Story of a Dog.

Castle of Eppstein, The.

Catherine Blum.

\section{Céciler.}

Châtelet, THe.

Chevalier D'Hakmental, The. (Double volume.)

Chicot THE Jester.

Chicot Redivivus.

Comte de Montgommery, The.

Conscience.

Convict's Son, Thz.

Corsican Brothers, Thr; and Otho the ARCHER.

Crop-Eared Jacquot.

DOM GoRENFLot

Duc d'Anjou, The.

Fatal Combat, The.

Fencing Master, Thr.

Fernande.

Gabriel Lambert

Georges.

Great Massacre, The.

HenRI de Navarke.

Hulène de Chayerny.
Horoscope, The.

LEONE-LEONA.

Louise DE LA VAlLìre. (Double volume.) Man IN The Iron Mask, The. (Double volume.)

Mattre Adam.

Mouth of HeLl, The.

Nanon. (Double volume.)

Olymifia.

Pauline; Pascal Bruno; and Bontekoe.

PÈri la Ruine.

Porte Saint-Antoine, The.

Prince of Thieves, The.

Reminiscences of Antony, The.

St. QuENTIN.

Robin HoOD.

Samuel Gelb.

SNowball and the SUltanetTa, The.

Sylvandire.

Taking of Calais, The.

Tales of the Supernatural.

Tales of Strange Adyenture.

TAlES OF TERROR.

Three Musketrers, The. (Double volume.)

Tourney of the Rue St. Antolne.

Tragedy of Nantes, The.

TWEnty Years After. (Double rolume.)

WILD-DUCK SHOOTER, THE.

WOLF-LEadkR, ThE. 


\section{FICTION}

Methuen's Sixpenny Books.

Medium 8vo.

Albanesl (B. Marla). LOVE AND LOUISA.

I KNOW A MAIDEN.

THE BLUNDER OF AN INNOCENT.

PETER A PARASITE.

-THE INVINCIBLE AMELIA.

Anstey (F.). A BAYARD OF BENGAL. Austen (J.). PRIDE AND PREJUDICE. Bagot (Rlchard). A ROMAN MYSTERY. CASTING OF NETS.

DONNA DIANA.

Balfour (Andrew). BY STROKE OF SWORD.

Brying-Gould (S.). FURZE BLOOM. CHEAP JACK ZITA.

RITTY ALONE.

URITH.

THE BROOM SQUIRE.

IN THE ROAR OF THE SEA.

NOÉMI.

$A$ BOOK OF FAIRY TALES. Illustrated. LITTLE TUPENNY.

WINEFRED.

THE FROBISHERS.

THE QUEEN OF LOVE.

ARMINELL.

BLADYS OF THE STEWPONEY.

CHRIS OF ALL SORTS.

Bapr (Robert). JENNIE BAXTER.

IN THE MIDST OF ALARMS.

THE COUNTESS TEKLA.

THE MUTABLE MANY.

Benson (E. F.). DODO.

THE VINTAGE.

Brontë (Charlotte). SHIRLEY.

Brownell (C. L.). THE HEART OF JAYAN.

Burton (J. Bloundelle). ACROSS THE SAL'T SEAS.

Caffyn (Mrs.). ANNE MAULEVERER.

Capes (Bernard). THE GREAT SKENE MYSTERY.

Clifford (Mrs. W. K.). A FLASH OF SUMMER.

MRS. KEITH'S CRIME.
Corbett (Jullan) A BUSINESS IN GREAT IVATERS.

Croker (Mrs. B. M.). ANGEL.

A STATE SECRET.

PEGGY OF THE BARTONS.

JOHANNA.

Dante (Alighieri). THE DIVINE COMEDY (Cary).

Doyle (Sir A. Conan). ROUND THE RED LAMP.

Duncan (Sara Jeannette). THOSE DELIGHTFUL AMERICANS.

Ellot (George). THE MILI, ON THF FLOSS.

Findlater (Jane H.). THE GREEN GRAVES OF BALGOWRIE.

Gallon (Tom). RICKERBY'S FOILY.

Gaskell (Mrs.). CRANFORD.

MARY BARTON.

NORTH AND SOUTH.

Gerard (Dorothea). HOLY MATRI. MONY.

THE CONQUEST OF LONDON.

MADE OF MONEY.

Gissing (G.). THE TOWN TRAVELLER. THE CROIVN OF LIFE.

Glanville (Ernest). THE INCA'S TREASURE.

THE KLOOF BRIDE.

GJeig (Charles). BUNTER'S CRUISE.

Grimm (The Brothers). GRIMM'S FAIRY TALES.

Hope (Anthony). A MAN OF MARK.

A CHANGE OF AIR.

THE CHRONICLES OF COUNT ANTONIO.

PHROSO.

THE DOLLY DIALOGUES.

Hornung (E. W.). DEAD MEN TELL NO TALES.

Hyne (C. J. C.). PRINCE RUPERT THE BUCCANEER.

Ingraham (J. H.). THE THRONE OF DAYID. 
Le Quoux (W.). THE HUNCHBACK OF WESTMINSTER.

THE CROOKED WAY.

THE VALLEY OF THE SHADOW.

Levett-Yeats (S. K.). THE TRAITOR'S WAY.

ORRAIN.

Linton (E. Lynn). THE TRUE HISTORY OF JOSHUA DAVIDSON.

Lyall (Edna). DERRICK VAUGHAN.

Malet (Lucas). THF CARISSIMA.

A COUNSEL OF PERFECTION.

Mann (Mrs. M. E.). MRS. PETER HOWARD.

A LOST ESTATE.

THE CFDAR STAR.

THE PATTEN EXPERIMENT.

A WINTER'S TALE.

Marchmont (A. W.). MISER HOAD. LEY'S SECRET.

A MOMEN'T'S ERROR.

Marryat (Captain). PETER SIMPI.E. JACOB FAITHFUL.

March (Richard). A METAMORPHOSIS. THE IWICKENHAM PEERAGE.

THE GODDESS.

THE JOSS.

Mason (A. E. W.). CLEMENTINA.

Mathers (Helen). HONEY.

GRIFF OF GRIFFITHSCOURT.

SAM'S SWEETHEART.

THE FERRYMAN.

Meade (Mrs. L. T.). DRIFT.

Miller (Esther). LIVING LIES.

Mitford (Bertram). THE SIGN OF THE SPIDER.

Montrésor (F. F.). THE ALIEN.

Morpison (Arthur). THE HOLE IN THE, WALL.

Nesbit (E.). THE RED HOUSE.

Norris (W. E.). HIS GRACE.

GILES INGILBY.

THE CREDIT OF THE COUNTY.

LORD LEONARD THE LUCKLESS.

MATTHEW AUSTEN.

CLARISSA FURIOSA.

oliphant (Mrs.). THE LADY'S WALK. SIR ROBERT'S FORTUNE.
THE PRODIGALS.

THE TWO MARYS.

Oppenheim (E. P.). MASTER OF MEN.

Parker (Sir Gllbert). THE POMP OF THE LAVILETTES.

WIHEN VALMOND CAME TO PONTIAC. THE TRAIL OF THE SWORD.

Pemberton (Max). THE FOOTS1EPS OH A THRONE.

I CROWN THEE KING.

Phillpotts (Eden). THE HUMAN BOY. CHILDREN OF THE MIST.

THE POACHER'S WIFE.

THE RIVER.

' $Q$ ' (A. T. Quiller Couch). TH E WHITE WOLF.

Ridge(W. Pett). A SON OF THE STATE. LOST PROPERTY.

GEORGE and THE GENERAL.

A BREAKER OF LAWS.

ERB.

Russell (W. Clark). ABANDONED.

A MARRIAGE A'T SEA.

MY DANISH SWEETHEART.

HIS ISLAND PRINCESS.

Sergeant (Adeline). THE MASTER OF BEECHWUOD.

BALBARA'S MONEY.

THE YELLOW DIAMOND.

THE LOVE THAT OVERCAME.

Sldgwick (Mrs. Alfred). THE KINS. MIAN.

Surtees (R. S.). HANDLEY CROSS.

MR. SPONGE'S SPORTING TOUR.

ASK MAMMA.

Walford (Mrs. L. B.). MR. SMITH. COUSINS.

THE BABY'S GRANDMOTHER.

TROUBLESOME DAUGHTERS.

Wallace (General Lew). BEN-HUR. THE FAIR GOD.

Watson (H. B. Marriott). THE ADVENTURERS.

CAPTAIN FORTUNE.

Weekes (A. B.). PRISONERS OF WAR. Wells (H. G.). THE SEA LADY.

Whitby (Beatrice). THE RESULT OF AN A CIDEN C.

White (Percy). A PASSIONATE PILGRIM.

Williamson (Mrs. C. N.). PAPA. 
PRINTED RT

UNWIN BROTHERS, LIMITED,

LONDON AND WOKING. 




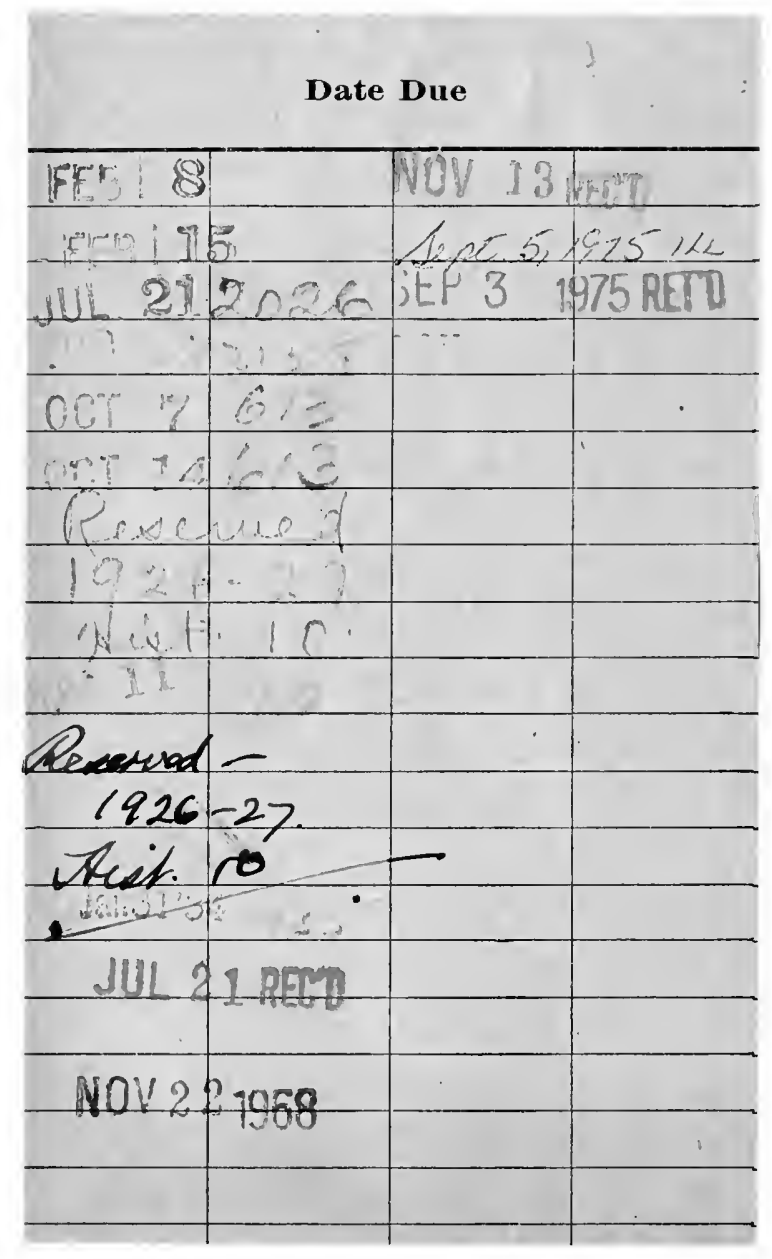




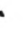


UNIVERSITY OF B.C. LIBRARY

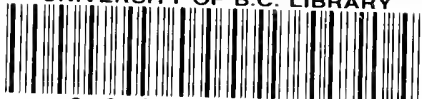

39424022242173 


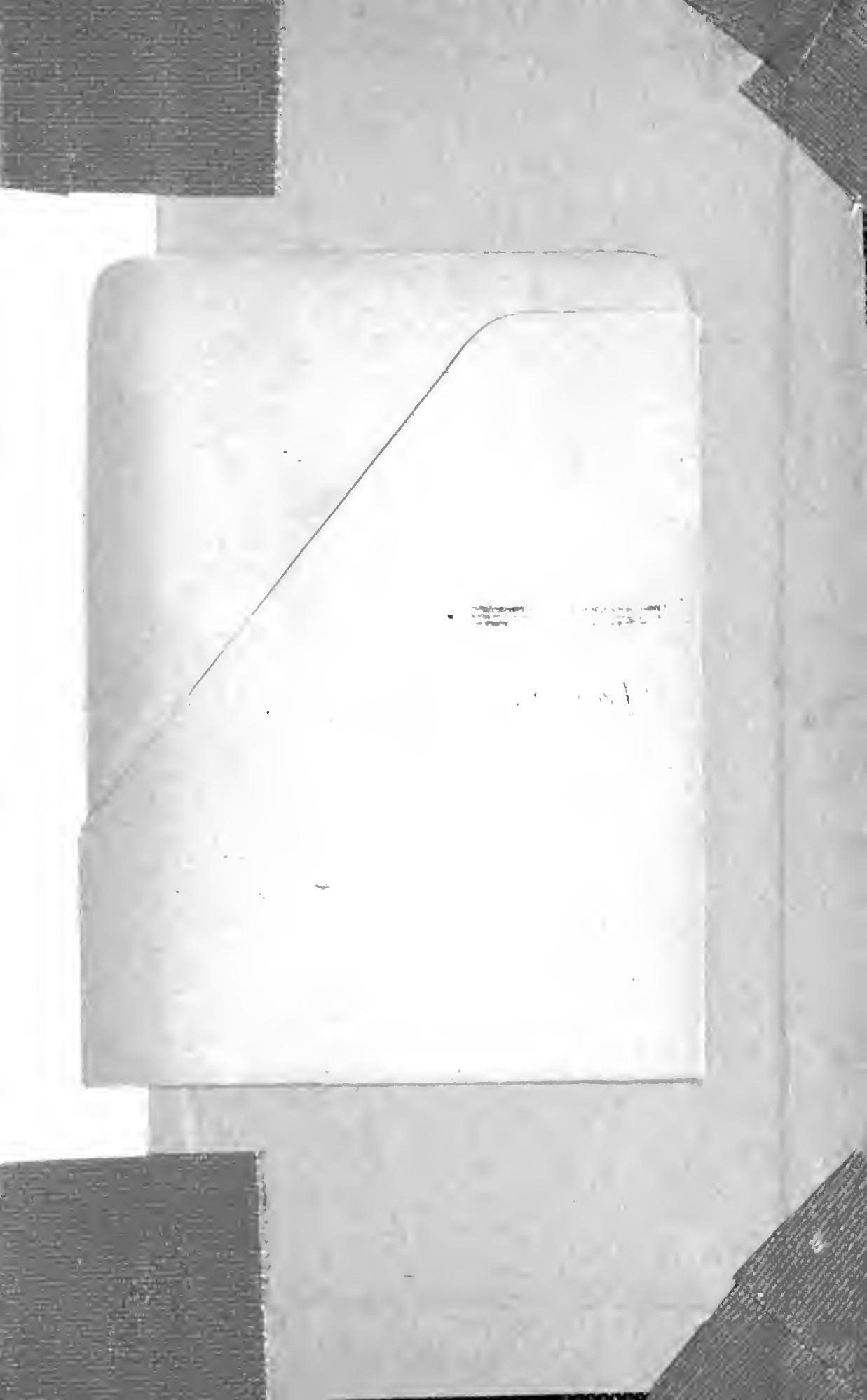


